


Q1. Oswald Weigiel


























$y=\frac{4}{4}+4$





$\because x+20+2=$






Deny Miontforts allgemeine uns befonbere



o e r

Weidwúrmer (Mollusques)

a $\mathfrak{l}$ s

Fortleţung ber $\mathfrak{B u f f o n f d e n ~}$ ?aturgefdidte.

2it e $i$ แ

Xnmerkungen, Erlåuterungen uno వuโäk̨en

bera

Don

C. $\mathfrak{P}$. If $\mathfrak{t} \mathfrak{t} \mathfrak{e}$,

Snipeftor bes Edultebres s Eeminarium in Deffau.

Erfter $\mathfrak{B}$ ans.

嗮 it

Şamburg uns Railt,

Lei Cottfrieo Boltmer.

1803. 


\section{Lecleres von $\mathfrak{B}$ uffon}

allgemeine uno befondere


nact) Der neueften


4 118

oon Sonnini beforgten 2uflage 4i berfet

oon einer Gefellidaft pon Gielehrten

uns

mit einigen 2fnmerfungen, Erláuterungen unb sulágen



o \&

C. $\mathfrak{P h}$. F $\mathfrak{f} \mathfrak{n} \in \mathrm{e}$





Funf uno breifigfte Sieferung,



ฏit

Scambutg und Mainz, 
704.70











$\ell$














\section{Borrede Dez Schaug̉gebers:}



as wichtige Unternefmen mefreter betůfmten franzofifichen Belefrten, eine vollftåndige Naturge:




befannt fenn. Die Sereinigung foldher talentodlen Måner zu Diefem ŝweck, ifre ausgebreiteten fient: niffe, ifre gluctlicte \&age, bie ifnen erlaubt, bie গatur felbft zu beobachten, biesิ alles beredigte uns วิu ben gróften Errwartungen von Dem, was fie zu lei= ften im Stande fenn wůrden. Llnd ffon find Seweife in unfern Şånden, daß uns diefe Etrwartungen nicht getåujut baben.


Dufte auf vaterlandiften Soben bedarf alfo wobl




lides befiten. Sunfonderfeit feflte es uns bisher an


Miollusfen, von Denen wit nut einjefne (Sattungen und


Bofadich, Foršfal, Mitller zc. fannten, Die uns abex feine volltåndige, zufammenfäangende und fyitematif






ङ()arffinn georbutet und mit einer Şenauigfeit aแรge=


Sein (Entfufiasmus fur die 2Biffenfchaft, dex er fein Seben wiomet, ift Durd) Das gahze $2 B e r f$ ficftbar, und theift fich unvermerft Dem fefer mit. Sertraut mit ben Ed)riften álterer und neuerer Zeit, morin biefel= ben Begenftánde, die er beftbreibt, abgefandelt find, benuţt er Die intereffanteften $\mathfrak{B e m e t f u n g e n ~ f e i n e r ~} \mathfrak{B o r}=$ gánger, uno vergleict)t fie mit feinen eignen \$eobad)=



Mgenn Montfort von Diejer Eeite fird um ben Theil Dex Raturgefdidfte, Den er bearbeitet, ein glanzendes Serdienft erworben hat; fo fann ifm Der Borwutf Def MBeitfaneifigfeit (hauptiąd)lith in Den 
Vués générales und ôm Discours préliminaire), unn thiget 33 iederfolungen, Det Itbforweifungen auf frembe S) Paterien, ber faft an fabelfafte grånjenden Hebera treibungen แmo ber stufnafme virflicter fabeln alb mafufafter Begebenfeiten, Der ifn wohl midet mit Un= recht trifft, wenig ober nichts oon feinem feit gegrưn= Deten Rufgme entziefien. Llm mur ein Beifpiel von tadelfaften Digrefirionen - Die \$N. einize Mal felbft eingeftef)t - anjufúfren: er begnúgt fid nicht Damit,




Der in eine (jefdid)te Dev Mollusfen gleid) fam bei ben Shanten, wie man zu fagen pflegt, ferbei gezogen ift, angefullt zu baben; fondern er mad)t aud) bierzu nod


Bernfteins gedenft. Und marum? SBeil Cinige Den Sernftein gelben $A m b$ ta nenten.

Mir fdien bafer eine freie, bin und wieber ab:


fenn, als eine foldue, die bem beutfden lefer alle up=


und Der Sct. Serleger trat Diefer Mleinung bei. So nui Montfort Gierdurd getwonnen oder vertoren bat, 
VI

saruber migen biejenigen entideibelt, weldse die Utbers feţung (bie von einem talentoollen SRanne Gerrúi)rt) mit Dem Driginal zu vergleidfen fid Die Mathe neffmen wollen.

Einige Berid)tigungen und Jufathe babe id am


Şerauzgebers, fo gut ich) fonnte, erfúllt.

Deffau, im Ipril $\mathbf{8 0 3 .}$

$$
\text { E. গ. Fun?e. }
$$




\section{Regiffer bes erften Santes.}



Srite 8


grofen $\nVdash b$ th:tlung:n oes Thier reidbe, eritenz in Ihe:


Filidentirbel, feft

Mixina glutinofa




Ylan dieics 2 gierfs -


weifīem 3 lat uno oh)ic Rlifenvirhel, milfen aber von ben פRo urfen abgefoudert verden, uno maden eure



Malf von Sdaltbieren und sabreporen

Dos Studium der Emalthicre iit fehr angsnefm, aber nut einleitend

4

Paris ift ganz auf Etpinen, bie fid von Staltbicren ber: ícreiben, und auf Trummern aub orm Nerre gebaut

Hagebeure Berippe, und Rhinoceroffe, bie ifr ffleifh bes halten baben, in Sibirien gefunoen


b. itefin

Der गRenich fam gulck̨t auf ber Er:be au

2 I

22

23

Ralfberge uno Ghaltbierlanen, dic man jiveitaufend fülf=


bent hat

Theorie ber Erbe


Berin, die Sourrnime, Ebampague, Eoiffons, Jamp: tonfbire $3 c$.

Dtehr oder winiget allgemeine ober partielle Heberftromuns gen




jers bahin

Felien von Franticich und Englans 
Serge von Batra



23érvielfăltigte Er reugung

2trten Der Erzeuguti 37


tanée); Das ganze gelefrte altertbum nimmit fie an

Die fuft ift vielleidt bas cingige Ëlement


grmok die Erde eines envigen Frübling

\$f .nzenfamenfornden behalten ifgren Sebengfeim folbr viele Sabre binourdh

Souffon uahm ore miakifintidue Ergengung an


zellgung ier $2 B$ irtmer

5ुlochs angeborne Ergeugung

Die $\mathfrak{W}$ úrmer werden mit ben Thieren geforen


श्ञstitmeteier



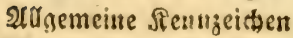

Befdreibung ier Siemen ober Srgene zum athmen, bei






verfeber

\section{7}





te im Sieere aufjufif

Seite $9 \mathbf{x}$

Derter, wo man fie fiubet


ober Saugthipfden (Shropftópfe, Ventoufes)


itentbiere, wieber

94

95

Gie bicucu ifuen im Sturme als Infer

96

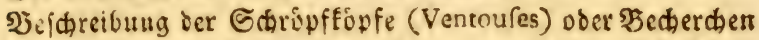

96

2lit unb 20effe, mit welder jene פicduerden anfdlieficn, und to ie in bieicu (Gauge:) SRapfdeu bes Diutenfis fhes ocr leere Raum entitebt

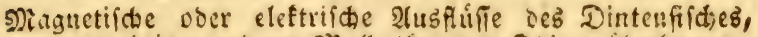
uno einiger anberer झ)Rollusteu uns Thiere tiberbaupt

פeobad)tungen uแb Erfabrungen in bicier Şinfict

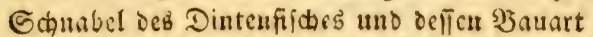

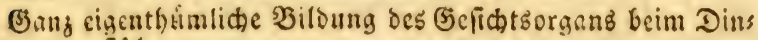
terifiche


Werlenart Durchbobit

98

98

Ior

ro6

102

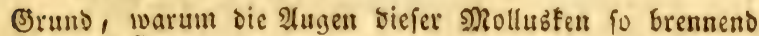
roth finto

108

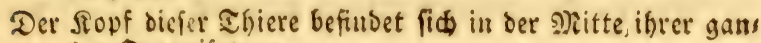
jen Drganifation

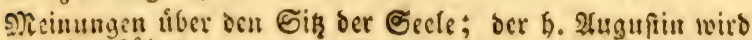
augefulbit

Eigenthumlid)e Eimridtung ber Sebenerben bei bent leder: büutigen গ) ollušten

2uf welde Art horen fie und bie fildte?

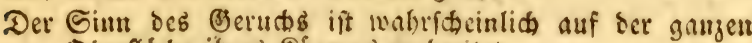
Dberflád) ilites Sorper's varbreitet

I I I

I 2

II 3

IIS

Der Dintenfifi ftirbt, fo wie er in Die freie fuft fommt, und jerfliest nach feimemi Tobe

Ëeftalt bes acmeinen Dintenfiches im Smern, wenn er ber \&unge und geoffuet ift

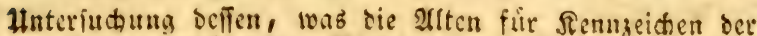

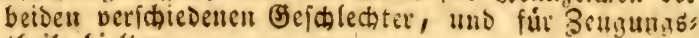
theile bieltent

I17 แแ⿰ Ix

Siemen uno Sraane zum Ittmen beim Dintenfiche Shle Siamiñfationacn

Dics Thtir hat orei Syergen, - Svftem Scr Eirfulation (D:5 $\mathfrak{3}$ (แแt)

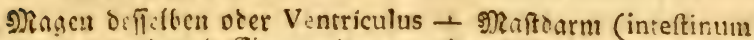
recrum) und Eingeneideganz (Dcr NB auf Der neuten Supfertufel umiditig "inuerer $\Re$ b brengang" genaunt ift)

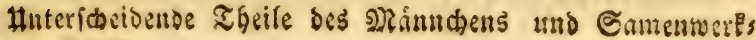
zeuge 
Eamentbierthen dis mänulidsen Diuteufifdies

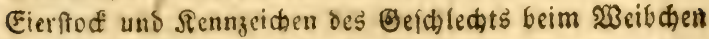

Das Legen bes Dintenfifhes

Eier des Dintenfildacs

Dintenblaie

Ebuefiftue Dinte ( $2 u$ id)

130

Sirodaent oes Dintenfifted

I3I

(3) isait sicies Sinodens (

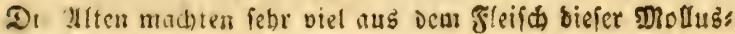
fer; wht fie zu faugen

2ian ierzte fie ielbit an feftlichen Iagen nuf fonigliche Ias fela

Jąige 2trt, bie Dintenfiche ju fangen

S) Zan fernt now Eine SBeriteinerung, die man Dem Dins tenfiche zufchreiben founte

ErFi rrung der Supfertafeln jur Befdidate bes gemeinen Dintenfifich

Tafei IV. G.tnabel, Eier, Samenmajdinen uno Gas mentbierchen bes Dintenfifices

Tafel V. Eiet des Dintenfiches uno des Ralmars



145

Supfertafel, sie ben geflecten Dintenfif von feinen beis ben follichen angrébu, entbàlt

Erklarung ber fectsten Supfertafel

151

155

* * * *

(S)eidichte bes hơđerigen (fnolligen, tuberculée) Dintenfis iches, und feine verficiedenen SRamen

Siebente Iupfertafel, die den hóderigen (NB. auf bem Supfer ftelt: Enolligen) Dintenfich und feimen Strodent entbalt

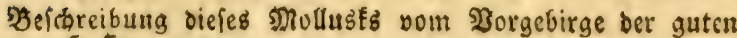
Jुofrumb



Die Dintenfiche lofen fich in cine fhwarje Feuchtigfeit auf

Sinme' fante mur cine einaige Gattung von ihmen, uno glaubte, man fünde Dicieg Ihier blö im 233 eltmeet und im mittellánsilaten Mieer

Silmars und Po!npen findet man in allen Niceren, bie Dintenfifme aber nur iu beuen ber alten 20 elt

Uి ISBopmorts. 


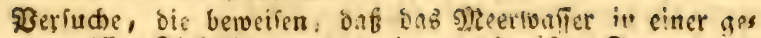

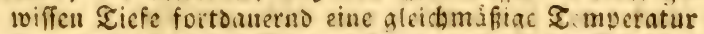
hat, wie es in Den Sjergwerfen innerhalb D:r Erbe der Sall ift

Einbrut deg Terebo mavalis in bie hollabifhen Deiche

Infunft ber Tarrocan Europa

Shuimmende Rorper auf oem Nipere

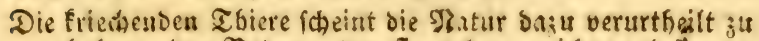

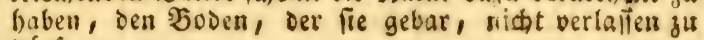
birfen

Sie verwuiften Nartinique uns ráden bie Saraiben furrds: tirlicb.

Thatfacn, bie biefe Shlangen betreficu

173

(B)ruc, ben fie verbreiten

173

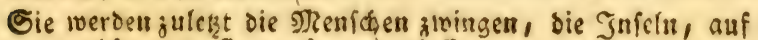
weld)e man fie twarf, zu verlaffen

Man fanu die Fifcheicr, wie die Eier ocr Jufeften, in ifs, rer Eutwidilung aufbalten

174

175

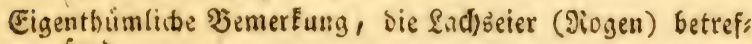
fent

2Bie Shiffer und Shiffe die Seetbicre aus cincr (5)gent in bie andere velídileppen fónnen

Sriechende uno ungcheueratige Thicre



fif the von einem 队ole zum andern zu crflären

פRecr: uno Randidilofioten aus beiffen fimmelsftriden, au beu fram jufict)en Jititen gefaugen


oft verlieren uno mit ibuen umbergetrieben werben

Reifen bicier vegetnbilifinen Mierprooufte

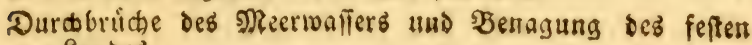
Santoes

Die graue 2 mbra uno ifre verfdatedenen Samen

2Anfang und Folge Der $\mathfrak{B}$ ewcife, die Dartbun, daf biefe foitbore Gpecerei nidats anbers in, alb oas exfrement ber $2 B$ allfiche odet Saltalots (\$ottfif

Schrarge 2imbra

Seeipedf

Trageu, bie bcm ediffstapitån Jofua Eofin burd bie

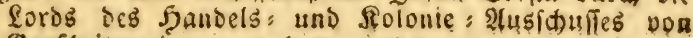

Brobbritanien oorgelegt wurben




Bomé de I'Isle's s) Ieimung

Geite 202

Sonderhare Mreiuung ocs Lopes de Caftagnetta

205

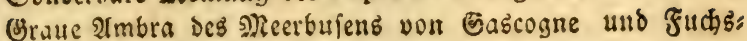
ambra

206

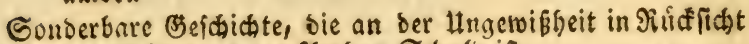
bes uriprungs ber 2 fmbra Schulo ift

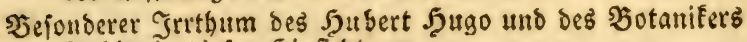
2tublet in diejer Jjinfitht

Die Thatiađen, weshalb man bie graue 2 mbra ben গুBalls fichen zuf

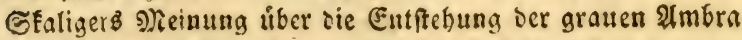

Эniel, bie aus lauter graner $\mathbb{A}$ mbra beftebn foll

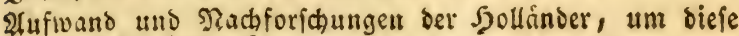
Sniel zu entoedert

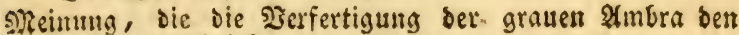
જienen 3ufthrieb


gethore, ift zwar ebenfalls falfo, aber Dod bie vers minftigre von allen unrid)tigen

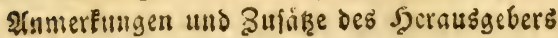




\title{
Dent M
}

allgemeine unb befonbre

\author{
$\mathfrak{N}$ a \\ Der
}

\section{Beidinúrmer (Mollusques), Thiere ofne

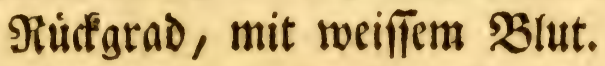

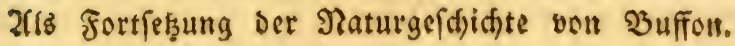

\section{भllgemeine (3) (d)}

\section{5}

et Renich alleill erfob fich butd ben (hes

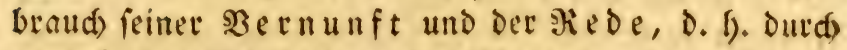
gegenfeitige Mittlgeilung Der Joeen, zu Den erfaben= ften Begriffen; und rutde Dadurd Der Seer Der (5rde, trorauf er, wie alles zu erfennen giebt, unter den fammtlichen Shieren julest entfand. Dutch Bereini= gung mit andern feines (3leid)en und Durd) Die aráfte

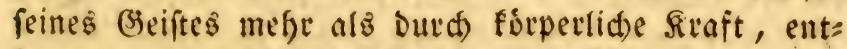
fernte er bie fdádiden und rilden abiete von peine SBofnungen, rottete ganje (Befd)ledter Derfelben, die iffm ju idádich trurben, beinabe aus, und siger und fome fogar wicten bem Menjalen, feit er in gejell= (d)aftlid)e Berbindungen getreten war. Cinige Iflete flofen aljo, andere aber beugten fid unter fein Jod. 
Die gemeinifhaftlide Barbindung fuffrte megrere

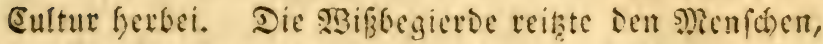
Die erigenidaften Der ifn umgebenden sefen ju etfor=

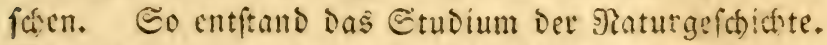

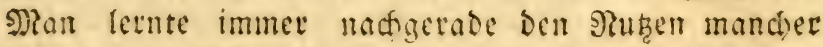
Báume uno \$lllanjen fennel, jog fie alt, verbreitete fie reiter und bediente fid ifter zur Saffrung, zur Scilung und zu anderweitigen bedúfnitien. Seţt entftand immer allmáffich Der Scferbau, Die B̈runolage jeder gefellifaftlidey Derbinsung. Durd ifn nafm

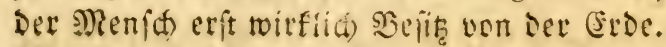

So wie man mit Den Sandtfieren allmåglid bes fannter mutbe, letnte man mefgreren 9iuteen atis iffnen fowoht als aus einjelnen ₹feilen berielben jiehen. Salle Gimfte tourben Daturd) beridjert, uno ber gedriffe

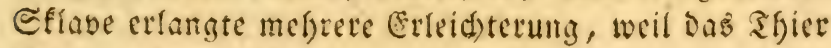
ifm mand)e Dienfte abnalym.

Blomiende \$unfte auf ber Dberfąche der croe

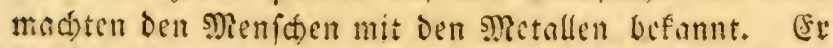
bemad)tigte fid iffer, grub ifnen naw, fant einige Derfelben gediegen und gammerbat, und lemte fie balo zu feinem Biusen verwenton. Epaterfin merfte or Der פatur sie Sunft ab, fie ungesiegen aus Den Erjifufen zu id)affen, fie ju fdmeljen und ju fdmieden.

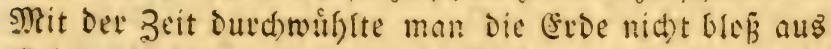
(3)cis, fondern aud un bic Grundfoffe Det Eroe, Etcime und Metalle aufjufuden. Selbit bie fuft= (d)idten blieben in unfern 3 eiten nicht ununterfudyt; um Die Suellen Des Rebens fonnen zu lemen. Det Menid) beang immer weiter in sie (3efreminife Der Tatur ein, und mer weif́, wo er einft now ensen wird, wenn nicht eine unvorfergejefene Rataftuphe fein ganges (sef(d)ledt vernid)tet. Se ausgebreiteter aber

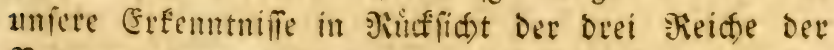
Natur nutben, Defto toeniget wat es einem einjelnen

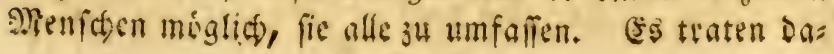


her einige auf, die nur ein bejondres Gejhlecht ber sBejen, aber bies aud Defto tiefer erforfaten.

3roar mad) ten einige grope slianner j. (5. Sinné, allgemeine Enft me Der Эiatur betannt, aber Die Jiatul= forlfier fonnter bod inmer nur einjelne Iffeile beats beiten. Da bie Mranizen fich fo leidht uno aleichiam bon ferbft enboten, fo mutde zue:ft Die Rotanté culti=

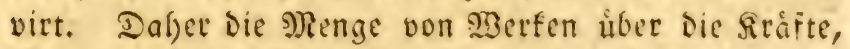

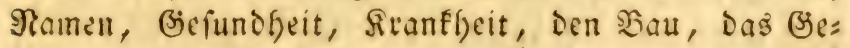
füfl zc. Der Pflanzen.

Die : Drineralogie beicháfigte zwar weniget fors ider uno Edrifofteller, aber fie rourie Dafir in uniern Sagen ein plilofopfifches Studium, Das uns , wie Der Faden Dex ?triabne, felbit in ber Dunfelfeit nidet ver= lię, in bie wir geritthen, als wir ber erferen \$illoung uno Der Simbheit unjerg Planeten im Junern Defletben nat)forfiden, uno auf eine Menge efemalizer bes f(t)led)ter ftiefen, die cinft Die (stive bewofnten.

Indre arofie Noanner beobacteten Dos ₹fierreid); Iriftoteles, \$linius zc. bis cuf simne, Buffon, \&ace= pede und fo vicle ansere, fdrieben bie Befchithte Der Thiere. Diefe atbthcilung trar aber viel grifer und zalfreicher, als Die beiben oben genannten, Denn fie erftrecfte fid rom Elephanten, vom 93 allifich uno von ben anoren befeelten lungefeuern bis binab ju jenen lebenden Atomen, Die fowentof in den Prfonjenauf: guilien und thierifacn Samenfeudtigfeiten entoecfte, uno beren cinfundert an einander gereift nod) nidt

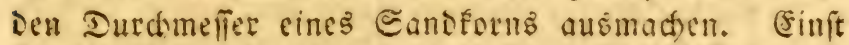
wat Die Milbe Das fleinfte befannte bef

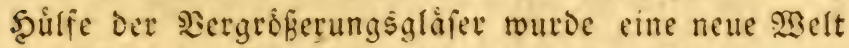
entbecft, Dic grófer noch war, alš Die vorherbefannte von Der s)tilbe an, bis zu Den 2 allfiphen hinauf. Ta, toir roiffen jeģt aus Der Inalogie, Daf felbft die flein=

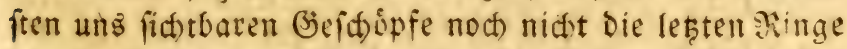
Def fiette find, Denn tiglich lernen trif ned andre 


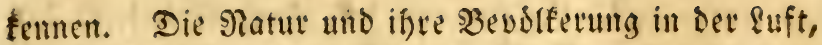
im $\mathfrak{x a}$ affer und auf der froe ift alfo fur uns endlos.

Den Bemuhungen grofer Manner verdanfen wir bie Befdichte Der zwei= und vierfandigen Tffere; ferner der vierfisigigen, die lebendige Sungen jur șelt bringen oder (eier legen; der friedenoen Tffete, Der 2ógel, Der MBallfijdarten und úbrigen Fifdue.

famarf und (Euvier baben in unjern geiten befon= Ders Das Thierteich in jwei Saupttheile getheilt. Der eine entfålt bie cben etráthnten, bie alle ein fnochiges febr zufammengefetetes Efelet, uno vorjuglid einen ios genanten अiuctigrad, Der aus einer MBirbelfaule befteft, und - warmes B B $\mathfrak{a}$ t haben.

Scier zerreift aber mit einem Male die thierifose

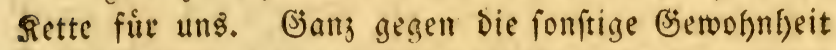
in Der Siatur, geratfen wir unvorbereitet *) zu einer

*) Die flebrige Nixine (Mixina glutinofa Taf. VIII. fig. 4. Mul. Friderici, a Car. Lin. p. 91 feu Lampreta coeca, oculis carens, Willicht. 10\%. Ragi Pife. 36.) Esunte man allenfalls als eitr Nittelglico zuwis fihen Der Sette Der Thiere mit und ohne SGirbelbeine anfehn. Diejer ganz cigenthúmliche Énorpelige șif́, ift fo fdleimig, Das ein einziger cinen ganjen (Fimer

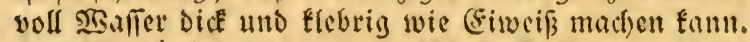
Da Lime' bei einer zu rafden Berlegming Diefes

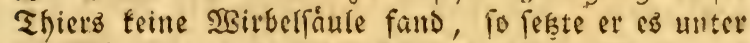
bie $2 s$ irmer, und andre Slaturforicher, Bruguiere fogar, folgten ifm. Epatere Soobaditungen baben Diefen serthum verbefiert. (Es if jefst ausgemadit,

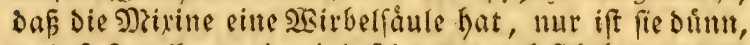
und faft gallertartig, indefimmer nod) fitftbar genug,

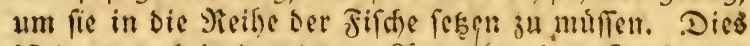

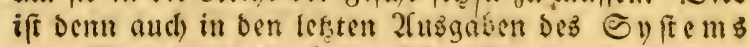
Der Natur geichelyn. Şbr (d) leimigez

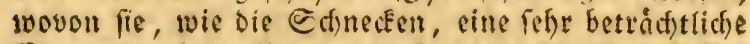

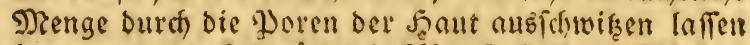
tann, und bie faft gánzlid)e afbwefenbeit ber Silckens

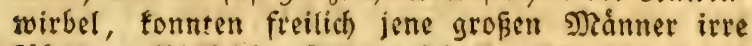
fúbren. כielleidst finden fid) Dereinft nod) anbre 
gnfllofen Shenge won Rlaffen, Gefdledtern uns Fami= lien von Thieten, bie ju eiter ganj andern Dronung ser Dinge ju gefoeen focinen, indem ifre fenngeiden nichtz mit den Sennjeichen ber Sfiere gemein faben, Dic $23 i r b e l b e i n e$ befitsen. Dieje $23 i t b e l b e i n e$ find nam=

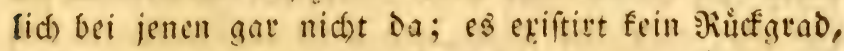
Deffen oberftes Ende Den Sionf Dis Thicrs tringt, und Dem Bitfemmate einen freien Dutit)gang láfit, um ourd) taufend Bamififationen Den aufeciten Theilen

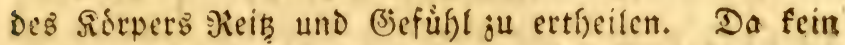

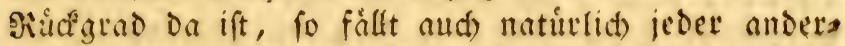
weitige inwendige smodhentau weg. Das shlut felbit bat eine andere farbe. (5) facint blof cine Irt wor

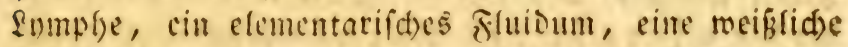
Fluffigfeit zu fenn. Diefe auffallenden Beridsieden= beiten verurfaden a!fo cine jweite stbtheilung bes

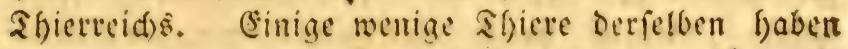
cinte Irt von Snod)enbau (oick imerer llnterftuşung), Diejer ift aber nid)t in Eelieder soer aBirbelbeine ges theilt. Die Snod)en fino nid)t gef(d)idtet, nid)t mit Dem Fleifae verbunden, nicht von 9ierven Duratsobet. (ev befteft viefmef) gewoffnli(t) aus cinem einjigen

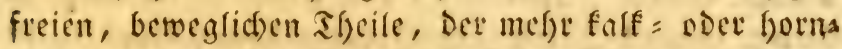
attig, als fnodsig ift. Saud finbet fid biciet lourn = oder vielmelgr falfartige Theil mut bei fefre romiges, Die etwa, twie Die Dintenfifae und Sialmarz, bie exften

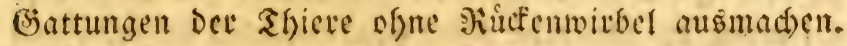

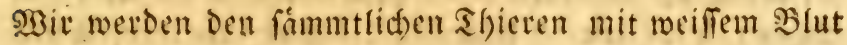
(ber zweiten Abtheilung Des Sfferreid) id)reibung Den গamen Mollusfen (2Beid)thiere) geben, weil er allyemein angenommen ift.

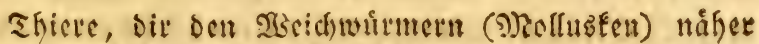

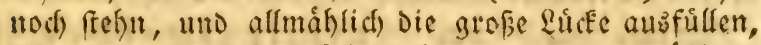
bie mit oer fonft îetz folgered)ten, uno regelmápigen

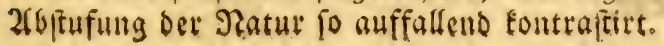


Traft alle jiefren fid mit grofier seidhtigiteit jus fammen. Shr fiorper ift reid), oft gallertartig. (ir ift nacft, biŝweilen indể mit folf = oder hornartigent Decfen uno frillen ungeben. Bei andern Indivibuen umidtieft der Siorper biefe Materien; fie vermandeln fid) nie, und ifre fribe, wenn fie anvers bergleidsen baben, fino vollig ungegliedert. Finige erjengen vers frummelte Sheife ifres fiorpers von neuem.

Unter Der Benennung Mollušén (Meit)=

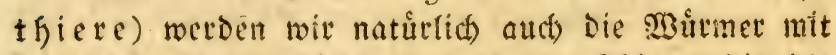
begreifen; Diefe god it fonderbaren Ifiere, die die Slatur faft alle ins Sinnere anores Thiere vermiefen zu baber idseint, und die die গaturforider unter bem

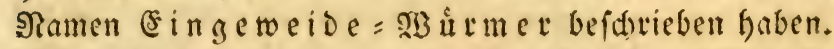
SBir werden fie gerillgelte Mollusfen (SBeid)= to úrmer) nement. Şierdurd) vermeiden rir jenen wibrigen Segriff, Der fich mit ifrer efemaligen Benen: nung immer verfnupft. Illes redtfertigt biefe গeues rung. CEs ift ausgemad)t, dafi mefrere neuere Earift: fteller vie beiden Morte $M$ ir $\mathrm{rmer}$ und Mollu \& fen,

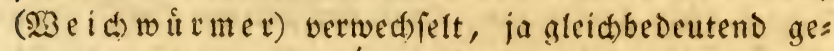
braud)t haben. Einné *), det zucrit das Dunfel in

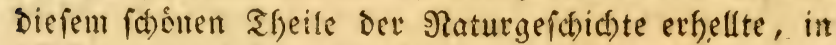
Dem er eine befefrende Doronung und gefunde firitif Datin cinfiffte, gab Dem grôkten Sheil ber ahiere, Die Die গIten Exfangues (Blutlofe) nannten, uno

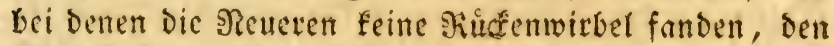

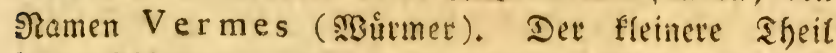

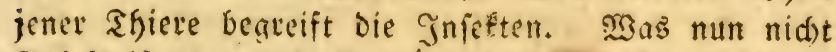
Infeft ift, verweifet Sinne' in Die filaffe der Mutmer.

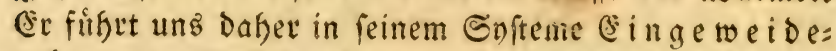

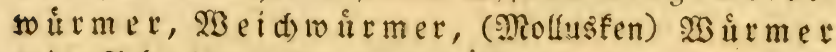
mit Sdalen (aondylien) Zooploytenturater (Thierpflanjen) und Snfufionsto tirmer (tfjer: d)en) auf.

*) Syftem. nat. tome I. p. 6 claf, 6. Vermes ed. I3. 
Rुruguiere *) folgte iflm bierin, follf aber nod) einte Solnung mefre, Dent et fonderte Simne's Sees

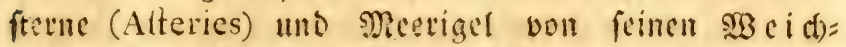
wo itrmetin (Vers mollusques) ab, uno namits fie Secigelmurmer (Vers e chinodermes).

somatf endlid) madote eine neue Eintheilung **)

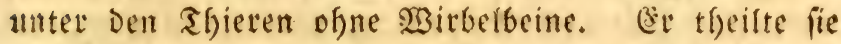
namlict) in fieben Rlaffen. Diei Davon fint fur bie Ginfeften. 1) Die Situfentfiere (Crultecés). 2) Die Iraduniben (arachnides), uns 3) Die Jnfeften. Die SBcidfwitmer (Mollusques), $2 B$ inmer, Mabertjicte (radiaires) und Polvpen mad)en Dab nod) ubrige feines Softems aus. Die Snfuions = und mifroffopifden Sfierden hat er mit unter die \$tolupen gejeţt. Scine Fibortliere fino Bruguieres (s)

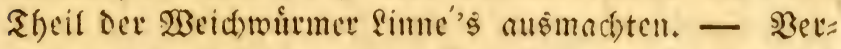
sleid)t man biefe Drei Snfteme mit cinander, fo findet man, Daf Das Des Eamate, Det mur vier Silafien bet

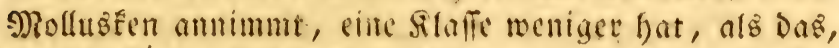

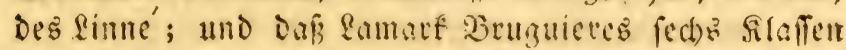

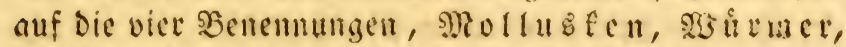
Pádertbiex, und

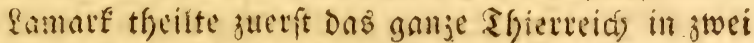
gennu gefonderte Syeile,

3) in Sbicre mit cincm Biufograde, uno mit vothent Stute,

2) in Shicte ofne suiufgrob, mit weiffem 33 lute.

Geftutrt auf Auttoritåten Der art, werbe idy, ben

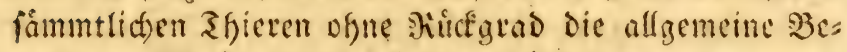
nentung Mollusen (

*) Bruguière, Tableau encycl. et method. des trois. regnes de la Nature, helminthologie Paris 1792 .

**) Syfteme des snimaux fans vertebres, ou Tableau général des clafies, des ordies et des genres de ces animaux. Paris I8or. 


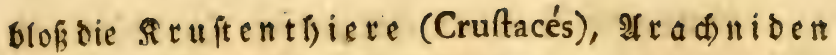
uno $\mathfrak{s}$ fieften Davon ausfdaliéren.

Td) theile fodann die Rollusfen wieder in zeljn Slaffen, námlia :

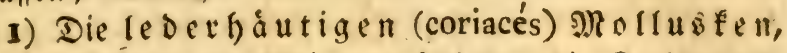
zu welden bie Dintenfifde, die $\operatorname{R} a \operatorname{lma} \mathfrak{b}$, Die grofen polnpen und alio's (clios) oder flitgelwurmer aeboren.

2) Die mit fihlfáden verfefenen Mol I haufe, und andere auf Dem Saudbe friechenden इfiere.

3) Die Mollugen, die sBafler von fich foriten, oder bie afidien (Meerideiden) und

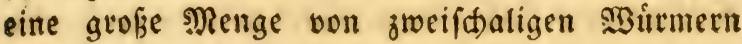
(bivalves).

4) Die geringelten Molluşen (dies fino die 2 Burmer).

5) Die gallertartigen Mollusfen, odet MRedufen, Iftilien $2 x$.

6) Die bepanjerten Mollusen, oder Mects igel und Seefterne.

7) Die mollusfifden Sobern, welde die æiementwutmer (ligules), die vielidaligen Thiere und bie \$olnpen entfalten.

8) Die mollugfifden Nadreporen, die Meandrinen 26.

9) Die gefónten Mollusfen, ober bie sitfoplynten, Gorgonen.

10) Die sinfufions= Mollus fen, oder miftos ffopifden Thietden.

Ille biefe Silaffen zufammen entyalten theils nacte Shiere, theils Schalthiere. Sm Berfolg Diefes $23 e r f$ sollen wir, indem roir fie eingeln betrad)ten, nach und nach ifge Dionung, ifr (Befhled)t und ifre Brattungen angeigen. 
Bon Den Rruftenthieren (Cruftacés), Alráfniden

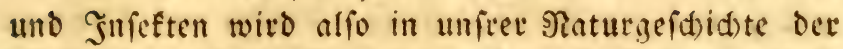

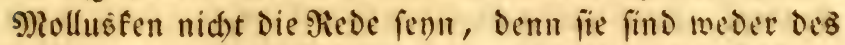
Bufammengiefiens fáfig, nod) weid): ifgr Róeper ift im Begentheil fefe oft mit einet haten und feften şaut oder $\subseteq$ d)ale bedectt, die meiftens fuod)en = falf = forn: ja oft fteinartig ift. Faft alle veraindern wáflend iffes

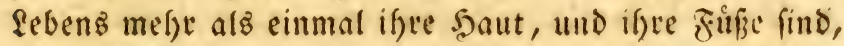
ofne Ifusnafme, immer gegliebert. Die Jnoiviouent Der beiden erften Slaffen verwandeln fide nicht, und

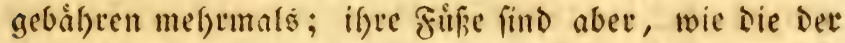
Infeften (britte Rlafie), mit Bliedern verfelgen. Die Infeften im Begentheil verwandeln fich fel)r oft, paas ren fid uno legen aber nur eimmal máfteno ifyers gan

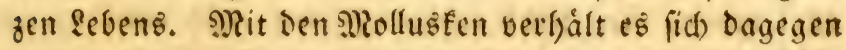
ganj anders, fie verwandeln fid nie, und ifye früre haben nie witflid)e Blieder. SBit wollen alpo die Sins feften, Irachniden uno Rruftentfiere Den Entomologen Inffen, fo erfalten wir feine Zwifhenabtfrilungen, bie immer Steine Des stuftofes waren, unb dic man nut gewaltiam ins Syftem Der Midlusfen mit aufnefmen Eonnte. Der Naturforfder fonn nun shne Unterbres

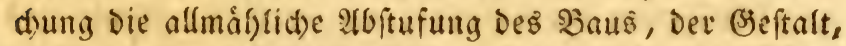

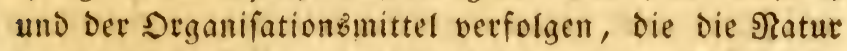
bei ber Sd)opfung uno Reptoduftion diejer Thiere nn= gewand zu fabein fdeeint.

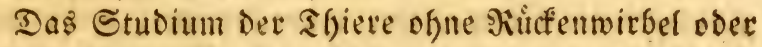
Der Molluafell, ift zwat múf [am, aber es hat boch viel Ingenef)mes. Man findet Datin bie tiefiten philopo=

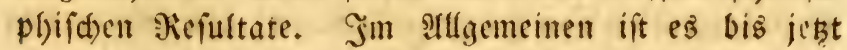
wenig befannt; Denn Das Beobad)ten diefer Sfiere ift wegen iffes jedešmaligen Aufentfalts und wegen an= Drev Damit verbundenen umftande immer befdwerlicf. Niele von ifnen leben in den tiefiten Meeren, oder an felfr entlegenen Giuften, uno nimmt than fie aus iffrem Elemente heraus, fo ift oft ein einjiger Iugenblicf hin: 
reidsend, unt fie ungugeftalten uno gufammenjufderunt pfen, elge Der Beobad)ter fic erblicfen und berifiren fonnte. Son vielen Battungen trifft man fodd) felten mefre als pimmal bas gleiche Gndividuum an, und ifre Tufbewahrung ift fait immer unmiglid). 3alo ers

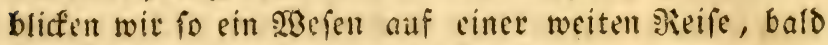
an einer jâfen slippe, balo an gefáćrliden farlen, bald im Eturm uno llngetvitter, allemal aber fehen

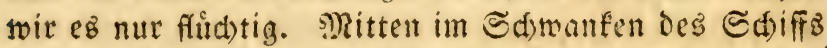
fátutet Dab fturmifde SReer oft beim Sdeine Des Slițes, Der Die Dunfelften Berwolfe Durd) fdincidet uno

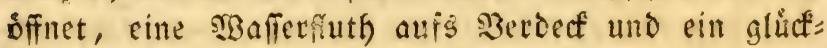

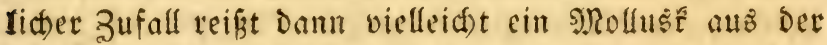
Siefe Deg abgrunds mit fervor, und witft eŝ bem Feifenden, der felbft feine ergiftenj nicht afjute, ju

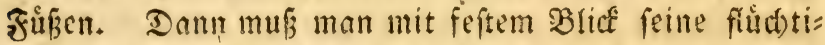
gen mur Ifugenblicie lang bauernden Mertmale auf= fafen; man muß bald nach biefem $\mathfrak{s}$ umult cilend zeicts, teln und befdreiben; denn faft alle Molluśfen find gal= lertartig, fie formmpen alfo idsull zufommen und man erfennt fie boun nidot mefre. Foft nut allein auf

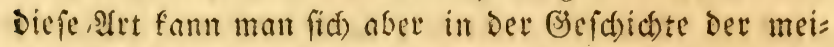
ften Molfusten vervollfommnen: (Erft nad) Dem man voin feinet Secife zurite ift, fan man ben angetroffenen Begenftanton eine falte und rufige llnterfuchung mid: men, aber nun helfen felbft bie æube uno Etille des Rabinetso nicht viel mefre, dem die meiften Seemollus: fen, bic man fid mulfiam verfichaffte, langen fo ver: fdrumpft und entitellt ju Saure an, Daf fie, ftatt ber Einbildungefraft zu Silfe zu fommen, ifr fefle viel zu buinfacen kbrig laffen.

গod) ift man mit Dev ängftiduften Eorgfalt, mit

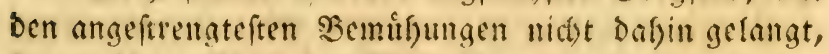
ben arókern Sheil Der Dollusten unverbotben anfu= bewafien. Daaegen haben bie forfiter in Den ansert

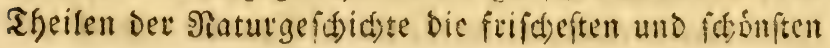


Bregenftante, bie ain meiftelt gecdiceft fint, fie gu ents frammen, vor arugen. Dies ift in unfern aagen mefr nls jemals ber fall, da bie Rumt, Die vierfüfigen

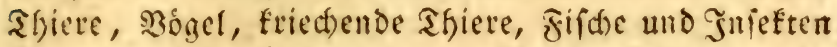
aufiubewahten, gleidy fam ifren (sipfel eritiegen hat *).

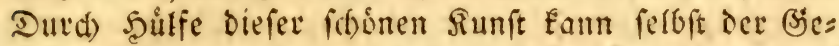
leforte, ber nie fein Bimmer verliefi, Den Supferglants und Das Edjillernde Det fdonen afrifanifden und in: Difden Gnfeften maflen uno befdreiben. F̧ur ifn vers liert Das zell ber vierfüigen algiere und das Gefieder Der 3 isgel nid)t bon feimem Sanmetartigen, nid)ts won feiner Frifide, nod von feinen foftlidsen Farben. Illes, ifye Stellung fogar, atfmet feben. Stud) baben cine Menge Jieifende uno Edriftfteller Die Giefdidte nller biefer Thiete feft ausfublid, genau uno getreu geliefert.

(b)anz anoers ift es mit Den Mollušfen. Einige unter ifonen fal) man nul ein einjiges Mal. Şon an= Dern trifft man Sheile an, ofne Dá̉ man nod bis ję̧t Das Thier, Dem Diefe sfeile angeforten, hat auffinden finnen **). vibieder ande fino fo unvolftándig be=

*) Dran befuthe in biefer Silfeffidt das Eaboratorium

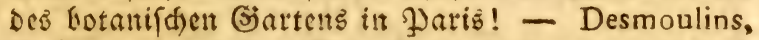
Dufresne, und ihre Dritarbciter halten es nicht blof fúr Dyflidt, alle ifnen vorgelegte Fragen getn $\dot{\gamma} u$ be: nutworten, fondern machen fich aud ein șergnugen Daraus, jeden, Der Luft baju hat, das Đुrápariren unt 2fufbewahren Der Thiete jul leften. Siltan lefe zú biciem Bwecke aud Nicola's 2 SerË: Méthode de preparer et conferver les animaux de toutes les Claffes.

**) 3. (5. Die Belemniten, Drthocerathitent, unb eitre )ienge andrer Folitien und Berfteinerungen, Die Fbieten ungehorten, weldye wir trof allen unfen

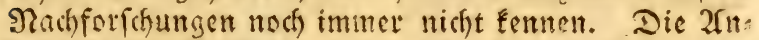
zaflet Dicfer Foflitien, Deren lebentosz 2fnalogon nody unbefannt ift, hat inder, befonders feit die Gefchichte Der zerfecinerungen fo grsfe Fortfhritte genacht hat, 


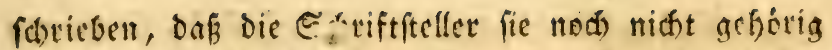
vergleiden uno erforiden, fie aud noch nidst mit Der

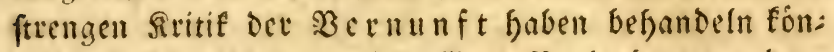

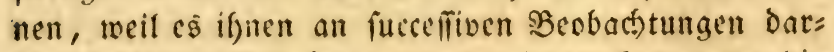
áber fehlte. (bef)irigbeobad) ten fann man die Mollusfen mur, to lange fie leben. Tlle baben cine

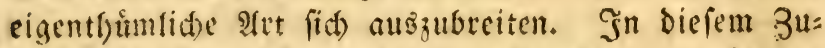
ftande Der Entwiffelung treiben fie oft mamnigfaltige

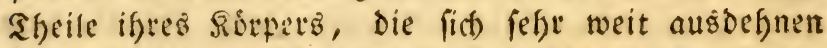
fómen, heroor; beim Sode des Ifiers aber falten uns jiefen fid biefe wieder nad innen zufammen.

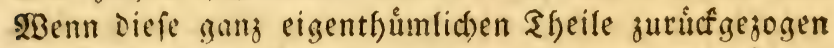
uno zufammengeforumpft fino, fo find alle Bemiffun: gen vergebens, um fie wieder zu beleben. Dafer bat Diefer ganj entgegengefeţe Zuftano der Mollusfen cine Menge Surthümer veranlafit. Sefters nàmlid beidrieb man bas gleiche Sindividuum in zwei vericticdenen Battungen, ie nad)dem feine ånkerliche Bildung im Buftande Der freien Eetiftenz, over Der Zufammenjiefung uno 3 eridgrumpfung eridsien.

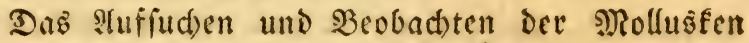
verurind)t folglid) unzálylige Ed)wierigfeiten. Selbft Daร Studium Der mifroffopifdeu Mollusten, das fo philofophifh und anjiefend ift, ift mit groben, vielleicht mit nod) grifieren Schwierigfciten, als Das Studiun

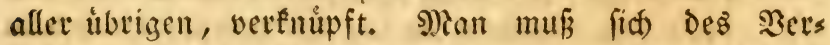
gróberungsglafes fdon jiemlid) lange, antaltend, uno mit গुedadht bedient haben, un es mit গluten gebrau=

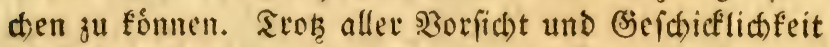

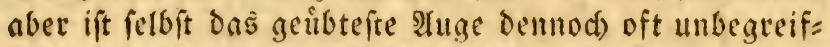

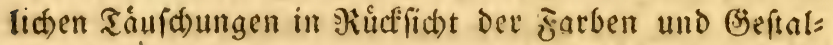
ten ausgejetzt, wie alle wiffen, die fid miftoifopifchen

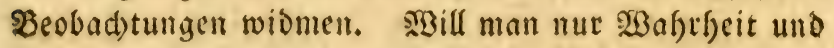

fehr abgenomment. Táglich teffert wir neue 2fnalos

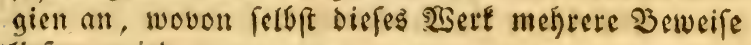
liefern witt. 


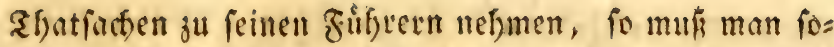
gleich) ftille ftefon, wo fie uns verlaffen: man mus, indem man fid mit indiviouen befalfigt, bie llebers fid)t Des ganjen Bejuled to und Die Berfettung Der Familien auffafien: man muß ferner bie ibatfachen, Die Die 3 eobad)ter uns cinjeln und ofne Zufammentang erzáft haben, an einanderteigen und oromen, aber man

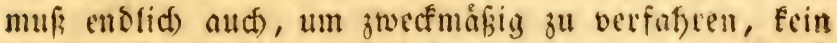
blok trocfen = fiftematifdes Sfelett, ofne alle Sefleis Dung, mit griedifden und andern barbarifden sisortern belaben, geben; fondern man fareibe leidst und ans genefim, wie Die (sefellifhaft ser Menjeden iprid)t, in ber wir heutiges Tages leben.

Buffon wollte eine Befdrid)te Der Jufeften (ju twelden er Die Mollusfen rednets) fdreiben. - Eo fdeint es mir menigftens ลแ einigen Etellen feiner 23erfe. - Zu feiner Zeit war aber die befdid)te diefer Thiere nod) bei weitem weniager eraruntet, als jeţt; und ftatt fein $\mathfrak{B o r}$ )aben ausjufuffren, verjweifelte er fogar Daran, ob man jemals cine folde bejỏidate werde fateiben fónnen. $\mathfrak{W}$ as man Damals mut mit Betwegenteit wagen fonnte, ift je ḩ leid)ter móglich, twenn gleid) mulfjamer, geworden. Man hat feit einiger Zeit viel beobachtet, viel geid)rieben. STBir werden diefe Miateriatien alle zur Şand nefmen; andre Ca)riftiteller nad) uns mogen unfre Srttjumer verbef

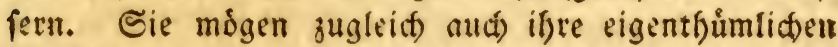
Brobad)tungen ju Detren, Die wir bier niederlegen binjufúgen. Die 3eit wito fie fictten. Die ridtigen werden bleiben, und neue Entbectungen merden bie (B)attungen und Giefdlect)ter ausfúllen, Die roir bier beidrieben haben. Sovier irgend moglic ift, werde ic) Die Supfer bervielfåltigen. Sie find in Der গlatul: geichichte Durchaus nóthig, wenn man die Besgenftánde, wovon bie Fede ift, bollfommen beutlicb fennen lernen will. Sie gaben aber auф noф Den Bortheil, Daf́ fie 


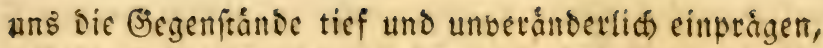
und bie llefade twerden, oaf wir fie beftimmt uns mit Sid)erfeit wieder berbotufen fonmen. \$?

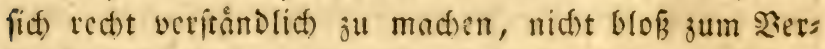

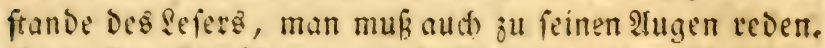

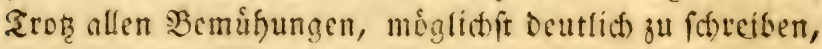
toitd man icnnach sft sunfel und unverftindich, weif man gånjlich) unbefannte oder Dod) nur reenig und ober= flåd)lid) befante Biegentănde ju beichreiben hat. Da muß man Dann zu zeichnungen leine Zufludst nefmen. Dies ift um fo nothiger, je mefr twir uns Dem Ënde Der Sette aller lebenten siejen nahern. Sjer merden Die $\mathfrak{B e d e c f u n g e n ~ u n d ~ D a s ~ S n n e r e ~ D e r ~ T h i e r e ~ i m m e r ~}$ weicter, indem fie zuleţt nur gallertartige Maffen aus= maden. Die Drganifation Der siefen vercinfacst fids in emigen $\mathfrak{A b f t u f u n g e n , ~ u n o ~ w i r ~ b e f a l t e n ~ e n d i d a ́ ~ n u e ~}$ Durd)fidtige Suffanjen ibrig, Die Der leidtefte Irudf, Der fanfefte Soud logar, zerftoren fann. So verbălt

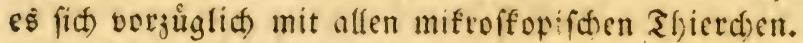

SBenn man etras tiefer in Das Etudium bet Mollusfen eindringt, fo erftaunt man hiber bie sienge von Edyriftitellen in biefem intereffanten Fad)e. $23 a b$ :

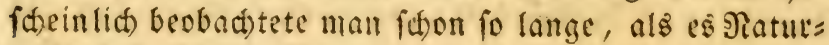

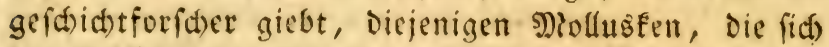
Den Blicfen Der MRenicten Darfellten. \$rgilofoplifide Fefuitate und Bejiefungen, Die fich aus ifren thebers legungen ergaben, muften fie naturlid) bei abieten ver"

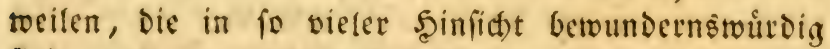
fino, und mit welden alles Befeelte feiten Infang ge: nommen zu haben lajeint. Ilnftreitig id)rieb man fden lange vor Ariftoteles úber Diefen G̈egenftant. Dirs alles aber murde ein ঔaub Der Zeit uno Der Zerftírun=

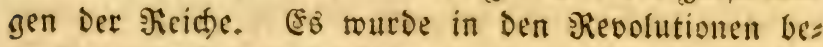
graben uno fam nid)t bis zu uns. Afriftoteles ift Der erfte Mfilofoph, oon Dem wir naturfiftoriftye Beobacts=

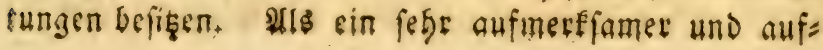


geflårter Schriftiteller, firmmerte er fich roenig un Die

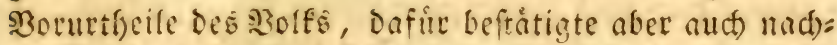
her Die Zeit foft alle frafta, Die Diefer Bater Der

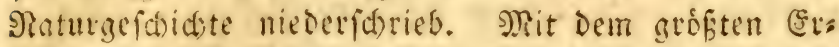
ftaunen temerft man, Dafjer fdon Die Sfiete mit weillem 23 lut von ben inbrigen abjonberte, und in vier Glafien theilte, die er I) weiche agiere (mous), 2) mit Siuften veriefene (cruftacés), 3) mit Sdyalen bedecfte, (reftrsés) und 4) Jufeften, neunt ${ }^{*}$ ). Nanch Diefum grofien Manne folgten fich Dic હuriftiteller Diefes

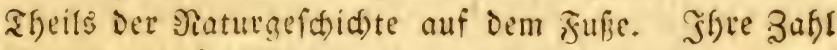
ift roeit betraddtlidber, als man glanben follte, unis nimme tiaglid) ju, reeil man Diejen Sheil Der Şatur=

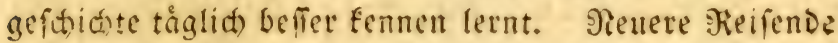
haben unfe Senntnifie in biefen sad)e fefre beteichert. Sicht pelten zog ein Senfblei, Das man in die Siefe Ginablief, die Micerpoime aus dem 216 ștuno mit beraus, und man erfarnte in iffe ein lebendes Fnalogon Der werfteinerten eilie (li um lapideum) und Der (sntro= c)iten unfrer alten Dinftoloaen, von weldien wir bei Den bepanzerten Mollusfen reden merden. Inore Male zog man mit ciner ganjen Menge Mecrgras, a c i na ria (tropif d)e Stuube raifuns tropique), Das fict) voin Boden ablofete, (und tneld)eŝ unter den 2̧endezirfefn fo båu= fig ît, Daß̧ es̉ bịe Edtiffe im Seegeln aufhált), eine unendid)e Minge fleiner Thiere mit aus Dem $\mathfrak{3}$ afier bervor. Andere ?aturforfeter reifeten zroar niá)t,

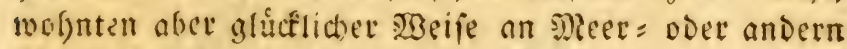
Ufern, und surdfufteten Daber bie jăhen seftade und fteilen felfen, uno mad)ten berrlidue esntDecfungen. Das Mifroffop aber bat uns vorzuglid) mit neuen $23 e j e n$ bercidjert. Taufende von Thieren, Deren $\mathfrak{D}_{a} a=$

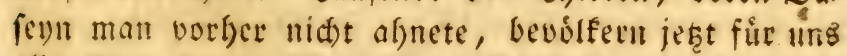
alle eremente. Unermidete Beobad)ter faben sie

*) Ariftoteles, Hif. I. c. 4. น. 8. 4. Lib. 4. cap, I. 
Seife Det befecten $23 e f e n$ mefr alz verboppelt. Sie betraten cine neue $23 \mathrm{c}$ (t) eine $28 \mathrm{clt}$, Die wir nun auf iffen Epuren bis zur abioluten Unfichtbarteit Durds)= rondern fónnen, Deren Grånzen aber einft vielleicht nod) neuentbecte Gnftrumente erweitern werben. Bei Diefen Thieren folgen bie (Erzeugungen unbegreiflict fanell auf eimander, Denn die Ěrfahrung lehrt, Daf Dic Thiere fict, je einfad)er fie find, Deftomefr ber Materie nåfern, bie immer beroorzubringen bemifft

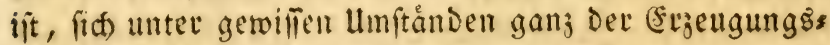
fraft úberiafit, uno willfiffrlich ganje ssulfen won les benden Ittomen f(t)afft. Diefe Ittomen fufflen wieder Das 3ediufnif, bervorzubringen, und nur Die Csinbil=

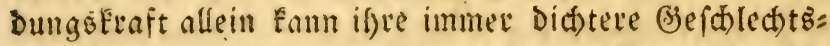
folgen algnen, benn fie find jaflloz. Berufigte die

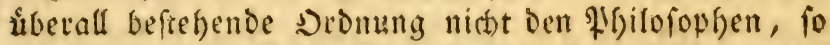

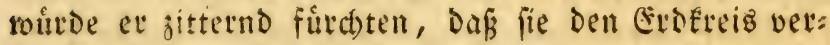
fallingen mód)ten.

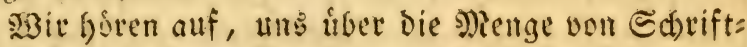
frellern in biefem Fadye zu verwundern, wenn toil auf Der einen Seite Den Siuţen und Den Эeit Des Stu= Diuns Der Mollusfen erwågen, und auf Der andern

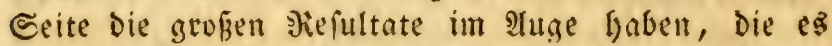

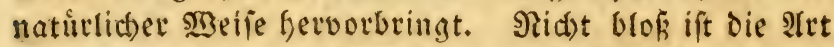
ber Erjeugung und fortpflanjung Diefer Shiete rum Derbar, fondern Der Menfd) lernte aud) einige derfels ben fefre nitglich gebrauden, uno vor andern fid fort= bauernd fithenen. Die Miedizin forwofl wie unfer

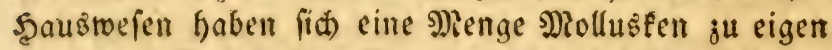
gemacbt. Das ticfite Meer und Die fteilften Sippen

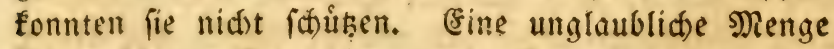
Dintenfilide, Schalthiert und Seeigel Dienen bem Meniden feit undenflichen Beiten zur Nafrung. Die unerf(t) ópfliche Menge von Siafrungsిmitteln, bie fid ber Menid) Daburd veridaffe, hat fogar auf die Bes

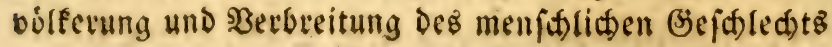




\section{8}

Die Cefinejer, Gapante, Sunquites uno Corect fenten

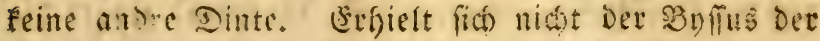
Stecfmulfol (Sdintenmuldel, Jambonneau) mit Glück neben ber Scibe? Sieferte er nidit, wie fie, die

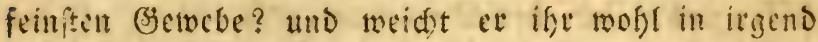
ctwas altoerm, als Darin, Dấ er weniger allgement

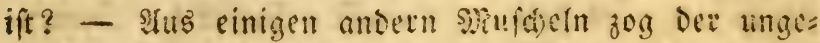
heute \&uxus Det Alten ben befanten foftbaren und

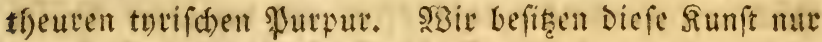
Darum nid)t mefo, weil unfere fdonecen farben, vors juglid) unfer Edarladroth ben \$urpur verdunfelte.

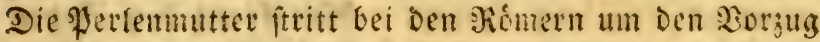

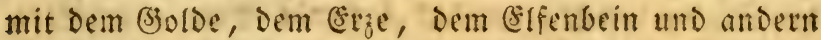
fehe foftbaren 2 Raterien. Cie ictmucte Die Jiednet= ftúfle, Die Sifhe, Betten und Bimmer Diefes pracht= liebenden, máchtigen und molluftigen ßolf́: Sie Dient nod) jest in (E) fina zu Fenfterfaciben, und bei

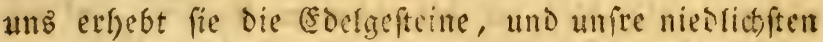

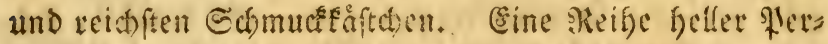
Ien (Produfte von Mrollusfen) veridbonett mandeu weifien Şals, wetteifert mit Dem Slanje des Diamants, und ift feltener und theuret oft als Biold. $23 e l c h e r$ Menict findet ferner nicht Bergnuigen Daran, eine reiche Mufdeffammlung zu befefn? Einige Diefer

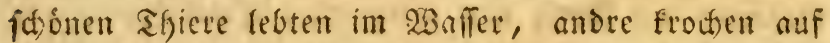
Der erve unfer. Alle aber fino mit ben mannigfal sigften, lactenoften uno febonften Farben gefdumict.

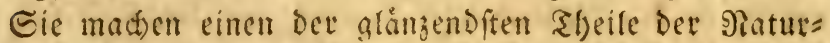
gefdidste aus. Ieuferlich find fie mit ben frifdeften

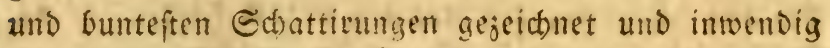
mit einem \$peremmutteríberaig, Der regenbogenartig fhillert und fpiegelglatt ift, befleidet. SRid) tล gleid)t iffer zierlicten form, iffer Nannigfaltigfeit uno ifrem glanjenden अcugeren. Eben: Dezfalb waren fie bon jeher bie ștende der berifinteften Manner. Man muß nber bei Diefem blof einteitenden Studium zum 


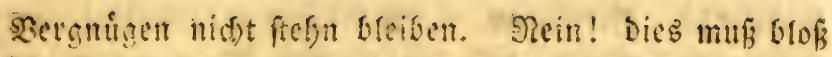
Die Reiter fenn, auf meldse wir ju weit erbabneten

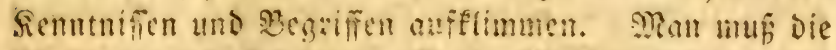

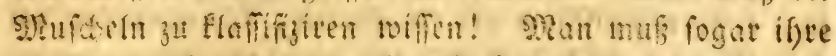

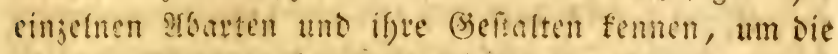
gleiden sndrddeln beftinmt tricder su erfomen, went

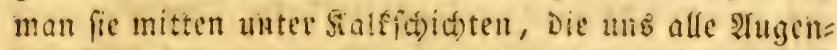
blicte Mufcheln und Sabreporen als Fonilien zcigen, verfteinert antrifit.

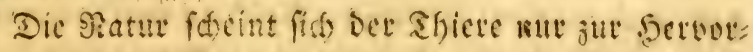
bringung einiget Gaborten uno Der salfmateric gu be= Diener, welthe lestere immer bos groduft ier shier= welt ift. Die Mroffusfen bildetent bie Grumblage Det Wofnung Des झूentien; ifnen werdunft men bie

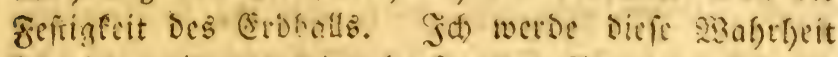
fogleid) meitu auscinamberfeten. Sie cutging fowon jenen Didetern und slbifofopfen, Die ben lltiptung Der

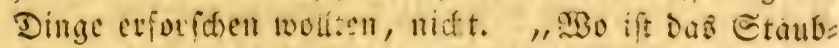
fornden, rufen fice, Das nid)t belebt gemsicn ware!"-

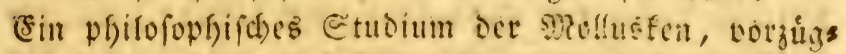

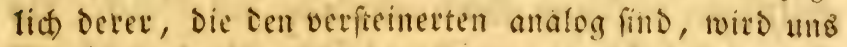
bie Indiviouen, und Die Detter fennen fefrest, wo

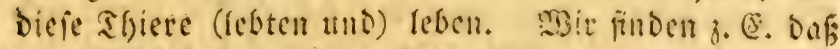
ganje Etiote, - iá) will mur sharis nennen - aus Steinen exbaut find, Die unter den Sebarden der Etobt gebrod)en wurden; wir finden, bafi diefe Eteine faft

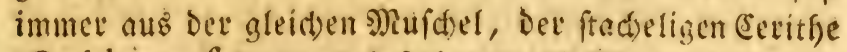
(Ceritheum ferratum) beftefen, und bie in ifrem na= tirtlichen 3uftand bis ju Coofs sieifen in unfern Rabi= netten unbefannt war. SSir finden ferner, Dar Goof fie im Submeer antraf, too fie nod heutiges sages, wo einft walfrifdeinlid) unter Dem Slima von Paris, in ganjen Gamilien lebt. MRนffen twir nicht aus biefem

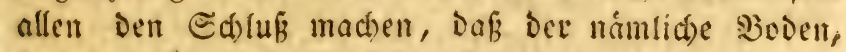
ber in unfern Tagen biŝmcilen fo falt ift, elemals ons brennende Rlima Der Ránder Des Eúdmeers 
Gatte *)? Dic Jeinumg toiro now mafridseinficher,

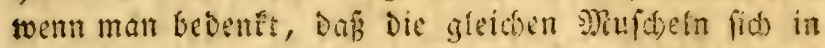
Diefen Ralfingen mit Der Saiffsmufael (Naurlus)

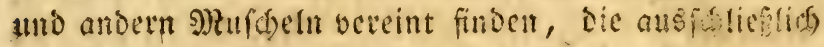

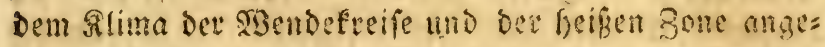

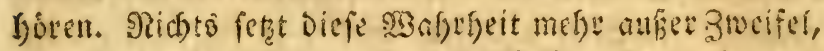

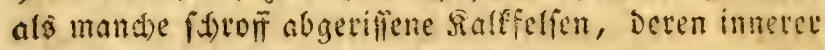
Snoácnbau Dem suge offen Darliegt, wo bant bet

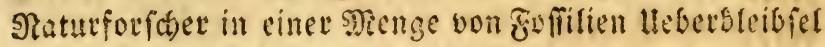
von aufeinander gefolgten Befoledstern organifaer Róper entdedt, bie bie allmåchtige গatur bildete, jer ftorte, uno umfduf. Cine Menge von Goen brängen

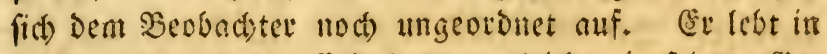
bielen vergangenen (jedaltern zugleid) mit feinen bis=

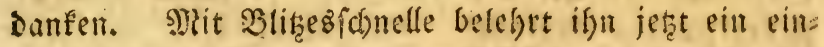

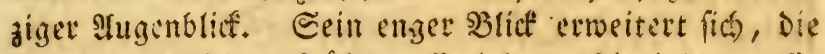

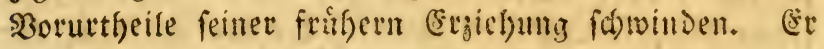
fieft eine ganj neue Sromung Der Dinge oor fid).

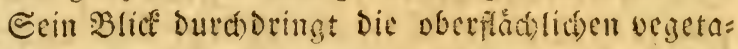
bitifhen Sagen des (scobooens, und beftet fid auf bie Salfelagen. Seictin finder et, wie Der Sjean, Det

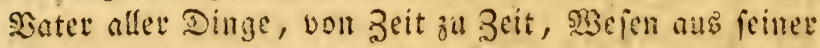
Siefe abjeţte. Seht levnt er, Daf Das Gerinpe und

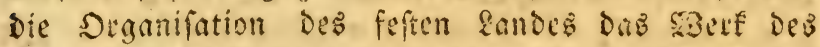
Meeres find. Die ůber einander gethúrmten Sheile Det efjemaligen Serwofner beffelben jeigen ifm unniser= fprechlich, wie felfe alt Der (Erdboden ift, und twie mans nigfaltige gievolutionan wedjelstweife auf einandex folgten uno ifn furditen. Sie find Sa aumimjen jener

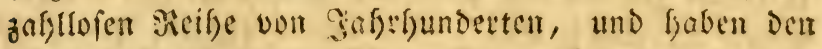
Abbruá Derfelben an fid). So erfdeint alles, was

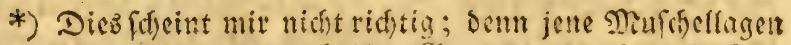

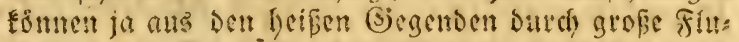
then inf fie Segenden von gु?aris 26. geworfen, und sopt zuricigelaften (ey)t.

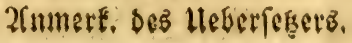




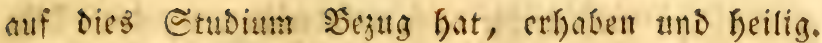
Feifen vorjuglić) unierridsten unb flaxen sui. Durd

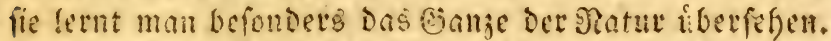
Cin cinjiger şick auf siefes noer jenes Terain ift oft

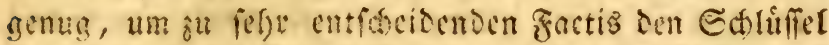
zu gcben. Sruf cince Cobue, anf Dem Gipfel einez Sietges ober an feinen eingeftirnten Geiten, ober am

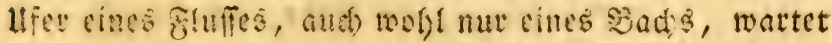
unfret bismeilen cin Eidiptrabt, ber alle unfte soeen erfictent toird.

Sjier bejengen giefenf́nod)en, bie ztwifden cinet

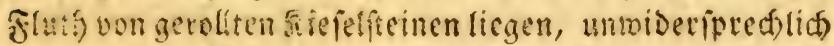
Das cfemafige Dafenn monfuofer Shiete, Deren Ge=

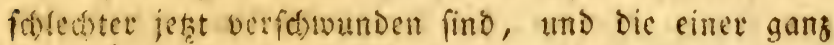

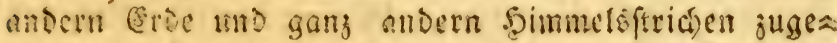
bivet all baben fobeinen *).

Dott jerigen ange felfen Hebertepte jabllofer Bse:

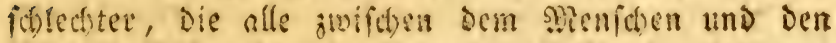
ungerunftigen Sfficten mitten inne ftanoen **). SBe= thadtet man fie ráger, fo mü man glauben, daf cinft sjeetfaten, Iffen und andre $2 B e f a$, Die fid) Dem

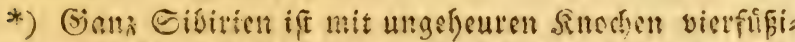

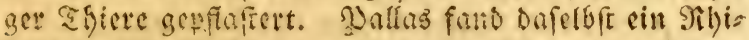

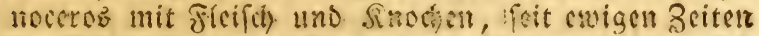
im Eife erhalten. Dergleichen (jerippe finden fids aber (oud) in Ftranfeidy, Deutfíland, an Den Ufert DCs Dhio in Interifa, it Jeru, und anderworte.

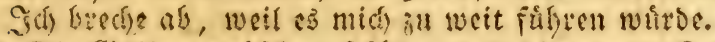

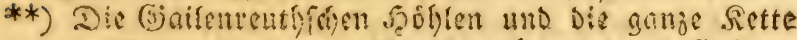

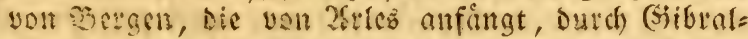
tat fortgeht, fich ins פlect fenft, use in ben Jnfelt

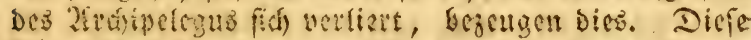

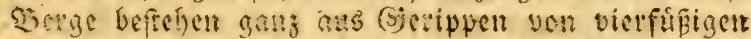
Shierent, Die alle, wie mon gloubt, 2lffet juge:

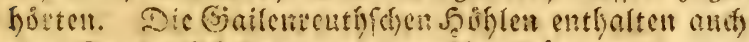

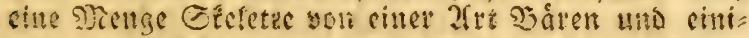
gen andern Thieren, Die bamalz viclleicht, wie isd jest bie Diber, in Gefellfhaft lebren. 


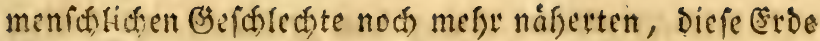
bevilfert, in einem gefelfdoftliden sertrage gelebt,

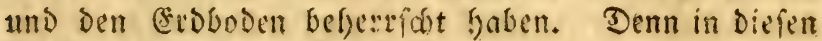
unterirdifaben (jemolben fincet fich nid)tŝ, was Dem S)icnfoden angebort batte: clen fo menig etwas oon

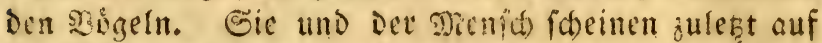

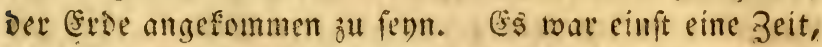

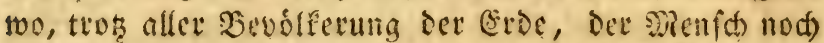

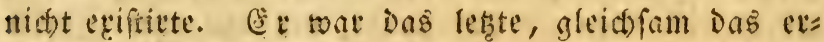
gånjende nisuf jener beregenden firaft, die unferm Wlaneten vorfeft *).

Sozeigen fernet mande abgeriffene Felfenabfurze ganje Gefided)ter von Ectacen, Fifden, Jnfetten, uno andern Sfieten, dic Dem Eroboden, worin man fie findet, nicht angeforen. Sie maden innerfalb Det

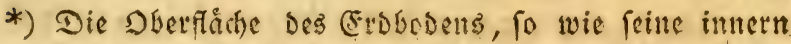
Ragen, jeigen cine solenge sieliteinerungen von sege: tabilien und shieren, nod aber hat man bis jef̧t

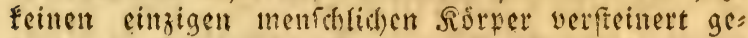

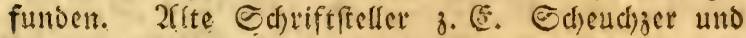
echwebentorg gaben einige verfreincte efelette von

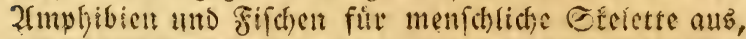

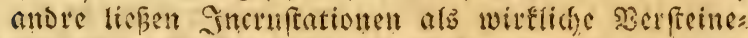
rungen in Sinpfer frechen uno bofonnt mad)en. Sests get 3eit aber bat mall angefangen, beidez richtiger zu beuttheilen. Gerade fo uerbalt es fith mit den

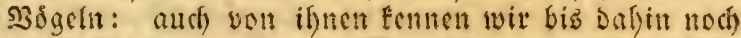
feine serfectnerung mit (5jewifgeit. Da man mun

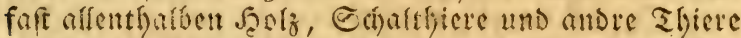
verfecinert finder, won Dehen man Giattung, (sic:

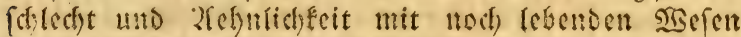
borthun fant? nirgend afer şerfteinerungen wou Denfifen, oder son menfolidyen Sunfewereen uns

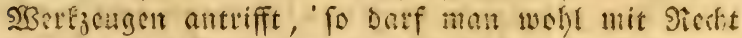

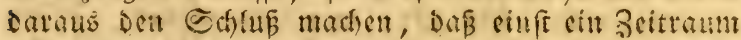

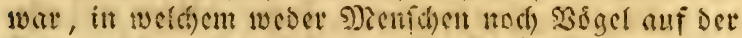
Groc lebten, und baf lie exft in fpatern Zeiten ges fouffer wuiben. (G. Ficruber audi) Fortis Journal de Phyfique, Jnht: 8 ber Siep. im Floreal). 


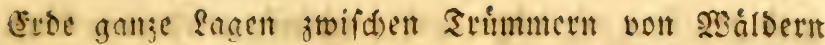

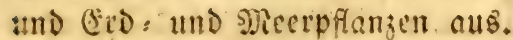

Brofie fetten von Bebirgen, bis ans lauter ehes maligen slectorpetn befiefn, Deren monnigfaltige (Geftaltent und unzålflige Gattungen nidat zu befdereiben fins *), maefgeure leberbleibfel, ja ganje erdagen won Mollusfen, Dereit vicle man in neueren Şciten er=

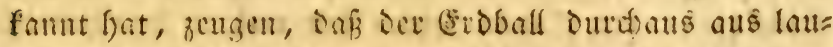
ter auf einanter folgenoen Stimmern ser Sfierwelt gebilset ift. Dutct) Den siergleich Der ausgentabenent Snvividuen mit ien noch lebenden; ber Sorte, wo fie jesct leben, mit ocnen, wo man fie verfeinert fintet

*) Die Sulfgerirge, ausgenon!nen dic von der zweiten

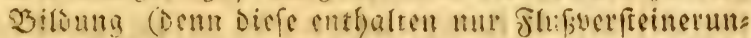

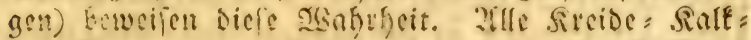

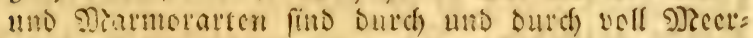

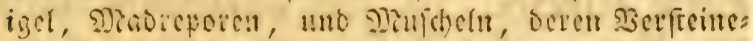

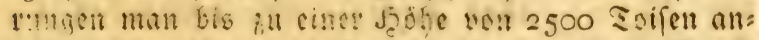
trifi: Don tlloa mo Demben fomben fie it Peru',

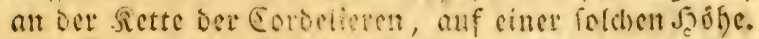

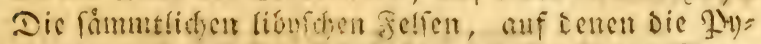

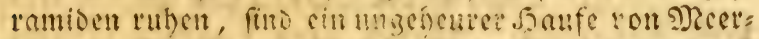

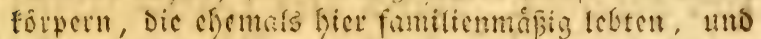

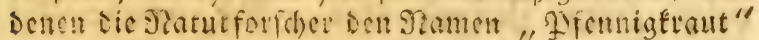
(numulaires) gegefon [aben. פJan finvet fie auch

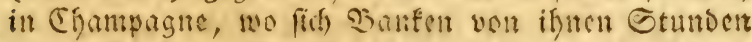

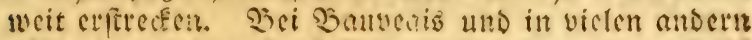

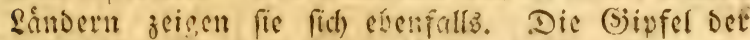

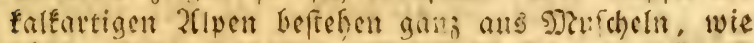

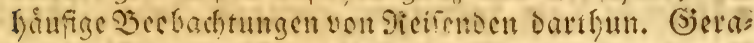
De to if es mit ansern Salfogebiegen, worin man Diefe giefere chemaliget Beitalter chenfalls, feft und

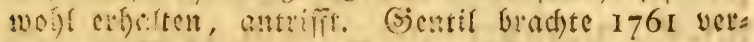

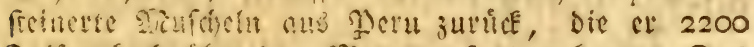
Eofen god thet Dem sacere grfunen fatte. Dab

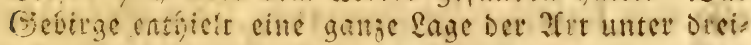

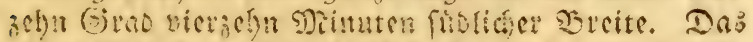

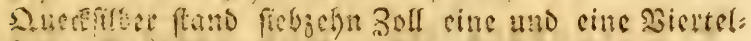
Sinic (Journ, de Phyfique tom. I, p. 436). 


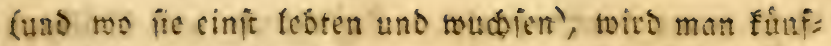

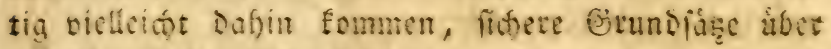
Die SGeorie ber Erse feitiscn ju Éntren.

Die Entitefung Der Cerbe beidaftigte son jeíce Sie becuffmtêten \$filojopgcn. Barum follen mit aber (mie fie) ju :3undern, jum f̧euer, ober (mie

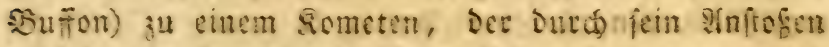
Etuffe on Der Eonne loşgerifien und in Den weitus Sham Gingeworfen Gitte, unje 3ufudt nefmen? -

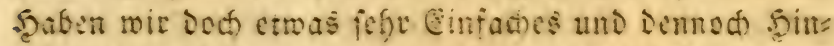
reidendes bor \$I ugen, tocraus toir uns ifyre Entiteflung

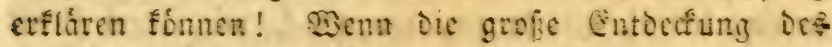

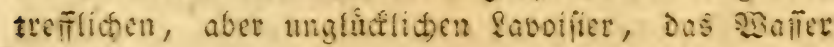

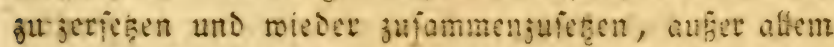
Brecifel itt, fo fonnte uno muthte fa Die gleiche sastes fung in Grofen in Der ungefouren Sitmoibghte ber Eonne entitefor. Sin sem grángenloien \&uftneete, Der Noutter aller foliffigteiten, verbanden fié alio

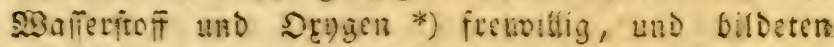

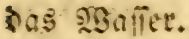

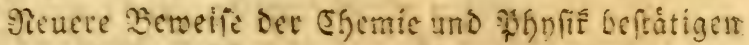
Diele Sopotícfe. Saglich gefa uberbies Gotarten in einen feften 3uitano iber. Iit iebigen Crolagen nefimen viel bavon in fich; Der salffecin 3 . (E. enthalt

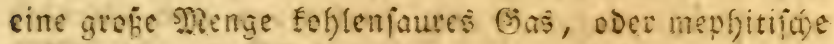
Quft.

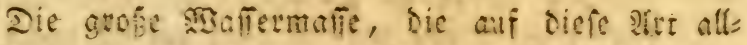
míblid in bem fuftraume entitand, exfielt Dind bie

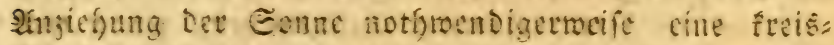

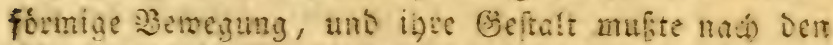

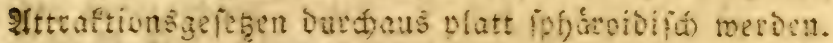

Die mátige Ittraftionsfraft gab bicier Mafie

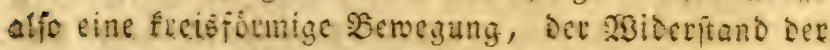

*) Brentrate und reine Euft, in for alten Ejemit: 
Recung aber waigte fie um ifre Ifte. Einmal in Bes

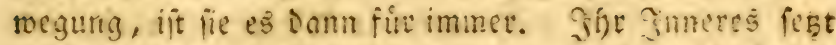
(id) allmáflid jut Bufle, uno nun entitefyen allmifflid) Die Monaden, die Jnfuivins = Mollušfen, bie mifto:

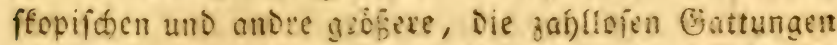
von mabreporifaen uns tubiporifuen Fofopen, die Sdyal = und Suften = Yollusten, Binten = uno andee

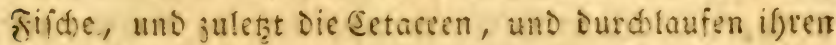

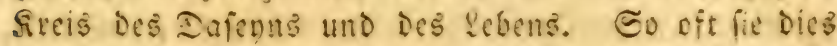
cnoiagten, fenften fid nach)den Gejeben der Centripedal: fraft ifre Ucberteje nach Dem Mittelpunft Der Bewsiliee hin. Sier bisuften fie fict allmablich an, uno formten cine fejte Eptátroide, die ber miffrigen, welche lie um=

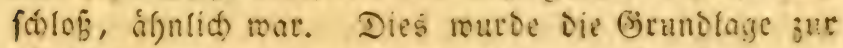

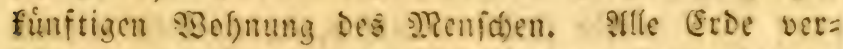

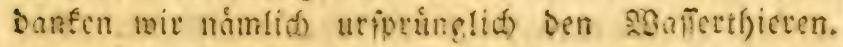

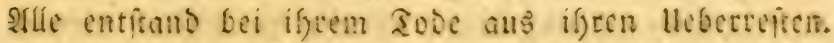

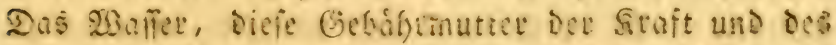

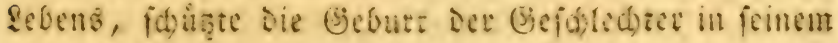
Edpope.

Sthove Gasarten vereinizten fís allmaingtio mit ben beiben eriteren. 2zorsinglid mute lid bas mephotịje bas ouf ber sisafferoberficue nicteridlazen;

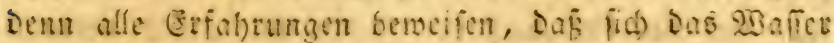
am lecióteften mit bemjerben vecubiniet. (Es permiráte

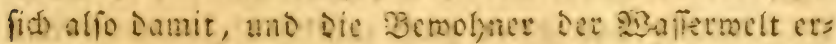

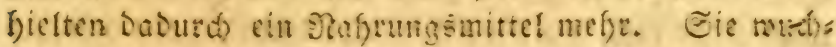

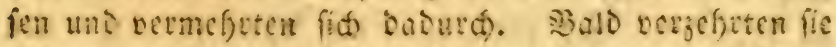
fid) unteremanter. Die fleineren uno fordéteren Dicnten ben gróferen und fíngeten jus Epeif́, ano bicie

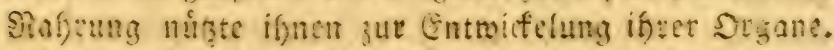

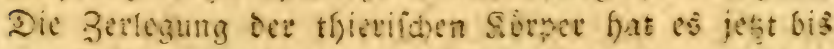

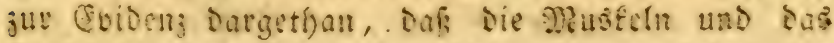

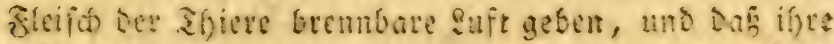
fefteren Simodien cin arohe DRenge figer \&uft cutbaltch.

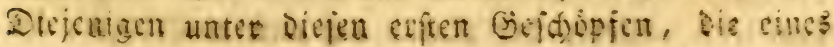


matirliden Sobes fratben, gingen in \$3erwefung uber, und Dic 洒ateric, Die cimmal in Setwegung twai, uno bas Şedurfnif, fich immer neu mieder zu reproduciren,

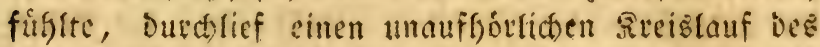

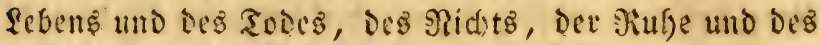

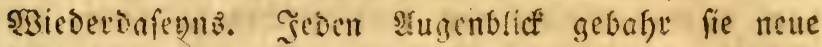
Sombinationer. Etatt baß fuerft Inorognues, Die beibe Befdecter in fich vereimigten, ba maten, ets theilten fpaterfin zmei Jndividuen bon verfdiedenem

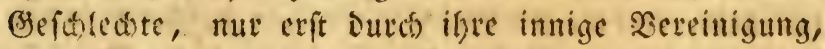
neuen secen das Reben. So oft fie, langfamer doet fómeller, bas ziel ifres Dafenns erreid)t hatten, wut: ben fie mit jenen Grundfoffen wieder veteinigt, bie aller Modiffeationen făhig waten.

Ber innere (Evboll mukte fich matirlidertoeife

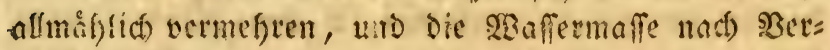
baltnif bermindern; Dem, fo wie Die Ificte barinne fict erzengten, vermefoten und wudhfen, eigneten fie

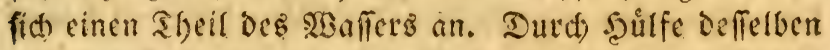
und Der Gasenten, Die fein şefen ausmaden erbauen

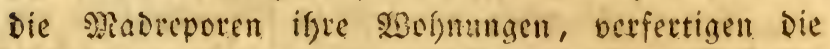
Ehatthieve iffer Gdalen und \$anzer, und bilden Die

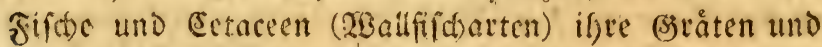
ifre ungefeuten Snodien. Seder arugenbliaf vermin=

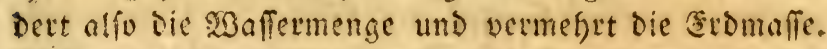

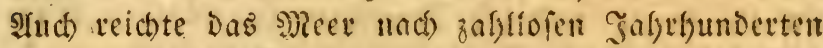

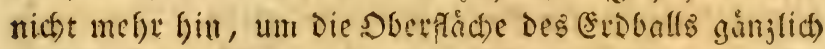
ơ bedecten. So entfanden die feften fander. CSin neucs Cilement, das Cilement der êtde ging aus Dem

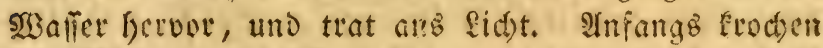
nul Moos uno Ufei = und andere niebrige \$ilanzen auf

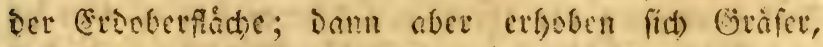

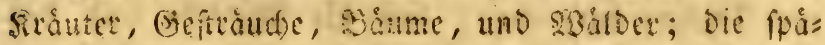
terfin toieder von friedenden, vierfiffigen, jwei = und

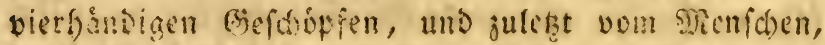

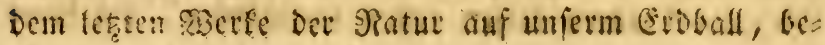
mobnt wutoen. 
Die aแลgegrabenen Mufd)eln wetben ung tereinft

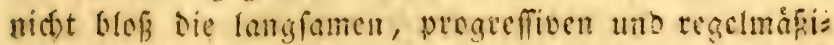
gen Revolutionen unferer cersfugel befannt mad)en, fondern uns aนd) Die inneven Berteifinngen, Setŝers inderungen $x$, auseinanterfeţen. Dann werden wir

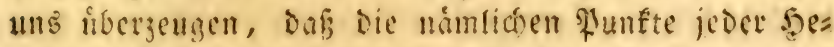
mifpare abwedfelno uno in beftimmten (Epod)en, allen

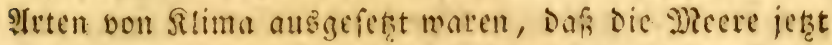

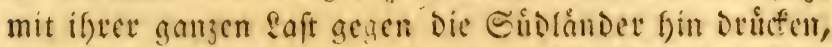
und fie fidber cinmal berfdingentwerden; fo wie baf fie Die norbifden fiuften melge und mefre verlaffen, umbie

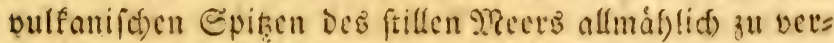
fenfen. Dicfes Sinneigen Des sneers nach Eitoen ift Durd)aแs nidut mefre problematifd. Im Begentheil man fann, wenn man Die Besbadtungen, bie feit drei Jafhethunderten angeftellt fir: $b$, an einanier bålt, mit

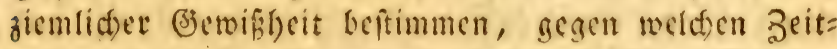

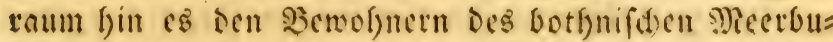

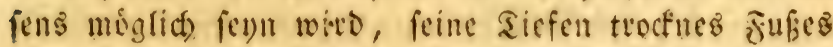
zu Durdhandern. Das şafier twitd sinft Den Euno verfaffen, und Irummer von meft als ei the in trauri=

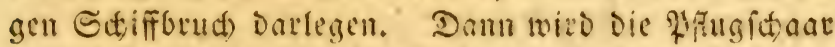
Den Boben Des efemaligen Ranals furden, und Der \&andmann feitic Eaaten in Durdyfingte mannigfaltige Ed)altblere ftrcuen *).

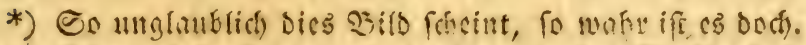

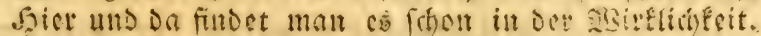

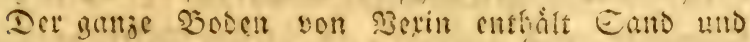

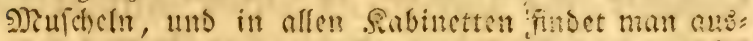

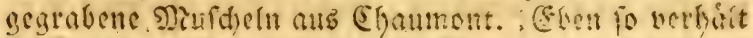
fich's mit Der Fourratue, mis Ehampagne, berousers mit Eourtegnon nabe fei Sifeins, mit frampton: Thire in Englano, mit ber Eisgens mn eothon, ja

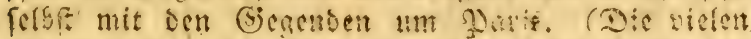

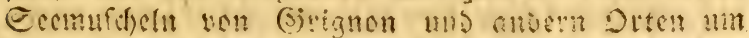

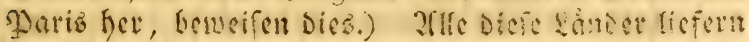

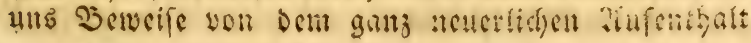




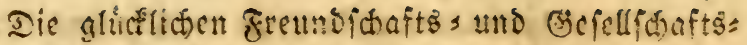
infeln, - Die cinen autfentifden şemeis des fefon fefre alten geféliffaftlicisen Sercins abgeben - wer= Den alfo cinft aufforen ba zu fern. Die zahlreia)en

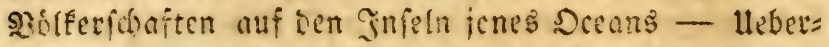
bleisfet ver ungefheuren Bevolferung cines ehemals hiet befindiden feften santes, - werben iffe 230 fmun gen verlafien und aufs fefte sand flichen miffen, aber Die Bergifien bế fêten Landes merden mit uer z̧eit

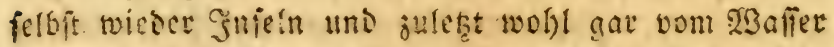
betfufungen weroen, um nać Gofrtaufenoen vielleidst

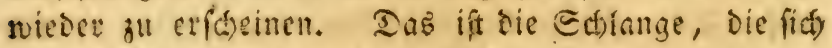
in Den Éstwanj beift; jenew volffommen entole Rreis; Dab Sinnbils ber Errigfeit.

Mian fángt nach gerade an, Dicfe Mafrergeit zu fíflen. Grofe Manner baben fie, meninfrens zum

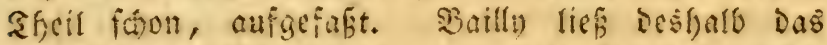

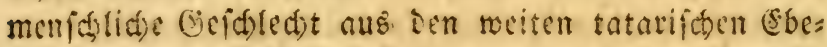

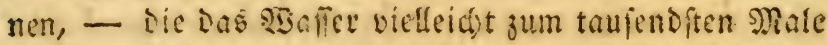
verlafien Gabe, - berworgefin. Sene, die das \$a ravies unjeres Etammvatis Dafin verjesten, fagten gewiñermaben Das (STleid)e.

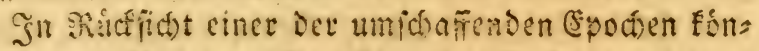

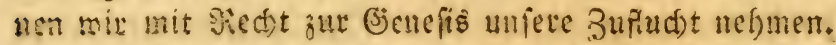
Sie crethert megrete alte fiosmogenien, uno mencise múndicie Stabitionen ju unfecer Šefefrung, uno ift cin Mere eines erfabenen, tiefen Gertes.

In Den keiligen Sieroghphen ber \$riefter von

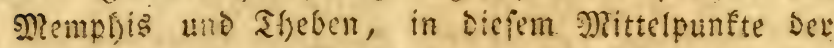
menfoficien sentniffe, findet man Epuren von allen

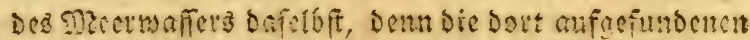
Somforeta fint, fo su fagen, gat nidjt verindert.

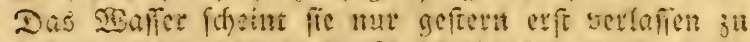

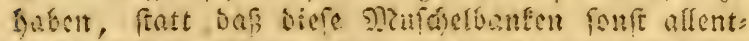
hotfert fich in sharmos und andern farten whe fefren sialtifeinen votintoen. 
jenen altan fosmogenien, Die, toie tic Menifontacen felbft, init cinander abtwedjelten, und wooon wir jeget

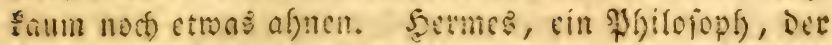
Die Siatu: mit einem cinfaben, ourdfictigen und reis nen Edyecer berecte, ifi foron zu weit von uns ents

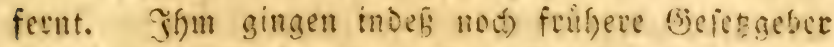
voran. Atle seseifen aber unfere: 3eit fowohl, als bez SIltertfuns, Die Boradimanten uno Efintejen, Sons fucing uns Die Bymmofosfifen, alle fino aub bet alcis

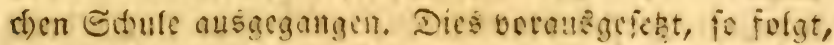
Daß3 Die verfotiedenen Stationen, Die bon 3eit ju Seit hier und Dort vertrieben mutesn, wie Dic sebe futbjt manderlei Berfirungen exlitten, wofer eb binn aut fommt, bark fich bei allen geffetu bie joce son einer

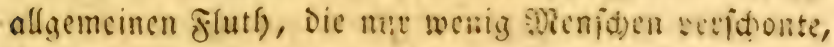
findet.

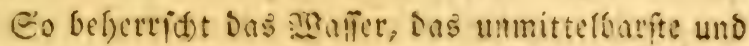

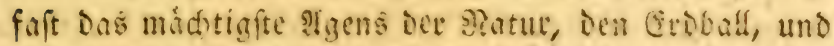
bebecft iffn mit feinex tiefen Mane. (E) jerfiste fier,

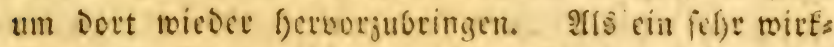
fanes Menftutum lojet es Die veridiedenen Slemente nuf, und mad)t fie flififis, fnetet und bentbeitet bie Paterie von neuem, un fie cinft unter taufens modip: fationen weder ju vethaffen. Sylfentbafben binterlápt cริ báufige Sputen Davon, Daf eŝ einit Daletbit wat,

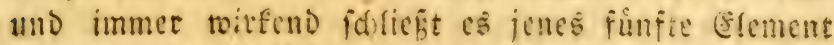

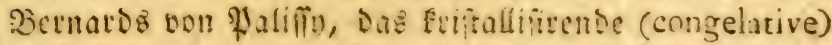

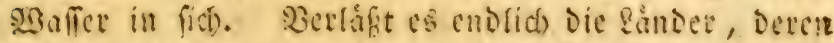

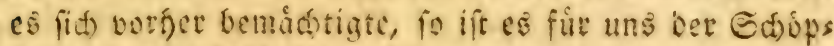
fer jetriget unt fintitiget stipent.

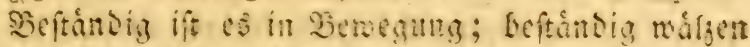

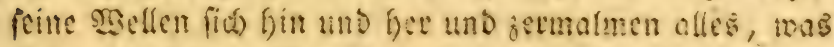
ifrer ungefeuten bemalt untermorfen ift. Dicjes ewis ge Echmanfen ift ene Jolge ber Gepere Des (sieidges wid) tร uno Der Eafmete. Eie fampfen gícitblam ges gen bie finfwafier an, Die sine sinenge Edfamm uno 
Unenth aus iffest abfoingigen şetten und von ifreth

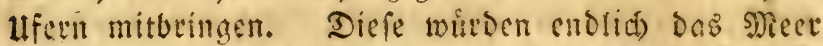
susfuffer, wenn bits wid) reieder an feinen llfern eine

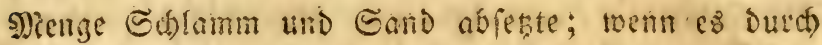
feine elvige serwegung nidt fict tiefe sgolee wifflte, und Dort ganse sbergatupen emporbibe. Reifiende

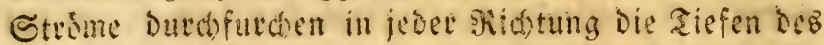

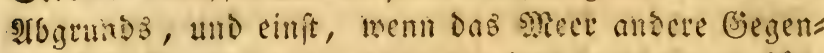
Den bedsift, went ein Sgeil ber jeţt verborgenen \&ăn ber von sisffer entblónt ift, wird man Jliffe burá) fandige Coeneh, umgeben von Edalthiergebirgen, flie= ben fefn; man wiro tiefe sisecten antrefien, die die em=

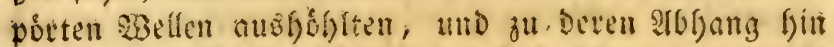

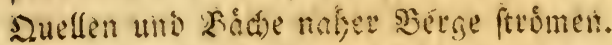

Das Dreer geft in frimem verzefrenden fonge imme: weiter fout, aber es fommt aud wieder auf

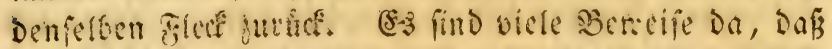

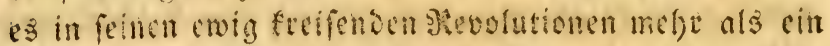

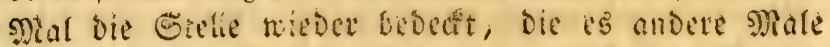
vetaffen bate. Shlev find me einige: Die Balme= Grotte, Die Das sole in Det Datrphine mit au Den fies

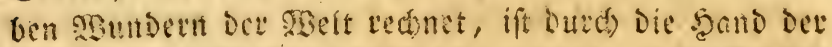

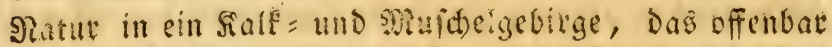
vom siallet gebildet wutde, eingegraben. Its das Dicermafier fić) weggezogen batte, fcigette fid Jiegen=

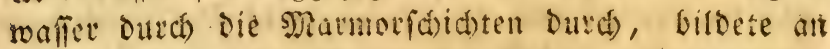
Dett (Bemolben Der Brotte Sropffteine (Stalaftiten), uno ifre Serabtråfelit brachte auf bent Boden Der Soffle Stalagmiten betwot. Dits tomte natitrlich nicht vor Dem gánjlic)en Mlblauf Dcs Miecrmafiers ftatt fin Den. Dann festen fich fpaterfin wieder madresoren,

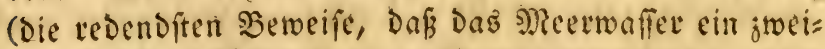
tes Mal zurudfefirte) an, und wurzelten und toudfen ouf Den Stalagmiten, Die Den Fubboden Diefer tiefen

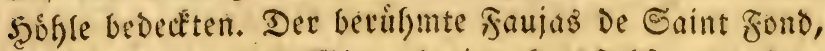
mein $\mathfrak{E}$ frer in Der Mineralogie, bat felbft unter Den 


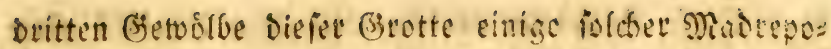
ren gefammelt, und Dolomicu hat mad feinee befann= ten Siffnfeit ansere in ben Spalten und obsten $8 S=$

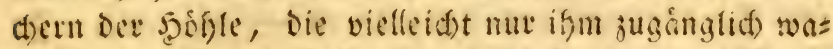
ren, abgeriffen. Beide legten biefe widetigen Bente máhler in Des ungludflianen ?ardd)efoucaults treffichent

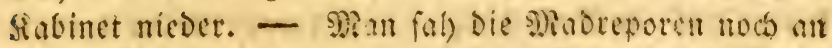

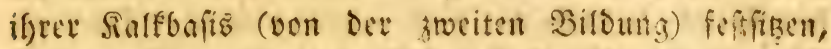
aber fie find unter Den Stirmen ber Bevolution vers fowumber. Gnock grofere und coibentere semeife

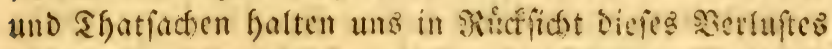
fadolog. Sikan Darf nut frantreids unt Cnglants Siliten vorjiglid, am Santil, bei Dover, Savre unb Boulogne bereifen tho unteriuden. N3om Eap Gristes an finbet man alle sialfeflen som lifer chtlonis $m \mathrm{t}$

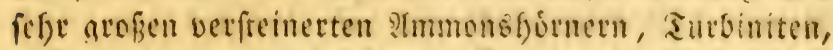
(Erd)liten, Pectiniten, Eamiten und Sjatreperen an= gefullt, die Den \$leten beifer Sander angefout baben, wie bie ifnen entipedebenden Driginale benerien, bie mir jetziger Beit won andern Meeren her erbalten *).

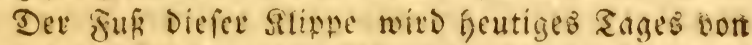
einem nordicten Meete befitht, ias ganj andie (Bat: tungen von Mufdeln auf Dempetben abjest. Deefori taines hat mir aber eine Mlenge von folnilien gëgeben,

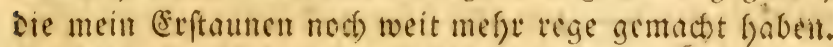
Cre pelbft bat fie alle in Iffrifa, all Den berigen von Zaara, zwcifundert Stumden weit vom s)eete gefan=

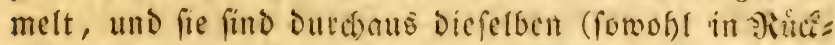
fict) Der Jatbe und Gattuna, als aud) in Hitufidat Det Irt, wie fie verferinet fint), Dic bie alte maffe bet felfen bei Şavre ausmacien. Wie fint ifnen fo vollig gleich, fage id), Das bas gribtefte suge fie nicist von ifnen unterfiteiden fann, wenn man fie vorffer unters einander mifdste.

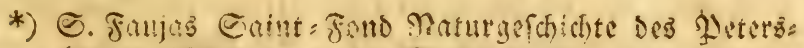

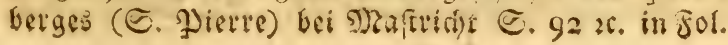


Dieje Beipicte twerben anch Dem Ungläubigfen Die periobifte Ritufefr Des seers auf Den gleidien

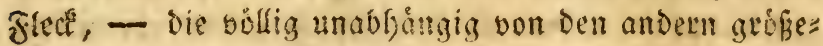
ren Revolutionen Des extbballs ift - beweifen. Sit

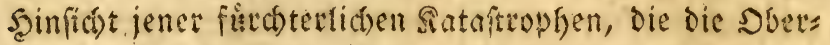
fád)e mefye af einmal foton muffer umgetwandelt faben, feglen uns alle Defumente. Sibir tappen in Der Dunfels

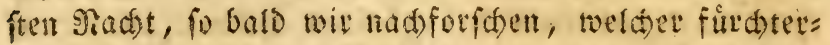

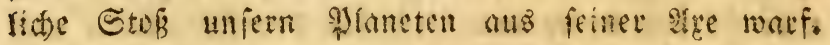

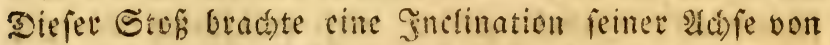

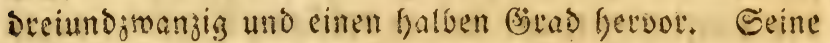
Gioundeften mutden an biefem forderfisen Sage Der Stater und ber. Bernidtung feiner viefen Betwofnet

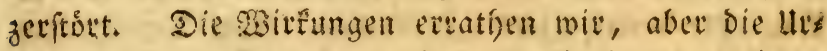

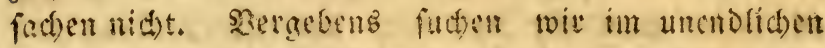

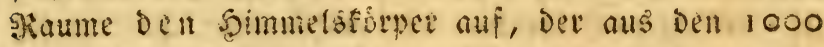
Dal 1000 Miltionen Eomen fich lostín, und an unfte Crobe antien.

In ciner Diefer furdetericion, fir uns unerfláts baren Bevolutionen, mifen wir ben Heforung Dee Granite fuden. Dffenbar beftegen fie aus verichie: Denen Elementer. Gigr şau jeigt ein sierfed)ten betes

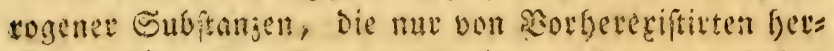

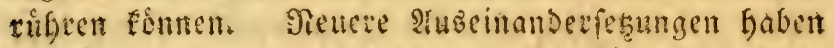
Saltmaterie - cin alleiniges und unläugbates \$ros Duft Der SGierwent - im Bent aufgerunder. MRn bat abet auth Alcali vegetabile - ein vegetabilifdes \$roduft - Datin entoect. Dex Gearit felbit ift alfo viel(ed)t blof das Mefultat ber firiftallifation von Ralf= mo vegetabilifon Cerben, bie irgeno sine filumiffeit, in ben Seiten jener Siataftroplyen, meldise alles in ein (el)aso vermandefn formen, aufgerbet fielt, uno bie mit bembarer Ruft itberfätigt wat. Die tiefoenfent=

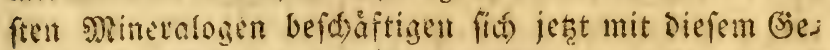
genftund. Shon baben fie eine s)lenge von Thatfachen inis \$sebachtungen gefammelt. Dis Berwandlung det 
Sialferbe in Miefelerde fiteint wenigftens betwiefen zu fenn. Bicteicut jeridneibet irgend ein glúcflid)er Zu= fall simft Diefen gordifter Sinden Der פatur.

Das Waffer ûberfteomte alfo (mefrmalŝ) Das fe= fte Rarid uno alles, was toir in Der Batur, die wir be=

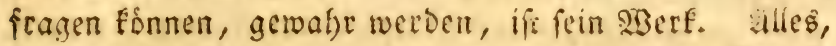

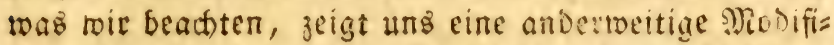
fation Der Salfmateric. \$on ber einfaden bló̈ ent= fårbtel Mufhel an, Die mit Dem Boben, Den wir be= treten, vermifat ift, bis zu Den pyramidalijacn sialt: Tfon = uno Branitpiken (Diefen ungeheuren Silial= [en, - Die Das Ifuge zwar nod) nid)t Dafir anesfennen roill, Die aber Pajlimot fo fdén als folche Dargethalr நat - Diefer entfieifteten felfen, die man bisher füt Donumente ciner Durd) Teuer oder fiedendes $2 B$ affer

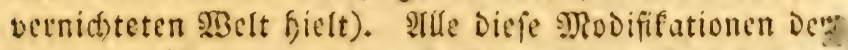

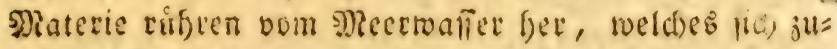
erft Der Salterde, - cines animalifichen lleberbleibiels, - Dann Der Shonerde, - eineś vegetabillichen pro= Duft fteffen, cinjeln oder vereinigt, alle felfen bildete, oie ben Sinothenbau unfers \$lancten aus๋mad)en.

Ja) mufre mid) Diefen Bemerfungen, Die fo nas túrtic) aนร Dem lieberblite meines llnternefmens folgen,

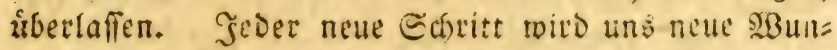
Der fefen laffen. Das ganze Dafern, Das seben uno

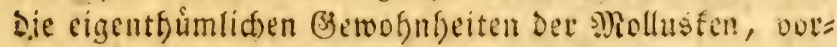

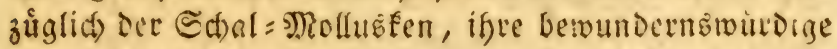
Mannigfaltigeteit; mefre ater, als Dieŝ alles, Die wills

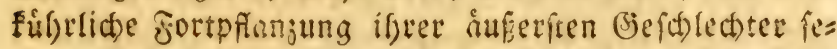
teen Den Beobad)ter in Sab tieffe dertauner. Bei Der Befdichte Der einjelnen befannten Gattungen jener oben angegebenen abtheilungen werde id) mich, in Rúcficht mefreter Entwicfelungen und mand)es mefre Doer minder eigentfúmlicten Shatfacten, forgfátriger berweilen, Denn iff indididuelles Studium wiro Dasjes 
nige, was ich bis jetct nut obenthin gleich jam habe el= blicfen lafien, beftátigen. B̧orjuglich werbe id meine Iafmerffamfeit auf Die letten Dromungen ridten. Die entfertiche 3ermefrung ifrer Sndividuen muf boch eine Itrfacte haben.

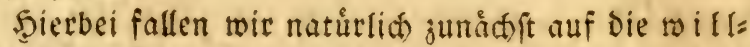

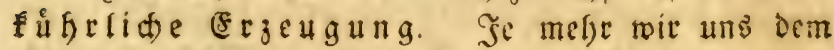
Biele der belebten sBelt naffern, - id rebefier noch

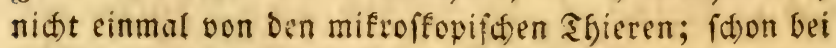
Denen, Die unjerm blofsen Auge fidtbar find, verfált es fict fo; - Defto einfacter in iffer Organifation find Die Gndivibuen, Die wir antreffen. Die Abftufungen bis zu ifnen binab find unmerflich, aber auch unjăglig. 23ei biefen (Battungen verengen fid), ja verfarwinden

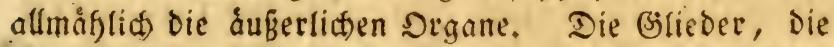

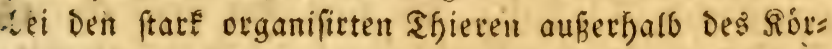
pers hinaus gefenen, treten bei benen, beten innerer şau weniger verwicfe!t ift, wieber mefr hineinwairts.

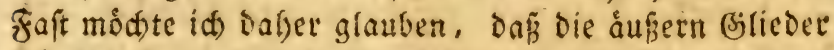
(id) um lo melgr zufammenfalten, verengen, und mit bem अiumpf vereinigen, je weniger झlats bie innern Theile einnefmen. Bei noch andern Sattungen ver=

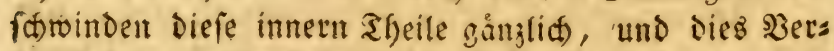

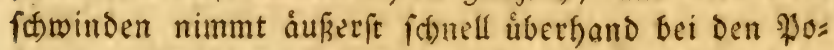
Inpen. Bei ifnen findet man nicht einmal Epuren ber vornefmiten Eingerweide, Die wir Der langen Gewofn= beit roegen, als jum peben refentlich geforig, an= refren.

Iuf Diefer Stufe madjt ein blofier Sacf Das Ifier aus. Man fieft fein Beflirn, feinen Sopf, fein Serz, mit einem SBorte, nichts von Dem an ifm, was ein $\mathfrak{M B}=$ fen haben follte, wenn man es mit Denen sficren ver= gleichen rill, bei denen Das Sers und das Biefirn Der

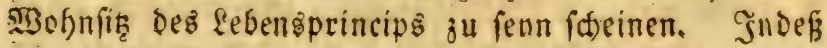

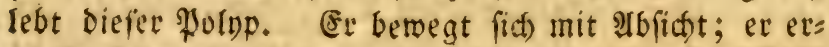

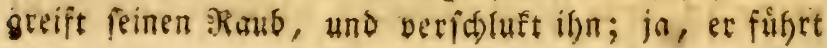


jogar ein fefre thátiges seben. Wenn man ifn aber nid)t freimillia fandeln und fid) beroegen fäfe, wenn er ofne Berwegung wor uns Da láge, fo mutden toir ibm faum eine vegetabilifhe Rebensflaft juichreiben, viel weniger ifn für ein Sgler anjefn. Mnilionen Battun= gen belebter $\mathfrak{2 B e j e n ~ f o l g e n ~ n u f ~ D a n ~ P o l n p e n , ~ l i n t ~ i f g e ~}$ Drganifation ritd in emiger Ilbftufung immer einfa: der. Da, to unfere Iugen nicit mefr finteichen, wo unfer Bblict nicht mefr Durchbringt, neffmen mit

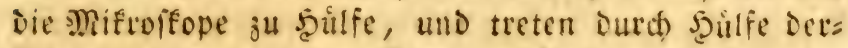
felben in cine ganj neue sigcl. Millionen uno syilliar= Den (jattungen von Sbieren jeigen fid uns, wie Durd) cinen 3auber, und iffer $\mathfrak{A n j a f}$ l fajeint Den ganjen अisum aubfüllen zu folien. Aber auch für Das funfiticte be: fict) ift eine Bitenje Da, und wir fennen Den fleiniten \$unft Der leşten mifroffopifthen Shierchen noth nid t. (E) folgen immer nod) fleinete, uno nux Die (Eimbils

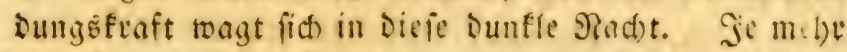
man fid) insefb Der Grenze Der Siscien núbert, Die ias Ifuge erblicfen fann, Defto vielfaltiger werten fie, und

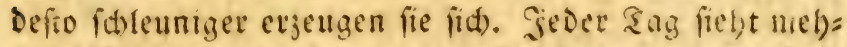
rete Bifidededter, Denn jedes Gndiviouum Durchláuft alह Stamm einer ungegeuren jamilie in menigen 24 genblicfen Den Rreis feiner Scriftenj, oder vielmebr ber Iugenblicf feiner (jeburt ift oft aud) Der feiner $\mathfrak{J} u=$ gend, feiner Beife und feines sodes. Zeit und um= ftäbe finnen hier allein Brenjen jeţen. Diefer lleber=

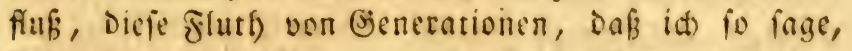
findet fich allentfalben, tho eine fanfte Semperatur Den Garmonifichen Ibeildsen ellaubt, fich ju organifiren, als lentfalben wo flima und şàme Den feimen binteis d)end ginftig find, um fid ju entwicteln, uno Durd Daŝ (Entfalten aller igrer (Figeniduaften zum Seben zu gelangen. Diefe Reime verbielfältigen fid), uno pflan= zin fich unbegreiflid fichell fort. Mran fieht Mintiaien won Snjeften gróbere Thiere befriegen, und toenn nid)t 


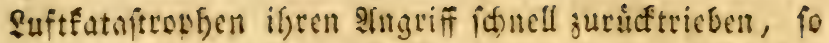
roirben fie Die grefferen Ibiere vernichten, unt fich Dez

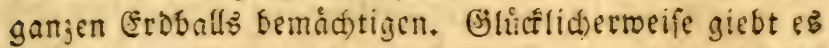
aber Frrenjen gegen biefe sarbreitung. Co roie die פlatur grof̧e s)littel ju erjeugen foat, fo bat fie cudf grofe Prittel ju jerftoren. Die Birfung Der einen Sraft unteroruct bie andere, uno es entiteft ichell

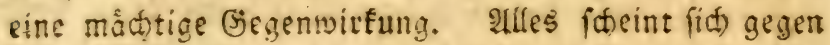
Die austottende Sraft ju berífwiren; fie roirb oon al= len Eeiter beengt, uno Der $\mathbb{2}$ ungenblicf ifres geroaltia:

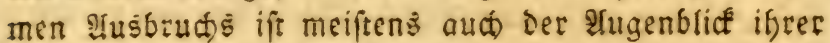
Bernichtung. अ(les in ber Natur ift im Gleidigeroid)t;

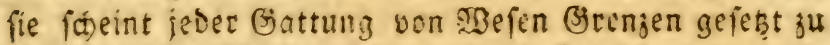
Gaben, die biefelbe nicit ungeftraft uberidereiten barf.

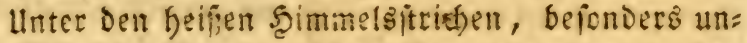
ter Denen, Deren regelmápige Semperatur neun \$:o:

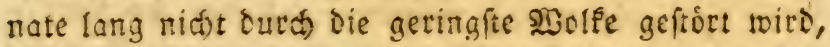

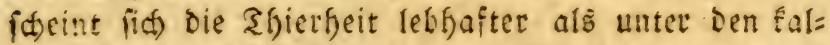

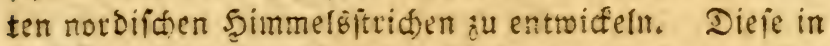

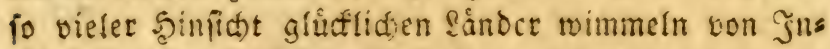

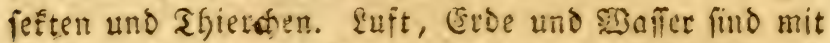
belebten IItomen bevolfert. albe: man fieft fie aud) fich graujam einander befrtiegen. Eie tidoten und vet:

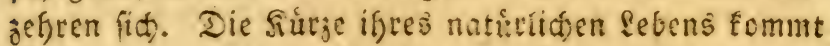
noch finju, und endlia) fegt ein Eturmmino fie oon ber Crrbe bintweg. Einige battungen find unftreitig

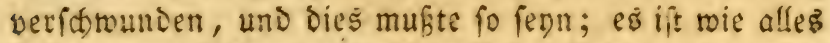
licbrige Der Dronung gemåb. Feine Gattung follte Die nnoere beferriden, Denn die herridende (sattung fann nur auf Goften aller úbrigen beftefn. Selbit Die jer= f:ótendite battung von Ifjieren, Die menifhliche, be=

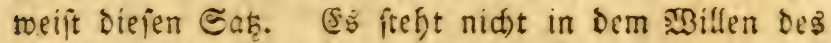
Incrifhen, Die 2Bolfen von Seuldurecten, die leine fels Der verfeeren, und Sranffeiten, ja ben Iod mit fich.

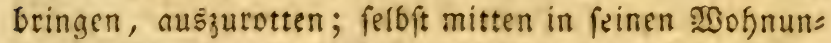
gen greifen ifn die clendeften Joreften unaufforlian an, 
unterbrechen fine Bube, uno leben auf peine soften,

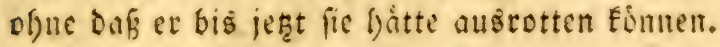

Eben fo tounderbar uns mannigialtig ift bie ?at,

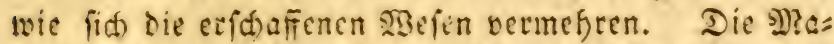
teric ijt fáfig, alle Geftalten und Modififationen anju=

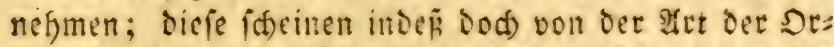
ganifation iffer einjelnen Iheildell abjufänget. Dics siscien follte gefien, ein andeces mur friechen; Demr bas eine hat Shenfel, Das̃ andere nidut. Ceben fo berz

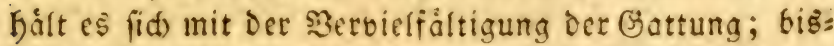
tweilen (vorgüglid findet biefe 2iermefrungsart bei bert mifroffopifden Ifielen ftatt) jertbeilt fid) Der Borper in zwei Theile; jeder cinjelne Ifgeil thut toieder bas Bleid)e, und in renigen Erunoen vervielfätigt fid sie Zafl ber fo entitandenen Shiere Durd) die Doppelte 9 re grefín bis ins Lingatglige, wie Der Sand am Meer. Sa, bies gefdieft oft jogar in einem eingigen Sage.

In Den Rallen, Die Diefer gan; junaddit fefhen, gefdiefft Die Rermefrung Durch Epróflinge, Dent wenn bie Prolupen fid felbit ubeclailen fino, fo vermets:

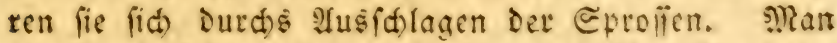
hat fie oft idson auf taufend Irten jerfsact, abee jebes \$oltpen = Itom brad)te wieder einen neuen Polopen her=

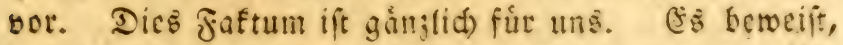

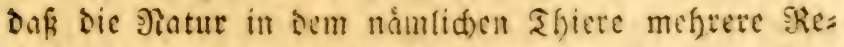
produftionsatten hervorgebracht Gaben fant. Das Sbiet fann aljo cinet sinenge ven Bufillen untermorfer merden, und dieje Gufalle fomen feine vorige Bepts= Duftionstocife jerftoten; es hat aber mefere andere

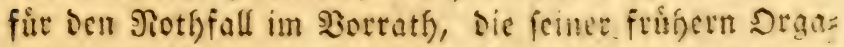
nifation wieber neue Mrobiffationen ertheilen merben.

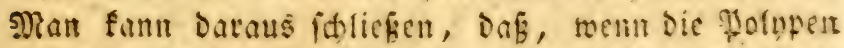

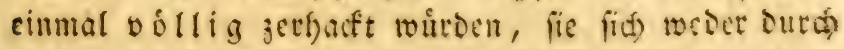
Ifeite, nod) Eprollen, nod) Ednitte mefre vermefrets timiten. 


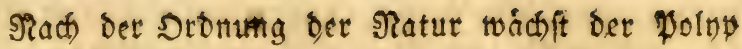
auf Dem Giorper feiner Mutter, von Der er fo lange

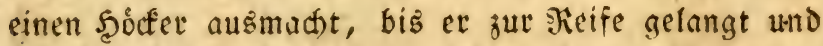
funftig felbit im Etande ift, fich zu vermefren, wo er Dann feine Mutter verláft, um abgefondert ju leben, uno felbit roieder andern Fainilien das \&eben ju geber. $3^{\text {war }}$ vermegren fie fich fefre, aber bod) nicht to fefr, als bie vorhergefenden (s)attungen. Das Thier ift ithon mefr organifirt. Seine Graeugungen folgen fich alfo nicht mefr to fårufig und fanell, als bei den weniger organifitten Sfieren. Dev Polnp wåd) entwicfelt fich åußrerlid, und gebiert lebendige Jüngen. Diele fortp

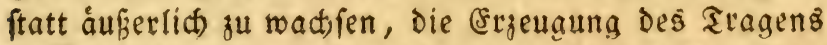
(geitanon) auszumachen ideinen. Şei andern Shies rell wåchft das Junge innerfalb Des Górpers, und es glebt eine Menge von Medififationen biefer 2 trt. Sald find fie Androgynes, D. h. fie vereinen beide Brefdled)= tev aufs volfommenfte in fich, umb ganze Shierracen, bie månnlich uno weiblich zugleich find, befructen fid

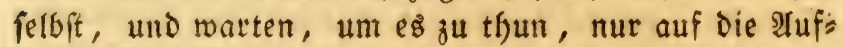

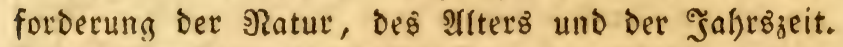
Indete find Sermapfroditen; ifnen wurde ber einfame

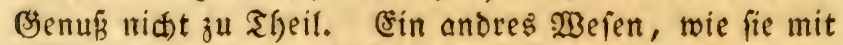
Den beiberfeitigen Befhlechtstheifen verfefen, muß oas

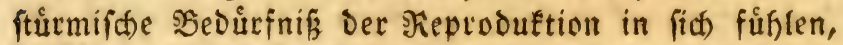
um baj auch fie die Freuden ber getheilten suft Diefer थrt empfinden fonnen.

Steigt man zu Sפgejen hinauf, Deren Drganifation verwicfelter ift, fo vertheilen fid bie (Befd)ledter. Die Ratur bleibt aber iffen Gefeben getreu, fie vertheilt fie alfo nid)t fanell uns unerwartet. Bei ben Fifdyen verfolgt das Mannchen fein Meibden; aber nod) vers fnupfen $\delta a s$ Mănnden feine fanfte umarmungen mit Dem Șdicffale einer গRad)fommenfd)aft, bie ofne daf= felbe empfangen murben, und die es blok an Sindes 
Sintt aufnefmen fant, went es fie befrudtet. S?ur bei ben vierfuffigen ifleten, befonders bei dem Men=

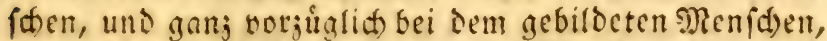
veridenerte das Befúl)l die Bande, Die oft nur Dec Bufall fnupfte. Der gefellifaftlitye menid liebt jeis ne Gattin und trägt auf die Jridte feiner \&icbe cinent Iheil feiner fonfteren Emprindungen über; inmer ru= fen ifm feine Rinder Tage Der Bartlid)feit, des J̦inges

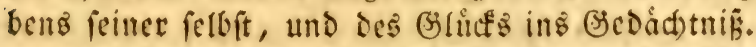

Das gelel)ete uno meife IItertfum nafm fifon die

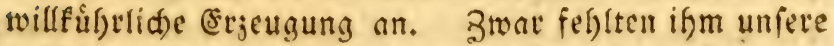
trefflichen Inftrumente, bennod) aber mat es in man= d)en Stucfen weiter als wir. Priefter, Aerste und

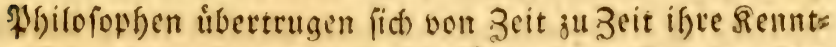
nifle, aber alle verloren fich firt uns jur Zeit Der Zer= ftórung bes romila an Beichs, auf welde die tieffe Barbarei und Unwiffentreit folgte. Eeit bem MBicber. aufleben ber sBifienictaften finden wir in ben twenigen úbriggebliebenen Refien Der alten Belehriamfeit allents halben jafta, Die mit ben neueren Entiecfungen über:

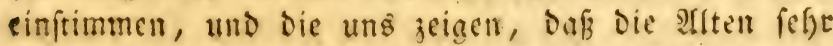

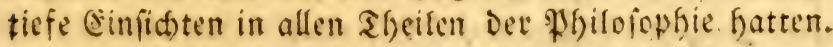

Die Gålte halt bistweilen die Graft ber Đatur jus

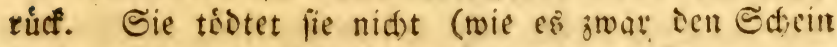
hat), fonocen fie lákt fie nur ausruf)en. Der gering= fte Şaud) Der ${ }_{3}$ arme bringt wieder neues \&eben in bie Natur. Bielleicht verdanfen wir allein Der Ralte die

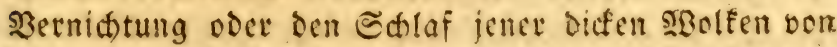
Ifierd)en, bie fid) freimillig ergeugten, bie nur einen Zag lang exiftiten, ja bie oft ein blofer Somnemftraft bervorgefn lápt, die aber aud mieder verfdzminten, fo wie $\mathfrak{e} \mathfrak{t}$ nidat mefre da ift.

33ir find getvofnt, alle Naturptodutte unter brei

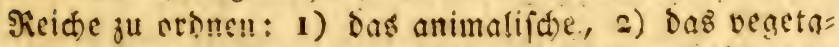
bilifde und 3) Das mineralifate. Diefe willfúfrlide

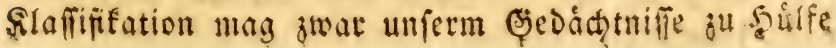




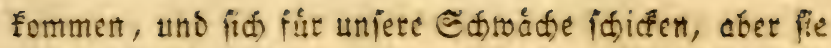

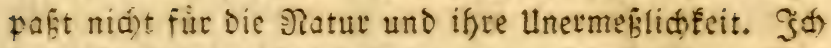
Eemerfe Dabei nichtô, Daŝ mid) an Die Elut, an iftre smodiffationen und smeteore erinnerte.

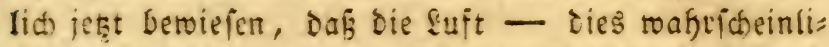
(h) Univerjalelement, - fith Dergeftait fombinitt und modificirt, dấ es unfenntlich für uns roitt. In fich felbit it fie fluffig uno ourdfichtig, rein, leidet jufams men zu oruffelt, uno untaftbar. NGer fie madts aud)

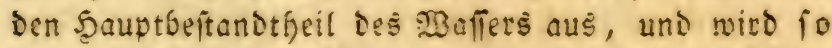
Die am wenigiten elajtifhe untel allen uns befanntent twirfiamen Giáften. Bald ift fie ătherifa und reit, unjeun Drganen folgtich unangemeffen; balo ift fie vers mifát, uno bilbet unjere atfmojphárifde \&uft. 2senn

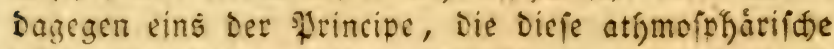

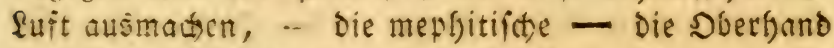
bat, fo greift biefe uns gemaltiam an, und verurfacht

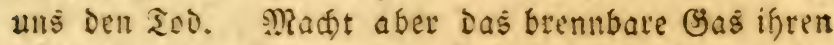
Satptbeftandtheil aus, entzúndet fie fich dann niet)t, uno jeigt fid) unjern Sinnen unter Der Beftalt bes

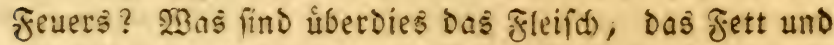

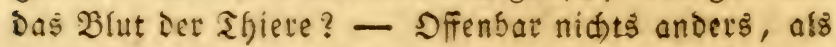
bennbare ?uft. Welch eine betrådtlidje Menge fiker

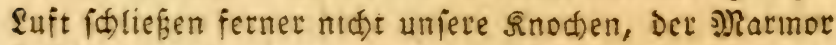

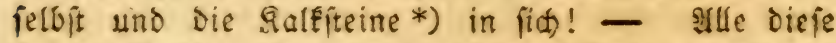
Ifatjachen berweifen uns, daf bie Ruft jener Proteus Der Fabel ift, ber alle Geftalten antehmen, fich in Feuer, Wafier, Erde, Stein und Solj berroandeln und fich unter Dem \&eufietn aller belebten mejen wieder jei=

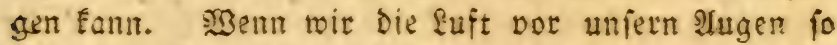

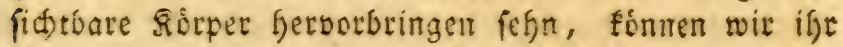

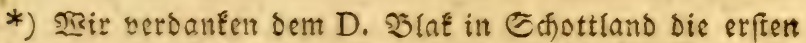
genauen 2fuseinanderfef̧ügen Der SalédDe. 176r belvies er Die Gegentvart Der Ruftiăure, Des menhitis foren und Soffen= Giafes ober Der firen Luft in bets felben. 
Dann nead tie Graft verfagen, eine Menge anterer,

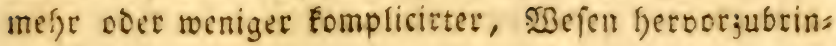
gen?

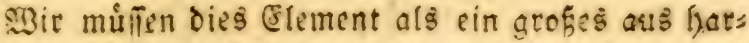
monifan Theilden beftefendes Bange bettediten, Die immer fith ju vereinigen, fich jufammen zu bajen, uno lebende abejen ju bilden jtreben. - Unter lebenden

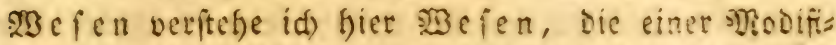
fation me hr fáfig find, als bie materie an fich, tho

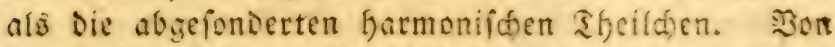
Dem Itugenblid an, Da Diefe sfeil(t)er fid) sereinigent fónen, von Dem Ilugenblice an, ba fie ein Beftreben

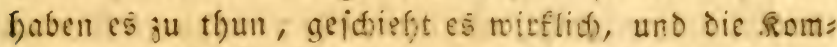

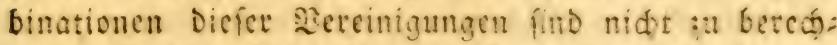

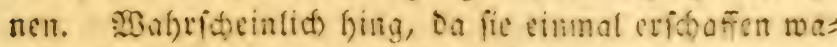
reit, ifre sereinigung blof bom Bufall ab. Snfangs vereinigte er nur jwei. Diele unfrudetbare Deccinis gung twitD nid)tg̊ bewirft haben; a!s fid aber cine hins longlide : Injalfl vereinigten, um ein Geftáude, das

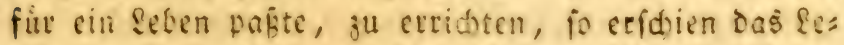
ben, eś ju befeelen, und madbe ein Shier saraus. Enaterfin enteano ein nod) volfommeres (jebadub; Das Slbie: wurbe mit nod) mefe (eigenidhaften begabt: es fontute alio jeines Gileiduen fervor bringen und jeits Befuledt veremizen. Sof filgle, daf dies Baifonnes

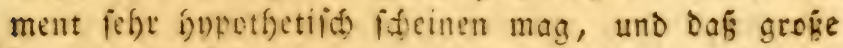
כoruttheile fid bagegen auflefuen metoen; aber ids

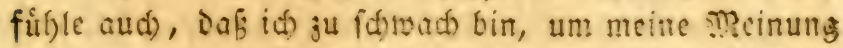
in iffer ganjen Eviden; Barjulegen. Fes twirb einft, und vielleiant balo, eine Beit fommen, two geidicftere Manmer bie Sheorie Der Euft entmifteln, uno betweifen

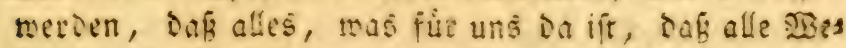
fen Der Drei Beide Der Datur nut Miobiffationen Des \&uft fint. Sino rvir iod) gegroungen, anjunehmen,

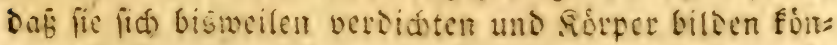
ne, Die jid betaften lanjen; marum follen nit nid)t aud 


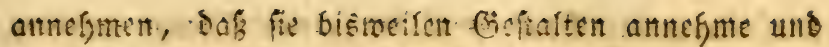
befleide, die des exbens fäbig fint.

Dies Seben felbft ift in jeinem geroógnliaen Sinne

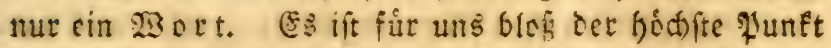
Der exifteng. Die abiete geniefen ciner thieri= fohen Erititen;, fo wic bie siegetebilicn einer vege: tabififten, uno die Minctalien einer mineralifhen. Denn Die ßegctabilien wájen ja, uno bie Mheralien nefmen ju, und verándern lida. Unter biefen lefteren giebt es cinige, oen benen es̉ uns unbetannt ift, to ie fie junelgmen; meiftents aber, und beionders bei ben Sriftallifationen Eonnen wir bie Natur alcicbiam auf

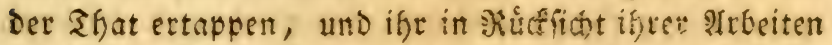
auf Dem fufe nadjolgen, indem mir unz iffes erftert Itoms bcmóditigen *). Der bártefte unter allen Stei= nen, Der Diamant, if blof eine zufammentangende und verdichtete Mafie brennbarer suft, wie ?Reuton afnte, und rie bie neuere Efnmie berwieien hat.

Sisir Durfen nur einen geloipatf) = Sirnftall, Deñen blàttrige firiftallifation einen längliden §ubus aus: macht, zur Syand nefmen; fo merben wir bald fefn, wie fich biefer গriftall unter Dem Şammer in andre fleine Siriftalle von Eer gleidien (Eeftalt jertheilt. Diefe flei= nen sriftalle werden fid wiecer in anbere oolifommen gleide theilen, und fo merten bieje হ̧geilungen, bie immer rocoer áfnliche Theilánen geben, uns bis ju

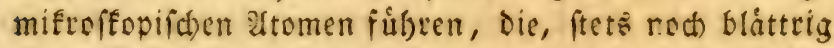
unt Exiftallitt, uns Das Bild des endida erften freld = fpatfatoms liefern. Whit biefem vereinigten fid) all= måflich fomogene uno gleidfartige Itemen, wiat juletęt einen Sriftall zu bilden, ber viclleidgt die Diffe eines Arins erteid)te.

*) ๔. Häuys und Rome de L'lle's Mineralogie unt Sitiftallographic. (อ. auth Loewenhoek, Ann. Nat. tom. I. p. 3. Buffon tom. XVII. p. 29. D. (50. 
Es biloeten fid surd) bie rillfuhrliate Bereint= gung barmoniláder Theilden die rabefen ftufentocife; einige mit cinen thátigeren Qeben, als anoce; einige mit (Geid)led)tEtheilen, andere shne biefelben; daher entitan:

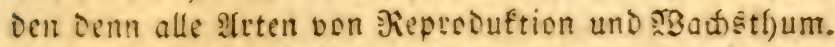

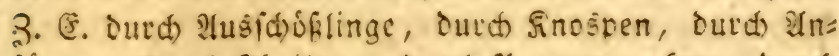
firgung, Durd) Theilung, Durd Paarung; furj, Durd cine Menge oon aften, bie mir fennen und nidht fen= nen; ja, die wir theils moff nie metden fennen letnen.

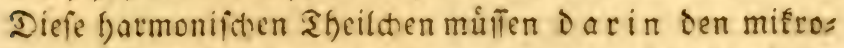

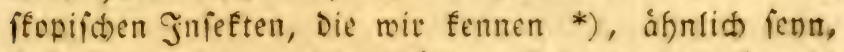
Daf fie mit einem lefre thătigen febensestincip begabt fino; Denn nad) Der beftefenten fronung Der Dinge Dirfen wir annefimen, Daf fie unauffertich in Serres gung uno Ifátigfeit find, fid aufiuchen, fid trereinis gen, und unter getwifien Umitánden belebte oder un= belebte sisejen bilben. Diefe freitwilligen fortbflanjunt gen múfien heutiacs Sages̉ viel feltner fenn, alş in Den erfen Gerten Deş Groballs, Denn bie Untegeimáfig= feit Der Gafresjeiren muf fich Dem Doridritt Der thies rijoen હdofping entgegenietsen. Die Ertage ift nun cinnal, - was aud) Der (j)und bavon fenn mag um Dreiund jmanjig und einen halben Grad von iffer fentred)ten ßichtung geneigt und Dieje Reigung ver=

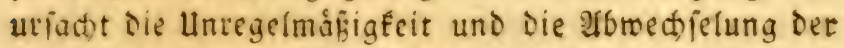
Saftesjeiren. Ege die Frofugel diefe Rataftrohe ers

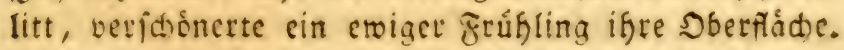
in jenent Beitalter widerfekzte fich folglid feine ftrenge Fialte, feine unbeftándige Semperatur der Seroorbrins

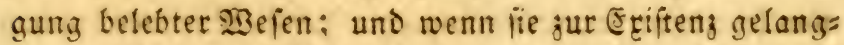

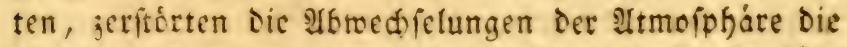

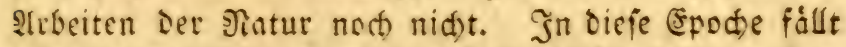

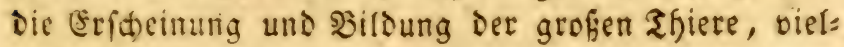

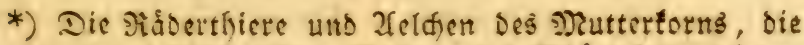

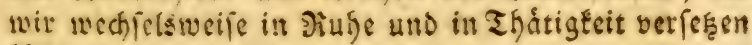

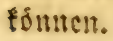




\section{4}

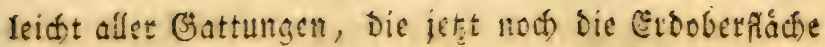

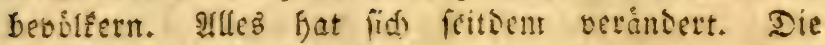
Datur mirb ietzt nid)t felten in ifien Protuftionen ge

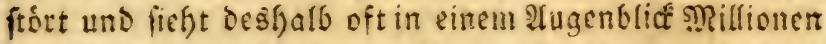
bon sisefen vernichtet werben, bie fie in cinent andern Iugenblicf wieber fervorbringen fann. Eine șenge von Geimen werden oft vetidhart, wie bies in ben

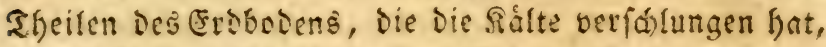

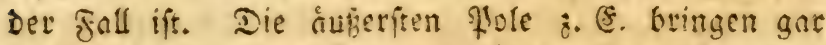
nichts mefre betoor; meil cine fưtóterliche Sálte bort alles unidsliefit.

Sibirien, Das eintt gifirocerolle, Elepfanten und andere Shiete eires warmen und mofitfiatigen

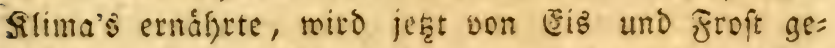
Dricft, und jene Shiere, fo toie manche andie, leben bort nidt melyt. Fiffielte aber die Crofugel ifre jent: rechte Etellung wieber; fande fid bort eine gleid)= måjige, fanfte sempetatur wieder eill; jo routbe die Satur fich aud) Dort trafrid)einlid) in ifren alten for= men wieder ferborbringen; Die nåmliden, ober ifnen ålntitbe sflete mirben Sibitien wieber bevolfern; und bie gleiden (seld)leáter, Die vor jente Rataftrophe sort lebten, roicber eridfeinen. Die chemaligen \$flan= gen wirden aนs Der mu Durd) Die Comenftraflen aufz neue befrudsten (Eroe mieber bervoripriegen. Denn ifle aufierft lebendigen ßeime erfalten fid), twie twit

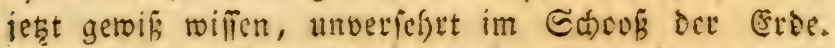
Iecfer, bie nad) einem Jafrfundert umgepfligt rourden, brad)ten Pflangen Geroor, Die einft Gier roudjen, Die (id) fdeinbar verloren Gatten, Deren Samenfornden aber in ber (erbe veritharet toaren *).

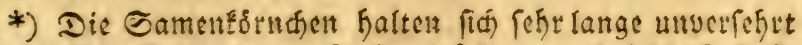
in Der Frbe, twem fie fo tief liegen, Dap die Euft fie gar nidit berúfren Eann. Sizent man im botantifshar (S)arten in Dariz nut eine einigermajen bedeutente Mrnge Croe yolt einet Otelle jur andert bringt, To 
Э() fonnte biet nod) ton andertreitigen Diobiffa: tionen reden, die Die Giejdópfe biemeilen erleiben, nactsem fie aus Der Sand Der Natur ferrorgegangen fino, und die fie oft bollig unferntlid maçen *). Uber

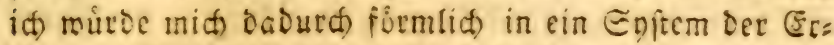

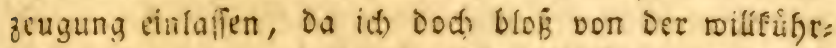
liden Crjeugung reben rill; id beforánfe midh Dafjer auf Dicie.

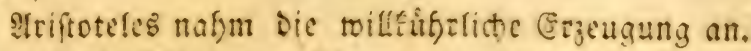
Jnoem er bie Sfiere im allgemeinen untericheibet, und in Drci slaffen theilt, lebt er alle Diejentgen in bie

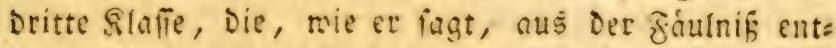
ftanden find, und bie nicit bon इfieren Der gleiden Gattung, als fie felbit, ergeugt rurben.

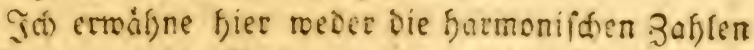
Des \$lato, now Die Eeclenrwanderung ier Biructmaner

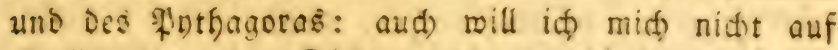
Etellen Der alten Dichter, Die ich Gălifig anfinfrin finnte, bejiefen, fondern blof bemerflid mad́en, Daf Birgil fie alle in scr Etclle feineŝ̉ Ģcorgicon vereinigt

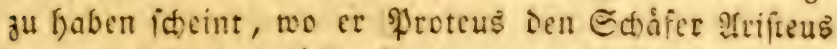
Das Dittel lebren lifft, fić) Durd, Die Fi̊nlnif eines ges

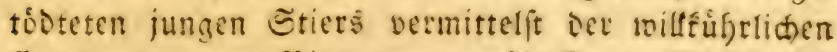

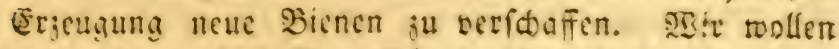

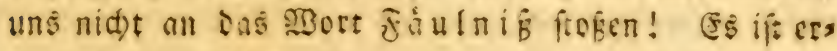

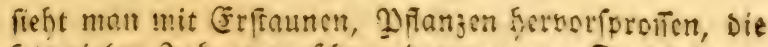
feit vielen Gafien verfatwunten waren. Da Dies nun

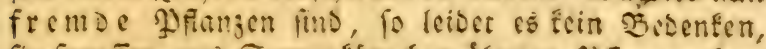

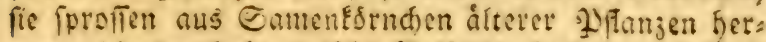
sor, bie Durch botanifale Fieifende biéner verpflangt wuten. Zfuf ber andern Seite bat aud Der gefthickte

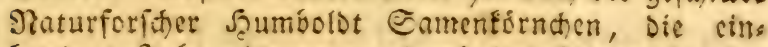
Gundert Jahr ait waren, Burch Das Drugen bie bea frud)tende Siraft wiebergegeven.

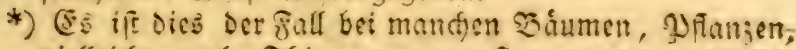
vielleidft aud) Effieren, wenn fie aus citem Slimán noer sincr Frdart in die andre veriest merden. 


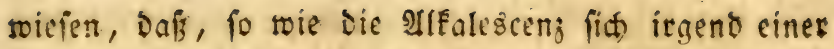

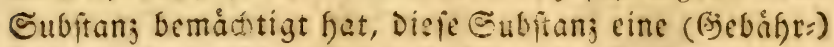
Dlutter miro, die jur (sntmicfelung ciner Mienge von

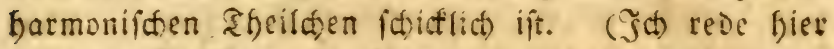
nidit bon Infeften, Die Daraus entfefen, to eil anore

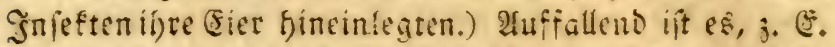
Daf́, als man fochende fleifabriffe in glaferne Gefábe goß, Die unmittelbar Drauf, uno ofne Daf Die flatiigs feit nur erfalten fonnte, jugepfropft murden, fich Doch in biefen fluffigleiten, fo rie fie faulten, eben fo, wie in andern, Die man Der freien \&uit auŝgefeţt batte, fleine Iflerden jeigten. Die milfúfrltaje Fortpflanjung ift Diefergalb aud) in unfern Sagen, von Månnern, Die mit æectht beruffmt find, angenonimen worden. Buffon nafm fie, ourch dic evidentefien Semeife baju genotfigt, in ifrer aanjen :2uśdelnung an. Sa, er ging nod weiter, er idsteb iffe die esnt=

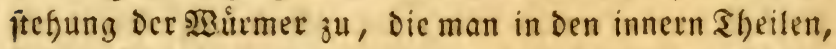
in Den (Fingerweiden, ja fogar in Den Adern Der Thiere findet *). Dem Ueberfluffe an Mild, pder vielmefre Dem Iheile Derjelben, Der nidft verbaut wurde, fdreibt

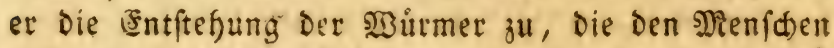
oom Augenolicfe feiner (jeburt an, befdureren **). Da auch andre Arten von SBarmern beim reitern

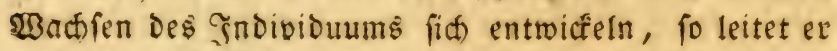
auc) Deren (Entftebung aus Dem Ueberfup einer organi= fhen Materie, und ifrem 2 fufentfalt innerfalb einiger Theile Des Thiers fer; 3. F. Die millfufrliche (5rzeu= gung Der Bandroirmer (taenia), Spultwurmer (ascarides) uno aller andern Arten bon sitirmern + ).

S) lefen baben, um fich eine Borftellung von ifyen felt=

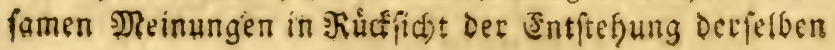
*). Buffon, tom. XVIII. p. 38.
**) Idem p. 289.
†) Ideis p. 227 ubi fupts, 
machen zu fonnen. alle bie, melde die tollfuifrlicte fortpflanjung nidat jugeben molten, waten fefre in Berlegenfeit, wenn fie erflären follten, wie in Die faft

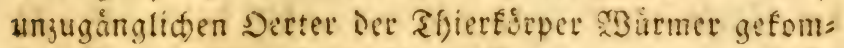
men feren. Man fieft oft mit Nermunserung, wie fie

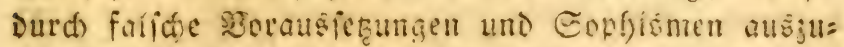
weidsen freben, bie fie mátig befrittin faben wirs= Den, menn Indie fie gefagt băten Da Dergleichen feffe oft von Mannern locstubeten, ile fom mit allem

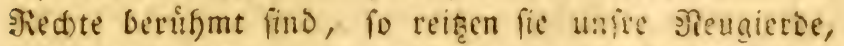
und jeigen uns, roie weit fid) Der menfdilide (seift ver= irren fann, wenn er Das sidft Des̉ reeftandes uno Dee Erfahrung juriaffitoft, und nur oen sigeg gefn roill, ben er fict felbit gebafgnt hat. ISGghler *, befauptete,

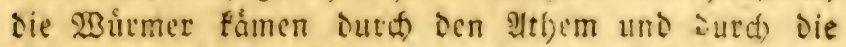

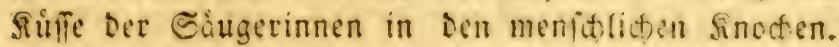

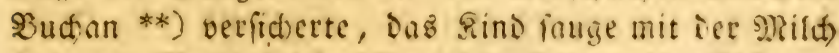
aus Der Nzutterbruft Die eriten Reime Der \$Birmer cin, Die fict) Dann in feinem Jnnern entmictelten. Ins Sere idrieben Die Cintitefung Der sisumet Der Ruft,

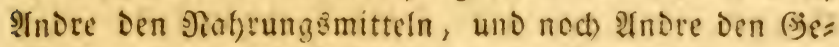
tránfen zu, Die bas Tffier verfolucfe. Da mun aber

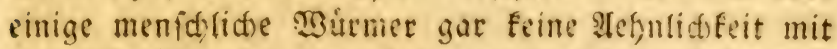
Denen baben, Die man bei antern Slgieten, bei Den

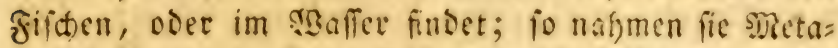
motpfofen an uno verifterten, Die sisurmer verån=

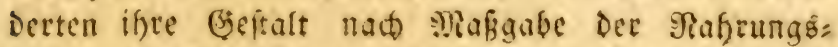
mittel, sie fie fünden. Jitifh $\dot{T})$ befauptete deșfyatb Der Bandwurun entftefe aus Den Spultwurmern, uno

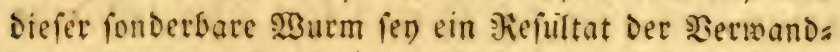
Iung, die die Spultrutmer Daburd) erlitten bătten,

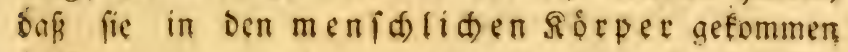

\footnotetext{
*) Naturforfder, Bano XIV. 5. 199.

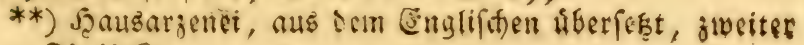
Theil Sap. 24.

†) Serlimer vermi thte Beitråge, Sand 3. 6. 47.
} 
såren. Sies lebtere fen aber saburd geithehen, Daßs

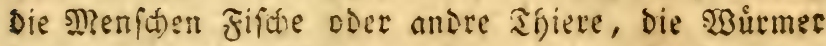

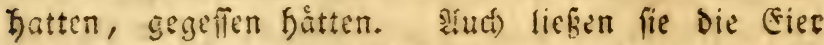
ber Epultirmer Durd Die Euft, oder Durd Das (Sie:

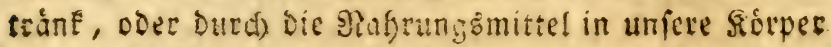
fonmen. Fus Diefen (Fiern founten naci) iffnen ganz berfdiedenartige Battungen entifefin, je nadbem fie im fidrper ses গnenfchen verichiedenartige Materien oprfanden. Sie mufien \$ranzenfirnern gleich fenn, Deren einige in Diefem, andere in jenem Rande feimen: fo Dafi jemand, Defien Sistper an Diefer Irt von Feuth= tigfeiten einen Heberfuß bat, Wirmer Dieier, und ein 2norer, Der an einer andern Irt von feuchtigfeiten einen Uleberfuß bat, rBürmer jener art, ein Dritter aber, Der sacr feine feudjtigfeiten bei fich hat, bie Den Eieun der 23 lirmer angemefien furd, gar feine hervor: bringen, alio immer frei von Siburmern fenn witd.

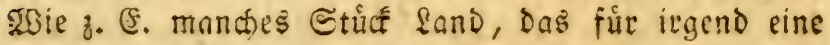
Gamenart unpafiend ift, ganz Damit befát merden fant, ofne Daf́ ein fiorn Davon feimt *). Fragt mant nun Den Dionis, wie Denn Diefer Same in Den menfas: lidyen Korper gefommen fer, fo ritrd er mit Anorn antworten: es fev eben fo moglid, daf fitc biefer Same in Den Эafrungsıntteln bepinde, als Dies von orm Samen nieler andern SBútmer móglid) (ey, Dak

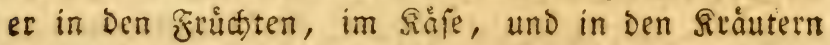
gegentoårtiz iey. Heberdies, Geifte es ferner, ift Det

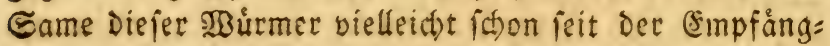

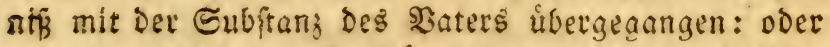
endlić, Der ßeim Der SBurmer fann fidon im Seime Des fótus da getrefen fern.

Die Siffniten unter Denen, Die bie trillfulfrlide Fortpflangung befreiten, nefmen eine angebolnrne Zeus gungs?:

* Dionis, Differtation úber Den ๖̧anduutm, อ. 8. Daris. Semercier. 
gunaefrait an *), uno fagen, bie mafriffecintidste Siefrmmung ber goturmer fon, im sorper ber Shlete ơ lefen. Eie juden ighte slecimung buté alles ju unterfiben, was fie antefmlict maden Eamn; es fommt aber am Ense fait aufs gleidhe feraus, ob sie Benzungefrafi angeboren oder millfibrig it: of Der

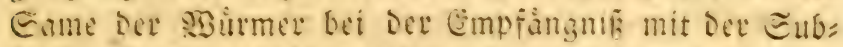

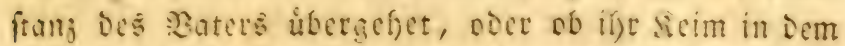

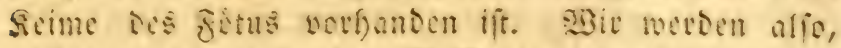

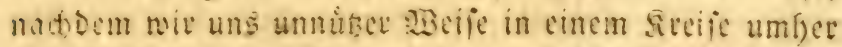
geverbt hoben, am ende immer auf Den Prunft mieder juthtfommen miffen, von weldem wit aแşgingen,

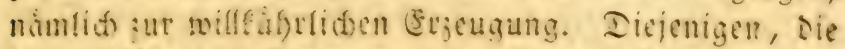

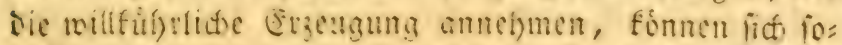

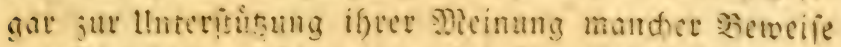
uns Shatiaden bedienen, welde bie Edriftitellet an=

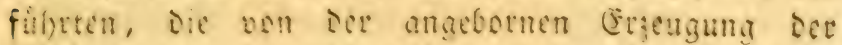
פ⿹\zh13一

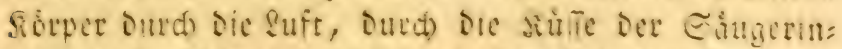
nen, Dutd Die Eamenfudtigfeit bes \$aters, obet

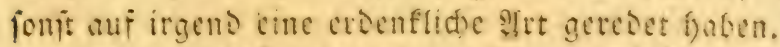

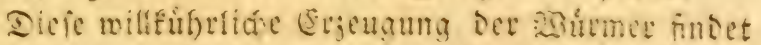

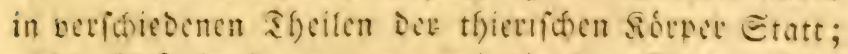

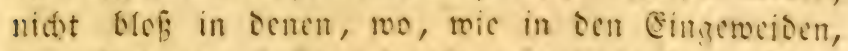

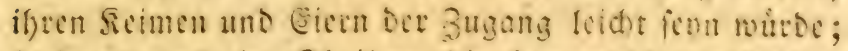

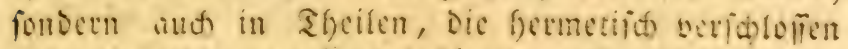

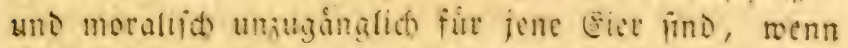

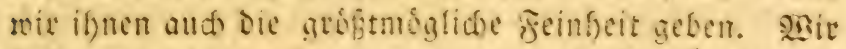
fint um nidots weiter, renn toir mut sumé **) unb Esbffer ***) annelmen, Dof cinige Derielben als

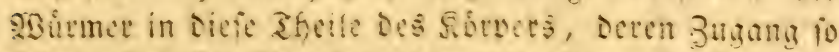
feit verfdolofien ift, Fommen, wie lis i. E. von ben

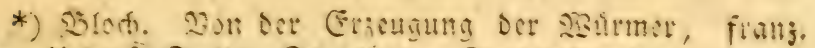
Hever. E. 83 . Enasburg. Sreuttel 1788.

**) Syft nat. edit, I2 p. $10-7-$

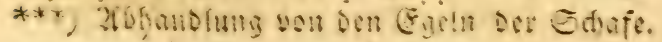


Egeln in Der seber \&er Ëaffe meinen *), Sis glaus ben námlich, Dieje Thiete Gătten fie beim Srinfen aus

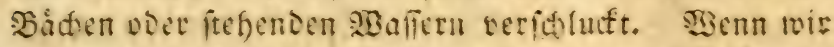

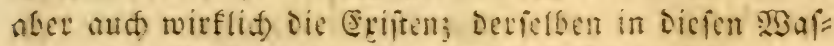

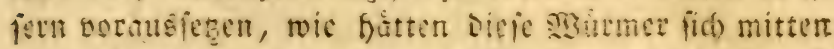

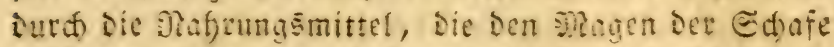
anfitlen, einan sieg bafjnen follen! Sole gătten fie

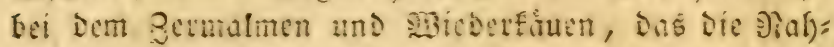

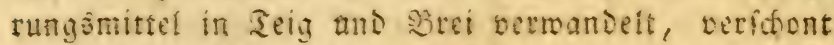
geblieben fem follen! - Shitten fie nidt Dued Die wellenartige Bartoegung, Die sie Pafrungsmittel unaf́ bovfić) na(t) unten treibt, mit fortacrifen weroen mili= fen? - lino angenommen, baf fie roiserftunden; fann

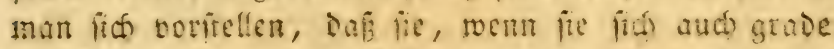
nact ter Definung oes Gorlenganges wenden, ifn wers Den Durdisufor, und Dutd Die Reber = uno cifitident Santle in ber seber und ifren 2 lajen anfommen fon= nen; Da Dod) Die Deffnung Des Ballengangs iund cine

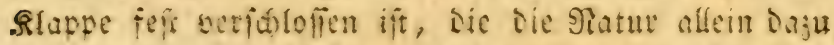
Eeftimmte, ju verfintets, Bof son Der Ecite ier Bin:

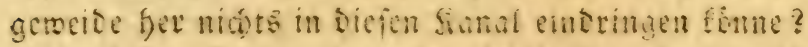

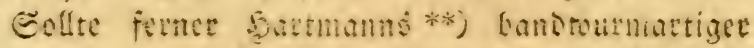

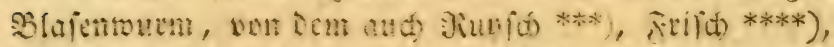

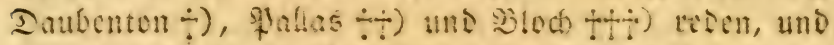

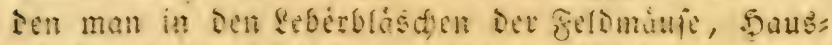

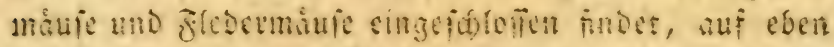

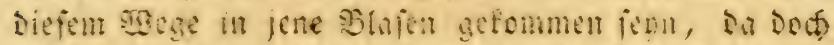
alles ju exfenten giebt, Daf er in biejer bejtalt nidat foll aupen Dafin fommen fo th $1 \mathrm{t}$ : ?

*) Fafciola hepatica. Linneus.

**) Miscellan natur curi, dec. 5. an. 2. obs. 193.

***) Rayfch, Op. omn, Nol. I. p. I7.

****) Mel, de Eerlin tome VI. part. I. p. $12 \mathrm{I}$.

t) Hift, nat.

t+ Difs, de inf, vir. p. 5 r. et Mifcell. Zoolog. p. 158 , tab. I2. fig. 12 et I3.

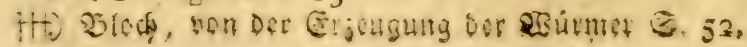




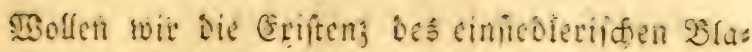
fentoums*), ien Sfofol **), Bactholin ***), Pever ****), Mitler + ), Simne' $\div$ ), Mallas $+t+)$,

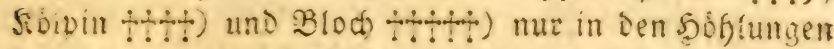
Des l!nter = und Dberleibes gefunden faben, auch Dem aletden coer einem áfgnliden luriprunge zurderiben, ungeadtet Dleje Doflungen Durăan feine Gemeins fchaft mit Den Gefśfen baben, ju meldien Diejenigen,

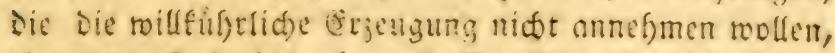

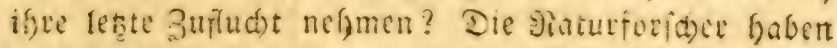
Dicfon Blajenturm angetrofien, im Interlebe ber Ectafe uno anderer toiederfiucnoen Thiete; in Der fes

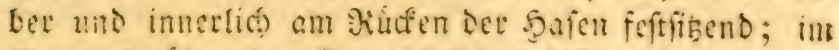

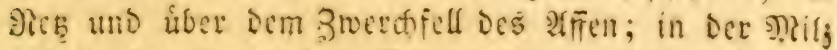

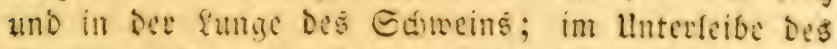
Penja) ferner im Sajen nux fo grof wie eine Erbje; arefier aber it sen miederfáuenden Shieren und int

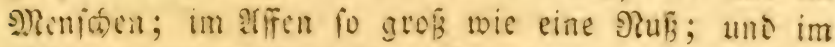
Edjucine nidte ielten io grof roie ein fleiner Sinters

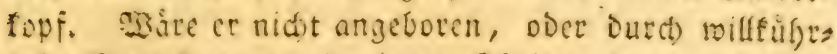

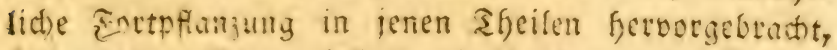

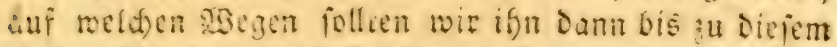
Bielpuntte fommen loflen? - Det gleiche fall pindet

*) Lombricus hydropicus, Thyfon, Phil. trans. act. Vol. XVII. no. 193. p 506.

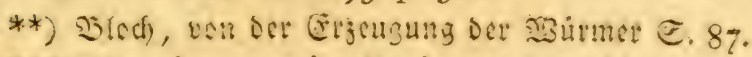

***) Ova in porcis. Barth. cent, 2, oblervat, 87. pi 293.

****) Hydatis a nimata, Peyer, Mifcell, nat, cur, dec, 1. ann. 7. obi. 206.

t) Die Signetbrafe. Mull.

t†) Hydra hydatula. Linn.

tt) Taenia hydatoidea. Pallas, Elen, Zooph. no. 4I3. no. 5 .

tttł) Kölpin, Mife, nat. cur. herol. Vol. I. p. 350.

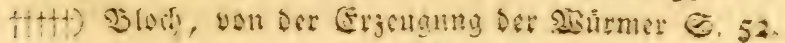




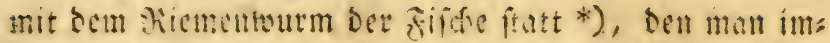
mex in ifrem thnterleibe unt ne in ifeen Eingeweiden findet. Diefe fdeint ex in egentfeit gu flefent. Sat

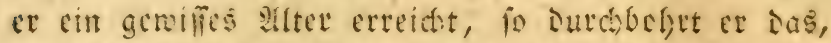
was ifn umitot. Mitten Dutes Die smusfeln uno Das

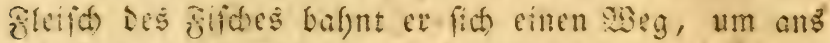

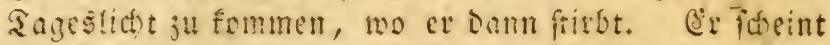

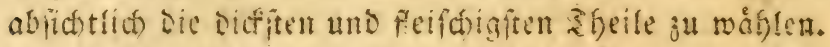
Gemofnlich ridstet er, intem er ben Sirtuer, ocr ifm

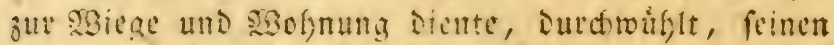

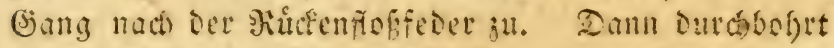

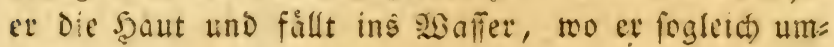
foinmt.

Da bie eben angefinten Sighmer oder geringel= ten Mollusfen in biefen unzugångliden und innerliden

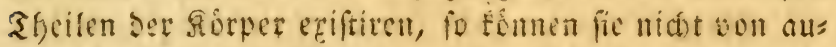
fien fineingetommen fern; man mub fie folglich fux

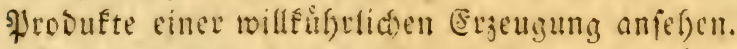

siber, mito man fagen, wir falten uns fiberjeugt,

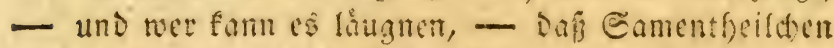

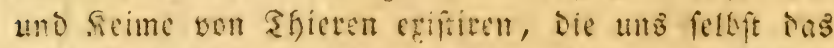
snderofen nidt jeigen fanm. Megen iffer unalaubliden Gleinfoit finnen uno milfen siefe feime allentfolben surfofeiten, uno nidts fann leverfindern, irgentwo Ginein ju fonimen; man mus alie bernimftagermeife an=

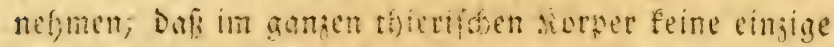

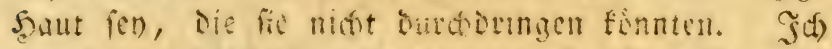
antwottete Gictoul, Das fam in getwillem Setrad)t mafor fen; aud acbe ich zu, Dob biefe ficime, wenn fie anders feibft thatige mo mirfente sgitemer moren, alfedinge trot affen Gindernifien intodoringen witroen,

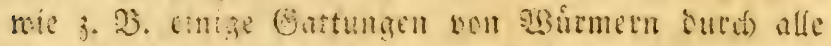

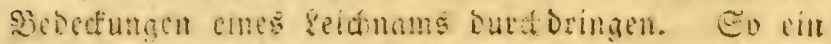

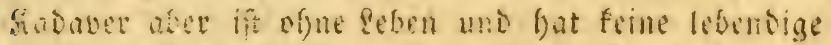

* Eafciola inteftinalis Linn. Fafeicla linea. ris longa. Fauna lues sult. 2. p. 5e5. no 20-6. 


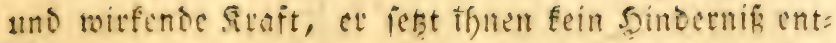
gegen uno nidhts Eam fie sa nuffalten. Die gleider

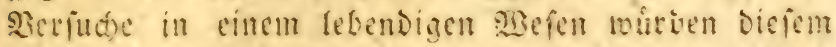
notfmondigerweife Eámericis, Siramp fe mo andere

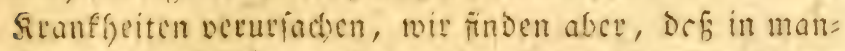

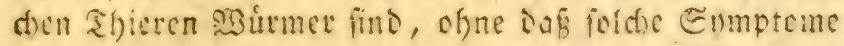

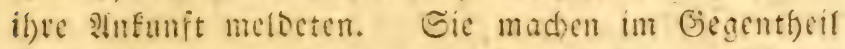
if) Dafenn nut Dann etit, menn fie im Siorper criftiren, wenn fie fion vervielfaltigt und cine setwille

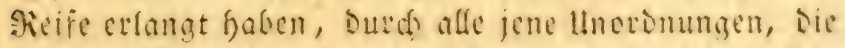
fie in ier therifien Defonomie anticten, bemerflud.

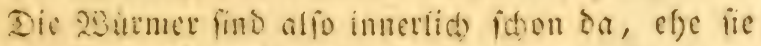
fiú) àberlich anfundigen fimmen. Sa, not mefr! the merien mit uns acboren. (⿺辶) epiftit, fo ju fagen,

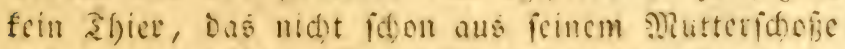

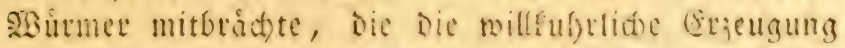

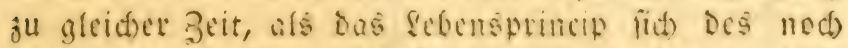

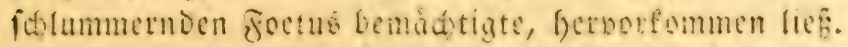
S2an bat nicht biof in Sinsern*) in Summetn **) uno

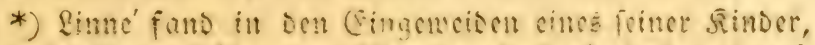

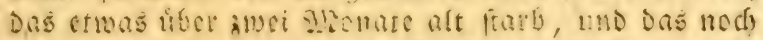

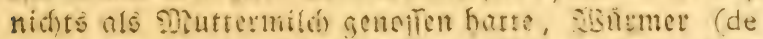
corp palpit p 133 ; traf in Den Cingemeiten enes

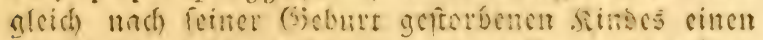

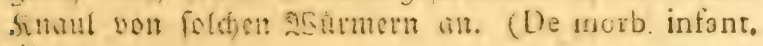
lib. 5. cap. Io.)

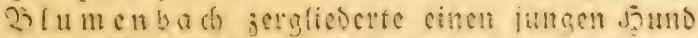

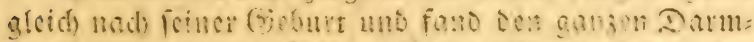

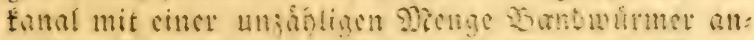

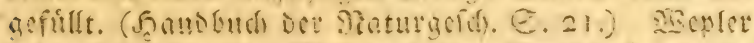

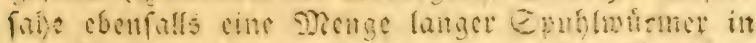

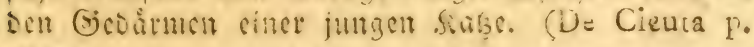
3.3.)

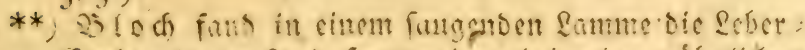

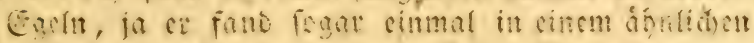

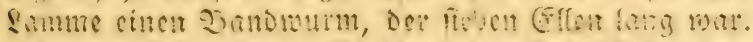
( loch ubi fupra. p. 86) Simulat naf evenfolis anen

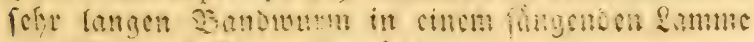
a!t. (Obiervat. Iur-lo Taenia) 


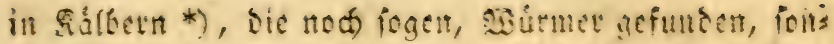
sern man traf fie aud) lebeno, entricteit, unt milfeno in Foctus jelbit an.

\section{Rouffus **) fand Epuflritrmes in stenge in}

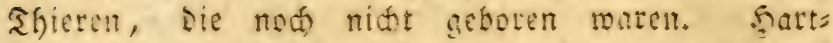
mann***) entocưte Faefn in cimem noch ungeitigen

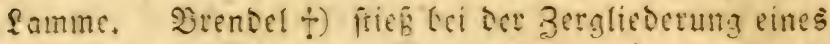

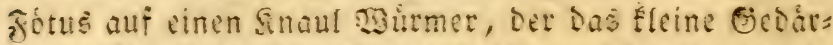
ne anfullte, uno bippoftrates filfit lagt, Daf Der Band=

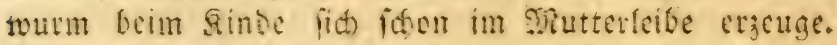
Sicje ancinung uno Bcobadtung mitd aud gar nict

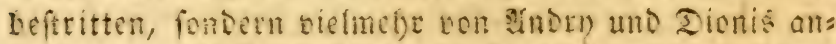

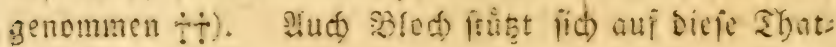

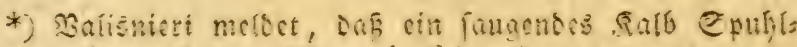
wurmer fatte. (Opera in fol, vol, x, p, 27I.)

**) De morbis, lib, 4 .

***) Mificell, netur. cur. dec. 1, ann. 6 et $7.0 b f, 189$.

†) 厄. Pallas, Dift de inf. viv p. 59.

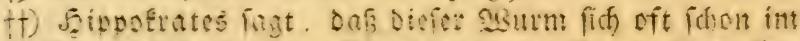
Mutterteibe bei ben Sinse cracuge. Dionis fingt abes

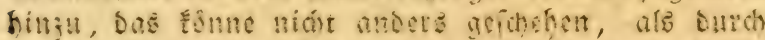

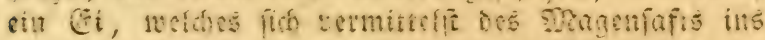

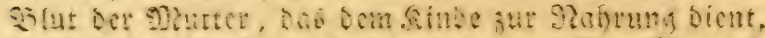

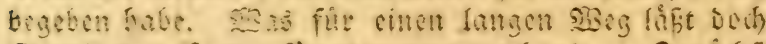

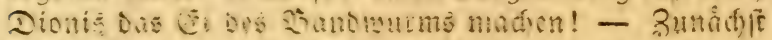

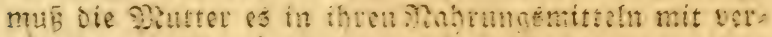

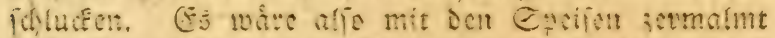

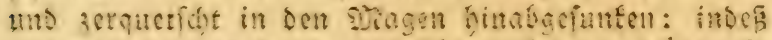

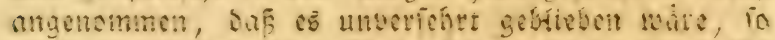

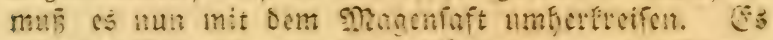

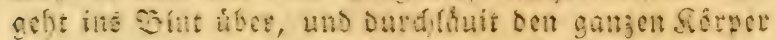

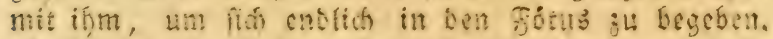

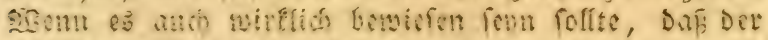

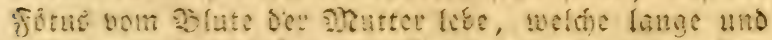

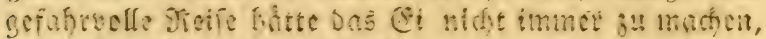
um an Den Det feinet Bofinmuny 3H gelangen, tho

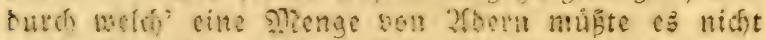

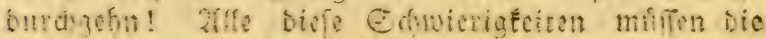

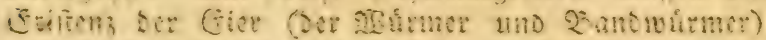

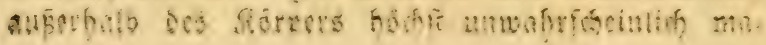


facticr, um fein Enfem ber angebornen fracugung bas ourd ju unterituten, uno ba Ecine Dicjer Erfaftungen

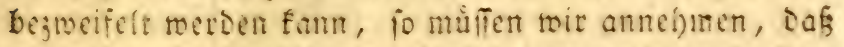

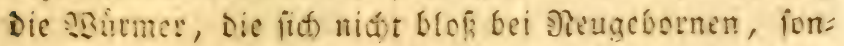
Dorn audi im fớtus uno im Embroo jeigen, in Dieien Dass Beinltat einet willfigrtiden Erjeugung fino. Ment

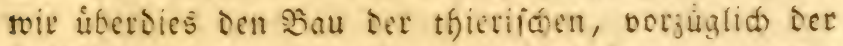
tweibliden Zcuaungswerfieuge unteriud)en, io fintert swir, ba 23 temer oder iffe cier, oder ifre scime in bie Bátmutter gleiten, Das Efortion uno Innton, futs alle bisute, bie ben fistus ungeben, io ibn ielbit, und feine şaut, uno feine smufeln, uno jeine Besecfun= gen, und feine twerbenden Eingewsioe burdobringen und fid) mitten in jeiner tísecilden Sernanifation nieberlai:

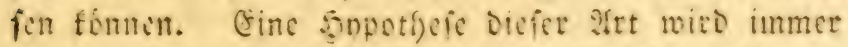

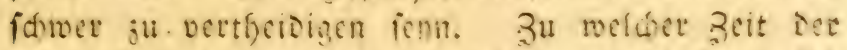
Estrangeridaft, uno auf reldem sibege hatten fid Dicie sistrmer un bie \$3Gemutter begeben follen! - ís) fage sis uner, benr son sermen uno

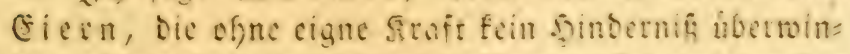
Den, feine Saut butdoringen fonnen, fom toeiter bie

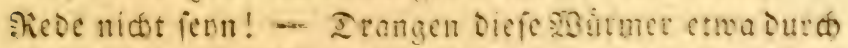
Den Shats Ber Bormutter ein? - Mhan weib it aber, baf Diejer fid in Mugenblite ber Empfangnif

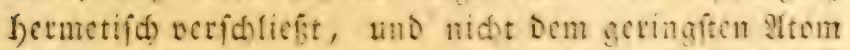

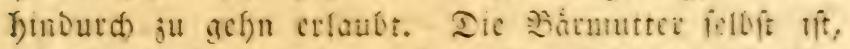
wie ber berúbe Blumenbad fie tefflid bejdretbt,

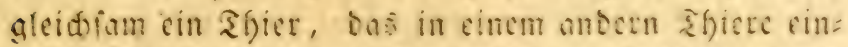

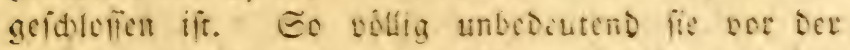
Edwanicuid)aft twar, fo wirfiam mito fie mad bet

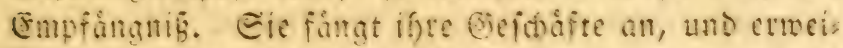

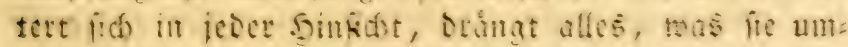

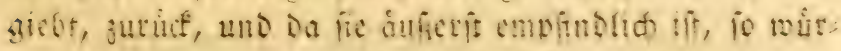
then. (e. Dionis, Diflert, fur le Taenia, p. I3
ant (Ende) 


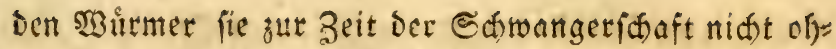

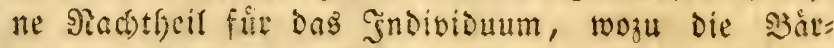
mutter gefort, angreifen. ŞBurmer fónnen fie alfo nidft Durdoringen; SBirmer formen folglid eben fo wenig Durch Die Şaute, Die Den fistus ungeben, noch Durch Den fiotus felbft friedsen, und ooci findet man

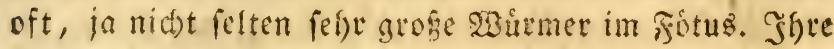
Exiftenj mus alfo am ende immer der freitrilligen

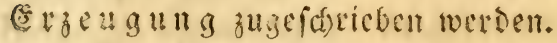

Mir fentren beutiges Sages - Danf fer es bet

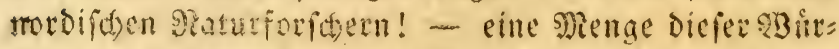
mer, uno fotmen fie unter einande: und mit andern

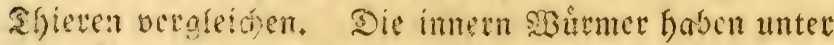
Den moern Shieren fein stmalogon, bern fobalo mart

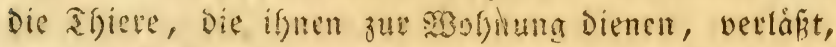
fincet man fie nicit weiter. Un $\mathrm{jel}^{*}$ ) uno \&inné**) begaupteten, Bandwhmer, frei im sigaffer umber= fdimimmeno, gefunden zu haben; nath einer genauen Interfudung der Sadje wiberfegte Stallas ***) aber Dicie Seobachtung vollfommen. SBettfein fand eben= falls zu wieberfolten Maten अicmenturmer von fifchen in einem Seid)e bei Bremen. (5r Gatte fie aud fure sisumet angefely, Die in cinem ifnen angemeffenen Clemente fidwammer. Sloch aber beroies, dafi fie

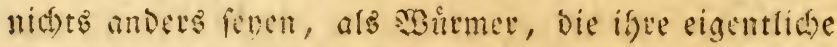

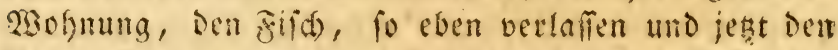

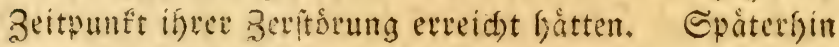

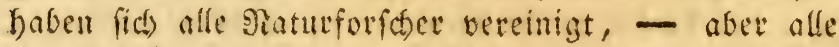
ifre Bemibungen waren vergebens, - um im sisafier

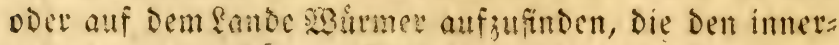
fichen analog wácen. Diefe innerfiben fanden fiá) nut allein inmerfalb des Sorpers ber slgiere. Eelbft bie,

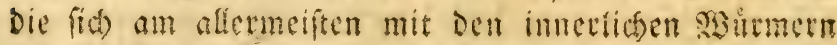

*) fenmburgifuc siagazir. Vol. VIII. p. 3 I 3 . **) Amoen. tom. 11. p 93:

1.**) Diff, de inf viv. p. 57. et Elench. Zooph. p. 407. 
befdaftigten, Gaben nie cinen 'einzigen anfinten fon=

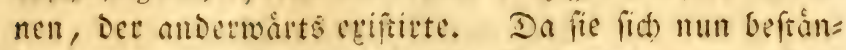
big mu innerbalb ber Shiere finden, und andes=

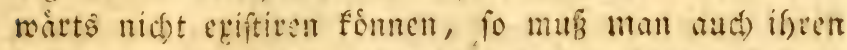

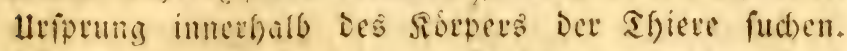
23it Gaben gefein, Daf fie willfubstich) Dafelbft entftan=

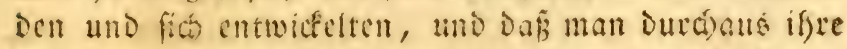
Exiftenj ciner ungefäfren ßeteinigung von Umftinden,

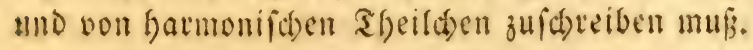

Die 23 urmer find mit Den Sertern, wo fie firts entruiffelten, fo innig verbunden, baf fie fie nidat ve:

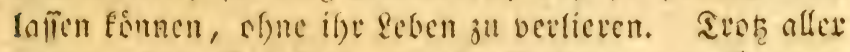
nilgewanden Eorafalt, um iffere siften ju verlänern, founte man Dod) nie Daju gelongen, auber bei cinigen werigen Gnoiviouen; aber bod) aud mut für cinige

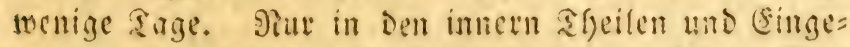
meiden bet sfiere finden fie die ifmen angemeffene

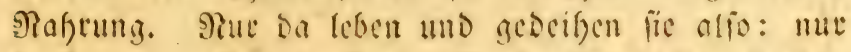
Da fann mur fie antreffen. Stult allenthalben fterben fie; fogat bas cintauden berfelben in Friffinfeiten,

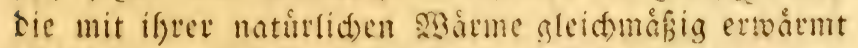
waten, war vergeblid. Ifud fict farben alle. In iftem gemolndiden Ifufenthalte fideinen fie aber aflen

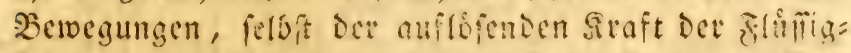

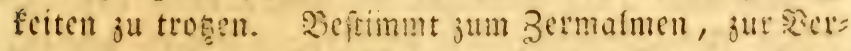
Daunng uno jur Efilitifation, bleiben fie unverfelget und in iffer wollen siraft; ja, fie walglen ifgen befion= Digen Sufentigalt an Sertern, in widben felbit ${ }_{\text {NBut }}$ zeln, troctine und gate firauter und andec fefye fefre Borper in Brei berwandelt, wo fogat Snoden, ja felbit

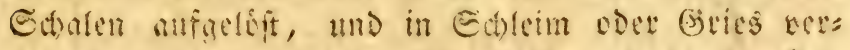

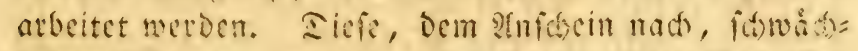

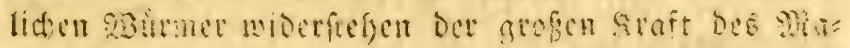

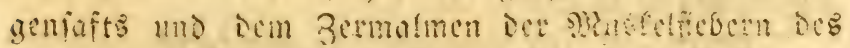

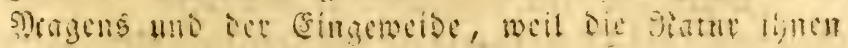




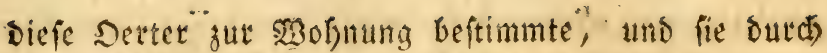

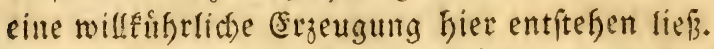

Simen fingegen bie 93 bitmer doer ifre Seime

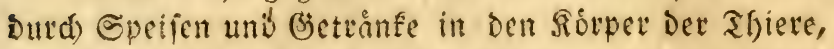
fo wusben alle gleidygebitbeten Reime auds bie gleidyen SOSurmer bervorbringen, und wir muiften bei veriffies Deren Ihieren, bie aber auf bem nåmliden Boben,

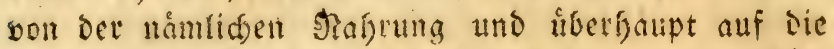

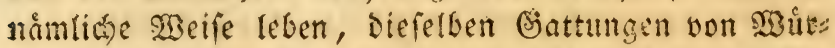

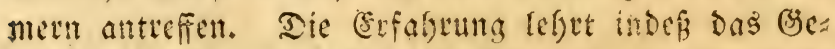

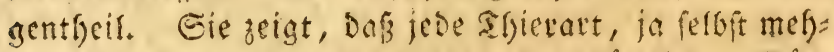

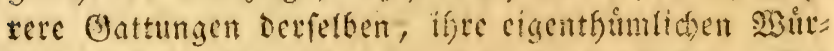
mer boven, bie fith mur bei ifmen fitten. Die menfd)

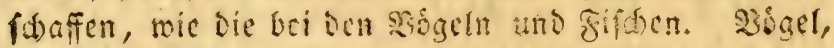

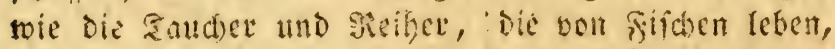

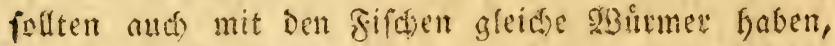

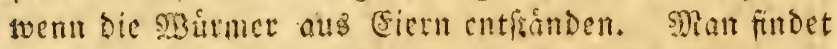

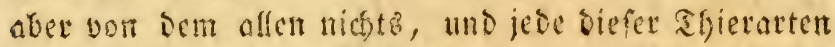

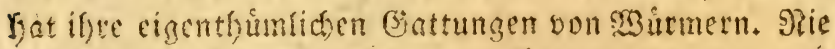

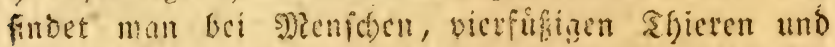
Bogeft, sBinmer, Die Bifchen sigen fint. Gind Die

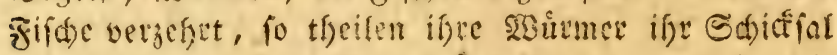
und werben in. Dem Magin bes Thiers, Das fie mit verjdtungen hat, zermalmt wie jene, ofne Daß Das

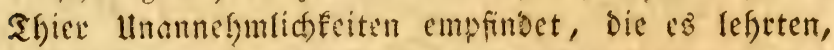

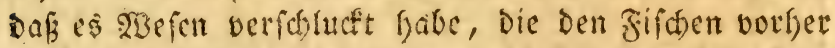

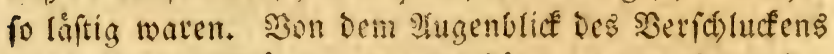

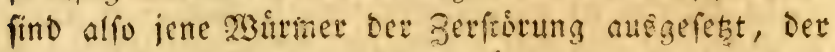

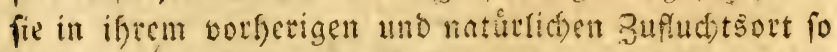

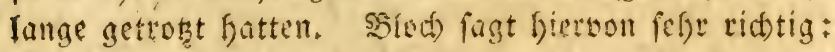
"two fir zugleids mit gevoren mutben" oter wo -

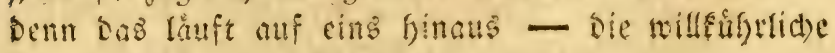
Evzengung fie entwickelt batte.

Unter gemiffen lim? änocn fomen ferner befondre

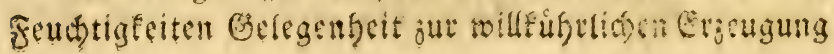


einer 2Renge von Siburmetn geber. Metfandige Rerate baben fie in vielen anfectensen siranfleiten wablges nommen. Indere mactiten bieŝ Snftem allgeneiner,

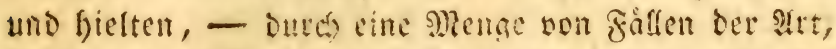

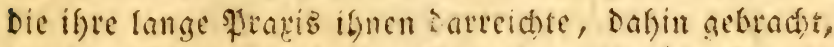
- Die ssitmer und ifre Erjeugung fir bie Grund= urfade aller firanfyeiten, bie bie Sfice = unb Mata fdenwelt quålen. (Es bat freilid) Serzte gegeben, bie sieje Meinng verwarfen, ober fie fonneen wenigftens

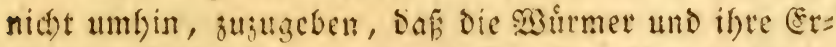
jeugung Die trifadse von gewiffen firantheiten feren. Co giebt fein Thler, fein Digan, feinen abeil cines

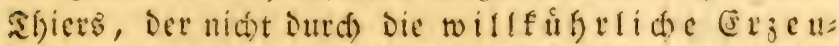

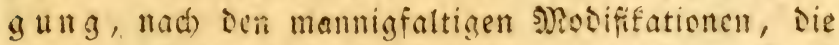
fie nnjunefmen im Stande ift, angegriffen werden fomte *). Socutiges Tages zeigt fie fid uns faft nut

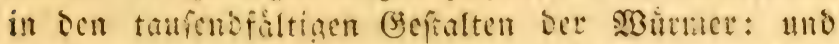

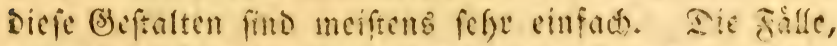

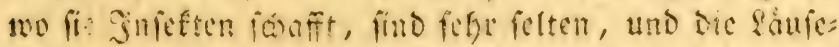

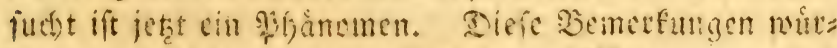

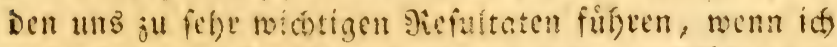

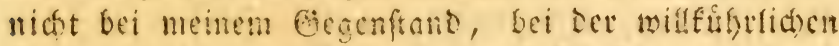

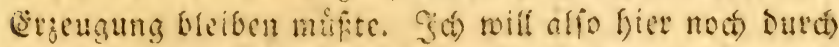
ien leţten siemeis, sen id aufgefunten habe, allen fibrigen ias volíe Gervicyt geben. Feins univer Degane

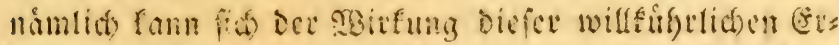

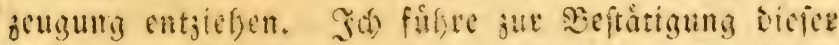
Sefouptung oen sgurm an, ien Epiegel in ber grafer:

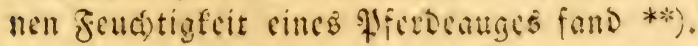

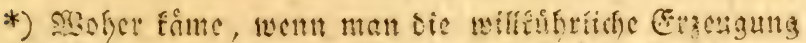

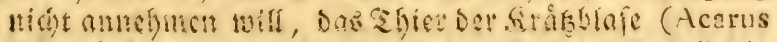

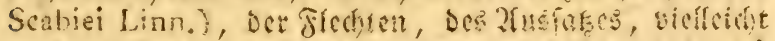

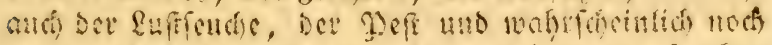

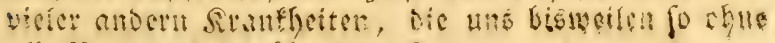
alle 3 chenlafinn liberfallen? -

**) Bonner, Sepulch. liv. I. p. 422 , 
Unts biciben noch einige roictige gragen zu unter:

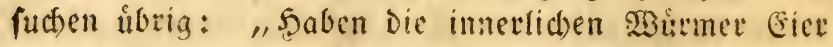

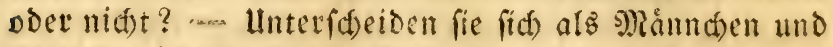

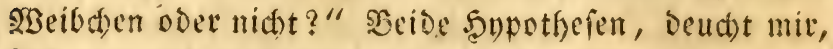
find nod) nidst volfemmen beitimmt. Sal) geftehe, dab fid) bei biefer fdwierigen lnterfuchung furdstbate atutos ritåten geģen mić) erfyeben. MRtuller, Sinné, Blod), Pallas, Bonnet, Tndry und cine Menge ander, eben

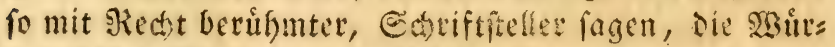
mer gaben eier; fagen: fie gabenfiegefehn, uno jorg= förtig unterfudt; wollen Millionen Berfelben in jedem Sndivious intoeft baben, mo babir fie in sielen Beidumgen bargeftellt. Eic verficiern fogor bemerfe

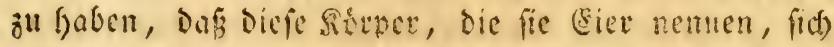

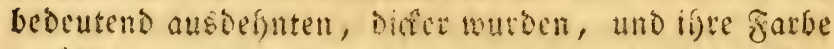
veróndertur. Es ift waft, ith felbft habe lange Seit

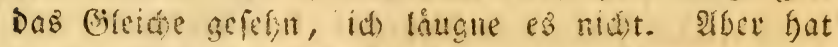
einew won diefen Gedriftellern biefe ciformigen ber fugetartigen fiorper (sic bistreiten aud) edig ja felbit vierefin find) fich forten und ein lebendiges shiet

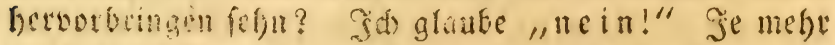
id) Icje, defto mefre merfe id), daf fie Der Inalogie folgten, und saufende oon Sitgelóen, doer andern

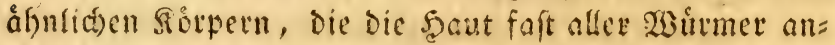
fullen, und von Deren Biegenwart fie fich butch Das

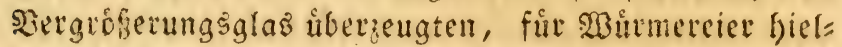
ten. Sie erfaunten iber ifre ungebeute senge, aber fie forfdeten nicht weiter. So vicle Gier fethen eine un: gebeute Bervielfältigung voraus. Die şirmer exí ftiren aber gerwefnlich nid)t in vorglislider sisenge; was folte denn alfo aus ben gebildeten Seimen werden, Die fid entreder bernidien poer zum fesen fonmen milien? -

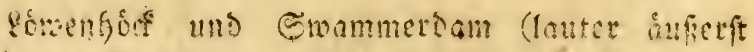

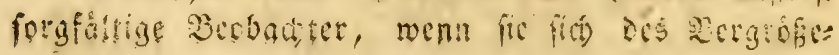




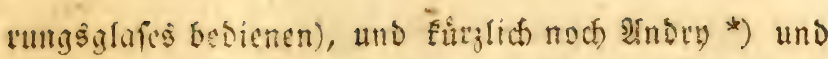
Slod) **) nelmen Die (Exifteng Diefer (eipr an, uno

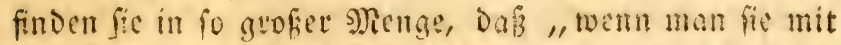

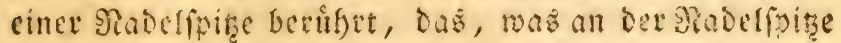
bàngen bleibt, wăte es๋ aud fo flem als bas fleinfte Ganberndsen, unter dein Ber offerungeglape dennod) alô cin unglanblid) grofiet Saufen bou flemen fingeln erfdeint." Satten aber siefelben Seobridter jede

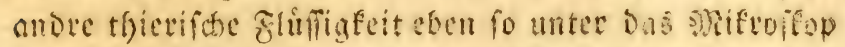

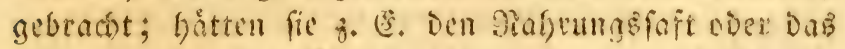

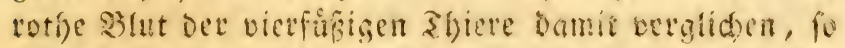
mirtien fie coenfoils "einen unglaublics grefgen gaufen

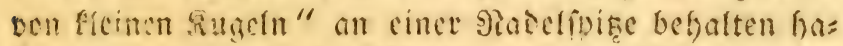
bon; Dinn unterm Sergroferumbalafe etfdeinen unjer

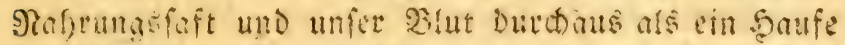

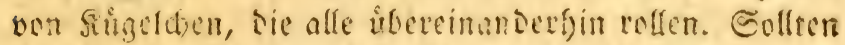

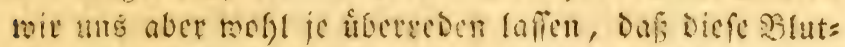

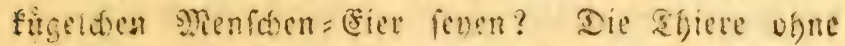

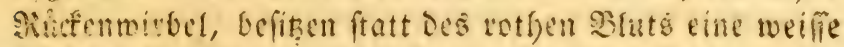

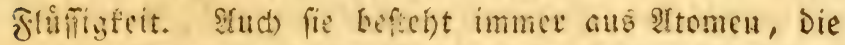
unterm g)ifroffop fugelformig find, bei verfatedenen

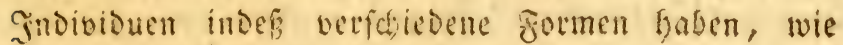
Bloct beobadtit bat ****).

Sile fat (x, nod) ids, nod) fonft jemant gefefin,

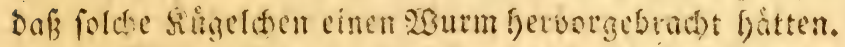
SBoff aber bat man - wie or aud eimgefteft - febl oft gefelst, wie bie siburmet fié) ifter gunjen fionge mach fpalteten, uno rine sgenge bon boflig ausgevils

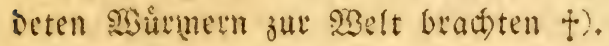

*) Plitorit bei Dionis e. I5.

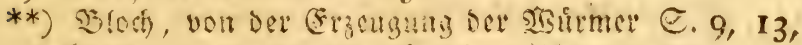
I $6,17,21,24,25,28,36,46,59,73,79,92$.

***) Silod), cbentiafelofic.

t) झुlod, ubi fupra.p. 74,77 und $8 \mathrm{I}$.

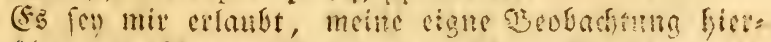

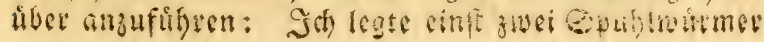




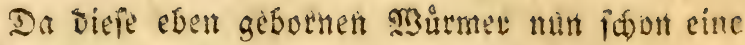
gewiffe range cruelet hatten (demn fie waren vielleid)t

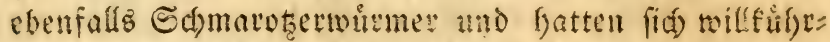

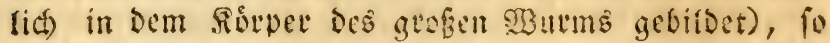

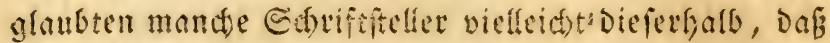
die şarmer fich verwendeln finnten *), SMGaten jene fugelartigen Sivperdyen (sier, fo mingten fie ausferchen, abee Das haben fie nie gethan, feloft bann nidht, wem

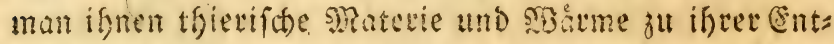

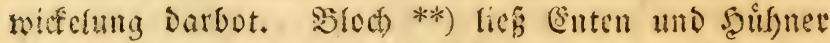

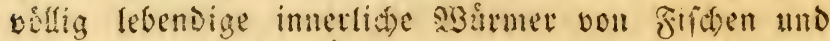
(S) snjen verfolucten; gefelyt aber, bei den Enten uno Shifnern nie cine Epur bon isne 23 intmergattung, Die cr fie werforducten lief, curdecit ju baben. (Daf ev Die= genigen risicmev die ifnen eigen find, bei ifnen fand, vewitelit jich.)

Die Branjen cinet allganeinent Cinleitung gebies

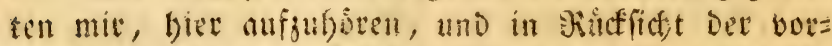

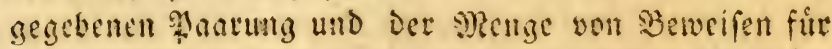

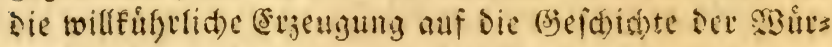
mev ferbit - Die id muter ser sementung "gerins gerte solollusen" begreifen werde - zu vel: weifon. 9seld)er andern Urjach fonnen mit bie unges betue Somefrung fener fleinen, gefingeften, fowat:

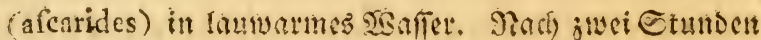

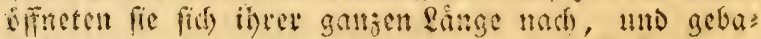

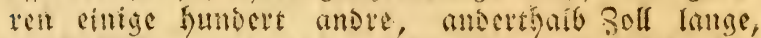

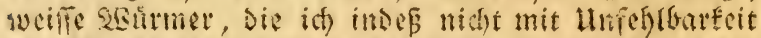

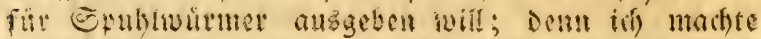

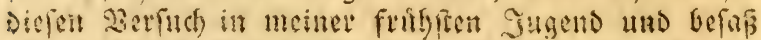

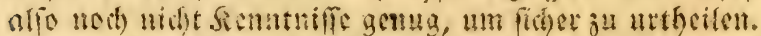

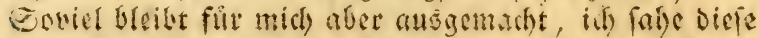

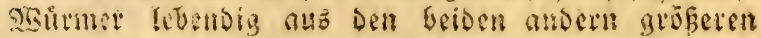
hervalfummen!

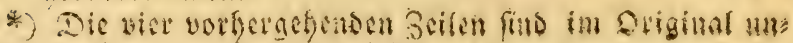
vartindidy. A. D. Hebrts.

**) Disd), cbendaforgft. 


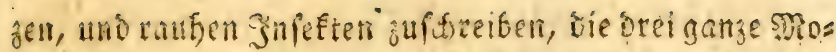

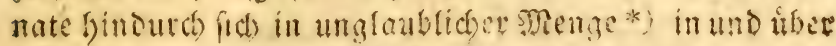

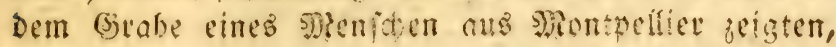
ber wăbreno peines Rebens Dem siscin ergeben gerveicn war? - (sine Beobadtung, Die twit iem gefólicter Strgt Moublet verdanfen.) Diefe Santfiecten, neben weld)en fid feil anores Infeft jeigte, ftritben gleich, fobald man fie einige Eestitte weit won bem Dite ent= fernte, wo fie herosgetradt maren. Enflen Die saum= franffeiten uno die in getwifn Efidemien fo gaurigen

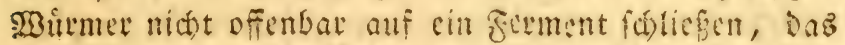

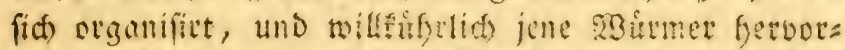

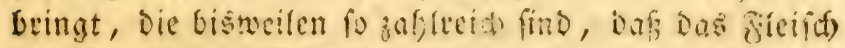
fid) fanmtlic) in SSirmer vertwandelt, wic Das bei bem

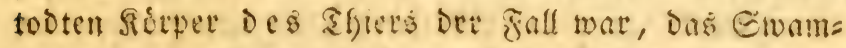
merdamm vor sugen fatte, und too fie Deraeftelt wim=

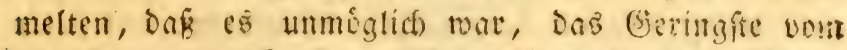
Fleifd)e zu cutbecfen? - 230 orer famen bunn Dic Shiere,

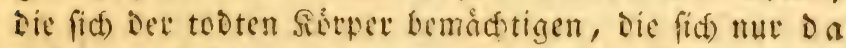
finten, who bie umfonmen, fobald fie mid)tô mefre jut

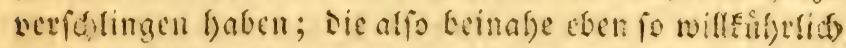

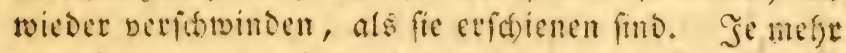
man fie berbachtet bat, befto meffe bat man fich stber=

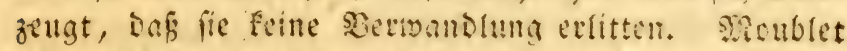

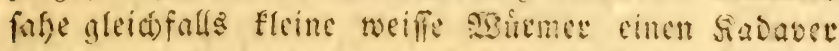
bededer. Cr benbadtete, Daf Diefe Shicte in iffere Figut, faube uno Geftalt, nach Befáaffenbeit Det Rianflyeiten abmed felten.

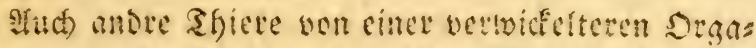
nifation ergeugen fich bisweilen freivifig. Einige lebent einfam; andere fefr verbielfätigt. Zu den erferent

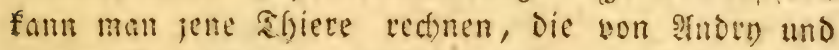
andern Beobachtern angefirfet roetden, und bie fid in

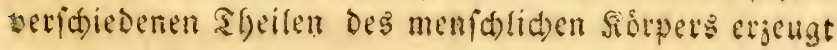

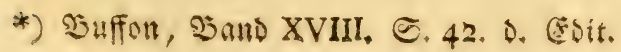




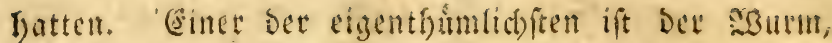
kiber weldhen Setillato (2rat in snans) Dem Buffon Beobadtungen jujófite, thind Den of juanzig Sage

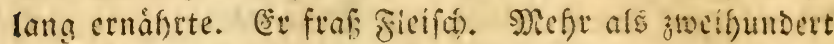
\$erfonen gaben ibn beobadtet. Matis man ju Den wills futgelich ergeugten Sficten, bie melgr organifit fino,

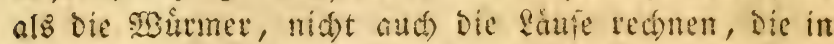
Der fáafefucit vollig gebifoet und zwar fo folnell mo

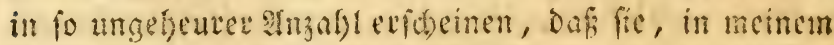
જ̧eipenn, am Şord cines Sthiffs in tinet cinjigen Gunde cinen Menfifen verzefrten? Ceine Sameraben und Deren Serten wutben aber Davon nidjt angeftect,

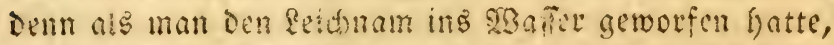

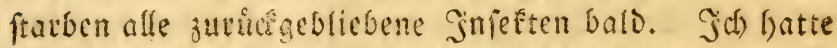
einige Davon in cher fleinen flafde gefammelt; fie

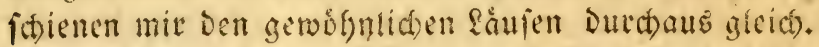

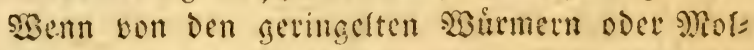
lusfen, und bon Den mifroffopifden Molfuefen die jiede feun wirb, werde id meine angeftelfen $3 e r f u c k e$ und bie giefultate anfüfren, Die fie mir gelicferthaben. Sc) ftimme nach) bellfelben volffommen mit Bonami

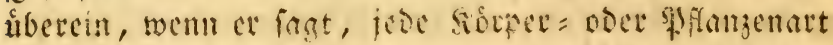

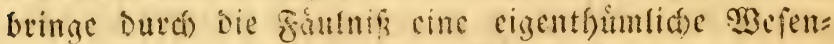
gattung freiwillig beroos. Jat boffe, meine gefex

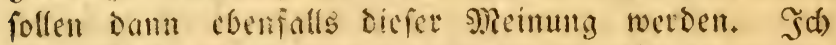
hatte ned cine Menge won Bemeifen fur bie will

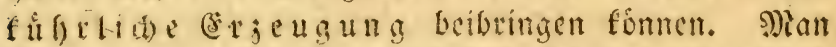
fann mix cinverfen, niemand babe bicfe gatmonifaen

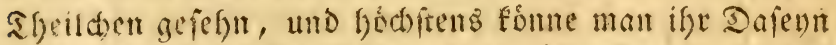

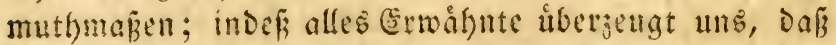

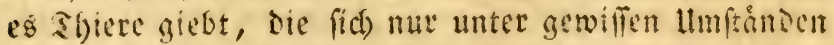

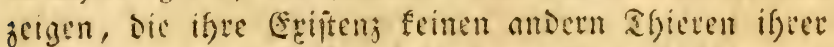
Gattung virbanten, und Dof mit ifnen if)e Pace an= fange uno entigt. Denn fie madjen zwat, und merden

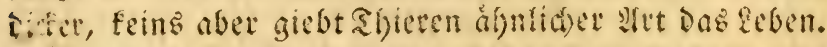
Dir unftetblide Suffon lagt Dabet mit Bedt: "es 
gebe eitte unendiche Mannigfaltigfeit von Utrfachen Der (frzeugung, es múgten bafker auch ifte fombina= tionen mannigfaltig feyn, und alle fonnten suellen neuer Produftionen werben. Es fenen vielleidst eben fo viel lebende oder vegetirende siefen, die Durd das ungefágre Zufammentreffen organliúder Atome erzeugt wetben, als es Sfiere und Begetabilien gebe, die Durch eine fortgefetcte folge von Črzeugungen hervor gebradt wurben *).

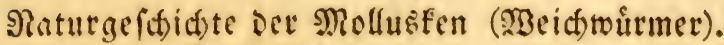

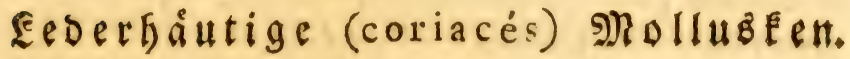

\section{Einleitung.}

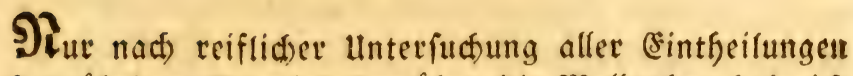
Der ubrigen Schriftfteller iber Die Mollusfen habe id mir eine neue crlaubt. Sene (sintbeilungen alle lallen

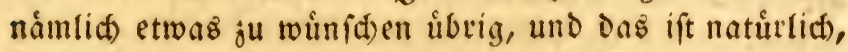
Da bie গatur, Die alle Beftalten und Derter amnimmt, über unfere Bemúlfungen, fie zu feffeln, lad)t. Jeden Iugenblick meidtt fie wieder von Dem Thiere ab, das fie fid) vorfer zum Miufter gerwáblt zu haben faden, geft bald teáts bald linfs, bildet jencm vollig fremoe (sinttungen, und fommt, bistreilen nad) einem fefre toeiten Ummege, bieder auf Den IJunft juritef, von weldem ite ausgegangen wat. Innire 2 bidnitte und Abtheilungen werden Dafer wie unfere Snfteme immer unvolftándig blciben. Dies mus folglich aud der fall

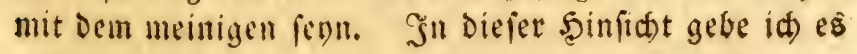

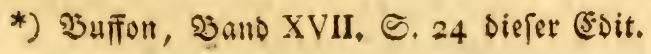




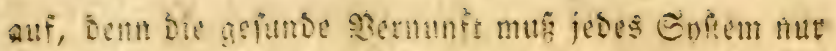

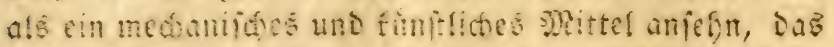

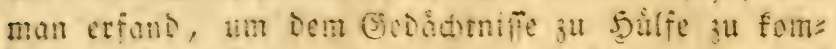

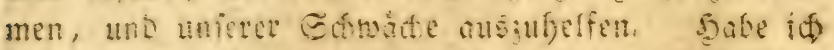

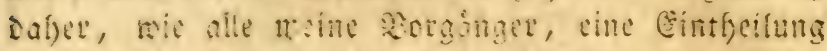

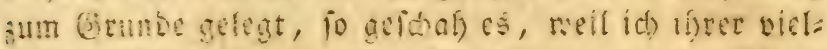
Ieidt mefre als feber andere beourfe, um meine Joeen abjutbeten, uno meinen fifen georonet vorjulegen.

Range vor ar riftoteles idon fytten fith einige

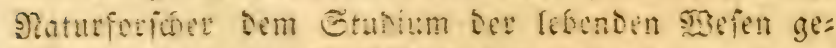

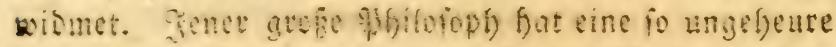

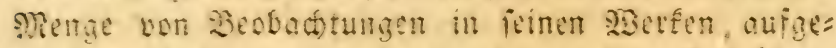

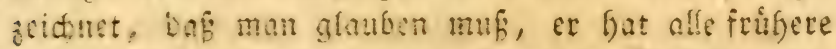
geiammeit, uno Die fenianen, fo mie die Hefultate lei=

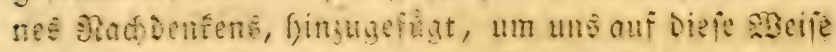

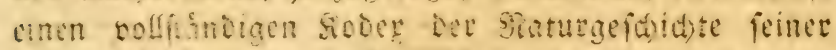
Beit jume zu fapen. Dom fon, rie ifm wolle, aes

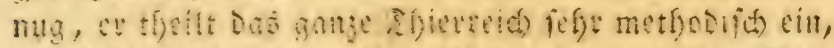

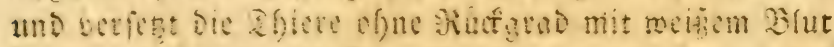

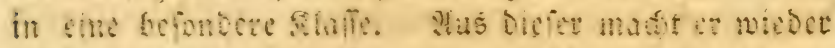
grofe abthoflungen, bie of weide, mit ciner

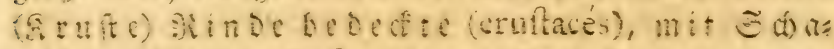
len veriefiene (teltacés) uns Jufeften*) nent.

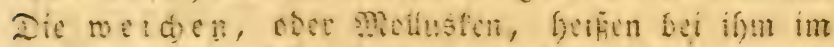
allgenteinem malacodermes, poce sflete mit reis

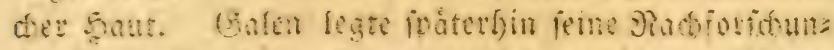

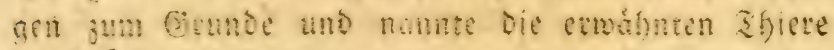

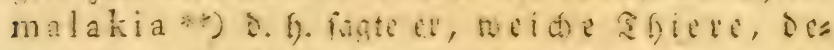

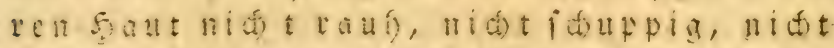

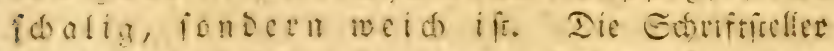

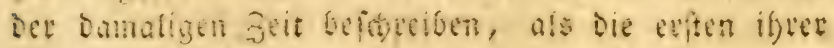

*) Arift. Hir lib. 1. cap 4. et 8 ., et lib. 4. cap. I.

* Malakia, i, e. mcllia vocantur, neque jifuamman, neque siperam, neque teftaceam cutem habentia, fed mollem, Gallienus lib 3. De aliment. facult. 


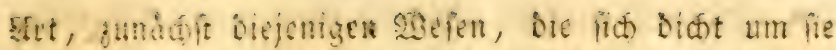

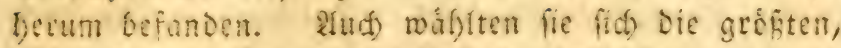

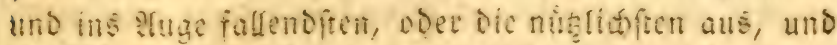
futoten mist etft in Der ferne fremie doer verborgene Gattungen auf, fonbern bicie murben fpater mit ben

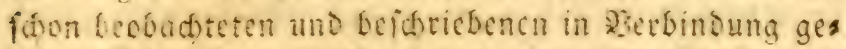

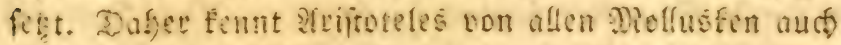
blob sie Dintentipe, Molnpen uno Ratmats. Faft wioer feinen millen serbindet er Damit now den Sees

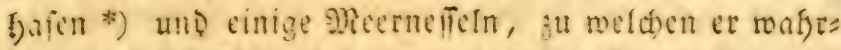

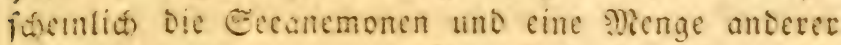

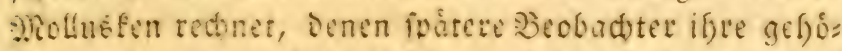
rige Etclle angewicien haben. Belen und ॠonbelet folgten bem ir riftoteles. Sie fellten bie ginturs

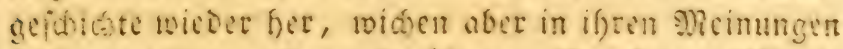

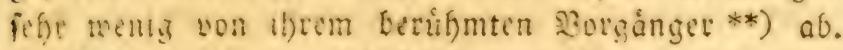
Fondelet bat otwar viel feloft berbacitet, uno cinige bis Dafin unbefannte Gattungen befannt gemadt, abcr it begriff fie alle unter cinem allgemeinen J?anen, of ne Sie veridwonen Gejofedter gehorig ju unterideioen.

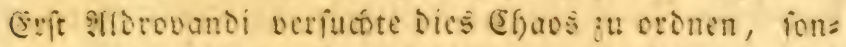

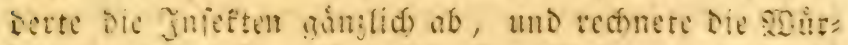
met mit Daju, natm and cine sfole mefge an als

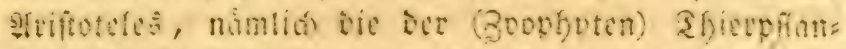

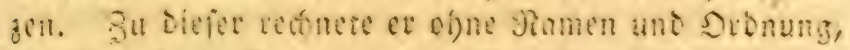
Die Meduten, Escuntmonen, Raplifien, Alicyons uno

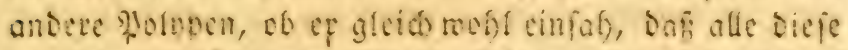

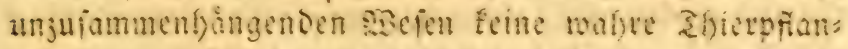
gen feven. Ga) bemerfe fierbet, bof man bamals sie (Ilition) Econcmonen, und foft alle Nollusfen, tie

\section{*) Die En plifte der Tecuern.}

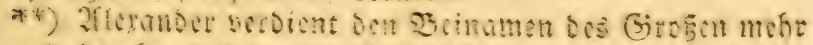

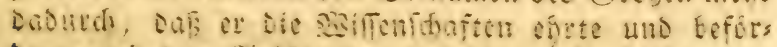

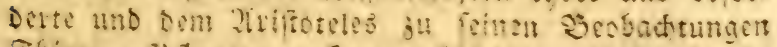

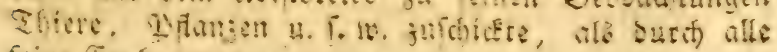
feine Eroberumgen. 
fich init bem Untertfeil igres sótpers an ben gelfen an: regen, Sfierpflanjen nannte. Die Sorallen und Bors gonen, Madrcporen und Edswámme fergte man unter Die Eeepfanjen. Maan muf́te nod) nid)t, Dáb Diefe áfigen Sidtper iffe Eriftenz Fotapen verdanfen, Die fie gemeinidaftlid hervorbringen. Diefer nidft $\jmath^{u} \mathrm{er}=$ múdende Sammler unternafm jefre forgfăltige Unterju= ct)ungen.

Man erftaunt úber die Menge oon Materialien, bie er fammelte. Ungeachtet er kiber finfundfiebjig Safir alt murde, fonute er bod) nicht alle feine $\mathfrak{A r b e i}$ ten herausgeben. Eeine (s)attin gab Dafer nad feinem

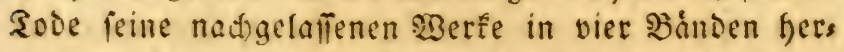
aus, und wiomete fie tem Mragiftrat von Sologna. Dieje nachgelafienen şerfe handeln oon den slol: I ben Salthieren uns bon ben Thietpflan jen. Gešner und Joniton ferieben Den Ildrovandi aus̃ ; ifr Seţt ift Der feinige, nur abgefủrzt; und ifre Beichnungen find ourdaus biejelben, Die er lieferte, nur fallen fie bistocilen meit fallect)ter aus. Jonfton fugte inder Dod) einige Brafilifiche, mit Sruften beocfite Ihiere binzu. Seit Der Zeit hat aber Diejer Ifeil Der Naturgefuidute grofie Fortiotitte gemacht; eine Menge einjelner Beobad)tungen vermefrte Die Injafl

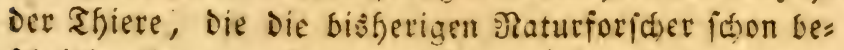
id)rieben fatten, tåglich); bis sinné fie enolich in Slaf:

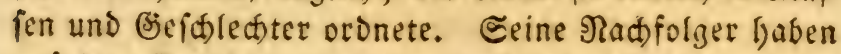
auf ben Grundlagen, sie roir ifm verdanfen, meiter

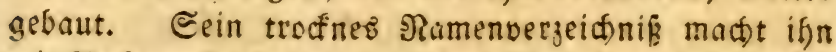

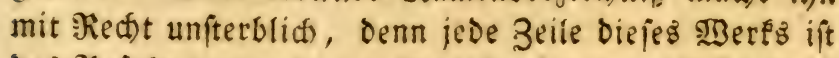
ins Refultat ungeheurer Unterfuchungen. Gebe arife enţált ein ஒৃud).

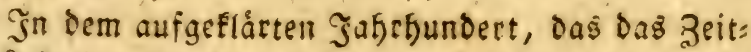
alter \&ubroigs Des Bierzefnten vorbereitet hatte, erfo:

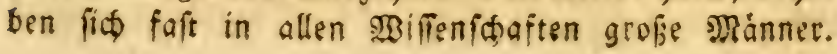


Franfecid legte in feiner allgemeinen Fncrelopábie ben Inbegriff aller icmaligen menidfliden fenntnifie Der 28elt vor. Die গaturgefthichte mad)te alio cinen 2 heil Derfelben aus. Buffon hatte bie Gscididte ber vier= füfigen Thiete uno Bógel baju geliefert. facepede gab die ber Fifhe und ber eierlegenden vierfibitgen Ifiere heraus; andere Naturforfder fdrieben Die ber Sd)langen und MBalfifictarten (Cetacés). Bruguiere

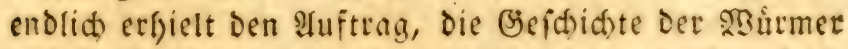
uno Mollusfen ;u fdereiben. Die vielen Rupfertafeln, Die er herausgab, liefern uns gleichjam nut Den umrín feiner Bimúfungen. Brtuguiere mad)te eine meite Peife; unvorfergefefene llmftánde verfinderten bie Serausgabe ber Enenflopadie und bet trefflide bru= guiere erlag Den Bejerweroen eben, als er nach Dex

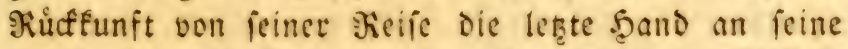
riserfe legen mollte. Das beilige Jeuer ter wifien= fis)aft etlofd) aber nidst mit ifm. (Er hat jafflrcicte 9lad)folger. Sie haben fein Enftem nod) beridtigt, und biele und widtige Sfatiaden zu benen finguges fügt, Die Bruguiete uno feine Boránger gefammelt batten. Tetht mad) Lamarf fein Enftem Dex Sficte ofne Ridfentrirbel bifannt. Cuvier fiellte Daş feinige in einem vollftandigen Softem bes इfiergefdedts auf. Diefen frifferen Edriften gab er bals Batauf surd

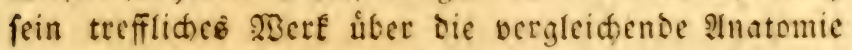

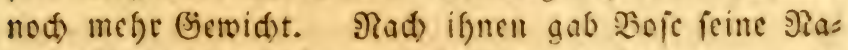

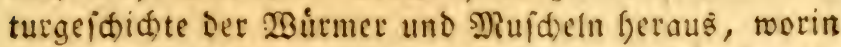
er mit Scinmeifung auf Die \&inneifde Э?omenclatur bie (Gattungen anjeigte, Die nod) bis jeţt in jeDem Bंes fdledte angenommen find. DaDurd exmies $\mathrm{et}$ Der

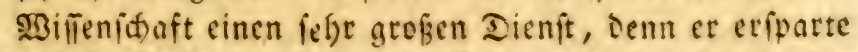

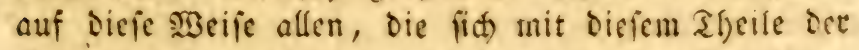
Naturgefolid)te abgeben, cine Nenge Unterfudsungen. Die Schriftitellex, bie fid mur mit einjelnen ?hat=

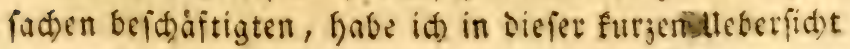




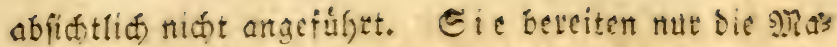
terialien ju, Die berjenige ammentet, Der Daŝ Gebchute

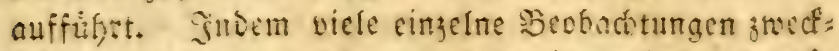
mébig vereinigt werden, entfést ein grofes uno fot: nes Ganje.

Eo treit id bis peţt Die Drganifation Der Mots

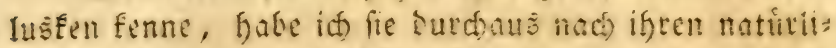

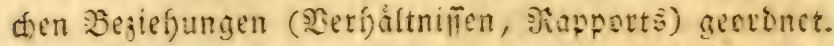

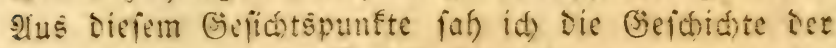

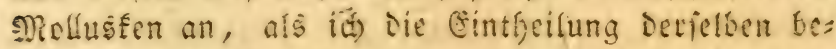

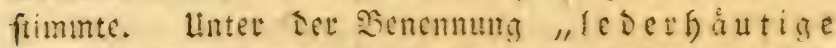

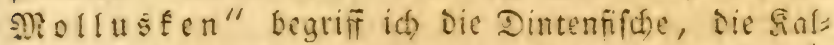

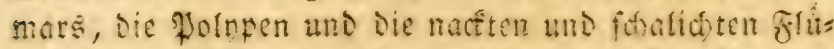
getrumerer (Clios); nicht tweil fie ihre vinge oberfalte

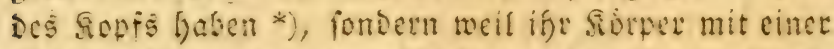
Edfeibe ober mit einem Eace umgeben ijt, sen alle Diefe aglere befiten.

Shre Rennjeichen find: E in heroortretented Sopf, undein flcifáaet serper, oet in.einem leserfáutigen Ea É (ober

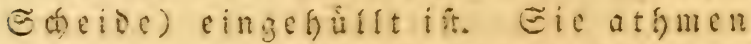

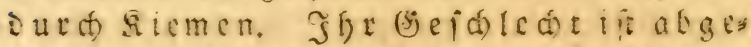
iondert, lie legen ficr, und fimbent (ic) $\pi u t$ im Micere.

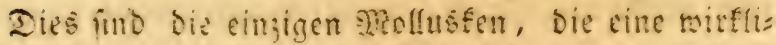

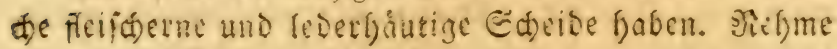

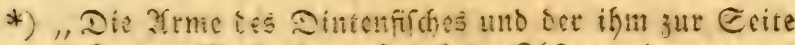
frefenton Drollusten, fino feene Fúfe, wie man aus ber griechioden bon Enser anacuonmenen Bencus

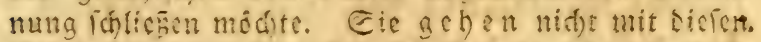

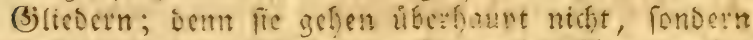

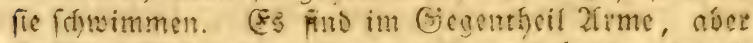
fie fint folie bieglan, fie ergecifen und baften biejent:

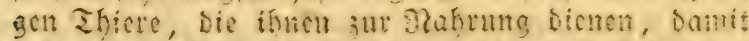

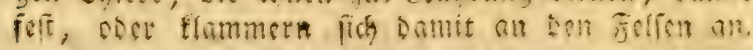


id Dicics Simnjeiden in irtengiten Eime an, to bes

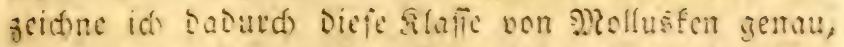
Deun fie fiffefit nut einen SGeil oer cepgafieten, ober

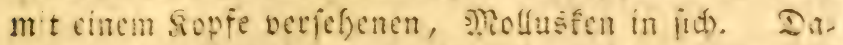

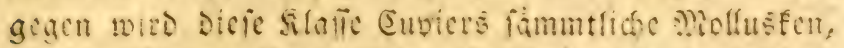
die bie fobfe am sopfe fyaben (cephalopodes), enthal=

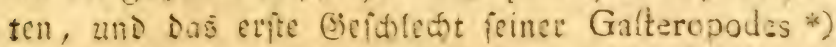

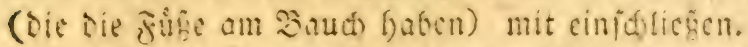

Jo will moine Cintígeifung gernoe nidot rediferti: get, aber iff bemerfe dod, Daf Eamate uno Boje allen ifren sholuefen mit cincm Sopie (cephalés) emen Diffen shonte! von veridicsenet Seftolt goben. Eie

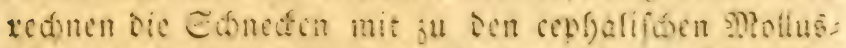
fen; is glaube aber, bof es former icon móste, ju bemeifen, bab sicie cimen fotben smantel goben. Die

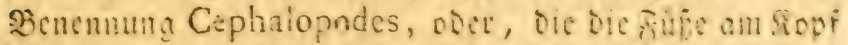
Gaben, fomte ió cben fo menia antefmen, Dem bie IIrme Dit Dintenfijde find (roie folon gefongt fine

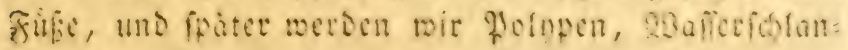

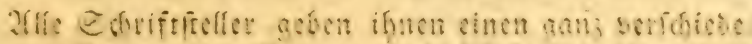

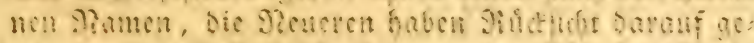

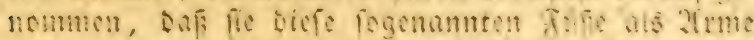

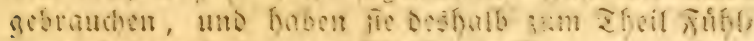
arme (ientacules), num Theil mit siburart verjefgene "Irme (bras verruqunav, actumit." (Bofic)

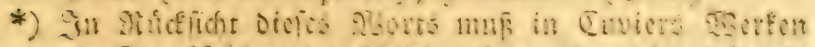

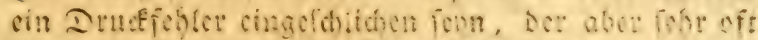
wieder sortommt. Galter bebentet 25 a a d uno

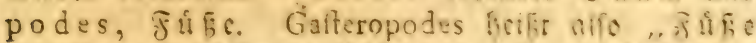

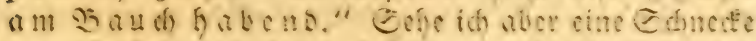

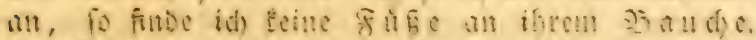

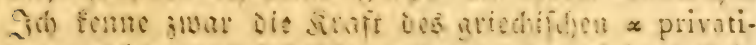

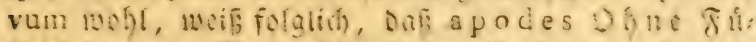

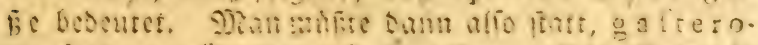
podes, gafterapodes tein. Dit Edmecte folepst lith aber anf bem şatue fort, bies Jart

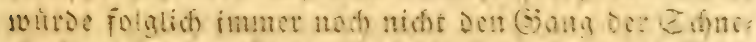

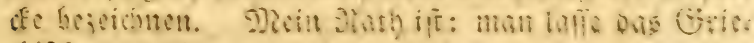
dyifde weg! 
gen, Aftinien, Solotfurien, Fereioen unt andre Thiere finden, Die ebenfalls am oberen Sheile Des Sorpers Irme haben, mit welden fie ifeen Baub $\mathrm{kr}$

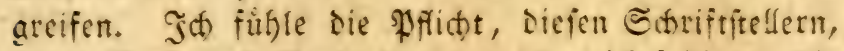
Deren Merfe und Beobadtungen it mid bediene, Die tiefite Irthtung ju etroeifen, aber ich fann both nitht Dafür, Daf meine Meinung nid)t gånglid) mit Der iffri= gen übereinftimmt.

มlle leberfăutige Nolluśfen reben im Meere.

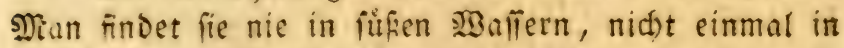

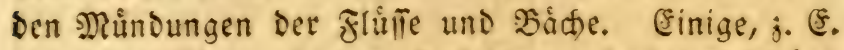
Die Dintenfifite, fterben iogleids an ber atmuiphári=

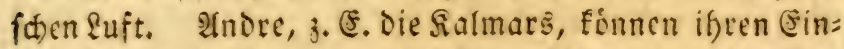
fús einige Zeit ertragen. Die Plolupen, Die ithon ftárfer uno fraftooller fino, folten barin aus ; ja einige gefen ielfit anș Sand, wie j. bien thun. Mande icheinen fid uber eine Mimbftille, oder úber fajones $23 e t t e r$ ju freuen. Sie ófinen und breiten fich Dann in Den Etraflen Der Eonne, Deren milde $23 a$ arme fie lieben, aนริ. Die flugelwurmer (Clios) erfeben fid ztwat aud) úber das i tauchen aber jogleich wieder unter.

Alle Diefe Nollusten atfinen ourch Siemen; Fondelet ertannte Den Naţen Derielben bei den Dinten: fijd)en juerît. Ere fafe, Daß̉ Die áftigen Siemen in Der thierifden Defonmie Diefes Mollustes die Etelle Det Siemen bei ben filften vertraten. Die 2ltten, die Dieje Urt bon platten Fingeiveio en (vifceres palmés) inner:

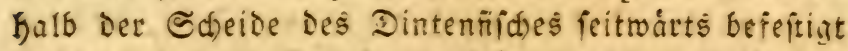
fanden, nannten fie fajerige blatter, haariges 2 ejen, (Capillamenta). Die Fiemen fino bei Den s)rollusfen, to as bie \&ungen bei ben vicribigen Ifieren fino, ein Drgan zum Itthmen. Um ifte Berrichtungen Deutlich D arjuitellen roill id hict bie Befdreibung herieţen, die

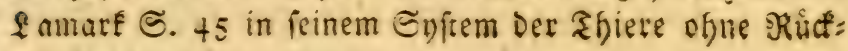
grad, Davon gegeben hat: 
„Die Siemen, fagt Diefer gelehrte Naturforicher, fino ein Drgan jum Itfmen, Das entblofît oa ftelt, und nicht roie bie \&ungen, Zellen, \&uftrófrenajie, ober eine Suftroffe ferbft, hat. Die Befafife, bie in ber Sunge fid auf ben 23 ánden Der Bellen uno Suftrdfren, afte umber befinden, um bie eintretende Ruft aufzus nefimen, bie fid) in IUzenblicf Des (Finatf)mens Durd Die Ruftroffer finein begiebt; - Die gleidien Befáfe befinden fid bei den filemen nuf ifrer Dberfiate, auf iffen Blatterchen, uno auf iffern frangen, theilen ficts in unendich viele flcine Irefte, uno bieten bem cin= ftromenden fluidum eine grof́e Dberflact) dar. Die

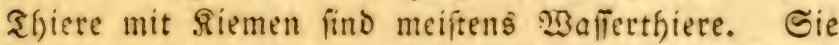

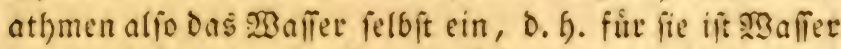
Das cinftrómende fluibum. Ffre ganjes antlmen bes fteft folglid) Darin, Daf iffe Riemen immer aufs̈ neue

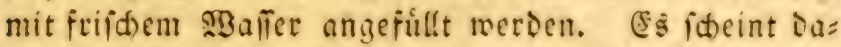

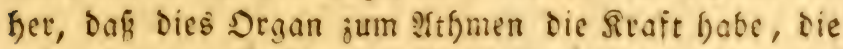

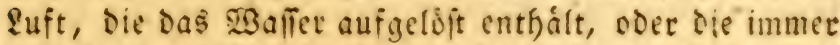
mit ifm vermifht ift, Davon abjuiondern, fie dann ju abjorbiren, und in bie flünigfeiten des sfhers úbers juleiten. Sid)er giebt es auth Eufteiemen, D. h. Ries

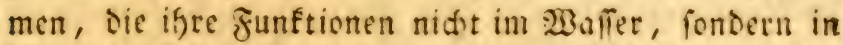

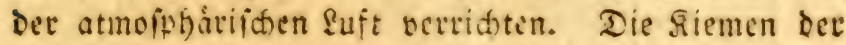
TBaflers und Rand $=$ Sannecten geben ein Beipiel bet

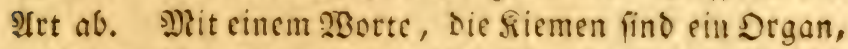
Das̀ Dic Fifif)e, Nollusfen uno Iiruftentfiete (Cruitacés) oum ?(t)men meientlic) nothig gaben."

Dicie Gitutentfiere fino oft Impfióen. Einige Srabben leben fogar lefir lange auferfalb bes Mafiers, ja fie fheinen Das Rano Dem Meete borjusiefin, Eent fie vertocilen in Dem lesteren faum Den vierten IGeil

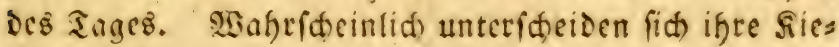
men im Bau von Denen Det Jilate, Denn bicie j. (5. Dee

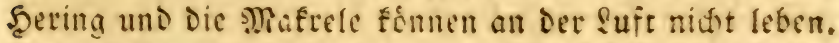

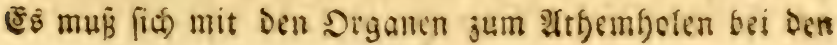


Icberhäutigen Mollusfen cben fo verfalten, bent cintge suter ifgen fterben fogleich an ber euft, uno andere fácinen, wenigftens eine zeitlang, den unterfotico

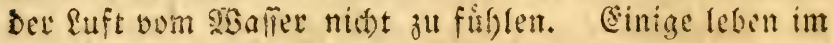
bohen meer, anire fdeinen fid mefre an ben fiufter

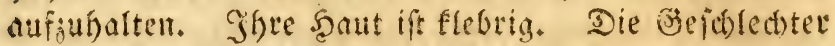

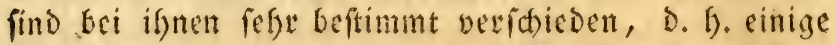
find månnlid), ondre weiblid). Stlle legen (eier. Das

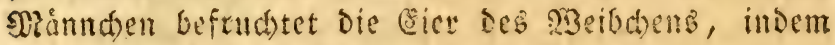

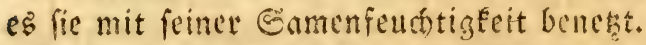

Si3africteintich leibet dies Gefet cinige Modififa= tionen bei Den Strigetwurmen (Clios); Deren (j)=

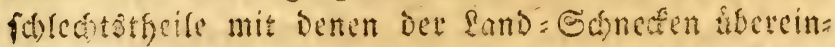
fommen. Der forper aber, ien bie farofonneffe im Augendite Dev Begattung beraus laßgt, ît befanntlich

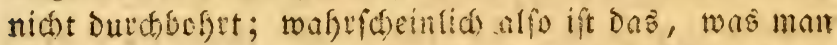

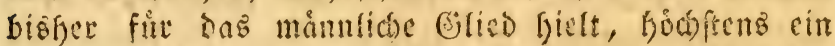

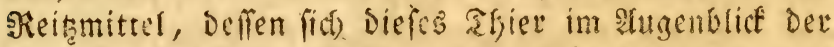
\$acung besient. Solten bie fltigetwirmer, wie

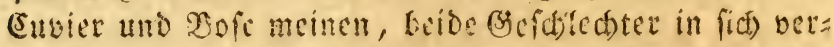
einigen, fo witeden fie die mittefniancen zimifacen ben leberfáutizen und ben mit filfifäoen verichenen

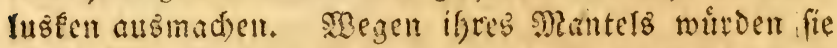
auf bieje leşteren folgen, ifrer Diganifation wegen aber jenen votangefin.

Die Irme aller biefer Mollusken find mit Sufts

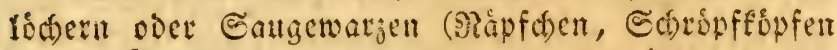

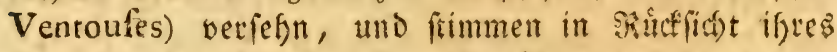
Waues nicht vóllig mit einander itberein; alle abe: $\mathrm{er}=$

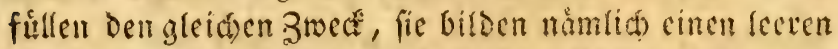
Reum, uno verurfaden, Dof Dee Serper feft ange=

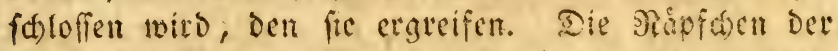
Dintenfifise fino cinfach und einerciartig; Die ber sents mats find furdtbarev und mit Saren verfegen. S3et Den grofsen Wofupen gleiden fie fámeidenden Maffen,

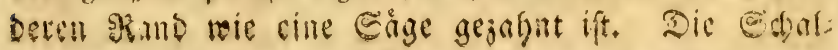




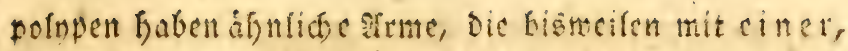
bisweilen mit a twe i Beifen bals parallet raufenoer bals

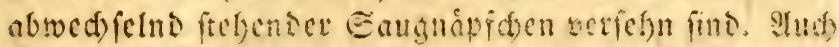
bei ben Fligefmitumern fonn man Dieje Giapforen on: nefimen, wenn man fie gleich auf ien furjen sremen, Die ณเ Dem Eate unte ifrem fiepfe nut sin menig

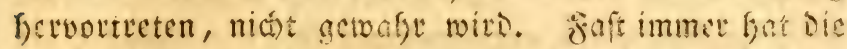

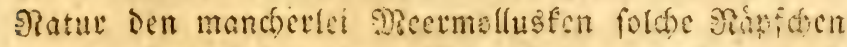
gegeben: ja, beinófe móchte id jugen, afle sicjenis

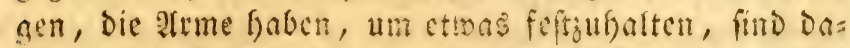
mit verfefn. Jat batse fic bei bei Eecamentste, bei ben \$olnpen oder Syoern, bei ben Borallen = Jufeften,

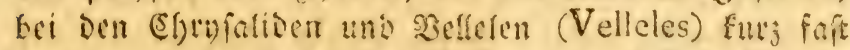
iberall, und beftumt bei allen moĺmben gefunsen,

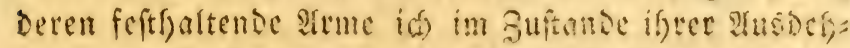

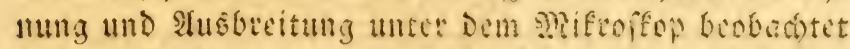
fabe. Pach meinen vielen baribur gefammelten 30

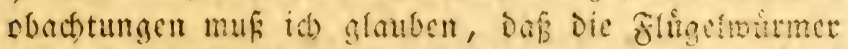

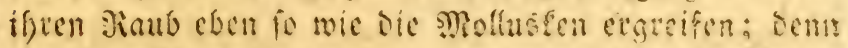
a umichlingen und unwinden fenten, folgt nod nicht, baf

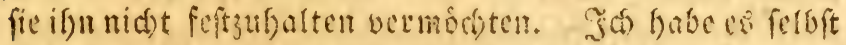
gefefn, Daf che Scancmone mit cher Dumen Epihe eines iffer Reme einen Stabben non Det Brofe cims

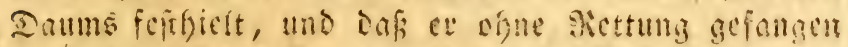

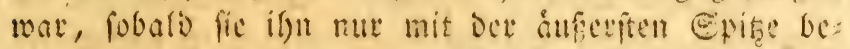
rifgren fonte. Dos gleiche mug bei ben flugelwit: mern ftatt finder, bic invefs, weit fie mut flem fins,

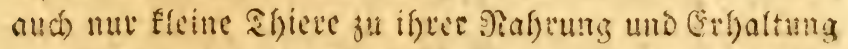

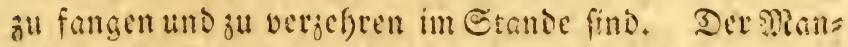

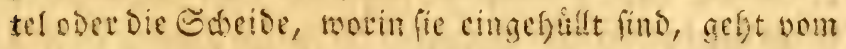
solfe finabwaits und beocft ben gunjen Sorper biefer

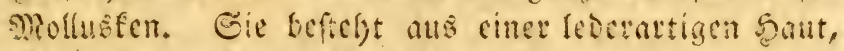

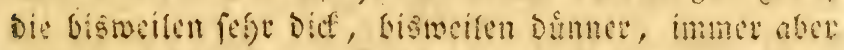

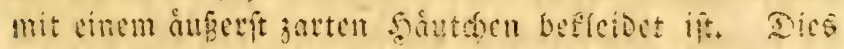

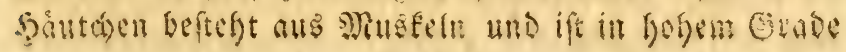


reiţbar. Der Mantel ift feinter Beftalt und (srópe nad) verfacben. Er fitht oberbalb des Magens des Thieres feft. Die Irt, wie er befeitigt ift, unteridheibet fid nah) Den verifhiedenen (5attungen der afiere felbft. Shre Irme wadjen wicber, wenn fie Durd) einen Su= fall abgerifien find. Man findet oft Mollusten biejer Art, bei denen ein oder mefrere Gilieber nicht bie ges soofnliche långe haben. Daran find die Rámpfe fauld, Die fie oft mit fifden, Die ftarter find als fie, iund bie ifnen einige ifter arme abbeiffen, ausjuftefn haben. Sie wadtfen aber, wie gefagt, wieder, erbalten allmál)= lid) ifree vorige sånge, und werden mit ber Zeit ben nod) ibbrigen vólig gleict). Weenn fo ein $\mathbb{A}(\mathrm{m}$ veriftimmelt uno vom Sisper abgejondert ift, fo bleibt an Dem Sheile, Der am fítper fiten blieb, cin oder mefrete Đierven=

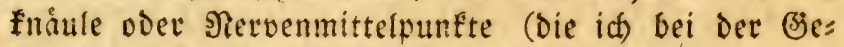

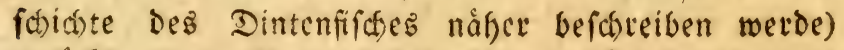

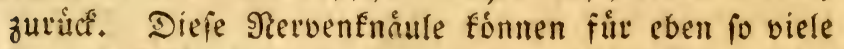
Reproduftionsferne gelten. Etatt Daß die 23 unde mit einer siarbe feftzumatien follte, fo wiro fie blok mit einem Şåutden ùberzogen. Das frecifa) wådjit und treibt fort, und bas Såutthen Defynt fich mit aนsิ. Da es aber blof eine Ausbefinung Der Saut ift, fo verlån=

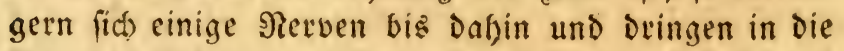
(Brundlagen ber neuen (Sauge =) গåpfden ein, bie fich allmåhlid) zeigen, um bie झrme rwieder zu berwaffnen. Sin jiemlict furger Zeit erreidfen diefe wieder ifre vorige

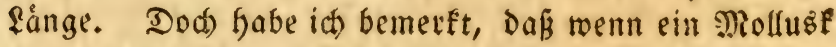
mefrere sirme zugleid verloten batte, es diefen fo bes Deutenden Betluft nid)t fo leiđt) als den eines cinjigen Urms wieder erfeţen fonnte. Befchieft $e^{\circ} j a$, fo find biefe neuen filieder nicht io ftarf, als bie, Denen fein

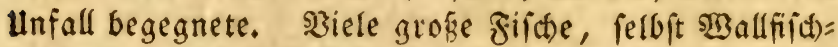
arten (cetacés) frellen bent Molluşten nach) und nábren (id) Davon. Die fleineren veridslucft Der $\mathfrak{W a l l f i f h}$ ganj, bod) greift er aud die grófern an, und bistweilen ge= 
lingt es ifm, ifnen einen oder Den ande'n ifter Irme abzubeilien. Die Gefdridste des Sirafen oder bes nordifden \$olupen wito uns in biefer Şinficit That= facten zeigen, Die wir unglaublich finden und fur Fabein balten witroen, wenn bie allgemeine Sebauptung fie nicht beftàtigte.

Die Sanfifthe, Sammerfifhe, Bolsfarpfen (Do= raden), Niutánen, Ripppifdye (Eeemólfe) und eine Menge andrer Baubfifde verzefren Die lederfátigen Mollusfen ebenfalls, und man findet fie nid)t felten noch) $\mathrm{g}_{\mathrm{a}} \mathrm{n}$ in ifrem Magen. Iuf biefe Art Gaben Die Reifenden fids oft (sattungen verfáafft, bie mut im boben meere, alfo in ungeheuren Ticfen leben, woisin zu gelangen dem Menichen wohl fü immer moratiph unnoglidf bleiben witb. Man verfaume itberfaupt nie, Den Magen und die bingemeide Der grofen ₹ifche ju unterfudien! Der Magen, felbit Derer, Die man auf unfern Gifchmårften verfauft, entfált Sruften = Mollus= fen (cruftacés) und andre SGiere, vorzingliá) Mieerigel, Die auf bem Micerezgruno leben, von Den erwágnten Fifden verfdlungen, und bismeilen noch unverfegrt in ifrem Magen gefunden werden.

Die leberartigen Mollugfen find bie vollfommen= ften von allen, uno iffre Drganifation ift am meiften ju= fammengefebt. Der fopf ift faft bei allen mit jwei Aru gen verfeben, Die ben fiftaugen fefre gleidsen. Int biefer, fo wie in allen andern Silafien von Mollusfen finden fich nacte und bef(balte; Do(t) hat man bis dafin nod) feine Dintenfifde oder Sialmarz gefunden, bie bes (d)alt gewefen wáren. Dagegen werde id, nad) dem id) Den Frafen und die úbrigen nacten Polnpen be= idtreben habe, auth die mit Ed alen verfehenen \$oly=

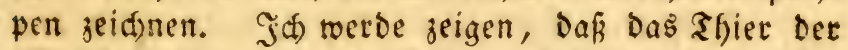

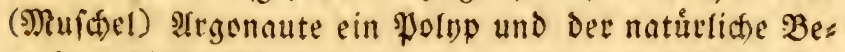
wofner biefer Muidhel ift, Die er Durd) Das falfartige IU⿴囗十) wiţen peitter Irme bildet. Эa) werde ferner 


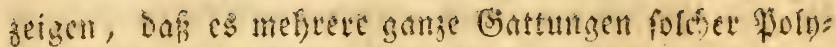
pen gieut, bie von emander wiflig verfotedene Edalen bitsen; Darang folgt Sann bon felbft, Daf Die arten in

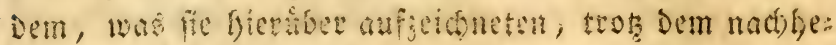

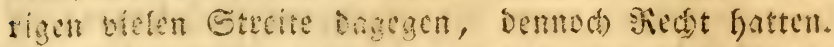

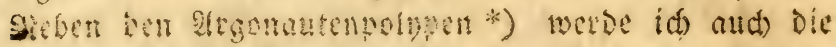

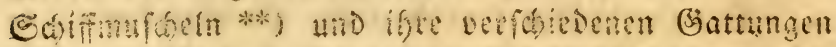

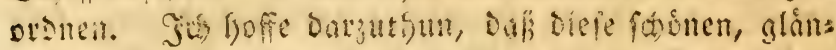

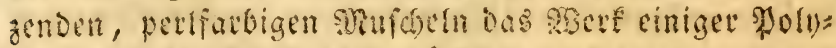

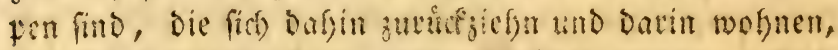

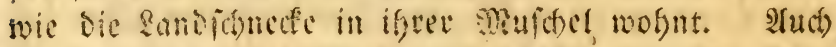

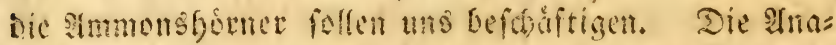

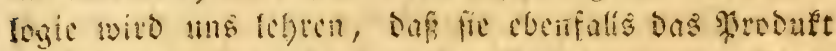

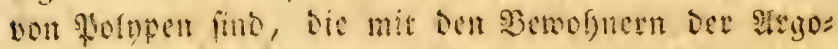

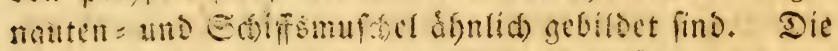

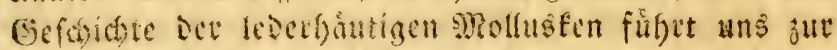

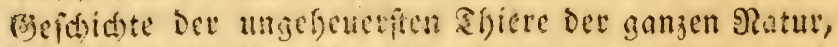
fut icnen novifón lugefgemern, die man fo mamnigs

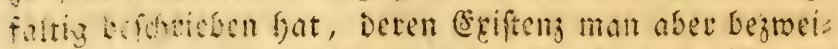

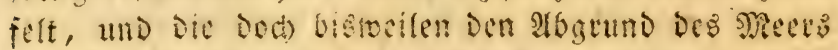
serfafen, nisot felten ganje edjffe exgieifon, und fie

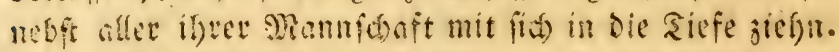

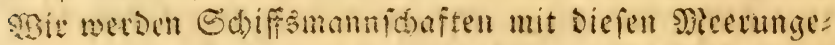
beucu, sie fie meist als ein feindictes Edbiff firchten,

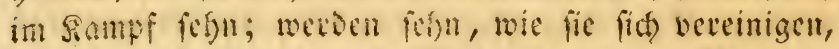

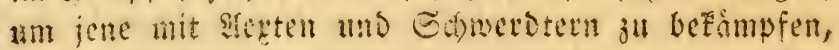
uno in sex anferfen Sloti) fogat mitten im Sampf Bes" libse zum simmel pencen, um sitfe gu extangen.

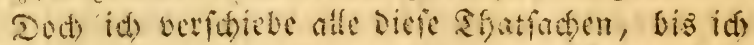

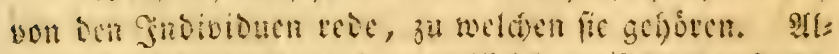

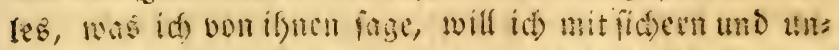

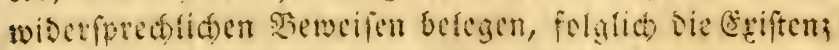

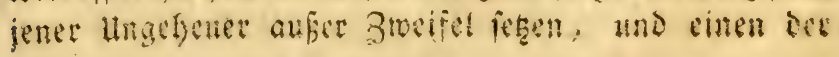

*) Argonauta argo. Linn.

**) Noutilus Ponjpilius. Linn. 


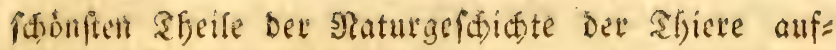
bellen.

Die Folnpen Der Argonatten, Ediffmuictelit und Ammonefforner befiten, wie viele andere Mollus:

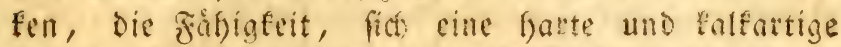
Eante oder sotlle zu bilden. Die g?atur fat ifnen, wie jenen, auf Der Dberftade ber Saut Edmeislider gegeben, die cinen falfurtigen Saft austimften, Det fid berbift, und eine Sohofe birbet, in welder fie fich nad Beticben einfultefen fonnen. Eie fins vom exfer IHgenblicf on bamit beffeidet; ja, unter $8 \mathrm{~cm}$ Irtifel

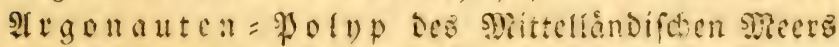
werden wir fefen, wie fogat fleitre (Smbrno's, nodh vor ifrem Susfeleden mit biefer Gotale bedect find.

Die witen, voriuglict) aber Iriftoteles und pllis

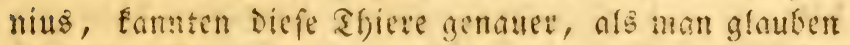
móchte. Cie baben zwar ifseen Bau nidst zinterfucht,

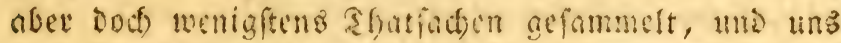
Diefe in iffer ganzen अieinfeit tiberficfert. In Defert Shinficht batten fie bei meitem mehr Daven gefefon, als

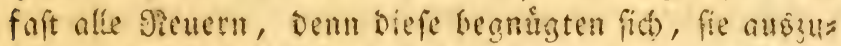
fdreiben, oder bas zu beztoeifeln, was jene Săter ber

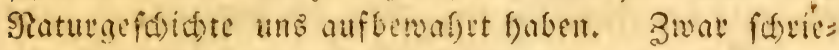
bell bie Iften matácb falfa nieder, meiftens aber fommt es nut Dafer, Dafis fie Bielfenten Dergleiden glaubten, weil fie felbit in ifree minge ponderbare Sas

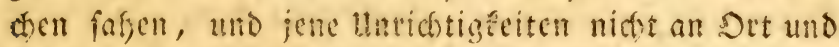
Etelle unterfuden funten. Eagt aber ein aiter Ederiftiteler "cr habe es felbft gefehn, fo foum mant fid) ficher anf ifn wertaffen, Demn ziemtich attemal bat bie forfafung finterfer beftatigt, was fie als eigne Sbeobad) tungen anfogezedinet batent.

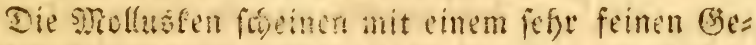
finfl begaut zu fern. Bei ber Beforeibung Derfelben

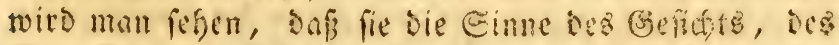

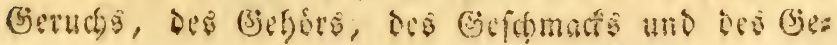


fiffls in einem fefre hohen Brade befiten. Mir wer: Den finden, Daß fie zu Eeidenichaften und Bergleichun= gen fáfig fino, daßj fie lift und Berwalt mit cinander vereinigen, und fict) wechfelšweife der Maffen, Der Sd)lingen, Der Salautheit und Der Sraft bedienen, um fich zu vertheibigen oder fich ifres अaubes zu be= mád)tigen. Ariftoteles fatreibt ifnen fogar aud Die úbrigen thierifthen Bedurfniffe zu. Sie wad)en (fagt er) wenn itgend ein Bedurfnín, oder die liebe fie mun=

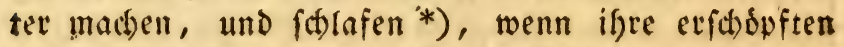
Sráfte Pufe verlangen. Diefer Sclulummer ftátft fie Dantr aber auch wieder.

S(b) torde nid)t anders von Den Muldeln reden,

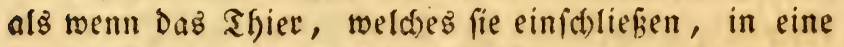
Der Mlaffen, worin id Die Mollusfen getheilt fabe, ge= bout; Denn id befalte mir 's vor, ein eignes f(thon fer: tiges Merf úber bie Muicheln heraus zu geben, Das alle befannte auf eine foldte Irt flafiffiziten mitb, Daß Daraus ein vollfommnes Snftem Der fonchnliologie ents

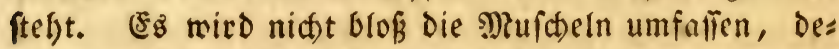
ren Bemofner id) befitrieben habe, fondern aud alle Die, Die zrar uniere Rabinette bereidern, deven Ifiete wir aber nod) nict fennen. Da bie $23 i f f e n i d$ aft heu= tiges Sages fo weit vorgeridft ift, fo Dirffen wir aus

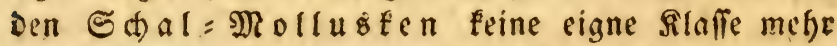
maden; alle Rlaffen oon Mzollusfen zeigen uns nacfte Ifjiere und Sdyalthiere. Dieie neue $\mathfrak{A t t}$, die Sadje anzufefen, mußs man Durchaus annehmen. So wie id alfo eine Muifhel antreffen werde, Die ifre Shier nod

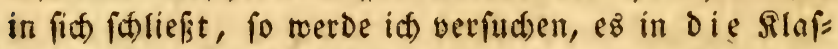
fe uno in $D a s$ Befthedt aufjunefmen, wohin peine Iennjeichen es verfetzen. S(b) habe nod) immer die Şoff: nung, Daḱ alle befannte (Sattungen fich einft auf bie gleiche şeife ordnen und an einander reifen werden. Dieje oronung fofeint mir weniaftens bie sinjige, bie Der

*) Arift, Hift, lib. 4 cap. 17. 
Der शatur gemán ift. Bofe bat fie aud fenon vorge falogen und mit Gitet verfucht, Denn ex fonoerte bie

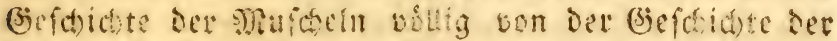
9netusten ab. Diefer sechritt mufie ge ban merben,

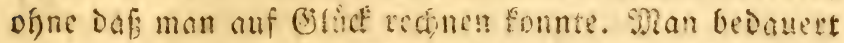
indef, in feince Đomenflatur Die befdyalten moluefen nicht ju finden, Die Doch mit feinen naciten Mofusfen von gleither alet fino. So fud)t man aud unter ben SBafferfonecfon vergebens mad ben Sonoidneden, un= geadiet er in ben allgemeinen Betracitungen übet Deso

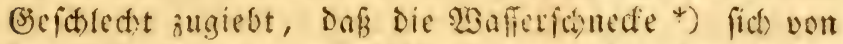

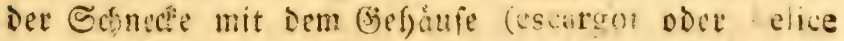

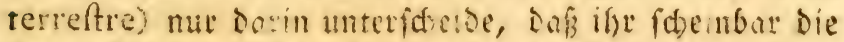
Schale felle. (bobleibt aber bemod wabe, Dof Bofe Durd) Shiffe ber (Bntbedungen famates und Enviers,

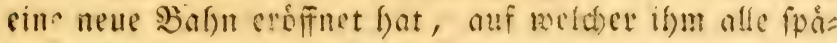
teren Siaturferfore fider folgen merden. Eein fleines

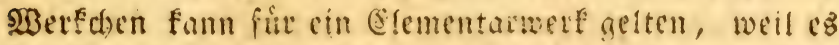
Den Pranen und Die nafiere Anzeige Der befannten Bat= tumenen enthålt, ju weláer er jedod aud diejcuigen binjugefigt bat, Die cr auf feinen Beifen fennen lernte. Sefre ift es zu bedauer, Dof das format in 18,

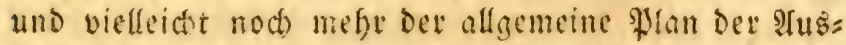
gabe des $\mathfrak{b u f r o n}$ (moran ex mit atbeitete), iffn fo cins

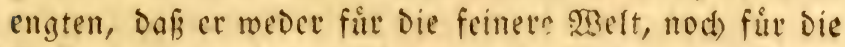
Sugend, fondern blok fur Gelefgrte, foretben fonnte, bie allein feine Srbeiten toerden bemutien fonnen. Jit)

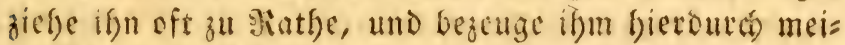
ne Sereffung refie gern.

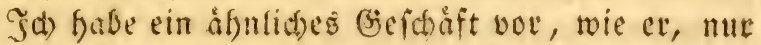
in einer andern Materie. Dft reeten fid mir pfilos foplifide Fefultate Darbieten, uno id gefefse zum voraus, id werde fie nicts aus befr Sugen laffen, denn

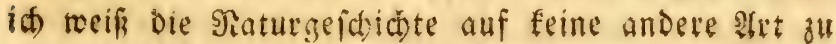

*) Bofc, Tom, I. p. 7I. Vers. 
befandefn. Siti butch fie fómen mir aftien, daf ses ben und Bervegung vollig unbegrångt find; irur Durct fie wersen fich uns Die Dinse oon if)rem entferntefter Uriprung ber mit inniger Heberjeugung entricfe!n. Sha Dem wir die enolofe fiette der fin ans dafinenden șe= fen Durdshafen, reiden wir bei jedem Edyritte ents Decfen, Daf nod eine Mente anderer extifiten, die

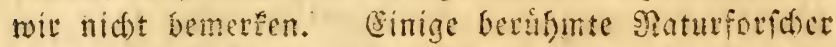
b)aben Der ssifienichaft blof Durd cine trotine Siomen flatur io mítige Dienfte gefeifret, Daf wir iffnell ewig Ertemtlicheit bafur fouldig find. Sfndere boven, ofy ne in ifren forfoungen zu cumiden, Das Chav, wo: rin fid) Die (Bnttungen nod) befanden, georbnet, jebem

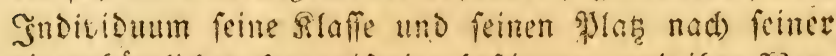
eigentfumfidson Srganifation befrimmt, who ifge Sibrs

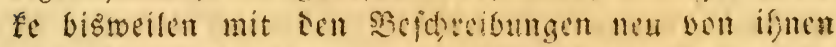
entiefted Thicte bereidert. Dft fitgten fie zu iem

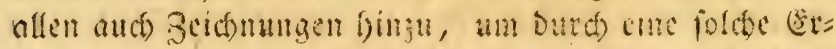

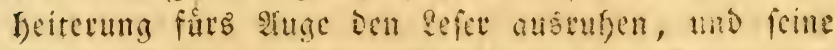
Joeen oronen gu lafien. Smmer breibt uns aber now

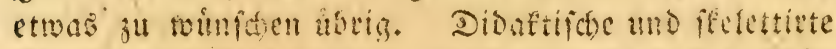

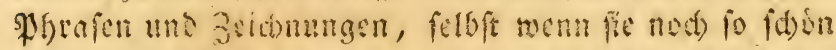
folorit fint, uno uns eine noch fo tidfige foce von

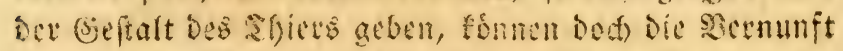

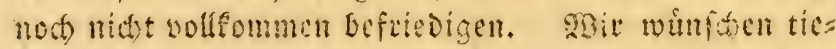
fer cinjubringen, und etwas megre als bloke storfecilum gen und farafteriftifa) Silafien fenten su lernen. SBit

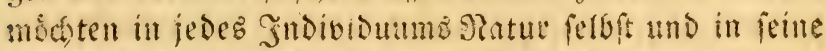
innere Drganifation eindringen, uns von feinen Sittrn, Betwofnfyeiten, Cigentfintich feiten und von feiner se= bensart untertidetefl modten bie jegenjeitige 3 ezies

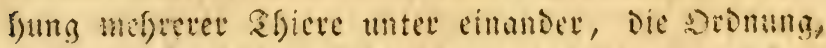

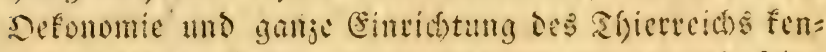

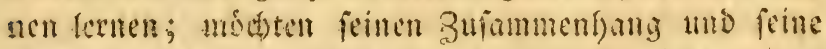

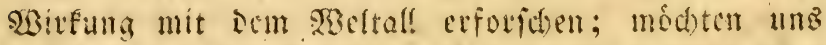

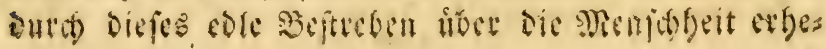


bett tho an Den Brijeimniffen ber Siatue Sintbeil nef)=

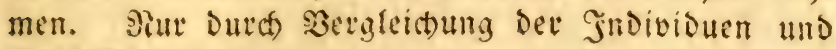
Thfofofung iffer Bejichungen unter einander, genieft

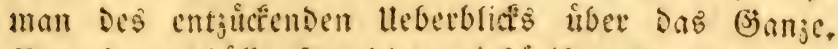

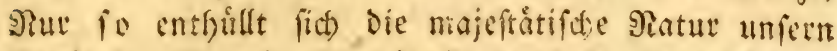
Şiten. Siur fo erwedt fie Durch Die Entwicfelung ifrer Gróbe Stamen in uns. SrDe 2useimanderies bumg zeigt ums neue Binge in ber grofen Rette. Dhne geroltfame llnterbechung greifell fie in einander und verid)lingen fít); fur;, dic vollfommene fermonie-Deg

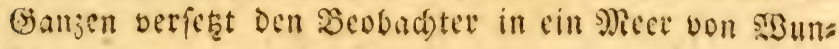
Dern.

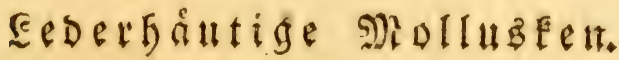

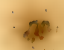

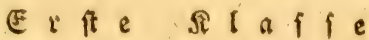

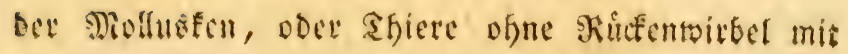
weiffen $\mathfrak{B l u t}$.

Erites (Hefकledt.

D $i \mathfrak{n}$ e $n$ f $i$ i e.

Der bemeite Dintenfif由 *).

SIs Scuren Der Edopfung beftimmen wir Den Sorth voet llntwetth Dev Sifiere nach Dem Shaten, Den wit

*) Sei Den Ffrebanem, opistholia. Brim Ireffotelez, sephium. Jut 'frabifaken, sarathan uto sarthan。

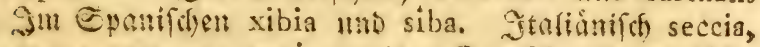
seppo, sceppa, sopi, cepia. Deutfín, Dintenfiche

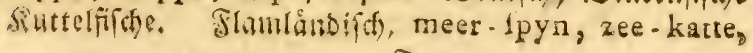




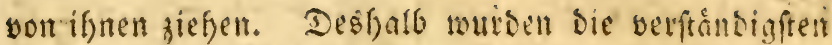
unter ben vierfubigen Rhieten gejåtmt, einige fogar

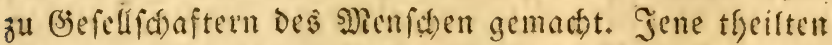
blog feine sabeiten, dicfe and feine 3 argningungen. Seiner Stimme und feiner Sand folzfam, belue fid) Det Cleplant mit Den fawerften Eniten, Das Famed

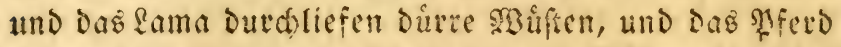
twagte fich mit ifm in Die Gefalts. Stiet und Büffel

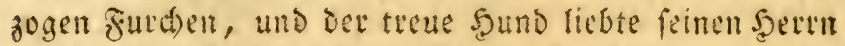

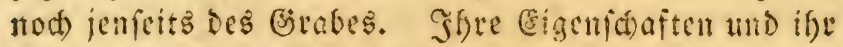
serftand madben fie uns febr meatf). Sh ne n baben wir Daber Die erften Gtellen eingerémt.

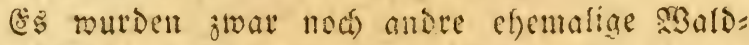
berwofner um Den Menfoten ber berfammelt. Cie waten

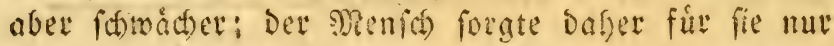
nad) Shafigabe des Plutents, Der er won ifnen jog. Eelbit Die wildeten Thtere, Die nach reie ver unab=

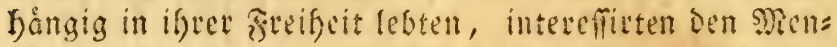
fden mefre oder weniger burd ifye Eitten und Be= wofnfeiten. Ser Sirfid) und bie Sindin, Der Dam=

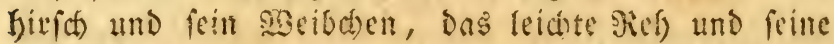
beftandige Befäfrtin wurden innerfalb ifter siálder

fpaenfche zee-katte. Englifi) blackffich, blackkuttel, cutcel-cuttle. (Silifiti), ciches, boufron, seiches. Eatcinifh, nauplium, sepia, sepia officinalis. Linn. 296, sp. 2 - Amoen acad. 1, p.325Seba, 10m. III. Safer 3, ฬigut I - 4. - Aldro. vandi, Exang. de moll. pag. 49 uill 50 . Bonno. nide, I606 - (5̈esner, de moli pag. 186. Tiguri, 1560. - Jonston, Exlang. Tafel 1, Jig. 2 uno 3, 2fmfrevoum, 1657. - Encyclop. Tafel 76 , Tin 5,

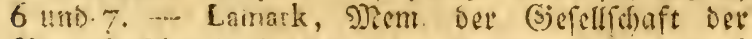
Shatufouthe: in Mortis, p 4. Belon, Pifc p. $338, i^{\circ}$. 341. - Rondelet, Aquat. I, p. 498 mis p. 365 , frantz. ILuẺ. - Olear. Muf 97, fig 97. - Salvian, Aquat p. i65. - Ruyfch, Theat, II exfang. tom. I, fi. 2 uns 3. - - Ewammerdam, Bibl, natur. tom. II, ₹afel 4. foll. uns lat, 2fusgabe. 


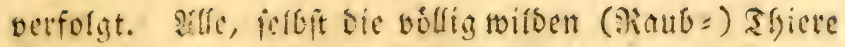

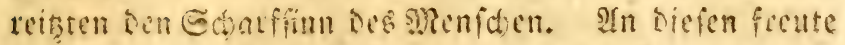

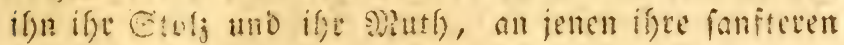

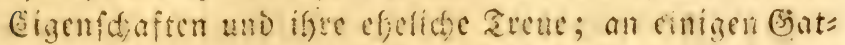

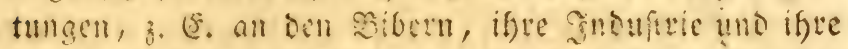
gemeinfájaftláan arbeiten. Gen fucien mir ifre

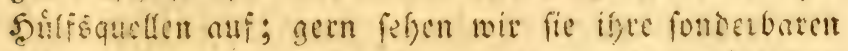
Dinme banen; getn nefmen wit an iffer tägliden Eobgfalt, fie im Etanie ju erfaiten, stntgeit.

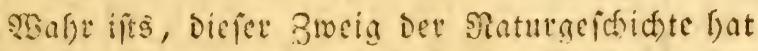

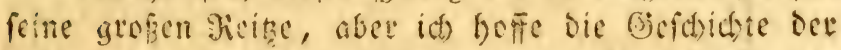
Mollusfen foll ans eben fo intereffante and eben fo

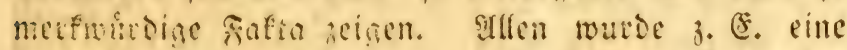

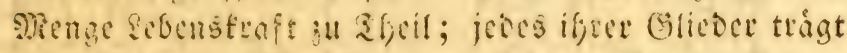
cinen fictio zum sibect) fen, zum seben und zum repen=

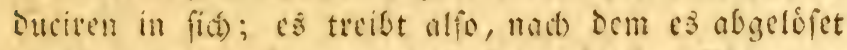

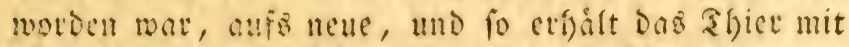

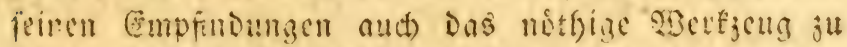
feinen Bebuthiffen wieder. Dic sjollusfen werden

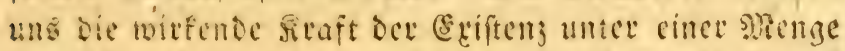
von Mlosiffutionen seigen, unter meláen wir fie mes

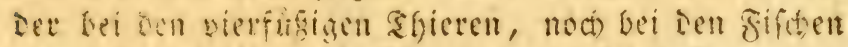

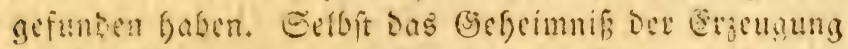
bat bei ignen ganj neue, bemundustordige und man=

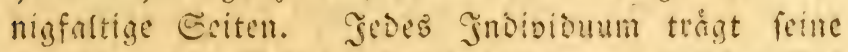

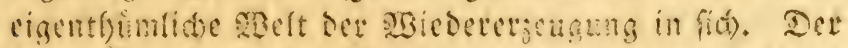

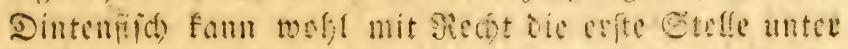

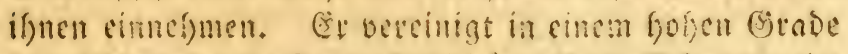

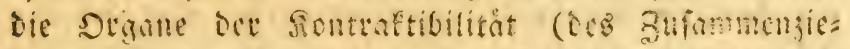

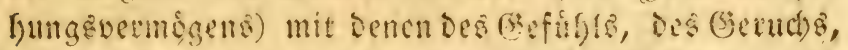

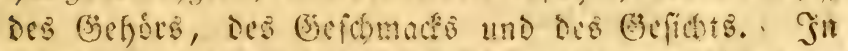

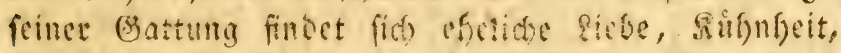

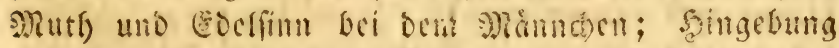

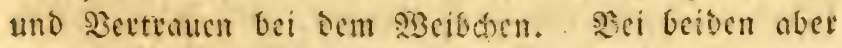

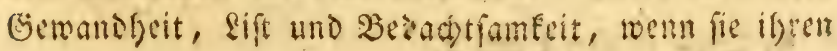


Raub ethaffert molfen, and Sitherheit in ber safbl Der Mittel, um fich zu vertheidigen ober fu flefen.

Der áder des Dintenfifdes ift mit eis

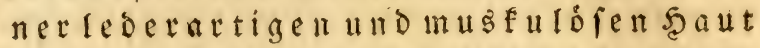
bolligbedect $t$; a fich leloft aber flec fíg und platt. Junethalb feines Ructens befindet ficheineingiget falt: artiger und blattriger fadten, der nirgende feft fitt. Die inneren age le umgiebt ein tings herum geflugel ter $\subseteq$ adt; Der syund befindet fich aut Der Spite dez Sopfs, offnet fid it Der Mitte von jefn armen, die ifn rings umgeben. Swei oon biefen jefn atemen fimb lánget, als bie a det ans detn und endigen fich feutenformig.

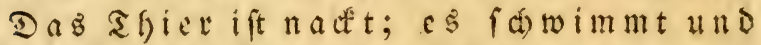
beregt fich wille úf lich fort $*$ ).

Die ånfertict): Bildung bes Dintenfiches ift fefte fonderbar und cigentfimlid); fic if ein neuer şeweis, Da je Die Natur alle moglide formen benuste, und alle Irten von Materien Darfitlte, fo mis, Das es feinen Silat giebt, Den fie nitht butch das seinnerfen einizes febensfeime beirudtet băte. Fuf Den erften anblice fonnte man bie Dintenfifde mit ben Salmats and $\$ 0=$ Inpen verwed feln; bei náferer $\mathfrak{B e t r a d}$ tung beider wird nober Das geubtere AHge des ?aturforfder's fefrer bald Die farafteriftifhen lunterichiede diefer verfacdenem Shiergattungen, Durd Shllfe Derer wit fie flaffifiziters fónen, gewafin werdeit.

Sisenn man bie Rataftere Dev Dintenfifiche bes frimmt und ftrenge angiebt, fo ift bas (jefdiled)t bers

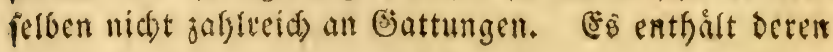

*) Tafer 1. Jig, I und 2. 
viefmefle mu: feft menige. Soffentlid merden neacie Beifende, sie bod faft alle bie Naturaeichichte fultivi=

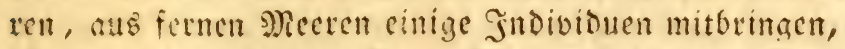
Die uns jett nod) unbefant find, und bie neue Sit: tungen aแลmad)en werben. Die Dinturitifle unters fiteisen fith von Den Gatmats Dued) Den blattrigen uno falf = (freibe:) artigen, aber allemal harten suboen, Den fie innetfalb ifres Bucfens baben. Dei gleide

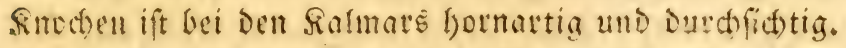

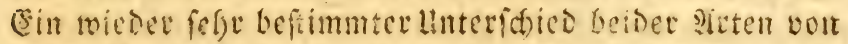
Molluŝten find Die fortlaufenden Flatgel Des Dintenfi=

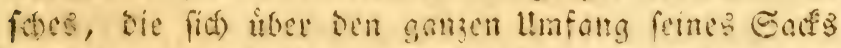

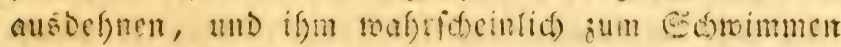

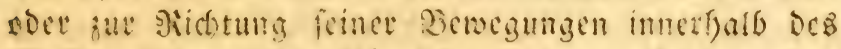

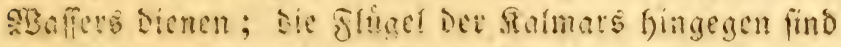
fury uno abgeftumpfe, befinden fid mue nat oem antern

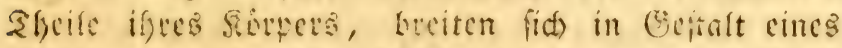
\$feils aus, une reiden fichfens bis jum vieten abeif Bex canjen Grufe des Shiers finauf. Die Wotnpen unterfoeisen fió von aflen beiden Gefalectern gäns: licf. Eie baben nue acis sime, ftatt Dap ber Ropf Dex Rotmats uno Dintenfifte mit jefn Samen bemaff=

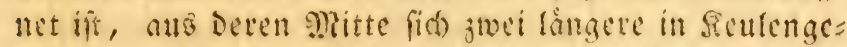

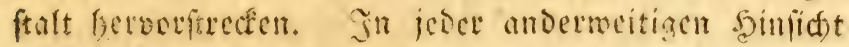

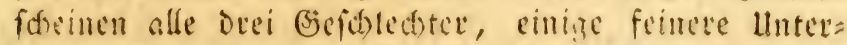

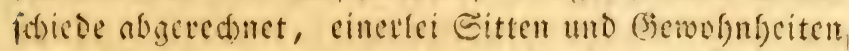
ou haben. Die alten gried)ifden uno romifden Edrift= ftellet verwedfelten bie orei erwánnten Gefoled)ter oft

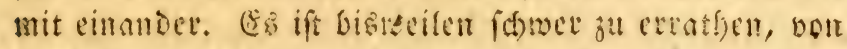

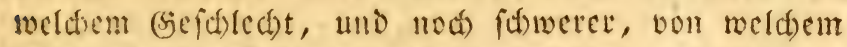
Shiete fie reden; man mus fie Dafjer im allgemeinen mit grober sorfidst und erft mad́ langer unterfudfung, soas fut cin Ginsivioum fie meinten, citicen. In Det

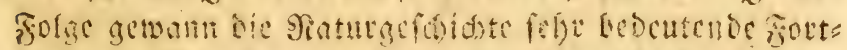

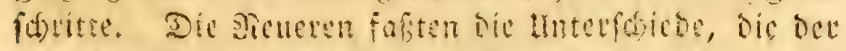

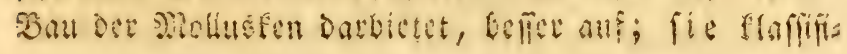


cirten fie endids, uno wiefen ifnen genteinide aftlid bie erfte Gielle unter ben SGieren mit meifem Bifut an. Einge Derfelben goben wiever unter den Molfusfen Dem Dintenfifhe Den erfen Sllate, andere abit fingen mit Dem \$oinpen an. Foniton, Gesnet, $\mathfrak{U}$ Drovandi, Rondeler und cine Menge Irnderet, die if =

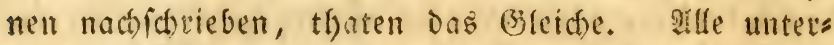
fhieden bie Dintenfifde bont den Salmat's und biefe bon bert grofopen. Sime', ber mach iffnen lebte uno vie allgemeinen lleberblicfe liebte, liefa fić) verleiten, fie in feinem Syltem alle wicber zulanmen zu werfen. Sier: Dutch verwirte Det grofie ARonn aufs neue. Die Ana= rogie und Die grofien siejiefungen Diefer affere unter einander verfithete ifn walfrideinfid); aud hatte er woisl nu! menig Sndividuen jum B̧eobadten oor fict); betrad)tete fie beshalb als gleichartig, uno vereinigte fie in ein einjiges (Befdhled)t unter Dem Namen Dins tenfifd, fing mit bem Slotip an, und endigte mit Dem Ralmat. Bruguiete fehte in ber encyflopabie eitie genauere und lefrecidaere Dronung feft, Denn ex fons Derte alle Gefidedeter Der Mzollusfen von einander ab. Eamate und (Euvier*) nafmen fein Syftem an. Det retrtere theilte vie Mollusfen in nadte und Sdhal = Mol=

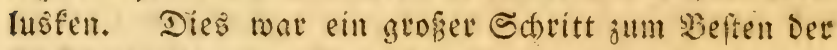
SBiffenfdaft. Die Madt Der annalogie brad)te ifn $D a=$ hin, Diefe feine Mncinung befunnt ju maden. In Dex

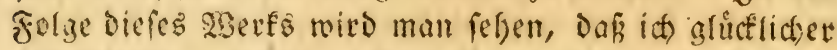
gervefen bin, als ev, indem id mancises entoecfen unb als Thatfact)e batthun fonnte, was einige Alte fd)led)t

*) Cuvier, Borlefungen iffer die vergleichente 2fnato. mie, unter feinen Plugen gefommelt uns Kerans geges

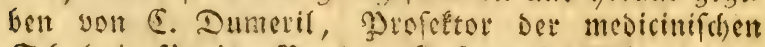
Esfule in syariz. Bamb I. Saf. 5. Rlaffititation Det Noslusten, erfte Fomilie, Cephalopodes. Dies

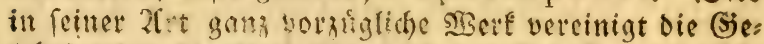

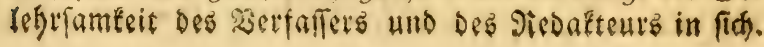


beforicber batten, uno was diefem gefeferen Forfare

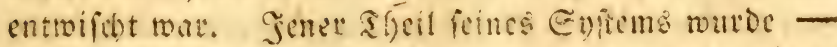
aber mit unrecht - engenriffen, senn Dic lederfouti gen डో recifon foffe, menn id) fie beforeifen werde. Cuoier,

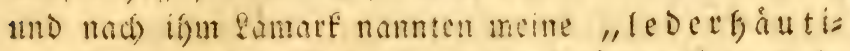
ge n" (corracés) Molusten, cephazopocies b. h. 1.ad) Dem griedifden: "Die Die Fitze am Sopf ba ben." Man Eam abe: Dic Irme Des Dintenfifaes

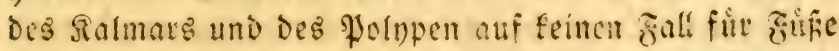

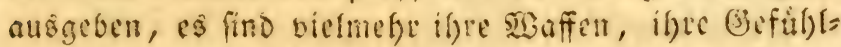
werfienge. Einige Eifriftiteller gaben ifnen rogar,

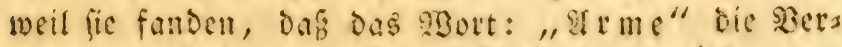
rid)tungen Diefer Glieber nitht gefortig anebrufe, Den

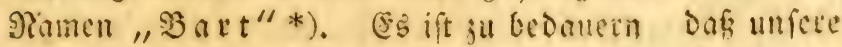

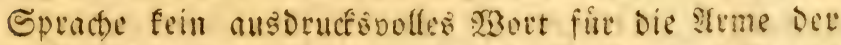
Dintenfifue hat, fo wie mit Die firnllen des Eigers Durd) griffes und Die fänge Der Baubvigel Durd ferres felfr gut begeidinen.

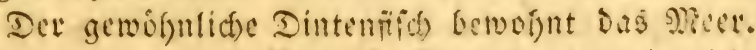
Sic wird man ifn in fiffen sibaffern gewaft, ja nidst

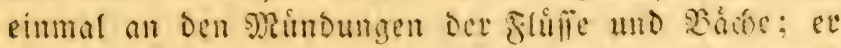
balt fich fouge eirre gemille Strecte meit von ben with

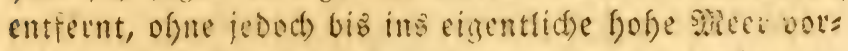
jubringen. Sim meiften fiebt ex alfo, twie ciscient, Die Etellen, Die einize Saftex Siefe haben. Clone

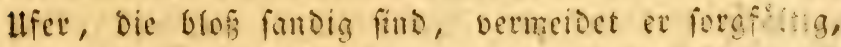

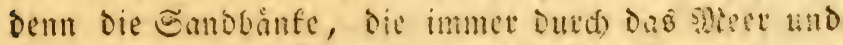
feine Etronungen rmgewift werden, geben ism fei=

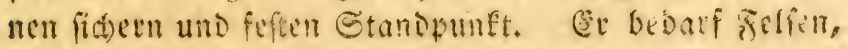
Die ifm feften Gegentgalt fur bie (Ẽdropifopte, Eaus ge $\Rightarrow$ Siapfden, womit feine langen Irme betnaffinet find, Darbieten. Durd Sulfe Derferben fegt $\mathrm{er}$ fid

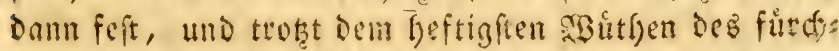

*) Gaza crura, barbas, cirros vocat. Ionfton, de Exfang, col. L, P. 3. 


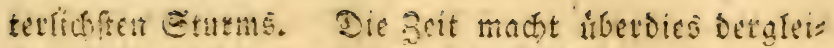
den felfon murbe, es finten fion alio hin uno her ge=

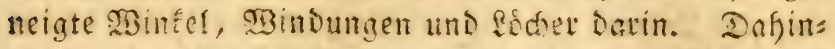

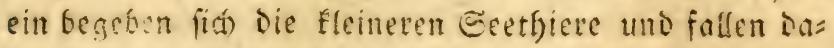
surch in bite immer offenen Sethe, und tobtliden heim=

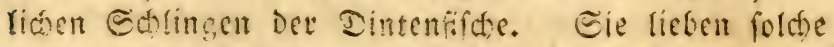

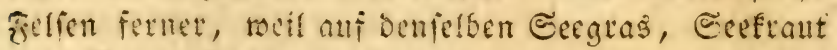

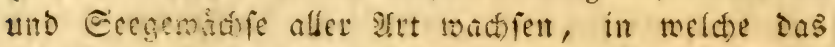
siseifoden bes Dintenfijdes feine cicr legt, und fie das

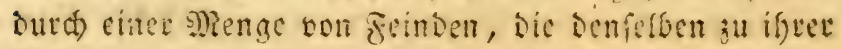

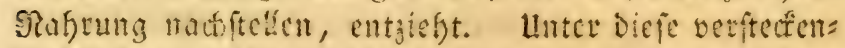

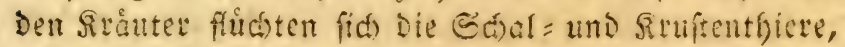
noer louern von bort aน auf ifre Beute. Dergleió) felfige Derter entralten and eine Mjenge bie Der Dintenfich vergeffet; ja, er felbft ift bout in

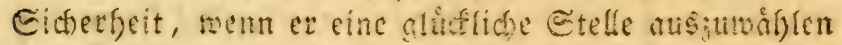

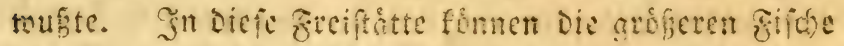

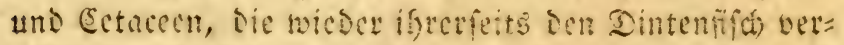

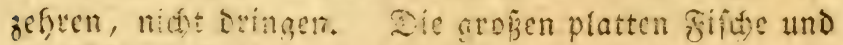
Balfifige fteten mantif, ben Bintenfidjen begierig nach und vergobren fie in magfener smenge.

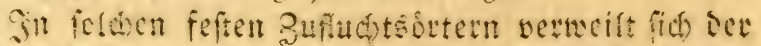
Dintenfife) alpo getn. Sier bebient ex fid alles feinet Soulfômittel uno bietet feine ganje sijt cuf. Selten nur berfolgt ar feinen Shaub; bagegen greit er alles

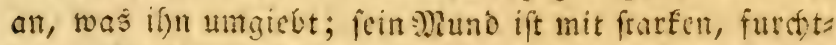

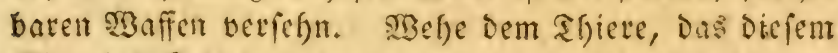
હiţe bes sodes uno bes Slutbades zu nafje fommt!

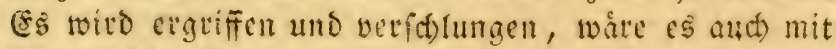

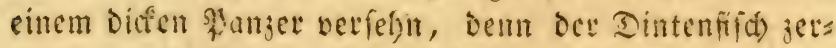
malmt mit feinem Ednabel fogat Die Cathalen Dev Eajofthicre und sie harten Bedecfungen Dex stuften=

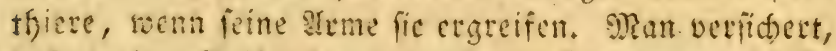

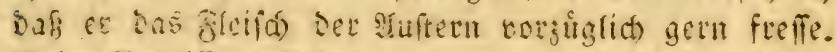

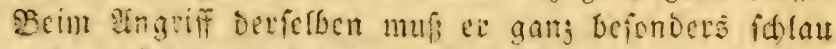
uno vorfidytig verfafgrem. Die suptern fiten ant bett 


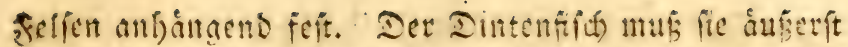
fduelf uberfallen, Damit fie nidat Beit behalten, ifre Ëd)alen wieder ju fobliefien. Sonnen fie dies nod mig=

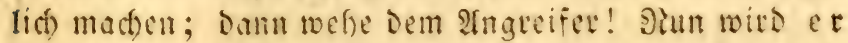
ton bet Jufter mit iffen strmen ctgriffen, und fant

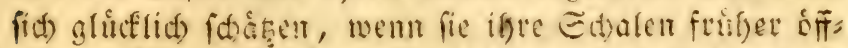
net, efje er ifre beute geworien ift; Dent fie fúsut feiner gerade ebent fo weniz, als er iffer:. In einigen

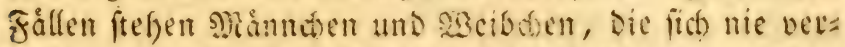

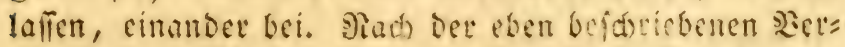

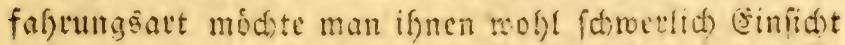
mo einen bofen Grad bon Jifrinte abfeciten fimner.

Saben fie alles um fich for ermotiet, uno iftert Ed)lupfwinfel ausge!eert, fo fiegen Die lleberbleisfer von iferen sictícerungen un fie foctum. Ilefe serftens ten llebertefe geiaen aber Den ubrigen fleineren Ees: thieren ifje nafle Befafer an, und marnen fie noe Ders gleiden s)?ordgiflen. Dann finglen Die Dintenifé alfs

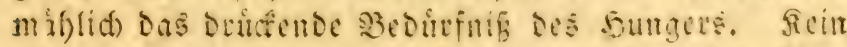
Shler fommt mefr tum fid fangen ju lamen, fie mifien

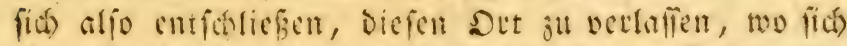
iffren bit Panfrungsuttel fo leidt, fo von felbit, unt fo im Ueberfus barboten. Siun trotsen fie aber aud

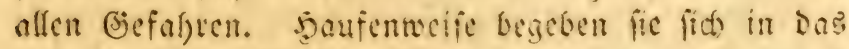
tiefere, flatere sBafler, fdwimmen batin tmber, uno

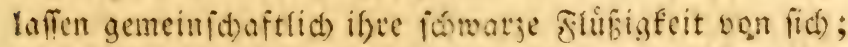

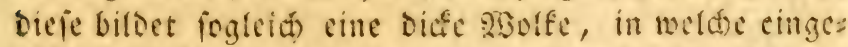

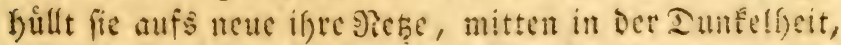
bie fie am bellen sane hervorbraciten, aufiellen. Sebem andern stuge als iffen eigenten unfiditbar, fdyimmen iffe Feinse neben ifjen vorbei uno wersen fie niche gewalyi:. Sit fommen lie aแs bieler Baube:

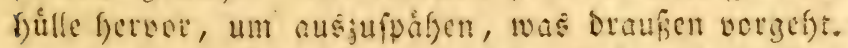

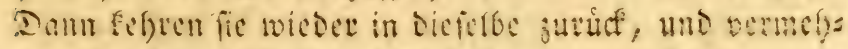

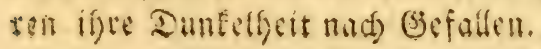


Dos Mect uno feine Ricken fint ein Sampfplat,

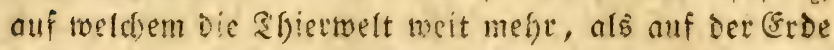
und in ber fuft ber Sorfferung uno zu frufjen 2 ers

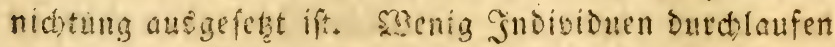

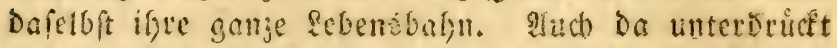
and veridylingt, wies allentgaleen, Dev Starfe ben Gdimadien. Ganje Gefdeledter werden oft Durd Den morterifoten Sunger, Dem dic S?atur alle Sficte unter= worfen bat, fingerafft.

Sev gemeine Dintenifich mird bisweilen nafe an

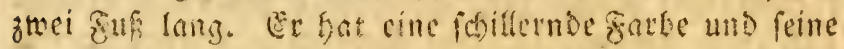
gonze sout if mit rotfliden uno fdrmatzen flecten leid) befpengt. Ex bewolynt Dab indifác uno ameri= fanifde *), Das atlantifge uno mittelläbifde sheer, borguglid aber Den abriatifáen Meerbufen. Man. findet ifn aud an ben siuften von Englano uno ser ebe: maligen Pormandie. Eben fo anf Den Sandbarifen bei Sellano, hier jesoó fefrefelter. Je weiter man aber

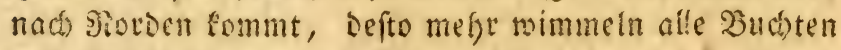

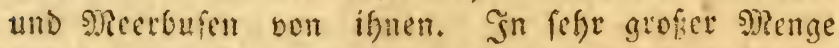
finden fie fich am die sandpiten det cinft beifen ?ander

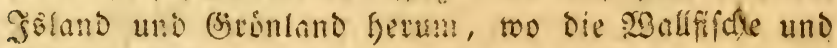
Refchelots fie verfolgen, zufammentreiben, und mit cinem Sdlage if res ungefruren Sdronzes, womit fie Das şaffer toirbelno madien, in ifte weite fieble jagen. Sim mittellandifácn Meere baben fie mahrfdeinlid) weit weniger Zeinde, Demn Dies Mreer wirb von allen Seiten

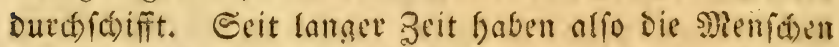
alle $23 a l f i f c h a r t e n$ (ceraceen) und ande grofie $23 a f f e r$ thiere, dic einft fiec exifititen, ausgerottet, Demn man

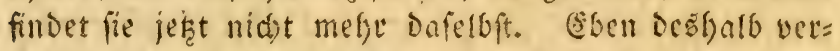

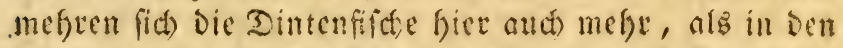
Sioromeren. Saft midete man ginuben, Dof aud fie, mie mande ande fif se ju gewiffen beftimmten zeiten

*) Saba, tom. III. 
austwandern ooct jiefen, Denu bisweilen trifit mon mit einem male feintu einjigen an Etellen on, wo fie werbat

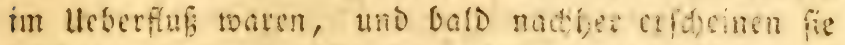
wieder anfs neue. Son ben Mecten unter cinem ne=

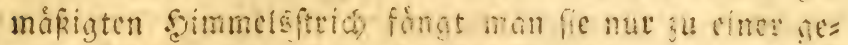

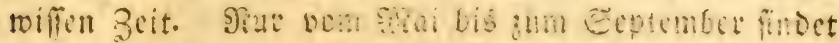
man fic auf icu Canse tar Sufen bon Thancan uno

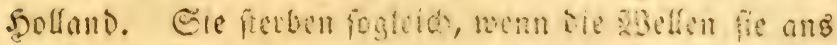

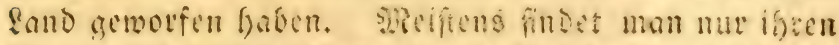

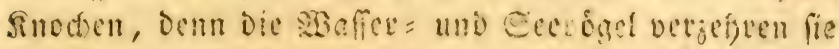
fogleió, ato tie lie unter ben suxteffrómenten sistlen Det ebbe gemsfre werden.

Der Sopf Des Dintenfifhes it, wie geragt, mit jefin armen verfelon, wooon acht fucjer, und anders geftaltet fins, als die beiden ibrigen. Dev linterfoled

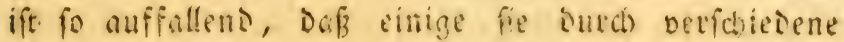
Slamen unteideciben woliten. Sie sllen nanmen bie beiden lángeren Promufides, uno Enannerdam

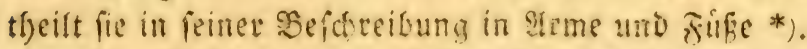

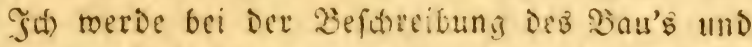
Der \$3iloung Der åuferen uno imern Theife ber Dinten: fifche meine eignen forfwungen mit bonen andret Edriftiteller uber Diefe Moltuôten verbinben. Emam= merdam bat fie mefor als irgend cin anoree beobadtet. (ar fat feine tecifliden Bometungen mit vorginglicten Supfern bereichert, die ein baternder Bemeis ban Dew GeDuld, Dem Edaminn und Dem linterfutungsgeifte

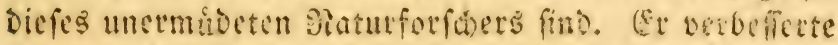

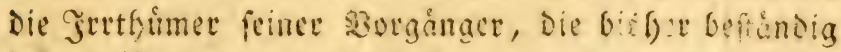

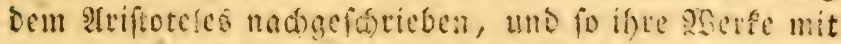

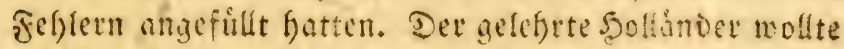

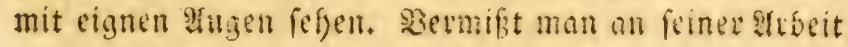

*) Partes notabiles crura funt atque brachia ejus. Crura, numero octona, - Swam. merdam Bibl. natur. Serpden 1738 in Fol. Foll. und Iat. ๑. $8 \%$ \% 


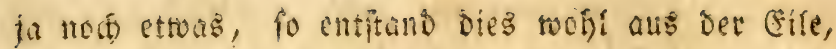
womit cr bie Sinatomic des Iintenfides ftudirte, ode aus Den renigen Gndiviouen, Die er, Den llmitånden nad), nur erfalten fonte. $3 u$ feiner 3eit war bie Sergficierungstunft, ungendtet fie fifon bedoutenie Fortidritte gemad) forte, Dod immer nod weit zuruct. Mandye fefre aufallende Shatiacten in ber thierifden Dofonomie cntmifuten iffr nod); nud batte man Damals noch feinch Begriff bou ben cirfulationsingtem dez

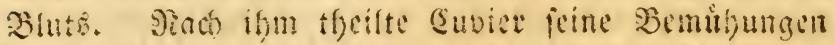

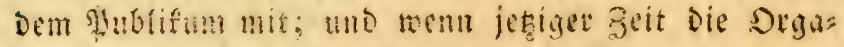

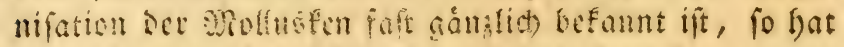

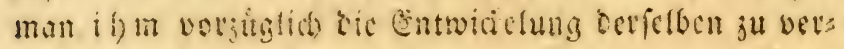
Danfen.

Die ast fungen Sirme Des Dintenfifches ftefen

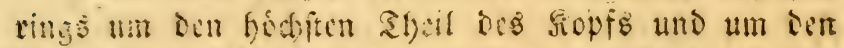

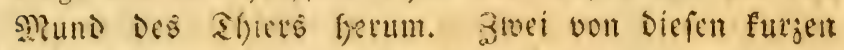

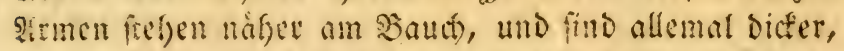
a!s Die afbrigen fed). Llebrigens aber gleithen fie ifnen

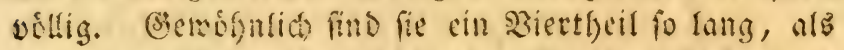
Der gunge Sorper bes sfyetro. Sín iffer bicten und

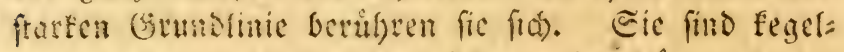
attig gefom und endigen fiú in eine Dumne Spik̨e.

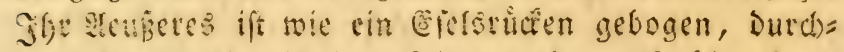
aus glatt, uno nit ciner feinen uno musfulofen bout

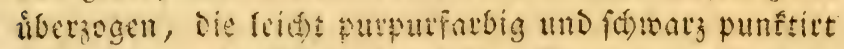

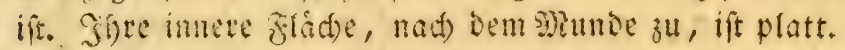
- Sie ift ifyer ganjan ?enge nat) mit mefreven perpen=

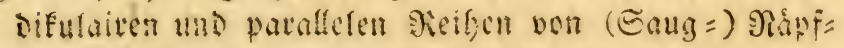

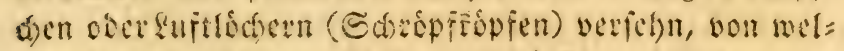
den Die ber mittlere: Beife vid fätfer uns beftimmter fino, als die thrigen. Nenn bas Thier fie cin meniy zufammenorangt, fo beriffen fie fit ganj nafe. Eic

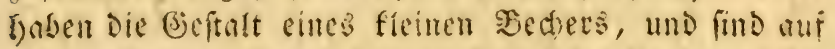
cinem feinem forg befoftigt, Der fich alfammenjibr,

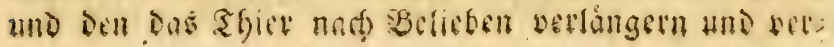




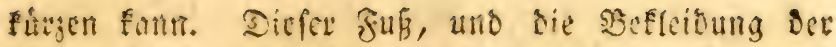
Saugentipichen befteft aub den inerhngerungen und

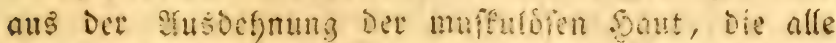

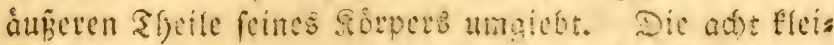

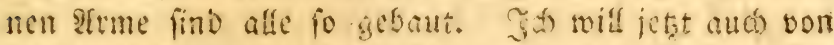
Den zroei langeren reben, bie ju einem befondern (3je= braud mitten unter Den úvergen am unteren Enoe Der jow Differen ifre Etelle crifaten haben. Sic haben ifren thrptung auf betsen Eerten des montes, ers beben fich als runie volfonmen glatte Sockmme, แno endigen ficts zutest in form ciner strute, die auf Der

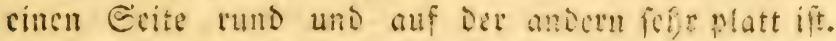
sisenn bieje beiben stme fith nusbecten, fo fino fie fo lang me bet gange fiotper bes Sintentifes. Die

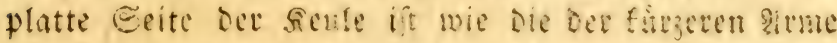

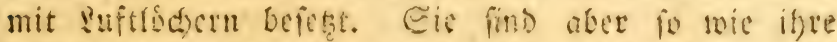

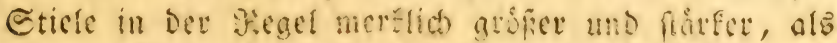

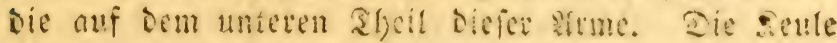

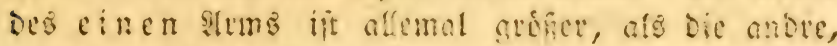
ofne Dab man bictuen ben cigentfimtiuten Gumo ans

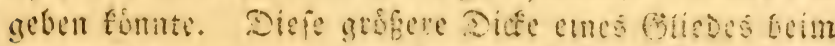
Dintenfifie erimert an Das gletóe iserfaltnif ber

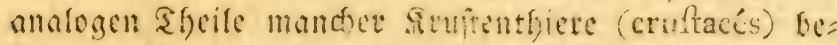

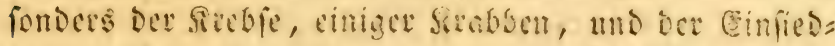

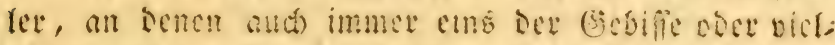

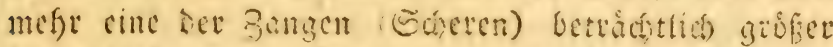
ift, als bie anter. Die Sime ber Dintenfifae madien

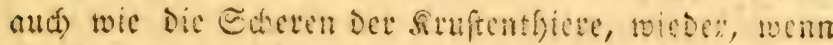

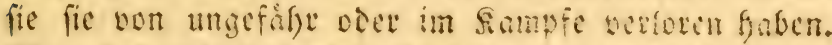

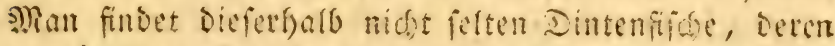
verftummelte elisoer now nidft wiever ifge geforige Eănge erfalten haben.

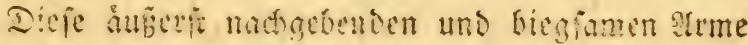
fonnen fict) mats af́en Eeiten bin bewergen tind wenoen. Eie Dreben fid fogar um fitf feloit ferum. Smon finnte fie Jieşi nenten, die immer ausgefpont uno imate 


\section{6}

in bem Butande find, den Baub ju umminden, ju er= greifen und feft zu verfallingen. Die langeren Ireme, bie in eine geule enden, haben nod) eine andermeitige

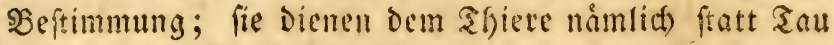
uni sfufer. Ces bridft die platte und mit seulen ver=

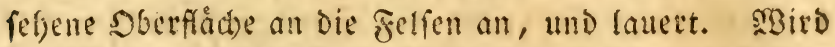

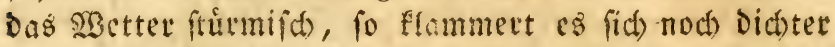
an Den barten und fefen Torpern on, Die es im Gimbe

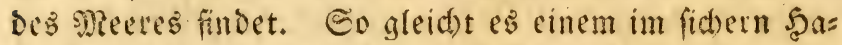
fen vor Infer gegangenen und ange!egten Edhiffe. Es? giebt mun Durd) Die Sänge Der bieglamen und runden

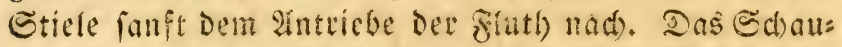
feln ber saclen und die ganje 23 affermaffe fot mut

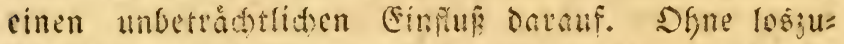

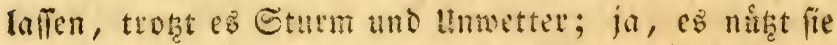
rogl gat now), lim mitten in ber Setwirrung fiffe, bie von ben 280 gen hin who gea geworfen werven, ju

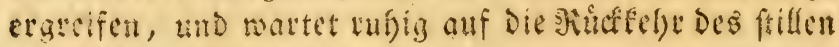
und jobnen gietters.

Die Euftloder (Edropffopfe) anf ber pratten

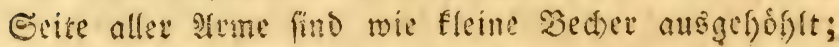
Die Sllten nannten fie Biefer Geftalt twegen Acerabulae. Linter ser fie bibecfenden saut findet man einen fleinen botnartigen Bing, Der ifle lmuffe bes fitimant und if nen fux Saltung Dient. Cer ift in oce Mitte feines llmangs wie eine 23 ulft cufactriben,

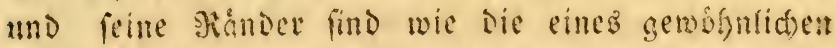
Xings glatt und einfad). SMan bat gemeint und ges (d) rieben fie penen gezalynt oder gezacft. Sier betrog wber bie Beobadter wohl ein fleiner bramer oder

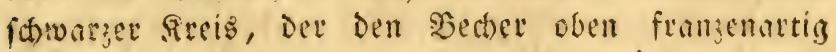
umfopt, wen diefer mit feiner Şaut hberzogen ift.

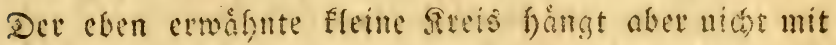
Dem æringe zuammen: er mast im Gegentgeil cinen

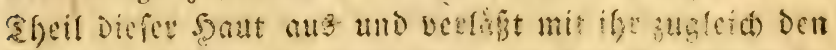
\$ing, wem man fie wegnimmt, um ben SBau Det Ruft:

lociser 


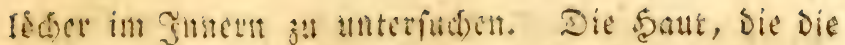
Sfme anderfid) befleidet, ift jiemlich bict und feft; auf Den Eciten, two fie diefelben Gecabfangend ubergtainzt, wito fis Dumnex. Sei Dem gemeinen Dintenfifo if Diefe Befetenng weniz berworfpeingens, folglids wenig bemefbar, voringlid an Den adt furgen Armen. SBei

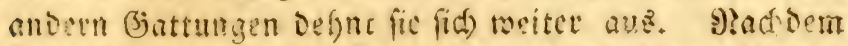
fie fich fo ansgebreitet hat, ziefyt fie fid uber fid ferbit wiedes zuride, wird binner, und bededt in platten voer imern Theil bes ऊufek. Sie befteider nidt blois Den (Brund, fonoern aucí) Den Etid Der S?apiaten und uberjicht iffen oberen Sheil, in Dem fie fits in Die Beáder fenft, wo fie fio zufammentegt uns faltet. Die

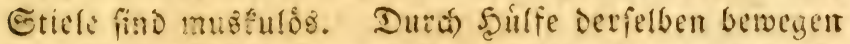
fid) Die Jiopfden nad) allen Seiten fin. IUth bie Sipfínen find - Den fleinen Binz ausacnommen -

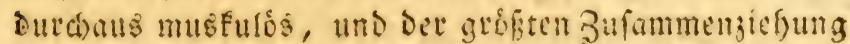
fåfig. Eroammersan, ben man in Diefer f̧inficht nicht oft genug citien fann, bat Die genauefte Zerglie= Derung Der Ruftecter befannt gemacht, id) verweife

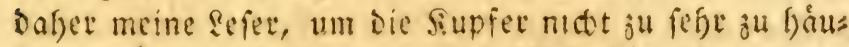
fen, auf feine Zcidnnngen af. XLI. Fig. Il. 1, 2, 3, 4, 5, wo man Den musfulofen Gtiel uno die \$insfeln Dar Brupfden, fo wie ben bornattigen fnochernen fireis in iffer Entwiffelung gejeictyet findet. Mon mirs bort aud Den fleinen Fing, mit Der grulft in Der

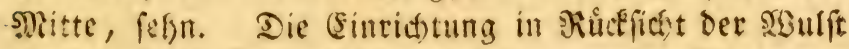

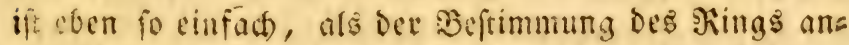
gemeffen, Denn er firt Dabure defto fefter in Der Saut, die ifn ungiebt.

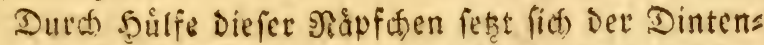
fild) an anbern Sótpern an, roie Sidroplépfe an Der Saut. Sפenn man ibere set zu toirfen alfmerffam bes trad)tet, fo erftaunt mon, wie fonft wol) 1 unterrid)tete Manner fdreiben fonnten, fie fögen fid an Den Korpern feft. Dir Siffos betoiff einen luftleeten Raum, bes 


\section{8}

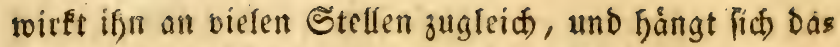
Durch allentfaiben, wohin ex feine Irme wirft, mit siner unglaublicten biewalt an. Dies Anfängen ges fatieft in cinem fo hohen (siade, Dap man ifn nicht an=

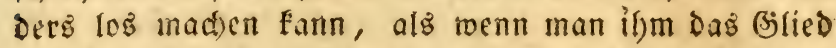
abreifist, toomit er fich an Den felfen anfegte. Denn in Dem 2 ugenblift, Da er fich einen 230 fnort ausgge fucht oder feinen Raub umfhlungen fat, in bemfelben Angenblick, Da er bie platte und betwaffnete innere Fla:

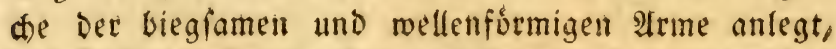
gisft fid) Die Seaut, Die Das gnnere Der jaffreident Nhipfd)en vollfommen (à fleur) auşúllt, nach Belieben Des Shiers zufammen uno zurutcf, uno úbersieht den

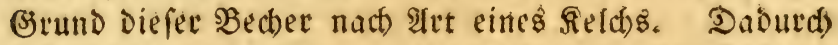
entfieft ein lecrer ßaum, uno jede diefer vielen Şólull=

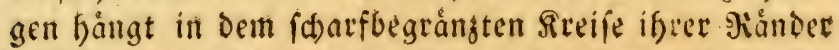
fo feft an Die Fiotper an, Dafis weder Euft noch $23 a$ fle in bie leeren Haume Det Reldye eindringen und bie grófte Gerwalt fie nicht von Dem fremben $\Re$ orper tren= nen, fondetn mut ben Dintenfific) ftücfweife bavon ab=

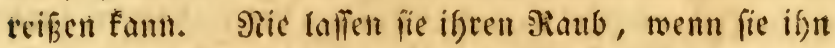
eimmal halten, wider los; ifre saaffen bringen alfo Dem einmal ergriffenen Sidlathtopfer untvidertuflich ben I0D. Mefrere Bevbathtungen haben mit twieber:

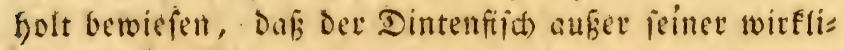

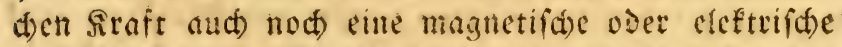

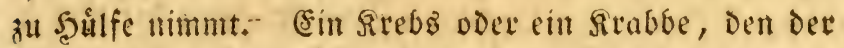
Dintenfifed eimmal gefabit hat, fudft fich gar nicht weis ter gegen iffn zu vertbeidigen, wie er bod gegen jedent andert feind genif thun wirde, und wie to nanents

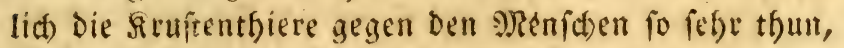
baf fie sen fifhern ofters bie Finger abfneipen. Sat aber Der Dintenficit) fie gefangen, fo verlabt fie mit ei= nem shale alle Energie. Sie zieffen iffere fraftoollen uno fägeformigen Ederen unter ilfe Echale zulammen und macten, als of fie ganj. betwegungsios geworden 
wáten, gat feinen Bebramb) Dabon. Ser Augenblicf,

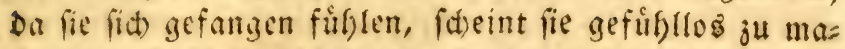
den, und ubergiebt fie den harten uno hafigen Sthe: ren, Die den Mund des Dintēnfija)es betwaffnen.

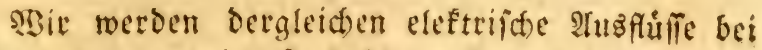
Den polnpen, wo ich fie felbit empfunden babe, wie= Derfinden. Der des Sirampffifues betåubt blof, aber

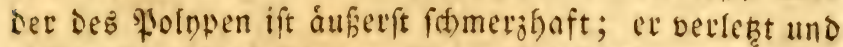
libifet jogar Die Saut. Fndere Molluéfen zeigen baร Bleicte, und mit (Erftaunen toerden wir fehen, dak felbft vie Seeanemonen, Die Doch faft ganj gallertartig und Dem Infidein naci) fraftlos fint, fich rie die Dintens fifche ber firabben bemádtigen, uno fie in ifte blajen. attige Falien bimunterif)luafen fomen *).

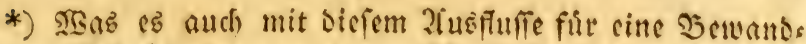

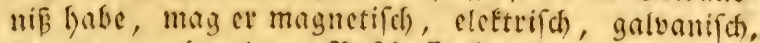

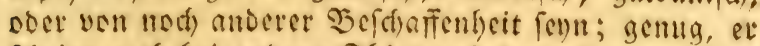
(d)eint aud bei andern Shieren fratt ju funden. (Einis ge (Fier legende vierfifize Thiere find vorzuglich das

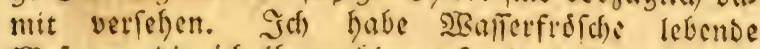
stseipen, die ith ifnen binwarf, begierig ergreifen, uno angenblicflich verfhlingen fefn, ofhe baß bet Etachel Der Sisefpen lie im mintefren verlerste. Eie verfoludeften melye als cin Dufent derferben, und da fie zulefit liberiatt wurben, bradien fie die leferten fo: gleich) wieder aus. Die angerpienen siseipen waren

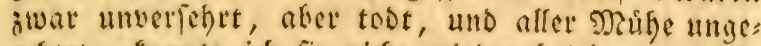
aithtet, Eonnte ich fie nicft wieber beleten, of fie gleid) nicht Drei Mrimten im Siftper Des Frofches zu= gebracht hatten; ftatt Dap fonit cine risepe, eime Jummel ober eine biene, Die man orei bis viet Etunden lantg im sisafler gelalien bat, und bie vollig

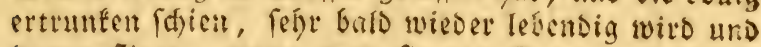
Davon flicat, wemt man fie ter Eome ein wentg

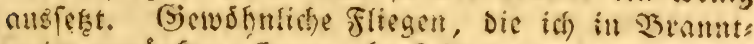
wein ertrantete, flogen ebenfalls weg, wentr ist fie wieder berausnabm unt cinige Stunden lang pits

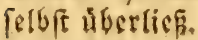




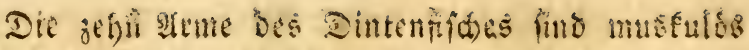
weich) uno feifitig, bic beiden forn = und fnorpelart: gen Binge ooer sielife aber, Die bie form ber Mipf d)en innerfalb runo eríalien, fint es nidjt. s刃atten

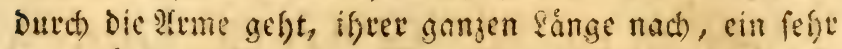

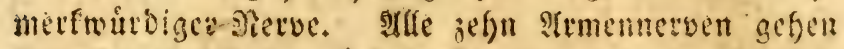
freisformig aus bem Sinte = Stamme ous, laufen vor: und oberwåts Des Gefirns fort, und machen in ge:

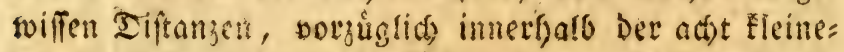
ren Arme, fnollenattige sistifte aus. Dieje Mrittel.

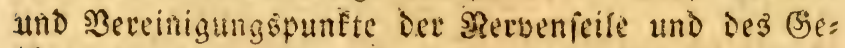

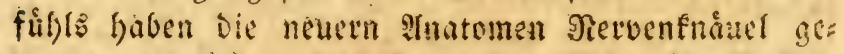
want, woh jeven? Derfelbea geffen ftraftenformig flei=

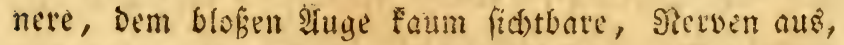

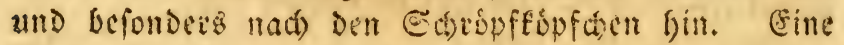
Menge Musfeli vereinigen fit Damit, um Den Ş3ilfen Des serven = Fituieung ausfuffern ju Gelien. Didt un=

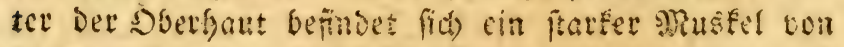
breitem Sservebe, ber befimmt ift, fie zu falten und

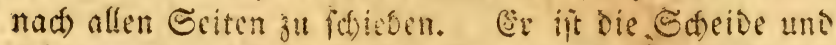

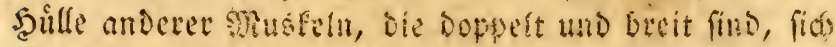
oon einem fuf jum andern begeben, um beibe burd

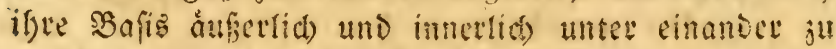
verbinden, und fie beim fuspretsen dost bet jeder alloew beftigen und getwalsamen Berregung zat untev" ftuthen. Gin Dritter fegelformiger Pistefel, Deften fis

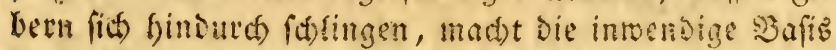

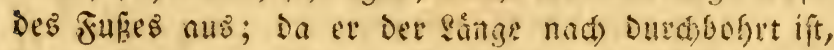

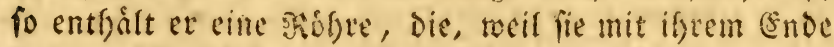
bis jut saut reid)t, Den Secren, fatme Rnåuel und Die notrigen Gefafe - oder eciter - Der meiflidgen Sluffigeit (bic bei Den Mollušen dic Cetclle des is $=$

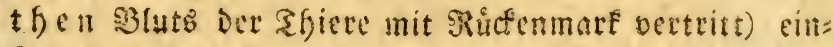
id)liebt. Srod ficinere Musfeln laufen nad den Släp = (d)en fin, unb vermigen, fie nach allen Seiten ju be= wegen. sisill das shier fict ooin felfen los madten, fo 


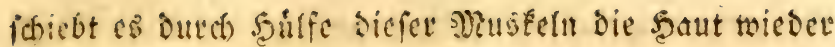
fo nad) Dem Mittefpunts ju, Dafi fie bie ficinen Becter wieder ausfult. Damn verfidwinden bie leeten Bitume, Surch welthe bas Tlyet fić) befto fefter anflammern

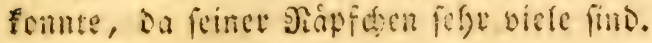

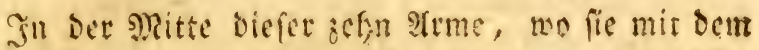
Sorwer zufammen gerwaden fint, wiro man cine villig frelsformige Definung gewahr, bie da, wo fie cin we: nig vortritt, Dutet) cine satrlàngerung ber Sout énge= fofst wird. Diefer hervorfefende und feifdige Rreis, Der im Buftande Def Bhluge jwar glatt und cinfad ift, fich eber bistweilen wie cin Beutel ober wie bángende 3lumenbifichel faltet, ift Der Muns. Sian finnte Den bervoriptingenden Theil bes Ficifder, Den Dieje Şaut besceft, mit ben fippen anderce sfiere vergleident,

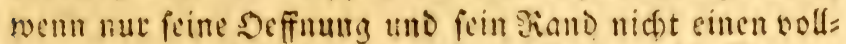
fommenen Secis ofine alfe Geitenfpalten ooer sten=

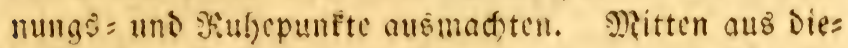
fen sippen tritt cin Ed)nabel herbor, Den fie foft ganj

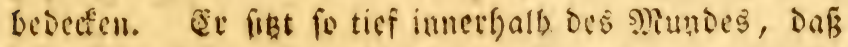
man faum sen vierten Ifgeif von ifm gewafge wito *? Erine Garbe ift braun, faft ounfelfaftantenbraun. Faft gleid)t ex bem plapageien(t)nabel, uno befteht aus jwei FGeilen, cinem soeten uno einem unteren, die wie eine fireipzange gegen cinnore nitfen. Cie find oollfom= men betweg(id), fugen fith genau in cinnonder, und brü: cfen fid fo feft zufammen, baf ict untere Ectuabel

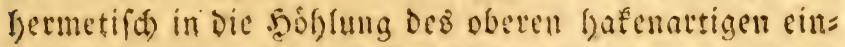

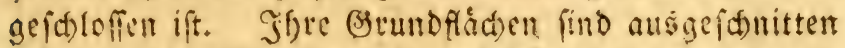
gebaut, un Defto feftet in ben s]?

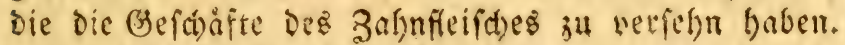

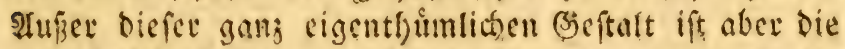
Grunoflać) Des innern Schnabels nod ein jweites Mhat ausgefóglt, um bev Zunge in bicfer soblung eine freik

*) Tafer IV. รig. I. 
Betwegung jugulaffet. Fach dem zode bes Thiers batf man ben Ednabel nut ein wenig hin und her bewegen, fo lofet ex fid) fogleid) von Dem fleifhe, das feine (Brtundflåd)e umfaíte, $a b$, ofne Das geringfte Davon zu zerreiben. Cer ift hornartig uno fajerig. SNit Dem

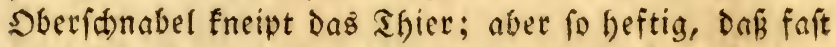

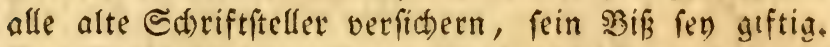
Das \$̧eriffen feiner Irme ift es unfeflbar; Daf fein

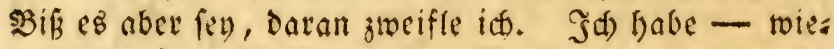

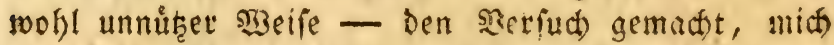
von Dintenfifaen beiffen zu lafien. Sindéz fann bies renig beweifen, on fie fogleich fterben, wenn fie an bie atmoipgartifas \&uft fommen und úberdies die Sand

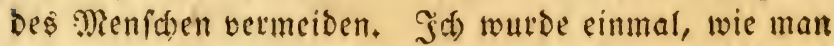
weiter unten fefon wird, von cinem \$lolnpen gebifien. Diefe 2 Bunbe heilte aber fruffer, als fị Der Sd)mers an Den Ifeilen Des Jiorpers, die er mit feinen $\mathfrak{A}$ tmen umivunden hatte, gånjlich verfer. 23ent es alio er:

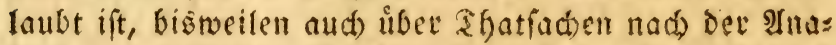
logie zu urtfeilen, fo fonnte man hieraus Den Sd)luf matten, Dafs ber Ednabel bes Dintentifues jwat wie jeser ander foneidenbe rorper vertoundet, aber nicht bergiftet. Der Dberfdnabel ift ftarf uno bicf, oben ibergéogen, gerabe fo wie şaffen zu ferntr pflegen, Die man oft und tid tig gefraud)t fat. Der Unter: fdnabel, an Defien Masulgel einige Musfeln feftitsen, leiftet einten nach heftigern sgiderfano. In feiner

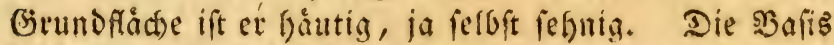
ift ourd)fichtiger, blaffer und róther, ats bas llebrige Des Sdmabels. Sei náferer lltterfudung fieft man

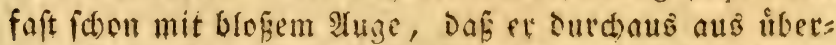
cinander gelegten und befeftigten fitbern uno felynigen

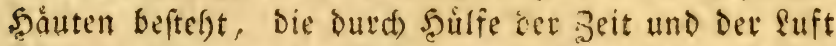
fid) in eine hornartige Subftang - Demn Deren Feftig= feit hat er - bermaniclt bat. Dies form gleidt tem

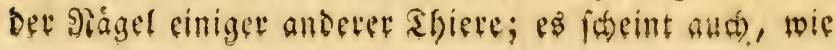


Die Niagel, blö́ cime Rerlangerung von Neroeit fut fenn, beren vereinigte Bundel fids in Den auferften Funften verfártet haben, movon bie neuere Fratonie und anderweitige ferfalrungen Beifpiele liefern. Der

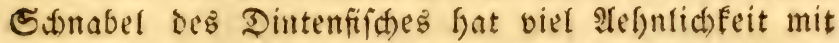

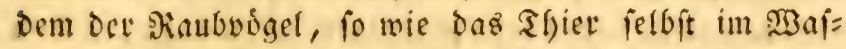
fer aud) jene Syrannen Det \&uft vorftellt. SBie fie bereat er fid willfúfrlich in ciner ungef)euren flúfirg= feit fort, Deren 23 Biderftanto ev leicht zu uberminden weip. Sie leben bom Baube in Der Ruft, ex von Der Beute im sBaflet. SBie fie, berfteft $\mathfrak{e r} \mathfrak{c}$, feine Beute mit feinen Prmen und mit feinem hatten, fidnei= Denden Sdynabel feitzufalten, zu Druffen, ju umflam= mern und zu jerreillen, Der Ecthabel Der Dintenfifide iit nie melge als ztrei singer breit; auf sieje midtrige Thatiacte werden wir wieder zurueffommen, wenn von Der grauen ambra die Bede fenn witd.

Die Zunge befindet fich innerhalb tes Schabels und tuhet auf Deflen untetem SGeif. Wenn Das Shier nid)t frif̧, fifseint fie vollig untfiatig ơ fern, uno blof

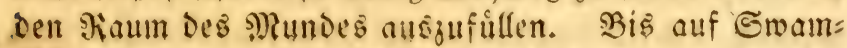
merbain fielt man fie fur blobes f(d) So (prad)en aud) bis dabin alle Sdyriftfeller bavon; Die - weil fie alle cinander copirten - Derglciden

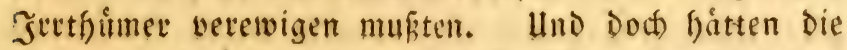
Reuern, vorgiglich die, die am Mreerufer (d)rieben, leid)t Bielegenfleit gefoabt, fich Dintenfifich ju ver= fdaffen, und fie feloft zu unterfuden. (5s ift jum ses= ftaunen, Dafis Die Gezzenfiande, Die uns am nád)ften liegen, oft am wenigiten ftudirt werden. Man glaubt,

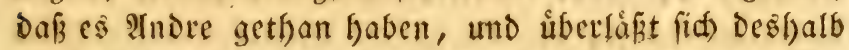

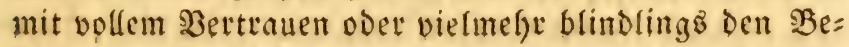
id)teibungen, bie fie Davon mad)ten. Man gewinnt nber jedeŝmal, wenn man einen Gegenftand aufs neue unterfucht. Cints sheils faft mant viel beffer, was Der Sdnriftiteller gat fagen wollen; - et ift ja unjer 


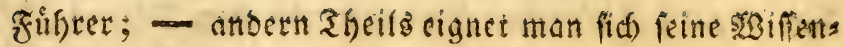
fóaft mefr an, wenn man bisher nod) unbefannte Fafta, worauf alle neue Seobachtungen und Unter=

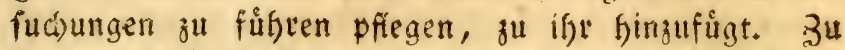
Sivammerdams Befhreibung Der Zunge bes Dinten: filtheg, und zu feinen dazu gefórigen Zeichnungen, módfte fich indés robl famerlich etras binzufitigen laffen.

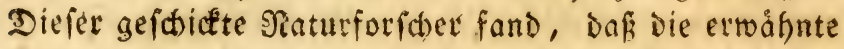

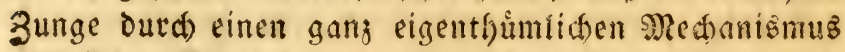
aus fieben snorpeln zufammengefetet ift, Die ourd) cine gemeinf(c)aftlide saut mit einanbev verbunden find. Shye Gpise ift ein wenig mad) unten gebogen. Dis Bafis ber siembrane wirb musfulós uno fdmammig.

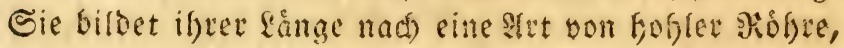
und roird an Den 29 ănden Des Sd) Sundes Durd) Seiten= musfeln befeftigt. Ant ifter Grunofiad) ift biefe sout gefaltet und in ifren faiten befinden fid einige Epei=

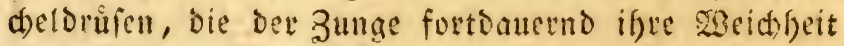
uno srifice erfalten. Cin Epeiáselfanal, Der bei rei= tem merfwintiger ift, entipringt gabelformig in zroci Drifen, bie im Snnern bes Sorpers cingefd foflen find, fteigt bute) einen langen gefflangelten (s)ang bis zur Safis jener to̊frenformigen Sant, und bio jur Mitte

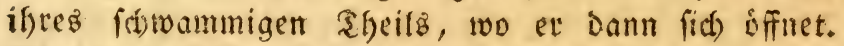
Dev eben befdricbene fanal geft Dutd) ben ganjen Şats. 23africheinlich Dienen sie beisen Drufen zur Ibfonderung Des Speichelв; benn fie find intondig holl, und iffe Subftanj fowolfl, als ifi fowammiges

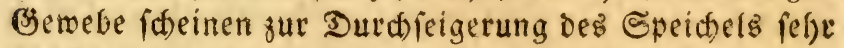
fdicflich zu feyn. Der Ed)lund exitreeft fich mitter Dutd) Die Babel, Die Der Epcichelfanal bildet, indem

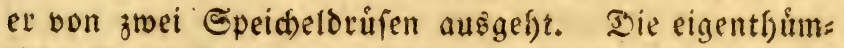
liche Srganifation der 3unge berdient eine nod ges nauere Befdreibung, wobel ebenfalls ber hollandifdse Senbadter unfer fuffrer fenn mog. SBir baben gefefn, Dá fie rógenartig geforme ift, und aus fieben feeinen 
fnotpfigen Sttoden beftet, bie bas Sbier imerfalb

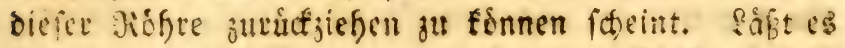

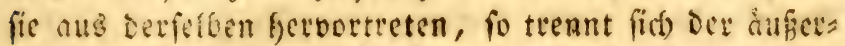
fte Sheil berfelben, und fie felbit bilben einen s3iffdel. In Dem andern ende find fie refre feft mit Dex fortorm migen Saut verbunten, Die fie bedect. Epaltet man Die 3unge ber fange nad, titio bringt fie Dant unter Dab anatomifas Mefier, fo zeigen defe Eleinen fnoryel

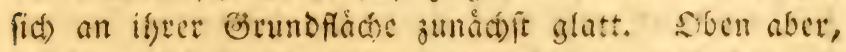
an bem Sheile berferben, ber finein= und gerats = treten fom, befinden fid sit jedem cinjuthen meht als

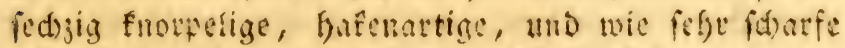

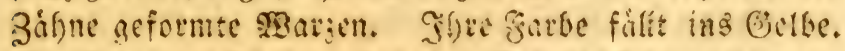

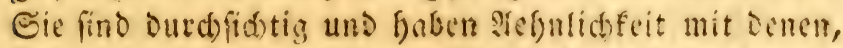
Die man auf einer Ddfenjunge fief)t. (ङ grfort cine

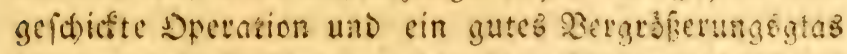
Daju, un Diefe sbarjen, bie sem Shiere wahciden= lid) jum (Evleid)tern bes Serunterif(t)

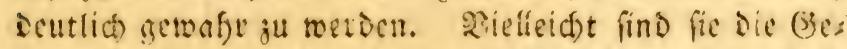

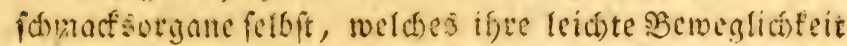

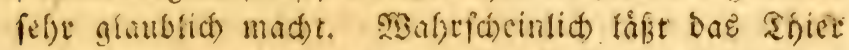
fie zu ceinem andern Befufe willfufretich Geroodreter,

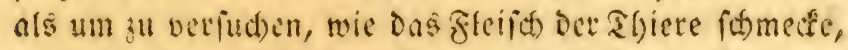
beren es ficis bemaditigt hat, und bie se fo eben ves= zefren mill. Diefe finorpel fino gegen ifre Bafio bin queriber mit einender verbunsen. Durdfitneidet man

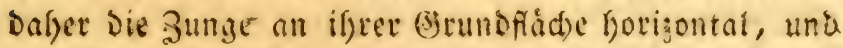
unterfudt) fie Dann unterm Bergrofizerungsgiafe, fo zeigt fie Das regelmânigfte Bittergewebr. Eobalo fie aber uad Dem Sode bes Shiers vertrectuet îf, fo bers (d)rumpfen alle Diefe formen. Sman muß úbergaup mit der ßergliederung bes Dintenfifá)e eilen, :Denn man burd sen Bufall beginftigt with, ifn beobadten ju fónen.

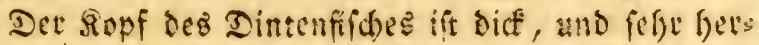

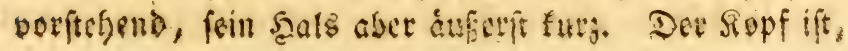




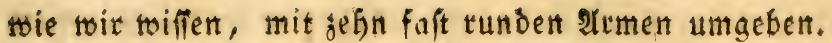
In den Seiten beffelben ftefen zwei arobe funfelnde Ilugen, Deren Farbe Dem brenmenditen \$urpur gleid)t. Sie etheben fich wie Sedfer und find fehr hervorfprins gend. Die Saut, die Den ganjen Unfang Dez Siurpers ungiebt, bebecft aud ofne alle Unterbied)ung bie

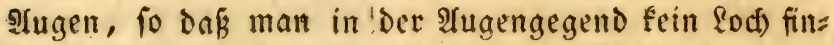
Det, went man bie Şaut des Dintenfilites abgezogen hat. Sie ift Dort blop ein wenig Dinner und Durd)= fid)tiget als andertwårts. Das গåmliche findet bei ben Sd)langen und Ialen Statt. Itud) Da bedecft bie Şaut

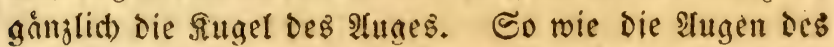
Dintenfifches auseinandev ftefin, Eamin cr ben gleichen Gegenftand nidts mit beisen zugleid fefn, aber dafur ficht ex auth, ohne Den fopf zu wenden, redhts und linf's fin, und ober = und unterwåts alles, was um

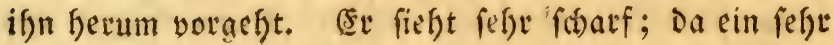
grofes Aluge faft immer ein Zeichen ift, Dafi Das

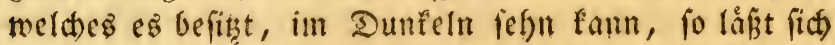

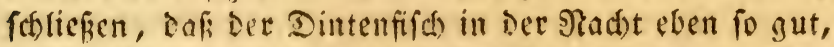
und viclleidt nod) beffer, als bei Sage iefn fann. Die

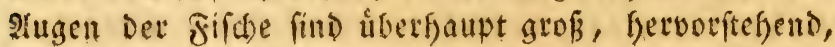
und wie cine Salbfugel abgeruntet, Das WBaffer, norin fie leben, ift viel bidster, und hat lange nicht Dis Durdffictigfeit, Dte Die $\mathfrak{E}$ ft - Das Medium, it welacm die vierfúfigen Sfiere leben - hat. Das (Sefichtsongan Der zaifhe mußste Dafer Dem Medio, worin fie fowwimmen, angemelien fenn. Aud) fefn wir, Daf ifre Augen nod) andre farafteriftifhe Berfoieden= beiten tarbieten. Faft in allen fehtt die wáfrige Feuchtigfeit, Bei Denl Dintenfifchen, Ralmars und Polupen ift fie Dutdaus nidht da *). Sie fehen Dafer

*) Swammerdam hat lid hier geirrt. (5i befauptet, „zmar nut in geringer פrenge, bod) aber bie giáferne Feuctigleit in Iuge Des Dintenfifches gefunten zu baben." Gern folgte id) bişger dieferm treffichert 
auf eine andre sitt, als bie tibrigent Thlere. Sie

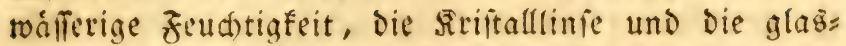
artige Fendigtigfeit, oic fid in ben II fubigen Thiere finden, liegen Deshalb fo hintereinander, um Die von Den Sorpern juruffectworfenen Sidteftrafler zu beed)en, weld)e ourd) Die Slupille auf bie গieţhaut gelangen und Dafelbft die Biegenftande abmaflen. Die eben genanten Deci Feudigfigeiten gehóren fur unfere Irt bes Sefhens nothmendig zufammen, ungefäfr wie Drei Gilastinjen von verfaledener Brennmeite das $D b=$ jectioglas eines achematiften Gernrofrs ausinacten.

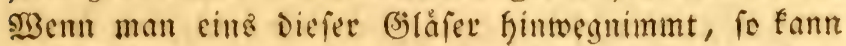
bas Sehen nicht mehr auf eben bie भit Etatt finden, wie bei iffer Bereinigung. Es folgt Daraus, Daf Der Dintenfift) und andere in bicier Sinticht áfnliche Mols lusken, Die feine wafferige fouhtigfeit baben, alle Begenftande mit farbigen ßåndern febcu, wie fie ung

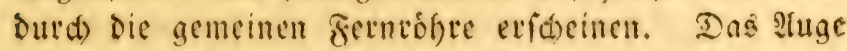
Det Dintenfigthe ift aud) mit jwei Pupillen beriefn, und

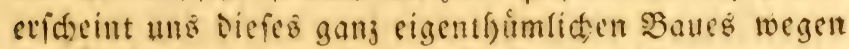
Doppelt. (Die Angen ciniger firthe baben die gleide Sorganifation.) Die jue \$upillen haten Die Forat

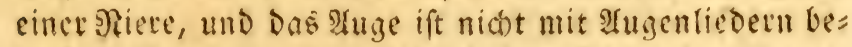

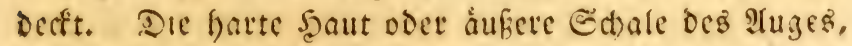
Die bei ben vierfungigen Thieren fo jatt ift, und bei ben Fifden fen fuberpelig miro, hat bei Den Mellusfer

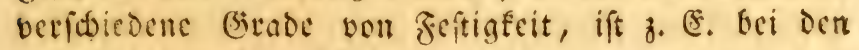
Dintenfifsten fefre feft, faft falfartig, uns mit Dem faboniten \$erlenglanze fabillerno. Sie fommt ben oriens talifden Peten nafe, wishalb Denn auch in siniger

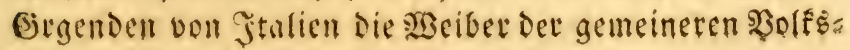

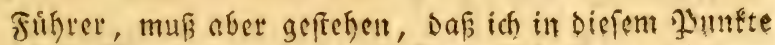

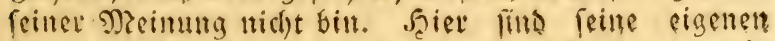
20lBorte: "Van binnen in het oug vont ik feer weynig van het wateragtig voyt,...." Bibl, nat, vol, $\mathbf{I I}_{\text {s }}$ p. 89.4 
Plafie fie now cinmal tutchoofrent unt anteifen, um fich Salsbanter barnus zu machen, womit fie an zeft= tagen fid) ismitfen. Bon botne lyat bie Diatur fite

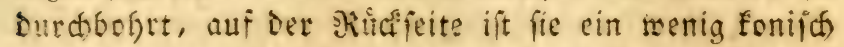

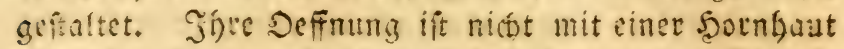
befleibet, Denn aud biejen Sijeil fáeint ber Dinten=

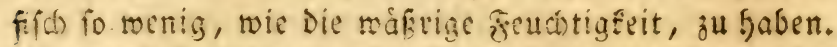
3ngenen umgiebt cine frine unt fobr jarte sout, bie siefen Ifferen ganj eigentyoumlich ift, bie hatte Saut felbit und bedect bie Seffinung, in weld)er fie Die Stelle Der Sornlyat vertritt. Die figl harte Sirifallinfe fringt mitten Durá) dies Sod unter Der etráfuten Saut fervor. Sie ift fugelfirmig, unt beftelgt aus mefreten concentrifara Eagen íbercinanoer, deren

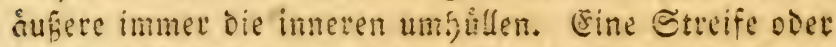

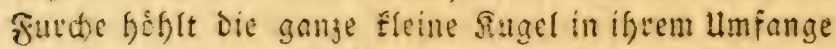

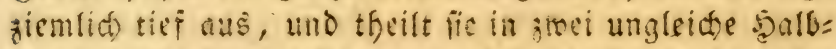

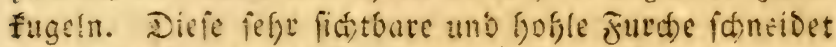
ein, uno cutgalt ben innern Rand beffen, was vou Iugenliede fercorfteft (procès ciliaire); Dif einen breiten Diśfus oder ein frenflendes Diaffragma bor, unflammert bie firiftallinfe freisformig und hailt fie auf Diefe gerife feft.

Die brennend rotge Garbe Der Ingen Deg Dinten=

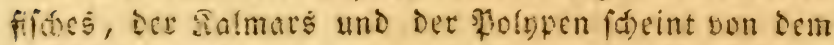
Esteme iu fommen, womit die runica Ruyfchiana diferzogen ift. Befanntlid) ift siefe saut bei allen

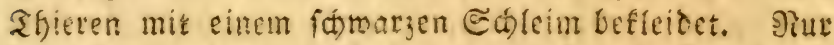
bei einigen Bogeln ift fie falb uno rotfgelbliá), bei ben

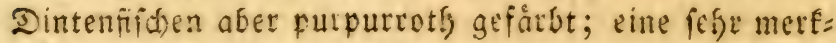

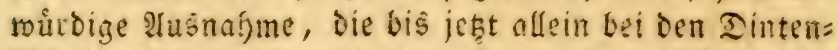
fiid)en, Salmats und Polnpen ftatt findet. Flyre S?eţ: Faut rito Durá) Die Deteinigung einer smenge von ops

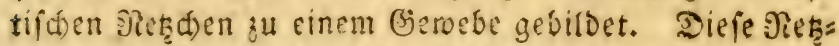
then gefen Durch einander, und mad)en jufammen nur eine eingige Membrane aนริ. Saร̃ Iluge beร Dinten= 


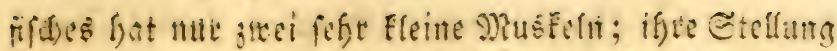
auf ben zwei Eeiten uno ifre Doppeiten Pupillen mach= ten nidt viefe 3erwegungen nothig. Der eine biefer

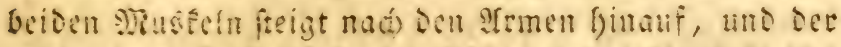

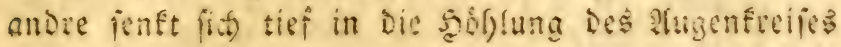
binab.

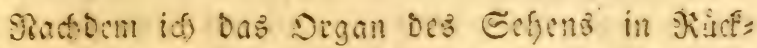

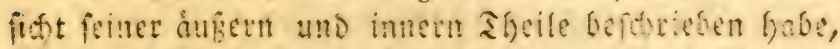
fo wolfen wir nan aud bie Eefgenerven uno ifore ur=

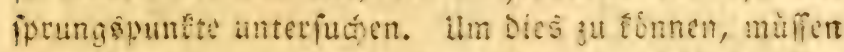

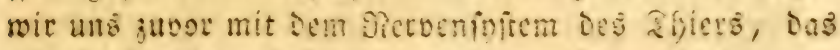
mir beobadten, befannt maden. Ia toerden mit ctenfalls wieder manches finton, wetées von dem

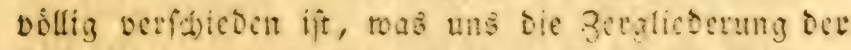
Shiere mit rotím Blut jeigt, beren sepi auf bem

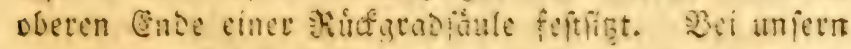
Roliuefen it Dex sopf io su fagen mitten in see Drgas

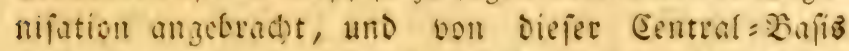
Laufen Die gletven - Diefe Sauptorgane deś Sebens, Der Enpfindung und Des Befulfls - in Divergirande

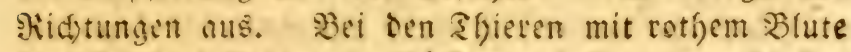
(t) gef)n Dann in getrifien Entiernungen Nerven aแsิ, ins

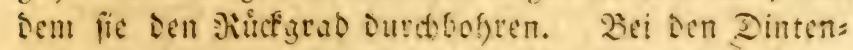
fijhen ?6. ift aber baร Gefirn Der DDitte!nunt beg Ge=

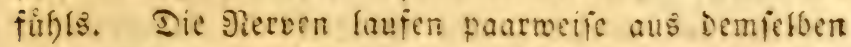
aแร, und begeben fich nach Dex recteten uno linten Eeis

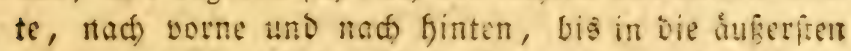

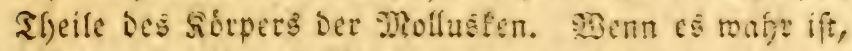

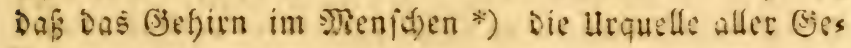

*) Die Dysuficer haber fíf mefr nod, alb alle übrige

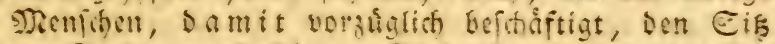
Der Erele ju erforlichen. Finige fefsten fie in Die 3ivs beldrije (glandula pinealis), oder in ben filwwiclian Theil; aber weser die sine, not) bie andere, finset

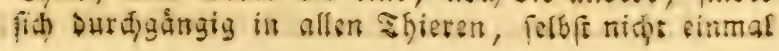


Danfen, Der Beteinigungspunft aller Cempfindungen, Der Siţ Deŝ Sebens und Der Seele genamnt werden fann; wie viel zroedmåjiger (d)eint es Dann nid)t beim

in allen, die rothes 3 lut haben. Indere fuct)en bie Eecte andersivo, und noch andere verlegten fie in bie ganze Drganifation bes Siorpers. Madhte man nach reiflichen Unterfuchungen nicht mit Tiechr glauben, Daßs

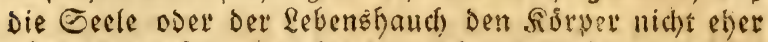

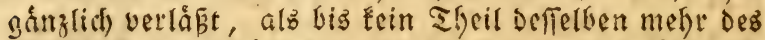

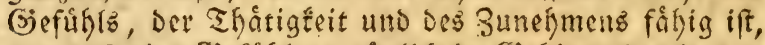

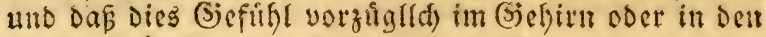

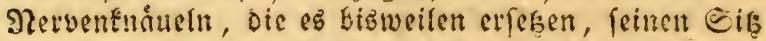
Gabe. Joth mag mich bier nicht in Difcuffionen ein.

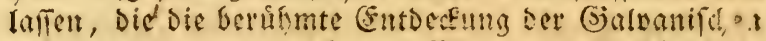

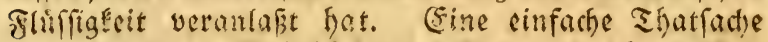

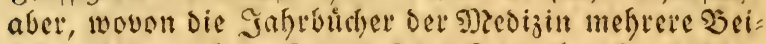
fpicle liefern, beweifet, Daßs der Rebenzhauth - Denn etwas anders fann Die Secle nid)t leun! - vorzágs

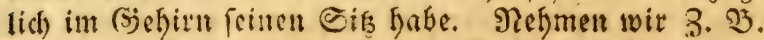
einen Drenifnen an, Dem ein Gelalagfup die Dbet = unb Unterfdentel durcisaub gelábmt bat, fo ift alles (Gefühl diefer Theile vernichtet, fie fint gleids fam im

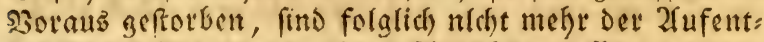

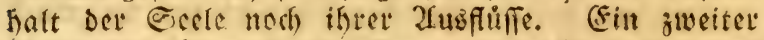

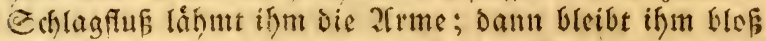
Siumpf uno fiopf librig; ein folches Siscen fann abet immet nod) allen friten (sieift, alle feine (Finfichten be: baiten; es Gat vielleicht feine von Den Sentminten ver:

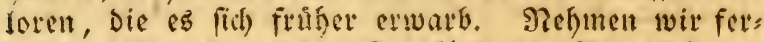
net an, Daf Die gleiche firantheit Den Siumpf biz zu Den Edhliffelbeinen uno Edulterblattern getroffen babe (wie man Denn (Erfahlungen Diefer $\mathfrak{X}$ th hat), fo

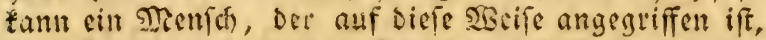
fieilid, mur nod) Ioenige Stumoen leben, Denn alle

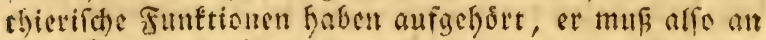
Enteroftung ferben; fein Ropf aber, uno feithe Ut: sheilafraft werben now jrei feyn, unt feine 3unge wirb in ben wenigen ifm librigen Stunocn feiten rabs: tell SBiflen Hod mit alfer fifarbeit und mit aller (Ener:

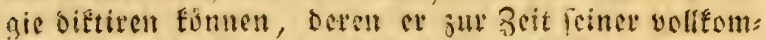

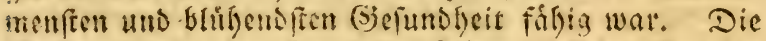

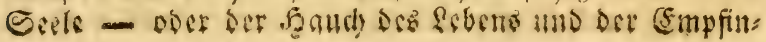


Dintenfifite angebract $z$ u fenn, too feine centrale lage ifm feinen ridtigen phofifden und moralifden Plats giebt, und alle Gefút)le, die die verf́tsiedenen (šlieder und Theile Deş Siorpers Der Dintenfifche, Ralmars und Polnpen empfinden, auf Dent geraden D. F). Furzeften SMege in Den Mittelpunft Des Sebens leiten.

Das Seftin des Dintenfifhes ift fert flein, uns in einer fnorpelartigen Butdfe eingefdolofien. (5s theilt fid) in zwei \&appen. Mit einet leiciten Sand fam man pb, fo roie Das ganze Nervenfiftem entblofit Darlegen, wenn man ben fopf von Ginten ber zwifden ben beloen

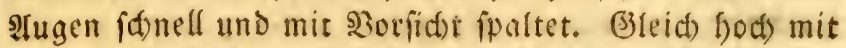

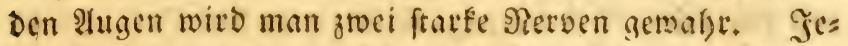
Der Derfelben geft auf feiner Srite aus Den Rappen Des Dung - eriftirt alfo wejentlid in Sopfe; Denn ift Diefer Dafin, fo wird fozleidh Der ganje úbrige Sodper Ieblos (entreelt).

Die Eccle uno ifre beftinmter 250 hnfit waren von jefer der (jegenftant Der menfs,ichen Unterfudungen.

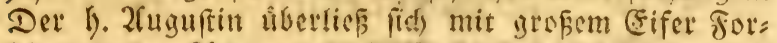

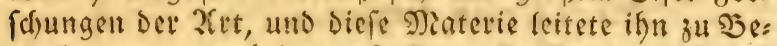
trachtungen, wobei er oft in grobe serlegenbeit ges

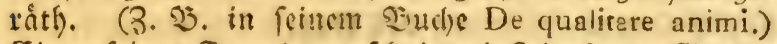

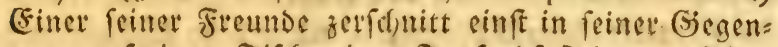
twat auf einent Tifche cinen Taufendup in jwei Theis 1e. Engleich fingen beide Theile an, ber cine auf bie: fer, Der andere anf jener Seite, eilento Davon zu fles ben. Diefe (Elfafrung, fagt Der gute Sirchenvater, babe ifgn zur berounderung hingerifien, zugleit) aber

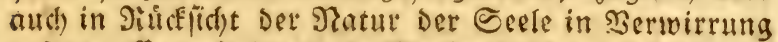

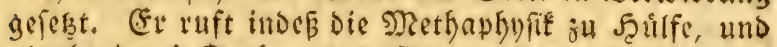
glaubt Durch Drefgen und 2 senden feiner Betweife bie 2Tuflofung bes groß̧en Problems gefunden zu Gaben.

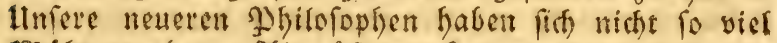
siúbe gegeben. 2fiz ruffigere Ecute zerbaueten fie Den

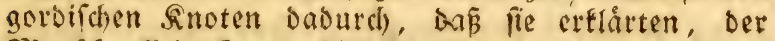

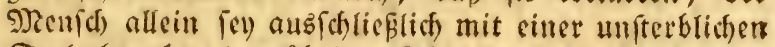
Eecle begabt, Den uibrigen Slieren fey fie aber Durdls ลนร verfagt. Das if mun freiliti - wis man fieft - viel ficherer, wenigftemb thrzer. 
Brefirns aus, und lát in gerabet Rinie so: fïh bift. Dies ift ocn Eeffenterben Der Shiere mit rotfem Blut

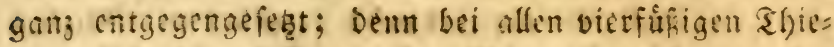

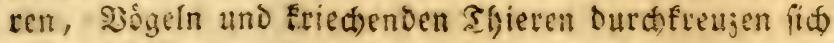
beibe Eehencrbat, nadjoem fie das Gefiun verlafien Gaben, unter eitander, und jeber bon ifmen begiebt fić) Hach Den Iuge Dex entgegen gefehten Eeite, fo Dof De: linfe 9ierve nad) Dem rectsten, tho Der tedte nad Dem linfen Iluge zutuft. Flut bie Sefenerben Det Filfye find Diejem allgemeinen befes unteriporfen, uno nur Die: Dintenfifde und Poínpen, viclietidt aud Die Rafunts, maden eine Itushafyme Davon: Denn bei if)= nen laht Der Eefenterve, Hathoem er tas Gefirn vers lafien bat, getabes siseges ju feintm Biefe fyin. Sicie פerven forweflen bals su cinem ftarfen feiffomigen

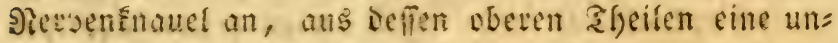
endiche smenge von Pervenfiden entftefen, Die fid in Form einte Fifdetnfe ausbreiten, uno jut Rugel bes 2uges finbegeben, un fie tricterisemig zu umfoliefen.

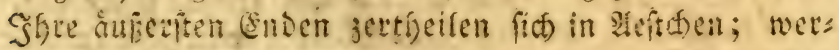
Den Gaardinn uno verlieren, fa vereinen fid mit Den

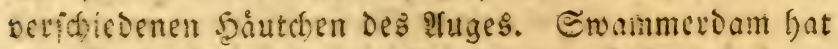
Diefe ganje zerafieberung in einer fefor fónen und ges treucn Zeidinuitg, Das গRerbenfiftem Des Dintentifldes befeffeno*), gefiefert. Zroat hat (Susier in frincm

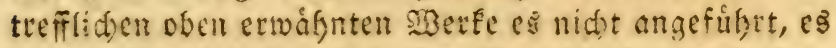
macht mir aber freube, if,m (Beredtigfeit riderfab)=

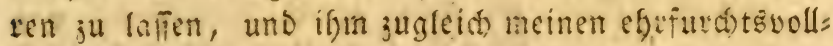

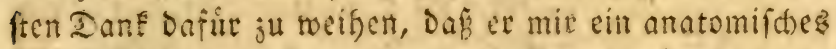
\$ráparat der Eehenerben cines \$olnps (meld)es te fellit verfertint, und roie io siele andere neue und treff:

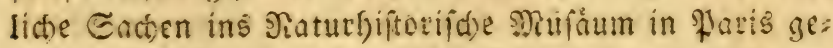
geben 5atte), anoeftraute. (E) erinnerte mid an Erammerdams miffame Arbeiten und leitete bie meis nigen.

*) Swammerdem, Bibl, nat. Tofel LII. Jig. 2. 
Iแร bem ootberen Theile bes Geboires treten Drei Fervenpaate herver, Die als Stámme Des̊ Eefnerven quet Durch ben finotpel gefin, Der ias befirn ein= fthliefit. Stoci jegr furje Sierven (bon Diefen fects)

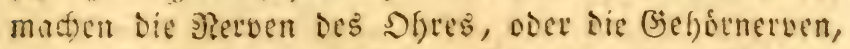
aนŝ: Die andern verbreiten fich nać) Den Muśfeln

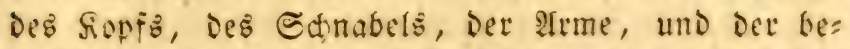
nadbatten Sheile hin. (Fin Paar zicht fich nad ier rediten, ein anoris naú Der linfen Eite fín; Sas mittlere beglebt fich nach Dem oberen Sheil Des Ropfe,

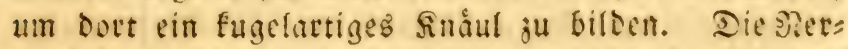

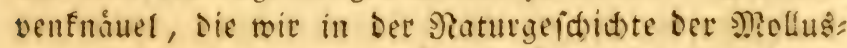
fen fo oft oor finden, fommen mir wie ßiugepunfte vor,

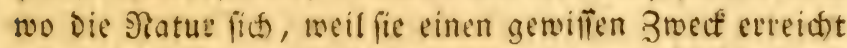
bat, einen afugentidef verweilt, ifre אirafte trieber fommelt, uns Dann ifge פiserf aufs neue verfolgt, un fie (Die firafte) in Den veridiebenen Wunften, wo lie

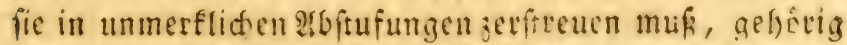
vertheilen zu fónnen. Bon Dem Sicrvenpart, daş wit

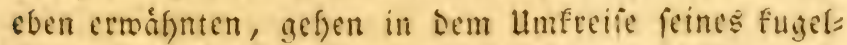
formigen Sintuls unternerben ab, Die fid mie Etrahlent jerftreucn, um Den Wrmen \&eben und Befithl ju brimaen. Dott baben wir fie fifon - bis ju ben äubetien fetres mitáten fin - Siervenieile voll Sinoten bilben fefn, Die, als Untermittelpunfte Der Jiervenfraft, micter neue Ramifífationen fervorbringen, benen aud) bie geübtefte

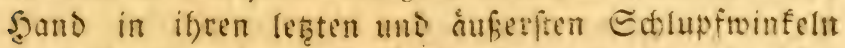
nidut folgen fann. Fin funftes Serventaar, Das ftate fer ifi, als alle, bie mir eben bejetricben faben, läuft

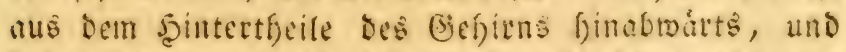

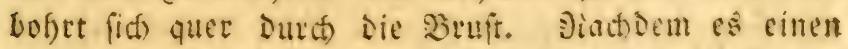
Theil Des Sirtpers Duthlaufen bat, birset jeoer eins gelme sietue, anfiduelfend, ein birnfómiges snoul. Son jeber Seite laufen meft als orcifig fascuartige Sierven ans, bie in ifren bis ins unemblithe unterab:

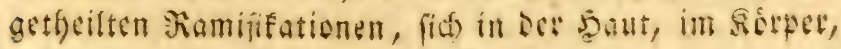




\section{II}

in ben innem Sgeiten und in sen ficmen (ooer Dorge men zum Stthemfolen) verbteiten.

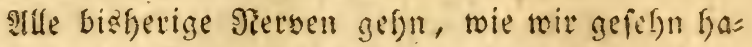
ben, bei ifrem (Entiteben surd) Den fnorpeligen Bing,

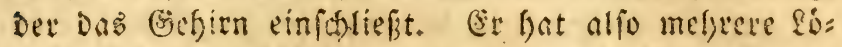
d)er, fo wie er uberibaupt fefre unegelmåsig geftaltet

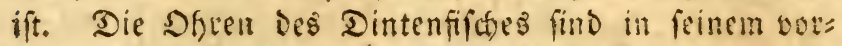

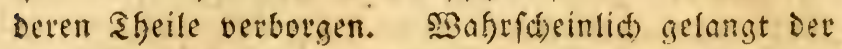

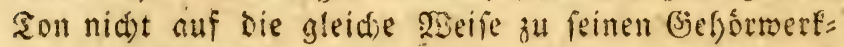
zeugen, als zu Denell Der grofen afiere, Denn berem Beformerf jeuge find wenigftens viel zujammengefetset.

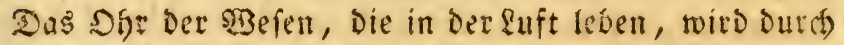
sie erfugutterte fuft gewaltfam beriffert; fo foleint is Demi aud), Dá̉ Das SBaffer, weldis unter allen Gót:

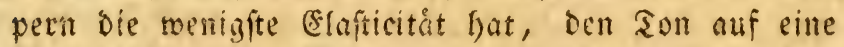
áfntidue

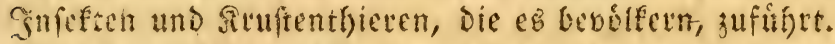
Motun fann fich oas 23 affer alb ein homogenes Banje worftellen, bas ben Son in ber Sirt fortpflanjt, whe es eill abgeffauener, licgender Baumframm thut, an Deffer

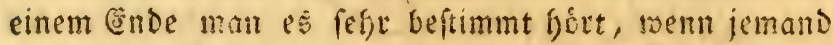
an andern (Ende aud) nur mit einem Fadelfnopie brauf

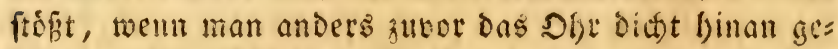

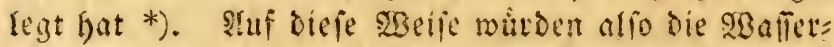
thiere Durct) sine art oon fortgcfertem Druct (compreffion retentiflane) und nicht Dutd) Bibration fioren. (Es wito fich siber zeigen, sab bei allen Ihieten, deten Gefororgan man bis jeşt femnt, von Den greşten an bis zu Den Dintenffiden, Fatmars unb Polppen fin

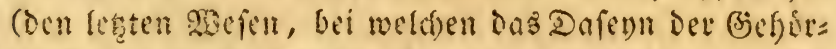

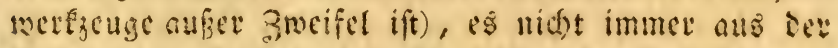

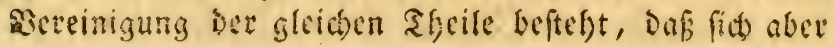

*) Eo auffallento dies fecheint, fo wable ift

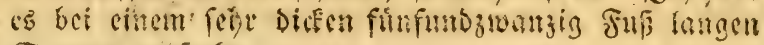
Etamm verfudt.

Inm, D. Heverfegers. 
bei alfen bie gallertartige Maffe-(pulpe) finoet, sie

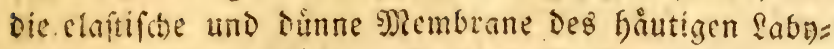

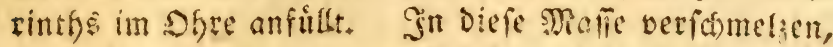

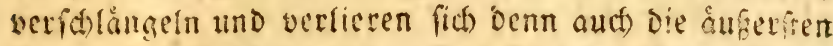
Zneige Des Befornerven. Das Dhr Deb Dintenfifers ift felte einfact) in feinem $B a u$, uno Die Membrare des Saborintfg frellt cine fleine, obal abgerundite Taidse yor, die inmendig mit fonitchen, unregelmáfig jer= freuten Servorragungen berfefn ift. Sfre gallertattige

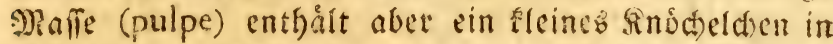

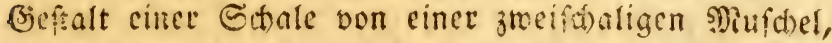

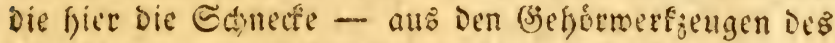
Menidien, - uno dic fieinen breiten Eteine, - aus Dem Gảutigen Eaborintf) Der filfhe - za vertreter focint. Fwat Gaben bie biskgerigen Reobnotungen bei Den ibtigen Mollusfen noch fein Befiororgan ent= Decte, ez foreint indef Dod, baf vicle unter ifnen auf ingend eine Itrt erfalsen und bemerfen fỏnen, was um tie herum vorgeft, unอ Daşjenige ju vcrmciden wiffen, was ifnen fid asen fimnte.

Der Dintenfifd ideint met Berudfororganen ver= fefgen zu fenn, renn man gleich) nod nicht befimmt

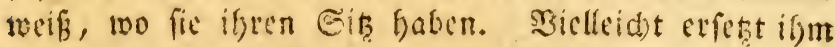
feine als lanter Sierven, fo ful fagen, gewebte sout bie Etcle ocr Edteimfaut. Dei Den Land = tmo Mafferidnecten wenighens ift bies wahridueinfich ber Fyall. Dies voraugefetet, fo wirbe ber Eim bes Berudis beim Dintenfifde auf ber ganzen Dberfláche tes fiutpers verbreitet fenn. Man lyat, uno zwal it felgr alten Beiten fhon, bemerft, baf er Den (Gerus

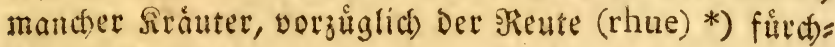
tet und flieft.

Cein Sals ift fefr fury, und auf Der $\mathfrak{B o r b e r f e i t e}$ frei und bieglam; auf ber अinffeite bedect ifn die

*) Aelian. Hift, nat, lib, I. cap. 39. 
Rưfenfaut fait gang. Cie nimmt unmertich an Den beiben Seiten Des̃ Rafens unterlarb der Augen ilfen

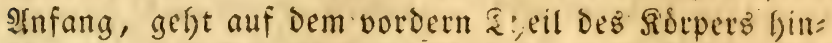
iber, und bildet auf diefe 2 Beife cinen Saif, ben Ia= marf einen Mantel genannt bat. Untel fined Saut ift ex musfulos und fleifdig, umfolieft ben ganjent Sírper des Thieres und erbălt dabutd feine åufete Geftalt. Det Dintenfifd) fann fid) Darin zurucijiel)n, und feine Irme und feinen fopf ba bineinfteden (faft toie die Sdbilbfrote fich unter ifuer Sdale verbirgt), benn peine silieder fonnen fid fels zufanmen zielon. Die Rưfent)aut bångt, wie ztwei feftons, ưber Deu ganzen Ulmfang des Sacts fin. Diefe verlängerte Cin= faffung, Dic áuberlić) Den Siarafter des Dintenfifdes ausmad)t, uno ifn von Den fialmars abfondert, ift bištweilen ziemlid) breit. Sie ift auch fefre muŝfulós., und Dient Dem Shiere wafrifheintid zum Schrimmen, fcinen \&auf zu riditen, und Die $\mathfrak{B e w e g u n g e n ~ z u ~ u n t e r = ~}$ ftuthen, bie es macten mub, toenn e áltoern will.

Die åltern Sadrifteteller glaubten, Der Dintenfifh fowimme vermittelft feiner Arme, indem et fie nad) einanoer bald rechts, bold links foin ausbreite; aber dic Geftalt feiner Irme zeigt, Daf fie dem Ifieve fochfents jum firieden, nid)t aber zum Sdwimmen bienen fón= nen; und doch finden wix, oafi er fofwimmt. Die ex=

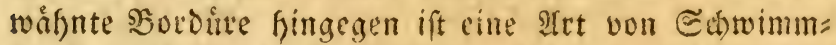

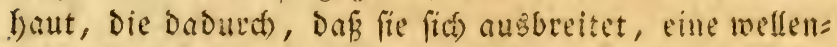
formige Berocgung annimmt. Siad) Dem sintwtfeile bes fiorpers zu ift fie in ber Sortte fefor beutlich ge= tgeilt, fo daf einige Sariftiteffer fich erfaubten, won

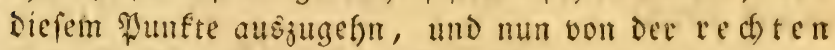
und linfen Seite Des Dintenfifches ju reden. Det Rưfen if weif geabert, getigett, mit purpurrothen uno fdrvarzen \$unftchen befreut, uno mit weiffiden Fleten gezeidntt. Sie Seitenleifte (oocr Sinfaffung) 
gertheilt Diefe Farben; fie ift broun gefoumt, und merflic) meniger getigert, als ber Biuck'n.

Da Der Dintenfifit) fogleid) ftirbt, fobald man if) nแร bem Mafier genommen hat, fo twirb er aute augenblictict) melf, feine sarben merden unftheinbai, und er fieft alsDann bleifarbig aแs. Eo lange brs

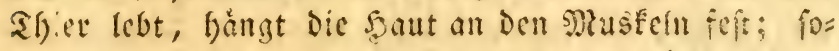

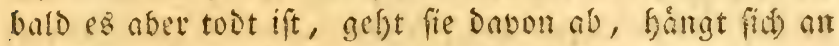
Den singern an, uno zereribt allentharben.

Sin furzer zeit, oft in weniger als adt Tagen, loft fich bas ganze snolluste auf, und jergeft in cint

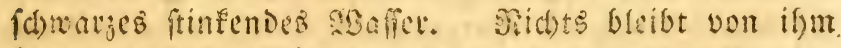
nibrig, als bet Givitenfnod)en und bie beiden Simbar den feines Edmabcls, weldie man oft an Merufer findet und bie von ben alten Satuforfuern fur Eduns bel won llfervoseln angefefn wurden.

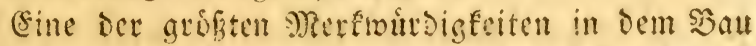
Des Dintenfifibes, Dess Salmats und bes Plolppen ift

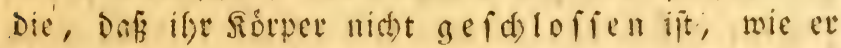

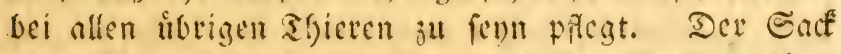

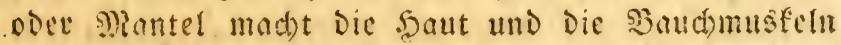
แแร. (5) ift boene unter Dem Shalfe Des Shiers berit

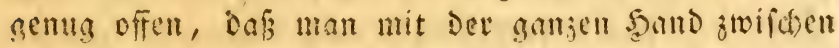
Den imern Ifeilen, Den Cingewciten und befem shan= tel Dud daften fann. Ẽe gleidst alfo voffig einer oben nffenen Safde; auf feimem innern Bande, am vberen

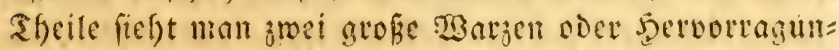
gen*), Die die alten ఇaturforfder (und alld) einige neuere 3. (E. Sonfton) fiut wirflide Brufte bielten und Desinalb glaubten, fie fánden fid mu beim weibli=

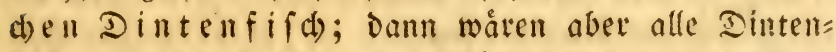

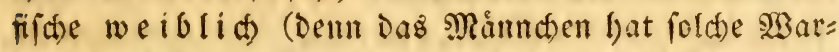
jen ebenfallš). Bei ber lnterfuctung Der Zengungs: werfjeuge wit' fid) aber jeigen, Dấ fie fich Dutd) be=

*) (. Tafel II. 
ftimmte und auffallende Sennjeiden, dic iften Ge=

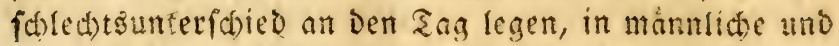
weiblidbe theilen. Die $23 a r z e n$ find aud ju einem gan andern (sebraud) beftimnt. Sie paffen feht gentan in zroei, wie Salzfiffer ausgegofglte Pertiefungen, oie

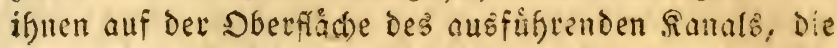
eine redts, bie andere lintes, gegentiber frefn. Die beiden Sertiefungen werden burd jwei ftarfe, innere,

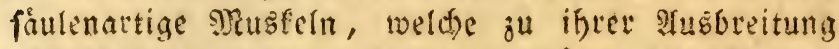
pder Bufammenjiegung dienen, geftutht, und focinen beftimmt, Die Şaut des \$̧and) nebft ben innert Theilen feftugalten und anufueften; Denn fierin birgt Dex Dintenffid feine 3 arzen, und Gilt fie barin zurick oder firecti fie aus, je nachoem er will. Sind fie (bie

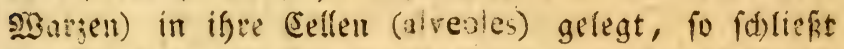
Der Rand bes Sacfs allentfalben an, und wirb Duré)

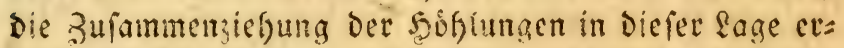
balten, indem fie ifn alt fich ziefsen, ifir Daburd sleids=

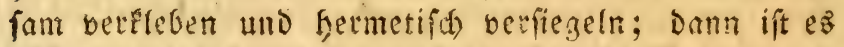
vollig unnoglich, baf irgend eine frembe Materic gwi=

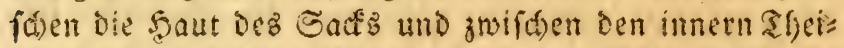
ren hindurd gieiten fonnte. Der ausfiffrende fonal allein jeigt fein ăuferites (Ende, nadi vorne ju, auf Der

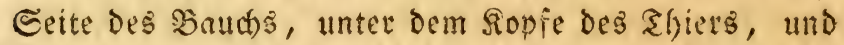

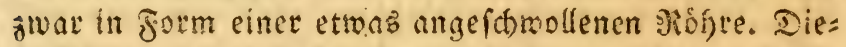

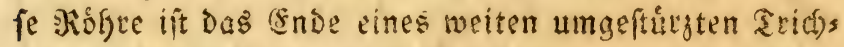
ter's, uno butch ifn - Deffen Rertur musetulos ift gefn Die Cier, Die Gamenfeudtigfeit, Die Dinte und

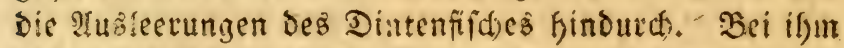
enden folglith aud die (singetweide. Ifriftoteles und trach ifim Fondelet befaupter, Dafs er Dutd jene Deff = nung aut bas Seeroffer, weldes ex beim freffen un= vermeidith mit einfdhlucfen muß́, toicber ausmerfe.

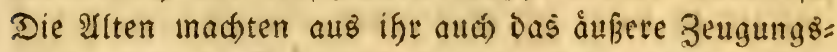
glied, Denn da fie bemerft Gatten, Daf unter Den Din=

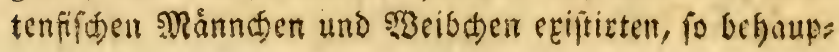


teten fie, saff fic fich aud begattetet. Ifm die Fit die= fer Begattung ju etratjen, fpannen fic ifsenn (Sicift gleidfan auf bie folter. Finige meinen, dicje shiete

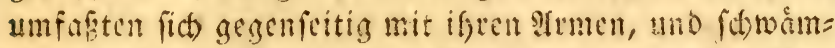
men 6o, Dicht an eimander ge fingt, in Dex immiafen Ser= sinigung, fort; andere fef̧en fie cinander gereniber, und lafien fie fatminmend fid begegnen und fid Duta cine Srt von finfdad)telung paaren. Drittens enolidy glanbten einige, fie begatteten fía) Durd) Den sllund, weshalb man fie fiu unxine Slicte fielt. 9ylythagoras,

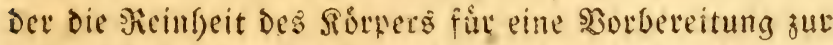

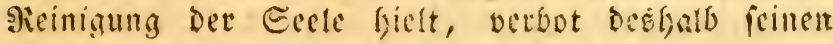

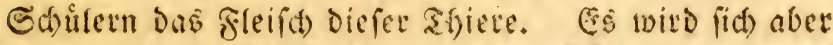
jeigen, Daß bei ber. Sintenfiften gar feine \$antung

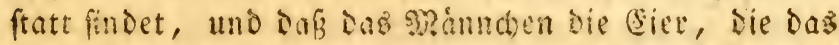

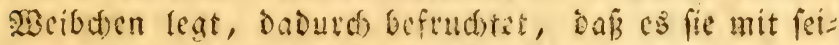
ner mirt over Samenfinctigfeir benetgt.

Se geneute man ben sintenfif(t) beobad)tet, befto

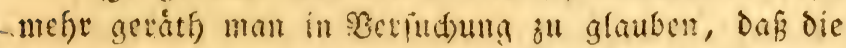

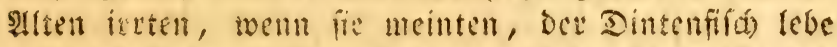

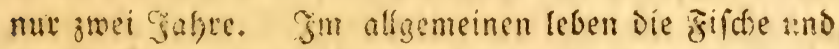
die 23 afrerbemohner hbethrupt tocit langer, als Die ans

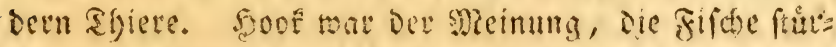

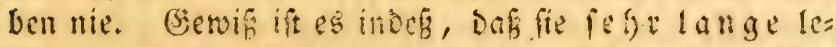

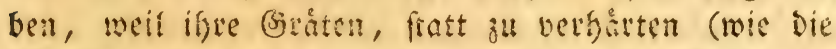
Sinoden, dic, twenn fie zll einer gewiffen Groge ge= Inngt find, nid)t mef) wad)fin), im Gigentbeil immet biegfam bleiben, uno aud an fänge mit Scm Thiete

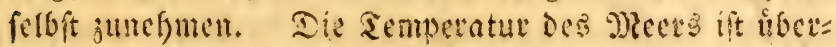

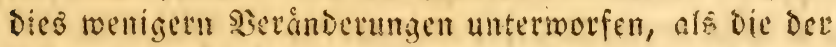
\&uft uno Det Febe; Das Ifermometer o. S. feigt uno fálf bafelbit, befonders in einet gevifien Tiefe, toic im

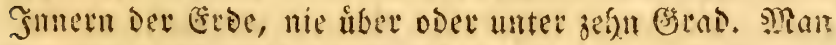
bat zmeigundertjągrige farpfen gefant, und Sedte,

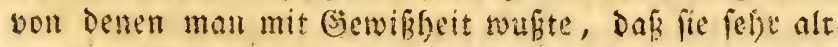

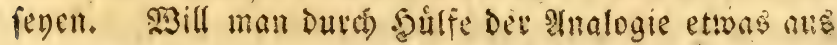


Dev Epocte befimmen, in welder Der Dintenfich zum

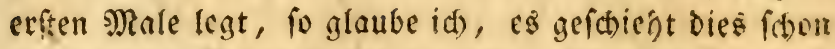

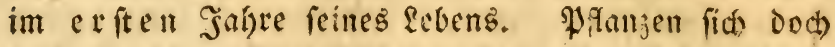
aud) fo viele andere firche in Den erften Jahren físon fort, ungead)tet lie bemoch weit von Der Brofipe ent= fernt find, die fie ipaterfin erteidjen metden.

s3ent man ben Dintenfific) auf ben Rúcfen legt, fo fanit man feinen Sact doev Mantel fefre leíft mit ei= ner Sdere langs dem Baude hill in Der spitte auf= fdneiden; nad einem folden Sd)nitt fam man benn be cingencide und innern abeile, ofne alle \$erlegung, fefon und unteriudien. Esimige liegen nadent Da, und andere erbfut man Durd) Die Sisute Der Situft und bes Bautbs. Gleidh beim erften anolict unterfafeidet man bie Riemen bor allem Hebrigen. Sie madyen fier, mie bei Den zifthen uno Rruftentfieren, Daş Drgan Des

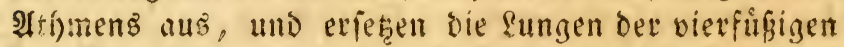
und friedenden shiter. Statt der Suftrofte, igrer

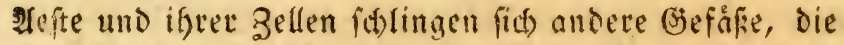

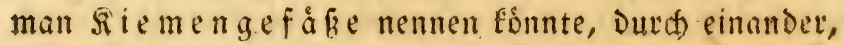
und bilden auf Den Blattd)en und mit Frangen beferten Ieftden Der Riemen tanjend $23 i n d u n g e n$. Diefe Bie: fäge fdetnen, outd) Sullfe abforbirender Deffnungen, Die Rebensiuft abjufnndern, die das $93 a f f e r$, weldes immer aufs neue die aiemen babet, einfdhliefit. Dir Fiemen Des Dinteniifdes fino weid) uno ithmammig; fie bilden jwei Sorper, wonon der eitre redsts, Der an= Dere linfś, von Der innetn Mitte Des Fidrper aus ges red)net, fteft; exfeben fid twie \$almjweige, uno zei= gen ifrer ganjen fånge nat) cin ftatfes hervorfterbendes Gefắb, Das fich nad) beiden Seiter hin in mildweife

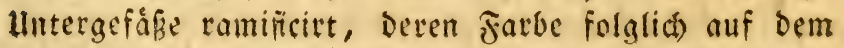
graulichen Grund Der Riemenblattden faneidend ab=

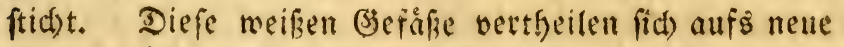
in Sauptåfte, und Dev unermitidete Smammerdam jåflt iffer melge als vierjig auf jeber Rieme. "Id)tet man 
nun, fagt er, anf ifle llnterramififationen, die fich innerfalb der Subftang Der Siemen verfieren, fo ift ifre Menge zafllos."

Die auffallendte Sonberbarfeit in ber ganzen Dots gonifarion dez Dintenfifides ift rofld die, baf er Drei

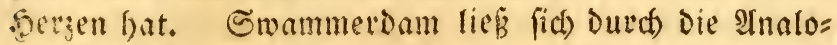
gie táufien uno erfannte fie nicht. Sollte man abce

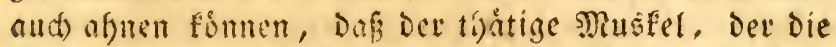
Beweaung uns sas feben entfílt, und ber fich forift immer affein und einfad finder, fict) in biefem Mnllust mit einera smale verdecifoden werde? - Sermittelft diefer Deci berzen wird Die zirfulation des meifen Eaftes, Det frin Blut ausmacht, bernitft. Sie ferhn im Dreieç. Şwei fino sinanict gleich, das oritte Das unterfte - ift Dos groffte bon allen. Die Enmphe, die Die ardern anfullt, wird ourd) Dic Serjen in Die Soglaber getricben; bieie theilt fich gabelformig in

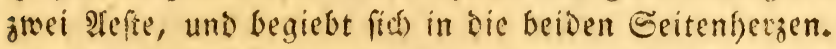
Son da lauft fie in Die Siemen, aแs meld)en fie in Das mittlere Set' Des Rotpers finliegt, binabfteigt. Durd bie Adoen fommt fie bann nieder zutuce und bildet fo Das fon: Derbarfte uno auffallendfte thierifd) Birfulationşuftem, das viclleid)t exiftirt.

Der Magen ift wie cine runde Tajde (oder wie ein Bogelftopf) gebildet. Dev Dintenfifd) fúllt ifn mit Seegarntelen (chevretres), Bătenfrebjen (Squilles), Frabben, und mit fleifit) von anbern Fifd)en an, beren Heberrefte und Stráten man bort vorfindet. Seine Såute find frarf und musfulós. (5e feeint fefr gut verbauen zu fónen; Denn id) habe Sheile von arabben= und Seefternidalen vollig aufgetweid)t Darin angetrof: fer. Der MRaftbazm (inteftinum rectum) fideint mit Dem Magen nur einen uno benfelben Ranal auşuma= d)en; Dev alfo vom Miunde feinen Infang nimmt Durch ben Schlund in den Magin binabfteigt, fo fortgebt, 


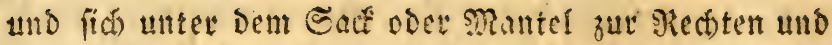
in ber Mlitte bes $\mathfrak{B} a u d y$ endiat. Untermeges erfialt und madit er einen eimfonite in Den Sanal Der Dinten=

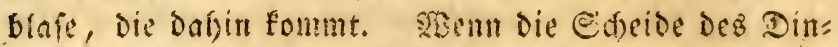
tenfifdes burd) Sulfe ber sonsen gefóloffen iit, fo ift fic bermetifa) berfiegelt. Dann fonn nidhts mefor uber Den ßand Diefes Mantels ginnus, fondern bie ăngete

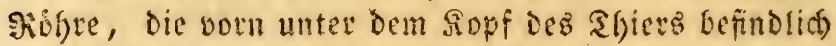
ift, witd Der gemeinforttiche Iluggang firt die Ciers

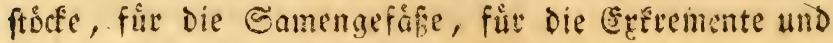

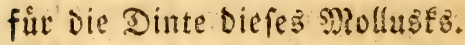

Die forafteriftiften Theile des Mánntuens be: ftefyen vorguglid in Eamengeföben, bie in ciner fefre

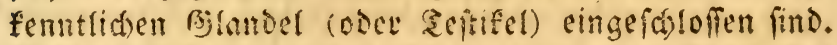
Diefe (3lonbel befindet fid in unteren Theil bes Givencts, nafe bei der Dintendafe. "atm Cinde des Teftifels fieft man ein ausincrfendes oder abfúfrendes

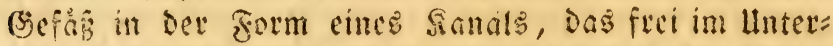
reibe Gin und fier fdyebt, und auf Der linten Seite, neben Dem shaftoarm, vollig entblopit mit feiner Deff= nung fichtoat ift.

Tic Drganifation bicfer Theile-ift bewunderngs=

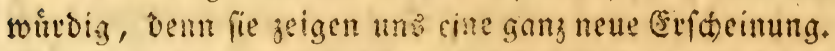
Man fann bir ganje C̈ubfanj bes Tefiffels in eine lange Eamenuobe aufwideln, bie an Den beiden Enoen. Dinner und in Der Mitte lelot angeld wollen ift. Cin meifier Same fullt fie an, ber fogleich bei ber erften

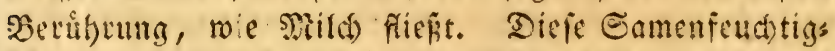

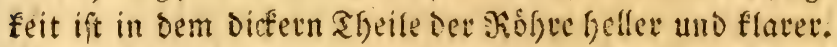
Gegen das Ende derfelben aber wird fie dicf, tho wim= melt hier von taufend faferaen, bie eine befonde Iufmerffamfeit verbienen. Smammerdam, Steedham, Suffon, und Sonnet *) Gaben fie ifres afufmerfianfeit

*) Swammerdam loc. cir. - Nouvelles Découvertes fuites par le Microfcope, p. T. Needham; Leyde, Luzac, 1747. Ches, 5. - Hift, nat, de Buffon. 


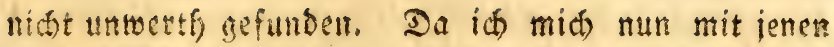
grofen Miantern nicht vergleichen fant, fo merbe if

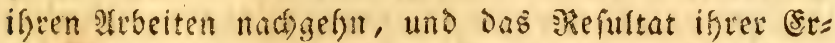
fabtungen, die mir, bei Der şiederfolung derfelben, Das Biteid)e zeigten, mittheiletr.

Sinammerbam hatie bei feiner Bergliederung bes

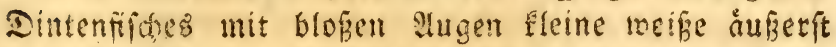
zarte *) Gibern entoect, bie fid gang von felbft bei Der Deffnung Des Crigiffungsgefäres zeigten. Diefer fd arfimnige Mann war befaciben genug, ju fagen, er wiffe nicht, moju fie nutsten, indem er fie vielleids fur Cdmarober: sirper, iic etwa fur Zeugung nothig fenn modten, fielt. Sach ifm fand Needfan die

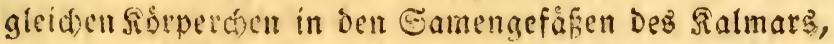
und theilte Buffon eine Beidonung derfelben mit. Swar find fie ben saferthen Des Dintenfifdes fefr ålnulids,

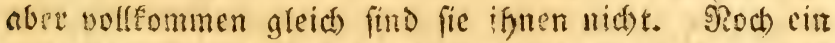

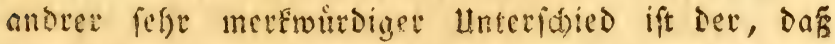

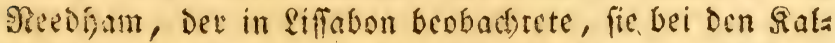
mats nut im Sanuar fond; wáfrend des ganzen Coms mers abe: nidhts bergleiden entbecten fonnte, und dag Eroanmerdam in Solland im Mai, alfo in cincm Som= mer = monat unterfudte, wo Der månnlide Dintenfifa Dos 3eugungstrumigen getade befiţt.

Diefe Jaferten, mie Smanmetdam fie nennt, find vollfommen weif, an beiden Enden burchidheinend, und wimmeln in Der Samenfentstigfeit, ber fie mehr sonfiften su geben idseinen. Sie find ein toenig bo= genartig geftủnt, vollfommen abgetundet, Ginten frei, vorn aber endigen fie fid in einem lofen gaden, Der fie un uno unter einonder vertwidelt. Det Fabest

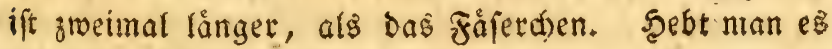

Tom. XVII. p. 3I8. - Confiderations fur les corps organilés, por C. Bonnet; Amfterdam. Marc Miche! Rey, 1762, p. 13 น. 86.

*) Tafell IV. Tig. 5 . 
bei feinem faben empor und hált es in ber suft, fo mird es feit und verfátet fict), wie der faden des Scibenwums; ergalt eine gewiffe Zåfigfeit uno miro glamjend wie Seide. Siocs wunderbarer ift aber fols gendes: Menn man Diefe fleimen fiorperden in ein Gefáf mit sibalier wirft, und fie einige Zeit Darin lafft, fo fangen fie an, fict bin uno gev zu betwergen, fpalten fich binten, - einige aud) vorne, - uno jogleids fábrt bie reiffe Mraterie, die in oer sortte einge falofien ift, feraus, stelgt fich wie cine Ecthlange *) fpirals formig un fic felbit, ofme bafs Dag Futteral, woraus fie fam, fid mieder verfoliefst.

llnterfutht man biefen fálangenartigen forper unterm szerarónerungeglafe, fo wirb man deutlich

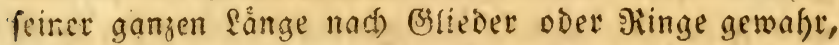

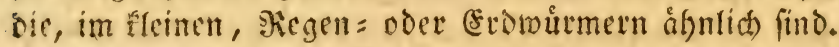

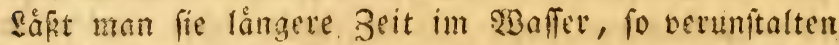
fie fith, und Defnen fid aus. Scaŝpelt man die ver= fhebenen winoungen Det Samentofye ab, fo ift iffe Saut fo fein, Daf man Durth Diefelbe bin Diefe fleine Gorperden fehr genau gewahr wird. Sie liegen da unordentlid) und affictlos itbereinander. Sft findet man fie auch eroffnet, fo dab fie if)en fpiralformigen Snfolt mitten unter bie andern, bie nod) im Zuftande Der gaufe find, gerorfen haben.

Bringt man fie unter Das Sergróferungsglas, um ifren $\mathfrak{B} a$ nåfer zu unterfucten, fo fię)t man, Dá Diefe faferchen an ifrem finteren Bande ${ }^{*}$ ) Durd)= fictig find, als ob fie eine \&uftblaje einfd)loffen; Dann fommt Die meiffe Subftan, die ein Drit:feil Des Ban= zen betriggt, uno dic mix ausipriten faber. Sach vorne zu werden fie wieder ourd)fictig, unb laffen Den Faden finein, Der fich jwei noer Drei Mral Dort um= biegt, und Dann nad aufen wirft, um fic an sie hbri

*) Tafel IV. Fig. 4.

**) Safel IV. Fig. 3 . 
gen ifn ungetenoen Sorper anjuhafen und banit zu berbinden. In fo weit er bie \&uft berufht, wird ex zugleid) feft, wie es mit dem faden Der Eeide zu fenn pflegt.

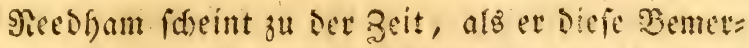
fungen mad)te, Smammerbams (ontbectungen, Die Dow

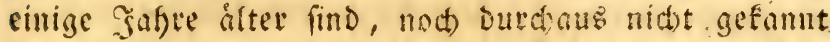

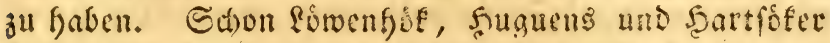
batten fich Durd) ifge mifroferpifonen Beobaditungen uno Durá) Die (Entbectung Der Samenthierden beruffut gemacht: Needham zreifelte aber, feitbem er Den

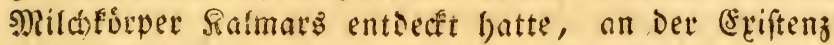
jenev ifferden: $i a$, ế foteint, als wolle er alle $\mathfrak{I} n=$ fufions = und Samen= Sfierden fưt niduts anders an= erfennen, als fúr fleine Mafthinen, die mit Denen im Solmar areflulid)feit batten; Diefe aber glaubte et Durctaus nidjt mit ef be ns f $x$ aft begabt.

Buffon wirderfolte muthig die Berfud)e der hol= landifden Beobadjter, ja er madte fogar neue, und vereinigte feine Deobachtungen farmmtlid) in ein Snftem. In allen Sinfulionen uno Samenfeuctitiafeiten findet er biefe Sfierden wieder. Mit ßergmigen folgt man ifm bei einet fo intevelifanten uno fur bie Reugierde fo ganz geeigneten $\mathfrak{a r b e i t}$, und bei ben fo fleinliden mi= froffopifden Beobachtungen, von weiden man glau=

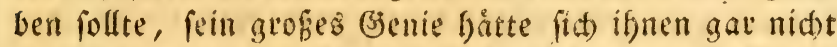
unterzogen, wenn man nicht faffe, wie er alle sate= rien und geuditigfeiten, bie er mut finden famn, unter

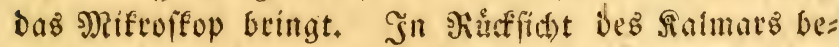

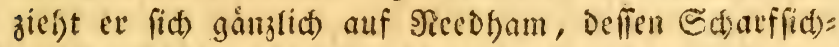
tigfeit allerbings nid)t beftritten werden fam. Ex hat pogar eine 3eidnung von Diefen Sorpern, Fifferthen, Docr Futternlen der Samengefäfze des Salmars geliefert, worauf id meine fefer bierourch verweipen twill. Da id) fier ebenfalls eine zeidsmung von Denfelben Gefápen Des månnlichen. Dintenfifdyez mittigeile, fo fonnen die 
Sefer Durd Den Bergleid beiber ifre Serfajiedentiter am befter auffafien.

Buffon unterfuçte Die flciten Majchinen, die mafriderinlich unter Needhams Mifroifop praparitt uno getrodnet waren, felbft, und eifennt oie Ridstigs feit Der Feedhanf(d)en Befdreibung an. Bugleid be= merft ex aber audh, Daf Diefer Befefrte verfăumte, Die fleinen singefden zu beobadten, Die mitten in Der ferdefen Feudtigfeit, weiche innerbalb Des fäferchens

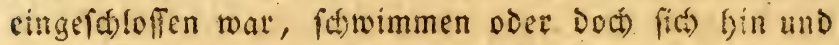
her berbegen fonnten. Diefe, von Needfam herfefencm Sitgelden, moditen, meint $\mathfrak{B} u f f o n ~ C .324$ in Der Note, Die wafuen Eamenthierden in ber Salmamild fenn. Sth habe fie in Dem flebrigen ङstem, Der die

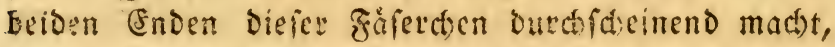
and in Dev ferofen Earrenfeudigfiget, Die den mitrelen Sheil Des Eomenfadens cinnimmt, Deutliof fid berwes gen fefn. Sachdem ich die fajerden in laumarmes Sgaffer gebrad)t hatte, watfen fie ifte Epiraliprings

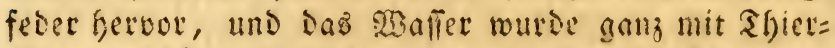
d)en angefullt. Sie fern wie ein tuntes sopfden aus,

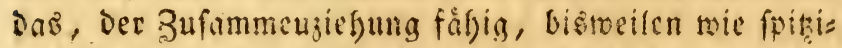

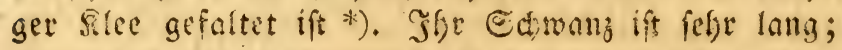
wenn das Sibier fotwimmt, fo beroegt or fid wellen: formig. Da es aber nad) allen Eeiten bin farvimmt, fo fann man wobl nid)t itern, wenn man es zu ben hibtigen Samentfierdien rednt, bie uns alle Sd)rift=

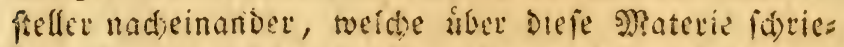
ten, fenuen gefefret baben. Zeit und lumfio̊nde ver: binderten mich meine Benbach rungen rociter fortzufeten. (Fin Botge doer Bandale **; mit Snomen Mingaud, Den iá) unglutelidjerweife in Boulogne-fur mèr, mo

*) Tafel IV. Fig. 6. פiza fanm fie zu Dem Protenz:

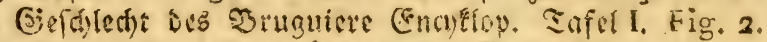
refnen, Denn fie verendem ifye B.eftait, wie jente.

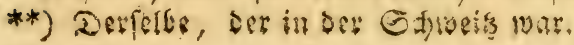


ex fic) oberfter Regierungsfommifián nannte, fennen

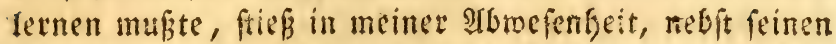
Salid)ern, auf gut foldatif(t), Die Thiur meiner Studir= fube eit, zerfolug meine Juftrumente, warf meine Sammlungen aus Dem fyenfter, uno frir Sråpatate Durdeinander; waflifueinlid um unter meinen Slapieren etmas zu finden, womit er feinem gånjlicten Bevgeffen Der Befetre, und einer mir ofne alle Beranlafing zugefugten Mikfandung, einen Inftrich geben woulte. Bielleidst bin ich in ber ălfunft nod) fo glúclica), Diefe sucte mieder ausfutllen zu fómen. Dies

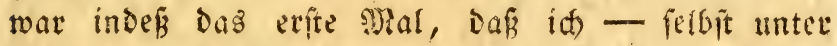
SWHoen und Barbaren einen Feind des naturbiftorifder Studiums, und berer, die es treiben, antraf, Dent fonft habe ich nod allenthalben Seilfe uno Satut ges funden.

Da fich Secofam nicht mit den Singelden be= f(t)aftigt, fondern Der Siorper, ber fpiralformig hervor= f(d)iffit, feine glufmerffamfeit vorziglich auf fid) gezogen hatte, fo nafym Bontet jene Beobacitung auf, uno

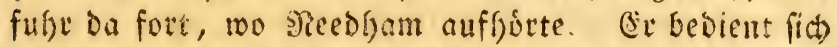
iflet in feimen Setradtungen úber Die organifitten

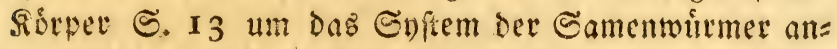
zugreifen. Seiner Meinung nad) macht biefe Ent= Dectung im folmar fie wenigfens z meifelfaft,

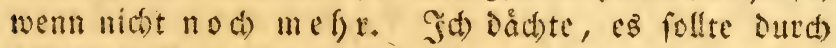
folgende Bemerfang nicht fdwer werden, alfe Diefe Meinungen zu vereinigen: $23 \mathrm{enn}$ wit von Den Beich des Dintenfifdes reden, werden wir finden, Daß fie alle unter einander Dutd cine $\mathfrak{A l t}_{1}$ von Sabronj traus benartig verbunden firro (tweld)e Rerbindung aber naw

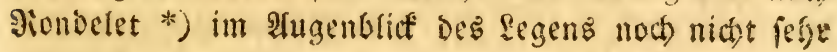

*) Cohaerent inter fe omnia ad fpeciem racemi unicuidam texui obducta; nec facile alterum ab altero detrahi poteft; mas enim humorem quendam emittit, 


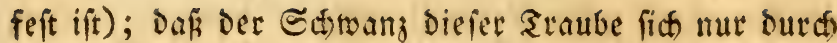
Die Berfiartung fleiner fajerthen, Die ciner feinen Biolinen = s.uinte gleiden, oerdidstet, nad)dem das Mannffen fie mit feiner Samenfeuchtigfeit beneţt hat: und dẩ nun erft Die (Eier fidc vereinigen, um alle mit: einander nut eine einjige diate Traube auşumad)en.

Dis weiblidaen Gebultsglieder unterfdseiden fied vou Den månntidsen durth einen groken Cierftod, Det tief unten im Sact, gerade all Dem geciden Drte fticft *), wo fich Der månnlicte Seftifel befindet. Diefe

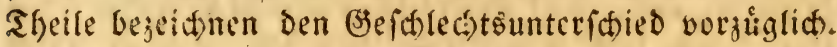
(5inige, felbit fefre alte Edriftiteller verfiderin, Daz

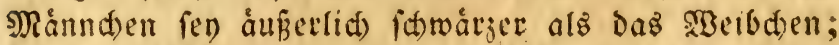

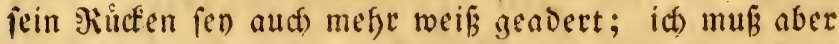
wobl fagen, Dafi diefer linterfated, wenn er anders exiftirt, jefse flein ift. M)tan fiefft bie rundricte form

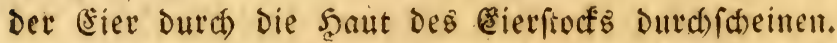
Einige Derfelben find volffommen, andre nod) unvoll= fommen: Denn es ideint, Daj Dev Dintenfiled megr:= mals im Safre lege. Sie fommen ourd) einen ejafu= Iationstanal, ber mitten im lunterleibe, aber $\mathfrak{x}$ d) $t$ s vom Maftbarm, feine Deffinung hat, aus Dem Ciet:

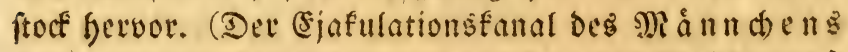
war, wie wir oben fafken, ju linfe n Des Miaftbarms.) Das şabden muß̧ feine Cier wobl alle einzeln legen, Denn fonft formten fie nicht Dutes Den erwáfnten Ranal,

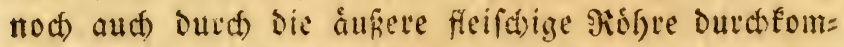
men, bie allen Funftionen bes fiorpers jur gemein=

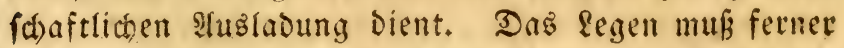
fel)r bejanerlich fern, dem ber Siorper, vorjuglict) Der Saud preffen fict Dabei wiederfolt juammen. $23 \mathrm{enn}$ bie (Eier eben gelegt find, find fie weif mit braun ge=

tipfelt

cujus lentore sibi adhaerescunt et augescunt. Rondelet, pag. 5 v. 5 . de fepiarum ovis.

*) ₹afel 11 . 
tipfelt uno von Der Brófe fleiner Erbien. Das Thier wåflt, um fie ju lesgen, Derter, bie vows alia mit Meergras und Setfáutern beradjen find. Das Mannthen, - weldes fein פBeibcten nie verläzt, lauert Darauf, daßj daz fegen geendigt fenn móge, Dam benetgt es bie Cier mit feiner Samenfeudtigfeit, und leimt fie baburd in araubenform feft zufammen. Seibe fpriţen nun gemeini(haftlid ifgren fdwargen Saft, von bem mir bald reden werden, hbev den Dit

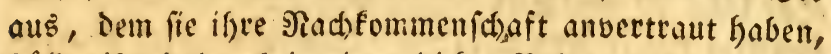

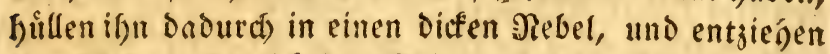

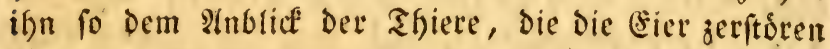
fonnten. Diefe nefmen von Der fie ungebenden feuch)= tigfeit jelbit eine famarze zarbe an. Die Dintenfiface legen bišneilen bis zu hundert CFier mit einem Male.

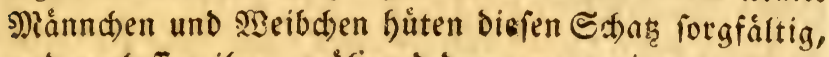
uno verlafien ifn, wåfrend Der ganzen vierzefn ange, bie zum Aนรfommen erforberlich fino, burd)nus nid)t. Sie bleiben als Échirowache in ber Nábe, und vers theibigen Den Ingrifi Derfelben mutfig. $23 a$ afrend Der Beit rachien bie (sier und werden bistreilen fo grofi, wie eitte fleine Şafelnußs. Obon find fie vollig rund, unten aber leidt zugefpibt. Der fleine Dintenfifd ent=

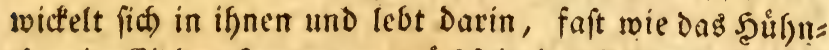
deen im (5i Der Senne; er wáchft in Demielben ourch die

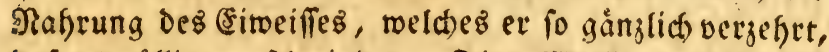

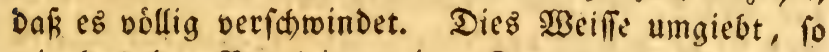
wie Das Der Bogeleier, einen Fetn, an weldsem wan

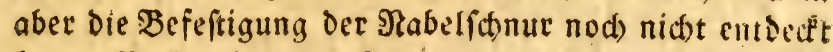
bat. গaud vierzefn Tagen Durd)breden bie jungen Dintenfifhe ifle Şulle, die (sierfanale; gefnn ganj weif and vollfommen gebildet Daraus hervor, und fucten fich fogleich ifre Rafrung. Son nun an íberlaffen bie Alten fie fich felbft, und pflegen der siebe anfö neue.

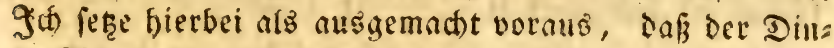
renfile in Den eriten Sagen bez frulglings zu legen ans 
fángt (wie striftoteles fiffe tidgtig bemeift gat), und meltere grale des jufres legt.

Die IIten fowngl wic sie sicueten bafen diefe Traubeat "Mecrucintrauben" * semamt, Gud

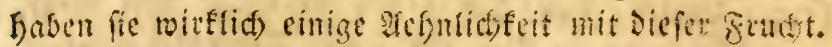

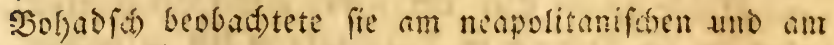

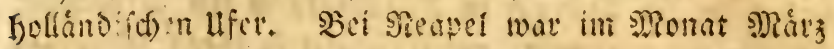

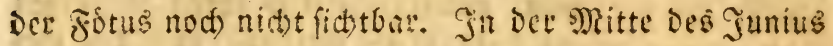
aber fand er abermats Dergleichen (sies, jerfanitt iffe (d) warje Saut, und fah foron vollig entwiffelte Dinten=

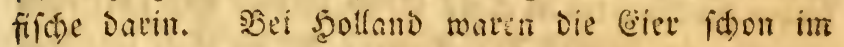

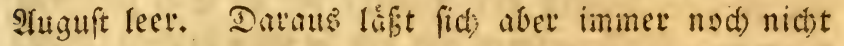

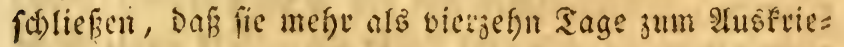
c)en bev Jungen brauden, es fey denn, daf newere Seobactungen dies beftätigten. Dev Dintentifal fádeint vielmefre ufter als cimmal ju legen, und Die झlten vers fidern cinftinmig, dic Eier lägen nut vierjefn Tage bis jum İ

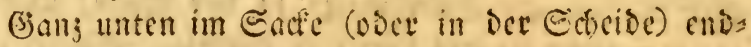
(ich befindet fich, und jwar nach vorne ju, Die Dinten= blafe. SBatm man ifte geringe Cerofe in crwaigung ajicht, fo critannt man uber die smenge Dinte, Die fie ven fith laffen fonn. Diefe Tajde ober Blafe ift wie

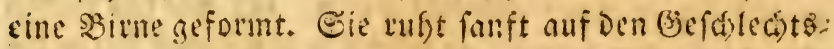
theilar, und befindet fia bai dem $93 \mathrm{eib}$ den gerade in Dev Mitti, bei Dem Monnchen aber ein menig acd ts, soeil fie bei biefem Duref Die (blandel, Die wir Reitifel nosuten, ein menig nad) iev rechten Scite hinúber ge: orucft wirb. S3ei teiben aber endigt fie fich oben in einen fleinen Sanal, bex fich ge en bie shimbung Des Maftoarms zu iffnet. Lluten in Diefer 23 laje bemett man cine fleine feifcrige s)

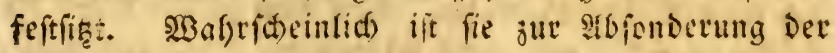
\{throrzen feudstigfeit bejtimunt. Sivammerbam wat

\section{*) Racemim marinum, uva marina.}


nie fo glúflich, fie zerlegen ju fonnen; Denn cine fluth von Dinte quoll unauffortich aus ifre hervor und

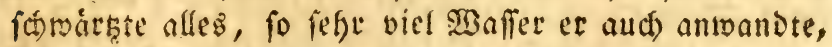
um fie ju reinigen. Deshalb roarnt et benn auth fehr, man moge fid) bei Der Zergliederung deg Dintenfijdes

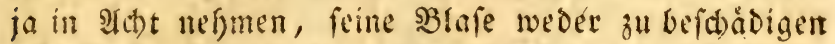

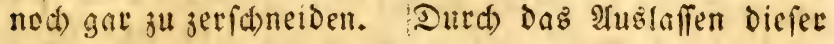
Dinte verdunfelt der Dintenfifd Das șaffer und ent= zieft fich baburd Den Berfolgungen feiner feinde. Sie glauben damn namlitis, ifn ju erfafden, und faffer ftat feince cinc SBolfe; efse fie biefe outchftrichen ba=

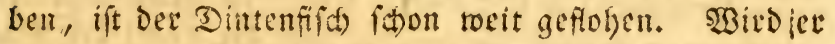
aufs neue verfolgt, fo thut er bas gleiche und entgeft Daburch peinen sgerfolgern fefre oft. Die Dinte Des Dintenfifdes ift unauslof(d) $(i d)$, vorginglid), went

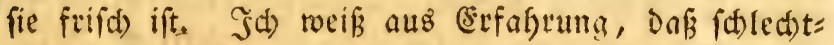
fin nid) ts fie aแs Det Seinewans wieder austilgen fonnte, bie id) Damit gejeid)net batte. Fin todter Dintenfifh giebt vid mefr $\mathfrak{r}$ Dinte, als einer, Der eben erft gefangen ift. (Sin Dánifder Ediffsfopitän, Der mefrete Feifen nad) Sffina gemadit batte, ver= ficherte mir, bie Efinefer fammelten fie ménere Tage

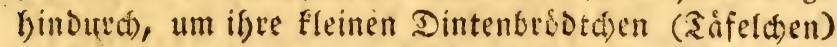
Daraus zu verfertigen; wirfen auch Die verbicte und angel)åufte Feuchtigfeit, Die fich in Der Blafe Des Din= tenfifhes finde, in ßeifmalier, um fie aufjuweichen, fie zu vinem Teig zu Eneten und Die froumen Damit ans zufillen, bie fie mit Beidnungen uno Sarafteren belas Den. Diefe Bróbtcten (Táfelden) *) rerden jeşt vie!

*) Seba, Der in Şolland lebte, und sine s刀enge Edjiffer fannte, bie und) Ehina gereifet waven, verfithert saf: felbe. Jath forteibe hier cime Etelle Diefes Erfuift. frellers ab, Die ç beweifet: - De swart ooftiodische inkt wordt ons uit Japan en Sina medegebracht, daar zy het uyt desen blakfifch in menigte weeten te vergaederen en uit drogen, nevens eenige 
leicht in Europa mef) gefutht als in Efina, benn tB

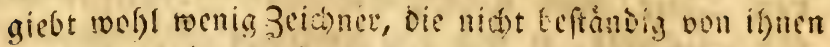

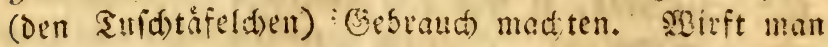

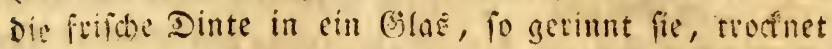
zufammen, und paitat fich, itwenn fie bollig troten ge= worden ift, in fleine sfrilden. Diefi lofen fict) aber im SBaffer twieder auf, und geben eime fefte fobone fawarje farbe. Die alten Sduriftiftler faben uns Beugniffe Daruber zurufgelaffen, daß̧ Die Boomer fich bev Dinte Des Dintenfiliches bedienten, um auf und slergament zu faraiben, fobalo fie groficte şberfe verfettigen wolltin, fie Ea!nten aber Die Sunft Det (5) nefer nod) nicht, cine fefte Maffe aus Der Dinte zu ma= (t)ell. Plinius etwåfnt nod) nichts Davon, dak man fie zum S(t)reiben brauche, fondern et bålt fie fur $D a s$

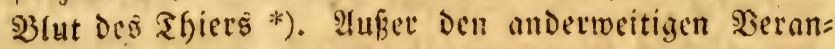
lafiungen, bei welden fid der Dintenfifd feiner fitwar= jell Feutitigfeit (wie mat geieln baben) bedient, ver= brcitet er fie auch oft im sibaffer, um Der Scand Des Gifa)ers und Den $23 e r f o l g u n g e n$ anderweitiger Feinde jul entgelgen.

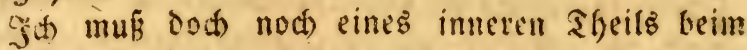
Dinteñifdue ertoálnen, Den bie Alten mutis namten. Sa id trop allen meinen Siardforfangen, nicht habe berausbringen Eonnen, wela e Rolle ex in Der thieri= futen Sefonomie Diefes sholluses fpielt, fo babe ids feine Betridtungen $x$. nid)t bejd)reiben fúnnen. (Sr befindet fid im oberen Theil Des Rótpers nad) Dem Kucfen zu, unter Dem Srid)ter, und ift faft ourdfichtia. IBare cine Siutlymabung erlanbt, fo wurbe id) mit

andere bymengselen in formen zeer netjes met karakters van japansche en sineesche letreren en figuren uit gewerkt waer van einige verguldr, en andere versilveit syn, wordende hier telunde gebragt voor de ekenaars en andere liefhebbers. (Seba, tom. 3. p. 6.)

*) Plin. lib. 9. 落ap. 29. 
Emanmerdam fanen, biefer Sitper erfete die \&eber. Ecine farbe fiult ins Rotgaeloliche, uno die geringite

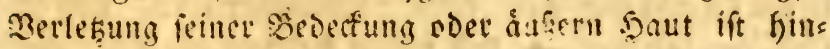
reident, saf $\mathrm{cr}$ fomilat und austicht, demn eine Eubfanj if Durd)aus frinfig. In mehr ale cinet Şin= fictet focint e⿱ bindung fterge. Die Dinte fonnte man etma fur bie

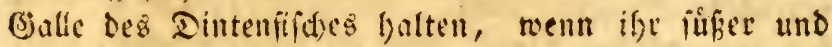
milber Beidunaff $\mathrm{dcm}$ nidst entgegenftande. Sie (id) meft fogar fel)r angenef)m; gemeinialid) múrzt man

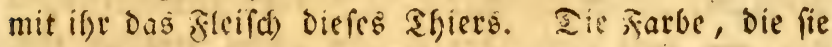
cinem jolden (Gerid)te gicbt, crimnert an tie faxwarge Suppe ber facedamonier.

Ius auffallendfe sennzeiden beŝ Sintenfilides,

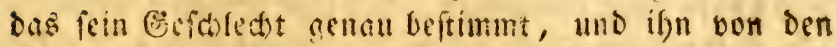
Salmars und stolypen abjondert, ift ber falle = (freide $=$ )

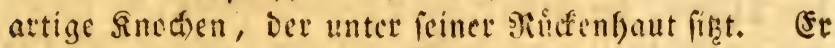

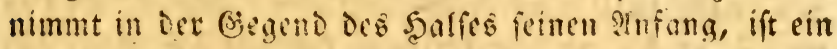
wenig abgetattet, längfial) oval *), uno etftrecft fid bis ans exde bes sorpers. (se ift inmendig, frei und in jeiner bedectung nur wie in cinet Edbribe cingeid)lof= fen. Zu bermulern ift, bas Ewammerdam, der boch

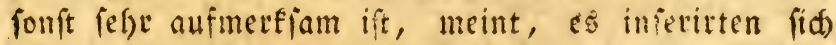
Musteln in biefem finoden, und man fante in ifm Mamififationen von Blutgefisen **). Die Srutgumer Der Alten in Kưffidat Det Mollusten babe id abfict) lich) weniger erwabnt, weil fie feit ben neueren ㅈt= secfungen nicht mefo von Beoeutung fint. Bei cinem 10. áuferft forgfåltigen Seobadter afer, wie $\in_{w a m}$ = merdam ift, und menn man bos, was er ridytig falee,

*) Safel III. Fig. 1 mo, 2.

**) Swamm. bibl, nat pag. 88 r. Hinc ossi musculi sepiae inseruntur. Et ibid prey. yo2. Imo vel clarisfimo insuper observanus, vasa sanguifera in os istud penetrare, ejus. que per superficiem semer distribuere. 
Dantbat annimmt, fo imuk man, benfe id, in Fictfictst

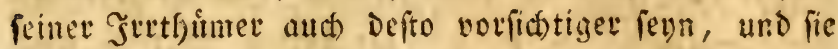
Defto porgfältiget - Der tiefen Sldutung fur ifnn unbe= f(t)abet - rigen, Damit man nicht in Den Jefiler Det fruferen গaturforjher, Die bie Srtthimer wórtlich $\mathrm{CO}=$ pirter und badurd) veretwigten, falfe. Die Inalogie berfufrte Srammerdam. (Si glaubte, Der Snod)en Des Dintenfiictes fonne, wie die Bructentwiebel, nicht

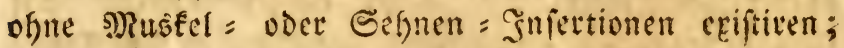
Rlein und andere Anfånger Der Jntus = Susception ga: ben, - weil biefe Joce fie von cinem $\mathfrak{s}$ tetfum jum anbern verleitete, - aud fogat den S(t)altfier = $S_{d}$ as

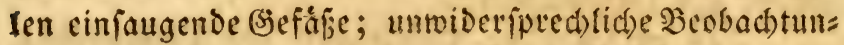
gen Gaben aber Davgethan, Dafi jene Edalen Durd) ei= nen falfartigen Saft, ben bie abfondernden Dirifen

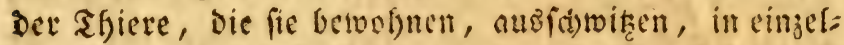
men Lagen táglich an Diffe zuntímen. Gerade eben fo serfillt es fich mit dem freide=, falf = ja faft fpatbarti= gen Inod)en Des Dintenfifdes; mit bem Ilter Des Shiets nimmt $\mathfrak{e r}$ allmåbrict) an llmfang ju, und jwat Dutch áfere fowoht als innece, feht beftummt von cin= ander zu unteridseibende lagen, Die feine Scille tågliç abjeţt. Cit ift Did)t, bart, unbiegfam und vollfommen frei. Sergebens fud)t man, felbft mit Dem Bergrófe=

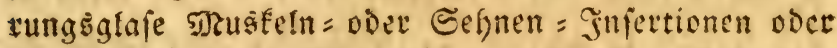

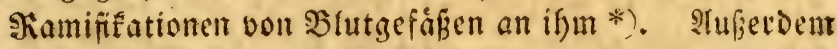

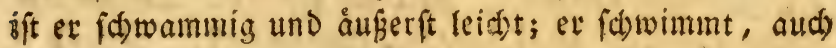

*) Diefer Rôtper bángt Durejaus nifft mít dem Steif(b)e, in weichem er fid befinder, jufonmmen; er foreint cin gañ frember fốtper zu feun, oer etwa von ungefíty

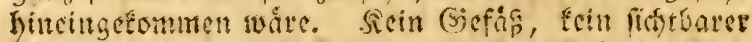

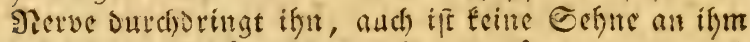
Ecfeftigt. (Cuvior, Leçons d'anatomie comp, tom $\mathbf{I}$.

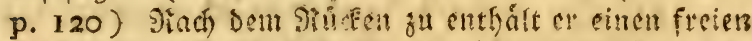
ereibentigen uno forwammigen Sitod)en (Lamark, Syifteme des an, fans Vert. p. 59.) 
wenn man ifft, nod gans feudit, fo cben etft aus Dem Sóper bes gifdes beraus gensmmen hat. SMenn idj suf fein Sellacwebe, und auf fein auferit leidstes

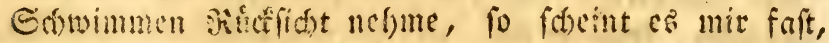
Dafb ex Dem Dintenfifí) Diene, um in Meermaffer zu

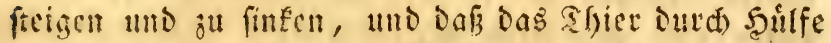

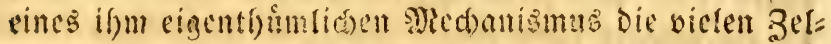
fen Diefes f(t)wammigen Snod)ene wifféthtid mit \&uft a lif itlen fonne, um zu fdimimmen uno zu fteigen; oder bie suft wiedct beraus ziefen, um fid in

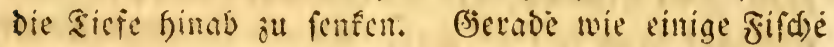
ifge Ruftolai ansocfnen und verengen fonnen, um

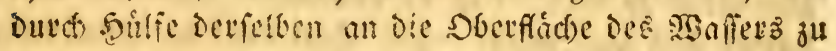
fommen, oder bis auf ben Gisuno dea frluffe untetzufin=

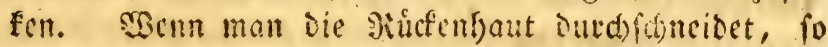

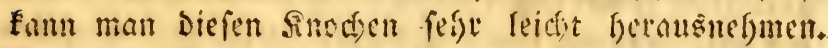
Die obere Seite ift wellenformig, fermig uni fraus.

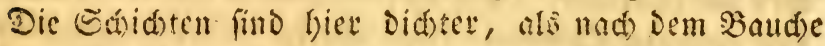
วu. CEs ubergicht fie cine gornartige Edficht, Dic bet Eubfanj Des finnd)ens, Den wir bei ten Sofmars fin Den werden, uto Der cirter Seber oder cinem Dolde

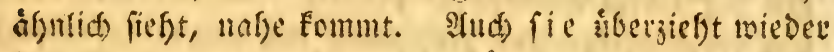

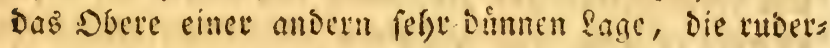
fómig geftreift, rofentoth und von falfartiger Sub= ftanz ift. Diefe orei Sdidten ragen wie frligel iber bie innern \&agen binkus; fie befnen fids gleiofformig

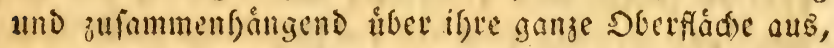
und eine Art von warzenartigem Snopf befindet fidis allf

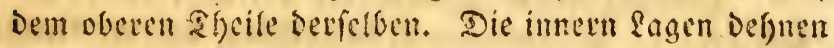
(id) verfdiedenartig, auer geroilbt, ats. Durd) Shulfe einiger Edntte in oer finge uno D.uere fonn man

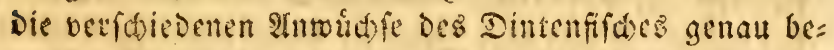
merfen *). Sgollten mir ifm, mit alles úbrigen Edvift=

*) Tafer III. Rig. 3 uno 4. Dic Bcidsmung Funn aber

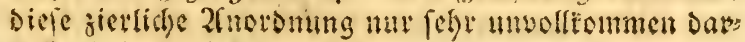
frellen. 
ftellern, nur zroei safyre gu leben geben, fo miften bies fe Inmuid)fe feht biufig und id) nell auf eimander folgen. Sede von biefen lagen, die alle von ocm gleidsen Piutt

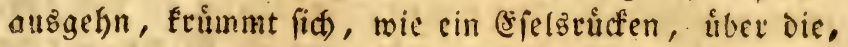
bie fie bedect, und ifgen aegenfeitigen 3rifidenraum füllen cine unjålige Shenas fleiner hohler Pfeiler,

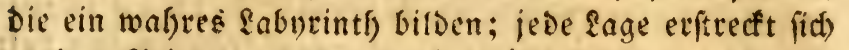
an ben Seiten und binterwalts tober diejenige hinaus, bie fie bedeft, und fo erweitert und verlangert fid Denn Diefer Inodsen, Der bei Dem Ausferiecen bes Din= tenfifuber faum fo breit war, wic ein Etectnadelfnopf, allmáflich fo fefre, dafi ir bistweilen einen und einer Galben gnk lang wirb. Die letste Rage bat immer die fanftefte und cine beinafye fo fanfte Politur, twie das geglattete chinefifche \$apter. Die Sordnung bet Sctid)= ten wirb man am beften gemabr, menn man Den fino'=

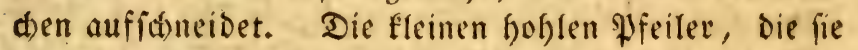
von einander abjondern, fino alle im bofjen (strade jábe, und eben fo freideartig, wie dic lagen felbit.

Ich habe mefrals hundert und funftig folder ?a= gen bei eimem Dintenfija) gezålth, Det Dod) mur einen und cinen halben Fuß groß war; wie vial mahrere muß es nicht in ienen brei uno einen galben fup grofen ge= geben haben, beven Slearius ermágnt, uno bie man auf Den Sanbbinfen bei હd) Eelingen gefangen batte Doer in jenem noth grofferen, Den man bei scamburg fing, und den $\delta$ as $\mathfrak{B o l f}$ fúc ein lmịcheuer fielt *).

Swammerbam glaubte bei ser unterjudyung bes Snodens in Dintenfiche zu bemetfen, baf die fleinen Pfeiler, die die lagen fruten, nid)t turdaus rund,

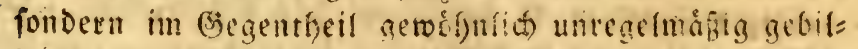
Det feyen, fo Daji ifre ránde, Durd das emae in ein=

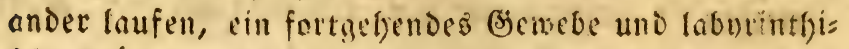
face Srummungen bildeten. Sn Der firt hat ex fie

*) Olearius Cabinet de Gottorf p. 44. 
Denn aud Safel XLI. Fig. 8. Des jweiten $B$ andes ge= zeid)net. Er behauptet felbft (Fig. 7. Der gleiden Tafel), Dab bie Pfeiler Durct Suerverbindungen ifrer săane nach mit sinander verbunden feven. Die ifm

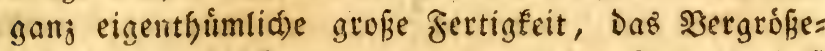
rungsglas geidicft anjumenden, madte freilid), dafiz Diefer berúfmte Mann mand)es entbecfte, twas andern Beobachtern verborgen blieb.

23ienn man die Blátterchen, Die ben Untertheil bes erwályten Sinodens begránjen, gefdict abjondert, fo ftóst man auf eine idarfe Episace, die, borjuglich bei Den alten Zijhen, Die Bafis bavon ausmat)t. (đa) habe Diefe Spitze, von Der meines 2Biffens fein Sdrift=

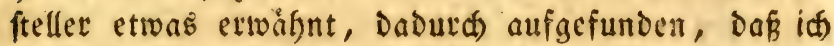
bei meinen Unterfudungen den Swammerdamiden ges folgt bin. Da id) Diefen finod)en nirgends rid)tig ge= jeidnet gefunden babe (novon man fich) uberzengen fann, wenn man safel LXXVIII. Fig. 7. Der (Enens flopabie felbit anfegn will), to gabe id ifnn nach ber গatule gezcidhnet; man fehe alfo safel 1II. Fia. 4. Die Epite, Die ifn innerfalb begrangt. Die (Sriechen namuten Diefen Sinod)en of tracon und cution*); Ifriftoteles hatte ifgn Sepi u m genannt **); Die fran= zofen nemnen ifn écume unto biscuit de mer; Die Deutiden fifabein**); Die Flamlanber uno Sollånder Zeefchu y m t), und die Englánder Cuttle-bone tt). IIn Den fiuften von Solland fieft man ifn ill Menge umbarforwimmen, und bie fa: fdber fammeln ifn auf, um iffn z̆ verf́nfen. Man findet ibn nach einem Sturme aud cuf Dem Sande bes Hfers. Die Boldidmiede vorjiglid) verbrauden jefr

*) Ahenaeus et Diofcorides, lib. 2. cap. 24.

**) De partib. lib. 4. cap. 5 .

***) Gesner, de Moll. p. 186.

†) seba, Toin. iII. et Swanmerd. p. 899.

t†) Borlas, Nat, hift. of Cornwall. p 260. 


\section{8}

viele, um in ber innern glábe deffelben eine M)enge flei= ner arbeiten abzuformen, Die fie Dann mit Der Feile und Dem Speifel teinizen und vollendet ausarbeiten. Pulves rifirt bringt Der finod)en des Dintenfifches bei einigen

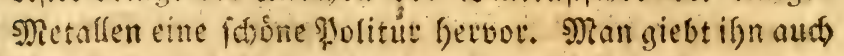
Den Sontrien= und andern fleinen \$ogeln, bie man in

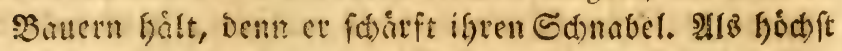
feiner Staub maćt ev aut(i) Das Sauptingredien zu faft al= Ien strten yon Zafnpuloer aนs. MRon fouft baffelfe unter bem Siamen "twe iffe Sotallen" und es ift biel leidt das beffe bon allen. Die romifíchen Damen vers fertigten fich cime S.tminfe aแร Diefem Snod)en; fie lies fen ifn nơmtici) verbernnen, uno evfieltest Dann cine

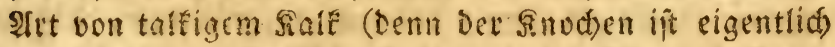
mefr (path = ais rein falfartig); und befanntlid) ift Der Solf nod) jeţiger Zeit Die Scauptiad)e bei ber rothen Sd)minfe. Die ebemalige Irzeneifunde bediente fia

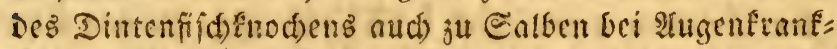
beiten; auch mathte ex bamals Den Sanpttfeil Det $a b=$ forbirenden \$ruber aus*).

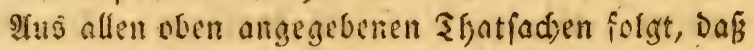
sev Dintenfifeb mit allen Drganen zur Empfindung be:

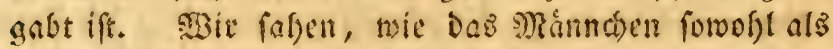

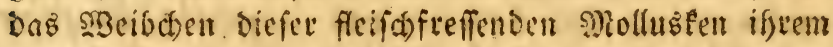
Binube manduetef Sdflingen legten, und thie fie Dage= gen Den Radffellungen iher Feinde zu entgefen wußs= ten. Şit faken, wie ber mannliche Dintenfifich fein 23eibchen, treu und aufmerffam, nie vertießs, ben Beits funft iffes segens bewad)te, uno bie EIternforge mit

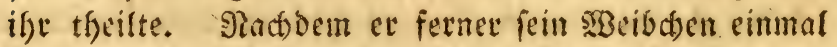

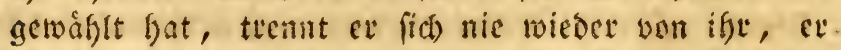

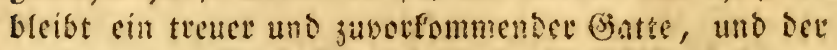
Sud alleit fam dic Bande jerteiken, dic die Einigfete

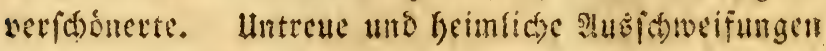

*) Mathiole, in Diofc. lib. 2. cap. 20. 
fennt ex nidbt; allentfalben hin begleitet er fein $23 e i b=$

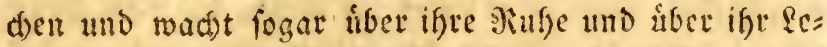
ben. Lum das iffrige zu retten, fetrt $\mathrm{cr}$ das feinige aus.

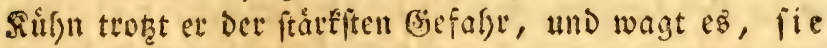
gezen jeden feind zu vertheidigen.

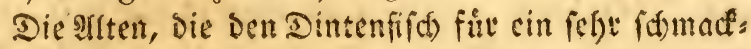

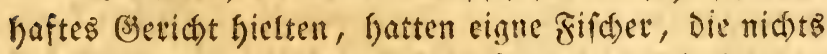
tweiter thaten, als Dintenfifiche fangen. Sie founten alfo bie Sitten biefes Shlets tweit meht als wir beobs ad)ten, und Die Sdrifien ifter beriffmteften Beobach= tev bezcugen, Daf Das Mämd

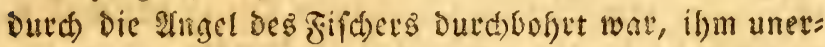

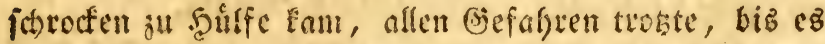
meiftens - mit Demfetben umEnn. Bei eine: Droben=

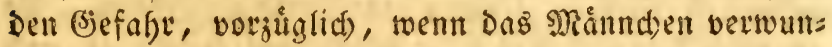

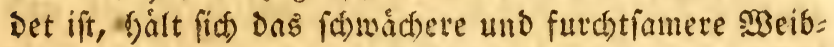

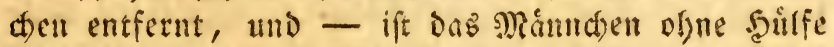
verloren, fo flieft jents, fo weit es fann. Es ift faft bei allen agieven fo, vorgigfici bei ben vietfurbigen,

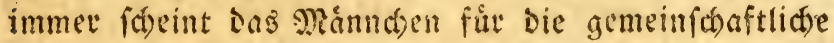
Bertbeidigung forgen äแ miffen; ja, bei einigen grofis

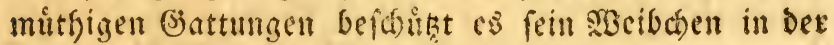
Эieger mit feinem eignen §órket.

23 en man Den Dintenffich aแร bun 23 affer nimmt,

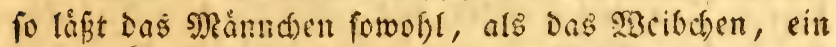
Grunjen hơren, Das Dem Grunjen Det Ed)weine nafe fommt. Das ift ifs: Todrsgeficter. Sic fterben faft

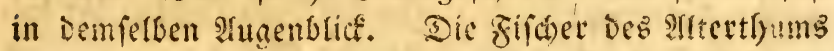

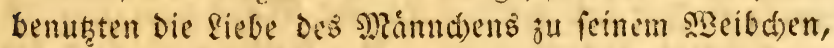

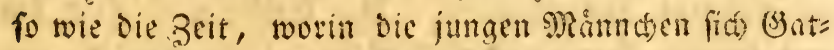
tinnen fud ten; fie banden namlicí) einen weiblidsen

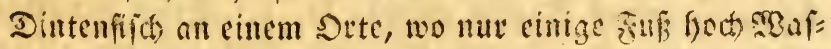

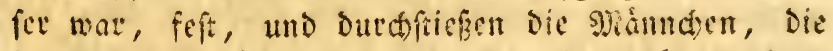

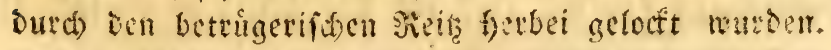
Indere Male taudeten fie cinen metalfenen mit frobs eingcfoften Epieget ins sonffer, und betrogen ouf Diefe 


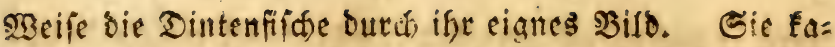
men hetbei, uno - fielen in bie ミetęe, bie man ifnen geftellt hatte*). SMenn bie Filicher etra nicht in Det Siake fern fonnten, un bie herbei fommenden Dinten= fifure mit dem Dreijacf zu Durdjitopen, io legten fie if = nen fir treuten. SBaren fie einmal bineingenangen, fo eridopften fie igre Ruafte nergebens gegen Den forb, fie fonnten iffe Arme molsl barin vermiffeln, aber den Ausgang fanden fie nid)t. Die fifher Der Damaligen Zeit berciteten fogar Şóblen und felfichte 23 infel, die mit Meergras angefuilt waren, zu, um Den Dintenf = iden einen zum eicrlegen bequemen Dot zu veridaffen, two fie fie Dann befto leidyter fangen founten.

Sic glanzen im Dunfeln, und geben, wie viele andere Siollusten, einen phosphorifaen Sdrin. Sn gewiflen făllen ift Dies gid)t felbit zientich lebhaft, und id)eint nad) sem Sode des Ifiets eine zeitlang zuju= nefmen, vorguglich wenn man es offnet, und peine in= nern Theile entolofit.

Die Dintenfifhe - jest freilich hat der \&urus fie von ben plád)tigen Infiln verbant uno fie Der Dutrtigfect úberfaffen - waren einft, nebit den Sal= mars und folupen ein fefre lectetes (Bjeridft bei den

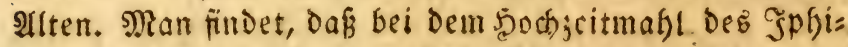
frates, Det bie sodter bes sónigg von afrezien, Cotns, feirathete, நundert Dintenfifdse auf bie finigl. Safel gebrad)t wurden. Wantricteinfid) rar bies ein grofer Afufwand, fonft håtten Die Edriftfteller ber Da=

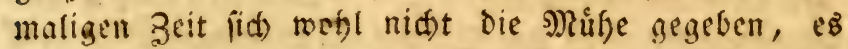

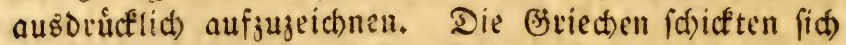
am funften Sage nad Der Geburt ifrer Simber, efe fie biefen einen Namen gaben, bei der feier ber $\mathfrak{A}$ m phidromien **) Dintenfifche zum (seidsenf ju. Det (3efdumat hat fid aber feit Der 3cit fefre rereontert;

*) Oppian, Halieu lib. 4 .

**) Aiher. Dipnos, lib, 4. 


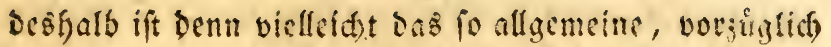

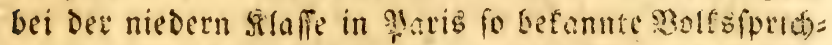
wort entitanden: "man fat mit Dintenfifhe gegeben" um zu frigen: Inan bat mir nidts gegeben. Die Brieden madten fo vie! aus den Bintenfifonen, Daf nad Den Zeugniffen aller Sstriftiteller, Die Diefer Sfiete erwágnen, feine gute Mablycit ofne fie gegeben werden fontte. Bon Dem berichtigten Diegemes er:

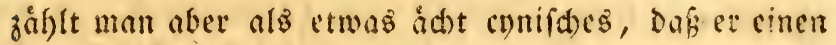
Dintenfich vollig rof verzefytte *). SBiclleidst serfuchte er inder nur, ob er fids aud ofne setrer bebeifen fónne.

Die giomer affen bie Dintenfifte etenfalls als

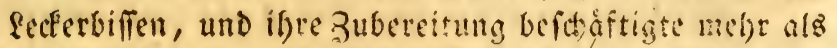
einmal bie ganje Fumft dev Iplituffe jener Somptifadt

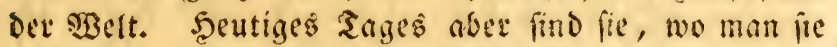
mur findet, Dem gemeinen Bolfe tbellafien, das fie abev ebenfalls verad)tet. Sinige suftenbemofner bes abriatifaten Meerbufens nåbren fid indeb́ jl: gemiffen

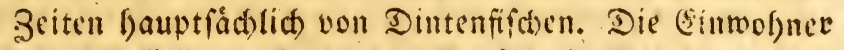
orn Sloffella 3. (S. In Der Brafafichaft Eebenico, die Fortis als bie allerfeigeften Mlenfiden befareibt $t$ ),

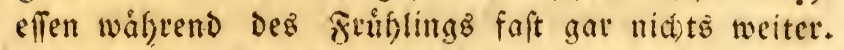
Sie fangen fie Dadurá), Dap fie Syoljbundel mit Baum=

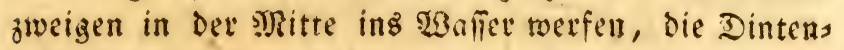
fifde fommen Dann bahin, umilgre Efer Darin zulegen.

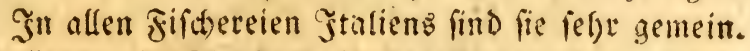
Jut Solland, in Flanderi in Der Normandie, und in Gingland if man fie gar niát. Sn Den ?ándern, wo man es thut, flopft man fie frarf; und briflet fie in

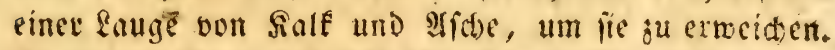

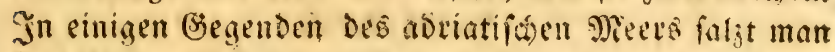
fie inder auch cin, um fie nad) ミenedig, nad) (5enua

*) Plutarch. lih an aqua iqne melior.

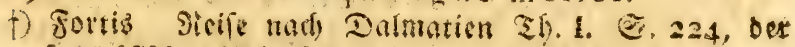
fremzorititgen Heberfergung. 
ullib nach Bom zu fhicten, wo man fie als zajtenipeife geniefit. Die bejte zeit, fie zu fangen ift im Sanunt,

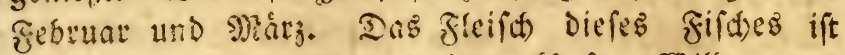
leberartig und von S?atur unfímactfoft. 2Sill man es

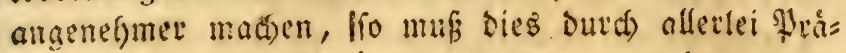
parationen und Geminge cristungen meroen. In

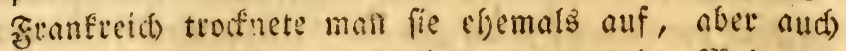

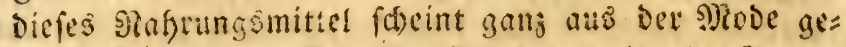
fommen zu fern. Die siet fino harntreibend. In bet \&anguedoc anent man fie: raifins de mer. Die

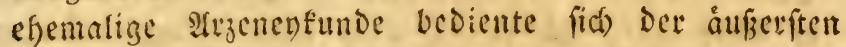

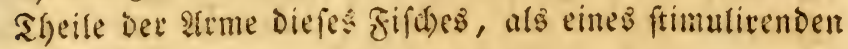
Mittels.

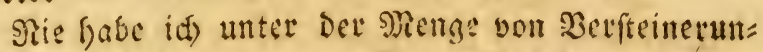
gen, Die id false, je cinen Dintenfilibfnod)en verftei= nert gefunden: und Dod ift Dies s)?olluse foft in allen unfern soleren verbecitet. Sich fenne fogar feine cin= zige Derfeineruny, bie beftimmt Dem Dintenfifd zus geforte. 53 of riderinlich exiftirte er, mie mandse andere Tfiere, ju einer gewiffen వeit nod) nicht. $23 e n n$ vom Ralmar die Rebe feun wird, werden wir cinen verftei= nerten Sisper unterfuchen, in Dom man einten Sheil yon Dem Dintenfifd)idnabel zu erfennen glaubte.

\section{ErtElårung Der Siupfertafeln.}

\section{Exfie Tafel.}

\section{Semeiner Dintenfifa.}

Figue 1. 2Anficht von vorne.

Figur 2. 2्Anfidt von binten.

\section{3iveite Tafer. \\ Meiblidjer Dintenfifid) (geoffinet).}

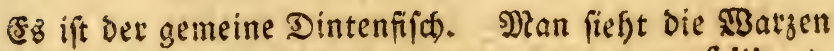

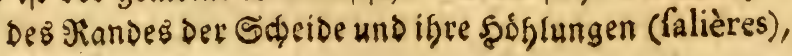


Den Sridter, bie Siemen, Das sprutis, icu M)?uno

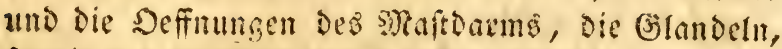
fo wie ben Gierftod und Die Dintenblaps, i is unten im Girunde des Sacks liegt.

\section{Dritte Tafer.}

\section{Der Thu丶tenenodjen bes. Dintenfigdos.}

Jig. I, Anfidst von oben.

Fig. 2. SInfict, von uitten.

Fig. 3. (Einfdunitt ber Lănge nad) (coupe longitudi-

nale). - 23 ent man von doen anfängt, fief) man Den allmáblicten IIntoutgs.

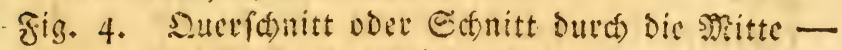
zeigt bie Dife der ritienplatte (lame dorfale). man fieft bier, wie in ber vorfgergehmen Jigut, Die Eage biefer झlatten fo geftelit, Dor dic cine bie andere bedecft. - Eeben fo Die Stelling Der flémen

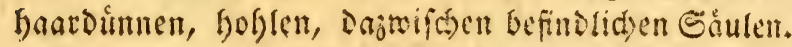

\section{Bielte Tafel.}

\section{Sthnabel, Eier, Samengefäbe, uno Samenthier:} den Des Dintenfifdes.

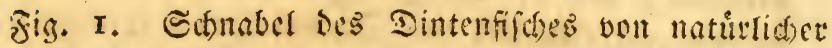
(Grópe. Man fieft fier Den Sber= und lnter= (d)nabel.

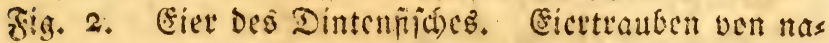
thrticher Bróbe, Denen man auf uniten Siuften Den Samen Sicer = (Shein $\Rightarrow$ trauben giebt.

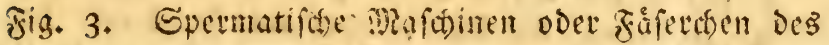
månnlichen Dintenfifhes. - Infít Dutch Das

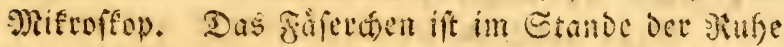
uno enthålt Die idnedenformige Epringfeder. Eso ift aud mit jeinem Faden verfeben.

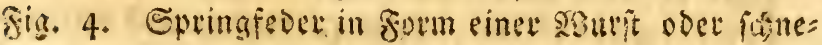


denfórmigen Epringfeber; ofne ifre Edgeide, ift gam geringelt.

gig. 5. Fofferden, ober Samenmaiffinen von natits

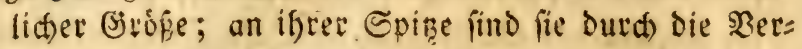
rebung ifter froben cine in bie andere gefugt. IIt ben $\mathfrak{B} a f e n$ beider fieft man bie Epringfeder, Die

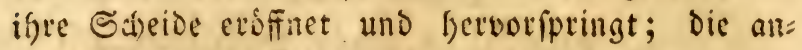
Dern find verfolofien.

Fig. 6. Samentfierden ber smild, deb mánnliden

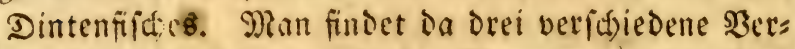
wandungen, die aus diefen Tfierden wagre Ptos teuffe madien. Sic gehoren à Dem, unter biefem

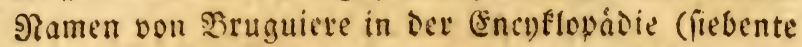
fieferung oer Selmintfolnaic. S. 2, Taf. I. $\mathfrak{A b}=$ theilung oce spitte) eingefutfrten (अefdicd)t. Bor:

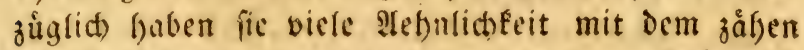
Wroteub (proteus tenax), Den man gewófnlid in Den slü und ভeeraffern findet.

\section{Junfte Tafel.}

\section{Eier bes Dintenfijches und bes Ralmars.}

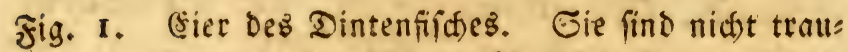
bentreife, twie die deŝ gemófnlichen Dintenfifhes, fondern um eine art von Stamm forum jufammen geleimt. Sie bilden mit ifm einen Tarfus. Dicfe (Sier fobeinen einer fremben Battung von Dintenfi= fhen jujugefóren. Bruguiere fopirte fie fưr die En=

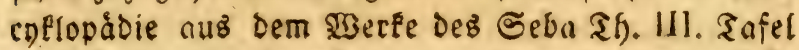
3. Fig. 7 und 8., roo man zrei verichiedene (sat= tungen Davon, bie fict einander aber burch ifre (Fin: ridftung fehr nåbern, vorfindet.

Siba hatte in feinem Sabinette aus allen viet Erdtheilen Produfte zu\{ammen gebradt, unt Doch zeigt ex Diefe Eiet bloßs unter bem গamen "Din=

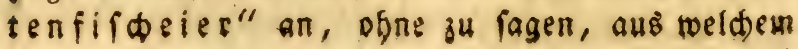


Sande fie fommen und vont trem ef fie erbalten bat; fider find es feine sier bes gemófntidjen Dinten: fifices.

Fig. 2, Ralmar=fiet. Die langen Fafern oder fă ben, auf ivelden bie und Da no(b) vollfommen rutide (Eiev zerfteut fimd, geben ung zu erfennen, dafzes Ralmar = Fier feren. Sas Gonze hat aber viel gelitten. Faft alle (sier, Die bie runde Nafie ausmad)ten, múffen verloren gegangen fetr.

In Fiuffict ber Drommin der Falmar = Eier vers reife $i$ d) meine seier auf bie zefnte \$latte im ztweiten Sante, und auf bie Dortige Erflàung Derferben.

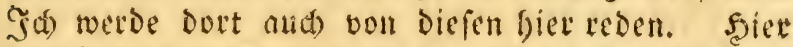

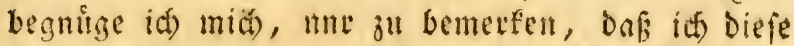
Beid)ming nad) Der ies ambrofinus *) in feinem

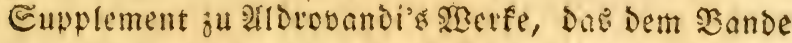
"von dell llngefeuern" folat, gentamen babe. And ex batte biefe 3cichnung nat einem stiginale fopirt, Das cinen Sfeil der Cammlung Des Nu:

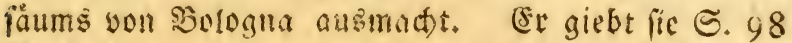
fủr fhwarze esier irgend cines frithes aนs. 23 ent bon Dell falmars die gede fern wird, werden wir

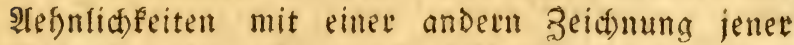
Sammlung bemerfen, und é fonnte - nach allem zu urtheilen - wohl lenn, dás diefe raer bier Eier vom netzformigen Salmat feren.

\section{Der geflecte Dintenfifich **).}

Sn Det vorzuglid)en unb ungehener grofen Samm lung Des naturfiftoriffen Mzufaums in Paris exiftirt

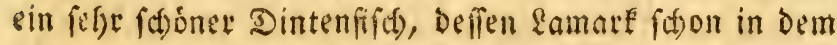

*) Ambrofinus, Paralip. in Aldrovando, "p. 98. edit。 bonon.

**) Safel Vs., wo er mit Der 2 mplutht fehter beiden Esis ten vorgeftellt ift. 
Memoive itbet bie veridesenen Gerdelecter Des Dins tenfifthes, des Ralmats uno dez \$olopen *) (ङ. Die Eammlung ber Memoiren Der naturbiftorifaen Gefell= f(d) aft vom Jafr 7.) erwadnte. Diefer-gelefrte uno

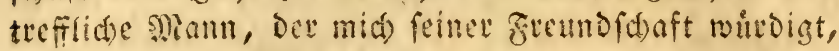
ift gittig genแg, mix in Den Gallerien deś mufăms Das Zeidenen bex bout befindiden Snbivibuen auf alle

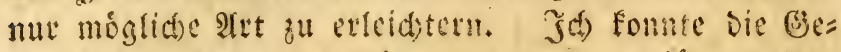
genftande alle in bex slabe fubicten, wofur id ifm Denn aufo neue Cetenntlicheit fátuldig getworden bin.

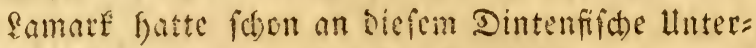
fafiede walyegenommen, Die Earafteriftift) genug was rell, ifst von dem gemeinen Dintenfifée abzufondern. Da el aber nidot tibercilen wollte, fo wagte er es nod) nicht, eine nete Battung Daraus ju maden, und ver= fand ifu alfo licber nod mit ber vorfergehenden, gat

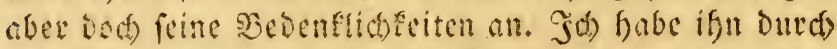

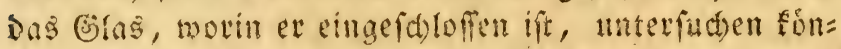
nell. Beim geidonen mufte id) úbervieg feine formen genau aufofien, uno glaube, farofteriftifo sigen= tfimlichefeiten genug an ifgm grimben gu haben, um ifin mit $\Re$ edit bon Dem gemeine Dintenfifal abfondern, und eine zweite Gattumg bon ifm maden fu finnen. Sei naferer Sergleidung beiber wito fid finden, ob ich

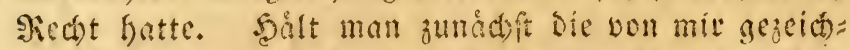

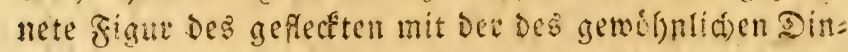

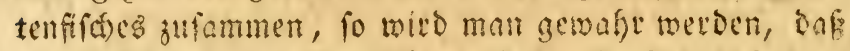
bie sirme bes geficeften furzer find ; fie find anf igre:

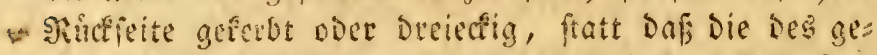
meinen sintentiffes ano und platt find. Sene find atch) pisiger nis siefe. Die Alme, Die fich bei bem gefecten mit ciner $a c u l e$ inden, find sud nidst folang; man fieft $e$, fie find weit ftáfer und firrger, befonders wern man bedenft, Daf Der singel an Raum mid) ver=

*) B. eadem? cotyle donibus brachiorum conicormn biferialibus. p. 8. 


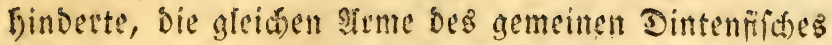

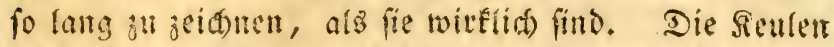
Diefer Gattling find and nidht platt, wie die bei votis gen, in Gigentheil fir find geferbt und zeigen anf ifs

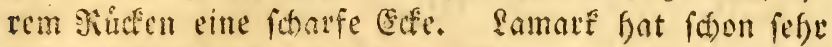
richtig bemerft, Dafí Die furan arme nur mit zwei Bici= hen von Rapfisen bewaffnet fimb. Diefer Saraftet nafjert fie Den Prmen ciniger \$olnpen, bei Denen wir Das gleide finden werden, fatt báb die des gemeinen Dintenfiffes - wie wir gefefn baben, - mit mef)= veren 9reifen befetzt waten. Die Saut, ja ferbjt Das ffleific) $\mathfrak{r a z e n}$ itber bie Seiten ber beiden Beifen won

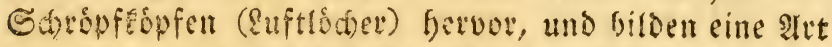
von Pefre se?afnter faft fägenfórmiger abfaltung Drum Gerum. Die Saut, die Den Mund umgiebt, und die

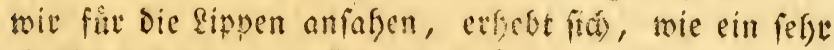

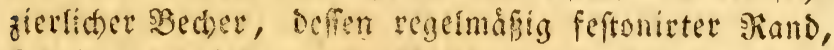
fid) in verfiblidencin Salbereifen anszact, in Dewen Mitte Der Sdmabel verborgen liegt. Die Augen find Durd aus nidit weit, glimzend und ftrahlent, fondernt im Gegentfeil wenig bemerfbar, gefdilo und fait verlofden. Diefen Sarufter werben wir bei sem befes rigen (fnolligen) Dintenfint) miebenfinden, bei Dem Die - Sugen nod unidjeinbaret find.

Der Mantel ift bei Dem geficesten Dintenfita) nidt fo, wie bei bem andern, begrangt. Etatt Dan felle Begrånzung auf ser Gite und nm obew Theil Dex Scheide boer Des Gacts feinen Infang nebmen follte, fingt fie unter Den Slugen, nuf ber Eeite bes \$alles und in ber Diffe Des łriffens, an, unt breitet fid Dann in einem Salbgurtel meit uber Die Єriten Des Sov: pers aus, und ftreift Den unteren Ifell Defieloen, wo

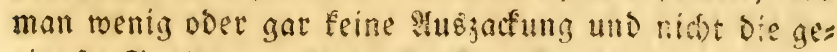
ringfte Spalte gemalgr twird. Ser Bauch it audi fómas

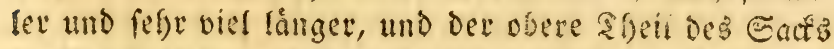
theift fict in Drei grope und febr regermagige IHsfanit= 
te, fo wie man fie in set fierbei berindiden Beidnung fieft. Das Gange Dicfes Dintenfiches ift im allgemeis nen viel iftanfer uno langlider, als Das Des gemeinen, Der firrot uno georungenter ift, und aljo plumper uno fdumerfälliger erfocint. Seine Saut ift nid)t bleifarbig, fondern sie!meferefenfarbig; fie if and tociber, elget gefect, alŝ getigett soer punftirt.

Dic Siapfoen ber Rlftroder (Edropftopfe), womit Die :Trme verfefon fino, fideinen mir glatt; ids Denfe fiberfaupt, Daf toofl mu ben falmars vorjuglid jene ginge nit fnotpeligen, gejafnten und hafigen Bian= Dern, jufommen, sie Den Girab Der Stärfe, momit biefe Sficte igren Fanb fefthalten, nod vermefren. Der Dintenfif if ein fried ames Sfier, menn man ifn mit ben sigtopen und andern furd)tbaten s)? vergleid)t.

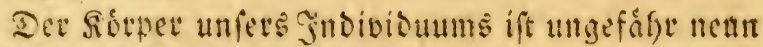

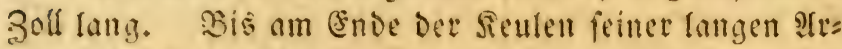
me mift er viefleidt Sos Drpperte. Die beiben Bei= ben Pabfen, fene fleinen, verlojdenen Sugen, uno

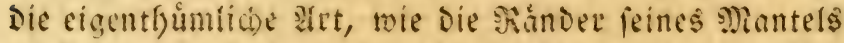
entitefun, - fie jetgen fid namlich faft wie Die Der sala mars an, - folenen mir die lnterfdeioung Diejet

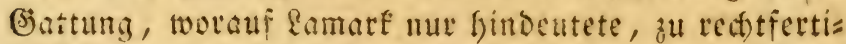

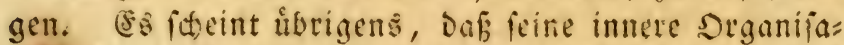
timet fich Dex Des gemeinen Dintenfifues niffere, went man anterś nach Der åusern Geftolt, und nad Der Sage Des aนร์futhrenoen Sinals urtheilen Darf; verfichern fann ich es aber nitht, Denn ict) fonnte blop peine åubern Frormen beidreiben. Dies gnoividum ift in bielet fonft grofien Gammlung einjig, eŝ wat mir bafjer nitht erlaubt, feime Singemeide und intern Tfeile ju Durd)= forfiden.

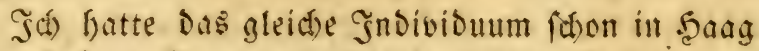
in Der idonen Eammlung Des Damaligen Erbftattfal=

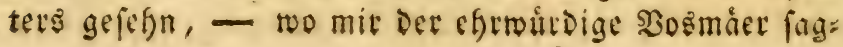




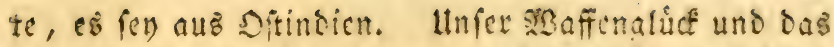
fogenanute Sicd)t Der (Evoberung braci)te jeries Siabinet in unfere sauptfadt. (Fs befindet fid mit in ben salen

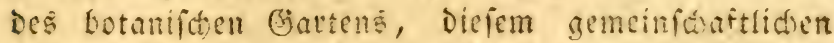
Mittclpunft Des Etabiums uno Der SBrobadtungen fur alle Plationen - Denn fie fino unjonfi fur jedermann

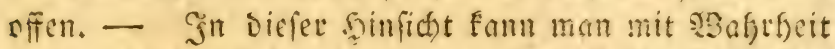

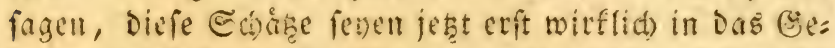
bet Der Milienfdaft libergegangen; oft, fefgr oft, fonnte Diefe vorfer fie nidstutiten, reil bald Der Fi= genfinn, bald die Sabjuct)t Der Sifffefer oder Unterauf=

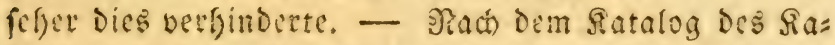

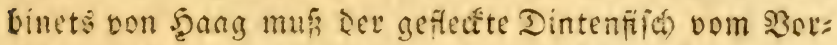
gébirge der guten poffrung gefommen (e)n *).

अlle meine Siad)iud)ungen, toas etwa Dic Ed)rifts

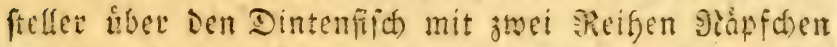
gefagt gaben mósten, find verigebens gewefen. Já) habe nichts befriedigendes gefunden. Der einjige

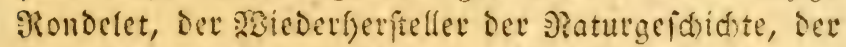

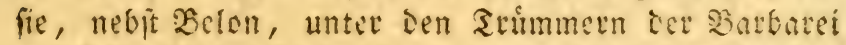
Des Mlittelalter's wieber herborjog uno neu belcbte, bat einen Dintenfifich gejeictuet **), an Defien 3 (rmen man nur zwei Reifen skapfden gewahr wits. Unterjudjt man Denfeiben aber náber, fo mettét man bald, Daf es

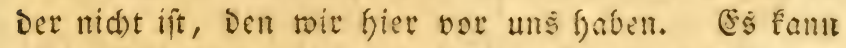

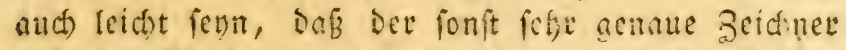
auf Diefe Igeile menig geachet hat, Da fie Damals Die stufmerffamfeit ber secobachter diberfinupt nicht auf fid

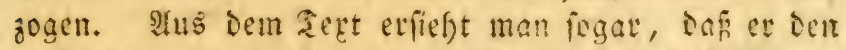
gemeimen Dintenfifó), D. F). Den ies adriatifen Mecrs vorftelfen wolite. Sb nun gleid bic gelieferte Fisur cinen Mantel fat, ber an feiner $\mathfrak{B}$ afis und an feinem Banbe Durch cine Scoflung begrangt wird, Die in iffer

*) No. 94. Vol XII. F. Nanufcript in Der Biblisthet

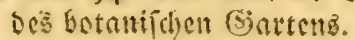

**) Rondelet, Aquat. I. p. 498 et 365 . 
Ditte mit einer Spige verfefit ift; fo reben boch alle nach herige Naturforfote von Dem gemeinen Dintenfirot, uilo citiren ju gleidjer 3 cit $\mathrm{Da}$, two fie biefe פenennung gebrauchen, die erwainte Zeidnung. Berabe eben fo

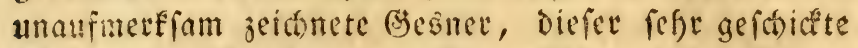

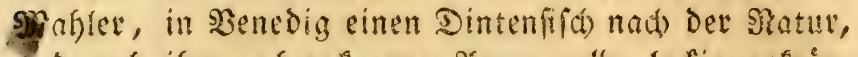

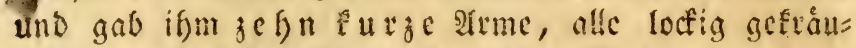
felt, fatt Daf Das Ifier, bns er vor Ifugen hatte, if = rev Dod) nur ad)t befaf. (Beşnev mette binterber fein Berfeigen, und madite es ben sefer in ber linterfarift anter feinem Supfer beÉnnt. Der Baturforfore Darf

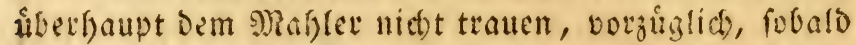

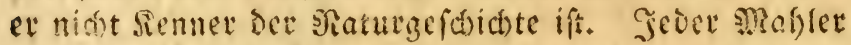

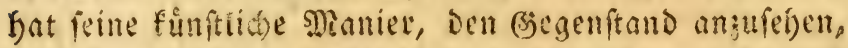
ev oronet und vertbeilt alles maflerifá). Qiá)t und Sd)atten, Inzahl uns Stellung, alles mus fich narb

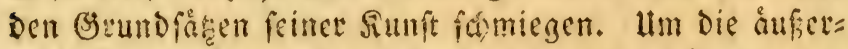
ften Sfeile oder andere fleime Details betumert $\mathrm{et}$ fich cben fo wenig. WBie fónte fein Genie fich cut:

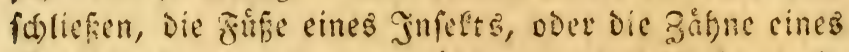

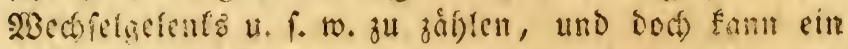
guter shaturforfder aud biefe sleingfeitin niot cuts befien, wenn er fith anders zu prilofopfifden ?anfich= ten unb crbabenen Şegriffen, bie Das grofie Ëanje al ler flenen fofta ifm einfofft, erfseben will.

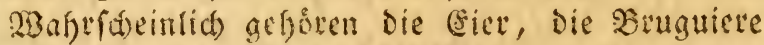
in bet (Encyllopaide (Sofel LXXVII. gig. 8.) fted)

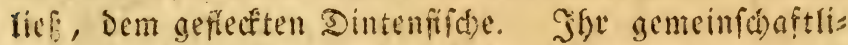
der Stamm ift an beiben (enten abgefdnitten, uno'

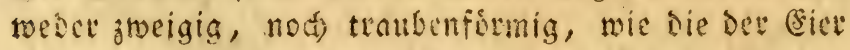

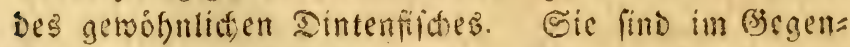
theil un einen faft bornattigen Mithtelpunt, ben fie bidet ungeben, meil fie ùber einander gef)ăuft fimo, gruppir. Da fie nue galb fo grón find, alo die des

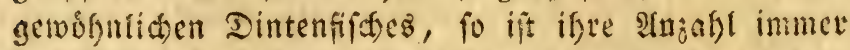
betrå(t)tić) und fann fid) leict) nuf zweifundert belous 


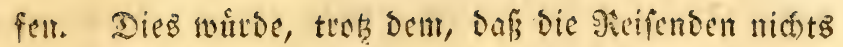

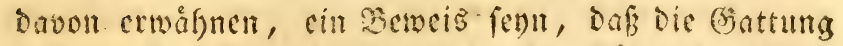
Des guedeten Dintenfifuces fich an Den Siffen Des filoli= d)en strifa's wenigfens chen fo fefte vermefyt, als die unfrige an ben Suffen des Sjeans. Butguiere batte bicke fict nus bam Ceba fopit. इafel V. Big. I. findet man fie.

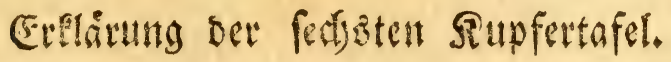

\section{(3)effectet Dintenfî́t).}

Pnfidet won oben und bon unter. Man muf finters

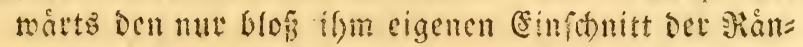
Dex feines Mantels bemerfen. Cincn folden Bin= idonit finder man weoed bei bem gemeinan Dinten= fifch, nod) bei bem foucterigen, ber mun folgt. Diefe ganj cigentfimlide Gejealt nibert ben geflectem

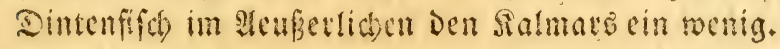

\section{Dep bૃäcrige (Inollige) Dintenfifón *)**) ***).}

Die netern Sicifon und ber in unfent angen mefre

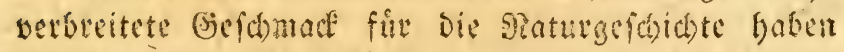
uns fdou oft (segenftande verfdeffe, bie Den alten

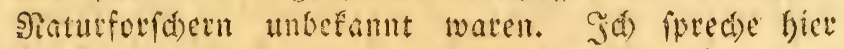

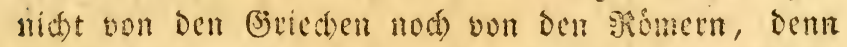

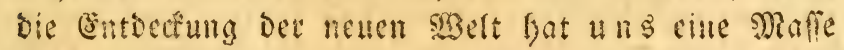

*) Şzóferiger (Enoliger) Dintenfifa. Sepia tuberculata. Sepia dorfo capitegue tuberculatis, brachiis pedunculatis breviusculis, offo dorfali 'patulato. Lamark, Memoires de la Soc. d'hift, nat. de Paris, Jabre?, ธ. 9, Tafel I. Fig. I a, b.

**) Vremd Knobelige Sepia, van de Kaap. no. II2,

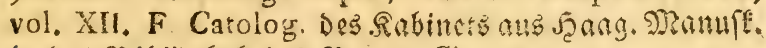
in Der bibliotye bes Dotan. Sortent.

***) Sepia tuberculofa, L. A. G. Bofo. Hift, nat. des Vers. p. 45. Vol, I, Deterville, Janft 10, 
von Senntniffen dorgeboten, wozu if nen fogat bes Zugang verfd)loffen war. Seffnet man aber bie :3etfe unfret Beobadyter jener Gegenden, fo erftaunt man bis=

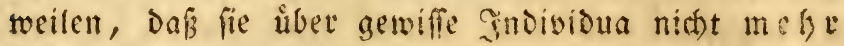

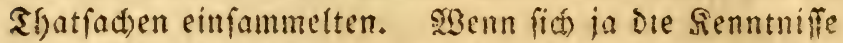
Diefer Art fehr ausgebreitet baben, fo geforen zu Den Urfacten, Die Das Ėtudium berfelben erleichterten, jene fdónen Samminngen uno Sabinette, Dic fich soirften, Bsefellichaften, und einize reiche \$artifuliers um bie 2Bette anlegtell, und dadurd ifr beld und ifge $\mathfrak{B e}=$ muffungen nưthlid) anwanten. Sie iwugten bei cini= gen Sdiffern die Niengierde, bei andern bic Riebe

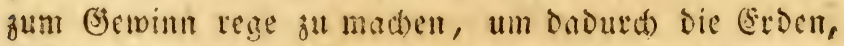
Shiete uno \$inamen anorer Erotgeife zu befommen. Uno fo ergieften wir oft unbefanate Dinge aus fermen Meeten und fandern, um unfere naturfiftorifaen Eammlungen ju vermefren unt ju verfobonern. Seit Ariftrteles bis auf ung berab findet man in allen Edriftitellen itber ben Dintenfifit) nur oon eince cin= zlgen Sattung Defferben Die Befdidute und Befidreibung. (E) war Dentbar, Dof Dies SMollust nid)t fo cinfam uno allein in feiner battung cxiftite. Die Natur jetbrid)t ifie Formen ja fonft fo fdutell nidft. In Der Regel nitancirt fie iffe Naterie noch, uno veratbeitet fie auf mefrerlei Irt. Sie thut nie Springe, gewólnnlid)

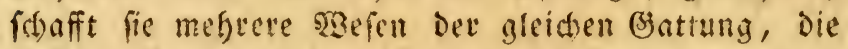
genou untereinande:, und mit ien Sfieven verwander

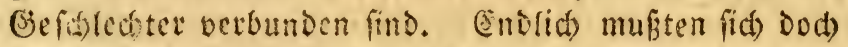
einmal Dintenfifie finden, bie man neben bem gentei= nen feflen fonnte. Somatf madite ben, von weldem wir reden, zuerft befant. Ce epiftirte fas feit cinis gen Gafeen in Dem Sabinette bes grumzen son Dranien. Dies mutde bam in unfte Sale vetphangt, und fo ge=

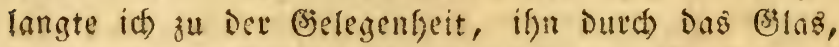
morin ar cingefuloffen ift, zu jeiduen. Die fiebente

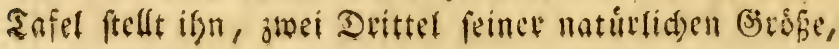


bat. Cु\& exiftiren zmei šndivibuen bet gleidien Bats tung, Die beibe genau gleich gebaut find, woraus fich

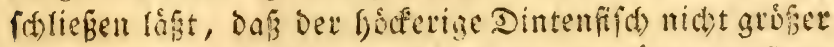
wirs. Det unfige if: Durdjans von ven ubrigen Gat= tungen abgefondert, uno wegen feites furzen, gedtuns

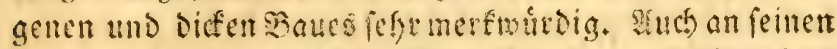
Itmen etfent man Diffon Sauptorofter; fie find furz und Dide, und auf ifger platten Ecite mit viev Meifen sapfonen verfern. Die beiden, bie fich retlenformig enden, find glatt und farte, aber faum balb fo lang

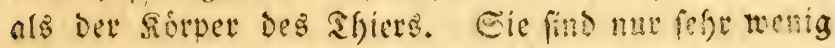

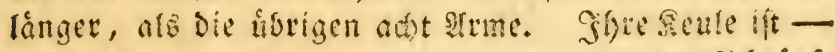

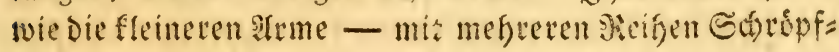
fopfen serfefen. Die adt fleinen arme find nidts Durd)aus fo gevomet, wie bei Dem gemeinen Dinten=

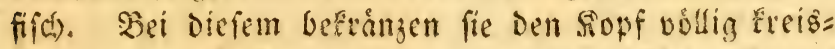
formig, und lallen jwithen ifren Grundfiaden feinen Bwifchenraum. Bei unfer neuen battung abei bleibt - ftatt cints vollfommenen Fueifer, - ein stwifacen= raum zwifhen den beiden armen, Die fić) untethalb Des Gopfes befinden, fo da man Den Mund des ahiets felon fann, olne fie erft wegnefomen zu muffen. Dev Sd)mabel befindet fid) mitten in einer 2 trt von Tricher, ben Der freisformige unfang Der \&ippen bildet. Sie find viel bicker, als bei ben andern Gattungen gemónn= (iid), und ftatt fich, wie eitt 3 eutel $3 u$ follisigen und ju= fammenjuzichn, find fie etagentocife georonet, und in fleine perpendifulåre furden gefaltet, bie cine Menge

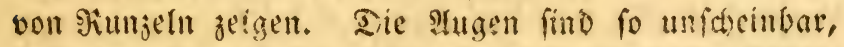
Dafi man fie auf Den eriten 2inblicf gar nidyt finset. Sic ftefln auf Dem Seintertheil des Sepfes, aber nidht zur Seite. Dev Sopf itt ebenfalle megr abgeplattet, s!s bei Den ibrigen Gattungen. Stud Der Sorper ift nid)t fo lang. Wildet faft cine Scheibe, uno bie Sefetung Des Mantelo, die úberfaupt nur wenig hets

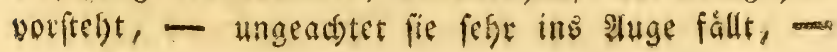




\section{4}

verliet fid gegen ben unteren igeil bes Sorpers bin ganglich. Den abjondetnden anal fiegt man unterbalb Dis Ropfs an feiner gewobnticien Stelle. Da Dev obere

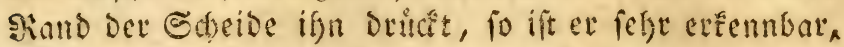
und erfdeint fteifdiger. Det $3 a u d$ ift glatt, aber

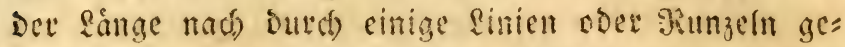
furcht, bie indef nidist tief find, und Die vielleicht von Der geiftigen feudhtigfeit berwifren, in welded er ein= getaudit ift. Geige viele ungleise, bervorfebende, uno fid in einer ftumpfen Epitze enoigende sedererchen bebecten isn Jituen, Den Sopf, uno Die adt furzen

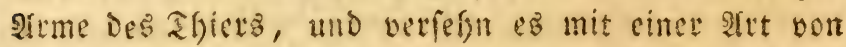

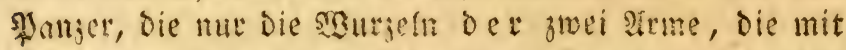
Seulen beraffinet fino, blof lafien. Die Saut ift meder getigert, noc) punftitt; fie got in (segentheil nut cine garbe, diefich Dem Dunfelgrnu dis Eifens nifiert.

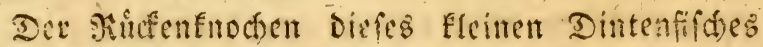
sweid, forge von Dem uns befannten $a b$, weil er, wie eit riber fid felb heriber gebogenes Spatel, acformt ift. Stn feinem vorderen Sheile ift $\mathfrak{e v}$, wie cin balber zuridf gebngener ßogen nad) voune $j u$, und an feinem binteren Sigeile eben fo nad binten fu, gefrummt. In =

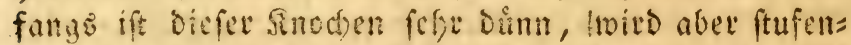
weife bicfer. In Der Shitte, wo er am bicfiten ift, frimmt cr fíd. Seine groffte Diffe betroggt mur einen

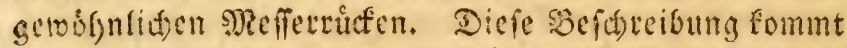
nid)t gan mit be: Des Eamar itberein. Er fuseint mir bie wafre Etellung Des finochens in Dem Sorper des Ifiets nidet geforig aufgefaft zu haben *), oenn un= móglich fam fein Sordertheil, D. F. Der Igeif naci Dem sopfe zu, breiter uno ausgedefinter genant werden, als ber am unteren CEnbe Des Rorpers. Diefer muste

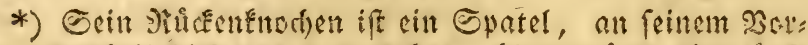

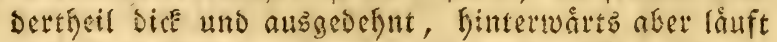
et in cine Epifse jufammen (Lamark ubi fupra), 


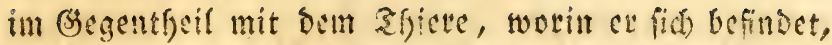
zunefimen, weit bie immer alfuaflid breiteren Edich

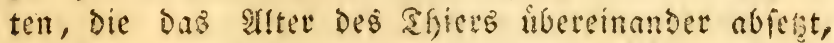
einander cutgegenfegen. Dem fen indes, wie ifm wolle! Diefer Jretbun, wenn es anoers cin Jrtbum

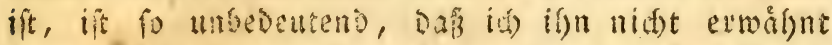

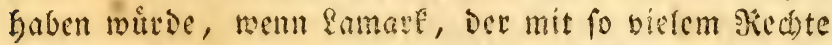
afs \&uturitat gilt, nidbt bis biefer grabe nue der cins

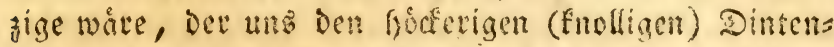
fifid etwas genaner beforicben gat. Ber erwálynte Ginodien if falfartig, glamzeno, talfartiz, mo aus etwa vierzig feftoniren Sdioten *) zumomengefetst, Die fo georonct find, Dof fie fict untereinnnder bedecten,

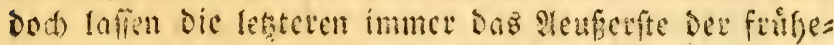

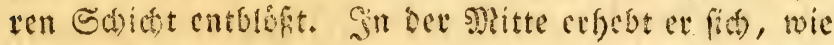
cin Echiffsticl. Die frumme Epatelform watre aber Den Buden unferes Dintenfifotes niffet runo baffellen,

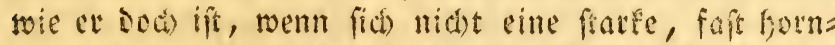
attige braune fant oben Daruber fingogge, und in ibreat

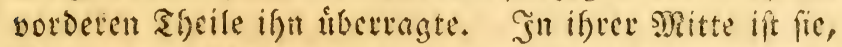
ifrer ganzen länge nach, gefpalten. Gie erimnert beim

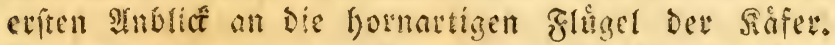

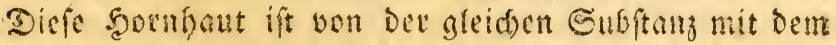
Sunchen, sen wio im Rutete ber falmats finden werden. Nit ben Rnowen unfers Sfiers bängt fie Durd)ans

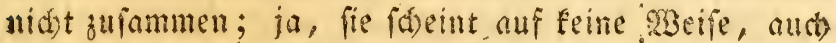
nut entfont, mit ifm verbunden zu jevn, wenigftens ift Dieg in ausgetroceneten Zuftande Der fall. Sie be=

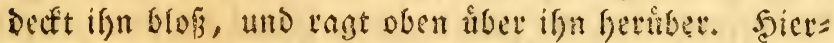

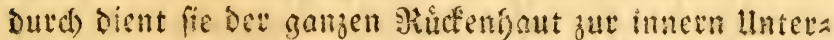
ftithung uno bejeiduet die Seftalt Des ßricens. Lamate,

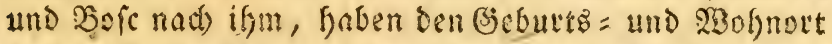
Diefes Dintenfifáes nidit angegeben. Sid habe ben

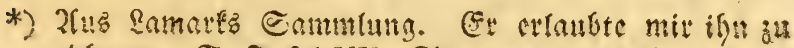
zeichnen. Б. Tafel VII. Tig. $3, \frac{4}{4} 5$ und 6. 
bollantilaten Satalog des Sabinete des Mringen bon Dranien Dariber nadigefefn, und gefunden, iofip biefes Molluśt beim Norgebirge Der guten Seffinng ju Sarule ift, uno in oer hollandifden Eprache - Die faft meine SButteriprache ift - bas gleidje bejeichnende Scirort

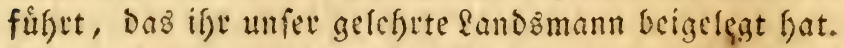
Ex merfte fo mofl, wie Der Berfertiger des satalogs,

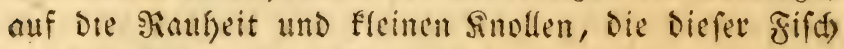
nuf Dem Kidten hat. Dies ift sbet aud fein nuffalleno= ftes äuferliches Rennzeichen. Das Sinnere Des Ibicrs.

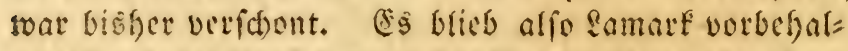
ten, Dutch Die Unterfud)ung bes Sinochens zu enticheiden, 3u wefóm befálechte die Gattung Deffelben beftimmt geredinet weroen milfe.

stle Dintenfifde zerflefsen, went fie todt find, und ber \&uft ausgefest werden, in eine \&tt von 2 affer. Dicfe fchmarze uno ftinfende Feuchtigfeit verdunftet von felbr, und es bleibt von Der ganjen Drganifation dicfes Ifiers blof́p Der falfartige finoden jurict, Der, wenn er irgentwo auf ber Eroboerfind oder auf ocin Dieeres= grund liegen blaibt, einige Fitrnettien zu Der Salfma= terie, die wir allentfalben vorfinden, finzufught. Diefem Bejetse find alle lebende Mgefen unternorfen. Sie find

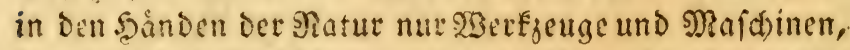
Denen fie das ङeffháft altvertraut, ifre melr oder meni= get Minterie, entweder \$hon = Doer Salterde, als Brunderden zu velfertigen. Die Beaetabilien liefern Durch ifyelleberrefte die erite, und die Sfiere bie zweite. Der sienfd liefert, aud renn ev hundert Salsie lebte,

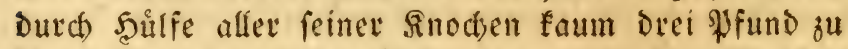
Diefer Materie. Alles úbrige ift nut zleifd), Muefel,

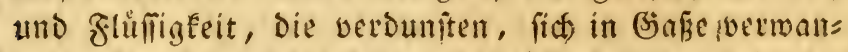
Deln, Die Durdsfichtigfeit und Fluffigfeit Der \&uft an= nefmen, und fern son Dem Sinod)enbau des siopers neue fombinationen bilben. Dod) id fomme vielleidht sin anderes Mal auf Diefen Begenftand zutuef, Det fut bie 


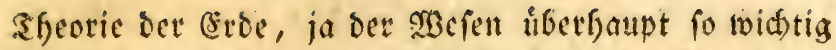
ift, und uns allein ju wirflid) prilofophifden ঐefultaten fưflet Eant.

Die Dintenfifde fins, wie eben gejeigt wurde, in Birfficht iffer Gattungen nicht jaftreich. Irot allen Nad) fuctungen habe ich nicht mefte als drei auffinden formen. Sair gaben ferner gefelon, baf fie fid in ben amerifaniften Meeren bisffer nod) nicht zeigten, uno Dafi man fie bis Dahin nux in Den Feeren Des alten feften Eandes angetroffen bat. Das Sabinet Des Prin= zen von Dranien allein enthielt zwei Battungen, die

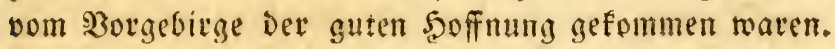
Sd fenne indef, feinen Sd)riftiteller, Der ifret erwågnt batte. Sofne den Ratalog Diefes treffliden Rabinets toutrden mil noch jetct die Begend nicht wifien, aus walder fie fino, und wir båtten vielleidft immer nod mit sinné *) geglaubt, Der Dintenfific) exíftice blof allein im Siean und im mittellandifichen Meete.

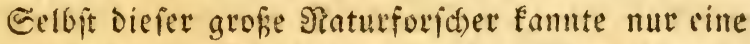
cingige Gattung. Die beiden auslandifon, bie wir aus ber ftotthalterifden Sammlung erbalten baben, maren in Derfelben bisfer, wie begraben. Samate. Deutcte' zuerfi nuf bie Sattung des geflecten $D$ in tenfifbes bin, und beforteb die andere Gattung wirflict, unter ber Benemmung, bofereriger Din= tenfifd (feche tuberculée), welden গamen iif) abfichtlitb beibegalten gave.

\section{Ertllirung Der fiebenten Rupfertafel.}

Fig. 1. 2. Siscteriger (fnolliger) Dintenfiict); ztwei Drits tel feiner naturlicten (s)rópe; Anfict)t von unten uno bon oben.

Fig. 3. Ser Fuffenfnochen oon vorne; er ift wie eill Epatel gebildet und an feimer Epitge von Der horn=

*) Linn. Syft, nat, verm moll, De fepia officin。 
altigen Sant, bie fid oben iber ifn hin elftrecte, umgeben. Ert ift feiner ganjen fange nach ausige: ferót.

Sig. 4. Detferbo Sincijen, won binten angefelgen und ofne jene Sout ; in feiner Mitte ift cr wie cine Bintre ausgethofit.

fig. 5. Die hornatige spembrane, von braunat fars be, in iffer ganzen Lange gefpalten.

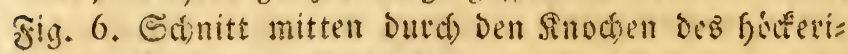
gen (fnolligen) Dintenfifócs ; feine Geftalt wie ein

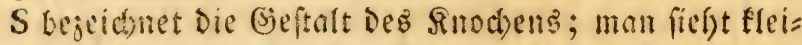

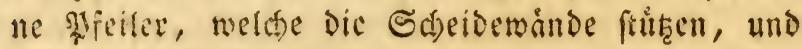
alle Hoer einander ftefrn.

23on ben 2fusmanterungen uns ber 2erpianjung Det 5) Rollusien uno onderer Thiere.

Sn Der Meeren von Imerifa werden trit Salmars uns stolnpen wiederfinden, die van benen in ber fruber befanten Croe und ifren sleeren verforieden fint, und ju Denen der neucn gigelt ju geforen idsemen. Cis ser Dergleichen ift 3. E. Der Salmat der Saendefreife Doer Des grofen Saeltmeers, Der Brafilifae und bie

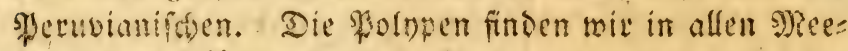

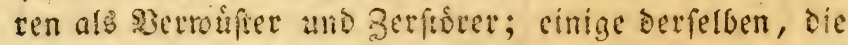
Die Suftengegenden lieben, faseinen an iften einmal geroáglten ufern zu Gongen, unb diefelben nicht ju bes= Iafien.

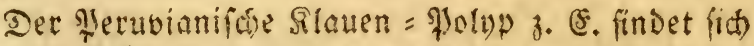
auf andetn Seftaden nie; der smetefus = Molpp jieft die Siften Ştaliens allen andern Gegenden vor; walkt=

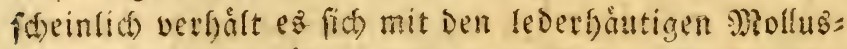

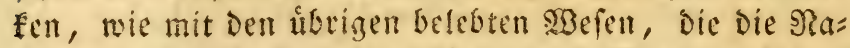
fur zum Ifyeit in befondere ?ánder uno SMeete, und zum Tyeil in gewiffe Simmelsftridhe voer engere Rinme ver= theilt uno verwiejen bat. Nandae Gattungen shollus: 
fen alpo, bie in einen Theil ber Mcete Des ceroballs zu= fammen georängt fino, Gaben fich aus obigen Brumbent noch nidft in andere meere verberetet. 3 fu fande laf

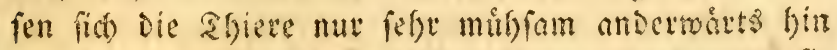
verpfanjen. Sir ifrem twilden s?aturjufande, two fie

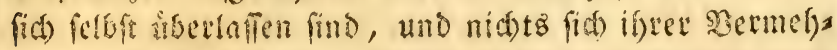

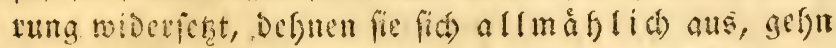

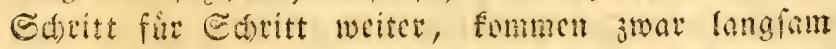
aber tåglid vormats, und hiberfareiten am Cende ge= mógntid dii lirgrånzen, die ifnen abgeftect zu fengr

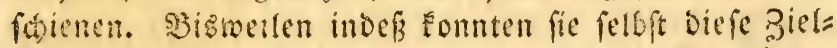

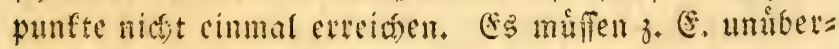
windidye Simberniffe nowalten, wesholb ber ebemalige

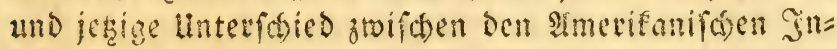
feten, vierfunigen und friefienden sfieren, und den gleidjen (sefdopfen anderer (Srotgeife nidht endich) aufs bivit.

B̧ei ben Fifichen und Şogein findet nicht ganj Dab

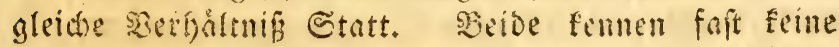
Grünzen, oder fie wiffen tochigftens mandse ju hibev fdereiten; oft fitgt man gange sigolfen von soggefn in Dichen Soufen weres Neer fiegen, um Der ranfent

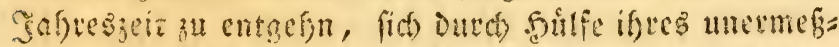
(id) weiten Finges einen fonferen sommeleftrić fuchen,

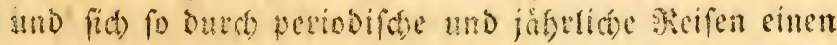

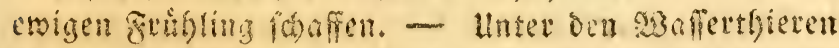
troben bie (etaceen j. E. bie Pottifiche (sof halots) und bie sisalffifte ben unermefliatsen sogranden bes şeltmeers und Duthftromen fie von Norben nat) Sü Den und von Dften nad) פeften.

Aber nidft bloí Die Eetaceen nefmen Dergleitfen Stus? wanderungen und weite, ferne \$eifen vor; nein,

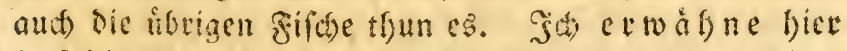
Glob die whth von Seringen, bie alle Gafre unter ben nordiffen eisbergen hervorbriát, fitgre die Meifen Det

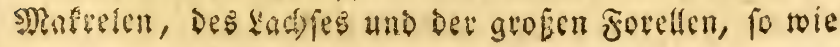


cinet Menge nnderer Shiete, bie bit Meere betwohnen, blok an, uno begnige mich, mefrere 9rten von ?is: wanderungen alrjuzeigen, Die nicht Dured brtliche uno gebietende luriadjen - wie dab bei ben eben erwågn= ten Sficren Der Foll zu fern fobeint, - erzmungen werden. Da es mun in Den Meeren feine materielle Gro̊nglinie giebt, bie irgend einen jeiner betwofner in peinen Streifaigen aufgalten fonnte, fo hat man fdon

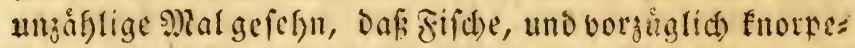
lige uno gefráfige Fif de, das Meev Der Silften, an trels c)en fie gebouen murden, verlefpen, fich in das grofe SBeltmeer fturjten, und Sthiffen, von benen fie fid eine recfere Seute verfpladien, nadyidionmen. So babe

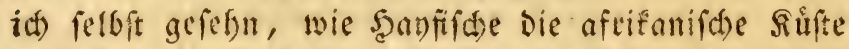
verlefien, und diefem ober jenem fabrzenge unzers trennlid), felbft mitten unter ben beftigften Eturmen, folgten, mit if)nen das ganje weite Mleer Durdhidsmam= men uno endida mit ifnen jugleid an ben Sititen von Amerifa anfamen, to benn bie Cinwogner bei Dem In=

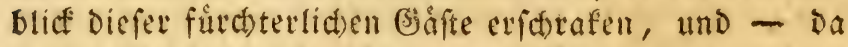
fie ifre Haubgier foton fermen und firteden gelernt bat: ten, - fid fogleich *) von diefen gefrábigen Hnge= beuern los zu madben fucteten.

গach

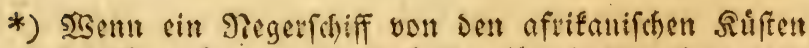
bei 2 fmerif́a lanbete, fo famen ifm immer einer ober megrete Şmpiffte nach, bie das Ed)iff feit feiner 2lb:

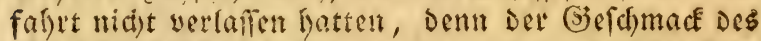

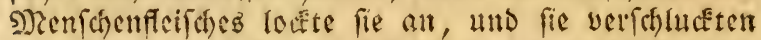

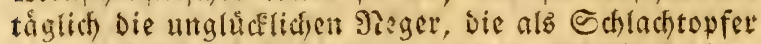
Diefes abjcheulichen Scandels auf Dem Schiffe frarben, unb som uber sord geworien vurben. Eo vic ein

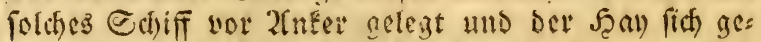
jeigt batte, entfano cin Tumult auf Det ganzen হit: fie, nuf Den Echiffan fithlug man Lărm, unt alle Edriffente beftiegen mit Sarpunen uno Dreizadén

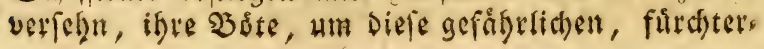


Nad) Diefen faftis modte man glauben, alle fis fide fonten uno wirden, wenn fie nidit etroa anden Sot

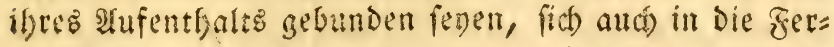

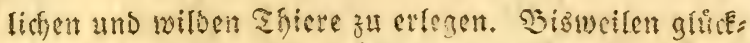

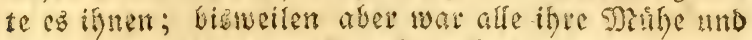
(Sefant vergebens. Des Scan fpiclte nut, und trokste thater. Dod aber habe id es ferbfe mit anges

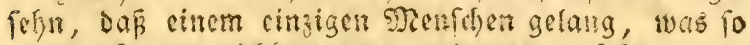
sisfen of unerrechbar war, und man verficherte mir

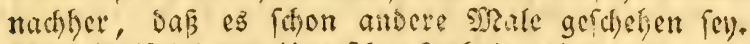
Dies Beifpier son linerfchrofentycí zetigt aufs neue,

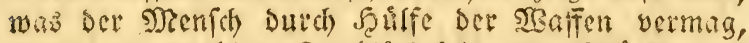

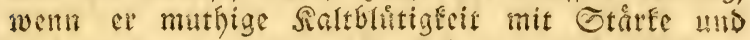

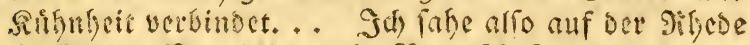

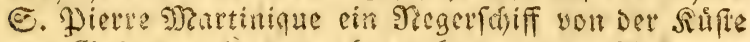
von Suther antanien; foum batte ez Die Znerer ges

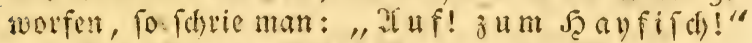

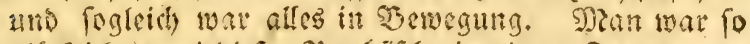

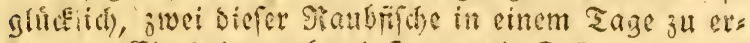

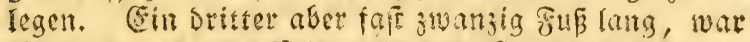

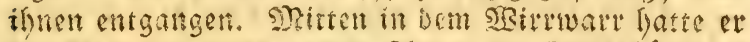
Die Dirogue cinez amen fowarzen fruththainders

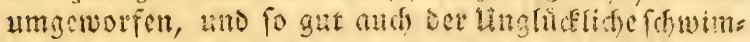
men founte, wat el Doch nidst wieder zum 3orfhein gefommen. $21 \mathrm{~m}$ folgenten sage lauerte man for

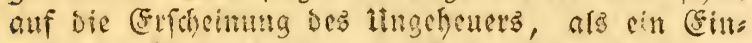
wohnet atis Sutrafao ganz ateft, tuns nut mit cirem

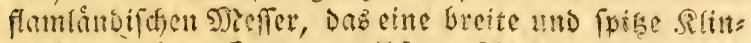

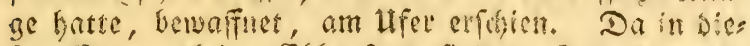

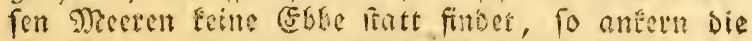
Echiffe tur ctiva cinen Thintenffus meit som Rande.

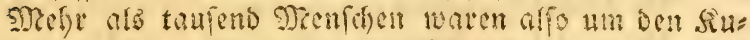

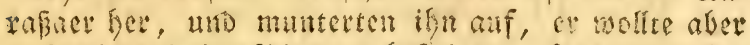
nicht cinmal cine sjtrogue beftigen, foitdern nafm

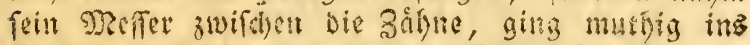

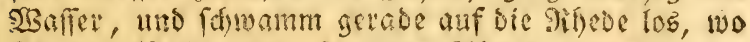
fid) Der furrthterliche Şay Den 2lbent zauor gezeigt batte. 2Bas unfer gefdickte uno unerichrodene Sibuimmer in voraus geafnet batte, gefisaí): Dab

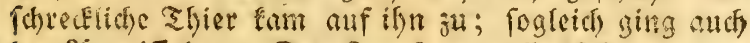
Der 2ingrifif los. Der Surabaer mollte fith gern Den

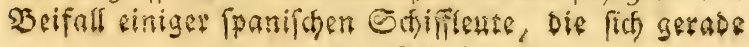


ne begeben, unb es ift allerdings̃ auffallend, baf man nicht in allen Mceren, DDex bod) wenigitens in ben hei= fen und gemápigten, jede Strt von filcien fomofl, als auch Die Eetaceen und Mollusten, antrifft. Diefe lese= teren fawimmen ja ebenfalls frei umber, und begeben

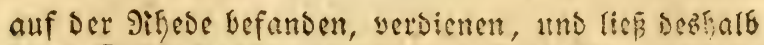

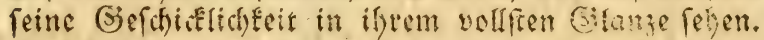

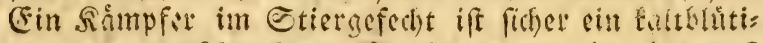
ger und unerfdrockener stenrich, ich glaube aber, Daß

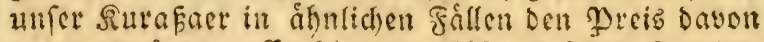

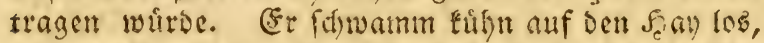
und tauchte, in bem 2fugenblick, Da Diefer fich wande, um ifn mitten Durchzubeißen, unter. Meefr alz cine Siertelfunde lang wieberbolte er Dies immer

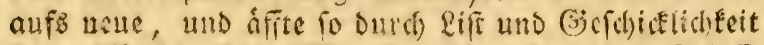

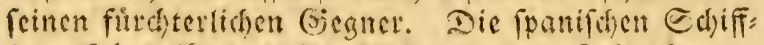

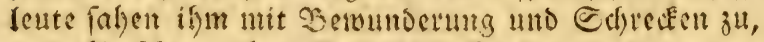

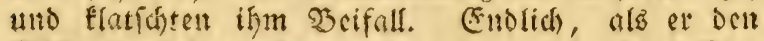
Fifch giemlich ermudet und mefle als hurbert פzal betrogen hatte, taud) er in cinem Etritifhen 2fugen= blick unter feinen Fento, erfojien auf oer anbern Eei=

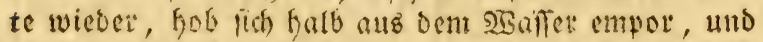

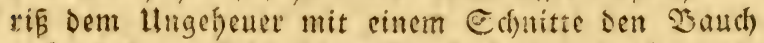
auf, bellen mórberifach finnbacken er fo eben wor: beigeftwommen war. Der fhai) wurde Dam aufz

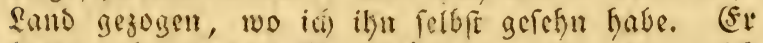
batte melje alś Deei SJannåkngen; meñen Eonnte ich ifn aber nicht, weil Der podbel fich feiner bemachtigte. Der Surabaer wutde im Srimmb anfacfilgtt, tuto ethicit vom Siommandanten eine Siefofnung, um fich ferner Die 2lugrottung fofidicher Ungebeuer - wie Thefeu und Jerkules cinf - angelegen jenn juloffen.

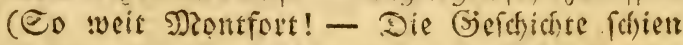

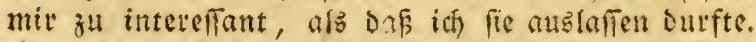
Peie uno da babe ith fie indés cin wenig abgeturgt. 2tllez diez finter auci bei Dem im Texte bats folgenden feftr funmeichen 3erfuche, un Die Temneratur Des Szanters in Der Tiefe Dez s)eer's getrau 34 erfahren, fo wie bei einigen interellanten Erzaflungen, fratt. 2(nm. D. Heterfes.) 
Pleime, tragbare, uns in iffen glajernen gevgren fyers metifa) verfiegelte Shermameter in geroibnlide glafune

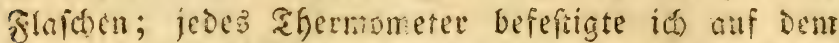
Sonden feiner Flafde mit \$led) in Der 2 rt, dof eŝ auf=

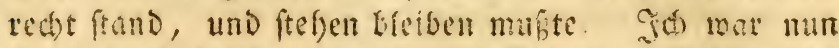
fo weit, Dof id́ meine fo eingerióteten Jlafden ins

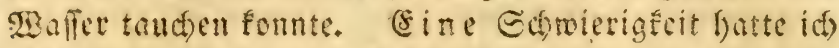
aber nod) ju befiegen. Já) mollte, oder vielmefr, ids

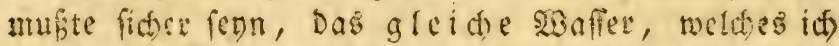
in ciner Siffe bon jweifundert ₹ü fchopfen mitrde, aud) bis auf Die Soerfåd) Des Maffers bringen zu fon= nen; Dics unuste aber unfefloar fenn, weil fonft entre= Der mein Berfuch misglicite oder Das gerfultat befiels ben mit Redit begneifelt werien fonnte. Siact langem Din = und serbenten fiel id enolid auf cin äuserfte cin=

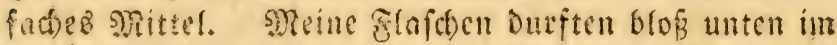
sicere geoffnet und wicoes jugepfropft weroen, uno sos muto mit feifr (cid)t, wie men gleid) fefun mirs.

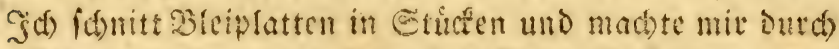

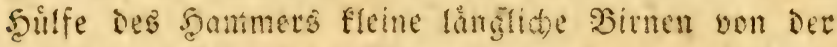

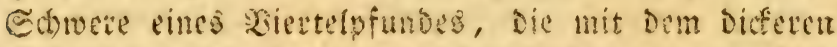

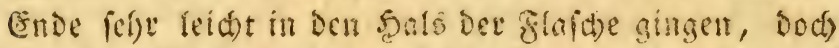

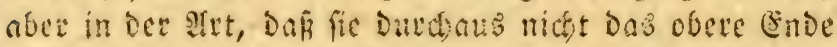

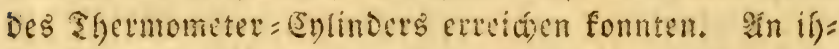
rer Epite befefrigte ids einen zugeipitaten, an feinem

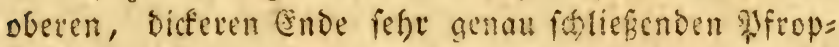
fen oon gestem leder, der bazk beftinmt war, meine Jlafthe zuzupfopfen, wenn fie woll fernn toinde; nun verfertigte id enen seig aus zerfaffenem arabifoben Summi uno geftofitiem Zucter, befdmierte Das bide (Cnde meines bleiernen Wfropfes bamit, und ftecte ifn zux Sålfte in Den Sals ser flafde; Der \$fropfen bout geoftem \&coer ftand folglich in Die Euft hinaus, uno main Zufferteig fidlof, fobalb ar abgetrodinet war, wie ein fefres Gummi, die flafde fefre genau. Der Crafoly

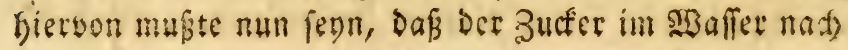




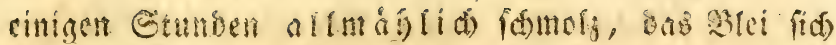
folglid Duth leine Eamete binablente, weil es nidft

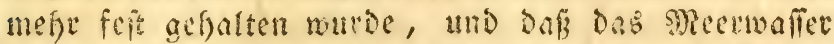

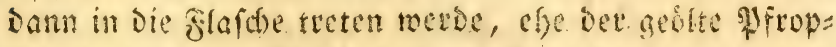
fen fie feit jugepfropft habe. Cobald alles fo einges

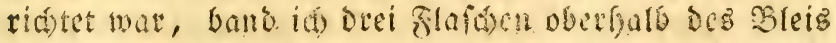
an Dem Eondefeil in perpendifularev grictung fo feft, als es mir moglich wat, befonders folf ith Dateuf, daff fie nidit gorizontal ju liegen fommen tonnten, uno lief

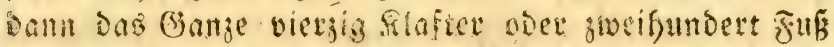

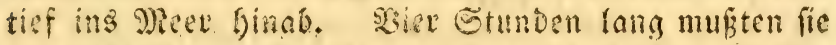
unten bleiben. CEin Ifermemeter, das denen in ben

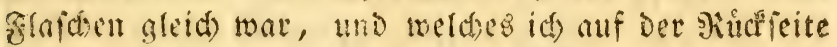
D:s Ediffs muter cinem Beite im Edjattin angebractit

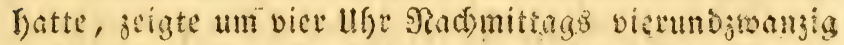
unt einen balben Brad úver o; in bempelben angen

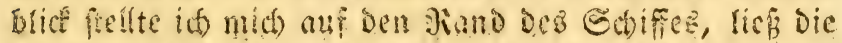

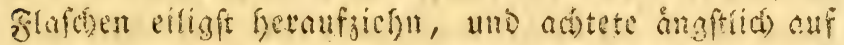

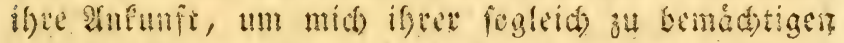
und ifre amperatur zu beobndotcr.

glles ging fort rofd); id untrfude mente enfe

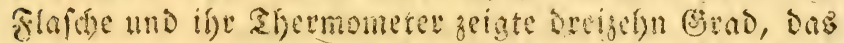

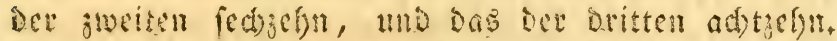
Diefer linterfoled fomm aflein an ben wenigen an:

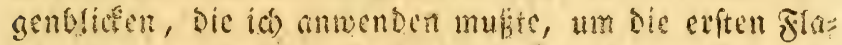

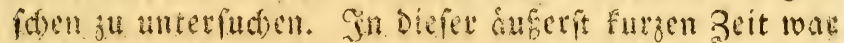

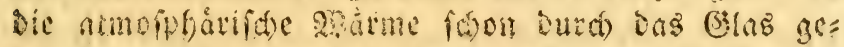

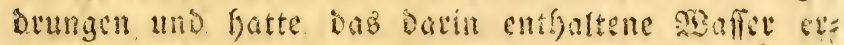
warmt. Llebsigeng batte meine plunpe sooridohng mix bimeládende Dienfte gleiftet, und meine fiafden wa: ren Duth das geolte leder fo boffemmen ant verfolof:

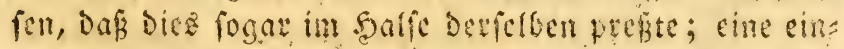

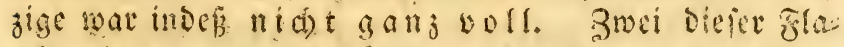

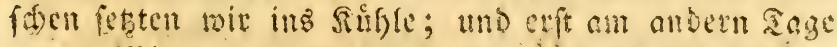
gegen Dittag zcigten die darin chingefoloffenen Ther: monter sine- Scmperatur, die mit Det gleíi war, 
weld)e bie britte (ber freien ?uft ausgefetzte) geigte. IIm গbend fonnten wir uns nicht entfalten, aus Dat Dritten glafde zu titinfen, um boch sisaffer getoftet ju

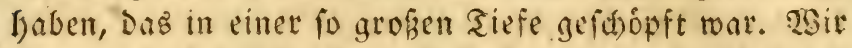
fanden es faft trintbar, fo daß man fić im Notbfall Damit håtte befelfen fơnen. Das Ẽdiffsnolf hatte

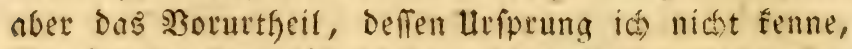
es miffie Duthaus fü (D.f). geid)macfloŝ) und dem ge=

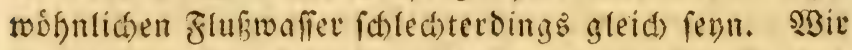
madten an ben folgenden Sagen Den gleiden $\mathfrak{T e r f u d}$

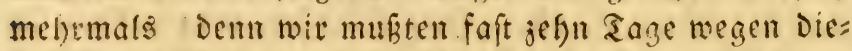

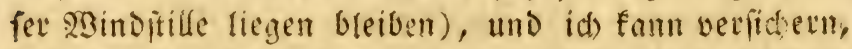
bafis Die Fefultate fid immer ziemlich alciá) blieben. 5ach Der Zeit verfenfte id) aud cinmal eine Slaid)e aber weniger forgfáltig verfaloffen - im Sroromert, nabe bei serve = Neuve; es war \$Binter und gerabe åuferft falt. als id die flafáe in bie Shano befam, zeigte das Darin enthaltene SBaffer nod) vier (stad uber o. Tids frunte zwar Diefe Seriude nicht fo reit fortfeţen, als ich getn getfan fatte, aber fie berwiefen mir Dod, Daf das Meer, wie das \&ano, in einer ge= wiffen Ticfe eine dibereinftimmende und fici) immet glei= d)e Semperatur hat, daf folglid die Fifche, die fich be= ftandin unterfalb Des SBaffers befinden, Dafelbft einte

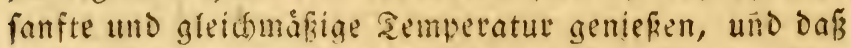
fie ifire Meere vellofien und fid in andere begeben foll

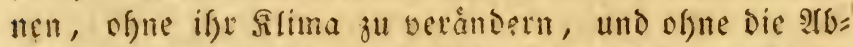
reedjefungen Der Sibe uno Sălte zu empfinden. Diefer Urfache haben wir es, wo nid)t gant, dod zum Iheil,

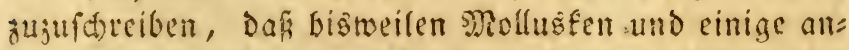
Dere Thiere in Europa anfommen, die die. Schiffe oon entfernten llfern mitgebrad haben. So wurden

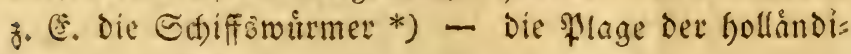

*) Teredo navalis. Adanfon, Safel XIX. Fig. I Valisnieri, nat. 2. Tafel 4. Enc. Enfe! CLXVII. Tig. I uns 3 . 
Fden Deithe uno ber Ediffe in unfern Seafen - die fith jeţt leiser in allen Mreeren finden, Durch Die Sdjiff: fafiet nach (E) ftungen vorzirglid) 1731 und 1732. Die Sollander, bie fie aus ben Meeren bev Intillen (bon Gore') mits gebeacht hatten, bebten faft fifion vor bem 2lugenblicf, ba bas Mker aufs neue úber die Sånder herfturjen wer= De, die fie if m fo múflam abgewonnen hatten. Hebers all, wo fid) Diefe Mollusten zeigen, marben fie fith Dutats

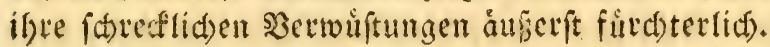

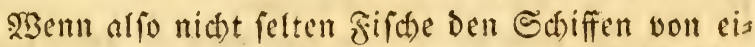
nem Mreere ins andere folgen; wenn aud Mollustfen fid) an den Ed)iffen anfetzen (Denn es ift nid)t blok mit Den ङ

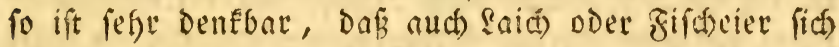

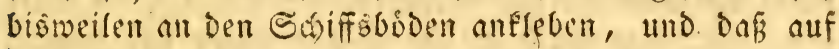
biefe sieife befrudtete Seime in frembe seimmelsftride gefúbrt werden, wo fie Dann ausfriechen, und ifor neues Baterlano mit ifm ganj fremoen 23 efen bevólfern. Sind fie aber Der Dortigen Siatur einft eimmal gefdenft, fo befält fie fie dann fúr immer.

Die Schiffafrt verpfangte aber nidst blof anf Den Neeren oder an ifren Ríten mandbe Thiere aus Diefem Simmelsftrid) in einen andern; nein! auch Das Snneve Der \&ander empfand Dann und wann die Folgen Davon. WBir wiffen, dof die Sunte, Crbet und Sdjen

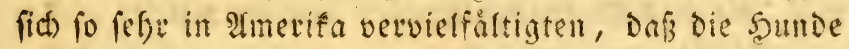
in fuzjer zeit willo und eine verfectende sanoplage wurden. Da biefe grofien Shatiaden aber burd vor: treffliche Edsiftfteller und Seobadter befdrieben fino, fo mill $i d$ mid) bei andern, zwar weniget auffallenden, aber eben fo merfwitdigen, verweiter. Der santel mit unfern Solonien hat einen Sheil von zennfecid) mit - einem ftinfenden Suffet, das wir jeţt unter Dem sa= 


\section{8}

men Sartofan oder Saferlate (blatte) *) fentten, fiber: (d)wemmt. Es gat fich nach gerabe, befonders in shas

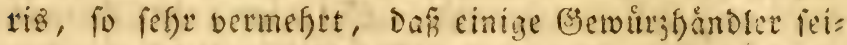
netwegen fich genothigt fafen, ifre Magazine gu wex: Iaffen, und in ein frembes suatter zuflefyen, wobin fie biefe \$left fider mitbraditen. Crinige Gebånde in botanif(t)en (Barten find onll bevon, und iá) babe fie nus allen Hithen cininer natuthiftorifder fiffen, bie aus ben Intillen angefommen waren, hetaus fommen

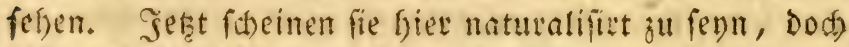
tôdet fie die sialte nod) bismeilen.

TGenn twil fo unter unfern Sånoen uno mitten in milern 230 fnungen Sfiertacen, Die aus entm anourn Erotigeil famen, fid vervielfaltigen fefen; fonnen wir

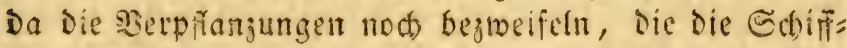
farth auf bem Drecen herbotbringen mufte? - Shie vielmefi: aber tverden wir uns hiervon úbrzeugen, wenn bir fatt bes glattei Sdiffeftels jene Ediffge= rippe und Trimner onn Gdifpbritien betradien, Die, unter ber Doerfíche Des Sisaffers id)wimmeno, mit

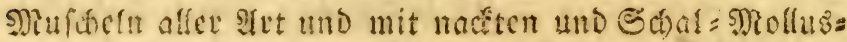
fen bedectífino, unt die, von Den SMelien und Strómen mit fortgerifien, meerengen und Siorgebirae voibeis

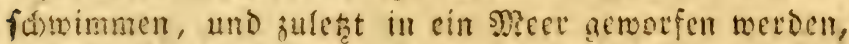
bas ifnen vollig frems geblieben fenn wurbe, wenn fie

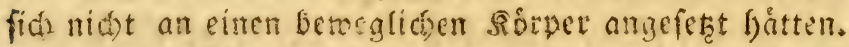
Man findet ofters auf den Meerufern atimmer bicfe Sirt, Die Das SPect Dafinmarf, und Die mit fefre felte" nen Sectorpern bedect fint. Sim Sanal, auf Dut Siufte

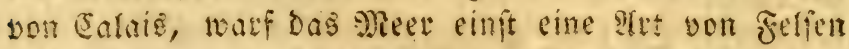
QuB, an Dem ntan Dutchaus feinen \$rnê, mit reldyem et ehethats itgerio movan modste befefrigt gemejen fenn,

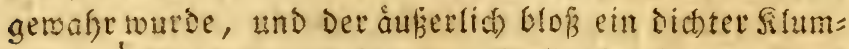

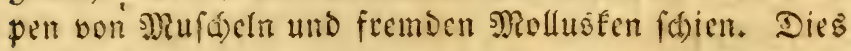

*) Blatta orientalis Linn. et Geoffroi, Hift. des infectes, Tom, I, part, 2. p. 688. 
Gelienfute - Denn Dafú hiclt man es - blieb einige Zeit auf Dem Sande liegen, bis cinft ein Fiffor site 2at und eine sacte natm, und biefe ifm fonderbar vorfommende Mafe láfor unterfudte. SRaćs vielet arbeit uno grube gelangre ex enolich bis zum sittel wunft, too ex cin altes far fand, bas nod) balb mit einem fefor geifrigin sigeine angefiflt mot. Ev mup

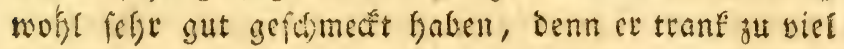
Davor!.

Th Die Tiften = MBacten ifn taumelns aus chter Gegend fommen fal)en, wo man getedfnfid treder $23 e i n$ nod) Maffer trinten fann, fo gingen fie feiner Epur nat), und fanoen fein Fof mit Bein. (fo war, wie fiit) riodiger feigte, Der vortrefflidfte madera, Der, nath foiner felfenattigen soulle zu urthellen, foron feit

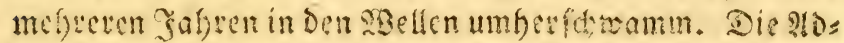
miknfitit bemidigte fid Deffelfen afs einen abeil cines

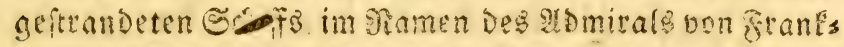

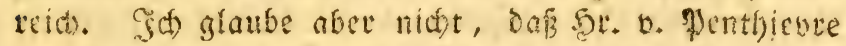
Dicfen Sieftar jemals a ut foften befommen hat. Das weis id) aber wohl, baf in Calais fein biurger ift, Det nid)t wenigften cin Eilas yoll bason getrumfen gu hoben

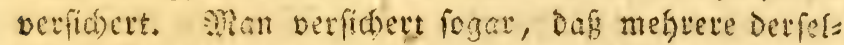
ben ben Fifker beneiben follen, Der als finder fenes Faubes ein 23 eincten genofi, und ifn fo gut ju benutsen mufte.

Man firfy auf Dem Meere ofters bergleichen Sold

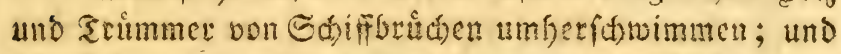
Der Mirreraloge eignet fie fid zu, men Stromungen

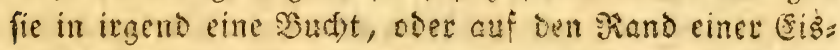
banf bei ben floten roetfen, um nit ber jeis Jilieln Daraus ju biloen, Dergleid)en Sapitån ploipps (jiţ Sord Mulgraye) auf feiren Kelfen cine amtaf; Dod biefe widtige beobadtungen geforten in bie Mineras

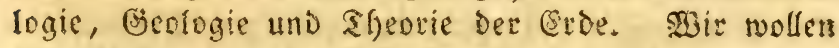

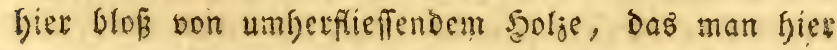


und da jectreut auf Dem mecre antrift, reben. Sक felbit Gave es mit suftera, Shufdein und Scethieren alfer Art belaber, und Eevobgel darauf hetumfirpfer aefelnn. Sie betradren $e$ in bicist Entfermung bom Sande wie cinen अugepuntêt, Det ifnen, wenn fie mide find, zur 3 ufactit Dient, und von weldem aus fie wipder mit neuer suft fortfitigen, oder ing 2 Baffer taucisen und ifren raub ergreifen fonnen. Jab gabe

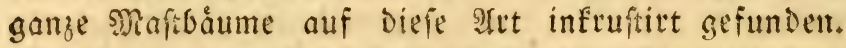

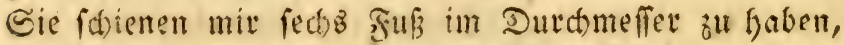
und forwammen feit langer zeit auf bem 2 Baffer umber. Ylle Diefe Serpflanzungsmittel find aber unbedeutender, alŝ jene grofen Ediffe, bie faft unverfefrt berfanfen, oder nad Dem Sode iffer g)\}annidyaft beftandig unterm Xisalfer fortfdrmammen, und fid bistweilen Det Dbe:

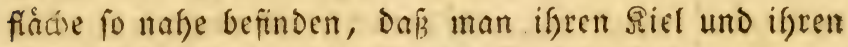
Soden Duref) das grune Meetwaffer fefon fann.

Ço criftit in Den Antillen, zwifrien Intigua und Monffertat cine Durd)fafre, Die surch mefr als e in en trantigen Sulfformd berudtigt ift. And) Die unet: fdrodfenfien હceleute furchten, fie die গand ju palfiten. llno muifen fie es thun, fo lâjt ifie arngit fie nicht cl)er ruffen, als bis fie fid́) wieder im bohen Meer und aufier alfer (Jefafr glauben. Sid) wate dolt beinabe unglitulich gewefen; und of ne einen gluffidsen Monden: fúcin, der uns die Slippen getoabr wetden lieb, wat

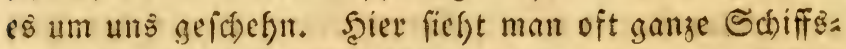
gerippe unterm $23 a f i e r$ fdroimmen; aud) to ir fafen

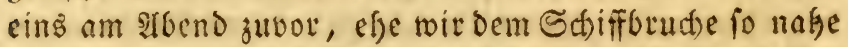
waten. Snan Dente fid) nun fo ein tweitlauftiges (sis: băube, vom sisaffer ausgeleet, dagegen aber mit einet Menge von Mecrtfieren angefullt, die es mit fid forts faleppt, wie weit eş Die Stronungen aud mit fich hinmeg reigen. Seierbutid theilt fich eine neue $2301 t$

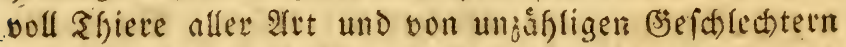
riner Brgend Des Deets mit, Die ifnen bis Dafin 
fremo wat. Mahtridf, wenn wir bie Bleichartigfeit Des mafier's geforig in Cerwågung ziefn, fo múfen mir

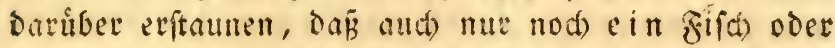
eit smothbe, die frei unter formimmen, vorzhglich wenn fie in einer gewiffen Tiefe, bon Den Ufern entfernt, Icben, eriftirt, ofme fia in allen s)eeren beider Salbs fugeln, gleitumåâig zu finden.

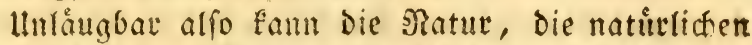
uno gemofnnliden Mnittel ausgenommen, Dutd) welthe fie bie Ifierracen ju zerftecuen, ju verpflanzen und in Die ferne zu fenoen vermag, jetht aud nod ondere zu Diefen zmed anwenden, die ifor die şereinigung Det Menfiten in Bulfe:fúaften und Mationen an bie Sand giebt. Die Sitinjte - eine folge ber gefellfdraftliden

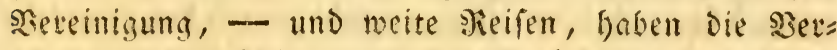
pitanjung ber şiere und die Bevolferungşart burd) Diefelben fefre vermannigfaltigt. B̧uffon verfolgte den (bang, Den bie vierfubigen Thiete uno Boogel wable= fideinlid nafmen, un von eincm \&ande fibethaupt, und von cincm feften fande befonoers, ins andere ufergu gefn. Unverånderlid bemifite fid dicjer groffe Mann, uns auf Die şege ju fuften, bie bie Thiere, weldse (iid) in ben beiben fefren sandern finden, bis zu ifyen jeţigen $2805 m$ maen bxingen fonnten. Foigt man Dies fem ficteren uno treuen firferer, fo genieft man bie Greude, Die Subftapfen wafrjunchmen, die die shicre bei iffer 23 anderung surteffiefen, und bie 9 tet und Sigeife aufjufaffen, wie fie biefelben ansfügtten. Diefe gtwat mirly fomen aber oud intereffanten und tiefen for= (d) ungen baben alle feine Radjolger fortonuerno be=

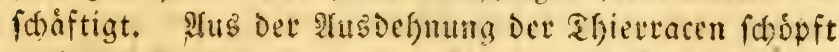
aud) Der Naturforther, der die Theorie der firde fu= birt, forgfätig. Er bebalf if:er, wenn er das slros blem aufoien will, Das ifm bie vorgefundenen Sfelette

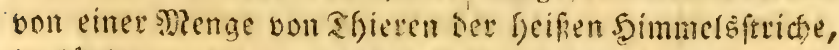
in Lăndern, die jeţt eiśfalt fint, aufgeben. SRad) bet 
jeţigen Sobnung Der Dinge Fontente fie Sort nidft aus: baucrn, aud find fie, wie ber Irugenichein zeigt, butd)

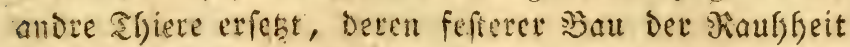
Des Gafreszeiten und Der Ettenge ber Bálte troht.

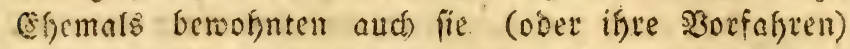

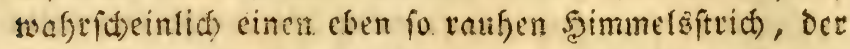

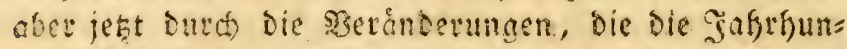
Derte und Sevolutionen mit fir brachten, brennend heif

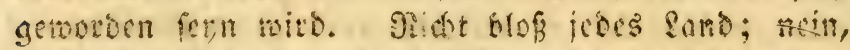

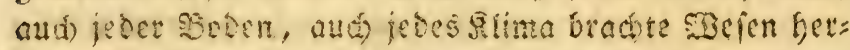
vor, bie banals nut if nen eigentiglmlich waren.

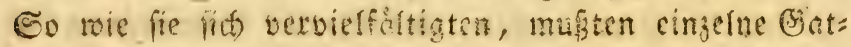
tungen fid treiter ansochnen, fid erft bie noberen, Dann bie entrernteren Gegrnben anmafen, bic ifnen

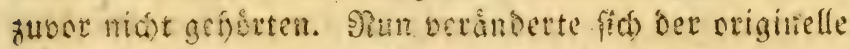
Bufand Der Dinge Dutcian?. Frembe Gattungen na=

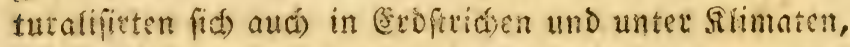
mo fie nidot geforen, didet aufgeroabjen waten. Die

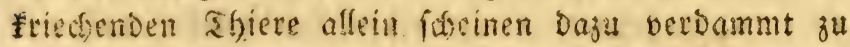
fenn, ben Boben, der fie geboten merden hah, nidst

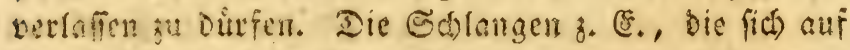
ser Croe nux foitmálzen fómen, wares, follte man glauben, nicht vermóaeno, fich son oem Drte peit ju entfernen, wofin daz Ed) was bie Shatur ifnen verfagte, gemaigrte ifnen bis= weiten bet spenfes. Sn feiner south wat ifm ifge stift bismeilen willfommen, um feire gende onourd su bes frisbigen. So verpefteten die Saraiben, die von der

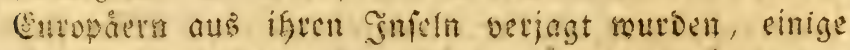

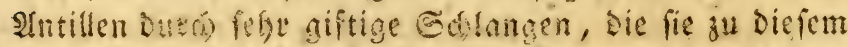
Defuf auf bem fefen fande grifin, und bort bin

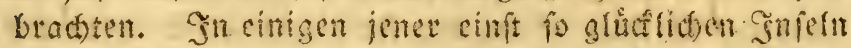

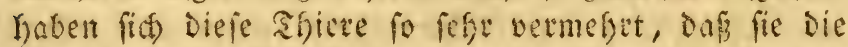
semolgnet mit ber zeit zidingen merden, fie zll ver= Iaffen. Shattinique Gat mefre als alle ande Durd biefe

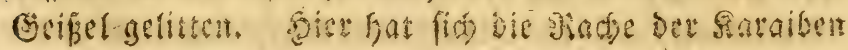


in ifrer ganzen Brỏße gezeigt. Das Snnere ber Jnfer ift fidon jest unbetoofyt, uno megen Det unglonbliden Mienge von Sd)langen, wovon es bort wimmelt, auth

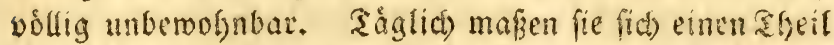
Der bewolnnten Gegenden, - Die nue nod an ben ufera unber cinen Gintel bilden, - megr an, uno baben

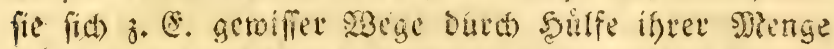
erfit cimal bemád)tigt, fo ragt es nicmand mefy, fie

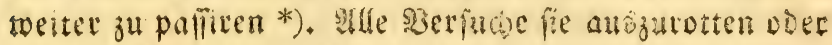

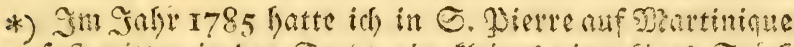

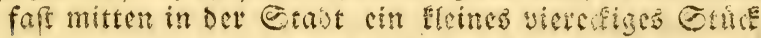

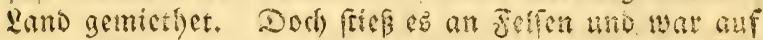

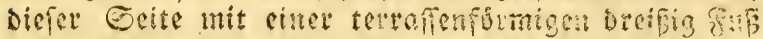

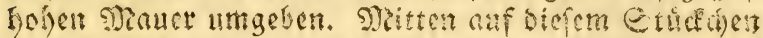

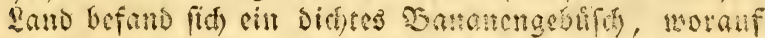
idh immer mir sergnigen finbticte, weil as mir alle

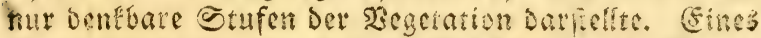
Tages folgte mir, zu meinem (sillicke, ein atter Sleges,

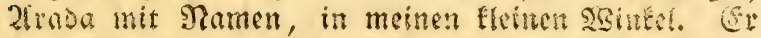

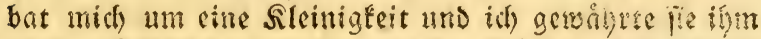
gern. Froblich vertief er mida, fehrte aber forneif wieder um, unb lagte lebhaft: "foet $\mathrm{f}$ ! $i$ d) riedge (E) fangen!" Da Der ganze ulbrige Gäarten fref und faft ohne Gebrifin wat, fo ging er fogleich $34 \mathrm{Den}$ Sinanen, uno verfitferte mir Dann, bó̉, nad Dem

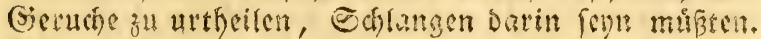

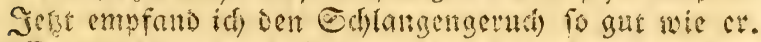

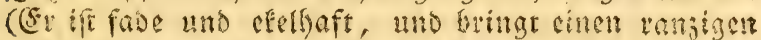

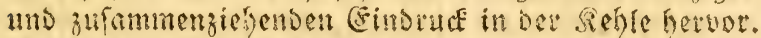

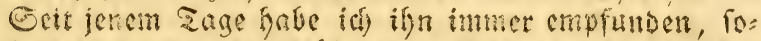

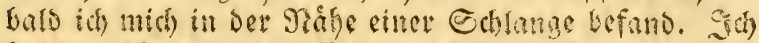
Gabe nadfer fogar in Europa, befonder' an den feifi: gen Seiten Det berge die gegen stitag'fiegen, be: merft, Daf bie Sisafferfolange (enuleuvre), fo un=

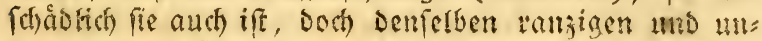
angerefimen (sierud) bat, und ich glaube jeft, buech Den blofen (sjeruch Den 2fufentgalt Der Lans= uno

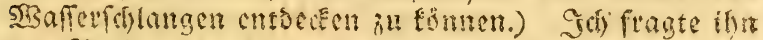
um Siatl, wie ich der Eshlangen los wersen folle, umb er verficherte mir, ef aflein wadle midi davon bes 
auf getwiffe Gegenden einjufdrånfen, find bis bahin

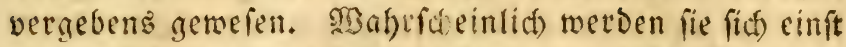
nod) auf Der ganzen Sinjel verbreiten und Die Menfiden Daraus vertreiben. Daf Diefe glage in Der Fache Der alten Snfulaner iften Brund babe, ift einte allgemein befonnte Stadition; ware dies aber aut) nid)t, uno bătte man aud) feine fificrifde fafta, un es zu ertweis fen, fo witue es doá) immer fehr auffallend feun, dab blof einige snfeln an Diefer łeft leiden, und Daf andere, bie fpåter berofhnt wutben, nichts Davon empfinsen; ja, Dafi Giuadaloupe, Das Dod) fo nahe bei Jattinique liegt, fein einziges fried)endes, folglich aud) fein giftiges Sfier fennt.

J(d) Gabe oben bemiefen, daf Die Gdiffifaht einen

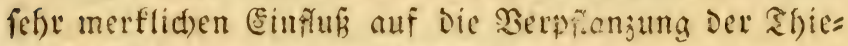
re, bejonders Der Seethiere baben muste, indem faft

freien. Er nafm nun cinen $\mathcal{E}$ tod in Die Scatt, und pfiff feht frat:, marf aber alugleid) Eteme in Den ba: nanenbuft). Eein ?ngriff gludite. Eine faufsicfe Edblange fam hervor, und fprang auf ihn los, aber meit topferer 2lrada frecte fie mit einem Sd)lage zu Soden, und tostete fie, verficherte mir aber, fie fer

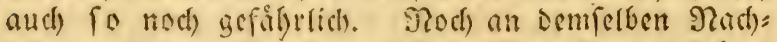
mittage lodfen wit jwei andere ans ben bananen her" sor, worin fie fich, wott Den Felfen aนs, verfecter

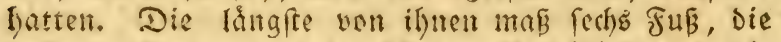
leiden andern waren aber firrzer. Itnfehtbar verdante idh Dem armen Elasen mein Eeben, aber id fomte

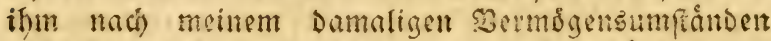
nicift fo Danen, als id) es gern gethan fjatte. Sich Gabe nachfer oft noch von- Eeuten gefort, Die mitten in Der Gradt won Gillangér gebifinen waren und dars an frarben. YUf einer sicife voit 6 . Wierte nach fort Sisual, bic man jẹt tmmet ju sisaffer marbt, bie idh aber gern zu Rande madjen wollte, Gabe ich Mitlionen

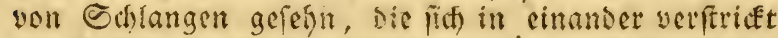
wie ?futertane um die felfent wenden, und mit einem

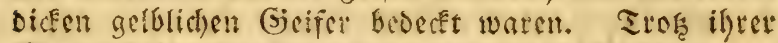
Decrige foben fie aber alle bei meines 2rnfunft. 
fein Schiff exiffirt, das midt aus fernen Begenden Fifuse, oder nadfte oder Gdal = Mrollusfert, oder (Sier

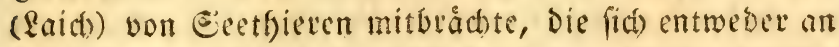
Demferben anfeteten ooer ifm folgten. Unter gewifien IImftäiden founen folde (eier fid lange halten, ofme (id) zu entwicfeln*) D. h. obne Dafj Der Darin einges

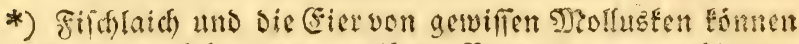

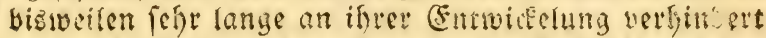
werden. Der gelegrte Sterumar z. E. hicit auf cine

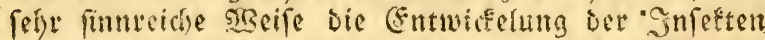
ganz nach sistleutgr auf; und vermebrte ober vermin:

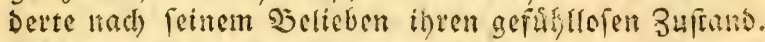
frifner" oder antore Begelcier bleiben, wenn man fie mit Fett ober Firnis liberzieft, snonate lanz frifo.

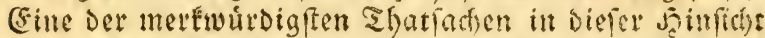
ift woht bie, Die Sonnet in feiten Settadtungen liber Die diganifirten Rorper (Th. I!, p. 159) anfuifit, Daß

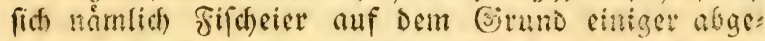

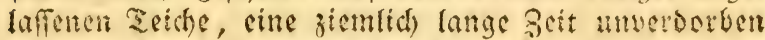
erbalten baten, fo dap die ₹eidje fich, nactsem fie wiesce mit sisalier ansefint waren, mit sen noimlichen Gattungen von Fifhen wiese! anfullter, Die vorber Darin gewefen twaren. Sonnet wentgfens füreibt

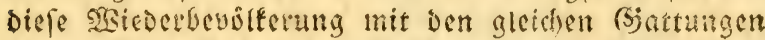
Den auf Dem boden Des Teidh unverfeitet enthaltenen

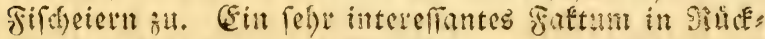

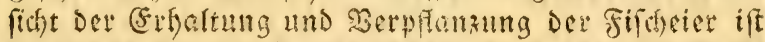
folgendes mir von Faujaz Gaint Font, Der cires seife

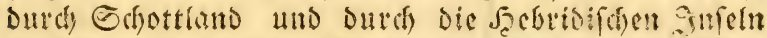
mafite, mitgethellt. Er befudste namtich einen (Fod: man, Der feine Befifsungen geltento su maden fuchte,

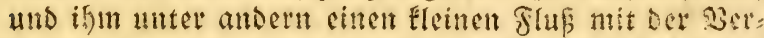
fitherung zeigte, Diefer-bringe ifm jeşt jâtrith Duret

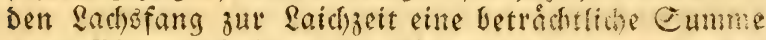
ein. Efgemals habe er ifm aber wentig ooer gar nict)ts

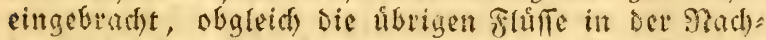
barfhaft alle voll Eatbje gewefen foyen. Der Beflet Fotte fich namlich Die Bemerfung afgejogen: Dor

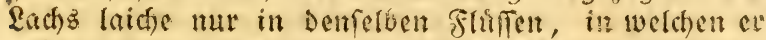

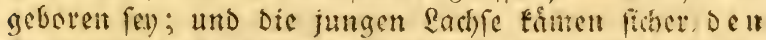
flus wieder binan, den fie binaúgefdwommen fenen. 


\section{6}

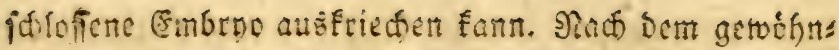
fiden Eauf ber Dinge frauden fie ofnebies cine gemif

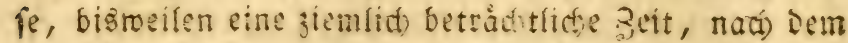
fie gelegt find, efje lie ausfrieden fónner.

Ingenommen alfo, ein Cdiff lege fich an bet aftis fanifoen ober ancrifanifoten Silite vor Infer; pogleith werien fich eine smenge Meertficte und Eceptanjen an

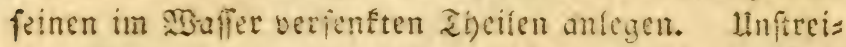

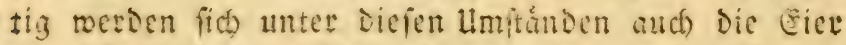
mancher Jifhe uno Molusfen anfleben, Denn fie thun es immer, too fie Mufhefn und Mreerpflanjen antrefren; dó Dieje siotper fich nun an Edjifien oder an folfen fins Den, ift gleid) viel.

Bleibt Das Ediff eine Zeitlang liegen, fo fethen

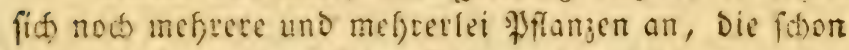
angeraatfienen vermefren fid, und endlich wito Dec Ca)ifreboden mit eliner Sirt von sibald ưberjogen, Der

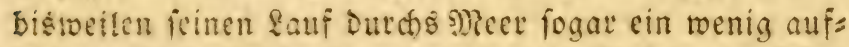
bált. Sicje Muideln uno ons viele Meergras nuiffen

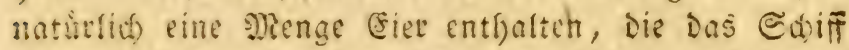
nun mit fich nat) andern Gegenden furfrt, uno bie zu if)ret Şeit allgemad) ausfrieden. Eo vertauidt alfo Die Soliffafet nidht blof Die \$rodufte, fondern aum

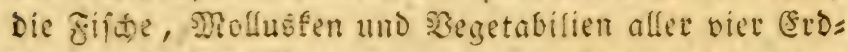
theile und iffer Necre; ja, eś bedarf nicht einmal uns

mé

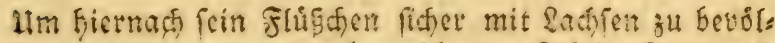

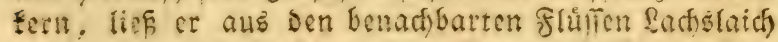
Jolen und in ben peinigen eimisen. Diefer Sunft: grifi gliffe vollfommen. Die (Eier famen aus, bie jungen Ractie twaijen sortreffition uno begaben pich sut

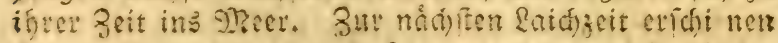

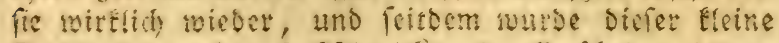

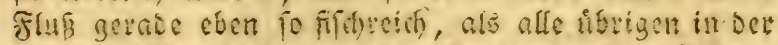
Dortigen Gegend, ultgencitet in Den vorigen Gohvert fein cinziger Earfis Darin gewefen toar Diefer féte

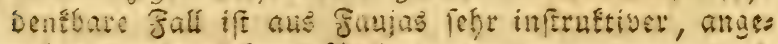
negmar und getértat Sisije genommen. 


\section{8}

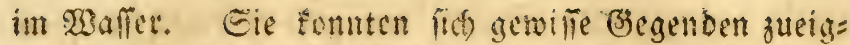
nen, uni nidjts zwang fic, fie ju verlaffer. Die $39 a$ all=

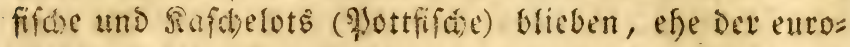
paifde fifoter fie mit der şatpune in ber f̧and aufs fud)te, und bis in sie enterntefien Meere verforgte, wie jesct gefóleft, - in einem gewifien, beftimmten

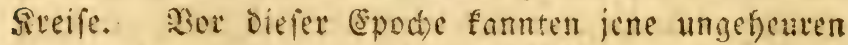
Eetceen mut wenig feinoe, fir fuithteten gav feinen.

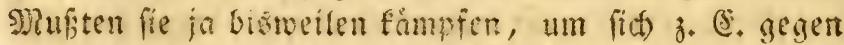
Den Sefmerdtific) Doer gegan andere feimde zu verthei= Digen, fo brauden fie bod nie, twie biefer Zweifampf nud alsificl, weit ju flielgen: benn nod griff fie Die (je=

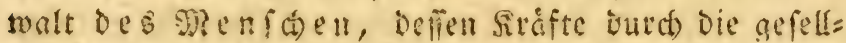
füaftide Bzereinigung fid inmer mieder crneuern und

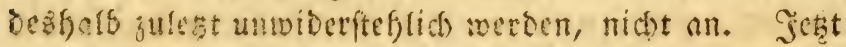
merden fie allenthalben, wo fie fit) nur zeigen, verfolgt,

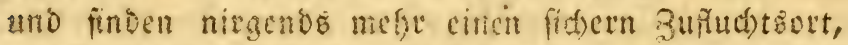
reder unter ien (eisbergen ser shole, nod unter ber Glufefitse bes arequators. Jmmet verfolgt und ins mer verfdeudt, turgen fie alle jene Edmorotarmefen,

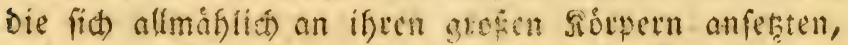
und batan feftwader, weit mit fid getu, uno jeten fie vielleidit in oen entfemefen Meeten theitueife ab.

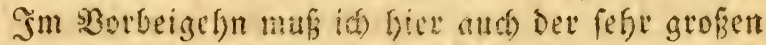

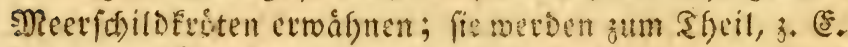
la tortue franche, adit bis jelyn folf long und fünf Fußz breit. Sie angefifyrte (Sattung findet fich, aufer Dinen Mecten, wo fie am befen forttommt, Geutiges Sages faft in allen, weldes frdier von Der Saffifarth herruigrt. Gim Gafle 1752 fing man im Safen vont

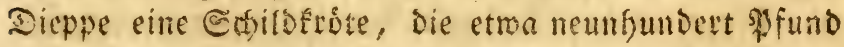

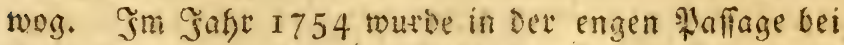
Intiodien eine andere ber sltt gefangen, von ber man

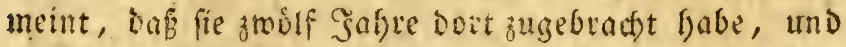
mit einem Schiffe von S. Domiatgo, :bas 1742 in bie: fer Duthfafrt fariterte, Dafin gebracht morden fsy. 
1784 fing math auth alt ber smintung ber loive fefte grope Sctilofroten. ltebrigens ift cos freilict) wafre, Dố bie fogenannte tortue franche fich ungefgener weis verftrigh. Man findet fie bistoeifen mitten im fofgen Mere iber febenfundert Stunden weit von irgand-eis nem Rande.

Die Sdale Diefer Schirofroten if nody unempfint:

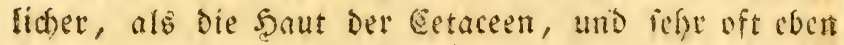
fo fefre mit Moflusfen, Meerpfangen und Mecthieren

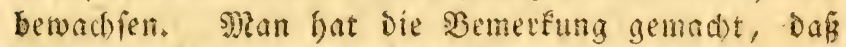
Diefe Edfitteroten auf ifyen Selfen immer von ciner Menge Kaufifidse *) baglettet mutben.

Suf ber Dberfiche bes Diceres ferbit finoet fir abev noch eine meit bederuteridere Urfadye zur S3eforbes rung Der 2 Tusmanderungen und Betpfanzun ent manther Siollusfen und gifde, als alle bisfor erwaignten. Das

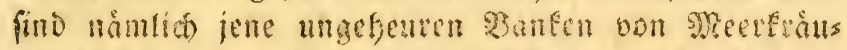
tern, Die faft ganz aus tinerlei Bjattung **, betefm,

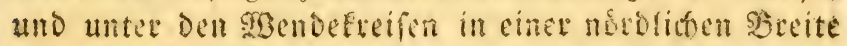

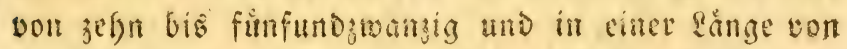
Dreifunsert und zivangig bis Dreifunoet uno fünfund

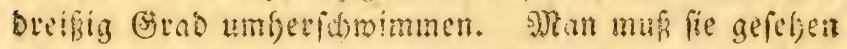

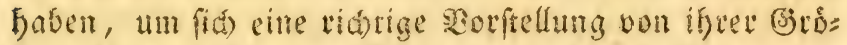
fe madien zu fonnen. Gie nebmen nidgt blof́ cinen uns

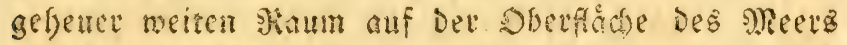
ein, fonden iffer Tiefe ift aud fege bedeutents; fie find oft fo Dide vermact)en, Daß fie ein Echifi in frimem

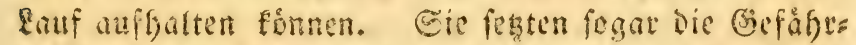

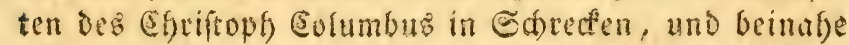

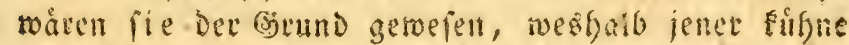

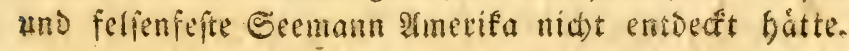

*) Diefe Semerfung madyte fíon Dampier.

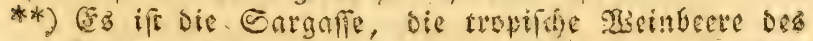
Donati, Agresto marino d'inpera-o. Sisers

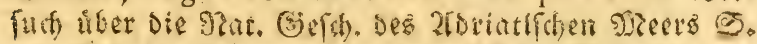

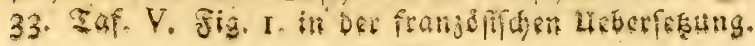


Diefe Menge yon \$rangen uno Eefréttern bienen ci= net ungefeuren $\mathfrak{A}_{3}$ ahl von Seegeldopfen zum $3 \mathrm{a}=$ fuctitsort. Cinge derlelben leben und weben in ifrem

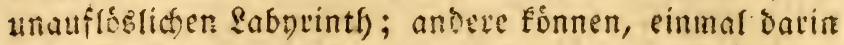
berwiffelt, nic)t twieder feraus fommen, und find ges s̆mungen, fich in biefen Seefråuterwåldern ben Strome

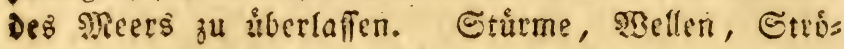
mungen und Sippen zereifen folche Banfen bisweilen, und treiben Den einen Sheil mit allen feinen Seetfieren vielleicht bis in Den mezifaniften Meerbufen; einen andern merfen entgegen gefetzte Stirme Durch bas gan=

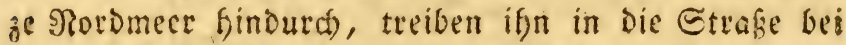
Bibraltar finein und verbueiten ifn nad) allen Eeiten bis mittellandijon meets, an Defien fammtlid)er Ufern man Epuen davon wirderfindet ${ }^{*}$ ); noch andere grop̂e Breiten biefer Metertater merden Dutch Etirs ne und Stróniungen gegen ben Eitopol jugetrieben, fdroimmen zisifden bem Torgebirge von Brafilien und

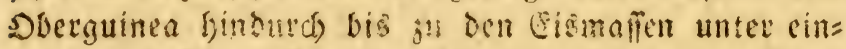
undfunfag Grod fitslider Sitcite. Det vierte aheil endid twird Dem Norbpol entigegen geworfen, uno ge= langt aui biefer Eeite vielleidit bib zum acistaigften Brabe. Itles, was fie unterwegens vorfinden, fdwem= men fie mit fich bintoeg, unftritig bringen fie alfo aud) eine Menge Mollusten uno Fifhe aus Den Meeren von Imerifa mit, und jerftreten fie in andern Meeten

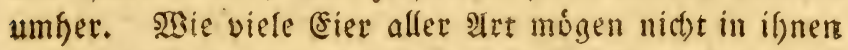
verborgen fenn, uno mit ifnen auf Den flutben umber= getworfen toerden!

*) Diefe Pflame findet firf in Dem geerbufen von Sftrien und Dalmatien in Ueberfuffe. (Donati ubi fupr. p. 34.) (Ez fdeint fogar, das fie heutiges $T_{a}=$ gez Dafelbft eintreimifa) ift, fo das alfo die Eamen= theilden, Die Die Etúrme mit Gertrieben, auch un= ter Diefer J̦immeleftriche múfen befruchtet worden feyn. 


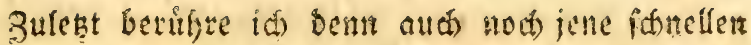
uno gemaltamen Durdibruthe der See, modund Deide

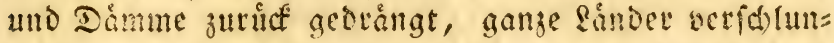
gen, und mitten in Sande Meere gebilbet rerden. Illud fie Gevolfern mandie Gegenten, bie vorfer nur

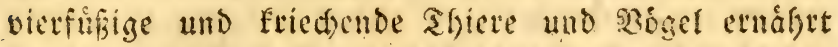
batten, mit Wolluben uno fjifden. SBei ber blopen

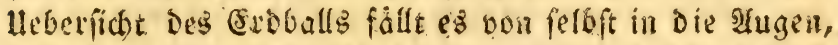
Sali aergleitien Durdbritde einft die Subfons = und

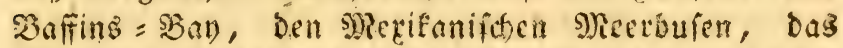

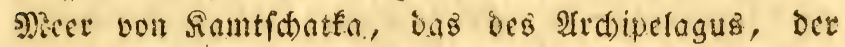
\$iblippinen uno Dev \$loluffen, Die perfildyen \$ecrbu= fen, Das rothe, mittellandifúe und baitifáe, viclleiche

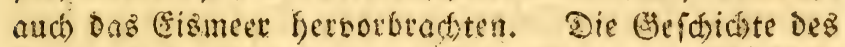
seloentfums hat ung nod einige sotizen in ßituffidt

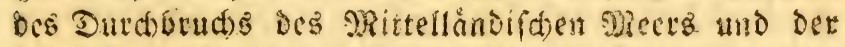

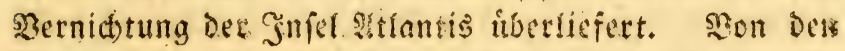
firtsterliden Sataftrophen Der Fit fondere id aber alfe

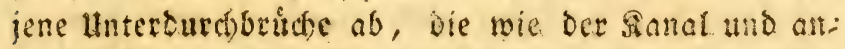
bere Meerengen allmálifid cintraten. Co wie fie aver

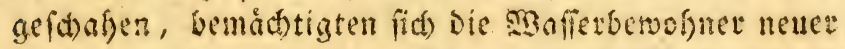
Sander, und verberiteten fith auf biefe sabife immen weiter uno weiter.

\section{3on ber grauen 2lmbra, oeer amber *).}

Şd rede bier von ben unterfudungen aber sie

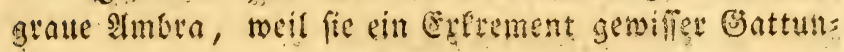

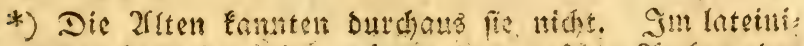

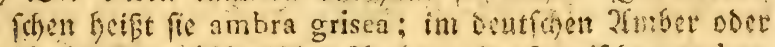

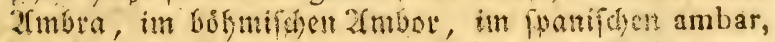
unt im italianifden ambra grifia lino ambracane,

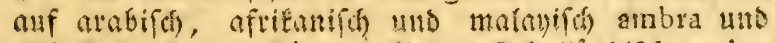

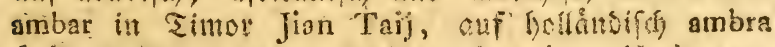
de grys mo graatwen amber. Serapion, Herb. cap. 196. - Zinga. Avicenna libo 2, Cap. $63,-\Lambda 10$ mendeli er sela chrifticum. 


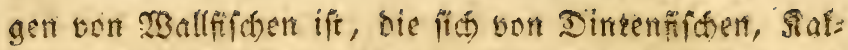
mats, und \$olnpen nåfren. WBit håtten igrex aud

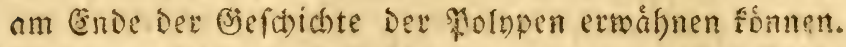

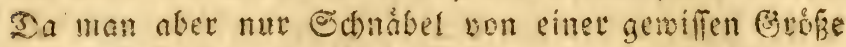
in ifre antrifft, und da biefe Echnabel nie grober find, als Die Der Sintentiltae und ciniger Ralmars, D. h. eines

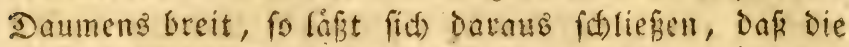
Ednåbel, bie fidh in bicfer Eubftang, die man bishet füt cin hargiges Gummi angefefon hat, finton, bon Diefen Ifjeren fino, welche - Den Sebfalmat von Ehifi ausgenommen, nie fefr grof und ftart werden.

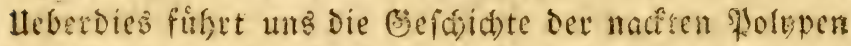

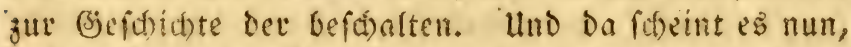
Daf Diefe (Dis befdalten) oun ben Madffifiden nictt ges freffen werden. Man trifft wenigftens in Der grauen Imbta buthaus feine llebertefte Dex verfichedenen feften Battungen Des Sautilus, Der sapiermuforel oder Ars gonaution, an. Sie wurben, da fie hatt uno falfartig firo, fia balo in feften uno bimnen Blatteteden woran ifyee shufde?n beftanden - jeigen. Nhan muß

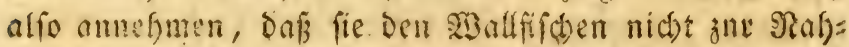
tung vienetr.

Die 23 alfifiche leben fiernach aud won nacten \$o: rupen. Die fleineren verfoluden fie ganj. Sie

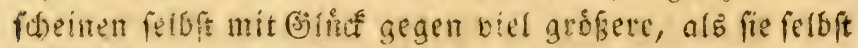
fino, famplen ju fonnen, bent mall hat fibon im

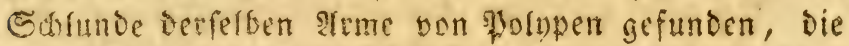
melye als treifig zuf lang waten *).

Coldie Sirme won Pormpen lonen auf eine unges beute Grỏbe Det Ifieve felbft, ju welchen fie geforten, fáliefan. Eobald wir folglid bereifen, Daf̧ bie graue शrmbra ein Ceferement von Mallfichen ift, uno daf die

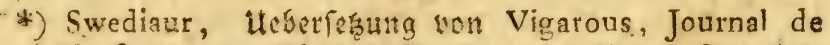
Phyfique 1784 Theil II. O. 294 in ber Tote. Costumi, Bugabe bum artifel bernfe in unt grauer itme bra, Thail V. Diefer ceritiont 0.257 . 


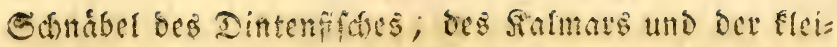
nen Holnpen, bie man in ifre findet, nie hber einen Zoll lang find, fo fornen wir bie stmbra me ben Eetas cen jufdreiben, dic feme groke shollusten wie z. (5. cinige Gattungen von shoispen theits fint, theils wers

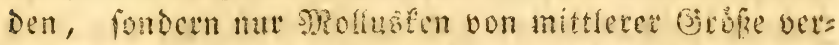

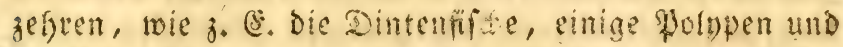
Die cafmars cinen cinjigen aแsgennmen - find.

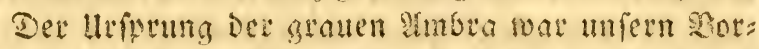

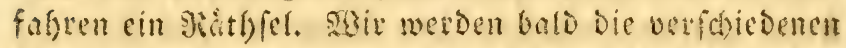

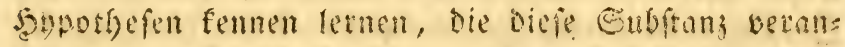
lafte; zuvor bemedfe id flat aber, dof Buffon zwat langs anfand, ob or fie unter "bie minatafifis = ovec

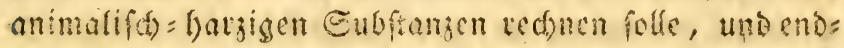

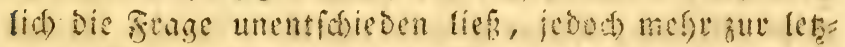

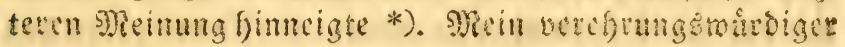

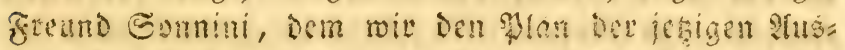
gobe des Buffon, uno eine smenge anmettungen, die es wertí) fint, neben cincm folde en Tegt ju frefon, verbanten, nimmt bie crife Meinuma an **). Fr falt

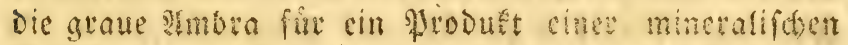
Deftillation; zmo fetet fie folglid unter Die Stemofe,

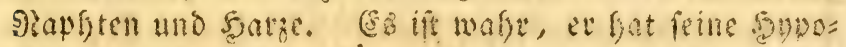

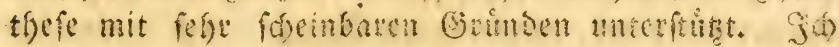

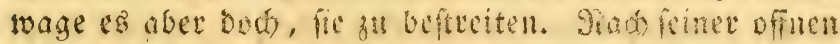
uno colen Denturgeat wiro eves min fidet nidjt het nefmen; fondern wenn meine Mecinng Oninde gen fur fith bat, fie ztedf unterforeiben.

Die grane stmora if eine meide no flebrige

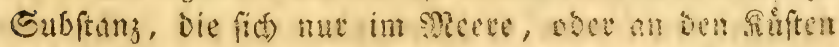

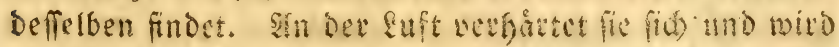
gerreiblich. Eolange fie weid ift, hat fie feinen (s)=

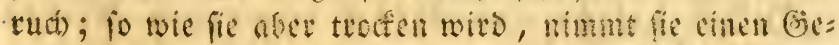

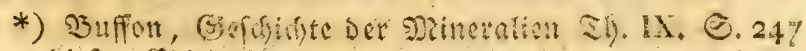
Diefer Csition.

**) Sonnini, thononf @. 248. u. [. w. 
rud) an, und in Diefem Sultande ift fie range Brit hit: Durd eine ganz vorguglidie Epecerei gewefen. SMan finder fie in Etuden, bie bard mehr bald weniger farbig, bald arober, bald fleiner, bald laatter, bald rocider, bald mefr, bald minder mofleied)end find. Smmer ift fie blätrig; und entigalt Sctnabel von Dins tenfifder und andern leberbautigen sollusen in iid), befonders wenn fie fid in betridstlid en Mafen findet.

Fyie Fatbe if zroar anfangs afd grau, gebt aber Durch alle Edbattirungen von Brau bis zum Sdinarg. Se nather fie Diefer Farbe fommt, Defto ferbredtidy und hâter ift fie. SMenn fie rein ift, fann man fie

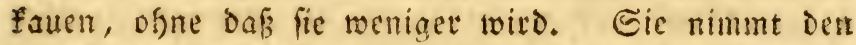

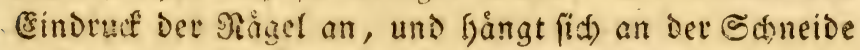
eines Meffers, womit man fie fifabt. Durd) Reribur mit Der Sond fann man fie glatt, wie Scife oder Shon machen. Te àtter fie wird, Defto angenefgmer wirs ifr

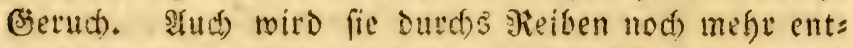

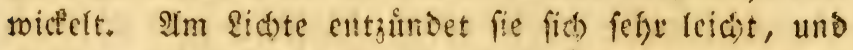
brennt, bis fie vergefret ift, mit cher felye lebraften Flamme. Wirft man fie auf grifiendes eifen, to f(r)milgt fie, und entjindet fid cbenfalls, ofjue cin $\Re e=$ fibum zurtid zu laffen. Ifuf Foblen raucht fie, vet= beciter einen fefia angenefmen sesud, uno jewfomilgt in ein idwarzes uns diçes De!, Das ofne eine Epur

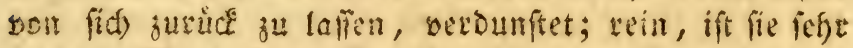
teifft. 23enn fie trocten ift, fdrwimmt fie nidht blofi. auf Dem sleerwofier, fondern aud auf bem funen.

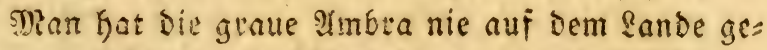
funden; wir iennen fie foled ththin niát als foliil, un= geadjet dies nicht onrd)aus ummog!ict wàre *). Das

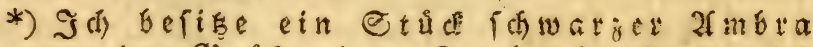

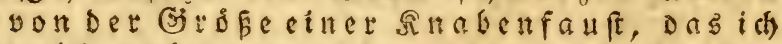
nebfe mefreren andern (Die a ber bei ber

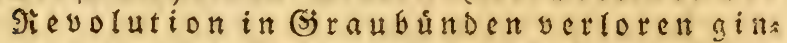

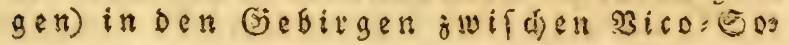




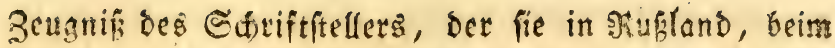
Unmeroben eines Etud Landes gefundon habon will *), ift menigitens verdåd)tig. Dagegen hat man fie in Dear Meeren afles vier (erdtgeile, vorguglich aber in benen, bie vicle Wallifiche und anore eetaceen entfalten, ges

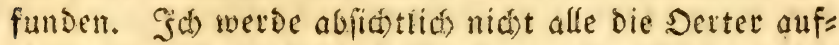
áaflen, wo man fie findet und gefunden fat; warum follte $i$ (d) SBuffon und Eonnini in biefen Punten $a b=$

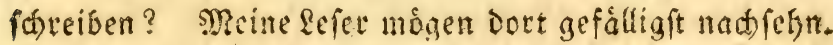

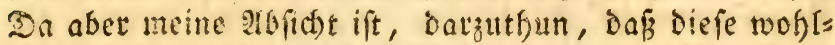
viećfende Subftan Das Extrement gesoiffer Cetas ceen ift, fo merde ich alles, was bicie Meinung bes ftäriger fann, neben einandebfeflen, und defen Srtifel mit cinigen fartis befthliefen, die ben beiden eben ges

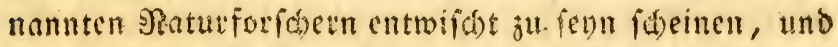
Die verforedenen şeranserungen betreffen, welde die

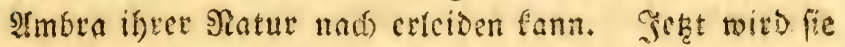

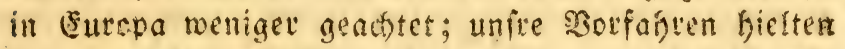
fie abe: Dem Golde und bem Diamanten glcid **). "Das s)ieer wirft oft graue ambra in grolsen sunanti= tåten auf bie Suffe ser sfrauter uno im Srdbipelagus von Efiloe, aus. Sie Gindier nenner fie $M$ a y ène (8. h. Ceftement Des SBalfifóes), und befaupten biefe Eubfanj fer, to lange fie frifo auggeworfen ift, fátrary, bann werbe fie braun, endidi aber, twenn fie

prano und capacia fand, unb oab alle oben a ugegebelten feigenfer aftest it fi vereinigt, uno noch risgo unther mit oet.

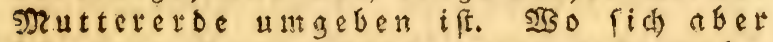

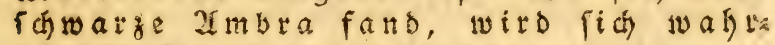

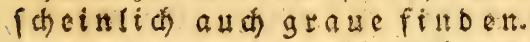

Inmert. Des lyeberfeserz.

*) Duffort, Hif. des miner. If. IX. Diefer 2luşgabe. O. 234, in ber Note.

**) Da cies Cirate find, fo babe id mit nur felten et. raute, fie n'juEurgen.

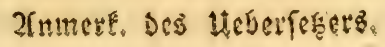




\section{I86}

range Der Eonne alfogfeft gemejen fen, merbe fie

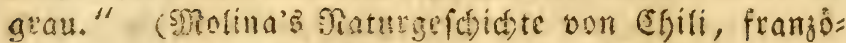
fifbe licberfetung S. 63.)

"I Man hat bic grate smbra im Soggen uno in sen Cingemeioen einiger Setacen gefunden." Buffon,

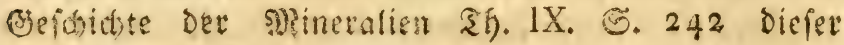
(edition.)

"Sămpfer fogt, mon ergalte fere vorzinglich aus

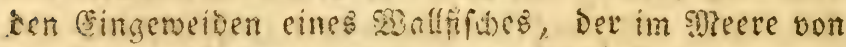
Goan gismlid gemein ift, mo Fiakfiro genamt

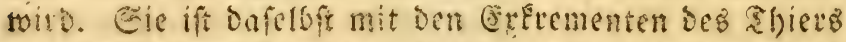
vermifut." (

"SMan belt bafite, Daf́ bie graue Ambra thieri=

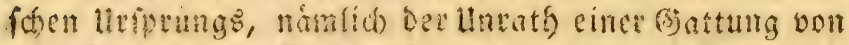

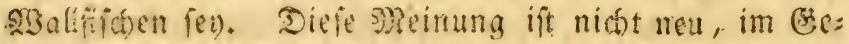
gentheil if fie viel äter, als bie Sdiriftiteller meinten,

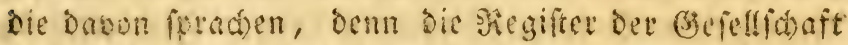
in Sondon vom ģafie 1063 enthalten einen Szricf, Der Don Buntam aแs unterm 14 . Fosember 1602 Dotivt

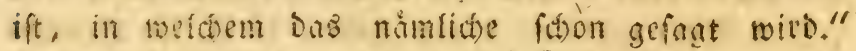
(eiche Den suszug der philofoph. I ransactions. Fift. nartie Tom. VIII. p. Io8. Paris, SBuifon Sonnin, 3ung fu Dent sertfel a mbre gris, Hift. des mineranx, Tom. IX Dielex (Soltirn.)

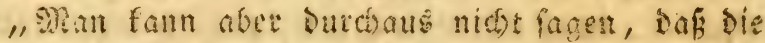
foron feft: alte oneinung, bic graue smbra fer tin

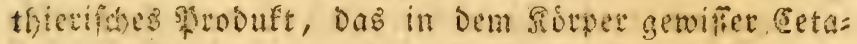

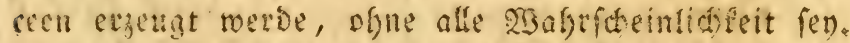
(Eie fitht fich vielmegr all unlaugbore fofta. Sill: Die folgerungen, bie man baraus zicht, ideinen mir noć) unfić)er zu fenn." (Somnini, am gleiden Dot, (5. 259.)

"Die neueren shaturforface baben Diefe Folges rungen angenommon, und beshalb aufgebort, bie graue Stmbia fit che minctifite Subjtanj anjuffhn. Sie

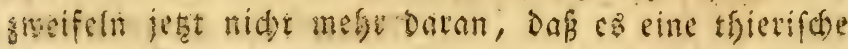


Mgatcrie fen, bie nie in ber erde berfadart toat, und bie man fo auffammelt, wie bie 23 alfifiche fie von fio geben." (Delamétherie, Sciagraphic de Bergmann, Tome II. p. 27. - Eomnini, am gleiden orte, ङ. $25 \%$ )

"Die graue 2 mber miro ju bell foftbarften Dingers

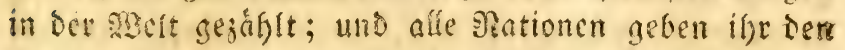

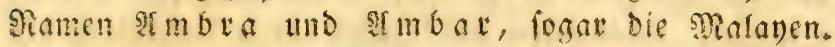

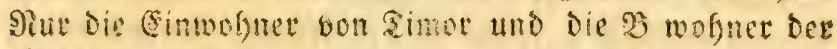
firoffriden Gmfern nidt, benn biefe nenmen fie vers gliden mit iferm bohen asertfe, fefor uneigentlich "Jian-taji"D. W. Ceferment Des Sifhes." (פum= pfins in feinem Sabinet oon Simboina, S. 255.

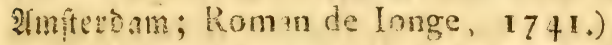

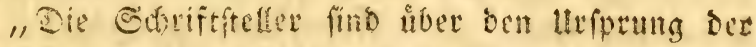

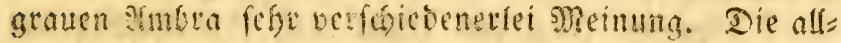
gemeinfte siolfôncinung unfer Gnfulane, uno die ju= gleith) bie altefte uno liberall angenommenfe ift, ift bie,

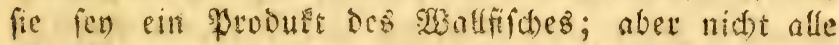

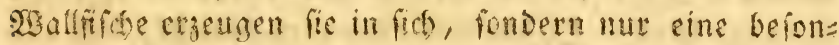
Dere Battung Derferben, Die Die Iraber $\mathrm{Azel}$ nens men." (Shumphitis auf Derfeiben Seite.)

"Fat von Ceclufe melbet in feimen Bementungen úbit Dic groue simbra, bof $\mathrm{er}$ in Franffurt einen ges wiffen Eeruais = Marel gefannt habe, Der, bei feinems

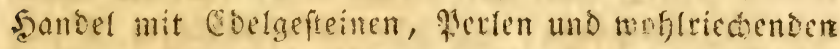
Gadjen, febr vicle fanter Durd)reifet batte. Diejer babe ifm verfithert, die graue Simber fer nidits meiter, als ein unverdoufictir filumpen, ber fich bonn uno

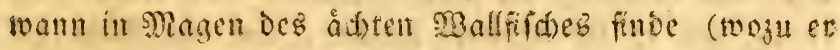
sber ocn Srea, \$forfeter, unb andre grofie mit zåfrnen

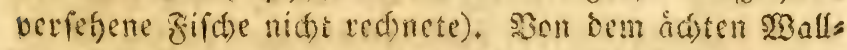

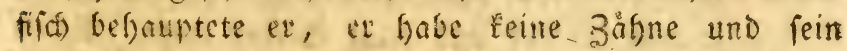
Sortund fey ferte enze, el fonne baber nur fleine

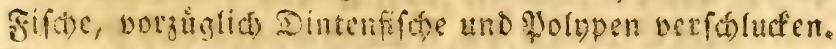

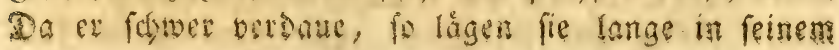




\section{8}

SRagen, uno bilgeten jultst einent gohen fulémigen Stumpen, Der fid dort fejtiete. Saerde abir biafer

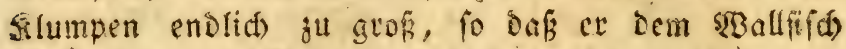
Echimerzen verurfache, fo fisffe er ibn fart. Wefer

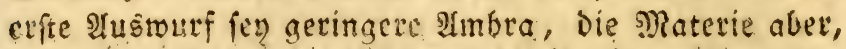
Die fo lange im magen liegen bleibe, bis fie geipirig

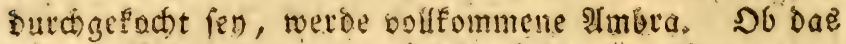
ermágnte sugiverfon alle Gabte ober mefrmals bes

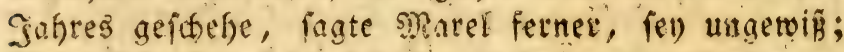
foviel fen aber ficher, dafis man feite atane smbra im Skagen des $23 a l f i f d e s$ finde, wenn ex benfetben vorfer,

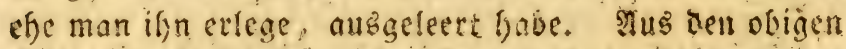
Giunden treffe man aud Dintenfifaldnabel - Die

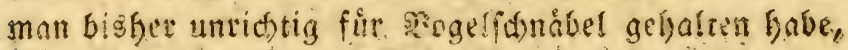
- in Der ambra an." (Rumphius, p. 256.)

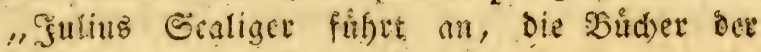
Manten feren voli gharfahen, bie beweifen, baf sie Imber in oen Mallfichen entfelit, uno daf in zet uno Marocco fogat biefe Sonttung von Eetacten $\mathfrak{A} \mathrm{m}$ ba $\mathrm{r}$ genaint wito. Ee Eemett aber eben fotoofl, Dof von allen 233 (Ififichen, bie ex in Der San yon Biscana fans gen lafe, uno felbft von allen, oon twelden er reoen boite, Ein entriger graue smbra enthietr." (Rumphius, p. 256. - Julus Scaliger, Exercit. 104.)

„I Sabja Salomon Epetmanis, elpemals Rónig

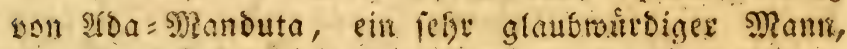

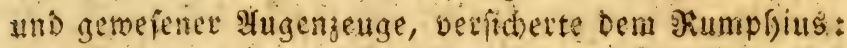
ungefăbr in Sabr 1664 fen in feinem ehemaligen \&ande

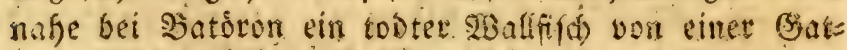
tung, bie ex iju-ambar nannte, auf die sifife ge=

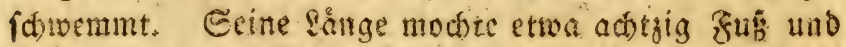

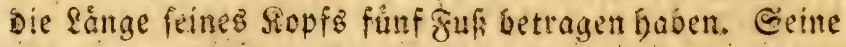
Eanauge toar ftumpf uno peite Etime rund. Ueber

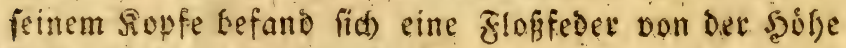
eines Meriden, bie fid) funfundiswanig fuf weit auf

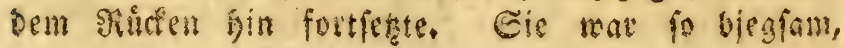




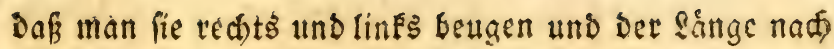
jurideflegen fonnte."

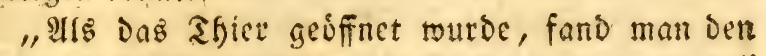
Baud) (Dev foft fo grob mie eine Etube war), ganz bolf grauer Ambra. Die vortere, náfyer berm Sdlumbe war reifílich und rofferig; Die aus ber Mitte war graugelolich, und Die hintere ganj fefwar's und flebrig

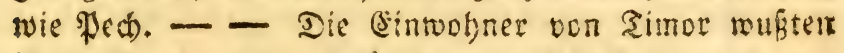

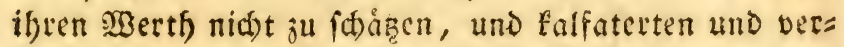
pidten alfo ifie Pitrogen Damit, bis endich Die Crin= wogner oon Macafiar fie Daourch belefrten, Dafi fie

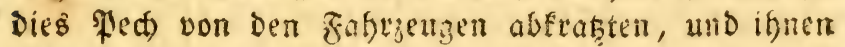
abfauften, um $e$ s mit nach Sauje zu nefmen." (Kumphius, p. 256 und 257.)

"Die Fintoofner von Sava glauben, die graue

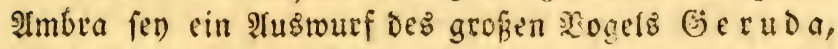
Der auf bem $\mathfrak{a}$ aume $k$ aes lingi mofnt, meldet al

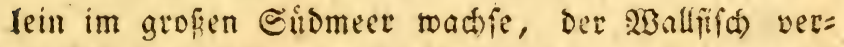
fd)lucte Die (Exfremente Diefes Bogels, und ba er bie Ambra nicts verdauen fóme, minfe er fie toicder weg= brechen." (Rumphius, p. 257.)

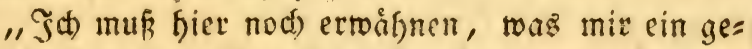

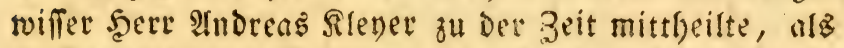
er Bouberteur in Sapan wat, und mir mefrere Briefe fiber Den Imbrafifd) (ambar vifch), Den man bei $\mathfrak{I} a=$ pan finde, foricb. Sein erftet Brief ift rom 28. Februar 1695. "Der Fif fa, fareibt er, yon Dem Die graue Imbra fommt, witd auf Japanefifid hay - ang. kie

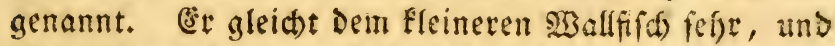
ift von Dem, ber man Sior b aper nent, Durch Dit

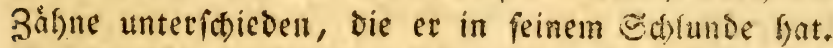
Der Pordfoper aber hat feine. Zwei Derjerten fino fehr bervorftefyend, und zeigen fid), wie beim smats=

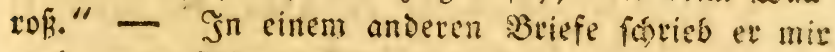
nod), man finde an fefre vielen Srten von Gopan, be: fonders auf ben Snfeln Riqui graue Imbra. Dieje foum 


\section{0}

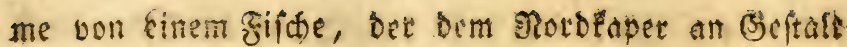

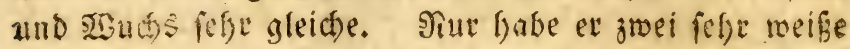
Sauer, dic aus feiner oberen Simnlade ginuntervărt

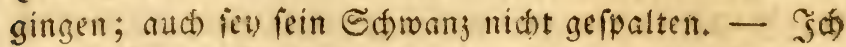
erficit feinen SBrief burd) einen Sapanefer, der fiá) ferbit lange mit bem sBollfifdrang befabaftigt hatte, uno der mit verficterte, man erfenne es an getwifien Zeichen, ob bie erwafgnten fifde cine bedeutende smen=

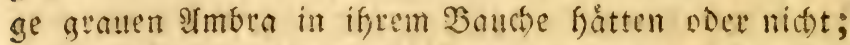

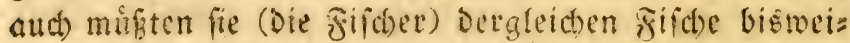
len ans Rano bringen, uno bei Rabengittafe in Gegen:

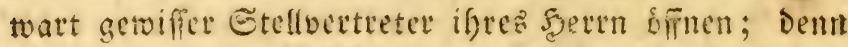
Die bebeutendfen Stude Smbra murben fir sen Serrt in Befits genommen, Der ifnen Dagegen Die fectigen Sticte uno Den noch firfingen simbra laffe; auth bleibe Der ganje Siorper Des SGiers ifjen, fie zerftuctelten Den= felben Dann, um Del Daraus zu fieden." (Rumphius p. 262.)

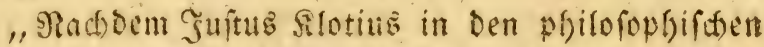
Anterfudungen mefrete Sonpotgeien, Die graue 9 mbra betreffend, angefungt fat, glaubt ex, fie fen nidts ans

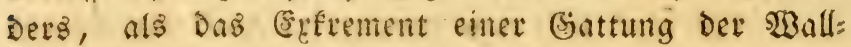
fifche." (Rumphius p. 363 .)

"MomatDus verfidert, man habe aus Dem Górs per eines malffictes fundert pfund graue Imbra ge= nommen." (Mifcellanea naturae curioforum. Rumphius p. 264.)

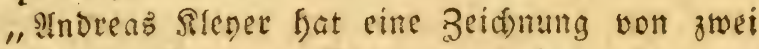
W3allfiften Der fleineren (Satting geliefert, bie man grwif(t)en Den Jnfeln bon Japan Befangen batte, uno in beren Sorper man eine grofe Nange grauer Imbra fand. SBagritseirtich folgte man Diefem Schriftitellex,

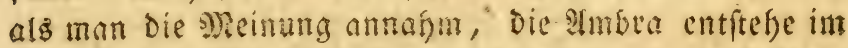

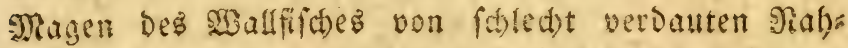
rungsuitteln, Die ber fifch folglich wieber von fid) ge= Een miffe. Dafer fommt Denn auch mofl dis Mrinung 
einiger Indern, welde Dic anbra fur Das certement,

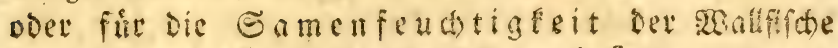
fielten." (Mircellonea naturae curioforum; zacite

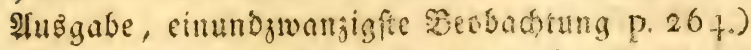

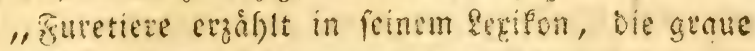
Imbra (en nad) Der şeinumg ciniger Edriffiteter ent:

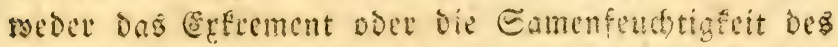

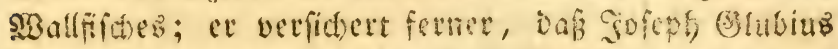
in feitier Gefdichte der grauen simbra lage, bicfe vors

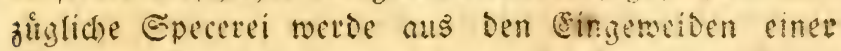
Battung $23 a l l i f d)$, mit Momen Iromp (mat Das Thier einen ßiffel (trompe) anf bem sopfe Gabe), ges nommer. Seine fiefle fen mit Săhnen won Det Sicte einer fouft, und won ber fönge einer sano verfelsu; auch finde fiós die graue ambta, (fonft auth) Spcrmacé - Sperma Ceri - *) im sopfe diefes soaflfiches." (Dictionaire Des furetiete, unter bem Irtift amb re $\mathrm{gr}$ is. Rumphius p. 205.)

"Furetiere werficiset ferner, nach ser Meinung

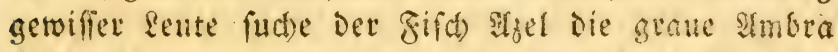
ferte begierig auf, frerbe aber, fobald er baton gegefien babe, und fdrwimme Dann anf Der sberfád de 23 af fers, wo ifm bie fiffer Den Souch aufrinen, um bie

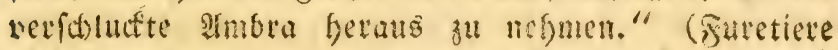
und Buripfius, an Den gleiden Soten.)

"Eefre unterrict)te und weit gereifte fanffeute befaupten, Die graue âmbra fen nidists ats cine sirt von (Exfrement, Das fich allmåflich im Dengen bes ióten

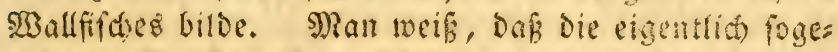
nannten $23 a l l f i f d e$ feine Băbne baben, fie fultuden ba: her die fifáe ganz finter, vorziglid bie, deren fleifd) weid) ift. Dies bringt natirlid) elne side uns

*) Sperma Ceti if eitte weifgetbrict) Subramz, die meiner

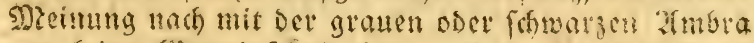

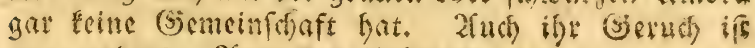
gonj anders. Zfmm. Des heferfer. 
verbaute Mlaffe Gerber, bie ailmáflich ben stoagen bie: fer Sgiere to fefre anfült, oafi fie gegroungen fino, fie entweder jåfrlich, oder zu gewiffen zeiten von fich zu geben. Die to entitundene und lange Beit im \$lagen

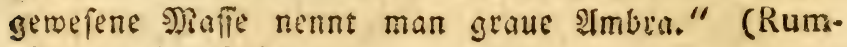
phius, p. 268.)

"Jch) Eann nicht lêtignen, fagt Rumpfius felbit, - Der, fo viel er auch úber Den uriprung der grauen Imbra beibringt, fich Doch nidot überjeugen lafien will - ich fann nidht låugnen, Daj man zu meiner Zeit in Der Gegenden Der fanariforen Jnfeln einen 2 Balfifica fing, in beffen Cingerveiden man hundert Pfund graue 2lmbra fand. So man aber gleidh nach diefer Entbe"

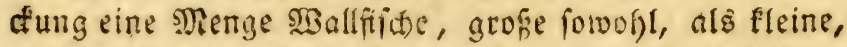
getodte: hat, fo fand man Dod) nut auferft roenig थm= bra in ilgnen." (Kumphius, p. 269.)

"(s) giebt Jienfiden, die befoupten, die giaue Ambra fomme oon einer getoiffen feft maflriedsenden Frudt, die an llfer Des Mecrs wadte, und in ben Sjionaten Afptil odet Man teife; Die Zrutht falle Dann

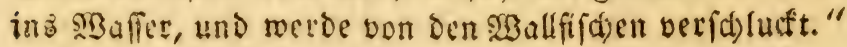
(Kumphius, p. 270.)

"Die fotwarje Imbra, die man unter bem গa: men ambar de Noor t fent, - welde Benen=

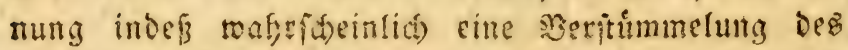
franjofiffen ambar de noir ift, wiro gemeiniglid

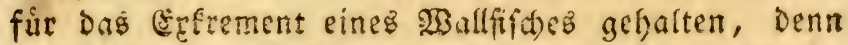
man findet fie geroofnlich in linterieibe biefer Shlere, two fie mit Der wafren grauen Afmbra vermifost ift." (Kumphius, p. 27 . Sap. 36. Son Def fatratzer शimbra.)

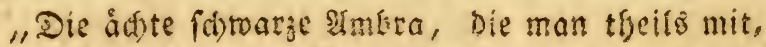

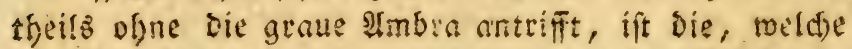
Die 23 olffiche custverfen, who bie in grofer Etuten in

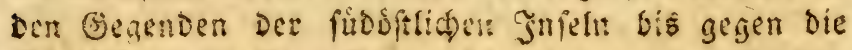

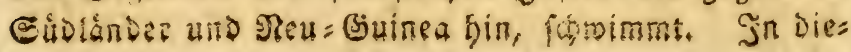


fen Begenden trifft man aud eine Menge SBallfifte ait." (Rumphius, p. 274.)

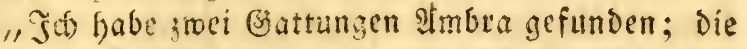
eine if mener Meinung nad) entweder mit oder ofme

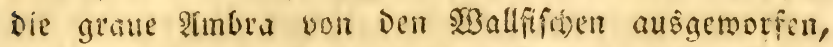

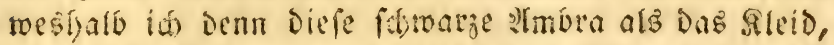
als bie foulle der grauten anfebe. Stie erlangt bie fdrwarze simbra Die Sarte ber grauen; fie befalt aud immer einen Eegeru(h), befonvers wem man fie auf glífenie Solfen wirft; man findet fogat mandhe, bie

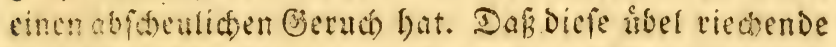
vom malfifide fommt, toeif id mit vollfommener (se= wisfert, Denn im Gab: 1077 beadite man mir ein Stuck gratier Imbra, bie dem effen Infefrn nath felfe vor=

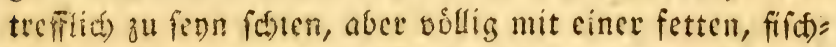
artigen Subftanj oder ștulle iberzogen war. Allmåb) litf nafm fie eine feftere Sonfifeng an, Denn es wat

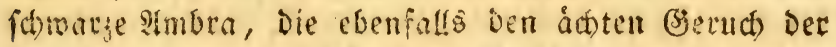
granen verbectêt. Die fiswarge Sulle, Die voll Din=

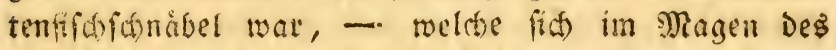

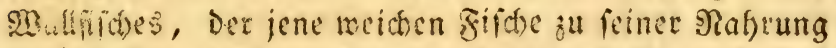
veridfute, notforndig mit biefer snafie verbinden mugten, - beweifi vielleidt, Dab Der flelurige Edhleim

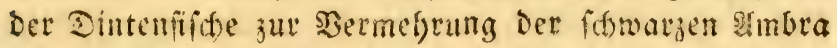
Dicnt. Die ganze Miafie grauer : Mhanippa auf Der Sberfledde Des Metrs, und mar von einer sjenge şogel uno fiftse umgeben." (Kumphius, p. 275.$)$

"E⿱乛龰 gefort noch eime andere Subftanj zu Der veribiedenen (3)attungen von Imbra; wir iennetr dies pelbe Seefpecf, auf malnbarifit) beift fie, I I an poenja monta " Sie hat einen ůbeln pechartigen

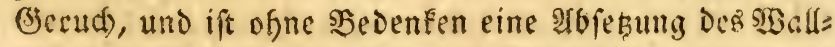

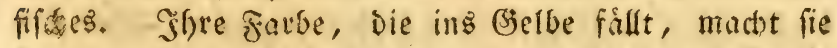
Dem zu alten und Desfalb ramig getwordenen Specfe

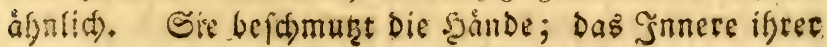


Maffe it faperig und fo in eimander vertwebt, baf ca

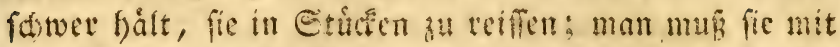
Dem Mrefer jeridneiden. Det Geruć) Des Erefpecfs, beim serbremen Defietben, if ftinfeno, wibetid und

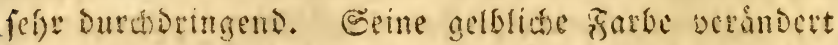
fid mit ber Zeit in Etwroargrau. Im Jahr 1640 matf

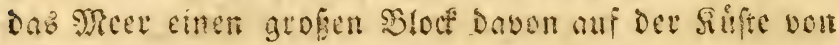
Manippa aus. Cer blicb it ber Gonne liegen, und fing Dafelbft an zu fdmelgen, ohne daf jemand batauf actete, bis ein mit jeinen sumsen ba vorbei geffendet

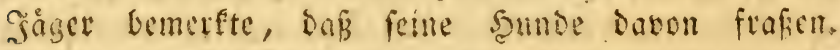

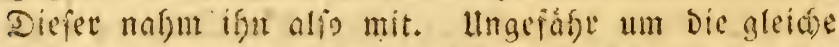

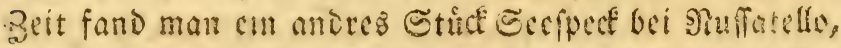

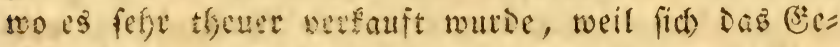

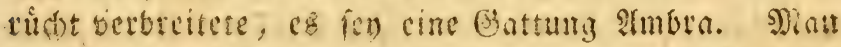
bead)te es nad Gava; bie Gabaner aber berladten Die

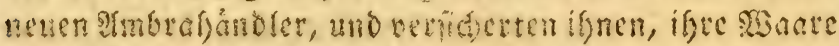

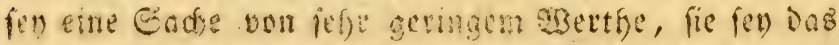

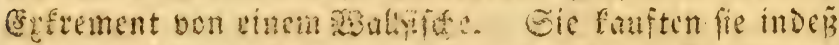
um einen billigen treis, meil fie son Eecfred fefor gut

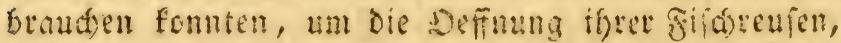

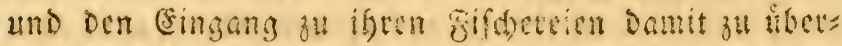

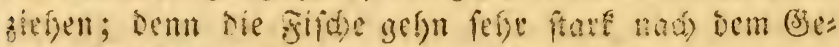

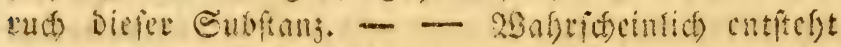

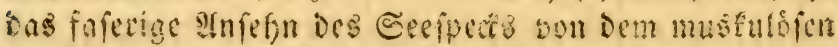

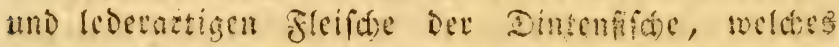
femet Sute wegen nidt gut ju veroanen ift, fid bofoet

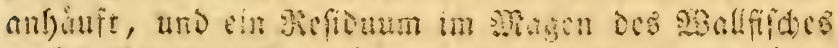

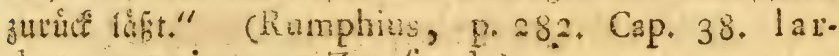
dum marinum; Zee( pek.)

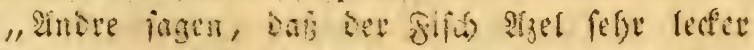

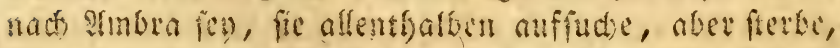
fobato et fie gegeffen babe. Die Bifore, bie (Exal)= rung genug baben, jebsen biefen ofich, wern fie ifn

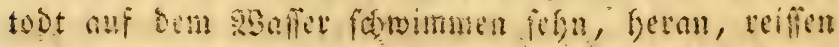

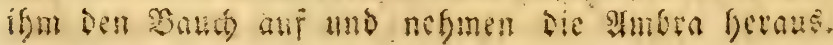


Gie verfichen, biejenige Ambia, die man am nåduter

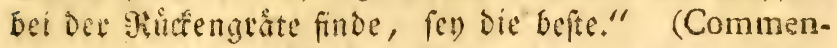
taires de Mathiole fur Dioscorides liv. I. cap. 20, gegen das (ende.)

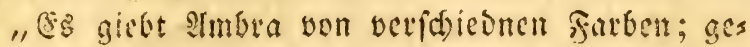
wifnelich ift fie gran, aber auth bon ounfler farbe.

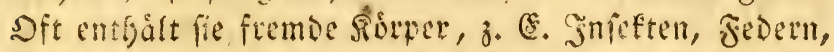

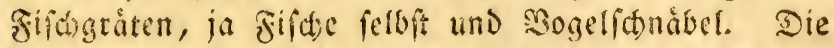
Itmbra, Die man altb Den SBalfififen nimmt, bie

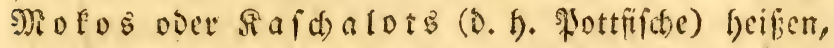

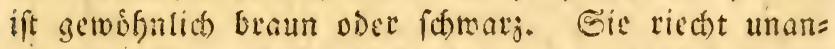
gentsm. Die gefecte ift die befte, befonders die gelb= geffecte; Die fdwargeffedte if meit weniger gut." (Transactions philofophiques, no. 385, 387; uno Bertrand, Dictionnaire oryctologique, bcim $230 t t e:$ ambre gris.)

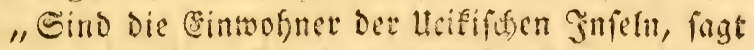
Sffeuct, glaich fo unwifiens, Dabj fie Die Perlen, Deren

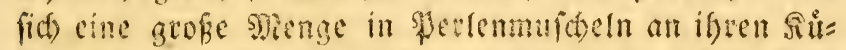

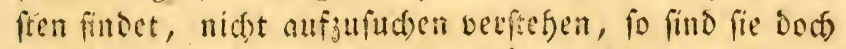

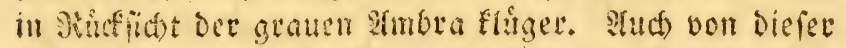
findet fia) eine grobe jienge nuf biefon Jnfeln; Die Mofyen fammeln fis und setfaufen fie andern Mationen

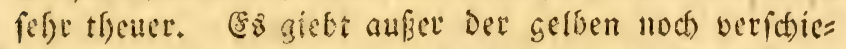
Dene Iteten oon stmbra, und wicoer verfdiedene Gat= tungen Diefer Arren. - - Dic rsue Prmbra ift nach) Der Meinung Mefreter nidits weiter, als Das (ex= frement bes siallfifches, bas fić) aus ben Sanalen bie= fes ungeffeuren filides ausfeett, und bald nadber ans llfer fidwimmt, wo es fid Dann reinigt. Se witf)ender Das Meer ift, Defto băufiger fowimmt Dics deferement umfer. In Der Conne verfáatet $e$ s fich uno erfált eine Int von Sdyale. Man findat es ouf ben jandigen ufern, Felien und Alippen. Semeiniglich bat Diefe Mraterie andere Unreinigfeiten angenommen, aber Die Mofren, Dis fie famment verftegn fie ju reinigen und die gute 
son der fabigen und hbefriectenden genau ju untev= fatiden."

"Einige Sndianer baben mir verfictert, fie fer

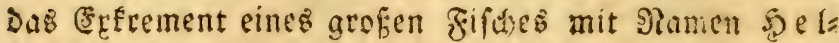
merich, ber fleiner ift als der Mallfifé), und die gute

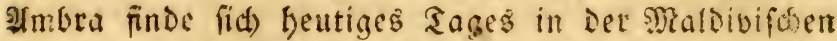
soer Dangedivifien Snfel, Dreifig Stunden bon Bra, too man auch einen gerfien firch, mit Jiamen \& anteffe, Der bem sBallfictie nacigeft. allen femen Samen verzefrt, und nie genug Davon befommen fant, fo Daßz er endida berfiet, mo if,n Dant Das Meet ans Ilfer wirft, Die Jgnfulaner ifgn finden, ifm die Einge= weide herausnefmen, und Den Srt, wo fein Eame liegt, aufuctien. Indre glauben, dié groue Imbra fer Der Same, Dent Der måanlide şallfif bei feiner Segattung mit Dem treibliden verfiete. - - If uvet fagt ferner, Der Bogel afd ibotuth fude ein anores Thier auf, Das Die Eingebornen Allofarcat Doer Algelouim nennen, fas meifrens unterm baud)e, nafe beim Nabel ein (Sefdrwir hat, welde's es fid nad) Der Sage Der Snfulanier - Durdbs fraten juziehe.

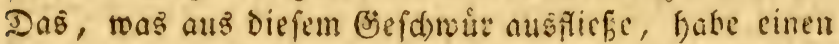

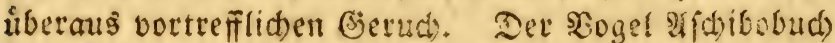
babe cine natirlide Zuneigung zu biefem Sfiere, made (id) Dafer zu ifm, und fange ifm fein ganjes sefdmus

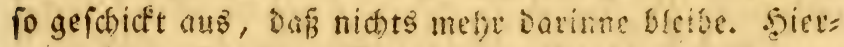

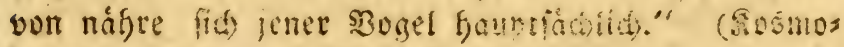
graphie von Ifenet. \$and I. C. 100 mD 101.)

Bisbor babe it die semumgen ber återen Feifenden angefurft. Jigre 3eobattungen waren no turlitherweife nue rag uno unveftimmt; bie, bie wit mun noch Damit verbinten roolen, um fie zu unterftitan, tycien weit beftimmtex fern. Sic befitsen alles, was

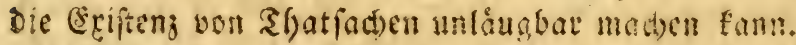

"Sh Subl 178: febrte Jojua boffar (sepitain

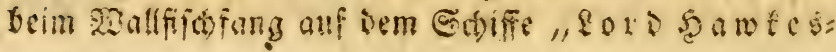




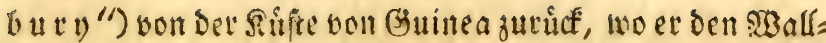
fiff fang mit vielem Srlide getrieben batte, und bradte

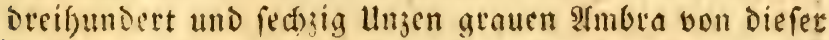
Reife mit, die ex faft alle in bem Baude eines meiblis d)en Safdalots (Wottifiches) gefunden loatte. Dies ertegte Inffern, und Gofua coffin wurbe eingelaben, in Der Katl)soerfammlung zu \$ib)iteball in (Segenmart

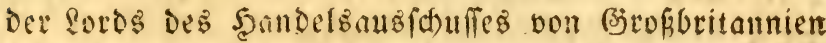
3! erfocinen. (5r beantwortete Dafelbit bie Fragen, Die man ifm vorlegte. Diefe juriftifde Unterfudong

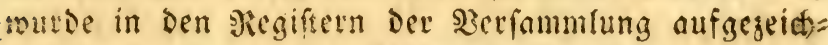
net, tho 1791 in den \$gilofoph. Transations im er= ften SGrife unter Dem Sitel: Gefammelte Benadiditi= gungen, Die der Rintiglichen Gefellidati nou fondor

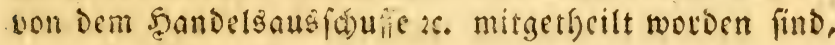
georudt."

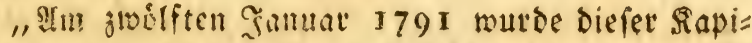
tán gefragt, ob et wifie, Dafi fruffer fáson bon engli=

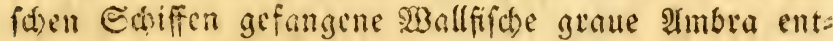
balten båtten?"

1/ If two ort: Cir fyabe bies nie gebort, wohl abet iviffe er, Daf amcrifanifhe Sdifflcute Dergleidnen an: getroffen bátten."

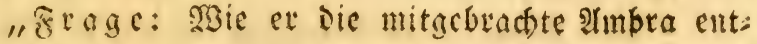
Drift babe?"

11 If twot: Civ babe untcrwarts Dem SGiere eis nige freaubommen fefen, und barb Darauf habe cin Etud auf Den गreete gefoloummen."

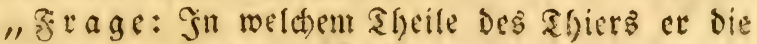
ubrige Ambra gefunben babe?"

"I ntwort: fas fen in Dem gleiden Ganal und, einige gerofen. Sab ubrige babe fid in cinet etmas tiefer liegenden und mit Diefem fianal in serbindung

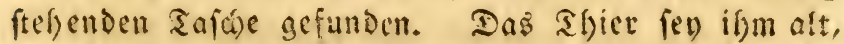
franf und magex vorgefommen, und ex glaube, Daß

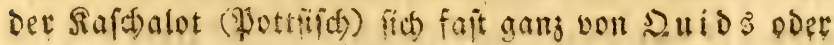




\section{$\mathbf{r} 98$}

ad)tatmigen Dintenfiffen naffec. Cre babe oft gefehent, Dof fterbende Mafdalots eine grofie sienge biefer fis The bald gans, bald theilmeife, von fict gegeben betren.

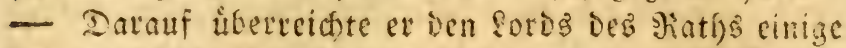

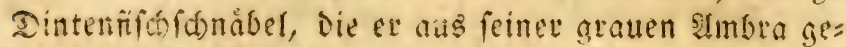
gogen und aufbefialten batte, uno verfiderte, ex habe einige Diefer Súnabel tief in ber Imbra, andere cufifrem Ifeubern gefunden."

Journa! de Phyfique, Sanuar 1792.

Ecit jedizelyn Jafren, die Diefer Geemant bert Mallfifhfang trieb, war Dics das crite Misl, baf ein

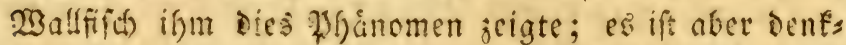
bar, Dafier forohl, als alle andere Schiffstapitane von nun an bus Snneve dev von ifnen gefangenen sallfifiche fefre genau retden unterfubt haben. Sch habe diefe

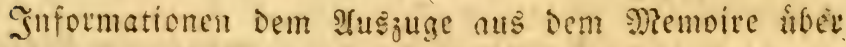
bie gram almbar voraus gefóidt, meldes Emedian befant madte, und meldes in lounal de Phyfique I784 Tome 11. p. 278 uberfetgt mutbe. Man barf nut Die Data umánoern, und alle Beobaditunaen tmo Ifatfaden, Die Diefer Gelefrete aút Jafie frifjer an: fitfite, werden um io mefre berwidt und beweifonve Silaft erlangen.

11 Dic \&ute, lagt Sivediaut, Die beim şallfif(t)=

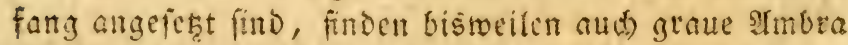
im Interteibe biefer (Eetaceen, aber inmer in Mafen von werfotedenes Beftalt und Brofize, bald eine balbe Urije, bafb bis fundert Pfund fismer."

"Ein Fiffoer von Intigoa, fágrt Swebiaur fort, fand vor einigen Jafren, ungefáfr jtoanja હtunder füboftlid yon ben Gnfeln Des şindes cine Miafie grauer

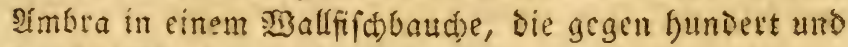
breifig \$fund wog."

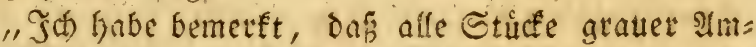
bra, Die cinigermafen betråd)tlid find, cine grofe Menge forwarger zlecte Gaben. Slach ciner forgfälts. 


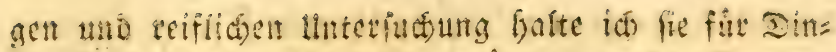

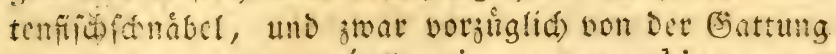
Der Eepia, Dic Emé Sepia octopodia nennt. Das befte ijt, Dofs Die Gtufe Smbra, die man auf bet Sbetfad) Des SBecrs gefmicn, mo Die, bic man aus

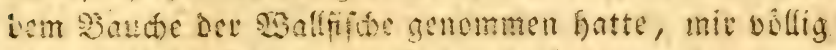

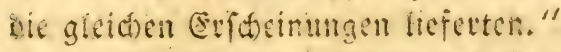

"Elle siselt weif fecuriges Sages, baf man die

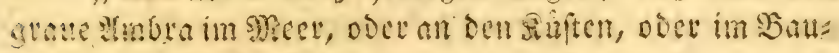
de ber siallfifite firbet."

"Man findet bic grane Ambra bismethen in \$̧an=

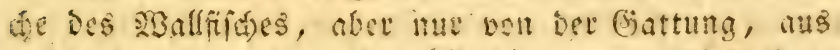
welder man ben Sperma Ceti nimmt. Diefe Gat= fung ift, nad) Der mic semndeten Beidureibung, - bet Phy feter macrocephalus ter fimé."

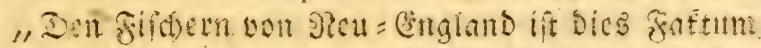
foron lange 3eit befannt, unto fie find fo tiberjengt Da:

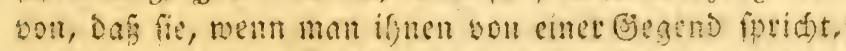

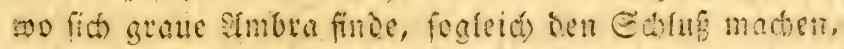

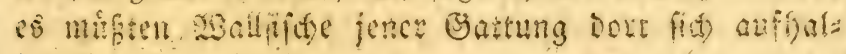
teni."

„Die Reute, Die Lei Dem 23 affifidange angefeht imo, fongen mur bea Phyfeter macrocephalus, und unterueden iba fogieich, of er grane simbra cut

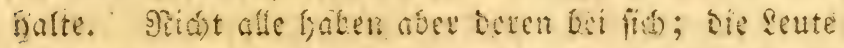
verferisen fict tornuf fo genau, sab fit allemal, fo oft fie cins biefer Ifore gefongen foren, who-bemeten,

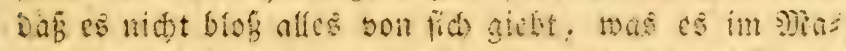
gen fatte, fondern auá) alfes, mas ti frmen fentes

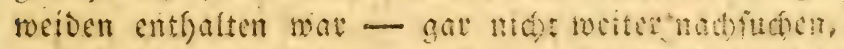

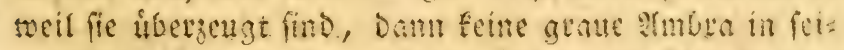

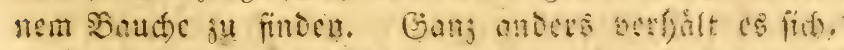

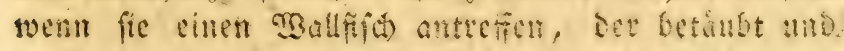

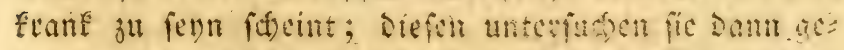

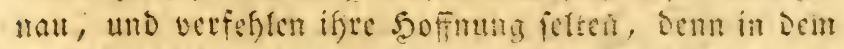

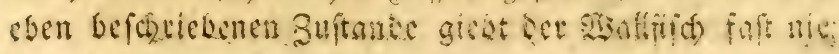




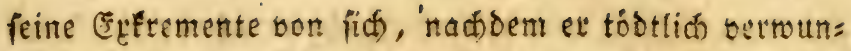
Det urerden ift. Die todten $2 B a l f i f c h e$, Die fie auf Dem Il?ere idvimment antreffen, liefern ifgen oft graue

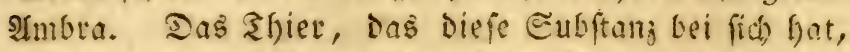
bejist in Der mittleren Gegend des Unterteibes cinen 2us:vuchs, oder wie fie fagen, eine Itet von @act, mor:

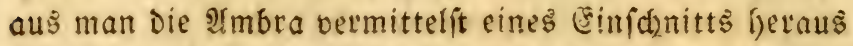
nimmt; außger Der erwålnten Setåubung benterft man

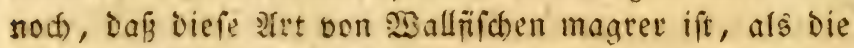
andere. Bieide eben angegebenen llmitande mit einan= Der vereinigt, bringen mich auf dic Mutfmễung, ob ein foldber Şaufen grauer Imbra im Unterleibe beŝ

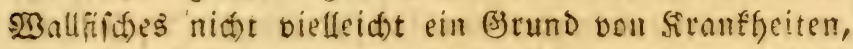
bistweilen feibit vom Sode Diefes Thiers ift. Eobalo nun die filder einsn betåuten, doer franten, oder

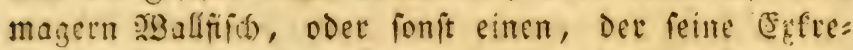
mente nid)t von fidt gegeben gat, gefangen haben, fo

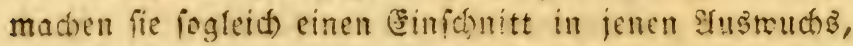
soen et cinen bat; wo nicht, fo effnen fie ifm ben

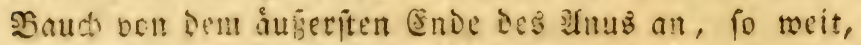
bis fie Die graue Imbra antreffer. Siefe Gubftang fint= Det lia) inmer im Darmfanal, etwa zmei, offer aber fed)s bis fieben fisû weit bom anus entiernt, bald in einer einjigen slalle vereinigt, balo in megreren non verifhiedenter Didfe, und wiegt oft awanjig bis Dreifig

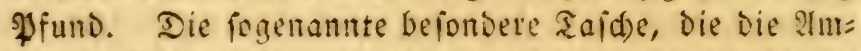
bra in fic entfilt, ijt ni()tร anders, als ber blinde Darm. Cin unlaugbarer Berweis hicroon ift Der llebers zug, Det fich an ben 23 ånden dicjés fogenannten Eacts befinoet, oeffen Gerud) feinen Zweifer úber feine গRatur ubria lást. Die graue ÎImbra, Die man aus dem Darm=

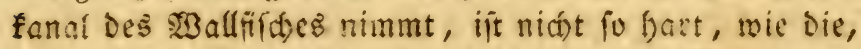
bie auf Dem \$lete fitwimmt, oder an bie Ufer geroor= fen roird. In Der Euft aber verfirtet fie fid cbenfalls fefe fonell. Sit Dem Augenblich, Da man fie aus Der

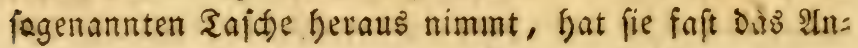




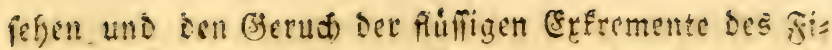
foes; an Der Euft aber verlitet fie Dicich unangenefs= men (setud bald, und erfialt, wie bie Egofolate, einen grauliden Etaubúverzug. S(s:d) eiriger Beit giebt fie Dann Den befunten angenefinen Geruth bon fid."

"Iic Ecelcute, mit Denen id tiber Diefe Materie gefpred en bate, verfiderten mir, dafif fie bie araue

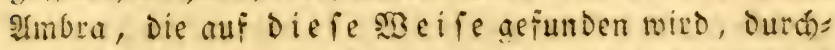

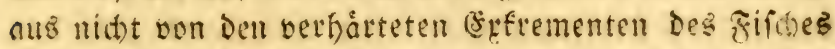
murten haben unterideioen fonnen, menn bic Crifah= rung fie nicht gelelget foutte, Dof fie mit Dare zeit jene

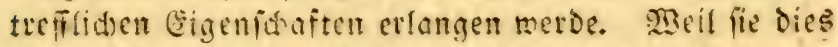
aber wifien, fo unterfudien fie jedesmal, nadiem eit gefongener siallitib) bergleidoen won fid giebt, bie

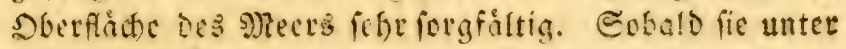
Dex fiusigen Snaterie, woron Sas Shiet einige Tomnen voll vertielt, Ertufe bon cince fefteren Eubfraniz els blicfen, fo fammeln fie fie auf, wafden fie, und ers watten von Der zeit Alufflarming úber ifre Beichoffon beit."

"Dic Seclute, mit benen ich Daruber fprach, Gatter Die araue झmbra fomohl bei ben mánnlicten als meiblicten Ballfifden gefunden; Dow belsoupteten fie, bei

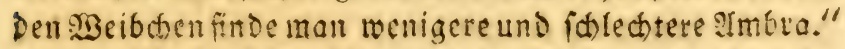

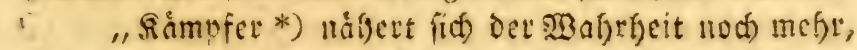
wenn el layt: Die gruae Imber ift Das fefrement bes 23allifiches. Die Sapanefer nennen fie beşfab K

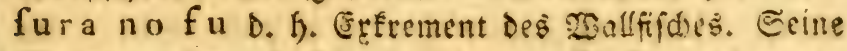
Meinung aber, to fehr lie fid) aud) auf Beobadotunger ftutste, hat nie Glauben gefunden, uno wutbe imure

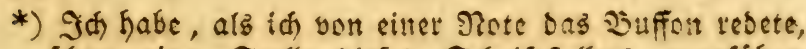

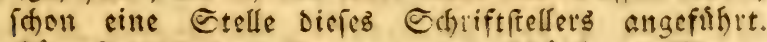

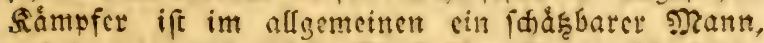

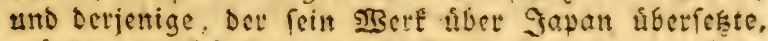

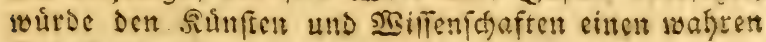
Dienft etucifen. 


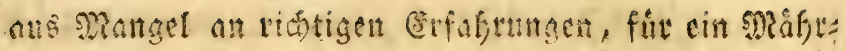
don gefalten, Das Die Sopanefer ifm aufgebeftet 1) âtten..."

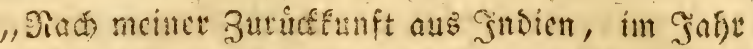
1764, zeigte ich Dem Srm. von Somare und Dem Sern.

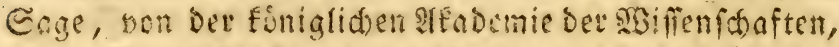

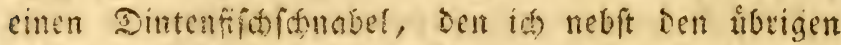

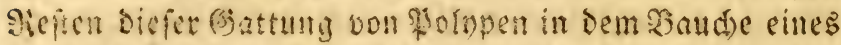
won unfen simatrofen getobteten Sanfiftes gefunden batte, mo madte fie aufantefom nuf bie vollfommene

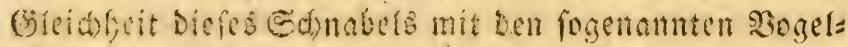

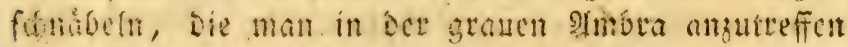

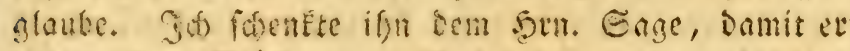

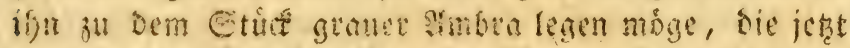

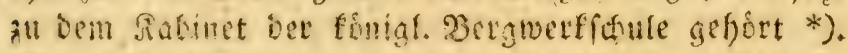
Sicine Brobactung verzcidnete id) in cinev siote zu

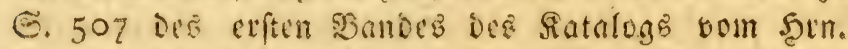
Davile, Det I 767 erfdien. Wie Prote feift:

, Nivir fitgen bie araue 2Imbra nichi als Bejoor,

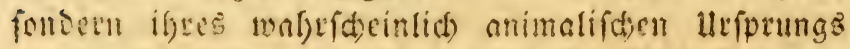
wegen, fierfer. - Cos ift nad) Den Dericten mefrever

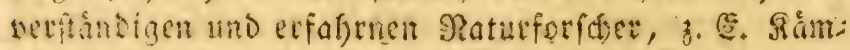

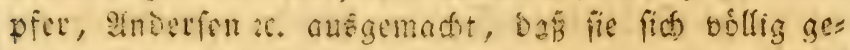

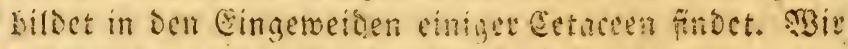

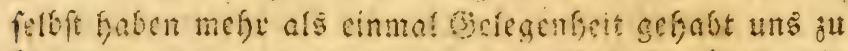

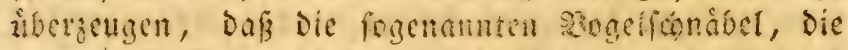

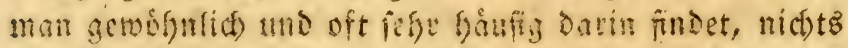

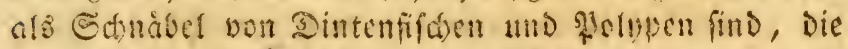
Den fiffen, weláe dic trone simbra berwotbringen, jur S?กฤนแng Dienen."

"Sn ocm Etrict grauer Imbra, bas fich in ber 3ergloctefichule befindet, uno deffen id oben crwabnt

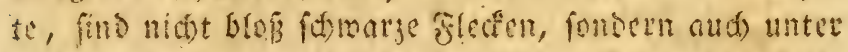
mefreren andern, sin febr fenntliare Dintenfifolduas

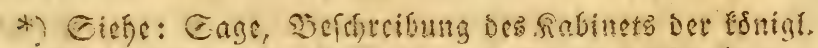

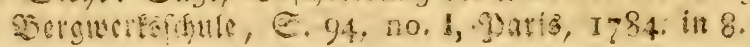


Ger, Der blof ein twenig fleiner ift, als ber, Den ith in einem Sonpifac fanto." (Romé de l'Isle, loumal de Phyfique Tome II. p. 372 . 1784 .)

Sid habe alle vorftebende Beobadtunach in Sives fict Des itrprungs Der grauen armbra abfitstid mit

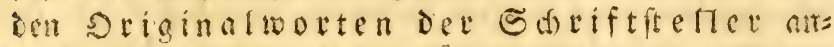

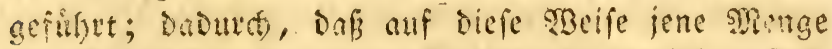
von Shatfachen in einem bremnumt vereinigt find, fonn man un to leideter zut vollfommenen leberzes: gung gerangen, bafj Dicfe fo feltene und elsemals fo foptbate Epecerei - movon nod) jest bie Unje in Son= Don adizig Pives (zmanzig Ifaler) foftet, - nichts anders ît, als Dos Ceflement einer getoiflen Sattung von Mallfifuen.

Man fonte (eict Durd ben Sdein und Durd bie

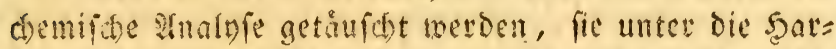

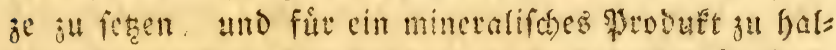
ten, Dergleichen Der âphalt tho das Bergól find. Silbft Die hafigen હchnabel, die man Darin in Mlenge antriffe, fonten diefe orage Damals nidte lofen, Da

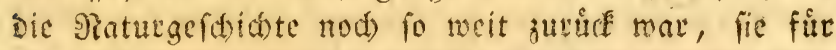

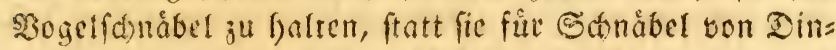

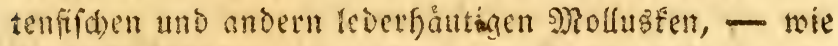
fie witflids find - zu etfennen. 5̧eutiges arages, oa man Dics lebtere gewif neif, und ba es ausgemacht ift,

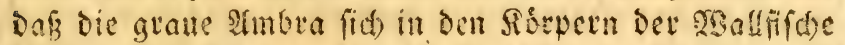
als wirflid)e smbra befindit, mâfen wir feft annef)=

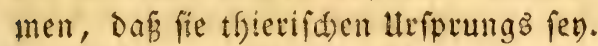

Sdjon zut Zeit ber återn Sopothefe, da mant bies fe Subftang nod fut ein sarz fielt, Gatten jene Sand:

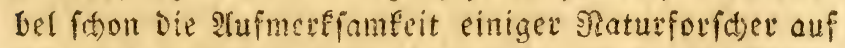
(ich) gejogen; weil man aber wufite, dap bicle Sfiere Die graue Imbra fefe begierig auffuthen und verfalu=

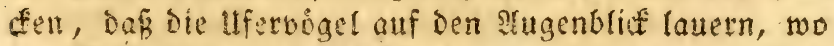
bie. Bellen fie an Die siffte sirfen, um nur bariber 
bergufallen uno fie zu freffen; ia, baf fie fich iffer fón bemådtigen, fobalo fie fie nut auf bein 23 affer fítuimmen fefien, fo meinte man, isne Schnabel mod)= ten viellciont benfelben Uferyogeln zugeforen. Man wutbe in Dicjer meinung Daburch noch beftátft, Daf Det Umath Der siggel, bic von Der grauen Imbea gefref: fen baben, jenen (3ertud in einem fo bohen Grabe bes fitst und befait, Daf́ man iffere weiflidien, freibeartis gen Exfremente forgfåltig won Den Felfen aufammelt,

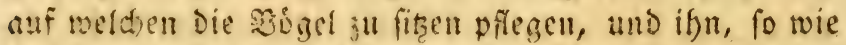
$\mathrm{er}$ if, mit setern u. f. w. vermifát, wie eine Irt von

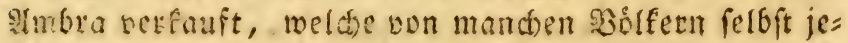
Der andern (B)attung pon Diefer Eubftanj vorgezogen wito *). Indere male raren bie Ceftemente des 23 all= fifcies fårtei uno didter, uno f(c)mommen folglid) nid)t auf bem smeere unther, fortern fanfen in bie Siefe fin= ab. In Diefem falle waren fie ber \&uft rid)t aแส่ge fetct, uno befielten alfo immer etwas meid)es an fids,

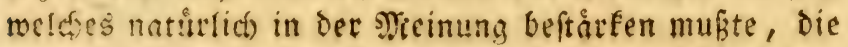

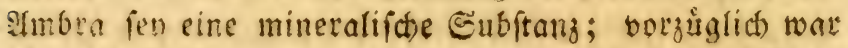
Dies̃ bet fall, wenn man fie cinige fuk tief auffifden

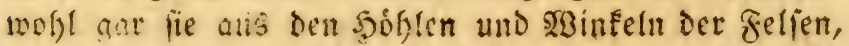
in welase Etrom uno rains fie vielleidst getrieben bat= ten, gevastud)en uno ouffangen mupte.

Gelbft Die Nationen, Die Die graue Ambra auf ifren sibten fanden, fonnten ifir bei nơferer unteriu= dung feinen mineralifaen licprung zufareiben. Ifles, mas jene Weinung etwa unterfiste, verioswano balb,

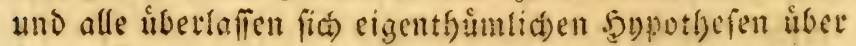

*) Die Sienofner Der Dzalbiren ziefen z. (E. Dicje von den şegeln verlorne 2lmbra jeser andern Gattung

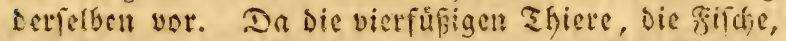

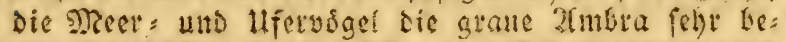
gievig verfolingen, fo nuffien ibte Exterentente freilich

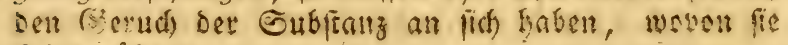
(id) ernåbrett. 
Den ltrpiung sisfer @ufftanj. Lopés de Caftagnetta *) 3. ․ fagt: "Die bef:e IImb:a trifft man in Den sals

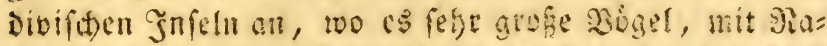
men "A uacangrispasqui" giebt, bie fid blofís von aromatifden Sråtern neffen, uno die Uierfelfen

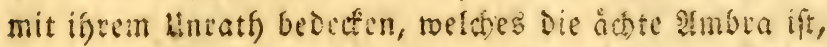
und pona a moar D. F. reigeldete smbra - senn fie gleid) weif ift - genannt toitd. Die externente

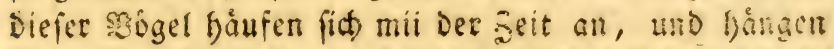
in grofen Platten von ben Seiten Der felien binab, zerteifen Dann entweder Durd iffe eigene Esmere doet Durd SBind und अegen, und failen enotids ins sieer, wo fie, oon den Jluthen ergriffen, fo lange umber= fammmen, bis fie ifre sacife villig vertoren baben, und nun als graue 9 mbra, sie man $C o s m b a r o . \mathfrak{l}$. ả afferamota nennt, ans ulfer gerosfen rocben;

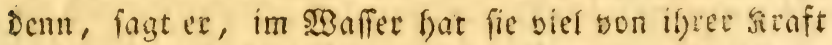
verloren, und fann Deshalb nut fur eine minder me: the Battung volt Imbra angeitinn retien. Die fíted = tefte Ambra enditith ift bie iritte Gatrung, Die man

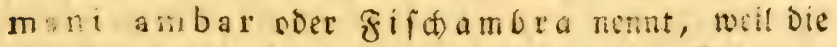
Mallifhe und andere greffe fifde fie verfuluct baben, fie aber wieder bon fich geben mition, indem fie fie nicht verbauen fónnen. Dieje IImbra, lagt unfer Edyrift=

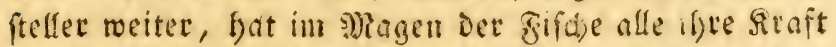
verloren." - SRan fieft, Dafi Eaftagnetta nit Dem

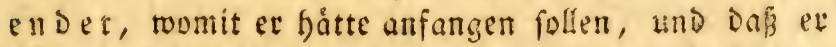
(ich) Daburth betrugen lief, Dafi Die Dortigen Jnfulanet

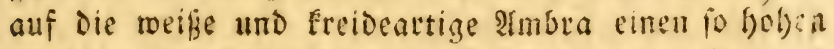

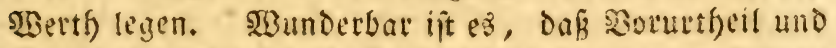
(Bservofinfeit die Maldiver fo fefe beferriden, Dáb fie Die reine und natúrlide Imbra verwerfen, uno ist jene worgiefen, Die Durct Den Rorper Der Bögel gerangen ift. Antere Bifler t), Die befier beobadytet, min alfo

*) Thaten Der गुJotugiefen in Dfíndien Sap. 35.

†) 3. (5. Die Sapanejer nab alle Diejenigen, Dic bemetft 


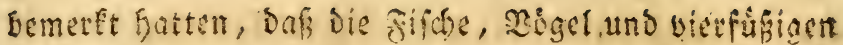
Thiere die graue simbar begierig verjefren, wiefer

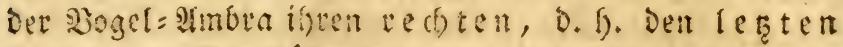

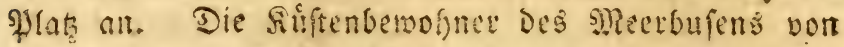

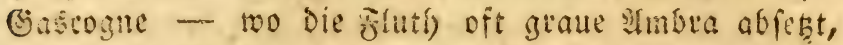
wificn die Ifmbra, Die fie an Jiecrufer auffammeln,

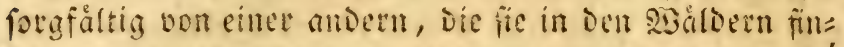
Dè, ว̆ unterfacioen; Die leketere nenten fie renardé

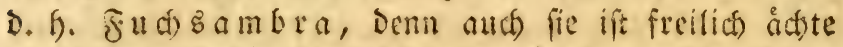

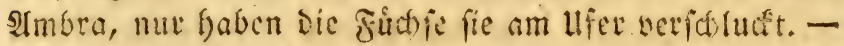
Diefe Thiere ried fen fie weit, und find fefor lecter bar=

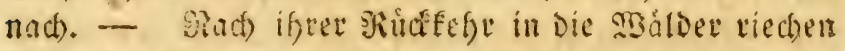

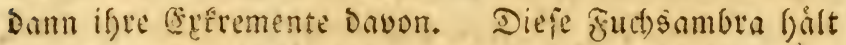
man aber allemal fure bedeutend minder rertf)*.

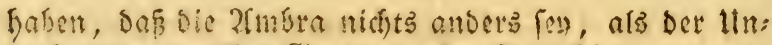

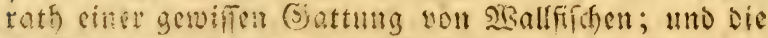

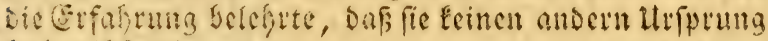
Gabert E⿱

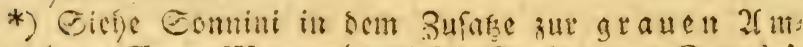

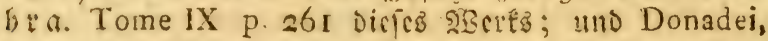
Journal de Phylique, DJínz 1790. Diefer lef̧tere

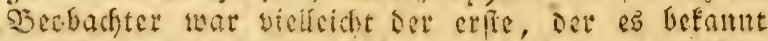

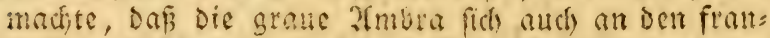

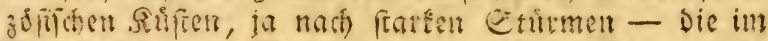

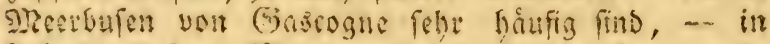

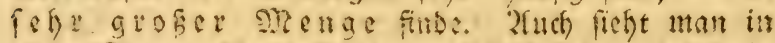

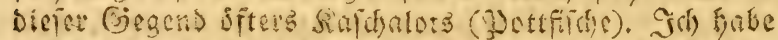

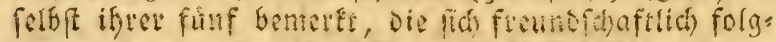

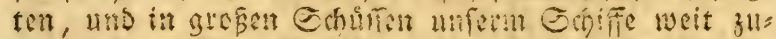

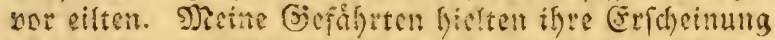

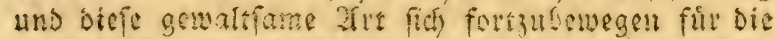

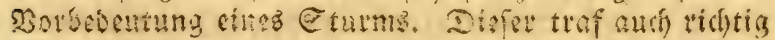
ein, und jivar fom et gerade voa Der Eeite, nach

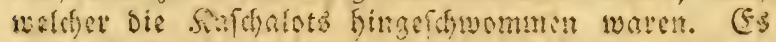

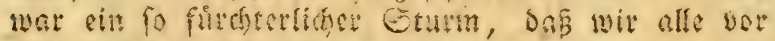
unferm Reben zittertent.

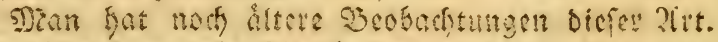

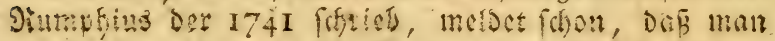

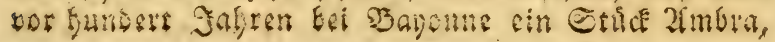


Wenn mant nids fo vicfe lingereimtfeiten, in die

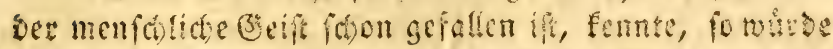
man fich nicht votifellen formen, wab bie snenionen alles erfonnen faben, um den litprung ber Stmbra ju es:

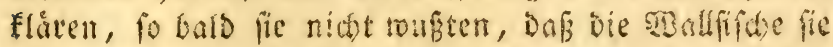

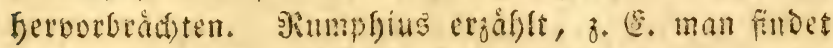

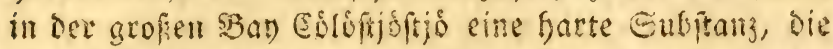
auf Dem 93 affer fdrommt, und bon dit id slaube,

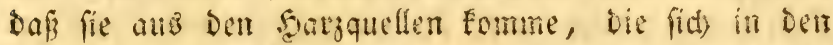

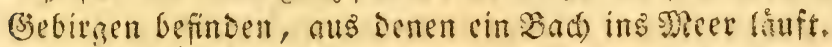

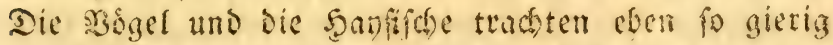
Had) Diefer fowimmenden shaffe, wie nad Der wafken

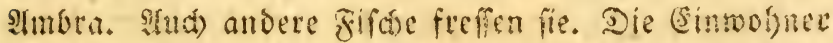
glatben, odet modsten sfrete getu glauben maden, es

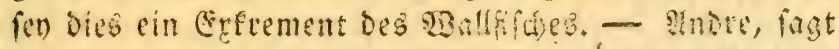
Jiumpfius ferner, die gerwif wiffen, baf bics sprobuft aus den bebirgen fommt, berfibem, notge bei bor Sharzquellen wobne eine ungebeure Solrmge bokulawa ober bankulawa genannt, ein mit ier grepten

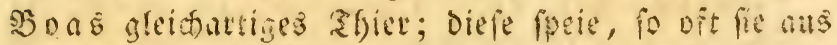
jenen suelien trinfe, vie Imbra aus, und sie Suclle

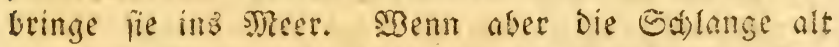

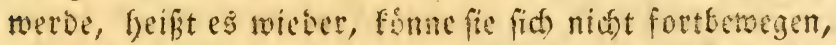
bleife lange zeit auf cince Etelfe lingen, und berond le

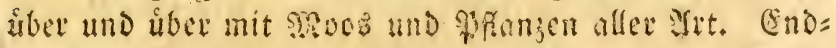

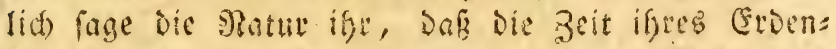
lebens berbei fen, sann begebe fie fith ins siect, und verwante fid in einen langen und dimnen 9 Ballfifh,

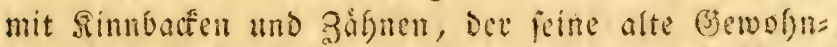
beit, fostwarze Ambra ausjupeien, nad) wie vor beis befolte.

vou hunbert \$funs an 11 fer gefunden babe. 9obse

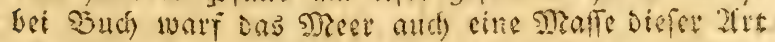

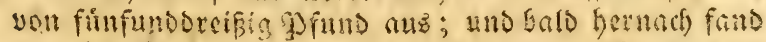
man bei g) aremes eine Derbleighen von siff und sine: balben Unze. 


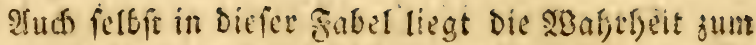

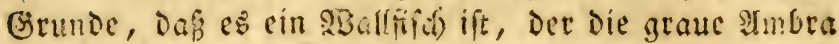
auspeciet. Gerate fo ifies auth, menn'man fie von

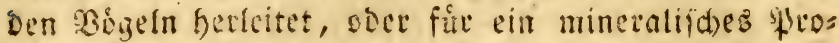

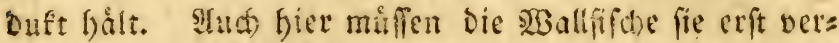
f(t)luten, um fie als ifnen unverdaulito, in ifret wal)= ren Befroli, bon fich zu geben. Sluth menn nan fie

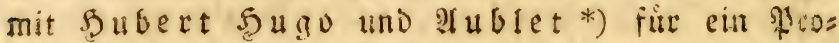

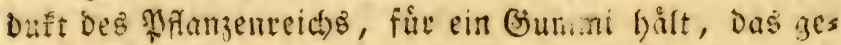
wilfe Båume ze. Gervorbingen, fo muifien auth nat)

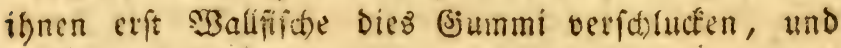
wieder vout fid geben.

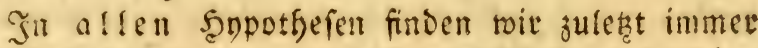

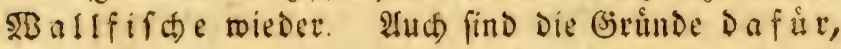
Da

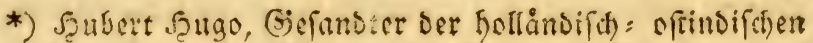

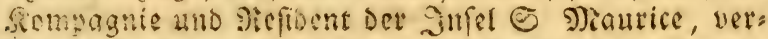
fidert 1671, "er habe iefst eriolich oen Utiptang Der

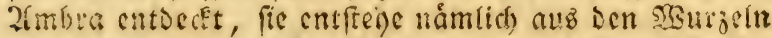
eines Saumev, Deffen gamen $\mathfrak{C l}^{2}$ nicht wifie. Et

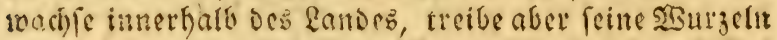
immer nad) Der Eerte Des Jicers zu, indem ev Dellen

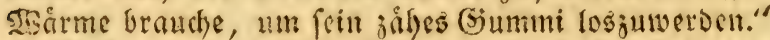

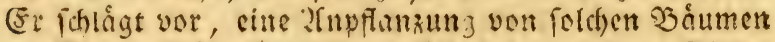
am speere feloft zu madten, ob er gleidi aud verfichert, Daf tob (s)ummi defro befier uno fetter (ev), je mebr innerfals Dez Rontez dicfe 5 siume wadjen.

Der varteffitiche Gotanifer Kublat meint, bie Imbra enfféte aus ocm Boume Cuma, im frange:

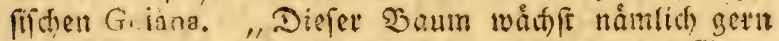

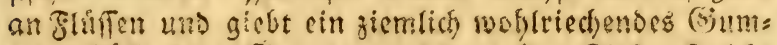

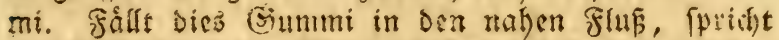

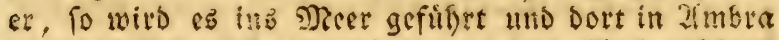
berwandelt." (5. Rumphitis p. 267.) 2(ud) gefjorete Diejenigen fierfer, Die begaupteten, die gloue Xnbra (ei) eine woílrisdjende Frudit, roelche am Hifer Des

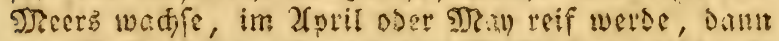

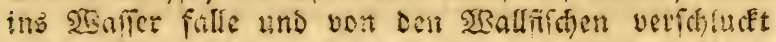
reroe (Rumphius, p. 270.) Troer auth fier firset

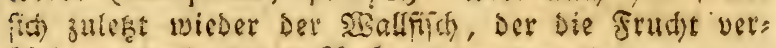
iffingen muf, oamit 2fmbra dapah torde. 
Dak die Ambra von ifnen herborgebradt toerde, viel enticheidender und ausigemaciter, als̀ alle die andern. 230 find 3. C. Die Semeife, Daf die graue 2 mbra ein

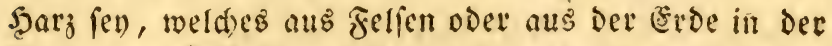
Tiefe Des Meerb ausfátrige? uno warum haben wit - bies angenommen - fein $\mathfrak{A}$ nalogon von ibr

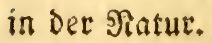

Der Mleeregagrund fann feine andern Sarje ent: Galten, alb die, Die das fefte Rand Darbietet; Denn der Mteresgrund it cine blokse fortfeţung Der Erdragen

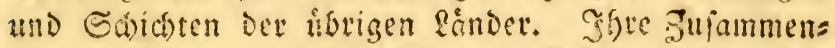
feţung ift bie gleidge, aud liefern fie feine andertueitis gen Materialicn und Subfanjen; Die Cidolagen fird

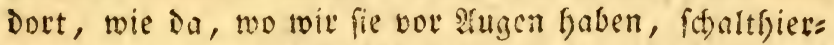
oder granit = ooer falf $=$ oder thon = oder fasiefer = odee foblen = oder feustiteinartig. Ruro, fie find vollig gleich) mit Den gàndern, bie ifnen nafe liegen, fiber Dem Waffer erfacinen, und fia) in baffelbe verfenten,

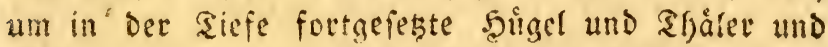
Ebenen non Derielben sefajafiengeit zu bilien.

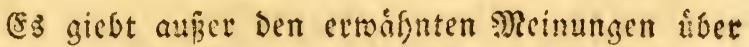
Den lirfprung Der ambra noch andere fefo fonberbare. Man Daif nus, - wenn Der Menid) ambers Den wall=

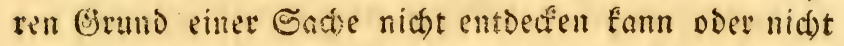
annefmen will, feine Fengierde reiten, fo roird man Olutfmafungen allex airt entféfn fegn.

Scaliger j. (E. *) meinte, die sambra wachfe roie Catramme oder Efampignons ouf Dem SBoden Des

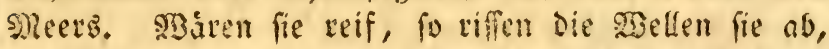

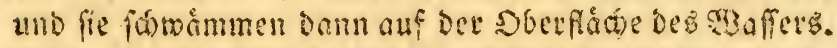
Der genannte Geleque batte nomlid melgere runde

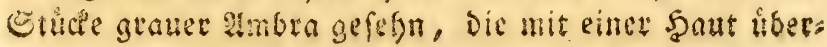

*) Scaliger, Exerc. 104. 
aOgen waren, und imterhalb fduppige \&agen, twie man fie in Den olten Ëdrammen antrifft, Gatten. Zut Unterfth thung feiner smecimung crimnert Scaligev an bie moftriedenten Sdyåmme in ben Pntenáen und in Biovergua.

Eetapion twat ganj ber gleiden s)eimung. Jofann Fabri*), Den Bumph Den झratacelfus feinet Beit nemt, behíbert, die graue ambra fer cine jafbe, fet=

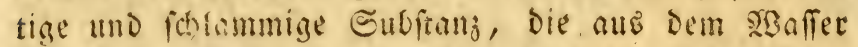
fertifite, aber, wie Die Ehampignuns auf Der Groe,

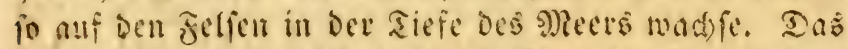

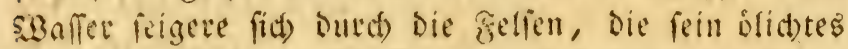
and fettes sgefen in fid fógen, und baourch Die Mect=

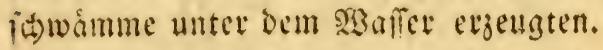

No(h) Inore befaupteten (Misc, nat, cur. I630),

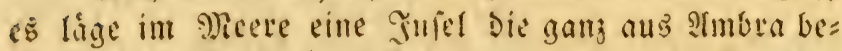
ftefhe, und cine fefte 9) taffe Davon altmadye. (Sin el)e=

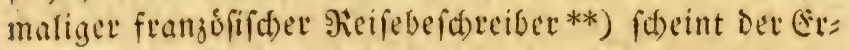
finder biefer Jnfel zu fenn, Die aber immer unbefount

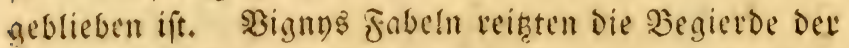
Jollander fo feftr, Dá̉ fie groke Eumme nuf die Ent= Decfung Diefer wohltried)enden Gnfel vermanden. Det ertwáfnte Frangofe verifiderte namlic), es gebe eime ge= wilie Gigend, tworin man die graue Ambia fo iber= flifing fănde, baj man wobl taujent Eáfife zugleids

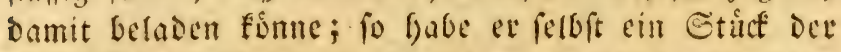
Ilt von jener Snfel mitgenommen, weld)es ex nad)het in (Europa fur 1200 pfund Eterling t) DDer 43,000 bollandiface Gulden verfauft babe.

\footnotetext{
*) Peter Johann Fabri. Pachinitus lib. 4. cap. 49.

**) Ifaac Vigny. (Rumph, amb. p. 265.)

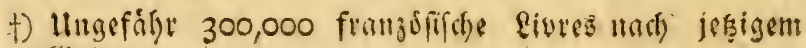
(Si) ibe.
} 
Da ber Sandel ber Sellander um diefe Beit, wo fie eben von Phifipps Intannei befreit morden waren, vorziglid) wid)tig twar, und faft alles (jold Der Erde

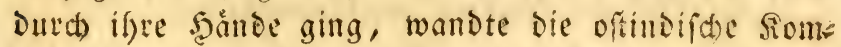
fanzic grofze Summen auf, um diefe Jnfel zu fuchen, fo wie Die \$rortugiejen und Spanier ifre Eldorado fuct)= ter. Siur erit nadjoem die Solländer jene Gnfel ferfe lange Zcit findurd, gleid)fam Sdritt fü Saritt, vet: geben' gefucis fatten, wurden fie uberzengt, dấ fie nitht exiftice, und entfagten dem 23 unjate, fie ju ent Decfen und zu befitarn.

SRoch Anbere *) verficherter, bie graue Simbea

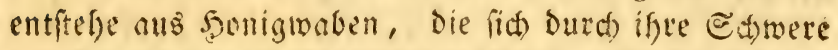
von ben felfen am Merufer lostiffen. Sin ben Soblen Diefer Felfen bauten fid) nemlich Die Bienen an, und bie saaben, Die über einander gefsulut, und an einan= Der geflebt fryen, wirrden Das Spiel Der Meflen, und

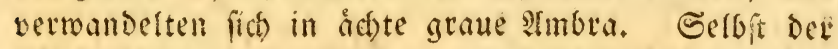

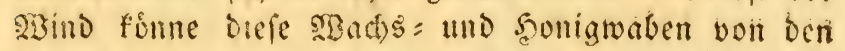
Sulfen los madien. SRonconng t) fagt ungefăbe das bleidse von gnoien, und fetst hinzu, "ee peloft habe in eincm nod) unreifen Stutu Ifmbra beim Berbechen jwei Jeifen Bienenjellen gefunden. Deshalb, fprid)t eit jul Beftétigung Des ofigen, loft fich Die simbra au(b) in siseingeift mit sieinfein auf, und wird wieder eine शt't von sonig."

Die einjige bon dicjen fanmtliden meinungen, Sie alle chander im foben Grobe entgegen ftefen, die eimjige, fage ith, bie einige sufmetfameit verdient,

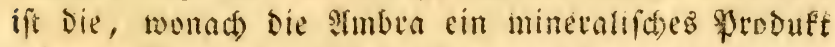

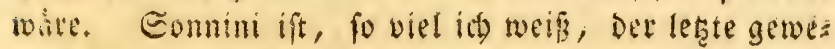

*) Oprechire Koopmann, of, algemeene Verhandelinge der droogeryen. Cap. 26. Amit.

t) Nonconys Heile. อ. 7 . 


\section{2}

fen, Der fie angetrommen bat. Ee bált námlich bie Imbra fur eit Sar oder mineralifdes \$lect). Jath glau= be aber, Daf es Durch Die grope Menge von Beobad)= tungell, bie ich grammelt und vereinigt babe, flat gi"s

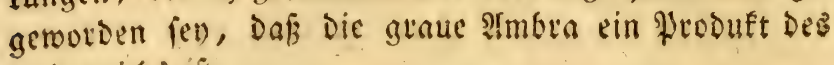
รfierretas ift. 


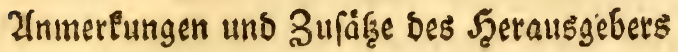

औิt

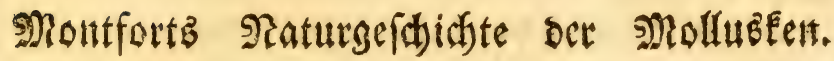

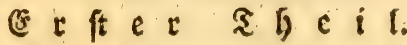

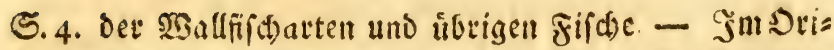
ginal heif́t ế: des cétacés et des poiffons, Der Cetaceen

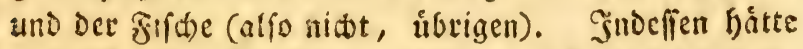
aud) Montfort bie Eetaceen lieber mit ben lebendig ge= berrenden Tfieren jufammenftellen und fie nidst erit auf Die friectienden Thicre und $3 \dot{B g e l}$ folgen lailen follen,

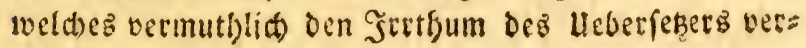
anlafit fat.

feren Dafalbft ward den mit SBirbelbeinen verfefemen

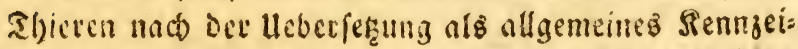
(x)

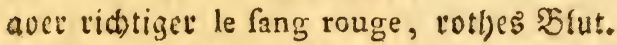

Mas Montfort gleid) Darnach von Der fonit ftet s

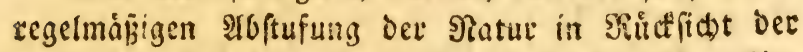

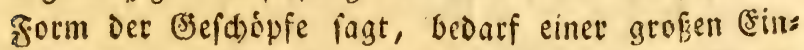
fidtånfung. Die llnterbred)ung Diefer Sicte Duted Thiece mit und ofnene sistrbelbeine, zwifthen relwen et

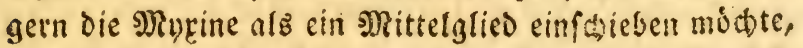
ift nidot Dev cinzige Fa!!, Der uñ nóthigt, Die Borftcl lung von ciner folden Etufenfolge aufjugeber. $\mathfrak{b}$ ! us menoa (a) bat lángit gezeigt, dán nid)t nur fein toaf)res Sindungsiglied zrwilden Den fogenannten

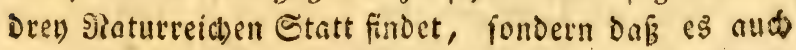

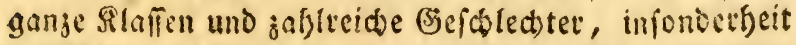
im Thierreche, von fo auşgejectoneter Biloung giebt, Dof man fie aud bei Der forgfáltigften sinlage einer 
foldsen feiter ier Patur bot nut mit Maife und sicht

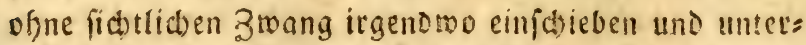

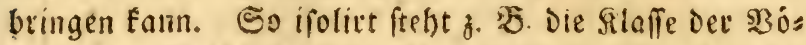
gel, oas Befthiect) Der Echreine 2c. Ëं gel)t unz bier mit Der IInoronung ber Ertigefdopfe, wo wir gern

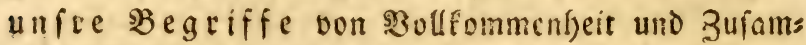
mentfang finden modeten, wie den siftronomen, Die fid bemúl)en, eine vollitánoige \$rogrefition in Den \$lanes ten = abftanten zu entoecfen. Wber Die Natlit ridtet

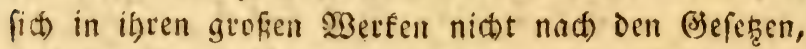
nad) Der Hiegelmábigłfeit uno Stymmetrie in Zalblen uno Piaungrófen, wie fie ber \$Menf(h) liid) Denft, fondern fie rotrft meift nach Sierbáltniffen, Die in unfrer Sprad)e irrational beifen. S. v. 3 a

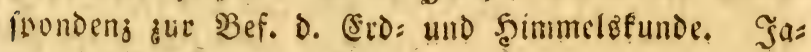
muar I803. S. 80.

(5. 5. 3u den wefentlichen Renngcidien ber Thiere olyne

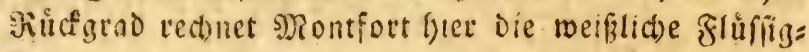

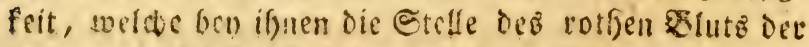

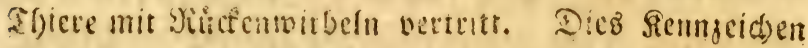
Ift abee nid)t allgemein, uno leibet Ptนênalymen; ein neuet Şeweis, wie mangelibaft unfre flafifififationen

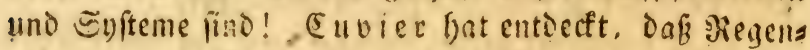
solmer uno Blutegel tothes blut haben: ja et

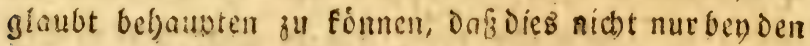
Stajaden, Siercioen, Ifphroditen, Almphitriten uno Serpulen, fontern aud) bey oen fámmtlicten ủbrigen gegliedecten, nid)t zu den Singerveiden gebórigen Wărs mern ebenfalls ftatt finde. Man fele Die feine Zerglies ocrung dea lumbricus marinus, in welchem Euvier cin twirflictes, in arteriellen und venofen, mit softole und Qiaptole begatten Gefáfen umlaufences But fand, in Miedemanns ânchio fur 3oologic und 3ootomie

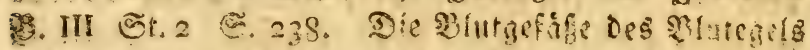

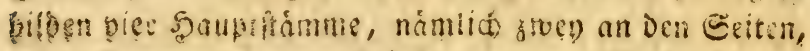

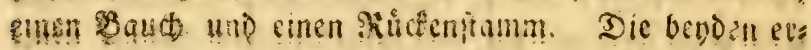


ftetut gefjóren gu cinter anbern 2 trt, als bie benden leţ= tern; (Euvier b) aber nod) nicht ausmachen fómnen,

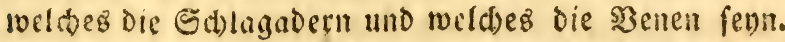
Die berben Seitengefáfe gef)en von einem ënde bes Sótpers zum andern, und bilden, indem fie fich bures)

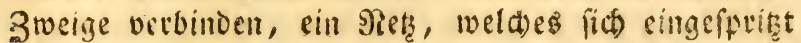

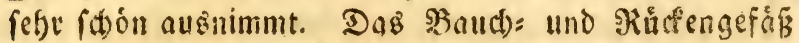
bildet feinfold)eร Dets; bende geben nur Zroeige, weldte

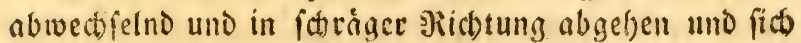

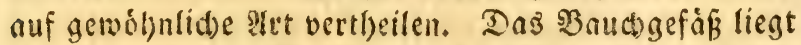

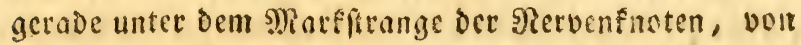

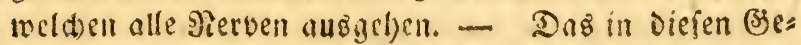
fágen befindide 3 lut iit fef)e verfaleden oon Dem, wels wes bas Thier gefogen bat, uno weldes in Darmé nal gleich verándert wito. Sienes lout ungefáate bie Farbe, wie das Sidragaderblut Des Frófde. S. WBies semanns Irocio 93.1 . St. 2. ভ. 242.

Dafi Mrontfort den fammtliden Shieren mit

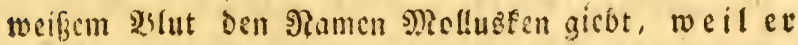
allgemein angenommen (ê,, gefort zu ben Sefauptungen dez 2 ?erf., Detenl Ungrund feinem Ren ner ber saturgeftidte entyelsen rito.

(Einfad)er und natưtider, als Montfortz (S. 7 und 8) Minfififation foreint mir die von Euvier zu fenn.

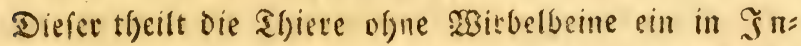
feften, J) oltuş fen uno Sd althiece. Die Mottasfen theilt er wieberum nach Der (bejalt ein in

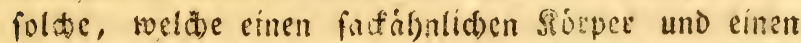
freien, mit fảken (oow vielmeht mit arrmen) befeten Sopf haben, uno nemt fie Cephalopodes, Ropiganger (3. 3 Die Dintenfifde); ferner in foldue, roclde auf bem Baude fried)en, Gafteropodes, Butftied er

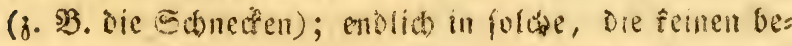
ftimmen fropf babon, Acephales, fopflofe (z. Dis I(ufterii). 


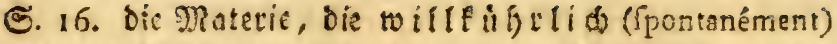
gange sBolfen bon iebenden alromen fđnf̂t. Die génération fpontanée, woron Montfort in Der Folne ofters fprid)t, ift nitits nnders, als Die unter gewiffen uns ftảnden vou felbit (fpontanément) etfolgenoe Ents

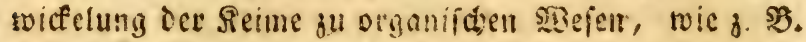

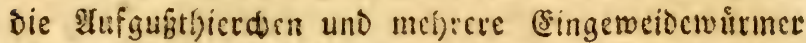
auf Dicfe Itt entfeber. Sie betweifet allerdings, Daf

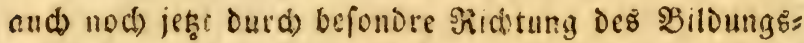
triebes neue fpecies bervorgebradt, ober wie $\$ 3 / u=$ men $b a$ (b) lïd) augorict, nad)erf(d)affen toerben tons

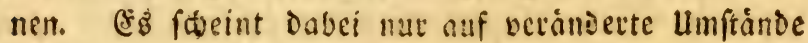

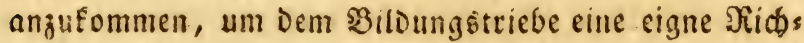
tung zu geben. Der Reim Deg frinnenwutms liegt ver's mutblic) ebcu forolst in Dem milden, als im zalsnien Satweine, of ma:: glcid) den \$Butm felbft bis jeţt nie im erftern gefunden lot. Şierúber fónte man leid)t Bewiffect erfolten, went man frifdlinge einfinge uno zábute, und fie und bic Saadfommenidaft oon Bermiftung mit zafmen Edweinen abbielte. -

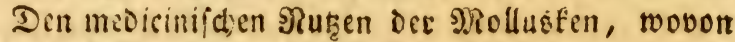
Dentfort im folgenden viel rúb)mt, mógen Aergte múr: itgen. Son der Ucberfetzung findet fich હ. I7 eine llns riatigfteit. Das̃ Sriginal fagt: La médecine fe fert utilement et dans beaucoup de circonstances de cetre faculté prolifique, qu'ont les teftacés et les autres mollusques. Die smedicin bedient fid - - Diefer frthtbatfeit, Dicfer Mnenge oon Sctalthieren uno श)

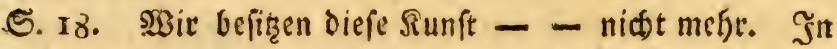
\$yern wird eine Gattung murex now beutiges నages zum \$urpurfáben gebrauct, uno Die Spanier treiben mit folden \$lurpurfäden eillen ftatfen 5̧andel, indem man mit ocnficlen auf zeuge ju fitîten pregt.

5. 19. Die Jlatur facint fici ief Ibiete nut zur Sers vorbringung einiger Gasartei uno ock Ralfmateric, 
welde lef̧tere immer ong \$roduft der Sfiernelt ift, ... Det fo genannte falinifde salfftein trito, meis

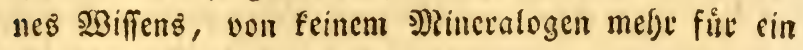
tbierifacs $\$$ coduft gef alten.

2Beiter Gin tritt MRontfort Der MReinung Derer bei, meld)e annel)men, Dá̉ bei Der Ichęten grofen Sintaftros

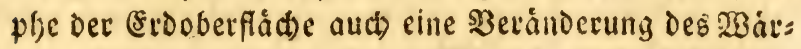
megrades vorgegangen fen. Mióglich ift dies freilich,

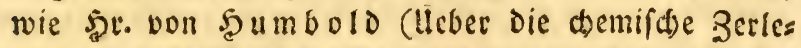
gung des \&uftereifes, S. 177) gezcigt bat; aber die

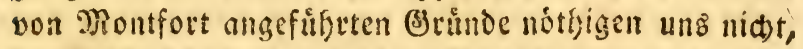

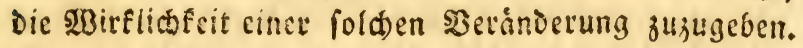
Bielmefle fdecint Die (Etfabtung fur Das Begentbeil zu fitreiten, indem die in nórolistern Begenden gefund nen snoden ftufenweife beffer erfalten firro, als bie ábnli= d)en, wilde man in ben fỉlichern entoect bat. (is mußi alfo fidon damals im stoven fo falt, wie jest, gewefen feun; Denn gefeţt, Der Jiorden bátte vor jener Rataftropge einen fóbern $23 \&$ rnegrad gel)abt, fo wurbe

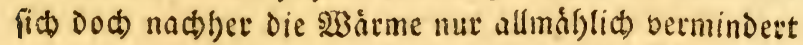
und folglida) twatroen die thievifoen lleberrefte fict nidst fo gut erfalten baben, wie 3. B. Das mit şaut uno Saar nod unverfelyt gefandne Jiafífocn, weld)es \$a ll a s beforeibt. Daju fommt, dẩ unverfennoare Spuren einet allgemeinen Heverfar remmung vorisal= Den find, Deten Bicitung von Sibweft nad) Joti: weft gegangen ift, moraus fich erflíten lápt, warum

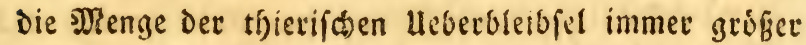
toito, je mefre man fid dem গiordpol nåbert. Wil

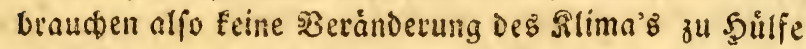
zu nefmen, um begreiflic zu finden, wie Wrodutte,

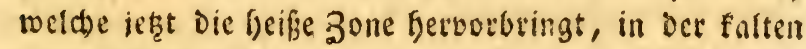
angetroffin merben.

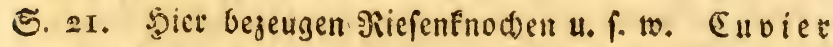
bemerft, Daßz Die in Den tiefen Sdiáten gefundnen Heberejte nod melde von Der jeşigen form Der Thiscic 


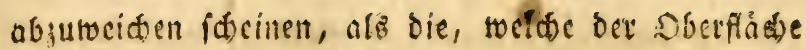

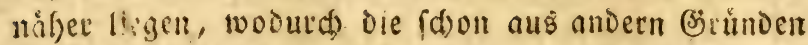

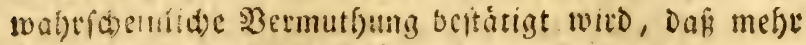
als eine Jicoolution bie (5:00oertinhe verandett bat. -

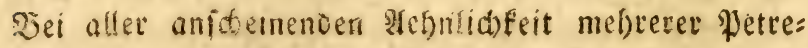
faften mit jest lebrnoen (siefdopfen fino fie ood oft theils in rex form, tijeilo uno vorgüglich nuffallend

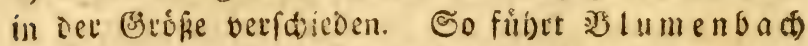

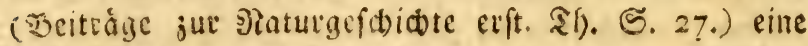
Sanecfe (murex defpectus) an, Die in Din notolfdir Deeten lebt, uno Deren Sdale rét Den ift; Dugegen ift die ain llfer von Sarroich ge= grabue linf ge twanden, welche ưbrigers in शllem fo grope Eebnlichecit mit jener bat, Daßj man auf Den erften solite eine mit Det andern berwed)feln

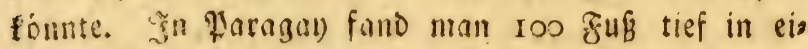
nem fandigan oden Das Efelett cines Sfiers, Defs fer sẻbe 6 wno die länge 12 fub betrảgt, uno wels

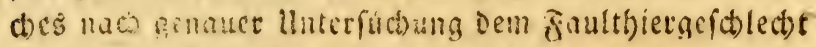
am nacticin fommt. SPefanntlich baben die jest le=

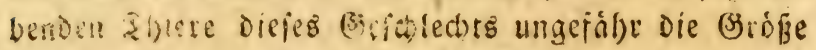

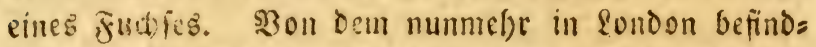

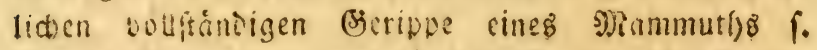

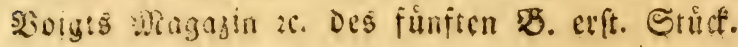

Uebrigenz lafic id) sabin geftellt feyn, mas Mont: fort von Den Gerippen Der Meerfaţen, grfen und an: Drer Dem Menfohengefdechte áfnelnoer siefen, Dis eine ganje bergfette, oon Irles an bis nach Bibrala tar und twaiter fin, ausmad)en follen, etzailtt. SBlus menbuab), der fonft fo aufmerffam auf diefen interefs

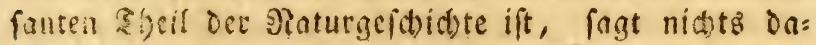
bon; wolnt aber fent er - was 9 Bontfort láugs net - \$istrfafte von Eampf= uno : Manfervojeln.

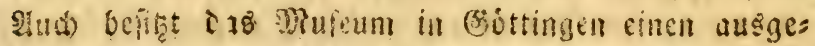

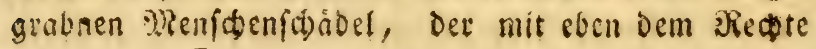


fofiil genannt wetden fann, twie vicle ausgegrabne Elephantenfnodien 26 .

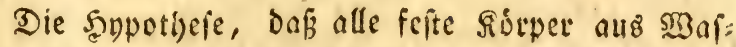

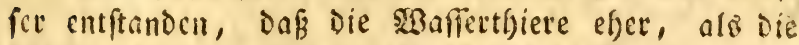
Santisicte da getwefen, und andere von Montfort biet aufgeitellte Bermutbungen baben fdon ältere গaturs forfher vorgetragen. SBon Der Sildteriften cines

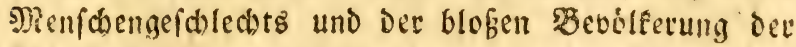
(5rde Durd) Ificre vor Der lesten grofien sataftrople

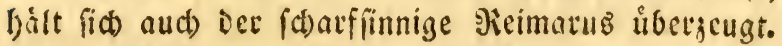

5. 33 "Die llmmandung Der Ralferde in Riefelerde fúcint wenigitens betwiefen zu fenn." allerdings; die evidentefen Bemeife davon liefert (Gerl)ard in reis ner atbandlung ưber bie llmmandiung Der einen (5ros und ङteinart in bie andre. Bertin 1788.

Ebendafloft: ,melre aber, als dies alles, die willfifirliche Fortpflanjung ibret áfferften (sjefoled), ter; ' nać Dem Driginal: la génération fpontanée de leurs derniers cehelons, bic von icloft erfolgenoe suts wicflung ifyer leţten Eprofien Unter derniers éche.

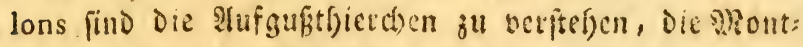
fort mit zu Den झुollušfen tednet. Fon Dev géné-

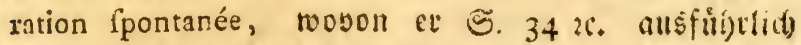
bañeit, f. die Anmert zu હ. I6.

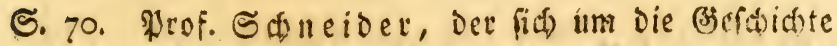
Diefer Thiere ausnefimeno verdient gemad) that, feţt folgenden allgemeimen (sefdeledtred)arafter feft: Sopf

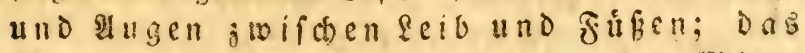

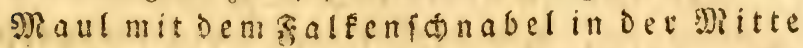
Der Safis von Den ooer zefn, inmendigmit Saugwarzen bes fetet. Derecib miteinem Dintenbeutel, uns ten an bersafis mit einer beffnung in bie Duere, und oben datiber eine hetuora

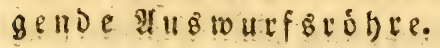


Die Bottungen bringt er fooann in fwei Slafien voer familien.

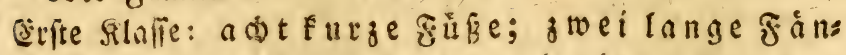
ger; floficn am lecibe undeinen finoden im $\Re$ in ce cin.

B)attungen:

I) Sepia (Eeefotec), mit breitem runolider feibe nit ganger floffe berum unde nemgtoben Rid de troden.

2) Loligo (Dintenfifí)), mit id malem fpiţigen feibe, in der mitte efige flofien, ein

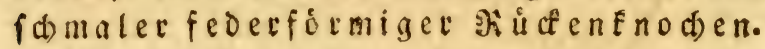

3) Teuthis, ventre depreflo caudato ancipiti. (Der \&inn. (E)aracter.)

4) Sepiola, mit fleillem tunden feibe, of ne

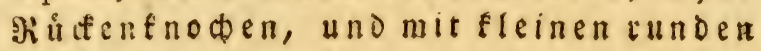
zloficn.

Zweite Slaffe: a d t lange Fif mit einer Satrimmbat verbunden, obne

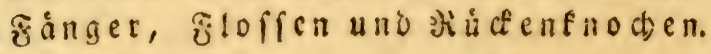

Biattungen:

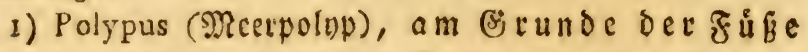
intondigeinzelne Ëaugnarzen; weiter hinauf eine zreifacte ofeibe zunebmen Der $\mathbb{S B}_{3}$ a jent.

2) Mofchites, mit langen fúben und einfas der Reife von Saugrarzen.

3) Nautilus, mit einfaden Bieifen von Saugs wargen, in einer Sdale wobnend.

4) Pompilus, mit zerlappten oderzertheils ten fúben ofne Saugwarzen.

Samat'f bat orei (befolect)ter:

I. Sepia, (Dintentwurm). Sennzeiden: Fleifdiger Sóper, welder flad) und in einem, an jeder Geite Der ganzen \&ánge nad geflús belten ङace enthalten if, gegen Den 


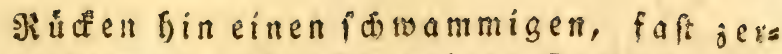
reiblichen unourdfiatigen froden ent= baltend. Das gall an einein ende mit

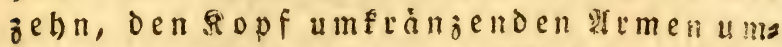
geben, welde mit warbenformigen euft= If wern befest find, becen ated geftielt und lánger als die úbrigen find.

\section{Battungen:}

I) Sepia officinalis, corpore utrinque laevi, offe dorfale elliptico.

a) Cotyledonibus brachiorum conicorum quadriferialibus.

b) Cotyled, brach. con, biferialibus.

2) Sepia tuberculata; dorfo capiteque tuberculatis, offe doríali fpathulato.

II. Loligo (Şalmar). Fleif per in einem untertade geflugelten Sace entyalten, gegen den Ficten bis einen oinnen, $d$ ux fabeinenoen, bornats tigen siorper einfdiefend. Da s Maul at einem Enoe von zefll, Den flopf frónen den, mit warjenfórmigen luftlódern

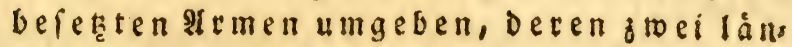
ger als die úbrigen find.

Dies Befaledt unterfaldeidet fit von ben Scpien 1) Daburd, Daf Der Sact mur am untern Fbeile, voer am (srunde mit ztwei flitgeln verfeten ift, wetche

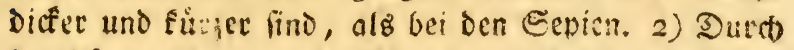
Den bủnnen bornartigen airper, meld te mir ein Des gen, oder wie eine federfómige \$latte geftultet ift.

Die Euftloduer ode: concaven SBarzen Det Irme find formofl bei Den Sepien, als bei Diejem Scidilcd te, mit eimem bornarigen Singe verfelyen, reldser am àuffern ß̉ande geiábnt ift, und Diefen Deffungen finte einer aftr von Slauen Dient, um fid bubalten. 


\section{(3)attungen:}

1) Loligo vulgaris, alis femi-rhombeis, limbo facci trilobo, lamina doríli antice sngufata.

2) Loligo fagittata, alis triangularibus caudae adnatis, limbo facci integerrimo, lamina dorfali antice dilatata.

3) Loligo lubulata, alis anguftis caudae fubu. latae adnatis, lamina dorfali trinervi utrinque fubacuta.

4) Lolig o fepiola, corpore bafi obtufo, alis fubrotundis, lamina dorfali lineari minutifima.

III. Octopus (Ad)tfifler). Fleifd)iger, unten ftum:

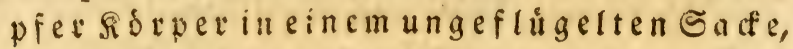
obue rnoden oder Sornplate. Das

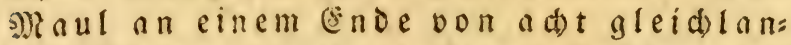
gen $\mathfrak{A} \mathfrak{c m e n}$ umgeben, Deren Deffunngen obne filauentillo.

Da Dieje Thieve nur adt Irme, eimen ganj an: gefingelten Suct mo neder cimen finoduen, nod eine bornartige \$ylate in Sivtper baben; fo unterfit)eiden fie fict) felfr von beiben vorigen, ob fie gleich fonft mit if) nen libereinftimmen.

Bsottungen :

1) Octopus vulgaris, corpore laevi, cotyledonibus biferialibus diftantibus.

2) Octopus granulatus, corpore tuberculis fyar. fis granulato, cotyled. crebris biferialibus.

3) Octopus cirrhofus, corpore fubrotundo laeviusculo, brachiis compreffis fpiraiter convolutis, coryledonibus uniferialibus.

4) Octopns mofchatus, corpore elliprico laevi, brachiis loreis praelongis, cotyledonibus unilerialibus.

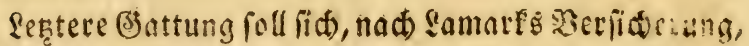
oft in Det Edjole ses Papiernautiuo einquartieren,

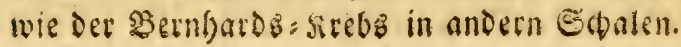




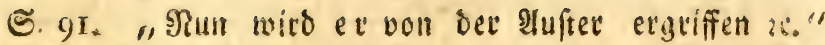
Trebiuz Riger fügt nod) (fefre unmaigrid)cinlió) binßu, Dof Der Dintenfif Eteind)en zrifach bie flaffenden S(balen fecte, roeld)e Sift befanntlid auts vom iffen gebraud therven foll.

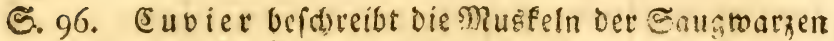
uno itgre silifung fo: Die Saugtwalacn (uçoirs oder ventoufes) fino aus einer smugfelfappe von frabligen

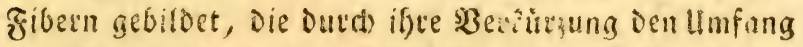
Derfelben verfleinern. \$llber es giebt am Hande det Sappe, ganz an ber Éteibe, unter bem colinberfó:

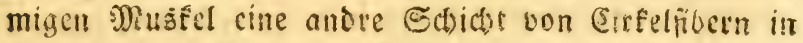
Beftalt cines Schliefmustels, weld)e Die Rappe cons

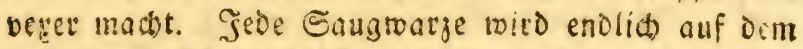
Fuíc Durd) Muefelbainder erfalten ano berogt, welche fid) in cirander verfeaten, uno fid endid mit ben

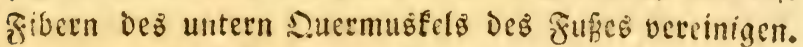
Dies ift wenigftens fo in Dem a d) $t f u$ b (Sepia octop. Lin.).

Sn Dem $\Re$ a $1 \mathrm{mar}$ (Sep. loligo) und in Dem Din: tenfifft (Sep. officin.) find die Eaugtwargen butch ferb Dน์nn Marfelftiele befeligt.

Wenn oas Thier eine ober mefytere feiner Eaugs wargen einer sobrfinge neibert, um oiefelben feit ans

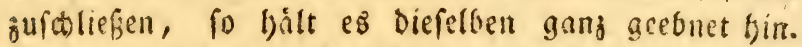
Wenn diefelbe nun bafeloft ourch oie (Ebent)eit bet

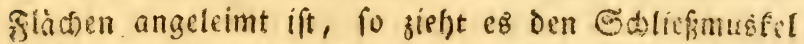
Serfelben jufammen. Dies bringt eine Sodgle in Mits telpunft fjervor, aus weld)er fid ein teerer knum bits

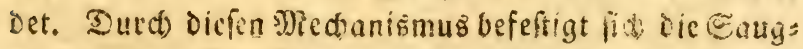

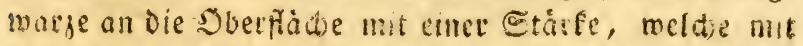

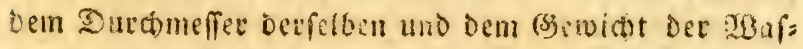

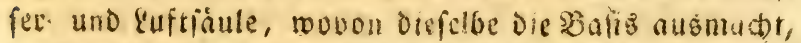

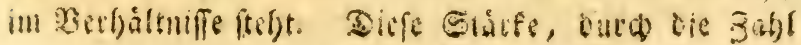




\section{4}

Det Sanglvargen *) vervielfältigt, giebt Die Sraft, mit welcher Der ganje Fub oder ein Theil deffelben fid an oen siorper befejtigt : auch iftes leidter, biefe frufbe zu zerreifsen, als fie von dem biegenftande, roclden'Das abjer folten will, 108 ju mad)en.

Sin bell Dintenfifden und $\mathscr{I}$ almaren ift Die Seffinung Der Saugroarze mit einem fnorpligen und ลแล่ nur eine fieifaige, platte, in ber Mitte burd)bolntte E(t)eibe.

Unabbångig von ben ađt fảzen; weldee twir bes

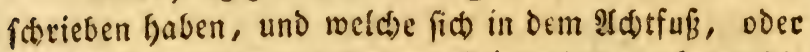
Dem Yolnpen mit act) Memen nllein befinden, haben bie Dintenfifae und Die $\operatorname{salmaren~nod~zrocy~ans~}$ Dre, viel lángere, Dinnere, welde an itfrem breitern Enoe Eaugroarjen tragen. Sgre Drganifatton ift ủbris gens diefelbe, roie die Der andern f̧uj̧e.

ङ. 99. Sd)on an Den Irmpolypen bat man beobactet, Daf fie eine Art ron clectrifder Sraft befitzen, intem

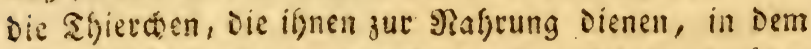
Ifugenblicf, Da fie mit Den Armen ii)eer Rituber beribrt werden, fretben. Sinen merftoutroigen fall erjablt Fol \& $₫$ of (Defcript, animalium p. 106) von. Der le. pia loligo. Ditfes Thler pacte einjt einen mann, Dec fid in Der 9latge non Mlegrandrien bacete, und umfdlang

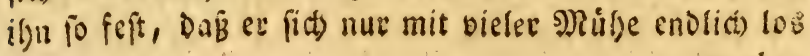

maden

*) Die 3afl nimmt mit Dem 2flter Des Tfietes zu, uno freigt bei manden Gattungen úber rovo. Sieed: ham zơflte an eitrem Fure cines Salmars mefle als hutrbett unt an Den Ensen Der Fánger megr als I 20. Die grópten Gauger frizen an Dent Föngert. Dét

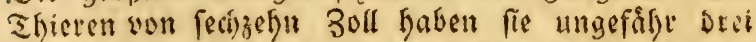
3ebuter 3oll im Durchmefler uno beingte even fo vid

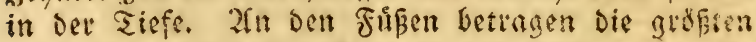
ein Swanzigftel zoll und gegen das Gande werten fie ulnendith flein. 
madien Fonnte. Die angejaugten Etellen entzindo ?n fic), jeod ofne (3efdivulft, und veruriatten cinen suffert beftigen Sumer, fo bng Der Menich ztoei 25otien lang nidt im Srande rav, redt zu geben. Forefal bóte diefe Anefoote aus dem munde Deffen, Dem Der Ilnfall begegnet war. S. 100. erailjlt JRonts

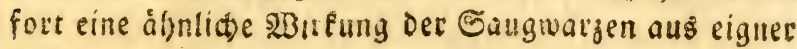
Cirfargrung.

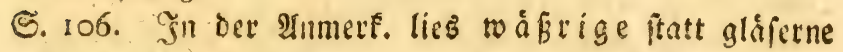
feuctigfeit.

S. 108. "Diefe fefr fictbare 26 " Sm Sriginal: Ce fillon très-apparent et creax donne infertion et fert de logement au bord interieur du procès ciliaire. Diefe fefrefictbate uno bohle Furd)e Dient zur finfis gung Des imern łandes Des Strablentrelfer (procès ciliaire).

ऽ. 129. Bon ben (eicrn bes Dintenfifhes hat aud ein

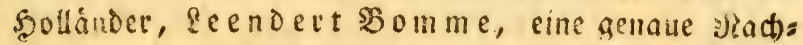
ridt gegeben, weld)e Son neider in f. Sa mmlung

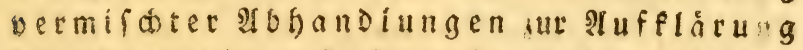
Dev 3oologie milo der Sanoelsgefdidte (Berliil 1784) aufgenommen bat.

Den 6ren oes Spumonats I 77 I fand id (eriaf)lt 2omme: auf bem Etrande Der Gurel 2Balderen eimen fritumigen sorper, ben id) Whangs für cine Eeequelle bielt; aber bei nåfeter lintelfudtung fard fidiz, ১ofí es̉ ein cierftoct (Die logrmannte Seetraube, uva

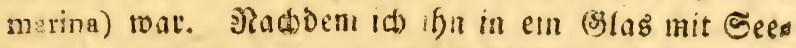

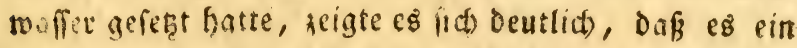
Soufen von iveit melor als jme!bundert trauben. oder Deerenattiger fócper mar, bon emem gallertartigen oder

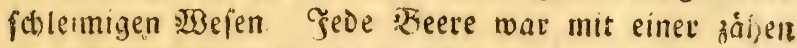
Saut ungeben, uno endigte fich von oben auf ein (itels d)en oder Sotránjden, modurd alle seeren fid an einem zathen Bande vereinigten, Deffen Enden mit ein alloer verbunden fino, und fo einen sunden Sians masts 
ten, wie ôie grig. \%. D. (in Feiner İbsiloung), aber feffer verfleinert jeigt, Der in der s)?itse mobl fects zoll breit war. Dex ganje Sarie war an einem fleiner şohjitångel befeitigt, Der bielleid)! von einem Seeges wadje abgefolagen war. Die Becten twaten von Ders reiben Brofoke, wie ein Bunded von funf Etưf, Der

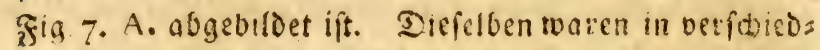
ner lagen uno als in Eifd)elden zujammengebsuft, batten eine afagraue Farbe, waren aber babei fo our(b)=

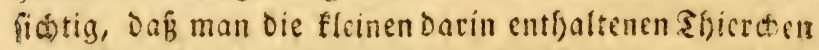
Deutll(t) refisen fonnte. Cis macen ifrei zmanjig bis Deeishig in jeoer Deere, jedes mit einer befondern flei.

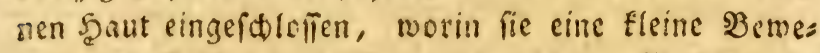
gung mit Diefen und SBenoen machten. Nad) Dem fie cinige Eunben in Dem Biaje geftanden batten, fano

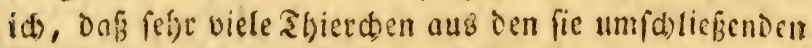

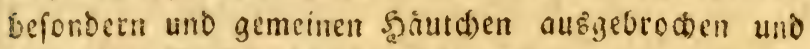
Durct Das 533 affer bingefd wommen waten; audf begas ben fie fig bismeilen fufammen ouf oen Brtund, und

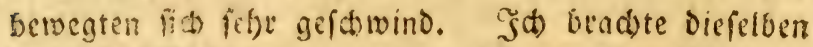

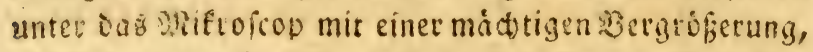
und od acigten fie lid, trie in der fig. 7. C. und in

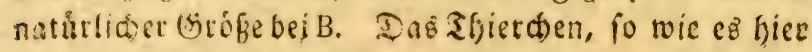
gereidunt ift, betreffeno, fo gieng oas oberfte frno im Eatwimmen voran, fo dák man uttheilen follte, dof biefes dee Saupttheil fei. J?inumt man aber an, Daf

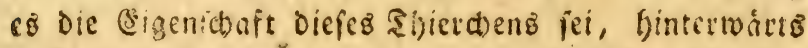
zุ

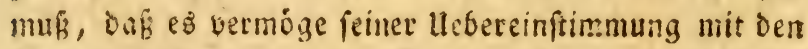
übegen wabrgenommenen Secfaţen Der bier vorgeftelle Theil ber overfe war; fo follen bie grofen fotwarzen Supfel bie slugen fenn, die Darauf folgenden hervorras

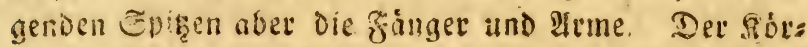

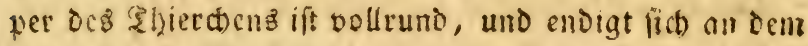
lyer vorgetrellten sobertheile wie mit einem fugetrunden

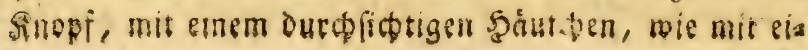




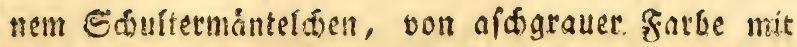
blafitotben Flecfen umbangen. IIn Defielben Dbertbeite

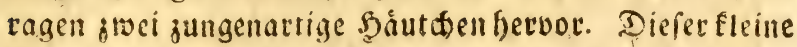
Mantel offnete uno forlofifid wed felstweife im men; aus Demfelben nach unien fam ein breiter Sheif roie zwei Sdenfel hervor, warauf zwei fowarje Tippel, waffretteinlid Die Ifugen, ftanden; er endigt fict mit ztwei halbmonoformigen frefzangen oder Făns gern, ämifden weld en baarfeine Gajern ftehen, welde roabrid)einlid die Irme fenn follen. Die Fånger zeigs ten liid) an Der innetn Eeite gezâlynt. Das Tfietcher

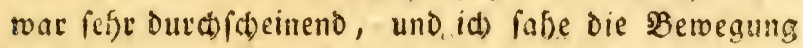

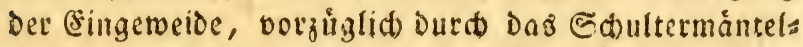
d)en. Sie ftellten cinge an oer Doerfeite berabliana

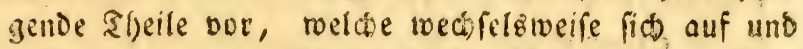

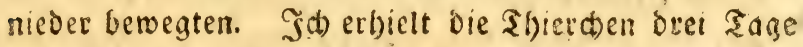
lebendig, uno in bem (sierftocfe nod) lànger, weil nads uno nach immer mefrete dataus famen. Shie 2 maaft

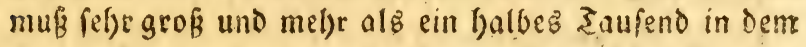

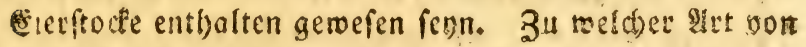
Eeefaken fie gefjoten, ift mir nod nidjt deutlids.

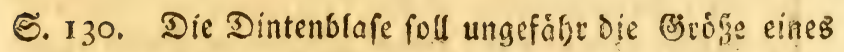
Daumens baben. Nit Der Darin enthaltenen Feusth ths

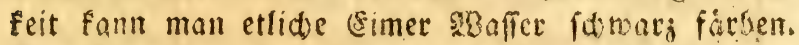

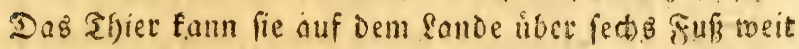
mit grofiec Seftigfeit bon fich fprifen. Sie lyat fefe wenig (serdimacf, und Dennod) glauben Dieicnigen, welde Dintenfifore effen, Das beridot werde erft fatmac? haft, wenn man bie Dinte ntitfod)e, Dabcr die Gififer

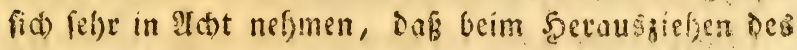

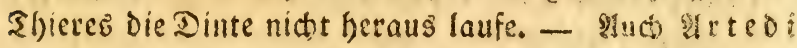

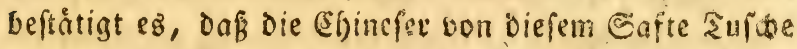
mad)en; indeffen ift er nid)t dos einzige sidateviale Dazus

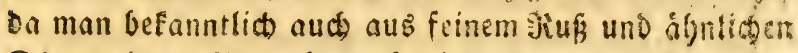
Dingen jenes Mroduft verfertigen faun. 


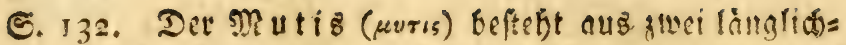
ten dicfen Sappen, weid)e fid mit ifsem untern fipas gen Ende tief in oen Baud) erftrecten, und liegt ju beiden

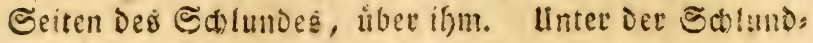
róbre liegt aud) die grobe Sd)lagadev, melde auỏ Dem

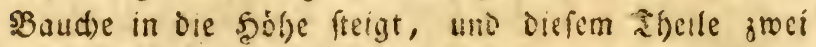

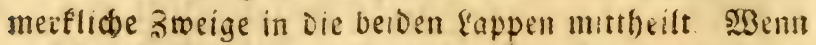
man bie áuftre háutige z̧eoecfung jetictrelont, fo jeigt fich Das innere sisejen derfelben felfer weid) und von eis ner dunfelrothen farbe, in meldom fia) viele blutge: fáfe verbreiten - Swammeroam.

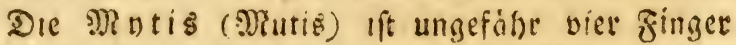
lang, einen fanger bid, llegt gerabe ber ?ánge nach in

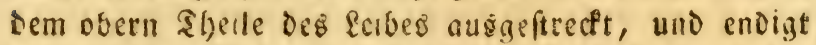
fitt mit einer Epise, inderm bie beiben sufferften fprizis gen Seiten fid) in (Eine Eplge netemigen. Die Ep.lfe: róbre geft oben Daruber han, und ift burch cine dinne Saut damt verbunden, fo bab man iferen (sang mit blogen Nugen bemerten fann, bis in Die smitte; brex get)t fie in oas Jnnere, fommt unten auf Der entgegen= gefekten હeite, einen Finger weit bom Ënbe, wieder beraus, uno vereinigt fid mit $\delta \mathrm{em}$ Diagen. Die Dins

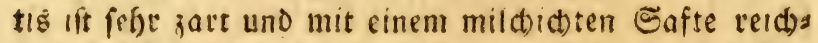
lich gefüllt 2luch) fieftet man Darin viel Hoern ober (3)e: fáke. Rermuthlich liefert Diefes (Fingemelie orn Stoff

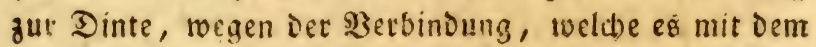
Darme, Der mit Der Epeiferóbe aus Dem Magen foumt, fat; Denn mit dem Darme verbundet fich aud Der Sintenbeutel femer ganjen Sànge nad fefor genau.

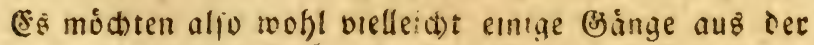
Minti̊ den taeniger verarbelteten Saft befonders in dea Dintenbeutel fülyren; oder dicfer Eaft modte auch Durd Den furgen uno geroten Darm in Den Beutel h!n= abgiben, um Darin jux Dinte jubcreitet zu merden. श्रn einem fleinen Dintenfifthe bate ith gefeljen, Don nici)t allein Der Dintenbeutel, fondern auc) Der Darm 


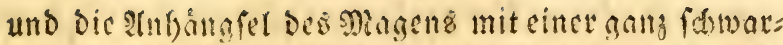
zen Fetdigfeit angefullt toaren; Dods fann id niche

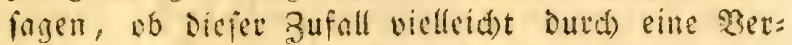
ftopfung bes Sagens und Der Darme verurfactit rod:

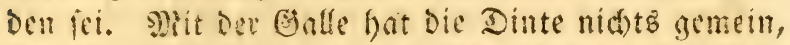

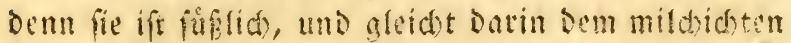
Safte Dex Diytió vollfommen. - Lifter exercitationes anatomic. Iil.

S. 185. "Die Aften fomnten fie Dutd)aus nicht." If tius, ber griedifide $\mathfrak{a r}$ t, gedenft zu Infonge

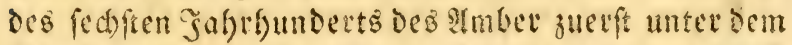
Sant d)erwerfe. Det Siame Sambat ift atabifat,

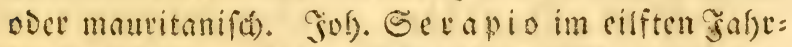
Gundert fagt, nad) Sem Borgeben Der Mauren fe! es Metrgewåd) (Eeeprosuft), weld)es oft von Dem ftutmifden sucere an Den Strano gewotfen waede. Dericnige, Den man aus Dem Bande Der SBallffide nefme, fen falect). Diefe Zlyiere ferben, mannfie gu viel bavon freffen, fotwimmen oben, und tweten an Den Strand getrieten. Alsomn idneiden bie

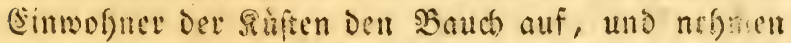

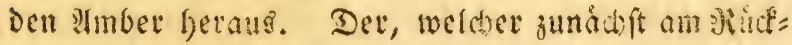
grade liegt, fey berbefte. Der Malfitio beife $\mathfrak{A}$ jel.

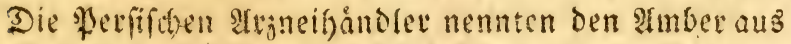

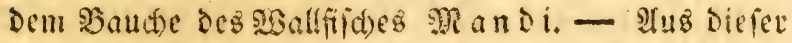
Piactricht fowofl, als aus 9iad)ridten von den tibrigen Ierjten fiefr man, Dap fie ifren amber theils onn Ifrifa, theilß aแร Cூfina uno Japan erbielten. Cic hietten ifn bald fúc en Sars, bald für den Eamen dece

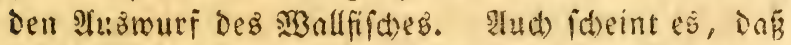
fie Infangs ben weiffen Ilmber mit bem eigentliden şallrat (iperma Ceti) verwedjeft haben (fo twie bies aud) von Futeticte gefdieft; Montfort S. 19:).

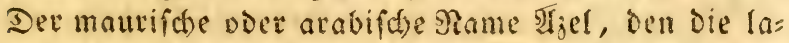

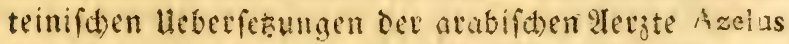

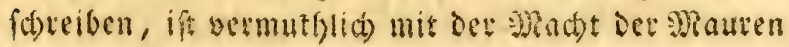




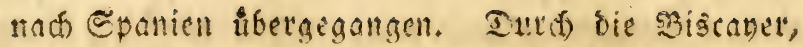

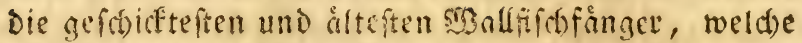
alle ubrige eutopaifde Dationen in Diefem fonge uns terridstet baben, mag Diefer Эane untev bie ubrigen S?ationen gefo!nmen und von ignen fo berfdiedentlid) oerdorben und oermitaltet worden feon, daßj man ifn jef̧t faum wieder etfennt. Nm nád)ften fommt Dem ådien SSorte Der Sollenter cagilot; meiter

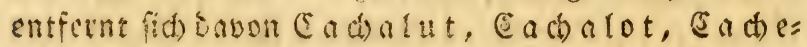
lot, ste Die Eranjolen fpredacn. S. Betmifde

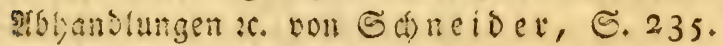

Soctr Siontfort nacbles bebauptet, und outa) eine grenge von scugniffen Darzuthun fudt,

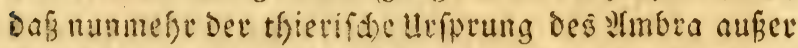
Bucifel gefeht fer): fo modste et wohl midut alle Stim= men ber llnbefangenen auf feiner Seite baben. Da Diepes \$roduft laufig in Den Cringeweiben ber (Sad)e=

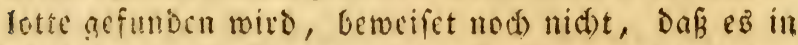
Denfelben entitanden ift, denn fie fonmen es ja, ebent fo, wie die Boget und andre Sfiere, die fo begierig Datuad) fins, vetfdludf baben. Sontfort focint

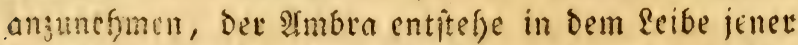
Eeethiere vorguglid aus oen unverbaueten Refter Der Dintenifibe, weil man Gonabel derfelben Darin findet. Allein biefe Sthribel find mur ein Serveis, Daf Der (Sadielot Dintenfifá) verzefret, Deten unver: Daulide Refte fich fobam mit bem oot = oder nad) fer

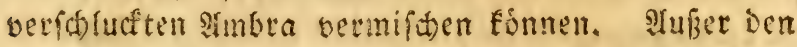

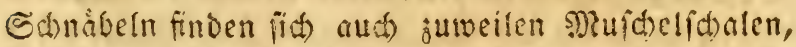
Sniften, fird)graten, Steime uno bergleiden frembe Gorper barin; folglich lôt fich mit gleicher $2 B a b r=$

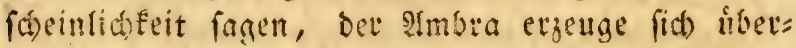
baupt aus Den genoflenen Sof):ungsimitteln in Dent Seibe der (5adelotte. Damn minften aber diefe Sficte eir befonderes Drgen Dazu befinen, fo mis s. Die 


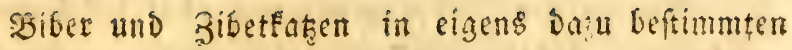
Beuteln eine wohltiediende Eubitan abfonoern. Man bat auch mirflict) Dergteid)en in Dem (Cad)elott

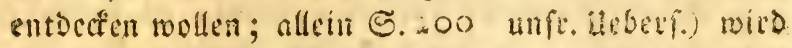
ganj richtig bemerft, Daf bie fogenomnte befondere Taide, welde ben smora cutfolt, cin ganj ge=

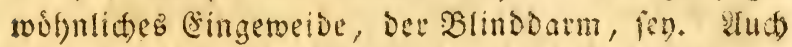

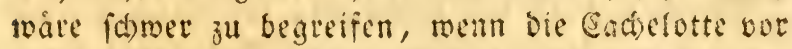
andern Sfieten zur Servorbringung bes Ismbta be= ftinmt uno organifitt wåren, warum nid)t alle J゙= Dividuen Diefer Battung ifn hetoororingen. Sian fagt, Daş Shier, weldes viel Imbra in fid have, erferanfe Davon und fterbe. Das faftum ift moljt naci) Den bewågrten Zeugniffen feinem Zmeifel unter: worfen; aber was foll es bemeifen? Jif ber 3mbra Ulrfad), oder Folge oer arantfeit? Jmerfern Jalle finder er fí in Dem nod) gefunden Sfiece, und macht es tranf, wenn er fict) anfăuft. Saie und woburct entacht et mun? Ergeugt er fich in Dem shiete felbft, doer folucte ifn - von Der Sintur fdon producirt - Das Thier von aupen ein? Diefe grage iff Durd) Den angencmmenen fall nod inmer nid)t ent= fdieder. Man hat, um fich bie Entfrebung Diefes merfwurdigen srodufts zu erflaren, es mit dem fo genannten Sthreinftein in Dex Ballenblafe Des ma= Incifáen Jgets und mit Den Şaarballen, Bemsfugein (Bezoar) verglichen. Sch uberlaffe Das Utrtheil îber Dieje Bergleidjung gelefrtern Månnern, als id) bin: mit fideint fie aber nidht redbt zu poffen, uno injon= Dertbeit bie d)emifhe Inainfe, die bei Dem ambra mefor auf eine Affonlictefeit mit Den Beftandtheilen Des Berniteins fingumeifen fheint, Derfelben ent: gegen z̆u ftefen. Die Moghlid)feit Dex (entftefung

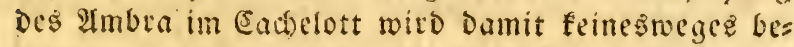

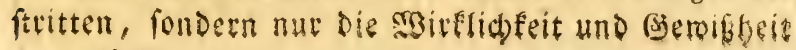
b̧izweifelt. 
Den gweiten Fall angenommen, Dof Der PImbra

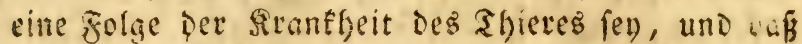
(av fid) in Demfelfen nux erft erzeuge, wemn Das Thier 3. 3. an Edwaid) Der (Singemeide, an llnverdau= licheit leibe: fo batte freilid, wofern bies ftreng

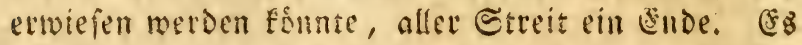

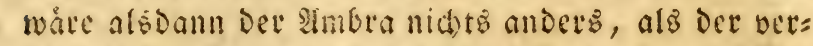
bartete Untath Des Cad́clots, Der einjig und allein Durd) Daร langere szerweilen im Darmfanal jene un= vegreiflid)e Berwandlung - eine wafye doemifde Iransิuดftantiation - aนs ftinfenden Excrementen in bic wobluied endfte alle: Subftangen erlitten bátte. Swat fout aud) Der Soth Des gemeinen J)?atders einen Silomgerud); aber ben hat er immer u: o von গ:atur, und er ift und bleibt ibrigens feinem âsefen nad),

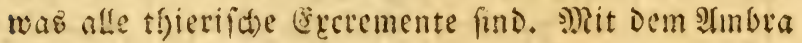
fingegen mur, wenn cr aub Den fercementen des

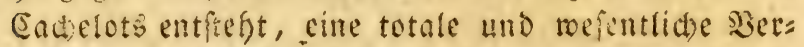

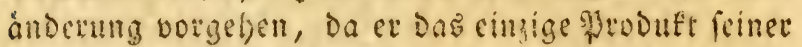
Fitt it, eben fo eingig, roie der Bemfrein, mut nit Dem linterfdiede, was bie Crezeugung betrifft, baß

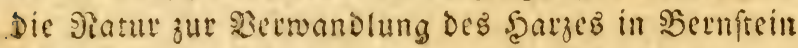
Gabetaupende und eime ganj andre $23 \mathrm{ceff}$ tatt, als Sie, mo dab Scar urforinglid) cntitano, gebraudite, indế Die Eecremente De Eachelots in einigen Jat)ren (lange fann Das Th:er bod) wohl nid)t franf feun?)

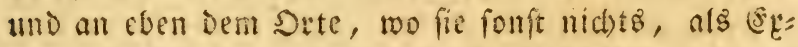
crearente blieben, eine fo beipicllofe Umwandung crletden *). Dod) alles Káfonmement a priori fann nici) tumftopen, was die (stfablung als wirf́lich auf=

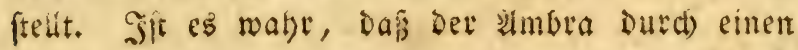
franf:

*) Die dbemifare zerlegung deb 2rmber jeigt befonutlich

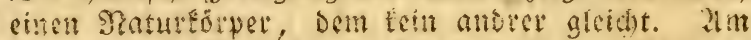

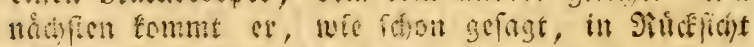

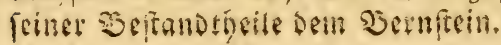


franlifaften Buftand in leibe Des Cadjelots erzeugt soiro, fo múffen unbefannte Naturfiafte dafelbit wirffam feun, und zwar nut, wenn bas affier er=

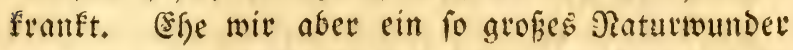
anzunefmen uns entid)liefsen follen, wito es exlaubt

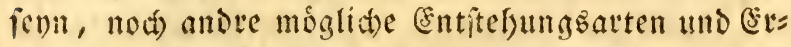
flarungen Der Exiftenj Deffelben im Eachelot ou vet: theibigen. Denn unmiglich i ît es Doct) nicht, Dấ Der Eadjelot den Ambra verfalucte, uns, wenn et fu viel bavon genofien gat, frant wird und ftirbt, weil es nicht fein naturliches গafyrungemittel ift.

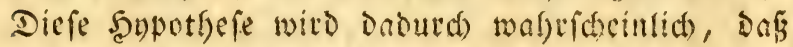
in Den erferanten Cadbetotten nid)t alfe excremente Smber firio, fondern Daß Derfelbe in einjelnen feften Stuifen unter Den walyen firifigen Egerementen fids) findet. Entfánde Der Sambra aus Den Excrementen

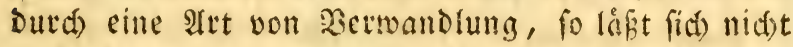
wobl begteifen, watum nid)t allet lintath wers walloelt wird, oder warum uidht wenigftens Spuren eines ftufentoeffen lubergangs des einen in ben an= Dern bemerft werder.

Eine genanete unterfudung ber verfacionen Eorten des Imbra witbe ur:s vernuthlid einent Swritt weiter bringen, um bie frecitige frage ent fideiden zu fonnen. Sift Der wahte ltrperung Diefes \$rodufts nicht im \&eibe Dev Eactelotte zu fudien; fo fann Der in biefen Shieten befindidye nud nidf melye feine eigentfumlidge farbe und andere urpringlidse (Sigenfaften haben; ex muf́ jid veranien, wie ct

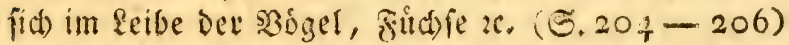
verindert, entweder jum 3ortheil, soer aum Shad)=

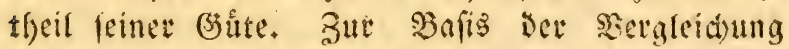
funnte man wohl am fuglidfert den geglabnen

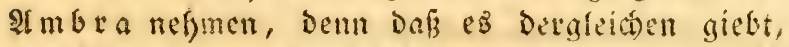
beweifet bas unverwerfiche Bengnif Des Soun. Lleber.

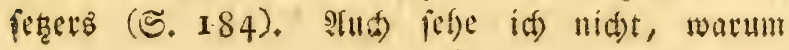


9) 马ublano beim Umgraben eines Alcters gefunden hat, fü verdadtig halten roll (ङ. 18j). Tuk હdabe,

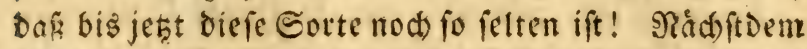
fonmt vorguglich die aus Dem Grunde bes Meeres au gefifichte in Betradtung. MRontfort meint grwar, Daf lebrere feine anore wàre, ala die yom cachelot

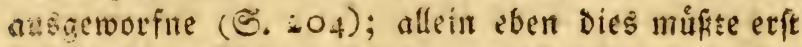
unterfucht werbon. Fånde man z. B., baßz allet

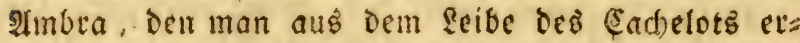
boilt, nicht unterfinft, fondern fdrwimmt: fo gåbe

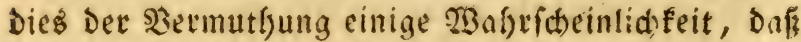
Der voin Cact)elot im Sirunde Des Meereŝ aufgefuchte und verfd)lucfte Ambra ill feinen (fingerweiden leid)ter werbe u. T. w.

Blumenbach fagt: alle Brimbe pro und contra abaerooger, fheint mic bies Produft immer mod) bis jebt feine fuglid)fte Stethe im Mineralteicte \{ูu befaupter. 



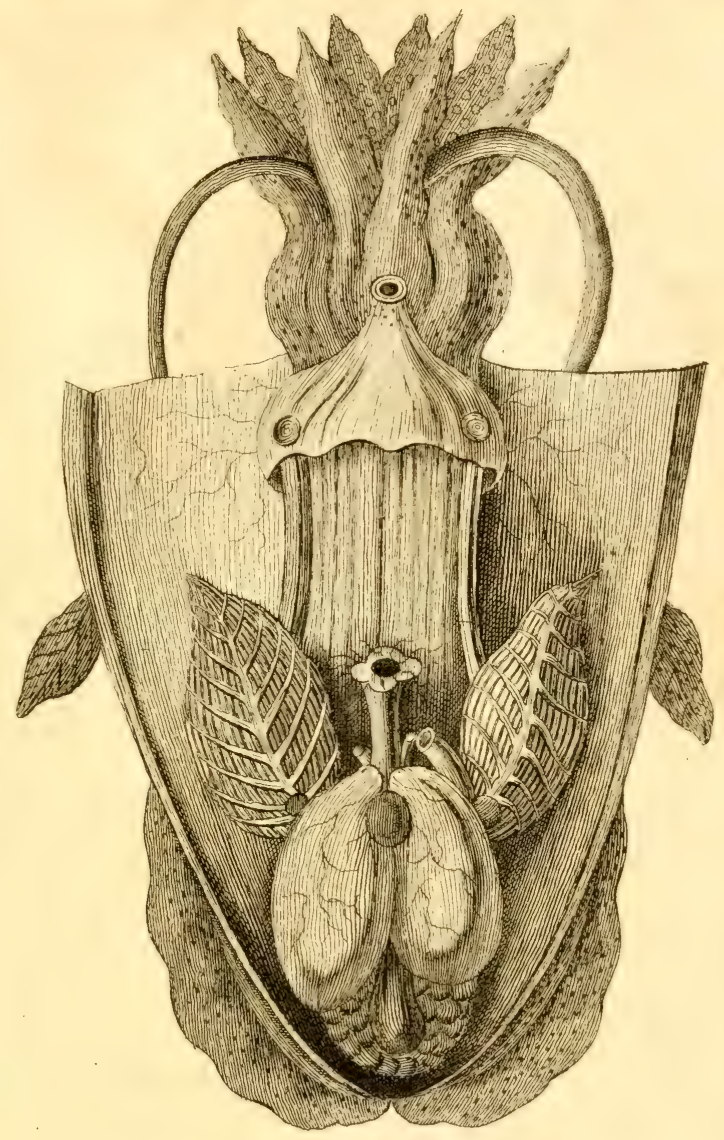

'Picle finelle oeverte.

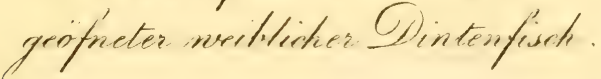





$$
00
$$






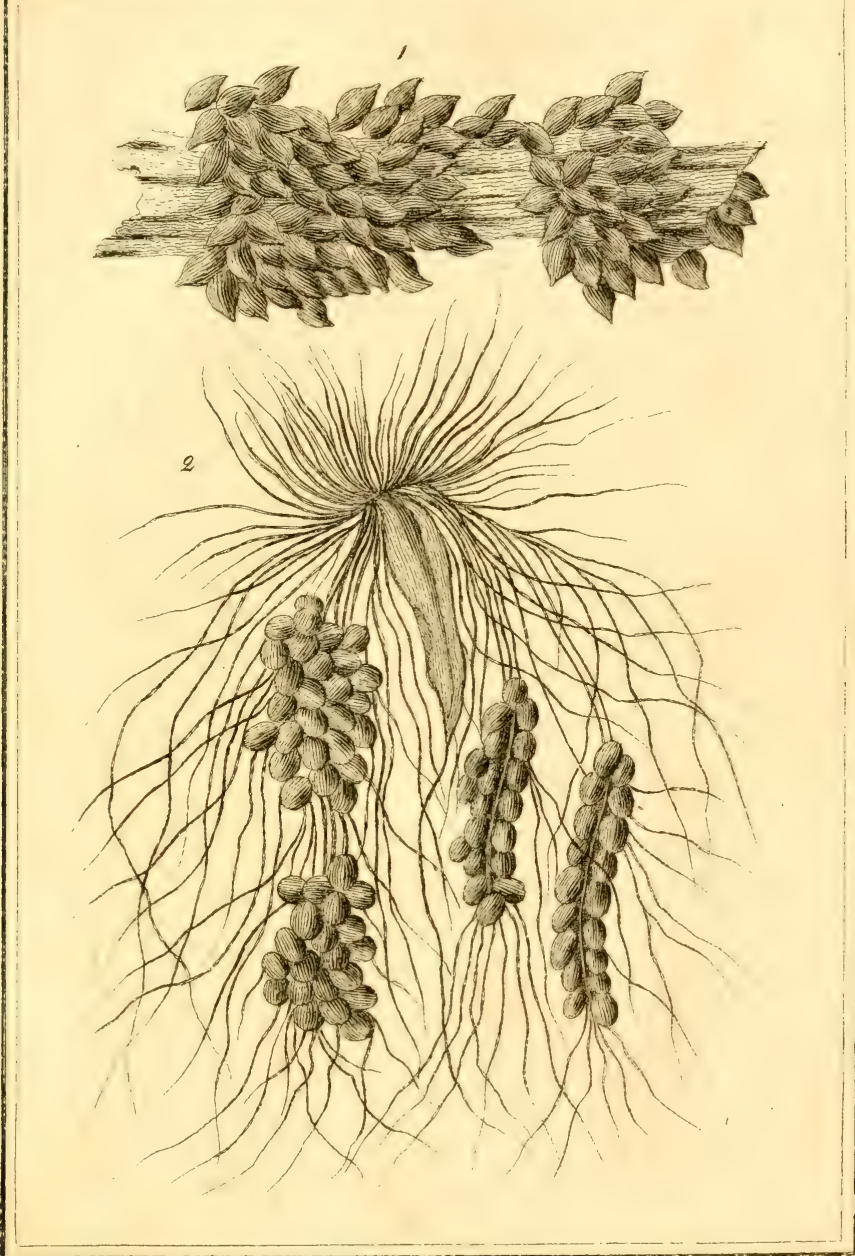

1. Ocupts de Pistir 2. Orufes de Palmar.

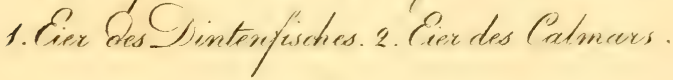




OPt. G.
B.1.Y.

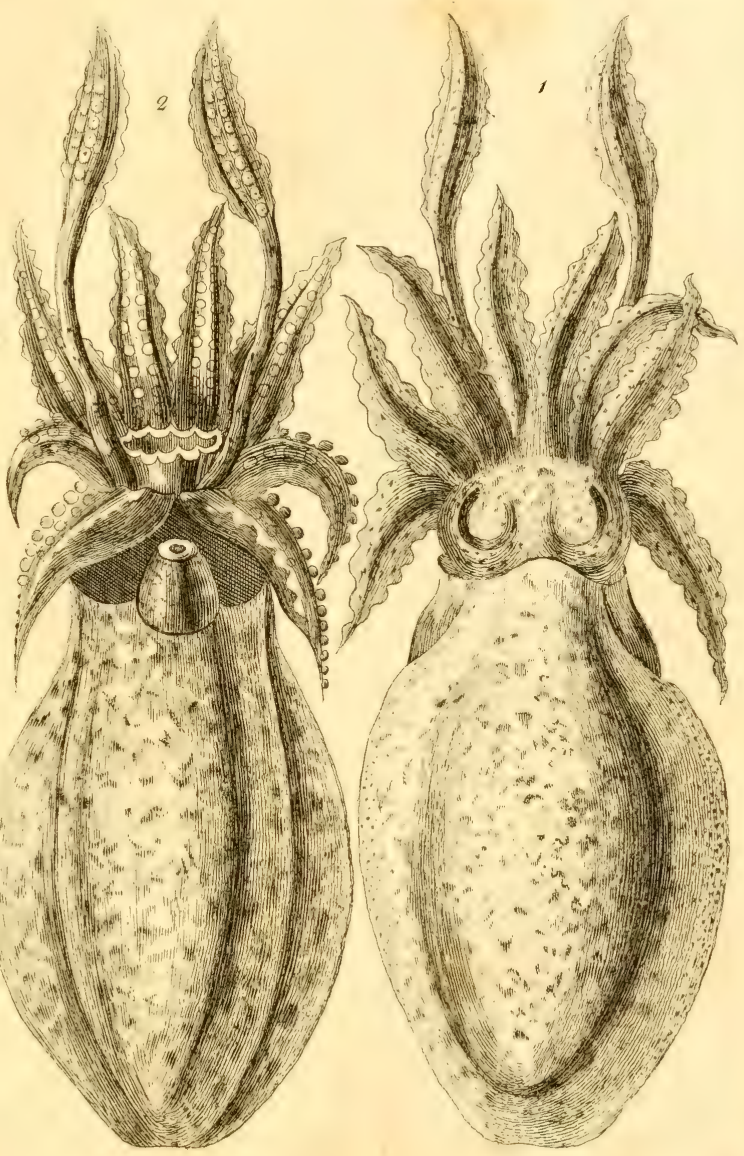

Sa Siche Triettie

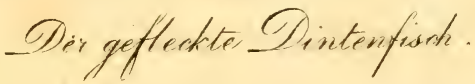





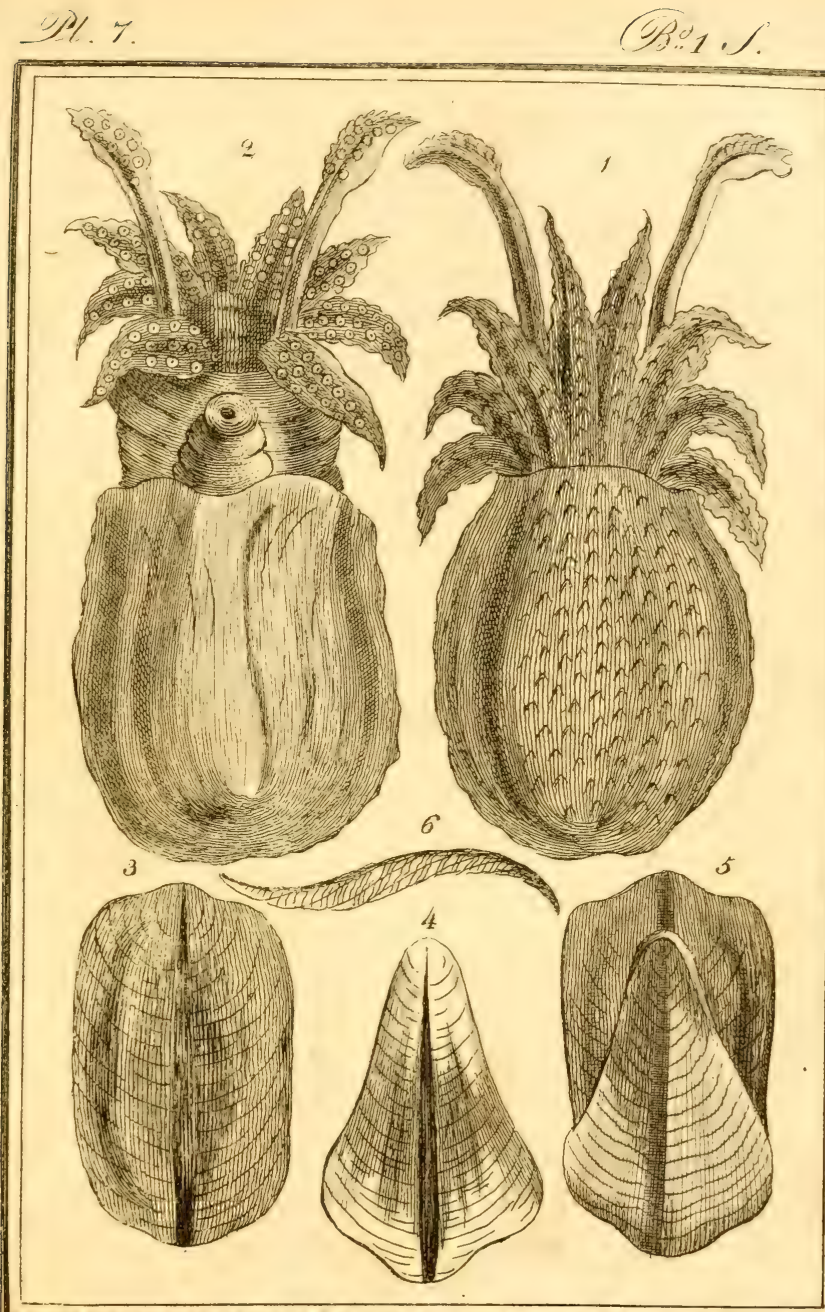

$$
\begin{aligned}
& \text { Ta Peche Suberculce. } \\
& \text { CDer inotidite Oninienfiuch. }
\end{aligned}
$$






\section{Deny Miontforts}

allgemeine unb befonbere

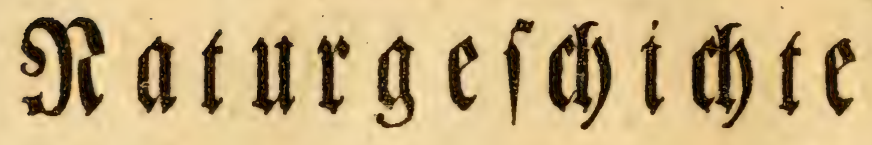
$\mathcal{D} \mathfrak{e} \mathfrak{r}$

פBeichwurmer (Mollusques)

a) 18

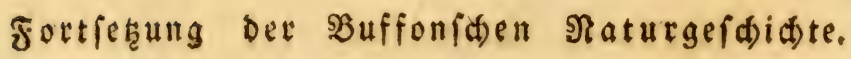

Nit e

Anmerlungen, Erlåuterungen uno Buโåk̨en berausgegeb en U ott

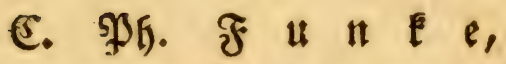

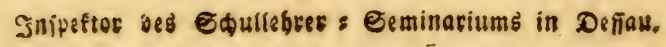

Sweiter $\mathfrak{B a n d}$.

Mit viefen $\mathbb{R}$ upfex.

Şamburg und Raing,

bet Bottfried Bottmet.

I 803 . 


\section{Reclercs von $\mathfrak{B} \mathfrak{u f f o n}$}

allgemeine und befonbere

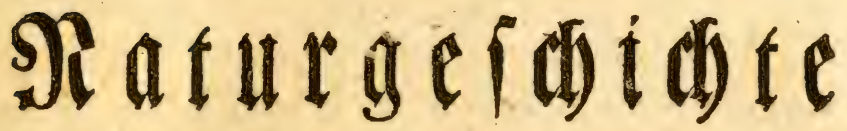
nad) Der neueften

mit fef̧r vielen Bufäg̨en vermeţrten แ⿰ \อ

bon Sonnini beforgten Iuflage a $b$ e $\mathfrak{x}$ e the

won einer Gejellfwaft von Gereferten

unเ

mit einigen anmerkungen, Erláuterungen und 3 ứácen

bera $\operatorname{sg} e g \in b \in$ a

v $\mathbf{n}$

C. $\mathfrak{P} \mathfrak{G}, \mathfrak{F} \mathfrak{t} \mathfrak{t}$

gnfweftor des อ(t)ullebrers Seminariums in Deffar.

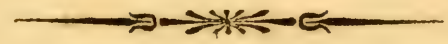

Sed) und breibigfte Sieferung,

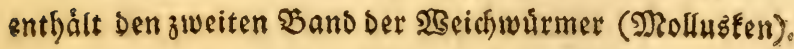

Mit

Şamburg uno Maing,

bei Cottfried Boltmer.

I. 803 . 


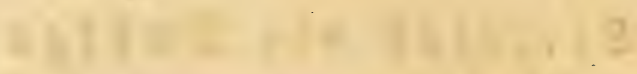

$$
\text { . }
$$

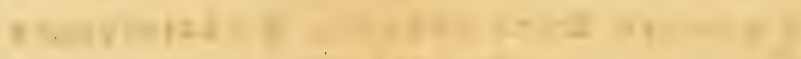$$
\text { . Nis }
$$

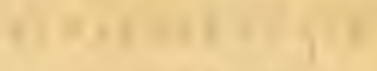$$
\text { . }
$$

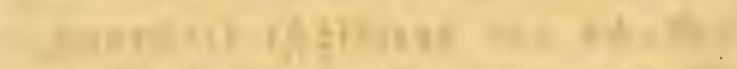
4.

$$
-4
$$

$\left(\frac{10}{2}\right.$

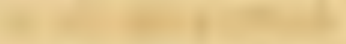

$$
\begin{aligned}
& +
\end{aligned}
$$

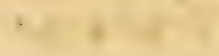




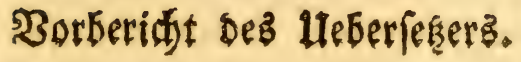

\section{S}

fortiften Suutste im Zuge zu begalten: 1) Daß mir die lleberfes

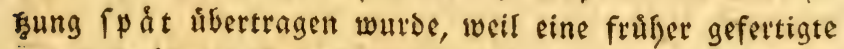

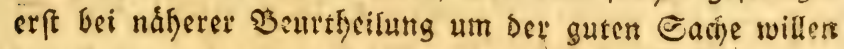
bei Eeite gelegt wutbe. 2) Don id) fie in siner 3eir bearkeiten mußte, wo mein 2Imt mich am meiften bes

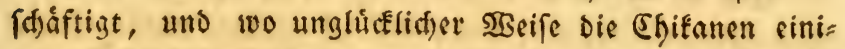
ger Edjlechtoenfenden, - tveil id) nidjt batte unrecht thun wollen, - mir meine Beit raubte und meine (E)

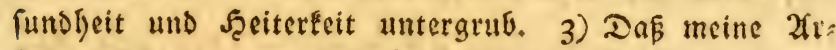

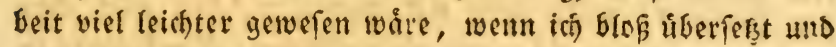
nicht viclmehr forgfáltig ju ủberlegen gef)abt håtte, was vev:

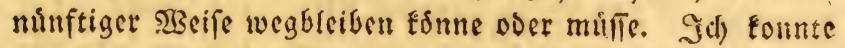
námlich, wohl zu metEen, bišveilen aus ganjen Geiten nue einzelne (Bebanken Erauclen. 4) Daß̧ Mrontfort nicht bró

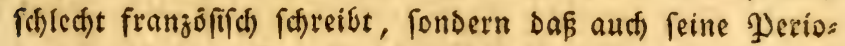
Den unrichtig gebaut, bie und ba auds roofl gedatit find. SBie viel vergeblidjes Ractbenfen hat mir beibes getoftet! - 5) Daß er offterş fdrvúlftig tvird, wo ev

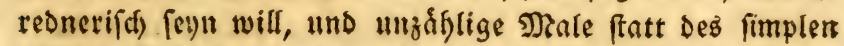
Etulz fich hodtrabender, oder im G̈egentheil unbefannter Échifferausbrúcfe bedicnt.

TSO idf etwas wegließ, gefdjaf cs mit Ueberlegung.

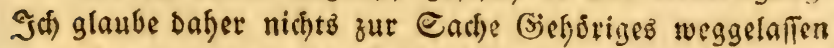
ju f̧aben; - im erfen Tgeil fellen einige פloten, obne 


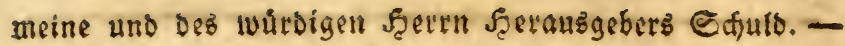
Rieber liés ith bier oder da etwas frehen, was id als

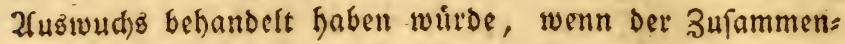
bang Doer Der innere 2 Serth Des (Sejagten mith nicht filr bie Bscibebaltung beffelben beftimmt håtte. Schtte iff a lles umántern twollen, fo wáre bas aser nicht mefr

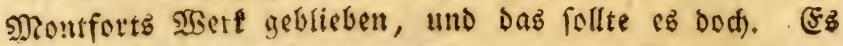
follte cille abgefurgte Ueberfegung fenth. Diefe gu liefert, war mir aufgetragen. Da Nontfort feine an: gefúfrten Luellen bann und wann unichtig überfect bat, fo fah id) mid) gendthigt, fie, wie er felbft, mit Den Drigie nalworten unten anjufúfien. J(b) bemerfte freilid) wohl, Daß̧ aud Dicfe Driginalworte bic und Da verorucft leyen, aber - id) befaßs Die Driginale nid)t felbft; alfo nusten fie meiftens bleiben, wie fie waren.

Da ich gegen 850 Seiten biz auf ungefågr 450 zน:

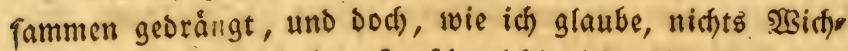
tigez aubgelaffen fabe, fo f(b)meid)le id) mit, Daf man mit mir nidjt ungufrieden feun werde.

Jd) Darf wobl nidit erft anmerten, Daß alles ebell (siefagte die feltenen uno vortrefflichen s) (Erfahlungen und $\mathfrak{B}$ eobad)tungen nid)t trifft, Fondern DaF ich) mich) iffer als eines berrlidjen 3umad) fes unferer Rit=

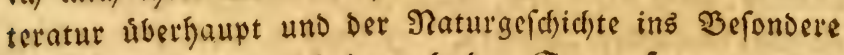
freue. Man tann fid ja auch Der Eonne freuen, wenn gleich) 2 solten liber fie binziebn! -

Den 28. 2tpril, 1803 .

\section{Rarl Witte,}

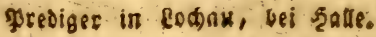




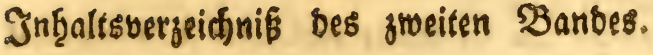

abbilloung bes gemeinen fialmars, Tafel VIII.

Der gemeine Salmar und feine vericoiedenen Siamen

Scite 1.

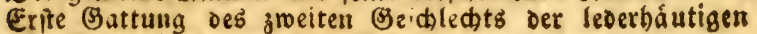

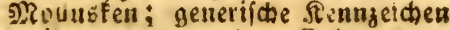

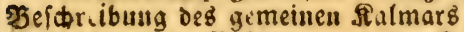

Eigentbumlide

tels

Rtideuplatte ber Ralmars

Ei wobnt im hohen श्रcere und hat ein záberes leben als

De Dintelfifiche

Die 2teltiren uno Reneren fagen ber Ralmar fliege

Svricawort Der Seelcute, Das fich auf Die \$olnpen bezies hen mag

(5ruppirte Sialmars (Eier in פaffen, und traubenformig ges oronet

Es lino ibrer oft achtzigtaufent

Sie wahicu, nadoem fie gelegt finos bie Art ifrer Ents viơelung

Diefe Eier werben im fodbenten 2 Baffer nidht hart

Einge \$bemerfungen Hiber Die Erzeugung unD $23 i e b e r b e r s$ vorbringung oer $\mathfrak{B e f e n}$

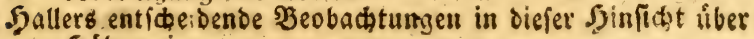
STibnereier

Eierfiode Der Mflangen

Fienfioffe ber Shbiere, bie lebendige Sunge gebăren

Eierftofe ber Fildae

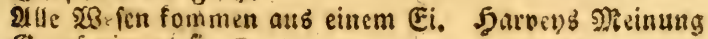

B): aaf nimmt fie an

Swammertam und $\mathfrak{B a n f o r n}$ eianen fie fic zu, eigentlid verdunfell wir fie aber dem Stenon

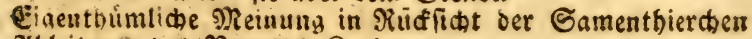
2ubleitung ves Namens $\Re$ a I mar

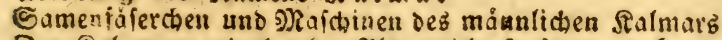

Der Sialmar wutbe bet orn 2liten nicht jo jebr gufuht, wie ber. Dintenfifó und der Yolup

Dies giollugt if an unfern frupten jiemlic felten 
Merftrinerung, bie man ben Dintenfilden ober Salmars aits fatrcibt

Shan fennt nod fein verfeinertes Şorn

Die fogenaniten Dintenfifch salmar: noer Sionelidnábel fonuen niकts anders als 3atue oon 2)ieerigeln fenu

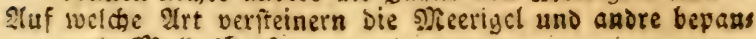
gerte Nollus? ?n?

Exflaruag Der fupfertafela

Zafel IX. Eingemeidenana unb formartige Platten bes ges meinen und Des Mfeilfalmars

जitlmar: Eier Tafel X.

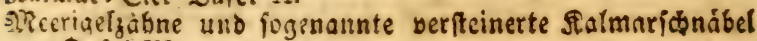
Tafel XI.

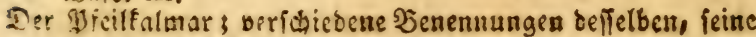
(Seltalt Fufel XII.

Dat Wufilifhe Ralmat, veridicbene ग2amen beffelben; fine (Beftalt Tafel XIII.

Der jarpunenfalmar, verichiebene Namen deffelben, feine Geftalt Qufel XIV.

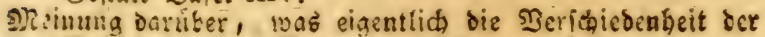
(Befकlecter und Sattungen beftumen fann

Eiflárung oer victzehuten 3 afel

2.r WBurfipis B́falmar, beríbicoene गumen befielbea, feiae Beftalt ₹afel XV.

Erflárung siejer Idifel

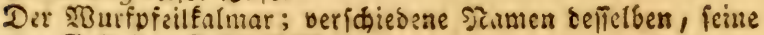
(3effalt. Tufel XVI.

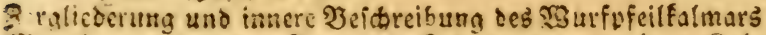

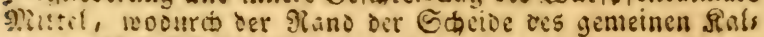
mors angebeitet wiro

Ein weiblitier gifrilfaimar, geoffnet, Tafe! XVII.

Erflarung ter fedzebnten und fiebjebnten Iaiel

tinc:pefurtige Sangen bes Dridter's beim gemeinen Ralmar

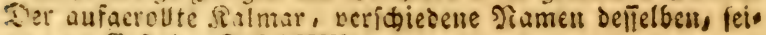
ne Beptalt, Tafil XVII.

Sornartige Blatte dieles Ralmare .

Erflárung Dit adt tiebuten Rupfertafel

Dei Salmar des twhen Meers (pélagien) verfuiebeme Nas men defielben, fene (5eptalt. Tafel XIX.

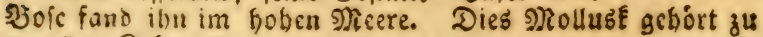
ben Salmars

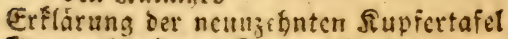

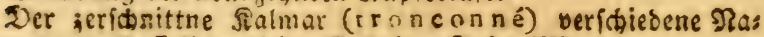
meu belitben, faine Geptalt. Tafel XX.

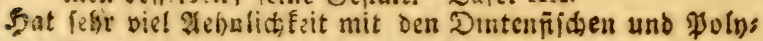
pen

Exflürma ber gmangiapen furfertafel

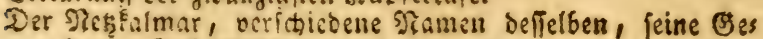
ftult. Wafel XXI

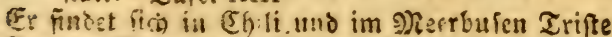

In ben gierera von (Shili wiro er felit großi

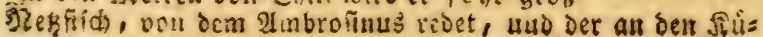

fen oer Juigl elba gefangen twar 


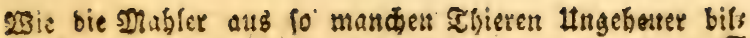
cen

Scite 6r

Der Dintenfich, Salmar, verichicbcue Stamen befielbca,

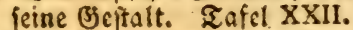

siondelet fprach juerf von ibm, bie Miten fannteu ibn nidt

Seine bormerne Platte

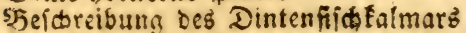

Die Eier befielben wachlen inmerbalb feines Torpers

Diefes Thier mant den Hebergang von den Stalmars ju ben

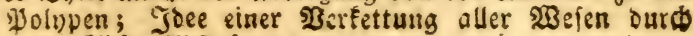
unmertliche 2 dbitufungen

Er:tárung ber jweitubjuanzigften Tafel

Nanfte \$e!npen, erfte 2atbeilung

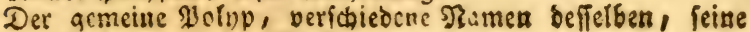
Beftalt. ¿afel XXIII. uno XXIV.

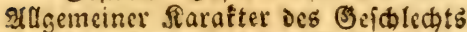

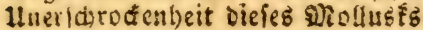

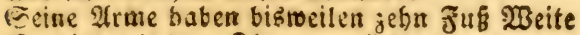

Er twit: mit dem ₹iger varalichen

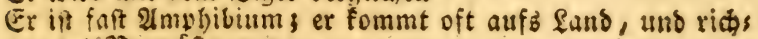
tet 53 ervuiftungen an

Sampf cines Polnps mit eittem Sumbe

Fir Echimmende ift es gefahrlith, ism nahe zu fornmen

23as Thevat vom fifch Porturof erjablt, past vollig auf Den \$lolngen

Die Wolnveneter find wie bie Nalmareier vereinigt

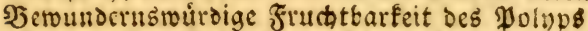

233arum Diefe 2):ollubfen nidt meht fo oft aufs lans foms ment

Der Wolup faun fic tobt fellen; brollige (jeichidte bavon

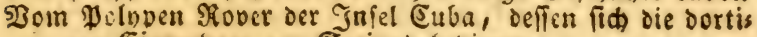
gen Einwobar zur Gejago bedienen

Rover oder Reverfus indicus bes झeter Martyr; Sesners (3) เіасанแร

Raraiben uno iffe Sernid)tung

Die rómiliden Fifider waren eben fo insuftrios, tvie oie Snjulaner von Euba

farbenállderung des \$oinpen

Sonderbare form ber Gedioe Der Polppen un Sebrdea Des. ₹ricters

Saut an Der গ̧aî̉ ber Arme

Näpfchen ber Wolupen, Tafel XXV.

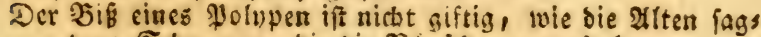
ten! Sdamerjen, Die Die Shipithen beruriachen

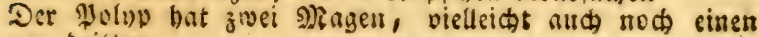
Dritten

Fingelveitezang siefes Dollusłs. Dintenbrafe

Das Ynmere beg Rorpet's phosphorescirt im Dunfeln

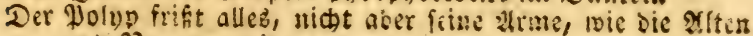
uno गiencin meinten

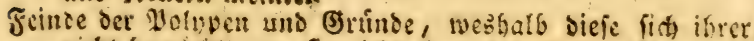
sidet bemichtigen, fie uidt eimmal feptgalten fonแu

70

70

$7^{2}$

73

74

76

81

83

85

86

87

89

90

9x

95

96

99

IOE

102

102

103

105

$10 ?$

$10 \%$

114

II) 
25iederibatbien bet Polyvetuarme

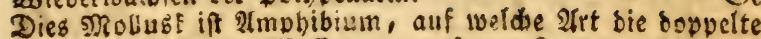

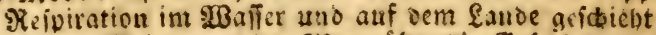

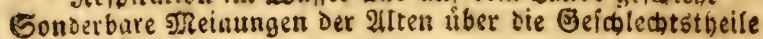
Der Wolnven.

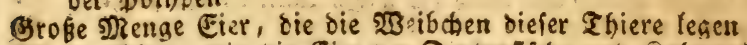

Eie madien, vie oie Eier jer Dintenfiche und Jialmars, ncd nadbem fie gelegt find

Ir fachen ber Berftorung jetrer ungebeuren Menge von Pos Inpertbrut.

23iderlegung ber \$ieinung ber 2alten, ber Dolyp lebe nur zimei Jahte

2Bahridacinlid verlaffen fie bie Stiften un bringen Die raus he Tai)reszeit it ber Tiefe Des Meers zu

Ehatfacten, woraus man vielleidat ichloß, oaf bie Pulypen uแr zivei Sabre lebtea

Der gemeine Pulup erreidt nur eine gerwiffe Brofóbe

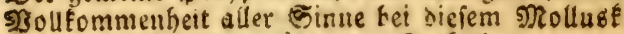

Fifdaers AbGallo!nng liber den Sirakatiza

Jefatombe von Polypen

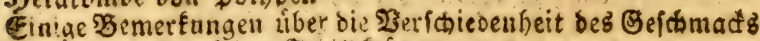

Die Ulten a

Die Froide tociden in Deutid'ano jebr acfucht

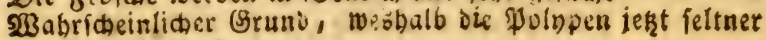
find ale foult

gift und Gnoufteie ber filcher

Geidithte eines beruhinten Freffers

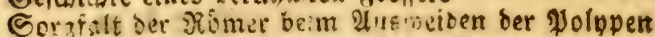

Pe Beride (frimulirende) fraft des Polnveu

Shieicity phin, nic dicje g)touasfen voritellen

Eir waren auf En) actrianichen: Diunjen abgebilbet

Der Polnp $n$ arde von ieber mit dem Bielarm vermedhelt

Erflirung der oreiumdziranziaften, vierundzivanzigften uno finfunizivangigiten ftupfertafel

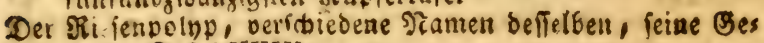
ftalt. Safal XXVI

Die Alten faunt nius in biefer f̧inficht erjáglt

Fulgoius eraíhlt fie

2h

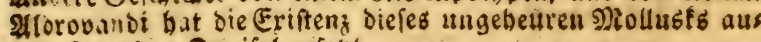
Ber nllen abueifel gelek̨t

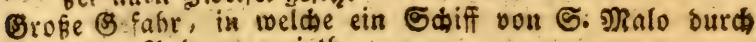
cieien golopen gerieth

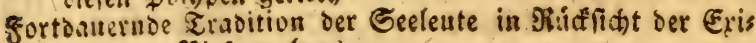
ften cez riefeupolups

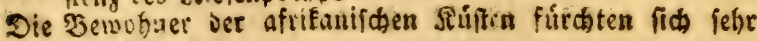
nor itim

Der Rapitin Dens vertiert orei feute von feiurm Schiffe, die der Rief́nvolnp itsm nirnmt

Die (E) tuceen lins frie lider $\Re$ itur 


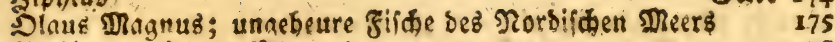

Xiplia Des Slaub 2)

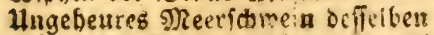

180

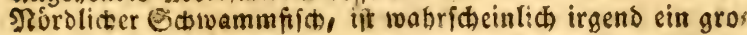
Bंes Mollust

Taucher Der Alten; auf weldhe Sirt fie ben Anfällen ber Syaififiche entaingen

Anbre? 9) Aerungebeuer, bas aud ein Riefenpolnp zu fenn ichentt

Die $\mathfrak{B a}$ anfice uno anore E: taceen fino frieblich

Broke Mubfelfraft bes $\mathfrak{M B}_{\mathrm{a}}$ nitices

Die Alter nanten alle ungebeur, Neerthiere, bie nimt $\mathfrak{M a l l f i f h e}$ mareu, bellua

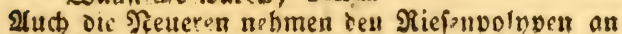

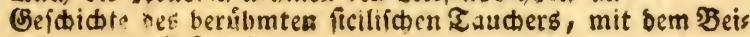
namen Pefcecola

Siebenun:ziwania fö lanaer 2 rm eines Riefenpolppen,

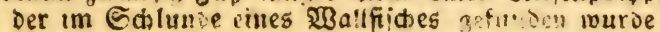

2(n rer Arm cilier Riefenpoly)ps, Der etwa fechjig Fü lang geveien finu modte

2rm einç Diefer Neuusfen, dą ber Rapitán Rennolos antrif

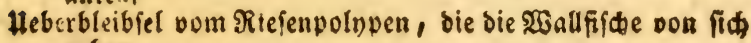
acben

Intifice und norblicte Nicerichlangen

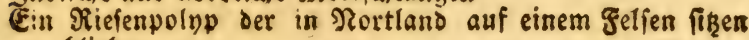
blicb

Hnteritied zwifhen Dem Rielenpolypen unb Dem Rralens pulnden

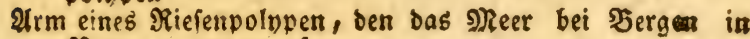
Porweren ausiwarf

Brofier Ulmfreis uno ungeheurer Abftano ber entferntefter Theile ocr 2 rme des Tiefenpotnpen

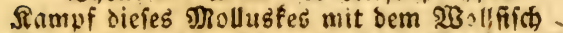

(B) fahr in velche 2Alexandors des B̈robien Flotte gerieth

Gange Flutben von SRerfiveinen

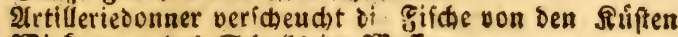

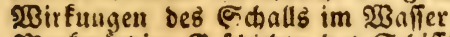

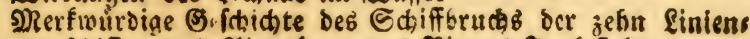
f́lffe, und $\mathfrak{a b e n t h e u e r ~ d e s ~ \Re i t t c r ' s ~ I n g l e f i e l d s ~}$

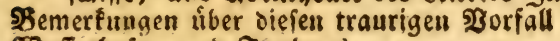

TBafierboien uno Inphons

S) Aelitrom obar freifen"e $\mathfrak{Y}$ Birbel

Reinum uber Den Remora (Saugefich)

$18 \mathrm{r}$

184

185

188

189

190

191

198

193

195

195

I96

197

199

200

200

$20 \mathrm{I}$

20r

202

202

204

204

206

207

207

208

2Cy

212

Hugebeuerartine $\mathfrak{x}$ atabilien

215

Dir Sinfen: Dolnp uno feime veríciedenen श्amen

Seeungetseuer dpฐ Plinitt8

Rrafen Deg Mantinus

218

219

219

Nirafeu dé sl vus Magmus

222

sirafeu oder Safgufe Des

225 
Situfen bes (s)egner sirafen ober Sjafgufe

SExit: $2: 6$

Rrafen bes $\mathfrak{3 a ! m o n t ~ b e ~ B o m a r e ~}$

Strafent bes Erich Pontoppisar

Srafen voer DRicrocosmus ocs Simué

227

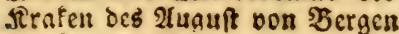

$2 ; 0$

Iirafeu Des \$of́c

231

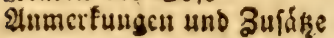




\title{
Denทs M:
}

allgemeine and befonore

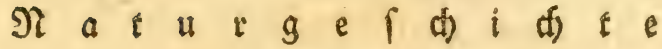 \\ b) e t
}

23ridbwürmer (Mollusques), Thiere ofne Stutgerad, mit wrifferm But.

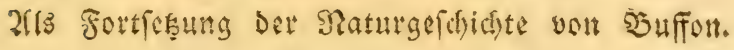

$$
\text { Sweiter afeit. }
$$

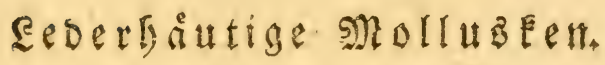

Bweite argtfeifung

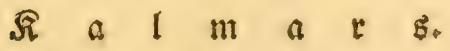

\section{D.r gemeine Safmar *),}

$c$

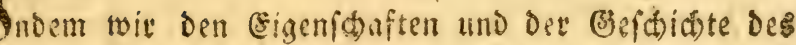
Dintenfirches nachforfaten, jeigten fich unb to viele uno mannigfaftige facta gleidb fam von felbft, bah wat fie nit

*) Die Thetis Der Girtechen. Ariftot. Hit. 4. cap. I. - Lolliguncula Plaut. in Cafina, Loligo

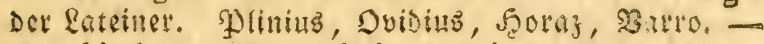
Gladiolum. Plutarch. in Apophteg. - Loligo, lollium Der neuern Eateiner. Calferon, Calamar

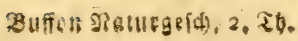




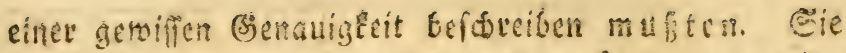
Dienen als (s) tigen Moltusten. Fluá) haben Dị Eigenidaften und Gis rofnffeiten Der Dintenfifac mit Denen Der Salmats uno

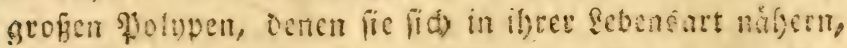
fefo vicl iberemitmmendes. Eie find alle stei mit gleis

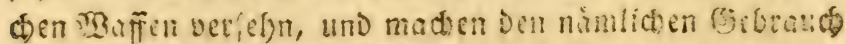

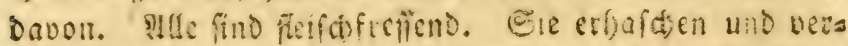

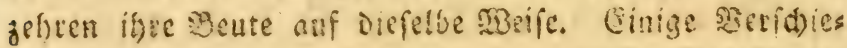
Denbeiten in ibrem geufern, fo to getriffe Mnodififatios

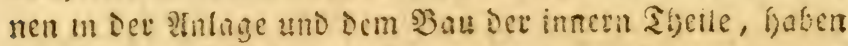
jedod einen gefefyten neutern Sinturforider beriodst,

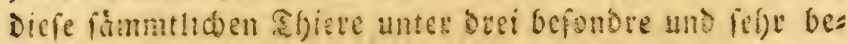

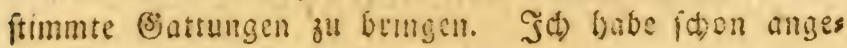

und Calmar auf frombinds. Theuthons, To-

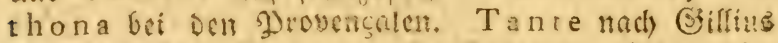
in Drarfulic. Cornetz in Bamente. Glaugio mud Glangio in Nontpeltict. Calnmar peicado auf fwanter. Chocco anf poitugiefor. - Oligaga in Sifyricn. Calamaro, Calamajo, Glaugio in Grafen. Totena in Sion und gencs

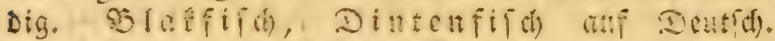
Raan-Kuttle auf pinttoeutich) (des Saxons), inkFich, fleve, flecve, calamary auf engition.

Loligo Belon. Pic. pag. 3 2. fig. 334. - Lo. $1 \mathrm{igo}$ magna. Rondelet, Pilc. p. 506. p. 358 ber franzoj. جuggabe. - Salvian. ayuat, p. 169 Loligo major. Aldrov de Mo!lib. p 69. 70 mio 71. - Gesner aquat. p. 5 S6 utid 583 -- Ionfton Exfang. Tom. I, fig. 4. - Ruylch. Theat, 2. Exfang. tom I fig. 4. - Lifter. Tab. 9. fig. 1. anat. Pemnant Zool, brit, tom. XXVII. no. 43. - Borlafie Hift, nat, Conwall. pl XXV fig. $2 \%$ p. 260, Loligo vuigaris. Lamark. - Alis femi. rhombeis, limbo facei triboloo iamina dorfali antice anguftata. Mem. de la ioc. d' hift. nst, de Paris, an 7. p. II. - Sepia Loligo; feche Calmar. (L. A. G. Bofe, Hif, nat, des vers, in 8. p. 46.) 


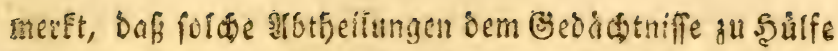
fommen, Dấ man fie alfo, - twenn fie anders in Det Datur gegrindet fino, - ja annefmen múfie, Ramare

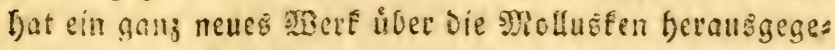
ben. Cit Gat Das Chaos, norin die berúfmteften Ed)rifts fteller fie gelaffen gatten, gcoronet. Die sififenfinaft berz Dante ifm alfo in Dicfer finfictit abermals viel. Sinne mathte nich blof eine einzige battung aus Dem Dinten fifd, Dem Sralmar tmo Dem solppen, fondern er watf aud nock unter Der fpecifichen senennung \&oligo alle Gattungen Des अalmars gufammen. Man fief)t Gicraus,

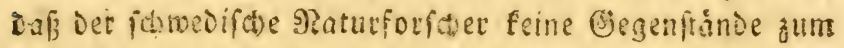

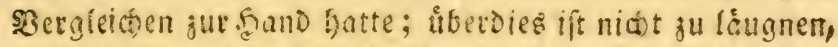
Dof im allgemeinen die atboiloungen Der vieten હdriftfels

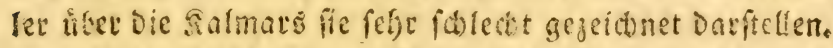
Dovf *) nimmt blob ?amat's (pecififo Plamen, nid) abee

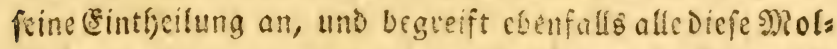

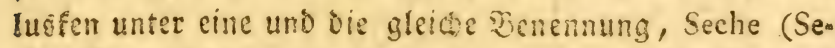
pia, Dintenfifó), und jwar, fagt ev, treil bie (Bstatuns gen niat zafflecid) fino, uno tweil man oie Itnatomie ju Şulfe nefmen muri, un fie von einander zu fondern;

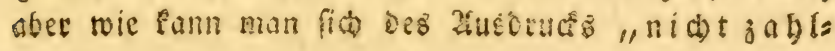

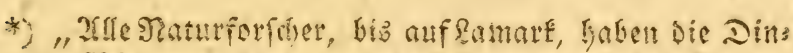
tenfifhe unter ciner und Derfelben getierifden bensts mung verenigi; fimé crwa antegenommen, fonft bes

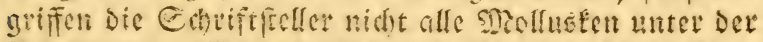
Dincmung „Dintenfifá." Eie unteridieven dent

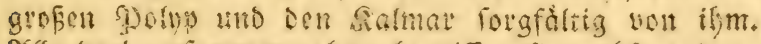
Zlle Deei zufammen aber begriffen fie nesfe andern Tfierent unter Der Benemung "Mollia" oDer "exfangues." Diefer Maturforfber Gat fie aber in Dré Triten getbeilt. Eeine (sruinde lafien fiá) aflerbings

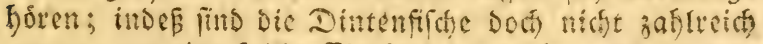
getug, um cine foldhe Gintlyeilung nothwendig zu mas

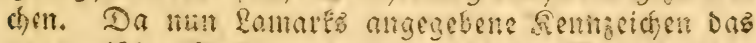

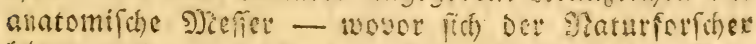
Füten mus, - verlangen, fo werve ifh feinem sosis

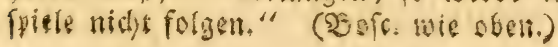


reict" bsi fo mamigfaltigen Sfieren bebienen, sie "ad

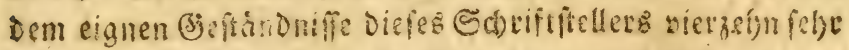
bon einander abgefonderte battungen enthalten, bie st feloft auf reinen Weifen nod vermebret bat, une die uns felloar immer nod) werden vermett werden. Heberdies

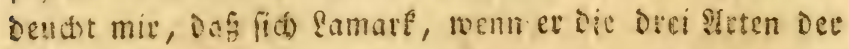
Mollueten, den Dintenfifid, den Sulmat uno den Moinp feftecte, ies onatomifden soseffers nut in fo fern bes

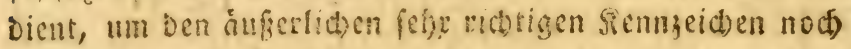

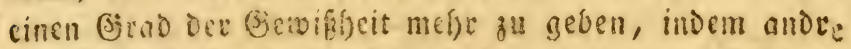

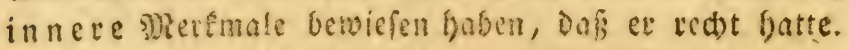
Die zefnarmigen Dintenificie entbicten nomlid immer cinen Snochen, und mit dicfer imern femmeich a twat jedesmal ein forthufender 3 ino (Umiange) um if)e

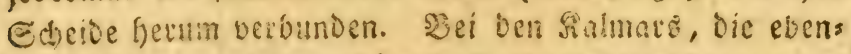

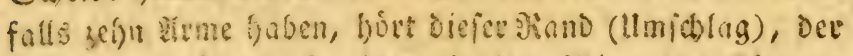

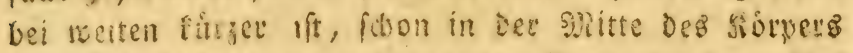
auf, uno fie balten eine bornantige Slatte in fich Die

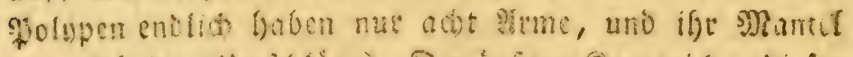

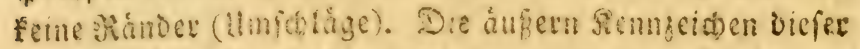

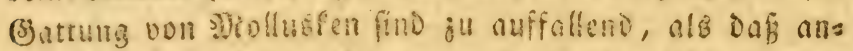
Dece Angaben no fyog wiren, um fie von oen beiden erfter

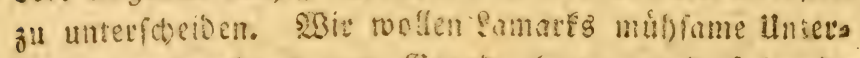
fuclungen bued aus zum bronte legen, und fo!gende

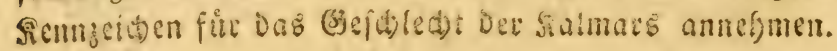

D* Sorper, Der Durd eine leverartige mo mófu=

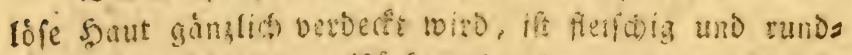

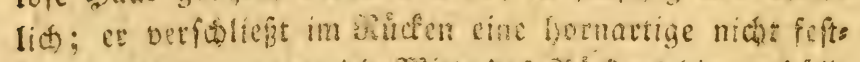

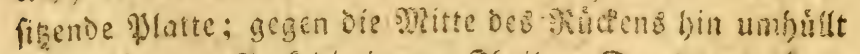

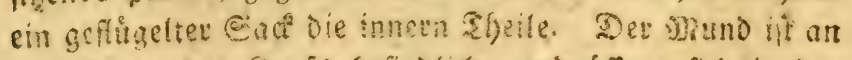

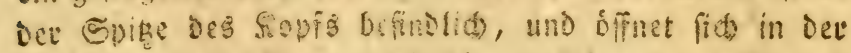

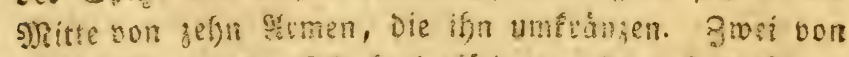

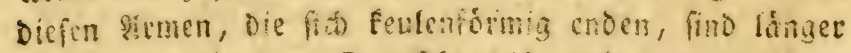
als bie adt andern. Das 2 fler ift nacte; es fotwimmt

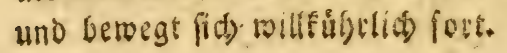


Bei Dem exfen Shbtict gleithen fio alle Brattungen

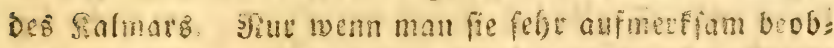

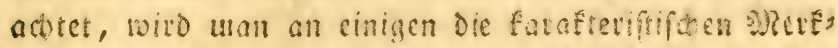

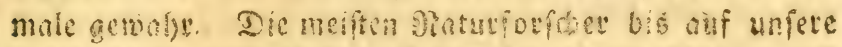

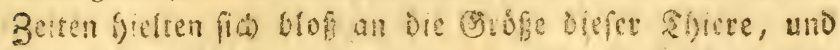
natgmen Dafer zwei Batungen Deffrben, Den geofent und oen fleinen Salmar, an. Sie anderten nod

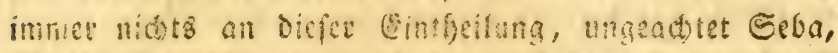

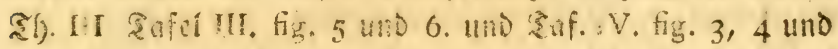
5 ; wei andere Cattunzen oder Berf voigefeflt hatte. Die Sontung Des geminen Salmars ift die grofitte des ganjen sefátedtr. Shan hat Mols Iuden Diefer Bsattung gefefn, Die. wenn man oie âtrme

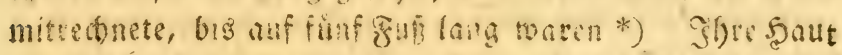
ift glatt und glafite, geloweifi, und tofentótilict am

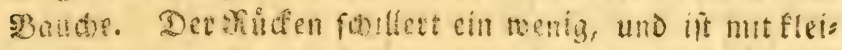

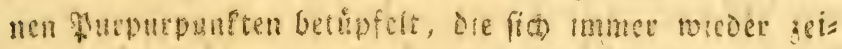

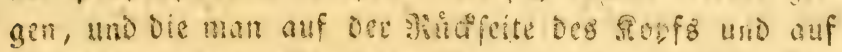

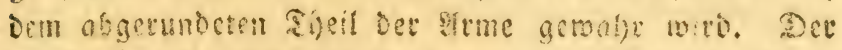

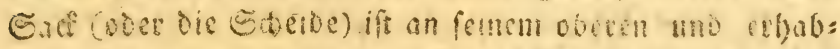

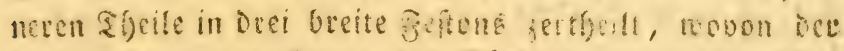

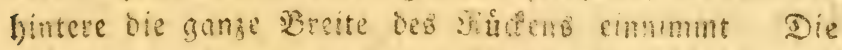
Glinget nefmen muten auf Oom suber Des Shicrs, nad buten gu, wo behabe beine auf Derfelben Etrfe, ibren

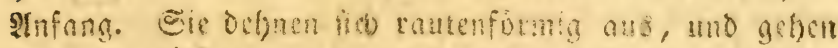

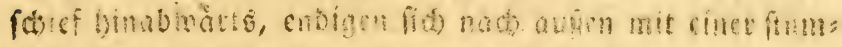
pen Epite, und giebn fró Samn in riner Dianonallime

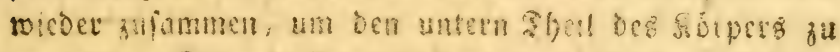
erteiden. Die abt stme funo mis zwei Beethen (Eoug) Fipiden (ober feldon) verichen, deren Cnel fid) bis auf eluen geminen Wunft verlaigern fann. Ber Etamm

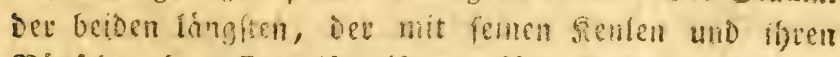
Sinplden bewaffnet ift, ift ungefobe fo lang, mie dec

*) Belon, lib. 2. de pisc - Dreanus (Cab. de Cot-

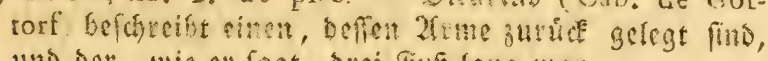
und der, wie ef fagt, brei ชub lang war. 


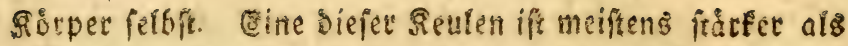
Die anore. Det Mund ift mit cinem bornetnen Sonnebet verfefn, det fids, wie beim Dintenfift), genau einfingt, uno ber aud Dem ßalmer zum Zermatmen und Zereeiffer feinet Feute Dient. Ecine Afugen befinden fids auf Det

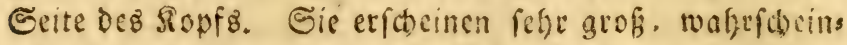
lich ifjer Etellung wegen, fino aber meles: uno meniges ftralylend, als die dez Dintenfifdes. Der sinontel ober

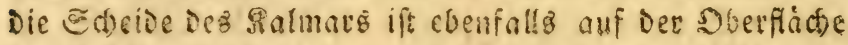
Des Iticters, ben Der gemeinichafticte und ausfülysende Sansl endet, befeftigt Diefer Stibter hat mot etron,

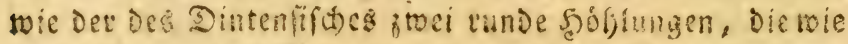
Ealzfaffer verticft lino, fonoen ex if in: (Segentlfeif mit

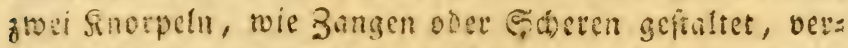
fefen, Die fich unter der Saut befinden, und in igre Defer

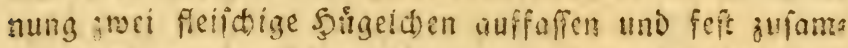
men furipen, bre fid verlangern, uno fo gebilbet find, baf fie mitten in biefe sinowel finabgleiten fómen.

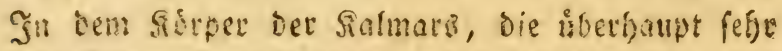
ennglici) fino, ift ingbefondere die şealangerung bes

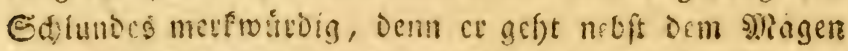

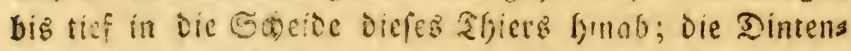
blafe befindet fia aber nicht unter cim Morper, fondern weiter gegen bie siditfe finalf, uno acigt fid mitten uns ter ben fiemen, Die länger find, alg̈ bei bem Dintenfifd)e. Diefe innere Sefdofrenbert fannte śrifteteles fon *), und fie Diente Diefem erften foftematifien פaturlebrev, um ben Ralmar vou Dem Dintufich su unterideiden. Die Dinte Des Salmars ift aud ridjt foward, fondern

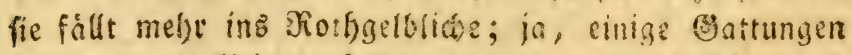
befonters die fleimen, baben mir immer enne fdóne uno

*) Atramentum habent, hoc ut polypi fupra apud mutim potius pofitum, Sepiae vero infra ad alvum. Arif, de part. 4. cap. s. 


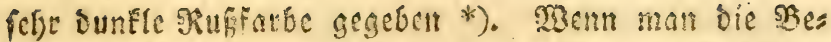
Decfungen bes stamars iffece ganeen länge nad) offriet,

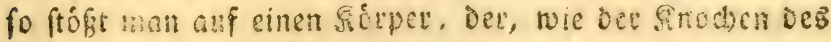

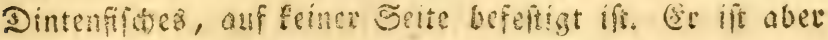
Dutodus nidt falfatig, ponsern outdfidtig uno blob

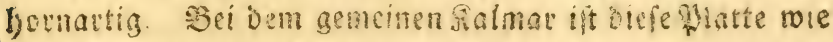

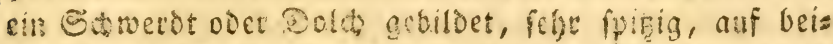

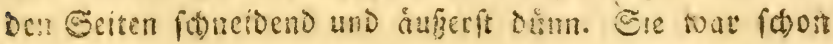

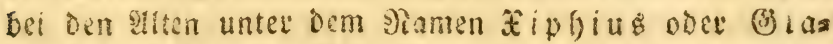

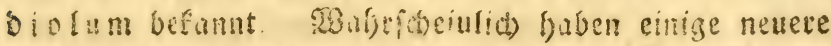

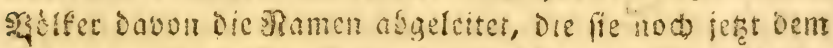

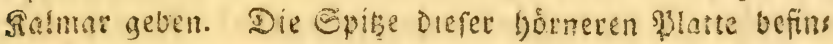
Det fiid am fintem Cende Des Sorpers Diefer Thieves

Die alten belgauteten, Dof ole Galmetb fuwoht wie

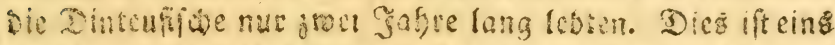

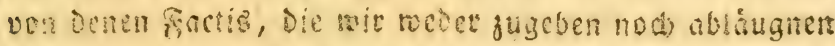

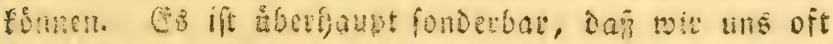

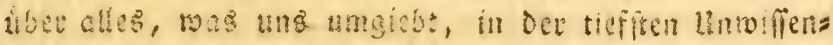

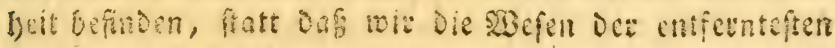
Rànder vicl befper tennci.

Der sulmar lit vôtig mecutbier, O. f) er zicht Das bofe meer jedem ondern Itufenthatt vor; er focint gern

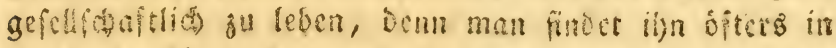
Soufen. Dit miro man ibus aud nofge on ben lefern ges

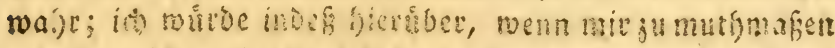

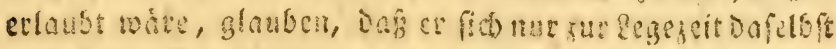

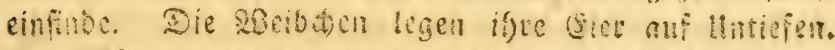

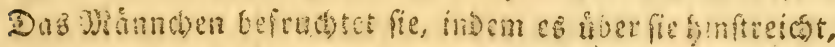

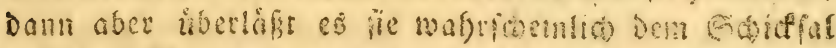
und Den Cementen, um fich retedes ing bolse sulect zu reverfer.

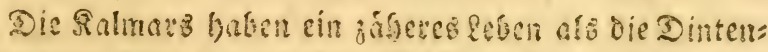

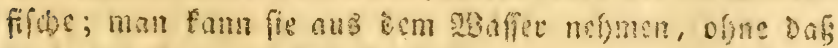

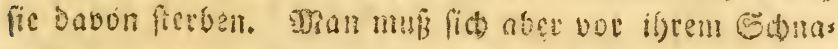

*) Athemaeus, lib. 7 - Opvian, halien, 3. fagt, fie (ci) faft totf. 


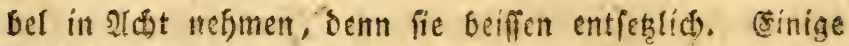

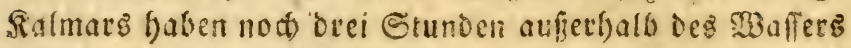
gelebt*), গRan findet fie faft in allen Miecren; ibve lan= gen Arme Dienen ifnen, um fid) feft zu galten. Sie wet= Den aber woht eben nicht oft Davon (brbraud) mact)en ourt: fen, Dem Die Deerezmogen find mue naje an den finften uno ain sande gefátlich Wuf Dem foben gheere varliert

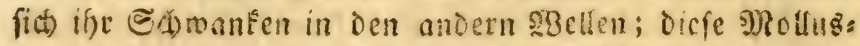
fen furduten bick alio, eben fo wie die Sdiffe, tein uns glud Die Ectifflcute jeloft beforgen eș mur nat)e bei

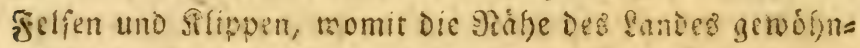

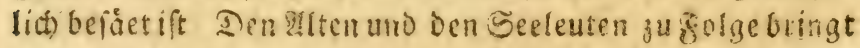
ein beborftefendes Untwetter cine gemiffe febhaftigfeit tee

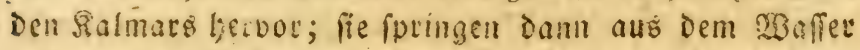
und balter fití) mit ben flingeln, Dic ibren Rótper ums glaingen, eine Zcitlang in Der \&uft; man bat fie fogar

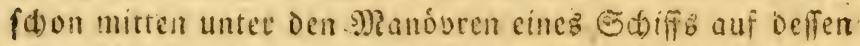

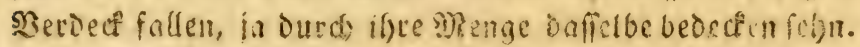

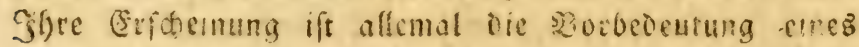

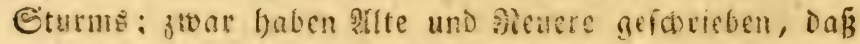
Der Ralmar fid iber Dre socrfade ber sisellen emporbes

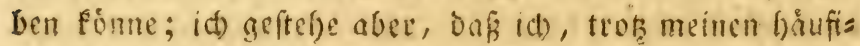
gen Secreifa, Dedh nie cincu Salmat fpringen gefefn, nod) irgend jemano angetroffen have, Der mit verfidert bátte, ev fen Augenzeuge davon getrefen **).

2Bir faben oben gefefn?, Daß̧ Die Sanonner den gemei=

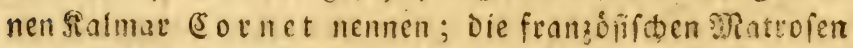
baben Diefen Ramen fowobl Den Dintenfifichen als Den Salmats, uno Den Slolopen (morunter Dicfe, gewófms

*) Olearius, ubi fupra.

**) Arift. Hift. an. lib. 5 c. 18. - Plin. lib. 9. c. 29. - Oppian lib. r. de pifc. - Aldrovandi de lolligi-

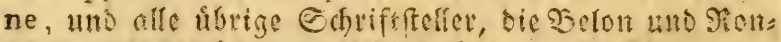

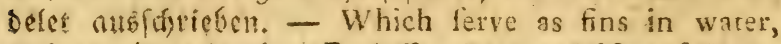
end as wings in air. (Berlaffe, Natur. Hift. of Cornwall. p. 260.) 


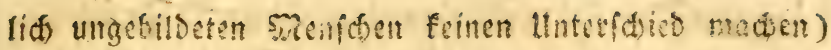

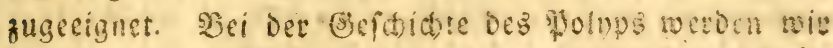

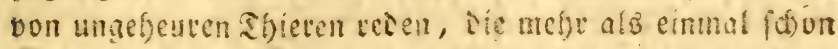
Daz Reben Der Seclente hit Gefafur gefetgt habear; biefe grofen Wolypen nun verwedfeften fie mit bem Stalmat,

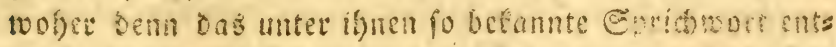

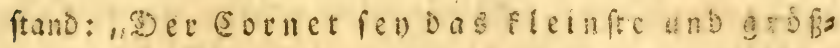

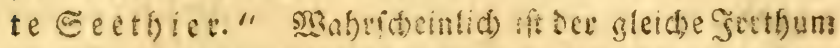
ftuld daran, bof felbit die beften Saturforforernody beu= tiges Fages nawiegen, Die Dintenfifwe gefoeten zu ben greffen beliannten Mollueten *). $2 B e n n$ wir von ben

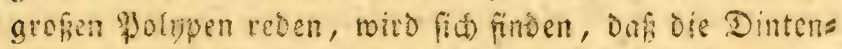
fifule gegen gemiffe jolppen faum Dog fino, was cin Grtunding in 98 ergleid)ung mit cinem SBriffifthe ift.

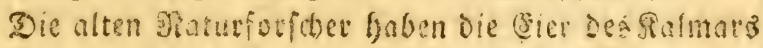
niớt getonnt; einige glaubten, fie gleiden ben esern des

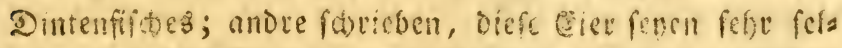

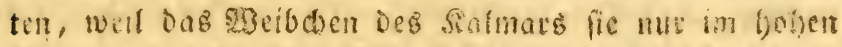

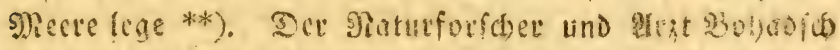

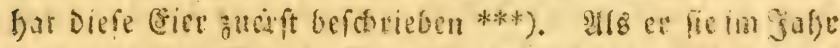
1752 auf Sem Eande (Damm), am Ulfer bes sheers bei Edevelingen in Bollano aumceften 9) Rate fahe, bizlt er fie

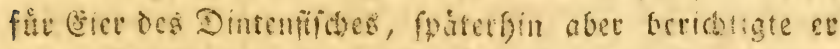

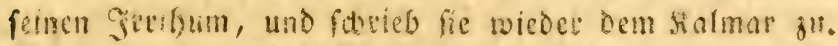

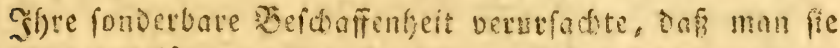
bis bafin fin cine Fit won midua oier syeerneffef

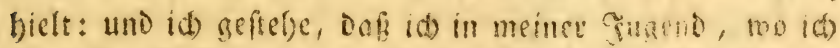

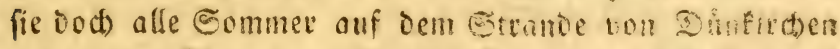

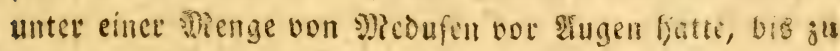

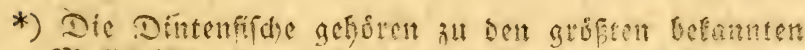

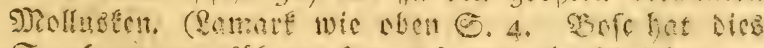

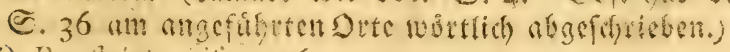

**) Rondeiet, pilic. 506 .

***) Ioan Bapt. Bohadich, de quibusdam a nima. libus marinis, vel nondum vel minus $\mathrm{n}$. tis. Ditsdae, I761. cap. 12. p. 155. pl. Xll. 


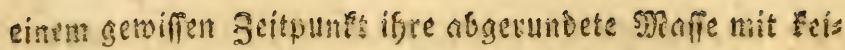
nem andeen Geoanen anfah), cls, ogf fie unter fi

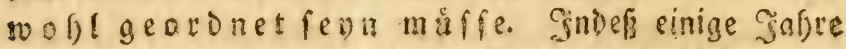

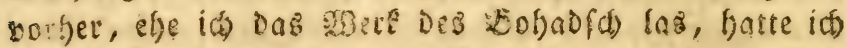
f(t) on bumerft, DaB fie einige Saufenoe von fleinen Suls mars in fift veremige. Denn Diefe Ilte von Moflusfen ift in Den Gervâffern Des Sanals viel gemeine", ale man ge: soúbulic glaubt; auti babe ibs oft einige derfelben, trie

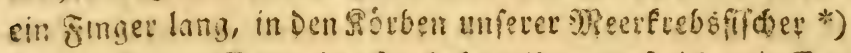
angenoffen. W3enn iá) fie beforeibe, mus id mit 50 s

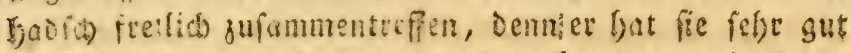
berbadset und gerase to whe id), foaterl)m, gefunden.

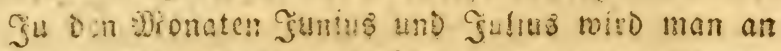

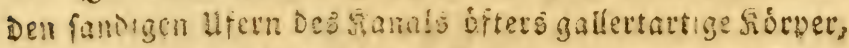

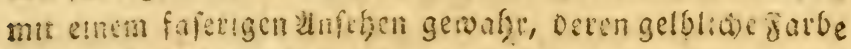

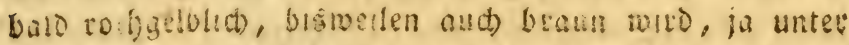

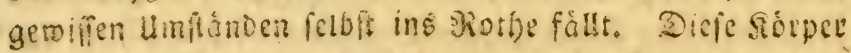

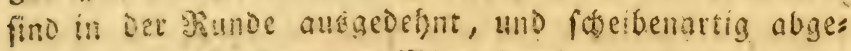
plattet; ifre Dides in Der Witte betrigt bišnellen sinen 3oll; fie vermindert fid nad Den Kindern fu allmálglid

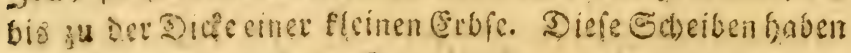

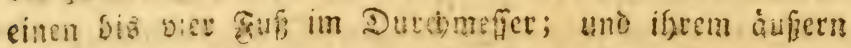

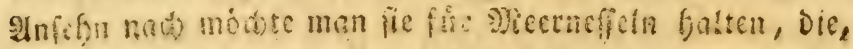

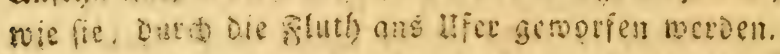

Watufud man aber Derglecten gallertatige Ëdei:

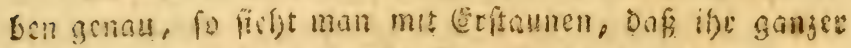

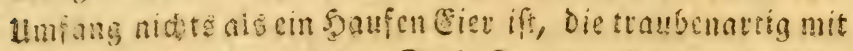

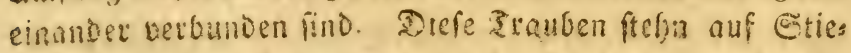
Ien, oie alfe an einem gemenfonofitiden onittefpunte

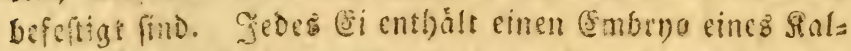

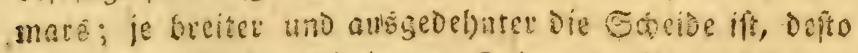

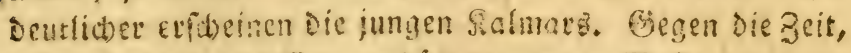
Da fie Das (3i verlaffen, ect)ait ore gange Mlafie cin hims meiblaues Infrinn. Die Dereinigung folder Eies in

*) Cancer crangon. Linn. 
Traubenform, wito but bic runoert unb aus einander

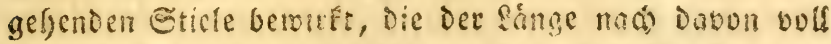
find; fie find felge regetmógig an iem Mintefpunft anges

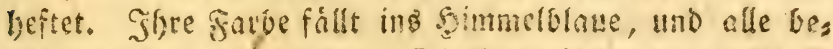

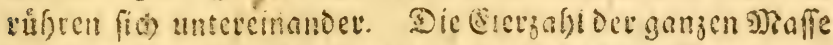

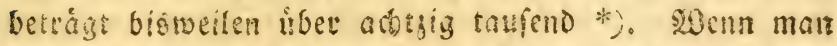
Die Eriele von Den eiern beficit, Die ringz fecum Daran

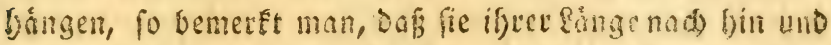
wicoer zufammen gedrut fint, ober ringfúmige (sin

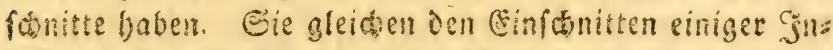
feften. Die Maffe, Die bobsofo jeidnete, tras, wie er folfft fagt, fefge flein, Dewn auf Dem Eande ausgebreiter,

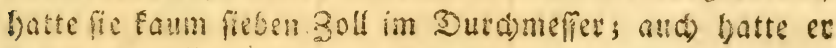
felbft foron weit grókere gefergn.

Gó gáblte einmal nabe an zoobif bunoest stauben, Die alte an einem gemeinfdaftliden s.tittelpunft befeftige maten, unb Deren gan;er Umfang mely als vick fun im Durduefer batte. Da aber die zlurf wieder cintrat,

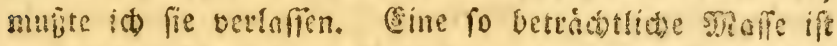

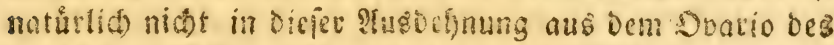

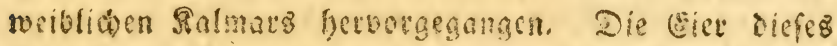

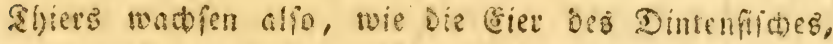

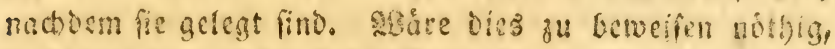

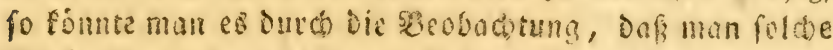

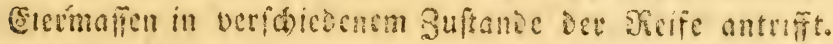
Sft Der gange slumpen flein, to find ez auth tie (Sier, und in Diefem Seitpunte folleffen fie brö cine the uno

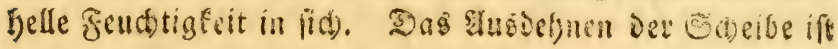

*) Iulos numeravi quingentos rexaginta octo, quolibet julo vero, quorum decem duntaxat diffecui, foetus feptuaginta Quod li igitur quemlibet julum totidem foetus continere fupponamus, et $568 \mathrm{cum}$ 7o multiplicemus, productum erit 39760 totiden nimirum foetus ab una eodema que loligine producti. Bohadfch p. I6t. 


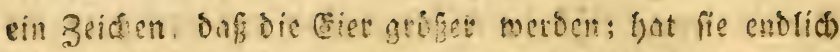

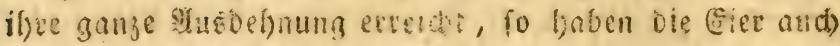

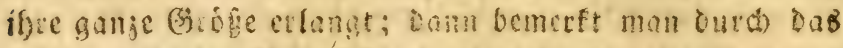

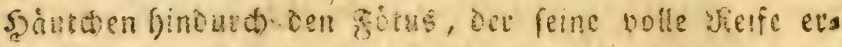

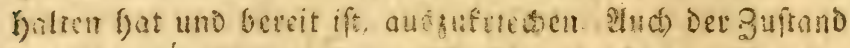

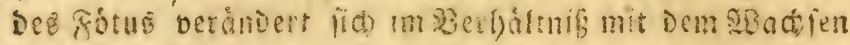

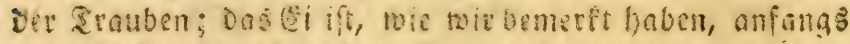

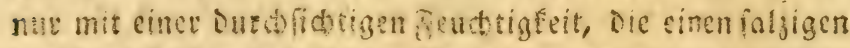
(beformad bat, angefilt. Sald beznad) firbt man mitren

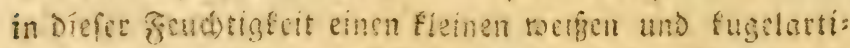

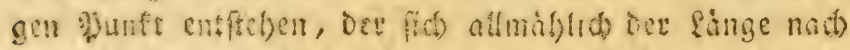
f)

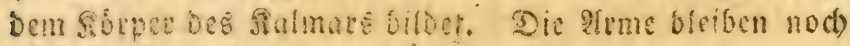

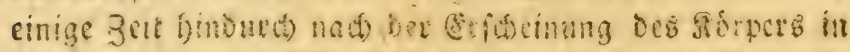

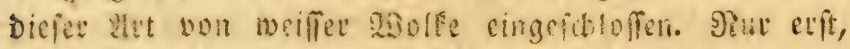

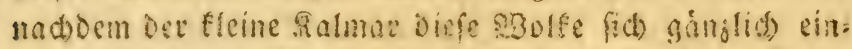

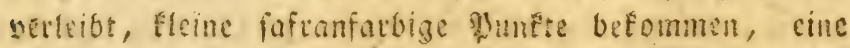

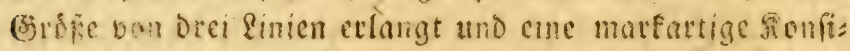

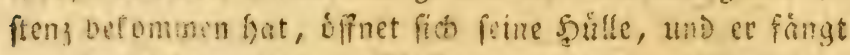

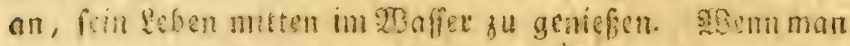
ib) jets unted cinem sjgeferfop unterfuct, fo bemetf

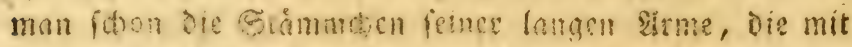

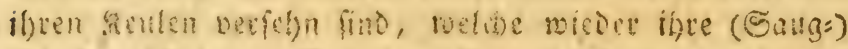

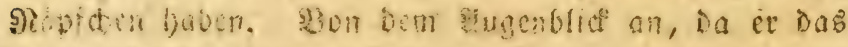

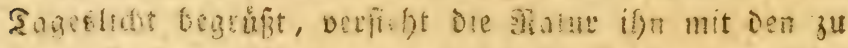

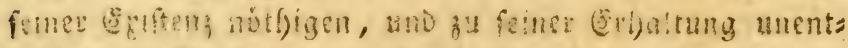

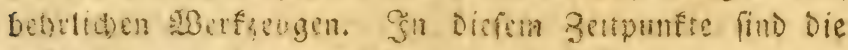

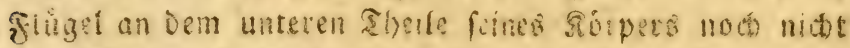

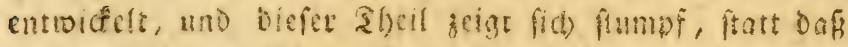

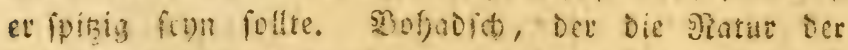
foubligfeiten in Diffen Ficrn gern fennen fernen wollte,

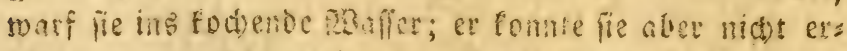

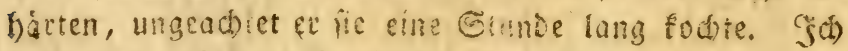
Gobe nith auf feme angitiche Genaugfert vertafien uno

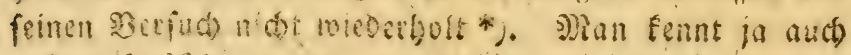
*) Bohadfch, p. 168. 


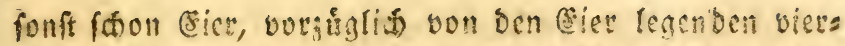

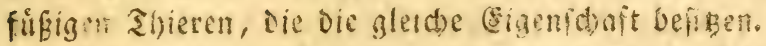

Shan bat imat now niegent andermo ciet des Salmars angetroffen, als nuf fanoigen llfern, mon fann aber Dartus immer nod) nidt folliênen, oaf fie

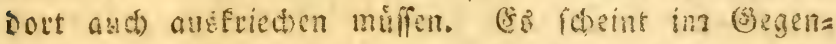
theil, Dafs alle Diejenigen, bie die fluth bathin whft, uno Die DiE azellen, beim Buructreten, Dott liegen laf:

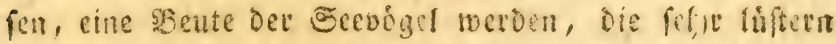

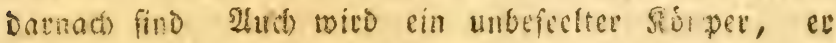

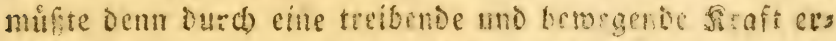
grifen weroen, fid nidt meder ing Deer metf en, wem

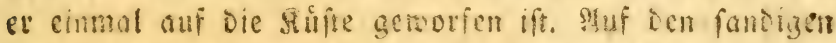

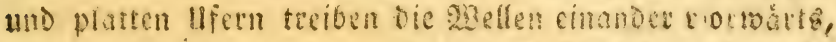

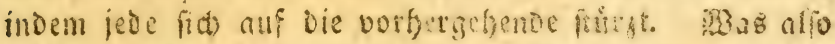
Die erfte berbeifubite, wird bon Der zinerten ergriffen

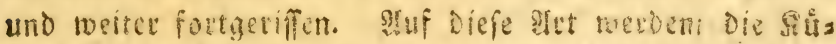
ften mit 2rummern und Eeeforpecn bedect. Siut die: jenigen falmareter, Die bcitanoig unet bem saffer bleiben, fonmen alfo augfticcien; betrabiet: man nun die unglaublide syenge von Cicrmafen, Die das Meer

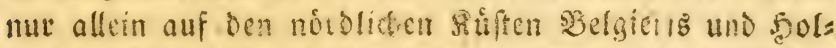

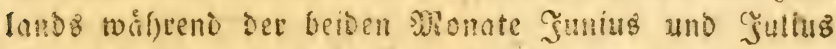

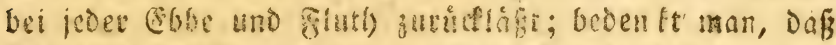

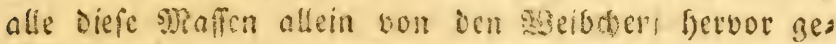

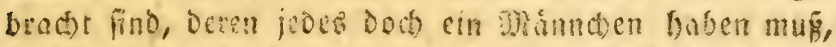
to folgt Daraus, Daf Die anjafy Diefer sy holluefen un= glaublid) grof fenn muffe.

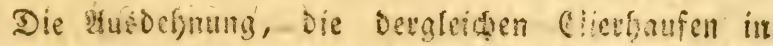
menigen Sagen allmaflich ctrangen, ift fider ene ber

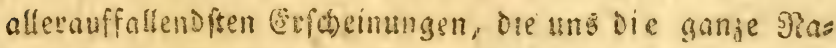

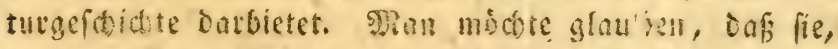
in jeocm alngenblid mit ber seaft ju wadifn und zu

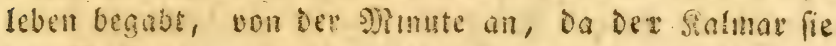

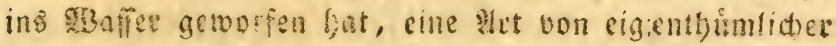

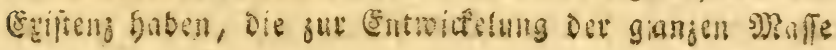




\section{4}

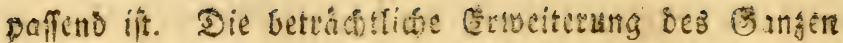
giebt iu ciner Denge oon soporbefen Ifrlab; id wilf

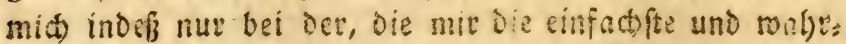

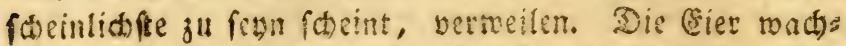

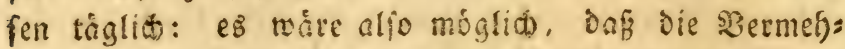
rung Des Ulmfangs aus Der allmálicter Bergrógerung bes Darin eingefalofienen fótus entftinde; Dem diefer

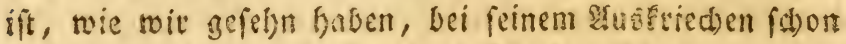
Dre! finien lang. Sie nawbem fit Der Gótus num ents sviaict, Defint $\mathrm{cr}$ fime balbgallertartige sulle, die die

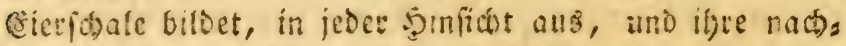

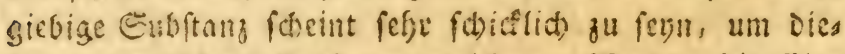
fer angewanden firaft ju weid)en. 2serden die Cies groffec, is nefmen fie natisliderweife mege \$late ein, uno muffen folglich sen Etid, woran fie innig befeftigt find, aus cinander secten; Dicfer felyt ciaftifd)e Stiel betsongert fich alfo; Da nun dieg Zerten an allen Sties

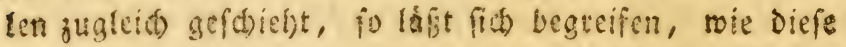

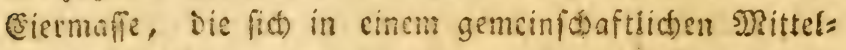
punft versinizt, und bic anfangs faum fieben zoll im

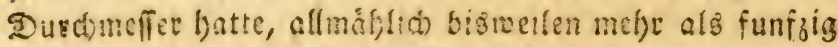

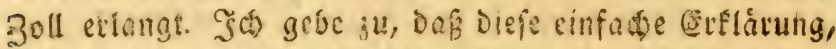
ftenge genommen, nici)t binteidt, um alle \$bánomene,

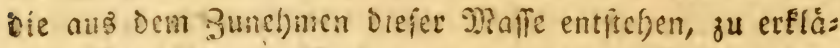

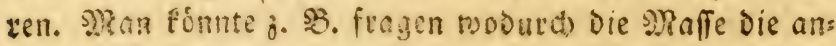
fange nut cinige linjeil wog, mit Der zeit, uno fo twie

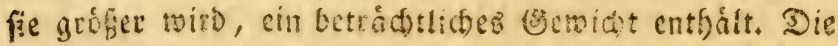

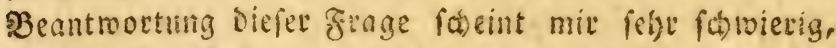

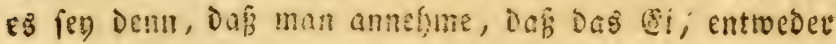

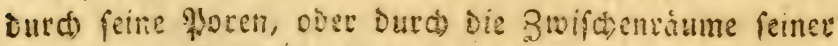
faft faferizen Schale, getvifie geudtigeten, bie im

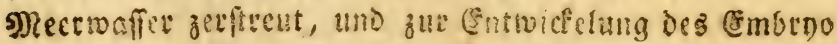

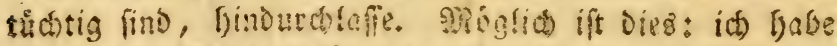

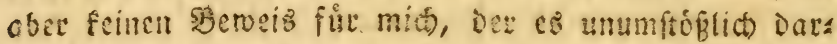

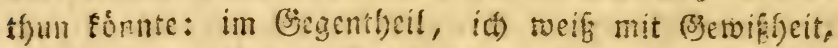

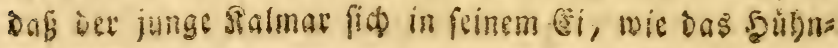


a)en in bem feinigen entricfet, uno baf bie 2 Botfe Dover der weife Ealeim, Dev fajt bis zuletit fenerz Sopf umgiebt, blofi eine innere freudtigteit ift, bie in

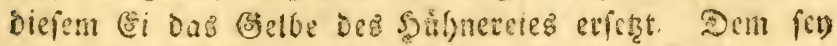
inder, wie ifm molle, fo ift tho bleibt fo viel ertoles

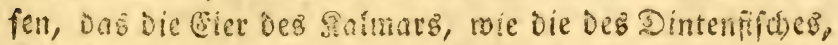
wachien, nacbocm fie getegt fino, uno Dafis ifte Ents widelung in einen sintel, in cincr Rlinigfeit, mit einem 230 te, in einer andern Barmurter ftatt finoet, als in Dem Dvario, worin fie empfangen wurden. Dies

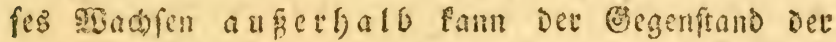
tiefiten S?adforfdumnen toerden, und viefleicht einen

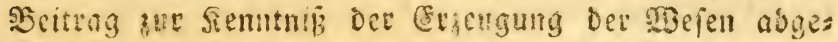

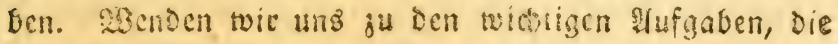

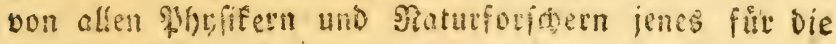

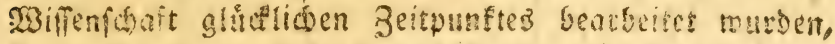
fo fefen toit, baf fie fammetich alle, boll des grofiten Eifers, fiob mit te, Die Statur bei Der Bilsung iffer ßerme ju tiverras

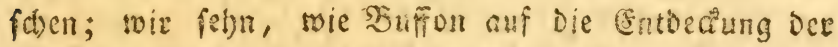
Samentbierden ein fareffinniges Cyftem grimoet, und

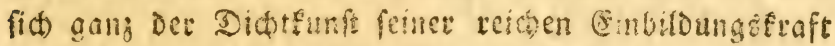

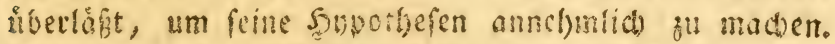
$530 n$ bev andern Eeite erfgeben fit Die Inginger Der

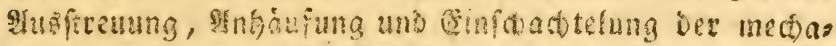

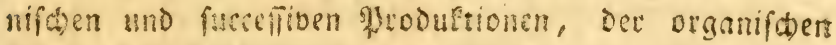

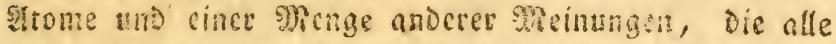
mebr coe: reniger Cdein fire fid baben; Denn jock Theil wandic die fafta allf feine şseife, uno brauchte

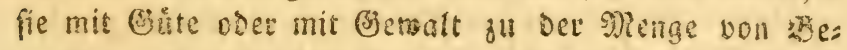
weifen, womit or fein Sigtem au ftịgen fuckse. Binige. verlangten Die şereinigung und innige Nificiung oer

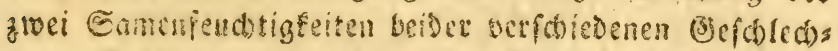
ter. Sie ftinmten wenig in ben Necbenumftánoen ibbers ein, une bewiteten alle Die Befrudung auf eine uns

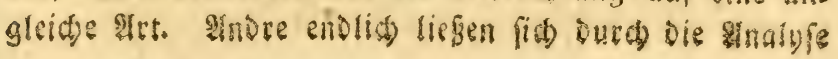




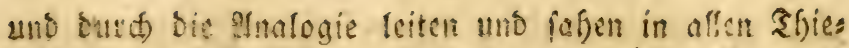

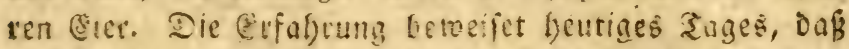
Diefe recit Gatten; Damals ober madyte iffe Meinung

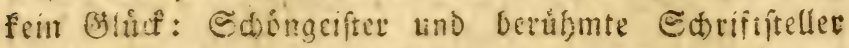

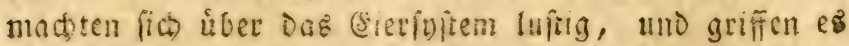
mit Den פBaffen Deŝ Epottes an. Soltaite, Der fict)

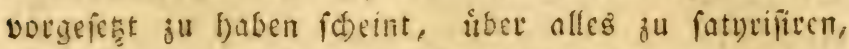
was et nid)t annefmen wollte, tritt in feincm "viers zig Thalermann" watíneno gegen Die Cier auf, toie

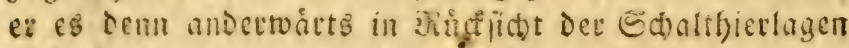

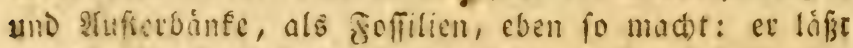
fie namlic won Ber Sappe Der \$ylger, Die von S. Ja:

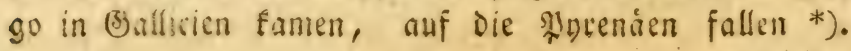
5allet

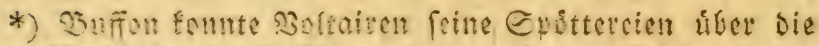
Drathen alo folliticn nie vergeben. Diefer lange Born jents grofen Detune focint nit unferin Paties nattarater jufammenjugăngen, nath weld; en wir ins mer geneigt lino, jeven ederz und jede epotterei, wie eimen Soufenbieb gu betráten, Der fein Echlodft= opfer fider erreicht, uno ilsm nidjt ertaubt, fich wie: Der anfatidhten. Die Beit bat betwe gerechtfertigt. Eie lief nus soltairs earkionen vergetīen, uno er: hicft un Dos Gute, Dob feine Serfe enthalten, fo

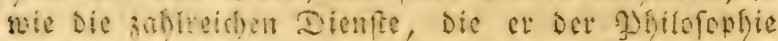

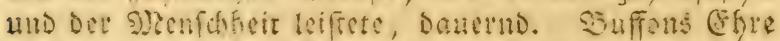

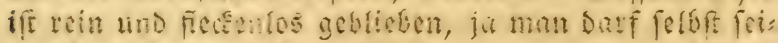

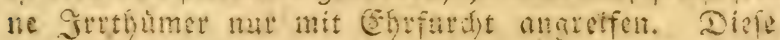

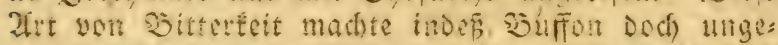

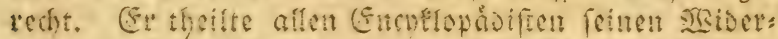
willen gegen Den Dichter von Ferny mit. Ifts mu

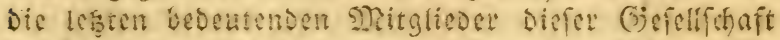

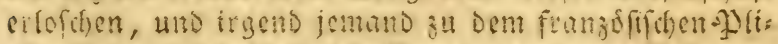

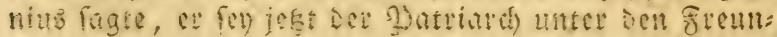
Den ber \$ermunft, antwortete er: "ití) made Ecincu Zupruth auf eine folde Edontoe." gin Dem. Ifu

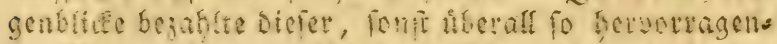

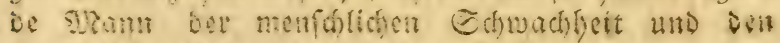

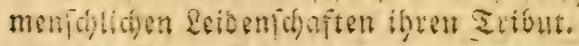


Scaller enthiffte juerft bas Beugungsploblem *). (5e

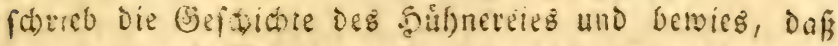

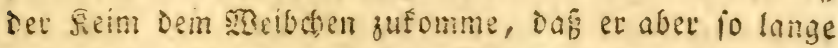
unfruttbar bleite, bis das mennden ín mit feinet

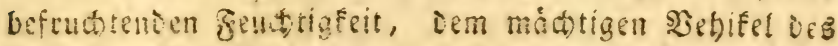

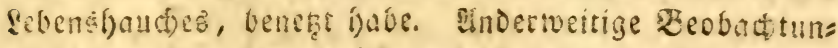
gen baben bewiefen, Doib Dic Geime allentbalben bei Den sontbon urpringlid in eincm Eicrfore egiftiren, ja, Dab ber menfot felbft, fo wie o is There, die lebendis ge Jungen gebaren, fein Bafon cinem $\$ i$ ju danken

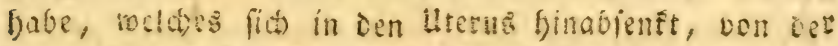

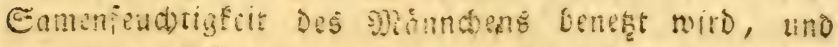

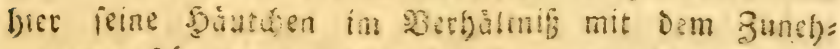

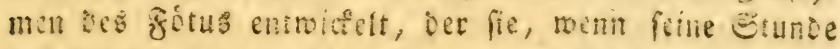

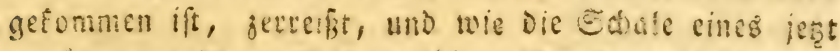

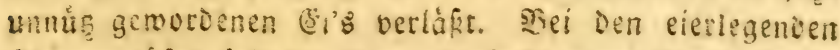

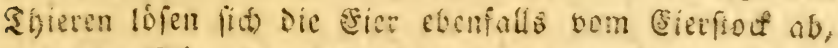

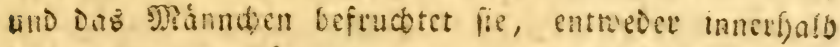

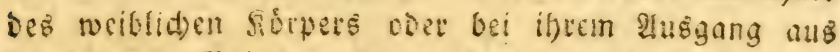
Demiciben. Bai Den Sermaphroditen, Die Deide Eese fateder in fich vereingen, mird Die Beftudtung Der fieme ourd einen frowilligen aftus beiber verenten Sirófte bitwirfis.

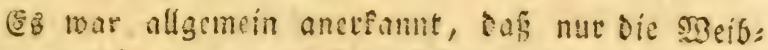

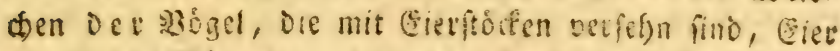

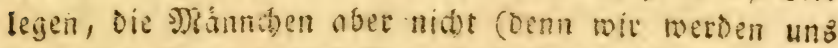
Glet nict traraf cinlofen, Das Buffemábecten, von

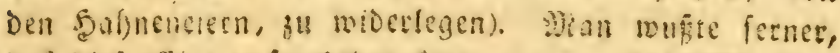

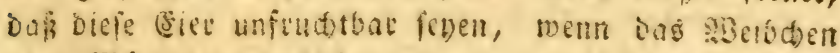
olgre Siamdsen geblieben wat; - aber, auts bleje un.

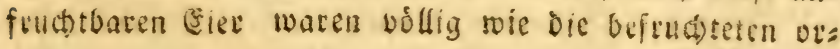

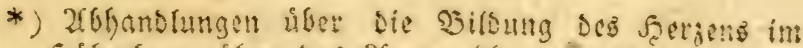

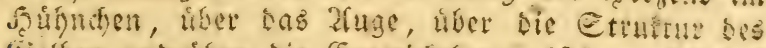

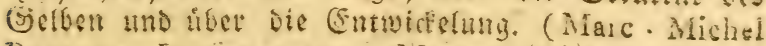
Bousquet, Laulanne 1759. Mem, I et 2) 


\section{8}

ganifirt, ja, fie öpigten in ifrem Snnern logar atá) Dett Serm: dics lckte faftum mufite alfo nod) wóllig evident Dargetfan werden. Da tiat Salier auf und beroice,

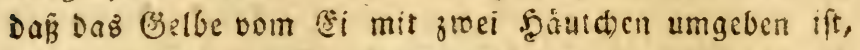
Deren inners che $\mathfrak{B}$ erlángerung oerer ift, Die ras noch

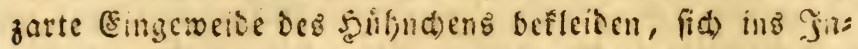

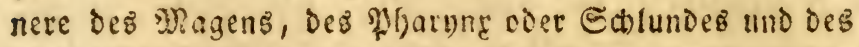
Sánabers fortietzt, um nachlyce bie şaut zu bilien; bas

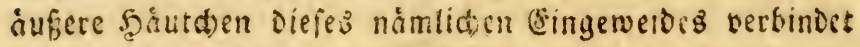
fits mit bem Meferterio (Eefrofe) und Peritonio (Darm: fell), uno defnt fich Dann nost) rositer aus, invem es Das

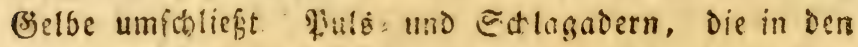

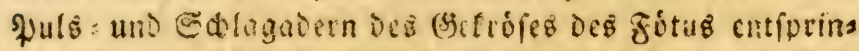

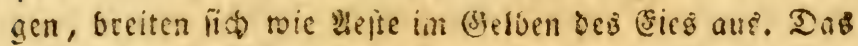

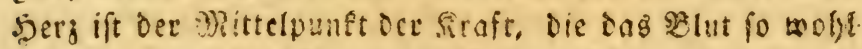

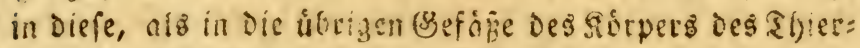

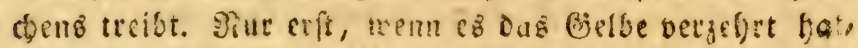

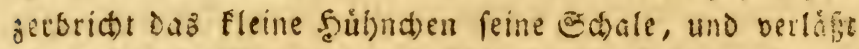

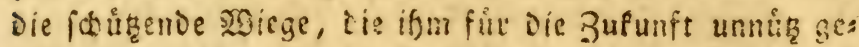
worden iit. Sad biefen unmioerlegliфen Datis ift alfo Das Gelbe voin (ji ein hodjt refentlicter

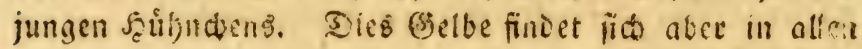

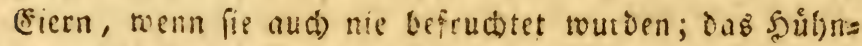
G)en equifirt folglión Darin ebenfolts, nue in ber Beftalt

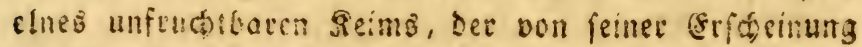

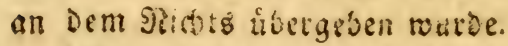

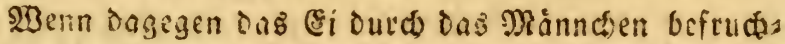
tet worden ift, uns Temperatur, Dit und aniste Umfrins De gưnftig fino, fo erbalten die (singerweide und die füf, figen uno unfidtbaren Táeife des (Smbryo Sonfiften?, uno zeigen fich in gallertartiger (3)eftalt, gefen alle Stufon deE Feftigfeit ourd, uno bilden, in fisnellen aber unmerfli,

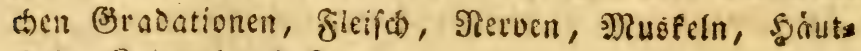
()en, Snorpel und Rnoden.

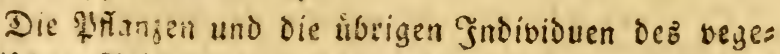

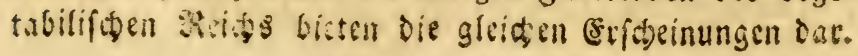


Der betúbmte Rinnébatte Den Rufym bie Gejalecter De: গิศ

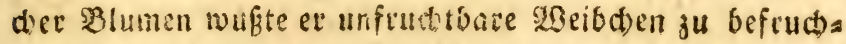
ten, die entfernt von mesmliden, - weldue alfein fie frudutbar maden fomten, - gepfangt maren. Diefe berúl)mte Entiectung verficterte uns theils Die (Empfins

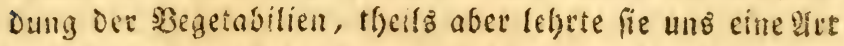
Der alfgemeinen Befrudtung, weldbe bei allen lebendigen sूejell, Die auf ser ganjen Dberfinde der Eroe zetfteut find, angetroffen twito. Das forn einer Prange mukg alfo nicht minder als ein (5i, Dab im Soario bet Nfanje Doer ber reiblicben $\mathfrak{s}$ lume empfangen ift, betrad)tet trees Den: Der Eamenftaub, ein ibeil des mánnlichen Froibis Duumb, fommt cbenfalls taisin, um dies (5i zu befints: ten; von bem zugenblice an, wáchft und ertiebt fich Det

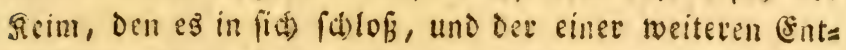
roicfelung făfig war, wenn er anders in ber ferde oder im 3 affer eine Bármutter, wie feine plyyifthe Sonjtitus tion und Siganifation fie bedarf, gefunden bat.

Eo hat die \#natomie uns Das Dafenn Der Eierftóde

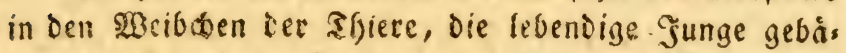
ren*), bewiefen. Dicje (5ier bleiben nun fretilit) uns

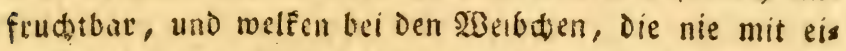
nem sannduen Bemeinfaraft batten: fobald fie noer,

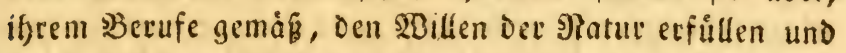

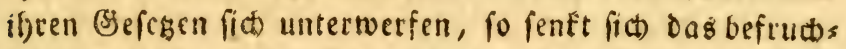
tete (3i in die 3 ármutter hinab, ver (Embryo waid) ft barin, indem ex alle Şautchen in jeder şinfidt auebelsnt, und fie am Ende Der S(t)rangerfid)aft Durd)brict. Siun nerláft er fie, - Desn funfitig fino fie ifm unnút - und genieft des Lebens, Des Tageślicts und Des Dajemis.

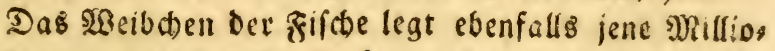
nen

*) Littre, Mem, de l'Academ. des fciences, an. ryor. p. 129. in 4 to, 


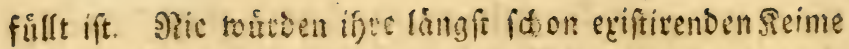

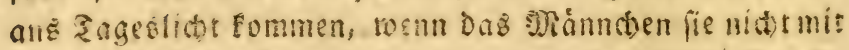
feiner Somenfeud)tigfeit benthre uno befuditte.' Šn die=

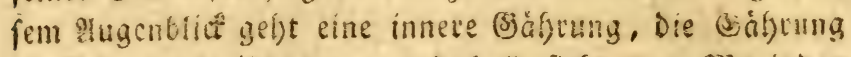
Des Rebens, in innen an, uno balo fieft man shoriaden

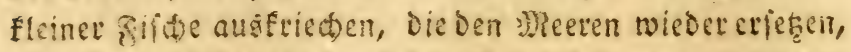

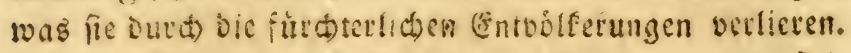
Bir fonnten Drefe \$arallefe nod viel :weiter verfol: gen, uno wir witben bei allen Sbieren uno allen sthan gen Data antreffen, Die mit Denen, bie wir cben anzes

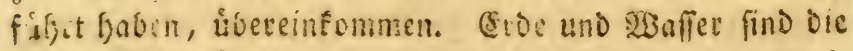

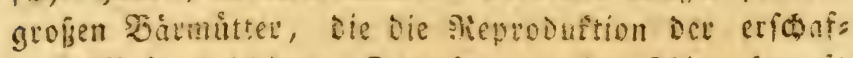

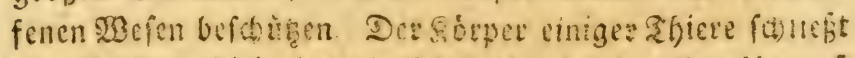
eine zeitlang Diejenigen in fich, oie nad Der exmpangn fi

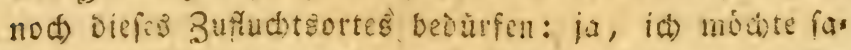
gen, die Euft felbft wito, wentil fie bis auf cinen gewifien

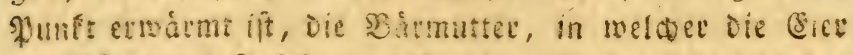

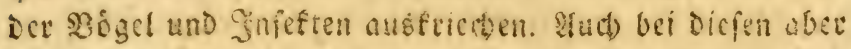
getjoen die fieime, wie bei allen lebenden reskn, dem

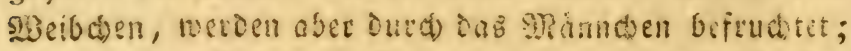
5) Taterie und Bewegung find die allgemeinen Befege Dee SRatut. SSollien wir Dicien Begenifand bis auf Din Brind

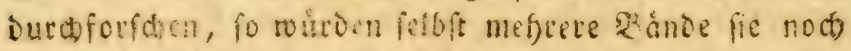

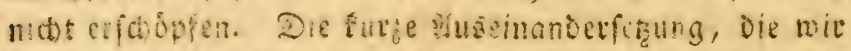
fo eben gegeben babcn, reicer aber bin, un e马 auf bie

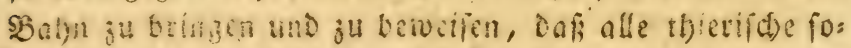

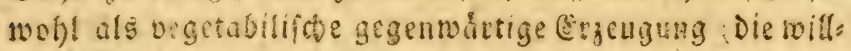

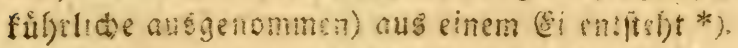

Diss war Satucis is Mcinum. Diejer berifimte und

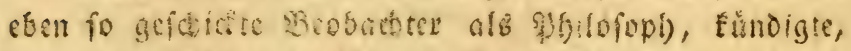

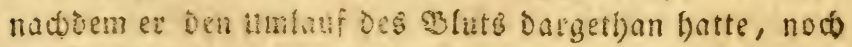

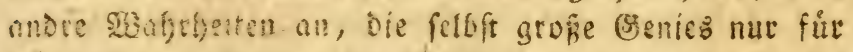

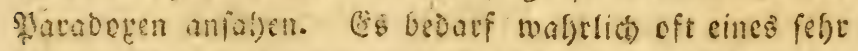

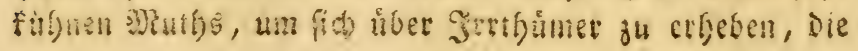

*) Omnia ex ovo. Harvey. 
Die zeit beiligte, uno die ein Menifienalter bem anvenz überfieferte. Sind Die menid)en einmal gu einem gerwifien NIter gelangt, fo fiebch fie gemeinigfid feft an i ren

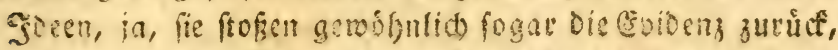
wemn fie ibren Metrungen wiscripeidet. Satuen Gatte

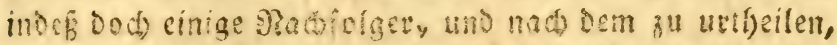

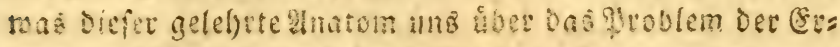
genoung foriftio gurba gelaffen bat, fann mun Den uns erfetiden weit an feimen shaperen crltt. (et ijatte nomlid) alle pei= me शrrobadtungen nicdergefósieben; feurem fionige, Defs

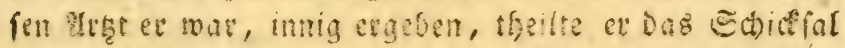

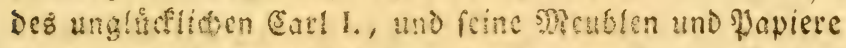
munen surd Die Whinderung jerfecut. Diefer Berluft

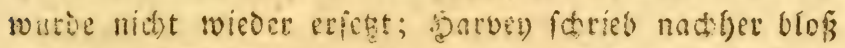
a is Dem Brodadnifie Oranf nalgm fid Der erntoectung

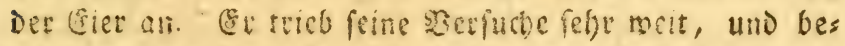

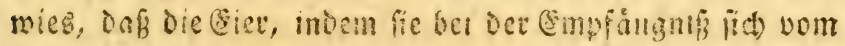

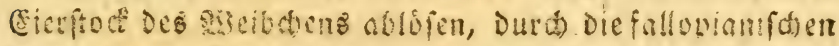
Tremperen in bie Barmutter binabfinfen, um bafelbit

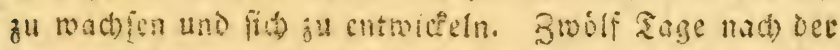

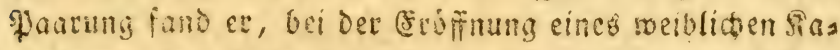
nindens, Den Cmbrno in foinen fristden elingetdoffen, uno gwa: fo beftimmt, Dafs man feine Bstiederden wafk:

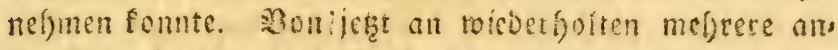

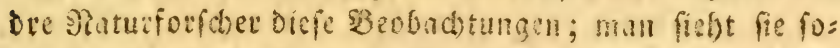

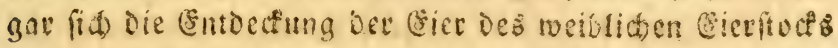

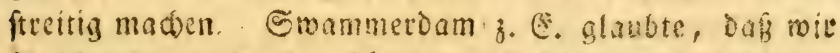
fie if $m$ ju verdanten hatten; und bafs ex, powoht wie Bantborn, Diefe cierftocte vor Braaf getannt bale; die (E)hre gefjorte aber bielleidit bem Crenon, Der zuenft die

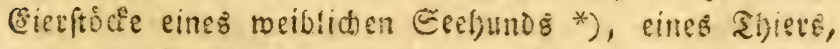
Das lebendige Jungen gebiert, und Das et jerlegte, ent, Decitte. Bei Der Befonntmadung Diçer B3cobattung

\section{*) Squalus Corcharias.}


magte ex logat binzuzufügen, baf it nidjt gtacifle, tie

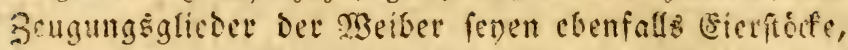
fen es mun, daf bie cier frlbft oder die in Denfelben entraltene Mraterie fid in Dic Barmutted finabfen= fe. S3on Der zeit an nannte man ile Rorper, die Die

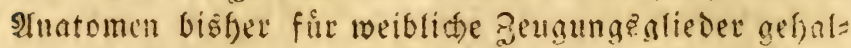

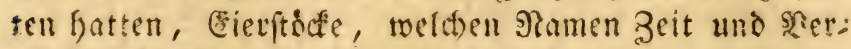
nunft fpaterfin gered)tfertigt haben.

EBas foll aber bei biefen fiern und feimen, sis aนGf (4) menthierden merden, die Esmenfóf und Sarftáfer ent= ieciten, unb Deren (Exifteng nad) Den Beugniffen fo viefer berufmen Sdeiftitelfe: * Die fie bemert und beob= a(b)tet haben, nicht mefre bejweifelt merden fam? Itus

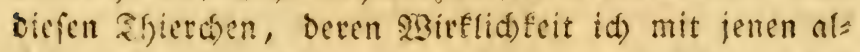
Ien eimbume? Eollen fie nid)t mefr Der Srim Der

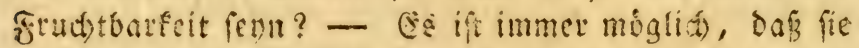
es nitt fino. Msenn wir námlich alle feud)tigfeiten uno

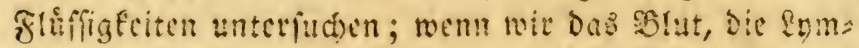
phe, Den Saffrungsfaft, bas zett, alfe naffecnden und abjufanternden Feuchtigfeiten, bie vegetabiliften afuf= giffe, fur; alle Jilufingfeiten, Die geiftigen alfeir auşge=

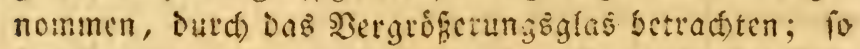
finden! wir in ifnen, toie in Der Eamenfeuchtigfeit,

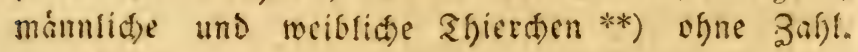

*) Vol. XVII Diefer afuzgabe p. 2I2. E. Comnini's 2(itmertung.

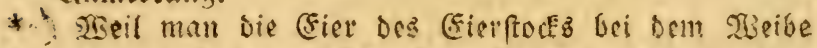

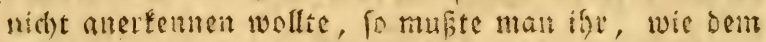

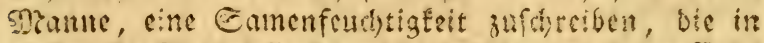

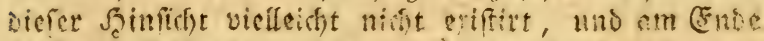

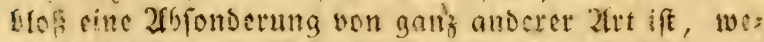

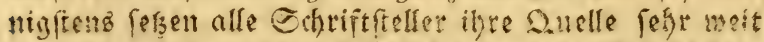

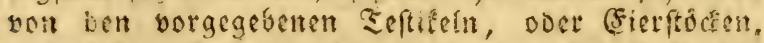
und laffen lie visemegr ring um Den! frals bet Bármutter uno rings un Die cinfere Mhinsung Des

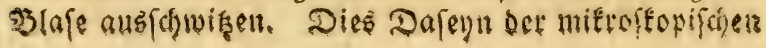




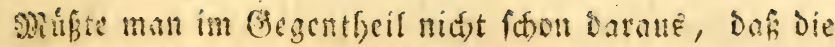

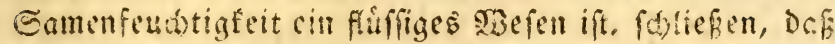
fie, mie alle ibrige, nothmentigermeife mit biefen Sfietden bebolfert fent mur? Da auf ber moers Sei= te das $\mathfrak{B l u t}$, bie enmphe und alle vegetabificien stuf=

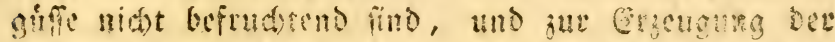

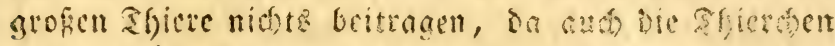

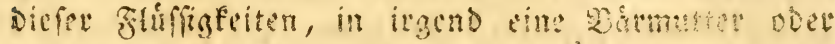
fonft in cin Miter seworfen, nut ansern Siblecten if;

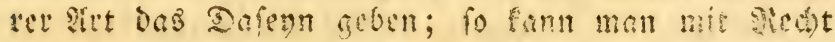

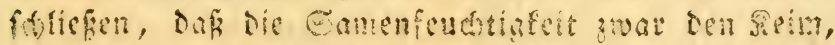
indem et zum sorfocin foumt, efeftrifuen folf, bof

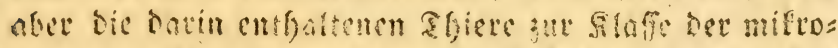

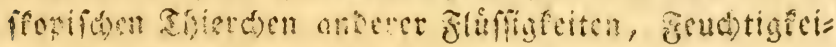
ten voce wa ginfe geboern.

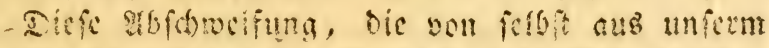

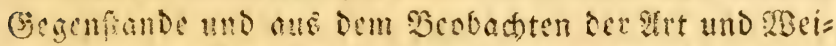

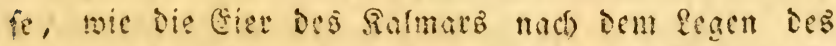

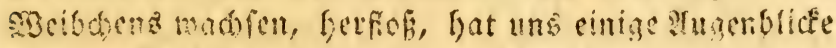

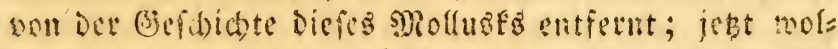

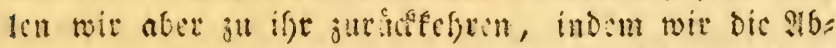
ftammung Des foft gefifden Fiamens, unter weldem biefes sfyer befonnt ift, auffuden. Salmat fommt won Cala mar, einem alten frambefifiden matte, das won Calamarium obfonunt; sics lette bedeutet im

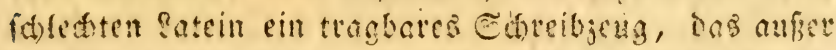
ser Dinte nod feder und federmeffer in fich follefit.

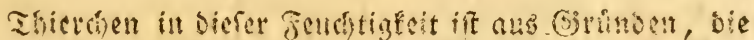
mat im XVII. Bande befer 3tubzabe bes Buffon,

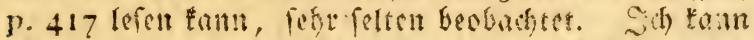

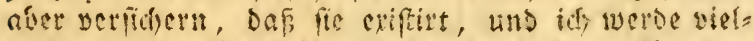

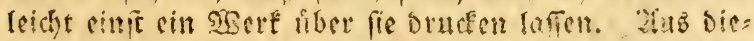
fem einzigen Grumbe aler falon, minte man nicht,

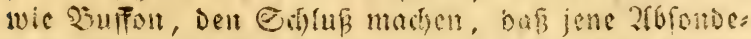
rung Camenfeuchtigfeit foin, well, wie wi: fésen bie Eamentgientiea fich in allen nidit geifígen fhifa figfeiten ch) Xuenahme findert. 
Unfere 3orfafeen glaubten bies alles im Salmat zu fins Den. Cer ift mit einter gefäuten senditigfeit berfefn,

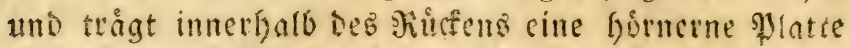
(lame, eigentlid) a finge), Der man fdncidende Sel= ten und eine (srundfiadse fuidrieb, Dic nact) Irt cinet Teder zugefdnitten fen *). Das (Ganje mat wie die

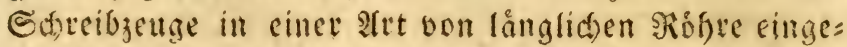
fd)loffen; man gab alfo Dem Thiere, das an fie etinnev= te, iffen ?amen.

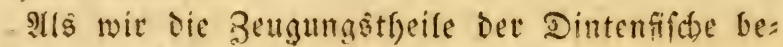
fdrieben, fafen wir, Dafi Die Der Pionncten fefer fon= Deroat organifiete fojerden enthielten, und bei forgs

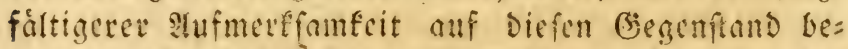
meteren mir, ing sieedram biefe fleinen fióper in ber

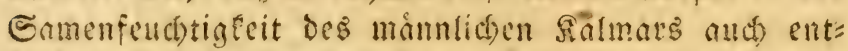

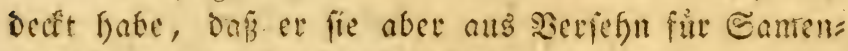
tfierchen biefer feudtigfeit ficit.

Diefe Eamenbeftandheile haben die grónte ofern= lichfeit mit semen in Der Samenfeud)tigfeit ies mann= Viden Sintenfiges; aber SRecblam fand bei ifnen Den Endfaben nidit, Den jone jeigten. SMan fieft tubrigens

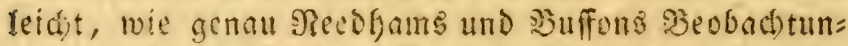
gen mit benen des Ewammerdam ibbereinfommen; da mie nun Die Mbbiloung Der Eamenwerfzeuge oes Din= tenfifices haben fteden laffen, fo mógen unfere Refer

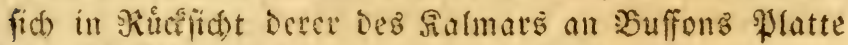
Theil XVII. p. 52 Dicice Ifusabe galten.

Die Alten haben fith, mie cs facint, meniger aus bem Ralmar gemacht, als aแs ien Dintenfifichen und

- *) Calamar noftrivocant, a thecaefcripto. riae fimilitudine, five quod in ea reperiantur, quae ad fcribendum neceffaria funt, vi delicet atramentumet gladiolus, qui aliera partecultrum, altera-calamum five pennam refert. Rond. lib, 17, de pifc. c. 4 . 
Pofnpen; man verfante fie suf iften MRarfen sufatt wohlfeil.

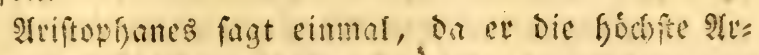

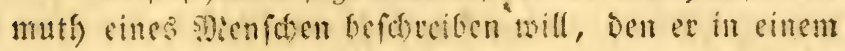

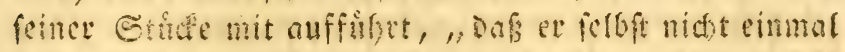
to vid habe, um fidt cinen saimat foufen ju fonnen." *) Dod) ẩes fie Die Romet. Eic madten eine alt von

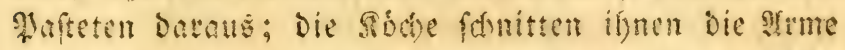
ab, farcirten fie mit Sorte, befeudteten fie mit Ge= wimen und liefen fie foden; Diefer Brfomad fópent

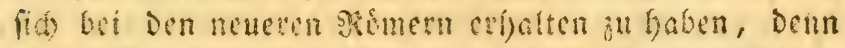
Diefe effen fie in ben sgintemonaten und zidigen fie ben Sintenffact vos. Dutds sedben miro Der Ratmar roth wie cin Sitebs. Nuf unfern Riften find Die Sal mato fefye felten. Dlestius (Cabiner de Cotrorp. p. 44. Tafel XXV1ll. Fia. 2.) Gat ung Die Sibbirbung ci=

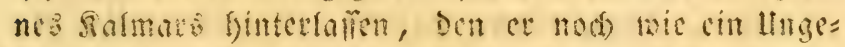

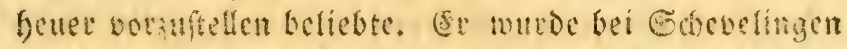

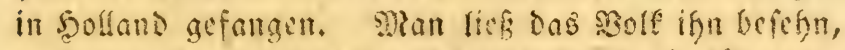

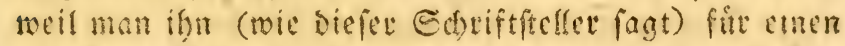
mecteufel hiet. (sr murbe besbalb aud in supfer geftoden, uno eine befondre erflorung onbei gedrute

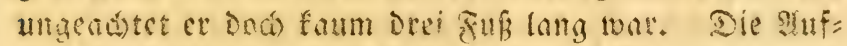
merfomfeit, Die Der Inblict Diefes affers erregte, zeigt, baf e\& febr feltell ift, wenigftens auf jenen sưfter.

STm Ende Des abfinitts vom Dintenfifdre bemert: ten wir, Dofs wir bis jeţt nod) feine SBerfetinecung fennen, Die Dicfom Mollusef zugehurt Gaben fonne. MRit

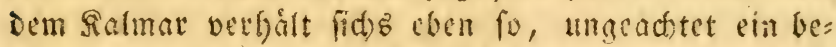

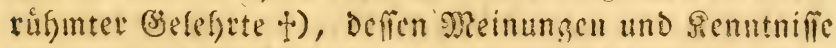
id) in vielen saidficten vereigre, feit furzem hat Deu=

*) Quem etiam video theutide egentem. Ariftoph. in Acarnan.

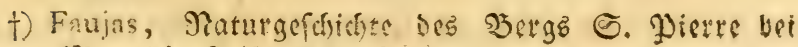
Mafrudit Tafel $X ! X$. Sig. 1 . 


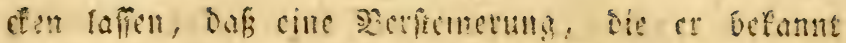

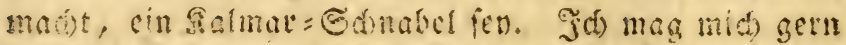
auf Beobadtunzen trefflider Saturferfore ftuthen, sie uniere fefrex find und uns burd Sefirntmadoung igrer satere untertidten, uno insbefnoere ift Der, non Dem id fo eben tede, einer son ben feltenen Diannem, beten Sistre man gern anfuffet; aber id wicterfole es,

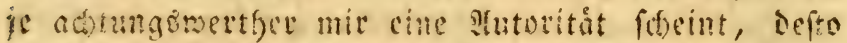
sorfiderger bin id mit ifle; id werbe slfo nur bicjent= gen als meine ?efrer anfel)!, won benen id imniz ubers jougt bill, Daf fie volfemmen reat baben*). Eo siel is fann, will id ourd mid) felbft fern, scm biefe cinzige Suelle bleibt mie nat, um Driginal fevn zu tỏns

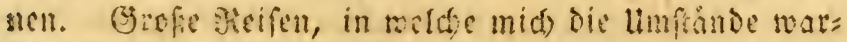
fen, Die meine friticfte Jusucno, fo zu fagen, unting=

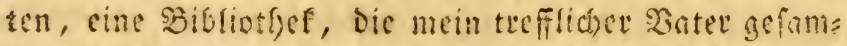

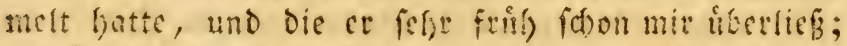

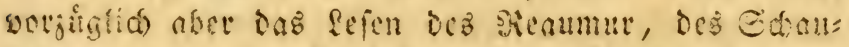

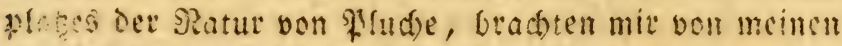

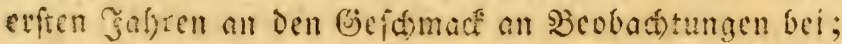
Ex folgte mil suf meinen weiten seifen, uno jest firfle

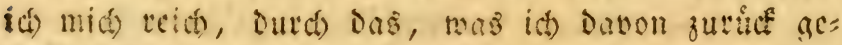
Wract, und was idh auf benielben bemert hate. Die

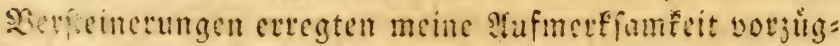
lich: eine innere Heberzeugung lagte mir von jefer, dab

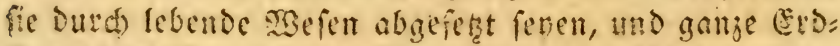

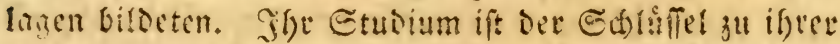

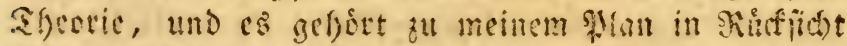

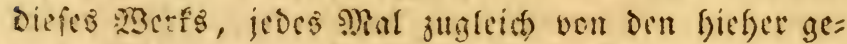
borigen s3erfteinerungen ju reoen, fo wie bie şefent, ăl weltuen fie gefort foben formen, yor unferm an= f(t)aun voribergefn werben.

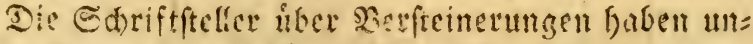
sev Dem Эamen bec d'oileau (Brgelfenabel) cine zicm=

*) Nullius intentus jurarc in verba magiftri. 
lic) feltene sictetincrung, bie man mur an wengen siten fundet, befant gemad). Cie fieft wirflid) aแร,

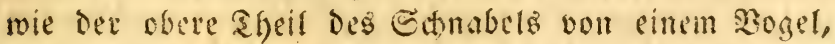
und if aet fremme wegen gleith fie dem Sonabel ber

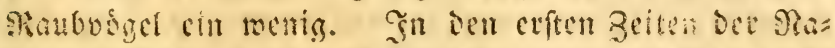

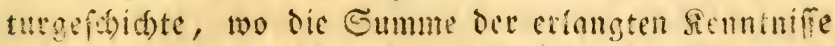
nod) nidyt bebeutend wat, gab man ben foffiticn uno Serfteinerungen \$amen von Dingen, wotan iffe Aeufe: les etimerte, ie nadjoem dies mefie ober meniget mit Den lebenden siefen, die man ror stugen batte, über= cinftimmte; Dafer findet man bei den áteren Edrift=

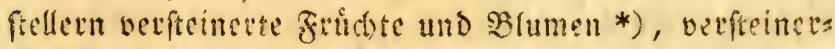

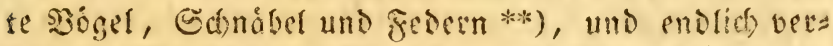

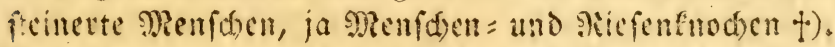

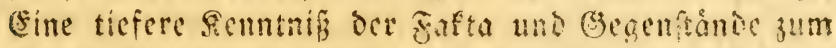
sergleiden hat aber bewiefen, Dab bis ject noes feine serftemerte Fridote, Begel orer Menfocn equftiren,

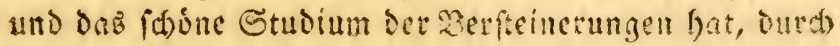
Ginforointung in Die geforigen Gringen, alle diefe Folfitien an Den ifnen jufommenden Dot gefert. Ecits

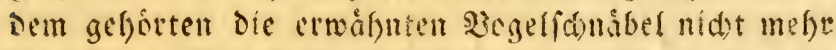
efomaligen Betwolinern ber Euft; min fuchte nim un=

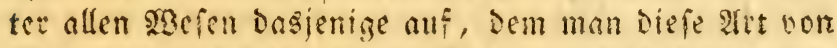
Sdunbel an beften zusignen fónte, uno fand - Ben Dintenfifo. Mit cinem Mate wurben alle jene $\mathfrak{B e r}=$ freinerungen Eddnäbel von Dintenfifhen, uno alle Sias eutforfder, bie ifier erroagnten, gaben ifnen mit bíls

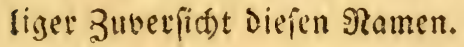

Faujaz be Gaint = Fondz, mein Lefret und Fiffect.

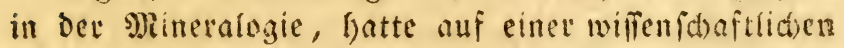
अeife, Die er mitten unter unjern Armeen und militaia

*) Lillium lapideum.

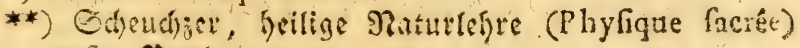
erfer शzans.

t) Derrelo, ebendafergat. 
rifien Sperationen *) sornafin, Celcgenfeit, Den

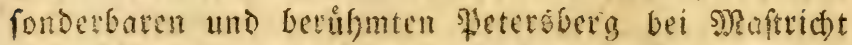
gll unterfucben. Man trifit Dofelbft Dief: Ëdnábel von Dintenfifden fefy: fáding unter andern verfemerten

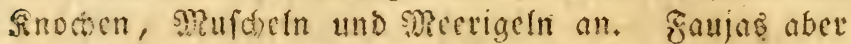
verglio fie in feinem ftillen sobinet nod ciner tubigen

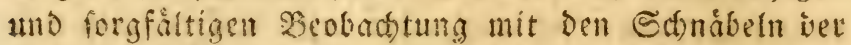
natiutiden Sintenfifde und fand unter beiden nidnt bis

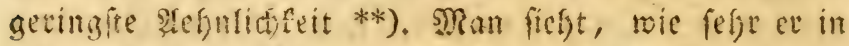
Betlegenfeit geråth, un biefer Derfeinerung ifren

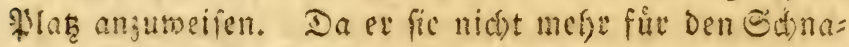
bel eines Dintenfifdes foalt, fo madt $\mathrm{er}$ Den $\widetilde{S}$ dnabel cines solmars Daraus; aber bie unbejtimmte Irt, wo: mit ex Davon rebet $t$ ), lafft gleich mutímafen, Daß $\mathrm{ct}$ nid)t Domit in aleinen fev. Cer weifet auf eine gelefrte

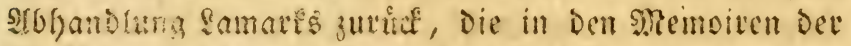
\$arifer naturforidenden (Gefellid)aft (S. 10, und

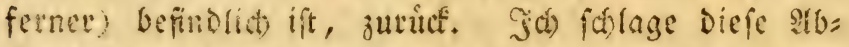

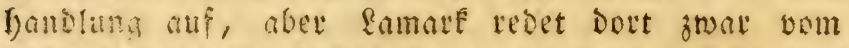

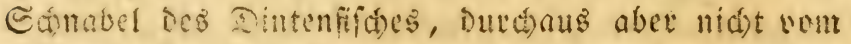

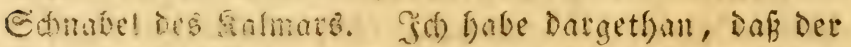

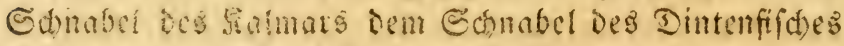
ágnliós fay. Man mus alfo sicfe şerfteinterung, als

*) Faujas de Saint Fonds, ubi fupra.

**) Dirfefre, ebentionefefr. O. 83 , in for. Ciflormug

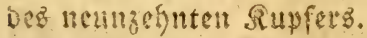

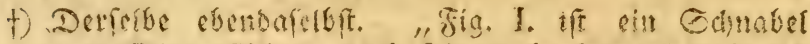

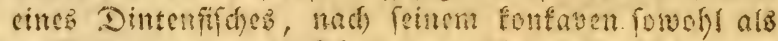

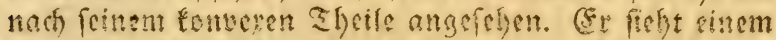

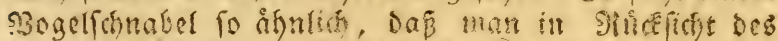

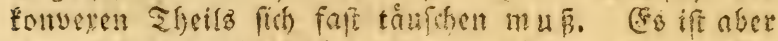
eigentich Det Cinnabel cines loligo calmar bes Lamare, nur von cirer unbefonnten siotung. Dicfer Sheil, ber bei dem lebencen shiere bornartig ift,

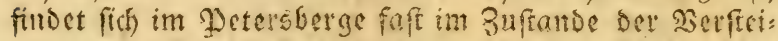

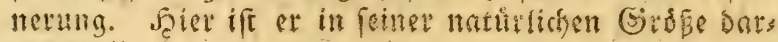
geftellt." 


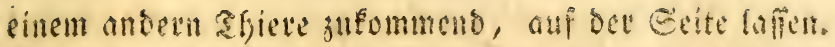
Denn Der Sanabel bes Dintenfinges fowoht, ats bes

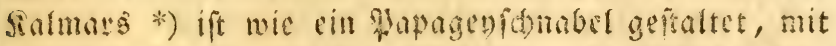
einet farfen begenatigen frumme, bie fict bei bem

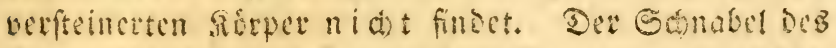

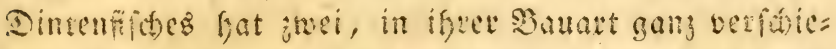
Dene fimnladen; man bat aber nie ande fogenamte

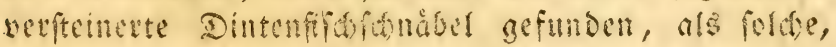

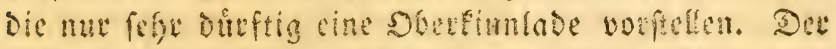

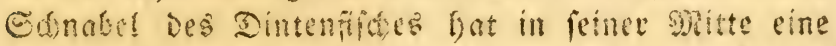
Cinfofing mit einem leberfolage, Der befiment ift,

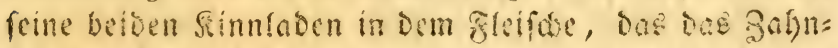
fleifa) etfeter, feftubaltan. Bei Den Bertsinerungen

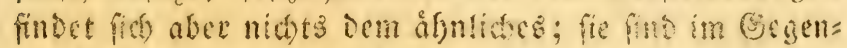

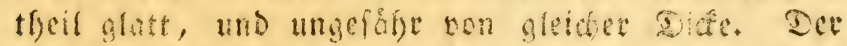

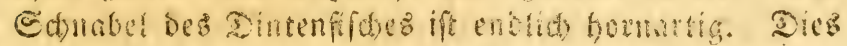

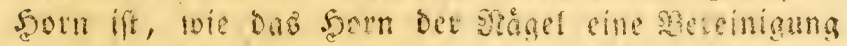

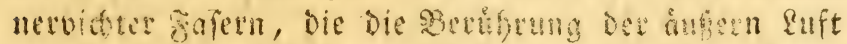
verfibtet zubaben forint. Th befenne biet jugleid,

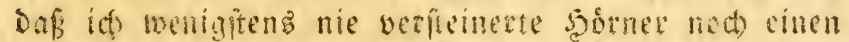
verfteinersen bornartigen Sơper gefelin fabe. SMan füge bier nidet bie ausgegrabenen somer an, bie man in ben sorfgruben soer in flufbetten gefunsen bat. I iefe sorner haben, wic bie bes sherodfen, bie man auf Den Eomma in ber sicarbe uno in einigen bjegen: Den Deutioflanos gefunden bat, igten fornartigen

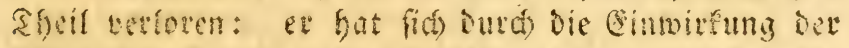

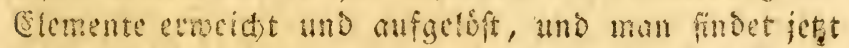
nut nod ben frodoemen sern ber eigentiden sounet.

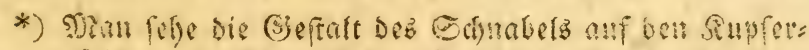
tafen vem Dintenfighe, Safer Vl Sig. I. wo man

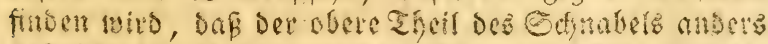

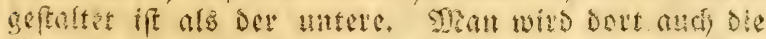

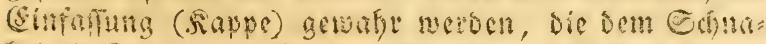

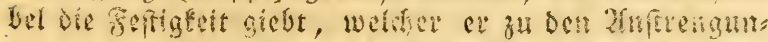

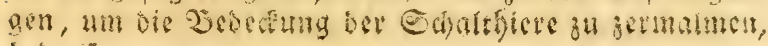
bevart. 
Eelbit Das \$rjinccerva, Das Paĺas mit zleifó uno Snoben *) in Sibirien fano, wo der froit eริ, Gote weifi, wie viele Sabutaufende, unverferget erfalten

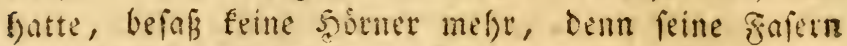
batten fid abgefondert und waren veridsunden. Sutz, id) lobe trob allen meinen Padjorid)ungen nies mals hornattige fiorper verfeinet angetroffen. 280 h $f$ babe id), und namentlich in ben Begenien von Strifiel, Berippe bon furpelartigen gifden gefunden. Snorper haben abev eine ganj ande Textut als Şorn; Finoiper werien fu finod)en t), wie die Anatomie betocifet;

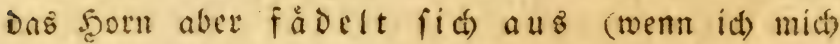
anders Diefes assoruff bedienen barf?, uno wito zu Echarple, jull Brei, nie abet vernandelt es fich in

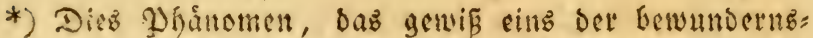
marbigfen in ber ganjen Naturgefdichte ift, wurbe

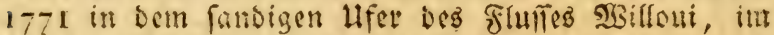

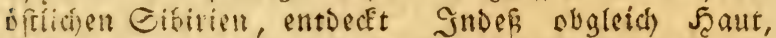

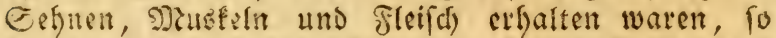

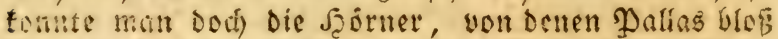

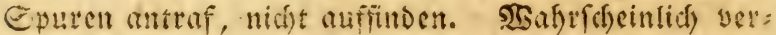
urfacte ifye forerige Eubfonz, bie fich nesformig ab:

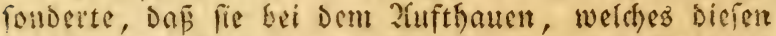
berintingten Sieweiz Der Satufrophen bez Gidoballs anz Tugeżlid)t brachte, in Etùteen fielen. (Palles, Mem. de l'academie de Petersbourg, vom Iafir 1772. p. 576 .)

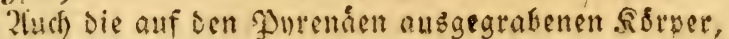
Die bistweilen wie אuhförner acbilder, aber immer vet. freinert find, Eam man mir nicht alb Şerner anuibren.

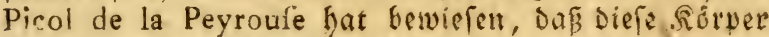
Diollusten zugeholten, und hat lie unter bem Name:s Urthoceratites beidrieben.

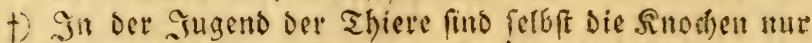
nod) eine ?trt von finotpel. Je álter Das Thier wirt:

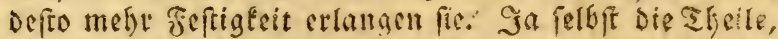
Die, wie bas sternum (13tuftecin) oder daz viafen:

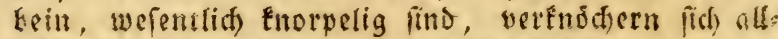
máflid) uno toerben zulekgt wirflidge Sinochen. 
Eteil. Genet berfeinete Sirmer mus alfo einen an= Dern ltrpetung baben. Sgenn tobrigens irgend ein

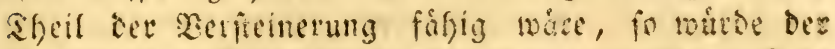
Sinoden des Sintenfifdes *) es fern. SMan witude

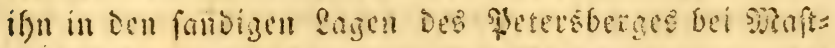
rid)t finton, aber feint von allen SBerfeinewngen, Die

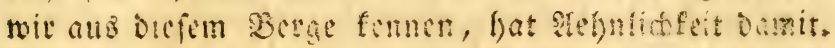

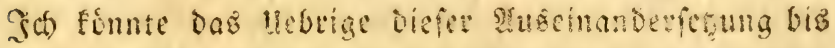

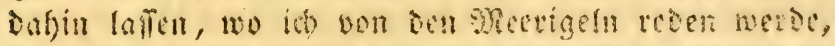

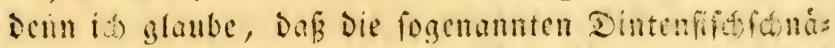
bel cinct Battung von Bdinus zugeforen; inbef Dies

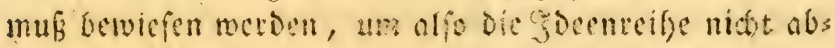
jubeden, roll id es lieber bier gletd ju thun ver: fuden.

I!nterfuchen wir nun bies folfil nafger, io werden

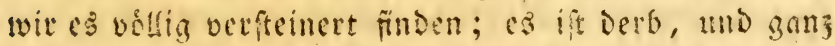
in Salfpatb vermandelt, wie ber bláttrige siscutó zeigh.

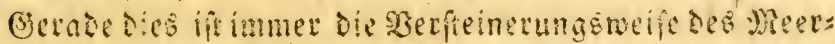

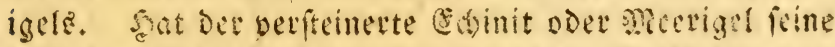
Edale behalten, fo ift fic allemal in salfipath bers wanocit, und id fabe nod) feine sustnafme von diefer

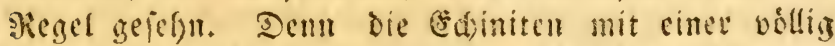

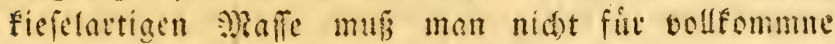
Ediniten falten. Der Siefil ift nut Det innere Rerr

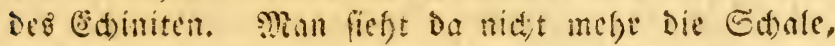
fondern cine Norftunerung von ganj answe: Irt, Die

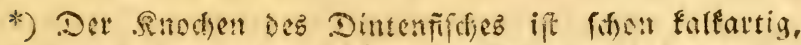

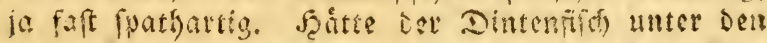

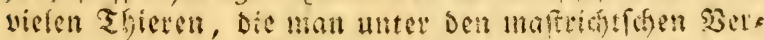
freinerungen antrifit, exifart, fo mulse man fiofer

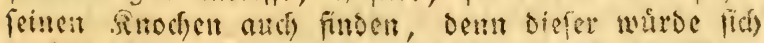

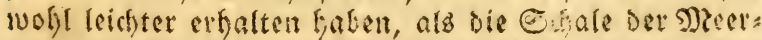

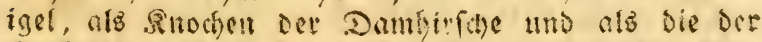

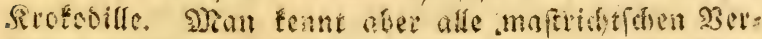
ftinerungen und Soffition, mul woven alse Pathfor:

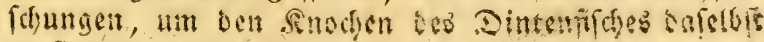
ju finden, vergeblich. 


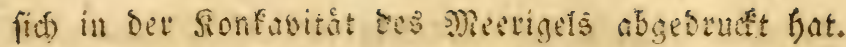

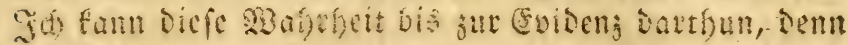
ib) Gabe in meinet Eamming cinige Sunderte vet:

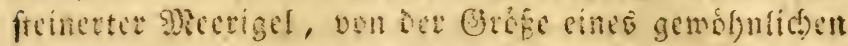

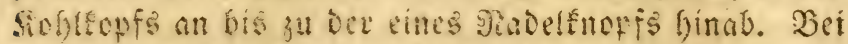
Denen, Dic iffe Edole behalten baben, ift fie aliemal

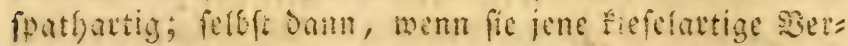

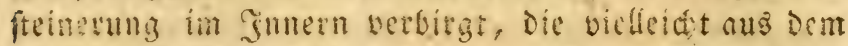

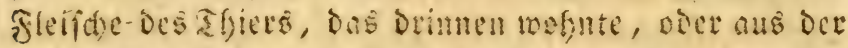
brembaren Iuft entitand, Dic bei feine sluflofung fict)

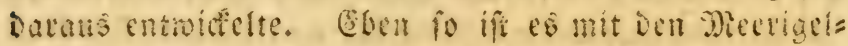
fradeln uno mit Den Jubenfteinen *). Jyan finset fie

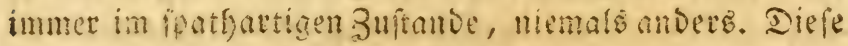

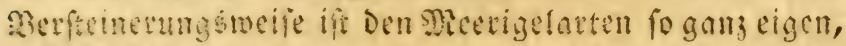

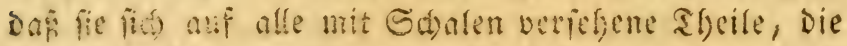
ignen angiforten, erftrect. Co findet man bemn auch

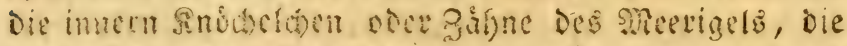
in senen, melde siein **) anocy ftes nennt, ouven ifle sereinigung bie on cinigen shoturforidyern foge=

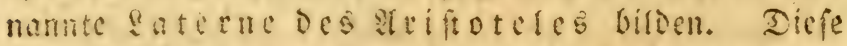

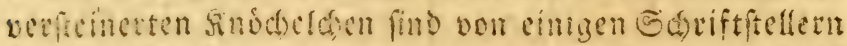

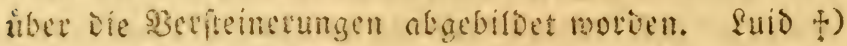
unter aniern, hat zmei foffifien Der Ift in Siupfer

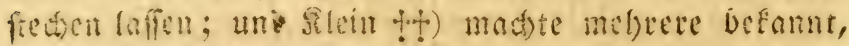

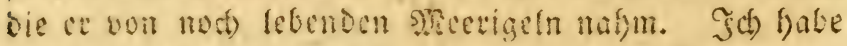
alle biefe Zcionumgen neff set Des pogenamnten maft= riatiden satmatidnabels vereint, win bie Gegen=

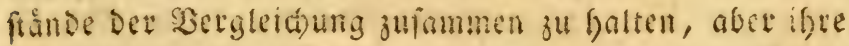
At

*) Echinorum clavicula lapidea ete. Bertrand, Dict. oryctologique univerfel, p. 125, vol. 11. (Esit. Sang.

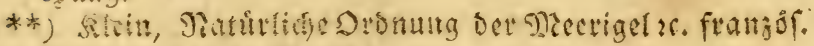

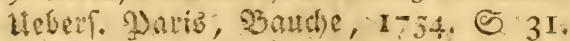

t) Luid. Lithoshylacii briannici ichnographia, no. 629 und 1078, saf: IX, und XII.

tt) Stcis, ubi fupr. ₹af. XVIII. Jig. g, i, k, th. ₹uf. x.s. Jig. h. i. k. 


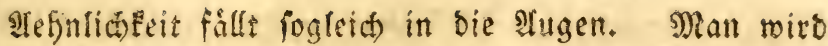
mir freifid) einwerfen, Daf bie vorgegebenen Dintenfifos. (d) nábel nicht bolifommen gleich mit Den andern aแs= gegrabenen oder naturficten Zăfnen der Meerigel fenen; ich bemerfe aber tagegen, Daf, forohl wie die Rnos= thelden des rofenfarbigen Meerigels fich von benen Des Surban = (5chiniten unterfacioen; wie ferner jede Gat=

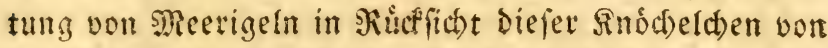

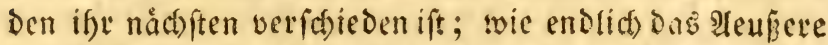
uno Die ganze (Finrid)tung bei Den platten, oder tunden (fugelformigen) nidut die gleidhe if: fo mús man

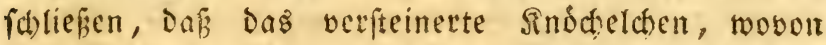
bier bie Siede ift, der Bosttung von Meerigefn zu= fomme, bie langlich und unten abgeplattet ift, uno bie fic) bis jeţt nur nod) blok im \$letersberge bei Maftricht gefunien gat. Shtar aber findet fich Diefer Meerigel allentfalben. (se ift das herridende folfil diefes Bergs *), und die fogenannten Sanåbel find biev ebenfalls fefo genein. Jigre blattrige und patfartige Berfemerunn ift vollfommen Die gleidhe. Sie ift die bei Diefer Art von Mollušfen gewófnlict). Alles ver einigt fich alfo, un Den Berveis an Die Şand zu gebert, Daf man Diefes finddelden Den Meerigeln wieder zus eignen måffe, weil es nut if)nen zuf́ommt.

\section{Ertelirung Der Rupfer.}

2ldite Safel.

Der gemeine Salmar von ber अitcleite, Die rfomboi: Daliftuen flugel aนṡgedefnt und auggebreitet.

\section{Icunte Tafel.}

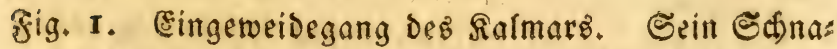
bel befindet fich am oberen ageile. 23 eiter fieft man

*) Spatangus Mofae, echinus radiatus, de Linnaeus et de Lefoke, Ourfin foffile de Faujas, Naturgei⿻, 2, ริ). 
Dent Súfund oier Cefophagus, Der, beionders bei Den groben Salmars, fefre lang ift. Der Magen oder Ventriculus befindet fid) unten in Geftalt sines

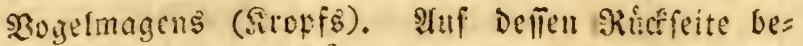
merft man Das Inteftinum coecum, Das cine Dop= pelte Tajthe bitset, beten Eingang in Den Venrriculus gemeinidsaftlic) ift. Das inteftinum recum gef)t vom Magen aus, fteigt grabe empor, und bil= Det in peinem oberen 3 heile eine Befdwulft. Seine Mindung clidet unter ber Sibeide doer Sact, etra bei zmei Drittel Der Sange Des Thiers. Die Slafe, bie mit rothgeltidaer Dinte angefüllt ift, befindet fich an bem gleithen Drte, und fteigt mit iffer Deffs nung fajt bis an Den llmficlag Des Inteltinum rectum binauf, wo fie iflen (Einfichnitt mad)t.

3ig. 2. Soumetme Platte des gemeinen Falmars. Eie ift Dimn, f(s)meidend uno anf Den Eeiten abgeplattet. Die alten Ect)riftfteller vergliden Diefe Eriten mit Der Edneide cines federmeflers. Der obere Ibeil Der Platte ift abgerundet, und zeigt im groben die Sigur eines etwas abgeftumpften Federid)nabels. Die Mitte Dicfer hórnernen \$latte ift Durd) Sculfe pines Sierven, Der bie fiante derfelben ?ausmadt, und ifre Das Anfefn eine's Sdiffeiels giebt, erfaben. zig. 3. Seorneme Platte hes Pfeilfalmars. . Sie un= terfocidet fids, wie wir an feinem Dote fehn werden, von ber vorigen mur Durd) eine fhrwarze und etfabene Borbirre mit einer Subftan, die der deş Fijabeins áfnlid ift, und Die iffe Umriffe Der \&ange nach be= feţt. Diefe Bordure ift ziemlid hervoripringent.

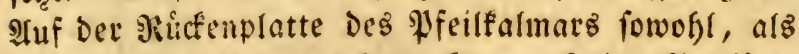
Des gemeinen Salmarz bemerft man fleine Streifen, Die eimen $23 i n f e l$ bilben, Deffen @pize Dem oberen

Hift. nat. de Saint - Pierre de Maeftricht, Tafel XXIX. wo er von Feinen beiben Esiten bargeftellt iff. 
Theil ber \$latte zugefefrt ift. Diefe Streifen tants man a!s cine Anzeige Des allmåhlid)en $\mathfrak{M a}$ a(t)sthum Der 270 !tusfen, zu benen fie geforten, anfehn. Sach ifrer Ingah) zu ütheilen, moddte man faum glauben, bafic die fialmars nut zwei Gafre leben,

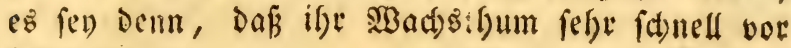
fid gefie.

\section{3ebnte Tafel.}

Fig. I. Sine Bruppe Salmar = Sier. Sie befteft aus ciner Menge von Trauben, bie fich alle vereinigen uno an einem gemeinfd aftlichen Mittelpunft befeftigt find, an weldem fie Durd) einen Nerven oder Durd) ein feht elaftifdes und balb burdfichtiges sigament angefnupft find.

Sig. 2. Etellt biefen Nerven von feinen Biern entblóft vor. Man bemerft an ifm eine frt von binfonit= ten, die ifon feiner !ănge nach in ungleide Theile theilen.

Fig. 3. Man fieft birs nåmliche Sigament cinjeln und vom Etamme abgejondert. Es ift mit feinen biern umfleidet, Dutch Deren Saut man fleine fdon ganz ausgebildete Salmars gewaftr witd. Llnter cinander find biefe (Fier nidts abgefondert, aud find fie an Dem gemeiniafaftlidsen Sigamente nidjt burd) cinen Schisanj oder fonft auf eine befondere alt befeftigt; jede Iraube ift aber ifolirt. Man mufich fich die grofie Menge Cier, bie eine foldhe sraube ausmad)en, nid)t als vollfommen fugelformig vorftellen, fondern

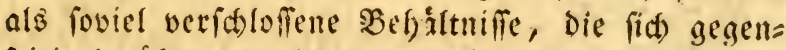
feitig berifben, und untigelmáfig an eimander an= fügen, etwa wie Blajen, die man ethålt, wenn man Seife ftarf fatamen lâpt. Sedeb Behåltnif umidyliefst einen fleinen Salmar, Der Darin zwei bis orei linien lang witd, efe er ausfriedt. 
Eiffte Sufer.

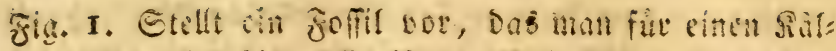
marfidnabel fielt. (5) ift von Drei Seiten gejeidnut. Die erfte jeigt es Dreivicrtel im \$rofil, Die andre

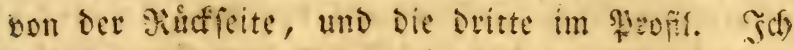
habe es nach Der Natur abgebiloet. Ja) gloubre, Darin eine अefnlichfeit mit cimm andern verfteines: ten Siorper Jig. 2. ju finden, Den enid Safel XII.

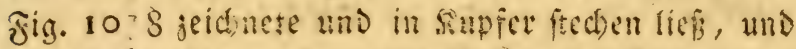

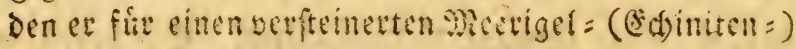
Babn ausgab.

Die Figuren 3, 4, 5 und 6 fiellen nod ande Baffne oder innete sheile von Mleerigeln vor, die fitem

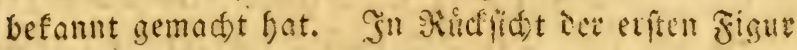
habe id mir cine andere sneinung ct!aubt, alo bie,

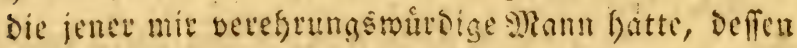
(eleve id war, und Der mich liebreich Das lelyte,

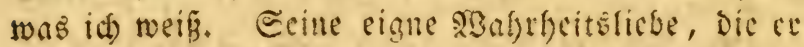
aud) mix eingufófen wuste, fant alfein mich) emt= fduldigen. Eo oft id fier und ba etwas finju=

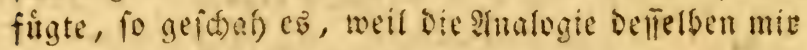
aufer allem zrocifel jdien.

\section{Der Pfeils Salmar *) (pfeilformige Salmar) Le Calmar flèche.}

Unter Den IGieren, die in ben Cålen bes nntul:

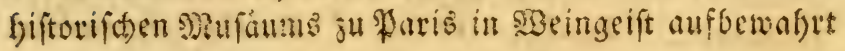

*) 2fuct Cslmar fagitté. ,L oligo fagittata. L oligo alis triangularibus caudae adnatis limbo facci integerrimo, lamina dorfali antice dilatata, corpore oblongocraffif. fimo, brachiis pedunculatis praelongis." Lamark Miém. de la Soc. d' hift. nat. de Paris, p. I3. Siche fagittee. Sepia fagittata L A. G. Bolc. Hift, nat. des Vers, Vol. I. p. 46 . In 
werden, befindet fid cin fert groker Rarmar, ber ptwa, wenn man feine langen strme mitred)net, vier Fuf lang fern fann. Eamart nennt feinen Bau tiefmmágig.

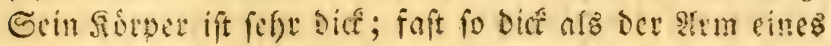
ruffigen farfen Mienichen; Dod) ift er Dobei fann!tid,

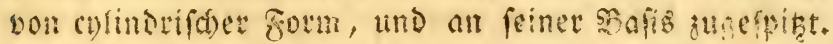

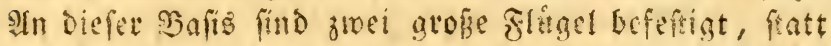

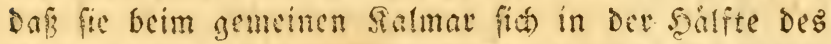
Sorpers anfeten. - Dort birben fie eine Diagonal= finie mit bem seibe. Seier macten fie mit bemfelben

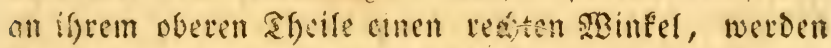
bann imner breiter, und endigen fid am unteren Sbeife

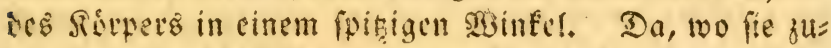
ext ben ecib bes Iflers verlaffen, haben fie eine sitt von Defluthen, welches die cben befartebene Bortung

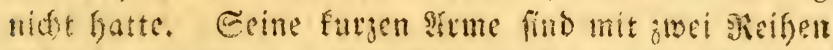

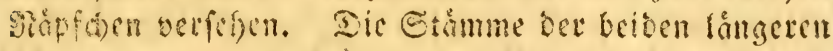

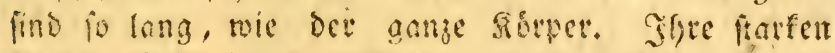

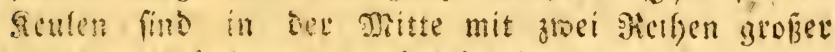

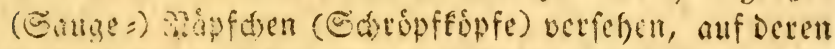
beisen Esiten fid andere vid feinere befinsen. Die Slugen fine nidte fo hervorftereno, als ocr Bau bes Thicrs es glauben lofien follte. Eeine garbe ift weifs=

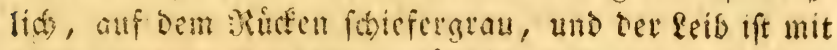
pumpurotgen sunfen getupfelt. So ift torrigfens Det gejeidnet, Der im naturfiftorifich sabiret aufs bewaht witb. Fes Mcingrift mis ifne inoces blaffer gemadt faben, denn fider waten die farben mafgend feites Lebens f fuble:.

WBafferd einlich erreid)t biefer Salmar bismeilen bie

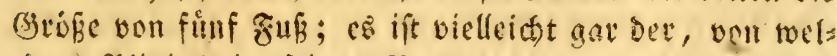
d)em \$linius in feiner Naturgefdidste redet. Eefr.

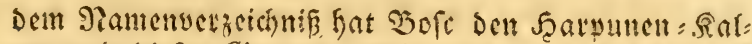

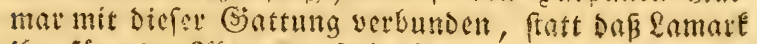

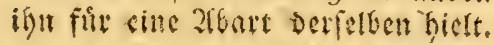




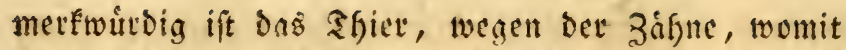

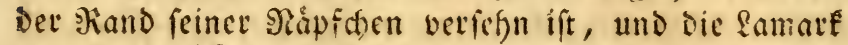
Durd) Griffes (žnge) bezeidnet hat. Der gileils falmax unterid)eidet fid alfo vom gemofnliden burd Die Sage Der flugel, Durth bie Defreden am snfang Derfelben, Durch Den rechten $23 i n f e l$, Den die Flügel mit dem Sorper maden, und burd) den einfaden nidbt feftonirten æand oben am feiner Echeide. Die horn= artige und Durdfict)tige Mlatte im situffen bringt eben= falls einen wejentlichen Unterfdied bervor. Die bes gemeinen Salmars wirb námlid) an theen ßåndern bỉnn wie eine Mefferfdneide, die des Pieilfalmats aber ift es $g$ a $\mathfrak{r} \mathfrak{n}$ d $t$, fondern bat auf beiden Seiten einen fawarzen bormetnen Streifen, Der elaftifd ift twie Fiid)= bein, und Den ganjen ltmfang Der Platte Der \&ănge nad) gernde fo befekt, wie es in Der voranftefenden Beichnung Dargeftellt itt. Das ubrige Der Tofel ift wie bei Dem gemeinen Ralmat Durd)fidtig, wie Denn beide faft úberall in Rúffificht ifret Beftalt miteinander übers einftimmen.

Der Ifeilfalmar lebt im atlantifden Meere. Man trifft ihn auf Den Rilften von Europa und von Imerifa an. Bis Laniarf feine Battung abjonderte, wurde ex mit zu Dem gemeinen falmar geted)net; und bod) itrte fich aud Samarf, benn er verwedfelte ifn mit Dem Dicfen Falmar, Den Geba aafel IV. Fig. I und 2 abgebildet fat. Dev ijt aber von ifm veridses ben, wie fich bald jeigen wird; Seba fagt úberdiez, ex fomme aus Brafilien, weshalb wir ifn aud Darnad benennell werbell. Sm Grande ift Seba felbft an jener Berwedfelung idfuld, Denn er hatte nidft bemerft, báz Der finlmar aus feinem Sabinet, Den er zeichnen lief, nicht Der gemeine war. Bruguicre, Det

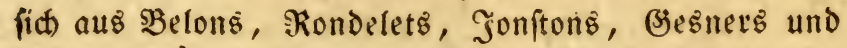
Ilbrvvandi's Zeid)mungen nid)t vcinelgmen founte, $f_{0=}$ pirte die von Seba als Die neuften und Der statur - 
feiner Meinung nad - getteuften, und barin batte $\mathfrak{e t}$ volffommen red)t. (ere verwed)felte aber Seba's Fials mars bicfer Battung mit allen ûbrigen grof́en Bottun= gen; und folgte Darin blindlings Den álteren in Biuff: fidst Diefer Shiere fefre untwifienden গRaturforidern, Daf er fie in grofe und fieine theilte. Samart abet ridtete fich nadh feinen Beobachtungen. Durd) forgs fáltige Bergleidumg Der Sindiniducn fand ex mit Redit mel)rere eingelne (jattungen anf. (Fe brad) hierin bie S3ainn; if.m wito man mun folgen, und alle neue Brat=

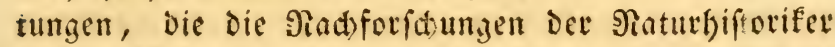
nod) auffinden werben, neben bein won ifgm feftge= fertert ftellen.

\section{Der brafillfáse Ralmar *). Le Calmar du Brefil.}

Dicfer Salmax, Der wegen feines furzen $\mathfrak{B} a$ 's

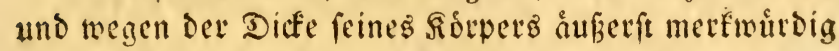
ift, wuede dem @eba von Sirafilien geblad)t, und dies fer bildete ifm in Dem grofen siserfe ab, Das in Sulland unter feinem Điamen herastom. Sieft man die Bes ftalt des Sifiers genauer an, fo móchte man faft glan=

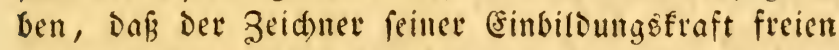
Sauf gelafien, und das, was ifn Der Saturforider geiónen bief́, ibealifá) (f́atrifaturartig) batigeftellt habe; lieft man aber ben Sett, fo filloet man im Gese= gentheil, Dafis er die Merfmale Des Tfiers, weldes ev vor fich batte, áuber ft genau aufgefáft, und fie mit einer ängitlicten ङsenauigfeit bargeftellt hat. Diefe Itugen, die to weit aus Dem Sopfe heraus hangen, finden fich roirflid bei diefer Gattung. Der Tertt ver= gleidst fie mit biffen sevesaugen, und Der Berfaffer fect binju, fie feren eben fo frei uno fpielten eben po umber, wie die 2 (tugen jener Rruftentbiete. Alud) in

*) Eebra, tom III. Tafel IV. Fig. I H. 2. Loligoofe van Brazil. 
Der $\mathfrak{A}$ t, wie Der Zeidner Die (Eauge $\Rightarrow$ Rápfdent ber Irme gezeidnet hat, merft man peine tiefe Sact)= fenntnip.

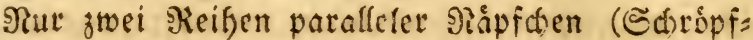
fópfe) find auf Der fladen Dberfache Der adt furzen Arme befeftigt. Die beiben langeren atme find unten platt, und gaben faft gat feitre Reulen, find aber cben=

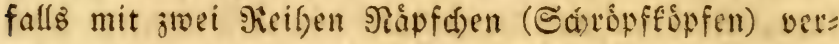
fefln, Dod mit bem Unterfdsiede, Daf faft iffer ganjen \&änge nad) immer ein ff leines glåpfden mit einem

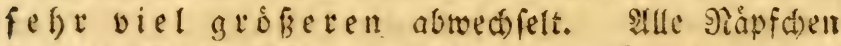

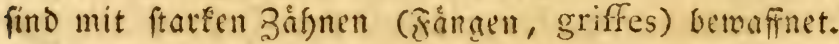
Die beioen langen $\mathfrak{A}$ rme fint greffer alo das gange

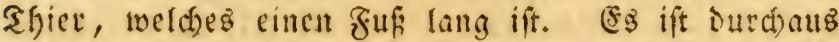
nid)t (c)lant, twie die übrigen Salmats, fondern funf

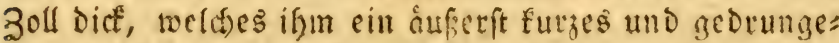
nes Anfeln giebt. Seine flingel fino Denen Des \$feil= falmars åfnfid), fie haben 3. (3: and cin Defreben an iftem ltrprunge, find aber viel breiter und tweniget how. Die jarbe bes sorpers ift faft Durchaus fafyl, unterm baudse aber gelblid); aud ift er nitgenos ge= tigert over getípfelt. Die feuet = gelben uno rothen $\mathfrak{A}=$ gen fino fo grof, wie ein Saubenei; if:ee Stellung und ifre Geftalt, nebit Den langen Armen, mit iffen ftar:

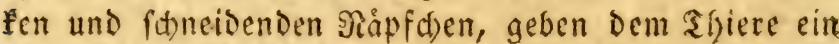

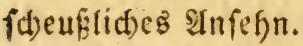

Samarf fat ifn in bem befanten, hbrigens vor:trefflid)en Memoire mit feinem calmar fagitré (Den wir Pfeilfalmar genannt haben,) verwed felt. (Fr citirt

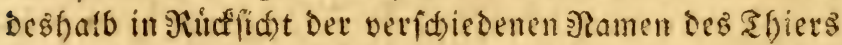

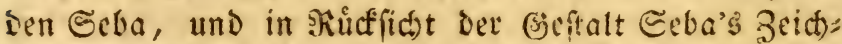

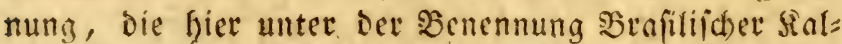

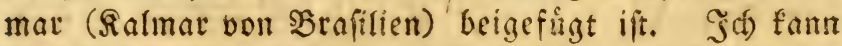
vielleid)t itren; nad) meiner Ueberzengung aber muß̈te id) von Diefem afficte eine befondere (jattung mad)en, benn es ift auffallend biel fưrzer und auferdem not 
viel bicker, als ber \$feilfaimat. Die farbe bes letetes

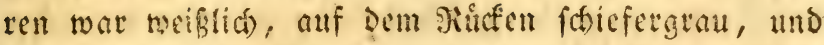

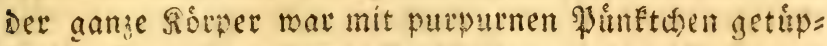
felt. Der Sorper Des SBrofitifón Salmar's aber ift

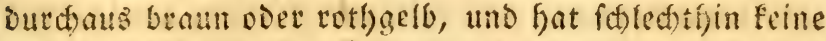
andere Farbe. 3twar ift bei beiden Battungen Der Etamm Der zmei langen strme fo lang, wie Der Sobper felbit; Dageaen hat aber Der Beafiliface fialmav gav

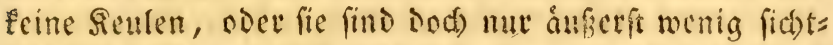
bar, ifge Stamm ift viefmefre unten ganz platt, und biô gegen Den Mund hin mit (S̈auge $\Rightarrow$ Pecipfden (Schupffupfen) verfern. Dicler Saratter ift fele mertwirdig; Der \$feilfalmar bat ifn theils nicist, theils find aud feine Reulen mit vier ßreigen SRapfáen verfethen. Die Angen bes speitfalmats treten monig

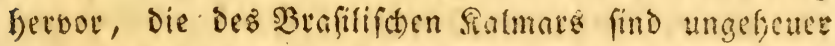
grof, und ftefon megr als einen zoll lang nus bom Sop= fe hervor. Pur Dutd fo anfiallende aufierticte linters fd)iede fonnte id bewogen werden, Diefes Mollusif von Dem vorigen abzufondern, und eine eigene Battung Dar:

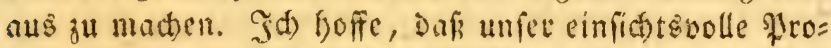

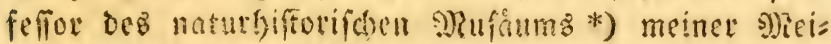
mung beipfictith mird, befonders wem et nod bevenfy, Dof Diejer Malmat aus sirafifien gebuitia ift, wie Geba

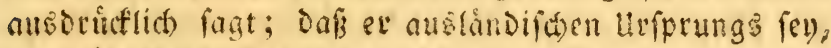
zeigt überbies for fen fonberbate Beftalt.

\section{Der Sarpunen?almar **) Le Calmar harpon.}

Eamanf foteint mir in feinem Metroire, das id) fo oft citire, und weld)es es in fo vieler Simfict vetpient,

*) Eamait.

**) "Loligo fagittata al is triangularibus caudae adnatis, limbofacci integerrimo, lamina dorfali antice dilatata, corpore gracili, brachis pedunculatis perbrevi. 
ånerft bejdeiden zu fandeln, daf er es auch bei bies fein Salmat nidht wagen will, ihn als eine befondere Battung aufi̧ufúlen, fondern ifn lieber als cine $\mathfrak{A b}=$ art Des \$feilfalmars befdreiot. Sein binnerer Bau und feine Dunflere und bráuncre farbe waren freilich nod) feine finteidend hervortechenden faraftere, um ifn ven Dem \$feilfalmar ou trenten; aber Die Şaut Des Sarpuncrifalmar's ift glatt, cinfach und hat feine Punf:den. (5) ift ferner ein nod) auffallenderer unter= fáled da, der \&amarfen, meiner Micinung nach, hatte beftimmen follen. $\mathfrak{S}^{\mathrm{d}}$ ) meine bie beiben langen Arme, Dic beim Sarpunenfalmat, ftatt fo lang zu feyn, als Der ganje Sistper iit, faum dopkelt fo lang find, als Die acht úbrigen furzeren; fie find aber eben fo fonder =

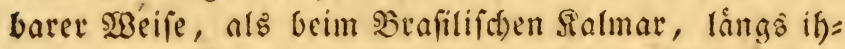
rem ganzen Stamm mit Nåpfoen (Ed)ropffopfen) net:

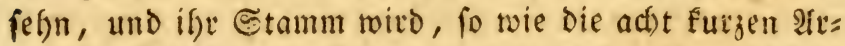
me, unten platt. Sind wir mit biefem Unterfáiede zuerft im Bieinen, fo fonnen wir bam aud) nod), als

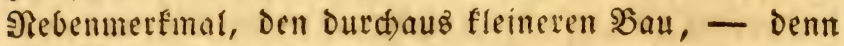
alle befannte Gndiviouen find, ifge arme mitgered)net, faum einen und einen halben fuf lang - geiten laf: fen. Die braune und fahle Farbe, und die einfarbige Scaut, bie Durchaus ifne Purpurpunfte ift, tragen noch mel) Daju bei, um Den Şarpunenfalmar feinem ånkes ren nad) vom \$yfeilfalmar ju unterfdeciden und gánzlid) zu trentren. Der Rorper ift úberdies viel fdanfer, Dinner und zarter. Seine runden $\mathscr{A}$ ugen fino fleinct unto weniger fugelformig; feine innere Platte ift zwar,

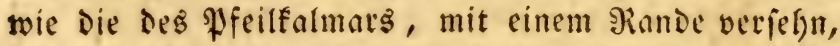
aud) ift nid)t zu láugnen, Dafict jencm im ûbrigen fefte nafe fommt, indéb darf man ifn bod nicht domit ver: wed)feln. Ifud cinige innete Theile gleiden fich. Das

bus." Lnmark. ubi fupra. - Seba, Mus 3. Ta fel IV. Fig. 3. - Brug. Encyclopédie Tafel LXXVII. Fig. 1. 
ift aber naturlida, benn malje an einander granzende,

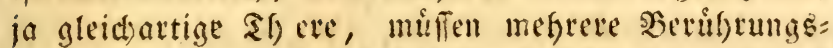
punfte unter cinander baben, unb fid), fo zu jagen, unter einonder betfetter. Diefe fanfthinancirten Gira= bationen bilden bie unmerflichen Gitieder Der Rette, Die

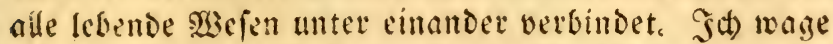

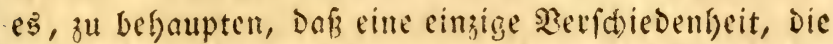
(id) aber fortwáfrent vorfindet, uno fict in mefreren auf einander folgenoen Genetationen wiederfolt, bie Battungen und (Befd)led)ter beftimmen muß $*$;.

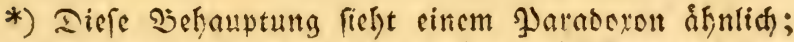
wir wollen fie aber cinmal philofopsifich unterinden. Im Norden exifticen lauter furge uno gedrungene SRenchen; man madht aus ifnen jwar eine verfobies Dene Menf(henrace, sine PGart, nidst aber sine vel's

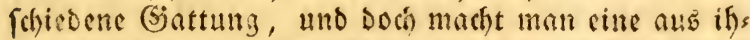
rett f̧unden. - Die Neger find fdhwarz, fie haten

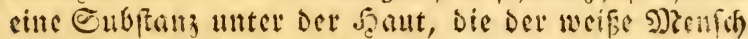
$\mathrm{ni}$ (d) $\mathrm{f}$ at, uno man fert an, aus Den Siegen cine

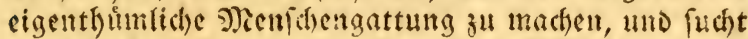

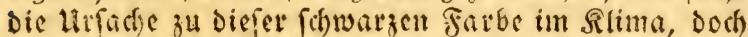
aber veretben bie 9reger ifge sarbe immerfort auf bie gleidhe 2 seife, went nicht etwa altbers gefárbte Menfiflen Dazivifach fommen. Findet firt Dagegen

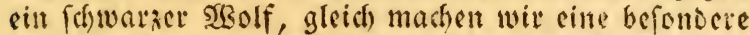

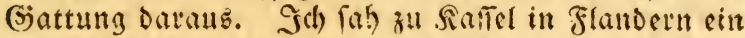

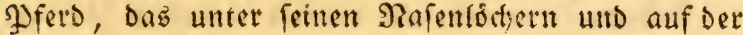
Doerlippe cin paar lange Echnurbárte hatte, wotrach

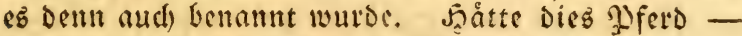

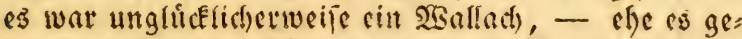
fhnitten wurbe, Fúllen mit eitren Schmurbart er: zeugt, fo wurdoe mar fogleidh eine Fjottung von Wferden mit Sdhmebarten gefabt haten, oenil daz

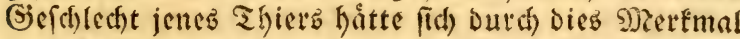
auşgejeid)net, went man nidht etwa wie bei ben Deens

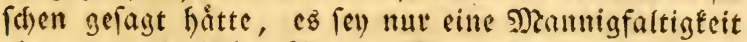

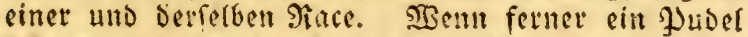
fich mit einer Đudeffundin vermifht, fo wito ifte כegattung Juber Kervorbringen, Jagbhunde mit Sagdfundinnen geben wieder Jagdhutde; Doggen 


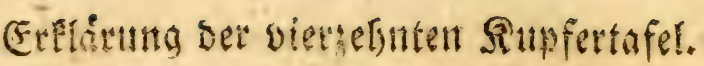

Sic ftelit Den Sarpunenfatmat, bon feinen beiben Ees= ten angefefen, Dat. Dix enge Sinum des Gupfers gtwang mid), feine grofien und weit auggedefnten Fligel zufommen zu falten. Inan bencrie bie diffe uno vieteffige Beftalt feinet langen II'me, die auf

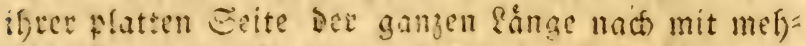

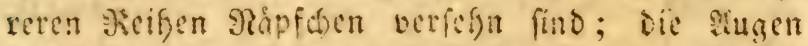
fefin jwat feft letuor, find aber mit einet fatfen Saut bedect, bie fie verounfelt und ifnen alles Eirabiende benimmt.

\section{Der S2urfipié, Sialme* *) Le Calmax javelot.}

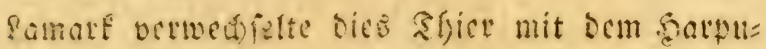

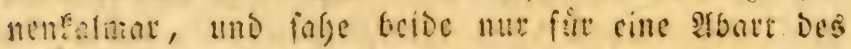
pliclfolmars (loligo fagittata) an; ev belegte al=

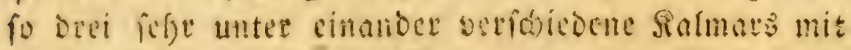
einctei গianen. Finnte fie irgend etwas einander na: Gern, fo witen eŝ bic putpumen \$unfte, die diejer Gien hat. Eeine Geftalt, und bie siloung feiner gwei

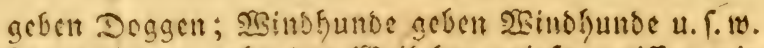
Eonge juvor, che Dog siscibden wirft, wițen wis foron, was fie uns bringen wirs, uno theilen biefe

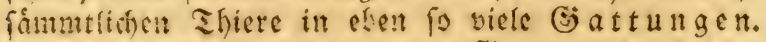
23arum wallen wit bem jene. Gattungen, Die

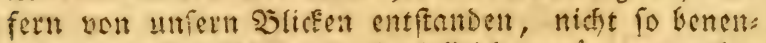
nen? - - Eic tôntren fich vielleict) veråndern, aber Dics gechiefit Dann nicht nach Den Ëerefen bes Miens

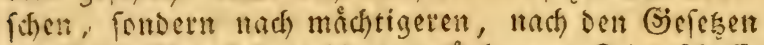
Der zeit, Die allein alles verandert. Sie fhaffet und verivande:t bie Umfrande uns zemperaturen. Durdf lie allein erfalten Die lebenten $23 e f e n$ nene

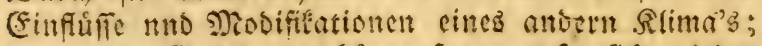
ja, sinige Gotatungen foren fogar auf, fich wieder hervorgubringen.

*) Seba, Tafal IV. Jig. 4. - Bruguiere, Encyclop. ₹afol LXXVII, fig. 2. 
langen same, entiernt ifn aber eben fo febe, als et

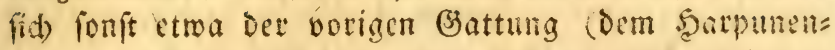
falmai) nåbert, Dod ift wieder bie S̈d)eide von jenem - wie foton bemerft worben, - nicht punftirt. Des SBurfipiesfarmar ift aud etwas langlider, uno in ber Mitte feines sorpers Dimner. Ungeadtet ar aber lån= gee it, find Dod fein Sopi und peine srme dinnex, und feine Irugen flemer; in allem lebrigen fomm biefe (Sattung our vorigen unenolión nafe, beide baben auch

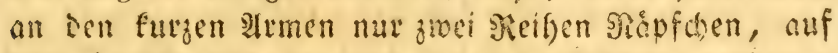
Den langern find fie aber offie affe Dromang zerftecut.

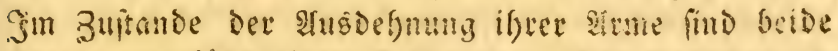

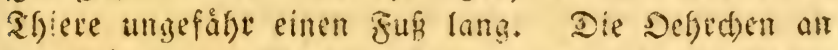

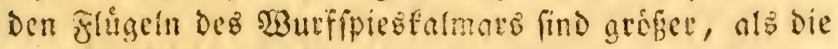
bei Den eben befdrebenen betrungen; and entfencm jie fid ein wenig vom Sórper.

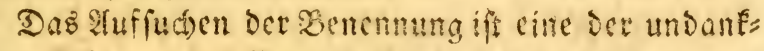

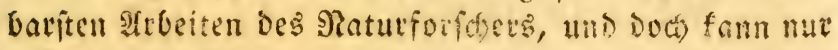
Daburd) Das (Ef)oos geordnet werben, morin die átern Schrifteller Die গaturgefdidste gelaffen baben. Die Dintenfifare, Falmats uno Solypen waren ganj vol= zinglid) in unordmung gebleben. Sur erfit ourch $\mathfrak{E} a$ marf's Bemúfungen ift einige Glarbeit îber fie verberi= tet. Sein șemoire muf ifm ferte viele Mad)forfoun= gen gefoftet haben. Dft ift er mein firferer. Deme:= fe id) aud witflid bann uno wann etwas, Das iffm entgangen ift, fo fommt es.bafger, bof er bor mir f(d)rieb, und ich alio feine Entocfungen nithen fonnte. Berade fo ift es mit Ṡruguiere, Der auf bet fie= benundfiebzigften Iáfel dex Cencuclopádie Seba's beide Ralmars mit einander verwed)fett. Diefer fleip̈ige

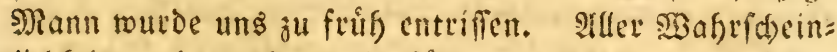
lichfeit nach twetden wir fưr immer bedancen múfinen, Daß wir feine Mamuffripte oon ifgm baben. Cider wilpten wir fonft den Brund, warum er von ben vielen 3eidnungen Diefes MHollubls gerode jene ztoei vorjog, 


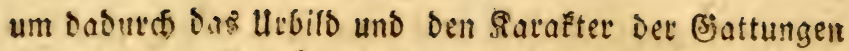
Dariutellen. Ex murde uns entráthfelt baben, wesbalb er Siondel trs und Allorovandi's Salmars in cinem 93 sefe, Das Dod alle betannie Battungen umfalīn, und if) (d) edenfeiten barftellen follte, nich t fopiten lieṕ; viels leid)t batten roir aud erfabren, Daßj er Diefe beiden (sats tungen wisflid) unterichieden bat. Aber wie gefagt, dev Tod entrif Dicfin witsigen (Belefferten feiner Falallie, fei= nen Freunden uno der şifienfwait zu frib. (Ev hat nue

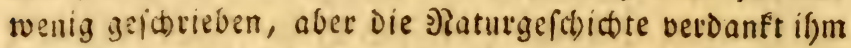
viel, Denn er theilte fid feffer gern mit, und feine Anfict)= ten Der Dinge blieben Denen, Die ifin gebónt hatten, im Indenfen uno toutben von ibnen gefammelt.

\section{Erflirung oer funfiglnten Fupfertafel.}

gig. I unt 2. Dar \$3urfipießs = Salmar, von vorne uno von Der ’hufficite angefel)n, ganj mit purpurflecten ges tigert; ieine Alrme fino fưrzet, feine fleinen Flúgel

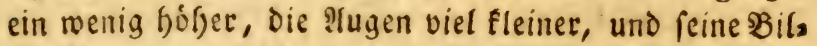

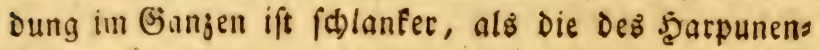
Ћalmarž.

\section{Der SGurfpfeil, Ralmar *) Le Calmar Dard.}

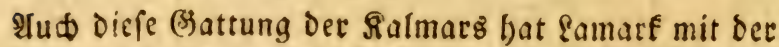
folgenden verwed)felt. Zum Eerweife fúfre i申 blop Das an, was er volt den Armen diefes Shiers **) fagt: "Die

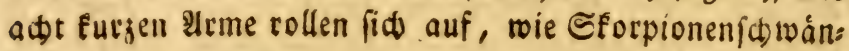

*) "Loligo parva." Rondelet, Pifces. 508 et p. $37^{\circ}$. Der franz. 2fusg. - "Loligo minor Ron. deletii," Aldrov. de Moll. 'p. 172. - Gesner, Aquat. p. $58 \mathrm{I}$. - Ionfton, Hift, an. de exfang Taf. I. Jig. 5. - Ruyfch, Theat exfang Taf. I. Sig. 5. Sepia media. Linn. - Bruguière, Encyclop. Taf. LXXVI. Fig. 9. - Corniche des bayonnais. Le petit calmar, le petit Cornet des francais. **) Lamark, ubi fupra. 
fommen ab. Suf bem Bilde in ber encuflopabie ift bee

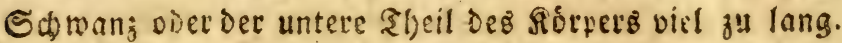
Da ich mefrere Salmarz Diejer Int zu meitrev Disz pofition hatte, fo babe idb Den einen mit feinen innera Theilen vorgeftellt; Die fiebzefonte Tafel ftellt ein $2 B$ eib=

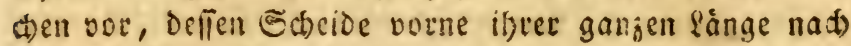
sufgeiduritten ift. Dben ift fie nicht, wie bie des Dintens

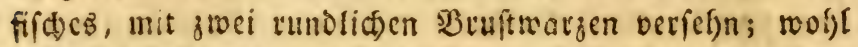
aber cbenialls vorne an Trifter befeftigt, und zu Dem Ende mit zwei lánglichen J̧aff(ben (Agraffes) verféten, Die in zwei ebenfallz auf Diefem Triater befindidaen falgen (ふ̋ugeii) (Coulifes) eingreifen. Unter ber şaut find bie beiben fralje fnotpelig; auda fann man fie ablofen, wie idf) Sig. 2. unferer Supfertafel gethan Gabe. Diefe Figut

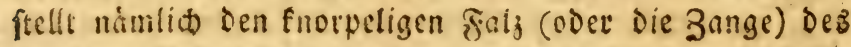
gemeineli Salmars vor. Fig. 3. ift Das fleifhige Sáf hen Des innern Rkndes dev Sd)cide, weld)eร fich beim gemeis

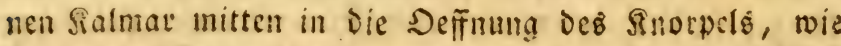
cine sanzenipitae, einfert. Durd Diefe form mito zwat

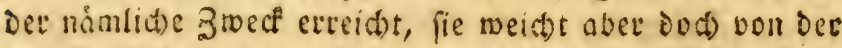
Des sourfpfcil salmat's ab. In Den fleinften, fo wie in Den grofften Dingen mag die Эiatur gern Die gleicten 3tvecfe euf mefretlei Itt erreiфen; fie vermannigfaltigt iafser iffere formen im Gnnern Des Fiotpers der belebten gefefen, io nie im Meufern. Die beiden ftarten faulen:

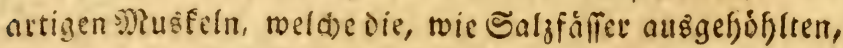
Bruftwarzen Des Duntenfifa)es emporfielten uno fprelen liefen, finden twie fier wicoer; ftatt Daßj fie Dort abes blog̉e Musfeln zufammen preffen, Drúcten und beroegen fie bier finderpel, Die unter Der Dberfláche Des Trichters mit ifren fortefpondirenten s)husfeln veridlofien find. So finden wit aud) das offente endoe Des 刃) ajtoarms (intertinum rectum) twicder, Das fict gegen Die MBitte Des Siorpers fin óffnet. IUch find Die Siemen viel länget als beim Dintenfifde. Şlore Befäbe und Blätterd)en fino

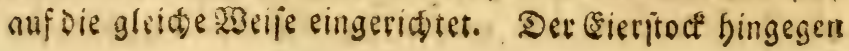




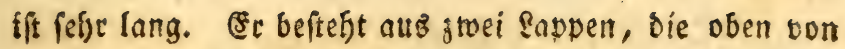
einander abgefondert find; Die fleine Dintenblafe befindet (id) hinter iffm uno ift gegen Die Mitte Des $\Re$ órpers vers ftecft. Die hórnerne, auf Den Seiten fefor dünne und

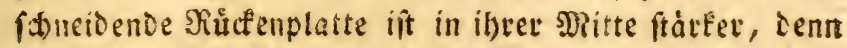

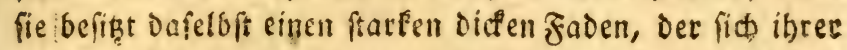
ganjen fänge nad) fortfetit; fie enoigt fich nad beiben Seiten bin in eine Spitze.

Broß r wird Diefer Salmar nie. Shan trifft ifn im grógten lleberfuffe an Den siuften bes mittellänoricten und atlantifasen Meeres an. Er. Iebt onfelbft in fefre grobien Saufen, und man fann ifrer einige Taufend ougleith fans gen. Sie twerden gegeffen. Es fueint rogar, oak ithe fleifd) mandem Dortigen Silftenbewofner redt mohl 14mect, Denn an manchen Drten iverden fie ziemlich báus fig genoffer.

\section{Erelårung Der fectigefinten und fiebzefnten Supfertafel.}

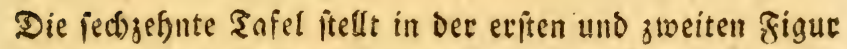
Den 23 urfpfeil : Salmat in zrei verforiçenen Infictet Dar. Die erite Sigur nàmlich von vorne; Die zrweite zeigt Das Bretůpfelte und Die geförbten Fiecfen feines

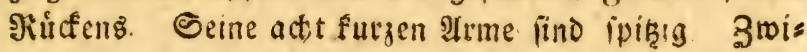

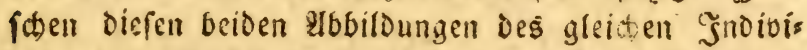
Duums ift Die bormerne 尔ưcenplatte Deffelben mitten inne gezeichnet. Sie ift dünne und aufierfit zart, alfo

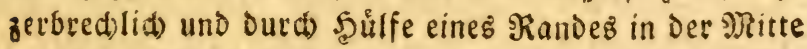
roie die andere auğgefóblt (carènée). Şbre beiden (En: Den aber fino faft gleich ipite. Das eime unteritheldet (iid) Darin von Dem gleiden affeile Dez gemeinen und Wfeilfalmars, $D a ß$ es fid) nid)t in eine ftumpfe Spige endet. Das âfier bleibt beftándig flein. 


\section{Eiebzernte Tafer.}

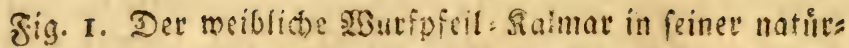

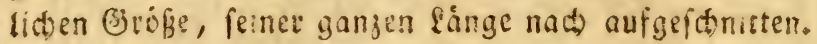

Der Tridter, over Die Sierlángerung Des gemeinid aft=

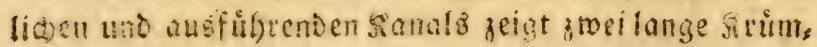
mungen. Sie find fliorpelig und clatich, we Sdaf:

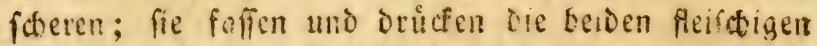

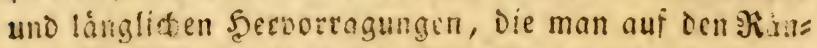
Dern ber ๔atide bemerft Die firemen, Die Slalmen=

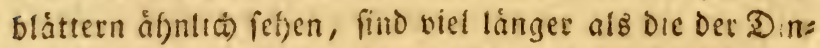
tenffiche; iene fino bagegen sicfer uno rundicher; Die

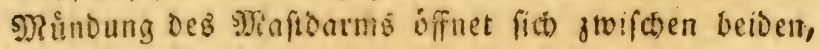
uno geigt fich uber bem $M$ utis voev Exifenartigen Górper, Den wir bei Dee zergliedering dez Dintenfis

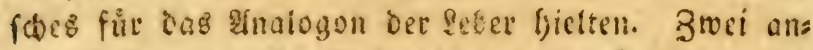
Dere Seffinungen oocr Siebentubren crftecfen fid neben

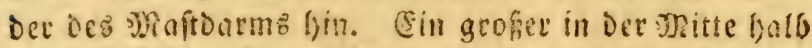

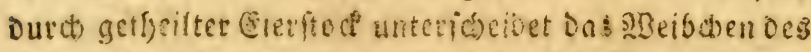

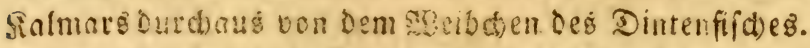

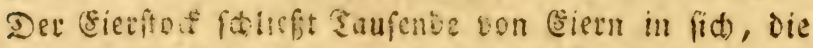

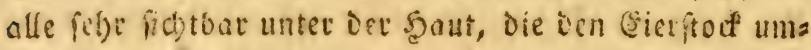
fd)lieft, bsuorblicten, und fo grof mie Mobnfoner

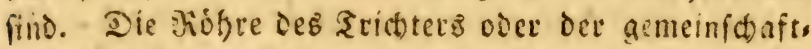
liche ausfü)tende fanal ift mit einer siapjel, Die ztoei Sappen bat, verfefen.

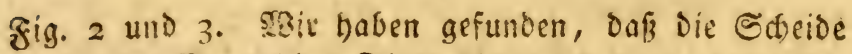

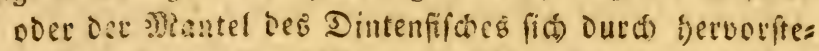

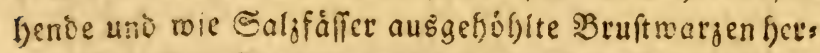
metirct an Den Zricter anfolof: bei Den Folmars bes feftigt fie fiá) jwar ebenfalls baran, aber auf eine ans Dre atrt. Zmei Şaeken namlich, die meifrens berzfors mia ober langliat) find, befeten Den ßand DeE J?antcla,

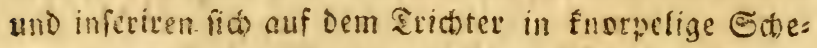
ren oder Jangen. Die zreite figur fiellt oicie fnorps llgen Zangen vor, Die von Der áuferen şdut Des gemeis 
nen Salmarz abgelofet finb; Die dritte rigur ift die Bruftwarze ober feift,ige, bergfo-mige Befeftigung, Die fid) bei dem gleiden Salmar Dort inferit.

\section{Der Salmat mit zuiammengerollten 2(rmen *) le Calmar contourné}

Dies Tfier ift nod fleiner als bas vorfergefende, Denn es ift faum vier 30 ll lang; feine gan eigentbintide

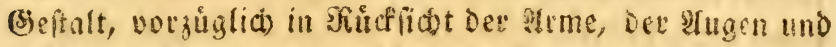
Flingel machen eine eigenthümlide Battung Dacaus, und

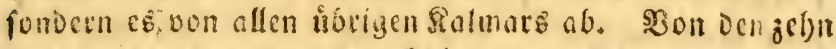

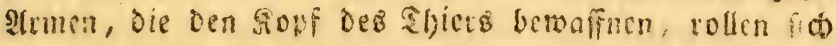
ifrer adt biz zur Bafis derfelben fpiralformig anf fich feibit auf. Eie find mit Edrepflopfen oder tuaciartigen

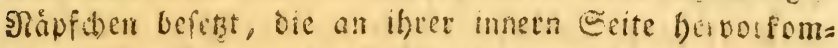
men. Die Stámme Dev beión làngetn enoigen fict) nict)t in seulen, fondeen in eine mut wipforn bemaffute Pers langerung; aut fie rollen fich, wie sie ad, thrzeten Irs me um fich feloft auf. Whe diefe altme fino runolid und baben feine fubbolung nod cine fonneibende Eeite: Der Sopf ift runo wie cine gyurft, und breiter als Der Sorper; cin paar mertict) Gerborftefsende elugen begrản zen den sopf auf belden Eetten. Die Echeide ift pebr

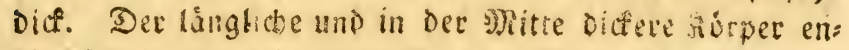

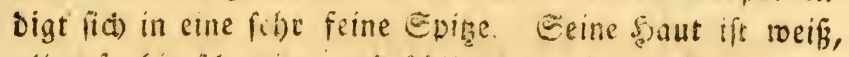
olivenfarbig fdatrirt, uno fdiltat an eimgen Stellen ro: fenfarbig, unterm Basuthe befonders felficharbig selle Purpurfeter, Die auf Dem Bitu'en breirer und bunfer werden, zieren

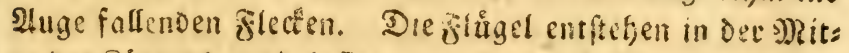

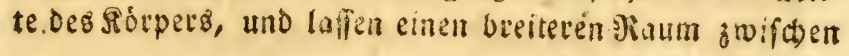

*) "Lamark, calmar fubúlé, L oligo fubulata, ubi fupra. p. 15. - Loligo alis anguftis caudaefubulatae adnatis, lamina dorfali trinerviutrinclue fubacuta." Ibidem 
fic), als fonft getoúfnlich bei ben Salmarg ber fall zu feun pflegt; Da too fie vom scibe abgelnn, befindet fid) eine Irt bon Déneden. Sie find nur fdmal, bilben ciner fej) furgen, faft recten șmfel, uno verlieren fid in einem żteisen áuperît fpitzen Winfel am unteren Sheife Dez pefre lángliaen Rórpers. Dieje gauz eigenthumlide (5eftalt fatte feiner oonallen Den salmars, Die biester bes forieben ruorden find. Seine hornerne Wlatte ift tlein, fdomal und wird ibrer ganjen l'ange nech in oer Mitte Durch) einen bicieren bórnernen faden gufammen gebalten, etro wie der Bart e!ner Feder Durch ifren Riel jufam= men geffalien wiro. Sie ift an den Eeiten fdueidend und auf beiden Enden fpitig. Samarf erfaubte mir oies fะB Mollust aus feiner fđjónen und lefrreiden Samms lung zu zeichnen. Sa er allein batanf bedadt, ift, bie פBiffenichaft gu befordern, fo ift cr soll Gite fur bie, Die fie fultiviren, und von jever niedrigan (Eiferfudt, fo wie

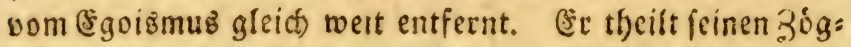

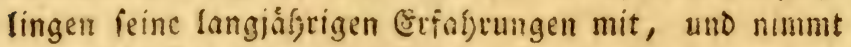

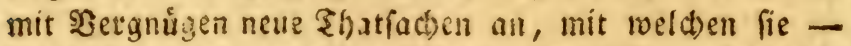
Durd feinen unterridat gebiloet - bie ginturgefdidste bereldjern.

IUs welden speere biejer fleine Salmat fommt, toeif man nicdt.

\section{Erélo̊rung Der achtzeftten ßupfertafel.}

Figur I und 2.-3er aufgerollte salmat in feiner nations lidjen Grófe gejeidurt, von vorne uno binten angefes her. Sein breiter und auseinanoer gedefnter Ropf ift mit aufgetollten und um (id) felbjt gemundenen Prmen verfeben; die flügeldyen fino fabmal, uno Der untere Ibeil des Rórpers fefre lángliá).

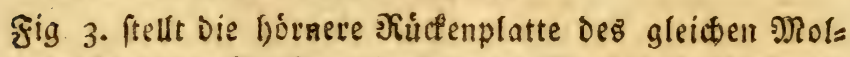
lus̆f̧ vor; fie ift, wie die Des .Mutfpfeil: Ralmarz, nuf beiden Cenden fpitgig.。 


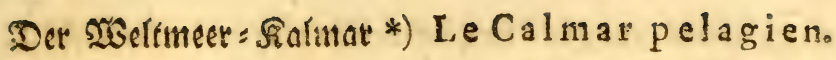

Differ Folmat if eins jener neuen $\$$ Befen, mit mels d)en fưhne Reifende Die uns befannte Balfl ber Shiere vermelyet haven. Bofc, Der in Imerifo umbergeteift war, madste $15 n$ befant: wir verbanfen iffm ad)t פ̧ande in

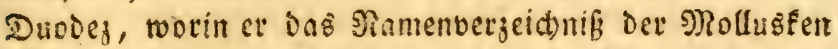
bercusgab, und zugleid Diejenigen bingufügte, Die feine eignen seobadtungen ifte fennen gelel)rt hatten. Coc

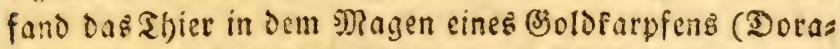
Oa), Der von Der Mannidaft eines Sduffes, worauf ex (iid) befand, gefangen wurce.

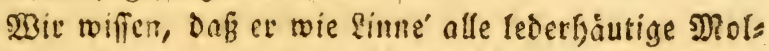
lušen unter Der $\mathfrak{B e n e n n u n g ~ D i n t e n f i f c h ~ ( S e ̀ c h e ) ~ z u f a m s ~}$ mentwatf, und Samarf B drei Notheilungen' nid)t annelymen

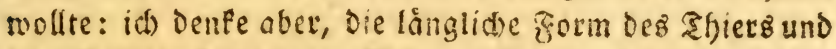

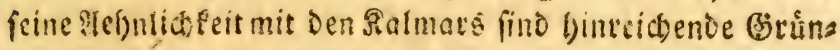
Di es ju biefer Gattung zu zóflen.

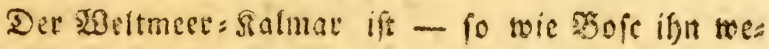
nigftens angetroffen bat - faum ovei 3oll lang; ads

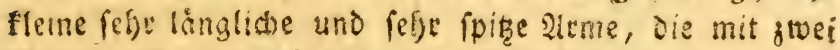
Reifjen (Eaug $\Rightarrow$ Irippiden berwaffnet fino, verbreiten fid)

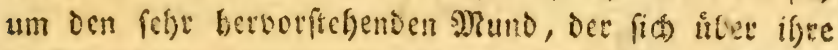
Bafis erbebt, betum; jwci lángere IIrme, Deten Stamm roenigftens fo lang ift, als oer gange siopper, ftén in ifret Dettie. Dee Stamm if runolich und bat an feines Ep:ţe feine sieulen, fondern eine blope Antwrellung mit

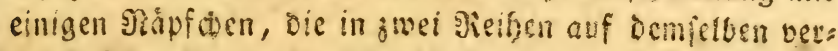
theilt fino, gerabe mie es bei den odt furgen Ilrmen ber fall iit. Der Fopf dicfes Salmats if sict, und in bie Scheide eingefent. Geine beisen Iugen fteberin nichetetwa auf Der Seite oder binterträtz, fondern auf ber sorderet Eeite Des Sopfs, faft unter Den a

*) "Sèche pélagienne docr pélargique. Sepio pels- gi ica." L. A. G. Bofc. Hint, nar. des Vers, p. 46. Tafer 1. Fig. I utd 2. Tom. I, Sou Pelagus, wie Die 2fiten Das weite Mecer manten. 


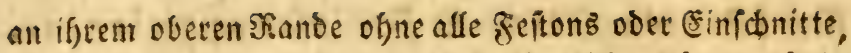
vollig einfaca, unt ber ziemlid langlid)e forper ift in feiner Mitte nicht dicfer; fur feine Beftalt bescidsnet einen Salmar. Die şlugel befinden fid faft ganj unten am Sortper; fie fangen mit einem Defistiben an, uno bils Den, wie Die Des gemeinen Salmars", ein verihobenes Bierect odcr einen vollfommenen Ribombus. Dex fiors per ift weiflid), blafis: gelb = roth) und blau mit Purpur, punftell getiofelt, vorgůglich auf bem Biủden, wo Die

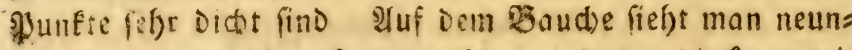

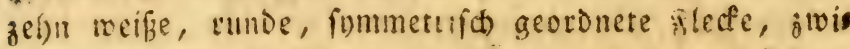

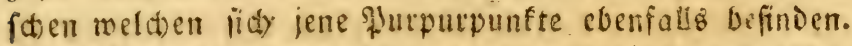

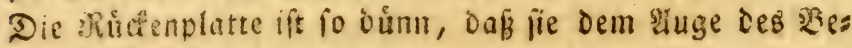
obact)ters entidstupft ift.

Dies flcine Miollusf fáteint im foben Meere, befons bers unter Der Breite Der $2 B$ endefreife, fubr gemein zu

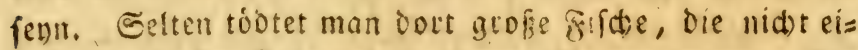
nige von Diejen Ralmars in threm sllagen batten. Die

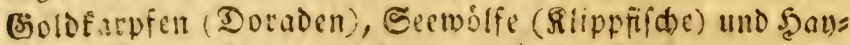
firde ftellen ihnen unaufborlid nach. Dieje flemen sals mars und bie fliegenden fifte fino bie Sauptnafrung

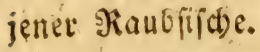

\section{Erflårung Der neungehnten Supfertafel.}

\section{Der $\mathfrak{N e l t m e e r}=$ Salmar.}

Er ift von feinen beiden Eeiten Dargeftellt. Eein feffe

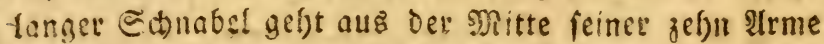
grifoten den Eippen hervor. Er ift hier in feiner nas

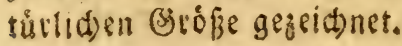


einem Stúcfie, bat aber ben ganzen Sobrper entlang viet

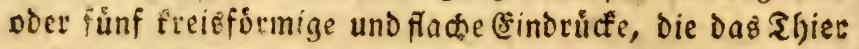
in fünf bis fect) Segmente doer 26 fonnitte theilen. Z Zwei

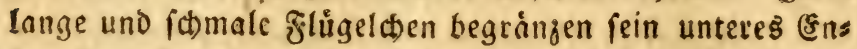
De; fie gefn Diagonal uno faft gámblich auf Den Eeiter

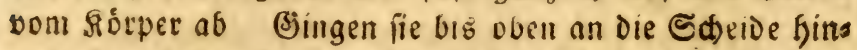

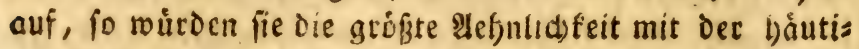

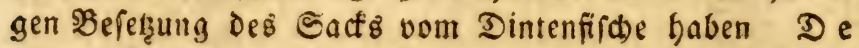
Nugen fint flein Der abgerundete fiop it bicfer als Der Rórper; fedis furje und twei lángere 2irme ragen

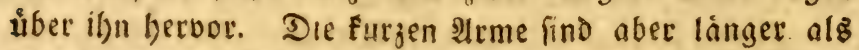
Die gleiden dez Dintenfifctes uno Des Salnars. Betwóbn= Iid) faltet das Thier fie ủber feinen sopf zujammen; ftrecft ç fie nus, um feine seste zu fuden, fo verbreis

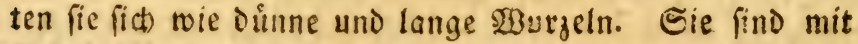
Sd)rópff́spfen oder Iiápfden verfehn, die aber fo flein fino, onf man fie mit bloken 2ugen faum bemerfen fann. Die Stánme Der beiden lángern zeigen an ifrer Spiţe feine in Die $\mathscr{Y}$ ugen fallende Reule. Breift man Dicfen Salmar mit Den bonden an, fo bringt ev eine merflide Erftartung Gervoc, fie ift aber Durdaus nidt fa)merg= Gaft und bỏrt balo wieder auf. Das ábier enthált eine

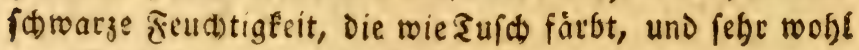
zum Sdireiben gefraudit werden fónnte.

Der Bufall bat midf) in ßituffict)t Der befdreibung

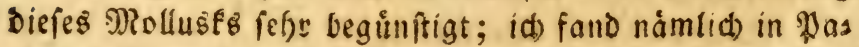

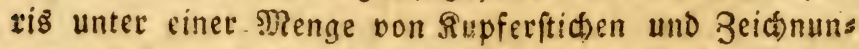
gen, bie ein gewiffer supferftidf fándler zu verfaufen bats te, eine bettád)tli(j)e Menge Sriginalgeit) nungen von

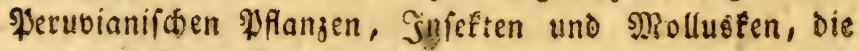

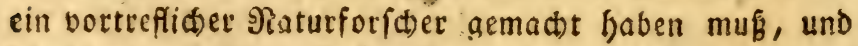

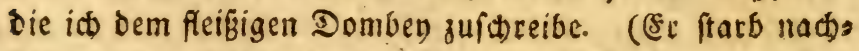
Dem er von feinen weiten Reifen zurưctgefommen war,

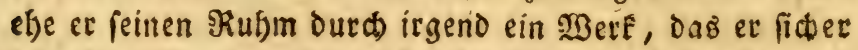
fír $\mathrm{b}$ ie $\Re$ a d to elt gefdrieben bátte, gründen fonnte.)

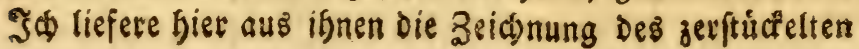


(gegliebe!ten) Solmarz, und Bin ůbergeugt, baß fid mefo

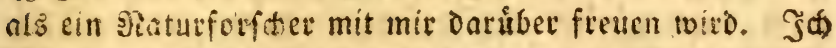
babe fie um die saifte verfurgt, Denn mein Driginal ftellt

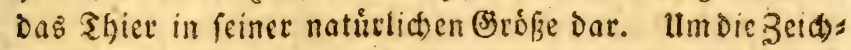

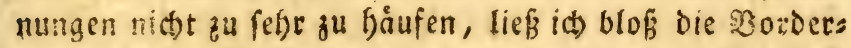

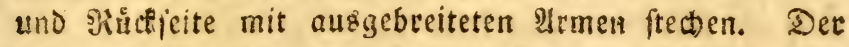
Driginaljeitoner hat Das frande Der $\mathfrak{T}$ u fe, und auf einer andern im 3uftande bee B e roegung Dargeftellt. Die Form Der Muckenplatte bat ev aber Doch zu zeidnen vergefien. Da mun Motina aud nicht Davon fprid)t, fo múffin wir unfer urtfeil oar=

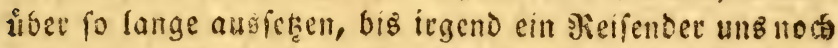

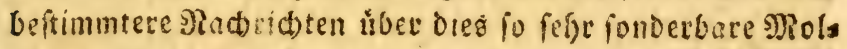
lusêf geben wird, bas leidi telnmal, wenn ficis anders nods netle Gartungen Daran anfidiefien follten, an Der Spize

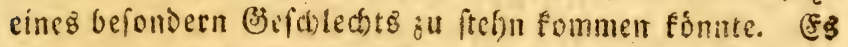

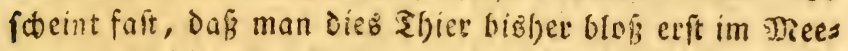

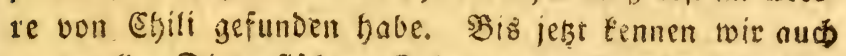

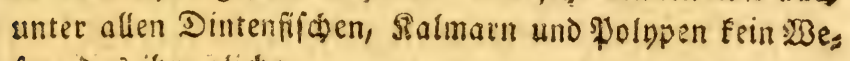
fen, $D a b$ ibm glide.

\section{Erflárung Der zwangigften Supfertafel.}

Det berftuctelte geglicierte) (tronconné) Salmar mit adjet Atmen, wowon ztwei lánger fino, als die tibligen, von feinen beiden জeiten Dargefrellt.

Molina nante ifn jwar "Dintenfif mit

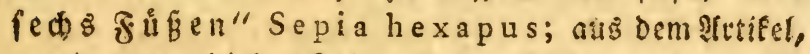

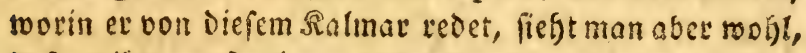

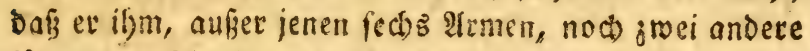
lángere zufdreist. Unläugbar fino biefe Alrme mit

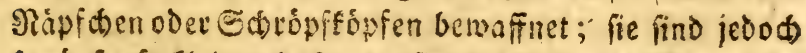

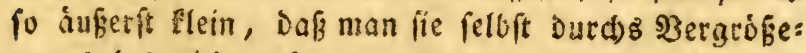
rungBgglas nidut erfennt. Rimmt man an, Daßj Der getftudelte Salmar dieje swei långeren Irme ebenfalls befitze, fo ftimmt Molina's ąct vollónmen mit Des 


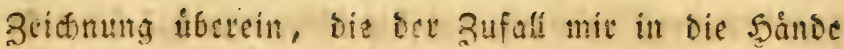
watf, und die idf bier fopire. Sollte ber Beidner

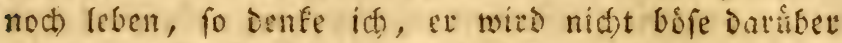

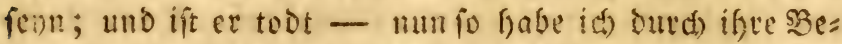
fommomadung peine abfichten befordert und einige 2 bu= men auf feir Birab geftreut.

\section{Der Tief = Galmar *), Le calmar reticulé.}

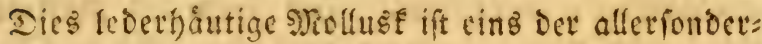
barften uns auferoroentfidffert der gangen Gattung; Denn feil ganjer fibrter ift, aufer in ber Extheide coder

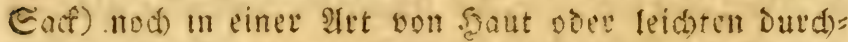
fidtigen lieberag, Dev alle Torben fdillert, eingejchlof= fen, uno wie in einem Septe eingervicielt. Motina bes

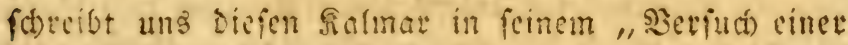

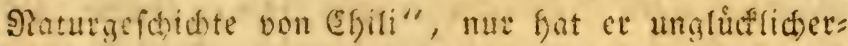

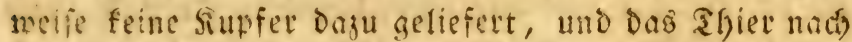
bem finne'iden Enftem mit Den Dintenfifden in cine

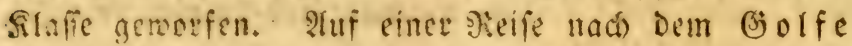
Irifte (sinem Ifocil Des sheers bei Therifa jenfeits

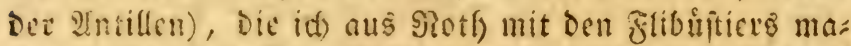
don muste, babe id Dicien Solmar felbft zu Gefichte befommen. Tá) fah aber nux cin einziges Indivioum; und aud bies mufite noch jung fenn, benn ftatt cins hundert und funfoig \$fund, wie bic fleinten Diefer Shiere, Die man an den fiffen von Shill föngt, wiegen,

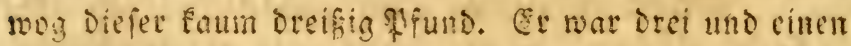
halben fonf lang, unb fatte fid mit feinen Edyropf= fopfen (Ripfdien) an ein Sthớ gefalzenes fleifh ans

*) ,Sepia tunicata. Molina, Hir. nat. du Chili; franiof. Litwerf. won (5) pore prorfus vaginante, cauda alata. Sepia tunicata. Linn. corpore toto tunicae nigrae pellucidae incluio, pofterius alis duabus femicinularibus. - Sèche noire, fepia nigra.6 - Bolc. Tom. I. p. 47. 
seflammet, oss ich an einem ftarfen eifernen Safen in Der Soffnung befeftigt und itber Bord gerworfen hatte,

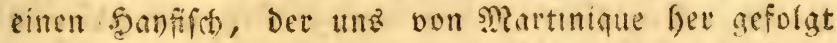
war, Damit zu fangen. Shein Sinture lief, feibfa da id) ifn empor zog, feincm sianb nidat fabecr. Sa

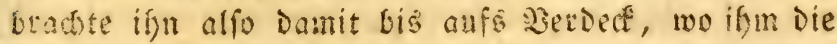
Flibintiers wegen feiner fawamen sarbe und fonders baren Beftalt Den Slamen "M? ecteufel" gaben. Saum fing $i(d)$ an, ibn nåber zu unterfuchen, fo ver= folgte uns eine fpanifche Sirftemmade; anfott ?atur= gefolicte zu treiben, muste ich mun zu Den sibaffen greifen und fedtecn. Das Befedit wutbe blutig, und

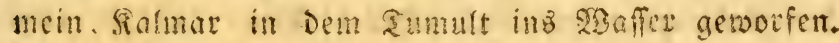
Stach fer babe id) nie wieber cinen von Diefer Osattung zu felst befommen.

şent (á) Den Mrolina lefe, fo fefle id Elan, mit

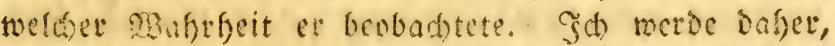
indem iof flete bie Seionung Diefes Salmarg licfere, feine Befureibung nisgent. Sud Dem, was ex fagt,

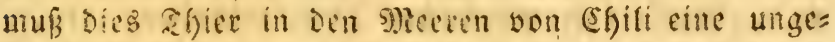
beure Grobe er!angen. Şa, is fobeint faft, als ob fich felge fetten fleine finben, und Dafi bie, die man Dout fangt, immer ungefäis cinfyundert und funfagig

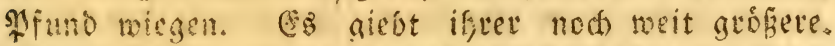

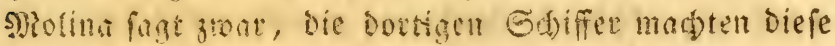

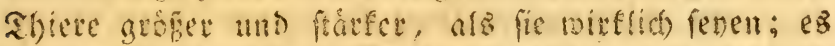

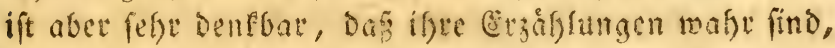
und Dafis Diefe Battung vom Silmar in bem smere bei

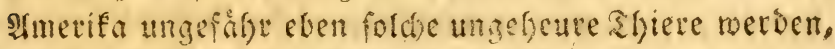
als Die Slolnpen ocs Pividmeers find.

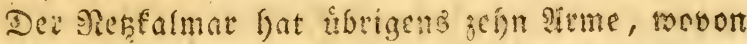
bie adht firrgen mit zwei Beigen gispfden bewaffnet fint. Der nbgerundete Stamm ser beiden längeten ift fury, und beide endigen fid in eine fdmale Reule, die auf ifrer flaten Eeite mit Surronftopfen verfefen ift. Der Sopf ift linglid), und Der Sannabel tagt fefte hers 


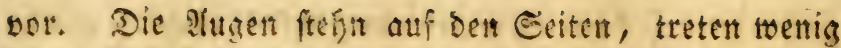
Geraus, find aber becit, und befinden fid oben auf Dem Sopfe. Die Ed)eive hat eine dunfle und patwatze Farbe, und ift trie bie ber ibrigen Salmars gebildet.

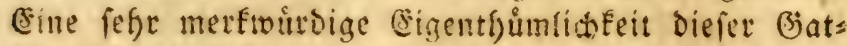

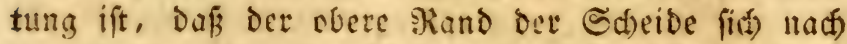
worne ju, twie eine biaienartige, butcfichtige und Durd Fafern gefaltene Saut ausiefgnt. Die Fafern

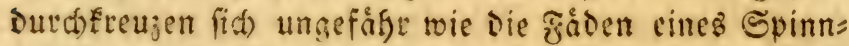
gersebes. Die crwáfynte Saut wird nach vorne zu bice nirib badsig, Defnt fid bann nach finten ju, wie eine

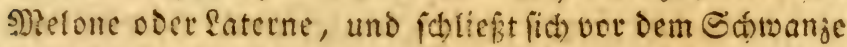

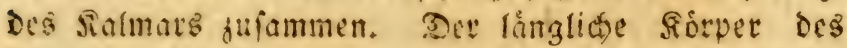

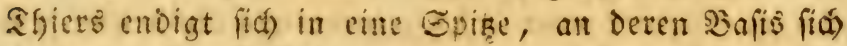
gtwei twie ein Salbfreis geformte Flingel befinden, Die

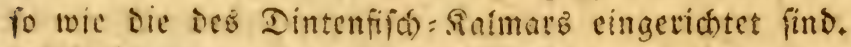

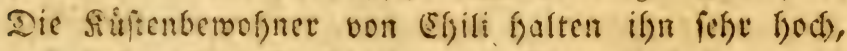

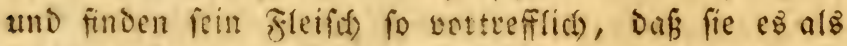
Secterbiffen geniesen. Sth habe aber auf Den Mårften in Den antitten nie ein folthes Shier gefunden.

Diejer fefre fortoerbare Salmar, befien Sórper in

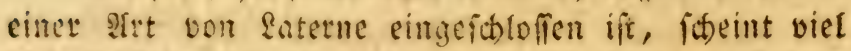

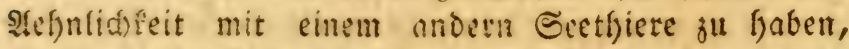
wonon Rmbrofinus ans in Der Cergainjung des alloros

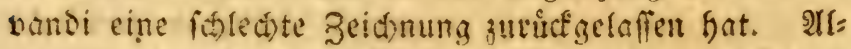
Drovandi, Diefer unermidoete (Sompilator, Gatte nămlia

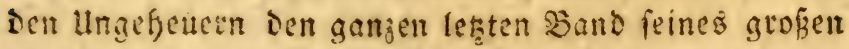

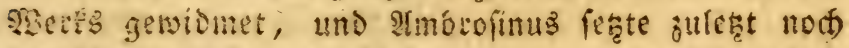

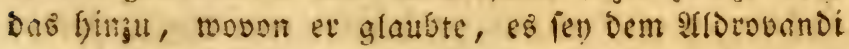
entrifút. Solit findet man nun unter Dem Famen: "Piscis reticula Nas" *) Das Bild eines, girdes,

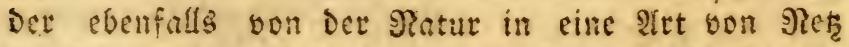
(grade wie ber Kalmat von Effili) eingeifloffen ift.

*) Paralipomena. hift, an, p. 95 u. 96 an Entbe des

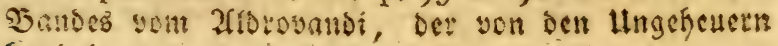
fanselt. 
fefn mit fintin, went fie anders nicht felbit sutifer In ver Naturgefobidte find.

\section{Dre Dintenfif : Salmar *). Le Calmar Sepiole.}

Dic Rften faben biefen Salmor nibt gefornt;

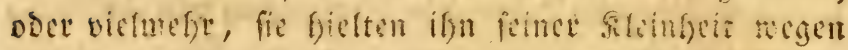

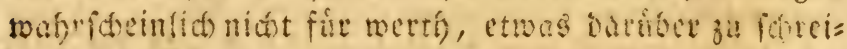
ben; Denn man fonn onch nidut annefmen, bof bits

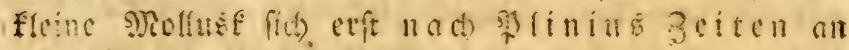

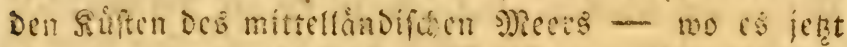
Bowon wimmelt - fo ungefener vervidfertigt baben follte. Fondelet emoifinte es zuesit mo gab ifm ben

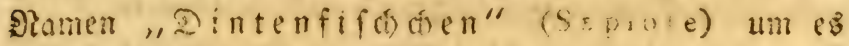
won den mitfiden Dintenfiten, mit welden ex es trot

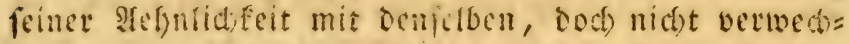
felt, zu unterfibeiden. Sile witd biefer fteine falmar

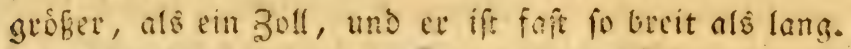

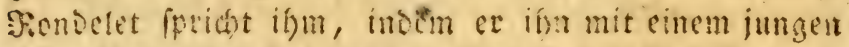
Dintenfif bet verleidft **), Den freidenatigen Rnoden vocr bie fornerte \$latte af. Eamare, Defien Meinung id) irgieid citiren twerbe, entDefte nad) peiner ge=

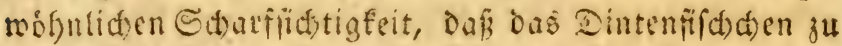
Den fiafmars gefore, und er fatte vollfonmen red)t.

*) „Calmar Sepiole, Lolig o S e piola. Lamark, ubi fuprap.16. - Loligo corpore bafi obtufo, alis fubrotundis, lamina dorfali li. neari minutiffims. - Sepiola. Rondelet. Pife. 519 und p. 375. Der fram. Edit. - Sepia Rondeleti i. Aldrov, de Mol'. p.63. - Gesner, Aquar. p. 18\%. - Ruyfch, Th exfang. Tafel $\mathbf{r}$. Fig. 8. - Ionfon, Exlang. Fafd r. ऊig. S. - S e. pi a Sepiola. Linn - Bruguiere, Encyclop Ta: fer IXXVil. fig. 3. - Sictine Braefifd oder Heiner Dintenfifob bei ben Deutfden."

**), Non quod ex genere fepiarum tir, led quod corpuris tom hepine fim tis fit pitciculus, quam vel lolighitus, vel polypis. "Rond, ubi fupra. 


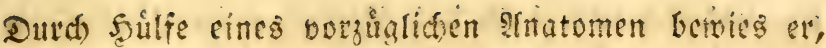
Daf das Dintenfiffoden zwar nue eine fefr fleme und fowad)e homene Whate enthalte, baf diefe abee boch Da fer), uno uns folghiof feinen gmeifel neiter libtig

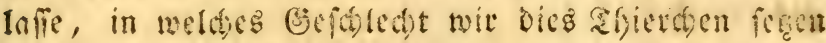
můfien.

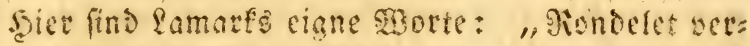
fichert, Daßs Das Dintenfifothen in femem Ginneten, weder mie die Dintenfiche einen fdroammigen sinodirn,

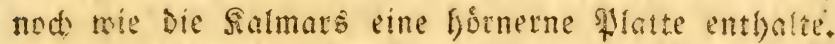

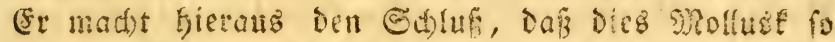

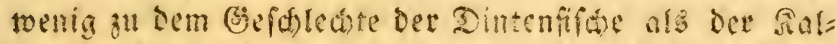
mars cefore; bof man es aber auth nidt

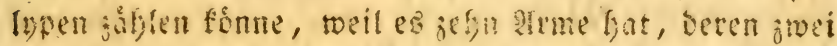
mit setulen vetfefn und lónger als bie ribrigen find.

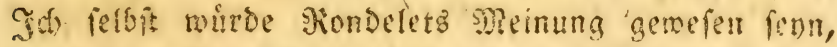
toenn feitie sibmerfung, bafs fis im Snneren ter Din=

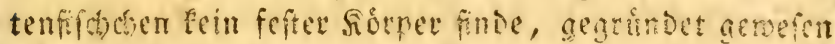

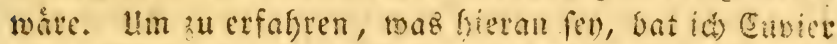
einige Nollusfen Diefer (Siattung ans sem noturbifrori=

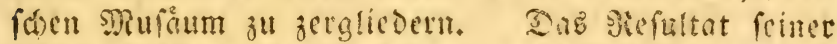

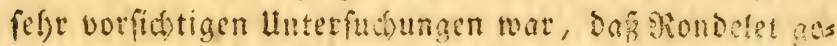
irt habe, wenn ex verfidere, bae Dintenfird den babe feinen feften firper in fids, Der bem anodien ver Dine tenfifde oder ber Platte Der Malmars álnnlids fer.

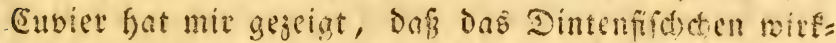
(id) cine bintune platte enthält, Die Dex Wlatte bet úbrigen salmars ånnlid ift. Diess suberden ift aber

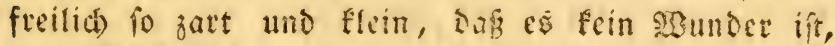
wenn Biondefet $e$ s nicht bemerfte."

"Der Dintenfifctéfolmar oder amergfarmar má)t

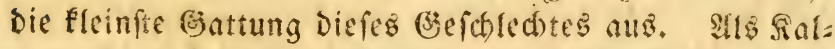

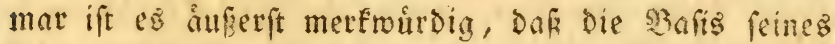
Sorper's fefir ftumpi und faft rund ift. Eein Sact ift an fcinem Kande unverichet und allf jeder Este mit cinem ơtugel oder runden sloffeder, die jiemtich grof 


\section{4}

ift, und fid unterfalb Des siandes inferite, oeriegn. Det Snorpel oder Die suctenpläte des Dintenfilid)dens ift ein febr fleitter, fefter, bornartiger, forträzlider, lineirter Sorpex, Der nach sorne fin eill toenig aus: gedefint ift *)".

Der Sopf Des Dintenifa falmars ift nidus fo Dict roie fein Sobrper; zefin sirme ftrecen fid obertbalb Der Augen, Die nid)t fefte fervosftefn, und ein wenig nacts binten gerwand fino, herbor. Die Yrme find jiemtich fury, und wie bie Irtme allex ibrigen Salmars mit zmei SReifen Nåpid)en befeţt. Die Stămme Dex jmei lån geren endigen fich in fleine und fure Seuten, Deser

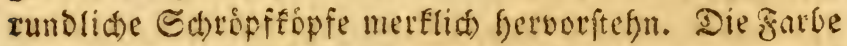
Diefes Salmars fällt Dutdyaus in Sellpurpur, roird nuf Dem rzaude toeifi, und auf Dem Bituten biel bunfler,

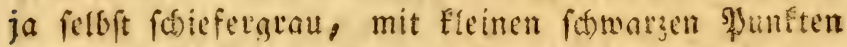
gefect. Die flingel, bie twie cin Sealbfteis abgetundet find, unterfideiden fid) Dur(h) ii)re Gitellung bon sint Fande (llmfdalage) Der Dintenfilde und von Den flus geln Der Ralmars, Denn fic endigen fid nid t mit bin Shroange in eithe Epitae, meil der Dintenfila)= Sals mar feinen Schanj bat, uno Det untere Ifyeil feines Sórpers felde ftumpf ift. Sie bilden zwei Defied)en, Die fid) Den forper Des fleinen Shiers entlang erfrecten. Die Dintenblafe befindet fich ebenfalls in Der Mritte Des

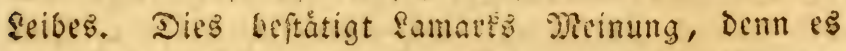
veturfacht, Dafí man unfern Salmar zu Den Dinten= fifforen nicht techuen Eann. BBei Diefen bat die Din= tenblaje unten im siorper iffen Siţ.

Die ztociundjwanjigite Safel zeigh Diejen Salmar in feinet noturfiden Grobe, Big. I und 2 von vorne und yon finten angefeben. Die oritte Figur zeigt uns

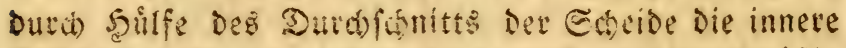

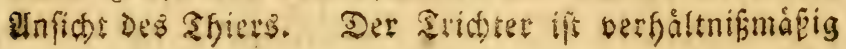
iefre

*2 Lamark, ubi fupra. 
fefre grof und geft fefre tief hinab. Cer bedectit das 2ienferfte Des Sinteftinums, Das fid foft mit ber Deff=

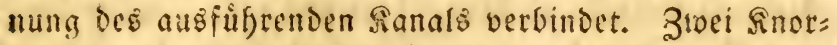
pel Dienen - wie bei Den ubrigen Salmats - ju bef= ten fü bie Edjeibe. Saz anfgeidnittene Ifier ife cin Weibún, twie man an Dem in Der Tiefe Des Snctis befindiden bierforte ficht. Sissiter in Dem Gónet binein erweitert fid bicfer (Sicrfecf fegr betrádhtlich),

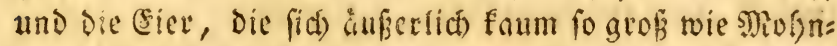
famen zeigen, nelmen im hinteren afyeile des fierfocts fo fefre ju, baf man iffer bon der Grópe eines grofent

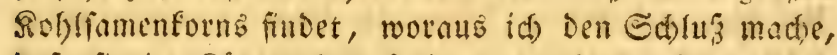

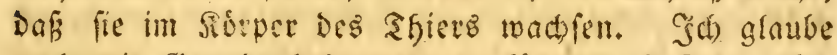

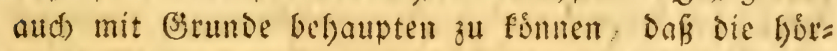
nerme Platte Des Dintenfif = Salmars viel grefer ift, als man glaubte; Denn fie nimmt, wie ein Syarnifd

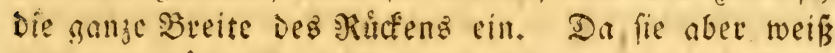
and jefe Dunn ift, und gans genau mit Der ăuferen Sout zufammenfaingt, fo foun man biefe foft nidfter: iffrnen, ofne jene mit zu jerfonneider. Doá) findet man

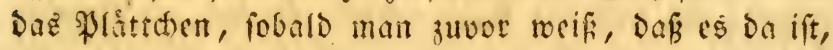

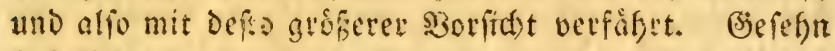
babe itf es; aber trof aller angerwanden serduld und J)kithe war und blieb es mir unmogliá, es auf ben Ceiten loşzumaden, ofgne e's zu zetreiffen. Dies ift

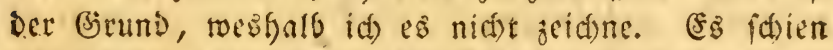

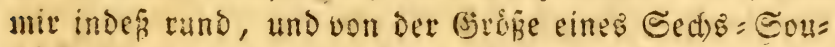

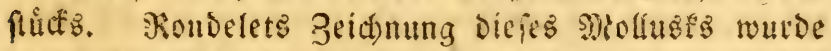
von alfen Sdyriftetifern nacheinander, bie binterfer von Dicfem Thiere redeten, fopirt. भlbrowand vers frippelte fie zuerft. (5r mad)te eine fleine faft form:

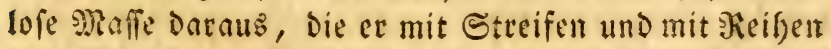
von Bieredien und \$unften verjierte. Alle die ifn wicber fopicten, ftellten Das Thier ebenfalls mefor oder weniger unfenntlit) Dar. S(t) verdanfe Dem Euviar Das Jndinioum, Da8 i

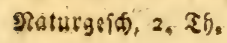


zeidfnet; und wie id) glaube, ganj Det Statur uno İafrneit gemår Dargeftellt habe. Das fleirch diefes Fleinen Mollušts ift fdumacthaft und zart. Man fångt Das Thierden am mittellåndifden Meere zugleich mit andern gifden in grofer SMenge; man firmmert fich aber, wafricheinlich rogen feiner fileinfeit, wenig Dorum. Dies Meer icheint aber auch Das cinzige zu fern, worin

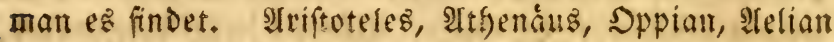
und Plinitus erwåfnen feinet gee níd)t.

Der Dintenfifufalmar madt Den llebergang von Den Salmars zu Den Folmpen. (jo lápt fich denfen,

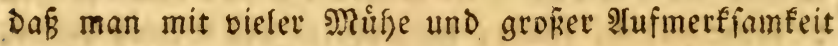

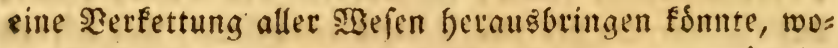
rin fie fid) Durd) unmerflid)e Ibmed) felungen gemád)lich

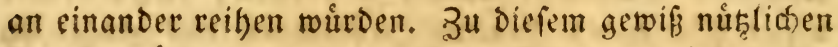

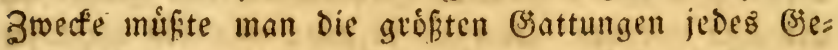
fd) lect) ts immer in feine Mitte feten, und ourd) fleintre ftufenteife bis zu ifgnen gelangen; Donn aber, weun man biefen grofien Mittelpunft erreidst båtte, wieder eben fo unmerfliđ) Durd) Eleinere (battungen finabrórt sิ geffen; wo uns bie fleinfte Dann wieder zur fleinften

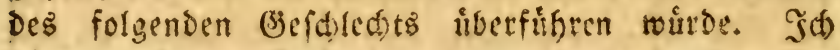

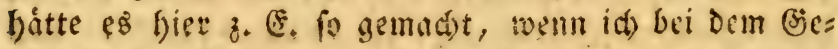
fatled)t ber \$olupen, daz nun folgt, mut cinet gand fleinen Battung, welde fić) an ben Dintenfifd) falmat anfalieft, angefangen, bie खiefenpolnpen in bie Mitte

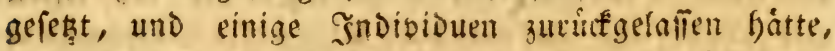
um mit einem Der allerfleinften 3 enden, ber fid) bann wieder ofne Eprung mit-Den Silto"s (ફltigefwiumetn)

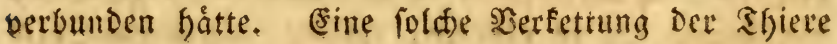
wurbe renigitens fefre angenefim, vielleid)t aud fefre nitslic fenn, uno fefre philofopfifore gefultate ber= vorbringen. Man muirde Daburch die S?atur in ifren

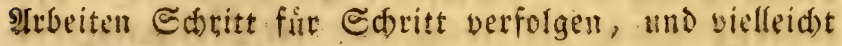
Den Beng ausffuren, den fie bei Đefcelung Der Mlaterie

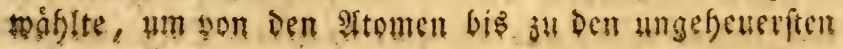




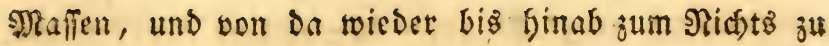
gelangen.

Iib rẹerde hier inder wenigftens jeigen, wie felse Der untere Sirper De's Dintenfifth = Salmars ifn Der (Beralt Der \$olnpen rábert. Ere ift abgerundet, wie Der ifrige. Sein Infefn ift dem iffrigen im allgemeis

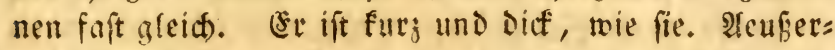
(id) unterfiteidet er fich nur Dadurd), Daf $\mathfrak{a r}$ jwei $\mathfrak{A r m e}$

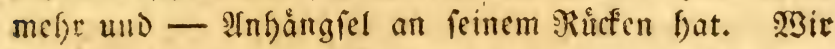
werten aber aud) auf Polnpen frofien, Die aujer ifgren

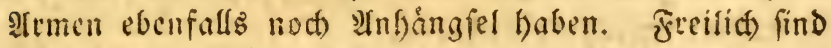

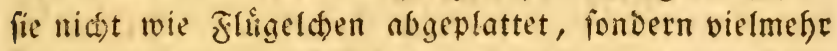
fonific) geftaltet, uno firfen aud nidst immer an bem= fellen Dite.

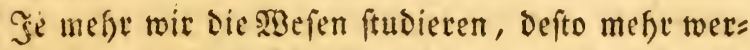
ben wir firion, Daß̉. fid alle untereinander auf mefre als sine sheife verfetten, und uns baduld betweifen, Dá̉ alleŝ ausgefúllt ift, uno dấ alle Materie fhon ingend eimmal aufgeregt wurie.

\section{Erflårung Der zweiuno;wanjigften Supfer. tofel.}

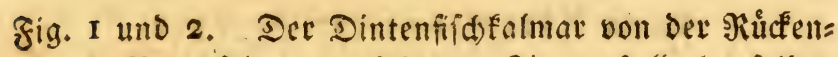
uno Baucheite angefeften. Fig. 3 ftellt Denfelben Salmar meibliden (Sefdiledits vor; feine Sdheide ift geoffnet, um bic innere snorinung Der Eingeroeide zu fefur. Der Irid)ter ift proportionirt fefre grof́, und bedecit das Inteftinum rectum, Dab bei biefer Battung fid nafe an Der Deffnung Des gemeinfd)aft:

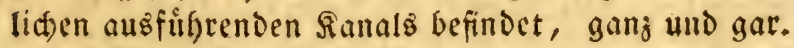
Hlm ifn fictbar berden zu laffen, mufite id fogar Den Trichter aufictneiden. Die langlicten Bruft= warjen am Fande Der Sajeibe merden, wie bei ben andern Falmars, Durd) Seúfe zweier fnorpeligen Såffuen befeftigt. Die fefte breite Dintenblafe be= 
findet fich ebenfalls untex Den andern (Eingeweiden, nafe bei Der Deffnung Des Inteftinum rectum. Zmei Riemen, dic wie bei ben sRollusfen von gleidem

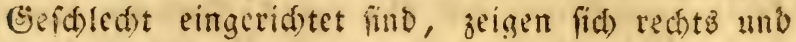
rinfes an Mantel befeftigt. Tigre Blatterdyen find aufereft fein. Sin breiter (sierftoc biloet ourch feine runde form den unteren Sfeil Des ßirpers, Dena ar liegt tief unten in Gacte. Die Eier, Die man vberwirts in Demfelben fieft, find, wie fhon bes merft roorden, bedeutend fleiner, als die, Die fir meiter innerfalb befindell.

\title{
Redergátige Nollusen.
}

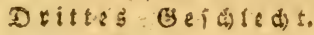

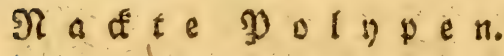

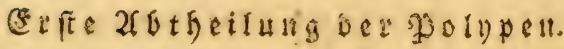

Der gemeine Moryp*).

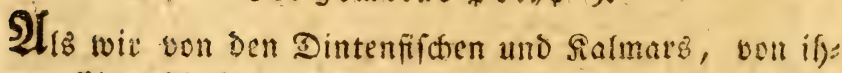
ven Eigenid)aften und bon ifrer lebensart tediten, fas

*) Octopus vulgaris. Lamark, Mem, de la foc. d'hift. nat. de Paris an. 7. p. I3. et Syft. des anim. fans vertebres, p. 60. genre 3. - Poly pus. Ron. delet, Pifc. p. 513. - Belon, Aquat. p. 336. Aldrov. de Moll. p. 15 et 16. - Salvian, Aquat, p. 160. - Gesner, Aquat. p. 870 - - Ionfton, Exfang. Tom. r. fig. I. - Kuyfch, Theatr. ex. Tom. I. fig. I. - Seba, Mus. 3. Tafel II. Fig. I.-Poly pus americanus pelagius.- Sepia octopus. 


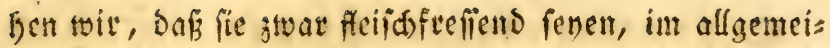
nen aber mef): Qift alš Gewalt anwenden, um fict) ifrec seute ju bemåcitigen. Die Ralmars finb evig thátige

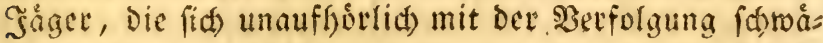

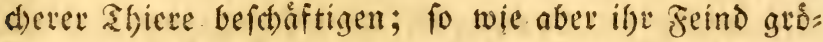

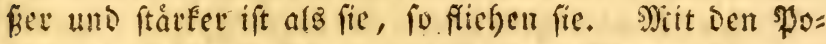
Inpen verfált es fich gallj nnocrs. Sie weidsen nie.

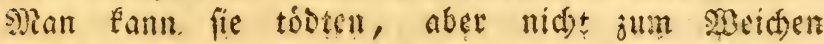
bringen.

Sinné ftellt bicfe Sgiere unter feinen Dintenfifden voran, Samarf aber nafym fie con ba finmeg, uns

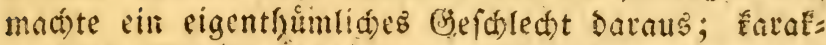
teriftifae Merfirtale gaben feine abtheilung getedotfer= tigt, und bie Erfafrung gat fie beftatigt. Die fienn= zeiden Deg Polupen find:

Linn. Muf. ad fig. I. p. 94. - Müller, Zool. dant prodr. 28r3. - S èche octopode. Bofe, Hift. nat. des Vers, p. 47. - Polypous Diz átifteteles. und 2tthenåus. Lib. 7. Diefer Pame chhielt bei Den

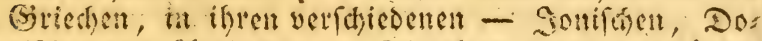

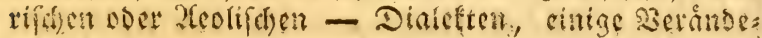
rungett.

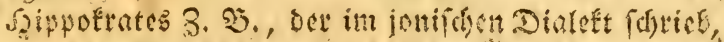
nent bie Jolnpert polypodes. - Anozeon,

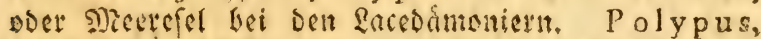
m Itipes, Octapodia, Catapodia bei sear fatcincen; Octapodi uns $C$ a tapodi boi sen S?en. griechen ; in iralidnifhen Polpo, in şenesig Polpo, in Gienua porpo, in Scscuna.pesce malattia, im Spanifáen Pulpo, in Micritanifan La uquentu, in Shrien hobotnizaza, in Sarbonte

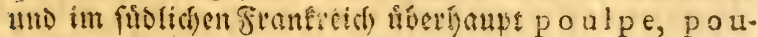
pe uno purpe, in ellififient porcuael, quid, preke, pourcontrel, in Deutflen Poinp,

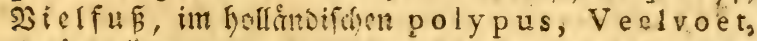
$\mathrm{Zuig}$ - fiar, in Silfiffien Kakatiza ober $\mathrm{Ka}$. rakatiza. 
Er hat einentunben sidper, ber in ei: nem Sacte ober in eituer $\subseteq$ deidecin gefdrloffen ift, hat abea bur dous fei

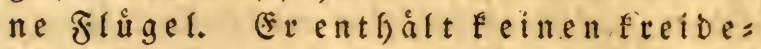
oder falfartigen anoden, nod eine hórnerne Platte. Alle haben nut a d t Irme, Deren (jeftalt nidit immer Dies felbe ift. Sie fithen oben am. Sopfe uno um den Mund herum. (Es giebt nade nno beibalte Polypen.

Rinne' folgte Darin, daf cr Den Polnpen den erften Wlak̨ antwies, allen feinen \$orgångern in Der Эaturs gefdidte. Aldrobandi *) thut das gleidie und rectst= fertigt fid Dadurd), Dafi er lagt: "Der \$oltpp ift bas edelite uno muthoolfte Shier unter allen Rollusfen.

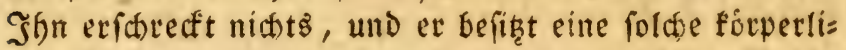

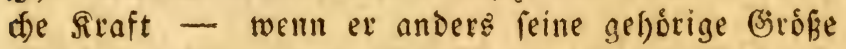
exlangt hat, - Dafer fich felbft gegen einen fónen mit (3)tuff vertfeidigen murbe. Mian hat \$olupen ge: fefn, bie Durdh einen Idolex gefaft uno in die \&uft $\mathrm{km}=$ por gehoben wurden, felbft in Der \&uft noch mutfooll mit ifrem Biober fámpften, ifn umflammerten uno sourgten**), Dann mit ifm ins şaffer ftur über ifn murden, ifnerfäuftell und verjefrten."

*), Qui a polypo inceperunt, ii meojudicio, rectius fesere, ob praftantiam et dignitatem, qua longe hic caeteris mollibus praecellit. Tanto inprimis corporis roborevalet, ut ne fortiffimo quadrupedum leoni (fi dareturoccafio) cederet. Quod fileonis faciendum foret, nil quidquam fortius praeftare poffet." Aldrov. de Moll. p. $\overline{6}$ cap: 2. de Poly. po.

**), Cum in faxum non admodum e mari eminens polypus aliquando correpens afcendiffet, ibique explicatis brachiis fumma cumvoluptate, quodfrigidatem- 
zeigt, und mit ber gróğten Faubaiev úber allés fierfállt,

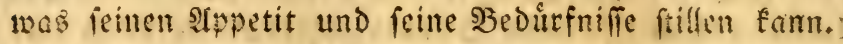
(er fósint Die Seefiften und Ufer vorzugglich ju lieben, und wifhit fich, ftatt bier und Dortfin ju forminmen,

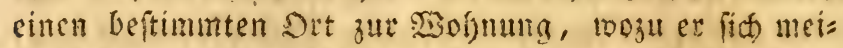

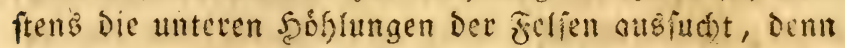
auf Den fandigen ufern triffe man ifn gar nid)t an. Gan

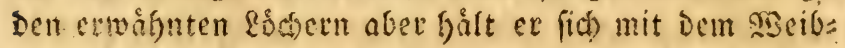
d)en, bas er fić) gewaiglt bat, auf. Sie bewofnt ges wófnfich bie Shaffe und fommt werig baraus hervor.

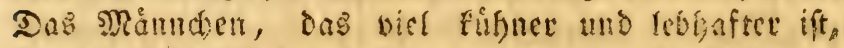

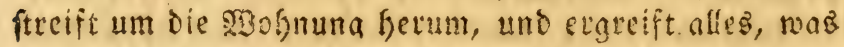
iffm begeanet; ja, es umflammert fognt mige als zis nen ३roub jugleich), uno fe,leppt alle's ju feinem rasib= den, um ifre einen Sfycil Der Seute abjutreten. Sie

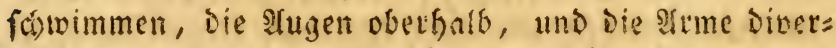
gireno ausgeftrefft. Sie ftitrzen vouswatts, und rid)ten

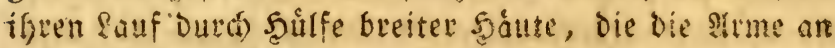

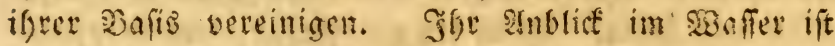

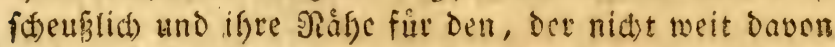

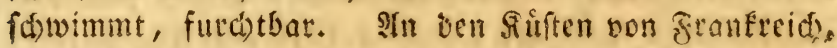
vorjuglid) aber ber Sormandie, teifft man sholupen an,

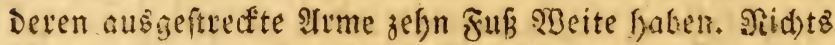
ift fo wellenartig biegfom, als bie Betwegungen Diefer Itrme, Die fith nath aflen Seiten anfrollen tno falten fonnen, aber nichts ift aud forectlider, als ifre 2 hn=

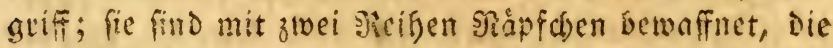
alles feft balten, toas fie eagreifen. Die Beute, die ein cinjiget Irm fajit, mird fogleid), uno zwat mit un glaublić)er Schnelligfeit, son allen fitben andern Stemen uminunden. Taufende von Soropsfopfan vereinigen ifjer Sraft, fich anjuijangen mit Den onaten, Die Durch

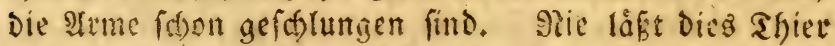
Ios, fo lange noá) ein febensfaud in bem (sefdiopfe ift, Das es fing. N\}an fann fich aus iften Sdlingen nidjt anders Getausjiefn, als baf́ man Den Wolypen 
zetfrucfelt. Det \$olnp ift feiter Raubfuctet toegen ber Siger Des Wafiers zu nemen. Wie diefer, moriet er

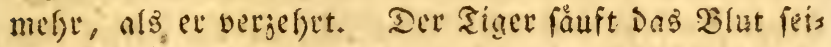
net Estachtopfer, verad)tet aber ifre strifá); gerade fo tobtet ber siolyp alles, was ifm vorfommt, und

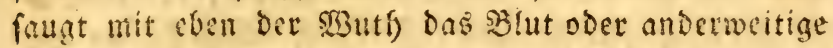

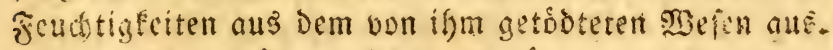

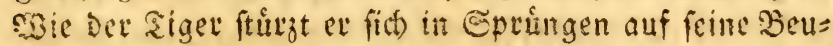
te los, uno feften ober nie verfeblt ce fie. Sit das Sfier, beffen ex fid bemadtigt, ftate und lebfaft, und mill es fein seven vertfcioigen, fo flamment ber \$olnp

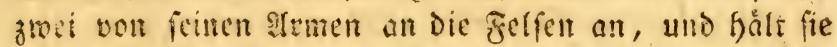

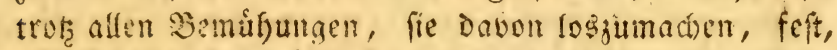
uno mit ben feás ábrigen umftammert, prefit uno ers

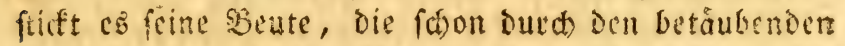

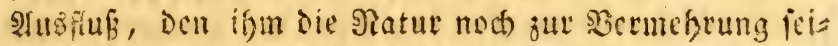
ne: Siraft gegeben hat, etftart ift.

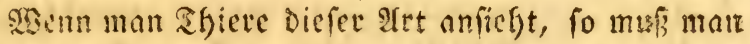
fait auf Den (Bebanfen geratisen, Daf fie zum Berftoren grfoneffen wurben; eriftirte dies \$pordgefes nicht,

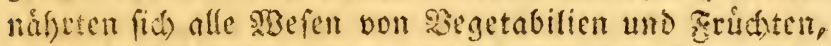
fo mitroe die crove nicht fo oft mit Blat bedecft werber,

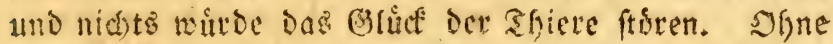
Futd und sual fonnten fie if)e Scbengzeit finbringen, Das Cno Derfelben ulfigerwarten, und das ganje $f e=$

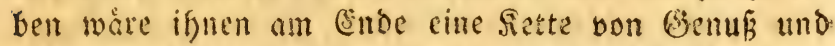

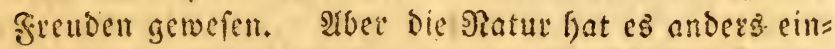

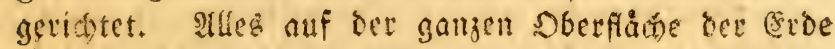
wird verfalunger. Die ganje belebte 3 Belt focitit fich felbft vernichten ju wollen, ung alle Bijieve find biefert Befetcen Der Zerftormig unterworfen. Dody fint fie

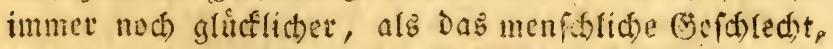

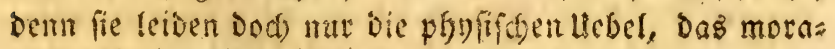
fifde fimmert fie nidst.

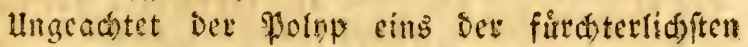

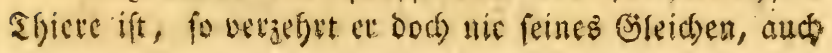




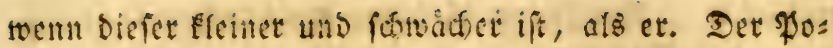
Inp motdet nid)t blok im Necere; er geít bis̄meilen ald Dataus feroor, ouf bie Ruften und in bie Felien *), Die bei Der Ebbe troffen jutudfoleiben. Bejonders

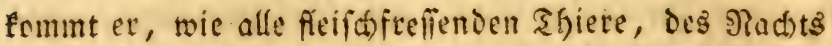

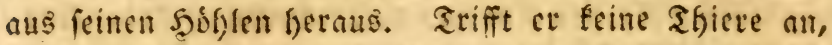
die er verzefren fonn, fo flettert er nid)t feltell buta) Şulfe feiner biegiamen Itrme auf bie şäume und brid)t fich frudbte **). Iuf ber Erde fdjeint er indek ben

*) Suite des extraits du porre - feuille de Dicquemare; Iournal de Phyfique, 1788. 2. Theil p. $36 \mathrm{I}$.

**), ,Nec minus etiam in eo laudabile dicemus, quod terram petat, et afperapera mbulet loca, quod profecto nulli ex mollium generia natura datum est. Sic enim duplicis (utita dicam) naturae videtur particefs, ut cum pifcibus et terreftribus quadrupedibus convenire poffit." Aldrovandi, de Moll. p 8,

"Et alibi polypos et osmylos in finum egreffos acftivo tempore, ex maritimis arboribus frugiferis fructus fubripientes (icandunt enim per truncos, et ramis fe implicant) faepe agricolse et deprehendunt et prodireptis fructibus poenas ex comprehenfis fumunt, et pro commiffo ob eis furto, fructuum dominis ipfos ad epulas adferunt." Aelian. lib. 9. animal. cap. 45.

${ }_{35}$ Ex plantis olea delectantur, ejus trun. cuin flagellis amplexos faepe offendunt." Athen. lib. 7 .

,Inficcum exire nonnumquam vififunt, afperis praecipue locis, laeves enim odere." lbidem.

"Polypus (crura enim ei quam caeteris longiufeula, et gradiendi facultate praedita (unt) exit in ficcum, graditur per afperiora, vitat laevis." Arifor.

${ }_{29}$ Exeunt in tersam, er qui maxini sut 
Menfulen zu furcisten, ungeadtet er im 23 affer mit ber

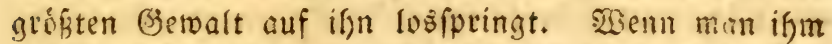
auf ben fiuften begegnet, fo bläit und idunardter, uno weid)t jutitcé, fdingt mit feinen frummen Ifrmen auf bie crie oder gegen die felfen, und breitet fie aus, wie cine lange \$yeitidhe; Der fuffnte Sund fürd)tet fid) alobant, auf ifn losjugefien, ber poltnp louet nach beiben, indem er zugleich dem Menf(hen zu entgeher

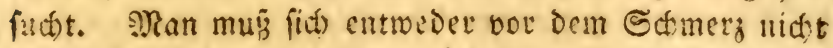
furchten, oder mit einem tichtigen Stocfe bemaffnet fern, um fid feiner bemåchtiģen zu fónnen. Evreidft et einen felfen, und fann fich Daran anfleben, fo ift $e^{2}$ unmoglid, , ifin Davon hinweg iu reisen. Sft fant man $\mathfrak{c}^{8}$ nur ftưf

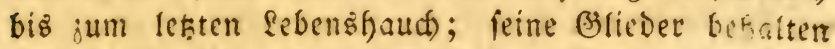
felbft Dann nod), weun er todt ift, und fie vom sidrper abgeriffen find, das 23ermegen feit ziu halten, und zu vertounden. Dicquemare fagt ficoon*): "Diefi Édripf: fipfe befanden fict zwar an Itrmen, die nachaemadjen maren, aber fie fetzten fich fefor feft an, fo lange daz Shier lebte; ja, felbft alŝ ç̊ todt toar, und id fie auf meine Sand legte, fingen fie fid nod) fo fejt an, toie

res vocantur, et polypi, et muraenae."6 Plin. lib. $9 \mathrm{cap}_{1} 19$.

"Polypo pedes funt vix hac appellatio. ne digni. Ita enim in folido fub aquis ingreditur, ut humoris beneficio fufpenfus fluctuet. In ficu a mbulatio cum pul$f u$, et tractu fiat, alterum folum $\in f t$ in polypi motu; qui neque greffis, neque reptis eft, tractus fcilicet, acetabulis enim jactis procul, ut cuique applicuir, id apprehenfum tenet, tum bracchiorum contractione corpus admover. Ita fubvehit fefe in eam.partem, cui adhaefe. rit." Scaliger, Exerc. 218 .

*) Iournal de Phylique ann. I784. etfter इநeil, p.214. 
es bei Dell gróferen ber fall ju feyn phest. Sas fino

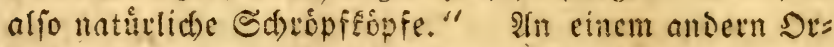
te *) fagt $\mathfrak{c r}$ : "Dos blope Şeviffren eittes biefer

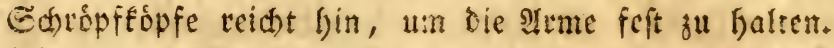
Die gleid)e 2 sitfung findet auth ftatt, ment felbft bas

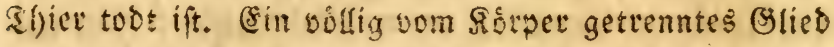
ummand mir cimmal ben 2 rm fo feft, bas rothe und weipe frlecfen barauf entitandem. Ein anderer Polnp, Der fidon vertwundet war, entidistufte mir unter cinem Felien, unt bielt fith Dort io feft an, baf id lange

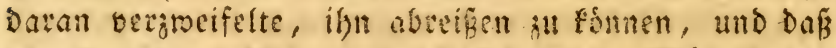

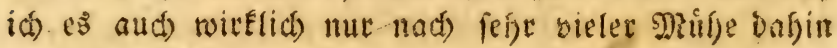
brad)te."

Ta) Yabe Diefe Gattung von Polnpen ebenfalls auf Den Ufern von Sabre, sie Dicquemare bereifet fat: te, beobad)ten founen; ber \$olup ift bott jeţt jwat nid)t mefyr fo håufig, als ocr erwálnte Belehrte verfi= dhett, Daßs er e's ju feiner Zeit wat, aber id mat bod) fo glidefid). mefrete auf bem Strande, und jwei nlldere im Mletre anjutreffen, von weldsen leteteren ber eine mich beinafhe umgebrad)t hátte. S(d) fudtete allenthalben

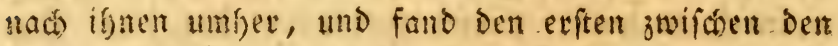

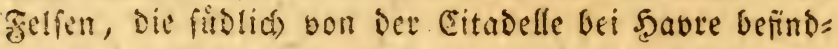

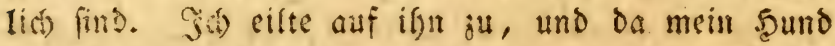
votontief und ifn necte, fo fonnte er nidst entfliefn,

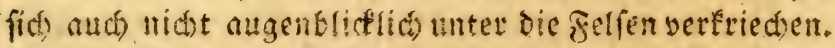

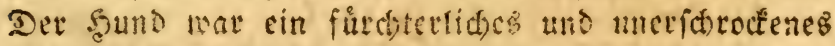
2lier. (er wid) nic, nuth wem bse Ingreifer nod) fo viele waren. $23 \mathrm{enn}$ cr in 23 utf) gericth), fo wat id

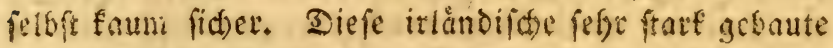
Dogge lief immer um ben plofyp herum, bie id daju fam, und ifn beim Sorper zu faflen fuctete. Das

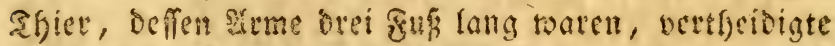

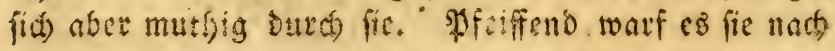

*) lournal de Phylique ann. 17\%88. gustet Theil, p. 372. 
allen Seiten Durch bie fuft und haute mit thitigen \$eiffdenfflagen nad bem Sunde. Sn feiner MBth

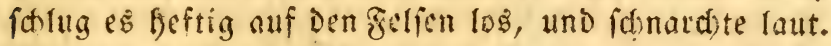
Meine sinfunft aber fotien es in serlegenteit zu fetzen,

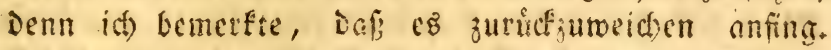

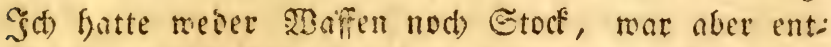
foloficn, mid) bes Ifiers zu bomeiftern. G(d) nof,m Dafjer cinen Etein, bor grofker wat als cine Souft, und warf ifn in Die Mitte Der Irme. Mein Sund

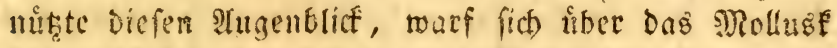

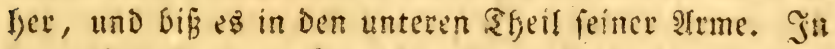
Demielben frtaenblick wurse er von biefen ummunoen.

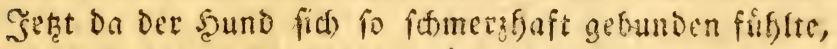
wutde er unbeichreiblirs mitgend. Er beulte, und

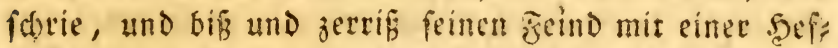
tigfeit, wie fie mir nod nicht, felbft nidst in einem Siampfe mit einem Wolfe, wo et Sieger blieb, an ifin vorgefommen mat. Det Şund und ber Tolyp bil:

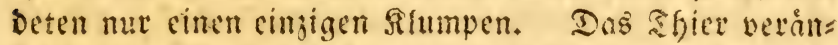
Derte feine jarbe; wábernd feiner $23 u t h$ nafm feine Scaut alle Cabattirungen an, vom Dunfeffen Siolett bis zum lebhafteften Sioth), und trob Den Stcinen, roomitict) es twatf, und trot ben vielen MBunden, die es erfielt,

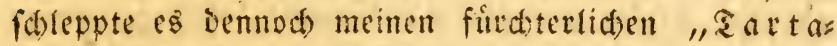
$\mathfrak{r} u \mathfrak{s}^{\prime \prime}$, Der ein zmeiter Eerberus beifen fann, mit fich fort, in ein Felfenlod). Seine \&ebenggefagr beptimmte mict, id toarf mid) ůber Den Nolnpen l,er, griff feime

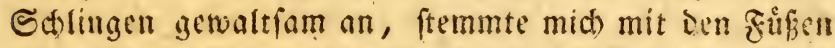
gegen Die Feffen, uno gelangte fo Dafin, feine Arme

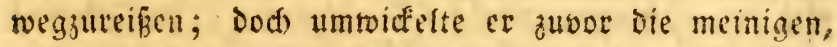
und verfud)te autd mich feftzuffolten, ungead)tet feine Arme Durd) Die biffe Des Sundes fcton falb von feinem Sisper abgerilien raren. Sicrdurd rurde ber Sund frei; er fonnte fid nun felbft los machen, lief aber dod

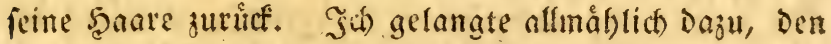
\$olnpen ftucf reife aus Dem Sods heroorjuzicfon, worin 
mein Sund wirde begraben warden fenn, went es

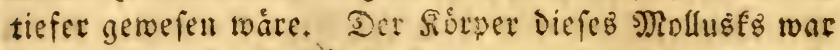

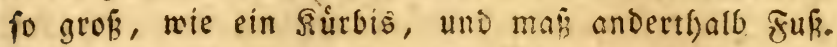

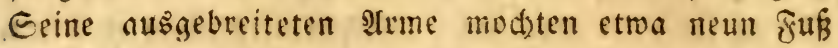
SBeite haben. IIts es todt mar, fomme Der Şund nicht aufforen es ju jerreiffen. Er Geulte vor şuth. Saum lief et midh einen atm Des Sfiers mitwegnefmen. Anf Dem ßuctwege nad) Der Etaot befam er nod cinen Infall oon Zorn, feftete wie ein \$feil wieder um, un Die noch ůbrigen æefre feines gefälurfichen feindes găuz= (iid) ju vernichten. Sin Der Nacht jerftúcfefte er auch

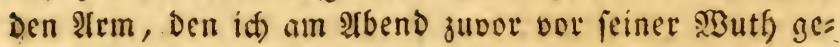
rettet hatte.

Seit Der Beit fuchte i(f) nie wieber Shiere Diefer

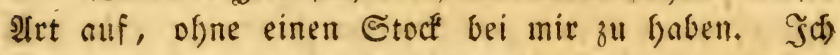
fano noch einige, aber fleinere, bie fich unter Den. Fet fen verftect hatten, Durd Sullfe meines Salltdes. Dann nber lief id Dis grofite Rebenszefafor durd ein foldes

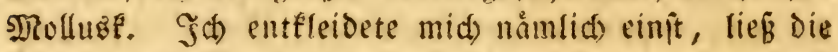
Sleider auf Dem ğelfen bei meinem seunde, ging ins SMafier uno fdwainm unfyer. Die Euft war vollfommen frill. Das $\mathfrak{B a f f e r}$ war der Jafreşzeit gemåz hinrei chend etwármt, fo daf bie Eeeanemonen und Miedufer alle ifre Straflen ausbreiten fonnten. Sal) gab genau auf ifre Bemegungen, auf ifre (Entfalten, und auf iffe

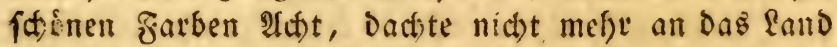
und glaubte ein $\mathfrak{B a f f e r b e r o f n e r ~ j u ~ f e r n , ~ w i e ~ f i e . ~}$ W3ar ich muide, fo fetcte id midh auf tie Felfen, wo

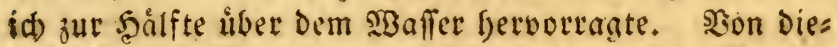
fem Standpunft aus blicfte id ůbet Die Soerfiacte bes Neers hin, ob etra irgend ein Mollusf, cine Medule, Doev fonft cins anfäme; wo id Dann fogleid) Dafin,

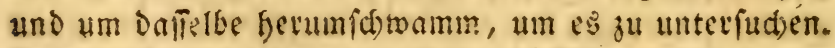

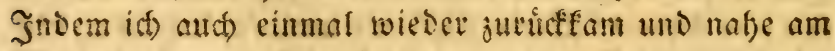
Mertufer mar, falge id unte: einer Fetfenipalte im

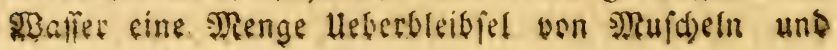


Sruftentfieren, bie unten an Tolfen, toie angeleimt fdienen. Diefer enbliuf madte mir viele freude,

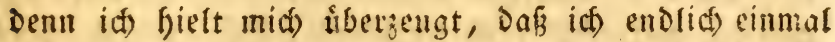
eine Polnpentioble oder Neft, movon Iriftoteles *), Sllinius, Aelian, Aldrovandi u. i. m. jo viel fprecten,

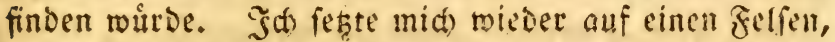
un mich ausjuruben, itserlegte lange, und verfelglte mir bie (jefabr nid)t, die id) Inufen wurde, menn ich

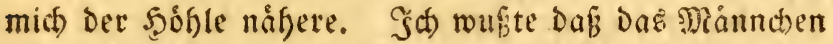
um Das sieft herumftreife, in reldem fein 2 Beibden

*) Dran trifft in Den Polupennefrern cine Dzenge zers brothener Mnifteln an, Demn fie leben von Murfsen

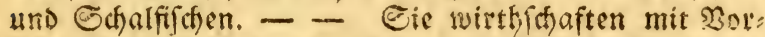
fidt, bemn fie fdleppen alles, was fie fangen, in ihr TReft. Scaben fie Dab Fleifh gefrefien, fo werfen fie Die Schalen umber, und halten fid im Sinteryalt ver, fted len etra fpiclen. Plinius, Hift. nar. lib, 9. cap 29.

„Polypi habitaculum, dederunt Home. rus A thenaeus et Aelianus. Latini qui. dam nidum, alii rectius cubile ransfe. runt, hoc enim fibiftruit polypus, non folum pariturus, fed alias etiam, ut putat Zoographus. Conchas tenuiores fcabragque efficere circum fe, velut loricam du. ram, eamque modo ampliorem, quo ipfi funt ampliores, atque de ea quafi latibu. 1o aut cafula quadam prodire aiunt, inquit Ariftoteles... conchylis maxime ex. tringentes carunculas vefcuntur; unde fit, ut eorumcubilia cognofcent, qui venantur congerie teftarum. Idem ex Arifrotele fcriplit Athenatus in librofepti. mo." Aldrovandi de Moll. p 2 I.

,Polypus foemina modo incubat ovis, modocavernam cancellato bracchiorum implexu claudit. Artificiofe haec exitru. cta et circumjecta concharum tenuiorum et fcabrarum eongeries velut lorica dura erigitur." Ionfton de Exfang. 8quat. p. 5. 
(iid) fortonaternd befribet; ids wufte aud, baf id oon iffr nicht greife, war aber auch liberzeugt, baj, fobald id $e^{3}$

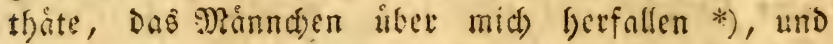
mich

*) „Trebius Niger, cine: Der Etattbaiter Des \&ucius

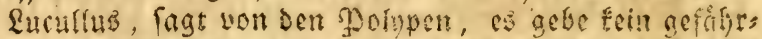

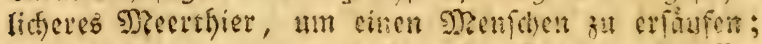

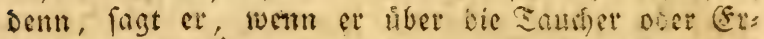
truntenen berfálft, fo umflammect er lie, clobsolite er mit ifften ringen, und mit ten vielen Midififen an feinen 2frmen fouget er fidf an Dem Doenfichen on, als

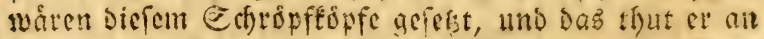
fo viefen Etelfen, Dấ es ifgme endidi gelingt, Den Mins fithen zu boben ju jieben. Plin. Hift nat, lib. 30. cap. 9

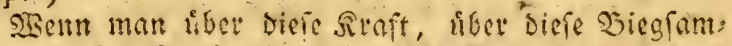

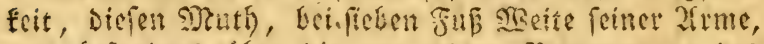
Imb Geforber gro Ben Socerpolypen nabsomet, . . . To zittert man,

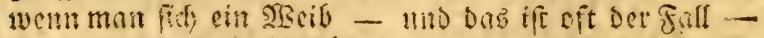

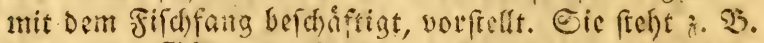

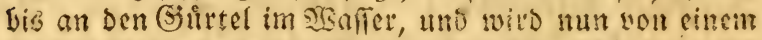
folden Polypen anden beinen ergntiffen. Sie fam fids nid)t los madien, fie mus alfo untommen, wern nidyt

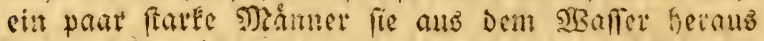

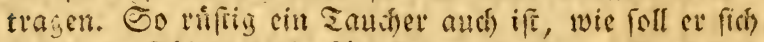

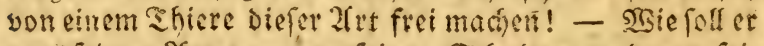
bon feinen Ifrmen, bon feinen Sdhultern uno won feis

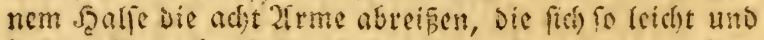

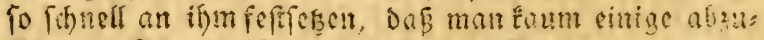
Iofen im Etambe if́, und daß man Edimetzen empfin.

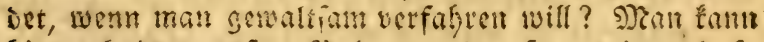

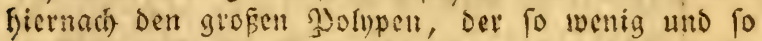

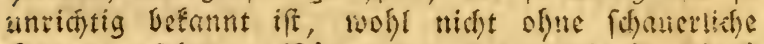
Ioren anféfen. (Dicquemare, Iournal de Phyl. I788 3reiter Theil, p. 372.)

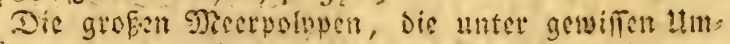

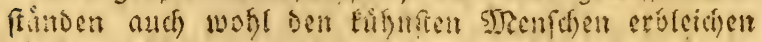

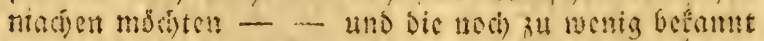

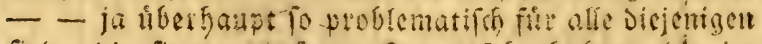

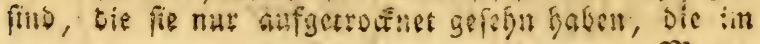
Miecte, 
mich mit feinen Armen, Deren leifefte Berifirung ich Durd) Die grmadte (Erfaforung furdeten gelernt hatte,

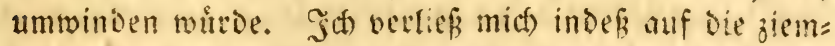
lid) grophe firperlid)e Ëtárfe, Die Die Sintur mit gob, Die meine landiche (exriefrung vermefrte, und die durth Reifen und Befdretden aller 2lrt nod) mefre geftált wurde, - und forwamm rieder jurufu, un ben feind

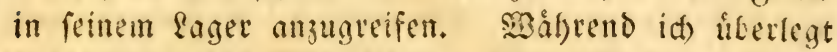

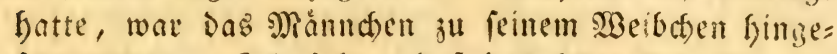

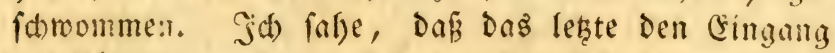
zur sobfle verwaljte und das andere fich ein twenig auf die Seite neben ifre, tedsts won Dem Felfen, morauf fie fá, juriớgezogen hatte. Sab fotwamm bis etwa

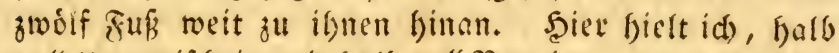
voll Ungerwigheit und halb voll Neugier, an, und fuct te mid) auf Der Dberfiad de Des $2 B$ affers empor zu balten. Эa) foffe die Bewegungen meiner Polnpen beobadten, oder fie irgend etwas erfafden fegn zu fornnen; aber Das sinamtien liefa mir Daju feine zeit. Sin Deci Gpringen fam es auf mich los. SEergebens taudte it) untet. (5) ergriff mí) in Dex Mitte Des Sorpers, und

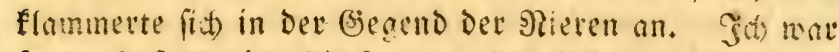

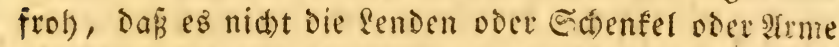
umid) Lungen hatte, und fatmamm eilend nad) Der nahen Rifte. SRach cinigen Inimuten fafite id) (Bruno, uno

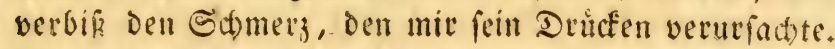
Der \$olup liể mid) nid)t faftere, fondern unflammerte

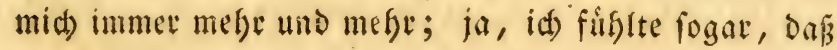

9) Teere, gerabe wie ber Tiger auf bem Lande, bie libri: gen ₹biele verfoigen; und Denen id) bis in ifte fedblen nadiging; Die Jjolinpen, fage ich, Deren vom Sidruer abgefonderte (silieder mir noch die folnde mit cinct folchen Gienalt mmoinden, Daf bie feaut toth wivo, ungead)tet ich fdion ifpe singemeio abjertine. (Dic. quamare, Journal de Phyfique, 1783. 3toeitet Shoil, ธ. 336.) 


\section{2}

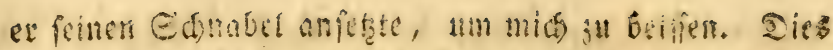
májte Denll bod - id fonn es nidt rangaen -

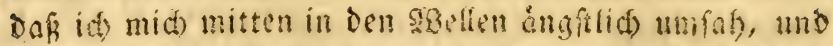
meinen feins, ben id mit mir fortgerte, betradtete.

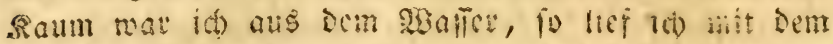

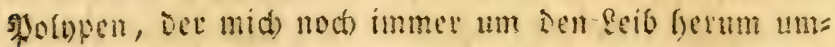
(d)lungen Gatte, uno der mich leid)t gatte toberen fonmen, auf Den Her bin, fog gu meinen filetbern und ju mei= nem Seunde. Diefer merte baf ich fom und blicte

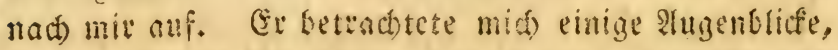
Dam modhte ex Das Shier, Das idi) trug, bemerft, und Die Gefabr in der id miás befand, begriffen baben; genug, ex frang fonell anf mids z"l, uno lief unauf= bórtict) um mids ferum. Da ić Den polppen gern $\mathrm{er}=$

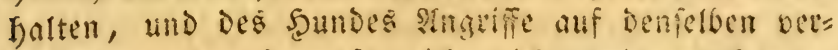
findern wollte, fo mafte ít mich, wie $\mathrm{er}$, fermu= Drefgen, und ifs mir abrefteren, weit er in ber 233 uth, mić) jul vertfeidigen, falt miá) felbjt gebiffen bătte.

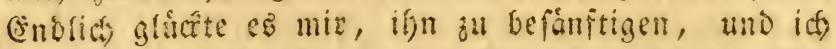

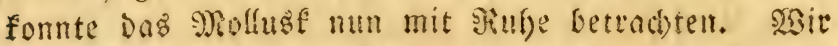
waven nift merte im Meere, fondern auf Dem sande.

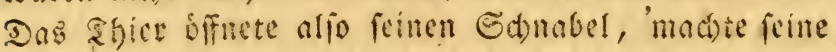
srme los, fiel auf bie' (erbe und felle fid todt. Sin Der Eegend meiner linfen Picte bhatete ich, und werde

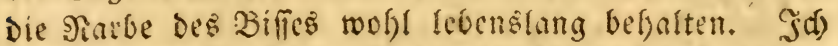
Gatte meinen Etorf ergriffen, und tobtete ben \$olnpen,

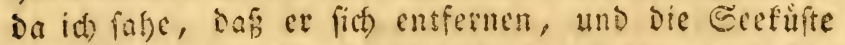

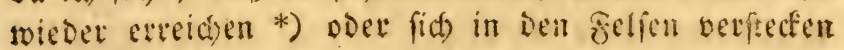

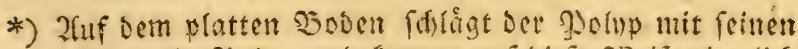
2t:men cin Siad, HHD fommt auf biefe secife zientith fdesell fort; biet ife aber bei weitem nid)t to ges

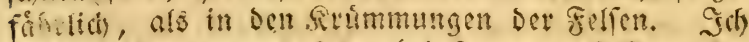

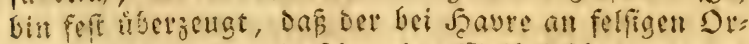

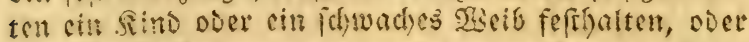

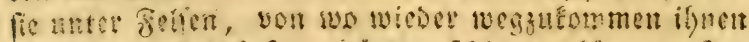

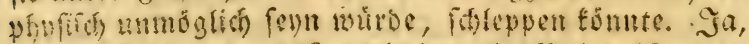

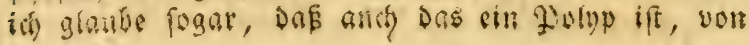


woilte, mit einem Ectage. Sob båtte ifn getn mit nach Sauje genommen, um ifn zu zergliedern und zu ftuditen; aber id wollte Dod) aud, wo móglich, Das Sisibden baben, und ifre Seft betwad)ten, wovon alte Satrifteller *) fagen, dab es mit (Eiertrauben, die

Den Thevet, - inbem el von einigen Gegenden in Zlmerifa redet, - fagt: "In cinem gewiffen See firtoet fich unter andern fiffjen cinet, Den dic Eins wofiner thebuch oder pontarot mennen, wet:

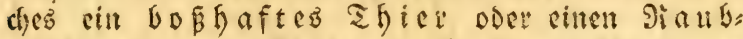
fif be bedentet. Eie nement ifn lo, useif er immer nahe am Secufer lauert, ob fich etwa cin fieben ober achtjåfriges Sind bade, odev ob viefleidht eine frau

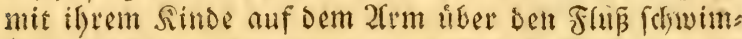
meit mơdite. So wie Der Fiff) Das Sind gewalit

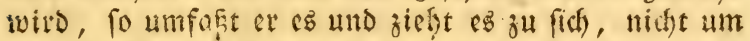
es zu frellen (Dem dies thut et nie), fondern Damit zu foielen. (Et macht cb Damit gerade, wie cine jun= ge Sâe mit cinet Maus. Eomberbar if es, Daß́ et eb bals empor bebt, balb finten lápt, balo in feine

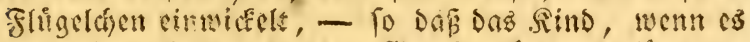
nicht balo beftect bitb, Gefabl lauft, etfouft zu weroen; fobalo es tost iff, fummert er fich nicht weis ter Dartum, fo bấ alfo fein $23 \mathrm{crgmigen}$ barin zu be: fteben fobeint, Daßj das Siub ficí) bervege, uno fich ihin zu entzicten frebe. Dicfer fifd ift ungefort fo

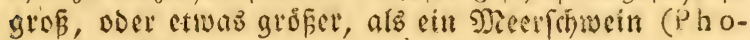
caena Marlouin), ood) nidit fo lang. Ecir Sopf ift runo uno feine Dlien feben Dicht am Sopfe uno fino beftánbig ausgefpannt. . Die Sannibalen verabjtheuen ifft fefr, weil cr fo mit iffen Sindert umgebt; fie whirben auth um alfer $\mathfrak{B B}_{\mathrm{B}}$ lt willen nichtz Davon effen, fo whthent fie ifn auth aus giad)e tit ifren Ranots verfolgen." (Thevet, Cosmogr, univerfelle. Tom. II. lib. 22. p. 955)

*) "Deponunt a t incavernis... aliove cavolocofimile quiddam labrufeae fimilis, et candido populi fructus. Edita ova dependent ab ambientibus fpecum parietibus, tanta copia, ut exempta, vas implerent longemajus, quamcaputipfius, in 


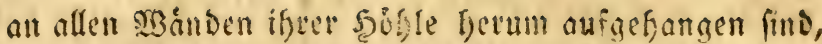

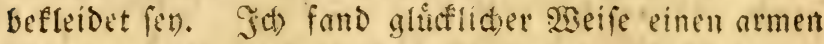

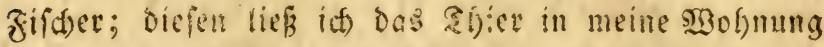
tragen, wo ib dem am waend, nadtem id es aus= einander gevicfelt bates, fand, baf bie beiben entge= gengefecten \$unfte feiner âtme fünf fuf weit ausein= ander ftanden. Sacare es grúber getwefen, fo hatte es nida vielleicht fefrgefialten, und ibermunden; denn nad) Der (serwalt zu ultheilen, - womit es mid). Drucfte,

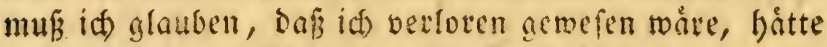
id) es mit einem grofizeren ju thun genaút.

Da mir Diefer glictiliche Aruggang Muth gemad)t

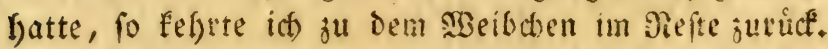
Sie befand fich noch auf Der gleichen Stelle und idtien gat untubig tiber bie Abwefenteit iffres Månnchens. Sie war ebcu fo ftact gebcut als jenes, und das llm= flammern bes erfteren mad)te mid) bech angftlich in

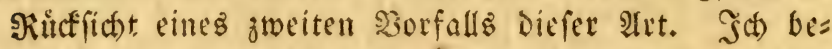
fd)lok alfo ifrem Ingriff jubor ju fommen, hob einen Stein vom Sirunde empor, und rarf Damit in Die Mitte ifter Arme. Aquenblicflich rollten fich Diefe jufammen, und bebecten das ganze afhier vellig und Didat. Dann zog es fict) tief in feine Soóhle zuride, wolfin id ifm nicht nachfolgen wollte. Jab verließ es alfo, madoem id) feine 230 fmung zuvor natge genug befefin hatte, um mit Siduerfeit glauben zu fomen, dak feine (Siertrau= ben "an Den sisanden bes গieftes aufgefängt fern, und Das ganje Junere befleideten." Und Dod) war $\mathfrak{e z}$ in

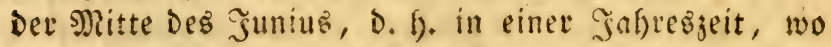
แan bišweilen \$olnpenciet auf bcm Sande, und in

quo ipfa continebantur." Arift, Hift anim. lib. 5. cap. 18. angefuhtet von Jonfton, de Exfang. aquat. p. 5 .

"Polypus foemina modo incubat ovis, modo cavernam cancellato bracchiorum implexu claudit," Ionfton, ubi fupra. 


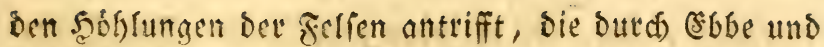
Fluth dafill geworfen fint. Da aber meine Beobad)s tungen in Diefer Sinfidte nidst zureidend find, und ree gen Der wefentliden Befalyr, in welder id lidrebte, wenn id) mich mit meinem Sopfe fo fefl: nefferte, Daf ict) von einem arme des Sfiers ergrifen meroen fonnte, aud moht midit fern fonnten, fo laffe id die Sadje unausgematht alf fich berufen. Sonberbar fommt eg mir Dod aber immer vor, dafs der weibfide Pornp feine Eier an die Gelfen innerbalb feines Feftes umber be= feftigen follte, um fie auszubriten, Da Doch iffer 2 et: theilung in Srauben fie in Diefer Şinfidt Den Ralmars piesn ábnlich madbt, wie id) fie Denn aud - und Diequemare vo: mir eben fo - anf Den Riften liegend gefunden habe. Der cbenermaignte unermidete Beobs= ad)ter verfiduert nåmlid, er habe, „endlich am 25. May 1779 auf einem abcrmalingen Etreifauge an Dev Rifte entlang, eimen Sappen Eier Des grofen silect: \$olnpen, in ciner \$erticfung auf einer Siefelfteinbanf, beim slbflieffen Des 2 Baffers entocat. Sie maren alle Durchfid)tig, wie weiffes (slas uno theiftell fich in viev= undzwanjig bis finfundzwanzig Zellen. Sede derielben entbielt einen fleimen \$olypen. Dicfer Sappen folob etwa adthundert Ciev, uno jebes (Ei ungefáfr fünfs undzwanjig \$olnpen in fich, fo Dafis alfo der ganje lap= pen 20,000 ausmad)tc *)" Dicquemare hat ju= gleic) Das, was cx ein (si anemt, gejeidstet, und eintert fleinen \$oltupen, Der aus cinem Zelld)en genommen ift, binzugefưgt.

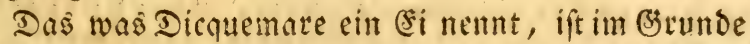
eine (Eiertraube DeB \$olupen, ungefägr in Der Art, wie mir Die Zeid)nung ser Siertrauben Des Sialmats oben gefefn Gaben. Saturitid ift aber eine \$olupen=

*) Dicquemare, Journal de Phyfique Jabr I788. zrveif

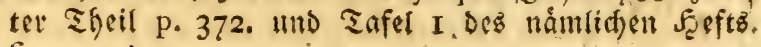
fig. I und 2. 
eiertraube bicier, als bie oben gegeidnete. Scoes eint= zelne fi Des Polypen ift weniger beftiment lunterfdes Den; fratt fich abzurunden, firt fie vielmefre glatt uno flieflen gleichlam in einander. Der fleme \$rlyp fowimmt mitten in ber Feudtiafeit, Die ifn ernafbren

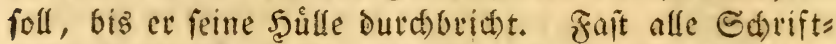
fteller fagen, drefe erier brauditen funfzig Sage *), um

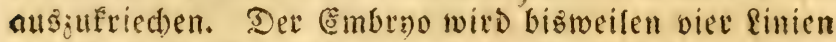

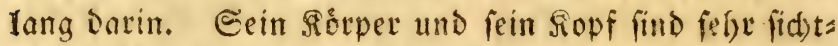
bar; aber feine arme find noch jufammengerolit, ja faft in einander gewunden: gevade fo wie fid alle Traus ben Der Ralmateier in einen gemeinfdaftliden \$ittel: punft vereinigen, nur if ifgr હdwang ober gemeins

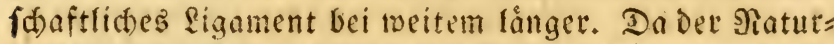
forfacr von Savre fefre vortlefflís jeichnete, uno alle Begenftailde feinet Beobachtungen mit der hód)ften SBabrfeit Dargeftellt hat, fo verweife id meine sefer auf feine Supfertafel in bem eben angefúfiten sefte Des Goutnalș Der Pfgrfî́.

Der gemeine Polnp fann fich biernach ins linges heure vermefren, und die Menge Cier, die das 2 seib: chen legt, fommen dem zaflecidaen rogen ber Fifthe bei, die fich am allermeiften vervielfältigen. C¿s múffen alfo aud Mittel Da. Fenn, modued Diefe ifrer 33 ild heit wegen furchtbaren Thiere in jener granzenlofen $\mathfrak{B e r}=$ mefrung aufgefalten merden; Denn ifge 2 nzafl muifte bei weitem gróper fenn, wenn fie nur biš nuf den

*) ,Polyporum itaque ovis diebus quinquaginta maximeruptis, polypuli modo arancorum perquam multi exferpunt, quorum naturafigillatim nondum confpicua eft, quamquam forma fatis tora spparet. fed ob exiguitatem, imbecillitatemque copia interit." Arift. Hift. lib. 5. cap. 18.

"Ova Polypi excludunt quinquagefimo die, equibus multapropter numerum in. tercidunt," Plin., lib. 9. cap. 5I. 


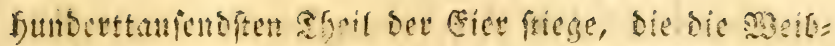

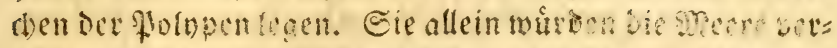

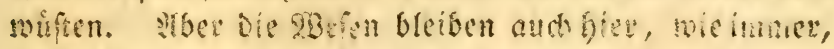

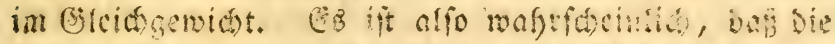

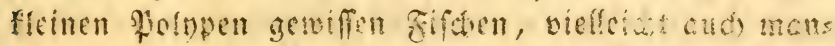

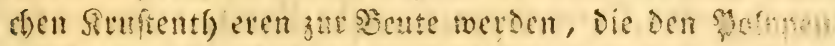

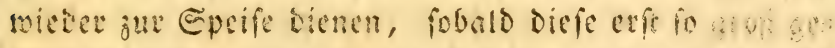

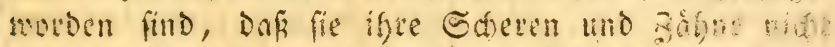
melge fiuchtell, fie mit ben sirmen fefthalten, who mut

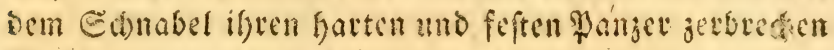
fomen.

Sistgrfdecintich entgefien nut wenig biefer Mrot=

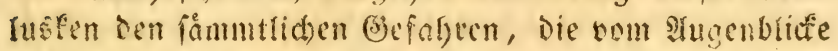

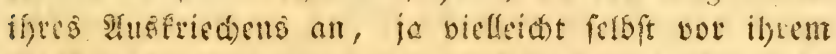

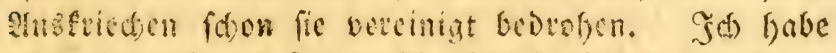

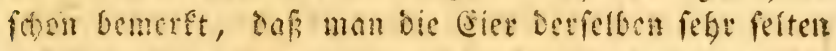
nuf dem Grtrnde - mo fie verderben - antrift;

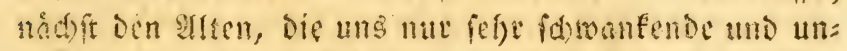

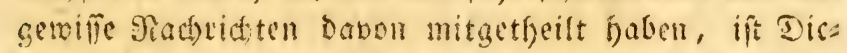
quemare ber erfte, ja, unter ben SRcueren ter einjige Beobadter, Det fie uns beftimnt und Deutlid) Cennen gelefret hat.

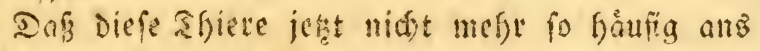
sand fommen, als fonft, davan ift fider bie Futd t

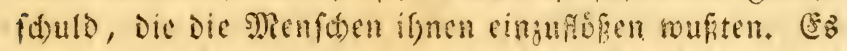

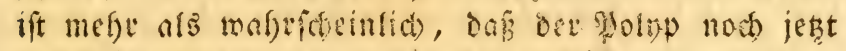
ouf wiften oder menig bemohnten fiffen won zeit gu

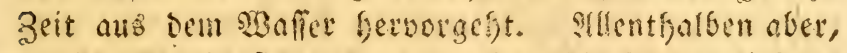

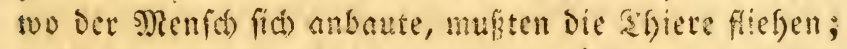

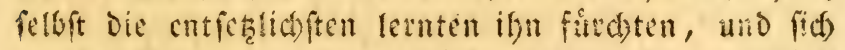

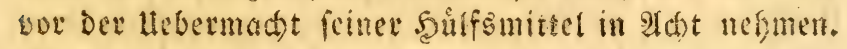
Man Darf Dafer nidyt immer gisid) won Fobritn reden,

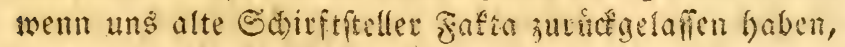

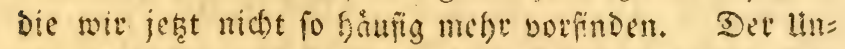
glaube felgit mus die vielen Srofosille gelten laffen, die man einft in lunteregypten foh, wem fie gleid) jertet 
unendid) felten gerworden funt. Die ehemalizen Rei fenien reden orn Eeefufien uno antern smpthibien, Dic in Guinea und in einigen Begenden von Imerifa

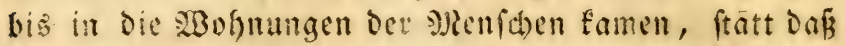
Defe Shiere jef̧t, Da fie fo viel feltener geworden find, (it) an biefen Drten gar nid)t mefre finden. Mird man woj)l ie geneigt feun, Diefe Thatfachen zu bejweifeln,

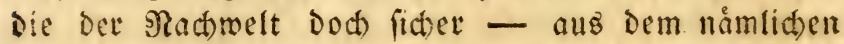
(S) unde, weil fie jeţt gat nid)t mefor vorfallen, - nod) forderbater vorfommen werden? Berade fo verfált es

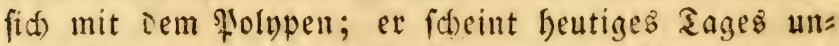

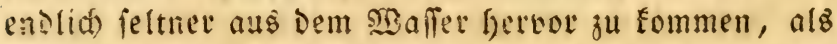
vormals; Da man ifin aber nod jetat - wenn gleich nat felten - an mancsen Ruiften mitten in Den Fel fen findet, Da er willfifrutict) Dafin gefommen und bort gebleben zu fenn fueint, ofne daß man fagen miliste,

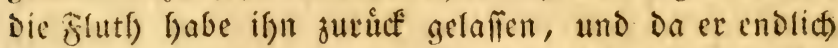

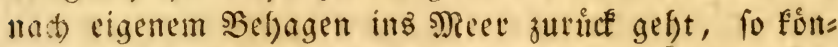
nen wit ifn für eine $\mathfrak{A}$ rt von $\mathfrak{A} m p$ fibium anfefn. SBir

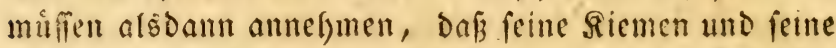
Cinzimeide auf eine Doppelte $\mathfrak{B B e}_{\text {Bfe }}$ organifitt find, Die ifn jum Itthembolen als Eand = und als Mafferthier faisig madts. Selerdutd ift er, to wie viele andre

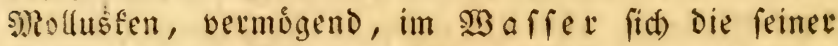
Eviftenj angemeffenen, wåkrigen Atomen anjueignen, tiiid am $\| f e r$ Die luftigen einjuatfmen und zu verars beiten. Der \$olnp hat iberfaupt fehr viel febens: vermoger. (se foreint mefrere Sage findurch aufer Dem $23 a f f e r$ zubringen zu fónnen. Dicquemare *) fah ifgn felbit in feiner Befangenfthaft auf peinen Raub Insplpringer, (5e fah, wie die, die er in feiner foges namten Seethiermenagerie aufberafte, deb Sad)tz, getade als wåten fie nod) im Meete, umbets

*) Dicquemare, Journal de Phyfique. 1788. 3weitet Theil p. 371 . 
fpurten uno liefen, aus ben Fenftern frochen, gegen Die Diauern anfiprangen, aufs Dach ftiegen, und mit

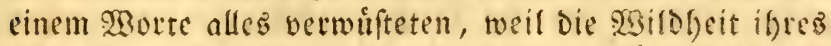
Ebarafters fie nid)t rufing fon lief. Der Plolop ift vielfeid)t eins Der allerthátigiten unter Den befannten

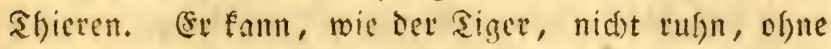
Schaben ju thun. SBie jener und mand ande Shlere, vereinigt er mit Dev sinferften Giauromfeit, sift und

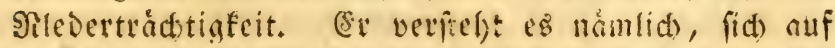
cine fo gefdicfte mgelfe toot zu ftellen, Dof man felbft lange scit bindurd) glauben muf́, er fer es witflid).

Dn dies alles unlångbar ift, 'indem es cin neuerer und fegr alaubwirdiger Đeturforfder aufgezcidgnet hat,

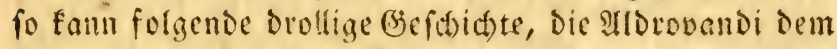
Berd)orius *) nacherjåflt, gar wohl wahr fevn. "Cin \$olup, beif́t es nomlich, den man fure toot bielt, und zum Sioden in einem siefiel aufs geuer fetrte, erbielt wieder fo viel Siraft, Dafi et zum Edyonftein binaus und fo aufs Dad) des Saufes frod), wo man ifn end= (iid) nad) vielem Euden wicberfand."

Diefe Fåthinfeit Des \$olnpen, lange Zeit hindurd)

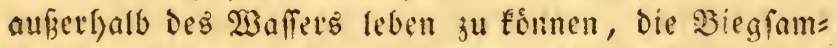
feit feinct Irme wieder ju befommen, und fie aufs neue betwegen zu fónnen, mad)t aud) cine von Thevetz

*) "Audivi quod femel in quadam provin. ciae villa polypus, qui videbatur mortuus, fuit emptus a quodam, cuius uxor ipfum in pelvi cum aqua ponens decoquendum, cum aliquantulum divertiffet, non invenit in pelvi, quae undique eum quaerens nec inveniens, tandem rurfus refpexit, et fupertrabem domus polypumvidit, quilentiens calorem aquae, per catenam, qua pelvis pendebat, furfum afcenderat, unde ip fum decoquendum retraxit." Aldrovand, de Moll. p. 34 . 


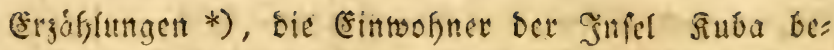
treffend, walgefdeinlich. "Sie bebienen fid, fagt ex, eines firáes, Den fir in igeer Sprache "Rover" nenmen, um andre filche damit gu fanger. (Ev fifmedt feffe gut, und mag etwa alldertfalo fur lang femr.

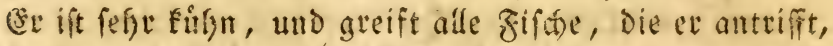

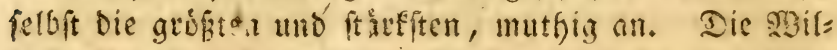

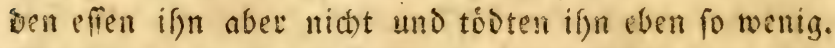

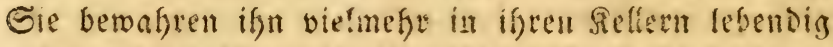
ouf, uno ernåfyen ifin forgfáltig, benn fie bedicner

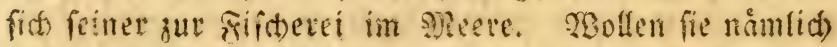
firden, fo negmen fie ifeen औover, uno binsen ifm ein ziemtidh ftarfes aber fefor bicgfames scil quer um Den eeb herum; nerfen ign bann ing Necel, und er: muniern ifn - gleidh alş ob ex fie verftande - fefre foigfaltig zun Tampf; Dann laffen fie das Seil fo weit nac), al\& er nur immer fortid)minmen will. Sobald Das Thier im Mier ift, geft es pfeilfchnell davon, und greift Den erfen den beften gifd on, der ifm begegnet, ex fer fo grof und fo furdeterfict) als er wolle. Diefer fud) bann gervofnlich zu fliefen, ber andere aber ver= forgt ifyn, uno berwictelt fich mit iffm, indem er ifjn feys umichlieft. Sobald die sifher dics merfen, ziefen fie Das Eeil aúmaiflid) an fiad), bis beide fiftse ifnen fo nalge fino, dab fie fie ergrafen formen. So wie Der sang vorbei ift, nefmen fie ifren Rover feraus, uno fesin eimen andern an feine Stelle, bamit er Der stn=

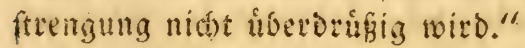

Das alles pafit, wie man fieft, nur auf Den \$ुo Inpen. - Broar giebt Shevet jenem frifde Cauppen, uno eine fo harte Saut, Dak fie nidjt burd) Die andern Fifole verwundet wetden fann; abar alles tibrige, o. safjer in cinen Sellet eingefpert witd; Daf man quer

*) Thevet, Cosmograph. univ. Tom. II. liv. 22 p. 683. 
iber feinen \&eib einen Strid bindet, unt ilin fo in mees

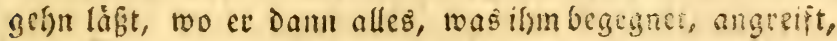
indem er oarauf zufáfit und es mit feinen armen sms fulingt, ón) eś wieder los julafien; dies̉ alles crimert uns genau an unfere \$olopen. Thevet giebt in feinem

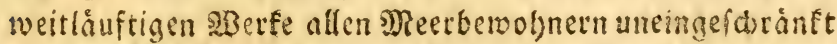

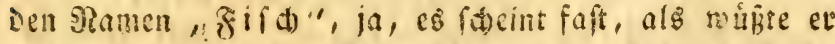
nict)t einmal, Dafi oce Dintenfifds uno Der polap nech bes fondere uno eigentfimlite Fiamen baben. Ien $\mathfrak{M}$ us $\mathfrak{f}$ us: \$olvp, Den er in Der Begeno von Majorca, in Der Meetenge bei Bsibraltar uno bei \$uzjolo, nitht weit von Feapel gefefn faben will, nenut er $j$. Cै. "Stern= fifd" (poiffon étoile)*). Seine Rosmograplie entfålt viel Buteś, fie toiro aber für unficher geibalien,

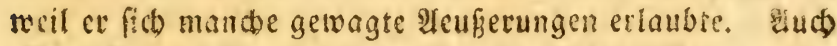

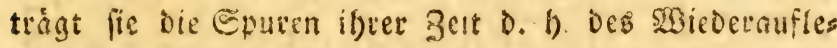
bens der 23 iffenfitaften an fith, denn er tedet nie von einem gifde, voer fonft ron einem झleerthiere, obne ifm Sduppen beigulegen. Fair werden das, Da ith il)n ofter citiren mufs, nod mandsmal finden. Die shabler uno Seid)ner jencr zeit fielen fámmtliá) in den gleichen feblet;

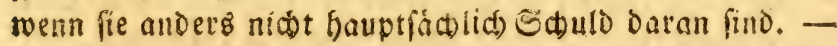

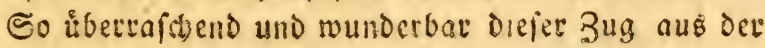

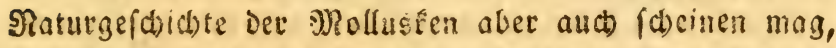

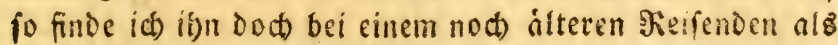
\$hevet, Den Diefer aber nicht felten mit vielem lobe ans

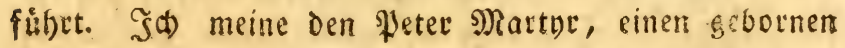
Flocentinet, und einen Miann von fefr vielem (Seift zu peiner Zeit. (Er wurde Anfübrer Der Eefte, bie man nach ifm Martyrianer nannte. Diefer fateint ein Mugens zeuge von jener $\mathfrak{A} r t$, die frifale zu jagen oder zu fangen,

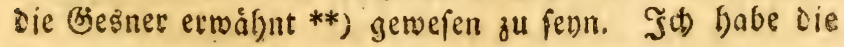

*) Cosmograph, univ. de Thevet. Tom. II. lib. I3. P. **) 502 .

sus vel Reverfus, pifcis indicus, de novo 


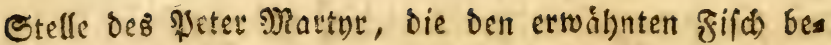
trifft, aus oen Beşner genommen uno fübre fie unten wortl (t) an, Damit man febe, Dafic id fie nicht einmal nad

pifcationis genere Petrus Martyr oceaneae decadis primo libro 3. Non aliter, inquit, ac nos canibus gallis peraequora campilepores infectamur, illi (pifcatores Cubae infulae in novo orbe, in Cymba, id eft, cava arbore pifcantes) venatorio pifce pifces alios capiebant. Pifcis erat formae nobis ignotae: corpus ejus anguillae grandiorifimile: fed habens caput grandiusculum, et in occipite pellem tenaciffimam in modum magnae crumenae. Hunc vincrum tenent in navis fponda funiculo, fed tantum demiffo, quantum pifcis intra aquam carinae queat inhaerere, neque enim patitur ullo pacto aeris alpectum. Vifo a tem aliquo pifce grandi a ut teftudine, quae ibi funt magno feuto grandiores, pifcem folvunt. lile quam fe folutum fentit, fagittavelocius, pifcemaut teftudinem, quae extra tefta partem aliquam eductam teneat, adoritur: pelleque illa crumenaria injecta, praedam raptam ita tenaciter apprehendit, ut exolvere ipfam eovivo nullavis fufficiat, nifiextra aquac marginem paulatim circa aquae marginem avecta, in mare faltat pifcatorum copia tanta, quanta ad praedam fufficiat fuftinendam, donec enavi comites eam apprehendant. Praeda in navim tracta, funiculi tantum folvunt, quantum fatis eft venarori ut ad locum fuae fed is intra aquain redeat, ibique de praeda ipfaperalium funiculum escas ei demittunt. Pifcem incolae gaicanum, noftri reverfum a pellant."

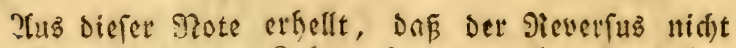
in cinem Qoche im Sagne, fondern neben Demfetben 


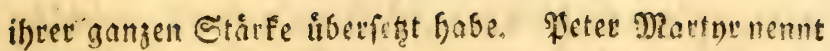

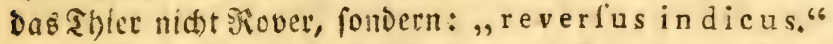
"Die Brfcher Der Sufret Euba in Der neuen Saelt, fagt ex, begeben fid in iffer Wrogen - die blofe

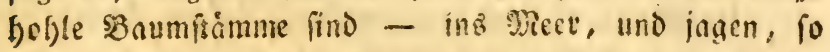

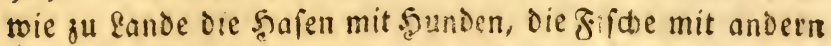
Fiftaen. Der zifich, Deffen fie fich Daju bedienen, wat mir unbefannt, uno gatte einen lánglicten Pórper wie eir Dicfer \$inl. Shu fatte er emen differen Sopf, Der vorne nit einer fefre záfen, wie cine groß̧e Saube georoneten Saut veriflyn war. Sie haben biefen in ifrem sanot an einem langen હeile. Begegnen fie nun, oder bemerten fie nus irgend einen grofen fir oder cine Echildetiote bie bier jum Iheil gróker finb, als ber breitefte Sd)ild, fo werfen fie iffen $\Re$ euer fid er fogleid) auf daz Thier los, gerift es mit feiner breis

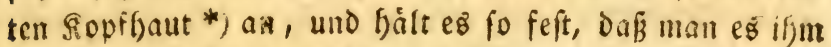

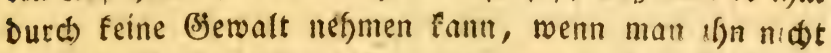

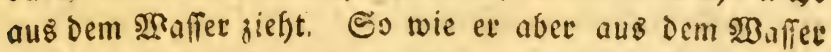
an bie freie \&uft fommt, fo láft er Dasienige fdoll fabs ren, was er vorber feftbielt. Die Snju!aner ergreifen Dann die Beute und werfen fie ins Boot. Der \$Rerverfas fried)t Dann wieder in fein \&od, Das mit $13 a f f e r$ ange=

im freien Neerwafier an einem måbig langen Seile

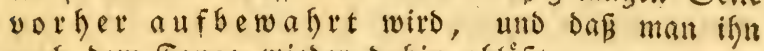
nad) Dem Fange wieder Dafin abläßt.

$$
\text { Zftmert. D. UteberF. }
$$

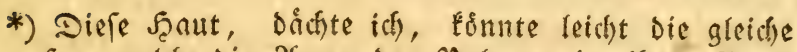
fenn welche die ?tume Der Pornpen in iffer Sofís

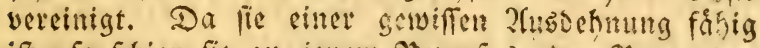
ift, fo forien fie an ienem sieverfir oder stover bas Zluffallendere. Sielleid)t hielt Der Eeftiftrefler Dab llebrige. Der 2ltme fúr blofe Zfnfänglel, Die an Den

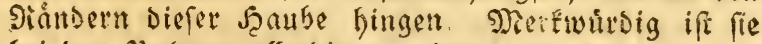
bei ben Solypen allerdings, benn ith Gabe fie nut bei ifmen, und weuer bei ben Dintenfifchen noch bet Den תatmats gefunden. 


\section{4}

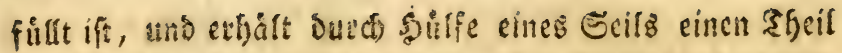
Des Raubes, Den er erjagt hat. Die Einto diner nennen Diefen fif : "Saiacano" id lyabe ifm Den Iinmen "Ieverfus" gegeben."

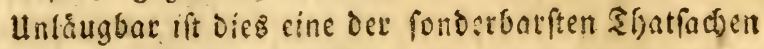

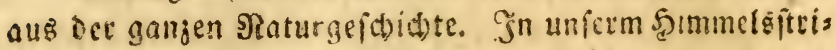
che fat man Dagegen bie ffif Fifdfang furr iffen Befitere abjurichten geroufit.

Stuc) Die Cbinefer baben eine (5)attung \$elifane faft zafm gemadt, legen ifm einen eifernen æing um den

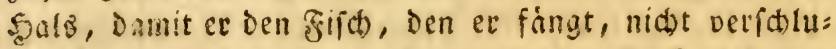
cen fann, fondern ibn in feinem weiten Gacfe bebalten

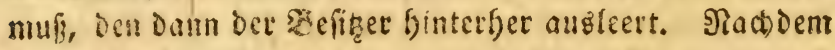
sies gerdyeben ift, nimmt man ibm feinen ßing ab, und

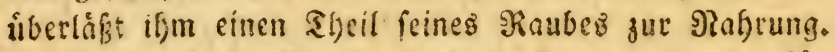
Sie nemen biefen 20 gel "lo uto a und balten ez fux

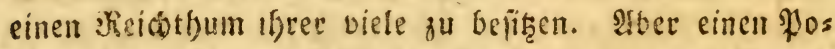

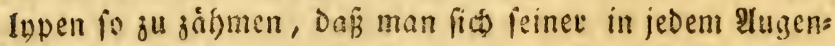
blict uno nach feiner Sibititefigr bedienen fonn, Das ift Dear Dod, meiner Mecinung nad), Det gód) fte (Stad Der mentd: lichen Snouftrie. Dieß Shollust ichien mit wenigfterr fo witt)end, wild, widerfpánftig und to auf feine פeute

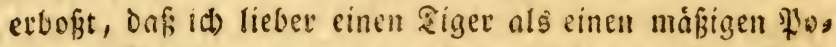

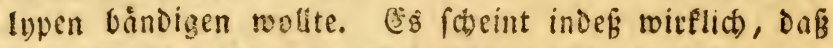
Die alten (Einmof)ner von Ruba Dafín gelangten; Dic neues

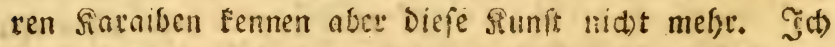
fand fie ftols auf ifie greiffeit und ituabiangigfeit, bie ifnen die wenigen Gnfulaner der newen $\mathfrak{S B}_{\mathrm{B}} \mathrm{lt}$, Die den fpa= niijten Sdrwerdtern, flammen uno Rerten entranten, vererbt faben; induftrios aber waten fie ourchaus nicht.

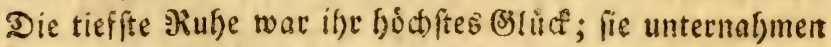

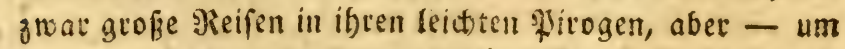
פisafien und Sranntewein zu folen. Samen fie Dann naw Tabago ober S. SBincent - Die beident einjiaen Snfeln wo no (t) Ueberbleibfel won ifnen find - zuti: , fo fros

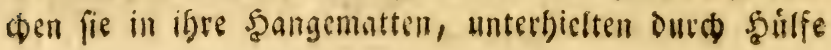




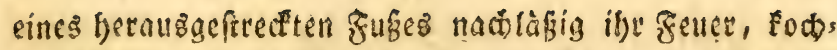
ten fic) $283 u r z e f n$, und gogen fie vom feuet ab (alles mit Den fruben), und famen oft in vierzefon Fagen nid)

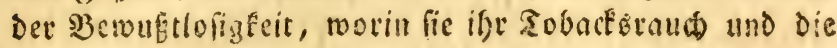
Stáumereien, bie er fervorbrad)te, verfenft jatten. Son

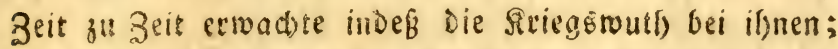
uno wefe dam Demienigen, Der fie etwa beleidigt batte. Sgre sRade fennt, wie bei allen wilden Bólfern, feine

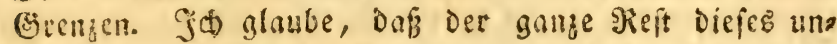

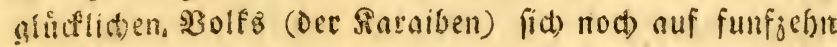
Gundert Gnoiviouen belaufen mag. Sie waren lange fefte

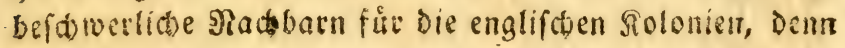
fie baften die Englander. Dicfe wanten Daber jene Ees gionen won Sunden gegen fie on, bie unter ben झianrro'z igre Dorfabren jerriffen batten, und to verfatwano all

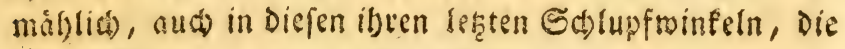
gange Viace.

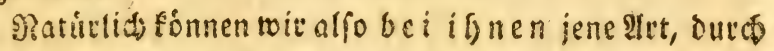

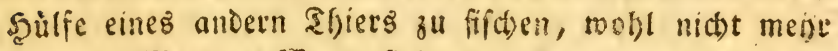
fud)en. Martyes Morte fino aber, deutbt mir, zu orut=

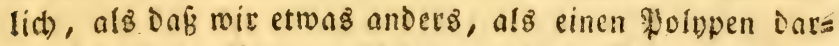

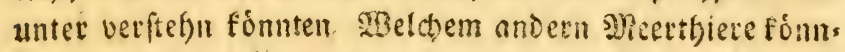
ten wir die erwálnte Syaube zuforeión, die vorne an Siopfe fo feft faffend und fict antjangend cingerictet ift, Daß́ fich alles, was fie ergreift, nid)t wieder losmadien fann? - Dee "lánglida) Rórper" fann (ich viel= leicht bei einer befondren rattung finden. In Den Intils len und voraiglid bei Bsuadaloupe babe ith gemeine \$olupen gefunden, Die unfere Seeleute Dort "פR a :

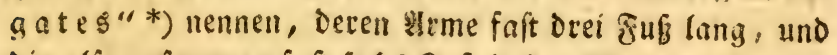
Die alfo zufanmen faft fed)s zun in Dev : Beite maß̧en.

ßei Dem gemeinen Dintenfifh faf)en wir, wie fid die Fifher Des 5 Beibatens zu bedienen twußsten, um Damit ans

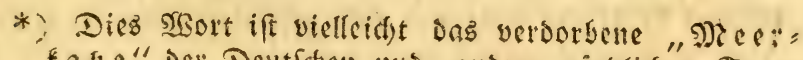

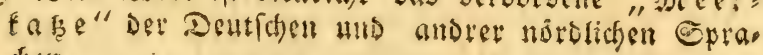
d)en. 
Dre Dintenfiftie zul fangen. Die Fifher bes alten

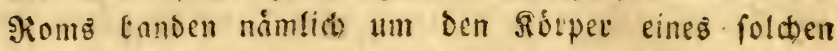

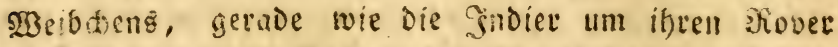
oder अroverus cin Seil, und liefenen

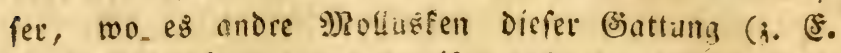
Dintenficit in innthen, die ifm nafe tamen, feft bielt. $23 a$ l)riderinlid fanden bie filder oft - welln gleich Davon n(d)tช́ erwål)nt ift - einen ganj andern fang alz Dintenfifue in feinen Irmen over an feinen গiapf: den: Denn dieje $\mathfrak{2 B e i b d e n}$ werden ibre Statur nitut verláugnet, fonoern, wie fonft, alles ergriffen baben, mas ifren armen nabe fan, um fich) Davon zu ernály= tell.

3twar hatten bie (sinwofner von Suba und die ibbrigen Silulaner die Sinduftrie nod) reiter getrteben,

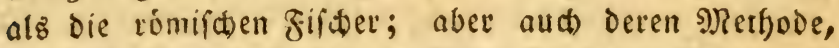

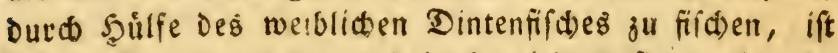
ja verloren gegangen; und Dot) wird es jid wobl nies mano sinfallen laffen baran ju jweifcln, daf mon einft (id) iffer beoiente. 23 enn man oie Riáfte uno fäbig, feiten Des \$olnpen gefoórig etrógt, fo láft fich nidt láugnen, daks ein Fifher, oer jeţiger zett dabin ges

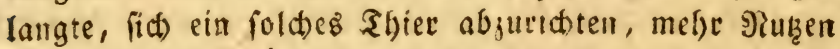
Davon haben wưrde, als cin Ságer oft von fernem

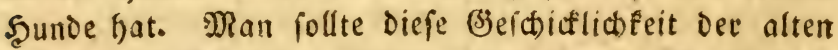
Romer und Raraiben wirflid) wieder zu errecfen fuden. Sie witrde vielleid)t mefrere unferer sưftenbetwolnner

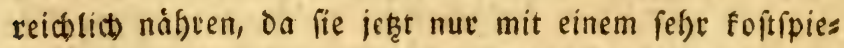
ligen Ipparat auf oen riftofang ausgefn fónnen, wors auf alfo Die Atmen ßeraidt than múffen.

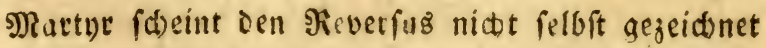

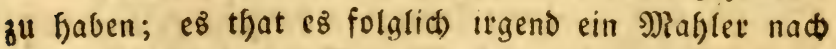
feiner Befdreibung. So entftand denn jenes $\mathfrak{B} / 10$, Das (Sesuer *) fopitt hat, und das dem gefunden Menfiden:

*) Gesner, de Ánimal. mar, ord. 6. p. 92.

verftande 


\section{8}

2Berben folde berfimmelte Beidnungen gar nod einige

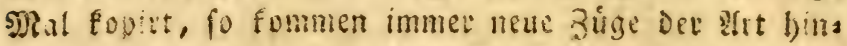
zu, und wir erfbalten juleţi fo viel Ungefecuet als

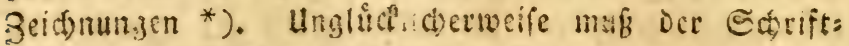
fellet, e er foiden verdotbenen Besdrung negen, mit

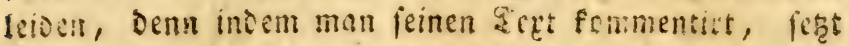

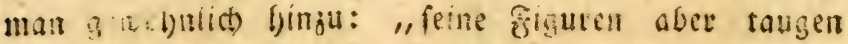

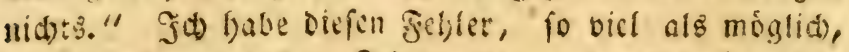

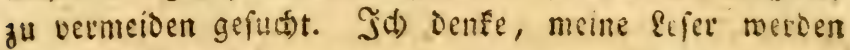

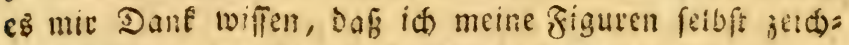
nete. Berderben fie mit bie fiupferted det nid)t - was id) aber fuellict) fürdie, - fo torto iffe Genaugfeit

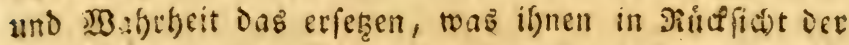

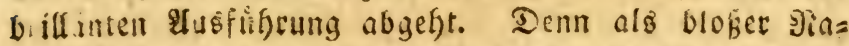
tucalift fonnte id) mid freilid) be: fiunitgriffe nidt be: Dienen, wodurd) Der Raflet in હtande ift, fidt uno

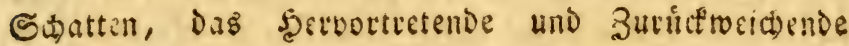
Darjuftilles.

Die Dreindogranjigfte Supfertafel ftellt ocn gemeis nen \$olmpen, von Der अiuffirte angefeben, vor: Die vierund

Eein glatter, gleidfom politter sorper ift allenta balben tofentotb und giebt cinen beildenfarbigen $231=$ Deridein von fid). Sehr Dunfle \$urpurpuntite uno purs purartize flecten befinden fid auf bex ganjen Dberifi,

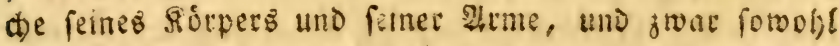
ouf ifret platten, als cuf Der entgegengeftrtell Seite.

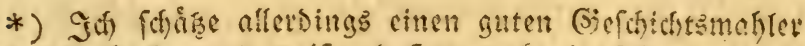

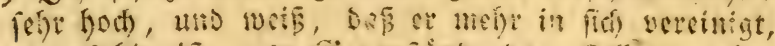

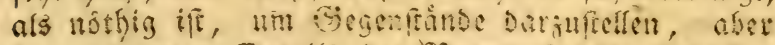

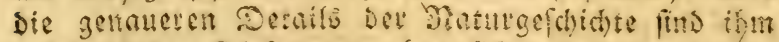
zu Elenitit). Dieferwegen hat fid in neueren Seiten

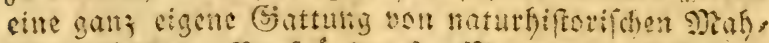

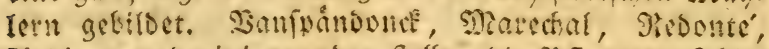

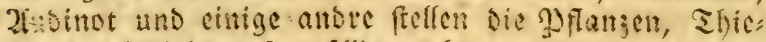
re und Infeften fo voffiz wafhe dar, daf fie nichts

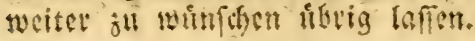


Dies Wunticte fringt alle forben feines fioupers i.t

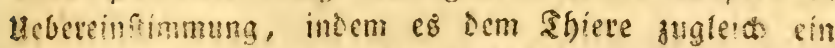
angenchnes uno prachtodles Infehn giebt; Der Şituer mo bic bafis des sopfo find bistueilen forefergrau. Der झुofyp verándet aber feine ratue?, ie nodtom

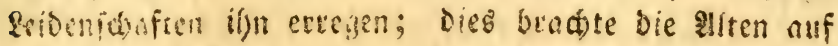
Den Besanfer, ex nefsme die jebsesmalige fabe bes Stre an, wo er fid befinde, dere ber Felfer, worin at feine soble habe. Sie befaupteten fogar, bafi bicz ein Sunfrgriff bon ifm fer, um Die Shiete bes M)eers

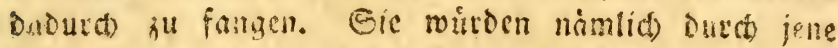
lofale farbe betrogen, uno fomen forglos beran, ofme

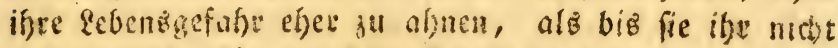

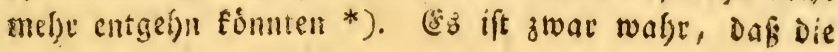

*) „Sui mutarione coloris venatur pifees, trahit enimfibi colorem fimilem, iis quibus approquinquant faxis; quod etiam cum metlerit facit," Arift. Hift, lib. 9. cap. $57^{\circ}$

"In hunc autem modum infidias pifcibus mollitur, fub faxafubtectus defider, et in harum colorem fe mutat, ut faxum effe videarur, pifces ad eum tanquam sd faxum adnatantes, incautos fic brachiis fuis tanquam retibus capit." Aelian. lib, I, Hilt, var.

"Colorem mutat ad fimilitudinem loci, et mexime in metu،" Plin. lib, 9. cap. 19.

"Polypodon fraudes populus vulgantur in omnes,

Qui fimilem petrae magnum flectunt. tur in orbem:

Nexibus et fpiris hominem pifcemque rapacem

Sic fubterfugiunt aftu, vitamque tuen. tur,

Si parvos videant pifces praedamque minorem 
Natur in Diefen Mollugf eine Menge von Mitteln, bie alle zerftoren belfen; vereinigt bat, aber die farbe

Rurfus et in pifcis formam vertuntur, et arte

Perquirunt victum funeftaque fata repellunt"

Oppian. Halieut. lib. 2 Rat. Ileberfeß̨ung Des Iippius.

"At contra fcopulis crinali corpore legn is

Polypus haeret, et hac eludit retia fra ade.

Et fub lege locifumit mutatqne colore m

Semper ei fimilis quem contigit...."

Ovid. in fragm. de pifc.

„Saxatilemque cum exfanguibus cirris Odi mutantem colorem polypum...."

Jon. apud Athenaeum in Phoenice trag. verfio Dalechampii.

,Et concolores rupibus, faburrisque Cirris dolofi polypi anchorae ritu Salaccifo, et turbido in freto freti." Iul. Scaliger in Athen.

Sunt enim a utores qui in omnem feco. lorem inutare affirment, excepto albo. Sunt qui petris quibusvis fe affimilare dicant, uti theognis et phillicides...." Aldrov. de Moll. lib. I, p. I5.

Quodque polypus in varios colores fe commutare dicitur; id quidem a molli ejus pelle provenir, quae facile glubi poteft; cujus colorem nunc album, mox rufum, poftea lividum, mox vari coloribus diftinctum videas." Áldrov. de Moll. lib. 1. p. 13.

"Mutatur colorejus ex lapidis colore, cui adhaeret, maxime accedente timore ob afpectum congri inimici fui, " Olaus 
alfer Derter, two er fid befindet, fann er benn Dod niđt annefmen; fielte er bismeilen fo aus,, wie Das, was ifn umgiebt, fo foumt es wofl mefre Daher, Daß̧ Der Eegenftand zufálliger $2 B e i f e$ eine Aefnlid)feit mit Den Farben hat, Die feine Şaut annefmen fann. Mnenn er ganz rufig und untbatig ift - was aber férer felten vorfommt - fo ift ex faft weí, er fann aber ftufens melfe alle Farben bis zum Dunfelften Fioth Durd)gebn. Diefe farbe zeigt fid oorzúglid, wenn er in $23 u t$ ) getáth, oder irgend eine beftige Segierde ifn reį̧t und erregt. Gin einem foldsen వufftande wird er runglid. Seine Şaut furd)t fid), uno fein ganjer Siorper zittert; feine alme berogen fich getwaltiain bin unb ber; feine

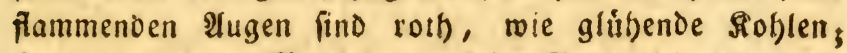
furz es ift feine Miusfel und feine Sehne feines ganjen Sótpers, Die mibt eine gráslid)e $\mathfrak{B u t h}$ áuBerte.

Der Mantel Der Polupen nimmt nid)t, wie die

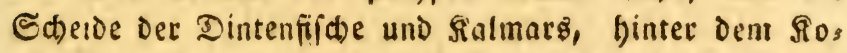
pfe feinen Anfang; fondern fondert fid auf oen Seiten bom Scalfe ab, und Drưft lid vorne auf Den Tridstet ooer gemeinf(d)aftliden ausführenden sana! feft. Burd Diefe (sinrid)tung ift er weit meniger offen, als et bei Den Salmars uno Dintenfifden mat. (Er bedarf auch nid)t, roie Dort, Der bruftwarzen und inneren Befefti= gungen; auch finver man fie bei Den \$olupen nidt. Man fief)t Dagegen blok beim Infang Deళ̊ Mantels

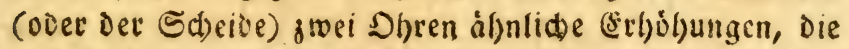
auf Diefer Eeite Die ßiander Des Mantels zu begrăn= jen und iffl zufammen ju balten fheinen. Dicje Sebr: den mad)en einen Theil Des Tridters aแs, uno gelstr an Den Seiten binab. Det Rand Det @d)eide nati vorne zu ift frei. (Ev fdeint fid) Dort blof ourd) cine zufammenjiefende Bewegung zu fdlic\{zen. Borne am Sírper wird man den gemeinf(bafilid)en ausfübrend magnus, Hift. de gent feptentr. de pifc. monit. lib. 2r. cap. 34. De poly y is. 
Sana! getrafir; et exftrecft fid oft tweit itad) aupen hees vor, uno fafi alle Sabiftfeller verfichern, Der \$olyp fóms ne thn willeifrutich nad Der reaten und linfen Seite him

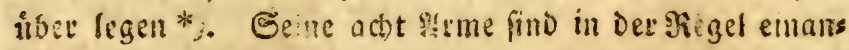

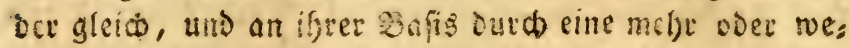

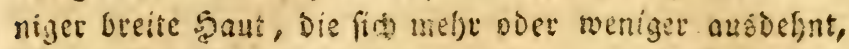
fo zu fagen zu einer Mafie verbution, von binten befors Dirs fetll: fie Die Beftalt einte besten Saube, bie Dutch ftatfe Biefie (nerures) ausigcfiannt, und jeder móglidea

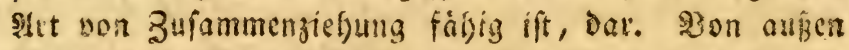

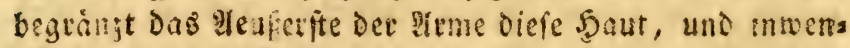
Dig eritreten fic die Siapicten (Edropffópfe), womit

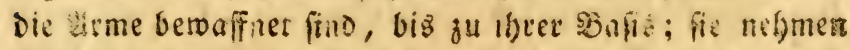
big an Den Jano Der Rippen, Die Den Sthnabel tmmalies fien, immer zu. Die Arme fino iljrer ganjen !̊̊nge nat

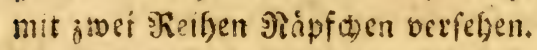

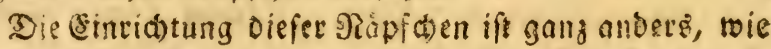

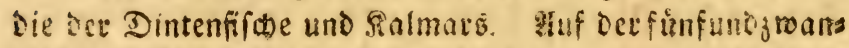

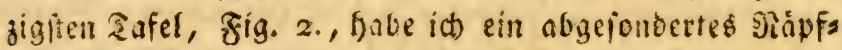
d) en Dargeftelt. Wei ben andern biefher berd)rebenen Molusfen waren viefe 9iapfden roie ein fleiner Becter

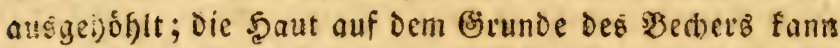
Dout bei Dem anfángen Die ganze \$̧ơblung ausfüllen. Bei

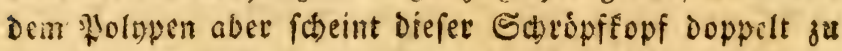
exifitiren; Denn ill feinem 3)kittclpunte befindet fich eine

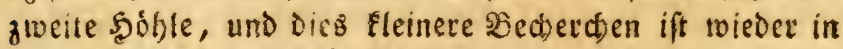
fcirer Mitte ausgeboblt. (E) Mene Streifen geben

*) Eft polypis fiftula in dorfo, qua transmittunt mare; eamque modo in dextram partem, modo in finiftram transferunt. Plin. lib. 9. cap. 29.

**) Fiftulam fupracaput et brachia ante alveum, gerunt, cavam, quam modo in dextram, modo in finiftram partem transferunt, et hac mare transmittunt. Arift. Hift. anim, lib. 4. cap. I. et lib. 8. cap. 2. 
tism ein ftrahlendes Infern. Sie laufert aug bem Rande Der innern fobllung aub, nat Dev limgebung zu, womit Der freigformize Wand aleisfam gefaltet ober gefurobt

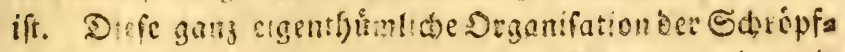

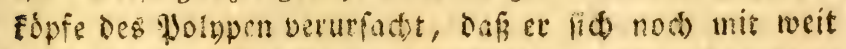

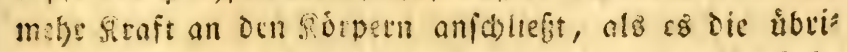
ger toderbatigen Mollusten au thun im Etande find.

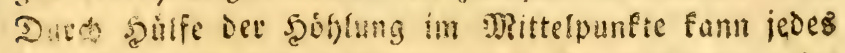

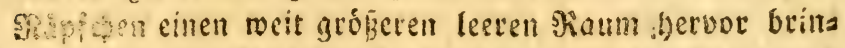

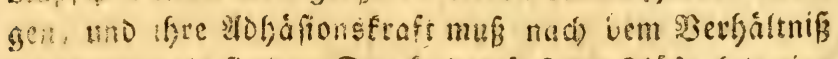

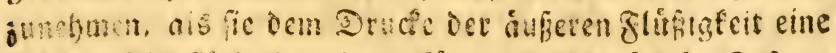

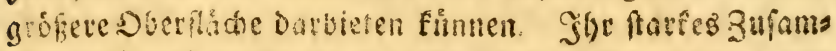

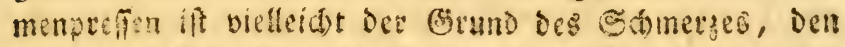

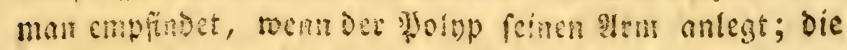

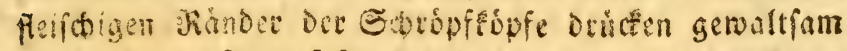
auf Die sout, fie mun folghá) in Dem innern leeten Raum febre cmpor getrieben wecien. Sft man endid dabin ges

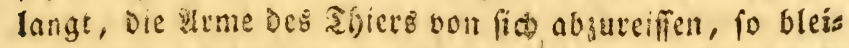
bell grobie, rotbe, runie sno fámerybafte flecte jurief,

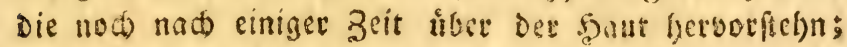

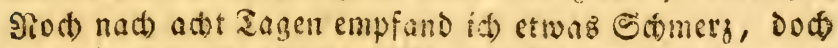
verior er fich allmálylich. Mgtrift es immervorgefommen,

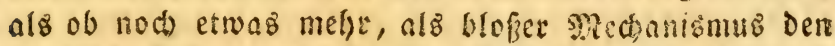

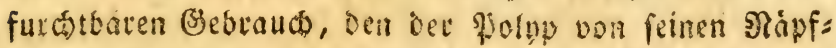
chen mađten fann, bervorbráchte, uto ib babe jeoesmal, fo oft er mict faf́te - befonders abor, wenn er nods lebte - cinen herben fefre ftedenden Solmerz empfunden,

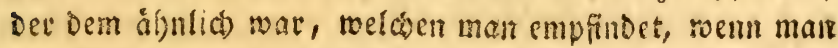
von Sieffeln geuremt oder von einer Biene geftoden miro. Das fomerzafte sbifien, Das man nod) cinige Tage nacthec cmpfintet, ift tem Juden áfntid) - nur ift es ftåtfer - Das Die Preffelnftictse binterlaffen.

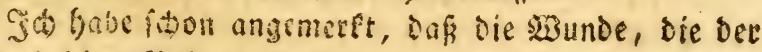

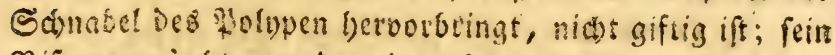

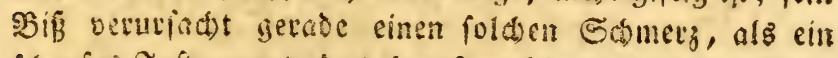
forfes Snftrument, Das fanglam fd) nsider; beide Sinns 
bacfent vertwunden, aber nur bie untere Sinnbocfe nimmt wie bei den \$apageten - das abgebiffene weg Die

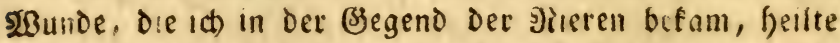

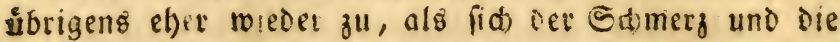

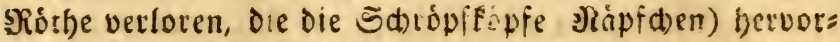
gebradt hatten. Die 2rme, Die mit Deniclben bis zu ifrer áuferften Epise befeget fino, mefien an iffer bafis biewellen welzoll, endigenfich in eine áukerft dinne uno

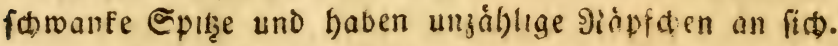
Die Alten batten alfo Datin unted)t, Daß̉ Der Bifs Der Wolupen giftlg fey, Denn id) wets daś (segentbull cus eigner (Erfabrung mit (B̧erwibbeit, was aud) Die शieueren *) bie allgemein die siltete s) Retnung angenommen baben, Das gegen fagen mógen.

Der Sthnabel des Polypen, Der wie ein Papageiens

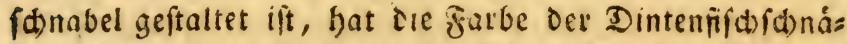
bet und iteft rele diefer in Der M)itte Der freleformigen Sippen und in Centro der adts Itrme, die fethen sopf umfiálien; feine \&ippen find ftate uno ferlodiz, uno fóns nen fïd) verlángern und zufammenjieben. MBern die ges machte beute unbedeutend ift, fo bindet er fie dict tu= fammen, und drüct fie zrwifhen feine finneidenden Sinns bacfen, belgt aber nur eınmal zu; Denn Dann halten die

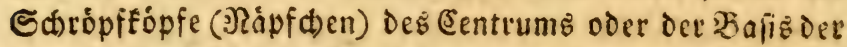
Irme bas Sdblact)topfer feft, uno Die Arme breiten fich

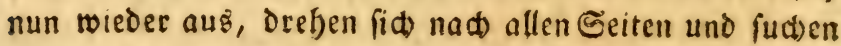
eimen meuen Raub zu erfajthen. Der Polyp faugt inder

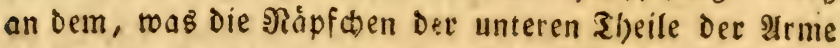

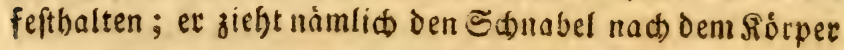

*) Teftatur Aelianus polypum mordere vio. lentius quam fepiam: minus tamen fuo morfu veneni infligere. Aldrov. de Moll. p. $4 \mathrm{r}$.

"Obvia non tenui laedit nos fepia morfu, Nec nos peftifero confodit polypus ore "

Oppian. Halieut, 2, Verf. Lipp. 


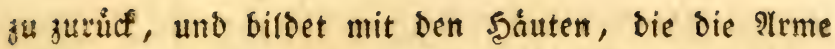
untercinander verbinden, eine 9 rt von musfulofem numerft fleifchigen Iridter, Der das arme gefangene Tffier bon allen Seiten gewaltfam zufammenprefít, und ouf Diefe 23 eife aud) Den leçten Sropfen Blut oder an=

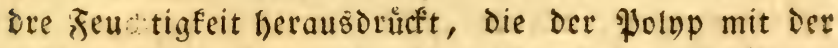

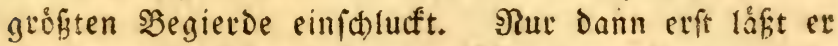
Das shier fafleen, wenn es vollig blut = uno leblos ift.

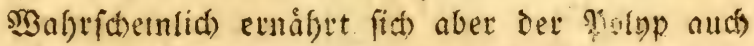
noch auker $\mathrm{D} \mathrm{cm}$ Saugen auf eine andre Weife. Bis: weilen namliá) jexteifit und verfollingter fernen

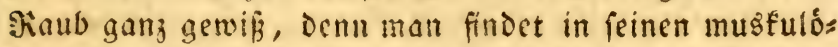
fen Magen Die lleberbleibfel von Miujheln uno Gruiten=

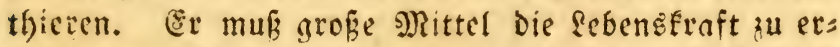
balten von der Ratur empfangen baben. Siddt blok get)t ex - ungead)tet er eigentlid) ein Seethier ijt ohne Staden ans fand, uno fert fid einem anderen Elemente aus; fondern fein Raub fann feinen cifernen 3anden aud nie entmifáen, und er fann jede Beute nutsen. Seine Digane zum Atthmen ideinen auf eine Doppelte NBeife einacridtet zu fenn, aber feine $\mathfrak{J e r}=$ baunganerf feuge find es ebenfalls; ja tei diefen liegt ez am Sage, denn bcide Magen find vollig von einan=

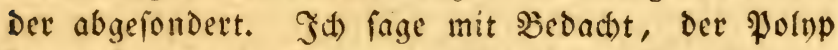
bat zwei von ellander ganj verfábiedene Magen, man fornte fogar Den blinden Darm faft nod) fưr ben brit= ten gelten laffer.

Die genaueren anatomifhen Details lafie id ju= tirte bis ich bon einem andern polypen reden werde,

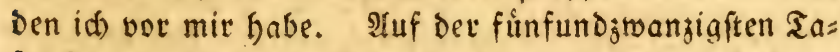
fel zig. 1. Gabe ich aber Dell (singemeidegang des ge= meinen polnps, bon allen andern innern Gefágen ents blóbt, gezeidhet. Mat Dem Sdnabel ift er nod ver: bunden, und fo erfitrecft ev fich fort bis jum Maftoarm (inteftinum rectum), weidher unter ber Sdeide Des Mollusf́s endet. (Es aeft vom Sd)nabel den Sdlund 
entiang binab und bibet in a einen bimformingen

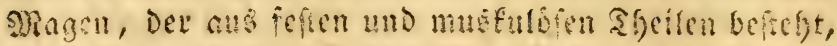

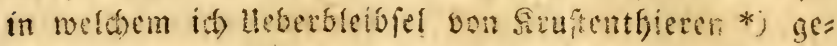
funden bobe. Bald Derouf finden twit chen zreeiten Magen, Der gleicifalls mit a bejeichet und foft sop=

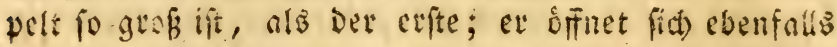

*) Der şofip zerbrigt mit feincm Odfnabet auth Dir

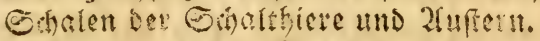

In bem erften Magen fand id cinnal zwei grobe गु)

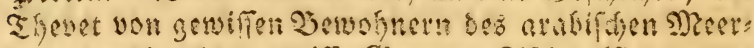

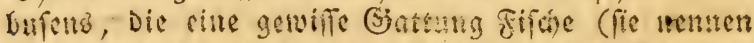

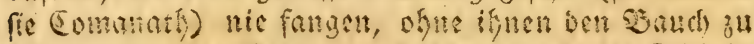

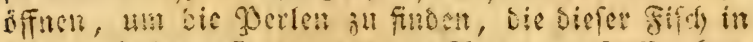

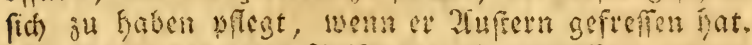
Dir Etelle bes aiten Secienden if interefrant gemug,

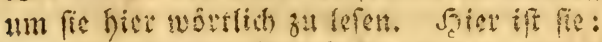

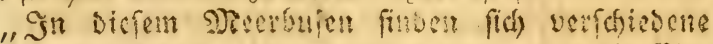

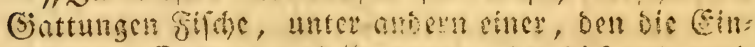
wobner "Co math a th" nemen, ber bid tho runo

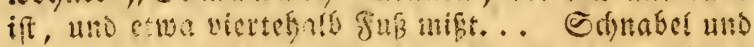

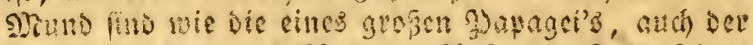

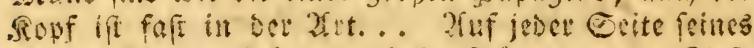

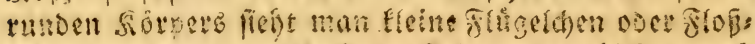
fodern, wontt or fich bein Edyummen filft; auds

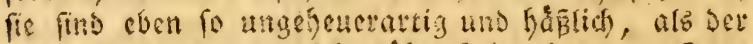

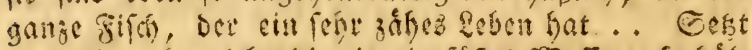
man ing aber lebendig in ein fises sganfer, fo fále

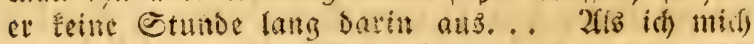
now auf Dem rothen Decere befand, fing ntan zwei ziemlity grobe uno cinen mittleten. Die falche: ver"

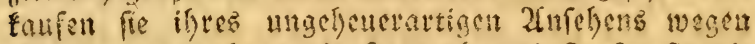

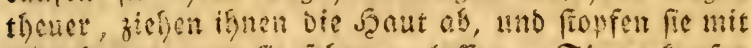

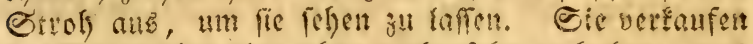

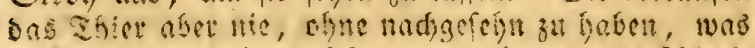

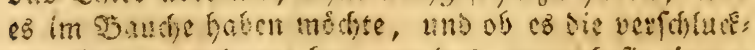

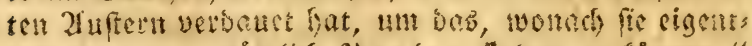

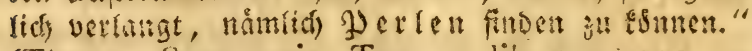
(Thevet, Cosm. univ. Tom. I. lib. 5. p. 123. -

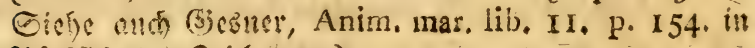

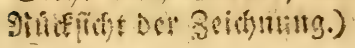


Itad) Dem Eingeweibegang ô, ift vóllig eiruno, uno eben to musfulos trie ber andere. Flle beide find braus ner farbe. Diefer zweite Jykngen entfiet meiner Meimung nad) blof eine airt Magenfoft. WBafirfbein= (id) nimmt abet Defer boutige Eact Das Btut und die

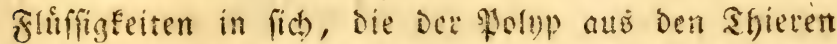
ausfaugt. Fiefer nod fieft man Den blinden Darm (inteftinum coecum), Dev eine bläulde farbe hat, uno fpiralfornig aufaerult ift. 230 Diefer Darm ein Crnde bat, wird ber Maftoarm (ireftinum recum) bi= cfer, madif meljecte siminngen und fteigt cnofich ges gen bie Mitte bes aurpers bin micoer empor. Co lant

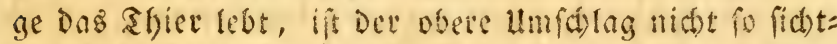

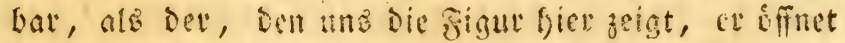
fits Dann vielmefre wie cine longlide Gpalte unterlgalb Der Sifeide. Shier aber follt ex mege auf, weil ex cins zeln Darge teflt ifs. Die fege langlide Dintenblape

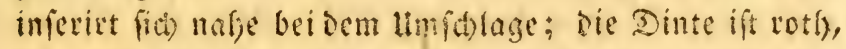
wie bei ben fiamars. Der ganje Eingerveibegang, Die Nagen, Der blinde Darm und ber shaftorm find

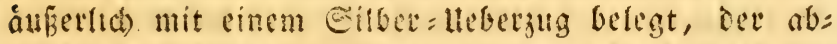
geft und fids an die zinger anlegt; gernde wie die Silberfubftan einiger fruffifde, bie man in bie fals

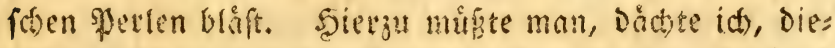
felbe Subfam von Den Molupen = Eingeweiden ebenfalls braucien fóntrit.

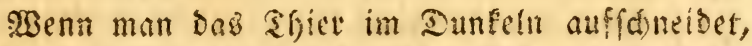

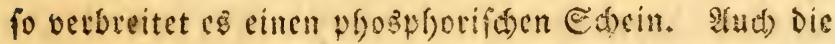

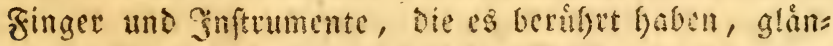
jen im Dunfeln Davon; felfit bas Mafier, worin man es taucite, und bie feinewand, womit mat ce trocinte: te, bliţen barnach.

Die Dinte Der \$rornpen ift nibt fortory, fondert toth wie bie ber finlmars. Die Dintenbiafe liegt etra

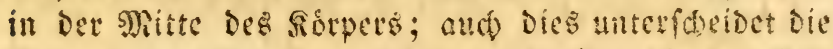
Woinpen von Den Dintenfifden und nafert fie ben fale 
mars. Sie haben jwei Sicmenforper oder Drgane zun Ithemfjolen, bie breit fino, uno an beiden Seiten Des

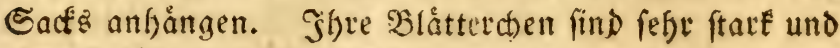
ihre (Befábe merf́lid) fichtbar.

Die IIten idseinen nut roinige Gattungen von Polnpen, und bejonders wohl nur den gemeinen und Den Musfus = \$olopen gefannt ơ haben; renigitens

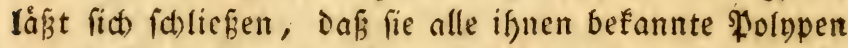
zu Der erften Battung jålalten, und blofi den davon aus:

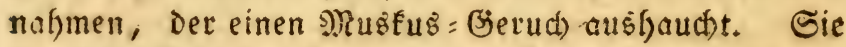
fpredsen námlich nicht von mefreven, fondern nut von

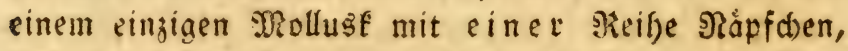
und erft fpåter fommen mefrere ber Art vor. Mau

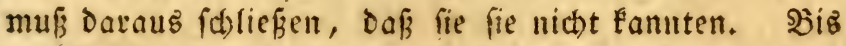
auf ßondelet und Ildrovandi gatte man feime andere bemerft, oder fie bod immer mit einander berwechfelt. Aldrovandi mad)te, benfe ich, zuerft eine Zeichnung

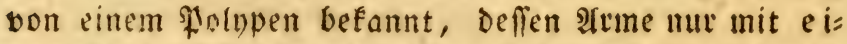
nex Beife szapfden bewaffnet find. Er war im mit=

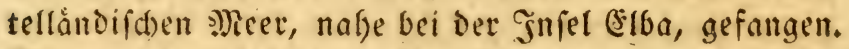
Mir merden "bei Den nacten \$olnpen mit einer ßeife

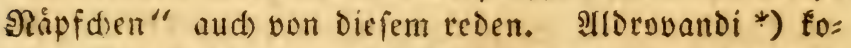
pirte feine Zeiánungen Degs \$olnpen von æiondelet, und lief Dann ofme weiteres bie Zeidhung beffen oon ber

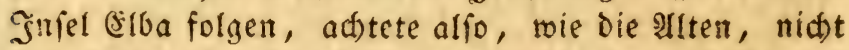
auf biefen farafteriftifchen unterideico. Irtiftoteles batte indé idoon mefrere battungen bon Polupen an: negeben; juerft fprid)t er von Dem, Der, wie er lagt, Der grófefte mird **), und movon bie Sindiviouen, die man nahe bei ben Giuften fieft, grúber werben, alo bie im folsen פeere; Dann von eilie: jweiten Battung, be= ren Sorper flein if, mand)etlei farben hat, uno nidyt gegeffen wird; Daun von einer britten, Die er , ele-

*) Aldrovandi de Moll. p. 15 unt 16. unter Den Sup: fern.

**) Ariftot, hiftor, 4. sap. I. 
d one" Nennt, bie ungleidye Irme habe; uno enolich ven einer vierten, bon der er verfictert, fie habe nut

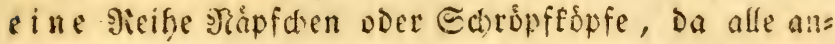
Dete immer zwei ßeifen hátten. In Diefe buatung berfetst er alle die, die man zur Damaligen zeit, , tolitaen i " uno "oftoli" mannte. Arriftoteles faf aber nac) feinem gewibnticten Edourfinn idson Damals ein, Dafi nod) zroei andere Battungen bon polnpen, Die in Sdhalen eingefdlofien fenen, eriftiren; Die eine Gat= tung nennt er "Nautilus" und die andere "Pompilius"t) oder poinpenti. Shre Schale ift fefre fon= fav, fagt er, eg fateint, Dafi fie Datin nid)t longe woh= nen follen; oft fuchen fie nahe bei den fitiften ?ath= rungsinittel, und Die sibellen werfen fie anz llfer, wo if)re Sdyale zetbridht und fie racteno da liegen breiben. Dann greift man fie, oder fie fommen clend ums seben.

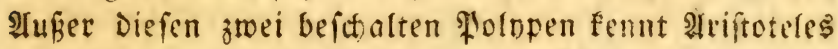
- wie man fich leidit úberjeugen fann - nod eine Dritte Battung, Die mit einer Sdale verfefn ift, mel

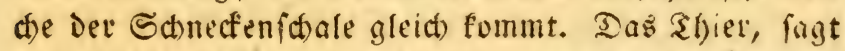
er, friecht nid)t Daraus ferbor, fondern begnigt fid), feine IIme auperbalb Der Sdale auseinander zu win= Den *).

†) Duo item vifunturgenera conchis indita, quorum alterum nauram aliqui vo. cant, alterum pompilium, five ovum pa. lypi; tefta iis ut pectunculis concava, fimplex tamen, nec ita deftinats, ut ei inhaereant. Saepius juxta terram pascuntur; unde evenit, ut fluctibus jactati in aridam elidantur, et tefta dilapfa nudicapiantur, aut in terra anima extinguantur. Conftantexiguo corpore, facie fimiles bolitaenis, et alius intefta velut cochlea, qui non exit e tefra, fed cochleae inftar fubeft et interdum foras brachia porrigit. Arift. ubi fúpra.

*) Diefe joblypengattung, Die wie die Echnecken mits 
Se mefye man ben afrifroteles lieft, befto tiefer mus man bies Sriginalgenie benundern. Montaine Gatte wofl tedit, menn er fagte: "es fen fein Stcin in D:m ganjen Sempel Der meniofiden Senntuife, Den

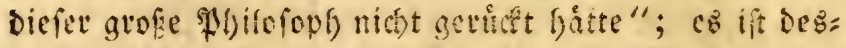

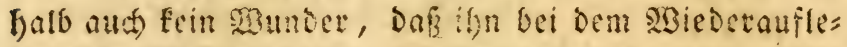

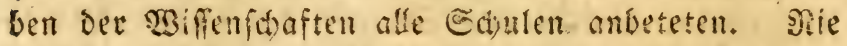

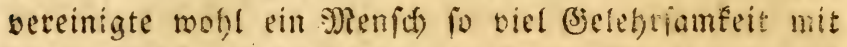

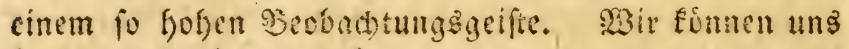

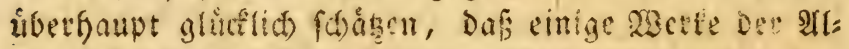
ten wenigftens ju uns famen. Se mefle wir fie tefen, Defto reider uno fruditbarer werden fie fith uns. Die, bie wir nod fennen, werben nun wobl alfe seeniden= alter hinduref leben. Shomumente werden zerfort, und gan ; Crotfeife serichlungen; Diefe Siamen aber

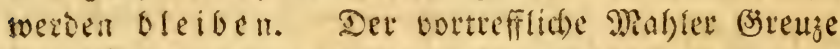

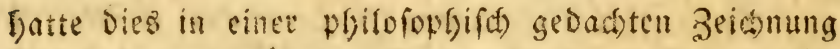

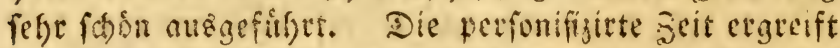
ben somer bei ber Sond, und forwebt mit ifm úber die whthenten Meerestellen fin, Die, Dutch iften furd)tba= xell Sott mit Dem Dreizact angettieben, die Bininen von Tgeben und die Pyramider von Iegupten verfeflingen. Biefe Monumente, die fü: Die erwigfeit gebaut faie= nen, verfinfen alfo, nber Wentiden, wie Scomer, le= ben fü bie Erigiget.

Sft nod fino Die SBgerfe Der Aften unfere Fiffere.

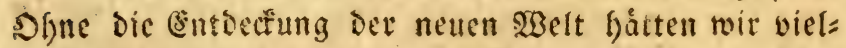
Ieid)t elvig mu ifnen folgen fómen. Die neuen Ge= genftande aller orei Reid)e Der SRatur aber, Die Diefer

einet Sd)ale betleibet ife, erimnert an bie (Sjeftalt bes Thieres Der fogenamten Zfmmonğgorner, die viel

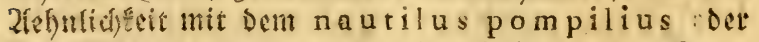

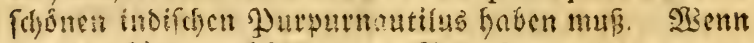
yon den 2tmmonshomem die Picoe fonn wirb, werbe

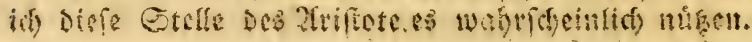




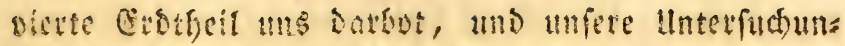
gen betfelben fieflen uns ben suten mofl gleich.

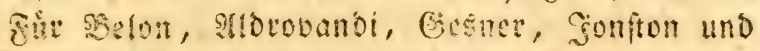

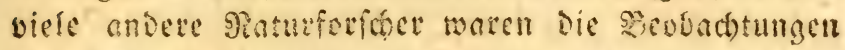
Des arrifteteles verloren; fir teradteten und begmei= felten fie. Desfalb wollte mon aud feinen befdelten

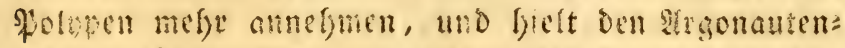
polopen fur cin Edmarotzentier, bis Cuvier feine Ëris fens mit einer Edate ats ber sinalogie ertieth, und ici) fie Durcí) ein genauters Endinm an Drt und Etelle

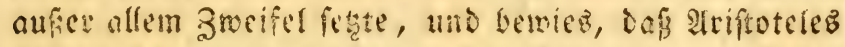
redit babe, men er fogt, der argonautemolyp fen

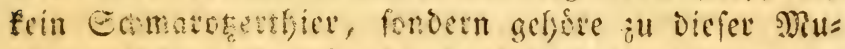

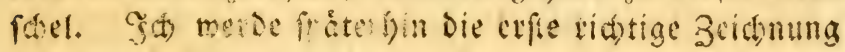
von bieren Iftere liefern.

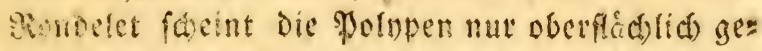
fomt *u beben; et befouptet, et babe Dns grébte Mola lief becant gemacht; Dod giebt er zu, es finnten

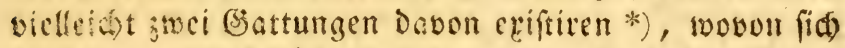
bie eine an ber filfte uno Die andere im gofen Meere outibit, bie - wie ex meint - in allem fich gleids

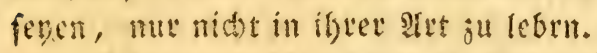

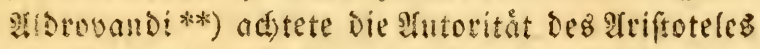

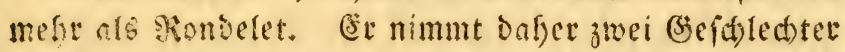
von Yolupen an, exftens ein beidaltes, bas er tweder ill ofwei battungen theilt, uno jweitens ein unbefthals

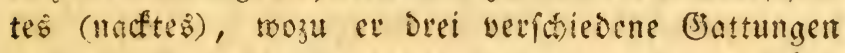

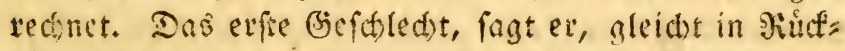
fidst feiner innern Drganifation Dem Dintenfifa) uno

*) Polypum hic depinximus, gui omnium maximus eft et notiffimus, cujus differentias duas effe diximus; alier enim littoralis eft, alter pelagicus, vita folum, fpecie nullo modo diffidentes. Rondelet de filc lib. 77. cap. 7.

**) Altrovandi, de Moll. p. 12. 


\section{2}

Dem Salmar; feine srme find fefr lang, und mit zwei Reifen SRapfchen oder Strupftépfen befetzt; auth

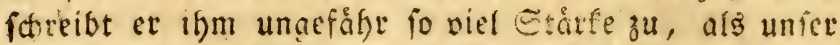
gemeine Polnp baben mag. Denn biefer módte moht aud, mie ber, boow Sllorowandi redet, im 2 affer einen \$ienid en angreifen, fich feiner bemád)tigen und ilin tóden fónuen.

(Ev hatte żufălliaermeife einen Polnpen befommen, Der bei ber Fnjel elba gefangen war, und nur eine

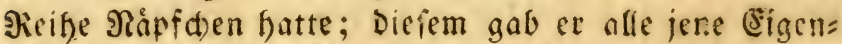
fhaften. (Er fucht if)m aud) cine Riefengreffe, wie Die Der Getaceen ift, beizulegen, und eignet ifm eine met:

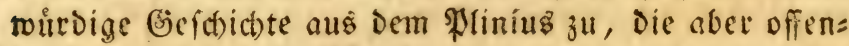
bar nut auf Den Jiefenpolnpen paist, von bem id eine eigene (sattung aemadt habe. Aldrovandi's zweiter

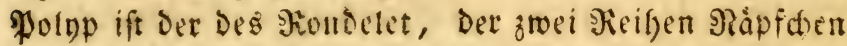
bat. Der Musfus = \$olvp (Den Bundelet ebenfalls

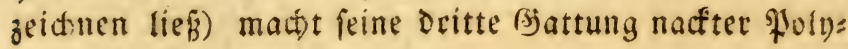
pen ลแเ์.

Gesner fagte gar: alle Polnpen, einen einxigen ausgenommen, båtten an jedem ifrer acht Arme jwei

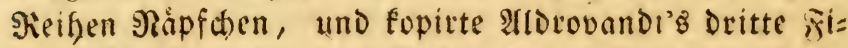
gur, Die Den gemeinen Polnpen von finten vorftelit, fflavif(h); mahricheinlich, weil Damals nod) fo allgemeis ner Nangel an tidtigen Beobadtungen mar. Er feftet fid) weder an Iriftoteles nod) Irtorovandi, fondern fagt Dem Nendelet nact, Diefer Polnp fen Der gróbte uno merfwurdigfte von allen, und theile fich in zroci (bat: tungen, bie nur in ifrer $\mathfrak{A r t}$ zu leben voll cinander ver: fhieden fenen, u. f. w. *). Selme britte Battung

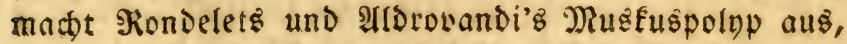
Den er ebenfalls fopirt. Daun erwăhnt er eines nact:

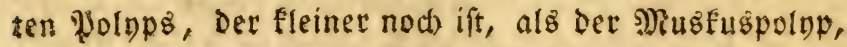
Den er nur mit einer Reife Råpfden vorftellt, und

*) Geraner, Anim. mar. oxd. Ig. p. 19Q. 
ruchorgane eqifiten in Den SBargen (papilles) ober \$o= ren Der åuperft feinen, wenn gleid) lediratigen, Saut.

Ser gemeine \$olup findet fich faft in allen Mecren,

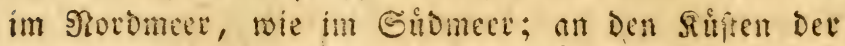
nlten fo wolf, wie ber neucn SBelt; aber immer im folzigen, nie im fiffen 23 affer; Dies fdecint er im Ges gentheil ju verabfocuen. Gefa banigh trifft man ifn an Den nordifoen Sufien und in Dem Dortigen SReere; aber in Der kegel ift man if n Dort nitut. Santz ans

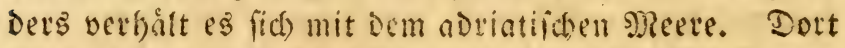
ift ex fef) gemein; und - zut jeit Des Aldrobanoi wenigftens, - waren alle Măte in Stalien und bes fonde: in Menedig voll Davon. Die Bemolnet Der Snfeln des archipelagus verzefrea fefr vicle Polnpen.

Man fann mit redut vom Wolnpen fagen, ex freffe alles. Ee ift ånferif geftåfig, und feine ftaten musfulofen fingerveide veroauen aud alles, waŝ el frift. Man f;at Diefer (jefrafigteit wegen fo=

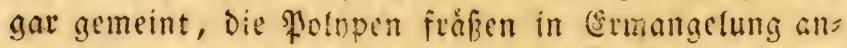
Drex Sabrung fogar ifge cigenen sime. Job glaule aber, dafi die slten, bon benen bicfes siorgeben bet: ruffrt, fich irten. Berftumelungen Der Art fonnen ja aus ganz andern Grumben entianden fenn. Frafie

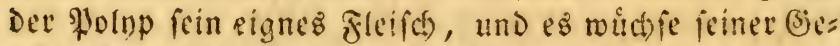
frázigfeit nict t fd)nell genug roieder, fo wurocer andre fdrwáce Spolnpen angreifen, aber oas ti)ut er mie. Bielleidt fonnten fie aud - wie es bei ben 3rmpo= It)pen (hydres *) Wielarm) Dev Sofl ift - nidt cimmal bas fleifh anurer Polnpen verdanen. SRan muf dies fo unjålige פglale angefubrte fattum, Daß Der \$olnp feine eigenen arrme vergebre, alfo für unridstig uno blok auf Bolfsoorurtbeile gegrindet anfeben. Fe bat fid aber von Gabilfundert ju gafrlfundert erfalten, und man fonnte es leid)t mit mefr sutoritåten belegen,

*) Polypes de Trembley. 


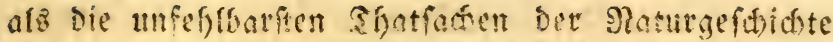

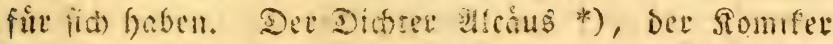
Sherectates **) Diplifus ***) Sefrodus ****) Op=

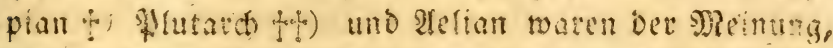

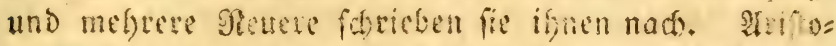

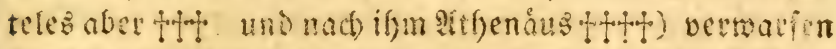

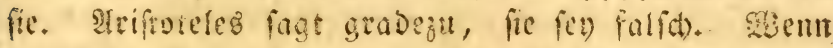
Dem Wolnpen, foridst er, strme feflen, fo find feine Semoe, ju welatat gan votzustia) Die sigerale (Congres) gefóren, físulo Daran.

(E⿱ die ben spoigpen nicht blof nidit firedten, fondern ifm fogar furdstbar find; bie feine Beruffung und feine

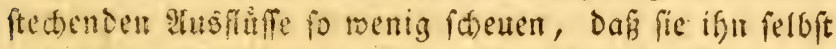
angreifon, ano ifn zu zmingen willen, peine biegfamen vielen Iblitea fo furdtbaren - Aame oor ifgen faneidenden Jáfnen in Eicherheit zu bringen. Sa, er mus of foldie angriffe meşuftefn baben, wie fich aus ben vielen gmbivituen, Denen theils eimgelne If 2 me feflen, theils nut galb und halb erft roicder ge: wab)pan fino, falleficn lafpt.

In Det Gefódite deb Bitefenpolyps wito fich zeis

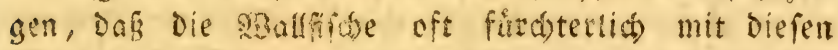

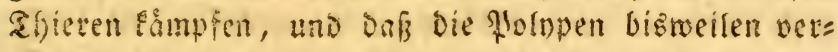
lieren. Menn fie aud gleid ifte Reben Davon brimaen,

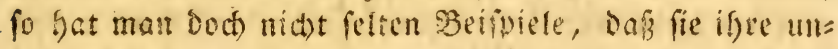
aefreuren Arme, Die Den Maftbantun grofer Sulfe gleiden, aufopfern musten; und ungeadtet die Irme

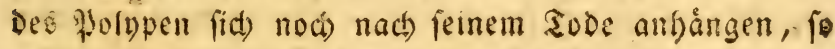

*) Athenaeu's in Alcaeo.

**) In fabula, Agreftes.

***) In Mercatore.

****) In Erg.

†) De Venatione. 3.

t†) Lib, utrum anim, etc.

(tt) Hift. 8. Cap. 2.

tttt) Lib. 7 . 


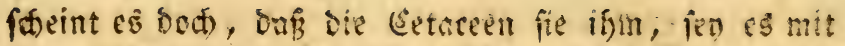

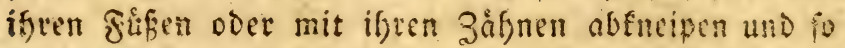
Diefen ungebeuen troten, ja fogar in ifier sefle det= gleiden abgebifiene arme ofye allen Sd)noen zuriotbe= balten founen.

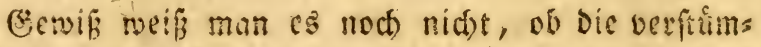
melten srme bei Dem grofen sholmpen, fo wie bei bem gemeinen, mieder madjien, ooer nidst. Dod lôft fid

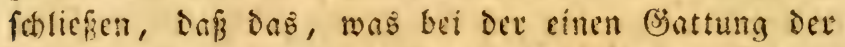
Fall ift, auth bei ber andern fo fenn werde. Diefes Solederhervorbringen der \$rme ift beim gemeinen \$rolnp fo ganj auserordentlid), oak id) mich babei ein menia

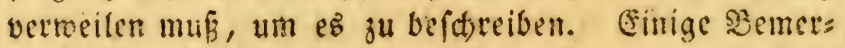
fungen Dariber hat uns fon en fefl geiftroller uno unermudeter *) Beobachter zuruffigelnfen. Sdjade, dok er, der am Mecrufer toobnte, und folg!ich Diefe

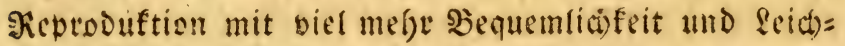
tigfcit, als jeder Indre feobacten fonnte, es nid)t

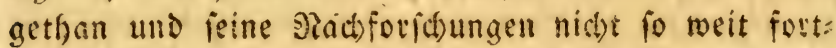
gefeçt gat, als $\mathrm{ke}$ wohl bátte thun formmen.

Sent Der Polnp Dutch Den Zufa!l cinige Irme bers loren, fo reproduciren die verfimmelten Sgeile fic nicht auf bie gleiche 23 eife, twie Die 2rme Dev Dinten= fifche es thun, Denn Diefe waófen allmálylia fort, tho erfalten mit Der Zeit iffe vorige Dide roieder; fo Daf man bei genauerer Unterfuchung jroer mohl findet, daf fie etwas voll iffer lange verloren baben, und fatt fich in einer Epiţe zu endigen, abgeftumpft fino; mar fonn aber einige Zeit nach iffer \$Berftummelung nid: mehe enau ben Srt angeben, wo fie fratt fand. Bet Den Folnpen hingeaen bleibt Diefer beftimmte fled wo Das B̧lied abgerbfet murde, immerfort äuzerit erfenn= bar. Bei ifnen vernatbt Die $2 B$ unde fogleich, ia man

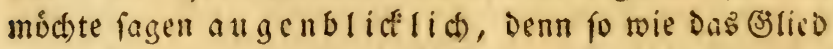

*) Dicquemare, Journal de Phyfique. Jab5: 1784 . Erffer Theil, p. 213. Tafel I. 
abacriffen oder abgebifien ift, überieft die şaut fos

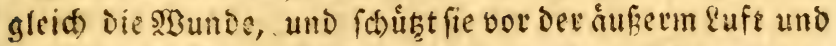
vor bein maffer. Banlo nadber treibt nuf ber oberen Ecite bes verftummelten Gitic bes eine fleifdige runde Serlängerung bitvor, und roidst unmerflid fort. Sie ficfe foft aus, wie cin Sagnenfporit, und if idon ei: nen soll long, che fie nud nut ben funften Theil fo

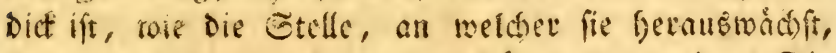
Doer wie ber Irm, ber berfimmelt wurte. Die Saripfespe fino anfangs unbemerfor, entwitieln

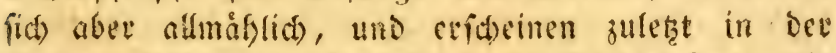
gleichen Deonung mo in senfetoen geifen fort, wic Die Des libriggebfiebenen 9ams. Mit Det Beit mite Diefa Szcrlingetung auch plate, und ethált eine twellens fanfe SBieghomfeit. Man bedient fich Der Slolnp ifper,

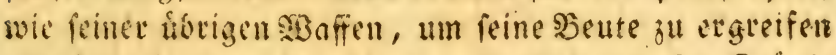
und feftangalten. Die inneren Sieroen uno thre finaule watsfen chen fo, wie die Saut ano die fiefifdigen

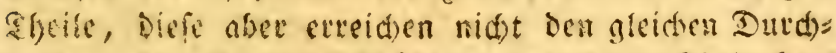
mefies, icn ber unbefádigt gebriebente syeil hat. Das gange neugemadicne bleibt immerfort meniget Did. Man fam Den Dot, wo ber aftm verftummelt moxion ift, beftandig an cince jålen

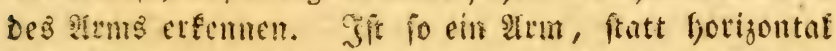
nbgebifien oder gefdnitten zu fern, in biagonaler अids= tung nusgetiffen, fo wád) ft et noch verunftalteter wie =

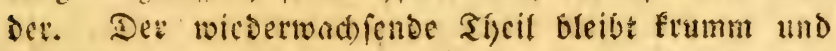

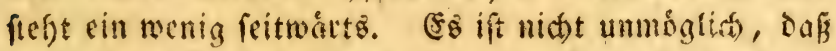

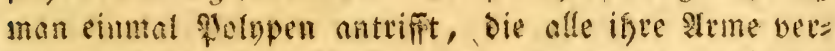

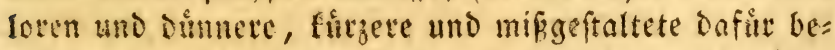
fommen baben, wefdes bann leich auf bie Gedanfen bringen fonnte, es feven gang eigentófimidio (sottun= gell. Sa) glaube aber mit Beftimmtyeit verfictern ju

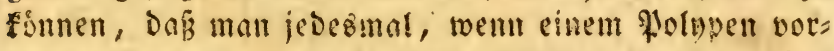
fommen, Dexen Arme in ifret stusochnung cine isfoc und unetwartete lnterbedung jeigen, wenn wan mi 
einem Rale auf eine bebentende Ferminderung im thm: fange ftofyt - etma fo wie man fie bei cincm spouteit: rengalie findet - annifmen foun, dap̈ biefe (Sticier berftummelt gewefen, und nach bent ifinen begegneten Unfall auf biefe şeife wieder ausigefdianen find; und nut erft, nadoem man bies boraugefect hat, fant man barauf benten, in weld)e biattung man fie fetgen will und welche Stelle ifge itbrige Sorganifation ifnen anmeift. SBir werben biefe Reproduftionstweife nods bei ciner Menge anderer Moltusfen wieder finden, uno

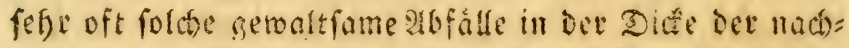
gewachenen Glieder bemerfen, befonders z. B. bei ei= nev Gattung von Gecftemen, Deten Sebentiraft io mácitig unto thåtig ift, bof cin cinziges ifret offeber, weldes vom fisper abgebiffen ober fonft getrennt wus: De, won felbit neue Strahlen treibt, einen neuen ${ }^{2}=$ bensmitterpunft bildet, uno cin neues abier barftellt, - inoefr der fiorper ju gleider geit an Der verfirms melten Stelle ein neucs bried bevortrcibt, Das aber befråndig Eputen Der efjemaligen Sbefdadoigung an fich trågt.

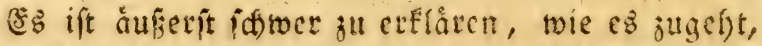

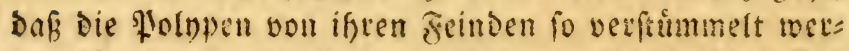
Den fonnen, westhalb die furdjtbaren હartipfípfe auf ihren SBerfolgern nidt haften und nidit mitten, und

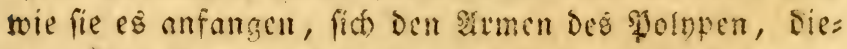
fen alles felielmben Banden, żu entziefen, ja wohl gar

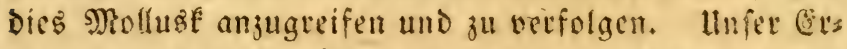
ftaunen wito nod) groffer, wenn wir bedenfen, Daf ber S1olyp fith aud Der gróbten Situftenthiere bemád)tigt,

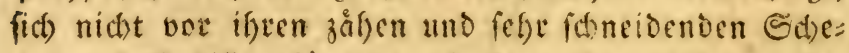
xen und Gebiffen fütdtet., fondern fie mit jeinen $\mathfrak{A}:=$

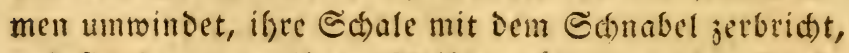
unb fid) Donn von ifyem fleifche nålyt uno iffe feud): tigfeiten einfauat. Mgenn man nun weiter forfot, wel= de Meerthiere diefe Mollusfen wohl angreifen uno if)= 
nen Irme ausreifen móden, fo finoet fich, bafi es Meeraale, Mutaiten, 23alfifiche und andere sifac ober Eetaceen find, Deven Saut iffer Glatte und Siferigfeit

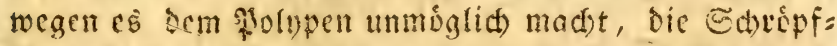

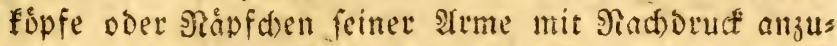
feţen. Daš ólige : wahrfdeinlid), Dafi fie ben fiedienden Druct Der Sd)topffopfe gat nicist fublen, fie fonmen alfo aus Deu zafllofen Sdlingen, morin fie der sjolop zu verwicfeln

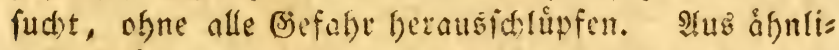
c) (Siunden falbten tornigftens Dic Kinger bei Den alten gumnajtifdon Hebungen ifren fiorper mit Del, samit bie arme iflet (Begnet fie nid)t feftínalten fonn= tell.

Sim :Baffer baben fonad) Die Polnpen eine Menge frinde (uno viefleidet mefle nod), als wit glauben), 'modurd) au(b) fie dem allgemeinen Berftorungsgefete un= terworfen werden, gefne fie aber als Implbibien aufs sano und fteeifen am lifer umber, fo foeinen fie, au=

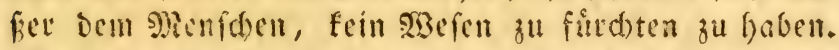
SBir haben gefefen, Daf́ cimer berferben fogne mit eimem शrofer in Der luft tang, und mit feinem befiegten Geg= net ins Maflet zuxud ftúrte.

Cis ift folon angemert, iof bie Sigane zum Athemfolen oder die Sicmen des \$̧olnps ganj andets modifijit find, als die Der Dintenfiffe, uno ifm Dafer

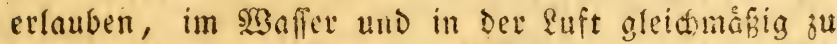
atfmen, D. h. aus briben fliffigfetten auf Die gleiche smbeife feinet feifren bie atome anjucignen, bie feinet Eubfanz angemeffen find, und Betregung und feben in ifim erfalten fonmen. Sicfe fefe fonberbare Siga=

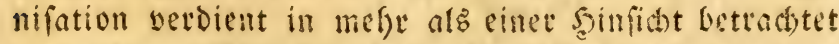
zu werben. AIs id fie Das enfe Dal ermalynte, fetste

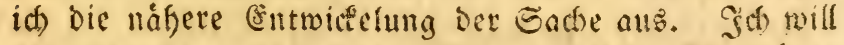

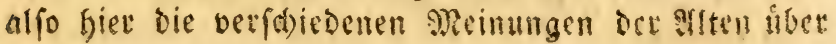


Die Fefpirationsorgate ber Foinpest anfuffert, un meine eignen Seobad)tungen Damit verbinden.

Das Athemfolen Der Mollusten twar uno blieb allen benen, die Daruber fárieben, cin \$loblem, bis endich) Die vergleidente Anatomie (Euviers) uns zeigte, dá̉ die breiten Riemen Den Mrollusten bie \&uns gen ber vierfúfigen und einiger andern Shiere erfeteter. Sdion bie Alten wagten in Diefer Sinficht eine menge ungegrindeter Mlutlmak̂ungen, aber aud) felbft bie neueren Sariftftller, j. C. Fonoelet, wrorovandi, Gesiner und Sonfton wufiten fie fdelechthin nid)t zu ers fláren, Sie begnighten fid baher Das ž miebebolen, roas die ålteren Nintutforfder gefdrieben batten. Irviftoteles glaubte, die \$yolyen wirfen bas 23 affer $_{3}$ Das fie Durdi den Sanabel veridiud batten, Durds Den auffiguenden Ganal wieber von fid. Einige Eduriftelfer nath ifm firferten biefe sonpotidefe now etmas weiter aแB, und fagten, bie Fofupen from=

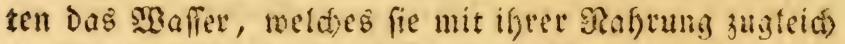

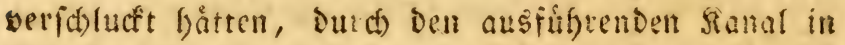
eben Der Art roieder aus, wie die Eetaceen und ins: befondre die sisallfifhe. Alber weder Iriftoteles nuch

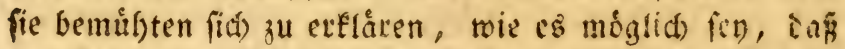

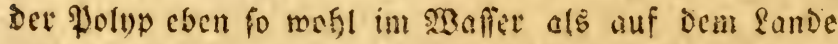
atfmen fonnte. Anore, 3. (5. (Sallienus *) glaubten, bie Folnpen atfmeten Dutd) Die \$oren ifrer Saut und (d) rieben biefe 23 eife 2 them zut holen allen Shieren mit weiffem shlute zu. Diefe nutden námlid) immer ale 23efen betractet, bie mit fefre menig febersimárme be= gaót fenen, und melor blof vegetirten, als fid eines 4fåtigen lebens = und Semegungspprincips zu erfreuen Gåtten. Ungefáfr auf biefe beiben Modiffationen be: f(t)ånften alle bie Refpirationstweife Der Molluŝfen;

*) Gallienus, in libro de refpirationis utilitate, ei ad. fcripto. 


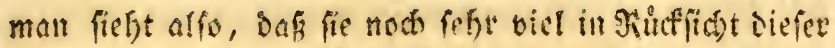
2Raterie zu minfohen tobria liefen.

Die neuesen Natweforfher felbit haben menig uns terfuchugen sartber angeftelt; Smammerdam war, wie wir gefefn haben, biclleidt ber emaige, bet die Hies fpirationsorgane Der Dintenfifte - und Dod) immer

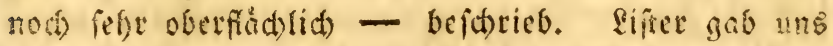
nad) Fed cime Hbbiloung Der lenglidsen Riemen bes Salmars, fief fich aber nitge Datauf ein, die ate uno sidere, in weldher ifge funttionen vor fidh geben, zu erfflåren. Ramaté ift ciner Der - ften, Det uns Den Bebeand) und die veridoledene Bildung Der smolluafen: fiemen fenten geforet bat. Linferm vortreffliden (Euvier *) aber verdanfen wir in biefer Finfidet Die gelebrteften uni lid)toolifen Beobndicungen.

Pad Den Entiectungen Diefes Anntomen find bie

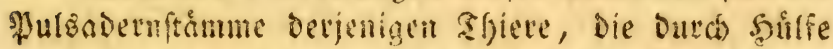
Der \&ungen die \&uft einatimen, butdgångia cinanoes ganz natge; fie fini abor beide bei allen benen getrennt, Die bas şaller einatfmen, und es suer durd) die vieter

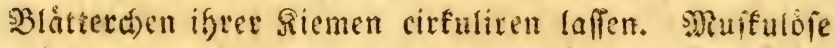
Bănde zeigen fict) blok bei ben vierfufbigen Thieten an beiden Stämmen ihrer Fulsadern. Bei Den Fifden,

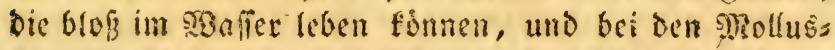
fen, die bló in ber \&uft leben, finden fid) folde Bảudse nut an einem jener Ståmme. Der polnp aber und sies ift felt merfwurbig - hat fie, wie bie viers fübigen Thiere, an beiben. $23 e n n$ alfo die \$olopen mie die $\mathfrak{B a f f e r t f i e r e}$ mit Riemen verfefn find, Die Das

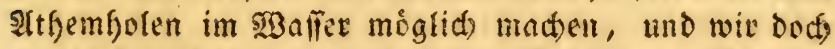
zul gleicher zeit finden, daf́ ifre \$ulsaderngefäze fid denen ber fand = und \&uftebiere nubern, fo mitfen wie

*) Cuvier in feinem forion oft angefingten getefreten Siscite: fur l'anatomie comparée (íber Die vergleis

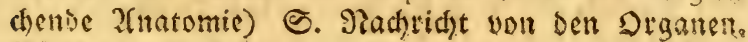
Bano 1, enfere Eeftion. 


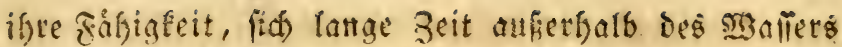
- meldes Sement ifnen die Siatur wofl cigentlich befimmt bat - auf Dem sande auffalten zu fennen,

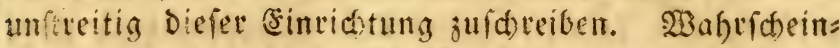

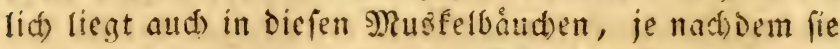
mefle orer weniger vorlanten fint, ber Grund, wega = balb bie Dintenfifhe gar nicht aufer bem 23 affer leben, bie Salmars aber bod) noch einize zeit exipititen, und Die \$olnpen viele Etunden lang in Der \&uft atfmen fömen.

Bei genauerer Aufmetffameit auf bie \$olnpen, Die id) zu beobactenten Gelegentgeit hatte, glaube id be=

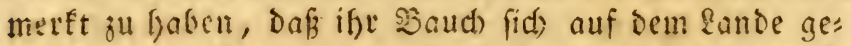
maltram zufammenprefte, und finterífer wiecer auf= id)moll. Saenn id hiermit Daşienige berbinde, was id) bei Den angefuigten faftis wolgrgenommen za haben glaube, fo benfe id), bafi bet stolup auf dem gande und im xaffer das burd)ftrómende - wáfzrige oder luf= tige Fluidum Duted Die Deffmung des ausfúferenden fia nals in fich) ficht, und Dadurd) feimen Sact (oder feine Sedeide, der Durd) Sulfe leines Randes vorne an dem Iricher fermetifd) veridtoffen ift, anfdrwellt. Das erwálnte fluioum mufi Dann Dutch Die Deffinung Dez Fanals in Den berwirften leeten ßaum treten, Dort nad) Dev Zufammenzief)ung Des Sanals - Demn ev verfeliefit (fid) ven felbft - eine Beitlang zuruffbleiben, Die Sie= men benesen, einige Beftandtheile abjetien, und eno: lid), menn alle Itome oder alles (3)as, wildes das Shier bavon entwicteln fonnte, abgefonsert find, wie= Dex auşgeftofen werben, um andere einziefien zu fón

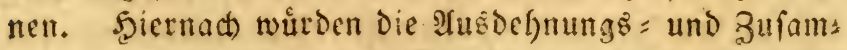

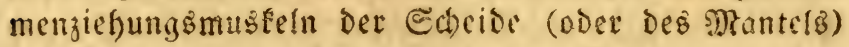
Des Wolnpen die zufammenziehenden \$ewegungen des

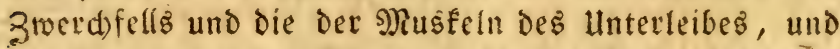
ber Ceiten bei ben 2 fieren, Die mit biefen fnodjigen uno musfulofen Theilen verfefen fino, erfeţen. Sev 


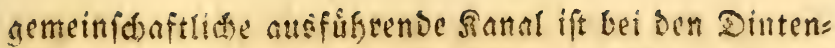

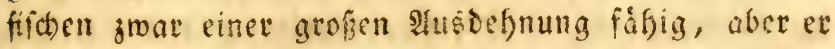
falint fich Dod inmer nidit fo febr zufammenziefn zu fonnen. Sget Den Galmars ift Diefe Rofre an iffer

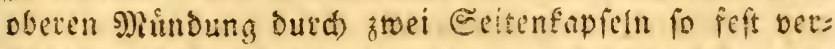

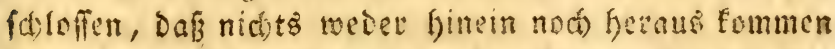

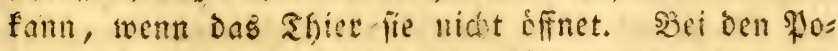

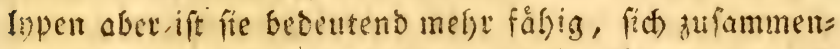

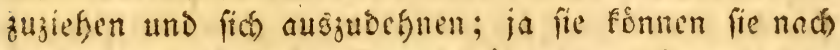
ber reaten und linten Seite hiniber legen, fie toeit hers vorfactert, abet auch, fo ju foaen, fait ganj gegen

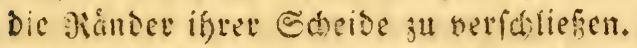

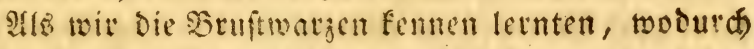
Die Edreite des Dintenfiftes verfaloffen miro, fahen wir, don dic alten fie für cin Gefdledtôfennzeiden bielten; wir widerlegten aber biefen Sitrthum zut be=

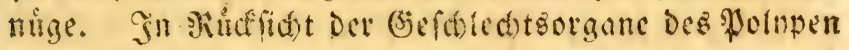
iuten bie alten jcood nod melge und auf cine nod fonderbarere siseife. Cie glaubten nåmlica), bas die zeugungstheile fid) auf ben strmen befanben uno in zwei mehe als alle fibrigen auffallenden Fiapfden be=

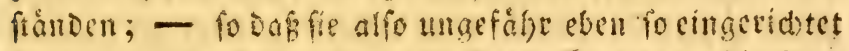
feren, wie nach Den neucren Secobadtungen, die Zeus gungatheile ber Spinnen es find. Arifotelis beain= ftigte biefe Meimung, und füfat fie an zwei Soten feiner 2aetfe an *). Ere wax Das Srafel feiner zeit, unferer

*) Discrepare polypum marem a femina, eo quod capite eft productiore, et quod genitale pifcatores appellant, albidum brachio continet" Ariftor. Hift. 5. cap. I2.

"Marem nonnuli ajunt, gerere quod genitalis fpeciem referat fuobrachio, in quo duo ampliffima acetabula habentur. Nervo id quafi porrectum conftare ad medium usque brachium confirmant, totumque nori foeminae annecti." Arift. Hift. 5. cap. 6. 


\section{4}

àlteven Edulen, uno in unjąhligen Jällêt aud noch, unier felbft; es ifit alfo fein 23 unier, oof fid) iene Seinung iffr lange ethielt. Ithcnåug *) dem fie rafkrid)einlich mifriel, roollte nicht getadeju fagen, bie

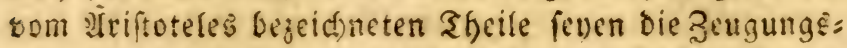
organe niát; - ex fpridht alfo, fie glichen ifnen;

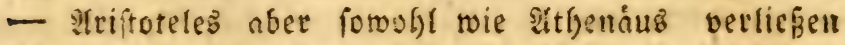

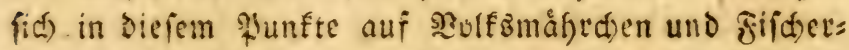
fagen, ofne felbit zu unterfuden, und rourden baburdo betrogan. Dabei blieb eE longe zeit Gindurá). Saum follte man glauben, baf erft zu uniter. Zeit

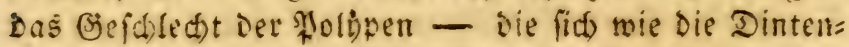
fijue und Salmars in Manndyen uno sBeibchen theifen

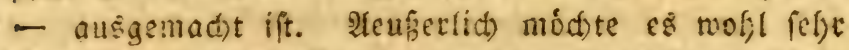

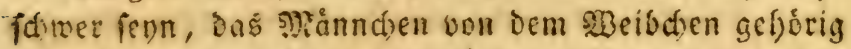
ou unterfheiden, Denn ifge zinge und ifre Befteit fins

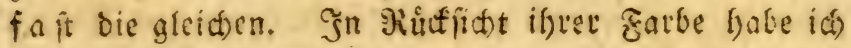
bar feinen unterichied gefunden; id glaube sáfer mit $\mathfrak{X}^{3}$ afurfeit jagen zu formen, Dafi man mur erft beim

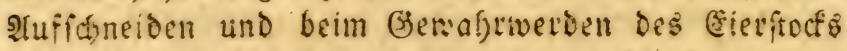
Die beiben jefthledter beftimmt unterfaeiben famr.

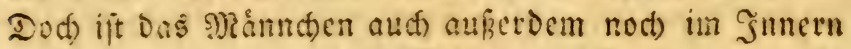
anoers geftaltet als bas sigeibd)en. (es lauert aud), mie sie andern leberfåntigen SPollušfen, Die mir bes

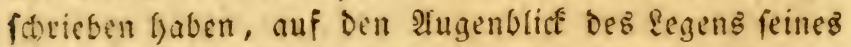

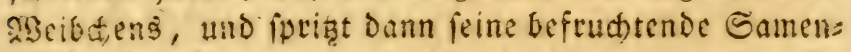
feudtigfeit iber Die (Eier.

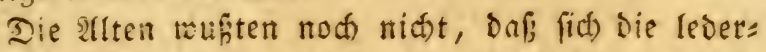

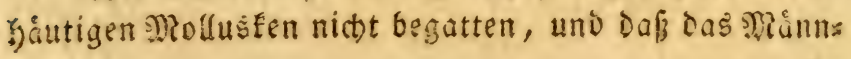

*) "Athenaeus non aufus eft hanc partcm vocare genitale, fed genitali eft fimile, et quemvis fuperius loquitur, tamen ex pifcatorum lententia, ex quorum opinione et haec tradic alibi; hrochio, inquit, ultimo (luod et acutics, et lolum albicans eft, et parte fui extrema bifurcatum, dorfoque annexum) in coitu utitur."6 Aldrovandi, in lib. 7. Athenaei, de Moil. p. 22 . 
den, gernde twie bei Den filhen, Die Cier bes 2 seibs d)ens nur bonetz; fie verfudaten alio auf alle nux mog =

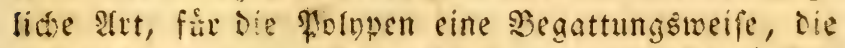
auf eine techt innige Irt gefteche, zu etoenfer. Fi: nius, Ifriftoteles uno Ittgenås ftrengten fid nad cin=

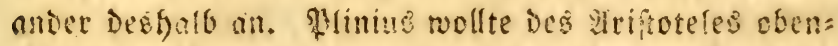
crokfnte s) seinung ebenfals nicht ganj getten lofien;

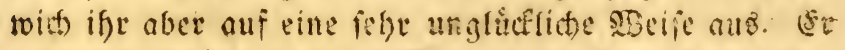

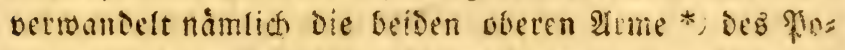
Inpen it cinen Sdiwanz, lápt Diefen Doppelt und fpiring feun, who fagt: Das Tfier bediene fida Deffelben bei bea

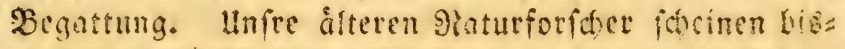
weilen ebenfalls diefer sheimun ou fern; uno Mloro= vanif felbit beobadtet ein tiçes Stillfowrigen iber

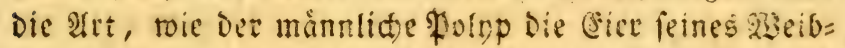
d) Beton fón vor ifm gethan, und Ealviani, Geenter und Junfon madhten es finterher eben fo.

Die Solupen find fefre fruchtbar, ornn fie legen

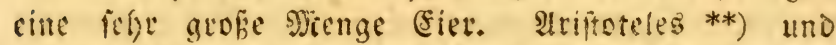

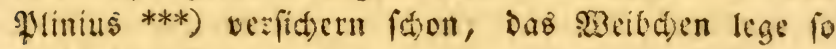

*) Caudaque eft bifulca et acuta, in coitu utitur. Plin. lib. 9 cap 29.

**), ,Ovumveluti cirrum editfructus popuIi albaefimile Perquam foecundum hoc animal eft Nam de eo, quod ediderit, copia innumera provenit." Arift. Hift. 5 . cap. 12.

"Ovum polypi unum incomptum foris, et grande, intus humorem candicanten concolorem totum, atque aequabilem continens Tanra eft ejus ovi uhertas, ut vas impleat amplius capite polypi ipfius." Arift. Hift. 4. cap. 1

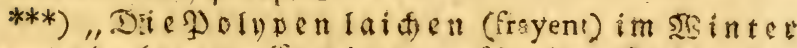

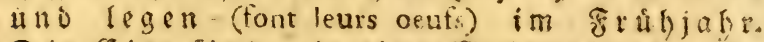
Die (Eier find wie eime sisetinebenturfipe

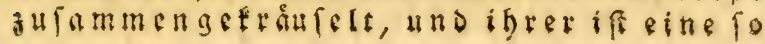


viele Ceier, bafs man, wenn man fie alle zufanmen=

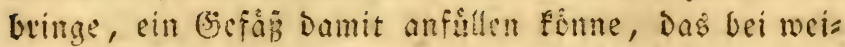
tem groffer fet), als Der Sopf bes Wolypen felbft. Dies Foftum fonnte folge in (Svftannen fercen, wenn wir nid)t

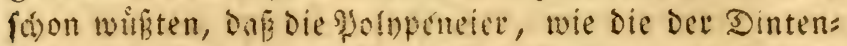
fifde uno salmars, and natocm fie idon gelegt fino,

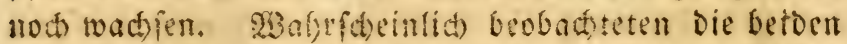

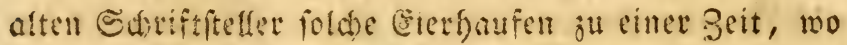
fie efon nusfrieden wolten, benn fie berfidern, fie Gätten fleine, vôllig ousgebilbete Folypen, Die Epimien gliden, Darin gefefn. Scibe fagen, Die (Eier braud)= ten funfig Bage, um alsubutiectien. Dies ift abet bis (cht nod Durd feine Scobadtung weder beftátigt, nod) riberlegt. Die Solnpeneier find an Den Sirfen fefte felten, Denn bie sisellen tverfen fie nid)t oft auz. Dicquemare beidafrigie fid zoar mit ifnen, ift aber aud) Der eimige unter ien Seucten, Der Davon ges

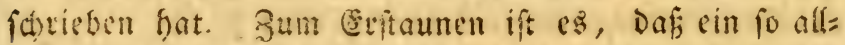

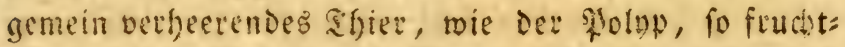
bar von Der Statur erfofoffen murbe. Ge mefr man Dicquemare's Details Girtoon lieft, beftomegr etfaunt man Darifiex *). Jeber Eappen von Der \$olypeneier= maffe, oet weniger länglid, fonft aber foft foeingerid tet ift, wie die Rappen der Sialmateiermafien, entíalt we= nigftens funfundzranjig Eallen, Deren jede mit einem fleinen in einet glafernen jeudtigfeit fdroimmenden

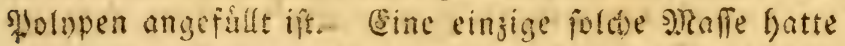
ad)tfundert Sappen, Das aanje entífielt alfo zwangig=

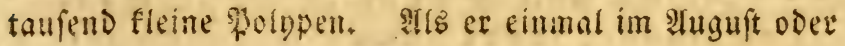

grofe Nenge, Dá́ber Sopf eines todten 2)ofypen nicht binreiden wutrde, alle Gier ju faffen, Die das weibsten legte." Slitius lib. 9. cap. 51. mach Der franzof. Ueberferung Des Pinet.

*) Dicquemare, Iournal de Phy̆firue Эaht I786, àweis ter Tfeil p. $37^{2}$. 
Séptember einen weibliäen \$ornpen iffinete, fano er

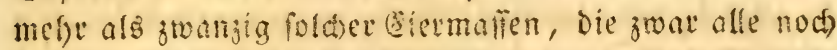

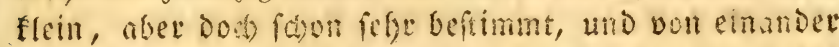
abgefondert waren. Bran fonte er ifre Raupen doet

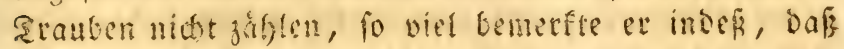
fie wenightens bis auf żmangig friegen, weldyes alfo

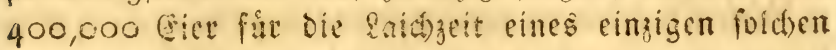

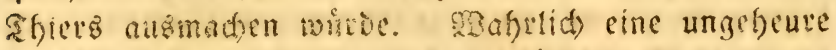

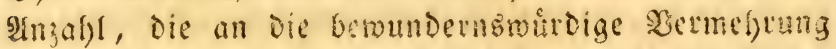
unD Frudtbarfeit ciniger Infeften erinnert. Sers gleitit man num in Gebanfen bie geringe sinzal)! Der witflich eqiftirenden Mzollusken Diefer Battung mit Der,

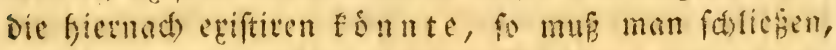
Dof wenige unter ifnen ein gewifis anter und cine ges

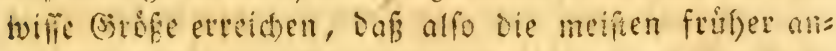
Dern इiferen zue Beute werden, un ifnen jut গaf = rung jul bicnen. Die, welde in Gegenzen geboren treeden, wo fith sallfifite uno Eetaceen finten, ent= geisen diefen secrungeheucen felten. Sic aber, melde nabe an firften jur sielt fommen, verfecten fits wath= reno ifrer fruibejten Rebenżzeit unter Den Selfenanoris

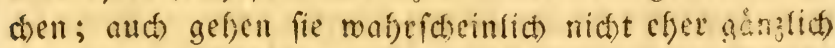
unter bicfen Sjoblungen fervor, als bis fie im Etunde fino, mit \$̧ortgeil gegen ifre seinde unter Den Fifden,

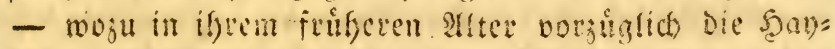
firde gefoiren - zu Eampfen. Sicfe gleichen sifde furchten fids aber in ber fpateren seit fefre bor bem Polnpen, Denn Dann bången feine Siapfesen fich lefot feft an bie harte und raube Saut diejer fnorpeligen und gefrákigen zifóe an.

Die atten verfidjerten, die \$olnpen lebten wic die Dintenfifd)e und Sialmars nur zrwei Gafere lang *), Dann

*), Genus polyporum, ex parte bienniovivere non potelt; fua enim natura tabi ob. noxiuu eft. . A partu fenefeere debilitarique tam marem, quam foeminamferunt 
ftivfen fic fraftiog uno nufgegefrt. Saturlic fucten fie alles feroor, um bicfe Mrcinung ou unterftutsen. Sie maditen 3. (5. Darauf aufmerfam, Daß́ man wiffrens Deg Somners und felbft bis ju Ende des Serbftes feine fo grofie Woltypen, a!s man vorber gefefn habe, fon= Dern blofi folthe antreffe, Die (ifler mieinumg nach)

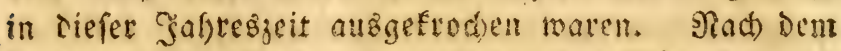

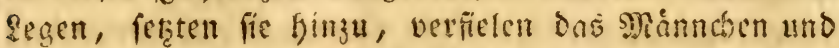

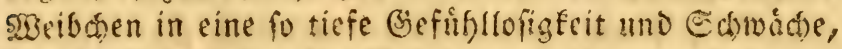
Dafs die fiffact fie ofne Befahr angreifen, ja dof man fie Icid)t aus den zelfenlód)en beraus reifen fonne. Dagegen blicben Die, Die Diefe (stóne nod) nicht exlangt batteil, fortbauernd ftatf, munter und lebbaft, of ne ein einziges jener Snmptome zu jeigen.

Sobald man den gemeinen Solupen in ber Nafge gefebn bat, fo toird es einem fel)e fotwer zu glauben, Daf er nut zmei gafue lang lebe. G(t) und cinige ans Dere Beobactser haben ifn auch in ben Sommermonas ten fraftroll, leb haft uno befonders febr thåtig gefely.

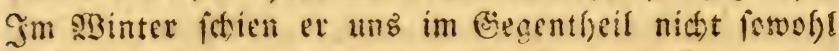
betỏubt, als vielmefre tief im sisaffer verftect, fo baf

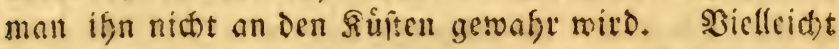
hailt er fid Doun im fofen Mecre auf, und blingt bie id) limme Safleşzeit, wis manche andere Shiere, in einet Sirt von Eatlaf ober tauben Reben ou. Dod láfit fid Das and nicht Denfen, weil er in biefem 3uftande ber Drágheit, in roelchem er fith alfo nidht vertheidigen fonnte, unfeglear andern felsft fowadien und fleinen 9) Reertfieren jur Beute merben múrde. Denn im Meer mird mefr now) als auf ber (5rde alles verifblungen, wie viel melfr Denu ein Sfler, welthes gefúfllos da låge

ut vel a pifciculis deyorentur, et facile a fuis detrabantur cubilibus, cum antea nil tale iis ufu eveniat." Arift. Hift. lib. 9. Even fo Plin. lib. 9. cap. 30. unb Aelian, de anin. lib. 6. cap. 38. 


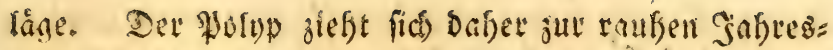
zeit wabrid)einfiá) inz tiefere SBBoffer zutưf, um Dort einer fanfteren Remperatue ju geniefen. Fanden bie Ilten alfo wirflidy bistucifen Dergieichen flénflicte uno f(t)wadd)lidhe Solupen, Die weder angriffen, noch fids vertfyeidigten, fo raten es fidser foldse, die iffe naturs lidbes febensziel - Das fid aber fither nicht auf zwei Safyre befaranfte - erreicht batten.

Sime fo furze Rebensbauet wito un fo unmatr= fdeinlider, wenn man bedenft, wie fie in Der Zeit fo

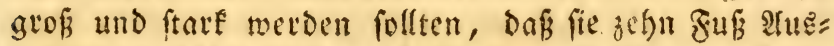
Def)mung erfyaltin, ungeadtet fie beim Alusfriechen faum fo groij fino, wie ein (Getreideforn. Freilich feglen uns ifbe: Dies alles now beftimmte Data.

SIuf Der andern Scite bemerft man, Dafi die $\mathfrak{M}$ ten fâft alle Battungen unter cinander virwechfelten; vielleict)t glaubten fie audí, wenn fie faben, daf cinge \$olopen an Den lfern von Briectentand und Stalien auruct blieber, ftatt baf andere veridywanden, vielleidat

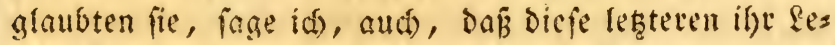
bensziel erreidyt, und den fifecten jur Sente geworder

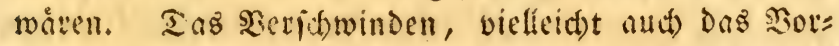
finden ciniger foldber Shiere, bie ifse naturlidfos Biel erreidht hatten, brad)te fie auf Den Gebanken, Diefe

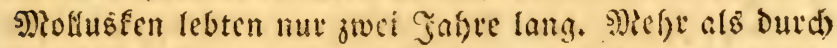
bies alles fonnten fie vielfeidst aud badutch sod) irte gefuftet werden, dấ fie irgend einmal etwa sin siann: den und seibden, beibe ait und (d)wat), antrafen.

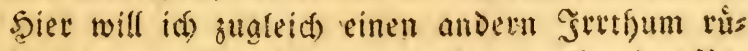

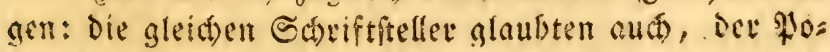

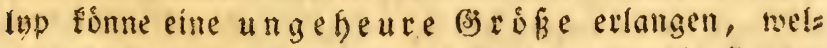
d)es Dod twiedev Der furzen febensoauer, Die fie it)m

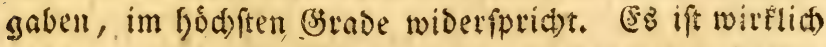
unbegreiflich, toie Manner, wie Arifoteles und wli= nits, von bem gleichen abiere bebaupten fonnen, ts werde ungebeuer grof, und bod zu beroeifen voet 


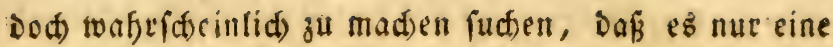
fefr $\mathfrak{r} \mathfrak{u} \mathfrak{r}$ e zeit lebe. Bielteid)t fónnen toir bei ná berer unterfudung Der Cache alles miteinander in Ilebereinftimmung bringen, D. h. auf Der einen Seite unfern \&efrern glauben, Daß́ es eine Battung von \$o: Inpen gebe, bie nur zwei Saffre alt werden, und auf Der anorkt uns úberzeugen, Daß Der gemeine Polnp länger lebt, feine Bróbe aber nie ein gerwiffes Maß̧, Das fdon fefr bedeutend ift, uberifheitet; Drittens endich werden wir jene siejengeftalt einer fictser exifti= renden befondern Battung beilegen, Deren Dafenn Durch

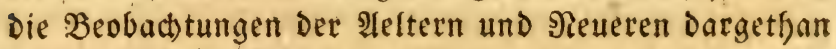
ift, Die aber glicflicterweife nur felten ift, ober fits

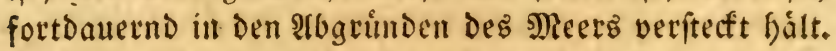

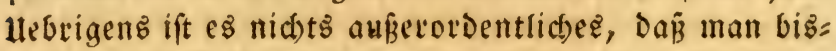
weilen zreei \$̧olnpen zuggleid) im 3uftande Der Şinfállig= feit antrof, fondern Dies mus vielmefr.nad) Dem na: tirtidjen \&aufe Der Dinge immer Der fall fern.

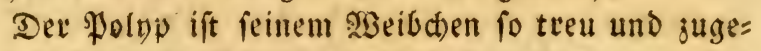
than wie ber månnliche Dintenfifa) Dem feinigen. CEin

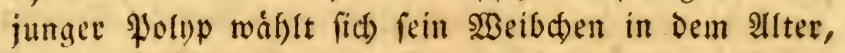
worin er fábig ift, ifje bier zu befrudten. Sefter als $i$ 'ts eine Mal wáflt ex nicht, Denn nut Der Tod zerbrid)t Die Feffeln, Die Die Zeit Der Jugend und Der erften erwaáenden begierde ifmen anlegte. Das Mannchen ift $e s$, welches megen feines fentrs und feiner lebbaftigfeit und - weil es eine grofe befuds=

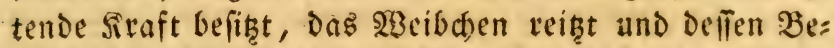
gievoen beftándigerregt. Co oft auch bei bem 23 eib= wen Diefe Begierden erwathen, fo oft befriedigt Das Mámnd)en fie unverzíglid). Das legen ber (Eier folgt fef)e fantrell auf einallder. Das Miannchen lauert auf Den Stugenblice bes legens, und befrudtet fie immer forleid), als fie oa find.

Die ebelide qiebe und Tteue desิ Polnpen find vitheicht bie cimjigen Baige, Die uns in feinem t'aul)en 
Barafter gefallen fónnen. (Doch mitilen trir auth nid vergeffen, daj er jeines gleid)en veridsont, und felbft bei Dem Dringendfen Mrangel, Den er biŝmeilen aนs: zuftelgn hat, Doch feine (d) wádheren Şolnpen verzeftr.) Dies Thier alfo, Das man fait die sisild beit felbft nen= nen fómite, zeigt uns einen fonderbaten Siontraft. C5:

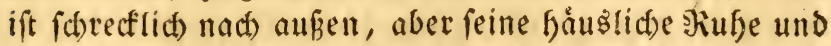
feitie Sorgfalt fưt fein $230 i b d$ en ift ofme (Bteiden. (5er theift mit iffe feinen æaub und bringt ifn iffer bis in

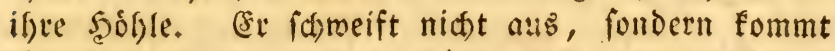
táglich) gleich) treu in feine Şoble und zu feiner (Sattin

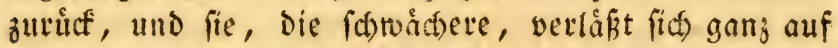

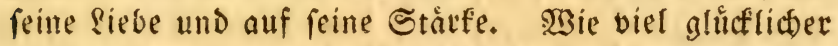
ift ber graufame und furdeterliche \$ornp als fo viele fanfte und friedide Sgiere, Denn er erreidst oft neben feiner Jugendgeliebten feine leţten $\mathfrak{a} a g e$. Der $\mathfrak{B} \circ \hat{B}=$ bafte, Der an \$ford und 2 lerfeerung feine Freude hatte, endet mit Dem glüctititen Sabicfial eines \$filemon und Baucis.

Dod) weg mit diefen Betrad)tungen, fie crwecten noch) unangenefmete. Denn a(t), - Die Biemiffengs biffe ausgenommen! - ift Diez ja gewólnnlid) Das

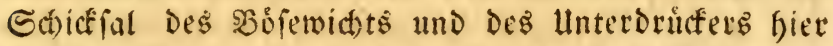

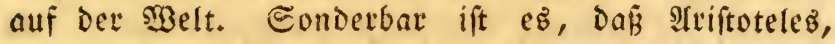
Itthenåus und ঐlinius *) Diefem Shiete Die Sinne und Den Seritand abiprecten, da es Dow alle beide wogl in

*) ,Polypus fatuus quidem eft, cum ad ma. num demiffum hominis accedat." Arift. Hift. lib. 9 cap. 37 .

"Imbecillum et brutum vocavit Athe. na eus." Lib. $\%$.

"Brutum, quafirationis expertem, quod ad manum hominis adnatet, nec perfequentem venantemve refugiat." Plin. lib. 9. cap. 29.

Aldrovandi wieberfolte dies, de Moll. p. 24, Ionfton, de Exiang. aqnar. p 6. 


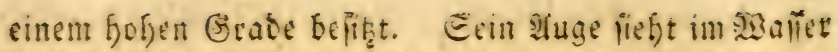

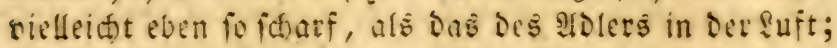

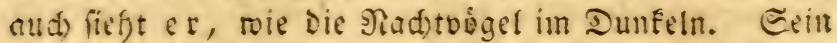

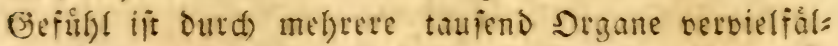
tigt, Die alle son ber grofften (Fmpionglid feit find. Die Emprinoungen Des Geichmacts Dauern vorjüglith lange

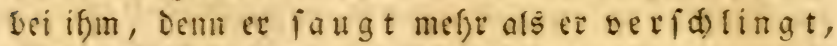
and fidlurft Das Blut jeiner Ed)ladtopfer ein. Die

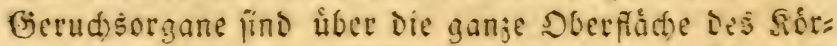

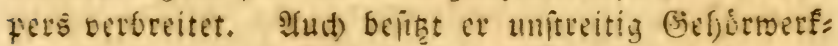
jenge, bie fid aber, twie bei ben tibrigen lederfăutigen

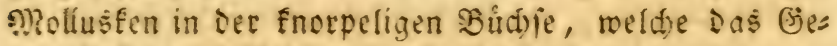

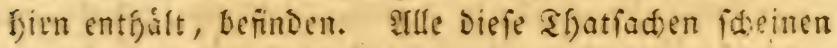
unmiberleglid); es ift Dafer unbegreiffid), wie fie ser Ed)arfilidtigfeit Der sflten entgehen fonntin. Zu ifrer (entichuloigung will id) indef baran erinnern, Dof wie ia faum erift feit einem Saftrfundert angefangen faben ôu glauben, Die Jnjeften - und Mlollisfen vitdienten einige Sufmetifiamfeit. Sorfher betrad) ate man fie als

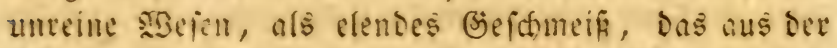
Fỏufung entiftefe, uno unfrer Ilufmerffamfeit nicht

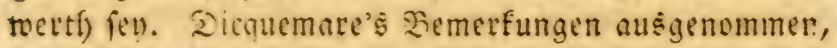

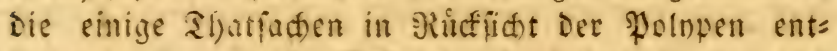

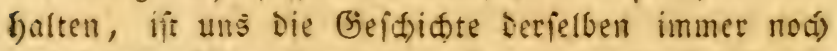
unbefanut. Der Simmel meí, was Der Brrund it, iaf en fo merfmurdiges Wroliusf jo menig beobud)tet nurde. Ěeit Iriftoteles Zeiten bat man, wie wir ges jefon faben, trenig oder gar nid)ts zu Dem binjuge= fingt, was biejer \$glilojopl) ilber fie lagte; 1752 mad) te

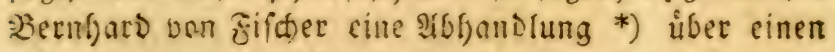
Fiolnpen, Dot aus Girtechenlano fam, befannt, und Ser offenbar Der gemeine Plolop war. Diejer झr'jt hat feire Difiertation unit jroi Suppern begleitet, wovon

*) I. Bern. von Fifcher. De Krakatiza Obferv. 79. p. 335. A cta naturae curioforum, Vol. IX. Taf. IX, fig, I. umb Tof, XIII. fig. I: 
bas cine Den \$olt)pen mit auggebreiteten 2irmen, aber mit jerriffenem Gorper, uno úberfaupt in einem fefs verdorbenen Zuftande darftellt. Daş andre zeigt Das gleidie Shier, aber aufgetrocfinet und birnformig ju=

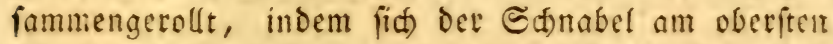
Theile Deflelben befindet. Durd) Das Sertrodfen fint Die sippen verftrounden; uno esิ wưroc úberfaupt idtrer fenn, nath diejer ungejtalten Figur bas Ifier beidreiben zu rwollen. Da aber bie beiden Reifen

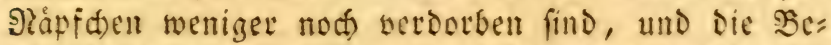
id)reibung des Sd)riftitellers mit ber meinigen úberein= ouftimmen fideint, io fteige id nidft an, ifn fur cin Sndivioum arjufefn, ias jum gemeinen Polypenge= ict)lect) te geffort.

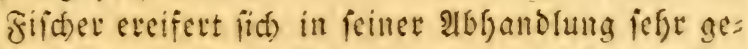
gen Siructmann, einen ùbrigens fefge verbientrollen Mann, Der in Den Eeipjigev f́fonomijden Eammlungen cine unrid)tige Bejetreibung bes \$olnps mit folgenten

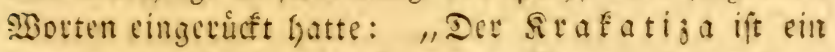

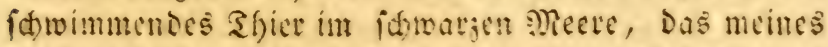

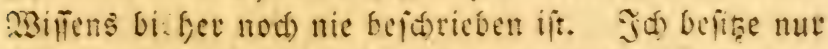

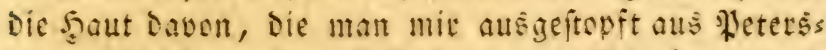

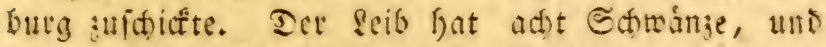

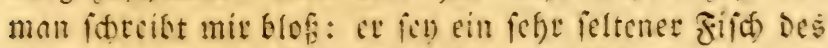

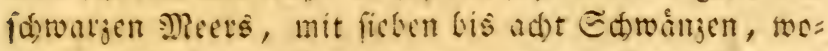

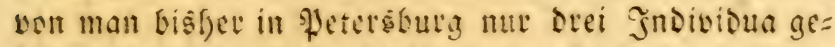

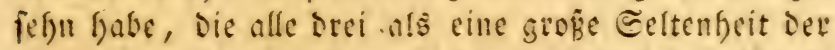
Saiferin und Den Bornefymiten Des Şofes geitenft murben. Ëin Ungefiuet fann Das Iffer aber barum nid)t fenn, weil (s) Dicimal nach einander und jwat

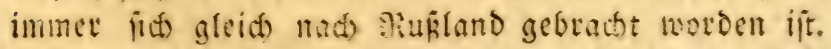

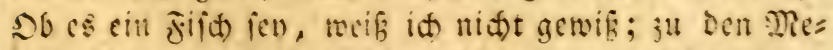

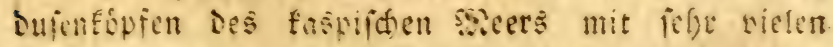

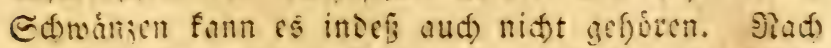

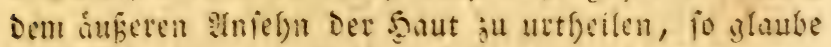

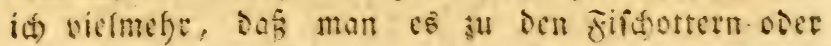


WBaffertaten rechnen fann, tweil es bamit einige Aehns

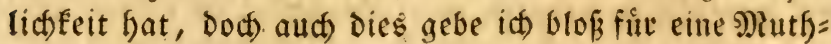

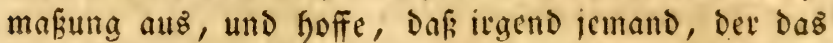
Bild beffelben anfieft, meine şefdreibung lieft und Die Sache beffer verfteft als id), ettvas Gegrumbeteres

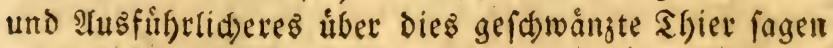
toild *)."

*), Krakatiza animal eft natatile, et inco1a Ponti Euxini, anemine, quantum fcio hactenus defcriptum ac delineatum. Hujus pellem detractam, et lana infarctaexpanfam, Petropoli in Germaniam miffam, fiftit figura decta, in magnitudine naturali, quoad corpus, et octo caudas, accurate depicta, quam in ulteriorem inquifitionem frudiofis rerum naturalium propono. Vis ifte Petropolitanus, qui iftud animalculum transmifit, fcientias a u tem naturales numquam excoluit, fequentia tantum litteris germanicis adjecit. Karakatiza eft pifcis practiofus, in mari nigro habitans, feptem vel octo caudis, in corporis extremo, inftructus Hujus animalculi marini tria exemplaria, tamquam donum peculiare, et rariffimum quid, ad regni Cancellarium principem de Cernasky, nec non ad imperatricem gloriofilfimae memoriae, fuperiori anno Petropolin translata funt. Monftrum certe noneft, ut quidam putarunt, hoc enim vel ex eo protiari poteft quod tria ejusdem condition is fpecimina hujus ani. malis uno eodemque tempore petropolin miffa funt. Num verofit pifcis, provero affirmare non audeo; ad caput medu$\mathrm{ra}$, maris cafpii incolam et multis caudis fuperbientem, pariter non pertinet; pellis intuita potius ad lutras velfeles aquaticas a me refertur, utpote cum quibus

- aliqualem habet fimilitudinem, fed hoc acertum quoque conjectura tantum eft, forfanalius, qui hanc figuram videt, faetamque relationem brevem hanc, ut th 


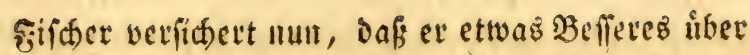
Den Solypen beibringen wolle, und erzálit, Daß el 1742 in Petersburg mit einem gried)ifden afrgte vom Sirafatiza gepprodien, und von demfelben gebolit babe, es fer ein Thier, das die (Jitiechen als Fajtenipeife

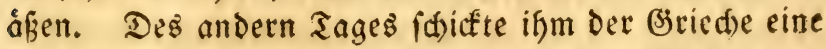
fugelartige, fnorpelige uno lederfáatige গ)?affe, nit Dem Srifugen: in ber allerftrengften Faftenzeit Der gried)ifden sirche lafie man biefe Maffe maceriten, práparite fie Dann mit Del und Eitig, unt fetefie fo

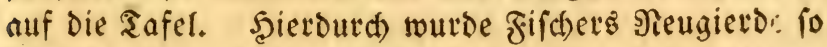
fefre gereitet, dafis er nidbt efger rufte, bis er einige

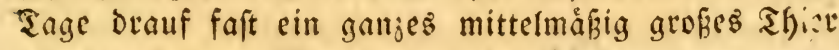
erfalten hatte. Dies legte er Der alfademie vor, ber= langte die Cintragung feiner Entdecfung und bat, Das

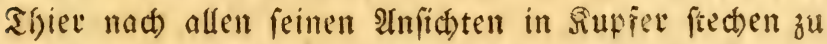
Iaffen. Sev Sitafatiza, fagt ev Dann, ift ein כ̈nfeft, Das zu ben Pflanzenthieren gehort, es ift fnorplig, le= Derfáatig und glatt, und endigt fid) in adft (Ełtremi= tåten. - - Ere fasliefizt Damit, Der Sirafatiza fey niduts weiter, als ein Medufenfopf des atlantifden, nicht aber (mie Brucfmann fagte) bess caspifachen Meets.

Diefer heftige Streit fiel 1749 vor, und ift um fo unbegreiflicher, da beide dic siserfe eines Belon, Fondelet, Aldrovandi, Salviani, Sesิnet und Jonfton vor Iugen batten oder bod baben fomter. fificher blieb fo lange Siézer, bis der Seranşgeber der Act. natur. curiof fie beide vereinigte. 2H. (5. Biht)net nafm námlid) Trifd)ers abfandolung mit auf, fügte aber eine Note bingu, uno batte Muth gerug, fie mit feinem

mancam, leget, meliora certioraque de hoc animalculo caudato, fibi melius noto, cum orbe litterario communicare poterit." Fifcher, in Bruckmann, Bano IX. Act. natur. curiof, ubi fupra.p. 337. 


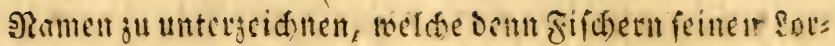
beev taubte. "Die genau nad) Der Natur genommene

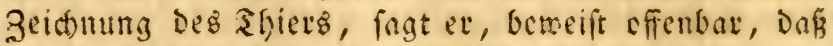
Der Rrafatiza nichts anders ift, als Die erfte und zweite Brattung Des Wolmpen De's Hondelet, Den Geŝner it

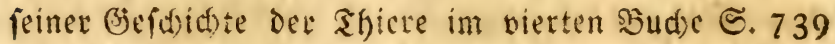
(Dev Fronffurter SDition won 1604) von einer Seite nut gezeicfinet hat.

Fifders bittere Ousfälle gegen Den trefflichen Brucfmann fielen nun auf ibn felbit juricf, bemn io beilfam fiut die $23 a b u f g e i t$ eine billige Rritif aud ift,

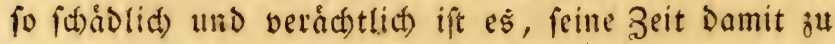
berderben, daß man Andre ofne Soth flånft.

Siele Semerfungen vetdanfen rir fifthern eben nidft, indep wir wiffen bod) Dutd) ifn, dafi der ge= meine \$olnp fid) aud im Irchipelagus findet, und $D$ af

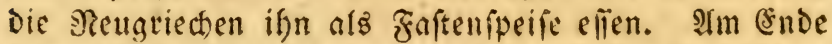
feinet abfandlung fagt ex nod), el befite dies Ifler nun foron fieben Jafie lang aufgetrodinet, uno blok mit Papier umwunden, aber nod) habe ju feiner gróften

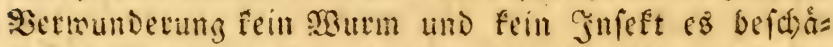

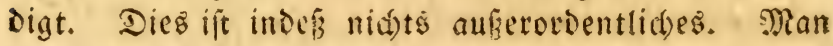
fiel)t ia tåglich in Den naturbiftorifden Sammlungen, wie fich bie meeriftrine uno ande Meerthicte im auf= gettoc aten zujtande unveriefirt etfalten, und vor je= sem angriff Der Sinfeften gefictert firto. Das Galz, roomit fie Durdforungen fino, faseint fie Davor zu be=

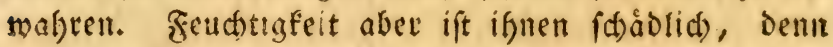
fie faulen Datmach und zerfallen in Stidfen. Den

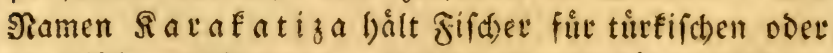
tatarifden Uriprunģ. Solepl Banfs fúfrt Fif hern itt Dem Ratalog peiner Sibliothet "als silten Sdiftetellet ube den Polnpen oder den

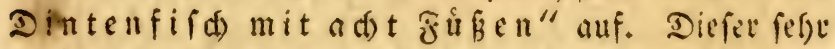
berüfinte englifde Belebrte fagt aber aud), Siolteuter babe im ficbenten bande ber neuern fommentarien ber 


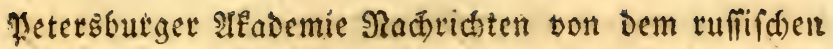
Srafatiza oder Sarafatiza gegeber. Die Rólteuteride Abrandlung redet abet von einer ganj andern (sattung von Polnpen, twie id) weiter unten barzutfun boffe, wenn id) Die zeidnung uno 3 sefdreibung eines fold)en

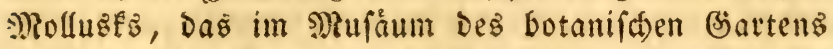
in $23 e$ ingeift aufberabrt wird, lieferm werde. Se mehr

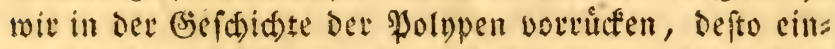
leud)tender wird es werden, Daj Darin nod) viel ju mimiflen îbrig ift, und baf faft alle Schriftfteller uber Dicfe Thiere fie niát geforrig fannten. Diejenigen, bie bló̈ mittelbarer şeife Davon fpradyen, baben ficher allemal Die fämmtlichen Battungen Des ganzen Bese:

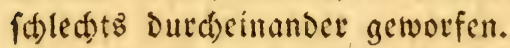

Die Alten aben febr viele Polnpen tno bielten fie für eine ganz vorzuglid)e Epeife. Man fonnte fie auf

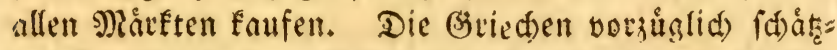
ten fie fefre hod). Sdyon vor Seomer's Zeiten brad)te man fie auf ihre Safeln. Wlautus will in feinen $\mathfrak{A} d$ at:

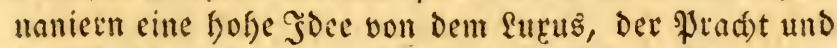

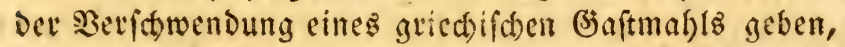
und rebet beshalb von einer Sefatombe \$olnpen, die

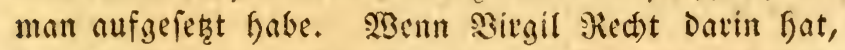

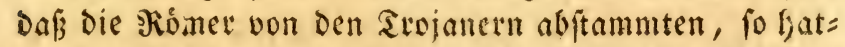
ten bie Abfommlinge wenigitens in biefer Sinfictst

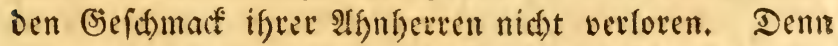
\$linius verfichert, Dof alle rómijaje Eecfermáuler die fämmtlichen Battungen Der Polupen fefre gern afen.

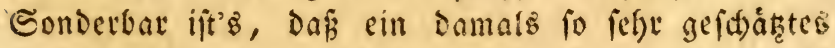
গaf)rungsimittel, weld)es Jafrbunderte lang als eine Delifateffe genofien wurbe, jeft nid)t blofs nidat

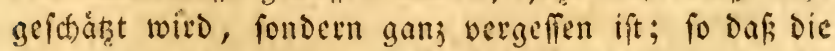
Siationen, die es ja nod) effen, z. (F. Die Peugriedsen,

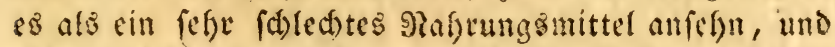
co nur in ben Tagen Der allerftengften Faften geniefen, was vielleidnt aud) ni(f) geidetgen wurbe, wenn fic 


\section{$\$ 38$}

nicht fo ftreng an ifren Seligionsoorideriften hingen.

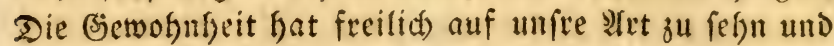

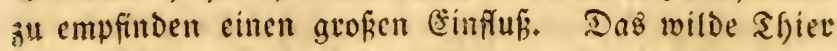
folgt blof Dem Inftinft Der Natur, aber das civilifirte

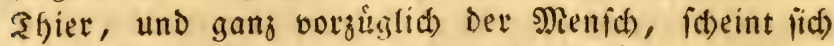
even fo viele fumftliche und idealifhe (senuife angeid)afft zu haben, als et Empfindungen hat. Diefe idealifhen Genulfe mudifiziten fich ins linendlid)e, Denn jedes Bolf bot feine ifm eigentfimliden.

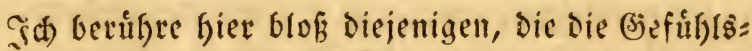

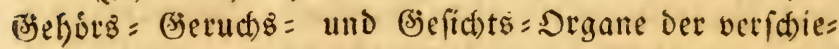
Denen গRationen Des Grobodens fo ganz verfdieden affi viren, benn $e \mathfrak{s}$ wurbe mid) zu weit fúfren, wenn ids alles dabin Beborige anfiffren wollte. Sine fettige

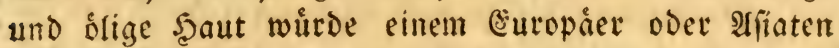
efilfaft feyn, bei einem Imerifener oder Ifrifaner aus Den heifferen begenden jenes (5rotheils *) gefort

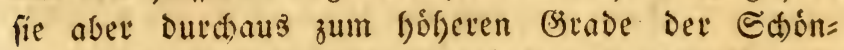

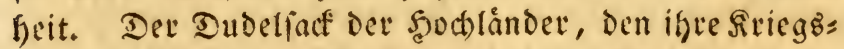

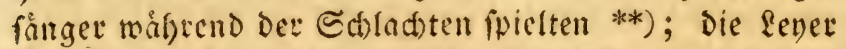
ber Savoyarden, die ungefähr eben fo farmonija fenn mag, als das ågyptifa) Syftem rar; Die Bambug=

*) Taft alle Bobléce Det warmen Lånder falben ifren Rơrper forgfóltig mit Del und Fett, um die Infletten jurúcfjubalten, Die fie fonft verzehten wirben. Das

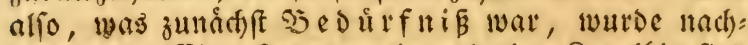

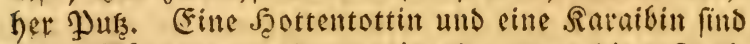

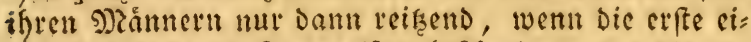

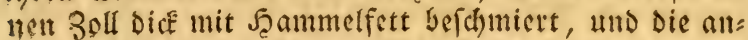
Dere yon Sioucou $=$ Del trieft. Şeides wirde unfere

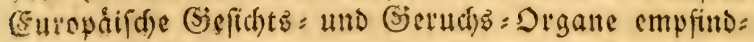
lich beleibigen.

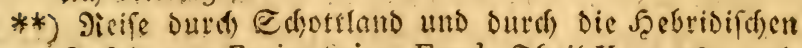
Inferir von Faujas Saint. Fond. Theil II. p. 280. unt an vielen andern Doten biefer intereffanten Dieife, Die mit siefen Detaits in Silisfidgt ber Semtutife,

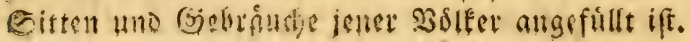


Mufif ber Stafitier und Das túrfifde Selárm *) belei=

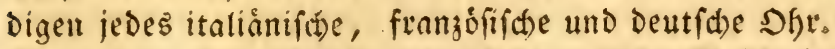
Dagegen macht unfre fanfte und fimmlifhe Miufit, ia Der jartmodulirte şelten żu fommen id)eint, feinen Csindruct auf bie Befournerven eimes $23 i l b e n$. Diffe, die das eine $\mathfrak{B u l f}$ als etwas Roftlides betrachtet, werden von andern

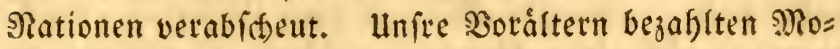
(d)us und Imbra fefre theuer, wir haben fie nicht blof vergeffer, fondern verbannt. Sedes Simb lernt rie= d)en, denn man wiederfolt ifm of ters, dak diefe Eubs

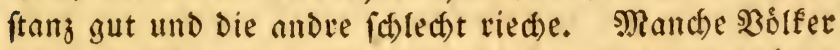

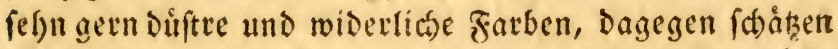

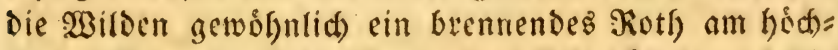
ften. Echwar ift bie Farbe Des Safrectens, unts die

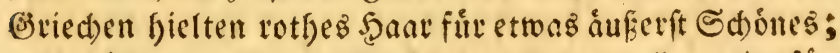

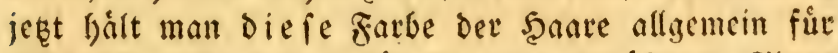
widerlid). Dies mag fưr die vier ertwábnten Sinne genug févit.

Iluf die Modififationen, Deten Der Sinn bez (3e= fd)macts fáfig ift, will ich midh aber etwas genauts

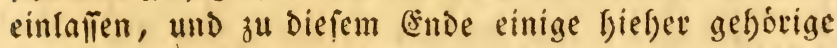
Thatiad)en anfüfren: Denn eŝ mód)te wohl unmóglicí fern, die tiefer liegenden phyfifáen llrfachen, die diefe fonderbaren Modififationen Der Drgane berborgebradt Gaben, anzugeber.

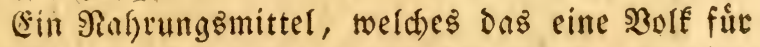

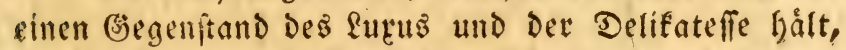
gereidt andern Bólfern jum Efel, ofne dáp man, auker Dem Sorurtgeile, irgend einen andern Brund Davon angeben funnte. Berwónnlich find aber dicfe 3orurtgeile fo ftarf, Daǵ Der \$obel Den benad)barten sationen ifre meife zu effen und zu trinten in Schimpfs

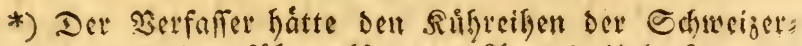

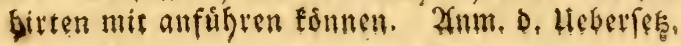


namen voursirft. Dew \$obel in England*), Glandern and Deutichland **) fdimpit ben Franzofen faft mit

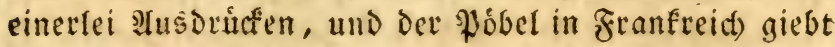
fie ifnen in eben ber $\mathfrak{A}$ t juruff. Sold)e Sduimpfreden vermefren und verlängern aber Den Nationalfák megr als man glaubt.

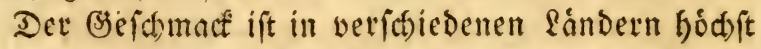

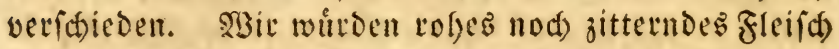
Durd)an nidyt effen fionnen, und bod) fal) Bruce am Sofe bon Gondar fefre niedidye Frauengimmer und junge

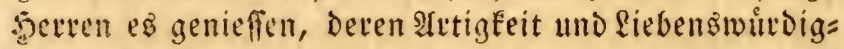
feit felbit in Den gewåliteften (अefellif)aften (Europa's gefallen !minten. Sair wirben aud) das Favoriteffen ber samtichadalen, iffen jof ala, fo wie bie vers fautten und gegofrnen Fifdfopfe, die die railden Des nfftichen Sibiriens als ecterbiften genieffen, zuruef=

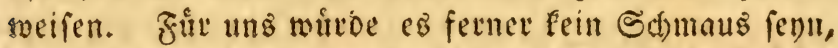
went twir, wie der Tatar, rofes mit Ed)aum und

*) „French frog, Soup miger, French fric affy." Der englifde Sandwerfer glaubt treuber: żig, Der franzofe (el) ein Frofh, Der nur TSallet trinte utno magere Suppen und Fricaffec's efle.

**) Pudt, Franche pudt, weldes auct Ftofts Eescutet. Der Dobel in Deutfd)tand ebenfallz

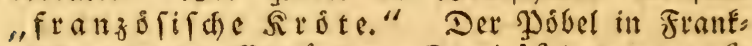
reich) nent Den Englinder "Rosbif" bon "roft beef" oder "gebiatenes Tindfleifh." Die

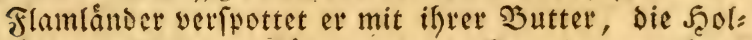
Iánoer mit ifrem Siáfe, unto die Opanter mit ifren

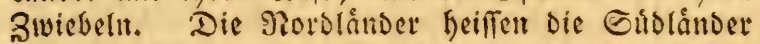
"Delfecfer und Sisaffertrinfer." Diefe nemen bie Nordánder Dafur "vuttedfeffer uns Sietronten."

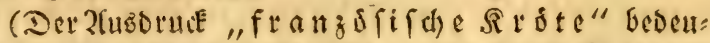

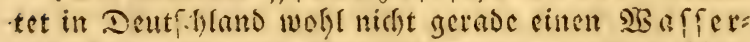
trituer, wie ber serfafer meint, fondern tibers

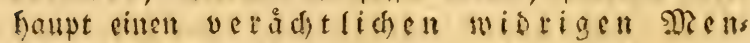

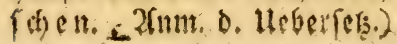




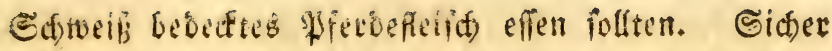
whrben wir aud nicht, wie Der Eftnefe, ganje Seet= Den von Sunden mápten, um fie ju effen; aud móchten wir fdreerliá) an ber feftlicten Safel Des srofejen, wo= bei Durebaus ein Sundebraten ienn mus, mit effen wols len. Mit (bfel wirden wir affenfeifth anfefn, Das man Doch an Der fpanifden Siufte von sietefo fo gern

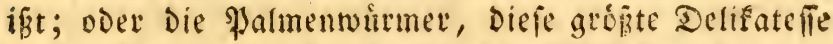
in ben fiolonien, soer die grofen bidectien, bie man bort ebenfalls fưr etwas gan vorzuglides Gălt. Die

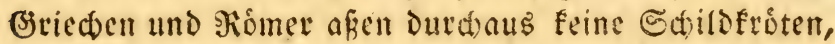

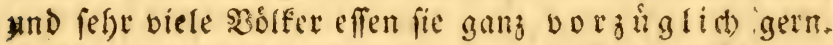
Ifu(t) in (suropa findet man nact)getade (Befdamact batan, Denn auf Den Sondoner Miáten fino jeţiger zeit Die Sd)ildfuten faft fo allgemein als in Den Intillerr. Die Ilten fingen fie zwar, aber blóp ifrer Sdale wegen,

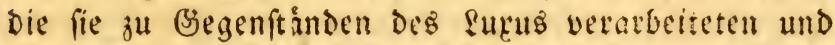
Dem Elfenbein und Dem (solde gleid) fichatiten *), Das Ifier felbit aber rufferten fie nidbt an. Sie afsen $D a=$ gegen vorjiglich gern murånen und Meerale. Die eriteren fennen wit faum, und die Meerale werden żwar háufig an unfern Riften gefunden, find aber fo verad)tet, Daßj Der gemcinfte \$óbel fie nid)t mag. Seit furzem fommen cinige Derfelben zerfanitten nad) \$aris, wo fie fefre woflfeil, aber nicht unter Dem Samen Congres fondern anguille de mer verfauft twe Dell. Sie Romer gingen in ifrer liebfaberei fur die Sinnecten ferge weit. Sie hatten eigne Saneclenmei= Den **), uno wa ir ůberlaffen fie Den Sabindfüdtigrn.

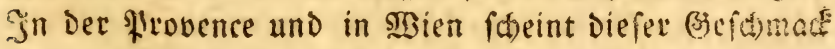
(iid) inder nod) erfalten fu haben, Denn da und Dor genieft man fehr viele đduneden. WBir effen feftr gern

*) Plin., lib. 32. cap. i I.

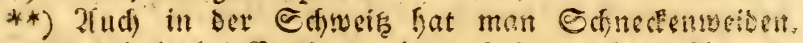

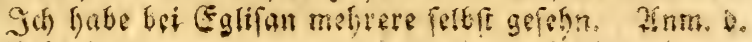
dieberfes. 


\section{2}

Frofdefeulen, in Eitgland uno in Flandetn verabidsut man fic. In 2 ien werden fie hingegen fefte von den Lecfermáulern geidáţt, und madhen einen bedeutenden

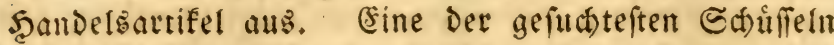
find Die blofien \&ebern ber Fruffes; fie erinmetn an des Ipicius Bericht, Das aนร blok̂en Zungen Der theuerften uno jelteniten $\mathfrak{B u g e l}$ beftand.

शud) Darin weidsen Die Nationen oft fefre von eins ander $a b$, Daf fie ein und daffelbe গafrungsmittel auf

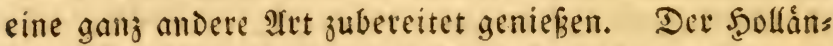
Det wurde fid es nie einfallen laffen, den gefalzenen Sering (Epeuffering, eillen Şauptfandunaģarig Der Scollánder) ju foden. Ext witrde, trot feinet

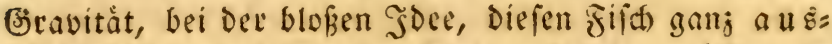

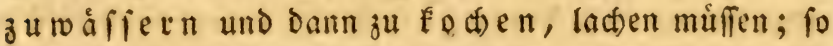

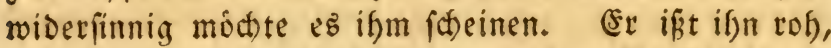
und ift ifn leidenfdaftlid) gern roh. Die Ruffunft Der eriten Sceringsififter if in Solland ein allgemeines Ferudenfeft. Ein Franjofe, befonders ein Parife:, Dem man roben Sering vorfecte, wirtde fid Dures Demielben

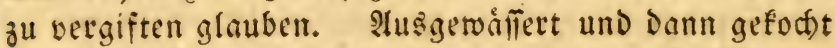
muß er werden, fonft geniefter ifn nid)t. Selbft Dann aber ifft ifn mu das gemeine $\mathfrak{S}_{0}$ lf und aud) nid) ein= mal gern; im গlorDen hålt man ifhn Dagegen fưr åuß̌exit gefund und hod fit woblidmecfend. Sivir halten cine Freifabruffe fur etwas fefre angenefymes, und ein gutes franjúfif Fleifi)fuppe anfangen. Sin England giefit man nod

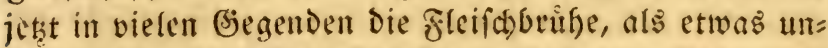

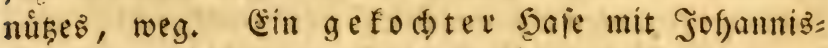
beeten = Belé ift in Ënaland ein fóftictes Beridyt; eis

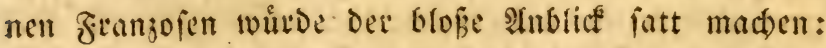

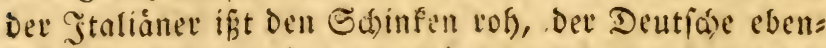
falls, und bie getáucherte Banfebruft baju: Dev gefals

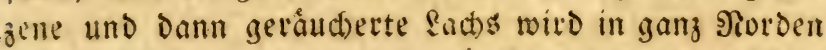
тоদ) น1: jwar als etwas vorjủglich Delifates gegeflen; 
einen Frangofen toittbe vielleid)t der Druffendite Şunger faum Dafin bringen, ifn ju berubren. Unjere $\mathfrak{B} 0 \mathrm{r}=$

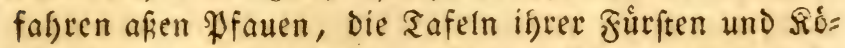
nige waren mit gefochten Pfauen, Die man mit ifren

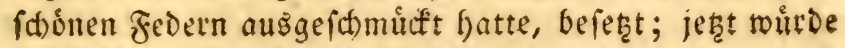
felbft Das gemeine Bolf fie nicht mógen.

2Benn man erwágt, wie fe $\mathfrak{r}$ viele Polnpen von ben Ilten verbraucht wurden, is mód)te man fiagen, ob Denn Damals mefa $\mathfrak{r}$ Thiere Der Art da waren, und wie das zuging; Denn jetst findet man iffer fo wenige, Dafi man meinen fónnte, fie Gåtten fid) betråd)tlict) ver= mindert. Llno Dod) follte man glauben, dafi ifrer jek̨t bei weitem mefor feyn múpten, als einft, weil fie nicht mehr fo weggefangen werben, wie Damals, folglid)

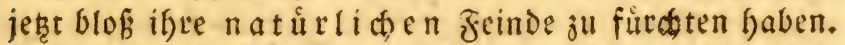
Statt fefr baufig auf Den silften zu erfdeinen, bleiben fie aber jef̧t wabridheinlich mefre im hohen झneere in ei= ner gewiffen Tiefe, two fie naturtict mefr grifhe findan,

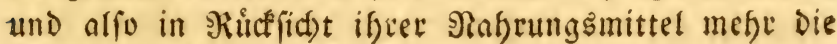
WBafl haben.

Die Fiffer haben allgemein bie fidere Bemerfung

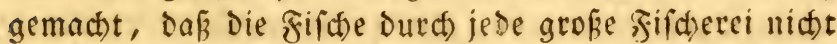
feltener gemadst merden, fordern daf fie fid) viémefrs nach einem fold)en Sort hinziehen, unD melge als fonft da gefunden rerden. Se mefre fie fifchen, defto mefr Sifft)e finden fite. Der (j)tuns ift ganj natúrlich. Die

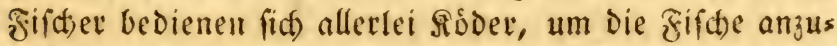
locfen, und mit ifleen Inaeln, 9iesen oder fonft auf is: geno eine $23 e i f e$ zu fangen. Sin Theil Diefeg §óders fállt, fo wie mandús andere, was aus ben Edbiffen heraus geworfen wiro, auf Den Bruno Des Meers,

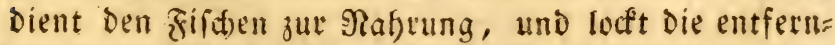
teren an. Maturliduerweife verlaffen fie nid)t gern eine Begend, in weldert fie ifle Naflung im Heberfú fin Den, obne fie arft muthfam aufiuchen doer Deshalb fản pfen zu muinen. Bleiben cimige bier, fo ziegen fich ant 


\section{4}

Dere von ber gleiden (stattung ifnen nats, und fie vers vielfåltigen fich nun f(h)neller, als man fie twegfeñngt; aud) lauern fie an folchen Drten fo na be auf alles,

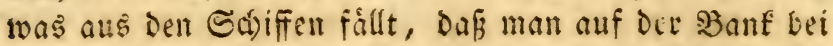

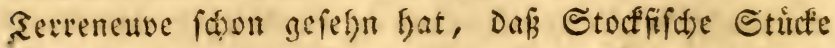

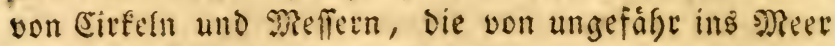
fieten, im গiederfirfen verfd)luctert.

Durd) Shilfe Der Fóder gaben induftriofe refid)er rie und ba fdon blope Zugfifate fur eine lángere Zeit jurict gefnatten. Die ungebeure Menge von Sardellen

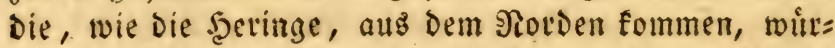
Den bie Sîfte von Bretagne, mo man jeţt mefre als otwei Millionen berfelben jåfrlich fángt, nut ft reifen, und fefre fahell wieder verfáminden, wenn das nidt wåre. Inber Die bretagnifden filder verftefen, fie Durd) Stodfifidgrogen, Den fie tingefaljen von Den Sols landern faufen, anjulocfen:uns gleid)fam zu feffelir.

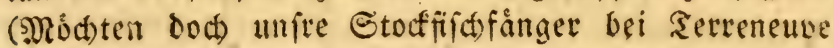

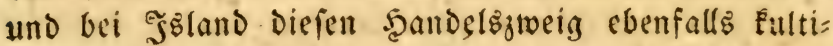
viren! -) Die gefalzenen Eier ftreuen bie fiffer ber

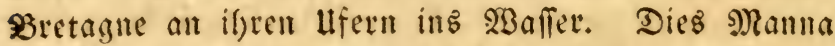
ziel)t Die Eardellen an, ifnen folgt wieder eine MRenge

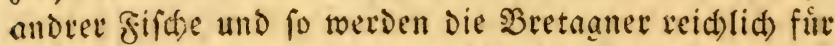
if)en Alfwand butd) einen glucflichen Fang bejahlt.

Sionnen fie des sirieges oder ander lumftande wegen folden rogen nid)t befommen, fo laffen fie ifle s3eiter Durá) Sulfe einer breiten feinewand oder eints

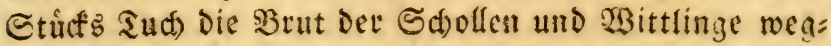
fangen uns bereiten Dawaus einen! Seig. S(t) batte aber

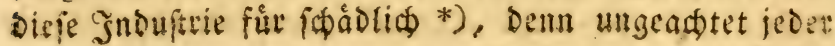

biefit:

*) Die fircherei Der Gádye, Gtrỏne und Tciche hat ichon lange unter Jjefergen geftanden, aber Die bes

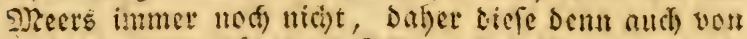

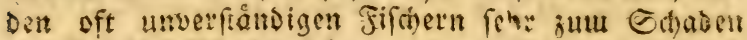

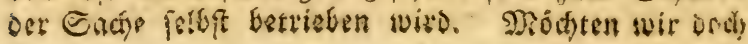


Diefer fleinen gifore faum to grof ift, wie ein Betreis Deforn, fo fanaen lie Dod in Deei Etunden oft einluns Dert uno funfaig Wrand Derfelben, und rotten alfo da

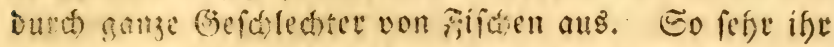

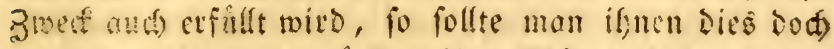
verbisten, benn fie wituden ifere abfidt aud auf cine ander siserfe erteiden lernen.

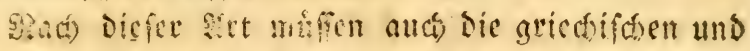
romifuen Fiffor bie झofipen an Disjenigen Drte zu locken wewanden basen, wo fie fie zu fangen pfiegten.

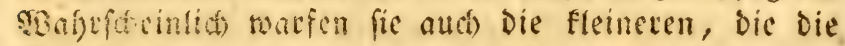
githe viót bejablt borten, weil fie fie nicht theuer loz wureen, mieder ing sisaffer. Infireitig exiftiten bei

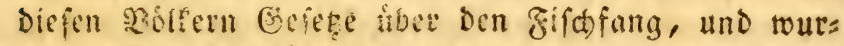
Den beffer ausagfübrt, als bei uns; Benn es fetreint,

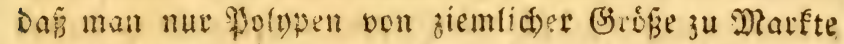
brad)te, wenigftens waven die grofften dic gefuchteften. Mran hat hiteroon eine brollige Anefoote Deg alter:

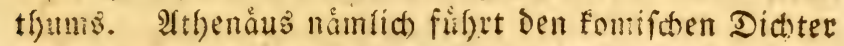
SRadon an, bet auf Den Ditfyrambendid ter \$filoxenus ein Epigramm verfertigte. \$1fifokemus cin befannter Sd)welaer, lief fich in Ëracus einen \$ointen von faft orei fub bereiten *j, und veszebrte iijn in eimer Mafl=

in Sildefict Des Firchfangs liberbaupt und ins befons Dere gute und anf jeocs Dotale angetapte Gelebe er: Galten, um Den ungebeuren serffhwendungen man: c)er fificice zuvor zu fommen. Llnfe Nacibaren find Darin weifer. Die frollénder z. S3. Laflen jeden Fia fajer, der gegen die siefere uno allo zum Echoden Des Giangen fifht, foine (Sicldftrafe plintitlich exlegen.

*) Egragium vero aiunt Philox num,

Dithyramborum poetam, fuife

Gulonem, Nan duorum cubirorum polypum

Syracufis aliquando ipfum emiffe,

Et preparatum conedifie totum,

Prater caput affirmant. Captus zurem crudieare

Vehementer aegrotare coєpit. Tum medıcus quidam 


\section{6}

feit ganz, bon sopt allein ausgenommen. Diefe

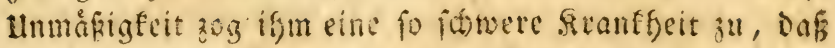
ifm fein grat nut noch einige Etusioen zu lefer gab. (E⿱ aber touste fich zu benthmen, empfall leine (3jesidete

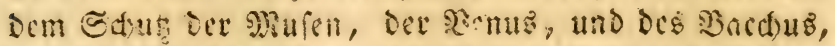
und lief fid bann ban nad hurigen Wolupenfopf brin= gen, um nidits auf bicfer cerbe jurneffulafien, was iffm bedaucriswerth faleine. - Die sfmefdote seigt Den Enconismus ber Damaligen \&erge, fo mie insbes

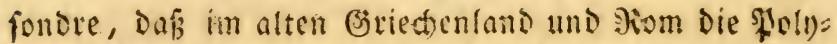
fen von den હdwelgern felse gefudt trutdent.

W! (nius fůbrt unter andern on *), auf welde forgs fáltige 2 rt man z̆ $2 B e r f e$ ging, um ibrer Zartheit und

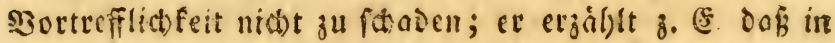

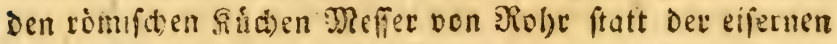
gebraud)t murben, um Dic \$oltpen auşoumeiden, Damit

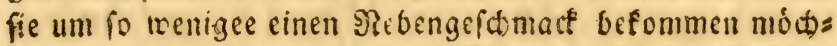

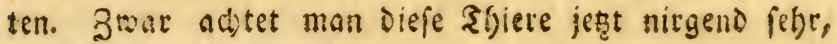

Ingreffis ad eum, ut magno tnalo

Eum preffum vidit. Si tibi quid, aic,

Nondum ift difpofitum, celeriter difpone

Philoxene. H ra enin feptima morieris;

Tun ille refpondens, omnia mea ad finem perducta funt,

Medice, inquic, er jam dudurn difpofita.

Dithyrambos diis relinçuo

Viriles, et omnes corona dignos,

Quis et meis collectaneis appono

Mufis Venerem et Bacchum turorcs effe,

'T. ft muntum hoc meum deslasar. Verum quoniam

Tim thei Charon nec otiare non finit,

Neque Niobes, fed fretum capiendun inclamat,

Otfcuraque me $P_{\text {arca }}$ vocar, quan audire neceffe eft,

Ut : mnia tnea abiens hinc auferars,

Date mihi, quicquid eft relictum polypi! -

*) , Muriam ex fefe emittere et ideo non debere addi in coquendo; fecari arundine; ferroenim infici. vitiumque trahere natura delinente." Plin. Lib, 32. cap. 10. 
aber dod falget man fie in manden fogenden of. in flo Incien uno in Dasmatien ell, und verfúltet fie nad $\mathfrak{B e s}$ neora. Die Ningrieden trodinen fie auf, wie toir ges

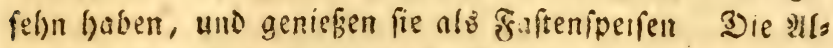
ten forieben ifgnen ftimulirende siráte ơ uno afgen fie vielleitit dirferwezen fo voriuglich gern sille damaligen

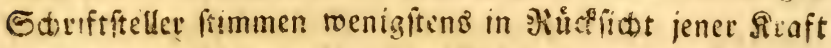

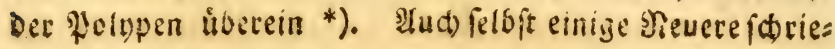

*) "Qui in venerea paleftra debiles funt, polyposedant monente Aëtio. Diphilus et $P$ a ulus Aegineta eos plurimum alere affirmant, et libidinem maxime irritare Diocles apud Athenaeum ait polypodes maxime inter mollia ad Venerem conferre." Aldrov. de Moll. lib I. p. 40.

.... Cum anes quid cibi comparafti ... Ecquid $\mathrm{m}: \mathrm{gis}$

Conferat, quam quod nunc praefent adfero; buccina,

Bulbos, magnuin poly puin.

$$
\text { pectines, }
$$

Alexis in Pamphil.

, Ruit domus inf esunda dominorum infortunio, Lab factes eam fubvercit alaftor quidam: pelopidarum Sterilis domus eft; nec e pr: fundo cervicem exerens, Ac Cereris contuberialis rerra procreacur buibus amicoruin

Cum elixus eft, adjuror, haic malo fuccurrerit;

$R$ in nec maris cueruleis educatus verticibus

Vinartin mutator polypus: caprus hominum

In torto vinculo cum rotam virgo circunduceret,

Implet repofirorii capacein pest ris finum, ".

Xenarchus, apud Athenaeum, lib 2. Verfio Iac Dalechamp.

"Adferuntur Venetias ex Illyriae Dalmatiaeque ora fale inveterati: quorum acetabula et extremitates cirrorum ad parandain fobolem expetuntur. Curvero Venerem ftimulent. . . Caufam putant quod durae fint carnis ac flatuofi.. vel quiafalfumfuccum contineant, caeterum 


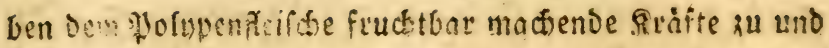

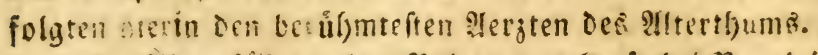

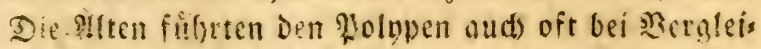
d)urae" auf. Ga feibit die Megubtier in den emfenteften

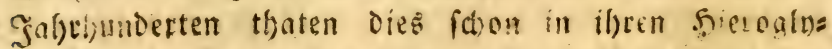

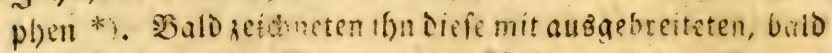
mit verftumelten oder gat mit biflig verlornen Atrmen: immer aber wollten fie Daeurch eiten Berfotmenter andeus ten, der nidtt nur anderer \&eute Bermógen verialewdert, fondern aud) jein ergnes fogar vergeht. Eie bezogen fid námlit) auf Das Damals allyameine Şorurtheil, Daf Der

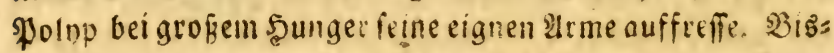
wrile!l findet man in ibren Seleroglophen auch einen शyoly: pen unter enem IJeeraal abgebildet; Dies folite bann

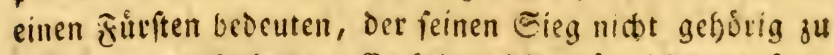
benuţen gemufit babe. Es fpielte dies námlich Da:auf an,

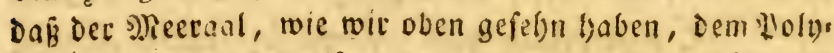
pen.feine 2ame abbeift, ibn Dann aber fo berftumelt und of)ne $2 B$ affen, womit ec fich gegen feine wetteren Ins griffe vertlgetoigen founte, fabren lágt. Zwei sloinpen in cinander gefdulungen bedeuten oas 2 Binterfolftitium,

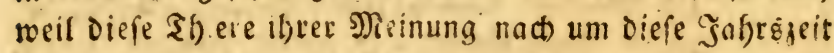
Der slebe pflegten, und fich dabei fo imnig mit enander vereinigten.

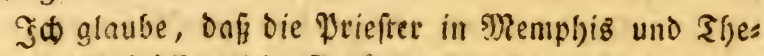
ben nict) blof iffentlictie (sebáube mit Şierogloplen uno

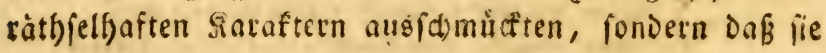

ego non tain propter allatas rationes, quam propterfeminis copiam, quam generant, fi probe elixentur, et concoquantur, libidinem exeitare affirmem." lovius, lib. de pilc. rom. - Aldrov. de Moll. p. 41 . ,Bulbi, cicer, fabae, polypodes...... inter edulia multi f'eminis recenfentur, " Galenis 5 fimp medec, facult.

*) Horus A pollo. Hieroglyph, 2. et 16. Pierius Valerianus. Hieroglyph, lib, 27. 


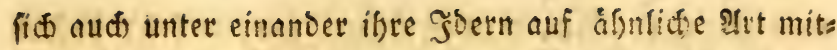
theilten. Wollton fie ferner einen syenfonen bezcidnen,

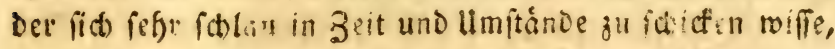
fo malsten fie einen polvpen, Der fich an einen felfen feftriclt uno die Farbe oefficleen annalym see ben Brres den war biefe Beraleidung, die fie aus ber beiligen

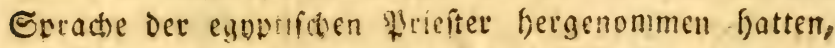
allgeme'll gebráuctlia)*). Uluffes, ber liftige und vorfict)=

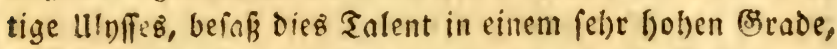

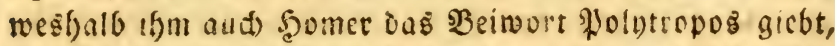
Das von Der Qeid)tigfeit fergenommen ift, romit der ${ }^{\circ} \delta=$ nig von Sibaca allen umftánven fich anjufidmiegen, "allen alles z ben einen foltien Rarafter als fefre gefabtidid getadeft, uno Tieuere veraleithen in riefer g!eichen Sinficts den Odmeidlex mit Dem Polupen oder (Ef)amdteon, weil er, wie fie, alle Farben anjunefymen verftifhe. Ifud) Den (seis bigen vergleitaen bie alten mit iem lolypen**), Denn ber

D) Polypi mi fili, Amphiloche heros mentem habe $E_{t}$ ad quorum gentem veneris te is accommoda. . . .

Clearchus, lib. fec. proverb. latine vertit. Iac. Dalechamp.

Marinae beftiae colori

Mentem potiffimums advertens.

In urbibus omnibus verfatur.

\section{Pindar.}

Tu rempublicain tractas, efto polspus moribus.

Athenaeus in Eupolim, vertit Dalechamp.

Nullus frugi effe poteft homo, nifi qui bene et inale facere tenet,

Inprobus cum improbis fit, harpaget, furibus furet quod queat,

Verfi pellem frugi convenit effe hominem:

Pectus cui frpit, bonus tit bonis, malus fit malis,

Utiunque res fit, ita animum habeat.

Plaut in Bacchidibus.

**) „Pecrore neve aliud caeles, aliudve loquar: :

Proque loco variere, perris uti polypus haerens.... 


\section{0}

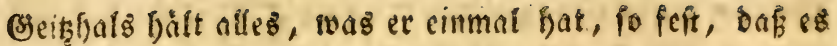

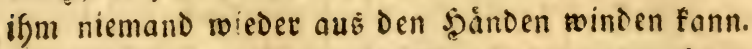

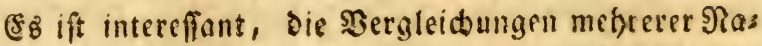
tionen naw ibrelt berfatedenen Sitten - in Xúcfict toez \$olnps - neben cinanoer ju ftellen. Die ermfte und tief Durdjoadte ßeligion Dee \&gopter bejog alles auf politi: $\{$ die Begenftande und auf Die gemeinictaftliche (Erija!tung. Die Brieden manden den gleiden Begenfand auf bie

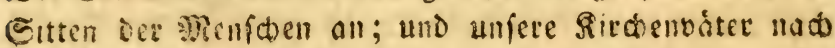
ifnen betrawesen bea Wolopen aแs enen melje myftis

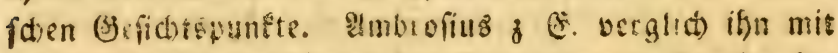

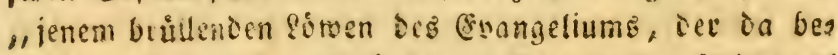
ftandig umifer gebt und fudet, welden er verfalinge."

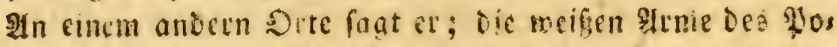

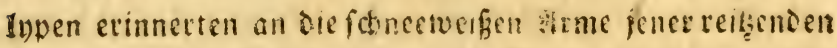
Everwen, Der Puefterinnen und Duellen des finulider

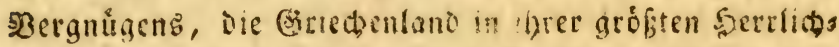
Feit fah, ja icnen es bišmellen fogat altáte erridtete.

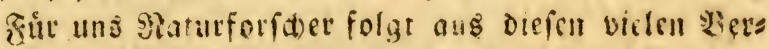
gleidtungen, Die man ehemals mit Dem Ploit)wen anftllte uno bie jest faft alle vergeffen ind, oafs cos shier fribit, bas dabei zum Gitunde lay. unbefant geworden icnn mus. Iuf einigen aiten Mituzen uno Mroallen von Sarent

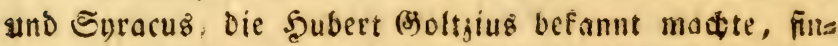
Det man Den Polopen ebenfalls abgebildet. Die Taren=

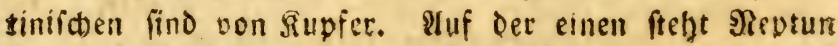
auf einem Delphin, in Der rectten feand fermen Dreigna und in ber finfen einen Woltupen, ben er fo ebell aufges nommen hat, haltend. Der Delphin ift mit einer Famms mufdelfdale ') gef ont uno oie limfdrift enthált ben

Saxatilemque cum exfanguibus cirris

Qdi mutantem colorem polypum."

Phocillides, et Aihen. lib. $\mathbf{I}$ in Phaenicis ion tragici.

*) Cine Ifrt Durpurfonteffe, der Difelfopf, murex rectirofter aculeatus.

Znmerte. D. Heber. 


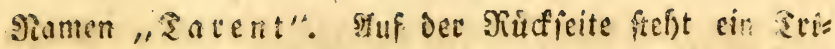
ton mit feinen Sorne (Eecmuftel). Eine zwotie Saremo

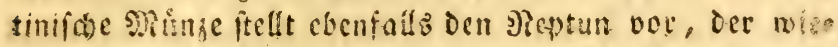
ier in Der enen sjend einet Polypen bat Der Sopt Des Delphing ift aber ofne smuffel. - Soon Den foraculanis idsen Mrinen it ore ene in supfer uno bie ante in

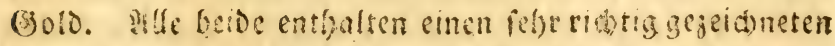

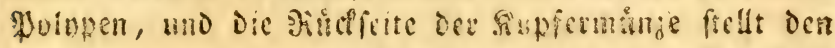

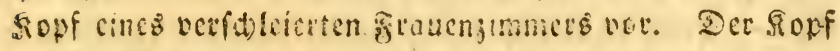
ouf Der solbmenge ift nidtminder, aber auf eine anore It $t$, betfolciet.

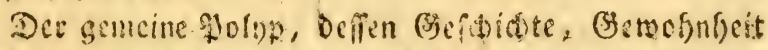

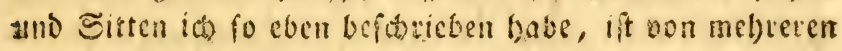
neueren ङdriftellesn mit Dem fogenamten armpolypen

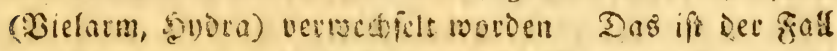

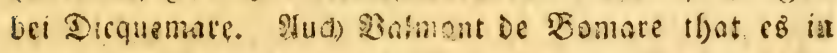

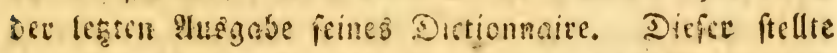
gat alleż, námlic den gemeinen Wolnyon, den Bicfenpolts: per, ben arafen, bie Edswamme, foraflen und mifros

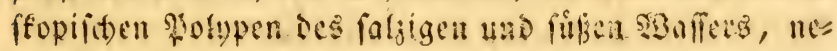
beil einander.

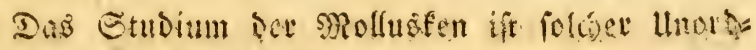

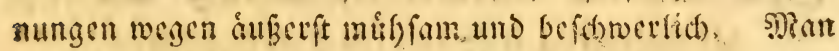
geráth nid)t felten in Die gróste siertegenfyeit, wemt man bie Gattungen mieder von einaner abjonbern will, Die die Edriffteller Durá) cinanart gemotfen baber.

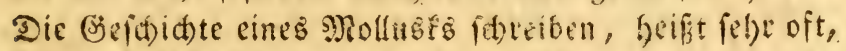

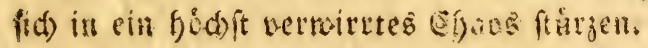

Siev endige id Denn die Befdreibung des zemei= nen Polups, Der fo recnig befannt tind dod in fo velet

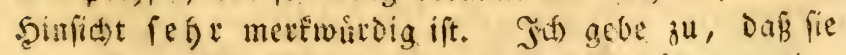

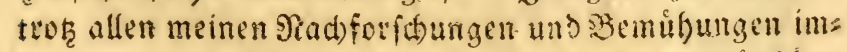

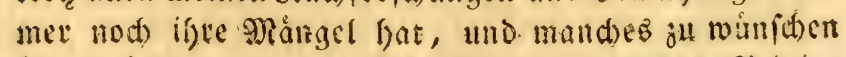
ibbrig läbt; wemn ein Sd)rifttetler aber Das. Eeinige getfan bat, fo mufis man aud gegen ifne wieder billig feyn. famart, id́) toicserfole es bice nod cimmat, fon: 
Derte zue!ft einige Gottungen Diefes Nollusfs bon ein: ander ab, Die vor ifym Duech einander gemorien geblies ben saren. Durd Stiffe finer Boratbeiten erft ift es aud) mix geglufft, neue Gattunacn ju erfomen, und

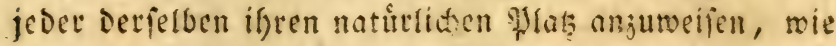
id) es mit den nod ibrigen ferner thun werte. 2tle find mefre ober reniger will, we ser gemeine stolyp und haben aud) ungefälys bie gleid)en (sigenlid)often mit ifim. Fe: ift immer noch Der befanntefte, uni foll bes= balb fü Das ganje Geidtect zum urbilde dicnen. Sebt wenden wir uns ju dem siefenpolypen uno jum arafen, zu biefen afferen, die man fo oft fir Fabel wefen gefalten hat, Deren Exyiftenj jeţt aber ausge: madt ift, und uns jeigen fann, weide ungefoure (s) fdopfe bie Satur hervorbad). SRad) ifnen merde id) Die fleineren fioinpen ornegmen, die mit son ge=

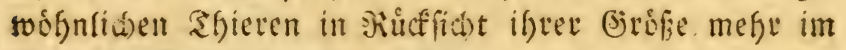

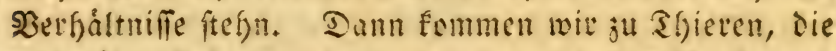
unts någer fint, von Denen wir unsิ aljo Deutlid)ere uno flatere Begriffe werden veridyaffen fónen.

\section{Crklärung Der oreiund;wantigften, vierund: ztoangigften uno finfund gangigften fipfertafel.}

Safel breiund;wanjig. Dev gemeine Polnp, von ber Phicfieite angefefen, die ärme welleniơmig ges frummt uno ausgebreitet; er lauert auf feinen Raub.

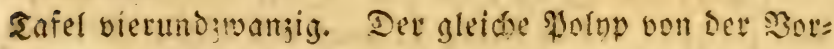

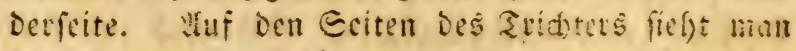

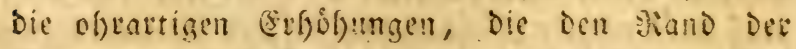

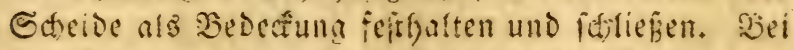

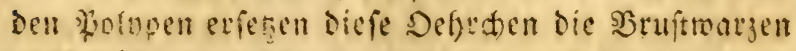
ooce Siffungen tes Dintenifiches, und die jangenar: tigen finorpel Der Galmars. 
Tafel finfundjwanjig. Fingemeibegang bes gemeinen

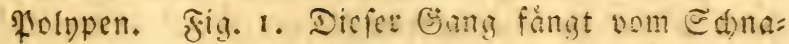
bel an. a, a, find jwei mazen, bie ifjet kinge nath auf einanber folgen; b. ift bas inieltinun coece m (Dex blinde Darm), Das fpiralfirmig in einandet gewidelt, und in Der soltte Diefer Pliftellung sutd)s lócect ift. Daŝ Inteft num recum geft ton bems felben in mefreren folten "innbluarts, Dann fteigt

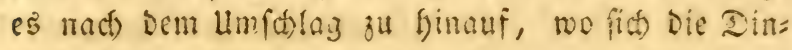
tenblafe c. imferitr.

5ig. 2. unten. Etellt bie Sberfide eines Sinpfonens

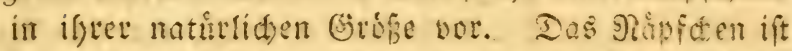
von einem Polypen, Der in feiner groffen suete

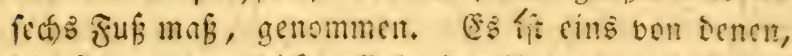

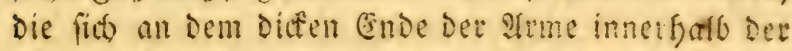
Saube, etra fed́s zo!l weit vom Schnabel be pinden. Die an Der \$afis ber sfme find cin wenig fleiner; Dann wetben fie groffer, weitcr bin abet nebmen fie micder ab, tho zwar immer mers, is binner bie Irme werden, bis iie zuletrt an ben Episen beviel

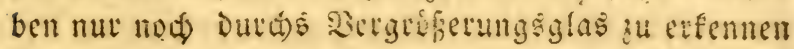
fino.

\section{Der Sieferpolyp *).}

Da id hiermit Die befoldte ber gresten ?asere,

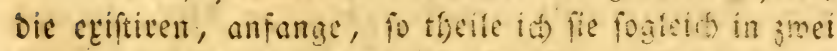
Battungen, die $i$ c) Duté) Diesamen: , thiefenpe=

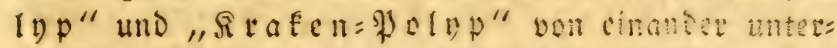
fitheiden merbe. Feins von allen befanten safen fam

*) Polypus monftrofus. Plin. lib. 9 cap, §oSenedectes. Plin. lib. 6. cap. \& - Polypum ingens. Aelianus et Fulgofus. Piftris. Ortus Canitatis. De pifcib. cap.69. - Quiphium bei אinigent. - Xiphia. Olaus magnus, - Encorner oder Cornet des marins. - Ankertroll auf bås niโd). 


\section{4}

ung bierbei fum Eegenftand ber Bergleidsung Dienen, benn fo viel bie feleplonten fleiner find, als die 25 all

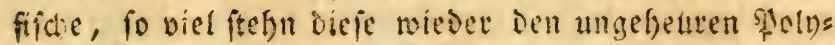
pen mat), von benen wir jeht teden werden. Sie fino dir grefften uns befannten organifitten Mefen Do: Satur. In if :e m refenmápigen fiorperban fheint

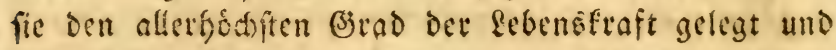
entwicfelt zu haben.

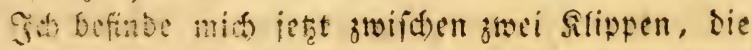
mir beide gleidse Befabr androfin, sod will id ifhen

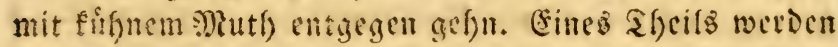

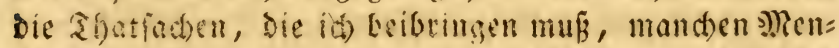

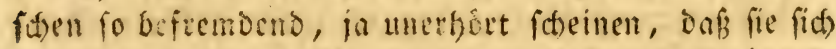

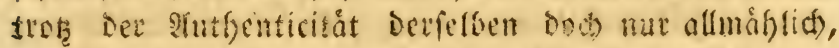
and Eiefleicht ungen entidflefon fimnen, fie gelten zu Jafien. Sielleicht wiro auch mander biefen exfen wi=

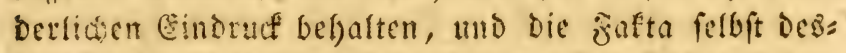

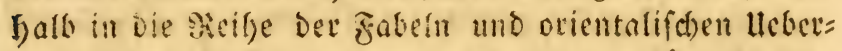

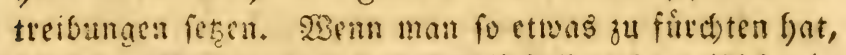
fo ift Die szerlegeniseit bes Sd)riftftellers begreiftich, ia fie muf Etatt finten. Dent wenn ex endern Theils

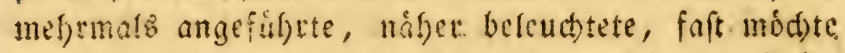
id) Fagen, oon Den Sinturforfdern anerfannte Fafta

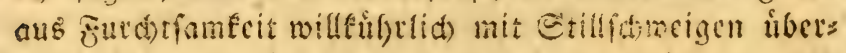

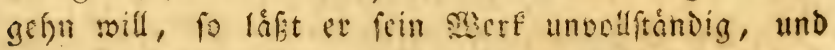
fein 3 wed ifs nioft erreidst, Desn er bleibt Dadurch

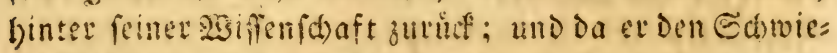

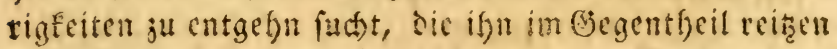

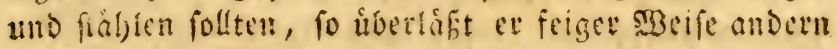
Die Effre fein $29 e r f$ zu vervollftandigen. In Diefer gants eignen lage bleibt feine $23 a b l$ libtig. Mill man fit

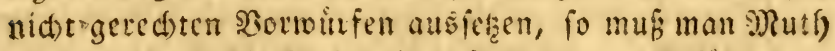

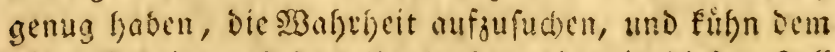
bijen Ga)eine uno Dem linglauben (Der in Diejem fall zu vergetifen ift) troken ju fismen, mus Den criten Da= Dutch bejeitigen, Daßs man Deweife fur jede Seuferung 
anfiilint, uno sicie serweife in ifler bolligen Glarfeit Darlegt; Den linglanben aber mus man unnerflid) uns fufenweife bis jut innigften llebersengung fughen, die

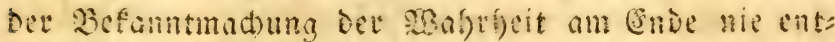

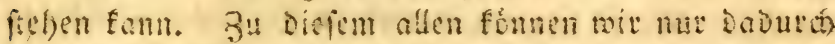

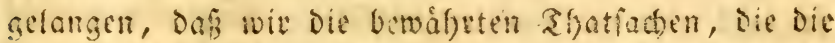

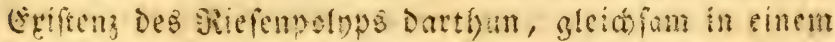
Brempunft bercinigen. Saem wir fie erf botndig uns unwibetegfid Sargethan faben werdon, fimes

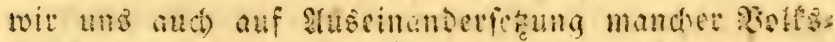
Trationen, dest Eteuten ciniget Edrifteder, uns

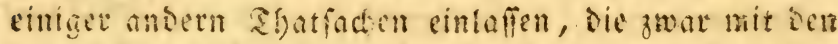

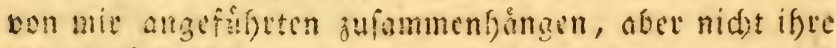
BStandminteigfeit baben, weif fie minser genan uno ftenge beobaditet mutbent.

Die aften haben ben sicienpolupen gefant. .

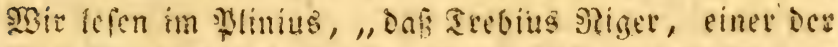

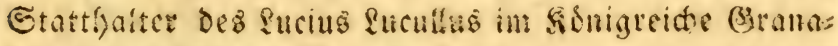
oa, ifm verfiathet habe, bei Carteja, - simer Sand in Gianada - Fen ein ungefeurer \$olnp, angitodt

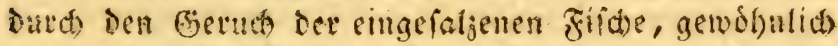

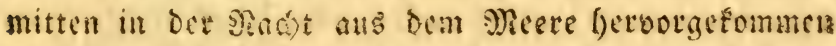

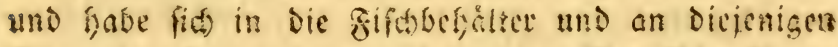
Serter begeben, wo man bie grofen Mecrfifde *) zus bereitete und einfaijte, Dann aber, wenn er fiá) and Selteben genommen, uno ungelyeuren Sd)aden gुetgan, (ei) er wirder ins Meer juritgegangen."

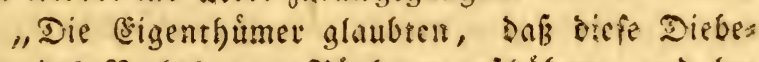

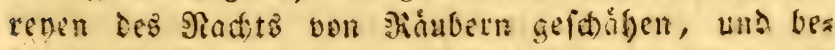

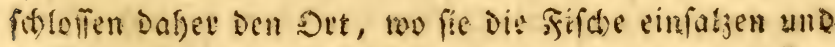
trocfmen fief́en, mit \$allifaten 3s. verichliefen zu laffer. Dirs Gimbette aver Den \$yofnp nicht, wisecizufommen. Er uberifiea des Bjefege ouf einer Etelle, wo cin Baum mit in Demfelben befindtidy roat, who fufte nun in feine?

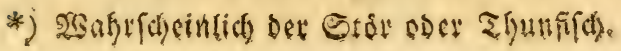




\section{6}

Rruberei fort, fam fefr oft, tund nafm jedesimal feinen Siaub mit fich, bis ifn dic sunde endich eimmal fpit: tell, unb ifn bei feiner Ruffelyt ins sheer anfielen.

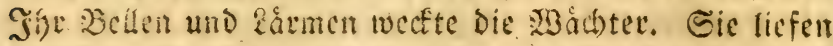
berbei. Man fann fich aber iften Schect denfen, ats fie witten in Der Dunflen פiacht - was Den Inblicf

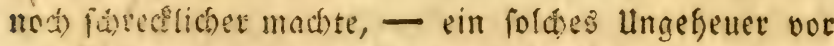
fii) falcen, das auser feiner Bitefengrofe, nod) ourd Die lleberrefte des Calzwaffers, worin es fich fo eben gewalyt hatte, bafilid war. Sgic fonnien fie ferner fos gleid an eiren Poinpen ieneen, Da fie von einem fo giofien nod) gat feine Borftellung gatten. Eie ent: fetgen fich alfo, benn fie waven ber fefen-Meimung,

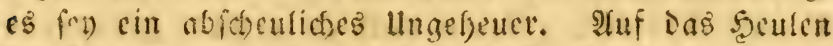
Der Sunde antwortete das Shier Durd) ein lautes Eanardsen, folug mit feinen Armen wie mit Sieuten

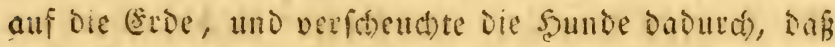

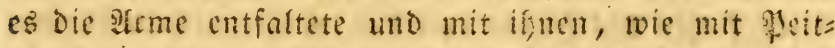

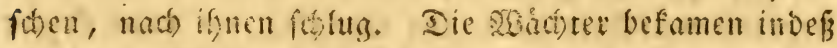

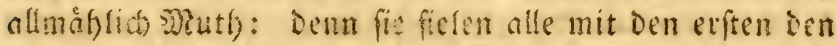

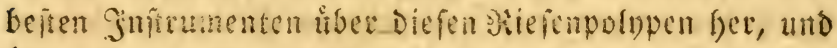

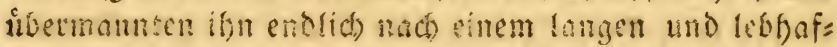
ten saibreftande. Ean fiopf wutve dem \&ucullus ge= bradst. (Et wat fo grof wie eine Sonne von funfael)n Imphoris *: Seine Bartioen oder Srme waren Dreisig Tuf lang, und po Dict, Daf cin thá)tiget ftitfer Mann fie faum umflaftern fonnte. 2uf ifter Sber= fiache fin fabe man Snoter und fnotenágnlide Berfár= tungen, wie o. (3). Die झinde Des Soljes fie hat. Die

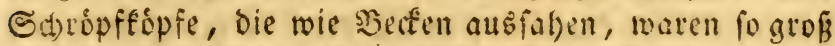
wie eine ltme **). Sein grofier Sthnabet ftimmte mit

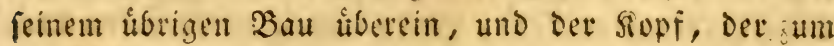

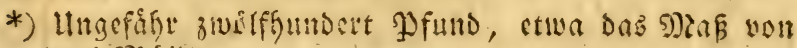
zwei jatítos.

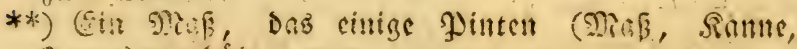
Duart) ctit!î́t. 


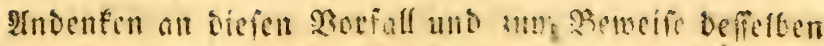

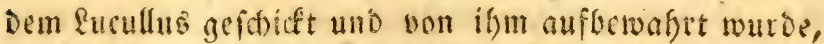
wog alicin fiebenfundert 羿und *)"

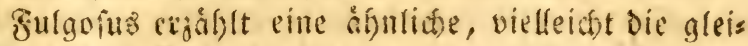
d)e (jefdrichte, nut mit einigen geringen albweichungen. fid bemerfe fiebei, dof aud) ex alfo ein zenge fir die

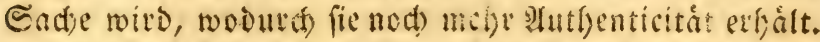
Ein Foftum, das mux ven cinem eimbigen fefanti wirs, madit imener nod) wenigen (sindrud auf uns; went

*) "Cactera, quae Trebius Niger retulit, monftro fropriora polfunt videri. Cartejae in cetariis affuetur exire e mari in lacus eorum apertus, atque ibilalfamenta populari, convertit in se cuftodum indignationem affiduitate furti immodici. Sepes erant objecta, fed has tranfeendebat per arborem, nec deprehendi potuit, nificanum lagacitate Hiredeuntem circumvagare noctu; concitique cuftodes expavere novitatem. Primum omnium magnitudo inaudita erat, deinde colori muria obliti odore diri. Quis ibi polypum expectaffet, aut ita cognofceret? Cum monftro dimicare fibi videbantur. Namque et afflatu terribilicanes agebar, nuncextremis crinibus flogellatos, nunc robuftioribus brachiis clavarum modo incuffos, acgreque multis tridentibus confici potuit. Oftendere Lucullo caput ejusdolii magnitudine, amphorarumquindecim capax; atque, (ut iplius Trebiiverbis utar) barbas quas vix utroque brachio amplecti effer, clavarum modo to. rolas, longas pedum trigirita, acetabulis five caliculis pelvium modo; dentes mag. nitudini refpondentes. (Die Eeiben Simnbar

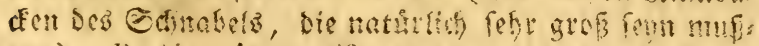
teit.) Reliquiae atfervaiae miraculo perpendere pondo D C C." " Plin. Hift, nat, lib. 9. cap. 3 Q 


\section{8}

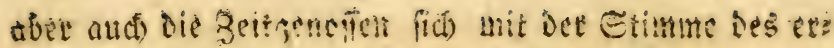
ften, Der diefen aufererdenticiden Borfall erjallylte vers emigen; wenn enft Das Everamen, Dann Der Unzlaube rege wurben, und verutfadten, baf man fird um alles,

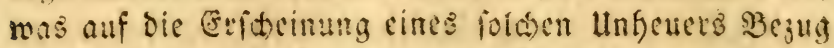
batte, genauer befummerte, und fid Doch) inmer nidht

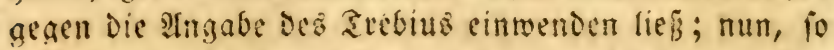
miffen wit fation zugeben, was sie, sie bamals leb= ten, uneingeidtånft zugeben. Die Zeugniffe beider. Beitigenofien uber Diefelbe Sacte fủge it Der unglá bigen wegen ald in ies thefdrift bei. Sacun wir bas

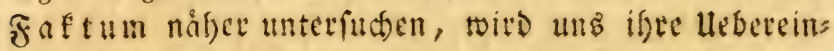
fitimmung widtig toerden.

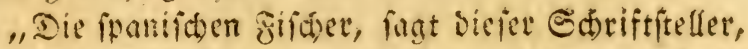
Die Den Shunfifet berciten, metften, Dab man ibnen

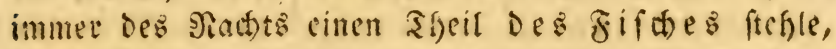
Sen fie ben Sag iber jugeridet gatten. Sie wadten alfo, und liefen mitten in Der 9ated eimmal beim Ges bell iffer sumbe binju, und fonden zu ifferm grósten

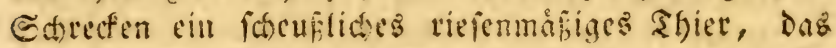

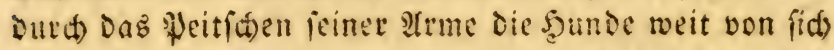
meg f(t)eudte. Sie ergriffen nun ifye $: 3 a f f e n$, und gingen alle auf bics llngefeuer fos, weldes fie nur mit

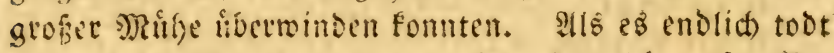

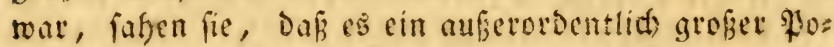
Inp fin. Der furdterlid) grofie Sopf Dellelben wurde

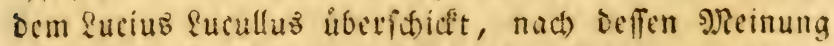
et etwa funfzef) :Tmphora (oder șafe, die Die Eee: leute hotrae nemmen), balten finnte. Ecine Itrme was ren fo grof, Daf eis smann fie faum unflaftern fonnte. Eie raren mit meiten bofflungen bejebt, die groken

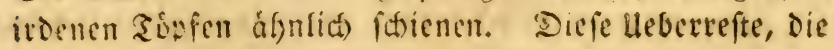
man zur Befå̉igung bes šorfalls aufbob, wogen megr als znoslffundert \$fund." *)

*) Crum in Hifpania pifcatores, qui thynnos condiunt, lingulis noctibus aliquid iis 


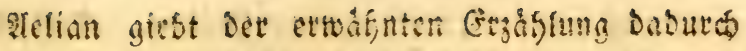

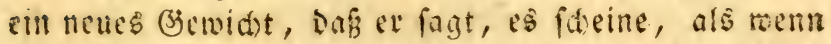

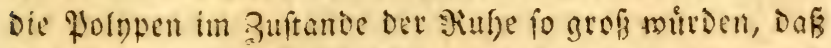

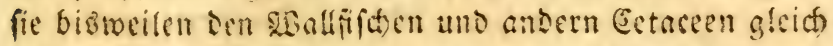
fámen. Dann werben fie aber aud), fabint er fort, ju ifucn gejafft. MBciterhin fingt er folgendeg zu Diejer

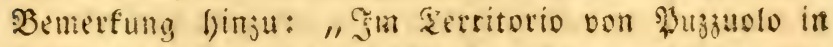
Stalien bat man einen foldten ungef)euren Wolnsen ge:

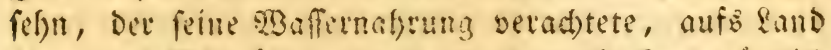
fam, und Mermúftungen antidtete. (ẻr frod) nåmlida ourd) einen unterirbifden Sanal, Der Dan lintath der Etast \$ajuuolo ins ancer abfiffrte, und gelangte fo in ein Şaนs, Das am șeere la\}, und ein Raumanns magsin von eingefalzenen Sadyen entfielt, bie Dort in

quae jam paraverant, a uferri animadverrerent, et propterea diligentius rem obfervarent, non fine ingenti formidine, cuin latratu fuo can es ad rem inlpiciendam invitarent, profpexeruntvaftam terribilemque belluam ingenti fpiritu, bra. chiisque canes a fe abigentem; ad quos defendendos, accurrentes, qui aderant, variis inttructi armis, magno labore tandem feram confecerunt, cognoveruntque polypum efle, qui ejusmodi cibi avidiffi. mus luperioribus noctibus quod pifcato. res deefle fibi quaerebantur, rapuerar. Hujus belluae caput immenfum horren. dumque fuit guod Lucius Lucullus, qui illud infpexit, putavit quindecim ampho. rarum, quae in nauticis rebus botrae dicuntur, menfuram continere: brachis autem ingentia adeo, ut vix hominis cora. plexu cingi poflent, internodiaque crurum magnae ollae magnitudinem complere. Ejus autem reliquiae in miraculi teftimonium fepofitae fuere, feptingentarum libraruris pondus excefierunt." Fulg, lib. 1 . 
grofen Somst verpact umfer ftander. Der Polnp ergurff be enfe bie befte derfelben, oricfte fie gewalts fom zufamsen, zerbrach fie baburd, und berjeflete ben

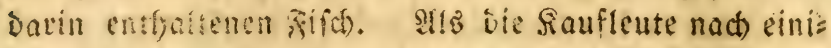

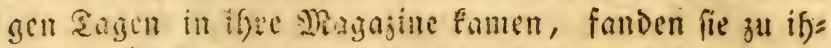
rem groften Sefoumen bie jerfolagenen Tonnen und

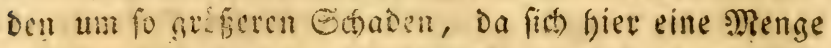
ma Der Freme gergefonofter Eadyn befanden. Da fie bie llefode biefer Beefecrung nidht auffinden fonts ten, fo unterfudten fie die SE, turen und Mlauern genat, fanden aber alles unverfefit, und wafien bafer nid)t, was fie Denfen follten, noch wet Der Káuber feyn mid)= te. Utm aber firr bie zufunft fidser ju jeun, wảhlten fie den fiffurten unter ifien seuten, und liefen ifn, mit

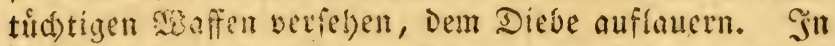

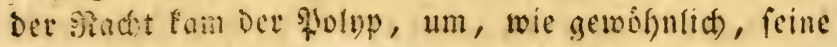
Nafylget fu bulten, und fidlang feine Irme um cine

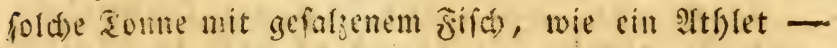
fagt Relian - um finen Bjegner, jerorad) und offnes

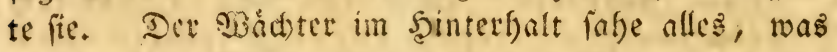
voritel, beim Siondenfáein, Der Das Magazin erkellte,

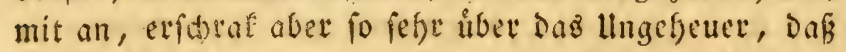
$\mathfrak{e r}$, weil $\mathrm{er}$ allin war, es nicht wagte, iffn anzugrei=

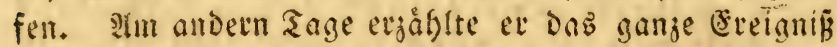
feinen Seren; Dieje hielten ifjn aber fúr cince 2 bet: wişiaen und wollten feinen (Eroid)tungen - Denn Da= fút hielten fie fiche (Ergáflung - feinen Blauben bei= meffen. Da ifre Edaden indef fefr bedeutend war, und immer nod) mefor merden muste, fo entifslofien fie

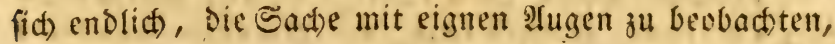
und alle mit eirander iffem zeinde aufalauern, uno ifn anjugreifen. Sie tiefen beshalb nod) mefrete

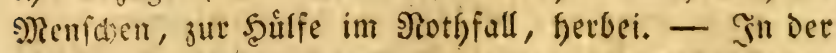

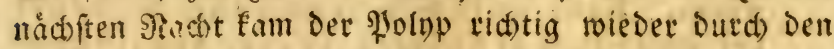
erwathnten unteriboifden (sang und mad)te fide an bie Sonnen mit gefalgenem fifd). Saum faben die sauf= 
leute bles, fo verfidofien ifin einge berpelben ben

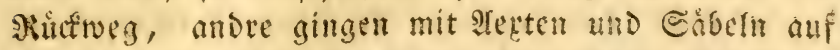
ifn los, uno hieben ifm, wie cincm Banme bie Aeite, feine arme nad einandit ab, fo baf fie endida mit vieler sarfe und Befafre Dafin nelangten, ifn zu tooten *j."

*) Puteolis oppido Italiae auditum eft, polypum, cum inufitata ad corporis molem factus progreffione ad maximam magnitudinem perveniffet, egregio fpreto et neglecto maritimo victu, in continentem proceffiffe, et terrenae pleraque vaftafle, et per fubterraneum fpecum puteolanos fordes in mare transmittentem in maritimam domum afcendiffe, ubi mercatorum zes, falfamentaque in magnis vafis effent; brachiorum circumplexione primum, vafaftrictecomprimentem, corrupiffe, ac deinde falfamenta depopulatum fuiffe. Mercatores vero ingreffos ubi dolia dis rupta infpexiffent, et permagnum earum rerum, quas navi advexiffent, numea rumque exhauftum deprehendiffent, ftupuiffe; ac nimirum cum ab infidiis foris integras, tecta ob omni irruptione intac. ta, parietes non perfoffos intuerentur, quisnam populator fuiffer, nulla conjectura affequi potuiffe. At enim cum reli quias conditorum pifcium nnimadverterent, cos confituiffe, ex donesticis au. daciffimum armatum intus in intidiis, ponendum elfe. Polypum vero noctu ad a fruetas tanquam epulas adrepentem rea vertille, et tanquam athletsm adverlaaum frictillime correpium fuffocalfe, fic flagcllis vafa circumplicantem pes+ tregiffe. Eum porro qui infidias molia Ietur, etiamfi lua fulgore domas illu itraretur; omniaque confpicua effent, ta men quoniam folus effet, beftiae tantae metu perterritum hane non aggreffum 


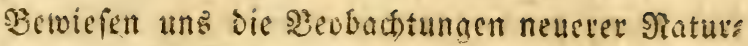

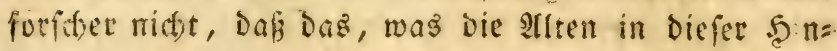
fidt gefagt haben, fehr wathe und riditig pein fónne,

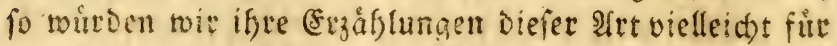
unglaublid) uns für wunderaffnlid)e (5rdid)tungen bal= ten, bie ifte 2 Berfe verunftalteten.

Aber Ildrovandi 3. F. Fagt ebenfalle, Dak Del Ilolup eine fo grofie forperliche araft befize, daf er ez felofi mit Dem ftátften Sóven aufnefmen fónnte*).

fuiffe, fed fane mercatoribus totam rem explicaffe, quod quidem ipfum ii audientes, ei fidem enarratarum rerum non habuiffe. Deinde tum negotiatores ob tantum acceptum detrimentum, periculi memoria depofita, ftatuiffe fimul ingredi, et congredi cum hofte; a liosque inufirati et incredibilis hujus fpectaculi ftudio fua fponte fefeauxiliatores una in domo illa conclufiffe. Polteavero, quam fubvefperain in folitadolia furinvaliffet, exeis partim cloacam obftruxiffe, partim armis tectis in hoftem irruentes, dolabris et cultris acutiffimis ejus brachia abfcidiffe, non aliter ac fyondatoreset puratores arborum robuftiffimos ramos fecanr, fic enimfaepius membra polypi circumcidentes, tandem nifi non pauco labore confeciffe atque opprefliffe, et quod qus dem admirationem habet, in terra pifcem expifcatos, hajusque belluae propriam veteratoriam nobis oftendifie." Aelian. lib. I3 cap. 6. de anim.

*) Tanto in primis corporis robore valet, ut ne fortifimo quadrupedum leoni cederet. Hominem fane vehementi brachioram amplexu e navis medio in altum mare detrahtre, quin conficere, cernitur, et quod amplius eft, ingentem hominum multituditem folus fuftinere, adeo ut aegre confici poffit. Quod fi leoni fa. 


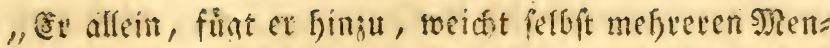

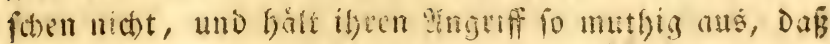

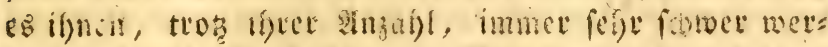
Den wiro, ifn zu befiecen. Sman foat, fetrt er finju, gefefn, Dafie fie Silfie mitten im shecre anguffen,

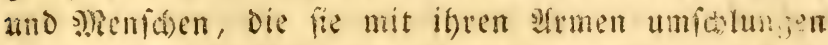

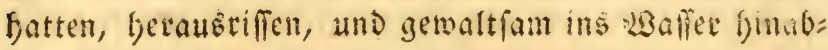
zogen."

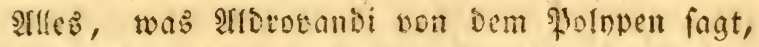
baben Besnex, Jonfton und faft alle folgende sototus=

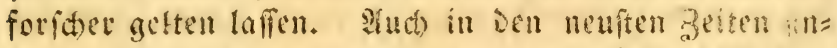
Den mit Bencife bon Diefen bentndennew

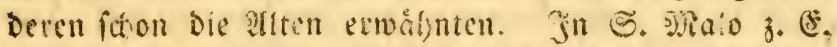
befand fid in ter Stapelle Des h. Sfomas, - Den die Setente jener Begend in grofien Befafren um șilfe anjutufen pregen, - eit Ex o n D. f. em (Bje=

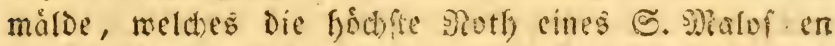
Schiffz, an Der fiufre von ingula, wo és Den Staven=

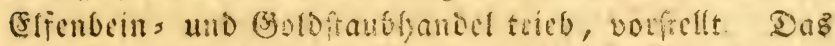

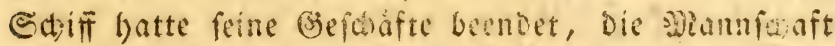
war eingefdifft; und gliciliderwife rolle ber šes

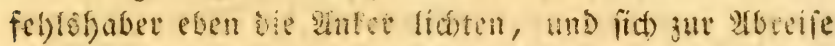
ntad) Den amerifomifien Gmieln bereit maden lalls, als fid) mit eincm soiale bei vollig fitlem sbetrer, uno am betem Sage, ein Eeeungebeuce von furdtetticter Brob́ce aus den filutgen ethob, Dicje foch empor uno uber Das Serbect hinmeg forwelle, fich bann an Das Schiff angangte, zmei Saue uno Mafien bis in Die Epişen mit entietich langen und bieglonen strmen umficlang. Durd feine ungeleure Edwere zog das Inneheuer Das ๔uiff vollig auf Die cine Eeite, und wate faft Dabin gelangt, es in Den Mbgruno zu gisfen.

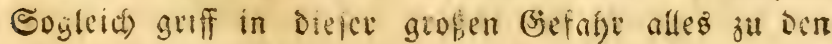

ciendum foret, nil quidquam fortius praeftare pollet." Aldrovandi ue Moli. p. 7. cap. 2. de Polyp. 


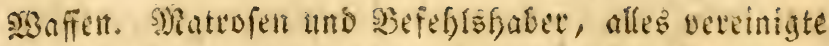

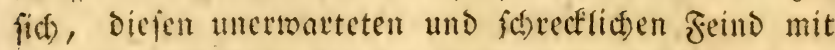
Den erften sgafien, die die গoth ifnen reidste, anzu= greifen und ifm mit भeteten und sieffern zu \&eibe ju sethn. Die Sioth mad) te aud Die Feigften muthig, alle foct)ten zux Bettung Des Bjanjen. Seinalge aber vets zweifetten fie, Denn Dab Echiff legte fiá) immer melne uno mefre auf bie Seite. Da tiefen fie Denn fämmtlidy, als åd)te Eeeleute von S. Malo, Den Schutepatron iffes Shafens, ocn f). STomas, um Sculfe an, und getobten

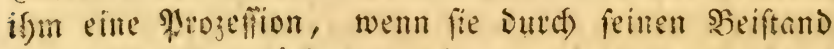
Diefer Gefafer aluctich entronnen, uno nur biesmal nod ohne Segaden wieder zul Sampe antamen. Sob

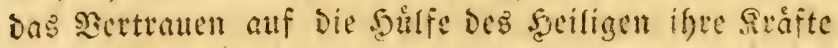
erisónte, und ifnen den Sieg erleidsterte; oder ob blof ifere fdorfen Mefrer dos Befte thaten; gemm, fie wut= Den gerettet. Mit ifen sleten, Sábeln und Mieffern

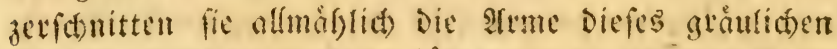

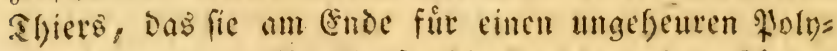
pent etfanntch. So twie fie bie Irme von Dem Forper abgeflaaen battil, fanf Dev Jiumpf zu Boden. Das Schiff, Das mun nidjt weiter anf bie Seite gejogen wurbe, bob fid wieder fenfred empor, und bic 9)?a ften ftanden it iem gleiden Ifugenblicf wieber ben

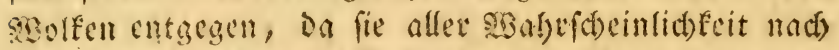

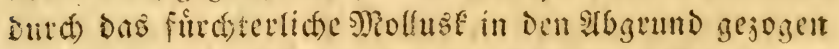
swerden musten, weil allein Die Edtwere beffelben bas Sd)iff to ticf hinabiente."

saum war das Sdriffovole wieber 'nact) S. J)\}alo

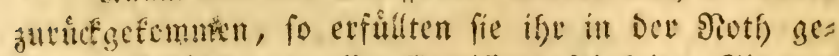
15)anes beliber mit aller (semilhenfaftigfeit. Eie ents sogen fich Den limarmungen iffer 9 geiber uno Sinder, und Den fonften Kiffrungen ber Frundidaft, Siebe

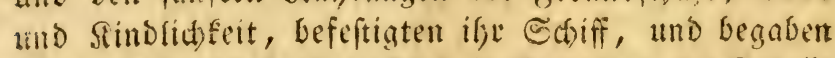

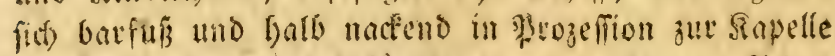

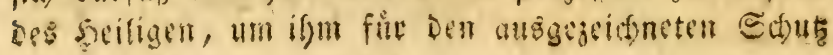




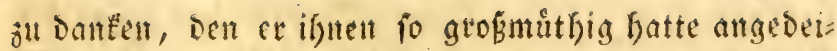
ben laipen. Sodann liefen fie den ganzen 3orfall, ifre bricfende Soth, und Den verzmeifelten Samp? maf)len, und zum ewigen Proenfen in Der Siapelle hes Seiligen auffängen. Da bie Sache felbft angemadt

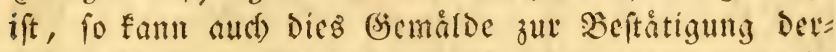

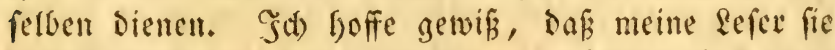
nid)t bezweifeln werden. - Denn, modsten die Satut= forfder bod) fo glitflict) fevn, alles, was fie in ifuen

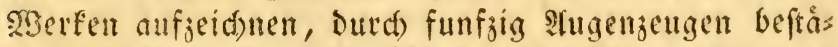
tigen zu fómen! - Das Supfer, Das fich) am Infange Diefes $\mathfrak{U}$ tifels befindet, ift bie gemane Sopie jenes Ex voto, und liefert zagleic) cine Abbiloung Des Wicfens polaps - Denn einev andern Gattung fam biefe $\mathfrak{B}=$ gebenfeit nid)t zugefdrieben werben - in bem Angen= blicfe, oa, uno in ber Yrt, wie er das Ediff angriff.

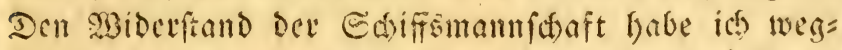
gelaffen, Demt in cincm fo fleinen Sianm witude is fdower gewefen fenn; ben Simpf proportionit Darjus feflen; Da jeber cingelne smenfid) gegen einen folden Polypen nue etwa fo grof ift, wic eine Э?njidbale gegen ciit grofies Schiff.

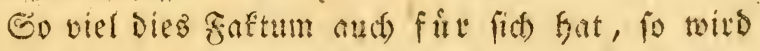

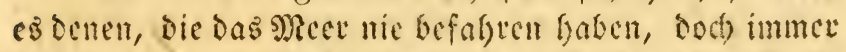
nod) weniger cinleuchten, als Den Eceleuten. Diefe wifful alle, theits an!s eigner (erfotgung, thecits Dutd

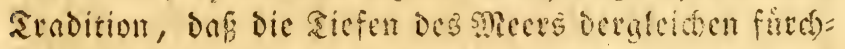

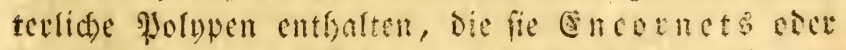
Eornets nemen. Sic oerwedfefnfecilich sic fummt:

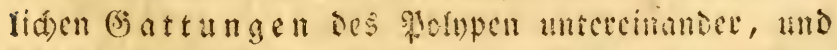
bie slofupen alle wieber mit Ben Solmors uno Din=

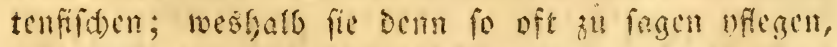
"Der Cornet fey das freinfte und grofite

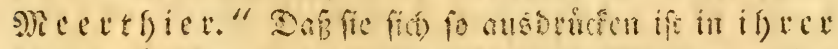

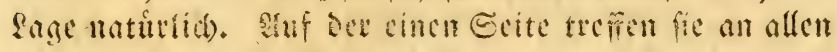
Silften und in allen Meeren solmats und Sotopen an, 


\section{6}

bie faum to arof fins, wie ein Betreibeforn; an bent gleichen suften finden fie ferner sullusten Dex Wert,

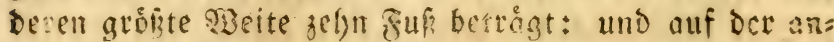
Den Seite fat ifnen bie Cerfohtung bewiefen, dafa Shtere Derfelben airt exiftiren, Die cine ungefeute und ricienmáfige (3ribise baven, in bie nidit felten ifre Fameraden verfdhuft tode in bie Siefe gezogen haben, olhne daf man je weder bas @eriff noch feine Mauns fec aft miederaejely hat; Die andere Male Matrofen mitten unter Der vibrigen monnfhaft feraus oom $\mathfrak{B e r =}$ Decte hinabatrifien uno fid mit diefer ifger beute fo fat mell : Denfelben die geringîe Şüfe zu leiften.

(3ranipte', 2ierfaffer ciner Bieife nad) Iffifa hat mir verfichert, Dag diefe ungefeuren Solupen an den Sirfen jenes \&andes, aber in einer geroiffon Cntiernung

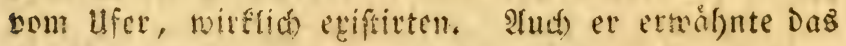

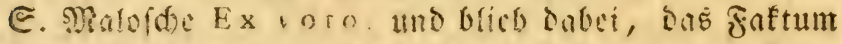
fer unlangbar, babe fid viltig biwabrbeitet, und fels nie mit Gorube bezmeifert. Die Sieger bet afrifa= mifden Sufte futcten, nad ifm, Diefen \$uinpen feft, Denen forlingt feine Wrme oft un ifge Solen oder פ̧ iroguen und reift fie in den Ibgrund.

2In Der Sifte urn (3)uinca f)at man biefem Moliuse Saher Den Namen ambazombi oder bo bigafter zifd (aud 3auberer) gegeben, denn die dortigen Einrogner halten ifn fur einen bofen Beift. Da bie

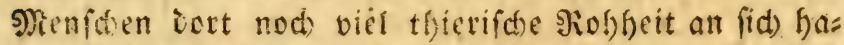
ben, fo leben fie ouch faft wie dic Thiere. Sie find

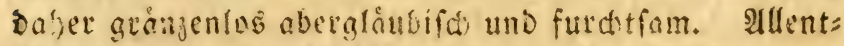
Halben zittern fie vor bofen Benien, vor Beiftern, bor Dem Seufe!, uno vor Befpenfern, momit ifre Refigion

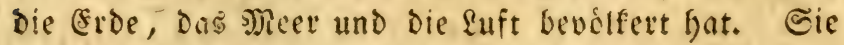
mennen fie $30 \mathrm{mbi}$, und glauben fo feft an fie, Dafi nidst fie bavon abbringen fann. Der grope Polup

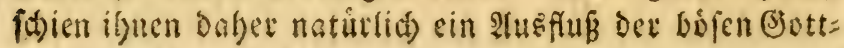


heit, ober itgend ein perfonifijirter bofer Geift felbit. feg verfteichen melfere sage, efse fie von ifrem Edisecten wieder rufig werben, wein einige iffer

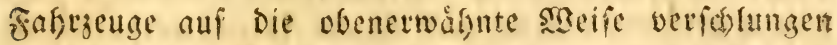
worden fint. Sie wagen fict Damn fo lange nidt wie:

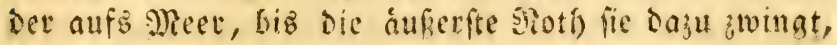
und bis fid iffere Singit aflmaflich verloren bat. Dant erfe fangen fie ifge şifiderei und ben sandel wieter an, Den fie nit Den Ediffen, bie fich Dort vor Infer legen, ju treiben pflegen.-

Dev Schiffấapitån Sofrann Magnus Dons, citt fefre efrenwertfer und waf) ffettlebender Mann, feste

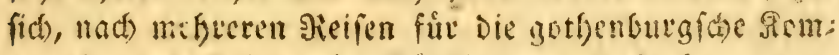
pagnie nad) (sfina, in Dintétaden zur giufe, wo er

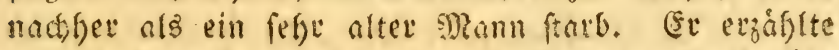
mir, Daf er fich cinft unterm funfiebreten sores fiibs

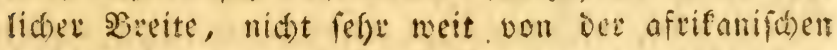
Sirfe, zwifden ber Jnfel S. Selena und zwifden Dem.

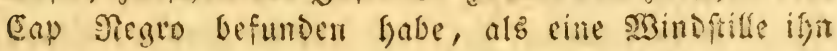
mefrere Sage findurd) zum Stilleliegen nothigte. (st: nuhte dicfe Zeil oaju, feine Extriffe von ausen uno imnen ju reinigen uno zu verbeffern, und licḱ deshalb, wie gewófnlid, einige Bretter an Scilen hinab, uno die Matrofen ftellen fid Darauf, un mit ifgen Dreiedigent siferinen Snftrumenten Das Sdiff absufraten uno zu

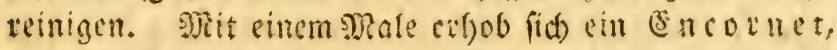

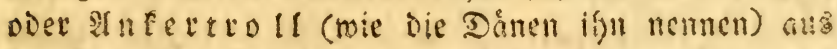
Der Siefe bes Meets, uno warf cinen feiner âtme um Den \&eib jweier Matuofen, rif fie mit fammt ben: be= ftelle, worauf fie franden, finweg, und zog fie ins Mcer. Zugleich warf ev feiten gweiten Strm um einen

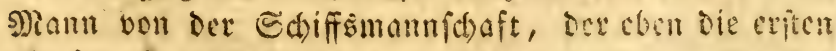
Stufen des Mafrieils emporfteigen wollte. Sa ber \$olnp abex zu gleider Zeit die ftarfen Etrånge des Mafteils mit ergriffen und fich in feinen Ducritricien verwicfelt hatte, fo fonnte ar Deit Dritten Menfdent 


\section{8}

nibst bintwegteigen, fonbetn blof quetfoen, weshalb Diefer furchterith ju beulen anfing. Die ganje shann=

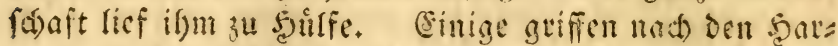
punen und warfen fie bem Sgicte in Den seib, wo fic ferse tief eimorangen. Antre fileben mit ifien Mefiern

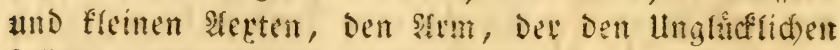
feffelte, entzrei. Bugleid) Gielten fie ifn feft, Damit

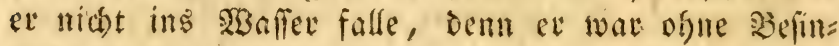
nung.

So verftimmelt und von funf Salpunen vertwun: bet (beren einige lanjenformig gebirbet uno mit eincm

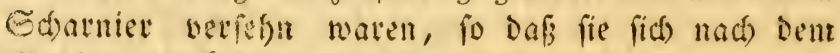
Dìule entwickelten, eine forizontale Steüung annaly= men, und mit zuei Epiten tief in Den Rouper Des ge= troffenen sfiers bincin drangen), fenfte fich ber grôf lidge Wornp mit feiner jwiefaden beute alfein burd

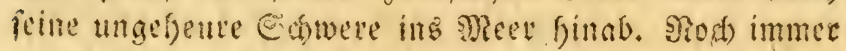

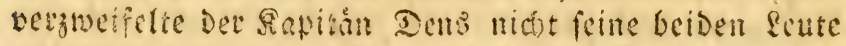

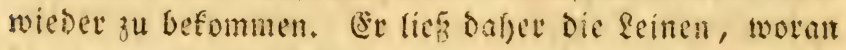

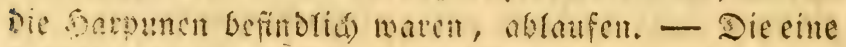

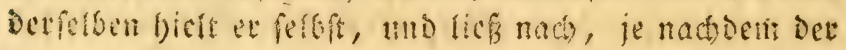
Wolip jog. Alts aber bie Scife faft abyclaufen maten, befoly er, fie wicoer aufzuminden. Es glucfte aud

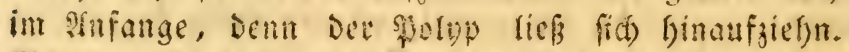

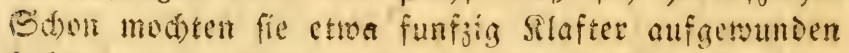
baben, als er ifnen aber alle weitere soffinung benafm,

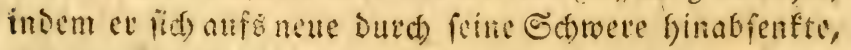
und bie Edfifletie jwang, bie Selle nod) eimmal ab: raufen ju lafien. Sie besuten mun bie Sorficht, die geinen an ifrem Ende forge feft anzufnupfen. Saber viet bon berfelben tiffen, als fie abgelanfen waten, und

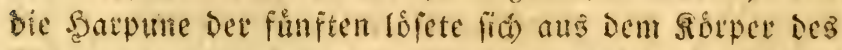

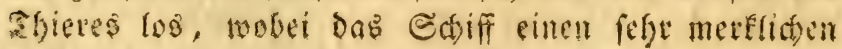
Strígetficlt.

So verfor biefer treffithe Sapitin zroci \&eute mit

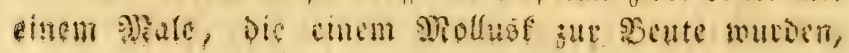




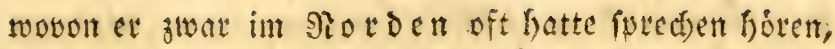

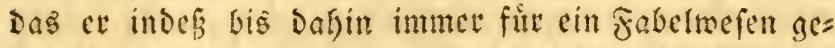
Galten Gatte, Deflen Eeviften cr mun aber, Durd) Diefes traurige Abentheuer Daju gejwunget, wohl glauben

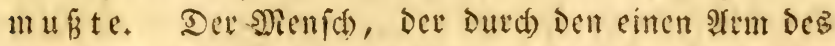

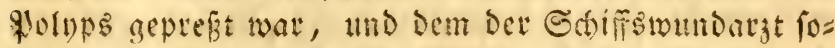
gleich auf alle nue móglibe siseife ju belfen fud)te, ex= lolte fid swar twieder, unt fidlug bie Alugen auf, fing

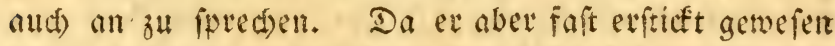
wat, fo litt er entictidid. Der Edrect hatte ifm fei= nen Berfand genommen, fo Daf et in ber folgender Эad) $t$ finn(os ftatb. -

Der Sheil Des Arms, Dex vom Rưuer Des \$olys per abgefauen, und in Den Suevtinien Des Maftfeils zuride geblieben war, batte an feiner şofis foft bie Diffe encr Segelitange des fofmaftes, endigte fith it cine feinte Spite, und war mit Siapfden oder Edroipf= ropfen, von De: Broffe cimes Sobopfloffels, verfehen.

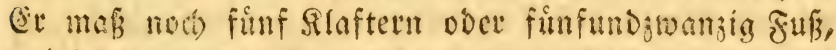

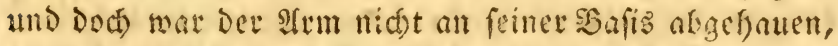
Denn bas Ungefgeuer wat nitht mit bem Sopfe au bem Syaffer bervor gefommen. Siach diefem allen fob åtete Der Sapitån Dic \&ange Des ganjen Arms ctwa auf finfs

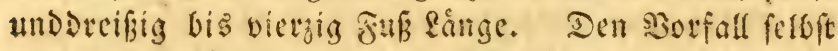

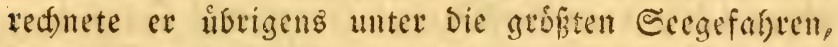
bie er je ausgeftanden, und fielt fich feft hoerzengt,

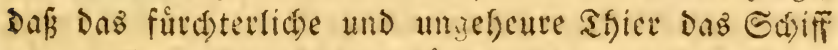

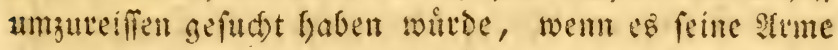
an Das \$ord angeflammert batte. Gin fold)er linfall. b) atte fie, meinte Dev Sapităi, um fo leid)ter ungludflids madsen minfen, weil fie vôllig unbeforgt, of ne an Ges faft und an saffen zu Denfen, fich) ifren arbeiten un= tetzogent.

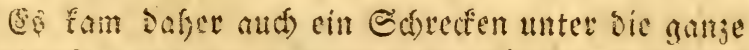

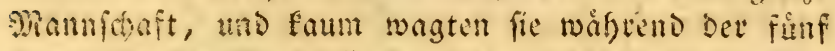

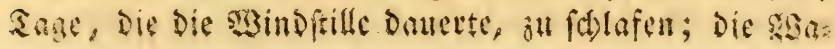




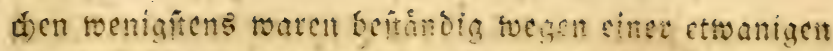

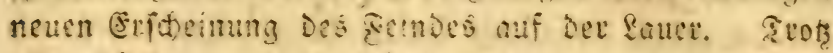

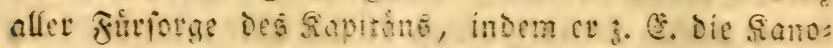

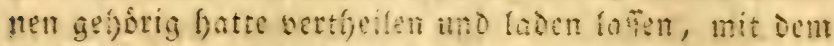

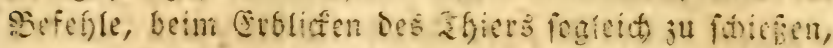

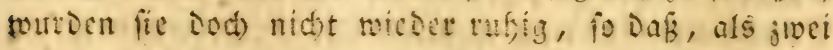

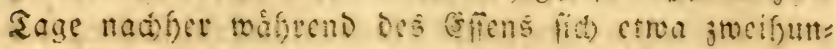

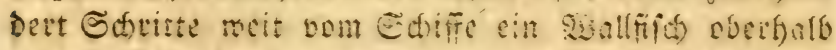

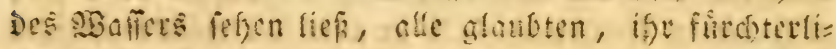

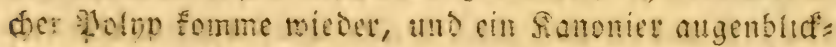
lici cine kanong losbranne, wh bem fifd eme Rugel Durch ien scib jagte, noburds or getiotet murbe. Sn=

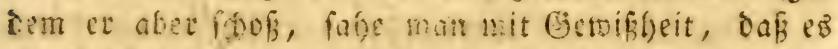

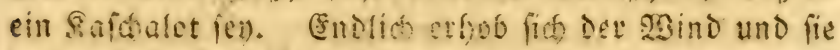
serlefen Diele trautige (Gegent, wo fie alles an ben

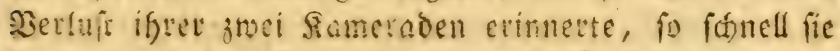

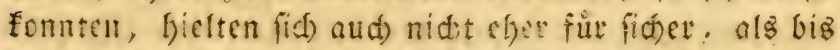

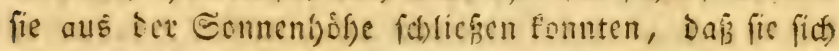

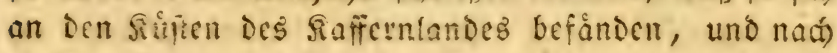
cinigen ₹agen bei Eap De bonne Eiperance ankamen,

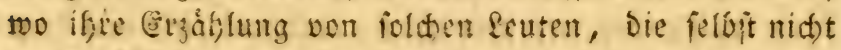
etwas afynlicises erfebt Gatten, nid)t geglaubt wurde. Der Sapiran Dens verficherte mir nod) aus feimer eig= nen Crfabrung, Das Centfiefen bes *iefenpolnps ge=

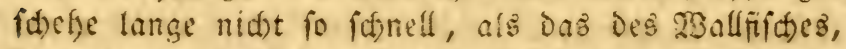
Dema fratt roie diefer cilige fortjufdiefien, fenfe ex fid) in geraber sinie finab, uno finfe nie sin Bleiffums

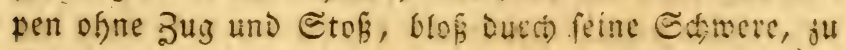
3oder.

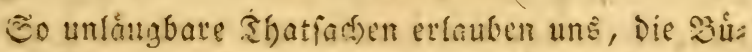
der ber Alten, von Denen man nur su oft glaubt, Dob

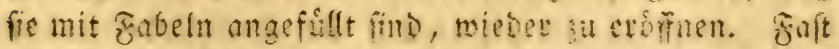

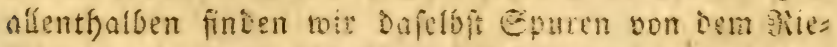
fempolypen. Demn fither fommen igm jene Ingeiffe auf

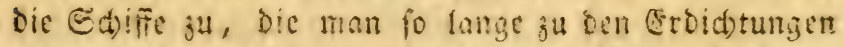

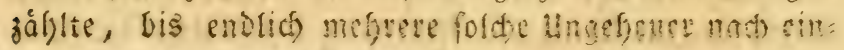


ander in verfdricbenen Beitpunften ift Dafenn buref ir: geno einen trattigen Borfall berolefen. Mas alfo die

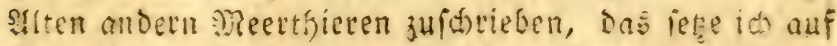

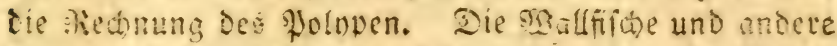
Cetacen find in Sinfict auf bie menten fefte irico=

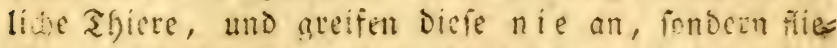
ben die Eafiffe bielmegr. Das ift der Fall bei den \$3alfificten an ben lifern, uno im hofgen meete. Biel=

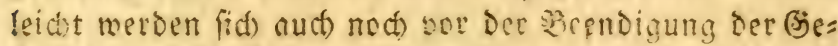
folid) Des Plicien olnps fafta vorfinden, wotaus $\mathrm{er}=$

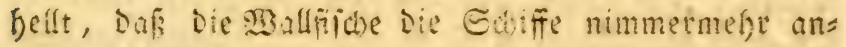

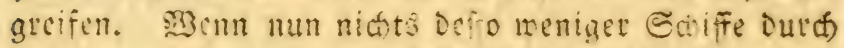

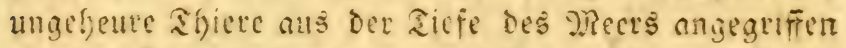
worden fino, und nod angegriffen werden, und wit vernumftiget giz if: nue auf Den Biefenpolopen in biefer Somfid tatfiet fonnen, - nun, fo finnen roir aús if un me jene mefo ober minoss traurigen Borfălte, Die feit ier Erfintung Der Edviffaget Den Eecleuten bes gegneten, zueignen.

gllinius redet bon eirem ungefeuten silfh im Deuticien meer (Der glordiee), Den er Sencdectes Doer Putras nentt*). (Er jagt, biefer Fild greife Die Schiffe an, um fie umzuteincen, und in Die Siefe zu zichn, und er etfege fid bei biefer Belegenfscit twie cine

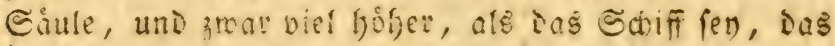

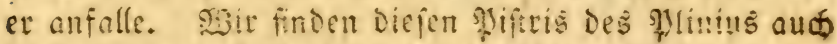
in eitrem alten Buthe mit gothifarer હarift, ofne Drutiort, und Das Den Site! "Ortus ianitatis" firift, wieter **). Shan lieft bier namlidf cinen gros

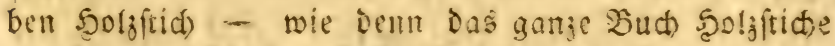

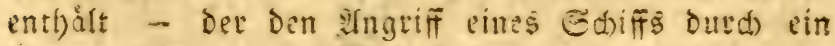
Eecungefeuer borftelt, Dem Der Berfaffer Die form

*) Plin. lib. 9. cap. 4.

**), Ortus faniratis" IsI\%. Dine Dructort uno Eeitengaflent uno mit gothifduer Echlift. Trastarus de picibus cap, 69. 


\section{2}

cines Stofodills mit gepaltentem Sowanje geacben bat. So cleno aber auch Die figut ift, fo bilft fie uns Dod) auf Die Spur; befonocts, Da ez beifit, Daf; Det Wiftris cill ungefeures Secthiei fen, das man bistwei= Ien im Djean ser biallier anteffe, uno das bfters un=

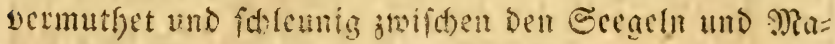
ften Det Gdiffenden in ber Geftalt emet fefle loben

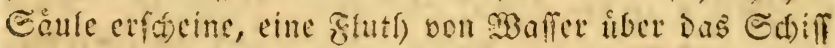

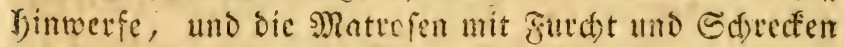

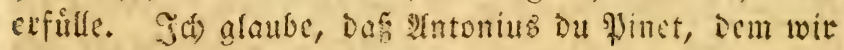
bie erfe frangofiche lleberfetang des Sliming veront= fen, fict iut, went et in feimen Sioten uno siommen=

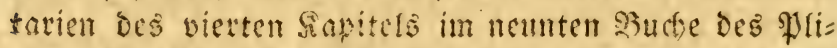
mus, nadbem er Das gstort $S$ enedectes unubrfeţt grlalien bat, fagt: "bie Griecien nennen ifn Phy-

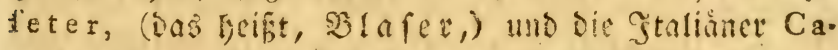
pidoglio. Ev ift bev Peis mular unferer grtoven=

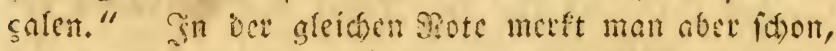
oab ber edwithelfer finen begangenen Futhum wabt: nabm, benn er fagt in ber folge, Diefex fifh móge pielleid ter grobe Gechern fent $\dagger$ ).

Cin Seefrern bat abet gat feine stefnliderit mit cincm Eetacesn, aud werben wit bald finden, daf die

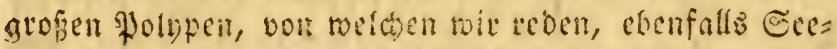

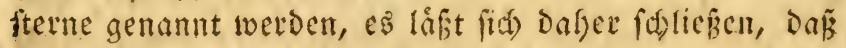

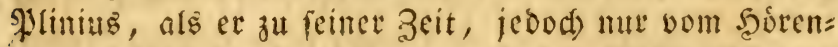
fagen, ubex die Senedectes des gallificu Mrectes forleb, nichts anders Damit meinen fomte, als bie grofen \$olnpen, Dic Damals in Dicfem Mecte criftiten, und bie jeţt bort ztwat feltener fint, oder fich bod) fel= tener zeigen, abex - wie nlfes bemcipt - immet nod) Dort gefunden werben.

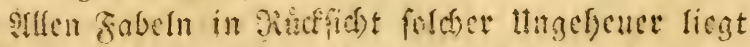

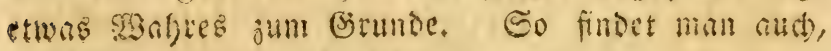

t) Plin. lib. 9. cap. 4. Pinets Hebarfentus in Der 9lote. 
senn man bie Gepdicte Des fogenarnten Eeepferdes von ifxen unnthen fabeldidtungen gereinigt bat, $3^{\mathrm{i}}=$ ge, die Dem giefempoinpen zufommen. Das Eeepferd

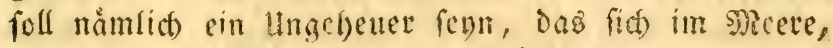
und an Den Mlindungen grofier fluffe doer viefmethe an Den Silfen findet. Dieg graufame Thier ift, wie der \$oltup, fefre begierig nach splenfidenfeifd, und went es cin Sd)iff in irgend einer $\mathfrak{B a y}$ antrifft, fo flammert es Den einen Fuf an einem gelfen oder auf Dem $\mathfrak{S} v=$

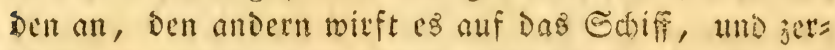

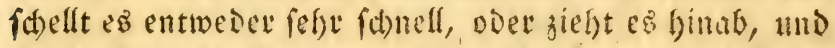

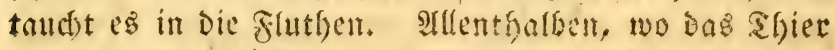
- Das jum (blticf felten ift - fict) aufíålt, tódet és

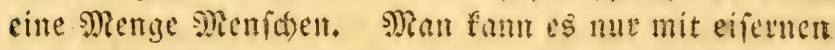
Feffeln fangen, und mit cifernen Seulent todtidslagen,

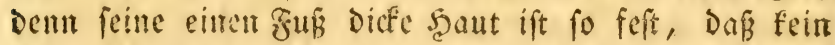
\$feil fie Durd)oringen fann *). Dicfe (Eigeniduaften, Die aflein unferm riefenpolypen jufommen, wutben bas maliger zeit mit andern sarafteren vermect)pelt, bie man allmåtlić) wieder Dem Shippopotamus (welcher al lein jenes Seepferd fent fomme) beilegte.

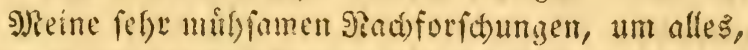
was bie (Gefchid)te bes giefenpolypen betrifint, in einem Brennpunft jut vercinigen, werden mefre als eine ges

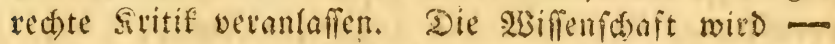

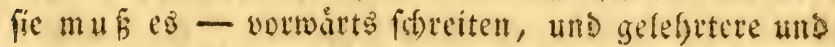
geidjiftere Saturforface fervorbringen. Diefe abec metden Dann meine Bemerfungen fiden, uno bas

*) „Monftrum eft ingens ac fortiffimum... unde in locis in quibus habitat, immanis multitudo hominum perditur per eum... Nullis capi poffic infrumentis nifi rhtti ferreo ex catenis... malleis ferreis occiditur. Pellis ejus unius cubitifpiffitadinem haberedicitur. Tantaeque effe duritiei ut rullo jaculo penetrare pol fit."s Orons fanitatis; de pife. cap. 32 . 


\section{4}

Sauglide berifelben Eeivenalten, bas linnibe binaenen seemerfen. Zu bem gleic en Zebuf ertoábre id brer

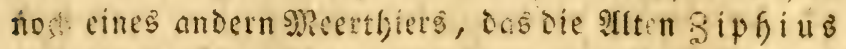

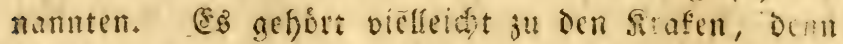
fie befdreiben es nidt blutsierig, nods lofien fie es s) nat) ifnen ein Seethici, das feirem ondern åljnlud

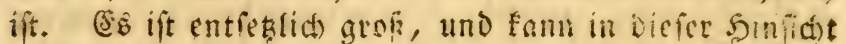
nur mit ben Setacen verglichen merden. Ser sopf ift ungefeueraztig, Der Schlund fehr weit, und bie Anen

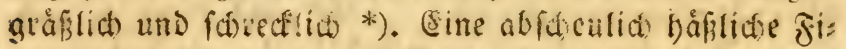
gut, Die fich bei diefer befafreibung befindet, zeigt uns inder immer nod den frummen Schnabel und Die flammenoen Aligen Der \$olnpen. Ias lebrige Des

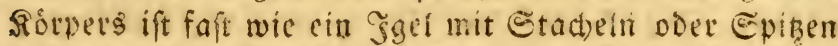
bebert. Der Echrifteller fagt zwar, man fónne bas Thier mu mit Den Eetaceen vergleicten, er giebt ifm

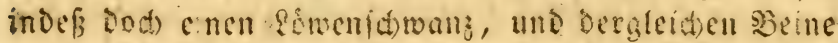

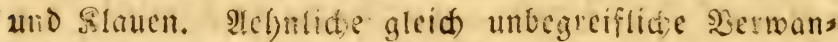
Delungen der eigentliden litbilder werben wir aud now bei andern faftis, bie wir nod) zu betrad)ten baben, porfinder.

Die nordifchen Meere entfjalten ebenfalls jene ferbe grofen \$olnpen. Es fdeint fogar, dafi man diefelben Dort mefr, als in andern Mecren gewahr werde.

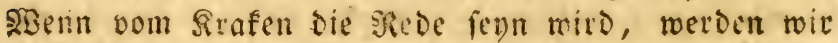

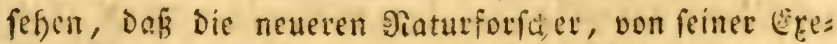

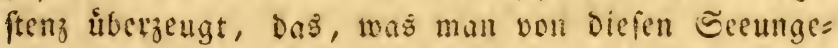
heuern gefagt hat, nid)t mefr fo ganl zu Den Fabeln

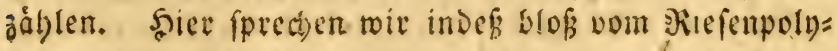

*) Ziphius eftanimal maris nulli alii fimile maximumer ingens de genere ctto. rum. Capur habet monftrofum (os profundum valde), oculos horribiles, in toro corpore nulli alii fimile, nili ceto.6 Ortus fanitztis. de gicicibus, cap. 106. in fol. 
fen, und serweifen das, was Ten firaten angelst, in

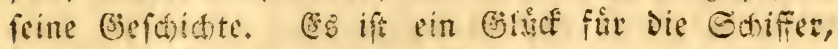
Daf Der ftarfe und graufane Polop meifens im sutere

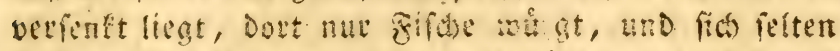
anf Der Dberfiade zeigt, Denn er winde fie fontt fo ge= fabrlich macten, als Crime uno Slippin fie nue ma d)en E̊mกาit.

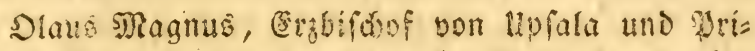

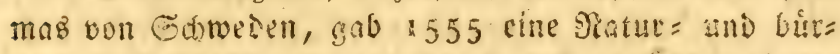

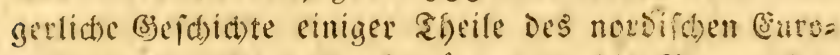
pa heraus. Dies şert tỉagt zwar bie Spuren ber

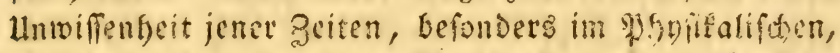

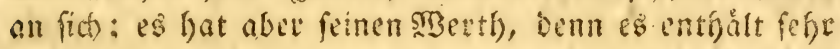

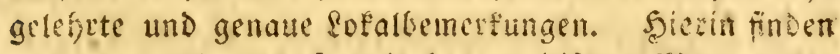

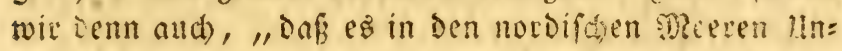

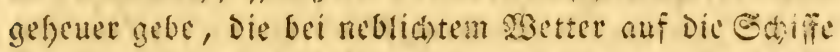

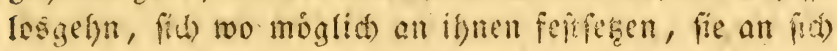
ziefien, und endich umidh lagen ober verfenécu *)." So fieft man, fagt unfer Eájiftfteller ferner **), im

*) „Suntetbelluae in mari... qui afcendere navigia nocturnis temporibus videntur... Et fi diutius permanent, etiam ipfae naves merguntur." Olaus Magnus, de pifcibus monftrofis. lib. 21 , p. 729

**), Sunt monfrofi pilces in littoribus, feu mari Norvagico, inufitati nominis, (licetreputentur de generecetorum) qui immanitatem fuam primo alpectu oftendunt, horroremque intuentibus incu. tiunt, tum in formidinem diutius confpicientes pariter et ftuporem vertunt. Hopribiles etenim formae funt, capitibus quadratis, undique fpinofis, et acutis, ac longis cornibus circumdatis, infrar radicis arboris exfirpatae; decem aut duodecim,cubitorum longitudine, colore nigerrimo, praegrandibus oculis, quorum ambitus octovel decem cubitosexco 


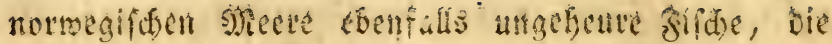
feinen befanten Sicmen baben, Dod foreint es, Dof man fie ju de ne netacengeid)ledtern technen fonne,

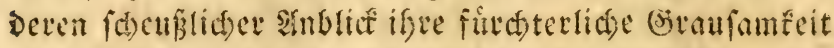

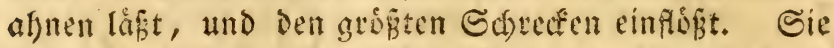

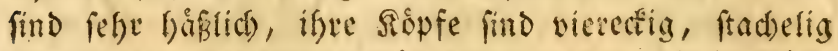

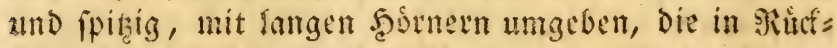

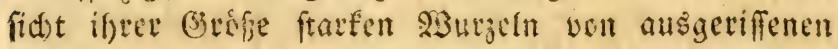

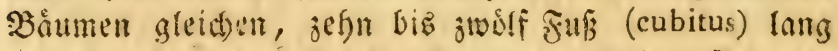
und ganj futwar fint. Die SAgen Des Shiers find ent= feţlich glof, Denn fie enthalten melye ais drei fup im

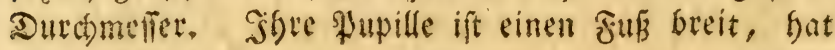
eine

* dit; pupillaverounius cubiti rubeum et flammeum coloren referens, qui a longe in tenebrofis temporibus inter undas, veluti ignis accenfus, pifcantibus apparet: pilos, ut anferinas pennas, fpiffos et longos, in modum dependentis barbae; reliquam vero corpus ad magnitudinem capitis (quod quadratum efr), valde pufillum, cum ultra quatuor vel quindecim(?) cubitos in longitudine minime habear. Una harum belluarum plures naves et grandes, fortiflimis nautis confertas, facillime fubveztit, aut mergit. Huic ad. mirandae novitati idoneum teftimoniam perhibetlonga, ac clariffima epiftola Erici Falkendortf, archiepilcopi Nedrofien. fis eccletiae (quae totius regni Norvagiae metropolis efit) Leoni decimo circa annos falutis 1520 transmiffa; cui epiftolae an. nexuth erat alterius cujusdam monftri horrendum caput, fele conditum... Totum igitur caput hujus belluae cornibus inftar duriffimi corii circundatum, valde grave eft, quia natura fic forte inftio tuit, ut citius mergatur, nec alibi majoi naturae lafcivia; lusit enim in cornibus ac armis animalium," Olaus Magnus, de pifc. monit, p. 734 . 
cime feuerrotbe farbe, und erforeint in Den langent

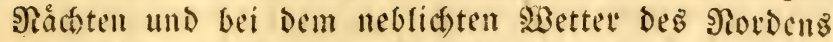
Den Fif dern faron in weiter ferne wie flammendes Feuer. Der untere Theil Der Refle ift mit langen, Fpisizen, und wie eine Bänfefeder dicfen Saaren be= wad) fen; ber Sorper ift bei weitem nicht fo grof, noch fo lang, als ber erwåinte vierectige siopf muthmafien laffen follte. Eev ift faum vierzefn bis funfzefn fan

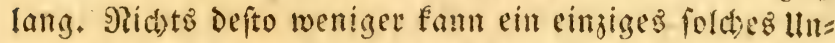
geheuer, nach der länge feiner Iltme zu urtheilen, leid)t

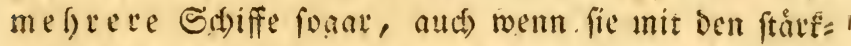
ften und tapferfen: Seeleuten befert find, zu Grunde rid)ten und verfenfen.

Daś Diele ungelfeuren abiere exiftiren, faght

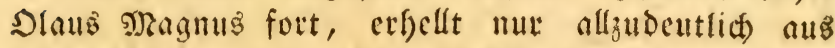
einem langen und fefr gelefrten Briefe den Erid) Falfendorff Bifdof von ?edros Dem \$abfe feo dem Befnitell im Safje 1520 íberfandte, uno jugleid) Den Fopf eintes anderŝ fürd)terlichen ungef)euers cingefalzen mitfdicfte. Det ganje Siopf Des Shiers, von weldem hier Die अede ift, war mit Sórnern ungeben, die fo

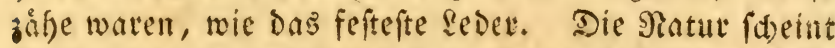
fie fo glatt gemad)t zu haben, Damit Das S Shiee Defto f(d)neller untertaudben und fid berfenfen fonne. Der Beidnter, Dem Slaus Magnus Diefe Befdecibung ůber: aab, zeidnete nad) feinem bef agen einen fif barnad, Der Doppelt ungefeuctartig ift, und Deffen 23 infel te mit monftrofen Masfen ausgefúlt hat. Dies bradte, wie toit balo fefn werden, eine Menge Guthimer her:

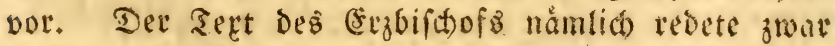

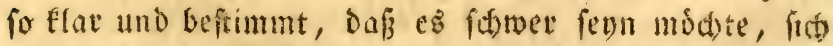

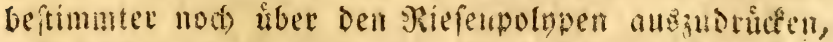
faft modte id logar fagen, ifn beffer zu beidereiben, und Dod) Gaben fid Die fpåteren Eddriftiteller an bell Zeid)nungen, bie bod) fo weit von bem entfernt find, was Slaus shagnแ fagt, gebalten. saik finsen di: 


\section{8}

felben un Altrovand, Geŝner und Gonfton wieder abs=

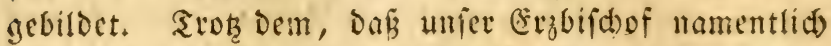
etflárt batte, Der Rórper feines Seeungefeuers fou viel fleiner, als ber Sopf, uno mit demfelben gar nid)t proportionirt, verånderte der Jtabler ifjn Dennod)

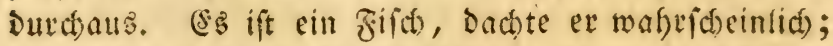

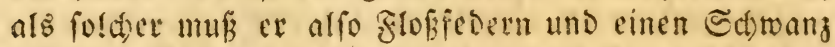
haben. Ere hat eime fiefle, die Gefle fam nidyt ofne Balbue fryn. Fach Diefem flugen Rafonnement verfieft ar Denn die cine Unterfinnlade mit Sauern cines Cebers, and giebt Dem Shiere itberfaupt ein taduldefes Bebif.

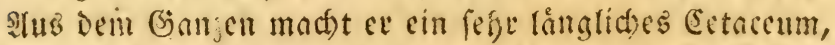
fratt bấ es ein ungefeurer, aber furzer uno bicfer Slofup twerden follte, wie Der Sllutor Deutlich) genug jut erfennen giebt.

(efye id) zu Dem ůbergefe, was bie'paeteren

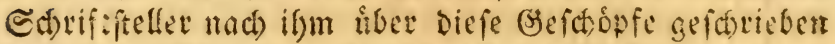
Jaben, wollen wit exft nod atles auffuchen, twas et in Diefer Seinficht angefúfert hat. Daßs er Das gabel= bafte liebte, ift nicht ju låugaten. Unter ben groferet

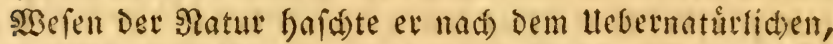
IInd glaubte, Dem ganz eignen religióen Geifte jener

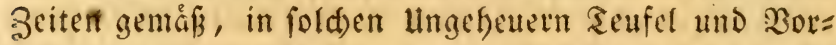
anjeigen von sereftórungen ganzer jeiche ju finden. (E\&

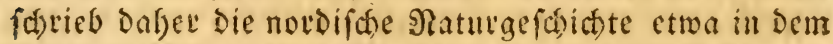
Son einer segende. So jefte id) auch feine Fartta vou allem fabelfaften Schmud zu entlaben fud)e, fo ift es

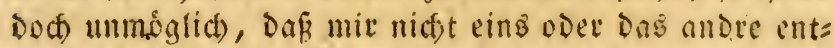

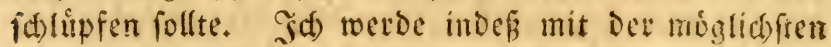
Sorgfalt verfargren, und Dies aud instbefondre bei Dem

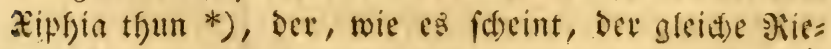

*) ,Xiphia eft animal nulli alteri fimile, nifi in aliqua proportione ceto. Caput habet horridum, ut bubn; os profundum $v a l d e$, velutibarathrum immenfum, quo terretet fugat infpicientes; Qculos horri- 
frupolup ijt, 'ocn Wlinius Senedectes, uno ben Ortus Sanitatis Ziphius nennt. Der Xiphia Deg DInus Magnus ift ein Seetfice der notdiftent Miere, wo cs mit andern Ungeheuern bicjer Merre gemeinlálaftlich) lebt. (Es gleicht gar feinem andern Thiere; Durch feine folofialifden \$roportionen náfert cติ fich altein Den (Eetaceen. Sein Sopf, Der wie eine

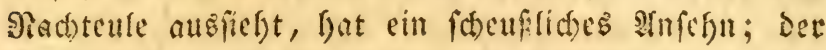
Sincisen ift ungefouer grofi, uno gleidgt wenn ev offen

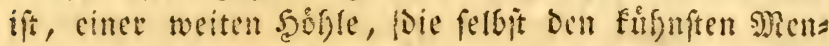

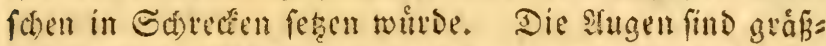

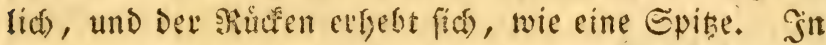

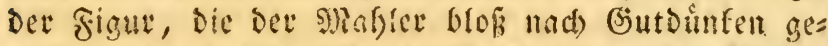
zeichnet, und Diefer furzen Beftecibung Des łiphia varangefetht fat, fann man indef den sholupenfopf noch erfennen. Cine sitt von, freilid) nux furgem, Bart umgiebt vorn herum ben Sopf Diefes Thiers. Die

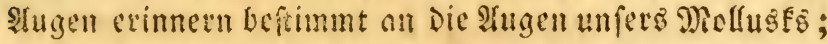
fein weiter, ja ungefyenter Edmaber, Der cben cin

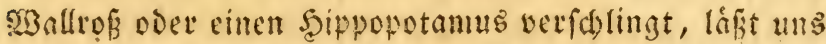
feinen 3meifel weiter librig. Der ibrige afgeil bes Sorpers aber, ber feiner Långe nad mit borten befett ift, hat sigentlich mit nid)ts Afefnlich feit, und móchte wofl ins Sand Dev Didotungen geforen. S3ielleioft vev= mifchte Stans Meagmis Das, was von Diefem Ungefeuev gefagt werden fonte, mit Dem, was bem $\Re$ arwhal Doer Meev = Einfjorn zufommt. Gerwifi ift bas Der Fall,

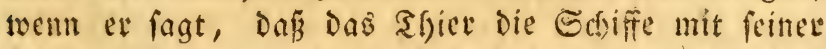
fpiţigen গafe angreife, unb fie badurd verfente, Das

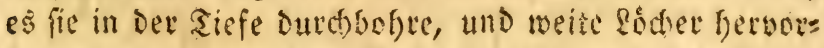
bringe, wohinein Das $29 a f f e r$ teete, und bie Ediffe finfer made.

biles, dorfum cuneatum vel ad gladii formam elevatum, roftrum mucronatum, quo naves perfoffas afferit." Olaus Magnus de pifcibus monftrofis. p. 743 


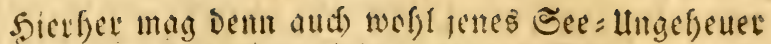
gefouren, Das fein Schriftifeller ifber bie Eetaccen auf genummen fat, und Das cben Deshalb wofl am beften ieinen \$lat neben dem Riefenpolnpen finden méte.

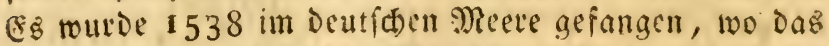

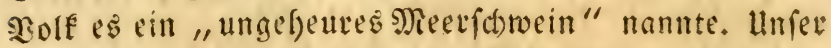
Antor zeigt feine Oróbe nidst beftimmt an, legt ifgm

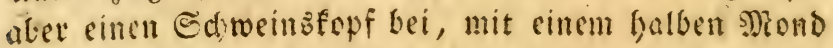

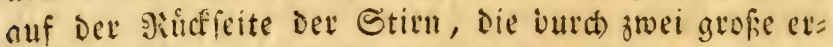
babene firmer febr ferborfpringt. Ferner giebt er ifm vice Dradenfufe, zwei grofe Alugen, die in Dex (segend ber Siteren Iftefn, ein anores noch auf bem

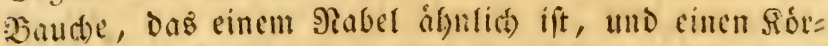
per, Der fids in einen langen, fefler gabelformigen Cawanj endigt *). Jath glaube, es ift unmoglich, hiet

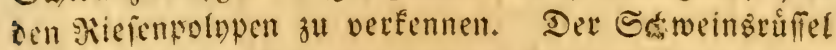
wito mohl der Ednabel unfers \$olnpen fenn. Die beiden Súner bes halben Mondes, nebjt ben virt Dradenfunen und Dem lang gefpaltenen Sdwange, find rffenbar bie adt Itme Des Folnps. Die beiden Sugen ftefen an ifrev redten Etclle. Das Dritte, Das Der Edriftiteflex auf Den Band) Des Thyier's vet=

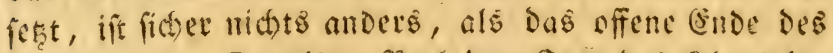

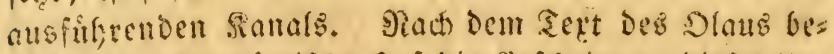

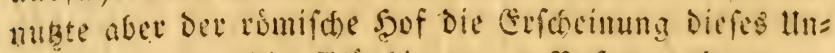
gebeucrs, um die Stanbigen zar $\mathfrak{V}$ ufe ju bewesn,

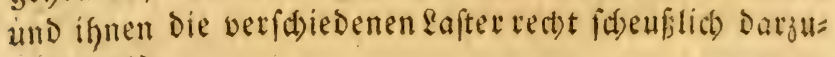
fellen **).

*) Nunc autem ad memoriam reducetur monftrofus ille porcus qui anno I538 in eodem Germanico octano repertus eft, totusque in omnibus fuis partibus portertofus vifus. Habuit enim porcinnm caput, quartam lunae partem in occipiti, quatuor pedes dirsonis, duos oculos ab utroque latere in iumbis, tertium in ventre, ad umbilicum inclinantem, atque in poftrioribes cand $m$ bifurcatam inflar ufinti pifis. u. T. w.

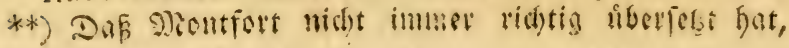




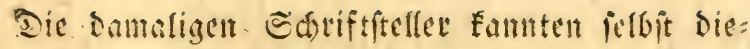
jenigen fiolnpen, die fie fo zu fagen, táglich vor $\mathfrak{A}$ ugen batten nue wenig, frimmen alfo in Bufficht iffer nicht

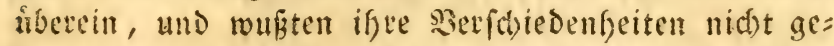
borig anzugeben. Daş Bleide muß̉ alfo befonder's bei Denen der fall fevn, die fid mur fefer felten vorfinoen. So ift es Denn, aud wirfliá) mit Den grofzen Mollusfen, Die zunåd an Den Biefenpolnpen grängen. Die nov= Difden Sd)riftetler erfaunen liber Die Sienge von 1 tn= gebeuern, wowon fie reden gefort, und die fer biswerlen gefén batten, und glaubten, jedes decfelben madie eine befonde bottung aus. Sft bemingten fie fich, fie

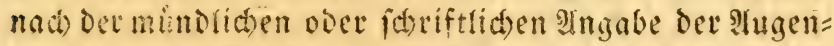
zengen ju befareiben. Sielleidst find dieferfalb det Xiphia, bas Meeridutin, und cinige ander grofie Meertbiere, Die Slaus sRagnus etwågnt, alle eincuet

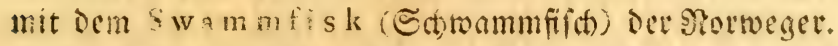
Dieje Edwammfijde nábern fid namlid, wie anore Serungefsuet *; Den normegifden Sifften; Dod find fie bafelofe bedeutend feltener, af Die Eetaceen, die fid) Dort siel ifter zeigen. Die Prowoeger fangen fie

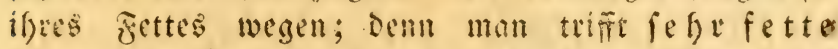

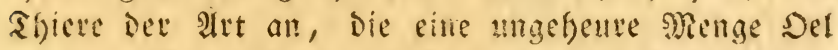
geber. Mran bebient lid Deffelben, mm Das ?ever ju gevben, uns um es in Den langen sointematcten ju bienner. Indre Gaben Een Edimammifid hahane oder a hu num genamnt. Sein ganzer Sirper ift fu= gelartig abgerundet. Cer wird mit ged fine eins ber.

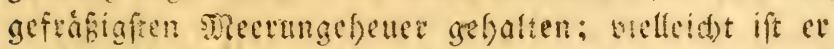
Das graufanfte von allen. (5) bcourf unauffódid nenen Jaub, um feine morderifden ewig hungrigen

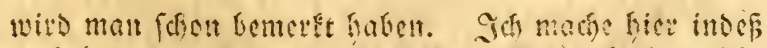

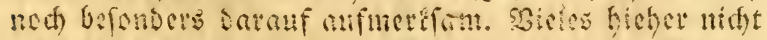

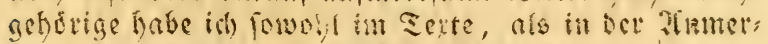
Eung weggelaffer. 2lumerté bez lleber.

*) Claus magnus ubi iupra p. 767 . 
Begietoell zu ftillen. Diefer Befráäigfeit wegen"glaub=

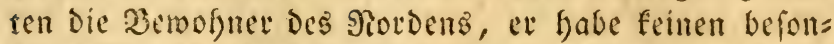
Dern smagen, fondern fein ganjer Sorwer madse nut cinen grofen Saú aus, in welden er ganje zomen

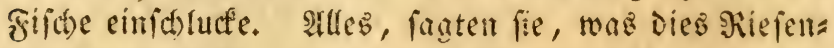
thice verfoludet, serwandelt fid bei ifsm in fleifd, und vetmelat folglich tåglid feine ungefoute Norfie, Die zuleţt nidyts, als cinen Fettflumpen Darftellt. Des Sd)lund des Tfiers fann fid fefre eng zufammenjiefn, aber audi im fohen (srade erweitern, und faingt genau

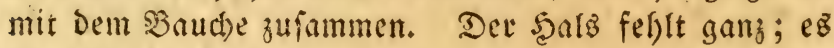
bat abex foviel jett, Dafis es, wenn cs irgend eine eses fafre befurdetet, oder fid gegen ande ungefeuer, die feine seinde find, vertgeidigen nuf in fich felbft zufommentollt, und feine şaut und fein fettiges berwebe uber feinen Sopf zulammenfaltet, viel

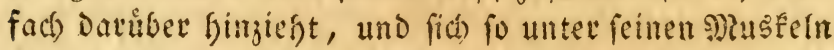

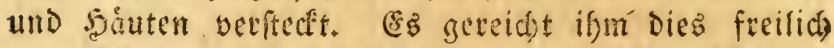

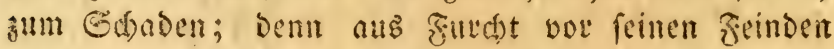

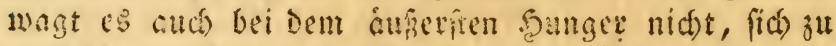
entfalten. Soviro Dofer fein Sounger zu feftig, fo fribt (s) fich theilmeife felbit anf, und opfert folgfich einen Theil feines Rórpers feiner ganjen Eziftenz, um nut feincn Feinden nid)t jut Deute fu werden. (5) rollt (iid) Deshalb audis nide eher anf, und entfaltet fich nidit fruiber, als bis die (sefarge Durásas voriber ift *).

*) "Varietas horum pifcium, five potius monfrorum, hic inferta eft, ob eorum mirabilem formam, ac multifariam naturae proprietatem, cum littoribus Norvagicis interalios belluas faepius ap pro. pinquant; capiunturque propter pinguedinem, quam habent copiofom, ac abundantem. Eam namque pifcatores, ut carnes, fupraignem, coquendo expurgant, venduntque ad ufum corii mungendi, a ur eanfa luminis in tampadibus, eum 
Fid biet erfennt man olute bie getingfte falfthe

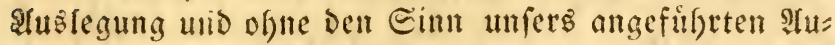
tors zu entftellen, eine- Menge Raraftere, bie nut Dem

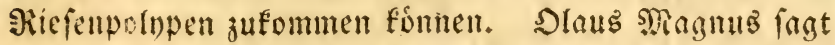
aud), Dafi bie Bewofner Des Siordens, gerabe wie bie Niten, glauber, diefe şbiete verftummelten fid bie Ifrme, un fich Daburd) zu ernáfren, wemn fie feine andre Seute haben. Llebrigens ift unfer \$olnp in Diefer Şeftreibung unverfennbat. WBir finden jene Saube, foorin er fid einnideln famn; ferner feinen

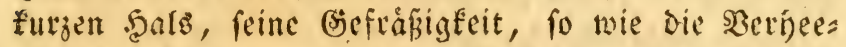

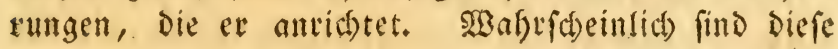

tenebrae continuae fuerint, confervandi Occurritigitur in primis rotunda forma monftrum, Norvagico idiomate, Saman. fisk dictum. ... Ali bahanc feu ahunum appellant, caeteris omnibus marinis belluis animal gulofius; eontinua etiam praeda vix fatiatur, ftomachum diftinctum non habere dicitur, unde quicquid comedit, vertitur in fui corporis craffitudinem, ut nil aliud videri poffit, () uam una maffa pinguedinis adunata. Dilatatur et extenditur fupra modum; cumque amplius extendi nequeat, pifces per os facile ejicit, quoniam ut caeteri pifces collo caret. Os ejus continuatum efrventri. Eft arem adeocraflum hoc animal, quod urgente periculo carnem, pinguedinem, et pellem fuam uti hericius, fuper caput reduplicet, et contrahendofe caputabfcondar; nequeid fine fui detrimento facit, quia inimicas beftias timens, fame urgentefe non aperit, fed efu carnium fuarum fuftentatur, ma$\mathrm{g}$ is eligens in parte confumi, quam a belluis totaliter depraedandum vorari. Scrutaturtamen ut falvetur, fi periculum eft fublatum." Olaus Magnus de pifcibus monftr. caput, $38 \cdot p \cdot-67$. 


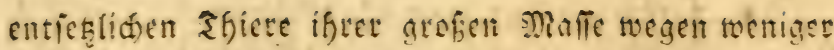
thattig, als bet gemeine \$olnp, ienn twir finder nirgeno eine Erwåfnumg jener Seftigfeit uno sebfaftigfeit, Die uns ben gemeinen Polopen fo furdebar mad)e. MBir merden nun balo feren, dof der grobe \$olop trob jemen

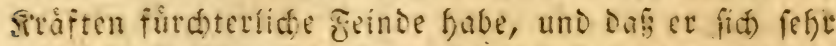
sot ifnen in Itht nehmen mus. Der Mallifich ift, wie (id) jeigen twird, borgugliá) einer bieler seinde, Denen Dex Bicfenpolap nidat ungeftrait begegnet. Die Ceta= ceen iberfanpt fan er nid)t befiegen, weder berwun= Den nod) feithatren, fonden fie find if $m$ im Gegens theil fo furdfotbas, Dá ex nid)t felten im Sampfe mit if)nen einize feinev ojlieder juructlafien muß.

Điefmen mit alio an, Daf Die Befdreibung bes Shroanmfijues auf Den Polppen paffe, fo letnen wir

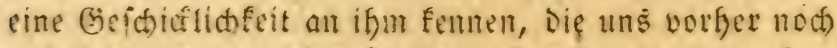
unbefannt war; bie nimlid, fid fugelartig ju for= men, und feine Frme jufammen zil falten, und zmar in Der :Irt, Daf fid nirgends eine hervoriptingende Etel= le zeist, unt bas ifgu alfo leine seinte an feinet Etel= le angreifen fonmen. Dicfes Derfaften fann, wenn

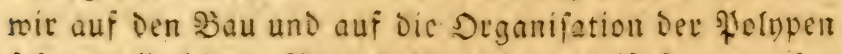
fefgen, allerdings Etatt finten; ia, es ift fogat maffe:

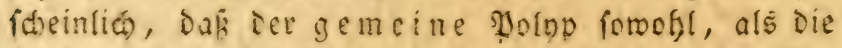

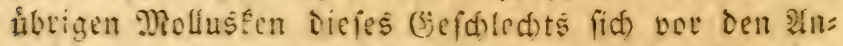

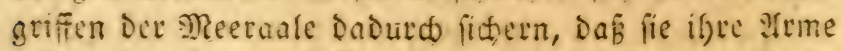
zufammentolien, weif jene Dann nidot roifen, wo lie lie angreifen follen, uno fie alfo verlalien. Dieš erinnert

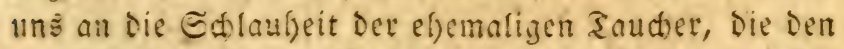

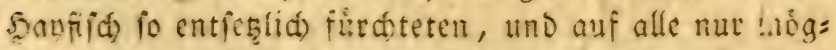
lid)e Mittel geiuad)t hatten, fid vor Den Ingriffen Die= fes furchtbaren Jeindes in Siderbeit $3 u$ fitten. Die

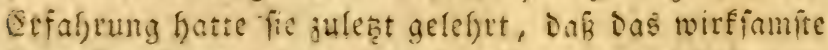
ien, fich fuzelartig aufjurollen*), uno aus iem gan=

*) Plin, lib, 9. cap. $\$ 6$. 
jen Sorper aleidfom einen snaul su madien, fo baf

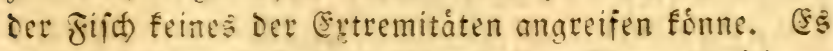
fácint felbft, Dafi Dies Nittel fo vollfommen ieinem Zuecf entiprach, Dof man bie Sauder fogar auš bem sibafier herausheben fonnte, ofne daf lie jenen merbe:

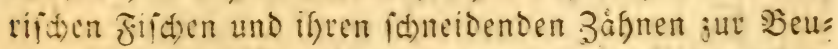
te wurden. Befanntlid ift Die Sebenģgefalde bes Men= fiten in Butcefid)t Des Sanjiches am allergrofiten und Dex IUgenblict am meiften fritild, wo man ben Mens fiden aus Dem Malfer herausfebt, Denn Dann gerabe, wenn Das Sfict fieft, wie feine Beute ifm entwifht, frtengt es jeine Geáfte boppelt an, um fich ifred ju bes måd)tigen, făfrt sarauf ju, hebt fict) ein menig aus Dem Mafler enpor und gelangt fo gemeiniglid) Dafin, ifm cinen sober soer linteribenfer abzubeifien; Die grofieren beifen ien Menid)en wolgl gar mitten Durat; Iuf Der fiebenfundert und fechsundoreifigiten Eeite Des Slaus Magnus finden twit abermals ein Nocerungef)eter, weldes untreitig ein \$olup ift. Eein

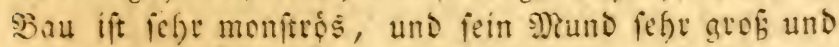
weit. Ce ift wie ber der Mutúnen freisformig; saz

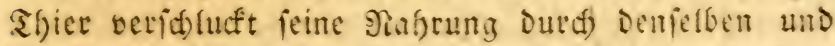

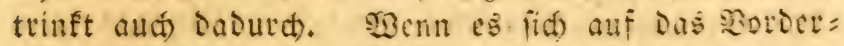

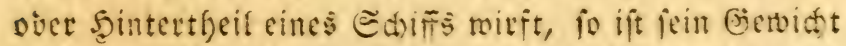
alfein binteidsend, um es ju verfenfen. Dft fitht

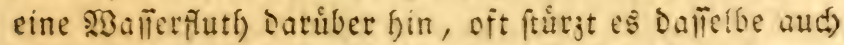

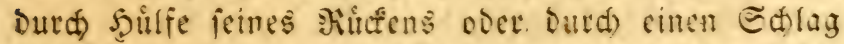

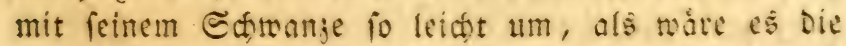
fleinfte siarfe. Eein sorper ift Durd)aus mit einer idwatsen uno formigen Sout beoceft. (5) hat Barts

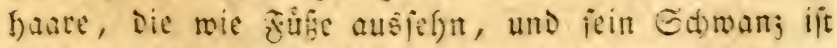

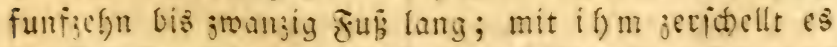
Dic Estiffe, Die es verjentef fat. Shan fam fid nicit

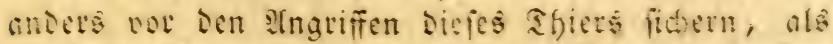

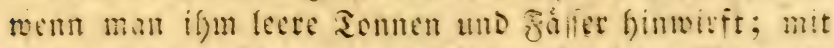
Bicfen fficlt is Dann, uno fiblt Dabei feine sisutl) ab. 


\section{Is 6}

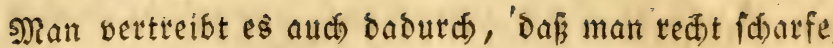
Tone auf der Trompete blät. Das wirffamfer Mittel gegen Daffelbe ift aber, cinige Ranonen bei Der Scand zu Gaben, die faneller als alles andere és verteciben, Denn fie vermunden es und bedecten das Naffer mit feinem zette *).

Die Fisut des affiers, das fich beim Slaus vor Diefem Sapitel befindet, fann hier jwat gat nidst in $\mathfrak{B} e=$

*) „De fuffocatione navium per monftrofos pifces...os etiam haec bellua magnum et amplum habet, circulare, veluti muraena quo efcam vel aquam fugit, pondereque fuo in proram, vel puppin injecto et impreffo, navem deprimit et fubmergir; quandoque fola aqua (ut praemiffum eft) nocere non contenta, dorfo, vel cauda hinim, ut minusculum aliquod vas, crudeliter evertit. Spiffum et nigrum corium habet in toto corpore, pinnas longas informa latorum pedum, ac caudam bifurcatam latitudine quindecim vel viginti pedum, qua circumventas navium partes vehementius ftringit. Verum malignitati ejus remedio occurritur opportuno, tuha videlicet militari ob alperum acutumque fonum, quem ferre haud poteft, et magnis ac immanibusvafis, feu doliis ejectis, curfumbel1 ua impedientibus, five pro lufuei oppofitis; aut validis tormentis feu bom. bardis, quarum fonomagis, quam ferreo, vel faxeo globo terretur, cum globus hujusmodi vel aqua, vel pinguedine ob. ftante vim perdit, vel paululum vulnerat vaftiffimum corpus, immenfa pinguedine, inftar valli munitum." Olaus Magnus, de pilc. monftr. 736 s)iontfort hat hick

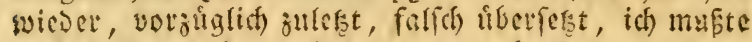
Disferfalb Des Dlaus Drizinalworte ferfergen.

ZImerere, D. Heberfeg. 
tlacht fommen, bow aber ift bas llngeheuer, das bort ein Sctiff angreift, rutDer, fugelartiger Form. Slur ein cingiger Sunft fómte uns einen Rugenblide lang it

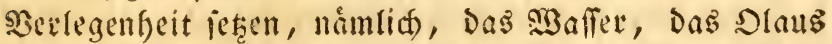

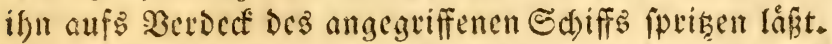
(es ift zwar wafr, Dafj Die Şlafer, Rafá)alots utid

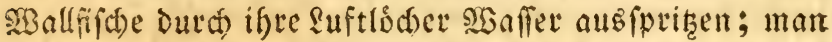

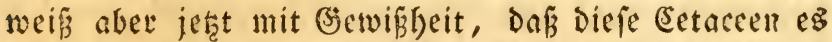
nie auf Die Edhiffe merfen, Dafí fie biefe aud) nid)t um= zufturzen fuchen, fondern im (segentheil vor ifnen flies ben, und aus manden begenden jagat voflig vers fowinden, fobald diefe von allen Seiten Dutebifhiffe werder. Der Biefenpolyp aber greift die Sdiffe an, wie ich) zu bemeifen fuchen werde, fud t fie zu uberwål= tigen und in Den Sitund binab zuzieben. Civ flettert an Das Botb hinauf, umflidt mit feiten langen 2 trmen

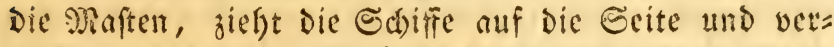

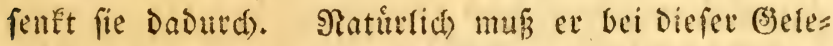
genfeit Das Sdhiff mit einer 2 safferfuth bebecten; Denn

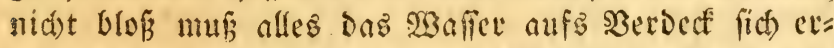

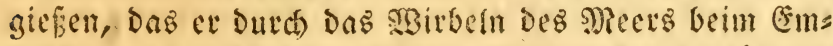
porfteigen vor fid binalftreibt, fondern ber ausfilfren= De Ganal mußs auch zu gleider zeit eine Menge 23 aller,

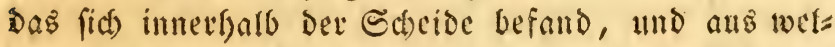
dem die Siemen bie lebenshluft vorfer gejogen haben,

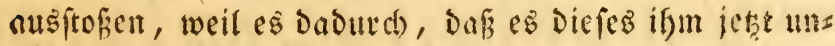
mitse in ber es fich jeţt befindet, einjuntfymen. Da das (s) De Diefes ungefeuten Trichers fefre fang ift, land das 23afiet alfo mit einiger Gewalt Daraus hervortteten mur, fo wird auch Dies fattum fid) Daju cignen, es Dem Sholnpen beilegen zu fonmen.

Heberoies werden bie Schiffe weder Dutch 233 alls fifáe noth Eetaceen angegriffen. Sin Den Mreten, die won allen Eeiten Duráf(c)ifft werben, flichen fie ben Mienfden; trifft man Dagigen feds : bis fiebenfunder 


\section{8}

Stunden toeit bon ingend einem lande cinige ant, fo fdeinen fie fict Durd)aus nid)t ju firthten; fdrinen vielmefre bie Gefaftr, Die ifmen droft, gat nidt zut afnen; intme". find uno bleiben es alfo friedicie Shiere. Sa, fie find fo fanft, dafi bie fiflder, fo=

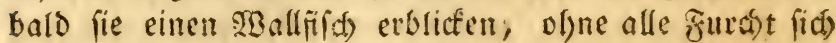
in ifre Boote begeben, didst an ifn betanfafren, ifn zuerft angreifen, und ifm ifje Sarpunen in den feif werfen. Statt fich zu vertheidigen, flielst alsoamn Dex sabalfifith fowolst als Der Safdalot. Man braudst fids aud) úberall nidst vor ifnen in $2 d^{2} t$ zu nefymen, auser etwa, wenn fie wieder an bie Sberfiad be des 2 Baffers empor fommen, in Den leteten Bugen find, und im Sodes: fampfe fid frampfartig bin uno fer wålgen; Denn als = Dann fdiagen fie gemaltfam mit ifren floffedern uno

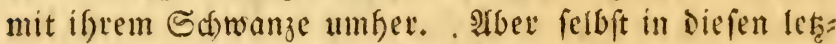
ten Sugenblicten greifen die Fiffter fie nodb von der Sopfeite an, benn Da baben fie, nach wie vor, nid) ts zu beforgen. Fin hohen Mieere ift es̃ noch anders. Dort greifen fie die Sdiffe reder an, nod fleben fie vor ifnen, fonoern fideinen fich vielmefr mit diefen fdrmimenden Maffen, weldye, wie fie, die fluthen beberriten, zu baluftigen. $23 a h r i d$ einfid fino $23 a l l=$ fifche, Du Dies thum, emig innerfalb des $23 e l$ tmeers geweien und geblieben, und nie vielleidst angegriffen worbent.

\$d) fab einft einen folden $23 a$ alfifich, an einem

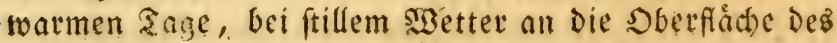
SBaffer fommen, und um unfer Schiff hermmipicten. (av blieb une den ganjen Tag finduted nabe. Des Mlorgens, bei Sonnenaufgang, wurben wit if)n juerft gewahr, und befit mit der Sonne verliés ex uns vicder. (er miegte fich gleid) foun neben unferm Sóbiffe ber, in= sem et bald woen bald hinten fid) empor foo (er wat langer ats unfer fahtzeug) uns feine stende an bem Sdiffe zu baben fdien. Sefre oft taudte el unter, 
Inoen er fid in biagonaler Sictsung verfente. Dann wirbelte das gBaffer, aber bis zu einer gewiffen Siefe fonnten wir ifn mit ben \&ugen berfolgen, meil feine sunfelgraue Farbe Die Stelle fdwårzte, wo ct finabs fanf. IUf eine ånnliche şeife fam cr roleder empor. Majeftatifich exfob fich feine Riefenmaffe, und fein

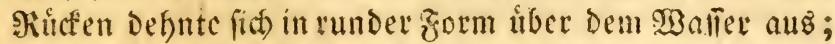
verienfte er fich wieder, fo folug fein breiter uno platter

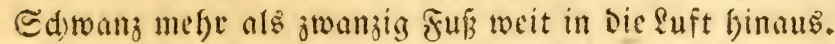

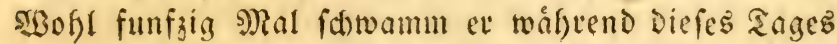
bon einer Seite des Sabfes jut andern, olne bem= felben zu nabe zu fommen. SBate dies aber aud ge= fdeben, fo glaube id Dod immer nicht, Dof er iffm Echaden getlan bátte, Denn feine Bewegungen waten Daju zu langfom, zu abgemeffen. Da ex fid) zu feinem Soranugen auf allen Eeiten umberwálzte, fo fonnten wir alle Sheile feines Siorpers betradten und berwu= Dern. Flintenfduf weit von uns zur red)ten Sand an die

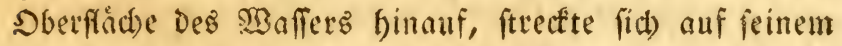

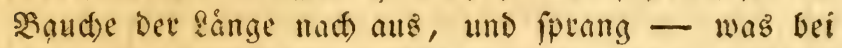
einem fo riefermábigen affere ju beroundern ift -

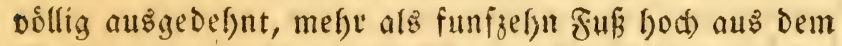
siaffer empor; fdrobete vónig in Der luft, uno fier Dann, inmer noch ausaeftecft, mit fef) lautem plat:

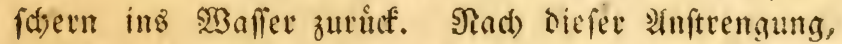
Die feine magheure Nhefelfuft beweift, verfomano et, uno wir faben ifn nidt wieder. Sצäre er bei bie: fem Sprunge uns nofber gewefen, fo fătte $\mathfrak{c t}$ uns ge: fáfrlich werden formen, aber ficher that ex aud if in blok zux \&uft, wie alle feine Serwegungen den ganjen

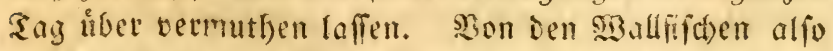
- Das forlicke if hieraus mit Unfeflbarfeit - baben meder bie sigenfden, nod ifje Cd)iffe das beringfte zu furdten; wolyl aber von ben \$olnpen ober von an: dern ?hieten, Sie vielleidt eben fo will find, wie diefe. 


\section{$190^{\circ}$}

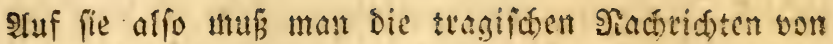
Inguifen, 3erjolingen und Serfenfen der Echiffe be: ziefren.

(jh) habe (chon angemerft, daf man eine smenge folcher Shatfacten, bie die Alten Den Cetaceen zus fdreiben, von ifnen, ifter fonftgin Eitten wegen, nicht ferner gelten lafien fant, fonden daf fie Durd)= aus andern Seeungefenern zufommen miffen. Der: gleid)en Secungeheuer begrifif man ebemaliger acit unter Dem gemeinfofoftlidgen গamen bell u a e, Det fict in unfern Sprad)en nidft findet. Seste bedirfon wiv feiner aber weniget als je; ba bie immer mefr

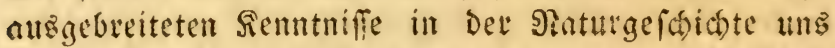
fåfig madjen, jedes $\mathfrak{B e f e n ~ m i t ~ f e i n e m ~ e i g e n t f l u m l i c h a t ~}$ Samen benemen zu fỏnen. Shat) foldhe Ungefinct fonnen wir nun nach ifger Drganifation oser nad) ifyen anderweitigen Merfmalen flaffifigiten. SBis wir tie nod) geneuer fennen, wollen wir fie indef unter bie rederfåntigen \$ollusfen fetzen, mit weldben fic, wic

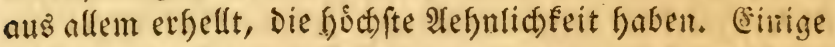
von iffren mogen vielleid)t gar genau von den andern verfecieden feyn, und felge beftimmt abgefondarte Got= tungell ausimacten; aber wir haben jwat allgemeine,

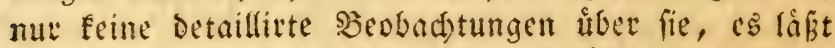

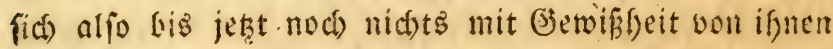

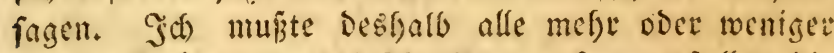

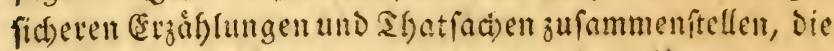
Den Eetaceen nidst jugeidrieben werden fonmen, und Die Die Paturforider, als fie betreffeno, vertorfen haben.

Die Saturfiftorifer find sber, meinet Meimng nad), and) auf ber andern Eeite wieder zu tweit gegan= gen, illom fie alle Frofta firt Fabefn elflarten, bie nidft nuf bie Setaceen pafien wollten. So wie roir bin neucu Zeiten náber fommen, finden twir, dof bie

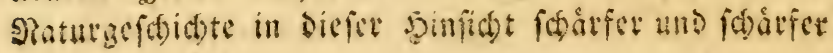


beichitten wirb. Siondelet, artorosandi, B̈esner und Gonfton reden nod) von biefen Mecungeheuern, die

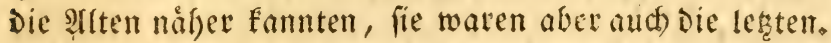
Spatere গaturforfder erwålnen ifrer faum. Doch fanden fiá) oon zeit zu jeit fel)e beftimmte und ppes d)ende Thatfachen, Die Die (exiftem Der Bicfenpolupent auker atweifel feteten; west)alb man denn endich ju det (sinfid)t gelangte, Dấ nicht alle jene Ftaditionen grund: los fenn fonten, fondern baf mefri als cine beobady= tung stid)tig fertu miffe. Sn cincm ganz neuetid ges Dructen GBerfe, Deffen Serfaffer woht nidt im Sers Dachte, Die Hebertreibungen und das sisunderbate zu lieben, ftefne witd, lefe ich folgendes: "Man finde

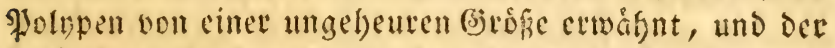
beriutigte Frafen *) von Dem bie nordifinen Eeefeute fagen, baf ex cin Sabiff umberfen fonne, fer offenbat

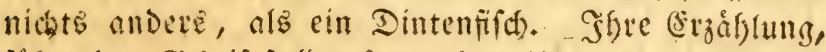
föbre Der Schrifteller fort, betweife aud, wemn mart fie von alfem $2 B$ underbaren entfleidet hat, zum wenig=

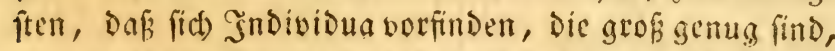
um mit ifien Nrmen aus Den Echaluppen uno fleitren

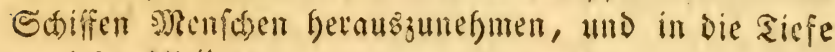
วิน รiefnn **)".

Dev treffliche rortis fogte mir, er habe in Penc: big cinen vorguglich guten aaucher gefannt, Der nidje mefre tauchen wollen, ja biefem (sefola âfe vollig entiagt f)abe, weil et in cinet gewillen Tiefe des Mlers Sees

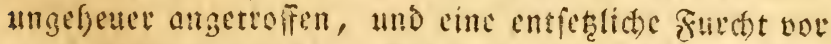
ifmen befommen fabe. Dies erinnert mich an Die bes f(hichte jenes ficilianifhen Sauders, ben bic Sicugierde

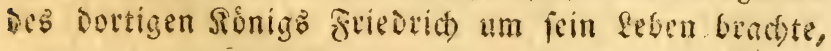

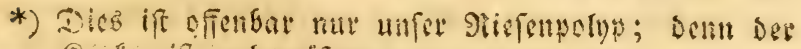
Sirafen ife noch grö́per.

**) L. A. G. Eose, Shaturgsifficte Der Torirmer, (Hift nat, des Vers) p. 36 . 


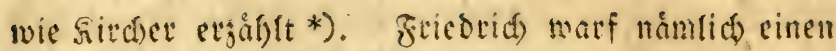

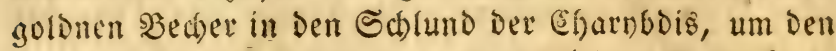
Saud)er Sicolas (Den man megen feiner (sejchicflidi): feit im Sdbimmen und Saudien aud \$eficiola - Den 马ifch - nannte) zu vermógen, Daízer in Den $\mathfrak{A b}_{3}$ rund untertaud)te. \$eicecola that eş, uno blieb mefre als Drei siertelftunden unter Dem $93 a$ aller. (5ndich fam er empor, uno fielt ben goldnen şećer triumphirend in feiner Send ; dann fagte ex zum fienige:

"Unter vielen Rebengifafren aller Sret habe er unten in Der Siefe ganze Seerden gräblicher $10(1)=$ pent*) gefunden, die fict mit ifren ârmen feft an Den

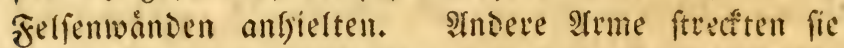
weit umber, weŝalb fie ifm das allerfutedbarfe von bem gewefen feyen, was er ba untell vorgefunden

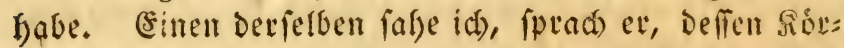
per langer als ber fiorpe: cines Menfuen war, und

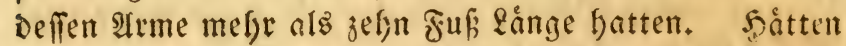
fie midh gefafit, fie batten mid) Dutch Den Diuct allein getodtet u. \{. w. t)."

Bielseid)t bat Der Sauder in manchen Iunften

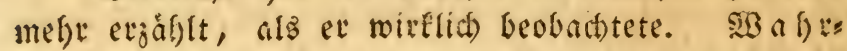
$f$ d) einliá) aber ift alles, was ev lagt, ja es fún,

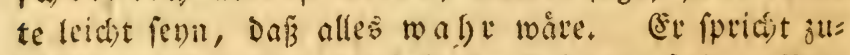

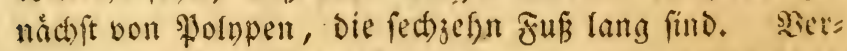
binden wir feine Bemetfunge! mit Dem, was ung foton befannt ift, fo beftåtigten fie uns, Daf Diefe arofibn Molluต๋

*) Kircher, mund, fubt. Tom. I. p. 97. cap. 25.

**) Ingentium polyforum greges.

t) "Hanc hiftoriam prout in actis regiis de"fcripta fuit, a fecretario archivi mihi communicatam apponere hoc locovifum fuit, ut marium vorticofi tractus luculentius paterent." Fircher, Mund. fubt. Tom. 1. cap. 15. p. 97. Dirs erimert an Szomer's Donfiet Gifan! 12, v. 73 biด 110 แแก v. 245 bis 259 .

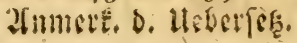




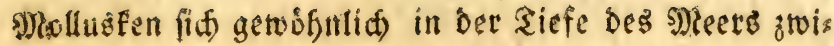
faten Felfen und Stromungen auffalten, Deren (3ewalt fie nicht adfert, weil fie fich feft an Den Ritppen ank flammern, und zu gleider zeit bie Filfae uno jede an Dermeitige Beute, die ifnen bie unteritdifthen mirbel zufügen, ergreifen fonnen. Sie bleiben Demnad fort: Dauernd in Der Siefe, bejonders fo lange das 2 Baller in \$etwegung bleibt. allen Meeren, porjuglich, wo fie fegr tief fins. Nach Den von mir gefammelten beobadtungen fdeint es faft, Dấ fie fich nut allein bei fefre ftillem 23 etter bistreifen

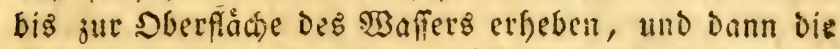

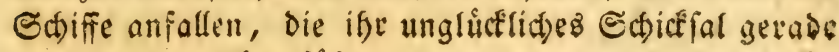
Dann in iffe গåfe fưfrt.

Dicfe uns faft unglaublich facinenden ifatfacten baben um fo viel mefre Autgenticitåt fur fich, wenn wir uns Daran erinnern, Daßz aud) 3 u $u$ fern Zetten (Slieder folder ungegeuren \$olnpen im Sd)lunde der Mallfifde von Secleuten gefunden worben find. So

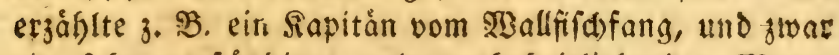
ein fef; verftåndiget und wabrfeitliebender Mann, Der fich mefrere Salfere lang mit ber englifhen foge: namuten Sudofict)erei (fouth firhery) befdyaftigt batte, im Safre 1783 Dem Doftor Ervediaur, feine Ediffimannichaft babe etwa vor zefnn Jaften einen

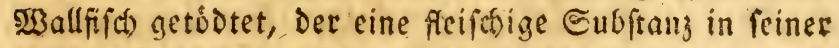
Siefle gefabt habe, Die er nidht g!eid ctînnt, twowon br aber bei nåferer linterfuct)ung gefunden båtte, daß

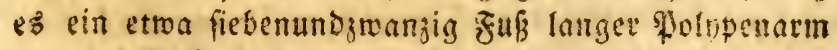
von Der Dicfe eines פTaftbaums fey. (5) a th wat er indef nicht, Denn Das eine ende Deffelbent war durch Den Slagenfaft berłefrt. Btefen wit num, lagt $D$.

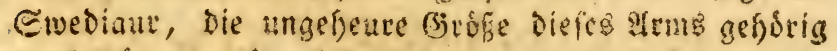

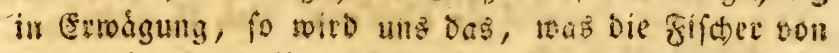

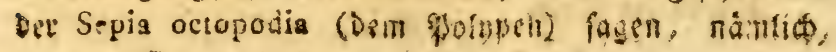


Dafs fie Der grobite von allen fif nid)t mefre wiverfinnig vorfoumen.

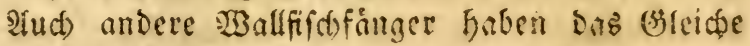
bemerft. Der efemalige Minifier (Salonne zog mefrere Suaferfamilien nad) (Europa, un burd) fie Den gánj: li(t) gefunfenen $\mathfrak{M a l l f i f}$ fang mieter empor j"l beingen. Sie liefien f:ch in Dinfird)en nieder, wo id) mid) mit Diefen åuferft verftándigen und fenntnifreidfen \&euten oft und fefre vertraut unterfielt. Biner Der siapitáne, mit গamen Benjofnion, verfictserte mir, er babe einjt einen månnlid)en Ballfijd getódtet, bem eine lange und runde ficifymafle aus Dem Miaule fing. Seine Matrofen yătten einen Şafen an Diefelbe befeftigt, und

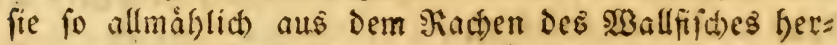
aus und aufs Berdeck gejogen, wo fich Dann gefunden babe, daf es ein ungefeuter Wolupenarm fen; er wat aber an beiben Eeiten verftummelt, und fein Dicffer Ende war fo dicf wie ein Maftbaum. Seine tiefen Ed)rópffopfe, ingte er, waren gróper als ein Sut. Das untere Ende fojien frift) abgebifien, Das obere (Ende war es rabridjeinlid) nid)t lange vurher, bennes war vernatbt, und oben Dariber befano fiá) eine Ber=

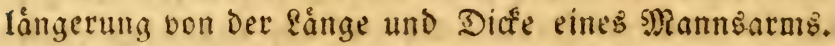
Diefer ungebeure \$olnpenarm hatte, - genau gemeffen - fieben Slafter oder funfundoreibig fub, in Der Sánge; feine Sctrópffopfe waren, wie beim gemeinen Polypen, in zmei ßeifen georbnet. WSie lang muste ber Itrm alio nicht eigentlich gemeíen fent, da ex an feiriem oberen (ende, und zroar in eirrer Dicfe von melfe atร finf zoulen fchon verftummelt war! - In feiner Bafis fotien cr rund abgefdnitten, und zeigte nichts von Infiảgfeln oder umferichrommenden f̧áuten. Der Wallfifd) batte ifn folglida) vielleid)t Didst an ber Sanbe

*) Swediaur, Iournal de Phylique, Vol. II. 1784. p. 284. in Dir Note. 


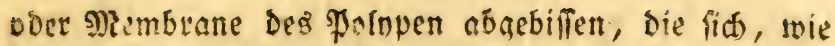
wir wiffen, bei allen Gattungen iener Ificte finter; bei ben naften fefor breit und ausgedefnt, bei ben be= foralten aber reniger weit itt. Da Der $9 \mathrm{~cm}$ immer

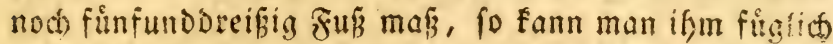
noch zefn fuf menigftens geben, als Das, was ifm an feimem oberen Ende feflte, um vou ciner Dide von

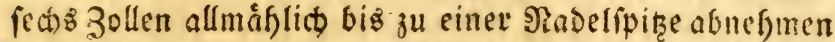
ju fornnen. Settad)ten mit ferner die Afbildungen Dev gemeinen Doinpen fomol)l als Der Hiefenpolapen, fo werden mir finden, dar wir wenigftens noch ander zergn,

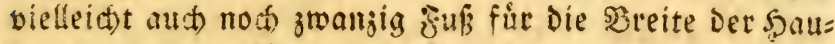

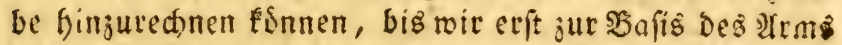
Dictt am Munde des Thierŝ gelangen. Das gåbe Denn

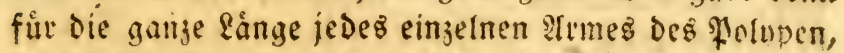

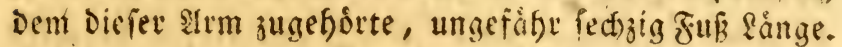

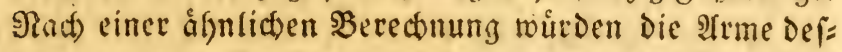
fen, vondem Sivediaur redet, etra vierzig fuí mefien.

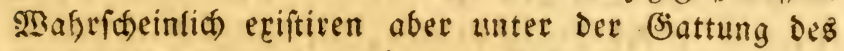
Biefenpolnpen nod) gróbere Jndividua.

(Ein andrer von Diefen amerifanifhen Rapitånen,

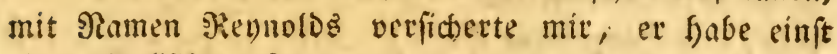
einen $23 a l l f i f()$ gefangen, Dem Die eitre Sarpune finters Ohr eingedrungen fen, fo Dás er nicht weit babe flie= hen, und nux felin furze Zeit nod) leven fonnen. Dann Gabe man mit einem Male einen langen fieifdigen Rór= per von rotfiet und fdefergrauer Farbe auf Dem Meere fatwimmen gefefin. Die Matrofen batten Derifelben fur eine Meerfallange gehalten, und fich fegr Davor entiebt. Einer unter ifnen fen indés, da er bemerft habe, Daf Die Schlange ofne Siopf fer, Deeifter gewor=

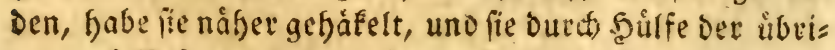
gen auf Befef) Des Rapitån a a wie aus fajt allen großen Meerthieren, Del Daraus zu fie:

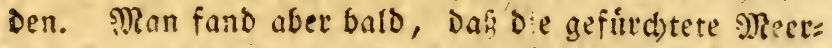

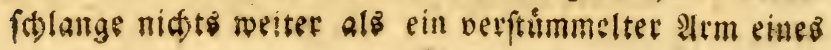




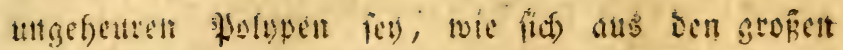

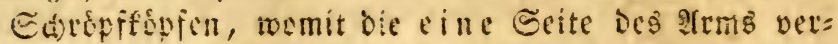
fifn mai, rrgá. Ám didern Ende Des ârms twaren

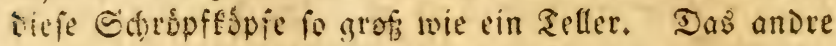

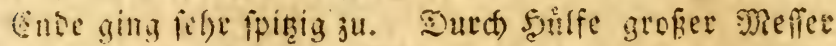
lick Der Siapitån einige Stucte Des Arms querdurch ab=

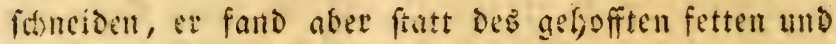

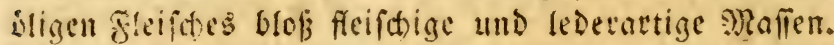

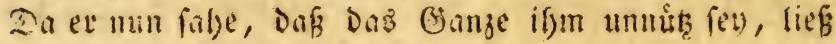
et es meficn, uno dann wieber tiber b3ord werfen. Die Bafis fatte zwei und einen falben ₹ु! im Durdmefier,

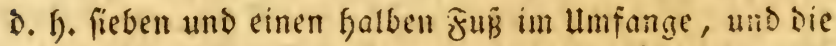
ganje ?ånge betrug neun Rlafter, oder funfundviergig gruj. Det Sapitån fonnte fic) nid)t genall befinnen, ob Das untere Ende Membranen an fich hatte, Doer ob eŝ glatt abgebifien wat. Einige Matroien fónitten Stúfe fleifd $a b$, uno boben es auf. Durch langes Slopfen und Mafden im Meerwafier madten fie eine ziemlid efpare Epeife daraus, Die einige Tage hinters bet fo gax immer befier wutde, und bie fie sem gefals

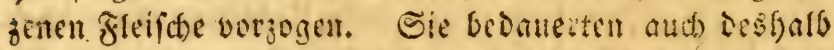
felfr, bas Gange itber Bord geworien oul baben, indem

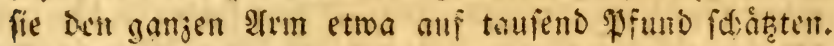

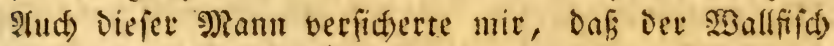
faft allemal, fobald er ither vertwundet fer), eine

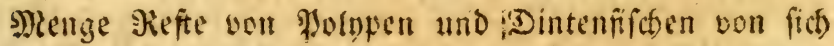
gebe; - wie roir bei der unterfutsung úber den

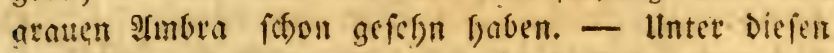
lleberteften, fufre ber Eecmann fort, finden fid oft fo

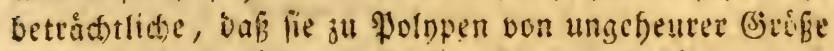
gefjout baben miffen. Diefer blaube ift fur uns um

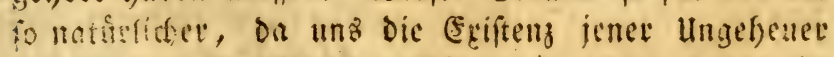

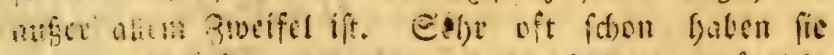

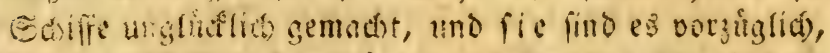

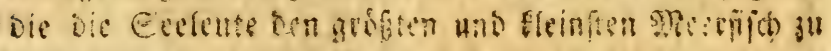
nomen pitgen. 


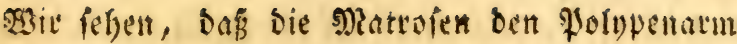
fur cine Meerifslange hieltert, und fich bavor fútcteten. M) grofen Meetfdlangen Dev alten Sd)tiftiteflev erimnern uno fie crtaten? Sie fagen, man trefie fie bfters in

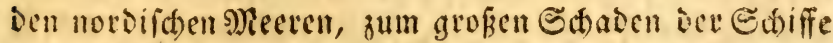
uno Edsiffer, an. S3ielleidt waten fie am Enor nid)ts neters, als atrme von-gicjenpolupen, die bieje quet uber cin Sd)iff binwarfen, und zugleid) einige Mrens fa)en von ber Mamm(d)aft Damit ergriffen. Job will

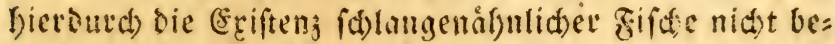
freitem. Das Foftum, Daßz Franz leguat und feitte

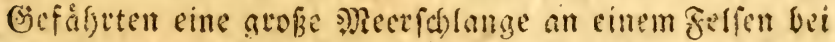

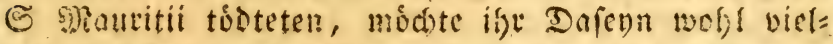
melye beftátigen *). Siloer aud) fie war immer fo grof

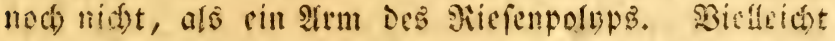
wat ex alfo, obct cinct feinet Iftme ofters bie 3eran=

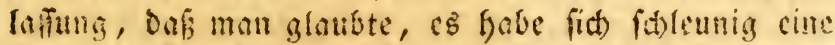

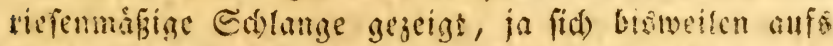
Serot der Ediffe geworfen. Dies verbint eine na. l)ete linterefứ)ung.

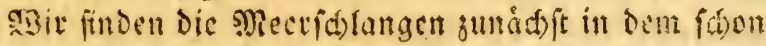

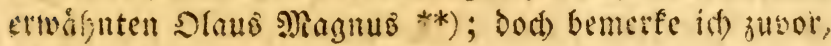

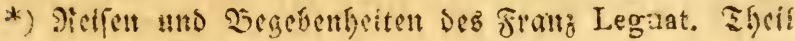
2. p. $40.21 \mathrm{~m}$ fterdan 1708 .

**) "Qui navalibus exercitis in littoribus Norvagiae, vel inercaturae, vel pilicaturae operam navant, eonformi teftimonio ftupendam fanerem aflerunt, ferpentem videlicet vaftaemolis, ducentorum pedum et amplius longitudine, a c viginti pedum fpiffitudine, in rupibus et cavernis penes oras maris bergeniium verfari: qui vitulos, agnos, porcosvoraturus, ab antris foIum lucido noctis tempore in aeftate exit; vel. . locultas er genera marinoru cancrorum ut doglutiat, maria transmitit. A collo deinceps dependentes pilos cubi- 


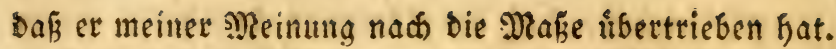
"Mllle fpridit er, die Die normegifde Rufte bereifen, ftimmen Datin ưberein, dấ man bort bisacilen eine

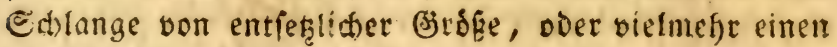

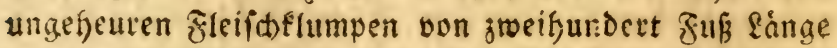
uno etwas mefre als zwanjig fuk Dicfe antreffe, bie in Den Telahiflen und Epalten robfnc, uno nur allein im Eonmer beim Mondenfarin ferborgefe, Dann aber Felbit an bie Sifte fomme und Ralber, Edweine, und Şammel megnefme. - Sie werfe fich aud auf Die Edhiffe, indem fie fich rie cine fefr hobe Silule gegen fie ertiebe, bie Menicten ergreife, und vom Serbecte

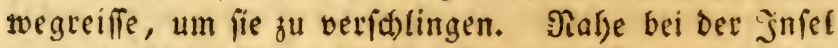
Doos fágrt Slaus fort, faf man 1522 eine foldte

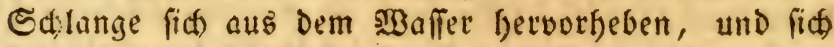
Dann fpiralformig zufammenzief)n, Deren långe man

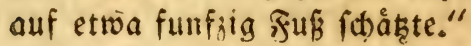

Álorobandi *), (ङeşner **) und Soniton ***) ba: ben den Dlaus fopirt, uno ju ben zmeifundert fufen Sänge no(b) einen Sopf und flammende sugen binjuge: feţt. Dergleiden rüfrt aber von ber Damaligen ros

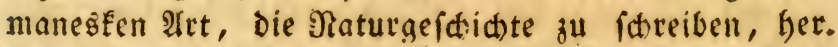
W3enn mir die ůbertriebene Maf́e des Dlaus jwect: mákig einfdránfen, und felbft bie Sd)lange Der Jniel

talis longitudinis habet, $\mathbf{q u}$ am asque acutas, atro colore, et flemmeos oculas rutilantes. Hic navigia infeftat, hominesque fe in fublime inftar columnae erigens rapit ac devorat.... Eft et alius mirae magnitudinis ferpens in infula Moos dicts, qui... vifus eft anno 1522 . Alte fuper aquas fe extollens, atque in modum fphaerae convolvens." Olaus Mago nus de pifc. monftrefis p. 771 .

*) De pifc lib. 3. p. 344 utto 345 .

**) De pifc. longis fpinofis p. 93.

***) De pifc. p. 10. Tafel V. fig. I. 
Moos jugeben, fo bleiben etwa jene funfsig suf sange úbrig, Die cin 9 rm Des झiefenpolups wirflid hat. Bis

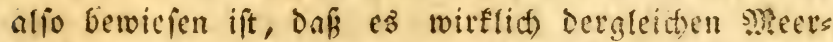
follangen giebt, falte $i$ d) fie fur Ame fencr rie?en=

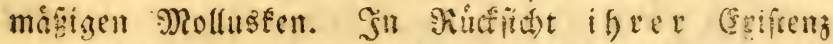

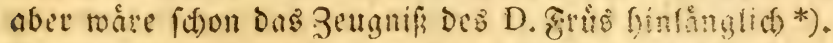

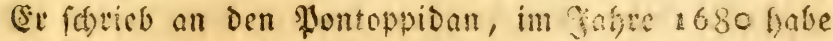
fid ein Fiefenpolnp, vidleid)t Doju nod) sin gon ituacr, nit feiren Itrmen und Sdropfropfen in sen selfen Des

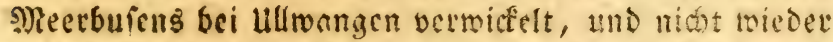
ins Waffer fommen fónncin, fer) alfo Dort auf Dem Sel= fen geftorben. Sein todter sorper verbertete sinten unererågliçen Beftanf, und fiel ben Becifemien lange 3eit findurd wegen feiner giftigen Ilusbinftungen be= id)werlian.

Seier ift nut nicht mefye von sinem Siefenpolinpen bie Fese, ber fduell uno fludtig im : ncin! Diefer lag ausg gebreitet auf Dem felpen Der Ginte.

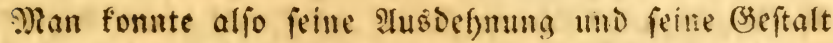

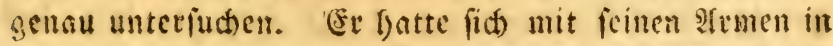

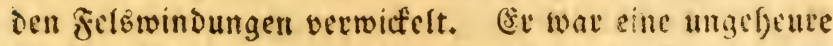

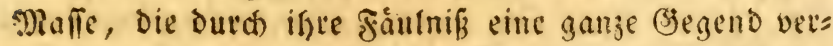
peftete. Shier ift forglid ser Polyp mit feiner Miefens geftalt unláugbar, ba man fie nåber ju betecd)ten uns

*), D. Früs, alfeffor Confiftorii in Norta Landia et Vicarius Collegii de curfu evangel. promovendo, anno praeterito, cum hic Bergae erat, retulit mihi, quod anno 1680 in finu Uilwangen, parochiae Aftaboughtalis bellua, forte pullus adhuc, fefe implicaverit fuis tentaculis in. tra rimas fcopnlorum, et ibidem mortua fuerit, cujus cadaveris corruptio intolerabilem foetorem, longotemporeiter facientibus moleftum, produrerit." Nov. act. curiof. Vol. II, p. 147. obf, 38. Carol, aug. a Bergen. de Microcofmo. 


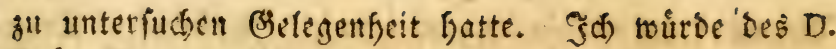

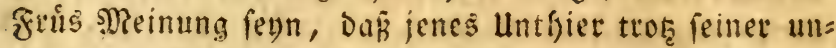
geheuten Birofe, Dod) vielleidt nur jung nod) war, toenn id) nict, Den \$olypen von Dem Arafen abgefondert, und von Diefem lethteren eine befondere Bjattung gemadt Gåtte. 2lber id) habe dics mit forgfältiger lleberlegung gethan; Denn allenthalben, two ber Sirfenpoinp fid

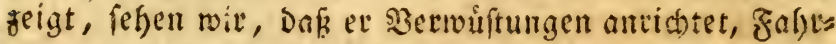
geuge umidslingt, Dienichen binausteint, ja lelbft biš weilen Schiffe in bie Tiefe hinabzieft. (e) ift alfo eitr

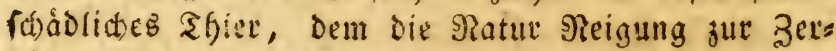
ftorung und aum গRorden gab. Der Srafell Dagegen fáseint fanftere und friedfichere Sitten zu habell. Die

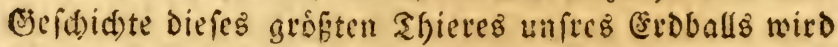
uns zeigen, Daf́ ev nie Sdjiffe unflammerte, wenn ev fich bei ftillem $23 e t t e r$ Dann und wann emporfob. Sat et ja bistreilen einige verderbi, und andre in Befaljt gebracht, fo entftand das nut Dafer, Dafiser fie beim 2luffteigen, mit feinem riuten umfturzte, oder baf fie bei ieinem Biederverfinfen Düch Das Mirbeln Des 5isaffers verfd lungen wurben.

Biele unter ben Norwegifden Ed)ifigfapitånen, bie bei uns lanoeten, baben mir gefagt, Dấ ifnen die risfictedenen Shatfacten, woraus die Ceriften jenter

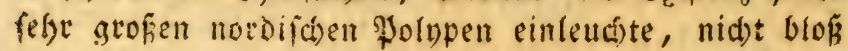
vom Şorenfigen befannt feyen, fondern, Daf fie fie felbit zum abeil erfaferen bäten. Einer von ifmen, mit શ̂amen Anderfen, verfiderte mir, er habe in bev

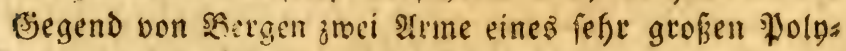
sen, ben er fưr einen Rrafen hielt, auf Den Jelfen ans getroffen, und beide fenen unten nod durd eiren abeil Der Sallo oder Membrane Des \$olnpen, mit einander rerbunden getwefen. Sie waren fo dicf, Daß el fie faum zal umflaftern bermocte. Seder Derfelben mar jefin Edfritte lang. Sieduen wir nun auf jeden Edritt

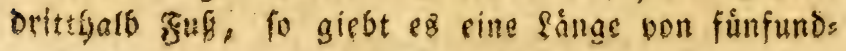




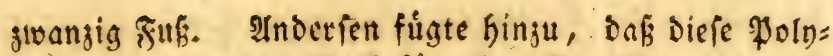
penarme, die Das $\mathfrak{Z}$ olf fur eine Irt Meerfalangen

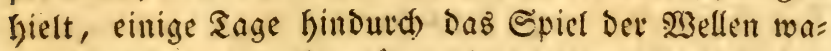
teit, Die fie Dann anderwårts finwarfen. Afud) fen eह่, fagte ex, fo gar felten nidst, Dergleichen giefte won gro: fien slolnpen anzutreffen. Sie lebten in Der Tiefe Des Meers, Gátten aber aud Dort, wie alle andere ahtere

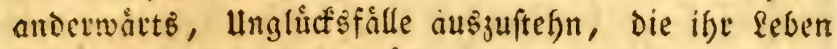
bebrofen. Ueberdics múfie ja auch dies einmal feit Biel erreid)en, wenn es gleid, nath Der $\mathfrak{x}$ rabition ber Eecleute, fefre lange baueve, efe ein foldjes a gier ftetbe.

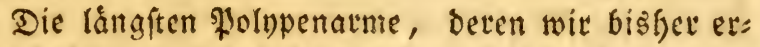
wálgnt haben, maken fectzig Fuß̧. Dod) mußs es in Der Tiefe Des Meers nod) grókere af́ere Diefer Battung geben, als die find, Denen jene Irme angebórten. 2Bir wollen indef nur bei biefen letereen jelen bleiben.

Mian Denfe fid alfo ad)t âne, fo Diuf wie Miaft= båmme, Die fid) nady allen Eeiten fin ausfitrecfen, uno

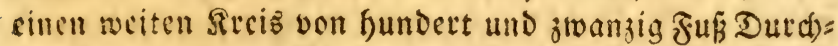
meffer bilden. Ille acht Irme find gefpant; alle æapfacn find offen und bercit, Dasjenige ju ergrcifen, soas ifnen etwa vorfommen fómnte. Die beiben furd)t= baten Rimnbacten Des Shiers find in jebem 2lugenblite fertig, Daŝ zu zermalmen, was die weiten Arme ifnen

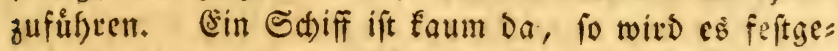
balten und verfd)lungen *). 23 as fur ein Thier fónte

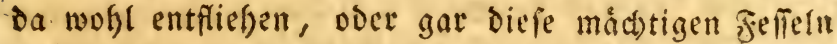

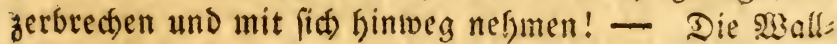
fildse thun eś, wie wir fdon wiffen. Âter weich ein fúcdeterlicker Sampf muß heure Mafie, wie Der $2 B a l f i f i f$, fid mit einem Mare von ben vielen Irmen bes Siefenpolopen umidylungen

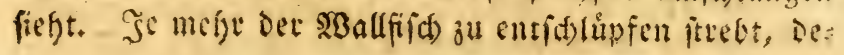

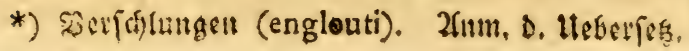


fo enger jieft Det slolnp feine atme gufammen, un feine einmal ergriffene Beute nid)t wieder zu berlieren;

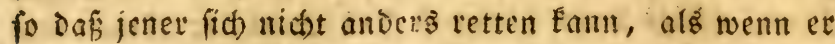
gluctlich genug ift, bie arme Des झolypen nbjubeifien. Bei einem ioldhen Rampfe gtwifden zrwei fo ungeheuren Tíieren muß aber bas \$leer bis in feine innerfen Ties fen aufgeregt roerden. Sturme in Der Begend Des Rampfplates entftehen, Der

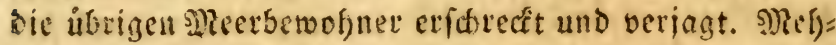
reve Eafife, ja cine ganje flotte, bie fid von unge:

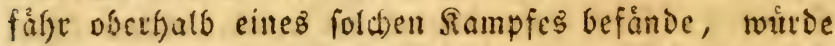
saiurch in (jefalyt geratjen. - Das unglút, bas Der folotie Alezanders des Grofen Drohte, entftant

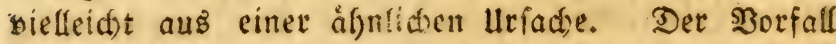

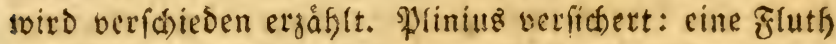
son filitsen habe bie flotte angefallen, uno giebt zu veritefien, eŝ feyen smeerfifroeine (Phocaena) ober Thunfifhe geweien *). ŞBer aber je Dergleidsen Şaufen won Mecrfdeinen gefefn hat, weißs, dakf fie burchaus nid)t vermogend find, ein Schiff umjufturzen, fondern bies geft, fo viel ifrer auch find - und immer fino

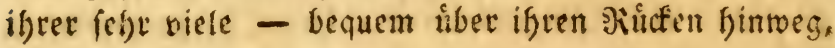

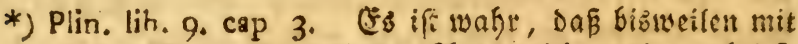
cinem गrale, fo weit bas Zluge reidit, eine zahllore

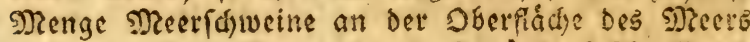
wohl eine balbe Stunde long, fid áuferit iffnell und

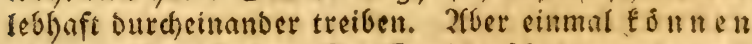

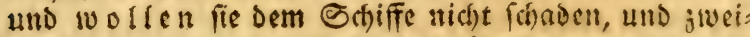
tens Darf man nut einz unter ifnen vermunden, fo

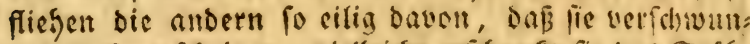

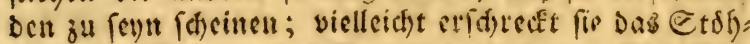

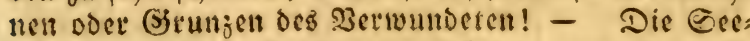
leute fehen Dicfe (Er r d)einung fefre ungern, Denn fie

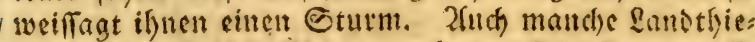

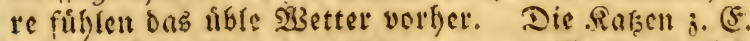

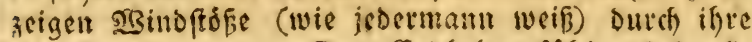

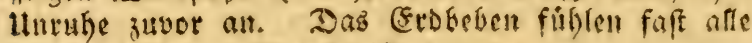
Thiele frither, als es ba if. 
smb febt feine Fante ofne bie geringfe Gefafre meiter fort. Der Biruno jenes augenbliatlid)en Sturms und Empórens der 2 seffen, die ber fylotte des macedoni=

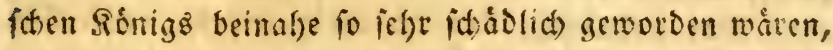
toito alio woff in bem Sampf ungetsener grofer fifde su fucten pern.

Die Miectungeffece, fagt Slaus Magnus, ete beben fich bistweilen wie eine groffe Såule ulber Dem 23 affer; andere Male madjen fie einen fold)en \&ärm und bringen eine foldhe flutf hervor, Dafi die Gecleute, soenn bie einander entgegen gefeteten Strómungen fie

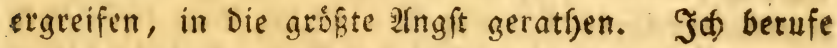
mid) Dieferhalb auf Strabo's Zeugnif *), mo er bon eis nem foldyen lofalen odet furdutertiden Sturme pridt.

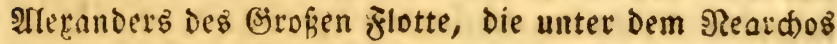
ftand, wurde (nach) Strabo) von einer Minge Meer= ungeheuer und \$hyfeters úberfallen. Sie wályten $x_{3 e l}$ len wie serge gegen diefelbe, und erregten ein foldes Ulnwetter, Daßz die Sdjiffleute einander niddt mehr er= fanten. Die Ifnfúfter erricthen aber bie Urfacte Das von, und erfláten fie ifren feuten. Dann begab fich פleard)oz felbft mit feinem Ed)ıffe auf bicienige Stelle Des̊ Meeres hin, wo eș am twithenditen war, und ver: ideuchte alle Secungefouer in wenigen 2 lugenbliffen Durd) Den fătm von Trompeten und andern Blafeinftu=

*) Eft bellua tantae altitudinis ut attollens fe fuper flu. ctus, ingentis columnae fimilitudinem referat, alriusque veluti diluviusn quoddam eructans, nauras pavefecerit fluctuantes; cujus calamitofae rei teftimonium Strabo lib. 15. De illo magno Nearcho bellica claffis Alexandri magni praefecto, affert, dicitgrte Phyfeterum magnitudines fluctum maximum, et accumulatum, et caliginem tantam reflationibus excitarunt, ut quae ante pedes erant, confpici non polfent. ... Nearchus naves in fluctum egit, qua maxime arcebatur, ac tubis belluas exterruit etc. Olaus Magnus de Pifc. monftr. lib. 21. cap. 6. p. 735 . 
menten. Safnell maren bie Mellen ftill, unb bie ent=

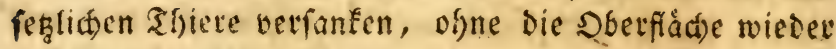
รัน beunthigit.

\$or Erfindung der Attillerie liefren Derglcident

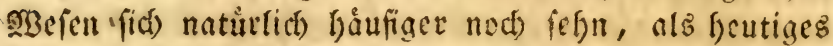
Sages. Der Sirall Der Fanonen bat fie jebt fajt von

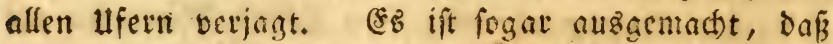
aud) chore firde die Gegend bethafen, wo cin See= treffer vorfiel ober wo das grobe Gefdith Domnte. Daber wito es ben aud wofl fommen, daf die vielen

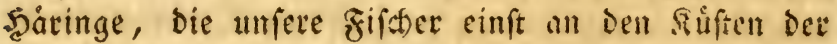
Bretagne fingen, feit der Edhlad)t bei Belle = Jôle ver: fdwunden find. 23orfer fonden fie fich Dort felde bau= fig, aber feit bet 3eit nidft mefre, weld)es um fo auf fallender ift, Da ber Sắring sin Zugfif(t) ift.

Bei Dem heftigen Alngriff Dea soro Relfon auf

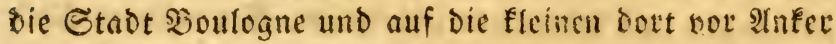

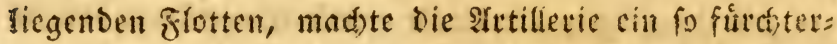

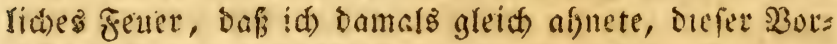
fall werbe einen idhäblichen (sinflußs auf bie bortigen zifthe baben, und bie Ciffalyrung bat meine Mutína: fung beftątigt. Die zilche find bort jeşt auffollend fel= tener als ztroor. Sollten bie verfunfenen Seid)name gar noch Raubfifde Dafin ziefn, fo whitben sicle bie Speifefifde immer nod) mefre vermindern.

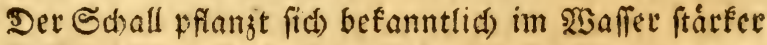
fort, als in ber Euft. (sin Saudere, ber einma! in bet Siefe auf cin Sorn blafen wollte, wutbe von ber Etäte

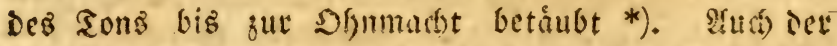

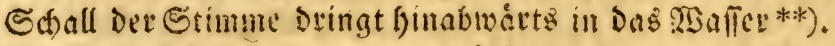

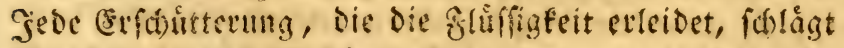

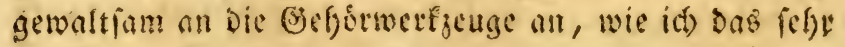

*) Nollet, Prob. d'acouftique, introd. p. 26. Roger, Med. monfp tentamen de vi toni etc. $\$ .98$. Lamark, Hydrogeolongic. p. 234.

**) Noilet. Leçons de phyf, Vol, III. p. 420. 


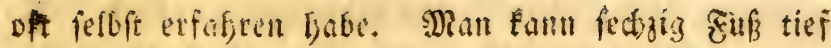

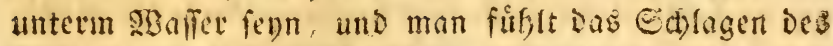
Ruders auf Defien soerficte, als ob es mmittelbar

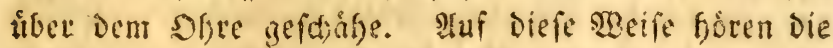

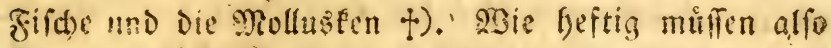

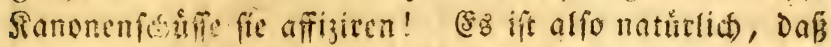

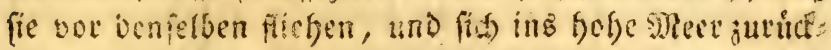

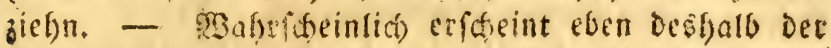

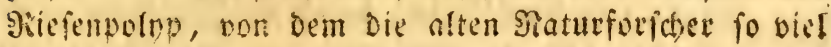
sfter als be sieueren reden, jegt io felten.

Derglciden entietzlid grofe \$ulupen eqiftiten ins Def noti in allen gyeeren, uno verberben bismeilen die grosten Cofife. $23 a s$ anders founte die Urfade von jenen Gợ unt bet withger Siufe des sdiffe, ofne alle Setran=

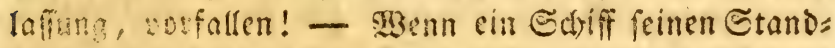
funft verandert, voer gar peegelt, roun eg fich um=

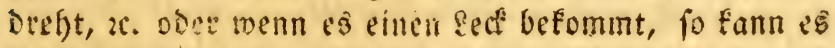
freifio fincein, aber immer bod) nur a ll

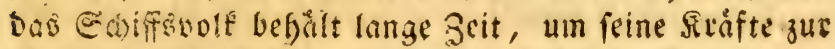

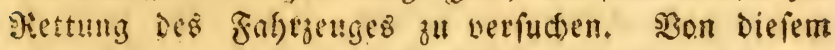
allen ift fier aber nicht die \$ecoe, fondern von jenen augenblictidsen Unfälen, Die lurfache find, dafi das Sduif mit Der Sdnefligfeit Deß Bliţes veridumindet, ofne dafí man cinen ftheinbaren अrund Davon anjus geben vermócte. Mir fino viele folá) traurige $\$ 305=$ fálle, die aber immer in felst tiefem $2 B$ afle: ftatt fanden, befant. $\Im$ a) will bier inoeß nur einen cinzigen an füfrell.

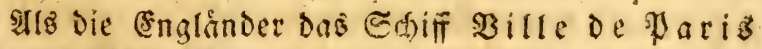
nebfi nod) finf altern weggenommen batten, bejeteren fie alfe fed) mit zrocitalleno Mann, uno wolten fie zat fermeren Dienften gebrauden. Die englifide flotte

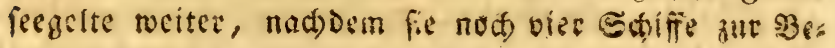

f) Lamaik, ubi fipra. p. 235 


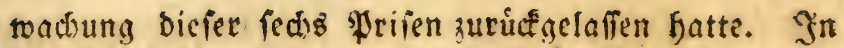
Der nádften Iad)t nad Dem Tteffen, that bie Bille oc Paris mit cinem Mrale Protbidulfife, und zindete

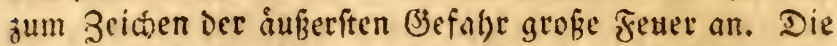
ubriagen Sd)iffe nåberten fid moglidyft fdnell, um ifre zu helfen; aber fie tourden mit in ifre unglucf vermicfelt, und alle jeljn verfanfen in biefer furchterlicten fatas frophe. Die $23 e l l e n$ verfhlangen fit.

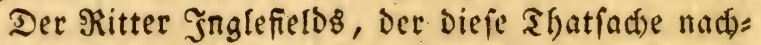
fer befannt gemacht bat, fommandirte eins biefer ๔diffe. Durd) ein unbegreiflid)es Blituf fam er nebft Hod vierzefin Matrofen wieder íber Dem \$3affer empor, und Diefe funfzegn Menichen entfamen Durd) Şulfe des

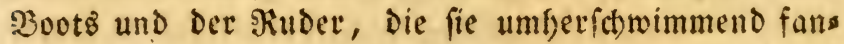

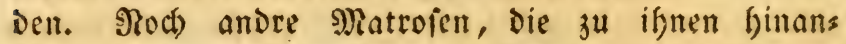
fd)wammen, mubten fie, um fid) ju retten, tóoten,

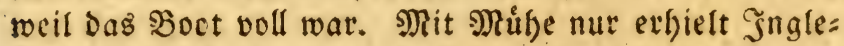
fields die Afufnal)me eines 9\}atrofenjungen; nber eben

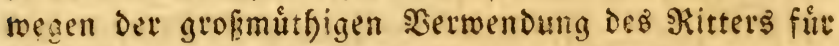
Denfelben, rief man ifn einftimmig aufs neue zum êfn=

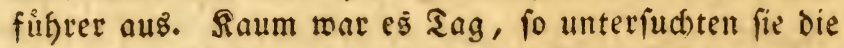
Bsegeno, erblicften aber auch feine Spur mefr von Den

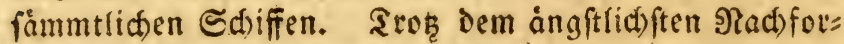
(d)en im Boote fanden fie nichts, als einen fáled)ten Eappen Seegel und einen abgenagten Sdinfenfnoder. Sie boten Diejen ifrem Infífter an, er aber warf ifn

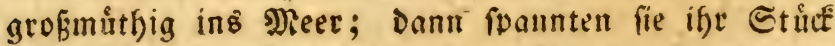
Eeegel fo gut aus, als es gefon wollte, tranfen Regen=

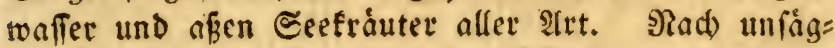
lidjer Jioth maren fie endrich fo glitrflidy, an eine fleine roúfte Čnfel geworfen zu werben. Dort náfrten fie fich bon Muicheln und 2lollusfen, Die Das Meer an Dicfen Felien auswarf. Fiele von ifnen ftarben, befonders am Sforbut, alle aber batten fefre angejhwollene Beine. (Enolid) ragten es bie nod) úbrigen, fich nod) einmal vergroeiflungsooll aufs Meer ju begeben, aber fie ftar 
ben - Singlefietos uno den Matrofenjungen ausges nommen - fammtlich bald; Dann trieben Mind und Şellen das soot lange unfer, bis es endlich an ber (panif(d) = amerifanifden Sirfte landete, wo man Det

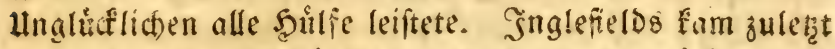

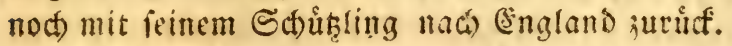

Ueberlegen wir diefen ganjen Sotfall naifer, fo fonnen wir ifn nidst falidsen Manóvern jufdreiben, Dem fie wurden niat jefin Sinienidbiffe in einem Il ugenblict verfenft haben. Die Sille be Paris ging ferner in Der Mitte Derfelben unter, of ne it th von der Stelle geruget zu haben. Wiste fonft ein Berfeben vorgefallen, fo wírie dies immex nux eing oder das andre Schiff getroffen baben, bier aber gingen alle in einem un demfelben I u genblicf unter, als ob eine unterirbilide und un= widerftefliche iraft fie in Den abgrund gezogen batte.

Ifuch eine șafferbofe fonnte nid)t fauld Daran fenn *); Denn wáre fie beftig genug geroefen, um jefn

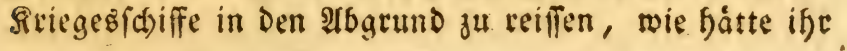

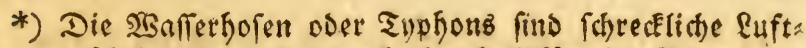

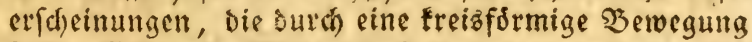
Ruft, (5rbe und s)keer Durch einander werfen. Die Lanomafferbofen find feltener, bånfiger fins fie Dages gen auf Dem Mecre, wo fie viele Eshifforúche verur:

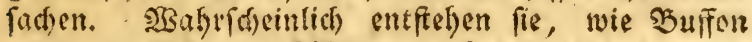
meint, aus ben verifiesenen oft eitander entgegen ftreventen 3ligen dez rsindez, zwifd)en weldhen etwa fdjwere Regenwolken gerathen, und Ereigformig fin: ab und umber geriffen werden. 1782 erlitt die Sins fel Formofa eine fold)e grâflidje Qufterf(heinung. Die

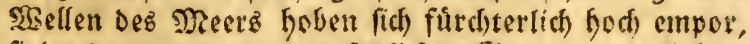
frelen Dann mit einer entreglictsen (S)ewalt wieder bin: ab, und verwuffeten Die ganze Jnfel. Die Hebere

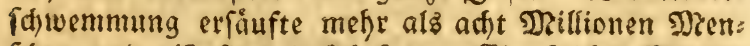
fdyen und ríp fie mit fich fort. Ein foldfes פgeteor b) ńtte bas $\mathfrak{B}$ oot nimmermehr úbrig gelafien, wenn

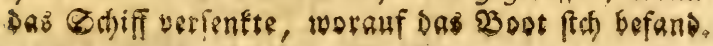




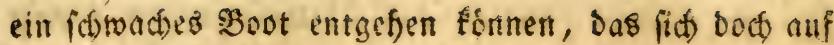
Dem 2irdect eines der Sáfiffe befand? - SBo ware fo fidnell wieder die SBinditille fergefommen, in welcter

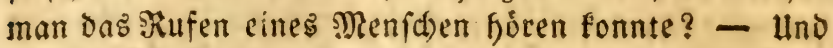
wie hàtten fid bei einer fo gemaltiamen গaturerid)ei= mung Suglefields uno feine Mlatrofen erfalten fonnen, Da Dod zefu sinienfofiffe, bis auf Die fleinften Epuren bavon, verfablonden?

Iuc) feinem SBafferwirbel nach Art Des nortoegi,

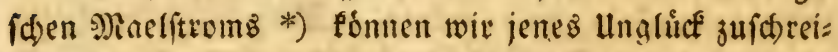
ben, Dem theils eqciftirt bort fein fold)er $2 B$ irbel, theils wáe ifm aud) Das fleine Boot nid)t entgangen, wenn

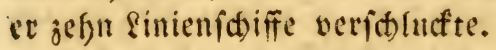

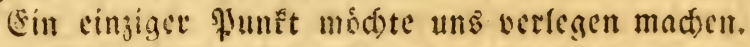
23oburd) vereinigten fid , fonnte man namlid fagen, fo viele ungelseure Polypen mit einem Male, un

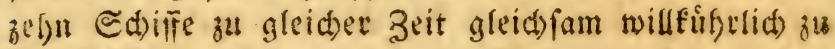
berfenfen? und fann man mit Becht annehmen, Dafi fít jefn \$olupen zu gleicher zeit vorfanden,

*) Dergleichen SBaflervitber find intertichen פizaffertin: Fer gleids, aber lange nicht fo gefáfyrtith, als bie in

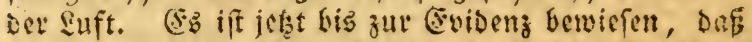
fie ant żvei cinander entgegen laufenden Ettúmen

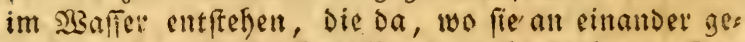

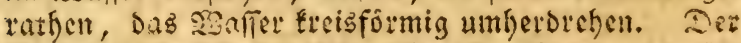

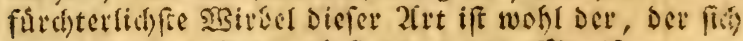
im norblidsen Dcean befinoet, und s]raelfrem zes nannt ivird. Die Uebertreibungen Des Dlauts Shangs nus uns Sircter baben ifn befonders fo berifht ge:

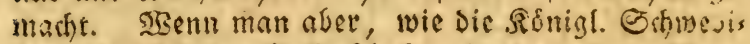

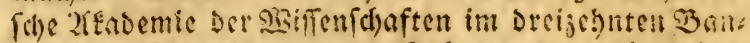

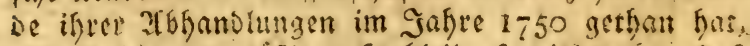

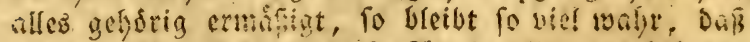

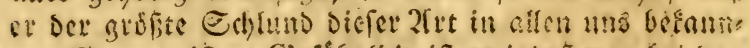

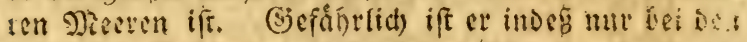

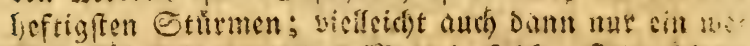

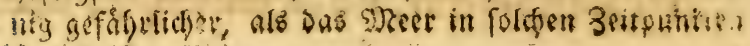
útetall ift. 


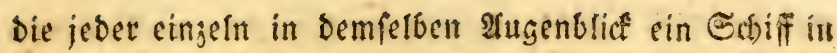
Den abgruno riffen? - Sid) geftefe als efricher Mann, Daßs id) bietauf nicht fintel(t)end zu antworten weí; aber das foftum ift ummiderfpred)lid) wahl, uno nod) oon niemanden finlánglid) erflárt. Bis bafin bleibt alfo einem jeden feine Senpothefe erlaút. Meiner Meinung

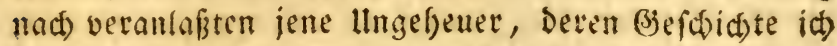

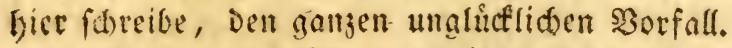

So lange ber \$olnp nod) jung ift, forn ev freilich fo gewaltfame $2 B$ irfungen nidst bervorbringen, aber ex

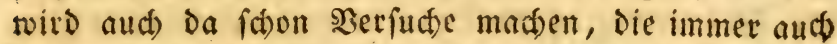
non Bebeutung find. Mir lejen in álteren und neueren Sd)riften fo fefre oft, baj Die Echineis oder Remora, (ber Saugefifh) fo flein biefer sifh aud fen, bie Sraft befiţe, cin Ectifif in volfem Eecgeln aufäufalten*);

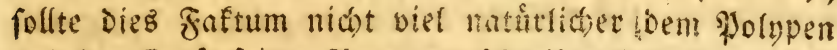

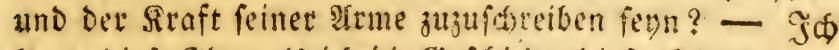

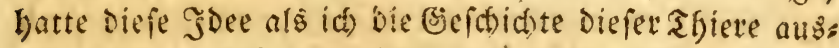
arbeitete, und freue mich um fo mefr, fie in einem

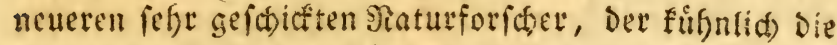
unterfuchung wagt, ob ber firufen exiftire oder nicht? - aufgefundell zu baben. (5e verwed)felt zmar alle grofe Polopen mit Dem firafen, fagt aber juleţt gonz

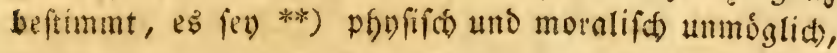

*) Daßs die ediffe bisiveticn in intrem Raufe anfgebarten verden, ift uncougbar. Darin frimmen ju vicle

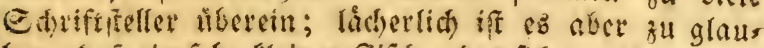

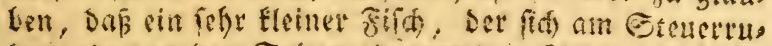
Ser, noer an ben Seiten oder an Dem. Siel Des Eathifez

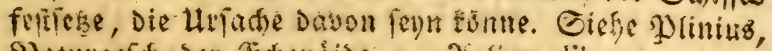
Shaturgeft. Der Sithenaide. - Lefian. lib. 2 cap. 17. urib 10. cap. 6. - Oppian, Hal. lib 3- Ariftorcles, Hif. an. lib. 2. cop. 1;. - Plutarch lib. 2, Symp probl. 7. - Cafiodorus lib 1.

Soiin. cap 18. - Olaus Magnus, de pifc. monft. cap 22 unt 23. p. 76r. - Cardan. de fubtil, Rer. lib. 30. - Aldrovandi, de pifc. lib. 3. p. 335. ete. **) ,Imo in hanc conjecturam incidit, pif-

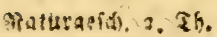




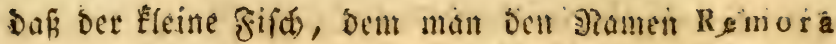
(Saugefifd) gegeben babe, ein Sd)iff auffalten fonme, woht aber fónne bies gefdelgen, menn ein grofier \$os Inp, Den ev Srafen nennt, feine Irme unterwåts um Das Sabiff falage. Der Sirafen ift jedod) zu Diefer

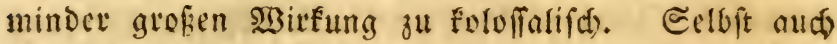

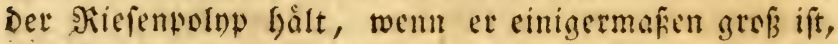
ein Echiff nidat auf, fondern er verfdblingt es (il l'engloutit). Int feinen frufheren Gafyen mag aber ber अolnp wobl ๔aiffe mit cinet folden (Bemalt aufgalten, Daf Die bereinigten Gráfte allet Jiuderet fie nicht fort: berogen fómen.

Plinius *) erwåfnt mebreter \$ুorfâlle bicjer :ret,

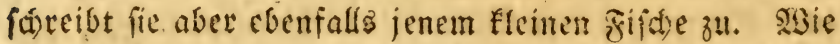
viel naturliater ift es jedod, amjunefmen, Dais eir Priefenpolop die thriacte bavon fery, indem er fich mit e inigen Irmen an felfen oder an Den Mecresgrund feitrialt und mit anoern an Dem Sdyiffoboden anflams mert. Salngt it fich Dagegen mit allen, D. b. mit feiner ganjen ?aft, an ben Boden irgend cines Edfiffs, fo wito es nid)t mefe aufgergalten twerden; có wird verfinfen. -

So fdreiben Die Siten bent and jents beriffmt: gemorbent Fefthalten Deŝ MDmiralfefiff Des SIntonius

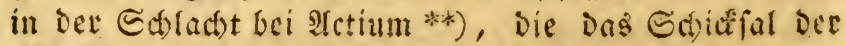
Damalz befamten Erde entid́ted, Dom Eangchiche ju. Fntonius fóniffe nåmlín von Baleere ju (jalcure ***),

ciculum iftum minutum, remoram dictum, naves in celeri luo curfu fiftere non poffe, fed talem effectum meliorijure latentis fub undis microcosmi tentaculis at. que antennis adfcribendum effe." Car. Auguft a Bergen, nov, act. nat, cur, tom. II, obferv. 38. P. 148 .

*) Plin. Hift nat. lib. 9. cap. 25. uno lib. 32. cap. I. **) Capofigo in Alban.

***) Plin, Hift. nat, lib. 32. cяp, $\mathrm{I}$. 


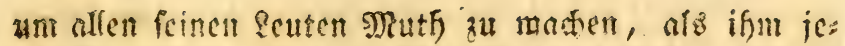
nes linglint begegnete. Die Arnee Des Thgufts be:

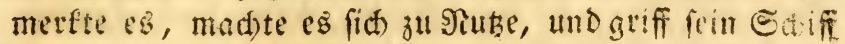
fo gewaltiam an, Daf Diefer linfall Die ganje Sulacit gegen Intoniแs entict)icd.

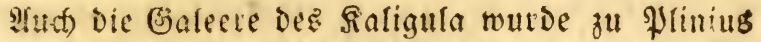
3eiten auf einer Secreife jenes Salfers an Der firfte von Stura, bei Intiun, aufgefalten. ङine Monge Saucher unterfudten dic Sache, fanden aber nidits atb

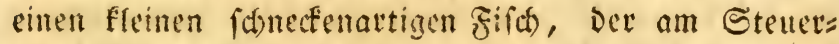
ruber feft fap. Sielleicht fatte jedod) Die Inftrengung von vierfundert Reutern, bie auf Der Galcere waten, ftion juvor verurfadt, Daß ber Wolup loz lief.

Sagte nidjt Das Zeugnif Der Befdichte ganj be=

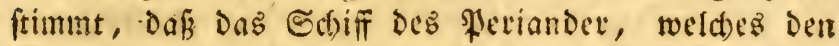

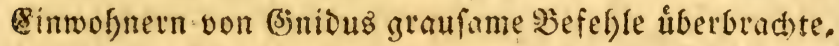
fo fefre mit Schalthieren an feinem unteren Ifeile itbes

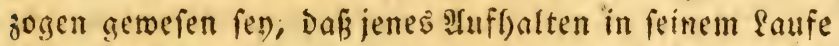
baburd) Gervorgebrad)t rerden muß̧te, fo fünnte man

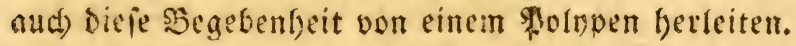

2ud in Den norbliden Mecren finden wir, Daf -

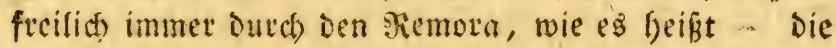
Sdhiffe in iffem snafe anfgefsalten werden *.. Da Dieb aber ummóglich ift, indem mue इfiete von grofser Siraft und albátiafeit fo etwas bewirfen fonnen, fo

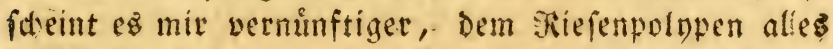
Dab benjulegen, mas Dlaus Magnus ber (E) heneide oder Remora jufdreibt; un fo mebr, da twit wiffen, da fich biefer Woltip in Den nordlicten Miecren vorzuglid båufig finoet.

Die 9reueren fonnten bie Sleinfeit Des Biemora

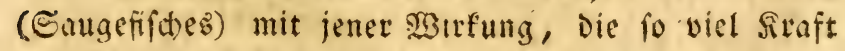
eriotocrt, nictet reimen, und zogen liebec bas ganje

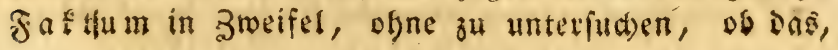

*) Qlaus Magnus, ubi fupra. 
was sic Aften facten, Grund habe noer nidft. Mir

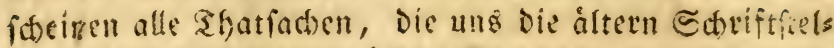

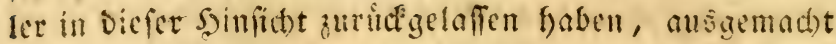

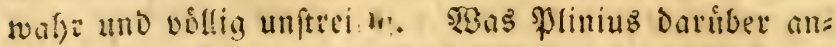

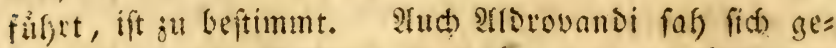
nêrfight, feinev secinung ju ferth, weil ein áfnlicber

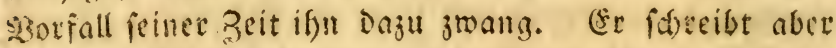

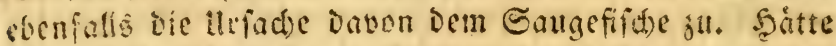
a ben Xiefenpolupen gefomit, fa wirde ex es ficher

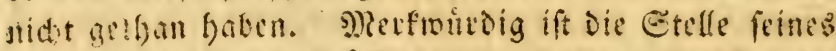

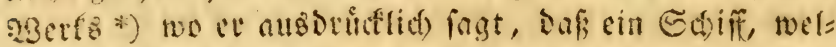

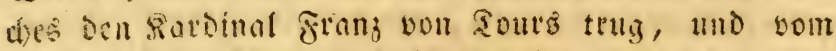
fiibliden Stanfreids nad) Stalien feegelte, mitten im

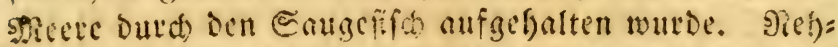
men wir mit Den Relten and SReutrn Die șirfung an,

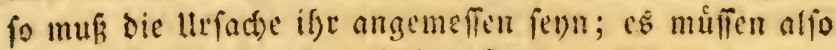
grobere und fraftuollere Shicre fie veranlaft haben.

Dem fet) inderb, wie ifm molle, fo glaube ich menigitens unwiderleglich bargethan zu haben, baß

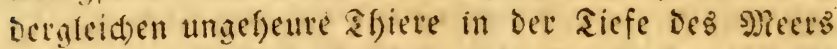
criftiren. Dentbat ift Dies aud um fo eher, ines

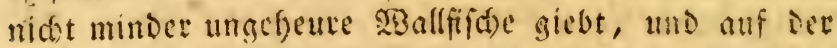
Erde felbft sime zeitlang Ficfentfiete gegeben hat, Die jetet entweder verforwanden find, vore fid in unjugengs=

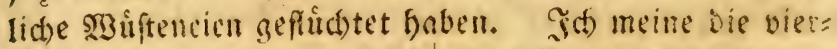
fubigen \$biete, Deren Uebertefte wir unter Den Эamen Mammouth, Mammotg, und Srammotovas foft fennen, Die man in Samaba "sd) fenvalute

*), Ne veroquis nugaricredat yeteres, pa. , rentum noftrorum memoria navem Tu"ronenlis Cardinalis, cum aliquandos "Gallia inaritimo itinere in Italiam per. "geret, ferunt, narrante Petro Melara "bonon equite, in lib. de Cardinal fol. .,99. fortiflimofimulac eruditiffino... "remoratum fuiffe in medio curfu," Adurcov. à pifcib. lib. 3. p. 337. am Ende. 


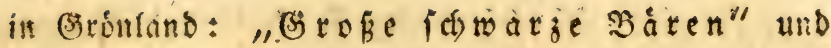
in Slaraguay Megatherium. oder Incognitum nennt. Freilid fommen ifre grofie finodsen nod im: mer nidt gegen die Arme deg Riefenpolnpen; aber toenn fie gleid nicht mefr ju finden jimb, fo bezweifeln

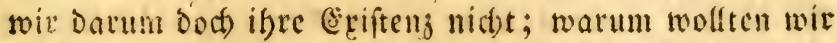

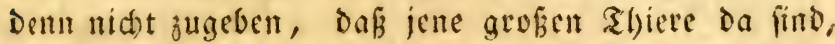
Die fid) Dod nod heutiges sages in ben tiefen (Sd)lun: Den Des Meers vorfinden! - Sfle Dit Stanugefdidste it) je jetigen grofien fortidntite mad)te, fannte man nod) feine ausgegrabenen fnod)en grofer victfofigel Ifiere; bobere Anfelarung uno cin weiteret llmfang von Senntniffen Gat uns allmaglid) mit biefer Soec fo wel= trant gemad)t, baßj man bas chemalige Dafinn jencu

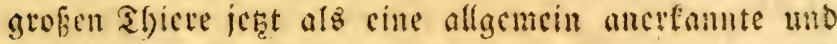
ausgemect) Shatfacte anficht.

Dant fen es. Den Siachforfdungen bez Sa Coubre niere, \&amanon, Collinfon, Metf, Eauias, Cuvier und vicler andern Saturforfder, Daf biefer widtige

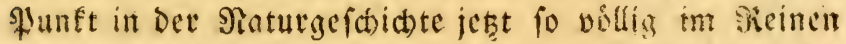

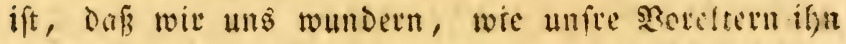
nermerfon fonnter. Scauterive madte befant, ec babe an Den Ufern Des Shio einen Unter: und Dber: fdenfelfnod)en eines grofen vierfüigen Shiers gefuns Den, die beibe an eillander gefetgt 32 fuk fange gege"

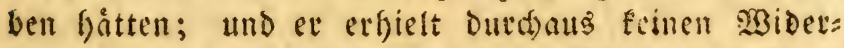
fprud, ungead)tet foldse ungefente finod)en cin Shier

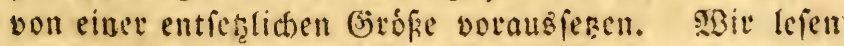
in Rabillatdiece's Teifen, dab́ er in Sieu= Seeland aup bem Fufboden gropie fugtapfen antraf, die mur bon ei= nem unbefannten vierfübigen Thieve fein fonnten, Def:

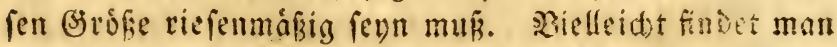
einft nod innerfalb der (Erde jene geoen igice, be ter die Staditionen eben fo ertoginen, mie fie uno die álteren Sduften des अiefents pen gederten. 


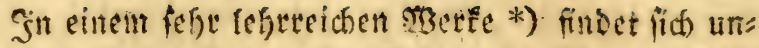
ter andern folgendes: Sn Givnlands Esbenen, alfo

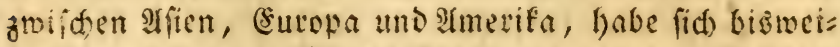
Ier ein grofese vierfúbiges Thier gejeigt; feine Eridel= numg erfárecte aber bie Bronlander, und fic legen ifm Die Geftalt cines grof́en biaren mit langen fdmarzen

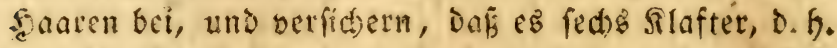
etma dreifig fuf hod), alfo bopyelt fo grofi, als ber

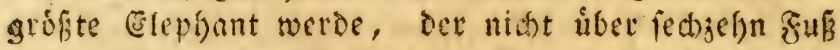
mift. Die ganje spaffe jenes Thiers ift aber fonach sicrmal fo grof als her grofite (stepfant, folglich fefr

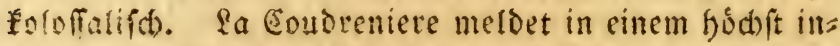
teceffanten Mremoize **), daf bie MBilden von Eanada biefe grofien vierfuffigen Shiere lebenoig gefehn haben wollen und fie "Dd defended felt aud) gat nidjt Daran, Daß Dies Thier uno ber xuf

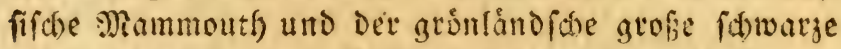
Zår einetlei feyen. Daf Das gleide Thier fich (wie ex (ant) auch auf Dem feften Sande von Imerifa finde, bes ftàtiaen jene ungeffeuren finod)en, Die Sauterive auf ben Ufern Des Shio antraf. $2 B$ ir fennen folglid) lange nod) nicht alle \$rodufte bev গotur.

Somberbat ift $\mathfrak{e s}$, Dofif faft alle vorguglids) grofie

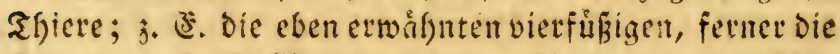

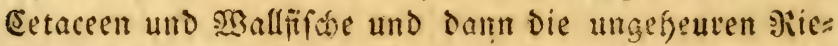
fenpolnpen fid befonders im Siorden finten, und baf Die Satur Dort ger a de ifre gróbten befecten Mafer entwictelt zu baben fobeint: fonderbat, Dấ fie bei bem \$olat = eife gleid)fam neue Sitifte befonmt, un bie

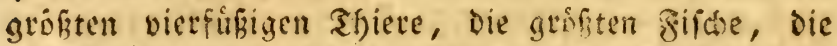

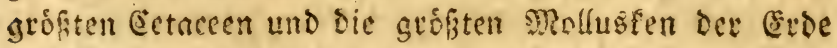
und Deg Mects bervorbringen zu finmen.

Die Menfthen waren zu voleilig, Der Setvorbrins

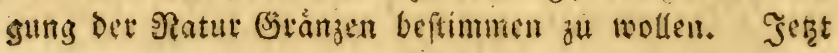

*) Hift sire ginnérale des Voyages, Tom. XiX p. 39 .

*) La Coudrenière, Journal de Phyfígue, May 1782. 


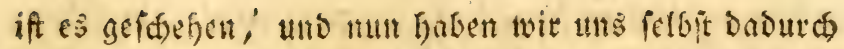
Feffeln angelegt. Sie allein bindern uns jeţt, uns

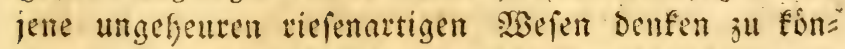

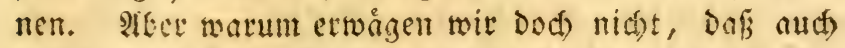

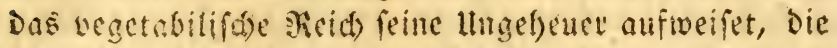
bie alten fodon fonnten und beidrieben, uno beren 25ituficfecit bamalige Reifende beftätigt fatten; -

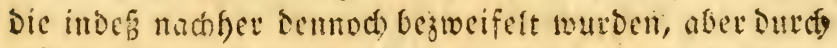

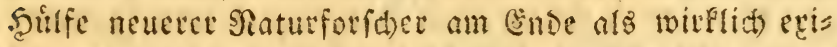
ftiteno anerfamt merden mub̂ten, weil ifte genautr

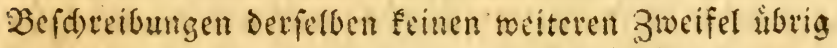
Iiefen.

So urfielt Das ricienmåabigfte alfer segetabilien Den Samen des berufgnten Sloninon; Denn wir verdan=

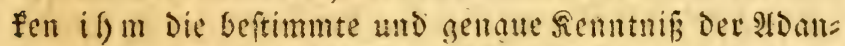
fonia soev $3 a 0 b a b$, Die in einigen 3 hidorn aud (rain de linge) Iffentrodt genannt wird. Diefer entietzlich grofe Bonum fobeint in Ifrifa beffer, als in afien uno SImerifa fortjufommen, wenigitens trifft man if) bort

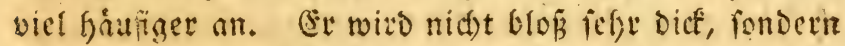
fí)eint aud) eben fo lange zu leben, als ex dide zu wel" ben vermogent ift, bemi man betednet fien leben nad) Jafirfunderten. IDanion *) glaubt beweifen.z fót=

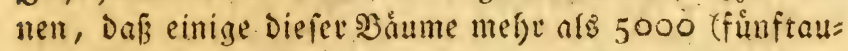
\{end) Jafic alt find, unb Dod - fett ex finju baben fie fein hinfalliges Infefn, fondern find noch voll araft uno Sebraftigfeit. Der etwaignte getefrte

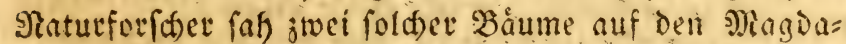
reneninjeln, in beren Sinde rutopaiscte Samen uno Datà eingeiduntten waten, bie 1500 bib $\mathrm{s} 600$ be= seidheten **). Thanfor glaubt, Shevet ober feine

*) Guanabanus Scaligeri. Bauhin. Hift. I. p. Iog. Abaro arbor, radice tuberofa. Bauhin, Pin. 434. - Adanfon, Memoires de l'Acodemie

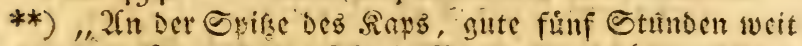

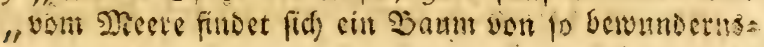




\section{6}

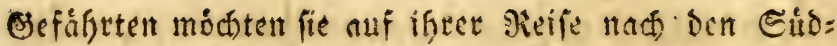
landern eingeidnitten baben; Demn Fhevet meldet aแs:

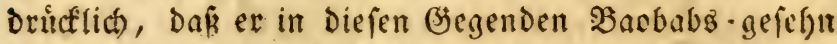
habe. Hoanfon traf Baume bex IIt an, die faft neun= gig Fuf im llmfange, oder dreifig in Durthmeffer,

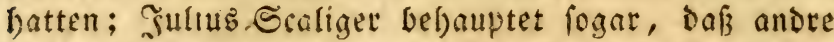
geifende einige Derfelben gemeffen, und fie fieben und Dreißiz suí dicf gefunden haben.

Piay beruft fid auf Das Zentrif mefterer Dieifens ben und ermålyt cines $\mathfrak{b a u m s ~ b o n ~ G u n d e r t ~ u n d ~ j t w a n = ~}$

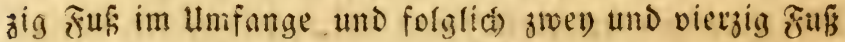
im Durctmeffer, Den man in Brafilien als ein Seriligs thum aufberwatere. In Dem Hortus malabaricus beifst c8: in ber \$roving (Eodin nafe bei dem Tempel von

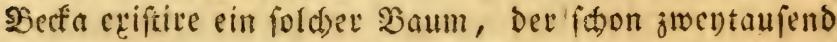
Sabre alt fen. \$linius *) lagt, die Eroberung von Ginden burd) Aletander ben Grofen habe frine armee mit 23 ăunen befannt gemad)t, Deren Diffe fie fefor in

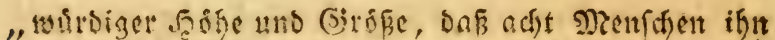
"nicht umÉaftern fóntuen; er Dieat als (j) rånzzeichen.

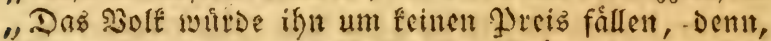

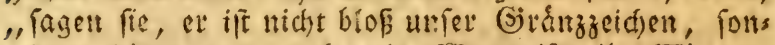
"Der!t bient unz auch als Sỉegweifer." (Thever, Cosm. univ. Theil I. p. 89. ค. U. Theil I1. p. 954. b.)

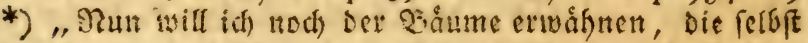
„Den grofen allexander auf feinem 3uge nach Sndien "in Strunen verfesten. Zuerfit faf er Dort eine 2irt "von Feigenbaum, ber fehr flese freigen trågt. Diefe

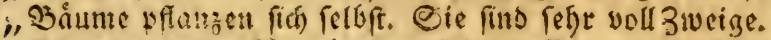

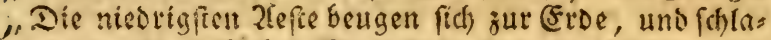
"gen in eitrem Safle 3utgel barin, fo Daß man it

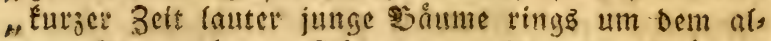
"ten Ctamm herum fieht. . . Die alten Etámme

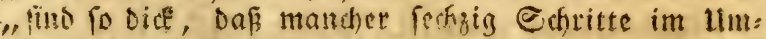

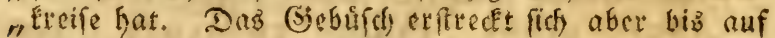
"zivel) Etadien weit. ... Dran findet Dicre Fstgens "báume am Siufle Zlecfunes entlang." (Plin. Hirt.

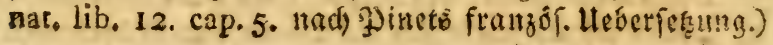


Eritaunen gefeşt Habe, indent fie fod);ig Ed)ritte im Ums fang hatten; अednen wir Drei Fus (?) auf Den Sd)ritt, fo bringt es fecbzig Fuf fur Den Durdimeffer. In einis

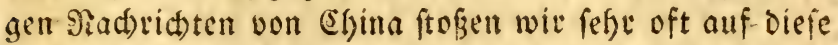
entfeflid groken Babume. Der ungeheuerfte von allen

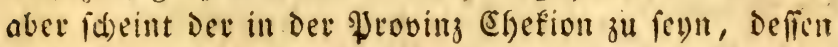
Ltmfang vierhundert Fuß betragen foll, und beffen Durdimeffer folglid) bundert und Dusisig Juß betragen wairde *).

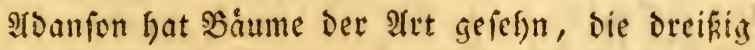
Fuiz in Durd)meffer fatten, und Deten forizontale 23 urjeln etwa fectsig fuf lang waren, fich folglich brei= bunbert und jwanjig oju weit im limfreife erftreftent.

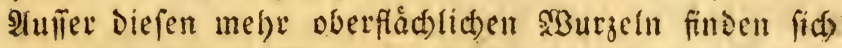

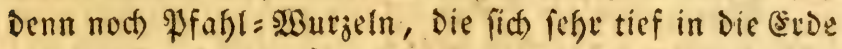
binab erftrecten, und viele (erblagen-butd) bohren**). Jian urtbcile aus biefen Zufammenftellungen, welde

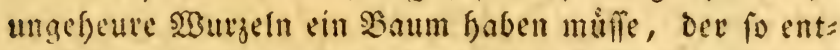
fetslich grof ift, Dafi ex bundert und Dreisig fup im

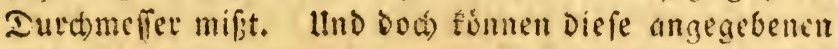
(Grófen nidat bezreifelt werden. - Der afrifanifde Snovab, Dea 3doanfon beobad)tet hat, bemeift alio Die Mioglidffét Dev (Etiftenz von vóllig unglaublid)en Mhaf= fen; von Maffen, welde die engen Gränjen, die unire

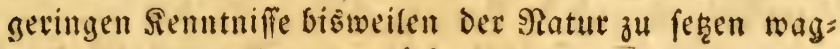
ten, fefr weit binaus gerúcft baben.

*) Sh habe Die 2fuboriffe gemildert, Denn Nontfort

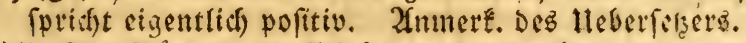

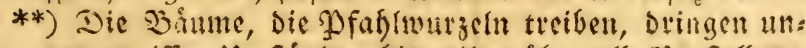
ter getwiffen Umftánden bisweilen tiber alle \$orftellung tief "in bie (Eroe ein. Jath babe unten in oen Etrin

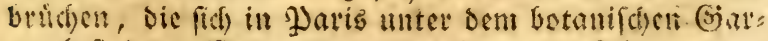
ten befinden, SGurzein yon Der ECDer Des Ribanon an:

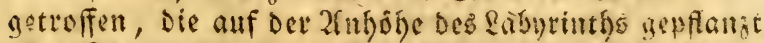

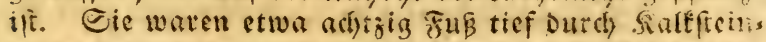
thyen georungen, und wutfien now meht als oreifig

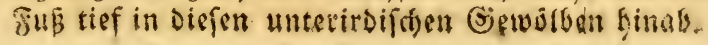




\section{Det Siraten *) (Gratenpolyp):}

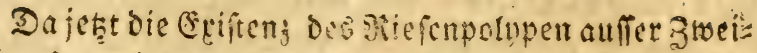

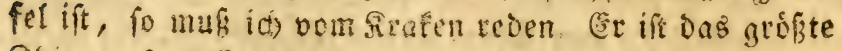
Shler unfers Erdballb. Bats vermies man if) unter bie Jabelwefen, bald hielt man fid gejwungen, ifn

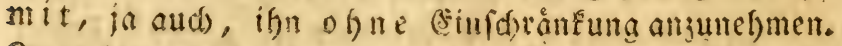

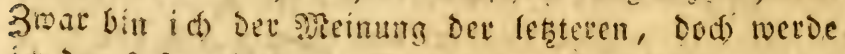

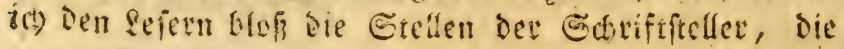
son diejem Iglere reben, one Augen legen, und mir sur bód) menige Sbemerfungen culauben, ifnen felbit aber Das (entrutheil in acicificht biefes grofen Begen=

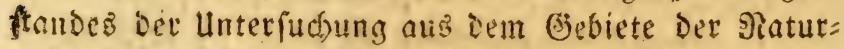
gefdidate Der Pliete úberlaffer.

Sine geteinigte Sritîf - Die unferm Gafufanders te bes \&iáts und der asiffenid)aften cigen ift, - muf ung jeţiger 3eit lefren, was mit verwerfen und was wir annefmen follen. Die Beiten fino vorbei, too man alles roeglängnete, was in Den ålteren uno neueven Equiften unmafrifdeinlid fdien, blop bestgalb weg= Iåugnete, weil bas Niebergefdriebene gegen bie ge:

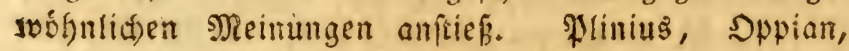
æibedi, Bartfolinus, Maulinus, Sontoppisan, Bes=

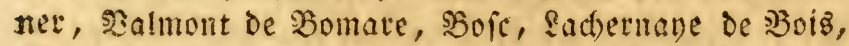

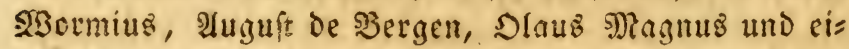
nige andere. Shriftiteller, bic alle felgr glaubroiroig find, baben biefe Intgabe nad) und nać) beftátigt, in= Def hat man fie bod) immer aud wieder firr fobeln er=

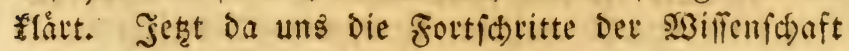

*) Arbor marinus. Plin. Hift. nat. lib. 9. cap. 4. uns lib.32. cap. ultimo, - Monftrum marinum, Chrift. Francis. Paulini. Eph. nat. cur. dec, I. ann. 8. obferv. 5I. p. 790 - Microcosinus, bella rharina omnium vaftissima. Car. Aug. a Bergen: Nov. act. cur. Vol. II. obf. 39 p. I $\div 3$ - Trolw a bei ben 9lordándern. Teufeliv a ll auf beutfh Siafen bei satmont de bomare uns bei sofr. 


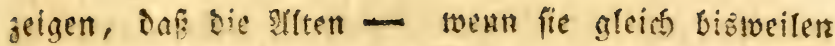
irten, - Dod aud oft bie $23 a b r f e i t$ fagten, wo wis e\& lange 3eit bindurd nid)t meinten, jeţt fage id), ift eŝ 3eit, zu unterfucten, ob bcrn bas, twas fie uber

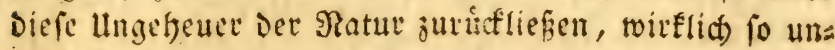
glaublid) ît, als wir bisfer gedact baben.

\$linius fagt, die Meere fdliefan ungeheure Thiere in fid); im groben Djean gicbt ea bergleiden Fircte, bie fefre hofen Băumen gleidien, Deren Zweige fich fo socit umber erftecfen, Daf fie Éaun Dutch die Strafe bei Bibraitar fommen fonnten; man fiegt bistweilet aber audh andere, bie tåberformig gefealtet find, und auf ifrem breiten Kutfen Irme haben, die fid wie fehe grofe 23 indmithlenflugel umbet)en fónnen, und von Denen immer ifger viete un ein Sfuge des \$fiers bets umftehen *). Shiet ift die Bildung bes Solmpen unver= fennbar. Einige zeilen früher fpridt Plinius **) aud

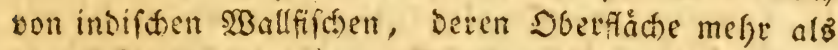

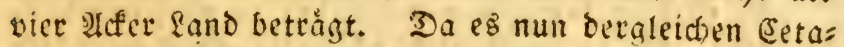
ceen ofme 3 Bidertede mat gieút, fo múfien mir diefe Siafe, baben fie anders je exiftit, oder exiftiren fie nod), auf Den srafen beziehen.

Untev sen গeueren war \$aulinus ***) einte der erfiten, Der Beobad)tungen, toelde mit benen des Ylis

*), , In Gaditano Oceano arborem (animal) , in tantum vaftis difpenfam ramis effe, „ut ex ea caufa fretum nunquam intraffe ,credatur. Apparere quoque rotas, ap,pellatas a fimilitudine, quaternis diftin, ctas radiis, modiolis, eorum oculos "duobus utrinque claudentibus," Plin. Hift. nat. lib. 9 cap. 4.

**) Plin Hift, nat, lib. 9. cap. 3.

***), Retulit mihi, olim in Borea adhueviventi, idque fua manu et antiqua fide, qua eximie pollet, hac ipfa feptimana confirmavit fufius Ambrofius Rhodius, 
nius einigemafen iberein fommen, befantut machte. Jn ber Begend von Rapplano und Finmarf, fagt $\mathfrak{k r}$,

med. et mathemat. Chriftianiae in Norvagia quondam regius, amicus fincerus, nunc Rembergae, in parria fua degens; in viciniacaftelli Wardehus, monirrum quoddam marinum Laplandiae et Finmarchiae incolis, fub elevatione poli 7 I. gr. 30 . Seekrabbedictum, confpiciendum fedare, mari a ventorum impetu plane tranquillo. Forma refert cancrum heracleoticum, vel majam ut Gesnerus in fua animalium hifroria hoc cancri genus depingit. At magnitudo ipfius plane elt monftrofa, et fuo ambitu tantum comprehendit fpatium, ut turma militum in ipfius dorfi plano commode poffit exerceri. Quando mare in Malaciam fe com: ponit, a ventis eft tranquillum, et fol tempore aeftivali fuis radiis ablanditur, folet hac monftrum paulatim et pedetentim, motu fere infenfibili, ex aquis altius atquealtius emergere, et fum dorfun radiorum folarium calori exponere. In quaftatione manet, immotum, donoc fol altiores coeli partes deferat, et horizontitiat proprior, calorque ipfius remiffior. Tunc ut motu lento et vix fenfibili ex profundo maris emerfit, it a fe lente quoque iterum demittir, et fub undis occultat in profundo. Videntibus vi. detureffe fcopulus mufco obfitus, quam. diu in planitie marisexcubat. At fi quis fcaphis propius acceiferit, brachia ex. pandit, et fuis hamis ac uncis, quodcumque apprehendit: ad fe pertrahit. Incola e putant, quod homines tali modocaptos devoret. Quando mare a ventis turbatur, lotet in profundo nemini nocivum. Addidit alius in feptentrione smicus, fide plents, in dorfo hujus monftri arbores fatis proceras aliquando fuiffe vifas. 
fieht man bistocilen ein Secungeheuer, das fich bei ftils

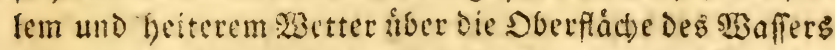
emporfsebt. Jm allgemeinen fief)

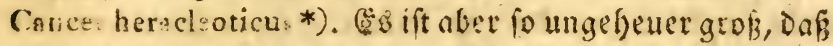
ein ganjes giegiment bequem auf feinem æhitefen manobri=

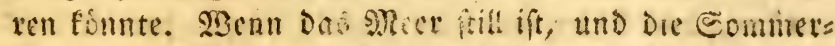
Eanne die Gluthen armaint und vergoldet, pregt bies Hngebeuer fid langfan, ia faf unmerflich, aus ber Siefe empor ju heben, mo breitet oben enofich allmăb= lic feine ungegeuren Maffen auseinamber, wa fid zu

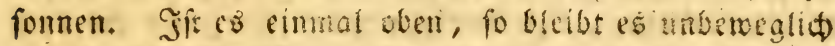
liegen, bis Die Gonne Den syotizont verlákt. Dann fentet es fic eben fo langfani tund abgemefien ricoer in bie Riefe jurưct, wo es nun nach wie vor begraben ju fenn fdeint. 23enn es fich auf Der Dberfád)e bes Meeres jeizt, fo glaubt man einen Saufen mit Moos

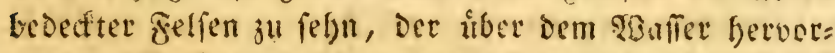

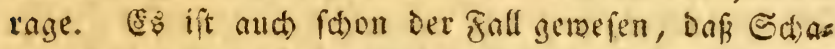
luppen ifm zu nalje famen, Dann aber von Den Armen Des Thiers ergriffen, uno in bie Siefe gezogen routden. Bei fturmifom metter erfebt Das Sfier fich nie ober Galb ies sbafiers. Cinet meinet freunde, ein febs glaubroiroiger s)?ann, fafret unfer slutor fort, bas

Sic Borellus, c. I. obro Io. Narrat, balaenas dorfo viridi et herbis decorato effe adeo, ur quandoque anchoras in eas navigantes projecerint, inquedorfis esrum tabernacula pofuerint, ignemque accen. derint (mole enimfua inlulam fatis mas. nam aemulabantur); fed calore tandem penetrante recefliffe, attonitos illos re linquentes" Paulinus abi lupra.

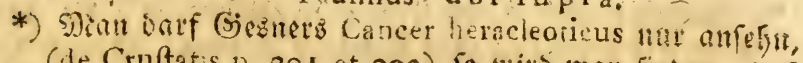
(de Cruftatis p. 201 et 202) fo mirs man finden, Dá

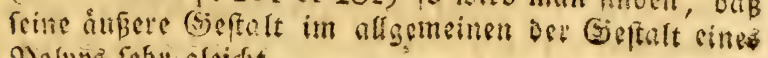

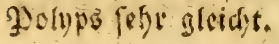


nix verfidert, Dof Der Kutfen diefes Thiers bismcifen mit ziemlid fohen 2 ăumer *) bedect fen. So, fagt

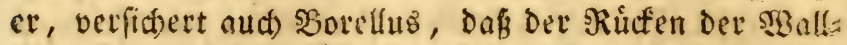
fif(c) nicht felten bergeftalt mit grunen Siáutern bes soad) fen ift, baj die Schiffer mandumal Daburd) getáuicht wurben, Das Sfier fur cine Sinfel fielten, und Anfer Datauf torfen, ausftiegen, ifre Belte aufidslugen und Feuer anmadten. Dieje Tálding war wegen der

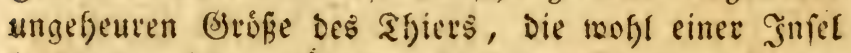
beifommt, febi naturlit. Auth merften fic, zuifrem grofien Échaden, ifr Berfern nidt efer, als bis das

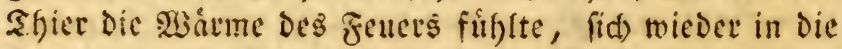
Flutfen verfente uno Daburch feine (53âte Dem Bufam: menfalagen Des 23affers, Das fein Serfinfen hetvov: bringt, ausfebte. Faulimus fügte diefen Thatfad)en abfid)tlid) feine woitere $\mathfrak{B}$ emerfung binju. S(f) wetbe Das (Gicicte tfun; und feţe das Thier, von weldem Det Betfaller rebet, uno Das icf) nad) Dem Borellus citive, neben bes शlimius: $23 a l f f i d$ von vier Nefera. Das

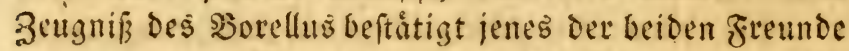
Des getefrten Nitarbeiters an Den Epremeriben Der Yaturliebfaber.

Dlaus sagnus, ebenfalls cin Betvofner bes ஒoriens, verfichert nicht minder, es befinde fich im Nordmecte cin ungefeures Thicr aus ber Slaffe Det Eetacen, auf Deffen Bucten Die Eceleute fdon bis= weilen Anfer getoorfin bitten. Die ganje Saut oes Shieres, lagt et, ift mit einem Ganbe bedectt, Dit Dem åfnlict) ift, ben man alt sen Diecufern findet, to

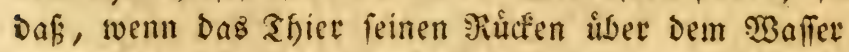

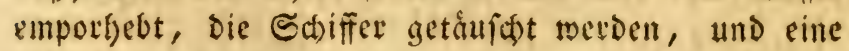

*) SBabricheinlich Secgrêler noer (Sjorgonen, die be: faun lich bistycilen funf Tuई boch werbe!t. Gobalo cs wafle ift, bas jenes ungebeule Thict exiftitt, fo muirs fen fich naturfich eine Dienge Edmarogerwefen auf

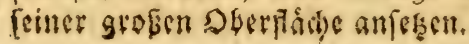


Jinlel gefunden zu haben glauben, desfalb anlanden,

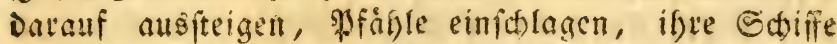
befeftigen, Feuer anzunad)en, zu fod)en anfangen $x$. bis das Ungefjener die T3åme des Feners zu fublen

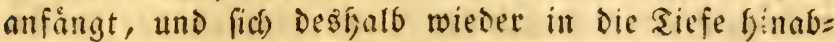
fenft, tmo alle Diejenigen ertronft, bie fich auf Diefe betrugerifde Gnfel magten *). Sft entfteft Durct Das

*) „Habet etiam cetus fuper corium fuum fuperficiem tamquam fabulum, quod eft juxta littus maris, unde plerumque elevato dorfo fuper undas, a navigantibus nihil aliud creditur effe quam infula itaque nautas ad illum appellunt, et fuper eum defcendunt, inque ipfum palos figunt, naves alligant, locos pro cibis coquendis accendunt; donec tandem cetus fentiens ignem fefe in profundum mergat, atque in ejus dorlo manentes, nifi funibus a navi protenlis fe liberare queant, fubmergantur. Hic cetus, ut fuperius de Phyfetere et Prifte dictum eft, aliquando fluctus hauftos ita eruc at; quod alluvie nimbofa pierumçue claffem navigantium deprimat, et cum in mari rempeftas oritur, fe fuper fluctus attollit, ut in his commotionibus ac turbidinibus naves emergat. Arenas aliquando dorlo fustollit, in quibus ingruente tempeftate. . nautae terram fe inveniffe gaudentes, anchoris demiffis falfa firmitate quiefcunt, ac ignes accenfos bellua fentiens fubito commota, $f e$ in aquas mergit, hominesque cum navibus, nifi anchorae rumpantur, in profundum attrahit. Quod vero navigantibus terra apparet cetorum ac balaenarum immenfitas, Ambrofius in Hexame, lib. 5. cap. I I. fidem facit. Dicit enim, cetus eft pilcis infinitae magnitudinis, qui fi quando fupernatat fuctibus, annatare infulam putes. montes altifimos fizmmis ad coelum verricibus eminere, qui non in acta, nec in littoribus, fed in Atlantici maris profundo fertur videri, ut ejus confpectu nautae a navigandi in illis locis praefumptione revocentur, nec fecreto elementorum adire fupremae terrorem ortis ufurpent. Idem eodem lib. cap. 10. Cete illa immenfa genera pifcium, aequalia montibus corpora. Et paulo ante: ultra terminos orbis terrarum mare norunt, quod nullae interpolunt infulae, nec tersa aliqua idtcrjaceat, 


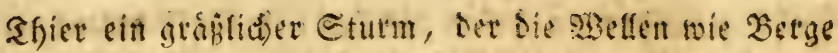
auftgùmt, fie geget cinanoer fdolagt, fo Dar eine

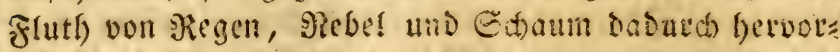
gebracht wird. SBenn ias ungebeliet fiá) verienft, fo

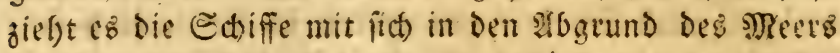
binab. Ilm Das Befagte ju beftåtigen, beruft fith Slaus झagnus auf Das Zethynf, Des Imbrofius, Der ebenfalls befouptet, dof es entieglid grofie Eetaceen gebe, und baßz man glauben midte, cine ganje Jnjel, bie mit Bergen bejegt ift, aus dem Scean beroorgefn

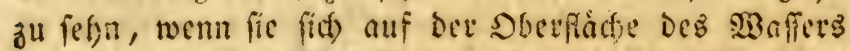
zeigen. Sorgiglid trifft man fie im boben s) deere an,

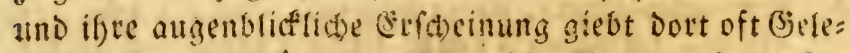
genfeit ju Juthimern, Denn sie Eecleute bemerfen

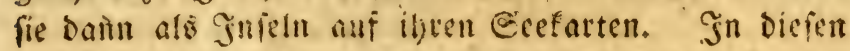
weiten Meeren foteinen Derglciden befeelte Maffen bes fonders gern zu mofmen. Fivos von ifmen lyat walls:

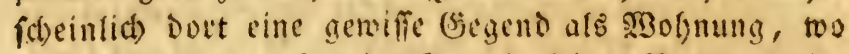

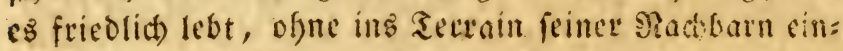

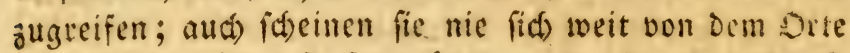
zu entfernen, Den fie fich roálylten, noer Den das Edjicf:

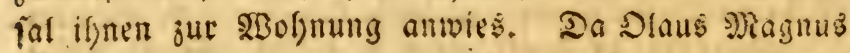

gern

vel ulterius fit pofita; illic igitur, ubi diffufum lste mare omnem fpectandi utum, utilitatis gratia navigandi interludat audaciam, condere fe feruntur. Dein:1: habent fuas regiones et habitacula diftributs, manent in his inoffenlo vicinorum limite, nec vago tranlicu mutationes quaerunt locorum, fed tanquam patrium folum diligunt, et in his immorari dulce artitrantur. - In cero (ut antor eft Iorath) magis terreftris, quara aqquea dominatur natura; quando enim fenefcit, radices, frutices et arbufta fuper fe coiligit, quae crefcunt fuper ipfum et mulriplicantur. Unde beatus Hie. ronymus inquit, cetos - - tanta magnitudine en: :nere, ut navigiis anchorarum ftationem capiendis $: n$. fa: infularun fufficiant. Olaus Magnns, de Anctioris dorío cetis impolitis. De pilcibus monitr. cap. 2,5 4no 26. p. 754. 
getn alles neben sinander fellen twollte, was ifm von ber Eriftenj Diefer Ungefener befant war, fo erwálnt er

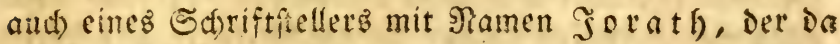

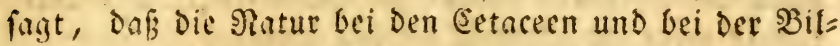
Dung Der Shiere, Die Die sneere beffertfoen, weit majeftatliforer fen, als fie auf oer (Srde es ift *), und Dafíg fo grofie Meerthiete gebe, Daj, wenn fie alt mers Din, eine sienge son Begetabilien fid an ifnen an: feten, auf iffen 29 uzzel fallagen und wad) fen. Slaus fagt audb, bet h. Scietommus verfichere, die Eetaceen mirden fo ungefouter grof, daß manthe Saffer fie fdion für Snicln gefaiten, uno saran, wie am Eanter fich vor stnfer gelegt bátten.

SBormius rebet aut bon cinem entietrlich grofien Shiere aus ber silaffe ber (Eetaceen t) bas an bie

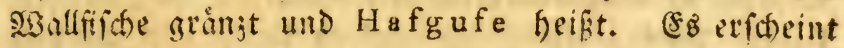
zroar fefre felten, fagt ex, aber es ift feiner úbermáßi= gen Grefe weacn merfivindig. Die, die es gefeht baben, verfidtern, cơgleige mér einer Jutel als einem Thfiere, und nie treffe man peinen seidnam an. Dics

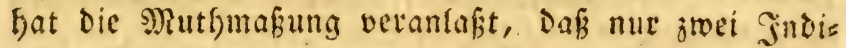

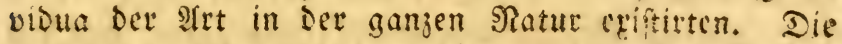

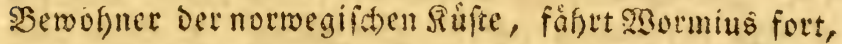
balten vie Medufen fur SBrut oder laid) (Eiet) Diefer

*) Diez follte nad) Dem Eateinifasen cigentlta hcipen:

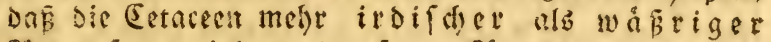
Statur feyen, indem es̉ u. F. 10. 2fnm. D. Heberick.

t) Reftat una fpecies (balaenac) quam lafgufe vocant, cujus magnitudo latet, cum raro confpiciatur. 11li, qui le corpus vidiffe narrant, fimiliorem infuloa quan beftiae volunt, nec unguam ejus inventum cadaver, quo circa funt, qui exiftimant, non nifi doo ejus genera in natura effe. .... Haec capita medufae $a b$ in. colis littoris norvagici pro foetura hujus belluse habentur, et forte ejus funt ininima ovula. O I a u $\mathrm{W}$ or. mius, Mus. pag. 279 in manus. Speculum regate dicto cujus poffeffor fuit, et Mus, p. sous. 


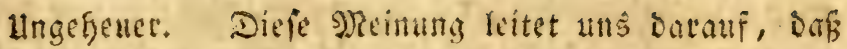
wir and hier an ben firafen benfen minien, benn unter allen Eecmothasen náfern fith sie Madufen und Meer= refiefn moly am allermeiften ben \$olnpen.

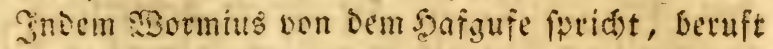
ex (id) auf ein ș?anuffript, bas er befitet, uno fefye toerth

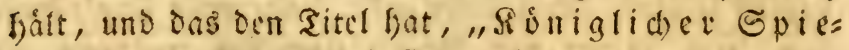
gel." Dir Berfaffer Defielben if unbefannt; mainet

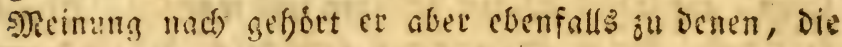
jiber ben graten gejurieben baben.

Geaner bait ebenfallo bie Eqifteng jenes lnges

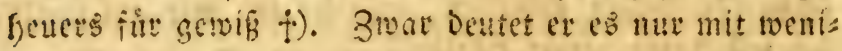
gen şorten an; fein 3eidmer aber that befto mefre hin=

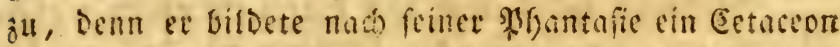
ab, Das cr ungefentartia uno fóseuflich Darftellt, arf feinem Buffen cin Ediff anfern läßst, aus rveldem.

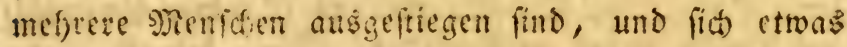
fodin. Gesnet fagt aut), Daf bie néroliden sy?atro= fen biess

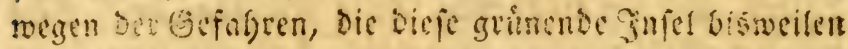
betwortingt.

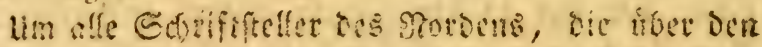

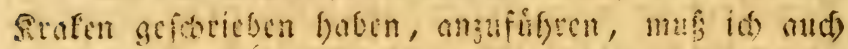

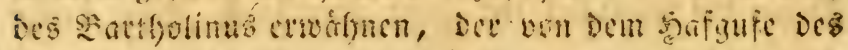

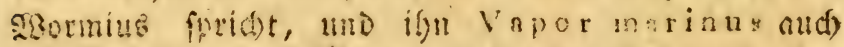

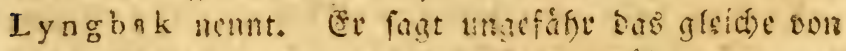
ifm, uns fugt fingu, baf bas Shier bethe, wem pe

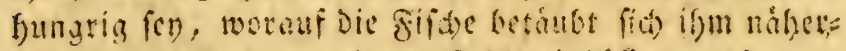
ten, uns in feine ungefoure sefte cimfisten, H. f. m.

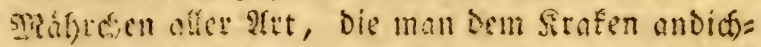
tete, veruffadren fwaterfin, Daj man bas gange Sfier bejweifete. Zalmont de Domate that dies fejonters.

4) Nautae in dorfo cetorum, quae infulas putant, anchoras figentes, lacpe periclitantur. Hos cetos Trollwall fus lingua appellant. Germanice Teufelwall, Giesner, anim, mar. ord, 12. de Cetis p. 177 . 


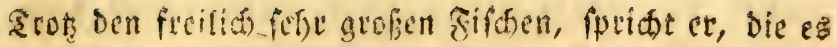
im Neete giebt, fann man Dod nist wobf an einen

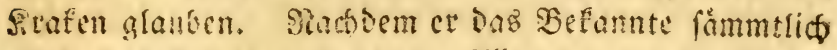

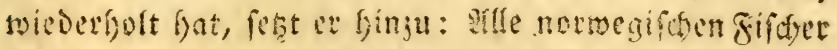

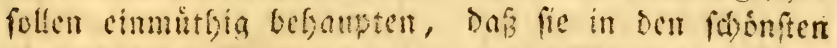
nhis wämiten Eommertagen, einişe Mcícn ins Mect

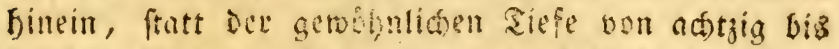
hundert Shaftern oft mur stunnzig bis vierzig finden, worans fie sann fáfiegen, dafie fie fich liber fitafen bes finten, die fich fo weit empor gefoben Gaten. She

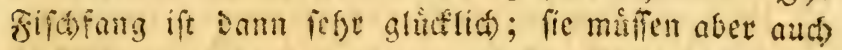

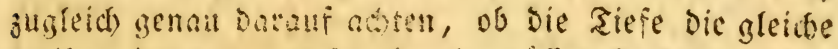
blcibe; benn nimme fie ab, fo miffen fie bavon eilen, Samit bas Siglet intw) feine Betoegungen fie nidut uns

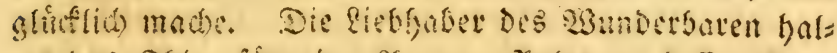

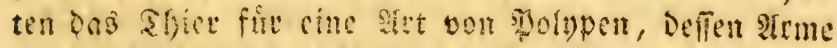

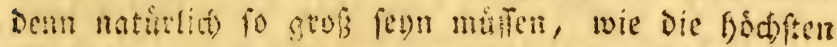

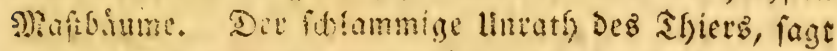

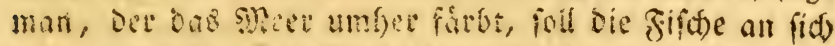

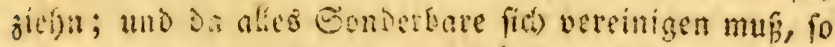
foll ber Sirofen bann fenca šiten etrffnen uno alle

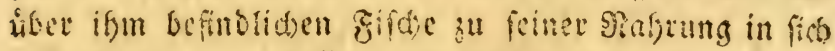
aufuefmen. - Sollte aber Dicfer Icţte Eatasmus

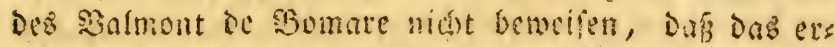

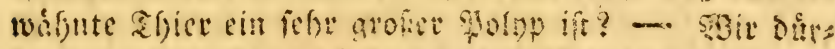

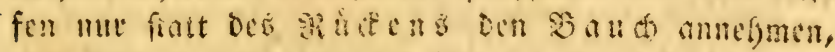

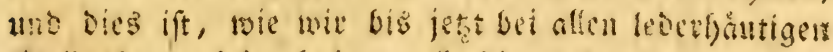
sholuxten acfefn baben, affersingo ber Fall, mo in

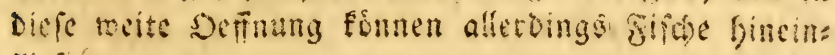
fliefín.

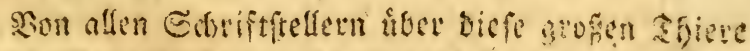

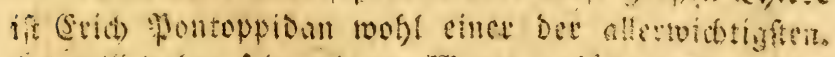

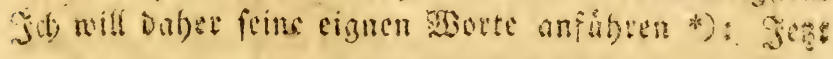

*) Nune venio ad vaftifimam totins telluris belluam, quam Kraken, vel Käben vocant, aut ut aliis $p:$ : cet, Krabben, quad nomen intuitu corporis in ipto 
femmen toir ju Dem grofiten Şfere unjeres erdobodens,

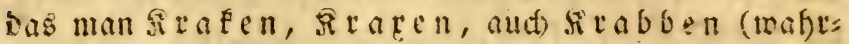
fiteinfict von ber rundiden form feines Rópers, sex

ciem orbis globati, plani, et brachiis inftructi, impofitum effe videtur Alii vocant Horven, Seehorven, Ankertroll, Kreuzfifch Quotquot ego feriptores confinlui', ad illuftrandam belluse hujus narurain, nullum inveni, qui mihi forisfecerit. ... Omnes noftrates pifcatores uno confirmant ore, quod li aeftivis diebus ad pilcandum feaphas conicendunt, et talem maris altitudinem petunt, ubi ordinarie profunditat:m 80 vel 100 Orgyarum habet, aliquando, dernifra bolide, profunditatem 30 vel $40 \mathrm{Orgyarum}$ fe invenire, indeque concludere, belluam, undos interpendulam, minorem hanc caulare profunditatern, monentumque adefle, ut, retibus laxatis, copiofam multitudinem pifcium concludant. Pifcatum interea continuant, demiflo per vices plumbo, quod fi cog. nofcunt profunditatem imminui, arbitrantur animal aitius adfcendere, pifcrturae tempus expirafie, et fuga falutern quaerendam effe. Quaqua verium retro. sctio fcaphis et inventa majori aquae profunditate, paululum requiescunt, videntque e longinq:o, elapfis aliquot minutis, horrendum animal fuper aquas in confpectum prodire, fuoque dorio infulsm qquafi formare, tantae vaftitatis, ur milliaris quadrantem, uninimo, duntaxat notato calculo aequare videatur. NulJus ceteroquin morralium totum hoc animal, quoad fuam formain et magnitudinem, unquam vidit. E longinquo incondita haec moles repraefentat feriem fecopulorum alga obfitorum, hinc inde colles qusfi et edita loca funt, ubi pifces faliunt, donec lateraliter in mare decidant. Ubi magis adfcendit bellua ritentes hami et brachia in confpectum prodeunt, quae altitudine mediocris mali eo magis craffefcunt, quo magis eminet bellua, ut fane maxima navis claffica fine periculo accedere non poffit. Aliquo tempore elapfo bellua iterum in fundum fe demitrit, quo tempore periculofiffima foret navium vel feapharum accelfio, quia tantam demiffione fua format maris voraginem, quae, inftar gurgitis moskocenfis, quaevis vicina fecum raperer et attraheret. . . C Cum itaque monftrum hoc hor- 


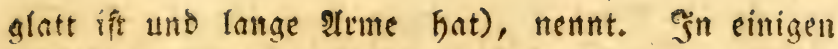

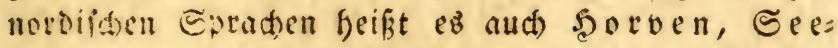

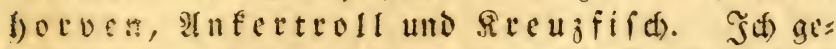
feffe, Dof midh Eeiner unter allen Sdriftifellern úbur

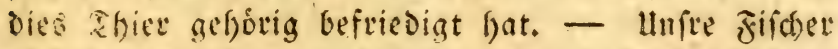
noer fagen cinftimmig, dap fie, wemn fie fich bei fdónen Eommertazen mit iften Echiffen etwaz reit von ber Silfte entfernen, fo Daffie eigentlid) ad)tig bis fundert Silafter sicfe vorfinden miristen, bod oft mit bem Sent=

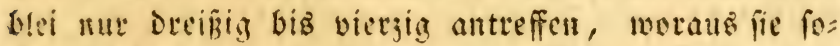
Danifolichen, daf cin Eesungeheuer in Der Mitte des sects fdrobe. Slan merfen fic fogleid iffe glete nus, weil fie fitser fino, jetst felfe biel ju fangen. Sont 3eit 34 3eit abet laffen fie das ๔enfblei fallen. Sinden fie menizer Sicfe, fo foliefen fie baraus, Dañ sas

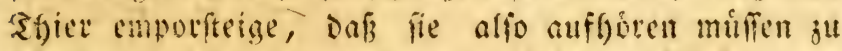
fifthen, und Dafs es Seit ift, zu fliegen. Sit ruocut aber blos ein menig weiter, bis fie die aemelgntione

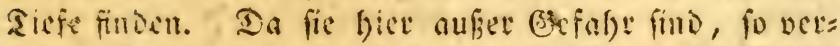

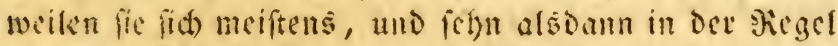

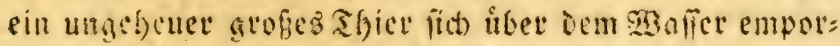

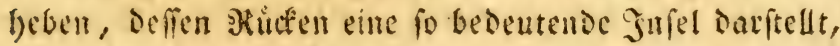

rendum commode ad genus polyporum. . . . referri poterit, videntur brachia defcripta antennae feu tenta. cula fle, quibus non folum fe movet, fed et alimenta colligit. . . Non tamen negaverim infignem fragran. tiam et vaporem, quem certo anni tempore fyirat, cujusque ope pilcium inyriades congregat, no: intimam fuae confervationis cauiam efle; veterani pifcatores ex experientia norunt, quod valtifitia haec beliua aliquot meses replendo ventri impendat, uti toridem pro digerendo et evacuando pabulo. Ultimo hoc rempore luperficies maris thuca, turbida et potris invenitur, et mirandam undequaque pifciam meititudincm slicit, ad feam omnibus experitam, quibus dein congregatis microcolmus iterum adfeenderet et apertis furs taucihus agregatum tium pabulum deghlutiret. Eric Pontoppidan. Hitt nat. norv. Tom, III. cin \& $n$ 39.4. 


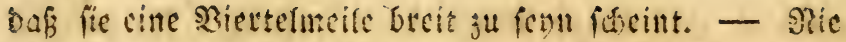

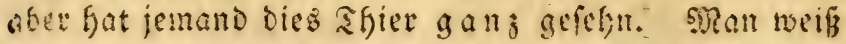

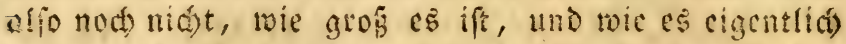
gefraltet ift. Gin Der Gerne fellt bit Mgaffe cunen Selfens

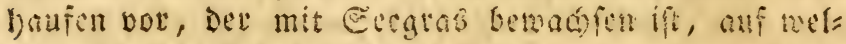

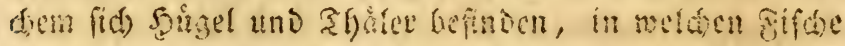

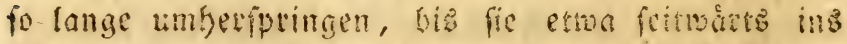

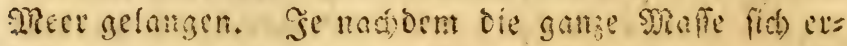

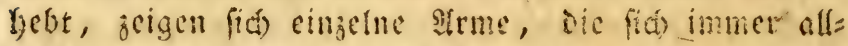

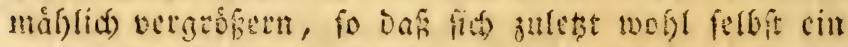
grones Echiff nidit leidt binan nagen binfte. Menn befer lebende $\mathfrak{B e r g}$ eine zeitiong unbewegliá) gelegen biat, fo finft er nad) uni nadi) wised unter. Siefer

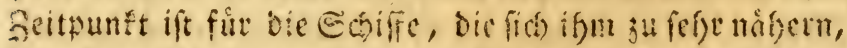

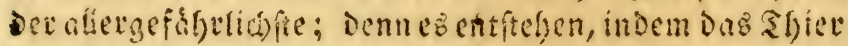

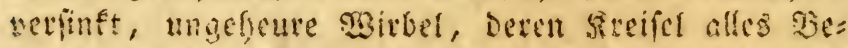

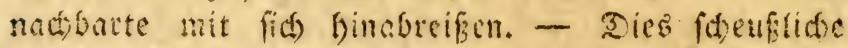
Unzelgeuer foun mit Jecht zu den grofupen getedunct

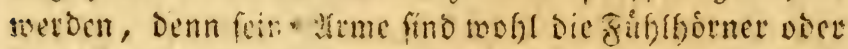

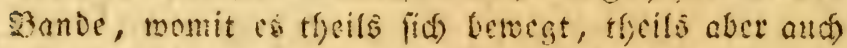
alles feft balt, was ifim zum Bianbe bichen fant.

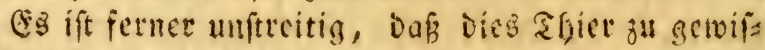

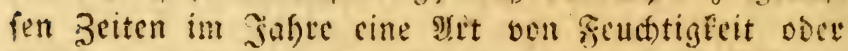
Dunft ausftromt, ber bie sifdye anfolft, bie sas Syice berfd)lingt. Sit alten fifid)er befoupten aus (erfaf)= rung, ber Siraten braude einige Monate, un feinen ungeheuren Sauć anjufitlen, und einige antere, un z" virbauen. In Diejer letertern Epode finden fie Daz Sheer idmutgig, gefátbt und fidon von weitem ned)

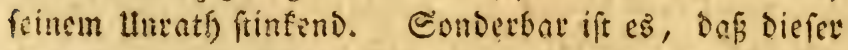

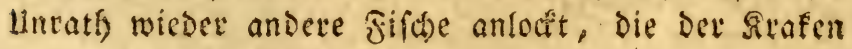
Donn abermals berfollingt.

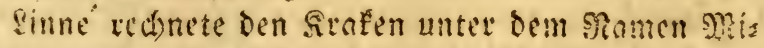

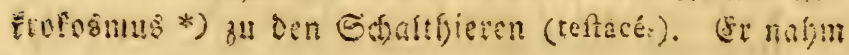

*) Lima Esun fuec. p 386. Syf?, nat, edit. 6. p. 75. 
feine Criftem an, bielt aber peine frinidste und felpens attige sulfe fitr fdontenatig.

sir fimmen alfo, nat) Den vielen Seugnifien at

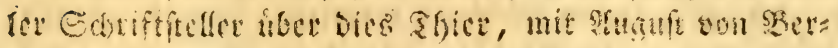

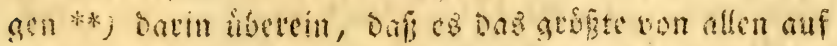

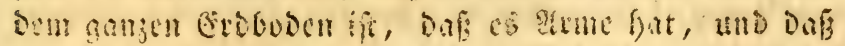

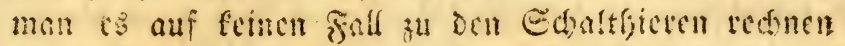

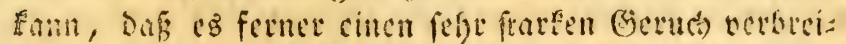

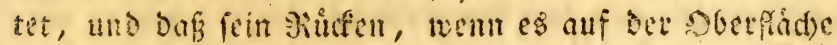

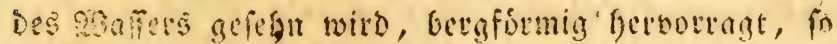

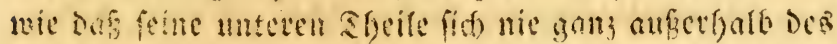

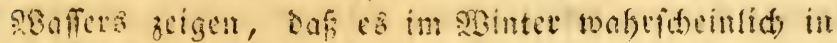

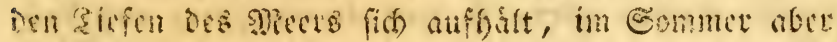

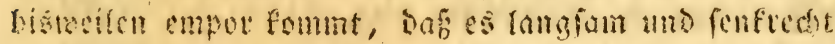

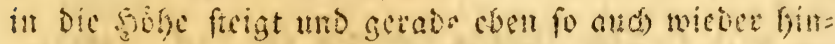

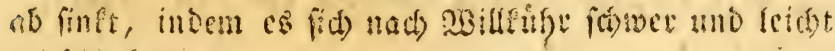
motoch foun.

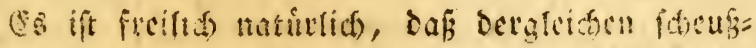
fiofe uno affen unfern 23 offelfungen chigegen fectende

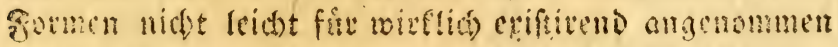

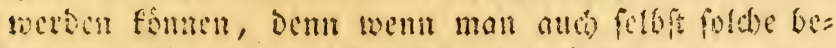
weglide jufelit vo: fich fafge, fo wirve man fie ond fiut Borfpiegelungen de: \$lgantafie zu halten geneigt

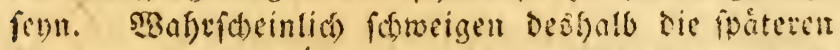

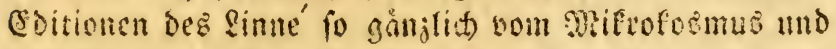

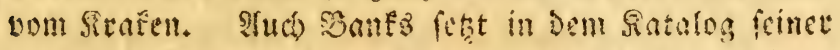

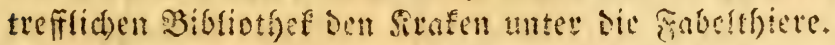

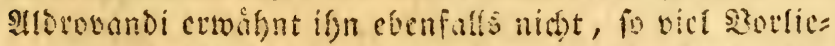

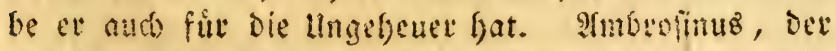
ifgn fortieţte, fdowieg niát minser, ungeudstet ex in feinen sharalipomenis bie feltfampen Ungefeuer ans Dem Dlaus sRagnus uno aus Den Eectartin juhamen gelefen batte; aud Jonfton fagt fein sigoet von igm.

**) Carol. Augufi a Bergen, ubi fupra, in Scholio. 
Sange ftand id an, Peine Sejdidite zu Pdreiten,

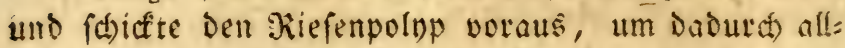
måflich bis zu ifm zu gelangen. Die liebe zur şonfe= heit ift allein meine fufferin gemeien. Miod) te id nut immer ibren engen $\$$ fad gefunden haben! - §at) freue mich indế bier abermals Das zcugní eines neuern Edriftitellers t) anfübren ju finnen, der, wenn gleitu

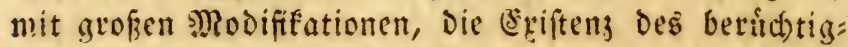
ten Sirafens, von Dem die Eeeleute fagen, dafj er ein Sdiff umwerfen t́onne, annimmt.

(58 veteinigen fich in Der ahat zu viele Fafta,

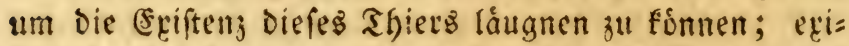
fritt ber arofen aber, fo muf er ein Polgp und bas grófte Thier unjers (Erdballs feyn.

†) L. A. G. Bofc, Hiftoire naturelle des Vers. Tom, I. p. 36 . 


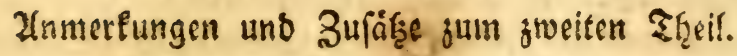

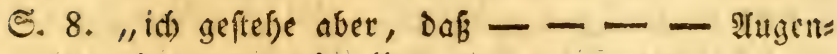
zenge Davon getwefen."

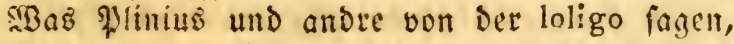

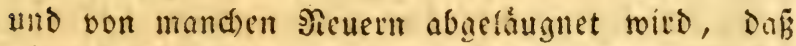
nàmlid Diefe Sfiere weite Sprünge aus Dem sisaffer thun fonnen, ift mir von ben zuberlábigften $\mathscr{A}$ ugenjeugen verfichert uno genau befdriefen morben. Sie fúlten fid) námlid volf ssaffer, Das fie Darn mit grober Bjemalt wie in cinem Etraft

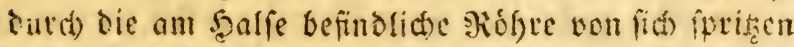
und fid badurd eine grofe Ettecte weit viber bas

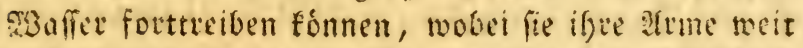
ausigeftrect balten. Ṡlumenbad) Scandoud Dit जi. (3).

C. I 4. WBie Montfort dic Exterteinung, Daf mit ju=

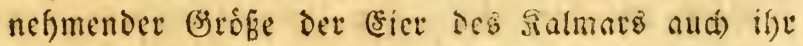
Berwidft zunimmt, unerflårbar finden fant, begreife id) nid)t. Jad) Dádfte, bie Sadfe erflarte fitt) von felbft, und es wáte mefrk za verwundern, wenn daz Bjegentheil Davon gefwálfe. So wie das junze

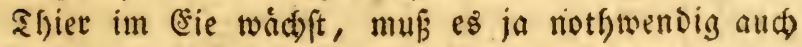
idswerer merben.

S. $15 . x$. folgt eine weitfaneifige Digrefition úber E⿺xzeนgung. M. tritt auf Die Seite Derer, wets d)e den uriprung aller Thiere aus (siern forteiten.

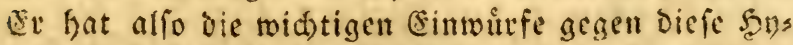

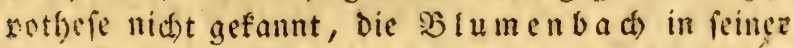

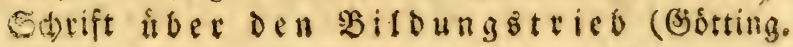




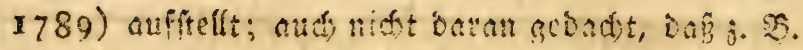
ber sampolnp (Hydra) lerendige Sunge wic હirof= fen aus feinem nóper treibt.

S. 19. "Det berifmte I inné- hatte Den अugn, Die

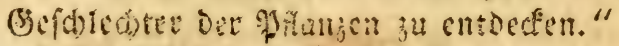

Sdin voi Rinmé erflatie fich millingthon,

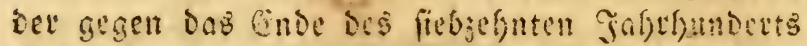

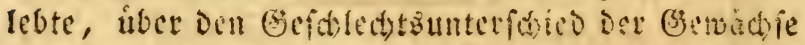

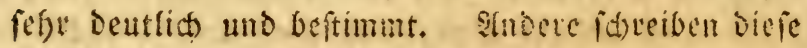

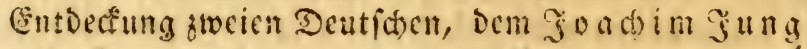

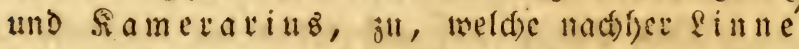
bembąt babe, um fin Scknalinftem Darauf ju batten.

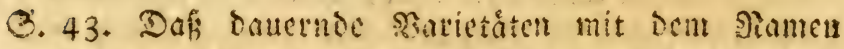
Gattungen bejcidnet meroen follen, móde foner: lid) von andern Raturforfacrn gebilígt werben.

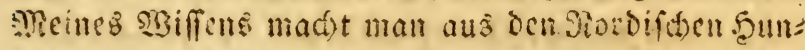
Den aud) nidbt eime eigne Gattung, wic bict in bet Sinmert. befauptet mird.

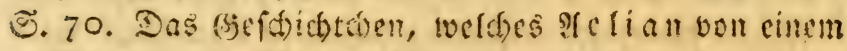
Polypen uno aroler croifit, ijt nad) cinem (ipigeamm Des In tipater (Anslect. Poet. gr. Brunk:i T II. p. I 20. n. 44.) vorgetragen, woraus fich allf Deffer

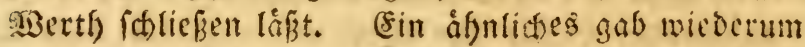
ợ einem Epigranum bes $\mathfrak{A}$ ntiphilus (Anal. Brunkii T. I. p. I75. n. 23.) Den Stoff het. (8)

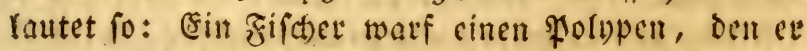
eben gefangen hatte an einen Etraud) an llfer, das mit er ilgn von ber Şand los wurde. In dem Etraus

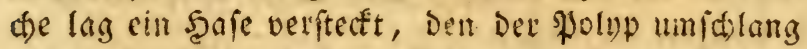
uno fo feit fielt, dafis der filche: ifin fangen founte. Schuciber vermifh Abhand. zc. S. 18.

5. 88. Daf Die Ecefube lamuntins) chemals bis in Die rgofmungen ber Mienfiden getommen find, ift

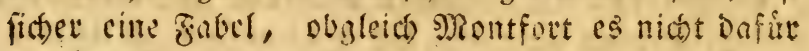
gelten laffen will. Edon ige siorperbau, worin fie 


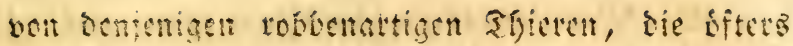
nuis Sans getgen, fefre abtweden, madt bies un:

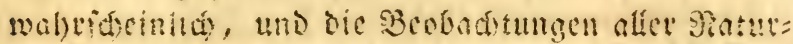

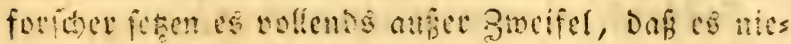

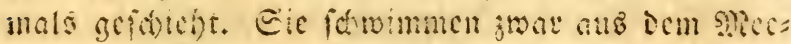
re in arose Etrone, etfiobe bunbert Meifen weit ins

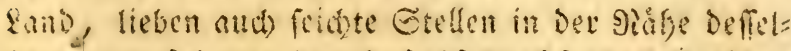

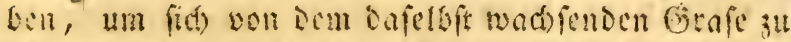
nafyen; aber nie bertafien fie bas Sabafer ganj, uno

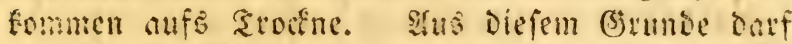

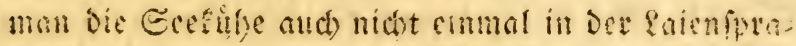
d) simploibien nemen (wie fich surntfort crtanbt);

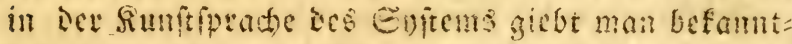

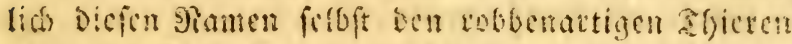
nitist, weld)e eben fo wofl auf bem sande als im sisafer leben fónnen.

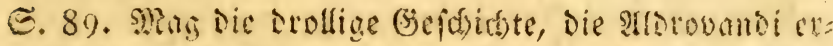

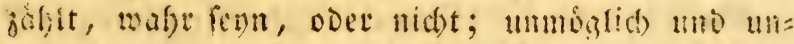

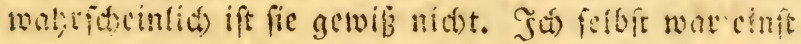

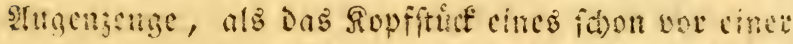

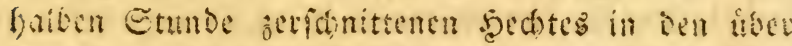
iem ficter frebenten Seflel gemorfen warde, weldes augenblictid) aus Dem Seffe! mit unglaublider Sinft

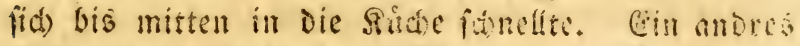
Mal bif ein foldect - ebenfalls gerame Scti zu= vor jerftucfelter - fifd iev ifin unvorfidytis an:

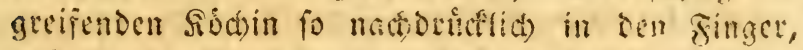

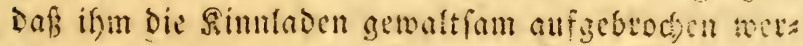
Den muften, um ifn los zu miden.

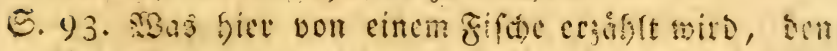

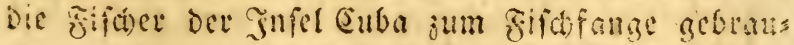
den, uno woraus montfort, wie cò mir ident,

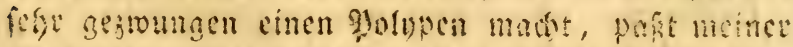

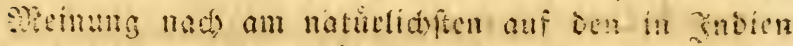

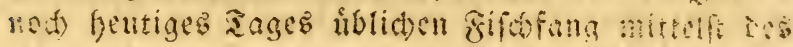
Cungeffies (Echeneis remora). Dic ssonte in ou 
gillal: habens caput grandiufeulum et in occipite pellem tenaciffimam in modum magnae crumenae, find entfacidend. Sein Spract) = und Sndfundiget wirb in Diefer Befdreibung, so fie gleid) eben nid)t idulgerecht ift, Das Sat)ito des Sau= gefijches verfenner. Hebrigens farm es wolst levn,

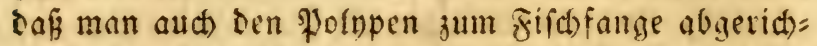
tet und gebraudit hat, Denn fajon Iifriftoteles bes unerft, Daf man Die Mlánnd)en der Eepien mit Şúlfe

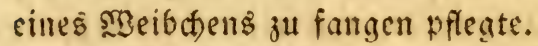

S. 116. WBie Die Cetaceen dic furditbaten Irme bes Polypen (Die nach Montf. Den Mraftbumen grofer

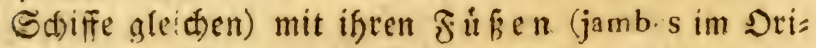
gittal) abfneipen fonnen, ift cin renig fober ju bes areifen, ba fie befanntlich feine haben. Eelbft die Båfne, welche bei cinigen Bat ungen gefunden wet= Den, móchten bies nid)t gut ju berwerfftelligen im Srande fenn. Leberhaupt velläbt Montfort bon biev an fefre oft bas feld ber errfafrungen, land fatmeift in Dem Sande Der \$yantafie und Fafeln umiger.

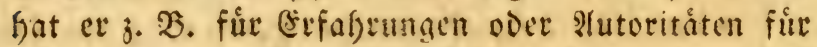
fid), wenn et S. 118 und 119 befonuptet, on Meeranle, Murånen, Mallfifde uno andere Tifdje oder Eetaceen (fo fteft wirfflt) im Driginal; follte man nid)t glauben, Nontfort red)me Die (etaceen ju ben Fifchen?) Die angreifenben Feinde ber Polnpen fino, Die ifnen die Arme austriffen? Die fdlupfrige Saut jener Scegefdopfe ift ein fidrad)er (5itunto zu siefer : $3 e r m u t h u n g$. $2 B$ arum nemt $\mathrm{er}$ nid)t lieber sen Mecrwolf und die scaien, benten man folde Simpfe und Siege efher zutrauen Eann? - 23 eiter bin nimmt $\mathrm{M}$. Die oben erwáfyte, einer Fabel nid)t untignticte, Sage vom 2loler und Polgpen als aus: gemad)te 23 affrifeit an.

S. 1 131 . Dem Shinilis und andern IIten wate ein fo

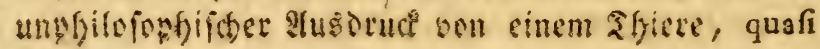


entionis expers, wofil zll oergeifen; aber von einem Siontfort erwartete man nid)t, Dafi er bem Polnpen Şerfanio (intelligence) in cinem bohen Giabe zu= fdreiben toirbe. Hebrigens finoe id Die Crelle im Plinius nicht in 29. Siap., fonocrn im 46. 1nto aut) Da ganj anoers als fie 92. cititt fat. Sic lautet fo: Et cum alioqui brutum hebeatur animal, ut quod ad manum hominis adnatat, in re quodammodo familia. ri caller. Onnia in domum comportat eic.

S. 32. Das Dfl Der Dintenifiche, Fagt Suvier, ift beinatse fo einfad); toie in beul sireben; aber es ift ganj in Der Diufe des Ringfnorpels verborgen, melder ien grofien fifflfiden oder Prmen diefer

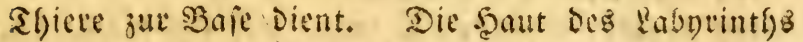
iit atth cin blofier 5 cutcl von ovalet oder abgetunde: ter form. In Dun gemeimen Dintenfilde (fep. off. cin,) bat Diefelbe nad innen mefrere fonifase Ser: vorragungen, weld unregelmágig geftellt firo. Dies fe Servotragungen felsten in ven anoern Battungen. In Dem Marfe, weld)es fie ausfullt, băngt ein flei= ner Sisper, weltiet in ben cigentlicis fogenamiten Dintenfifiden von fnod)erner, in Dem $\mathfrak{I} d) t f u[B e$ aber vou cintel der Ståte ágnlichen Subftanj iff.

5. 138. SBas mag Dod mofl Mrontfort unter cimem civilifiten Ibiete werfefen, meldes fid) fo viele funftidse und idealifte (Benúfie angefhafft of baben facint, cils cs Cmpfindungen bat? Iomn Daß Der leţreve Sath fich aud) auf animsl civilité bezicht, ift aus der Conftuction ganj Flar, uno Daf animal civilifé nid)t etroa Den Menfácnen bezeictonen foll, fieft man aแs Der 2bfonderung: et principalement l'homme.

S. I 4T. Saton Der Serr Uleberf. Gat unter Dem Sert

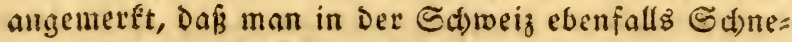
fen máftet. Daffelbe gefdiebt aber auch im fídis den Deutidland fie und Da, $3 . B$. in Der Segent 
bon Ulm, wo man jâftlidy 12 bis 15000 Gubeas aus Dem Sandel mit gemarteten Edunden lofet.

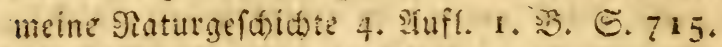

6.153. Dev fogenanne Milefenpolyp it Sepia octopodia Blumenbechii, wovon Diefer beriffinte Bes

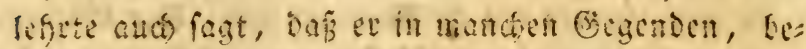

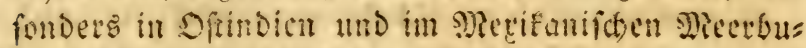
fen, von gan ungefeurer Groffe gefunden werde, io sois er Boote umeiffen fonme, und abgeriffene cingelne atme von ifm, bie man gemelien habe, bet

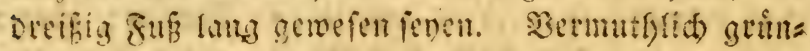

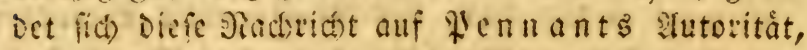

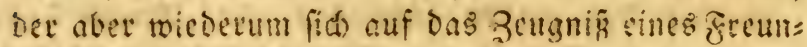
bes bernft, welfier fitg lange auf ben incianifinen

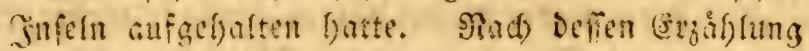

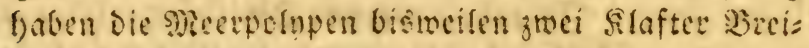

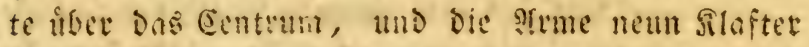

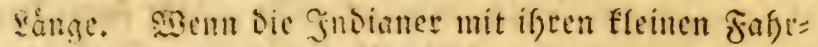
zengen auşgefen, fo fîfren fie allezeit eine Trt mit

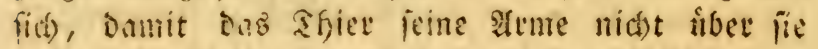
fislingen und fie verienfen mege. Die Pachridst -

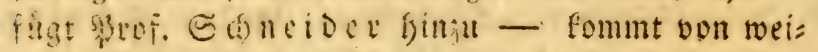
ten; fie mag afp wob! unterwegs jugenommen fas beri.

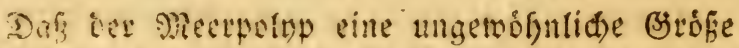

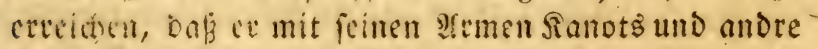

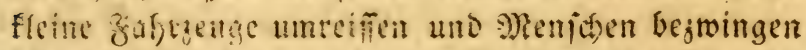
finne, wet rotid Das lougnen? So etflatt fid auth

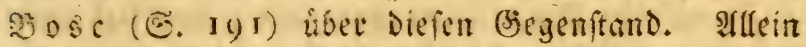

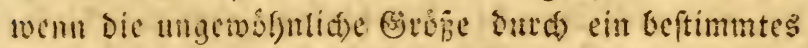
Maforgegeben mitb, und wenn man abentgeuerfide Gubaflungen von Der Kiejenitarfe jenes Thieres fort ober licfet; fo fragt man biflig: wer hat gemeffen? wer fino Die Crzåfler ano zeugen? Diefer for: Firung ber Fititi bat skontfort feinestoeges Benitge gethan. Er, Der Die alte Enge, Dafi ber Jolnp 


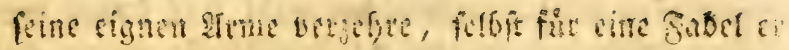

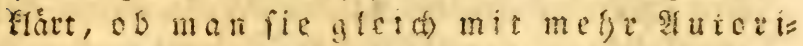
táten belegen tonnte, ols die unfeqleats fen shatfacen be shatuegefold te fire

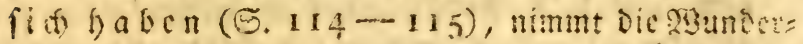

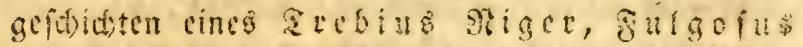
und Ifelian bone fide als alsigemadyt mafye an, ofne auch mur lleberteibung uno fintfellung be:

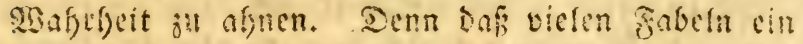

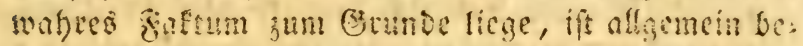

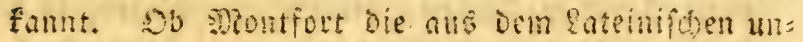

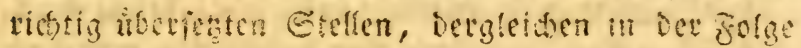
wetfomen, me beftemoen, ofer feinem 3roed:

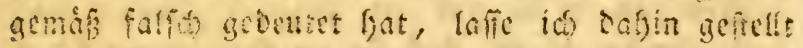
fort. Co vid focm mir gewis, Dab fein linbs:

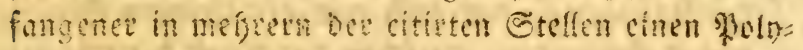

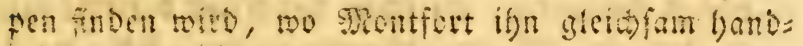
sreiffich findet.

Cin grofes Genidot legt er auf ein Ex vot ju

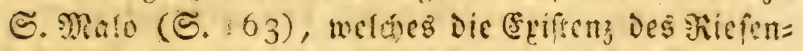
polnpen bemeifen foll. Silfein eş giebt (3emálos alter

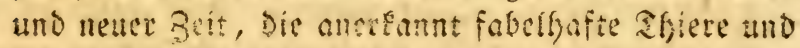
fabeififate Begeberibeiten als mafir voritellen. Ituch Seidune fiten Das Munderbare, twowon S. 177 ein \$eifpiel vorfommt. Zubem feílt es Der Beng= benfeit, weldse Durd Das Ex voto bewafybettet werben foll, all allen Erforderniffen einer glaubwir: sigen Gefolid). Coz ift nicht angegeben Dit seit,

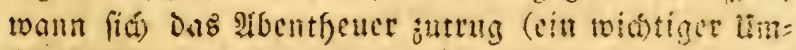

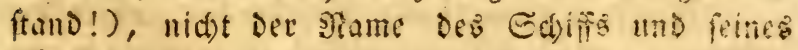
Finferes, oder des Befehtshabers. Mian wein ia, wie gen Eeefeute mit auggefanonen (sefafyren proty= let, wic voll fic sen mituno nebmen, then fie suvor fpecthen, uns wie ailes von ifnch ins lingrigence

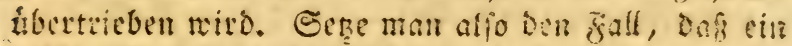

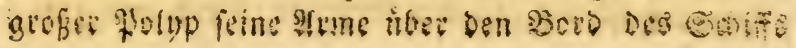


grtoorfen Gabe, weldies gar wofl fern fant wenn

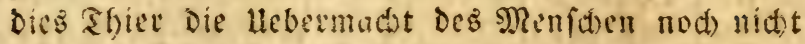

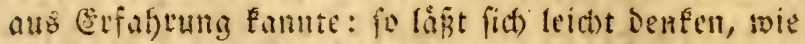

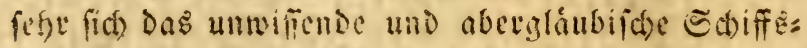
volf oor Dem Inblif eines fo feltfam geftalteten M) Wnftrums entieht, unb mie Dafielbe, von Pfaffen verleitet, feine erfte Buflucht ou Gebeten und Befub: Den gendmmen und Dann erft die 23 affen ergrifien Gaben werde. S?un muste freilict), un Das Gelúbde ful redifertigen uno fia desfalb oon serftandigen

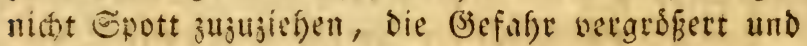
Das Monftum fo in Ungefeuere nusgedefnt werden, Dafi ber Sampf zroifdoen ifm und funfigig bewaffreten Mienfiben nicít gat zu ungleich fadeinen módete. Sonserbar ift cs, Dap fie zur (s)egentwebr fich nid)t Der fianonen, voer ouci) nur bes fleinern (d)iefge= wefré bebienten, Da fáson der Anall Derjelben nach હ. 204 Die Mecrungefeuer verjagen foll, weldes oud nidft unmofrlfdeinlich ift. Soer trug fid Die Begebenfeit vor frefindung bes Feruergemefrs ju? - Dann fonnte fie aber nid)t zu Den Faftis Der

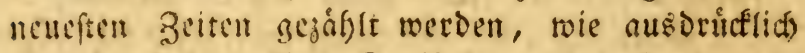
ธ. 163 fteft. Ifud) Sinuffaister, befonders went fie Eclabenfandel treiben, füfren wenigftens sin \$an Eleine Sanonen, Die, mur ein Dral auf Den Sopf Diš Unthiers mit Siduerbeit abgefeuert, Dem Streite gleid sin ende gemad)t haben wurben. Surz, die (Sefdidate, fo wie fie fier erjåglt ift, fat wenig imtere șafrifueinlidbeit.

Die ธ. 107 erjåhlte Begebenfeit erfålt Durø

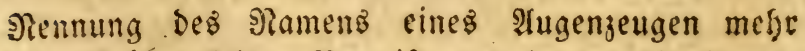
(Slanbwurisigfeit. Nor ift nod immer die frage,

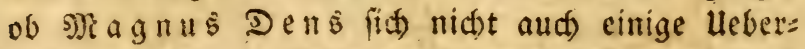
treibung gave ju Sdulden fommen laffen; oder do

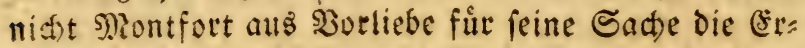

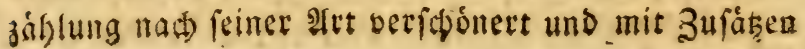




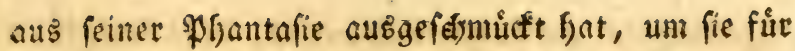
Den bुefómacf Der \&efer pifanter zu mad)en. Die Saturgefdidate ift fo vielfältig Dutd) Fabeln uno Llebertreioung Des $33 a f r e n$ entfellt worden, Daf man nidft vorficttig genug bei unterfuctung iange= gebuer Ihatfadjen verfafren fann. Zwar gefúre ich feinesิtregę zu Den Galştarrigen Unglåubigen, die aแร Furd)t, leid)tgláubig zu fabeinen, Fafta, welde Durd) unvertwerflidse Zeugniffe beftátigt fino, nods immer bez̧weifeln ober láugnen; aber id) verlange aแch) unverwerfli (d) Ze Zeugniffe, twenn id) etwas glauben foll, bas mir bişfer unglaublid fdien.

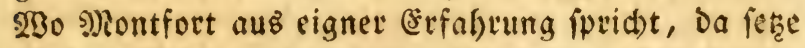

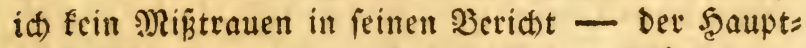
facte nad) - wenn mit aud bei Nebenumitånden cin Bareifel aufitofen follte. So wiro 3. 3. (S. $7^{6}$ bis 78) cin \$olnp, befen Sorper etwa fo grob it, twie

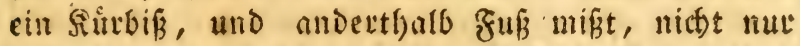
Sert uber eine ftart gebauete irlandiche Dogge, fon= Dern ex fhleppt fie auds, feiner vielen Şunden'un= gead)tet, mit fidt in eine Felientiofle. Dies gefdrefts nid) im SBaffer, condern auf feitem $200 \mathrm{en}$, uno man fieft alfo nidyt red)t ein, wie das móglich ge: wefen feyn farm, da ber \$olnp auf bem Sande fid nur mit Şulfe feiner Irme fortberwegt (ङ.82), bie

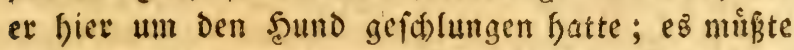
Denn fern, daḱ er Did)t vor der Sbigle gefeffen gàtte,

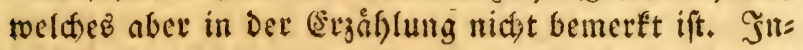
Deffen glaube ids, wie gejagt, ifm felbft als Augen= zeugen; wenn er fingegen Indern nad)erzåglt, io bin ich etras mißtrauifich.

Bei Dem alfen verbient Montfort Dane, Daf́ er felbft fabelfaft fdeeinende - alte und neue - গach= ridaten uber Diefen begenftand mulbam jufammen= gefud)t hat. Bielleid)t, Daß Die Zeit feime \$ermu=

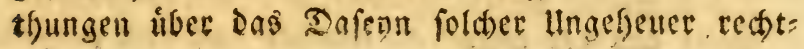
sonturgeri由, 2. xh. 
fertigt, fo twie fie fdon SD?andes, twas fonft fưr ums mógliđ) gebalten wurde, Der ietzigen $23 e l t$ als wirtlich gezeigt bat, $3<$. Den Eteinirgen.

Jah entfalte mict), ưber die nádaftfolgenden Stellen

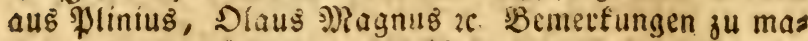
屯) ftellers jevem Sefer von feloft einleuchtet, wie renig feine כeithreioungen auf Den \$olypen paffen, und aut Montfort bies zum Sheil geftebt (S. 179.). Dod fann id) nid)t ůbergehen, dafi nad) S. 184. e\& (d)eint, als ob झlinius bas fugelartige Bufammentollen ber ₹aus

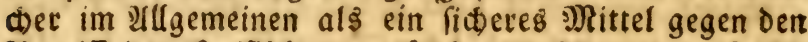
Ingriff des seaifif ift. Die Stelle findet fids aud nidit im 29., fondern im 70. Rap., to \$lin. fagt: Ac faepe iam fubducti (urinatores a fociis) e manibus auferuntur, fi non trahentium opem, conglobato corpore in pilae modum, ipfi adjuvere. Die Rede ift alfo nur vom 3ufammenfugeln

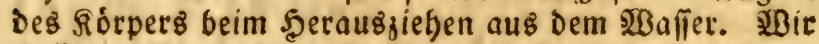

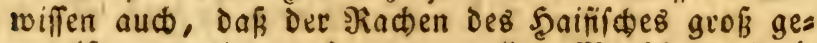
nug ift, um einen zufammengerollten DRenichen mit eis nem sole zu veridblingen.

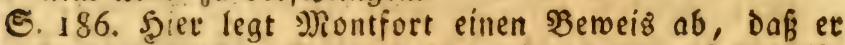
Der lateinifaren Epracte nicht fonderlich máchtig ift. S3ielleidt two llte er aber aud bie Şyperbel bes Dl. Mragn., Daf́ Der \$olop logar von Ranonenfugeln nicbt berwuns Det twerde, verftecfen.

S. 193. Die Mallififue, reelde fo ungeheure \$olnpenars me abbeifien uno verídlucfen follen, fónnen unmóglid Die eigentiliden fogenannten gronlándifden 23 allifiche (Bal. myfticet.) fernn, Derell ङ ift. IUd) Der शordfaper (Bal. mufculus Linn.) fann es nidt feyn, Denn obgleid) fein ßaden groß genug ift, fo twito Doch Des Esingang Des Galundes Duth ein \$aar grobe fleifhéltimpen an ber 23urzel ber Zunge fo verengt, Doß́ nut fleine fifiche, Seef́ráuter uno bergl. in ben sagen fommen fónnelr. $\$$ bleibt alfo nur ber Eadelot (Phyferer macroceph.) íbrig, Der aud ziems lich grofie Şaififace verfallingt.

D. 201. Berílungen, lanitich vom WBaffer; aber

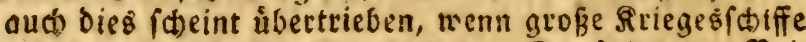
mit barunter verftanden merden. Die folgenden Beis fpiefe aus Der alten uno neueften Seit vom plóşliकen 


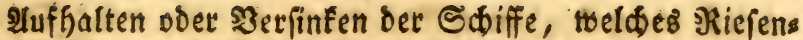
polopen zugeidrieben wird, beourfen nod) einer ftrens gen blftorif theuer mit ben zefn frangdifidsen (nad) ber Berfides

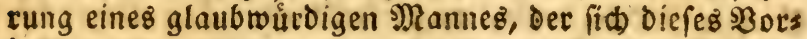
falls nods wohl erinnert, wurden auffer Der $\mathfrak{B}$ ille de Paris nur wei fleinere franjófifthe Sdiffe - nicbt Sriegesf(diffe - erobert) uno englicten Ariegsidaiffen (ङ. 205 biß 207). (E\& lit mir unbegreiflid, Daß́ eine Erfdeinung, oie, wenn fie fid ganz fo jugetragen fat, wie bier erzàblt wird, merf wúrdig genug ift, ob fie glei aud nod aus alloern lltjacten, als bie $\mathfrak{M}$. angiebt, erf́lárt werden fónnte - in unfern Sagen nidjt mefre Iaffefen erregt haben uno iffentlich zur Sprade ge. fommen feun follte, weldhes aber meines \$ֻiffens nicht

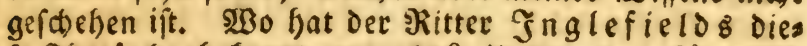

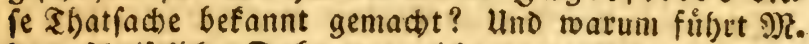
Das ideriftlide Dofument nidst namentlich an? Die Englánder find Dod fonft bei Unterfinchung folder widtigen Borfálle forgfáltig, uno pflegen múnoliche

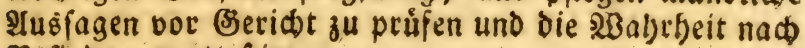
פefiinden zu atteftiren.

Sodann findet fich hier ein 2 Biberiprud). Pontfort

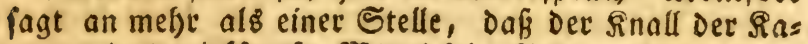
nonen das wirffamfte Mittel fei, Molnpen uno andere Seetfiere plóblich zu verfdeuchen. 2Bie fam es nun, Daf fie fich nidht perjagen liefen, als die şille De

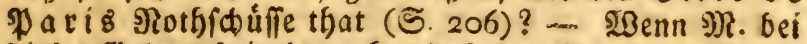

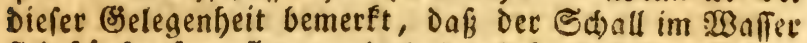
fid ftát'er fortpflanje, als in Der \&uft, fo hat er Jiect)t.

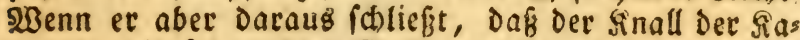

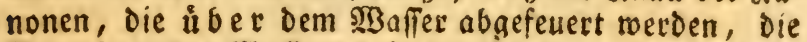
நewofner des 2 Baffers beftiget afficicen mùffe, als bie auffer dem saffer exiftirenden Befdojpfe, fo wider= fpridt ifm die Erfabtung. Jeber Shall, oer a uffer

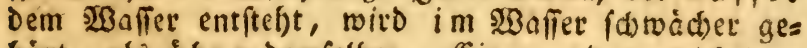
bót, als úber bemfelben. Einen andern wicbtigen und unbeantroortlidsen (Eintourf gegen feine Solpotlefe gefteft M. Feloft S. 208 und 209

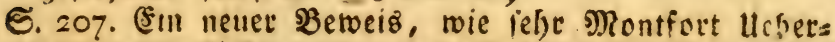
trelbungen liebt, und wie er Zahlen und Broben ing Ungeheure vermefrt. Die ganie Snfel Fo r mro fa bat

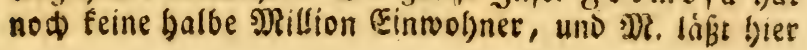


burd einen Typhon 8 Frillionen, foreibe a lionen, Meniकen auf ein Mlal umemmen! Jit Dies Unfunbe in ben geographifकen wififeniduaften, odes B̈asiconnabe?

๔. 2 r๑. il l'engloutit, er verfentt es.. Die Mlóglidf ait ift nicht zu láugnen; es fommt nur Datauf an, oafi bie

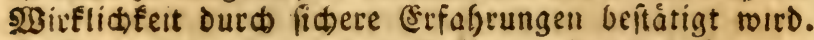
Daffelbe gilt aud) von Dem Hufbalten Det Sd)iffe, toels des freilic) ourd einen Riefenpolopen eijer gefdefyen fann, als Durch ben Saugefifich

త. 216. Der Fergenbaum, Deffen \$linius ertwálnt, ift entweder Ficus fycomorus (Miaulbeer = Feigenbaum), bon Dem auch neuere Reifebeid)reibir beridten, Dẩ fein Stamm zureilen funfig $\mathfrak{F} u \tilde{B}$ im Durchmefier babe; ober Ficus indica, ber zu ben fogenannten $23 u$ u'zelbåts

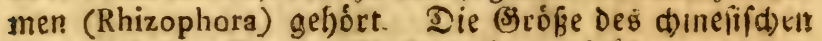
23aums in Der Wrovinj Shefiou ift getolf ůbertreben.

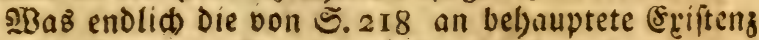
bes sirafen betrifft, fo grundet fï) Drefelbe bis jehtt blok auf gemeine Schifferfagen, und fann Durchaus nod) nicts als ausgemadt angenommen werdell. Riefet man bie von Mr. angefúl)tten S(briftiteller, fo berufen fie fich zuletzt immer aif die Seeleute, melche ell fol beś Şbier gefeben baben wollen. Wie leidt oiffe aber ju tåuf(ben uno wie renig fie gefdicțt fino, unbefan: gen z beobactent, ift befannt. So lange alfo uas Bafenn Deg Sirafen now nidt beffer bocumentirt if , fo lange wird er zum mindeiten unter die smeifelbaften, senn aud nicht unter die fabelbaften (Béfdopfe gered) net toerden múffen. 


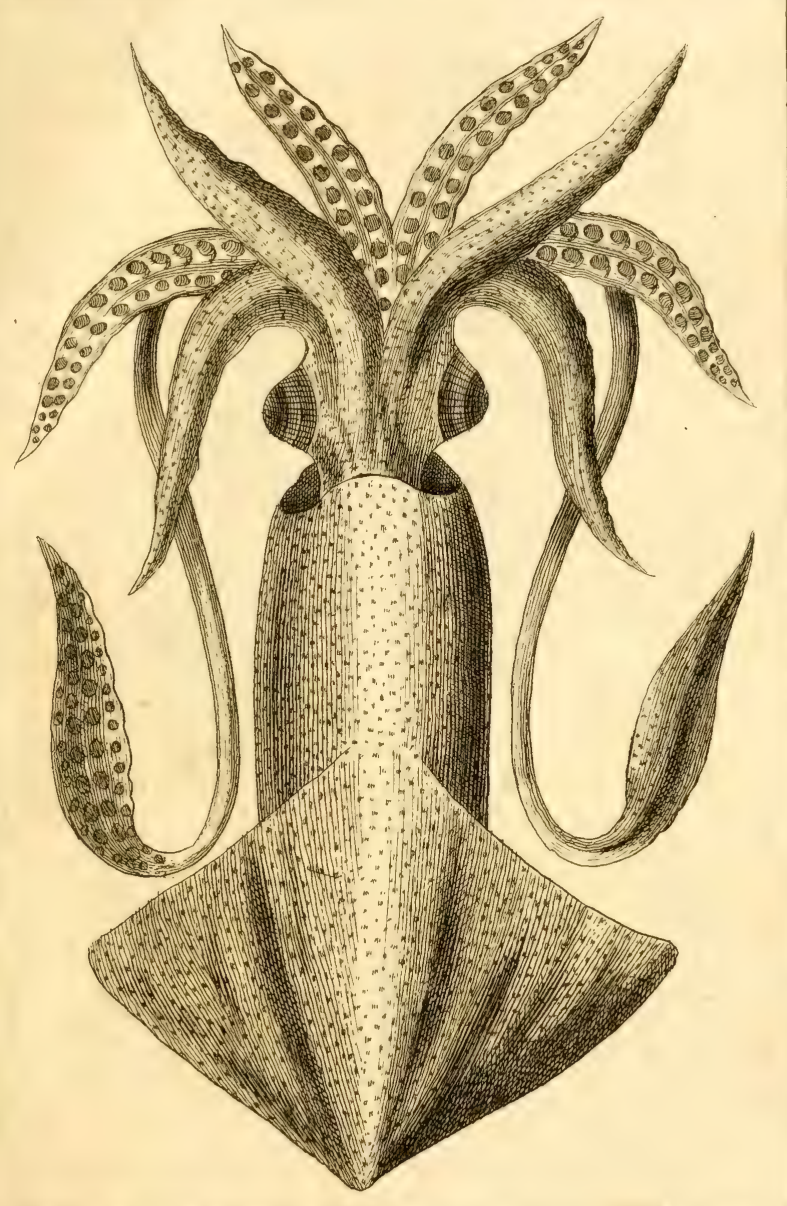

$$
\text { Der gemeine Golmare. }
$$





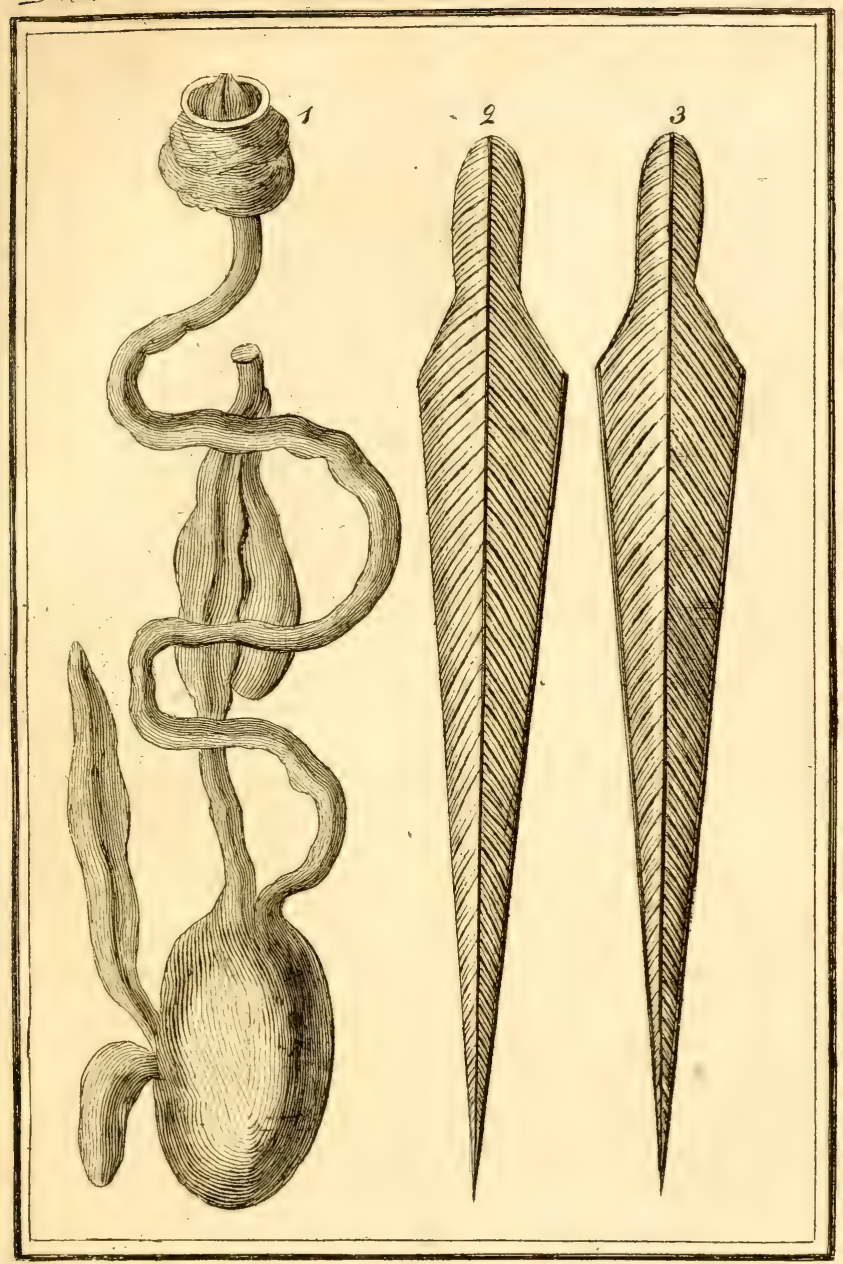

Conduit intestinal \&lames cornées de Calmars.

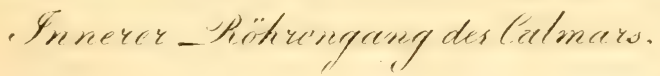



Pl.10.

Ba11J

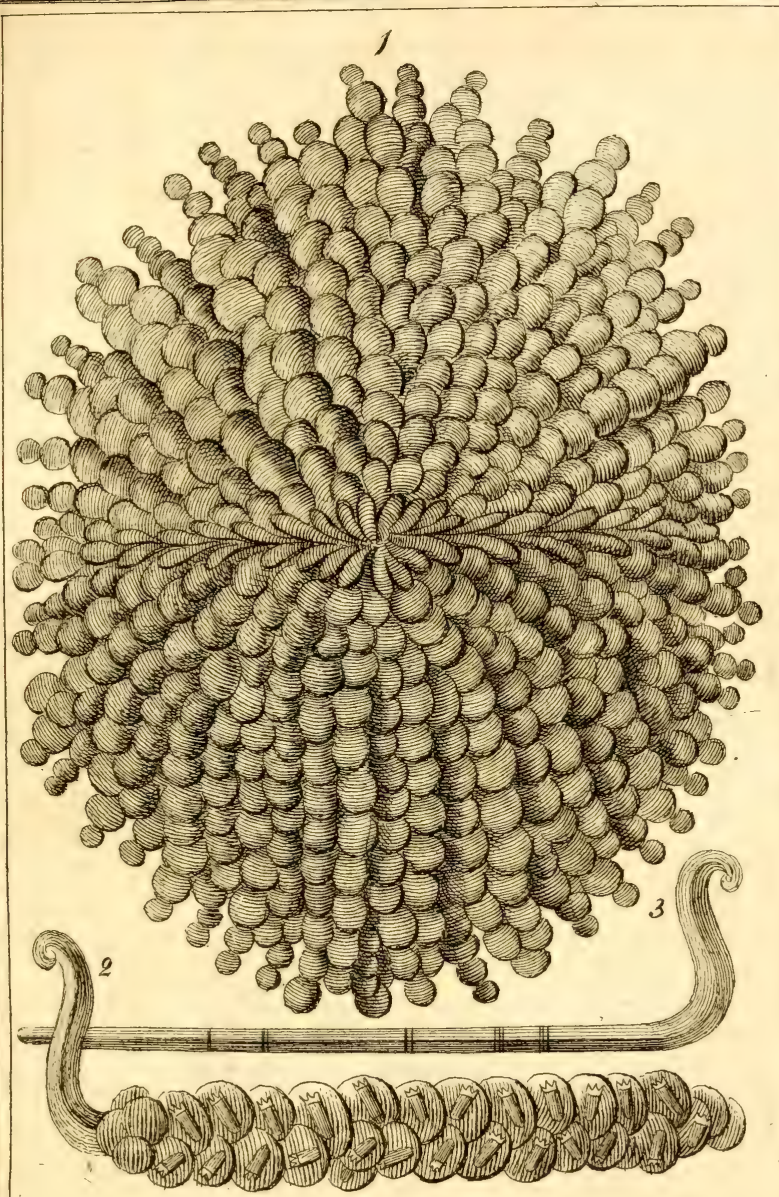

$-$

Veefó dee Cealmear.

cierdes lalmars. 



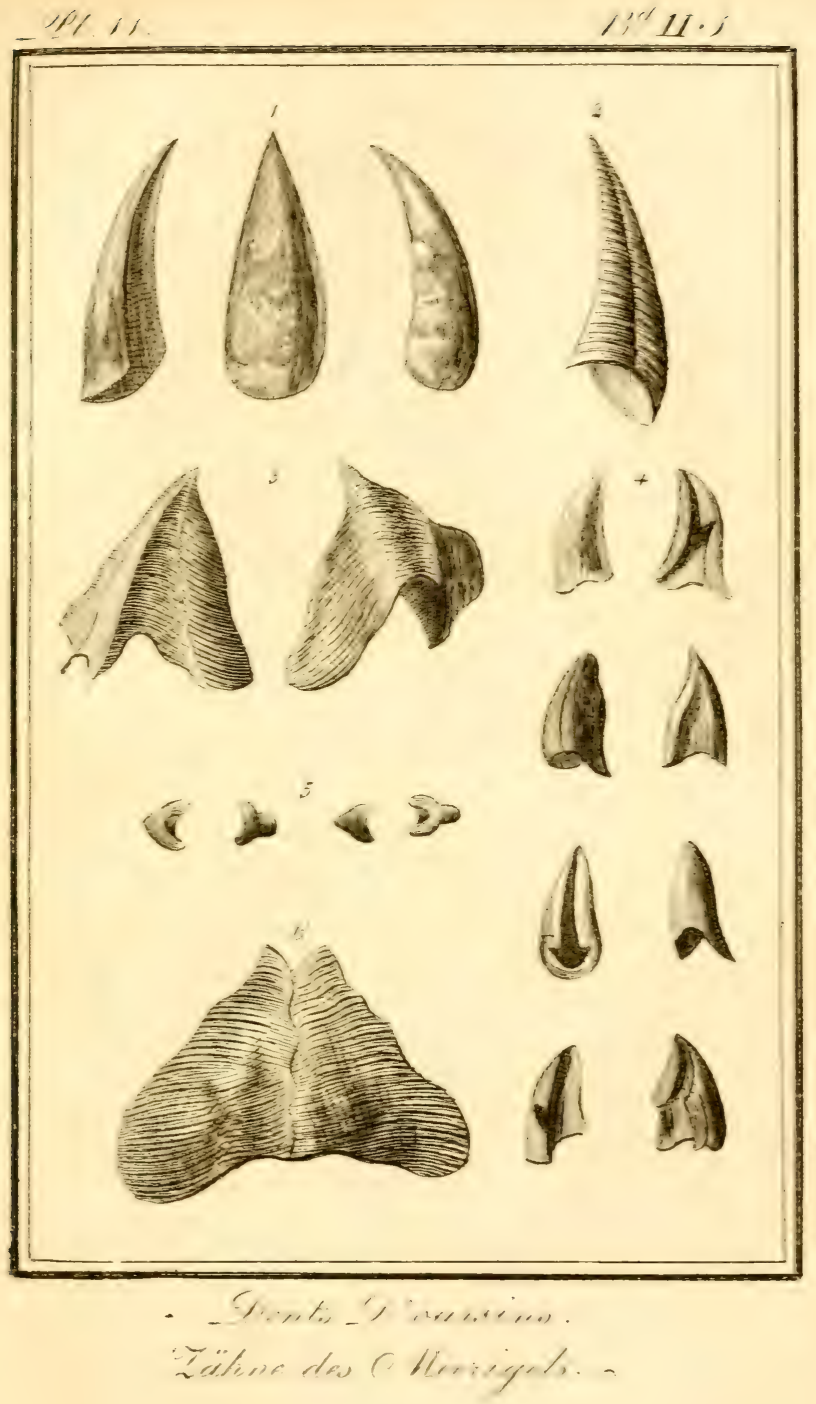


$y$ 


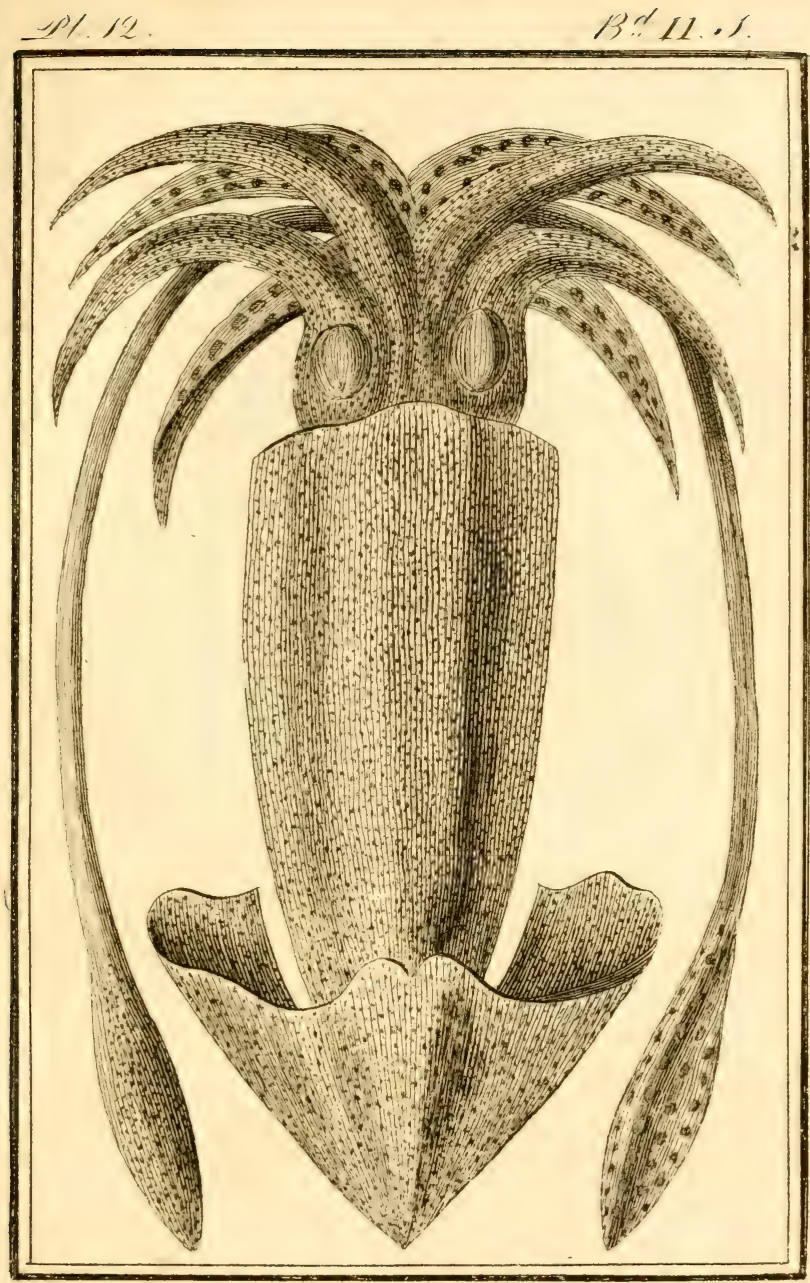

$$
\begin{aligned}
& \text { Pe Corlu...r firitis. } \\
& \text { oxer ffeilformige Calmar. }
\end{aligned}
$$





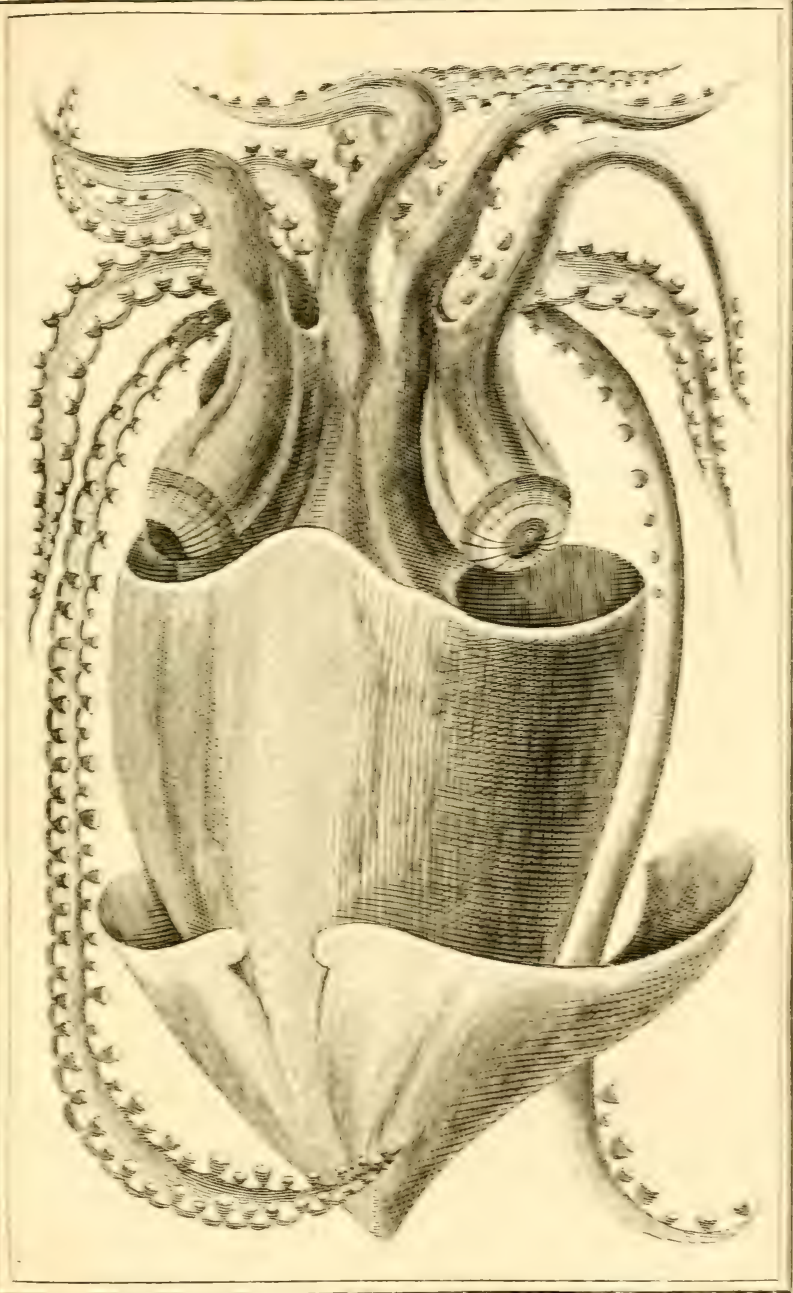

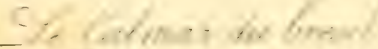

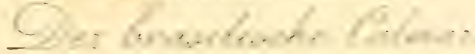





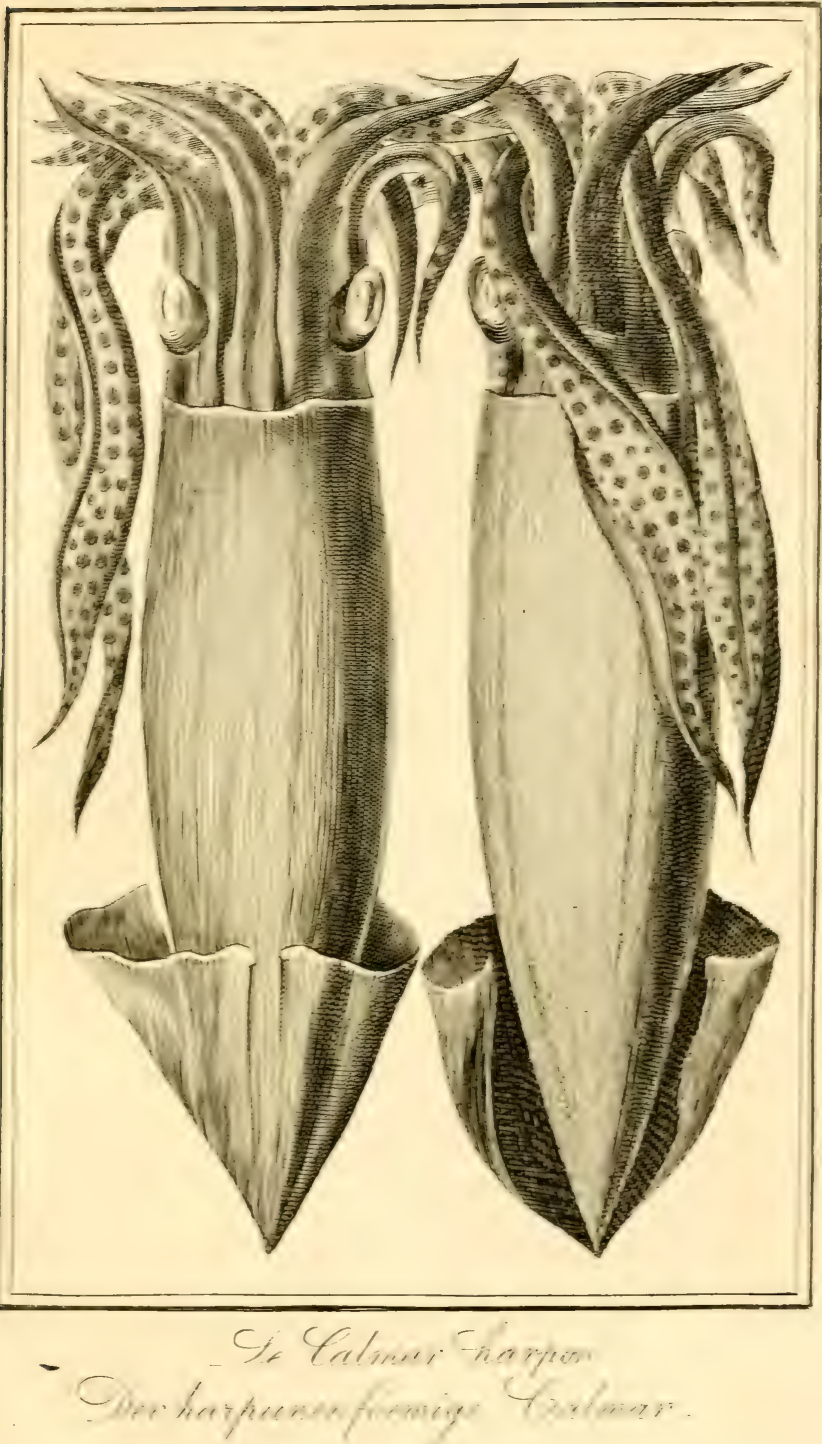





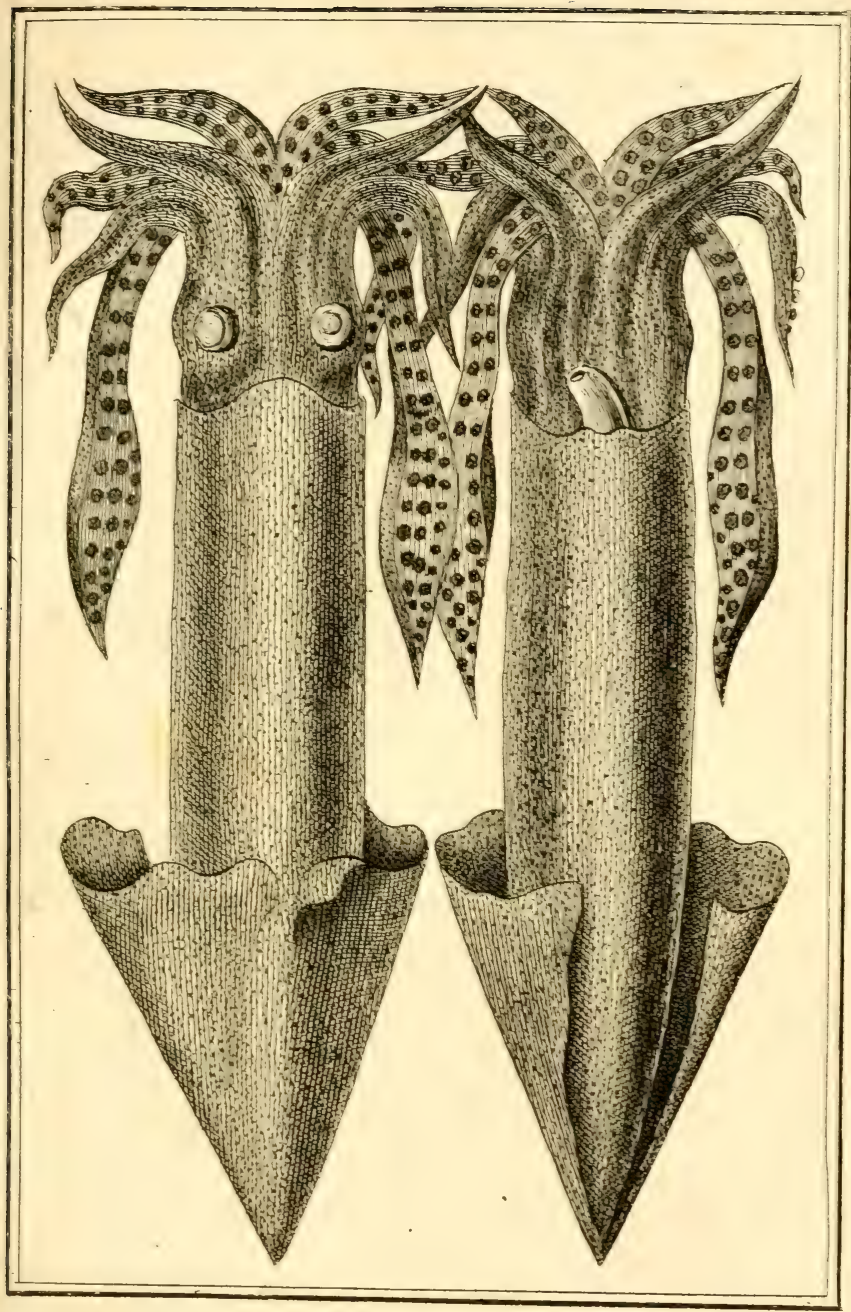

$$
\begin{aligned}
& \text { I Calmariavelat. }
\end{aligned}
$$

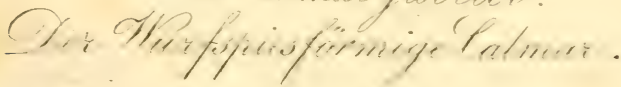





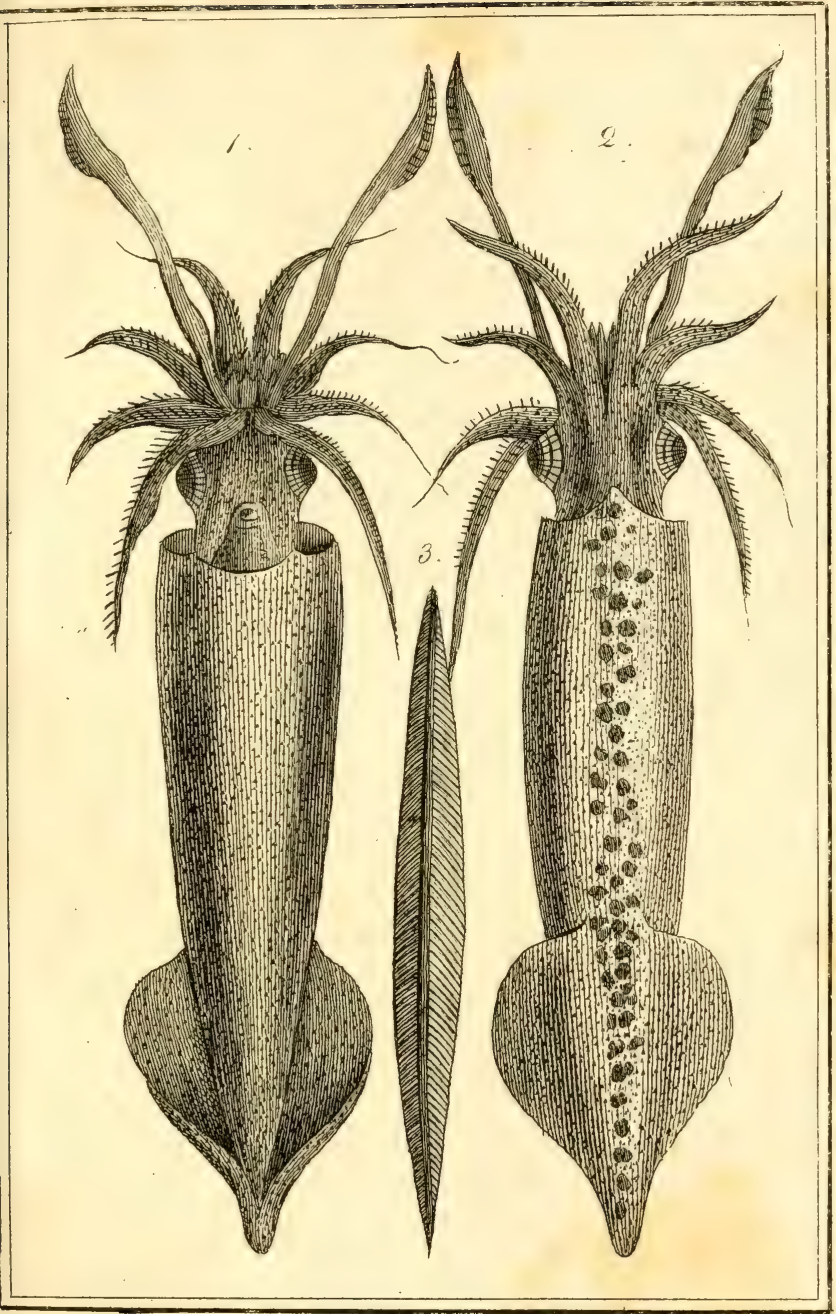

ie Colmar dard.

Iner pfeilfömiar Calmar. 



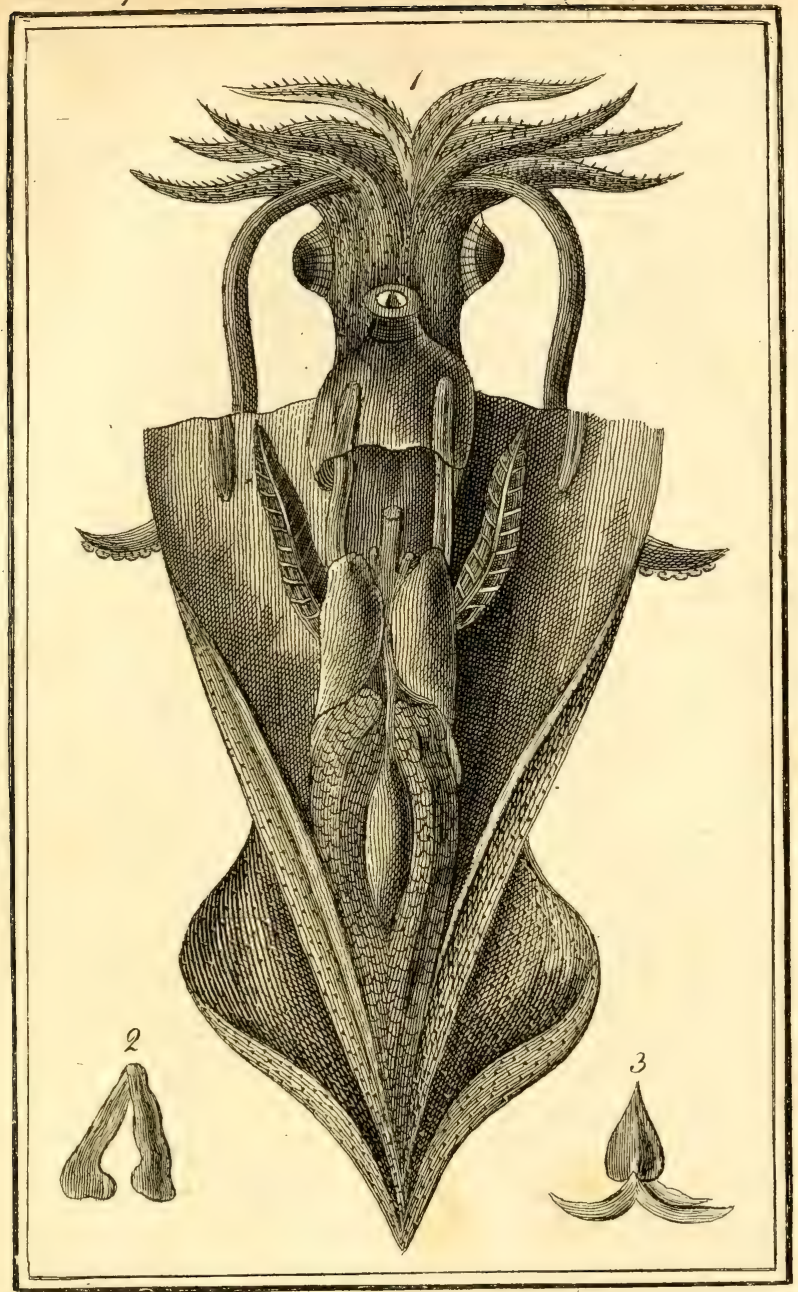

Intérieur du Calmar dard.
Otós. Innere des lefeiformigen Calmars. 



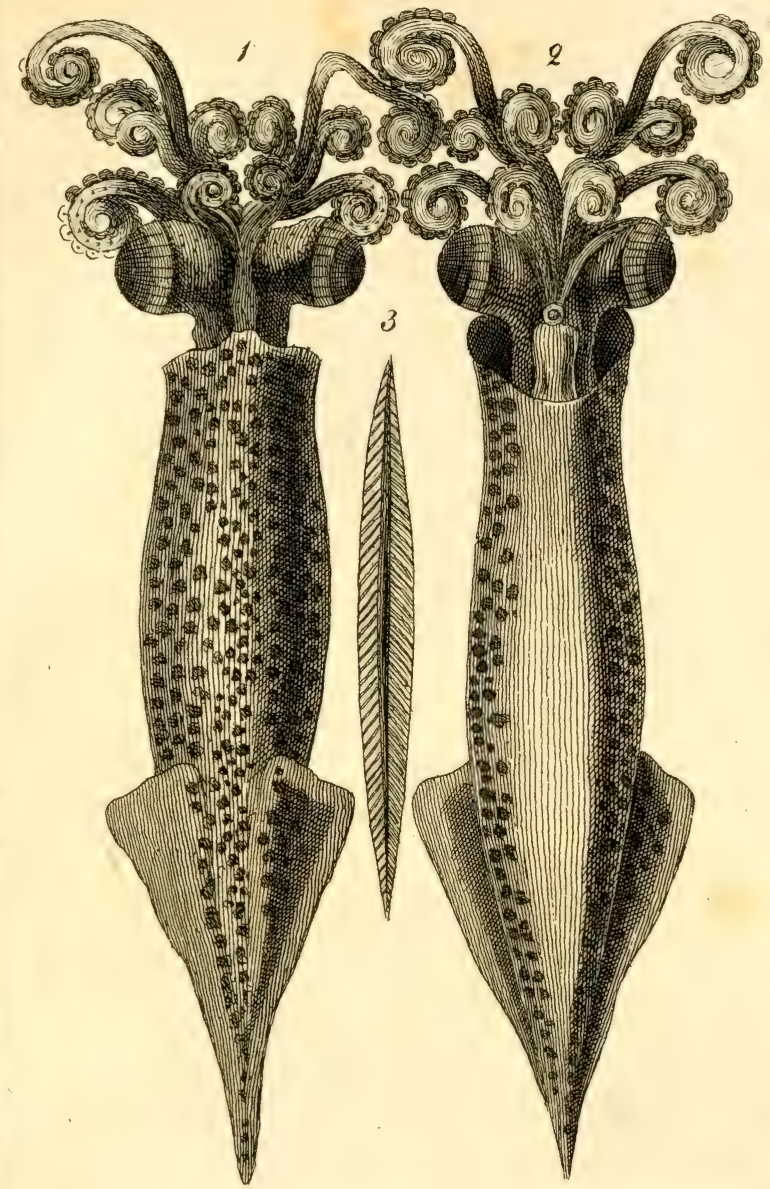

$$
\begin{aligned}
& \text {-Pe Calmar contourne'. } \\
& \text { Oter verdrehte Calmar. }
\end{aligned}
$$





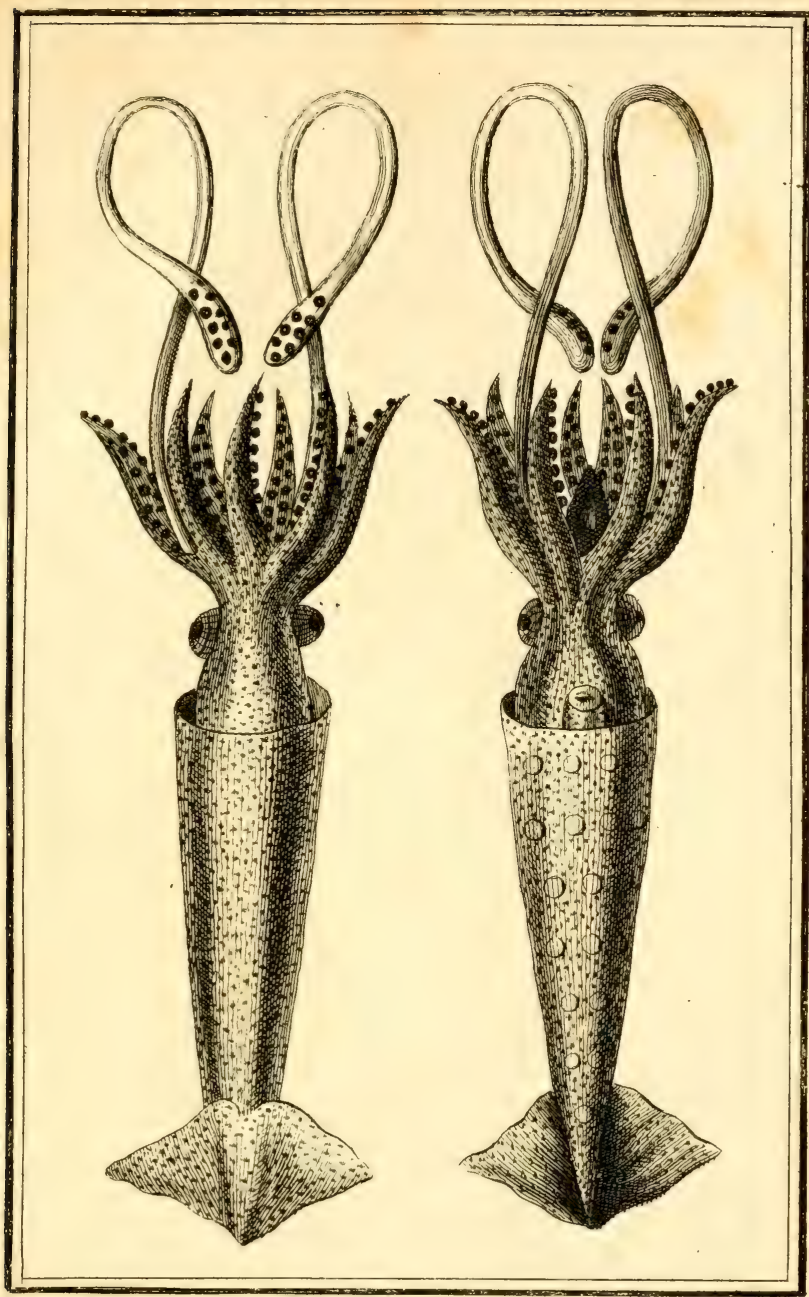

$$
\begin{aligned}
& \text { Se Calman piélagien. } \\
& \text { - Der pulaquiche Calmar. }
\end{aligned}
$$




2011

$283-48$

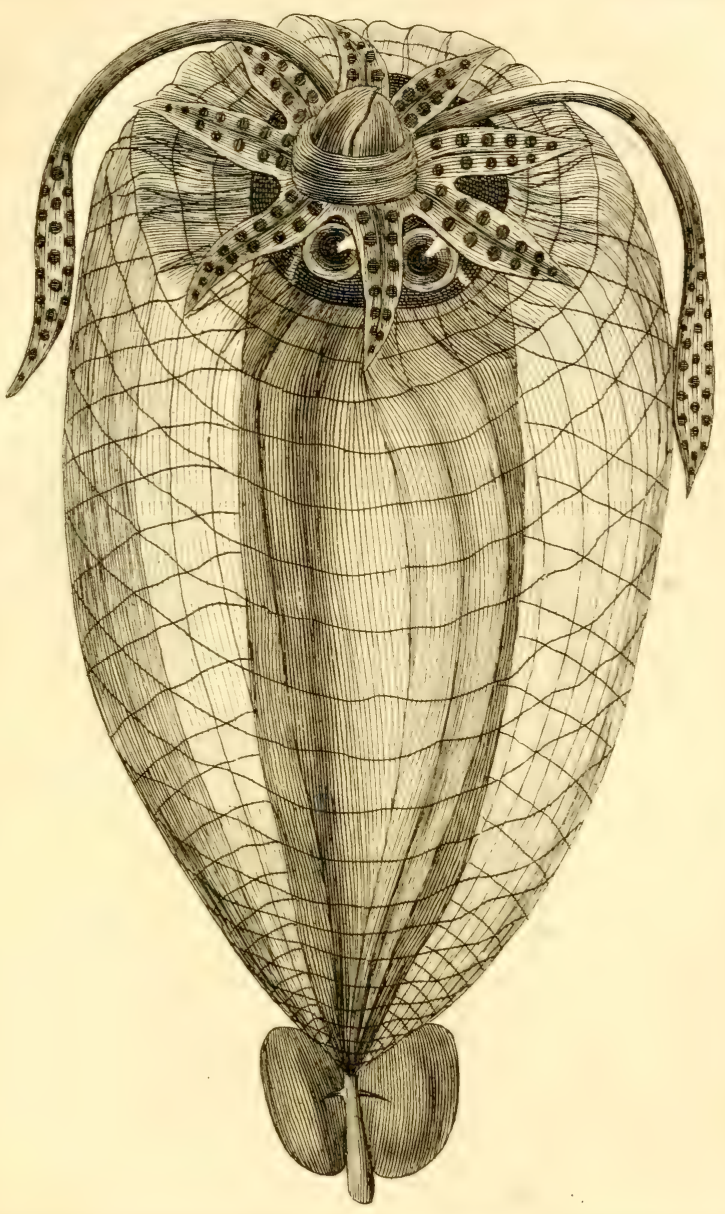

$$
\text { De. Galmar Réticulé }
$$





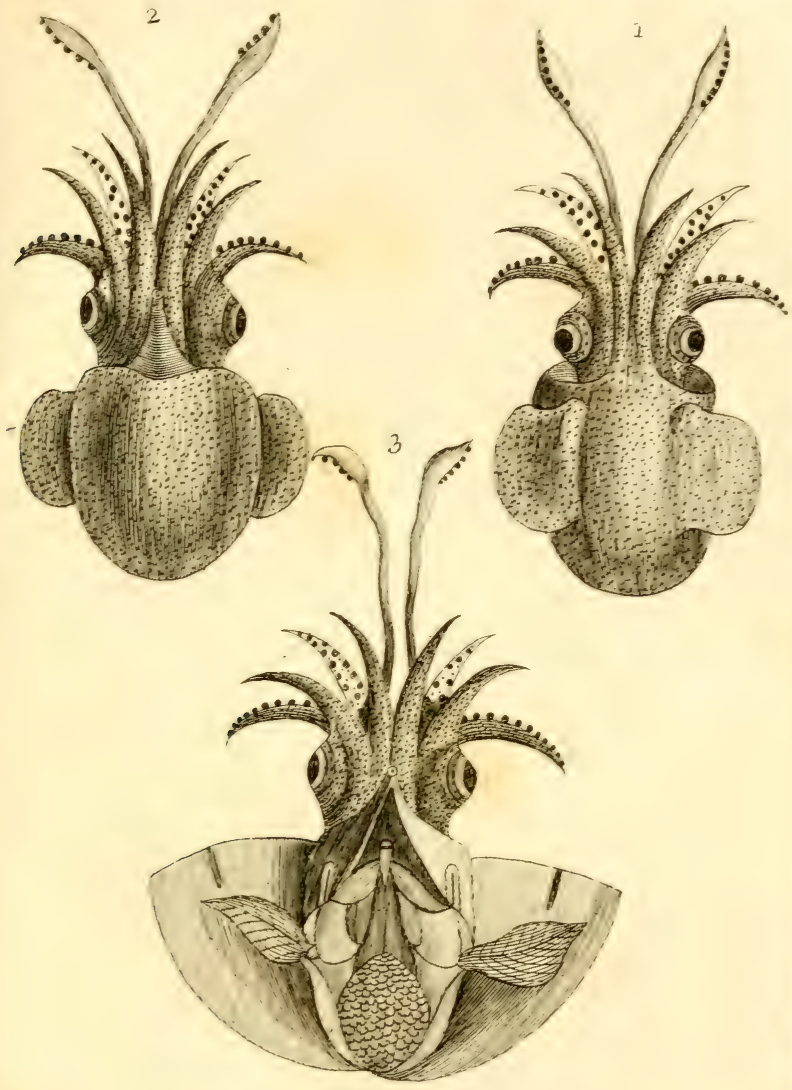

Se Colmair Pépiole

Oor Sinterifurte Catmar 


Q 1.24

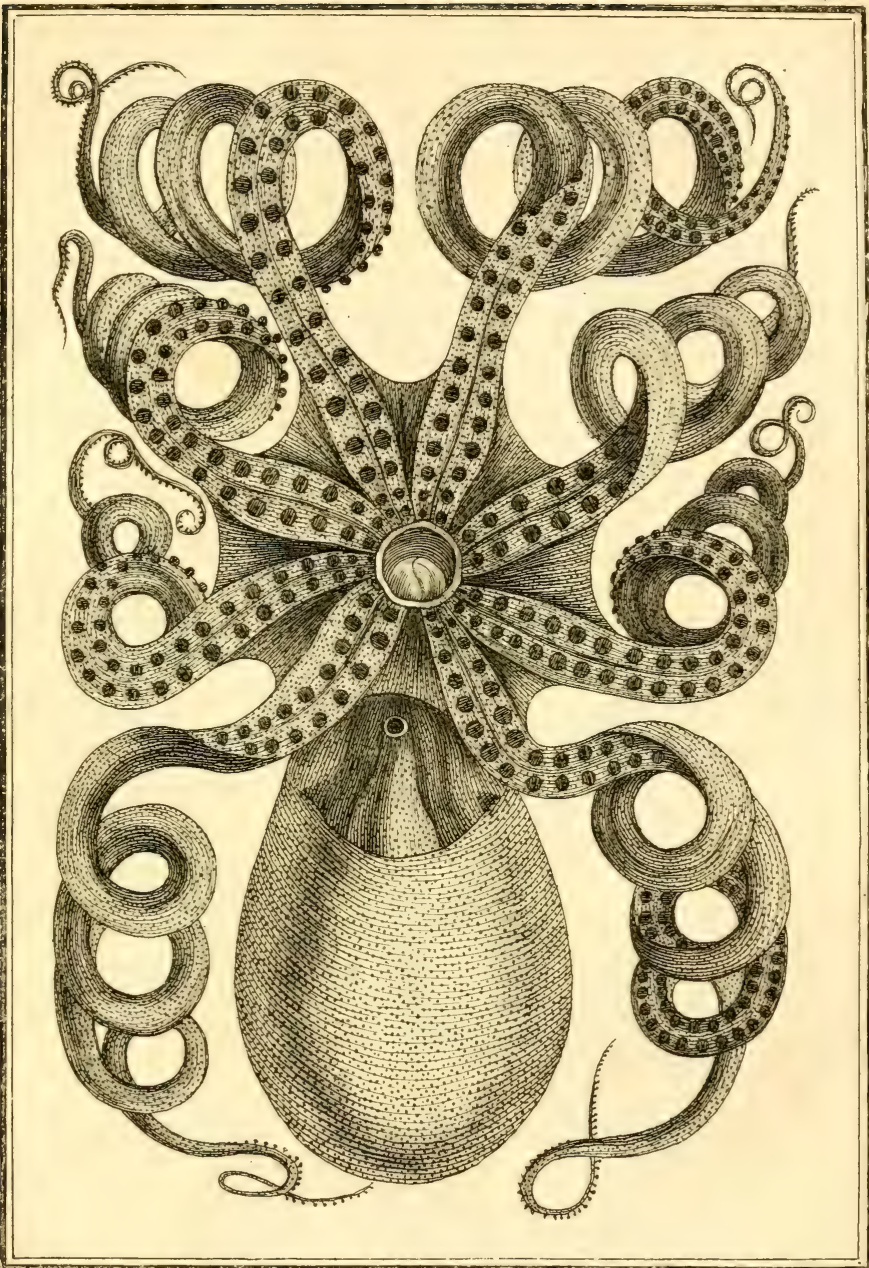

Le Loulpe Commun un par-devant Der Gemeine Lolÿp von der Vorderfeite 



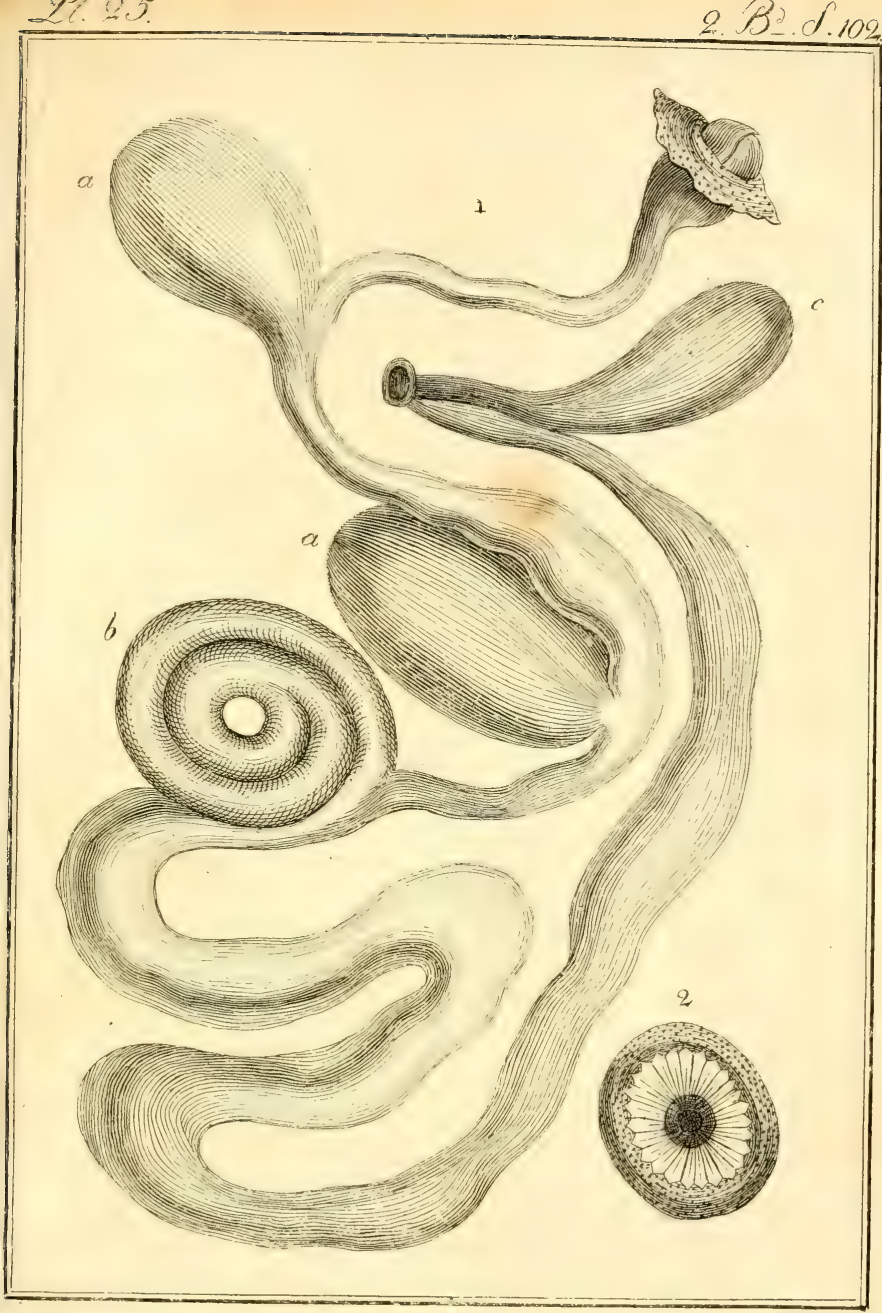

Conduit intestinal ct une Cupule du Poulpe. Einqueveidegung des gemeinen Dolypen netft
dem Jaupchen. 



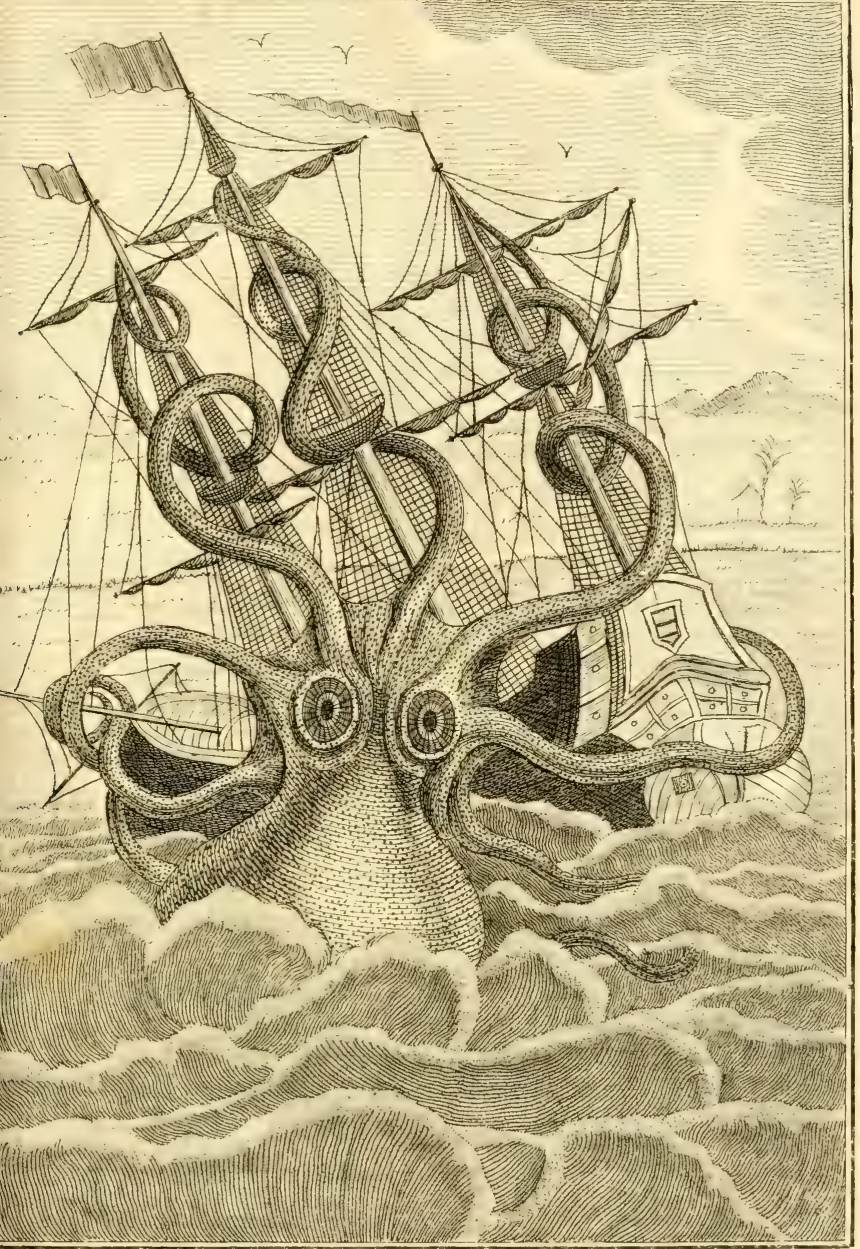

$$
\begin{aligned}
& \text { le Goulpololofsal. } \\
& \text { Ser stiefenpolips }
\end{aligned}
$$





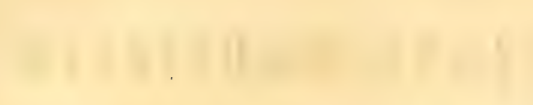

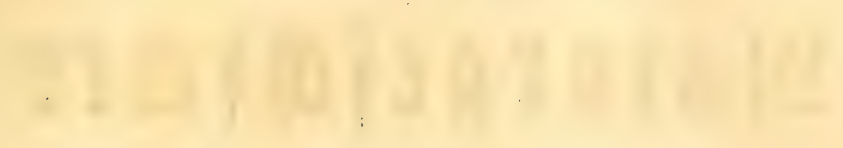




\section{Den y $\mathfrak{M}$ ontfort}

allgeineine und befonbere

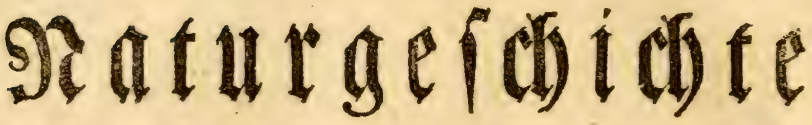 \\ DeE}

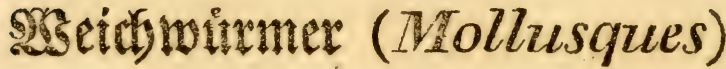

\section{ก 1 .}

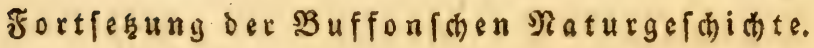

\section{S) it einizen}

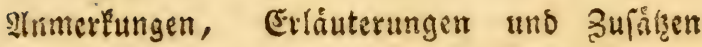

$$
\text { bera }
$$

บD

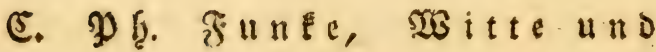
$\mathfrak{M} \mathfrak{\mathfrak { l }} \mathfrak{l} \mathfrak{l} \mathfrak{e} \mathfrak{l}$.

\section{Dritter Sans.}

פzit vie!en $\Omega$ uffer

\section{Shambirig und Alttona,}

bei Gottfries Bollmex.

2808 . 


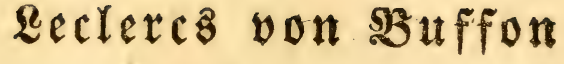

allgemeine unb befonbere

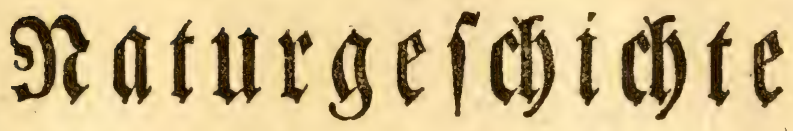

$$
\text { Fortgefert }
$$

yon einer Gejellid)aft won Gelehrten

$$
\text { uns }
$$

beraugegeben oon Sonnini.

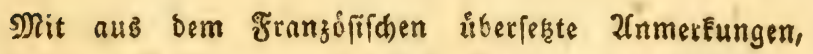
Erláuterungen und Surák̨̧en vermebrt

von

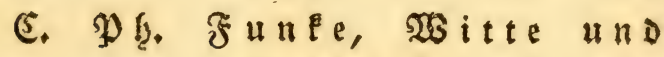

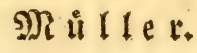

Dritter $\mathfrak{B a n d}$, Mit bielen $\mathfrak{s}$ uf fex

Şamburg unb Altona, bei \&ottfice Bollmer.

1808 . 



\section{$\mathfrak{B} \mathfrak{O} \mathfrak{x} \mathfrak{i} \mathfrak{d}$}

Die 2uffaline, welde Monfouts in siefem Sambe hiber bie 2fryonmen insbefondere liefert, firto Dem Freunde Der Datur und Den Taturfor:

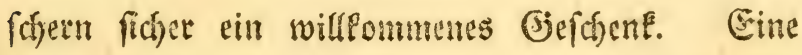
Heberfegrung im frengften Sinne Des SMorts, Follte Diefe Şearbeitung Dis franzoffichen Sertes

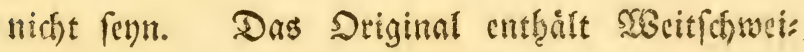
figfeiten, Die unbefádet der guten Sache des

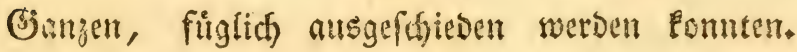
Es fino Dadurdy fur die Serftandindthereit feine Lidfen entfanden unb von Dem soiffenswurbigften ift Dem sefer nidgts verloren gegangen. Eolten

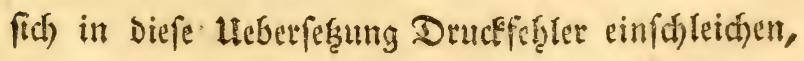
wooutch der Sinn etwa entferft a. f. w. whitbe; 
fo trågt Der Heberfef̧er feineswegs barin Die Shuld, Da er yom Drucforte entfernt lebt. Midchte man ben Der beurtheilung Diejer Uteber:

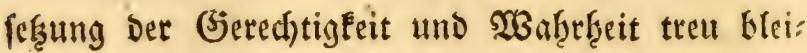

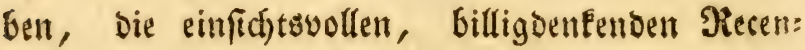
fenten fetts zu firhteretimen Dienen.

Den 26. Iprill, 1808 . 


\section{Snhraltsuerzeichnißs Des sritten Bantes.}

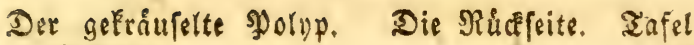
XXVII.

Ez gieb̆t ein Sndiviouum, im 2 singeift nufh:= wahtt, unter ben Pुolnpen in ben Siltan Des Mu[cums der Naturation.

Beftyraibung biefes গুolyper.

Er rúhrt auz ber Sammlung bez פgrinz?n von Sranien ber.

Er ift bem Publifo idon burch Fótreutern be: Eannt gemadt worben.

(3)efrákigkeit yon biefem গুolnpen, welther bie Eits ten aller Molluzken biefer 2frt bat.

Der gek̂råuflte Doolnp geofnet uno von vern gefehn. Trafel XXVIII.

Ex bat wenigftenz sine 20 cite von viet Fub.

Die Beichichte ber Seetliere ift nod nitht hins 10 reiberno befant.

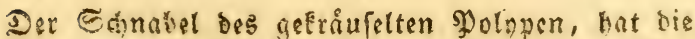
(Geffalt, wie ber Ed)nabel ber anderit פgo= Inpen, 
Er ift in bom griechifhen Mecre cinbrimi\{d). Seite 14

Erftlinung Der XXVII. und XXVIII. Tafel.

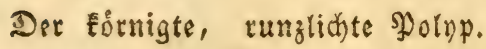

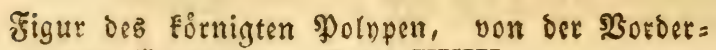
uno Şinterfeite. Tafel XXIX.

Seine SEephreibung.

SOb ar gleid) cimen Eleinen $\mathfrak{B} u$ the hat, fo iff er wegen feinar nabefétender Eajropfépfe boch furd)tbar.

Er ift, wie alle Nolluben, ein verwiffendes Ihier.

Seba und die Encyelopedie, haben folschte Fi= guren von ben פolypen geliefert.

Erellirung Der XXIX Iafer.

Der amerifanifthe פুolyp XXX. Tafer.

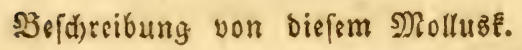

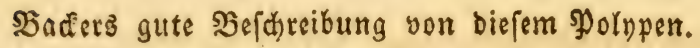

Die Slafe eines biefer \$yolnpen, ber wabrfhein, (id) sin Minnchen war.

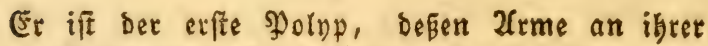
Safis burd Eeine Şaut verbunden finb.

Erflairung Der XX. Tafel.

Tafel XXXI.

Der झুolyp von arbrovanbi. XXXII. Tafer. 30

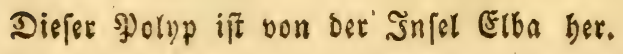


Seine Bephroibung.

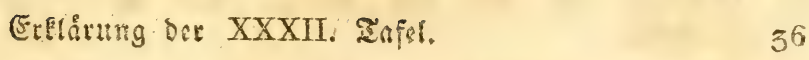

Der gelodita গুolnp. XXXIII. Infel, 3 ?

Ceine Bafüreibung. 59

Ereli̊rung Der XXXIII. Tafer. 41

Der Mušępoinp. XXXIV. Tafer. 42

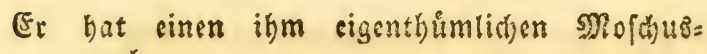
geruct).

Seine Befdreibung.

Eamar bat ifm bem \$ublifo befannt gematht. 4.5

Er ift yon Marechal geftodhen.

Die 2flten apen inn.

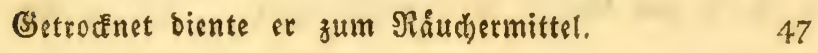

Erelárung ber XXIV. Iafel.

Der mit Rlauen verfekene Molnp. $\quad 48$

SBefdreibung depetben.

Molina ift ber einzige, ber ifn betannt ge= macht hat.

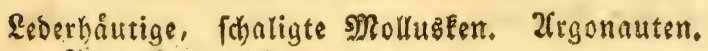
Shre Sennzeiden.

Der Sgapiernautiluz mit aufgefpannten Gegeln. Infel XXXV.

Die Reuern glaubten bns Dafenn yon biefen. शolfuge nict)t. 


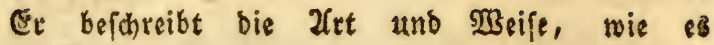
fowimmt.

Nutianuz, ben \$ुlinius anfưhtt, hatte biefes Molfuş fegeind im Sanal von Conftantino= pel gefelln.

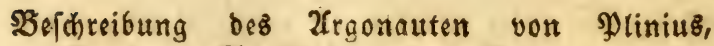
sppians Sabiloerung bes 2rononauten in Berien:

2lthenåus will ifn (ben 2(rgonauten) nid)t mit ben gewoifnliden Şolypen verwed)felt wiffen.

Nach bem 2triftotelez, befthreibt 2felian von allen alten Soriftifellern ben 2frgonauten aufz bepte.

Selon färieb unter ben Neteen zuerfí ůber bie= fen Gegenftand.

Fonbelet unb (siefrer folgten ifm nach.

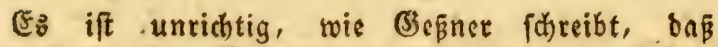
man ben 2frgonauten aud an ben englifchen Siuften finde.

Zlbrovandis Unterfud)ungen úber ben 2argonau= ten fino faft alle critifa oder blos lites rarifd.

Softon copitte bie fehlerhafte Figur bez 2frgo= nautear von Zlorovanoi.

Rumphius theilt unz bie (sefdrid)te bes 2 trgos nauten mit, ben ex auf 2 mboina offer fab.

Selbft an ben sioften von 2 mboina finbet man ben Árgonauten felten. 
Die Irgonautenmufdern finb in Snbien theuer. Seite 88

SBismeiten wetben bie 2trgonnuten bie 93 sute bet Siatboóget.

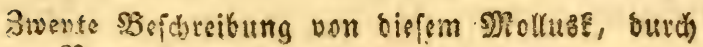
S?umptíuz.

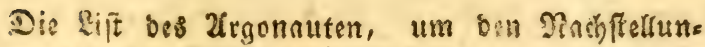
gen Der Jifcher zu entgeter.

Eet prişt $\mathfrak{B}$ affer auf feine Feillos.

Bin niebliches Mietnillon, bas ben Zegonauten vorftellt, mit Dem bas $23 e r s$ vom Rum= phius auf bet erfen Ecite gegiert ift.

Bualtieri vermandelte bie Rafmen şapienau= tiluz un' 2legounute und nannte ihn (S)onde!.

Lifter yat 2tronovandis 21rgonauten copirt.

De Sonen hailt bas Thier begs 2rgonauten firr ein beforderes smolluỏe.

Satuiguieres glaubte auch, baß ber Betwohner biefer Muldat ige wabrer Eigenthimer wåre.

Lamark war nidyt feiner Meinung.

101

102

Faft unůberwindiche S(b) Urgonauten zu bemåd)tigen.

104

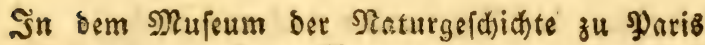
finbet man zwey argonauten.

Befchreitung, wie ber 2frgonaute forift.

106

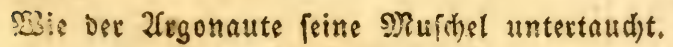

106

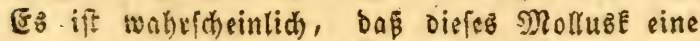
Syortion Ruft in fich verbergen tann, wie $p 8$ auth) anocre Gestewobner thun. 


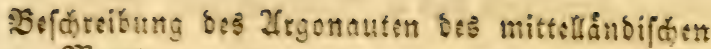
2)ไกстร.

Esite 108

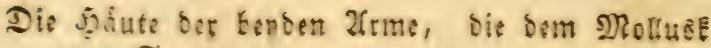
รुนm Eegeln Dimen.

Die iments Siloung ber Xrgonauten ift ber bor

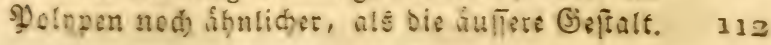

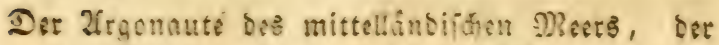
3и Grumbe geht. Tajel XXXVI.

Eyar, die bas $\mathbb{B}$ bibden in ber teeren Etellung

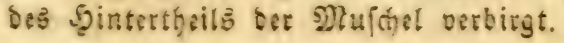

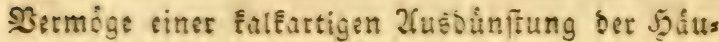

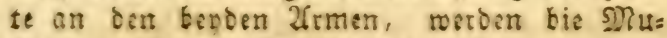
foteln gebilbet. Sie Urfactes, marum einige

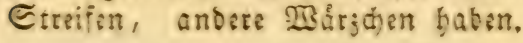

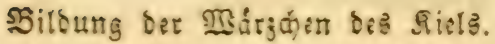

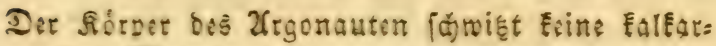
tige Naterie aus.

Witle idfalige Noltusken flingen mit ifren Nus fd)eln nidft sulammen.

Wie bie andern Edalthiere, iff ber 2rgonaute mit fainet Mufdat ver[afn, eh er aus Dem Ey Eómmt.

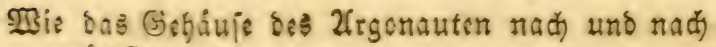

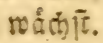

Dise Moltust vermsibet bis Iiefen, two Gelfen fino.

Dis Neere, wo man biefes Molluse antrift.

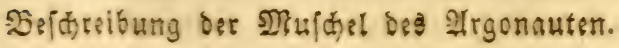

Sitten bss argorauterr. 


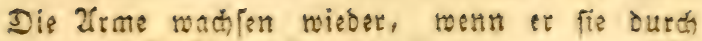
einen సufall verloren hat.

George Ehato bat in Englano ben Xigonauten

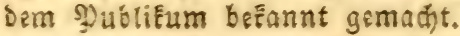

Bey den 2ften war Der 2lrgonaute bsilig.

Erelårung ber fủnf und orenfigiten Rupiettafer, bie den Papiemautilus fegelno vorfellt.

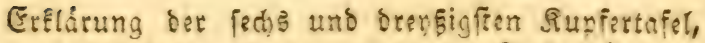
wo fich der Alrgonate in bie Tiefe fiutzt.

Der Misiätron. Ciebon und brengigfte Iafet.

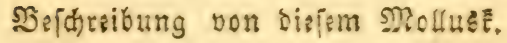

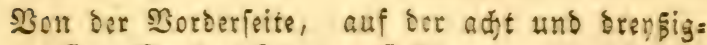
İen Sitpfirtafel vorgeftellt.

Wie Nuphet biefp Irgonauter. XXXIX. Tafer. 145

Die Utrad)e ber fibener auf bat Müübel.

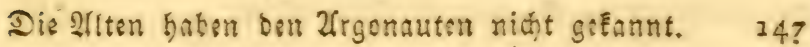

Nan glaubte, fï flome aus ben inbifaten Mleeren, 148

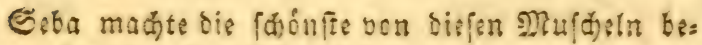
Eannt, Die wir Eennen.

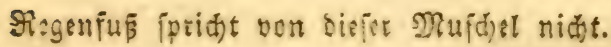

Es ift fobe wakridsintid, bas fir aus ben afris fornichen Neeren formmt.

Evflitung der XXXVII, XXXVIII und XXXIX. Sippertafel.

Dir geofrte- SIrgonaute.

Dot Irgenaute mit unterbrotienta ซuthen. Iafs! XL. 
Sann ber Alrgonaute nad Selieben feine Mufdel verlaffen und fich eine andere baun? 160

Eretårung ber XL, Rupfertafel. Der 2frgonaute mit unterbro(t)enen ซurd)en.

Das Rófdpapier.

Ssine $\mathfrak{B e f h r e i b u n g . ~}$ $36 ?$

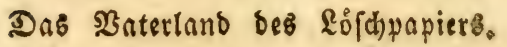
167

Der verfruppelte Alrgonaute. 368

Seine Seporeibung.

Der zunelfmento Alrgonaute.

Eeine Befdrreibung.

Die Safferforafel.

Der 2 rgonaute yon Rimini.

Die verfteinerten Irgonauten fino felten.

Der faltige Alrgonautite. Tafel XLI. హigur $x$.

Der geftirnte Argonautite.

Der gefielte Irgonautite.

182

Der glatte 2frgonautite.

Cretlatung ถet XLI. בafel. 




\section{Den ที : Montfortz alfgemeine und bejonore \\ $\mathfrak{N} \mathfrak{a} \mathfrak{t} \mathfrak{u} \mathfrak{x} \mathfrak{e}\{\mathfrak{d} \mathfrak{i} \mathfrak{d} \mathfrak{t}$ \\ Der}

Weidjwưrmer (Mollusques), FĢiere of̣ne Rlic: grad, mit weiffem Solut.

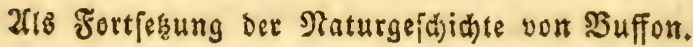

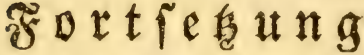

Der Beflidhte Der Polnpen.

Der gefråufelte Polnp. *)

Le Poulpe fraisé.

$\mathfrak{D}$

ie (seichichte ber Riejenpolnpen, fülyrte unb bis

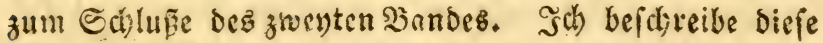
befannten Rospermaffen weiter nicht uno felge nun zu

*) Poulpe granuleux, octopus granulatus. Octopus corpore tuberculis sparsis granulato, cotyledonibus crebris biserialibus, Lamark, Mem. de la soc. d'histoire nat. de Paris an 7. p. 20. Polypus marinus, seu octopus Karakatiza Theoph. Koelreuter, nov. Comm. acad, Petropol, tom VII. pag. 321. planch. XI. 


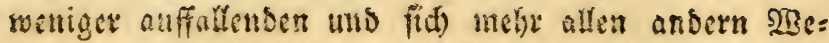
fen nabenoen Geftalten zurúd, mit benen uns bie Patur umringte. Treu bem Gange, ben fie uns fe!bft

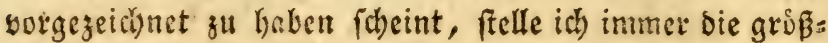
ten Thiere berfelben 2reten in ben Mittelpunft ber SRaffen, Die Sab Ganje Diefer Geid)lechter bilden; Die, an benen fie ben galzen Jieid)thum einer Drgas nifation entwidelat za wollen id)ien, zu beren hódhffer Bolfémmenlyeit bisfe Platur nur Edyittweife uno burch bie unmerfliche şermehrung aufferer skeile gelangt, um bann burd) ebett fo auf einanber folgende 2 tbitu=

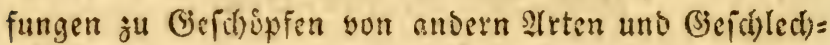
tern überzugeten, in beren gitte fie ihre Echattirun= gen von neuem abinbert und burch anbere Mittel uns

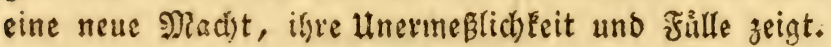

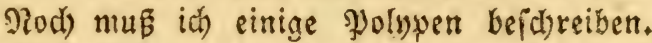

एా

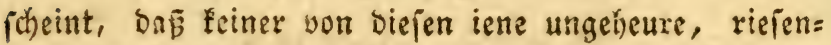

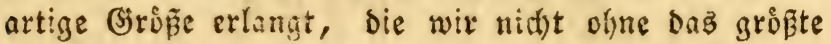
Staunen wafrnelimen fonnten, und die man bezweis

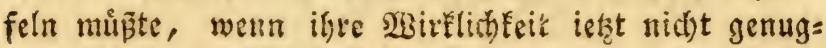

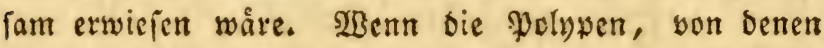
id) iefzt reben will, nads vielen Gahren unb ber läng=

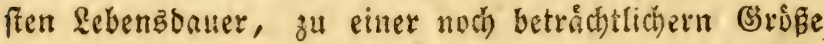
foumen, fo entrernen fie fid bod) nie, wie ber rite= fenpolyp uns ber Serter, won ben Orenzen, bie nut fie allein auf be: cerbe in ser thierifinen Edjops fung biz iekgt zu hiverichreiten fồeinen.

Det gefråufelte Wolywe iff viefleidnt einer ber aufiallenoften won alfen feinen (Sejd)led)tzestwanden;

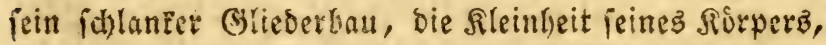

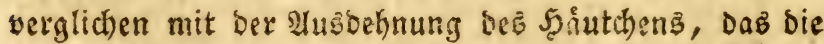
Ilrme am feibe mit einander verbindet und wenigftenz żweymal långer, als ber אưrper, ift; feine verlån. gerten 2lime, bie auferorbentlich biegiam, getrumt 


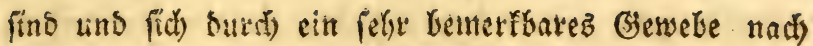
ifyer ganzen sånge fortietzen uno mely alB biejes noch,

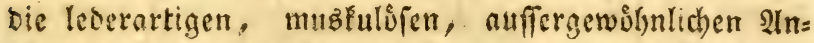
binge auf bem Ridten und unt bie 2lugen: furz, alle Diefe Merfzeid)en zufammengenommen, machen ben ge= firuluelten Molyp zu ciner befonbern Sirt, bie, wenn man fic nafher unterfucht, mit feinem andern ahiere feines (Be Den id) gezeicthnet babe und ben id) bem Iluge bez

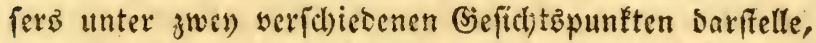
befindet fich in ber Euftlichen Sammlung ber Begen= frinbe ber Praturgeid)idste, bie bie Galerien bes botas

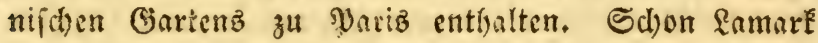
ftellt ilin als eine bejondere 2trt auf; *) allein aus

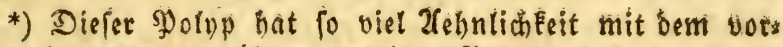
hergehenden, (Dem gemeinen \$Jolnp) Daß̧ er vielleitht

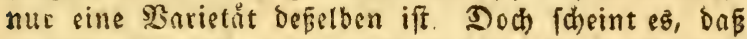
ex nicht fo gró mird; und da feine Scaut fohagrai= nirt ooer fórnigt iff, fo ift Diefe Esigenthumlichesit, soenn fie fich nidt verliert, vollig binreichend, um ben fórnigten (gefråufelten) Şolnp, yon bem ges meinen Spolyp zu unteríd)cioen ....

- Die bey ben Individua biefes झुolypert, vie id in ber Eammlung Des \$uleumg beobachtet habe, fino meit grofier, alz ber Sepia rugosa (rungligte Bintenfifth) von Sofe; oennoth fheinen fie

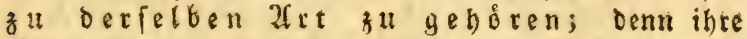
(S)lieberhiloung ift faft diefelbe, wie bie bez runz= ligten Dintenfiferez. Diefer Dintenfifen von SBofe, fiatt eigentlich) runglitht zu fern, wie ifn fein eigen= thumlicher Nabme failbert, bat nur, soie mein ges fro̊nfelter গু) Doer S3arzchen, bedeciten Fórper. Davon Eann man fich felbfít ưberzeugen, wenn man bie Figuren und bie $\mathfrak{B e f ( h r e i b u n g , ~ d i e ~ B o f e ~ v o n ~ b i e f e m ~} 2 B e i c h=$ wurm (Mollusque) liefert, nåber prúft, Die A 8 
Der IInzeige, bie or bason giebt, fielyt man, Saßz cr

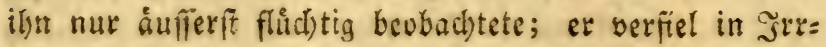

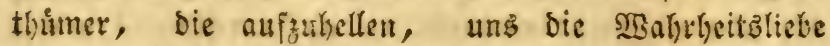
allein Eerbindet. Diejem berifynten Meijen, id) wies berlyole es nochmals, verbanfe ich) alles, ex liberlifipt

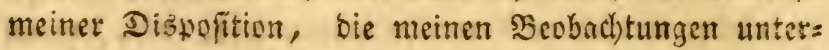
worfenen Begenfiunde; biefe Giefalligfeit allein giebt mir die Erlaubnis̃ , Dem, was er geid)rieben, nod) etwaş binguzufígen, und mit cinigen neuen Fanctis bie gu vermehren, bie er effentlid) befannt gemadyt hat. Eben baher barf ich mir'z yerzeilyn, wenn ich nicht bejtinnbig jeiner meimung bin.

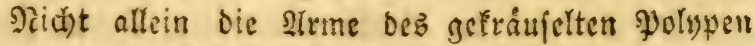
find unendlich långer und aufgefåpelter, alz bie iebez andern Wolypen, aucl fein sorper uno fein Siopf ift nod) mit mustulijen uno (el) meristichen fleifdigten IInhången vesoarinet: auf feinem suicten nimt man becy) Derlángetungen waht, bie triangelformig felehn, moyon bie cine aufwirts freigt, bie andern nad) Den

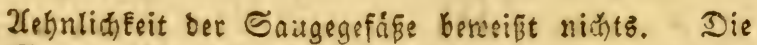

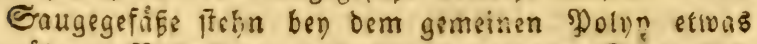
nåher. Bofe fagt, Daß pein runjlichter Dintenfifoh aus ben benadgbarten Neatan von Eenegal ber= formmt und vermuthet, Das bies die rothe, wohl= risdente 2fat fery, yon ber bie Elinefen bie dines filthe Dinte erhalten. (Lamark, Mem. de la societé d'hist. nat. de Paris pag. 20.) WBir bemer=

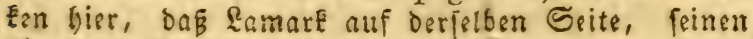
fånigten গুolnpen wie Şofi, Sep̉a rugosa, nennt (Act. soc. hist. nat. pag. 24, planch. V. Fig. 1. et 2.); alfein wir wollen bewsifen, on ber פolnp, ben mir befdreiben, ber berfelbe ift, bon bem $\mathfrak{L a}=$ matk (prid)t, nicht bet rotbe Dintenfifch yon $\mathfrak{B}$ ofe (ev), fondern sine offenbar verfchiebene 2frt auss matot. 
Eciten hinfallen; ben (Betbrauch, weld)en baz בhier bason macht, fenne ich nidjt; aber alle Beobad)tun= gen, bie id) anfeflen fonnte, baben mich feine SRåpf=

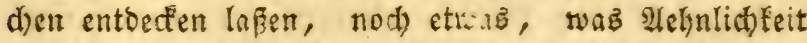
mit ben Sdropffiufen lat, ober audh nur an ibre Geftalt erinnert. Diefe fleifibidten, ein wenig plat=

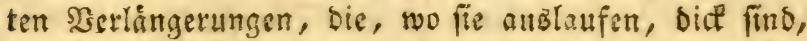
enbigen fich in eine Spitge und (d)einen fid) zu[am=

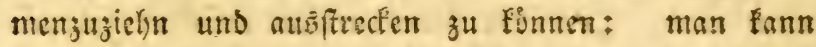
glauben, daß fie şulf me, bie, indem fie fith) mit ben ad)t strmen, bie den (E)arnter ber polypen atismachen, verbinden, bie

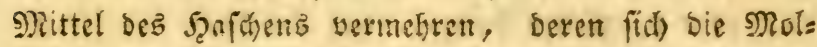

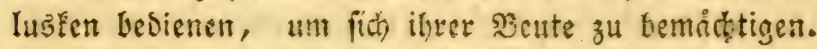
Dieje bren muglulujen Erkabenbeiten, Die bey bem Inbivibuum, was id) yor mir babe, einen balben 3oll lang find, find nicht bie einzigen Seionderlyeiten, bie mich veranlaßen, Den getriulelten झolypen von allen andern Srrten zu untericheiben; andere hersor= fpringende, werlangerte unt fleifoigte fortiåtze, bies

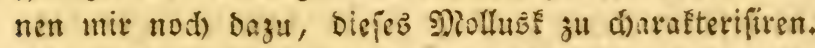

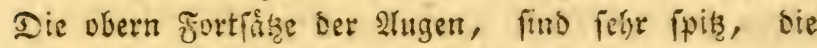
untern, nod) linger als bie Erhabenheiten auf Dem

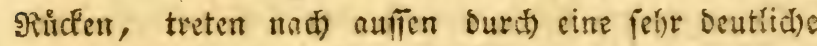

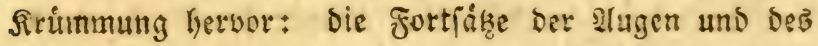

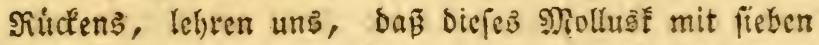

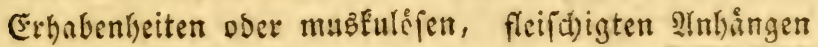
bewaffnet ift; ein hervoripringendes uno bemerfens:

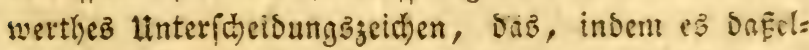
be von anbern glolypen trennt, baraus unter ben ant=

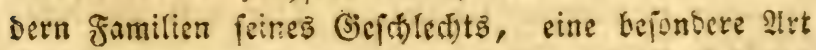

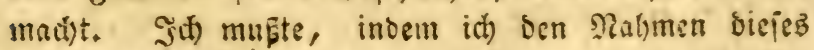

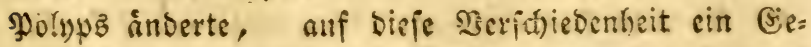
wid)t legen, und ilyn einen sabmen geఏen, Der auf 


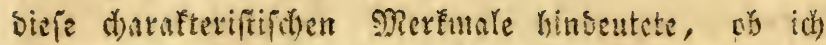
gleid) innig uberzeigt bin, baff bie Nerinberung bev senenming, immer nelye obei weriger 3iveifel uno

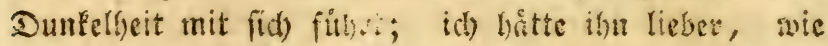
Samate, benannt, ob basurd) aud nat bei (Eharates Deb fornigten פgefene (granulosité) angezeigt wiro,

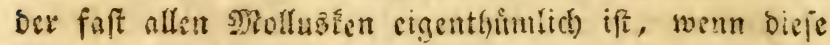

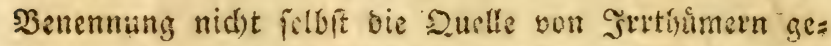
wejen whire, bie diefen Taturforidjer verfinlyt haben,

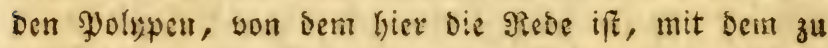

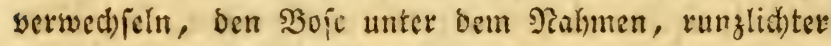
Dintenfifit), anfưflut *); aber ber runglidte Dinten= fifich, oder runzlichte Syolnp, wie il)n Bofe gezeichnet hat, exid)eint olye Innlánge; unb wenn id) ihn be=

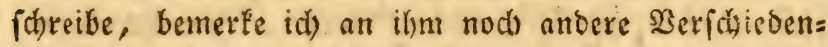
heiten, die es unz nid)t mehr verftatten, biejen \$yo: lypen nit einer und berielben art zu vermensen.

Der gef́råujelte spolyp, Den unz bie XXVII, Sup= fertafel worfellt, won binten betrachtet, befano fich in Der Sammlung bes Srinzen won Dranien; in Dem

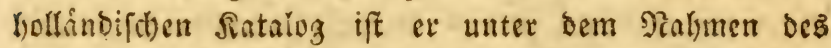

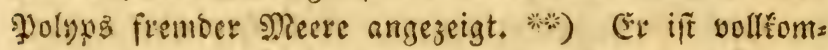
men eikalten; itnd of feine 2(rme gleid) ieste noch, oa fie eingezogen fino, meht als brey fü . cirranber baben, fo gleid)t ber fiorper bet Grofépe einez

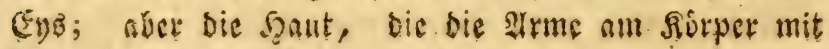

*) Saepia rugosa. Bosc, Actes de la societé d'hist. nat. de Paris. I, pag. 24. pl. v. Seche granuleuse, sepia granulata. Le meme, Hist. nat. des vers tom. I, pag. 47 .

**) Vremde Zee veelvoet, Nro. 120, vol XII, F. Catalo:gue manuscrit du Stadhouder. 
cinander wetbinbet, if bagegen fehr weit ausgebergnt; benn fie ift zweymal linger, alsె ber Rơrper; Dieje

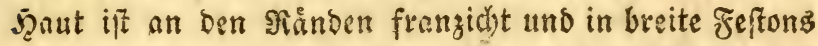

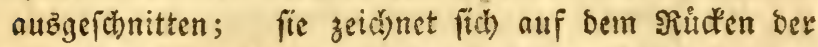
acht Sirme, wie cine Sarte, so nuan fie bis zu ben

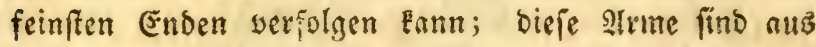
Der platten: Seite mit zwen Reihen Släpfhen bewaff= net, bie in berfelben stonung, wie bie ben bem ges

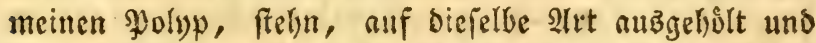
binreichens yon einander entfernt; biefe Sdurupffeppfe finden fid) nach ber ganzen Range ber 2 (rme hin, Die, wie wir gefagt haken, fehe ausgefåfelt und aufferor= bentlid) lang find. Stuf bem (S) unbe find fie trid)= terformig serengi, fo zuliammengezogen, Då̃ eริ un= muglid) ift, bie Rippen und ben Schnabel walyzunels=

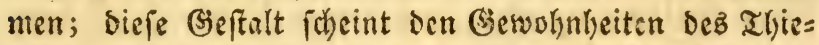
res̉ angemeffen zu ieyn. Sein Sopf ift feitwårts mit

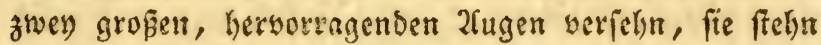
in einem Sreife, werben Durd) zwen fleifhigte (Errib= hungen befdhittzt, cine oberwirts uno cine nach unten.

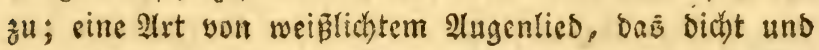
faft bornartig ift, fteigt won unten nad) oben auf, be=

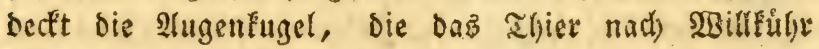
Effinen und serfchliegen fant.

Unabgeflyn bev Unebenbeiten, ober fornigter SBárzben, mit benen ber gange Rlaten uns sin Theil ber Şaut, bedecct ift, mus man hier nod) eine Art yon neşformigem (setwebe bemerten, leid)t wie Fifich= fohupen bingeworfen, weldes man auf ber ganzen

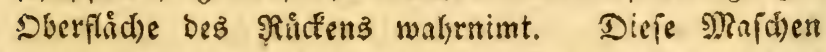
werden uns dazu Dienen, den gefráuflten solypen auf Der Stelle in bemienigen wieber zu erfennen, won bem Rolreuter in Den neuen Serichten Der sjeterşburger

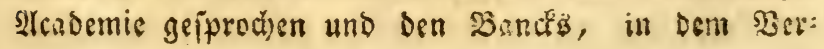


zeid)nip feiner fürtueflichen Biblinthat, angezeigt fat: bende verwectjelten ifgn inbes mit bem gemeinan sjou= lyp. Ein alseil ber Jubisibuen, bie ber erfere biefer Alutoren fcinen Sbeobachtungen unterwarf, war getrod"= net und bårter als ber, ben wir befd)relven, aber iene fo bemerfbaren 2ynginge, licpant fich noch beutlid) baran walyrnelymen. (5.s wire zu wurnchen getwein,

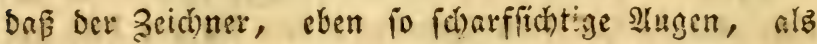
die Rolrentets waren, gehabt baben muchte:- Denn er hat bie IInhinge in feinem Bemålbe gan vergeb̉en; bey ineinem Jolnp fellen fie nicht; unter ben Fin= gern rollen fie fich auf unb belynen fich aus; inbem man fie zicht, fann man fie felbft bis zu einer gewif= fen leinge bringen. Lebensig mus man bas ahier ge= fekn haben, um zu entjdetben, worin ber (Gebrauch

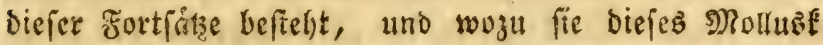
anwenbet. Selbft angenommen, daß fie weiter nid)ts,

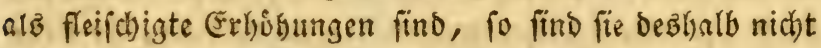
weniger fonderbar und unterid)eiden den getråufelten Syolyw, won allen ambern \$olypen.

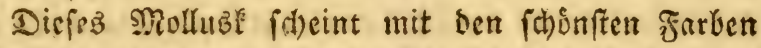
gefd)mictit geweien zu fern; ob fichb gleich) in bem Stambe Der Serwefung, Des 3ufammenf ocs Entfơubens befindet, bennoch hat "es in bem 2 bein= geifte cinige Ueberwefte feiner fonftigen Farbenishunbeit betalten. Nod) iff's won eitrem gelben, braunen uno rofenrothen Farbentemifa) ůberzogen; ein blaues, vios lettes Farbenlidit, fieht gegen weit hellern Schattirun= gen in Dunleln. Das fdonfte Rofenroth fheint Den

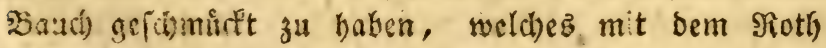
ber Mispfaren wo bem Sormin ber innern Jeaut, riwas Wifite.

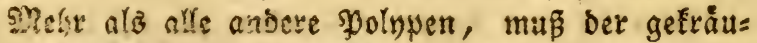
iclte yolsy wit bcm seremigen zu fangen, im vorzing= 
lichften Crabe, begabt fean; bey aller \$yroportion fins fei=

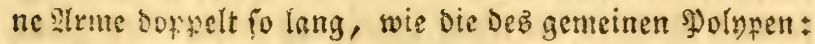
ba fie zarter, gffumter, folglici) biegfamer find, unr ichlin= gen fie, was fie croveifen, ungemein feft. Šn ein un= auflostiches Neds verwidielt ex fetme Beute. (E) fer nod),

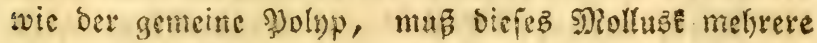

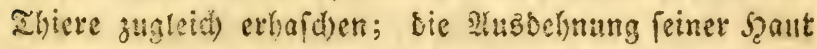

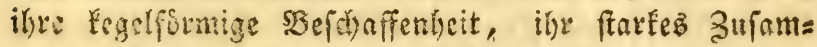

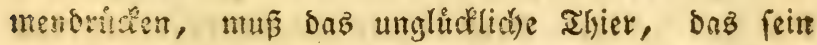

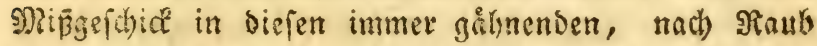

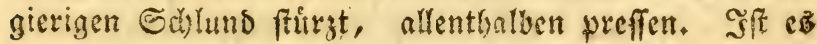
verichlungen, fo entzieht ifm cin lebrafter, unanter= brochener Druct, Das letzte Theilchen won feinen Såf ten, inbe⿱⿰㇒一乂

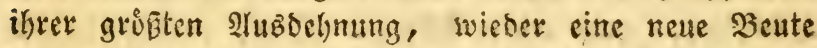

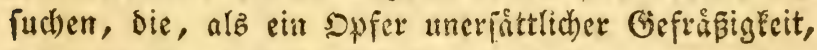
beftimmt ift, bapelbe Ectjictial zu bulden.

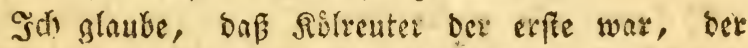

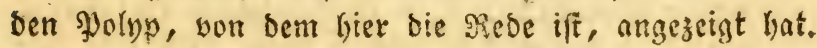
stber ex verwedjelt ign mit bem gemeinen spolyp.

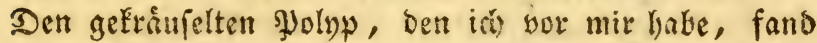
ich aufgeid)nitten. Er zog fid)er sie 2lufinerffamtest

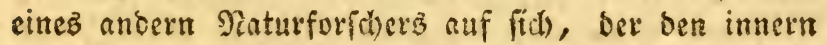

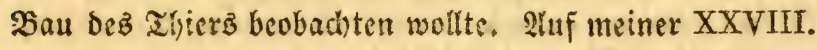
Supfertafel babe idl) bie sorginglid) fien (Fingeweide uno einen Theil ber innern sigane bargeftellt. Siur Rol= reuter fpricht won biejem \$ुolyp mit פeftimmtheit und auf eine Sirt, bie ifn fenntlid) macht. (Ex, a! Mit= glieb ber şeteraburger Alcabemie, erhielt fieben gefråu= felte \$olnpen zu feiner Dispofition; funfe waren an Ser \&uft getrodinet und bie innern abeile fehlten gang:

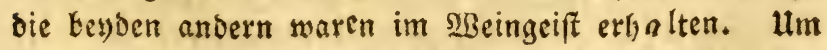

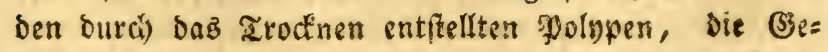
(d)meibigleit zul geben, bie se ifm erlaubte, fie zu 
beobaditen, legte er fie adjt Tage binter cinander in

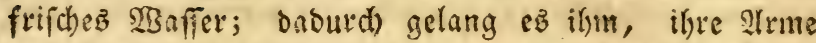

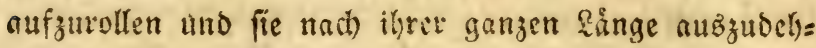

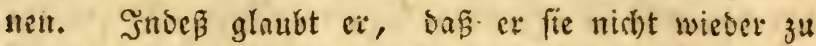
ber Ränge bringen fonnte, die fie wáhreno bem Reben

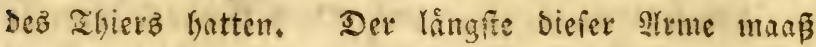

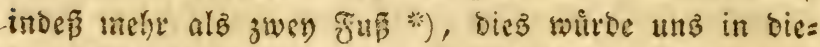
fen 3uftanbe bę 3ufammenziehenz, eine Sheite won

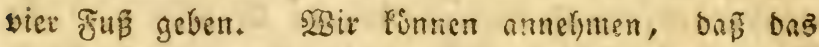

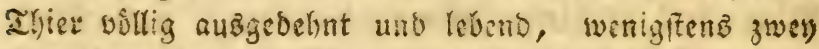

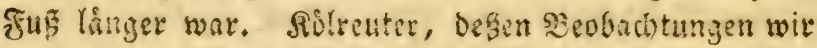

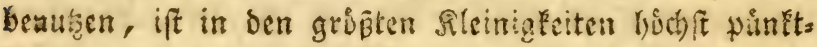
lid): man muf ilym bafür banten, beforderz wenn man mit ifsm erwegt, bas bie Naturgeî(t)id)te ber Geetriete, noch wenig befannt if **) uno vielleid)t

*) Longitudo pedis longioris polypi inter istos septenos maximi, post sufficientem in aquam emollitionem erat I. ped. 6 poll, et a basi pedum ad extremum usque curpus 6 poll 8 lin. Koelreuter nov. Comm. Pet. vol VII, pag. 327.

**) Cum animalium marinorum historia, qualem nunc habemus, omnium maxime manca, et multitudo eorum atque diversitas tanta sit, quanta terrestrium vix esse potest; naturae scrutatores hanc scientiae naturalis partem ulterius et accuratius perficiendi, omnem suam ut imperdant operam, necesse est.

Exiguus valde eorum est numerus, quorum internam perspectam habemus structuram, paucorum externa rite est descripta facies; et quam plurimorum huc usque desideramus notitiam. Mulcorun quidem exstare descriptiones, latendum, et suum cuique auctori tribuere fas est, verum hae ipsae quod maximam partem tam bueves sunt, tainque superficarie confectae, ut 
bietet fie ben Seobad)tungen ber Nenturforfder ein grenzenlofer fello dar.

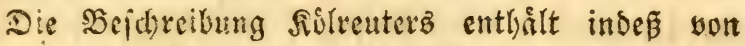
bicfem gyolypen bei weitem nid)t allez, waz man won eineni Daturforid)er fodern fonnte, Dem fieben Exem= whre zu (Bjebote fanton. Er batte uns beftimntere

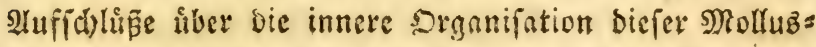

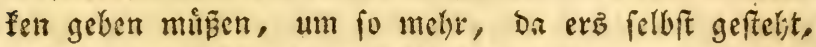

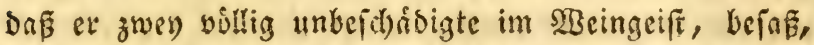
bie er nit ber grof̂ten feidh)tigfeit anatomiren fonnte. Die åuffern Formen ber Norlltsefen hat er mit unge= meinet (jenauigfeit bejü)rieben, Denen wir ben Panb=

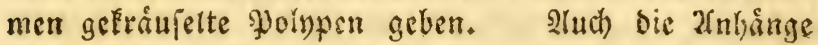

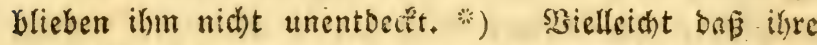

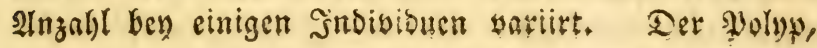

in diversum potius trahant, quam certiores reddant lectores. Perficiamus igitur ab aliis neglecta, et, quae restant, incognita, omni cura describamus.

Sedula aquatilium disquisitio eo plus delecta: menti et utilitatis nobis afferret, quo majorhaec inter et terrestria obtinet dissimilitucio. Koelreuter, ubi supra, pag. 321 ,

*) Vidi etiam in capite omnium, quos disquisivi, polyporum, unico-tantum, et minino yuidem, excepto, qui iis caruit, appendiculas tres $\mathrm{cu}$ tales, angustas, tanquam totidern barbulas, quarum una ante, altera supra oculum, cantho tamen ipsius postico proprior, quam antico, tertia denique pone eum, erat disposita. Ouae supra oculum "caeteris duabus duplo major erat; absolutam véro omnium longitudinem cert determinare difficile est, quoniam ultra modum se exiendi elongarique facile sinunt. Koelrenter, ubi supra, pag, 339 . 


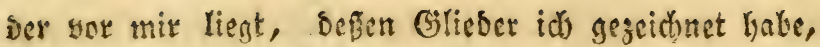

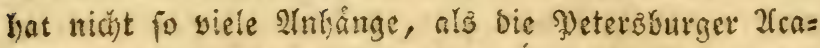
benie angiebt; bent fie fugt: Dós iebes sluge biefez Bobyen mit sroy biutign, bastartigen Ingängen ver=

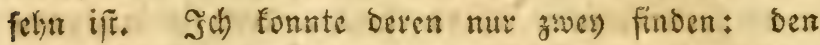
cinen oben, Den andern unten, unb beyde etwas bin=

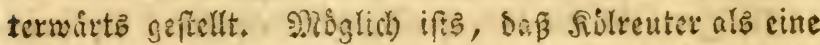

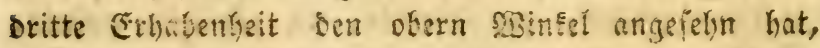

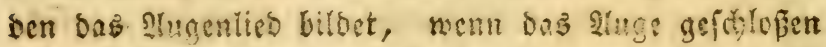
ift, ms Dona fimmte meine seobactung mit ber feinen hberein. 2 thet mit ben Croblungen nuf bem

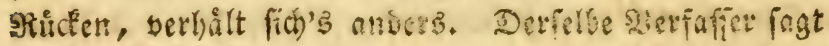
beftimmt, bur er Deren viare geforn hat; die cine yorwårtb, bie anbere nad) binten zu, bie benoen Ietzen nad) Der linfer und rechten Eeite hin fallend. Die genauefte Unterfud)ung liễ mid) mur beren brey entbecten, bie vierte, bie mad) binten lin fålte, founte

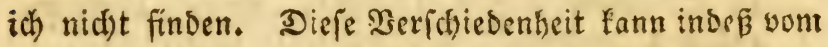

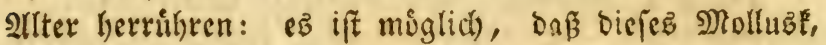
wenn $e^{3}$ ålter wirb, meljere bergleid)en Slnfånge Doer Bartfajern erråalt. Rólreuters seobachtungen, machen bieje Sermuthung noch wabricheinlider, bejon= Ders wenn wir baz erwaigen, waś er felbft fagt*),

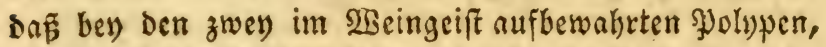
bie fleinex, alz bie fünf andern getrod'neten waren, yon benen ber eine fdjon grófer, alz ber andere war,

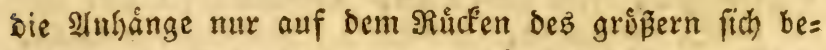
fanben, inber fie bem zweyten ginglich fehlten. Dieịe

*) Easdem in omnibus observari polypis, si duos istos, in spiritu vini servatos excipiam, qquorume mafor is tantum, quae in dorso sunt, minor onaibus plane caruit. Ibidem. 
scobad)tung, die ausgemad, zu fert fideint, zeigt

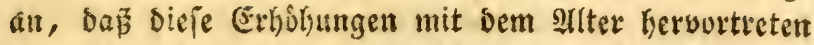

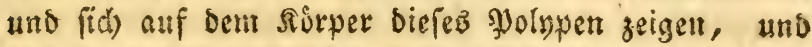

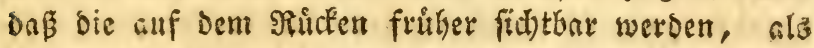
die an ben siugen. Ez ift jogat móglich, daz bieje Erlyobungen mit ben Şshren zunelgmen, uno ie meth= rete da find, das grofpere ober fleinere artere bes Thiers andeuten.

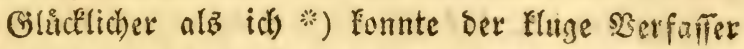

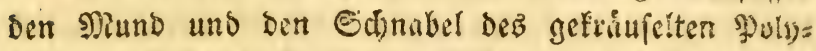
pen unterfuchen: die Rippen find ungemein flein, ges faltet und in melsere fappen getheilt, bie franzenars tig auș!aufen; ber Schnabel, Der burch zwey braun= gefårbte Sielsmen gebilbet twirb, gleicht Dem gefrumm= ten Ed)nabel bez Yyapageyz, wie ez bey allen Nol= lušlen ber Fall ift. WBenn man nun mit biefer ångft:

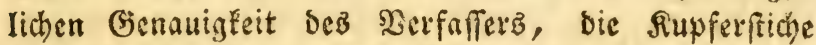
feinez Memoirz vergleidjt, **) fo fennt man ben 》o= lypen nicht wieber, won befäen åuffern Theilen er eine

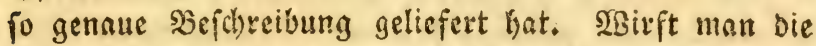
2tugen auf bas $\mathfrak{b i l b , ~ f o ~ g l e i d ) t ~ e b ~ b e n t ~ i m ~ T e x t ~ b e = ~}$

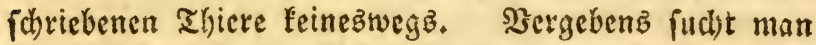

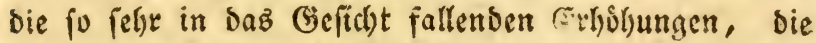

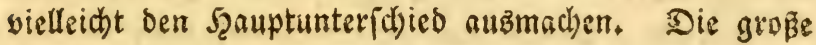

*) Eundem situm sequuntur dentes bini, nigricantes, quorum extremitates, prominentes, aduncum psitaci rostrum quodammodo forma ireferunt. Oris labia, istam apperturam coarctantia, tenuia, plicata, in varios lobos divisa, et ad oras fimbriis linearibus ornata sunt. Koelreuter ibidem, pag. 338 .

**) Nov. Comm. acad. Petropol. vol. VII. tab 11. et 12 . 


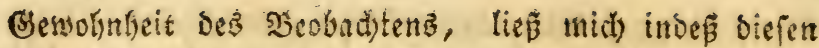
fo id)led)t abgebilbeten Dolupen ber bet gefriufelte

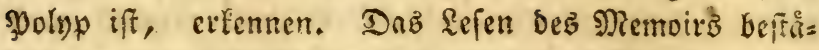
tigte meine erfte Bermuthung; bie Sejdoretbung Der strhinge fonnte mir keinen 3weifel librig laß̧en, ob fie fid auds in bev 3eichnung nidft finden. Die far= ben uno bie Ståre bericlben ben Süreuter Polypen, finb iufi biefelfen, als die id) wahrnalym. *)

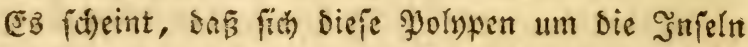

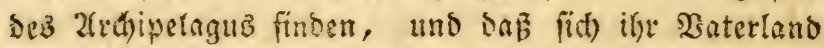
anf bie griechijd)en झReere befchrånt. Die neuern

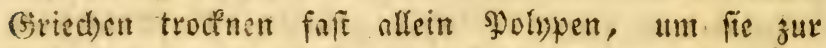
Foftengeit zu efien. Son Den fieben Wolywen bes Ber= foljers, waren füne auf bie গltet, daz̃ fie zut Epelie bienen follten, zubercitet. ${ }^{* *}$ ) (Gried)ifhe Fifder, bie

*) Color in prona corporis parte, scilicet in dor. so, capite et pedum facie, acetabulis adversa, ex purpureo nigricans, saturatus, abúominis latera rersus dilutus, juxta acetabula, seu ad late= ra pedum profundior, in tota vero supina parte pallidissimus. Si corporis pronum accuratius adspicitur, margines apparent plurimi, saturatiores, plana, ut plurinum ovalia, vel oblonga, pallidiora coercentes, in medio corpore, ubi saturatior est color, contigui, ad latera vero, medio pallidiora, distincti, quibus cutis quasi squamata redditur. Praeter illos, in ambitu saepe cernuntur maculae subrotundae, obscuriores, in fundo pallidiori dispositae; puncta desuper innumera, nigricantia, cuti undique adspersa videntur. In junioribus modo descriptus color pallidior est, quam in aetate provectioribus; nec illorum cutis tam relaxata rugosaque, quam horum apparet. Koelreuter, ubi super p. 328.

**) Quorum quinque in aere leviter siccata, om- 
fie fingen, Gatten fie prånarirt, fic lebers att sen Silften gemeinichaftlich mit ben gemeinen \$yolywer.

Man fann biejen \$̧olypen nid)t, wie ez \&amate gethan, werithen auch Soje bejdurieben hat, mit citter andern 2let Mollusfen verwechfeln, bie biejer in bie benad)barten Meere dez Eenegald verfegt. Bofiz

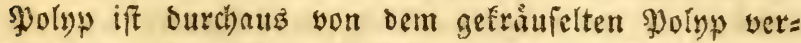
fdieben; feine strme find bey weitem nidjt fo lang, aubgezaciter und ftårker; bie auf bem গluden befind=

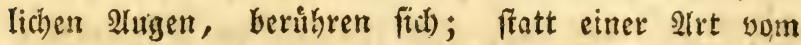
Iugenlied, fideinen fie burch die Şant ober ein Fell bebeclt, weld)ez, wie bei ben Dintenfifidsen oder Sal= marb, Den ganzen Fiorper uiberzieht. Diefe Jeant ift aud) mit anbern Erfubumgen itberzogen; man fiefli feine 2 thlainge, feine Ilugenwarzen, feine Erthaben=

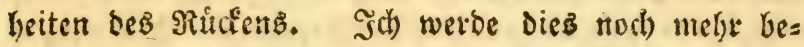
weifen, wenn ith in Dem folgenben 2 (lbid)nitte ben YJolnpen won Boic zum Gegenftande meiner Lnteriu: (b)ungen mad)e.

Erefárung Der fieben แno zwanzigftet Supfertafel.

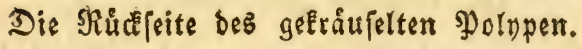

Ran muß hiet bie aufferordentlid)e fange bet Scaut bemerfen, die bie $\mathfrak{A}$ rme an bem seibe verbin=

nibusque, praeter pulmones, cor, vasaque majora sanguinea, visceribus erant spoliata; quem in finem sectione longitudinali alveum is incident piscatores, ut, a putredine defensa, jejunii tempore, gratum praebeant alimentum. Koelreuter, ubi supra, pag. 326. 
Det, wie auds ilyes tridjterformig zujammengebrångte Beftalt.

Die auf ber Eeite befindliden Slugen, find oben und unten mit zwer) fleifd)igten, båutigen \$eriån= gerungen, verfelin.

Drev) Errbobungen Eriujeln ben Ritcen sicjer \$o: Iypen, befien ausgefăfelte Irrme ungemein biegiam und gefruut find.

Erefarung ber adit und juanzigften Fupfertafel.

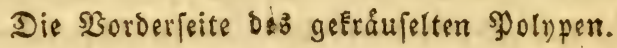

Der Mantel ift nad) feinet ganzen seinge geof: net, um das Junre felfo zu fentren. Nian bemerft bier ben Eingeweibegang, beffen sefnumg fich in ber

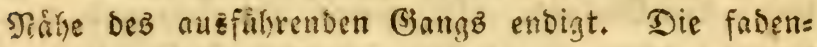

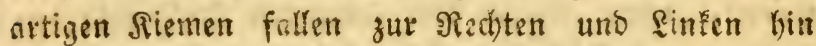
uno unter ilynen liegen bie beyden Scerzfammern; die britte fann man unten ain Sact fely, bem untern Theile Desె Rûruers diefes agierz.

\section{Det feirnige, runglichte Moltyp. Le Poulpe granuleux. )}

(5) bloge Stnzeige, bie Soje in ben Sil)riften ber naturforidonden (Sejellid)aft zu झaris befannt mad)=

*) Sepia rugosa. Bosc. Actes de la societé d'hist. nat. de Paris, premier volume, pag. 24. plaxich. V. fig. 1. etc. - Sepia corpore ecaudato, rugosa, tentaculis pedunculatis nullis, cotyledonibus approximatis.

Seche granuleuse, sepia granulata. Bosc, Hist. nat. des vers I. pag. 47 . 
te, Gat uns ben Yolup fennen gelehet, ben wir iest zum Gegenfitande unferer lunterfuchungen machen wol= Ien. 3u ber 3eit gab er biefem Spollust ben פey= nolimen $x$ unglicl)t. Ramar gloubte, oné er bem Syolypen, Den wir ben gefraufelten nanten, ålntids (ey, er verwedifelte beybe 2liten, indem er an bey = Den bie fornerartigen (Erfabenfeiter fand, bie ihrer Dberiaut eine fibagrainirte 2 tufinfeite geben. Sof yerinterte, obne cine anvere Unterfuchung, feine $\mathfrak{B} e=$ nennung uno, nach einet neuen Meinung, lief er pei=

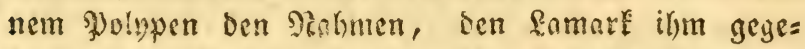
ben lyatte. Serfelbe $\mathfrak{S e r f a f f e r}$ hat bafferbe Ihier uns te: zwen verfechiedenen Benennungen Veidureben.

Der Nurper Des fornigten झुolipen ift owal; feis ne slugen find berworitelgend, befinden fich auf bem

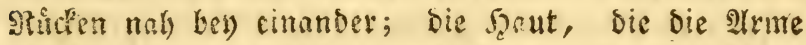
ain Seite mit sinander verbindet, if nicht långer als Der Sisper; fie ift offen, an ben Randern fran= zid)t und felse ausgebelint: adjt fefir rurge sirme be= fronzen fie; auf oer pratten Eeite find fie mit jwen

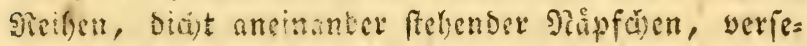
ben, bie fith, on fie fid a affrectent funnen, auf ei= nem Eticle von Derfiluen Grüpo, wie bie Ed)rupps

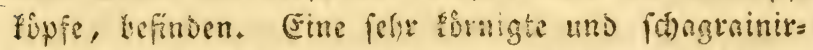

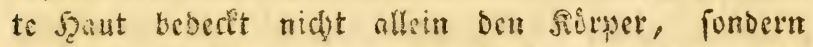
nud) Die Membrane auswenbig uno einmentig, wie

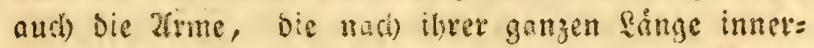
balb unb oufferha!b fohagrainirt find. Diefe formiga

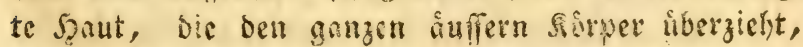
bebeft feltit die Irugen, bie Keine Zugenlisoer, ober eine bewegliche Sbebectung baben: auf Dem Ridien uno bem obern Theire des Şarfes, find die Rứrner am fithefien; fie vermindern fids, is meiter fie fid

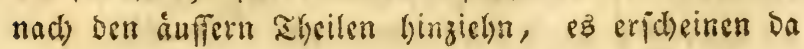


blope Flecten, Grubditen, rothifahl angelaujen, biele Farbe wito burch eine vollfommen weipe j̧aut un= terbroden. Dab Rofenroth und bie rothe Farbe, find lerrict)end, fo lange baz Thier lebt, und bejon: Derz ift nuf bem Rưden Der leblaftefte Inftrich. Wirb es in 2 seingeift aufbewafirt, fo verwanbein fid) alle Dicje Sd)attirungen ins アothbraume; und in bie= fem Zuftande hat ez beinaly ganz die gleinzende 3eich)= nung verloren, bie regenbogenfarbig ipiegelt uns bas

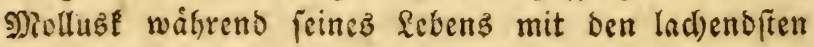
Farben fdimictet.

Diefer syolyp ift an Den Sitifen bez Eenegal felyr gemein. Sojc, Der meljeere gefelyn batte, fdheint zu zweifeln, ob fie eime anjerstidse cirope erlangen;

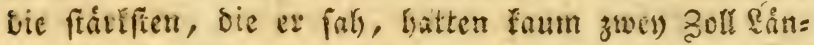
ge uns einen 3oll in Durdineffer. Die sime frect: ten fid) wirflich weiter aus; alfein er gicut ilje grüpa

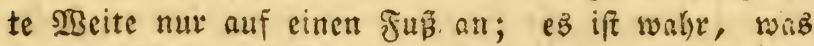

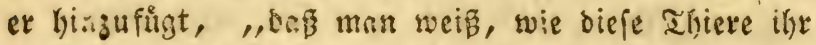
ganzes feben binoura) wndj) artig werben;", allein wahrijdeinlid) serwechielte er alle Solyperacten; uno wenn, wie wir gejelin laben, ges

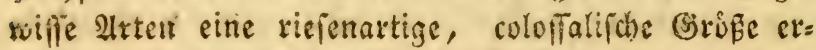
reia)en, fo legt fie Der \$erfaffer nur allein, wie wir glauben fínnen, Dem fornigten \$olypen bey, ba er bod nie cinen anoern jah, ber hber fechs 3oll groz war.

Die nah an einander frehenden Edropffupie, muffen biefen Spolyp ben Thieren felir furchtbar mas

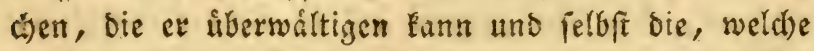
vermòge ihrer grofiten Etårfe yon feiten singriffen nid)t liegen, wenn ex fich einmal angefogen hat unb fie fich) Durch fo viele Sauger, Maipyflien, bie an einan= ber gereift fint, feftgehalten fúflen. Betmige ilyer 


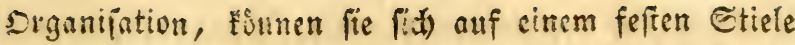
erbeben unb exhalten baburch mely Etirfe uno Siraft, fich) zujammenzuzielun. Wric ieder anbere polnp, rith=

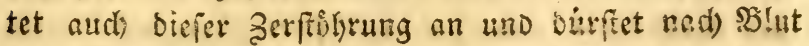
und Morbluft.

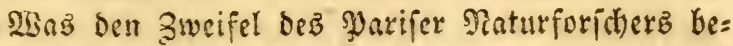

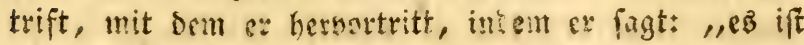

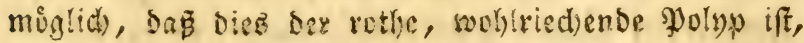
von bem, wie man meint, bie Erinejen bie dinefifder Dinte zieken, *) , fo glaube ich betviefen z" haken, Dap bie Dinte, oder Der Eaft be: Dintenfifibe, eigentlid) ber cinzige (dywarge ift; Der Saft bey ben Salmor: uns \$ुolypen belsuptet immer eine rufige,

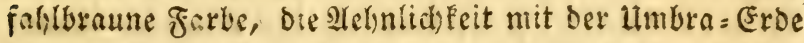

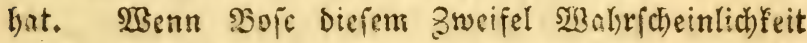
geben zu fornen glaubte, fo hat er fid felfot burdis bie allgemeine Benennulig, bie er angenommen hat, indem er mit Den Dintenfifden Thicre serwedbielte, bie von iryen unterfdieden and getrennt fino, jum

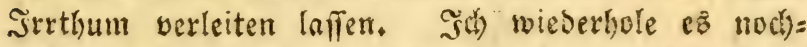
mals, cine falfd)e Senennung fielyt immer şweifel nach ficl); im Infange baben bie oft wenty sul bebeuten, aber in Ser folge fnipfen fich an= Dere Jrthtyumer on bie nerbergelbenten und Dann

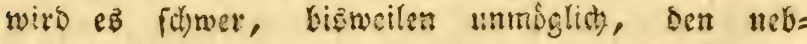
lichten 5 blerer zu exlendyter, in Den fich bie

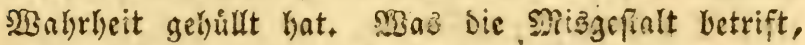
mit Der einer bet 3eichner des Seba, bis jmente

*) Diefe 2frt naht fith Derienigen, bie in Eeba $a b=$ gebilbet iff, Sano III. Supfertafel 2. Niro. 6. 7 . "Eg ift móglich, baß bies ber rothe wohtriechende

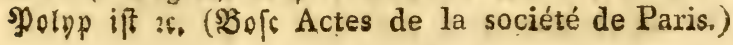


Supferplatte Sez britten Bantes, Nir. fieben befucelt but, suf bie fid) Boje bezielt, als ftelle fie feinen

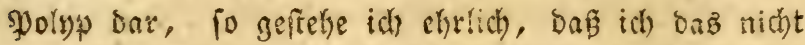

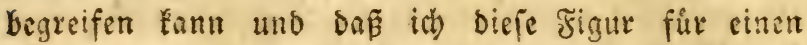
neuen Beweis erbaimlid)er Malylerei balte, obgleid) ber rebacteur ber Encycloyebie geglanbt hat, fie zu feinem zowect braution zu fornmen. Se länger id bie Supfertafel anfah, Defto wiberfinniger formnt fie mir

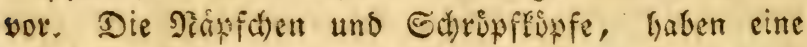
ourd)aus unrichtige Stellung. Sein Naturforid)er fann won biefer (Seftalt im Seba, Gjebreuch) machen. WBas hie fedste fighur ber zwenten Supfertafel in Seba betrift, Die Derielbe Berfaffer alb ben Pornigten झolyp anfititret, verbunben mit ber fiebenten Figur,

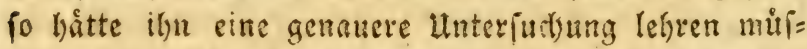
fen, baß̧ bieje beyoen Figuren nidbts mit einander gemein baben unb bap bie fect)ste Figur im Gegen= theil eime andere 2 trt iener Mollubien baxfelit, Deten

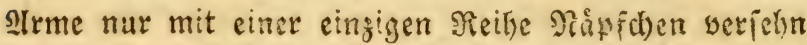
fino, ftatt zweyer Seeihen, ohne unter einander burch eine $\mathfrak{S}$ aut verbunoen zu feyn. Dieịe eigenthimficlen

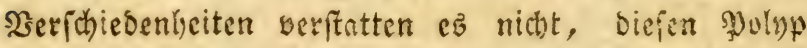
mit benen zu wermengen, Deren Sirme jwen Seihen

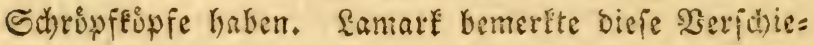
benlyeit felye richtig und trug fein Sedenfer, Diejen

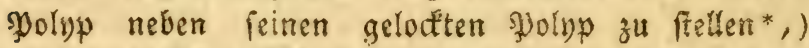

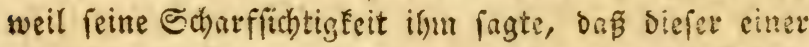

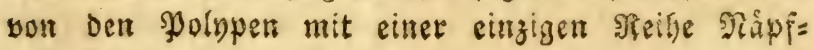
d)en fey.

*) Cotyledonibus uniserialibus. Lamark, Mem. de la soc. nat. pag. 21. 
Erflerung Der neunzef̧nten Supfertafel.

Sie frellt den furnigten Wolnp yon Sofe, won zwey) Morberieiten; bar; er ift bier nach feiner na=

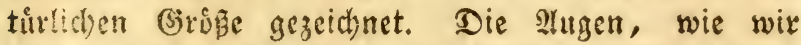
fiton wiffen, find burdh bie Şaut bez Siorperz be= bertit uno bie Edripffopfe ber Alrme, bie in zwey Sechen ferien, find einanber felyt nah. Die $2 \mathfrak{e}=$ fob) ffengeit ber memurane erlaubt es ben S(rmen, fich in ihrer grufiten 2lusbebnung zu zeigen.

\section{Der amerientifáce Polyp. \\ Le Poulpe americain.*)}

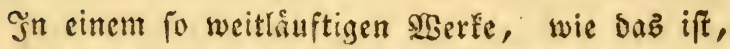
wab Seba unternommen hat, muf́ man nothwendig bie Ialente vieler Sinftlex anwenten. Mllein es wimmelt von Sorthưmern. Einige Siupfer fino von

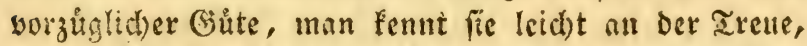
mit ber fie Die Natur copirten. Seba hat Den $\mathfrak{D}_{0=}$ lap, den id) wegen feines 3aterlandez; ocn ameri= fanifchen nenne, in Supfer freblen laffen, oryme bie Figur mit 2 (nmerkungen $z^{4}$ begleiten und ihe eines: charafteriftifaten stabmen zu geten. Die finftern unb verbrannten farben, mit bemen $\mathfrak{e x}$ auf ber colorirten

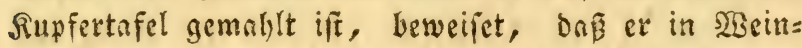
geift unter einer Menge von Gegenfinden anflecwahrt war, die bem Rabiuret Dez hollánbif́chen Pinturfor= (d) bienten.

*) Seba, tom III. planch. 11. Fig. 2 et 3. Encyclop., planch LXXVI. Fig. 1 et 2. Backer, Transactions philos. Vol. L, partie 2, année 1758. p. $777^{\circ}$ 
Die Figuren it ber Encyclopedie, bie nadh de, nen Dez Eetha copirt find, frellen uns biefe șollaß

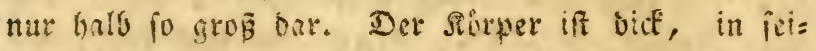
net Seine zuismmenacorice?t, feine Geftalt und fein

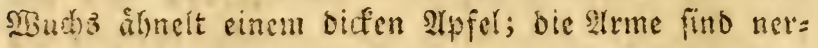
wigt uns turz, yon unten auf uno in ber glrt zufans mengeniefelt voe* gefdrumpit, banit man bie vielen

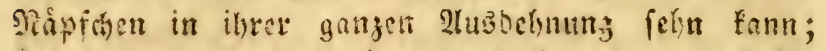
fie inaben zwen Sielfen nus; vermoge einer mertwir=

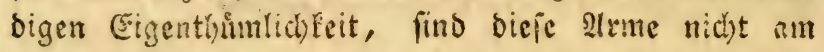
feibe burd) eine Scaut verbunden, bie wir bisber ben allen Molywen ais ein Nittal wahruabmen, Eaz sie

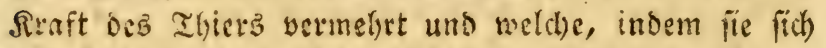
bey) ben gुolyuen, bie Damit veriehn fins, weit at: Defunt, Den Fulftrice oder Den Gruns bez tosbrin=

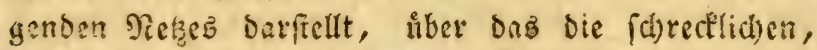
raubiübtigen Z2rme linaušragen.

Die Slrme bes amerifanif(hen Solspen fins in:

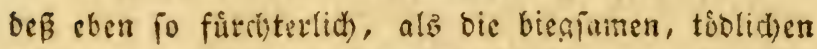

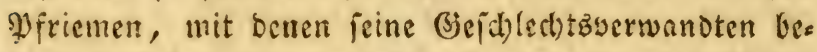
wafnet find; und $\mathfrak{e}$ (d) burch) anoere æortleile entid)ábigen wollte, bie fie ihu in gewiffer binficht entzogen zu bahen foreint; bei) ifyn fins die Gjlieber nersigter uno differ, bejon= bers fino fie am leibe felse fleifá)igt uno unter cins nnoer feit verbunden; alle frehn fich wed) felfeitig bey,

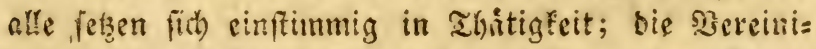

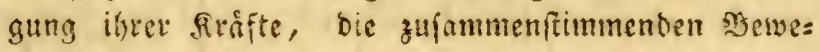
gungen, minen eire bebeutende uno foif unbermeid= liclie Gewalt iffen beoauernowertlyen Spfern enige genfeller.

Sic weit von einenoer entfernten 2 lugen, fiefln

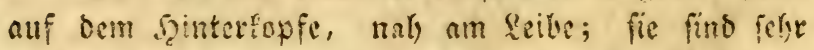
matt. Dispez ift contigftens bie slut, wie fie fich is 
ben beysen sriginarfiguren ber beyben Merfoffer zei= gen, bie wir beshalls als fehrer betract)ten Esnmen; Denn ber গুolyp dez̉ Seba, ift ficher berfelbe, won bem wir reden, a!b ber Szeinrid) Sacters, *) Den et bejchrieben hat, welden ifun Der Graf yon Maccles:

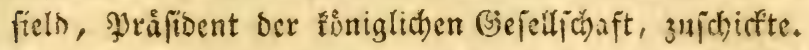
Diefer vorzingliche. Gelegrte, ber fo viele Unterfudyun= gen úber bie Wolypen anfellte, Der alb eit whrebigek

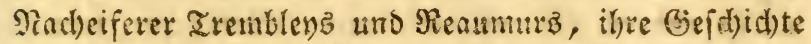
mit fo vielen Ihatpat)en bereicherte, ${ }^{* *}$ ) fajeicb cin Memoir nete bicicn \$olinen, bab bie Rebactem ber philolowhifaden Iranfactiomen, in biefe furt sie SBiffenid)aften uno Sinfte fo vorzaglidbe Sanmlung fogleich) aufnabmen uno fie beglaiteten sies Memoir mit ciner foftbar uno gut geftochenen supfertafel, nad) (5owatbs zeichnung, Die biez Niollubi unter melys rern verichiebenten Iinfichten barfeüt.

Die Figuren bes Eeba fino bey weiten nidjt fo

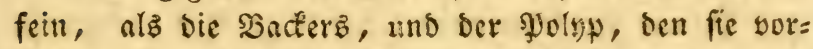
ftellen, ift auch weit grofser; man funnte, wenn man feine Itrme aubbreitet, ifgm eime fånge von ad)tzelin biz zwanzig zall beimeffien, Die Ränge Des Nurpers

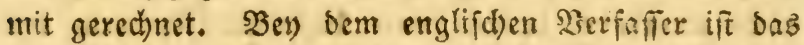
Sndisibuum, was er befdhreibt, bes weiten steiner, Denn yon Der Bafiz bez Sorwers, biz zur Epitze ber 2rme, finben wir faum vier zoll, weim math fie auth múglid ff auşbelnnt.

*) An account of the polypus, by Henry Backer, philos. Transactions. ubi supra, tab. 29, pag. 779 .

**) An Essay upon the nat. hist. of. pol. 2fus

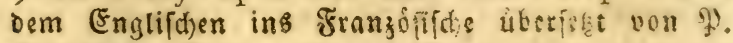
Demours. Paris 1764 . 


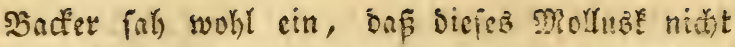

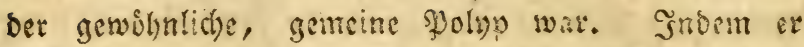
nadylubte, zu weldier sirt er gefiuren midhe uno in

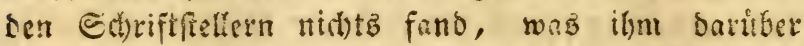

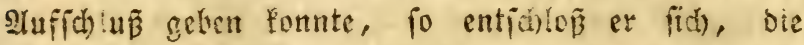

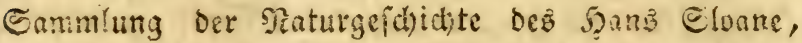
Die fith in bem brittifian Mitienm befinoct, genaut zu Durchiuden. (5r hatte die Freube, Derin unter

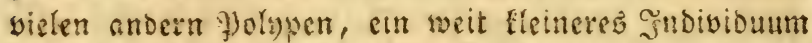

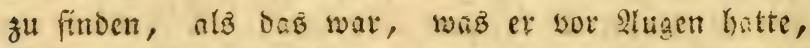
fibrigens aber bemielben genau glid). Tloch fano er in bicjer Sammluatg einen weit gropern polnpen,

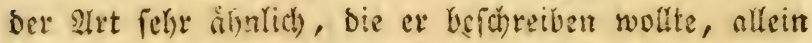
és Wheben ihm bariber 3weife!. Eine cingige Eathe whise mid) bebenflich machen, wern man auf bie

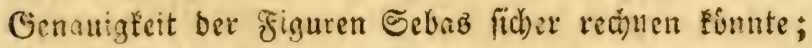
in feinen Siupfern find bie slrme nad) unten zu volls Yig runo; bie bey Sarder fitto glatt, vieredig, an

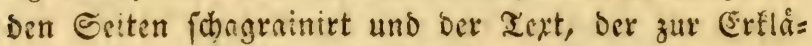

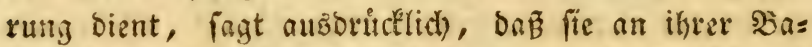

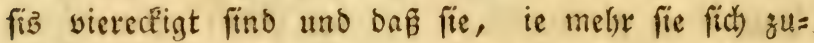
fpitzen, tricangelfurmig werben. Seba, waz wir be= reits angefirfert haben, bat feine Supfertafeln mit feiner Befidjreibung begleitet uno baher finnen wir feine Sergleichung anfellen: vergleicht man inder bie

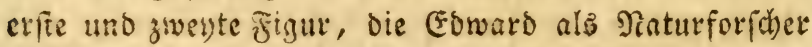
zeiburete, fo finbet man an benjelben bie zufanmen= geiollten Arrme, bie uniern \$yolywen characterifiren; biefe slrme find in ber oritten uns vierten Figur ber: fe!ben Supfertafel, susgebelint uno aufigewidelt, Die uns alle Denfelben Wolnp won vorn barftellt. Die britte figur zoigt unz felbit eine felbe mextwirbige

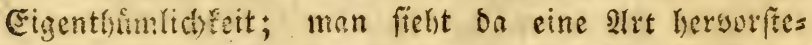

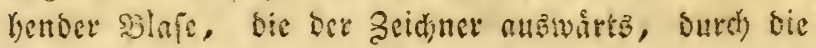




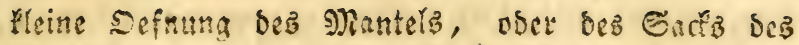

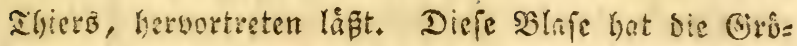

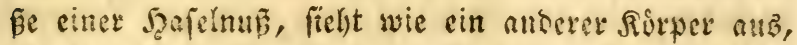

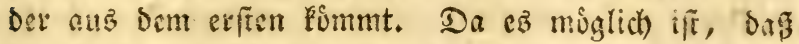

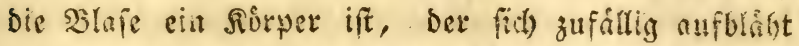
unb won eirer vorifbergehenden forperliden Fulle her: ritint, fie ben bieien Thieren auch nut zu gewiffen Seiten fich findet, fo ifit fie in oer Defonomie befer

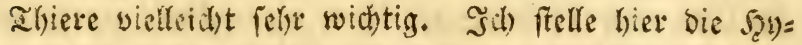
potíejen bes englifden Derfafferb auf; feine (senau=

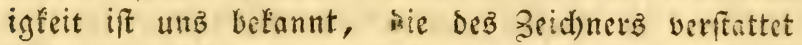

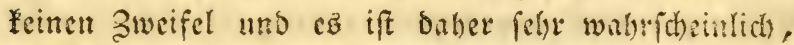

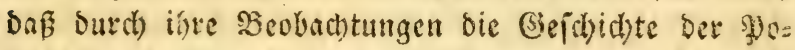
lypen neue Sacreidrungen exbålt.

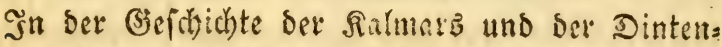

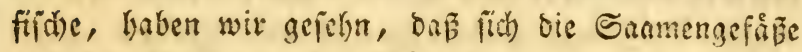

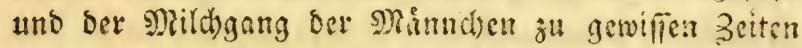
mit einem mildigten Saft, und eigenen Sefranothei= len anfullen. Reebham war ber erite, bev bicfe (5r: (d)einung beobachtete. Backer beftabigt bieje Seobach)=

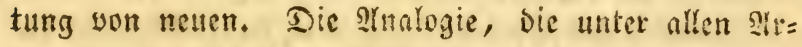
ten ber leberbåutigen Nollusecn frott finbet, zwingt

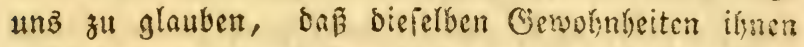
nid)t nut gemein fino, forioern bap aud) ilye 2325 ridhtungen uno ifre thieriforle sryanifation, diefelbe

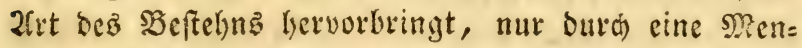
ge verid)iebener 3ufammenfingungen mod,ficirt. Son

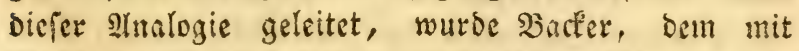

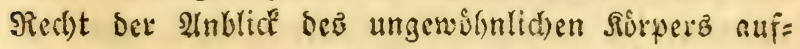
fiel, ben er bey andern şolywen berfelben 2 (rt nidit fanb, zu bem Ed)lufie benogen, Dar disfer \$ुolyp ein Minnchen fer), ber in Det zeit feiter grufften 3eugungerraft gefangen wurbe. Die arbern Syly= 


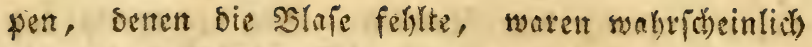
entwaber exidjipfte Siannden ober, nod) ficherer, Bseibden. Diejer Docinung mus man unt fo mefir

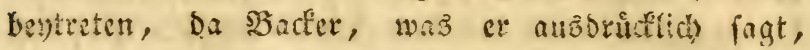
feinen bou den glolypen, bie ex unter ben Jeanden batte, anatomirte.

Der 3ufall ift mir noch weniger ginftig gaweien, als ifhn, alle meit Euchen balf mir nicitis, nie habe

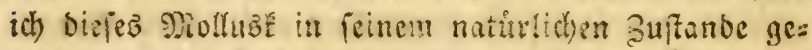

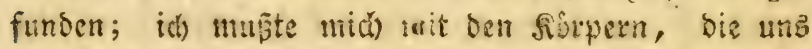
Seba und Bacter nachadafien hat, Hegnigen. Sie Etidte bes erfern, fo merfwirbig fie aud find, funnten feiner feyn, fie founten mir nur als 2 Inzeige můţlid) werben; Daringegen bieten unz bie Supfer= fitche Sacters, bie wit genauer firt, cinen befriedi=

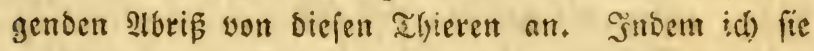

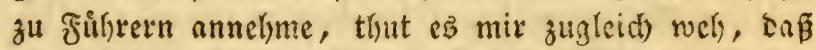

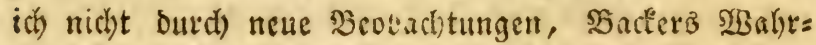
nelmungen beftátigen uno fie buch) Besveife unter= fruben Eann, bie mix eigentryumlid angehouren. Ueber=

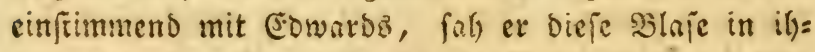

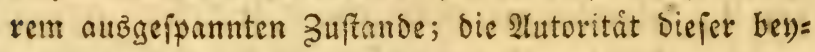

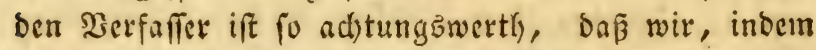
wir ouf ifre Seite treten, mit ifnen glauben muij=

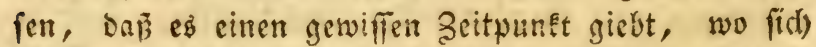

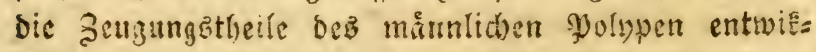
fein, fḯn nusbelinen, inbem fie anfecbsellen uno, wie bey Det Miannchen ber Ralmars uno ber Din= tenfifche, fith yorziglich Kraftwoll und fratE, gallz an=

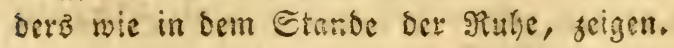

SEen wir bie oben angefulyten Berfaffer auba

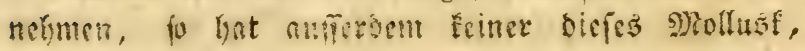


bem wir ben seannalymen amerifaniface Yolyp getben, alö einer bejonbern 2 irt gebad)t. Sie Natur=

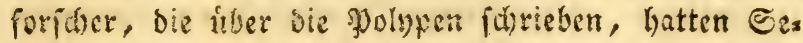

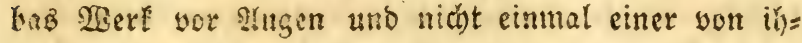
sen hat biz zowente und sritte Figur ber eilften Siup: fortafel des beitten Bandez diejes Sammlers, als ibereinfitmmeno mit irgend cimer andern polywenart,

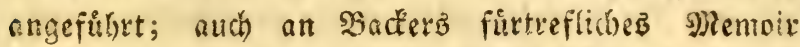
baciste man eine lange 3eit nid)t; felbit Eamart, ber

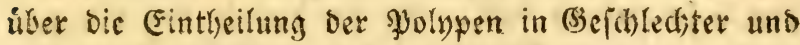
Irten, fo viel Ridft verbreitet, fdetien weder biefe

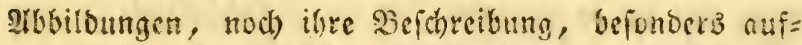
gefallen zu feyn. Sie reiffe lititerfubatig lisgt mich

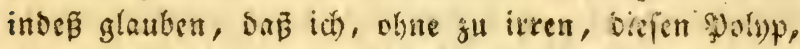

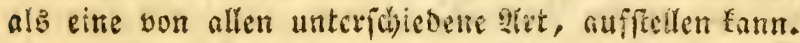

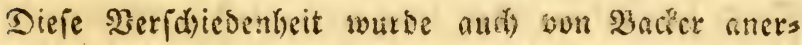
fannt, Der ifgn nidst mit bent gencirien \$olspen ver= wed)ielte, neldyem or in mandibr sinficht ifindt. Unm feine Meinung befto melye zu behaunten, zeigte ex uns getrau bag \$aterland yon biefem Miotuge an, indem er fagt,

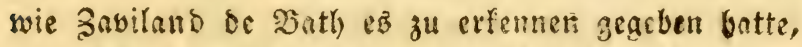
yon bent dieß Şnbivioum herrifgete, Der Graf son Macclesfielo ilberfojifte. *)

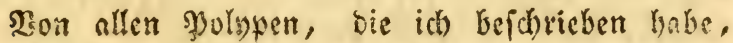

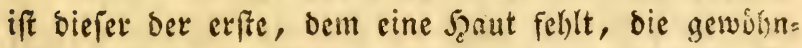
lich an feibe bie 2 reme nit cinnober verbinbet. Ev ift auch ber lekzte yon Den Molluseen init zwen ?let= ben গiåpfden und zwar ben nacten, die wir bis ietzt fennen; bie, bie mir nod) zu beid)reiten librig

*) Backer, úbi supra, pag. 765 . 
find unter ben naceten Syolysen, Yaben nur cine Rei= be Sdronfripfe uno im algemeinen felglt iene Jaaut (membrane) allen; eine frledite figur in $50 !$ ge fidnitt aubgetiommen, bie srrorowanbi hernusgegeban hat, bie den andern Siatuforfuern entgangen zu fesn foreint.*) grber bey bin Jolywer, bie reine Niembrane baben, find bie arme am Reibe unterfets= ter uno die Etiufe, mit der fie fie zuĩmmenzielyn,

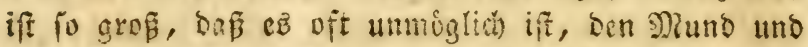
Den Schnabel zu felon, bie gewshnlit) bey den spo= lupen, bie mit 2Rembrane verishn find, offen balies gen; ber biefer bagegen fund die Schropfeuple fo nuf cinander gehåft und im Mittipunte ber 2rime zu=

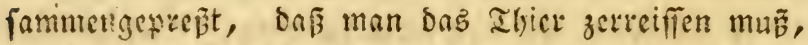
um ben ipitzen Sothnabel zu felsu, ber, inbern ex bie Seute zerichneidet ober zermalmt, nuf einen sugen= blick den immer wieber erwadjenden Slutourfe diejer श्रlollusicen fillt.

Everlarming Der Drenß̧igften Supfertafel.

Die breypigfte Rupfertafel fteilt ung ben ameri= fanifthen Jyolns Dar. Dicfe Figur iff Dem Memoir 3àcters entíelynt. Wir baben ben Polnpen hiee

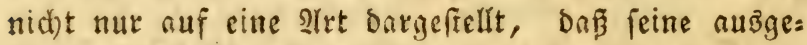

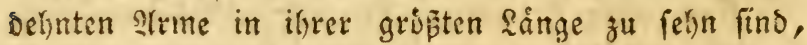

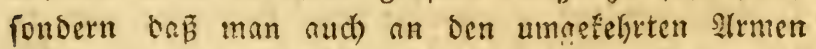

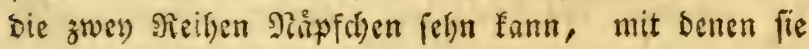
beietzt fino.

*) Aldrovande, de Moll. pag. 14. Polypus is, quo una tantum acetabulurum series exprituitur. 
Ituten auf ber Supfertafel fieft man cins gon

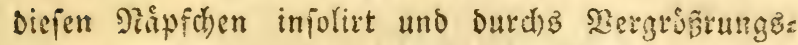

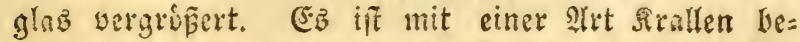
wafnet, wie bie bes Salmars fino.

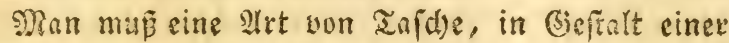
Ş!afe, an ber Figur bemerken, bie aub ber Def= mung Deß Sactiz oder Mantela dez Thiers hervor: tritt. Dieje $\mathfrak{B l a f e}$ if angejăbullen.

Eutertutig bet ein und Drenfigfen Stupfertofer.

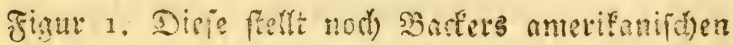

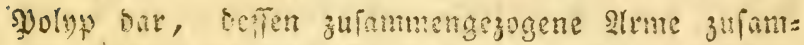
mengerolt fins; bide supfertafel war barum nothig,

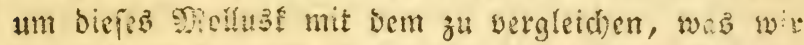
im Eeba firven, Band III. Supfortafel 11. Figur a und 3 wo eb unter jwey slufideten vorgeftellt iti. Diefe Figuren fino nadiber yon Sruguieres in bet Encyclopedie copirt.

Unter Niro. 2 ber Rupiertafel, wan ber wir eine Errlårung geben, lyaben wir bie cieftalt biefes po: lypen, nad) Seba gezeichnet, inbem wir die slnfidt

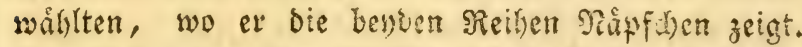
Dos Zufammenrollen ber Zfrute beweift bem Rejer bie

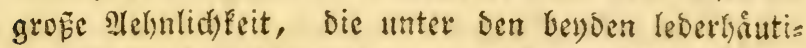
gen Prolluşen ftatt finbet, won benen ber cine von Bacter genau beictrieben, ber andern won Seba nur angezeigt ift. Sind bicie beyoen Mrollub̧en nidjt sin uno siefelbe 2lrt, fo miffen wir wenigitens ihere gro:

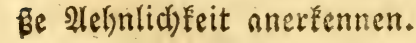




\section{Der Polyp Des 2flbrovandi. *)}

Le Poulpe d'Aldrovande.

Sol) einem fluct,tigen, sondh gremjentgien şlict,

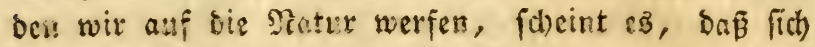

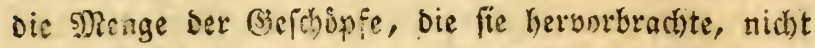
fo mertid) son pinanoer unterifheiben und Daß nur einige Schattirunger entfteken, bie fich in einander veridjmelzen. 2llfes lebt, alles hat cine gewiße (bes= fralt. Die Formen, Die Farben, Der A(nftrid),

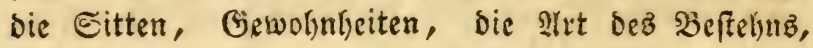
fliefien in einander; wollen wir das 2 Ul umfaffen, fo felin wir ein Elyaob, nur \$erwirnung. Dann, wenn wir unjere Sirafte amftrengen und bie Sdhatti= rungen ergreifen, bie uns entịl)!ùvien wollen, Dann, wenn wir mit (sifer und Sieljartid) Eeit nach forid)en und burd) tiefez Ctubium erfalgen, weides bie un= terfolede find, bie uns, indem fie unz nefelueca, ber unfern Unterfucuungen, behilfflich sverben uno bazu Dienen, um die bejd)upfe von einnder zu trennen, um fie nach ihren forhigfeiten, ihren åufern Fomen zu choffificiren, oronen wir fie in gewipe Familien, und find diefe erfit beftimmt, bann erlau= ben wit uns, ibuen allez das beyzulegen, waz ilnnen eigent'jumlid) fesnn (ann. Dies aber ift nur Das 3̧iel, was ieber bura) 2 siffenithaften gebildete Menith mit gejundem skerfĩande erreidjen faun, aber ber

*) Aldrovande, de Moll. p. 34. lib. 1. Ziuigstar wyfken oDer poulpe famelle. Seba, tom. III, planch. 11, fig. 4. - Een groote wyftje polypus van boven. Polypus faemina major prone. Seba, vol. III, pag. 5. - Gesner, Icon. animal. Ord. 13 de moll. pag. 191. 
Daturforichar mu而 noch weiter gefin. Die lebenden

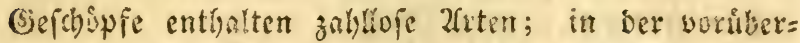
getienden Erifheinung, bie wir suf ber Erbe haben, weil unfere Iage begrenzt fins, fibeinen Die aljers arten bieferben zu Helben; allein ez ift methe alz

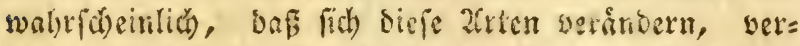

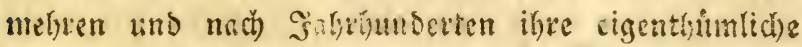

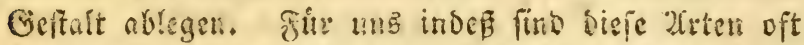

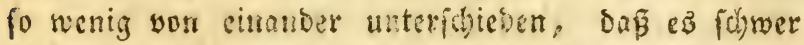

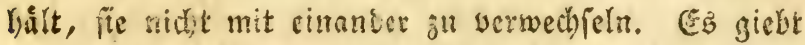
cime fo grope \$lange feimer Schattirungen, bie mux bem unermibeten \$eobad)ter nid)t entgehn, bie nux lange Gewulinteit im Foriden, ein fo ficherer a!z cinbringender SBlicke, ergreift. Die Ricbe zur şifi=

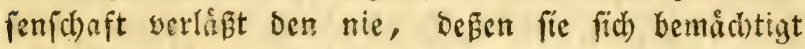
bat. Zim Enoe feiner Iage fann ex ben Rebenzabeno burch) bas Stubium nod) verfchonen, bas ilym immer

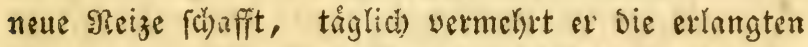
Renntnife. Die Begeiftrung Des Geriez, hat ifhn nidht yerlapen, er bezeidjnet feine lekten Sdyritte burd) neue Entbeçungen. So batte aftsroyand now

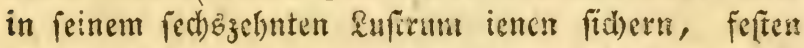
Zact, ber es nidjt zugiebt, ein Indiviburm mit einem andern zu verwedbieln. Das Stubium ber

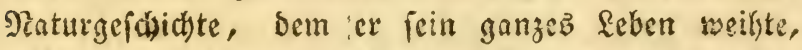
mad) te aus biefem berifynten Manne, ben erfen Naturforid)er feiner zeit. Fr verbient eine Stelle zwifhen Ifriftoteleż uno \&innée, weil er, wie fie,

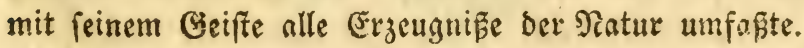
Diefer Elye ift er um fo melye werth, wenn man

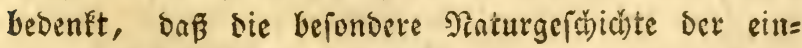
zelnen Gefobopfe in ber Zeit, wo ex lebte, faum

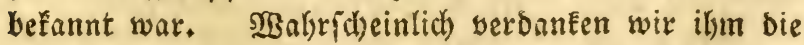
Wiedererneurung biefer ertinbenen SBiffenithaft uno 


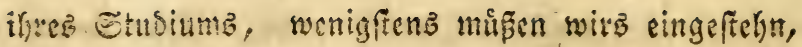
Das ev jebr viel bazu beytrug.

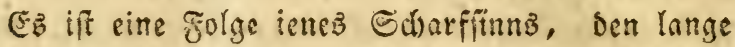
SBeobnd)tungen ergengen, DaB biefer Paturforfder, nadibem er ben gemeinen झoly mit zwey Seithen

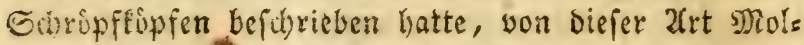
lusten cine andere zu unterfa)eiben wuste, woson ikm nur ein eimaigez Exemplar gebrad)t murbe. Dieß wurbe bey der Snirl (5!ba gefangen, die mit ju ben Siniein bez mittellindi hen Meer gehurt. *) Seine Singe, mit Şnegriff Der Xrme, betrug zwer) Jü;

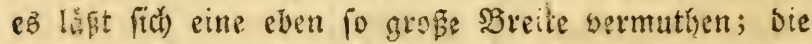
glatte Seite ber 2trme, bie, auf ber man bey bem

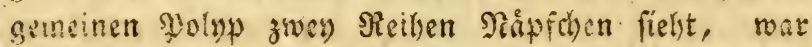
barban weis unb nur nit einer Peifle biefer furcht= barel echropfínfe bewafinet; unten uno auf ber rutolidien Eeite berielben, zeigte bie weife Farte beritben arme, Fileden oder Gruben ober $=$ ober

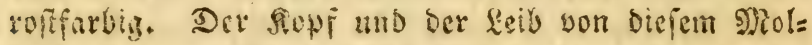
Inbe, war verichieven iúattirt und fpielte in bie rothe, blaue mo folwarge Farbe; in ber Edyeibe

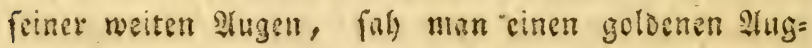

") Nos quidem hujus generis iconem damus. Captus is est prope livam inaris Mediterranei insulam. Longus erat pedes duos: cirris duplici acetabulorum ordine inferna pate insignitis, albis: supena maculis fertgineis aspersis. Cãpite vario, coloribus praesertin, зйbro, саетиleo et nigro. Oculis magnis aurea irite, pupilla nigra. Hujus iconem ita expressimus, ut unica tantum acetabuiorum series conspici potest. Aldrov, de Miloll. lib I, pag, 13. 
apjel, ber mit bem bunfelfarbigen Irugenftern unge= mein controftirte. Mlochte Doch Die Figur, bie 2aroros

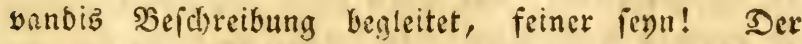

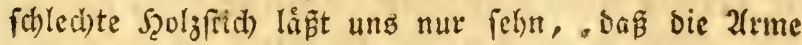
faum noch einmal fo lang finb, wie ber Rorperlund

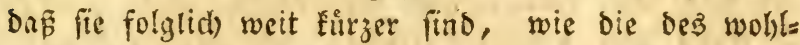

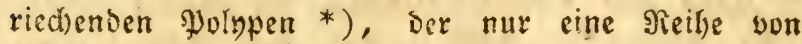

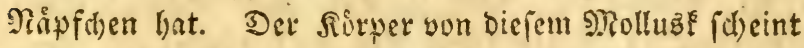
auti) weit griper nact) Der syroportion ber 2(rme zu fern, alż ber beż gemeinen Polypz. \$iefe Unters ficheidungsjzeid)en finden wir aud) bes einem ber Thiere, das Siba befannt gemad)t hat, **) unter bem $\mathfrak{N a l}=$ men bez weiblid)en Polypen, olne eine şeidjeibung binzuzufigen oder irgeno etwas zu fagen, baв unz den Sort anbeuten fonnte, wour wober er ihn erbielt; Dar er ifin abee ben weiblithen Mo!nyen nennt, beweist

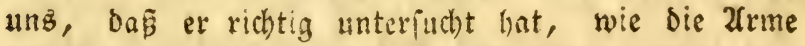
Defelben nur mit einer Reithe গåpfden verjehn wa= ren. Die (j) bergrúbe dez Jolypen won Eeba, fd)eint unz biefe'be zu feyn, wie bie bes झुolypen won 2lbrovandi uno bey bem hollindifden Seobad)ter ift er unendida) beser gezeichnet; allein Da Seba ifhn im sBeingeift aufbewailste, fo erfobeint er ganz braut. Dieje Farbe verbrångte die Farben, die baz ăhiel

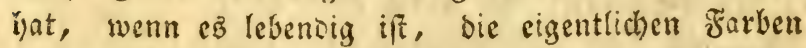

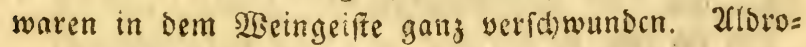
wanbi, ber ifn lebendig fah, beidreibt bie fidstten Farben, die feine Jzaut zieren, genau, wenn er in

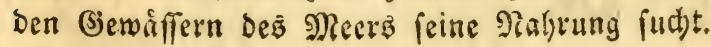

*) Eledon, eledona; ozolis, ozaena; osmylus; bolitena Der Iftten.

**) Seba, tom III, planch. 11. Fig. 4, pag. 5. 
Noch mitren wir hier bemerken, dẫ die Figur

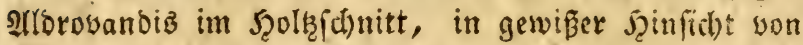
ber verid)ieben ift, bie Seba unter bie vierte 3iffir Der zwenten Aupfertnfel feines britten $\mathfrak{B a n b e z , ~ f e c h e n ~}$

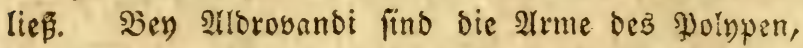
son bem wir reben, auf ber innern Eeite glatt; bei Seba fino bicjelben Alime, Der ganzen sange nad), vollfommen rund. Sey bem bollindijchen Naturforicter ift baz 2 luge von biefem Mollust gnnz exlofd)en; eż fieht bleid) aแb, vielleid)t bat $\mathfrak{e z z}$ ber Weingeift entfärbt, viefleid)t hat ev biefeb Drgan be= bectende Membrane verfitrzt und biditer gemacht, bie bey allorowandi ausggedelynt, glänzeno, vder we: nigftens felie bemertbar uno hervoripringend ift: allein

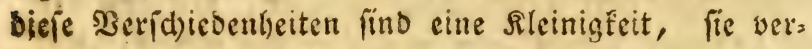
lieren fida), wenn wir erwegen, Dá̧ bie Ârme ber \$olnpen nicht nur biegfam uno nach) ifjer ganjen Långe ungemein gefchiçt zum 3ufammerizielsen finb, fonbern $\mathrm{Da \beta}$ fie eb aud) auf alle andere 2 trt in cincm

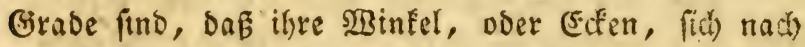

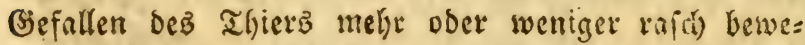

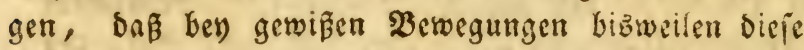
Eden veridhwinden, und bann fieft nian eimen vier: edtigten, oreyedigten $9 \mathrm{rm}$ in ber Beftalt eines rutben.

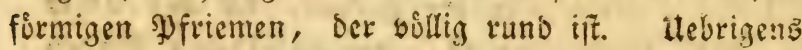
Eommen mir biefe Edhattirungen wenig d)arniterififif vor uno ids felse fie für siel zu wenig unterideloend

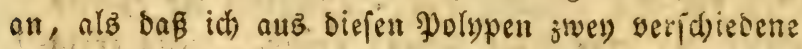
Inten mad)en follte.

Bey Eeba hat ber Solyp ourdians bic Seinte

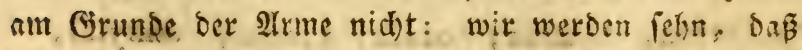
Diefe Şaut im allgemeinen allen Âlrten berienigen

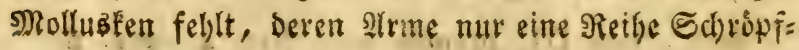


fupfe kaben. Die Figue sllorowandiz if bejonbers in bicjer Şinficht mangelfafter, alb in ber 3eid)nung

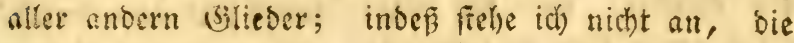
beisen jolypen unter eine Sirt zu begreifen; biel= leid)t have idh mid) betrogen; viefleidht finb ez zwel)

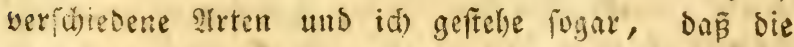

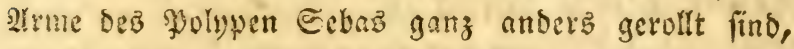
alb bie bez an Ufer ber Sniel Ella gefangenen \$o= lypan. Die zeit muf bieje Edjwierigheit entidteiben: man niro sieje Ihiere fisteren, ober fie nod) meht

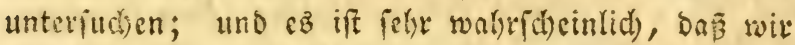
unter ber sisnge berienigen, die man in unjere (3)a lerie und firbinetter bringt, neure girten finden wirb, und bar andere, indem fie fie ben Polupen, bie id befareibe, an bie Eeite fiellen, entweber meine Mei= nung, sie idh siffentlidh befannt madjen zu muisen glaubte, ba idh to viele Unterfuchungen uno Seob= ach)tungen angeffellt hatte, beftítigen ober cntEråften.

Șas fernet nod) fir meitte Mieinung enticheibet,

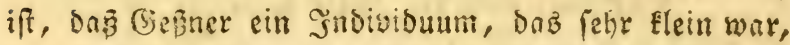
won berfetben 2!rt, won ber biel bie Rebe ift, wor Itugen achabt zu haben fijeint. Sbgletia) diefer flets

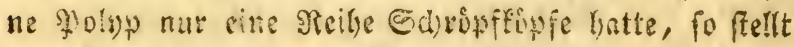

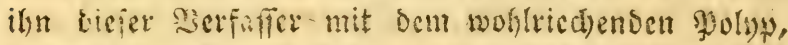

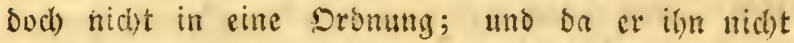
fur ben gemeinften bolten fonnte, ergreift er eine

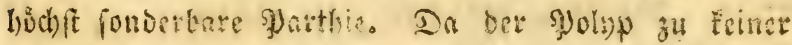
Der ifm belasnten Itren perpte, glsubte Biepner nos. lici) Den gywapen gefunder zu baben, ber ben Irgos nauten bewufget, ") and lieş yon ifum; unter biejer

*) Nautilus Avistet lis. Argonauta argo Lin. Syst. nat. Vermes testacea, pag. $5 \tilde{3} 6 \%$. Ar-

(i) 2 
senennung, eine Figur in Fupfer ftedien. *) SBenn wir von ben פpolypen mit Edhanlen reben, werben wir einfehn, Das bie alten Grrthimer hier burds cimen neuen bereichert wurber. Iflein fo viel ift ge=

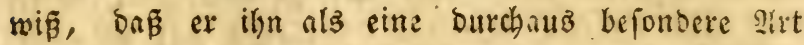

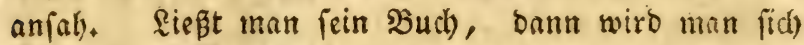
bavon nod) melse tiberzeugen. Nadboem ex von bem gewohnlid)en \$olypen mit jwey Reihen Edjropfeopfen geiprodben und ben wohlriechenden Polnpen beichries ben hat, unterlailt unz (GeB̈ner erfit von Dem \$yolys pen mit einer. Reibe Sdrupflupfen; eben to madit ez 2llorvvandi; Eeba betrachtet ilyn ebenfallz alsె eine befondere 21rt; biez alles beffinmt midh, hier

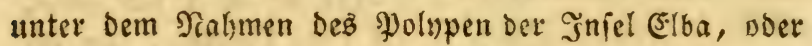
bę अolypen won sllorowandi, eine bejondere \$ुolnpen= art aufzufiellen.

\section{Erelårung Det zwen und Drenfigften Siupfertafel.}

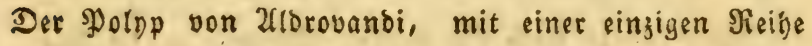
Nåpfhen, von ber Seite betrad)tet.

Ran fief)t bie ad)t Irme, bie Durd) Éeine J2aut mit einander verbunben fino; bas sluge iff fait er:

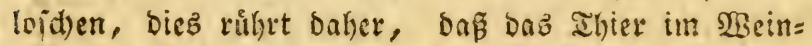
geiff aufbewalget wurbe. Die ganze Sefdraffentseif biejes Thiers mußte nus cben bem Grunbe cine grofe Serånderung leiben und ber Sîrper zufammengezogen werben. Die Figur bez Eeba, bie recht gut ift, lei= tete mid) bey meiner 2frbeit.

gonaute. Lamarck. Syst. des anim: sans vertèbres, 74 genre. - Céphalís, pag. 99.

*) Gesner, Icon. anim. Loco citato, pag. 191 


\section{Det gelocfte Polnp. ${ }^{*}$ )}

Le Poulpe cirrheux.

Dลร vorkergetyende, leserhåutige Mollube, ift nicht bas einzige unter ben nacten Thieren, bas uns

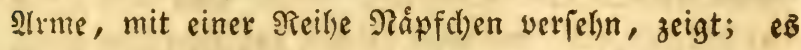

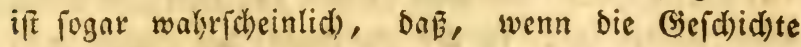
biejer a liere befinntex wirb, wenn man eine grübere 2(nzal)l von 2(rten fennen lernt, Diejez Sennzeichen bazu bienen fann, immer notfwendige Unterichiebe anzunelymen, ie nachbem fidd) bie (segenftånde vermel)= ren. Theilt man bann bie Molypen in naclte und in Syolypen mit Schaalen, fo finoet man in biefen na= tirlichen S(btheilungen nod) andere s(bweid)ungen,

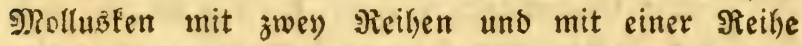
Ed)ripffopfen. Sae melyr wir bieje ahieve ftudieren,

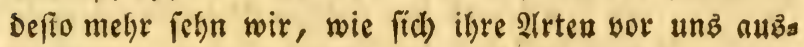

*) Lamarck, Memoires de la soc. d'hist. nat. de Paris, an 7 . pag. 21. etc. Rupfertafel I. ¿ig. 2, a. b. - Octopus corpore subrotundo loeviusculo, brachiis compressis spiritualiter convolutis, cotyledonibus uniserialibus. Sepia cirrhosa; 1. a. g. Bosc, Hist. nat. des Vers, pag. 47. - Vremde Zeeveelvoet van Benga= len, (frember spolnp von Sengalen). Catal. du cabinet du Stathouder, XII. F, aquatil. varia. Seu; Zee of Zoetwater dieren. Diefer গুolup von Bengaten wurbe burdh ein Sdiff ber englifthen offindifchen (Sompagnie nad) Stollano ges bracht, bas nach Noormidi verfhlagen war. Er war an bem Edhiffziele befeftigt. Nan lóste ihn mit einer Menge Mufcheln $a b$. Vremde Zee veelvoet van Bengalen; van het gebleven englesch oostendish schip by Noordwich in $\mathbf{1 . 7 8 1}$. et 82. Ubi supra, Nro. 119. 
breiten und entwideln. Zablreicher uno wichtinex eins

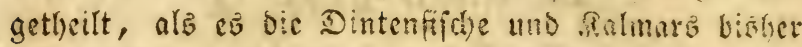

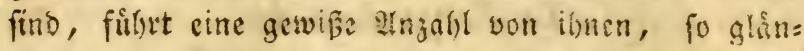
zente alz leid)te șofinangen umber, Die fie fid) zu baan verfithn, die ifhen die faft immer unver= meiblichen Sorgen erfinen, wenn man fith einen Dot warlylen will, wo man bleiben und aubruken fant.

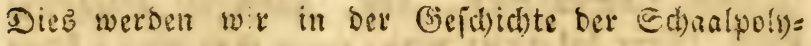
pen oder slrgonauten feryn; aber eh wir bieje begin= nen, må̉en wir exft yon eirigen iener nadenten

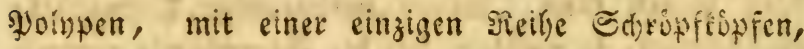
reben.

Ramatk hat uns einen son ben Syolypert fenrèn gelefyet, Der fir gleichiam unter ber shenge neuer, auffillender (Segenftände verlor, bie fids) in bem $\Omega_{a}=$ binet bes \$ुJrinzen yon Sranien befanden. Der Ëi=

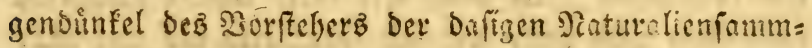
lung bătte unsิ beß̂̉elben auf immer beraubt; *) Denn Yoosmåre, ad)tungswerth in anderer feinfidt), be= fâhaftigte fich nutr mit ber Sejethreibung ber in bie Slugen ipringenden Gegenfanoe; uno bearbeitete fie langiam. Ex mulite alleb, wab Diejes sabinet fiut: treftid)es entlielt, fir fich befalten; er forien zul

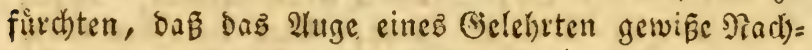
rid)ten won (siefdopfen auffapte, bie noch nicht be= fannt waren, yon benen man im şublico nidbtz

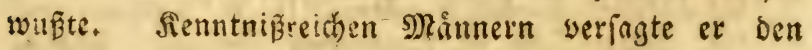
Eintritt in Diefe Galerie.

Der Molyy, ben wir ieght beicheciben, gog bie

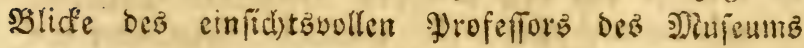

*) Die Naturalienfammlungen murben aus scolland nach) Şaris transportirt. 


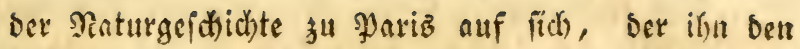
lockigten nannte, wallrid)einlid) weil bie strme roir Rodin nufgewidelt fino. *)

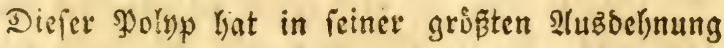

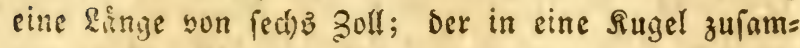
mengero!lte Sisrper, bie unten ctwaz georidit ifi, mişt Erum einen 3ull, Dex Sopf ifr um die Şålfte

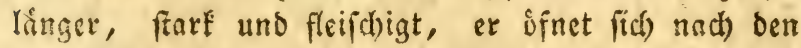
Irmen lin und if mit feiner Nembrane verjefn; an feiner $\mathfrak{2 a f t b}$ zeigen (id) zwey) fugelformige 2 lugen;

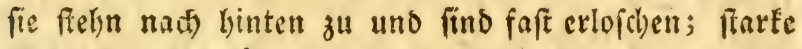
Miugkeln, bie hiber fie hinlaufen, fangen an, die Slrme won biejem \$ु)

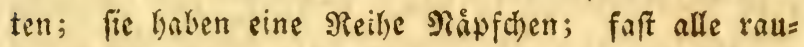
thenformig oder fedlsecfigt, verecinigen fie fid) im Mittelpunlte Deß Ilyiers uno find ba fo zufammenge= brångt, Daß̃ man ben Nuno nid)t wahenehmen Eant; bieje Schrupfeupfe ftelnn maly an einander. Die an ihrer Safib ftarken, fleifdid)ten alrme, endigen fich in eine ftumpfe Spikse; an ben Seiten find fie etwas glatt und ilyre fånge betrágt nid)t liber brey und einem halben ådf.

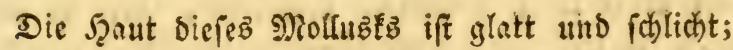
bie Şauptforbe iff weis, mit purpurnen \$ुunften getiplelt und (d)agrainirt; auf bem siuten wirb Die Farbe bunkler, bier iff blau bie J̧auptfarbe. feid)te rothe Echattirungen fallen bier ing Şimmel=

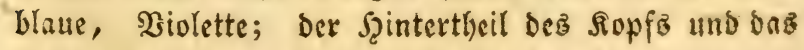
Ilntere ber Arme, bat biefelbe Farbe.

*) Cirrus, Şaartod?e. Cirrutus, locigt. 
Der augfurlyentide fanal if rund und fehe her= yorfethend; er zeigt lidd) gewúgnlid) an oer Ecite bez Sauchs; ber Miantel ooer ber Cart ift hier, wie bey allen anbern \$olypen, geifnet und feine Szaut,

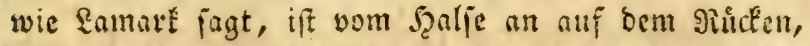
getrennt: bicjer Ulmftens, wie id) glaube, rilfyt

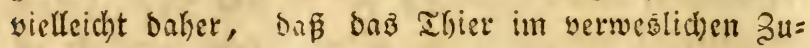

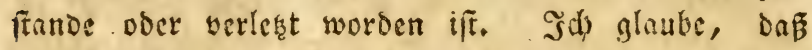
hier bie Şaut zerriffen war, um fo melye, da baz Sbiro, mit bem Lamark fein Memoire begleitet, von

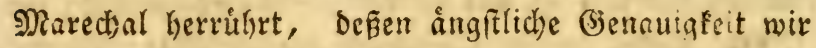

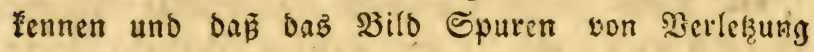
zeigt; will man $\mathfrak{e B}$ genau betraditen, fo fielt man, on oder Snat befeftigt zu fern, vortritt, und in cinem 3uftande, Der nicht naturlid) iff, fid) an ber Seite Dez auछffưlyrenden Sanals nach auffen zu zeigt, ftatt won bent Mantel bedecft zu werden, wie ez bieje Srgane in ifrem gewolgnlidben auftande find.

2luf ber andern Ceite, Gålt biejer Naturfor= fher ben lodfigten Polyp firr benjelben, yon bem

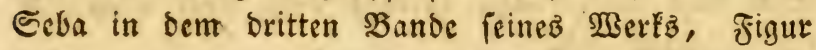
$(\mathfrak{e d}) \bar{b}$, zweyte Aupfertafel, eine (5opie liefert; *)

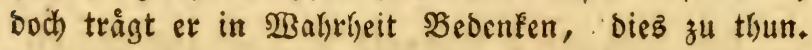
3wey Seiten in feinem Remvire weiter, glaubt er

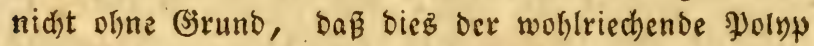
feyn fơne, bem Seba aber nid)t genug augigefajelte Irme gegeben hatte. **) §an Diejer Figur ift ber

*) An Polypus. Seba, mus. 3 ; tab. 2, Fig. 6.

**) Birft man nur einen aufmerefamen $\mathfrak{B l i d \mathfrak { a }}$ auf biefe Figur des Seba und vergleidst fie mit Der 
wolyriectinde \$olyw yon Samart, yon bem wir hers nact) reben wollen, unberfennbar. Die verlánger=

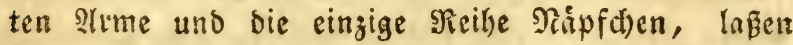
feinen 3weifel úbrig; bie bez gelodten \$olypen fino fers nersigt und furz und ftatt zufommengedrutit uni glatt zu jeyn, fino bie bez wohlriechenden \$oly=yen won Ramart, wie bie 2lune ber fed)sten figur

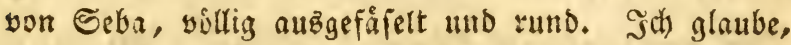
Daßz wir fie, wie zwe!) Jnbivibuen einer und berfels ben Zert, anjelin fonnen.

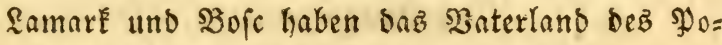
lypen nislst gefannt, bem fie beyde ben Talymen bes lockigten geben. Sein fonberbares 2anjeln beftimmte famart, ihn als eine von anderen villig unteribis= Dene 2fit zu betrad)ten.

Erelårung Der brey uno brenfigften Supfertafel.

Sie ftellt Den lockigten झुolypen auf beyben Esiten vor.

Die obere Figur zeigt ihn von hinten: hier muz 'man bie runde Esbene feinez Rorpers bemerten, Die

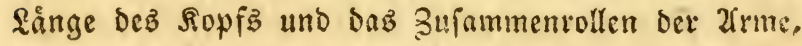
baz. zum unterjaheibenden Sennzeichen bient. Dic Ifugen find flein und wenig hervorftelend.

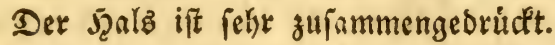

Die zwente Figux ftellt uns Daß̧elbe Nolluät son vorn bar, um felgn zu finnen, wie felyr bie

bes woblriechenden Şolypen von Ramare in ben Memoiren ber Sefellifhnft naturforfibender Freunde, fo fafll einem, icis will nicht fagen, bie 2fefulit)= Eeit, fondern bre vorrige Gleidhbrit auf. 
פi̊pfden nad) Dem Nittelpunte ber 2(rme bin zu= fammengebriaft finto. Sa fic fo naly an einanoer ftelyn, baben fie cine ecrigte (befsalt, eine natirliche ซ̌lge ihtec giåke.

Diejer Dolup woknt in Bengalen.

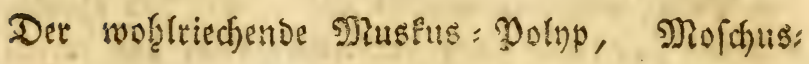
Polvp. *)

Le Poulpe musqué.

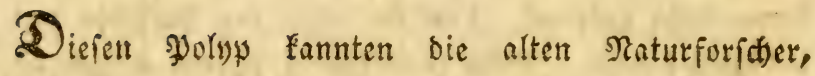
und fie serwedjelten ifn niost mit andern Fुolapen.

*) Ozoena, osmylus, eledon, bolbotion, bolbidia, helidona, osmylia, bolitana, moshyte, ozolis, Der Zftten.

Eledon - Crurum prolixitate a ceteris differt, et serie simplici acetabulorum. Arist. Hist. 4, c. 1. - Ozoena Plinii, lib, 9. c. 30.

Polypus tertia species. Rondel. pisc. 516 , et p. 373 . edit. gall. - Bolitoena, sive ozalis. Belonii eledona. Aldrovand. de Moll. pag. 42. - Polypus tertii generis. Gesner, de Moll. icon, animal. pag. 191. - Octopus moschaius. Lamarck. Mem. de la société d'hist. nat. jag. 22. Octopus corpore elliptigo laevi, brachiis loreis praelongis, cotyledonibus uniseriali. lous. - Seche musquée, sepia moschata. L. a. g. Bosc. Histoire naturelle de vers tom I. pag. 48. Polypus juvencula alia, minima corpore rotundo. Een polypus heel klein jong met een ronde lyf. Seba Vol. III, pl. II. fig. 6 , et pag. 5. - Zeyl polyp, oft veelvoet gehouden woordende voor de rechte visch van de 


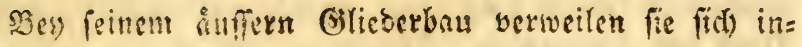

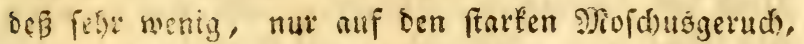
bet ex ausbunfet, fo wolst wenn er lebendig, ols wenn er nadi tem Tode getrodinet ifi, waren fie aufmerfam. Diefer ftarke, burdbringende (Serud),

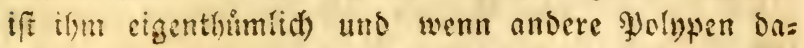
mit begnote fint, fo feunen swir feinen, Der ifln in

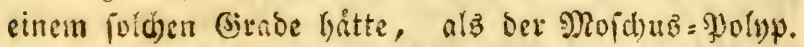
Mit Diefen Mersismen ifĩ ex zu allen zeiten unb von allen stuto:en, bie Nadyridten úber biejez Thice finterlasen baben, bejeidunet noweren.

Mir baben eimen von biejen Bjolypen wor Zfugen: ex ift ben ahieven ofine Belente bengeltellt, die in ben Galerien Deg Mufeums Der Naturgefthid)te firls befinden und war ehedem eill Stid der Eanmlung

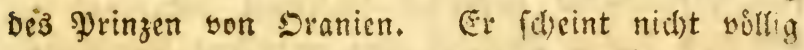

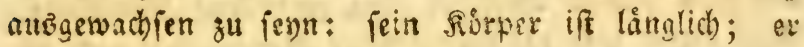
bilbet cinen vollemmnen Sact; bor Sopf liêt fich faum baran unzerjectoen; fum ift ex von, Demfel= ben getrennt, und fd)eint mit bem Sacte cire Miaffe zu fenn: Die Defmung bez Cactis obcr. Mantels,

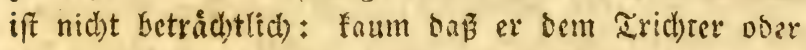

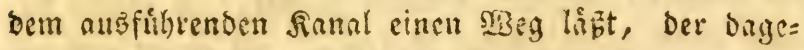
gen recht frat ift. Sie obgleich weiten 2tugen, find

dunne gekoraalde, ook doekehurft oft schippertje genaemt. (Cat. du stadh. vol. XII. Fig. Nro. 23.)

Moshiten et gopos, Dex neuern (S) riechen. Muscarolo, muscardino et muguetino, im Itas liånifhen. İm Deutfhen Difemer, Bifanling, $\mathfrak{B i}=$

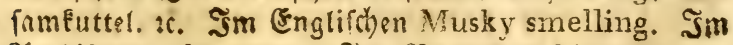
2frabifden, becropt. SIm Siufifden bisemer. 


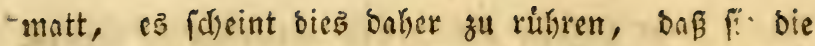

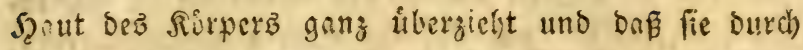
ilye Dichtigleit, Den Gilanz Der Etrahlen Des Zlung= apfels verbunkelt. Seine freien, Durd) feine Şaut serbunbene 2lrme, fdecinen fefle lang zu fern, ob fie gleid) nur zweymal linger, als ber fiorper von bie= fem Mollusit find: allein biefe Tåufchung rịbrt won ihere aแรืgefifielten Geftalt her, bie fich riemenartig verlingert: an -ben sufferfen Epitzen fino fie fo Dinn wie ein Faben! eine cinzige Feilye yon Sd)ropf= Eispen, bie didyt an einander fteln, bedectit ilyee in= nere Sberflåche. Die Sirme mitgered)net, betrågt bie liange biefes Syolypen faum ein und einen halben รันิื.

2luf ber zweyten fupfertafel, mit ber \&amark fein furtrefliches Memuire bereidyert hat, gab ex unz yon biefem Molluble cine getroffene grbbildung. Nan findet bier bie forgfáltigfte Genauigleit uno bie rulige Heberlegung, bie alle 3eidunungen Mered)als begleiter. Diefe Sollfommenlyeit, indem fie ben Gegenftand vollig nad)bilbet; contraffirt aufferor= Dentlich) mit ber (ibled)ten Figur beBelben sporypen,

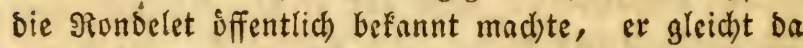
melyr einer angezindeten Granate, alsె einem anbern Dinge, und biefe Risgeftalt baben 2 llorovandi, $\mathfrak{b e}=$ lon uno Beşner copirt. Jonfton, ber biefe Figur

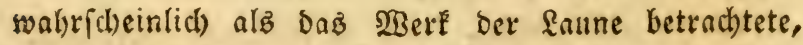
wollte fie (Allorowandi 2c.) nid)t nadyalymen. Man finoet biejen פolyp unter feinen Figuren nid)t, $\quad D E=$

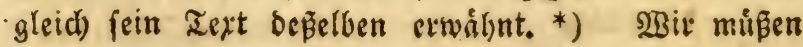

*) Tria sine conchys conspiciuntur, inter qua lẹvem et exiguam moderni differentiam esse 


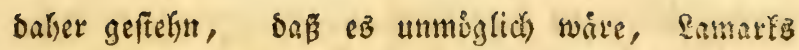
worltriechenden Jyolyp in ben zeichnungen ber ange= fülyten Sdyriftfeller wieber zu finden, wenn ifye sefdreibung uno ifre beftimmtern 2tuşbricie, bie fie gebraubiten, uns nidgt zu Scilfe formen und in

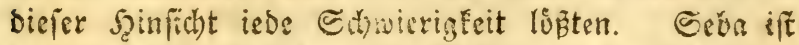

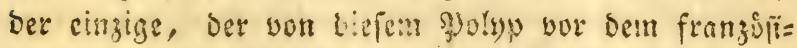
ichen Slaturforicher, cine gute, wenigfrens fennt= bare gigur lieferte; Bennod) forlte nicht viel, fo bitte ify auch famare nidjt erfannt; *) Denn ex ift zueifellyaft uno meifip es nid)t beftinmt, za wel=

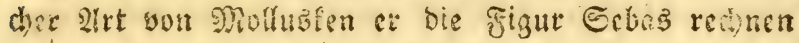
forl, nach einer reifen prifung veridjwindet erfit ieذer 3meifel, tebe ungeasiêheit.

Die Şaut bez wohlried)enben \$olypen, ift burd)=

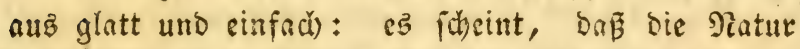

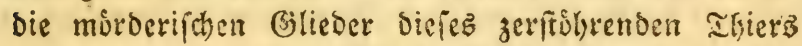
unter einer atlaffenen, glatten Şaut verbergen wolles; nid)t fein Echagrain unterbrid)t bie angenelyme (Silafur bies fer Rilien=und rojenfarbigen Scaut, Die Durch eine Pareisenfarbe gehoben wird, und Durd) Das reizende

putant. Eledone-omylos, a gravi capitis odore nomen habet. Ionston, de Exsang. aquat. pag. 7 , col. 1. in fine.

*) Das Snoivibutsm, was ith eben befacheciben will, fann bie 2rt forn, die Seón in feinem syureum abgebildet hat, vol. IIr. Supferrefel 11. Fig. 6; allein in biefer Figur find bie Wrme nicht genug= fam außgefiafolt. (Lamarck, meme Memoire, pag. 23.) An polypus. Seba, Mus. 3, torn II. Fig. 6. pag. 21. 


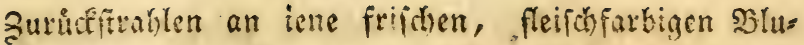
men erinnert. Die angencilmften farbenabîtufungen zieren bie äuffern Formen von biefem Molluge; die Mußfeln fino gerunbet; in ifren weid)en Umriffen zeigen fich hollunderblaue uno hellblate Ed)attirungen, bie, indem fie ben Sibattan madien, bie hervorfprin= genoen Theile vortreten lafen, beren weicher uno rei= ner Inftrich unwillfillyrlich an bie Mablerei cuinnert,

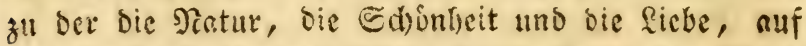
Dem Garbenbrette bein Illbani bie Farben rieb. WBenn bicie trufdiende 2 (unfenicite mit ber Mad)t auf bie sBafferberwohner, wie auf bie Bewolnner bez feften Runbez, wirlt; wenn ber 2lnblict einer fidonen Ges

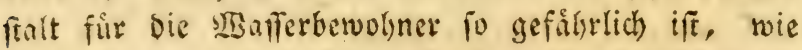
für uns, was bod) keine offenbare unmuglidyleit ifi, Dann ui ber wohlried)ende झJolyp felyt furditbar fur fie. stllis un ihn if anlocteno. Ein wohlried)ender Suft serbreitet fith um ben Dot Becines 'iufenthaltz;

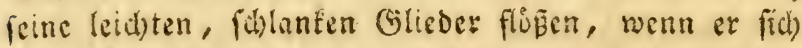
nalyt, feine Furdit ein, erft Dann, werill er mit fei= nen graujamen Strmen ein ungludflid)es Thier un=

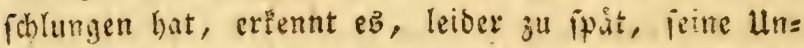

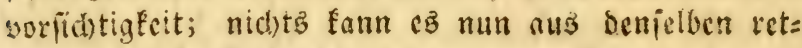
ten; Dic Tåu(t)ung (đ)

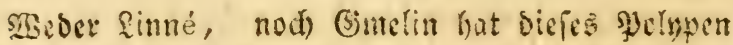

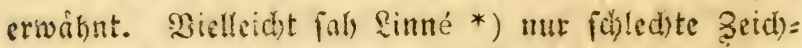
nungen von bemfelben unb hielt ifm ber Ilufmerfian=

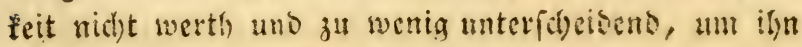
als eine bejondere Ilit alfouftellen.

*) Nur forgeride 2rtell zrigt er an: Sepia octopusunguiculata. 


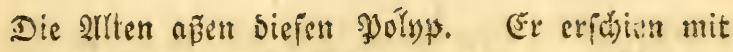
Den Dintenfifiden uno Salmarz auf ithren Iafeln.

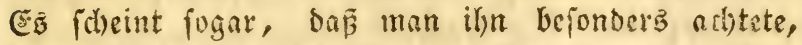

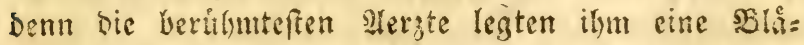
hunizen vertreibende und fintulimente firaft $b(y){ }^{*}$ ) Dis Diditer bejangen peine Eigenfáaften. 2ruf cine anbere sirt vermelyten bisfe slolypen bie sisergnigun=

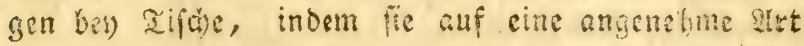

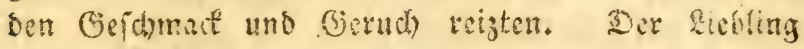

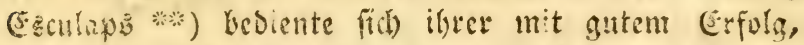
um gefirgrtidyen firanteiten zusorzutommen ober fie zu heilen, die fint bie neure Şzilfunft cin Etein

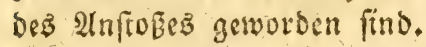

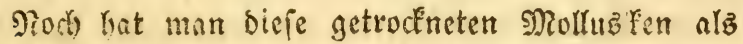

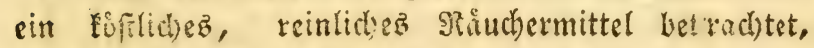
bas man in fiofferz does Edrunke legt, Darnit bie Reinewand doet bis Nleider, einen angenelymen (Be=

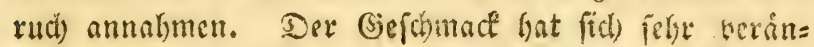

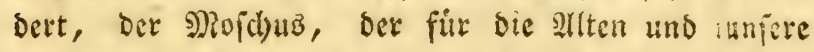

*) Ad venerem excitandam plus caeteris valere creditur. Hippocrates, lib 2 , de morbis mul.

Polypi, sepiae renerandaeque, loligine's Et quae mare olet bolbytis.

Epicharm, in nuptiis hebes.

**) Praeparatur ad cibem utraque species eol quo superior modo ad uterorum cancros futuros bolbydia et pisces cartilagineos. Et si u terus ad coxam aversus fuerit, bolbydia in vias et oleo cocta praescribitur Et eandem similiter praeparatam, aut sepiolus ad menses ciendos. Hippocrates, de morbis mul. lib. 2 . 
Sitter, fo fofflid) war, als bie theurften Epeces reven, if foft gang auz uniern Raud)erbecten ver= bannt, fo wie die buben unferer Epezerentråmer verjd)munben fino. Sisaz bavon aud) bie Urjache feyn mag, lurz, ex gilt nicht melyr. Er wirft nicht melir angenclim auf unjere Gerublsnerven, wie ę bei) un= fern $\mathfrak{B a t e r n}$ ber Fall war. Seine Stårfe und ber Tervenreiz, Den ex erzeigt, baben iljn serdåd)tig ge= macht. Jath fal \$erionen, benen ber Nofdjusgeruch গiajenbluten zuzog.

\section{Ertelärnng Der vier uno Drenfigften Supfertafel.}

\section{Der wohlriectente Şolyp.}

Er if nach) bem Sndiviouum gezeid)net, bas fick in ber Stationaljammlung befindet; fein Sorper ift linglid)t; Dev furze Sopf madht mit ihm eine Maffe ลแลี; Dns 2luge ift matt.

Die Slrme in Geftalt runber, fohmaaler Siemen,

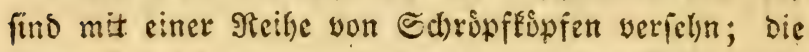
Irrme find felhe lang und laufen in eine Epilge aub, olne aufgerollt zu feyn.

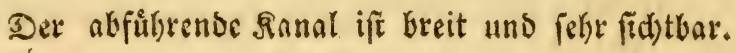

Der mit Silauen verfefene polyp. ${ }^{*}$ )

Le Poulpe onguiculé.

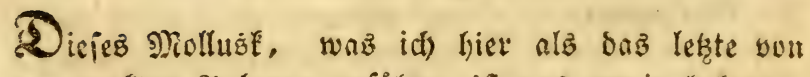
Den nactiten Solypen anfuirite, ift uns wenig befannt,

*) La sèche onglée. Sepia corpore ecaudato, brachiis unguiculatis. Molina, Hist. nat. du Chili. 
uno faum wiffen wir etwas bon bem, waz bnäelbe betrift. Nolina ift ber einzige, Der friner in ber

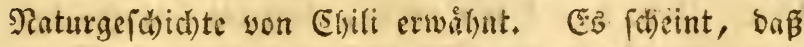

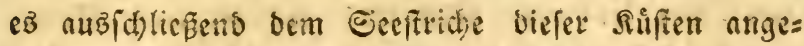
lourt. Nolina giebt uns von ifm cine blof̂e Inmer= fung uno theilt uns von semfelben feine ausfintyrliche

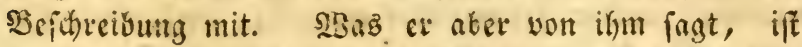
beutlid) uno beftimmt uno lispt weit mekr wuinjhen.

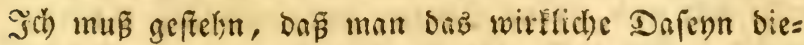
fes spolypen nicht verfernen fann; ob et auch nue mit wenigen sinien gezeichnet iĩt, fo find bieje senn= zpid)en won bein fpanifden 2 futor fo auffalleno barges

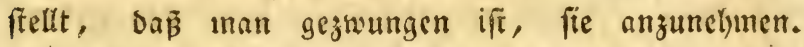

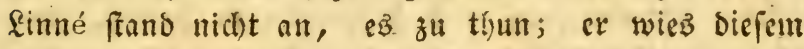
gJulapen eine Stelle unter Den Sefdhopfen an, Die

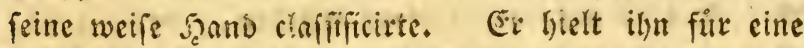
befondere 2(rt; feincm Seifpiele folgte cin fromzopil=

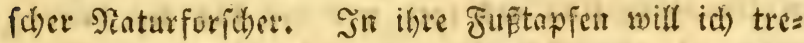
ten. Diefer stolyp, der von alfen, die id bisher

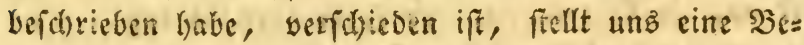

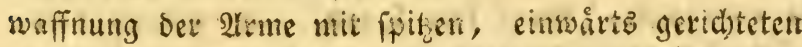
Firallen Dar, wie die ber furdytbarfen, fleifhireffen= Den Raubtyieze unter den vieriłígigen abieren find.

Diefe ganz neue Mode ber Siemaffunng mit Slauen, die unsิ etwaz ganz nnoercb, wie bisher,

Sepia ungaiculata. Species 6, Lin. Syst. nat. verm. prig. 3150. - Corpore ecaudato, brachiis unguiculatis habitat in mari pacifico, Chilli alluente, rarior capidissima, brachiis loco verrucarum unguiculis armatis in proprias vaginas retractilibus. Ibidem. - Bosc, Hist. nat. des vers, tomic I, pag 47 . 


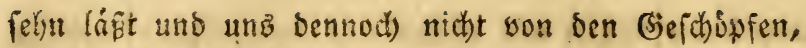
Die Der Gegenftano unịerer Betrad)tungen fino, ent= fernt, beweift unz won neuen, Daßs die (d)uppfrifd)e, fraft = und lebenoolle attmact)t, fid) in ifrer uner= mesflid) feit bie exhabenfte slbweichung von ber geworkn=

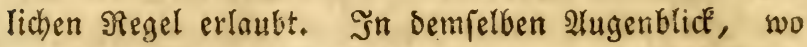
wir biefe Natur feftzulalten meinen, entid)lípft fie unz; aber fo flitditig fie unz auch focheint, fie weidt't nid)t von uns, olyne Epuren zurưdzulapen, bie unz beluhffict) fint, fie auf ifferm verid)lungenen Gange wieber zu finder; unb wenn wir auf ihrem \$fabe unz verirren, inbem wir ilfe nadifolgen, fo wiro

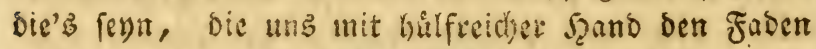
reicut, um unz nus dem faburintly zu helfen, in bas wir gerathen find, weil wir fie ergreifen woll= ten. Sie if tiber alle Gepetge erhaben, weil fie fie woll tiefer SBeizheit beftimmt; an biejer unbefchråne ten Unabrångigleit erkennen wir bie Daß All bewe= gende und regierende Rack)t. Nergebens verfud)en wir $e^{b}$, fie feftzuhalten, fie flielt allen zwang; fie, bie erhabenfte, fennt fein Band. Bergebens ver:

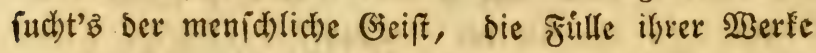
zu umfaffen, obgleic) bie Cirenzen, die fie biefem Geifte bezeichnete, unermeslid) fins, feine Begriffe erreichen ifyre Majeftåt, Den grenzenlofen umfang ifles (jontizen bodi) nie. She Schoos ift geufnet, um alle nur moglid)en (jefchônfe zu erzeugen; benn allez, wab antftehn fonnte, exiffirt. Boll Rulbe, aber immer wirffar, ftreut fie eine Menge von (Sefd)op= fen um fids ber, die mit (Siefingl und Leben begabt find. Şier verfagt fie diefe Graben und weniger frei= gebig, fdheint fie fie nidht bem Sanzen fichenfen zu wollen. Mitten aus einer, f(heinbaren Berftúl)rung, unter Sdbeden und zoben, fehn wir, wie auf eins 
mal ein unter nllen Beftalten bermebrtez feben her= vorglänzt; was nod) melgr iff, nus Dem Sturm und bem friege ber whithenden Elemente, treten neue Weien, nene Mobificationen Der Materie herbor, wowon Der Menich, Det flamme bes (bientez unge= ad) tet, bie ify begeiffert, nur ein fleines Ilyeilden ift. Mit weld)em Enthufinzిmus mus unz biejer $\mathfrak{B} e=$ griff bon 2tilmacht nicht burchbringer, und welchez if ber ungeheure 2 bffand, Der uns von biejer bene= genden Siraft trennt, uns, bie wir uns auf ber Sungel, bie fie unz anwiez, alż bie oberften Ges= bieter, als ben unmittelbaren 2luşfuß̃ (émanation) Der (5ottlyeit betract)ten, Deren unabjelbares Ganze nid)tb ermeffen fann.

Dicie Bottheit zarblte unjere Iage uno beftimmte ben lez̧ten Derjelben; unter ifrer ḩand find wir, wie die andern $\mathfrak{B e j e n , ~ b l o g e ~ B e f o r b e r u n g a ̈ n i t t e l ~ D e r ~}$ Generationen uno funftigen Mlobificationen: wir formen ifye Unermeblid)teit hienieden nicht einfelyn; und ift ez bem Menfchen einft verginnt, melyr ba= von zu begerifen, fo wiro ez bann gefdelsn, wenn er, frei von feiner ferblichen Ş̧ille, mit bem gôtt=

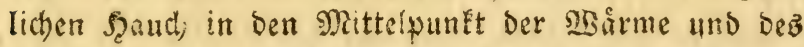
Lebenz oringt, yon Dem er, in ber zeit feinez $\mathfrak{e}$ benz auf Erben getrennt war. Diefe extabenen goeen begeifterten Die Taturforicher immer bey ifgren 2 lrbet. ten, ein ieber hat fie nach ben Empfindungen, bie

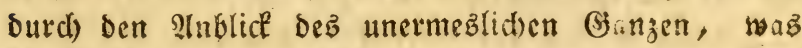
bie (Beid)opfe vor ifm ausbreiteten, erzeugt wurben,

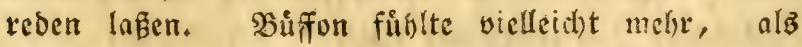
irgend ein anberer, diefe begeifternde firaft, und

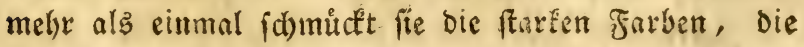
ifm feine glihende Einbiloungşfraft lieh, un feine 


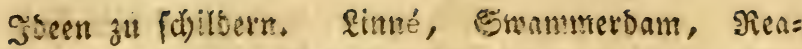
mur, und al'e Paturforicyer, baben immer ibre Erimme ertoben, un die $2 B$ under der Seatur und

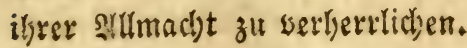

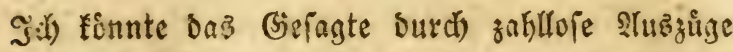

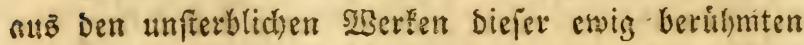
Sybilofophen, beftâtigen; allein meine unpartleiifchen, geredyten uno cben fo unterridyteten ?ejer, wiffen

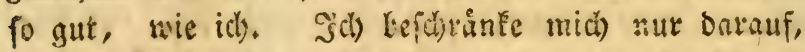
woirtlicl) bea 2unfang der నorrede, mit Der \&inné, Dec beforoibenfte, geldyrtefte alfer Scaturfurfdyer, fein

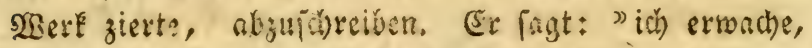
wie aus einem ticfen Edhlaf uno bete meine $\mathfrak{A}$ (ugen auf; fie sfuen fich uno ber) bem stnblict oet Uner= meslid) Eeit, ber ewigen, unendictyen, allmådytigen Bottheit, werben meine Einne vom Etaunen erfduct= tert. Mallenthalben iel ich feime, Den Singen, bie ex (a) uf, eingebructe Spuren. Srltentíalben, in ben fleinften und unbebeutenoften Cegenfianoen, bie grós̆te

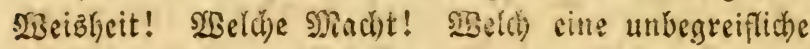

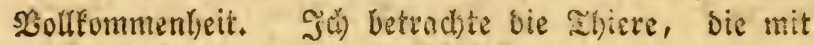

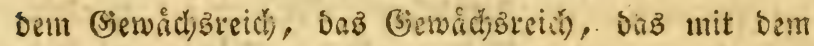
Ihireretich uns biefer, bas mit ber Sugel, bie alif ifrer unverånoerliden Solfa un sie Eente rollt, won Der fie feben empfangt, in sep innigfen 3erbinoung

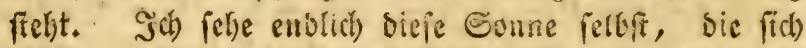
nit ben anoern Bieftirne! um eine grye bewegt; und

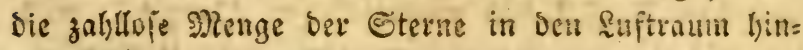
geftefl, ber unenolid) iff, bur(h) ben silllen bes

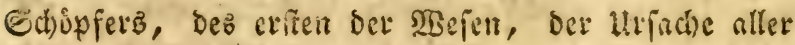
Urfachen, Den Erhalter, Den Scerbid)er Des Ilt!

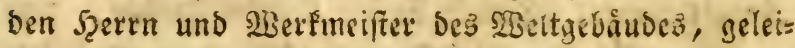

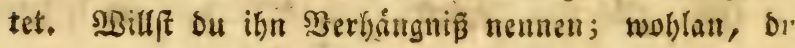




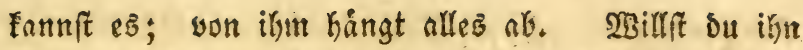
Natur nennen, auch) bas fannft bu; er ift Der ltrlye ber und Sater aller Dinge. 2Billft ou ifn ben Nents=

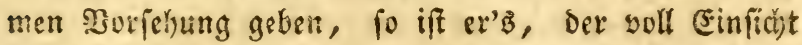
Dem (5)anzen vorfel)t. Er ift lauter Sinn, Sluge, Slyt, Secle, Geift, ganz felbft; fein SBefrn i, ein 2logruns, in bem fid) ber menichliche serftans werliert; et allein ift Gott, ewig, unermeslid), nicht geichaffen, nicht gezengt; ohne ihn wáre nid)tz, feine Mend)t hat allez gebilleet; er iff unfern serblendeten 2lugen unfictsbar, allein e: offenbart fid) bem Siad)= benten; in einem undurdsoringliden fidte serbor= gen, entyullt er fich) bem (seifer....

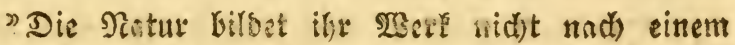

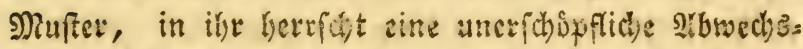
lung; fie láp citte form nlif bie andere folgen, be: gnight fich nicht mit eittem silbe, fondern madj) wou ilyrei Siraft bie borfdicbanft 2lumendang. (c

"Diefe Betrachtung bet Natur, ifi ber Sor: (d) mact himmlifd

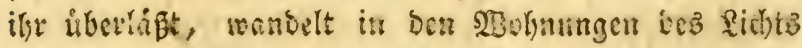
uns brinçt paite Iage wie in cinem Sgimmel onf

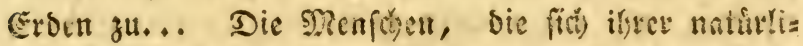
d) Nen Neigung hiberliefen, Gaben bie tunterfutbungen, bie bie Ratur zum Eegenfiande hatte, inmer hod)ge= ad)tet; bie wahten $\mathfrak{B}_{\text {Beifen }}$ beid)aftigten fiil) immer gern mit ifle, (Snftem Der Niatur.)

Sie Sciptze Der Natur find civig, fo befinmmt und allgemein fie inber allid) find, ifye fortgciefzte

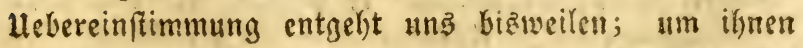
in alfe ifye Srummungen madjuflolgen, wiro cime 
Sette ununterfrodhener Beobaditungen und Ihatfad)en erfobert, bie, inbem fie bie Gefdoupfe yon ifferm ent= ferin umfaßit, unb ben 3uftand aller sibejen, ben

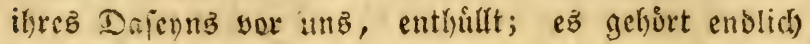
bie Geichid)te aller aeiten, aller sorte, aller (Frichei= nunzen Dazu, bie natirficher $\mathfrak{B}$ eife nad) und nad)

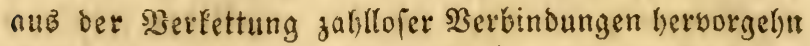
musten, Deren (sirundfoffe fid) zu ben verichiedenen

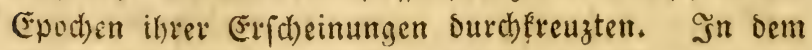
Grabe, als unz neue Begenftånde der Bewundrung aufiroßen, mitpen wit's anerfenten, oaßs alle migli= deen Formen fowolgl in bet Paturlefree, wie in ber Plokal fintt finden.

Det mit Srallen weriefene Molyps won Ebili, entfernt fid) alfo won andern Sुolupen, wie ber Din= tenfifch mit fechs armen, Der fich ebenfalle bafelbfit befinbet, wor andern Dintenfifden verifbieden ift. Scin Norper ift rutto uno gleicht Dem ber Spolypen; wie fie bat $\mathfrak{e r}$ acht 2 frme, bie sermige ihere $\mathfrak{B} i e g=$ famecit, allex wellenformigen Bewegungen fähig fino,

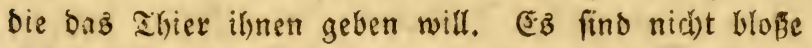
Ed)ropffipfe, bie fie nad) ifrer Eange lin bewafnen, fonbern eine boppelte sieilse won forarfen, fwitsen Sirnlfen, die biejez Miolluả beliebig in eine Scheibe zuidtziefn, fie in berfelben verbergen fann, weld)e

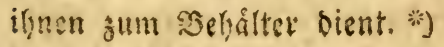

*) Rufir bein gctoofntichen Dintenfifich, Sepia octorodia, findet man in bem Meer von Ehili,

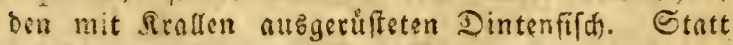
ter Rafaugetheile, hat ex \$foten, die mit siner boppeiten sReithe Rrallen, wie Die ber Saben, be=

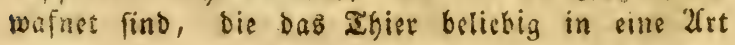




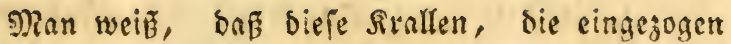
werben funnen, ein sorzhiglicheß Unterfibeioungżzeis (i)en Der Tiger uno ber andern Thiere fint, Die, gleich ithen, fid) iffrer beute bemåd)tigen uns mit langen 3̧igen baz vergoffene Slut einjĕhlürfen, mehr um ifjeen graufamen 'Durft zu Ptillen, alz iheen zers frobenden Şunger zu befriebigen: biefer Bergleid")= unģ̋unft fellte ung nod), um ben goinpen ben blutsureftigften Eharafter benzulegen. Dicje 2telntich)= feit mit ben graufamiten, vierfä̧⿰氵㔾刃en ahieren, be=

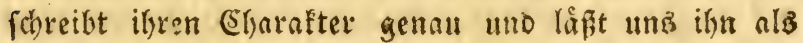
benfelben betract)ten. Gal) babe die Groufamesit bes gemeinen solnpen gefdilbert: menn ber fralligte

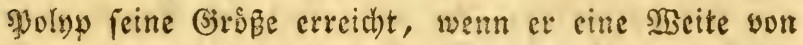

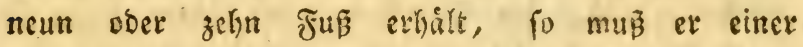

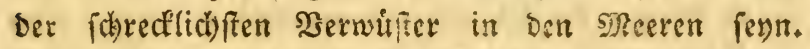
Seine gebogenen, vielfad)en Srallen, feft an cinn= Det gebridt nact) ber ganzen fiange ber actht alme ljinab, immer auzigeftecelt, um einen nid)t gu geni= gensen $\mathfrak{B l u t b u r f t}$ zu befriebigen; fein fdjarfer fobnet= Denber Schnabel, der faum cine Beute hat falyren laffen, um eime andere zu zerreiffen, die feinen un= erfättlichen und immer wieder entferenden Durit, noch) nid)t geftillt hat, macht ilyn hocbif furchtsar. Dies alfo fino bie sisnffen, mit Denen bicfer झुolys iedes 2 sejen, felbft in ciniget Entfernung bon ber

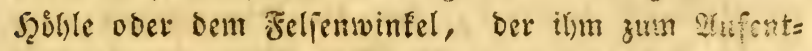
halt bient, anfållt. Ev fưrzt aแz bemielben, wie

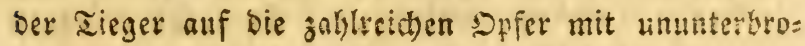

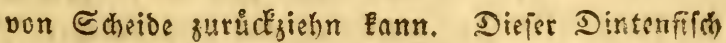
hat einen Efftichen (S) fohmarf, allein men findet ihn in ben sepern nur felten, (Molina, Hist. nat, du Chili. prg. 175. im Fravizoofifden.) 
dhener 2 Buth hersor, sie nidstb befinftigen fann.

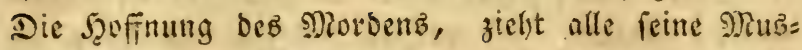
feln zufammen; feine Sgaut, bic fich finifternd runzelt, wirb roth und b!a

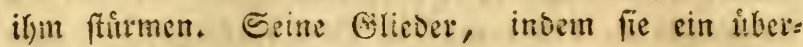
sounbenca zhiet umfiblungen hatten, fuchen andere

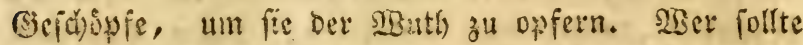

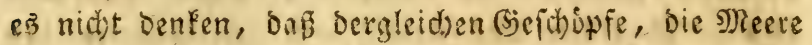

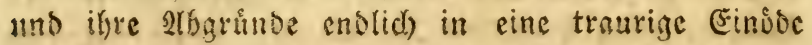
serwandelten? Die Natur foheint ihere Berberung cin Sringernis entyegengeftellt zul haben: fie fino nicht zablece(c): und weldhez aud bie lurfache fenn mag, bie ilyer Sermelyrung zuwioer ift, Der Serfalfer,

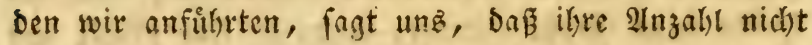
betråd)tlid) ift: Die Menfiden felbft fiulgen gegen fie

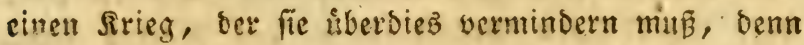
ifye Fleifd) wito fefle geiudbt uno giebt ein herrlides (sericht, Das fich) bie Einwolyner yon Itmerifa mit vieler segierde zu verfachaffen fuchen; uno bie fif her, burch ben Berbienft aereizt, inbem fie auf ben Fang

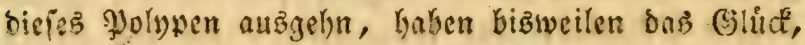
fich eines ber blutbixrftigften Seety:annen zu bemád)= tigen.

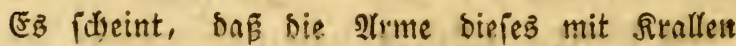
aubgeriffeten \$olupen, wie bie Syolywen mit einer Sieilye Echropflipfe, an iffen bafiz burd) feine

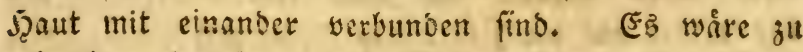
whinichen geweien, daß̃ Molina feinen Biegenftand weitlinftiger befandelt baitte; ftatt siner zu gedrings ten Seftreilung, muifte er uns solffinnbigere গiad)= rid)ten uber ein fo auserorsentlidjeg Thier mittheilen.

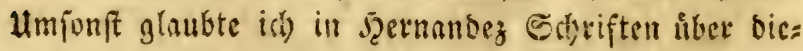




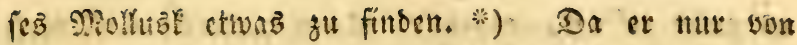
Byfanjen und einigan auffalienden Thieven fprisyt, hat $\mathfrak{c r}$ fich mit den Thieren ofye Gelenfe, gar nicht

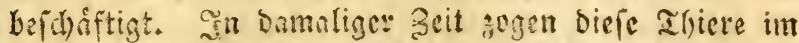

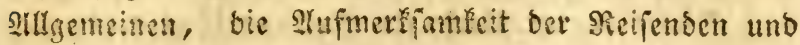
Naturforice nidet suf fith, be: mit Rithen bewaf=

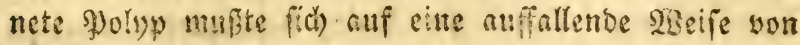

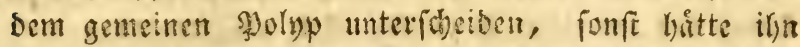
Molina nicht alo cine vou Demfelsen zu unteridyei=

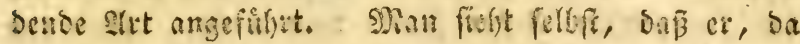
er bie Sintenfifite, Salmars und Molywen unter cines uns berferen senennumg serbithot unt fie mit cins

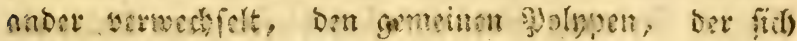
auch an ben Sinfen won Egili findet, als eine zert

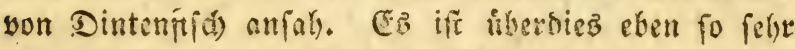

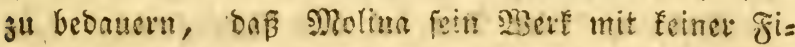
gur begleitet hat; fie biatte bagu siemen finmen, die

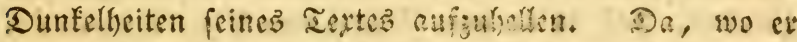
zu gedrångt fobreibt, hatten bie figuren bie wanigen Beilen, die ber $\mathfrak{S e r f a f f e r ~ s e n ~ i e t e m ~ G e r e n f t n o t ~ i t ~}$

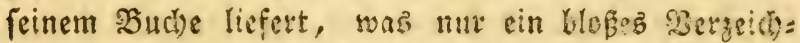

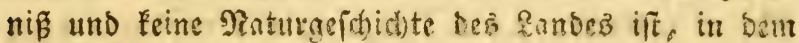
er reifte, beftátigen fimen. Dirfer Manget zuirgt

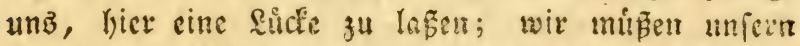

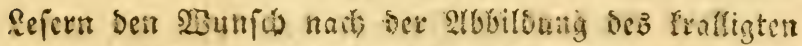

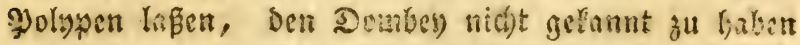
fctseint und ben iă auf mainen Reifen sid)t fars. Dic Tead)foufdurgen, bie ich fonft nod anffertte,

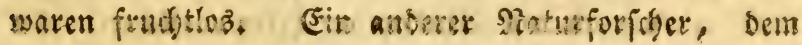

*) Rerum medicarum, seu Thesaurus novae Historiae. Francisci Hernundez, in Folio. Romae, 1751 . 


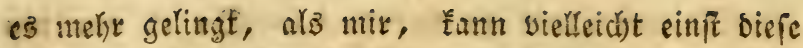

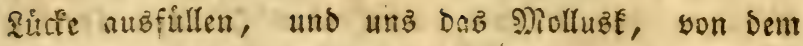

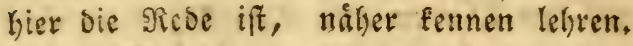

Diefer fuzzen Padfridyt Melinaz ift vielfeidt) bas

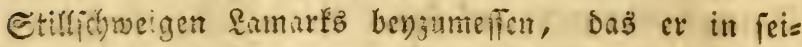
nem Nemoire itber biefen şolyp behauptet; obgleich Rinné ifyn alb eine bejoniere sltt aufgenonmen hat,

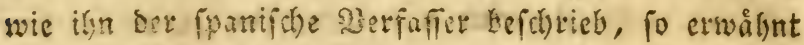
ber frallzifificie sluter feiner bod) nid)t. Soje hat

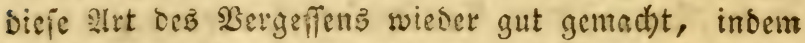
er Die 3eobacítungen Molinas aufnalym. Ere war §innéz Neinung und wir fino biefen brey 2tutoritå= ten gefolgt.

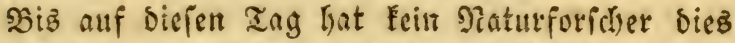

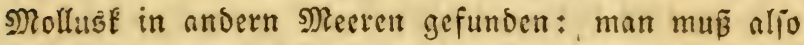

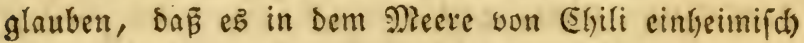

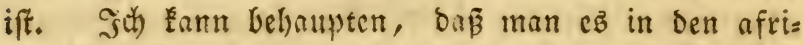
fanifiden solecren uno um bie IIntillen nicht antrift;

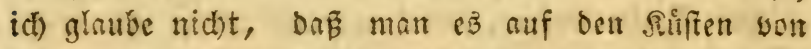
Mexico entoedt, wo e⿳亠丷, wie cริ mir vorkn, ganj unbersnnt ift.

Diç Molluą ift fin unz bas lekste ber unbes

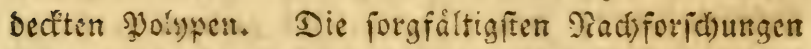
baben mich) ưberzengt, baj bie slutoren, Die libet Diefe Thiere fátrieben, weiter reine, alz biejenigen fannten, bie ich Den Bliden ber Rejer vorfülytte. ËB hat mir unglaubliche Maill) gemad)t, Diefe N(rbeit biz zot Der Solffommenlyeit zul bringen. SBie viele Bidber

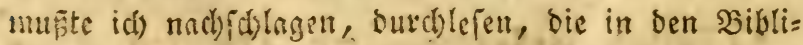
cthefen zerfersut lagen, bie id) in ber Menge nut in

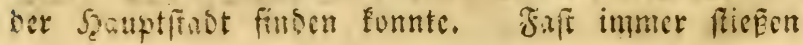


mir bey biefer STrbeit grope Cdywerigeriten auf und id) glaube nid)t, fie alfe befiegt ju baben. Berwipe Jolyparten waren fo unter einamber geworfen, fo in einander verwicéslt, wie ein ungeftalteter Snaur; anbere Slrten waren zweifelfaft uno inz Reich ber 233 unberthiere verwicfer. Sielleid)t giebt es unter ben sielen Paturforidjern nod) welche, bie bie ungeheuren belebten Minfen in Erftaumen fetsen, sie fie fir wirl"s

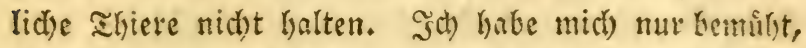
Ihatfachen aufzuftellen, id) ůberlaß̧e meine sieinum= gen ber syrifung. Eine gerechte Eritif werbe id fos nutzen; alle Naturforicher werben inde无 barin hubers einftimmen, Drế Die genaue Unterfaheidung ber Strten, fiu einen Echriftefteller ber Paturgeichidyte, Daz

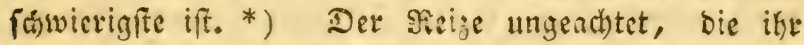

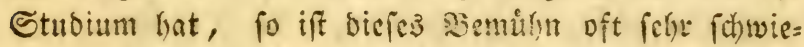
rig, oft fogat unbantbar, unb bis asit allein fann zur 20 offommentyeit firber.

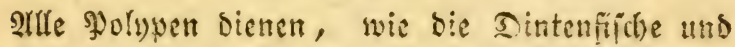
Salmara, in genipen Gegenden ben Menjojen zut Nablung und in vielen biefor finder vergelyet on

*) SBenn man aber bedenEt, daÉ vial 3eit und oft unendiche Rachfuchungen erfodert werbsu, endich bie Befohidhte ber 2frten aufahtellen, um iebe einzeln auf eine beftimmte, unterforibende Zrt zu charakterifiten, Damit Die Ihiere, Die zu Derfelben 2frt geforen, aud benfelben Plahmen

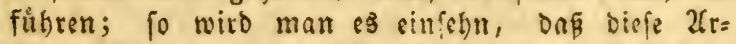
beit nicht von einem SMenflen, in Eeiner alege= melienen Zeit, verrichtet werven Eam. Sie

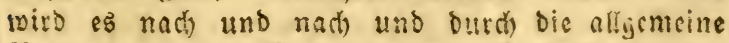
Berbindung aller Meturforforer. Eamark, it fois nem. Mtsmoire, Eeite 2 . 
gemeine Nole cine bedeutende Nenge berfelben. Diefe Ihiere, Die nu ben firfen liegen und fich an bie Felfen feiffaugen, fino weit teidjtor ju fangen, als

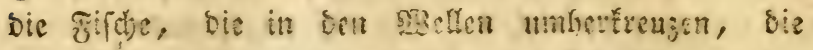
yiel mithe nothementig madyen, um fid) ilyere zu be=

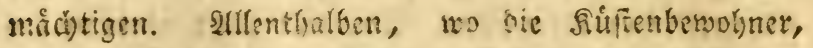
orm, träge, verftantozarm fint, wern fich bey

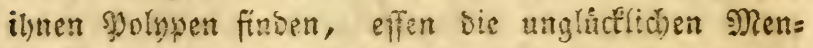
fden fie und machen fie zu ifyer Sgauptoft: *) wenn im Siegentheil ber Şandel, Die ¿iebe zur \$lrbeit und Daz aub ifr bersorgefende Mzohlbefinuen, biejen uns

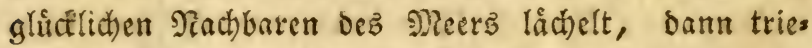
ben fie bie weit ichwerete Fifherei, oie aud eits

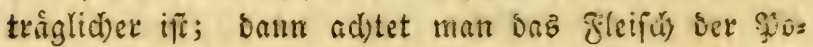
Inpen nidat megr, bas yon Patur unverbaulich tich,

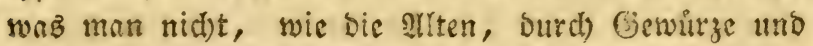
foftbare 3abarcitungen, erweichan famr. Dab vor:

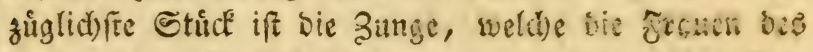
2rrdbipelngus begierig fud)en uno volg effen. **) Eine

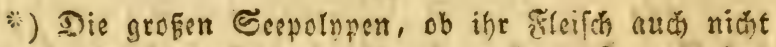
fo gut formedit uno nid)t fo gefuno ift, ats bas Der Fifche, dienen wegen ihres Ueberflußes ben Griechen boch zur Nabrung, bie, on fie in Det

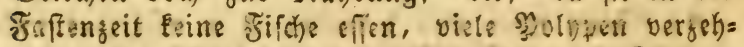

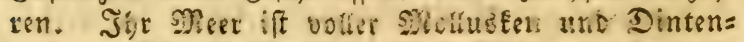

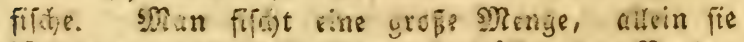

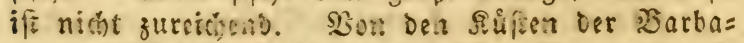

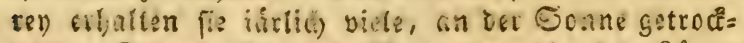

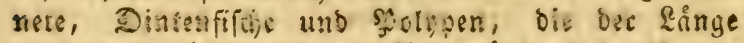

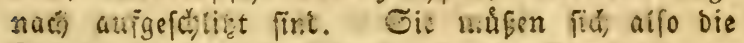
Soffenfpeife Eatifor, Die fic fid) in i.)rem eigenen Eanoe verfăaffer Eonntea. (Sornini, Voyage en Grèce et en Turquie, tom II, pag. 215.)

**) Daz Ficifch von bicfem Molluä ift bart, lcoer= 


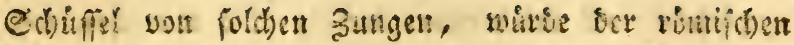
fecterthaftigfeit fo foffere als delicat gewefen fenn.

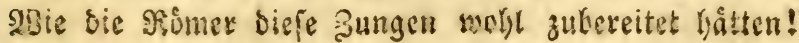

Die Wolnpen fobeinen itm allgemsinen die Dintent= fifthe zu verfolgen, entweber um fie zu verzehren, ober indem fie ifnen bie cingeweide nusleeren, fich Des Mlidenbeins zu bemiditigen, nach Dem fie febr

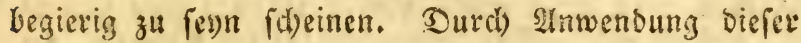
Lodipeife, fangen bie griedifden Fifd)er foff alle

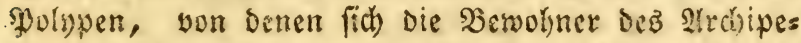

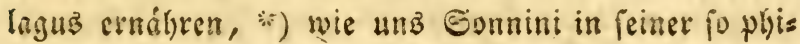

båutig und unverbaulich; es hat biemeilen sinen )) (ustuggeruch, †) Der ofnftreitig von ber Siahs rung berrihnt, bie bas Thier zu fiti) nimmt. MBenn es getocht wiro, nimmt es eine róthliche Garbe an, bie es Dem Mafifer, tino andern Dim= gen, in Denen man eg fortht, mittheilt. Lim Das hrutige $\mathfrak{B e f e n , ~ a u s ~ b e m ~ d e r ~ \Re o r p e r ~ d i e f e s ~}$ Sholnps beftalt, ju erwsidhen, flopft man inn einige zeit, wirft ifn melyeremal tubthing auf Steine, indem nan ilgn mit füsem $2 B_{n} n$ fier be= fprengt. Die griechilaren Weiber, die diefes (Ge=

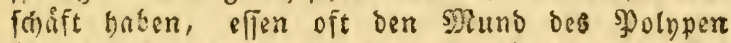
(la noix) roh, unb diefse ift fur fie cine 2trt von $\mathfrak{L}_{\text {ec }} \mathrm{erbifien.} \mathrm{Sonnini} \mathrm{Voyage} \mathrm{en} \mathrm{Grèce} \mathrm{etc.}$ pag. 215.

†) Wsie wir gejern haben, effen bie (3riedjen ben ges

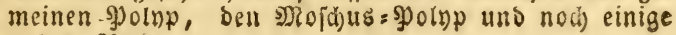
andere 2irten.

*) Der fefte uno faft fnochigte Ilecil bes Dincenfís

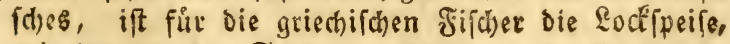
mit ber fie inte Sthnuren verfehn, Durch die fie Den Polnpen fangen, (sepia octopus, Lin.) Den fie Klapodi nennen. Ein an Der Esthur befeftigs 
68

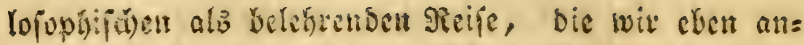
gefülyt haben, meltet. Ifllenthalben, wo bieje

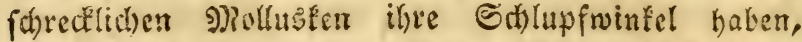
wiro allez aufigefieffen, sllez zerfithrt und fie laken

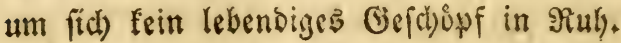

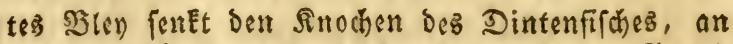
ben man Fif changeln bindet bis auf ben (B) Deß̉ Mecrş. Der Mुolup verlåst die Rllippen, an die er fich mit feinen 2frmen oder Făhlhórnern fefts

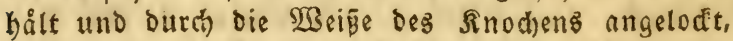
beist et in bie 2frngetn und fangt fich. (Sonnini, Diefelbe Reife, Seite 214). 


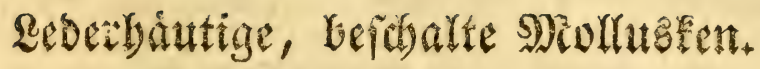

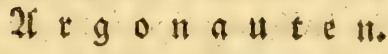

(3)

\begin{abstract}
D.
ex Sivper ift runb, wie ber ber \$ुolypen und in einem Sacte ober in einer Sdheide eingejd)lofien, olyne Flügel. Er entralt feiner freibe = ober falfarti= gen Rnod)en, noch eine hornerne झJlatte; Der Sipf

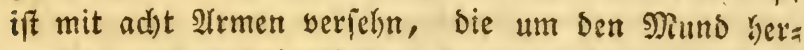
umftelin und Edhroppfeipfe haben; bie bevoen exftern,

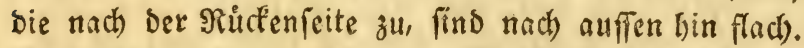
Diefe Thiere bauen fid) eine Muldhel, bie nidbt an fie angewadjen iff; fie ift einfdralid)t, nicht in Siammern abgetheilt; in Der Geftalt cineż Schiffz gefalfatert, Die SSinoung gelft nad) Der Defmung.
\end{abstract}




\section{Dur Mapiernautilus. *)}

L'Argonante Papiracé. Argonauta Argo.

Sut ben vergangenen zeiten, wo sie Paturgefdjichte weniger befannt war, gebiely der limfang erlangter

*) Argonauta argo. Lin. Syst. nat. pag. $336 \%$, sp. 1. Animal sepia, aut eliv. Testa univalvis spiralis involuta membranacea unilocularis.

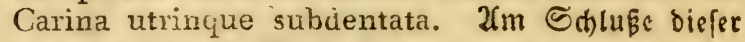

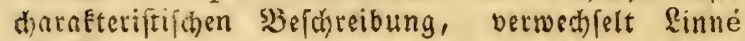
alle 2Trten mit einanber; or mad)t Esinen Unter=

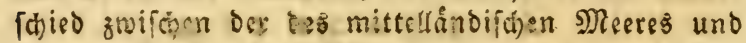
ber von Snoicn. - Nautilon et nauticon. Arist. Hist. lib. 4. c. 1. et lib. 9. 37. - Naupilus. Plin. lib. 9. câp. 29. et 30. - Nautilus Aldrovand́. de testaceis, lib. 3, cap. 5. - Nautilus graecis, riautilus, vel nauticus latini. Muscarolo napolitani. Nautilum vulgus neapolitanum muscardinum et muscarolum nominant. Belon, de aquat. lib. 2. pag. 378 . et 380 . Rondelet, lib. 18. cap. 7. pag. 374. - Nautilus. Gesner Animal. mar. de moll. ord. 13, pag. 192. - Ionston, Hist. nât, exang. de turbinal. tab. 10, Fig. 2-7. - Bonn. Recreat. pag. 142. Fig. 13. Kircher, Mus. Fig. 33. Eefine ofiguren find biefelben, wie die bes Bomnani-Gtaliteni. Test. taib. 2. Fig. A, B. et tab. 12. Fig. A. Nautilus. Olearius, Mus. pag. 66. tab. 32. Fig. 4. - Scba, tom III. Fig. 5. 7. tab. 48. - Lister Conch. 554. 556. 557. - Rumphius, Amb. tab. 18, Fig. A. et 4. - La galere, ou le grand nautile papiracé. Favannes, planch. VII. Fig. A, 2, Fig. A, 8. - Petiver, Gaz. nat. part. 1, tab. 10, Fig. 1. et tab. 127. Fig. 7. - Klein, Tentam. method. ostrac. tab. 1. Fig. 3. Nautilus sulcatus. - Knorr, Delices de physique, tom. 


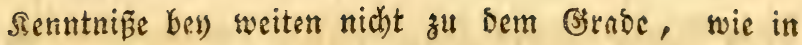
unfern Tagen. ąu ben 3eiten, Die gleid)fam den

1. planch. B, x. Fig. 3. pag. $40,41,42$, et Delices de yeux et de l'esprit, premiere partie, planch. 11, Fig. I, pag. 7, 8. - Davila Catalogue, tum. 1. pag. 108., art. 82, 83, 84. Hill. History of anim. tom III, pl. VII, the paper nautilus. - Catalogue de Latour d'Auvergne, pag. 57. nr. 245. - Argonauta argo. De Born, Index. mus. vindonbon. pag. 119, A, 1, et mus. vindonbon, pag. 139. 140. Lavignette, ber alle \$olypenarten vermedifelt. - Argon: papir. Bruguieres, Encyclop. Hist. nat. des vers, tome VI, Iexte, pag. 120. etc. Nautil. pap. Gere, Monatliche $\mathfrak{B}$ eluft Seite 11. Inf. 2. Figur 4, 5. - Nautilus tenuis et striatus. Lesser, Testaceo. pag. 149, Fig. 6. Argon. arg. Schroeters Einleit. tom I. Iaf. 1, Fig. 1. - Cochlis plana intorta monothalamia, sive nautilus papyraceus vacuus, carina. angustiore, spina acute serrata, striis copiosis flexuosis interdum furcatis costatus flavescens. Martini, Conchyl. tom. 1. p. 231. tab. 17. Fig. 157. - Argonauta Argo. George Schaw. Argon. Lamarck, Syst. des anim. sans vertèbres, 84, genre, pag. 99. - Bosc, Hist. nat. des coquiiles, tom III, pag. 261. et pl. XXVII. Fig. 6. Der 3eichner bat nod) feiner Pुbantafie gemalt.

Jm frnnzofifôn le nautile papiracé, ou le nautile non chambré et la galere. Im italiåni= fhen, moscarolo und polpo moscaxdino. In englifhen, paper nautilus; tub paper sailor haddesfond, uno the great sayler. Sm boffanoi: fhen, nautilus uno duekehuif. Im beutichen, ber Segler, Farkuttel, Schiffiuttel. STm ơnifitien Kronjayten. Sัm malaif 
alten Naturforidhern Dagu bienten, Raterialien zu fammeln, yon benen wir ief̧t (sebraud) madjen, hatte man nur allgemeine beobad)tungen anftellen finnen; bie, bie unz auf biejer glånzenden $\mathfrak{a} a$ fbahn ủbertref: fen, úberlieferten ihre 2(rbeiten und Betrad)tungen Dem Nachbenken ber Nachwelt. Sie, burch Den Schat menfd)lid)er (Erréenntnipe begeiftert, haben faft alle, won ber Riebe zur Mrabrbeit geleitet, im vor= allz Data aufgeftellt, an benen fie felbft nod) zwei= felten, woll ber Jeoffnung, baf́ bieienigen, die nad) ifnen liker biefelben Materien fabrieben, nach

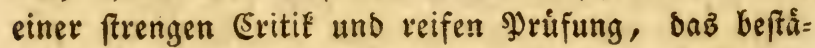
tigen wirben, was if)nen mur auf eine unbeftimmte

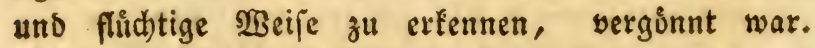
Iltein ifyre Arbeiten wurben mehr als cinmal gar nid)t beadbtet, weil es̉ leid)ter ift, fid) fo zu ftel: ten, alż ob man nid)t wise, waż fie úber nod') bunfele (siegenfåande nieberichreiben, ober ihre gleid)= formigen \$Beobachtungen, bie fie anftellten, in 3wei= fel zu ziefn, . alz mit ifnen bie fhwierigen 30 fabe, auf benen fie wandelten, zu betreten, inbem fie Itac) forfchungen anfellten, bie wir ieķt benutziten, uno bie fie, wegen Dez 3ujtandez der 2 Biffenjd)aften zu ber asit, wo fie lebten, nid)t weiter treiben fonnten.

2(bwed)felnd hat man baker baz angenommen uno verworfen, waż unz bie alten গaturforfd)er über

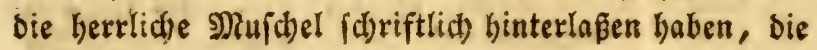

Ifmboina, kika wawutia. Sm polnifめen, Zaylik. In St. Domingo, galere. 2fuch nennt man ifn \$oltypenter). (ovum polypi.) 
bey) ben neuern Taturforidsern unter bem Sahmen Sapiernautiluz, befannt iff. Man nal)m aud) oft mit blindem 3utraun ihre Scobachtungen an, und fchrieb baßs, waz bie Allten ůber ben Alrgonauten gefagt hatten, wortlid) ab. Eine Menge Echrift: ftellex begnigt fid) Damit, Den Ifriftotelez oder spli=

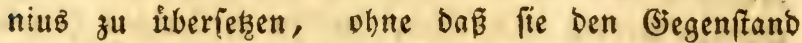
ifyrer Beichreibung felbft geielnn hat, olye bie gering= fte ltnteriud)ung anzuftellen, nodutch ifke Meinung Soffitigung erkalten håtte. Dieje bequeme, forglofe Manier, zu id)reiben, låß̧t Z̧weifel ủbrig, bie bey melherer Mlúlse, ficher gehoben worben wåren. Dies

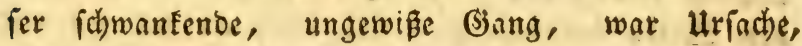
Das bieienigen, bie nad) ilinen Eamen, an bas hibet ben. Sapiernautiluz geid)riebene, nidbt inelyr glaub= ten. Man betrachtete ilje Seobad)tungen alz ungull= tig und ferste in bie Reilge fabellyafter Thiere basiles nige, von bem bie Alten, alż von bem Eigenthü= mer und 28 ertmeifter biejer zerberd) lid)en und leid)= ten Nuichel, fprachen. Faft alle neuern Naturfor: fcher und bejonders die in Der lezten zeit, fino Der cinftimmigen Mieinung, Den Sapiernautilus alz ein Schmaroberthier zu betrachten; und ob fie es gleid) geftelyn, סaв fie Daz eigentliche Thier biefer Mlufdbel nid)t Eennen, fo beloupten fie Dennech, bas die 2trt yom Jolyp, bea man in Der Muichel beftåndig findet, nid)t ber ley, ber fie gebaut håtte. (Erft Dann fey er Sefitzer berfelben geworben, nactberm er ben wahren Ėigenthusmer vertrieben habe. Şåtte ex fich) einmal in biejes leichte Gehånie eingebrungen, es an Fid) geriffen, fo biene es ifym nux zum Epiel.

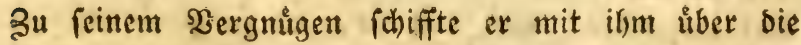

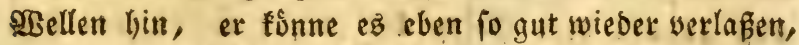

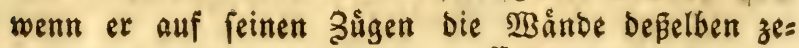
(5) 


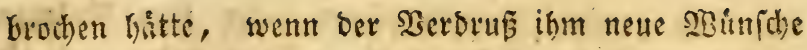

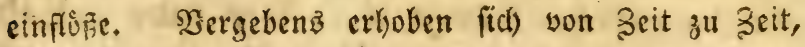
zu Siunfen ber 2llten, einige Zeugen. MRan Katte einmal syarthei genommen, es̉ war wie man fagte, unmuglid), wab bie Alten von biefen Alrgonauten behaupteten. SBey Dem fortgange unjerer unterfu= d) ungen werben wir felin, weldhe fonderbare Goeen

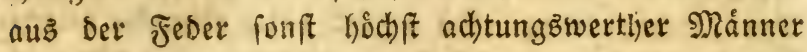

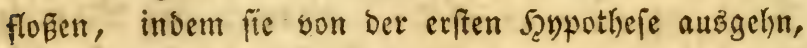
felbit Dem šcugnif̧e ihrer 2 lugen nicht traun, und ben 2 (rgonauten nur alz einen Sd)marokzer, alz cinen Sivrber betracteten, ber, invem er aus Dem (5runbe Dez Neers herworfteint, fich) nicht anderz alz mit einer Şeute geichmuidt zeigt, bie er. Durch 'Morben und Hebergewalt an fid') geriffen hat.

Genaueve Nadjeideten uber biefez fonderbare Zhier, werden dieje sephulbigungen zerfishren.

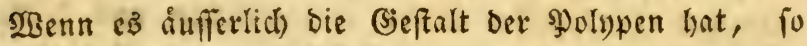

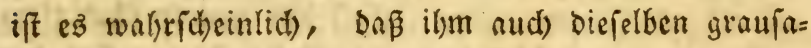

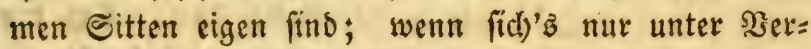
wilftung uno Mord gefållt, nur vom Blute, wie

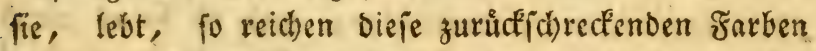
ichon hin, um feinen blutburfifigen Elyarafter zu be=

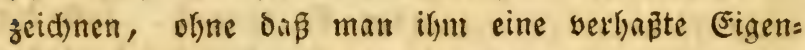
(c) aft beilegt, bie ifym nid)t eigen ift. Die fd)a=

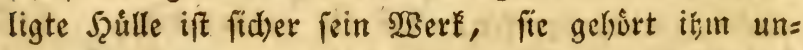
miber(pred)(id), als bem Saumeifter und \$erfertiger

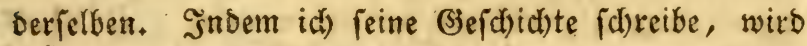
iman fekn, Dar ihn bie arlten volffommen fannten, Daß fie inn immer alz eine befondere, unterfobiedene Irt auffrellten, und $\delta$ ã fie, ob fie gleid) geftelyn, baß of mit bem 
if ne mie mit ben Sreten biefer ahiere verwecthelten, die fic beftandig nactend funden.

IYriftotelez, bep̃en unfterbliăe গ্Berte ber בెer:

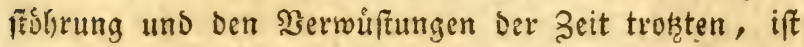
einer von Den ålteften SItutoren, Der unz beftimmte Pacthrid)ten ủber eine Menge yon Gegenfianden Det Platurgeichichte hinterlanen lyat, in ber er unjer er=

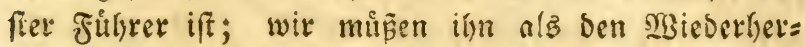
fiellev biejer exhabenen sibiffenidonft betrad)ten. Die= fer weife ghillojoph iff oer erfte, Deffen בeugnis wis

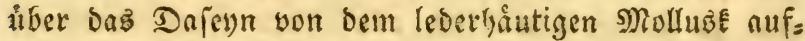
fellen, Dern wir Den Palymen Irgonaut geben, wels c)en \&inné in feinem Syfem ber Patur, feiner Ru= idhel beilegte.

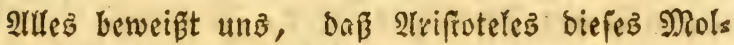
luşt vor Ilugen hatte; benn $\mathfrak{c r}$ fagt ę beftimmt, Daß fich biefez Ihier burd) feinen (jitiederbau ben spolupen naht, z̧u benen es geredjuct werben tann; weil eB, wie fie, mit frîzen verfelgn ift. Sa ex

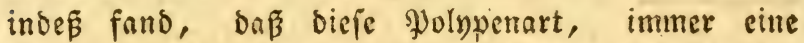
Schaale hatte, fo serwedyjelte ers mit benfelben Poo Inpen bod) nidst. WBenn er yon bem Papiernautilus

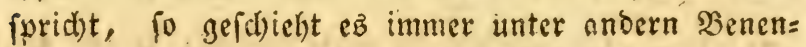

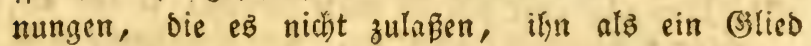
Der Familie nacter Molluşen anzuichn. SBalo giebt ev Dem 2trgonauten ben Nahmes Nantilon, balo Nauticon; Diefe unbedeutende Seridjiedenlyeit rifhert vielleid)t von bam verichiebenen Dinlect her, ber bie Sewolgner ber vielen Ståbte Griect)en!ands d)arafte=

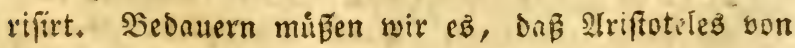
biefem Thire, und bem, mas ben in fammern 
abgetreilten Dautilus *) bewoknt, nux cine blope Inzeige gegeben hat; indeß biejez grofe Genie, be: fitimmtere Thatjad)en, umftándlid)ere Nadjrichten, elier alอె ieber anoere, auf bie Radiwelt bringen

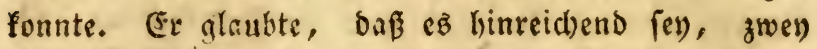

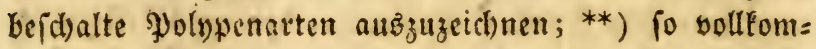
men er oen slrgonauten charafterifirt, fo find bie swey) 3cilen, bie er bem Erbauer, Deb mit Sam= mern werfehenen Sinutilus weiht, nidht geeignet, einen eben to Deutlid)en 2 lufidhlus zu geben. Jnoes fino fie bod) binreidsend, unz zu beweifen, baß man zu feiner żeit nicht allein Den Papiernautiluz fannte, fonbern aud) eine andere $2(r t$ biejer fdalig= ten Molfusten, bie fich, wie biefer, eine Mufd)el bauten, eine fteinigte, feite, barte limgebung, in

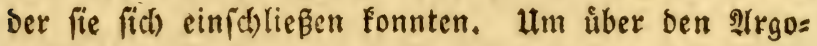

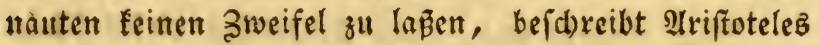
alli eine fo angenel)me, alsె zierlid)e 2 (rt, oaż Sd)if= fen beselben; er wendet bie lachendfen Farben an, wit ifn unz nach allen feinen Formen zu fdilloern,

*) Nautilus pompilius. Lin. Syst. nat, verm, test. pag. 3369 , gen. 318 , sp. I.

**) Duo alii sunt polybi testis inclusi; is qui dicitur a nonnullis nautilus, sive nauticus, sive ovum polypi. Testa hujus pectinis testae simiJis, quae cava est, nec ita ut ei cohaereat. Saepius is juxta terram pascitur, unde fit, ut in eam a fluctibus ejiciatur, et testa excussa capiatur, vel in terra pascat. Isti parvi sunt, et facie similes bolytoeni. Alter cochleae modo testa munitur, quam numquam deserit, sed brachia duntaxat interdum exerit. Arist. Hist. lib. \&. cap. 1. 
wic er auf bem Rưden fanftbewegter 2 Bellen fdimimm,

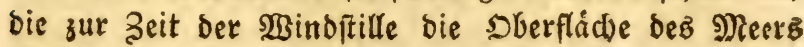

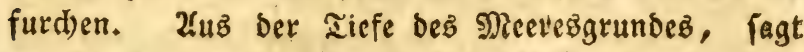
er, ") fteigt Der Sholyp in bie Şóh, indem ex bem

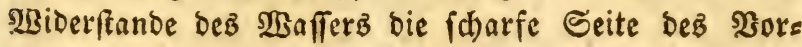
bertheilż feiner leid)ten $\mathfrak{B a r f e ́}$, entgegenftellt, bie auf=

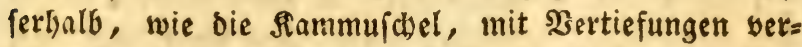
felln ift, bie er über baz $\mathfrak{B}$ affer hinfübren und úber bemielben zu erhalten verfetht. 2 Bill er fid wieber untertaudien und nach feinen unterirbifd)en Şiblen

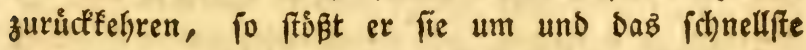
Untertauchen bringt ihn wieber auf Den Grund besె Meerez. Schwimmt ex aber auf Der Dberflåd)e um= her, Dann fpannt ex eine breite Şaut auz, mit ber feine Fủpe, wie bie ber Schwimmbogel, werfehn find; inder einige biefez Segel auşppannen, verílhn bie andern Füße den Dienft besz Cteucrz und Ruderz, inbem fie fid) nad) ber fanften Suft rid)ten, bie bie

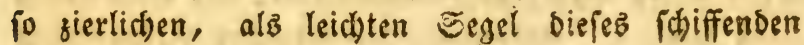
Zlyiers, aufichwellen.

*) Est nautilus quoque polypus et natura et actione mirabilis: navigat enim per maris summa elatus. Ex imo gurgite effert se testa inversa, ut ascendat facilius, et inani scapha naviget. Cum vero emerserit, concham convertit. Brachia membrana congenita connexa sunt: quemadmodum palmipedum avium digiti: sed haec crassior est et densior: illa longe tenuior aran. earum telis similis: hac ut velo spirante aura; brachiis ut gubernaculis utitur et demittit latere. Si quid metuerit, testam protinus mari replet, atque ita demergit. Arist. ubi supra, lib. 9. cap. 37 . 


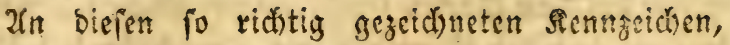
müpen wir ben syolnpen erkenten, der ben sirgos nauten bewobnt. Die Sichilderung ber äffers Be= fralt, enthalten bie wenigen sisorte wolfermmen, de=

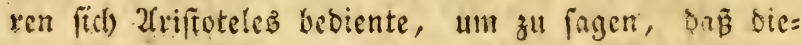
fes Thier eitr glolnp, aber in einer edorle cinge=

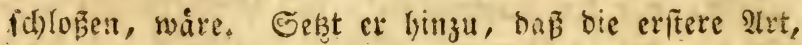
bie Dez भुapicmatilus, mit feiner Echale nicht zu= fammengerwadjen ift und fo mit ihe einen Rorper bils Det, jo fonnte Dies einige neuere Raturforicher zu

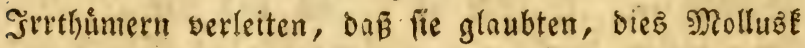
(en) ihm unbefannt geweien: allein 2 triftoteles hatte beşfalb nid)t weniger recht, indem bieje Bemerfung unz jeinen Scharfiunn beweipt, beutet fie uns zugleid)

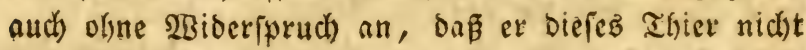
nur (d) wimmen fah, fondern bon er auch gewahe

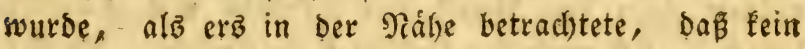

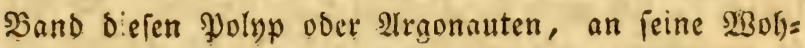
nung fnupfte. $\mathfrak{B e n n}$ wir bie genauere $\mathfrak{B e f d r e i b u n g}$

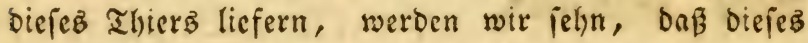

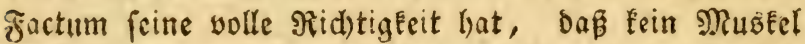
biez aljer an feine Muiddel feffelt, in ber ez fić)

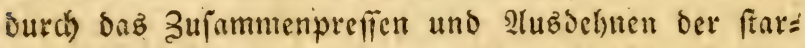

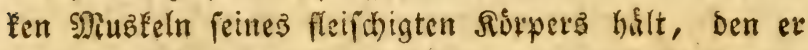
zwningt, fich feft an bie leid)ten, innern $\mathfrak{L}_{\text {ånde }}$ fei= ner reizenden 230 hnung anzuidmiegen.

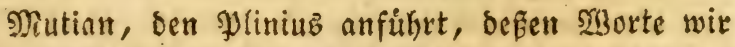
nithi rennen, bie fiur unz in ber Tad)t bes 2llter=

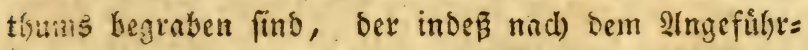
ten, nis Reifenden und Seobachter vid unberge= (d). fit zh haben fideint, hatte in bem Sanal won Sonjtantinopel bie 2 trt uno 2 Beife bemerft, deren fiit) Wat Xrgonaut botent, um feine Sarfe liber 


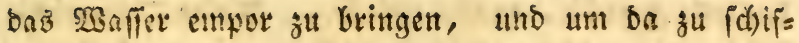
fen, wie es bie Schiffe unb (Baleren thim. *) Diefe Mufüel, fagt biefer Neifende, hat bie (sejtalt einet Brigantine, ber \$orbertheil ragte felhe herwor und ber Şintertheil if linfz gewand uns felge erhobt. Sogne Plutian hatte richtig beobachtet; Dutd) bie

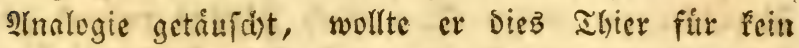
andereż, alb fitr einen Dem Dintenfifd) ålunlicken Fifid) halten, bem er indep ben Narhmen naupilus giebt. Ee betrachtete ifyn als einen Sd)marokser, ber barum won biefer Mufchel sefit nimmt, um fict) mit Echiffer auf Den ȘEllen zu beluftigen. Mution bejdbreibt bas Manưre volffommen, Daz biefes Mol=

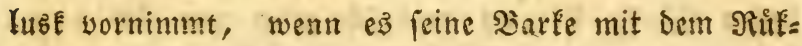

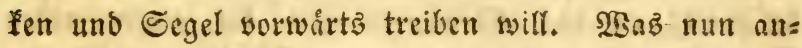
zeigt, wie wenig genau bie Senntnife biefes アici= fenben waren, dies beweişt ber Teyt, ben id an=

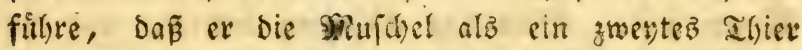

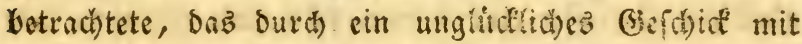
bem erfern verbunden wurbe und son bemperfen aufo

*) Navigeram similitudinem et alium in propontide sibi visam prodidit Mutianus, concham esse acatii modo carinatam, inflexa puppe, prora rostrata: in hac condi nauplium animal sepiae similee, ludendi societate sola: duobus hoc fieri generibus. Tranquillo enim vectorem demissis palmulis ferire ut remis; si vero flatus invitet, easdem in usu gubernaculi porrigi, pandique concharum sinus aurae. Hujus voluptatem esse, ut ferat, illius ut regat: simulque eam descendere in duo sensu carentia: nisi forte tristi (id enim constat) omine navigantium humana calamitas in causa est. Plin. Hist. nat, lib. 9 , cap. 30 . 
åufferfte gequålt, endlich ftůrbe. Diejer ungeteimts

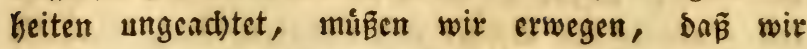

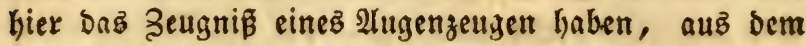

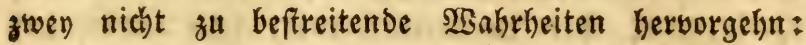

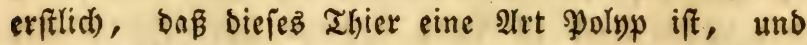

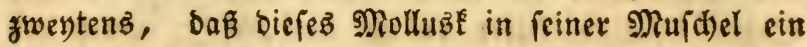

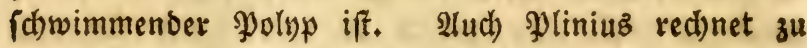
beil bewundernswoirdigften und bemerfenswertheften Dingen, bie Solypen mit ben Nufdyeln ${ }^{*}$ ) bie von Den andern butch bie Nalymen nalitiles und pompiles unterichieben waren, welü)en शal)men, wie ę̧

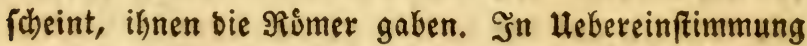
mit ben (Eried)en uno nad) Der 2tutorttåt 2lriftoteles, beßen 2 Berke Plinius walyrid)einlid) wor fid) hatte, bejd)reibt ex bas Manóuvre und bie angewansten Mittel bes 2 rrgonauten, wenn er fid ulber bas $2 \mathbb{B}$ affer exlyeben uno ba fd)wimmen, ober fid) in bie Tiefe ftürzen will. $\mathfrak{B a z}_{\text {ben }}$ Schwang betrift, Den ber rómijd)e शaturforid)er feinem beid)alten \$olypen bei= legt, yon bem er behauptet, Daß er fid) befen, auffer aller \$erbinbung mit ben 2 trmen, in Beftalt eines Steuertuderz bebiene, fo ift biez cin neuer

*) Inter praecipua autem miracula est, qui vocatur nautilos, ab aliis pompilos. Supinus in summa aequorum pervenit, ita se paulatim subrigens, ut emissa omni per fistulam aqua, velut exoneratus sentina, facile naviget. Postea prima duo brachia retorquens, membranam inter illa mirae tenuitatis extendit; qua velificante in aura, caeteris subremigans brachiis, media cauda, ut gubernaculo, se = regit. Ita vadit alto, liburnicarum ludens imagine, et si quid pavoris interveniat, hausta se mergens aqua. Plin. Hist. nat. lib. 9. cap. 29. 


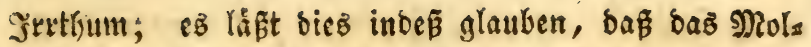
luż feine beyden 2 trme vielleid)t nad) (d)leppen |lást und ba si biefe, indem fie fid) zufammendricten, mad)=

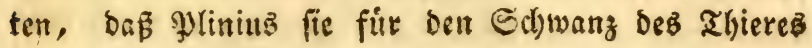
bie!t.

Einige alte 2 hutoren beftätigen bas burd) $\mathfrak{b e o b =}$ ac)tungen und fpâtern গachrid)ten, was Ariftotelez

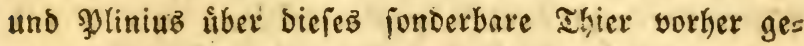
fagt hatten. Durch Den Reim feiner Merfe, vers ddont Sppian bie Befchreilung von dicjem Molluâ und feitrem umberfdiffen, und bitrachtet eż alsె bie

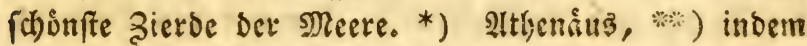

*) Est quidam curvo tectus sub cortice piscis Polypodi similis, quem dicunt nomine vero Nautilon, insignem ponto sua gloria fecit Per freta dum cautus sub navis imagine ludit. In sabulo domus est, summa defertur in unda. Pronus neu pontum capiat, plenusque gravetur,

Cum nando vehitur per fluctus amphitrites, Extemplo versus tumidam per marmoris undam

Labitur, ut nandi doctus puppisque peritus. Atque pedes geminos tendit de moro rudentum,

Quos inter medios tenues membrana tumescit. Ex lenta atque pedes contingunt aequora subter

Themoni assimiles navem, piscemque, domumque

Deducunt, si forte malum supereminet ullum, Absorbet fluctus intus, lymphisque gravatus A tumidistrahitur cum pondere fluctibus undae.

Oppianus. intorpret. Lippii.

**) Qui vero nautilus dicitur, sicut ait Aristote- 
er in einize, ơu Damaliger zeit faft unvermeibliche Sretfiumer gerietfy, wo ber Geift Der Seobad)tung yon ber Stufe ber Bolffommentheit nod) weit entfernt war, bie wir iekst fodern unb oline die es feine Ges wibleit giebt; Xthenåns, indem er bem 2rrgonauten

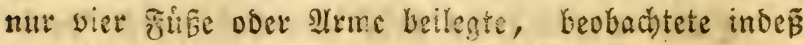

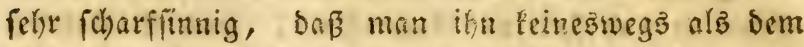
Syolyp ourchaus ánnlich anjeftn mife, weil ex mit eirem harten, fabaligten fiurser, D. h. mit einer

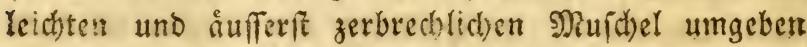
fer), Die fid wirktich ber fefter, bidsten Bebectung Der Sreble und Srabben nabt, ben wir bas Seymort (d)alicht gegeben haben, melyr alz ber umgebung, oder ber feftern, bid)tern $\mathfrak{L B}_{\mathrm{B}}$ hnung, bie, indem fie bie eigentlid)en Ed)althiere cinjichließ̧t, bismeilen felye binne ift, wie bey ben Bobrmuid)eln, den Sd)netien; aber allmåhlig fuffenweife bey) ben ver= (d)iebenen Thieren immer ftirter wito und endicis

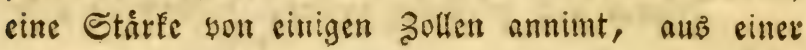

les, non est quidem polypus, ut similis quod spectat ad cirros, dorsumque habet crustatum, emergitque de maris profunditate, in sese concham habens conversam, nec aquam excipiat, atque ita conversus navigat, duos cirros superius exerit, iuter quos membrana quaedam tenuis conspicitur, iis similis, quae digitis palmipedum avium insertae continentur, alios duos cirros pro gubernaculis in mare demittit. Si quid vero ad se veniens videat, pedes protinus contrahit, ac concha mari repleta, quam celerxime in profundum demittitur. Athen, 1. 7, cap. 32. Interpret, natali. 
Ealfartigen Naterie beftert, bie an Feftigfeit Dem

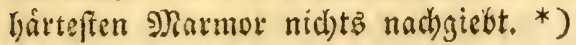

Zelian *), won bem unz Philoftrat eine fo tref= lide Robrebe hinterlaz̃en hat, welcher, ob ex gleit) ein Romer war, mit einer folchen attij bhen Ëleganz

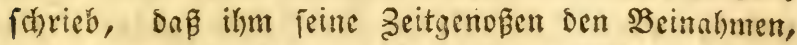
j̧onigmund, gaben, felste in feiner a siergefchichte

*) Tridaene, tridaena gigas. Pumph. Amb. tab. 43. Fig. B. - Encyclop, pl. CCXXXV. Eig. 1.

*) Nautilus e genere polyporum concha una praditus est; is eum eximia maris sede ad summam aquam effertur, invertit et mutat concham deorsum versus; ut ne hausta aqua rursus demergatur: ubi vero ad summam aequoris pervenit, et mare ab adversa tempestate conquiescit, supinam concham vertit. Hac enim tamquam scapha navigatione fertur: et duo brachia in utrumque latus demissa, sensim atque moderate movens remigat, domesticamque et nutivam navem propellit, quod si ventus flaí, brachia quae tamquam remos prius longe, lateque porrigebat, gubernacula constituit, ad quae caeterorum brachiorum media est membranula praetenuis, ea passa et intenta pro velo utitur; sicque, cum est sine metu, navigats Sin quippiam a valentioribus belluis metuat, se demergens concham aqua complet, et simul ex pondere in profundam delabens, sese occultat; atque ita hostem effugit. Post ubi mare est tempestate vacuum, et a buluis quietum, de imo maris gurgite se extollens, 'rursus per summum mare navigat, unde nomen habet. Aelian de polypis vide. Hist. an, lib. 1. cap. 37. - Lib. 5, cap. 44. - Lib. 14, cap. 26. 
einige Seilen auf, um ber Plachuelt bie fenntnipe

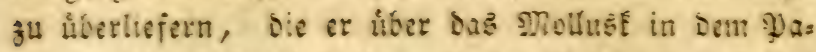
piernautlus exlangt batte. Diejer Slutor ifi vielleićt

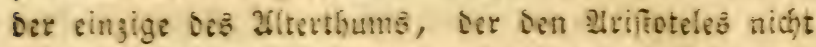

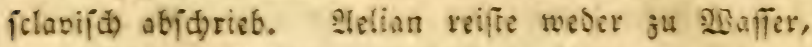
nod) verlie⿱⺈ Jtalian, wanigitens lejen wir babon

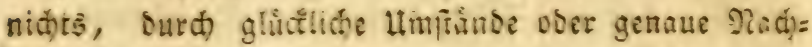

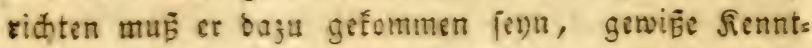

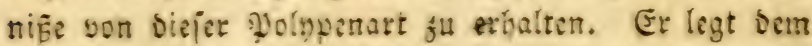

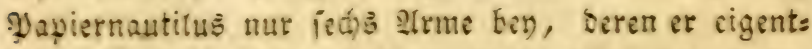

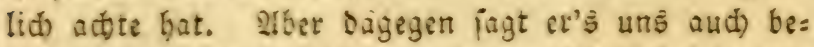

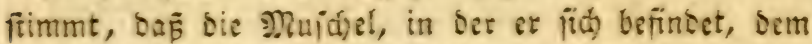

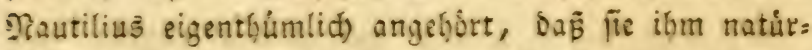
lich uno mit ifm gebofyen ifi. Fir bie bantige 3eit war ber Derfafier ein Galebrter und bie Platurgejdidte, was jeine Wretfe aud bejeugen, wat fúr ihn eine Suelle son Beobad)tungen und Heberlegungen.

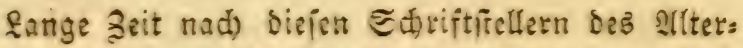
thums, giebt unż Belon *) eine Bejđ)reibung von Dem Irgonauten, bie mit eirtem iä)lech)ten Sgolyfitich, ber

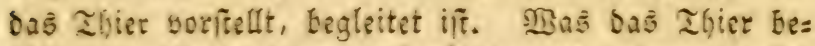

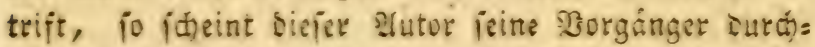
aus copirt ju baben; batte er biele Mollusfen por Xugen, woran faum ju zweifeln iाi, da jeine alb: biloung bie erjte ift, bie wir gon biejem Molfust belighen, io bethielt er wenigiteng die Semennungen ber), Eeren fids bie arten in igrer Sejüreifung bes

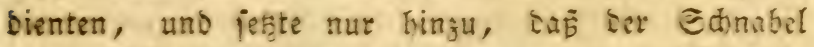
biejes Yolypen bie Cieftalt eines Mapagaienid)nabels

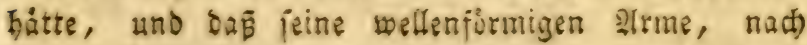

*) Belon. de aquat. lib. 2. pag. 578. - 550 . 
Der Weife der Polypen, mit echropffopien und

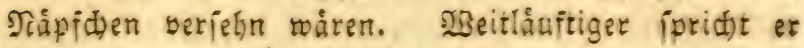

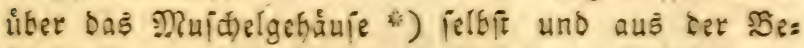
id)reibung, die er bason mittheilt, erfiteft man,

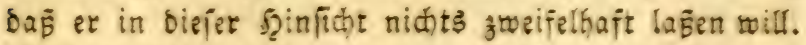
Fr úbernimt, io zu jagen, bie Xnatomie ber Nu=

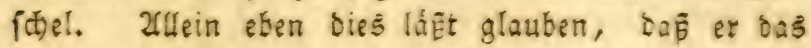
Thier nicht mefte eor Ilugen loatte, oa or ifm eine grof̈e 3aht 2lrme beilegt, uno ber Ilrgonaut boch nut ad)t Irme bat. (Fin anterer beutider Edififiteller, Der allgemein unter Dem Nafmen Des 3oographen an:

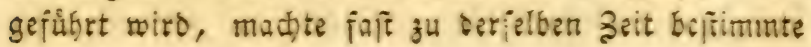

*) Ejus concha tribus fragmentis constare videtur (carina scilicet et lateribus: cum tamen una et simplex sit), quorum latera utrimque seu carinae junctae apparent, ea ut plurimum magnitudine, quam ambae manus amplecti possunt: latitudine autem quantum pollex cum indice comprehendat. Omnes autem non excedunt crassitudinem membranae pergamenae, striisque in oblongum ductis ad oras crenis laciniatae sunt, in formam rotundam abeuntes... concha... fragilis est, lactei coloris, lucida, admodum polita, omnino navis rotundae effi= giem referens. Narigat enim per maris summa, elatus de imo gurgite, effertque se testa inversa, ut facilius ascendere possit, et inani scapha enariget, atque ubi emerserit, tum concham invertit. Ceterum nautili brachiis interjacet membranula..... Cirris quos utrimque multos habet, pro gubernaculis utitur, atque ubi metuit, tum concham protinus marino humore oppletam demergit. Caeterum psitaci rostrum habet, suisque cirris polypi modo graditur, atque eodem modo acetabulis sorbet.

Belon. 


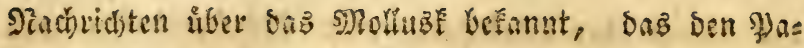
piernautilus bewobnt.

2reer biefer (bejd)idtidfreiber ber Thiete aud jern mag, ex trat in bemjelben zeitraum des bes lon uno Ronbelet auf. Ex ftano mit ben gelefirtefien

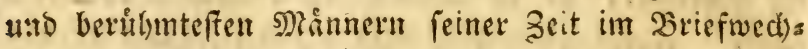
fel. 2aldorowansi bat uns eine ahatiache *) aufbes wayrt, die von feiner auşzebreiteten Gorrefponbenz

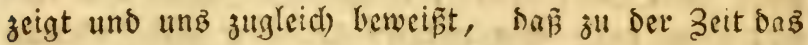
Thier bes Slrgonanten wohl befonnt war. Mian fielt

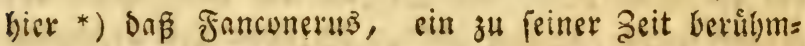

*) Nautili picturam Ioannes - Eauconerus medicus egregius ex Anglia olim ad Zoographum dedit, his verbis in epistola adscriptus: mitto ad te picturum cujusdam piscis, ex testaceorum genere, puto Aristotelis nautam esse; quam mihi primum, cum in Italia essem, Caesar Odonus doctor medicus bononiensis exhibuit, vir ut humanissimus, ita in exteros admodum hospitalis: postea vero hic in Anglia ipsum piscem vidi, quem pro loci ac temporis opportunitate pingendum curavi. Testam habet externa parte ex fusca - rufescentem: internam vero partem ita nitentem, et splendentem, ut cum unionibus praetiosissimis de coloris amoenitate certare posset. Multa quoque habet in ipsa testae carina tabulata eodem colore nitentia. Velum constat ex pellicula tenuissima. Membranae ab utroque latere demissae carneae sunt et molles, ut polyporum cirri, reliqua corporis pars cenfusa erat et indiscreta, nt reliquorum testaceorum generum, confitentem quod ignoro anclicum hujus piscis nomen. Aldrovand. de testaceis, lib. 3, pag. 261.

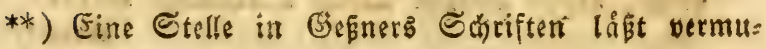


ten SIrzt, yon England aus die 3eidhung bem $300=$ graphen, Der, wie'wir vermuthen, (Siefner ift, zuidbiclte, weld)e er mit einem Stiefe begleitete, in Dem er fagte, Dof er bie zeid)nung bez Ed)althiers,

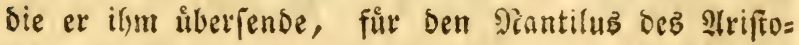
teles balte, $2 x$.

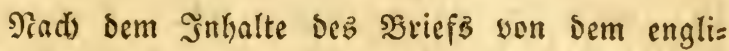

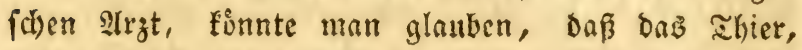
was er befdreibt, an ber englifden Rirfe aufgefifd th

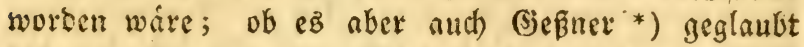

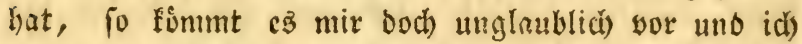
verunat'se, bie zeichnung won einem biefer Molluafen, ift bon einem im Beingeift aufbewalyten Polyp ge= nommen, Der fich in Der Sammlung einez bamali gen Paturforid)erż befand, ob unż gleich ber eng=

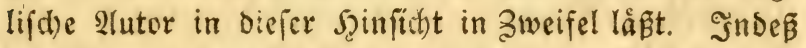
war er einer ber erifen nad) ben alten, Dem wir befimmte Beobachtungen ibler Den Argonnuten vers Danfen. Selon ober Fauconeruz, lieferte die erfte 2lbbildong, bie, indem fie unz baz yon neuen bar= ftellt, was bie 2llten bej̈brieben haben, uns zugleid')

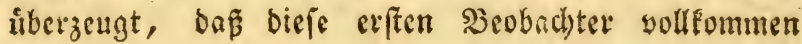

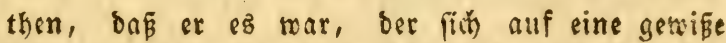

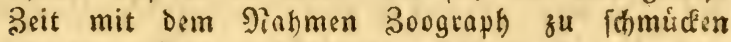
glaubte. Er fogt beftimmt, Daß́ er es war, bem

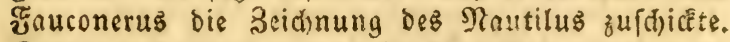
Gesner, Animal. mar, de Mollibus, pag. 193.

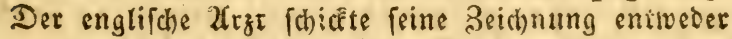

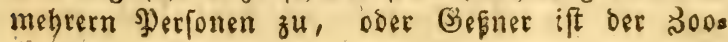
graph.

*) Reperitur quidem in oceano britannico. Ges. ner, de Mollibus. pag. 193. 


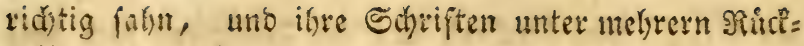
iid)ten glaubwurbig find.

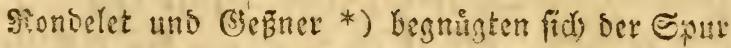

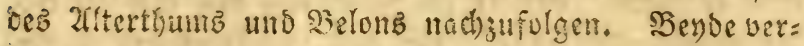
melirten foft um nichts die (jefchichte von biejem Mols luğ. 2florobandi trieb bie Unterfuchungen etwaz wei= ter, allein fie fint foft alle critifo. Diejer unet: míbete Cammle: forieb feine 3̧eile, wosurd) Das

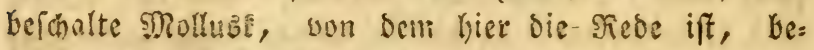
Fannter wurbe. Die figur, die er inder von bem= felben liefert, ob fie gleid) mu cin Szolsfict) ift,

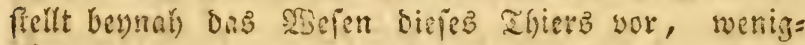
ffenz giebt fie cinen Degriff von Demfelben; nadh ber Siatur wurbe bie Figut ficher nicht gezeihnet. Die s)

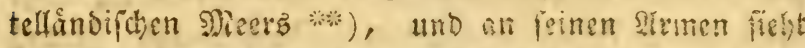
man nut cine seihe bidyt an eimanoer febenver Mopf=

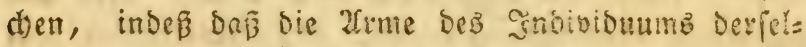

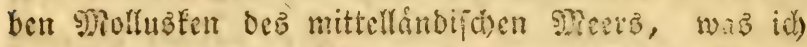

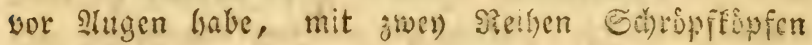

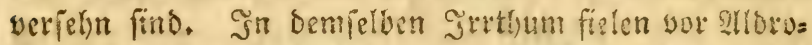
bandi, Selon, Fondelet uno Ges̄ner, beren מb. biroungen unter aller critif find.

Siod) unvorffinoiger, ale alle anoeve, hat Jons fton ***) Die Figur Des slrgonaten sirorowandis copiren

- *) Rondelet, première partie ce l'Hist. ent. de poissons, lib. 18, chap. 7 , pag. 374. Gesner, Anim. mar. de Moll. pag. 192.

***) Aldrovand. de testaceis, pag. 260.

*a*) Ionston, Hist. nat. de exanguibus aquat. p. 30 , et tab. 10. Fig. 2. 
lagien; fie ift in supfer geftodlen: entrialt bisfelben

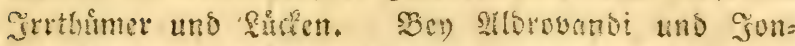
fon bat ser. 2lruonat feinen Eunnbel und Miunb.

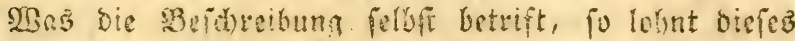

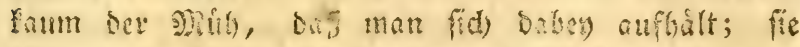

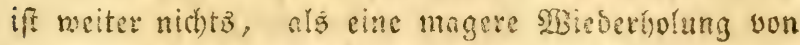

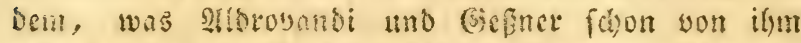

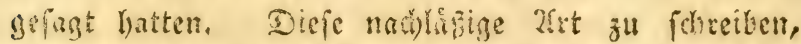

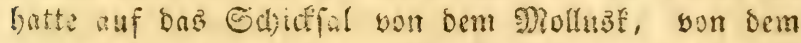

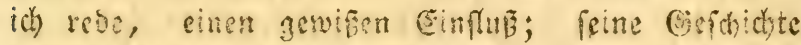

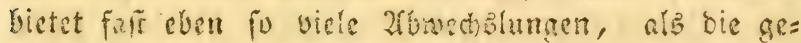

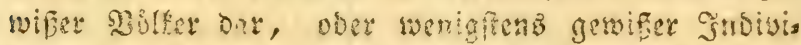
bucn, von benen mat in cintm gevig̈en Beitraum

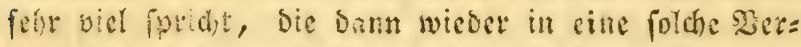

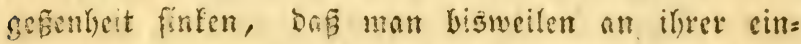
ftigen Exifeng jueifelt. Ser Slrgonout gerieth in cine foldse Dergefentseit, bne man in neuren zeiten in georuditen Gariften behouptete, Daß er nie be-

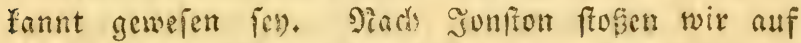

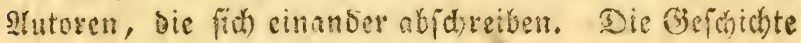

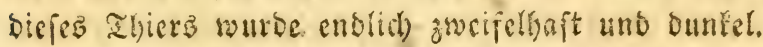

תumptius *) Der Det Befdreibung DeE Srrgo= nauten ein sinpitel weift, giebt liber biefez Ther beftimute Padhricliten, weld)ez er felber fah. Sch uberiegze Das Sapitel faft gang.

Sluf ber XVIII Supfertafel, Figur A, fickt man eine Mufdel ober ben Sapiernautilu3, Dep̧en

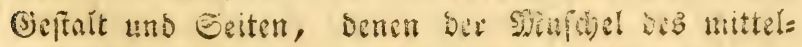

*) Rumphius, Amboinsche rariteytkmmer, edition 174.1. Lib. 2. cap. 3 , pag. 65 .

$$
\text { ระ } 2
$$




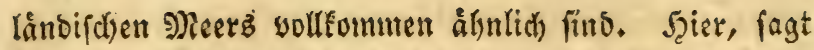
Rumphiub, felfn wir ben wahken Plautilus wieber, ben bie aflen vollig fannten und fo rid)tig beid)rieben. Seine Form erinnert an bie einer Galere, deren Szintertheil er'yaben, beren Riel binn und fdheibent, beren Borb, wie bie Seiten bes Schifz geftaltet ift. Эd) fenne Dason zwey Arten *) eine grổere und fleinere. Die critere enthålt gewớnnlich eine Ránge von funf biz fieben zoll uno eine vierzullige Şóke;

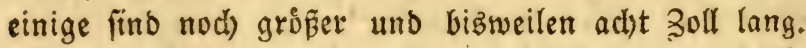
Dieje Nujdel ift ganz einfach, buinn und ifje Diffe

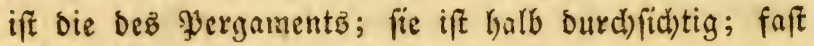
fo weiß, wie Yapier, allein bişweilen fpielt ifyre Farbe ctwas inz Gelbe. Der Riel ift faum einen halben finger breit, fpiralförmig gewunden, beutlid)e Erhóbungen zieren fie nad) ihrem ganzen Umfange und bie Falten oder Furd)en, Die von Diefen Erhos hu:gen auslaufen, ziel)n fich liber bie Mufd)el bin und faft alle binterwairtz nad) bem Schnorfel (Volute) zu, Den fie con biefer Seite bildet; ba aber alle nicht gleich weit von einander abftelyn, fo fliefen einige biefer falten in andere uno verlieren fid), eh fie ben Mittelpunft erreichen, wohin faft alle fom= men. Nach oben bin hat ber fiel einen rothgelbli=

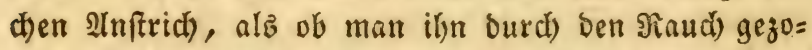
gen håtte; Diefer $2(n$ ftrid) iff unvertilgbar uno ber Mufchel eigenthumlich. Shre Eeiten erbeben fich in Det (Jeftalt einet Diaponallinie, laß̃en ifye eine zwey

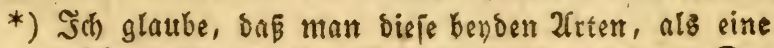
anfefrn muß̄, ba ihre Bewohner fich gleichen. Det unterfdied ber Mufheln befteht nur in ber ver= fhiedenen Broóse. Diefe verfohiedene Grópe verleis

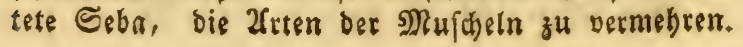


biz orey Finger breite Defnung, mo ber Rand bie=

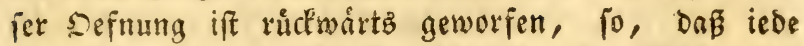
Seite cine Iirt von Dryefaum biloct. Ser Jifd), Der Den Japiernantiluz bewolynt, hat ganz bie åufere Geftalt und Sildung Der Yolypen. (Er hat nach fei= nem innern Sau acht Fine, fechle find thirzer alB bie beuden andern, mit Sdrupfeupfen oder Tiapf= d)en verfelyn, wie bie Arme aller Irten von Dinten= fijüen. Sdjwimmt bas aljier, fo breiten fid) biefe

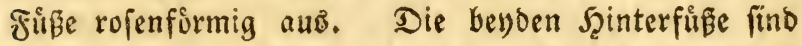
boppelt fo lang, als bie anbern; indem fie bas Thier

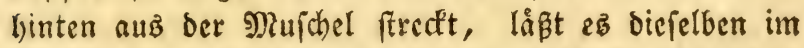
Sglafier *) nadjichleppen, indem es burd) Şülfe ber= felben, feine leid)te \$arke birigirt. Die beyden f̧üe fino glatt und runo, an ben Sciten auch mit Niåpf= c)en veriefly, wie bie jed)B andern, aber in Beftalt cinez Ruders am Ende erweitert; fo, Daß bieje (5)a= rere auf bem $\mathfrak{B g a f f e r}$ eben fo birigirt wirb, wie eine Irt fleiner Schaluppen, Deren fich bie Sayaner bebie:

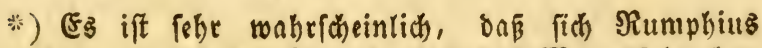
hier geirrt bat. Der, Der inm ons Molluse brachte, hatte es vielleid)t auz der Diufhel genommen, wollte es wieder hineinftecen uno ftect te es in bie Suere binein. Dies, was wir fpriter felbn werden, begegnete fdon andern Naturforiderm. Der hol= linndiche Naturforfher, ber bie beyden $\mathfrak{Z}$ rme von Den fechs andern verfhieden fant, die er binter= warts fah, ftatt fie vorn zu febll, madte bar= aus zwen Ruber. In ifrer cigentliden Eage wult: De er fie wie Segel betrabtet baben, bie ex vers

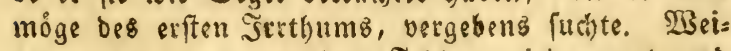
ter unten madht er Den Fehler roieder gut und fagt: bie benden lirme dienten bem Thier fum Rubern odar Edtwimmen. 
net, bie fie Tingang ober Tinan nennen, bie butch

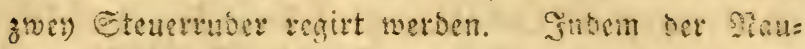

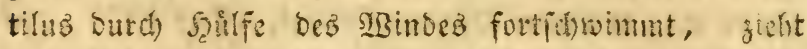

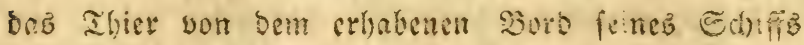

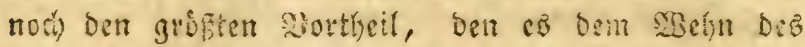

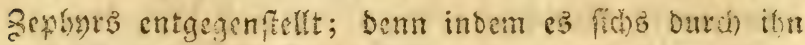

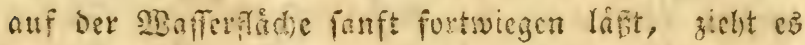

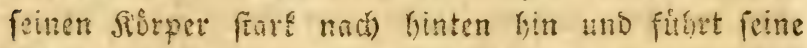
Sarte mit den gowen Irmen, bie ể Daju brandat,

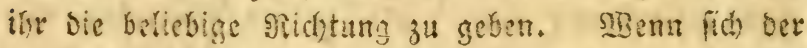

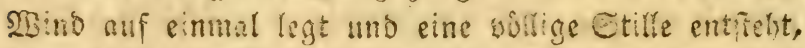

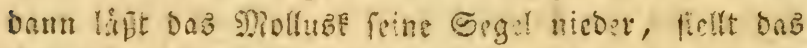
(Gleid)gewid)t in feiner Echaluppe wieber ber un's ru=

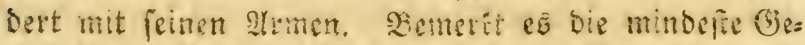

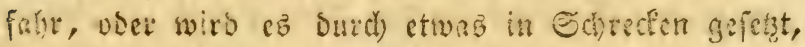
fo zicht 23 auf eimmal bie Glteber ein, Die liter bie

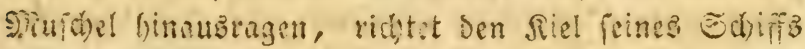
in bie Ruft, fullt ç mit affer und madit, bnß

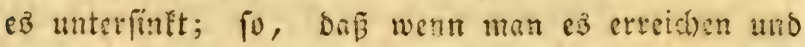

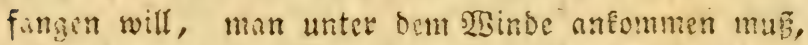

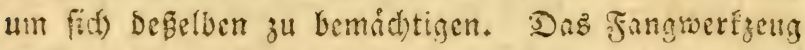

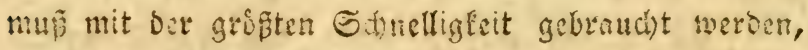
um feiner sàeveguttg zuvorjutommen utio das Unters finten zu vertinbern. Es wird fo felten gerongen, bas bie fifcher, เvenn ca ifinen gelingt, diez für

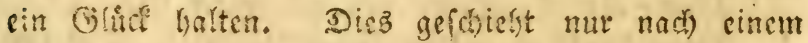
Stum, wenn grofe Stille cintritt. Nod) fitht man eb hisufing auf bem specre unherdboimmen, inbem

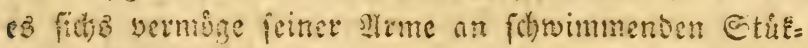

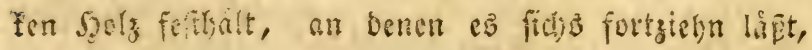
olsne loǧzulafien.

Snoem man bus Thicr nafyer unterfucbt, fo wirb

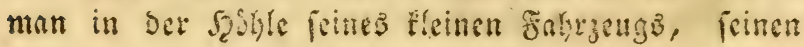




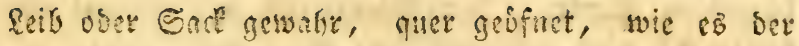

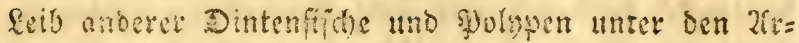
men ift. Sernoge biefer Defnung, fieht man aud Den nusfirizensen Somal, Der thim bazu bient, ons sherwafer, was in ihn eingeorungen ift, wieber

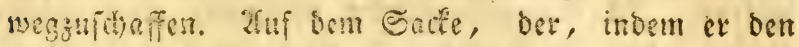

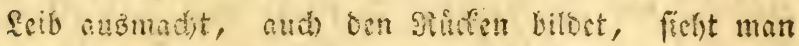

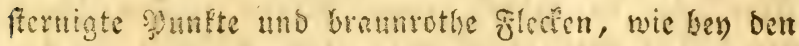

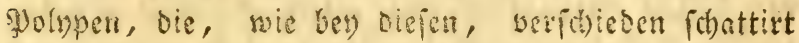

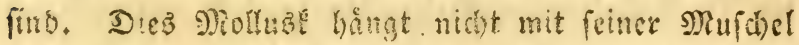
äummen, wie ber Pinutilus mit fommern; folglid) wirb ez oud) leitht anb feine: Sante geworfen, bie bann iber bem $23 a f f e r$ fidwimmt. Die Tifcher fan= gen fie bisweilen suf, elf fie an ben Jelfen zerfeldmets

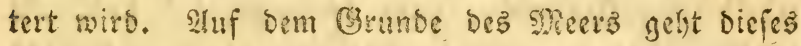

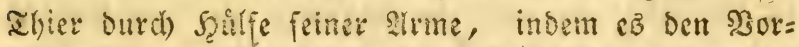

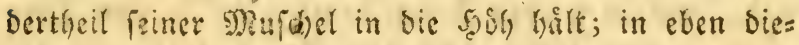
fer Ceteflung, freigt es̄ zu bet sbetficte emror; abev in oem zugenblicte, wo es bafeleft angetommen ift, foingt bie smufdel an zu fdwimmen, invent ez allez

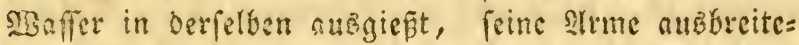

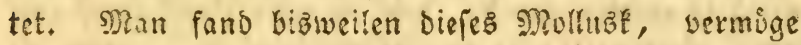

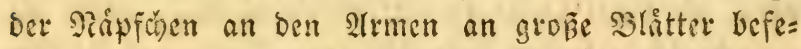
figt, mit Denen fidd's auf bem SBaffer umberfitifen lies. Seine 2lugen find berworftelyend und fidjtbat.

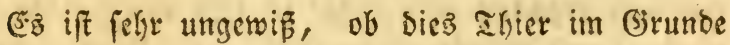
bes Meeres leben Eann, wenn eš durd) einen 3ufall feine Muichel verloren hat. Jids erthielt faft in bem Zugenblid, wo biefe Mollusien geffidt waren, eimige, ob idl) fie pogleid) in Decerswaffer wieber truthte,

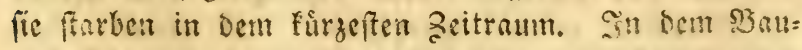
d)e ciniger fand idl (v)er, fie waren weî́ unb rums und bilbcten eine Maffe, alle batten aber cimstr 


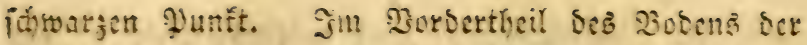

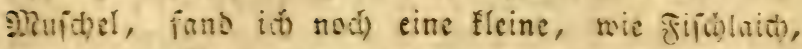

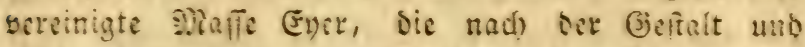
Farte, bem fuid anoerer filide glithen. Diepe Eleis

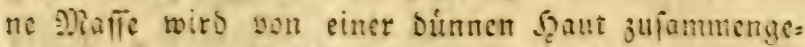

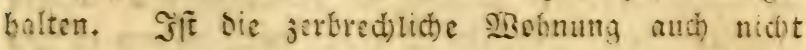
arifict, wie ein Finget, fo finoet man sot) ciren Encrifoú, in Geftult cines filfens. Dor shuno son biciem Molust ifi mit cincm Echnabel serfehn,

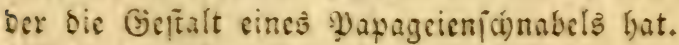

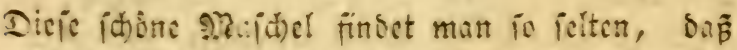
fie jelbit in Jnoien, als eime foptharfeit angejefin wiro. ") Die Eingebohrnen betraditen eื a!ş ein

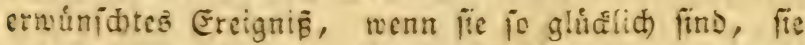
3u erbalten; fie beben fie porgfíltig bey ifrem Ed atge nuf, nur an grofen Feften bringen fie fie zum 3or=

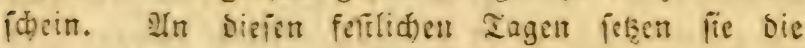
frauen allen Błticfen aแs. SBenn fie ben Tanj im Sreife tanzen, Det unter bem Pafimen lego, lego,

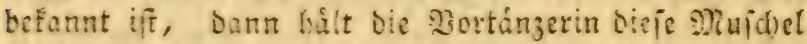

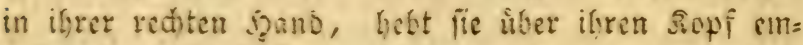
for; fie bient lange ju dicjen (siebraud), menn fie

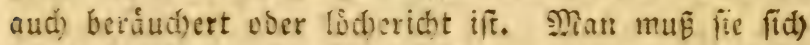
burch) (belo ober glatte Thorte zu serid)afien fuchen, menn wan bie Muidel unteidabigt, ober in gutem Etanbe, irgalten will. Eie iif iefre theuer: fưr cine

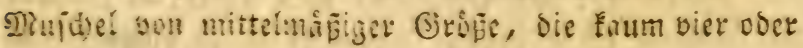

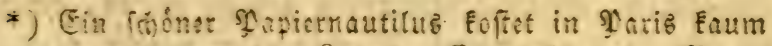
biet und zirarizig fivrs. Ce giebt eine Menge

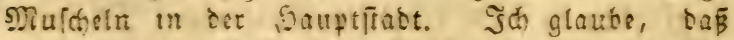
man einen vortheithaften Şande! Damit nack Jn= bien treiben fonrti. 
funf fleine Sielche SBaffer fapt, bezablt man, olye

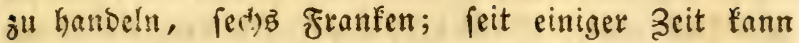
nan fie nid)t cinmal fur biefen gjreiz ethalten. Sius faheln, die faft ein Maa sa fap̃ten, fah man, cine brvon, zu fed) jig Franken serfaufen, weil fie ferte felten find. Eine von ben grofisten, habe id) nie gejerinn.

Rumplius erzåkit unz ferner nod) eine fleine (Gefdid)te yon cinent Dolyp, Den man gleid) fam alb

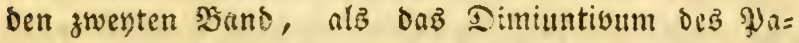
piernautilub, betrachten furnte, Der von einem groler in bie \&uft emporgethoben wurbe. (E⿱乛龰 if unmoglich),

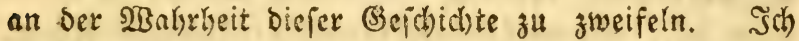
úberietze fie evenfalls, ba fie bie Gierigteit uno Echnelligkeit Der Seevigel auf ber einen Seite be= weiñt uno uns auf ber andern zug(eid) einen Feino

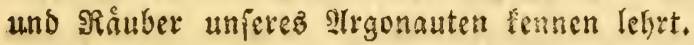

Ein Seeabler (halioetos) ber immer auf ber Dberflåche bes Meeres fásebt, bemåd)tigte fich) cinez Wapiernautilus, Der auf Dem Wrafer fowamm; ba ex ihn mit feinen Sirallen gefage batte, erbub ex fict) mit ifym in bie fuft; Da fry aber mehr an bem Thiere, alz an ber Muidel gelegen war uno ex ienes mit Dem Schnabel herausrifo, entid)lippte ifm bie Muidhel, fiel burchi ben fonberbarften 3ufall auf eine Eleine Sandftelle zwijhen ben Felien, jo, bar fie nue wenig verleste war. Ein Fifder, Der fid in ber (Siegeno befand, nalym fie jogleid) auf und brachte fie mit.

Sm Salire 1693, fáfrt Rumphius fort, im Ronat Sanuar,- fing man ju Siton einen Nautilus, 


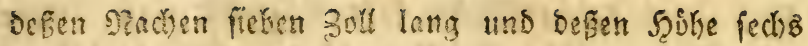
3olf rod war. Dies Ihier war ven bem ein wenig

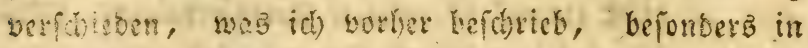

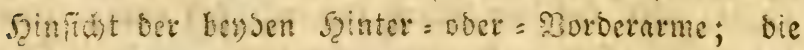
pedis strme waten etwa zwolf bis biergehn 3oll lang, fehr simat, nad) Den (Ensen hin ausgefafelt un' mit Dioffechen verfefin, bie beysen Sinterame (einige

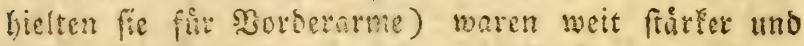
bitfer, als bie andern; *) ifgee Dire glid) Der einez Fingets; fie hatten abwediflno auf einanoer folgenbe

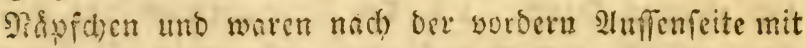
einer binnen, breiten haut nad) binten zu fdmaler alb vorn hin, verfefin. Şermige ber breiten Szaut

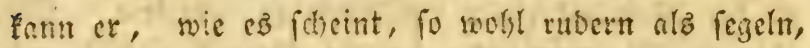
benn mit ben Edrupfebpfen lisit er fid) am Rande feimes Pachens feft; und bann fonn ef mit ber brei= ten Sonut, fo wie mit ben anbers syrmen, bie tiber ben Sor'o hinaubigeferect find, rubern. WBill er mit

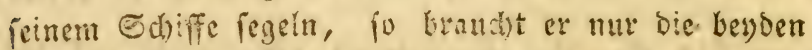
nubigeriannten Sagute in sie luft zu ergeber. Nie rabe id bel) einem eingigen Prautirus biefe bersen 5eåte **) Durd) cin binnes Soutchen verbunden ge=

*) Das Thise hatte sine unrichtige $\mathfrak{a g g e}$ erbalten; man batte ben Bopf befelben vormarts gelegt, ftatt Das ber Zrgonnute in Der MMufdel auf bem Siucien liegt. Donn fallen die benden Scinterarme mit ben breiten Şäuten vorwårts, um bie Stelle Der Esgel zu vertreten.

**) Diefe beyden Jृaute find bell bem Yrgonnuten nie verbunden, aber iede von ihnen fefint befon= Ders am furferiten Ende der benden Jrme rads

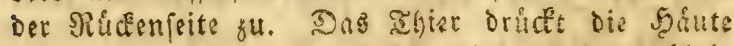
fufammen, wzan es fotjifien will und dann fchei= 
funsen, fo, bas fie einen ungertuennlithen fiuspet nusmadten, wie cinige entopififo Edhiftetler bes bauptet haben. Jarum bleibe ici) nod) bey meiner erfen meinung und glawbe immer, bat bies syots

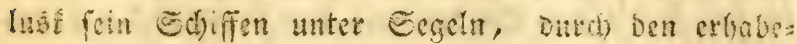

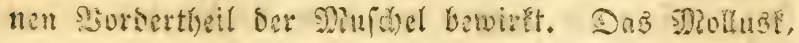

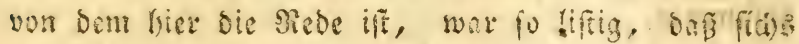

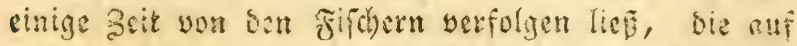

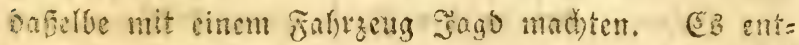

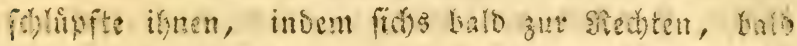
jur Simfer tinmarf. Enoliti) nercten bie fifoes,

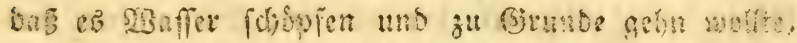

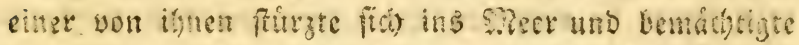
fid) feiner Duterl Sdyinmen.

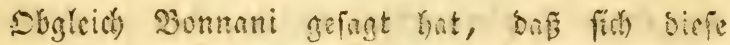
Dolypenart in Gation mit andern gyolypen an tie Rifite begábe un ba za weiben uns thriwng gu fus

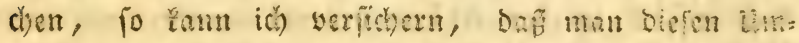

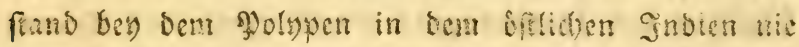
bemerft hat, bagegen "trift man ign in ber Gee uns immer cinfan an. Diefer, wat bem ith teoe, fwritet

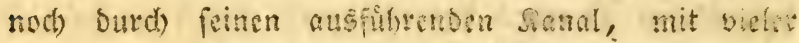
Stritre Waffer und aft mit cirer fution sentigfeit

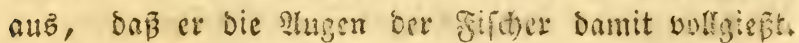

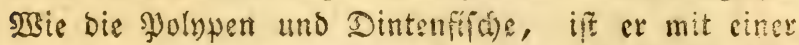
Dintenblafe verfelin, aber fratt Dar bie Feudtigkeit

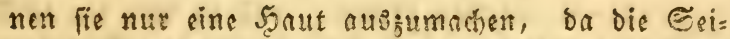
ten berielben feft an einander gedruldet find. \$ies

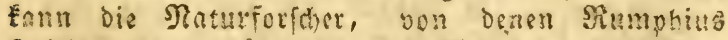
fpricht, itre gefihnt saten. Sie fahn das S)iol=

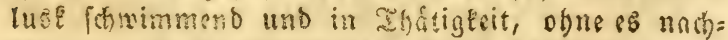
bet genauer zo unterfuchen. 
ficwary ober roth ift, bat fie eine braunblälidide Farbe. In feinem Magen habe id) Sthicte son Atrmen gerunden. *) Neue Seobad)tungen haben

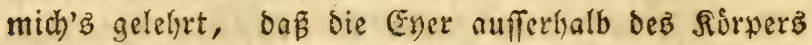

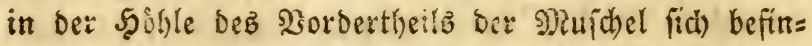
Den, allein fie băngen mit bem Siorper Dezి Thierş zufammen.

ŞaIma, Der in Der Folge einer Erflårung bes

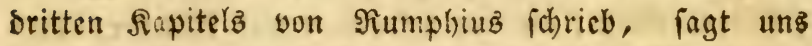
îber ben 2irgonauten bez mittellindifchen Meers jebr wenig. Die Streifen ber smlufalel find cinfach uno man findet fie nach den Beobad)tungen bes hollanoi= (4)en Naturforichers, auch in Den indiphen Neeren.

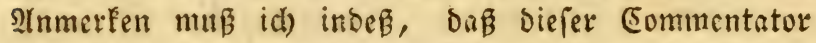
son einem Mapiernautilus fprid)t, Den er in Şolland

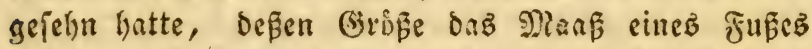
betrug. (Ex meldet unb aud), baß́ biefiez feltene Rabinetifice in Der sibfitht gefauft wuroe, um bas Rujeum Deś (Dermaligen) Grublirizogz won Florenz zu bereichern. Ein 2autilus von biefer Orópe iff bơd) fe felten. 2luch in Yyariz, in ben Eâlen bez botanifăen Giartenis insuefondere, findet man Der= gleichen, bie hochitens zwolf zoll grof fino: anbere, bie noch) gropser find, miñen áfferft felten feyn.

*) Dbgleich Rumphitts beftimmt lagt, baß biele Drudjphide Ilseile vom 2 rm waren, und man Daraus fhliesen Eonnte, Das fie von einem פoly= per wárn, Jaß̧ ber źrgonaut Seineşgleidten vergefrte, fo glaube idi bodi weit eler, Daß man fie für Thite des Geciterns halien muई. Co blutsurifig bie syolnzen fint, ifre Berchlecits verivanben fallen fie nidt an. 
Mran fann es iefst nicht wiffer, nad) weldyer zeidinung bas Miebaillon copirt worben ift, bas ber hollandifa') Supferfited)er mitten in bie nieblid)e $\mathfrak{B i g}=$ nette geferst hat, mit ber bie erfte Seite dez 2 Berks

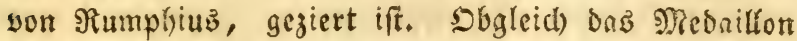
nid)t gruêer ift, alz ein vier uno zwanziger Souss=

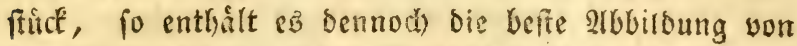

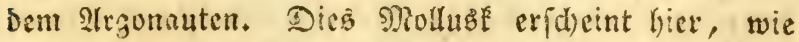
$\mathfrak{e}$ fichs fanft auf ben 2 Bellen wiegt, feine fech) $\mathfrak{A} r=$ me, auf icber Eeite beet), auz ber Muid)el firedft, Die ihm zum アruter uno Steuer bienen. Ein liebli= ther 3ephys unterfitht feine Inftrengungen uns fein STauch fd)willt bie Seegel auf, bie baz Ihier aus=

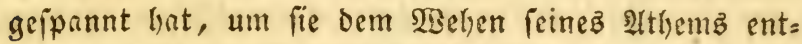
gegenzuftellen. Diefe niebliche Figur, fo flein fie

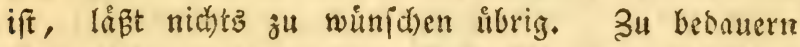

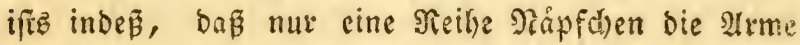

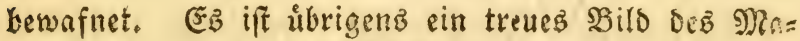
nưurez, waz unfer Echiffer anwendet, wenn eş bie fitlle $\mathfrak{B B}_{\text {Btterung }} \mathrm{ifm}$ erlaubt, auf Der Sberffád)e Dez 2 Baffers, bez Einflupez ber atmozphárifden \&uft zu seniefen, bie zu jeinem feben notrig zu feym (d)eint. Der Rerfaffer biefes Medaillonz, hat fider biefes Molluät felbft fdurmmeno gefelyn. Sei=

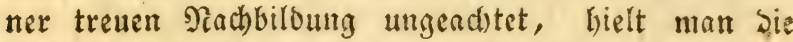

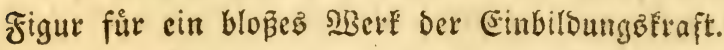

Nan findet in Dem 2 Berle von Rumpliuz feime anbere 2lbbildong bes Irgonauten yom gemeinen Nautiluz.

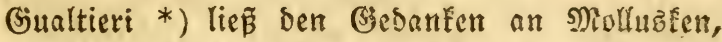
bie Dieje zerbrechlidben $\mathfrak{T a c h e n}$ bewolnnen und (d)affen,

*) Şualteri ließs auf Die silf̣te Supfertafel unter bem 
ganz forben, uns lieit fith blob bey ban infirn

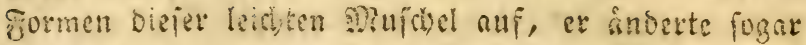

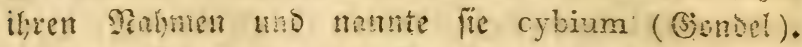

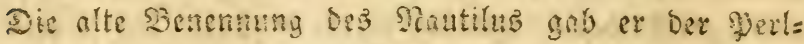

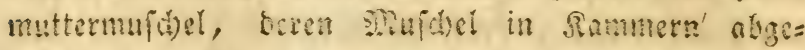

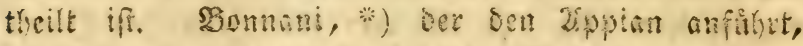

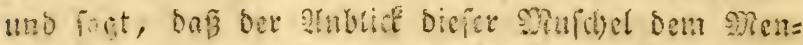
fiben die erife Joe cine Gialecre ober ein Echiff zu buun, geben fonnte, begnugte fich rucib samit, nut

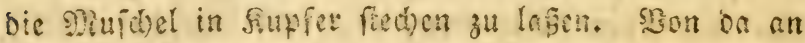
findet man mut cinige Ifutoren, sie in ifren shu=

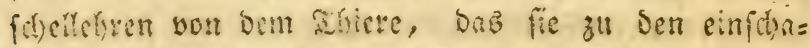

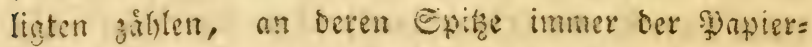
nautitub felt, auf eime melyt ober weniger Duntele slrt reosn, indem fie einander nadjofheciben.

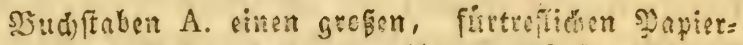
nautilus frecicn uno nent iín: cymbalum maximum, striatam striis crassis, rotundis et raris, aliquando dichotamis, spina acuta serrata, cujus testa est valde subtilis et folio papyraceo similis, pellucida, fragilis et lacteo candore imbuta. Cin anderer S?autilus aนf ber= felben Supfertafel, unter bera s3umfaten B. if flciner, gebort abee zu berfelben 2irt. (Gualt. Index test. Conchyl. tab. 11:

*) Univalvium non turbinatorum agmen ducat nautilus. Talis dicitur a verbo graeco nauilos, quo piscis et nauta significantur. Ab hujus testa navicula repraesentatur eminenti puppe in so ipsa aliquantulum refleza... ab eodem navium fabricam, navigandique artem desump. iam Oppianus affirmat. Bonnani. Recreat. ment. et avuli. class. 1, pag. 88. 
Siffer *), 2irgt ber finiçin srma yon Engroms, begeifert burí) Die Worte feinar Borginger, bie hber

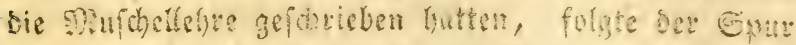

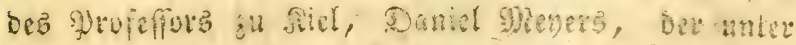

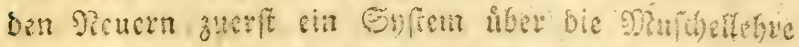

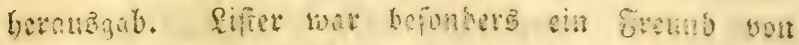

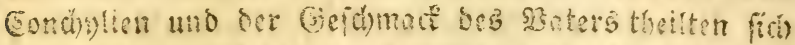

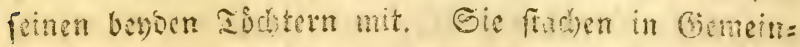
ficofe mit bem 2 siter, an fimprymbert shufteln in

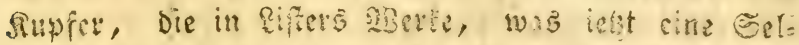

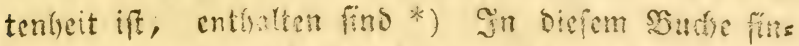

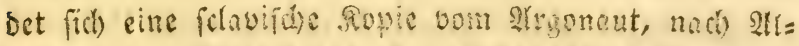
brogansi. Das zhier if aud hier ofne spuno ge= zeid)net.

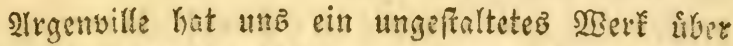

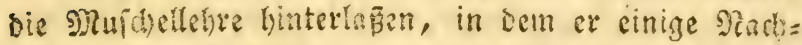

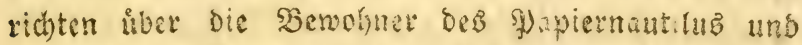

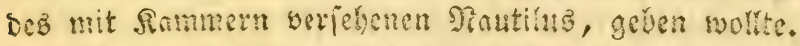
Die Figuren, lie er liepert, find falfiti copint uno

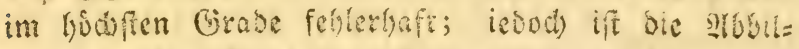
bung von bem झुapicmantilus gienlidid) gut.

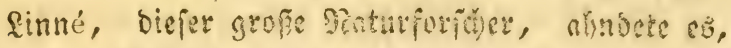

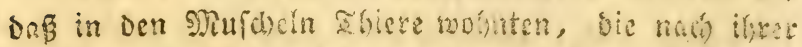

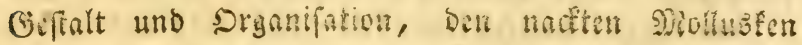

*) Lister, Hist. conch. Fig. 557 .

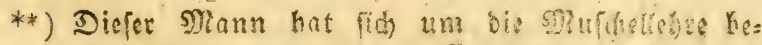
fortoers verbient gematid. Se war bur calte, ber

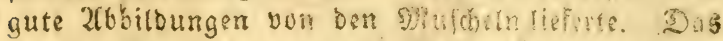

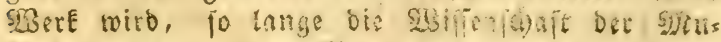
fhetn baurt, feimen siserth bergaten. 
gleid)en, aber etwas beftimutes bat ex bariber nidjt gejagt. *)

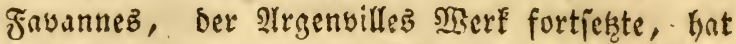

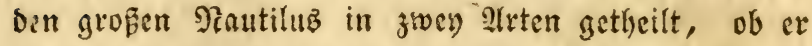

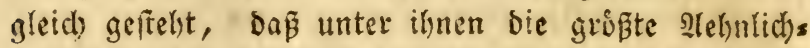
feit fratt finbet. Er verwirrt und verbunfelt baz, waz feine Sorgångex úber den Nautilus fibrieben, und wiebertyo!t zum Theil basienige, waz Argen=

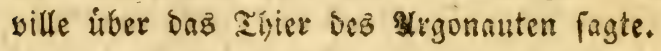

Faganues glaubt Feiret Meinung ourd) Die bes જerfaffers, Der bie Sentertungen uber bie Supfer= tafeln ser (Encyflopedie Dern झुublico mitgetheilt hat, noch) mel) Szaltung zu geben. *) Diefer 2 lutor fagt in Dem fed)3ten Sannoe, Seite 7., Figur 14.**)

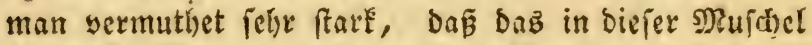
vorgeftellte Ilfier, nid)t ber wahre $\mathfrak{B}$ efiftzer berfelber iff; obgleid) ieber Plautilus ber slrt, ben man vols=

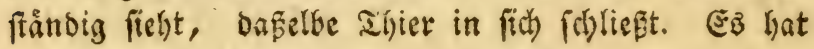

*) Argonauta animal saepia aut cliv. Lin. Syst. nat. vermes testucea, gen. 317 , pag. 3367 .

**) 23ir wiffen es noch nicht getwíb, ob das cathice Des Papiernautilus sin गु)olnp ift, was alle 2fiten behaupteten. $23 a s$ unbezmeifelt ift, befteht batin, Daß́ Eein Seifender bas ftigt geiehn bat, was eb in feinsm naturlichen Buftande boch feyn milite. Der solyp ber s)lu= fêtel, diez lifift fich vermuthen, hat fie niát) ju Dem Srabe ber Bollfommenleit gebracht. (Favannes, Conchyl. Vol. 1. part. 2, pag. 702.)

***) (Fz ift ber fe(t)fe $\mathfrak{B a n \delta}$, die 67 . Iafel und bie 15. Figur, bie Fabannes anfübren wollte, 


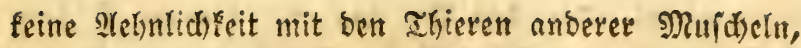
und gleid)t dem \$olapen volfermmen. M?an vermu=

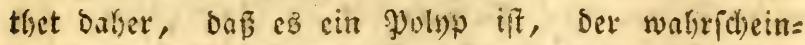
lich in bie leere Murchel einfelyt, wie ber (Eremiten=

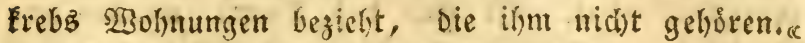

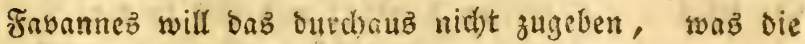
Alten tiber bieję Zlyer gejagt haben, waz aut(h)

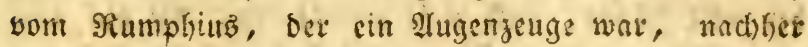
beftåtigt worden ift. (Er zeigt, wie es 2trgenville

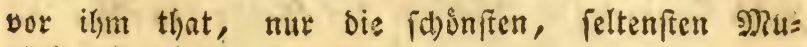
fobln an.

Sirrzlid) will id noch son einigen Sammlungen

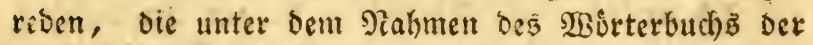
Paturge(d)id)te (Dictionaire d'histoire naturelle) be= funut fino. Sie find mit bloĝen 2 (n) ftaffirt, die ifjen Serfaffern Keine weitere Mlite mad)ten, alz Dä fie fie aus sviginalichriftifellern

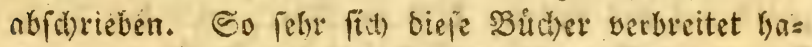

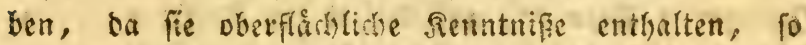

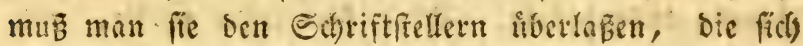
felbit mit tiefen Unterfubungen "uche befd)affigen wollen, weil ez lcidjter ift, fici) ber Intueit eines

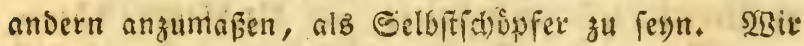
ad)ten auf Favart o'scerbigny *) nid)t, ob er gleidy nid)t olne Serbienft ift; eben fo weni,y auf ben Bers

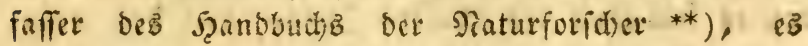
entlyålt nur unvollftåndige Nad)rid)ten ủber Den \$a:

*) Diction: d'hist. nat. concernant les testacés etc. par l'abbé Favart d'Herbigny.

**) Manuel du naturaliste, ou Dict. d'hist. nat Brukelles. 
piernautiluz ober ben 2 rrgonauten, bie wil in bem åñ mare finoen. *) Somare hat bie Piact)ridjten, bie ex im Mrgenville iver Den Irgonauten vorfand, 4 th=

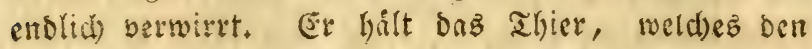

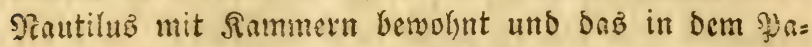
piernautilus, fir cin uno daß̉elbe, legt ifym auffer ben acht Jispen, noch viele andere bey, die auf eins

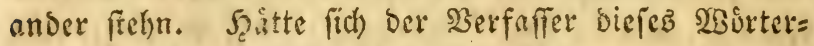
buchz Dem erniten Ctudium ber Natur gemeift, fo

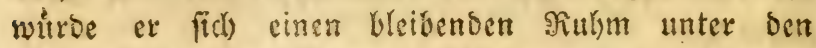

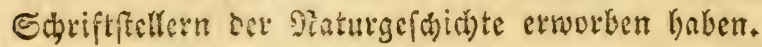

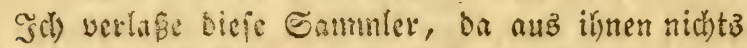

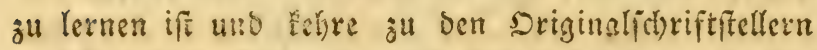
zuruict, bie, wenn fie aud) Fehler begehn, fie ims mer wieber gut mathen. Şndem wir uns denen in unfern Beiten nafn, fo wenden wir uniere slugen: zuerfit auf bas fdoune, loftbare sherk, waz ber weife

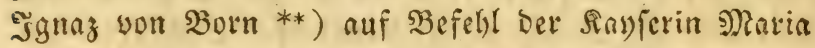

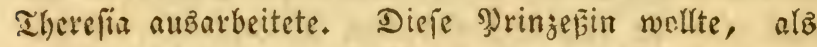

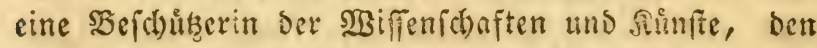
Ratalog uno bie Seidhreibung fer Gd)aalthiere, bie ilyt (Semalyl gefammelt lyatte, auf bie Padiswelt brin= gen. Born, Den fie baju waiklte, red)tfertigte ifr ลutraun. Diefer berúl)mte Minerwloge bewiez

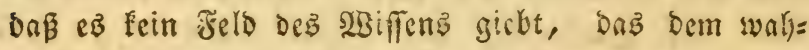

*) Dict. raisonné universel d'hist. nat, par Valmont de Bomare, 5. edition.

*) Testacea musaei Caesarei Vindobonensis .... disposuit et descripsit Ignatius a Born. Vindobonae 1780 . Fol. 
ren 2 Beifen unberannt bleiben fann, wenn ex fich Sineinwagt und foridtet und prift.

Nachsem er bie Muichel vollfåndig befchrieben

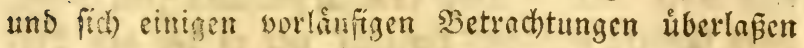
hat, Die bie Itet uno sReife betreffen, wie finné Den 2frgonouten ummittelbar alif bie Etocfmufcheln folgen liễ , fagt jorn, *) naih der cinftimmigen

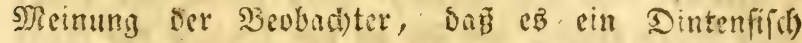

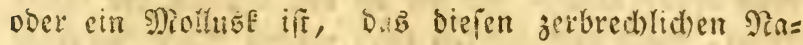
d)en brwolint. \$b er aber anth Die stbbildungen bez

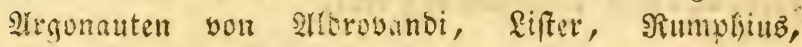
sligyanville uno Martini anfirfyt, fo ftimmt er boch

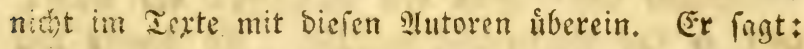

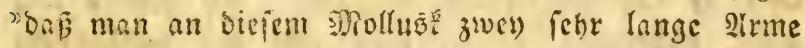
waifrnimmt, Die mit bell ad)t andern $\mathfrak{A}$ (rmen in gar feinet zerbinoung frehn, bie mit einanber burd) eine Sd)wimmlyat verbunden fitio und Tapfden ober

*) Connectit quasi Linnaeus testas univalves cum bivalvibus, dum pinnae pestremum inter conchas, argonautae vero primum inter cochleas lcum assignat. Quemadmodum enim e valvis binis in unum prope testam coalitis componitur pinna, ita et argonauta univalvis e tribus fere partibus, ut recte explicat Belonius, in unam testam compactus est, nempe e lateribus duobus e carina, ita ut cymbii figuram, puppe inflexa, proraque rostrata, perfècte satis referat. Testae huic naviculari, membranaceae, frugili, monothalamiae, apertura est condata, spira involuta, occultata, et basis seu carina modo latior, modo angustior, saepissima dentata, nonnunquam mutica lateribus compressis, undulato plicatis. Deborn, Test. mus. caes. pag. 138; de argonauta, 
Chropffopfe bie und ba haben; weldes itbrigens, was Den Sd)nabel und feine Rage, bie 2tugen, ben soirper uno ben aużfútirenden Sanal betrift, ben

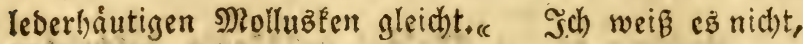
was şorn verleitet hat, bem Argonauten zelyn 2(rme, gowey) lángere und ad)t fairgere, wie ez̉ bey ben Din= tenfildsen ber Fall ift, beizulegen. EG ift ein srt: thum. Dab Thier bez 21rgonauten hat, wie bie Yolypen, max ad)t 24rme, zwey bavon find breit: biefe breite J̧aut, bie fich an ben Epikzen ber 2 lrme finbet, nach bem Rủcten hin, machte Sorn bey einet oberflachlid)en Unterjud)ung irre.

Sidher hatte Sorn ben Rumphius vor Ilugen, weil ex ilgn meljreremal lanführt. (E) fonnte ihm nidjt unbefannt feyn, was unz der lodlandijche Sadriftifteller über baz wirthlid)e Thier bez 2 irgonau= ten Ginterlaben hat. Sorn bejdreibt auf berfelben

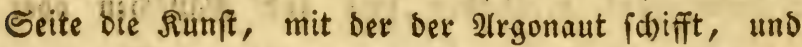
bebient fid) ber 2luabricfe, die झlinius anwenbet, um biez Manouvre zu id)ilbern. Sogleich bie Reu= ern burd) ifre Beobachtiongen bas beftatigt "båtten,

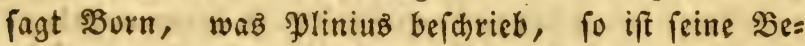
(d) reibung boch bie treffendfte. *) "

*) Celebris haec navigatione sua cochlea supina in summo aequorum pervenit, ita se paulatim. subrigens, ut emissa omni per fistulam aqua, velut exonerata sentina, facile naviget; postea tranquillum mare demissis palmulis, ut remis, ferit, si vero flatus invitent, prima-duo retorquens brachia membranam inter illa mirae tenuitatis extendit, qua velificante in aura, ceteris subremigans brachiis ... Quidam innuunt: argonautum libere taestae suae insidere, 
Sieucrn behauptet baben, fáhut ce fort, babs bies Thier bie Mufdyel verlaffen, und fids won ber Sd)ale befreien fonne, um fich) beym Intublid einer beborftelenden Siefalye in ben 2lbgrunb zu fturzen;

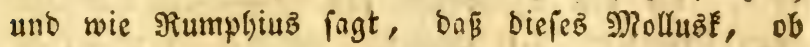
eB gleich mit feimer Mufchel nicht verbunden fen,

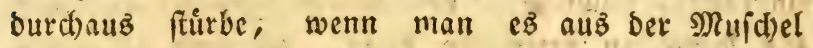
zicht; fo mus id vermuthen, wenn wir bie Snd)e

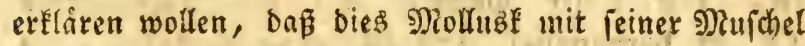
ourd) âfiferft feine Eelnnen zufammenbingt, bie burch Den leidhteften Stop zerriffen werben. «

Dieje Sermuthung Deż Deutichen Neaturforid)erz

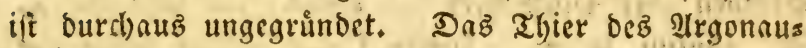
ten haingt mit feiner Mufdjel nidht zufammen; wirb ourd) eine gewiffe 2lusbehnung, burd) ftetes Ilufid)wellen in berfelben feffgehalten, sermoge Der

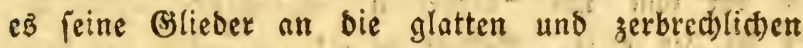

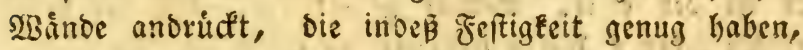

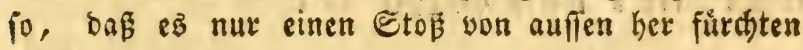
barf.

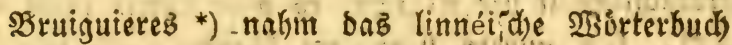
an. SBey ber arbeit für bie Encyflopebie befält er aud) ben Nalymen Sirgonaut, şapiernautiluz ben, begnigt fid) mit zwey sirten berielben, bie in mel): rere sarietáten zerfallen, nod) zalf(reicher als sie

imminente autem periculo osseam cutern exuere, ad abyssum descendere. Deborn, ubi supra, pag. 138. 139 .

*) Encyclop. metkodiq. Hist. nat. des vers, torn. VI. pag. 120. etc. 
son Rimné angefitbrten. Der blöe Slnblicé siefer

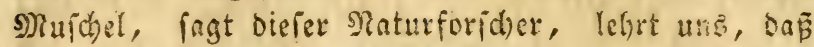
fie gemacht wubde, aui ben sBafter zu fíwimmen. Sindem er bie Jeinung einiger Cedriftiteller wioer=

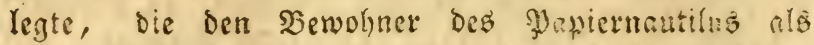
eincn frembling betrabteten, ber fich in Denfelíbn - cindrange, nachdem er ben reditmisigen Figentfumer aus bemfelben vertrieben baitte, bie anch bebaupte= ten, Daz biefer Joly», wie ber Iafdenfrebs (Cancer bernandus) feine Molinung veraindere, ie nachoem fein Aorper gröer wurbe; glaubte Sru=

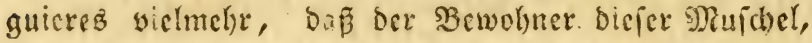

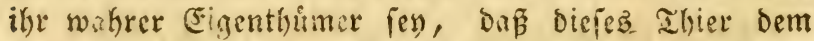

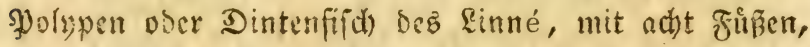

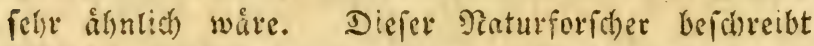
felbit Den Gifieberban vou diefem Mollubl mit einer gewifien Genauigfeit, die man bey denen nicht findet, bie sor ilym iber benfeloen Gegenftend ficreiben. Er iff ber erfite, weldyer gejagt hat, Das ber fiet= fdigte Surwer biefes polupen itl einer Edreibe liegt, bie vorn offen iff, wie bey ben Dinterfifhen und

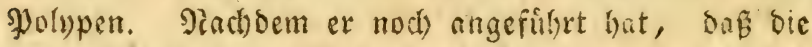

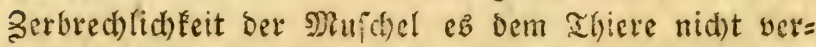
ftatte, fid) anderis luber bem $2 b_{a f f e r}$ als zur 3eit Der gropten sBindfille, zu zeigen, weil fie fonft ofinfellbar burd) die Bewegung oer SBellen zerfd)met= tert werden wirbe, befidreibt er nach Irriftoteles,

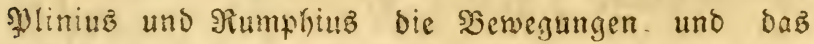
(E)!ffen won Diefem slolluble. Srllein man ficht, Daß

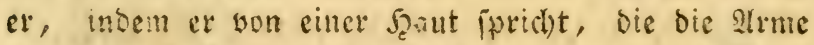
an ifree $\mathfrak{B}$ afiz mit eimanoer verbinden, bie Men= brane nirbt fannte, mit oer bie Epiben ber beyben arme veriefn fino; uno baß $\mathrm{el}$ folglich in ben ge= meinen Grutfum fiel, inbem er fagt: welon ein fonf= 
ter Sुgins welyt, fo richtet bas Thier zwey won bie= fen Jimen lofrurect in bie Şofh, und balt fie in

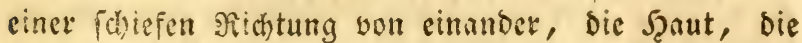
fie an ihrer Bafib vereinigt bålt, ftellt, vermóge

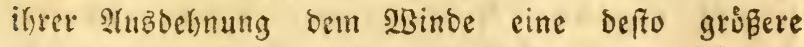
Süerflactbe entgegen, biefe Şaut dient bent fleimen Schiffer zum Segel. Druguieres fonnte fith burch

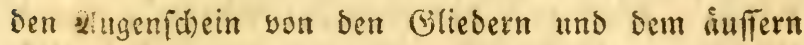
Şau des Alrgonnuten belchren, , $c$ be befand fid) in ber

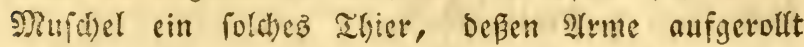

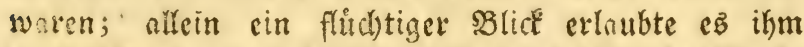
nut, bie borizontale Epalte deg Mantelz oder Sad'z

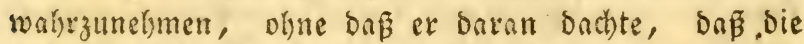
beyoen lesten Strme an ifren Enoen mit breiten Şåu= ten verfebr wåren.

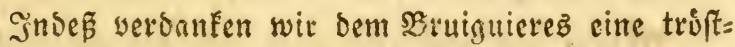
lid) SBemerkung. Dicfer Tinturforfder fagt utbื,

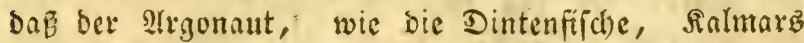

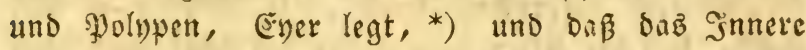

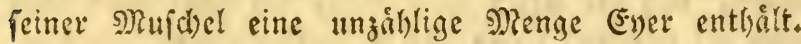

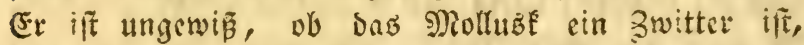

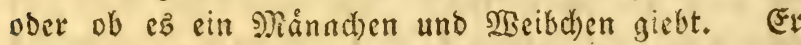

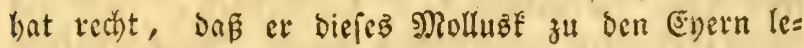
genoen rechnet.

*) Der TBurm des Sapiernautiluz legt (Ever; eir

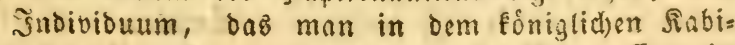
net aufbewahrt, zeigt eine grofe Mienge Eyer it bem Snnein det SRufhel. SMan weif nidt, ob ber 23 urm ein 3witter ift, oocr ob es cin ver: (d)iedenes Gefdiled giebt. Bruiguieres, Ens. pag. 121 . 
Sruiguieres redinet alle Pुopiernoutilus unter eine 21rt, uno theilt fie nur in orey Darictaten; ob and), wie ey fagt, biefe Mufdel in ihrer form,

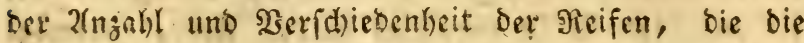

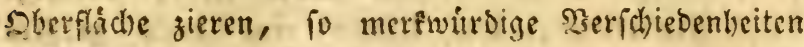
sarbistet, man fid) bennod nicht wundern mǘ, wenn fie viele Taturforid)er fiur verfdiebene Sirten halten. Man muß ber Meinung Rimné's beitueten. Sllle biefe mannigfaltigen Befbaffenbeiren fin blö̃e Barictiten berfelben Muid)e!.

Diefe Manier, bie(e Muf(c)eln zu clafifificiren, fann id) nid)t annelmen, weil Der Yapiernautiluż, oder Der gereifte 2legonaut uno Der $\Re$ Rišbren) (L'argonaute a grains de Riz) nid)t $\mathfrak{T}$ arietåten won ein = ander find, fonbern beftimmte 2 (rten.

Snoem wir nach ber Reih alle bie Schriftifteller angefulbrt, bie von bem \$apicrnautiluz ober bem 2lrgonauten geiprod)en baben, fo entging eß̉ unzె nicht, onf bie Ilten behaupten, ez gåbe ein İhier, bem Die Muidhel Durd) Dab Eigenthumbrecht angefore. Se mehr wir vorfaritten, fahn wir, das fein $D_{a}=$ leyn ohne Altžnalime bald zugeftanden, bald mit Finfarrånfungen angenommen wurbe. Einer beftátigte

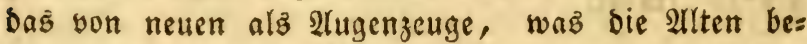
baupteten, andere låugneten Thatíad)en uno ließsen fich) nidht ůberzeugen. Die Peuern, bie unter biejen Ungewiôsheiten fo verlegen fins, crgriffen cine Mit= telftrape, inbem fie bülig einraumten, $D \subseteq \tilde{\beta}$ baz

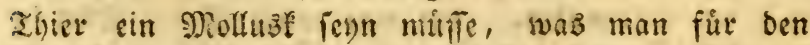
2rigonnutert balte. Sie vereinigten fich gemeinichaft,

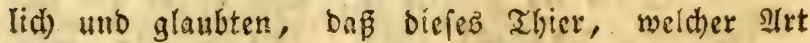

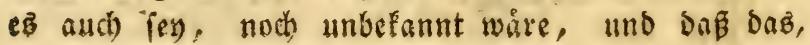


weld)es man in biejen Mujdeln finde, ein Sdymas rukerpolyp waire. Diefe Neinung wurbe allgemein angenommen, fie fdien mit ber gefunden Bernunft in Hebereinftimmung zu feyn uno erregte keinen $2 \mathfrak{B}:$

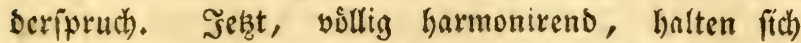
alle bey ber äuffern Beftalt ber syotypen auf, uno nelymen baher ben wichtigften Grund, indem fie ia

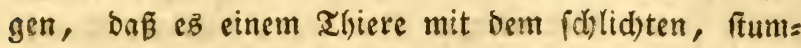
„yen Rirper unmóglid fer, eine folche Dluid)el zu baun. Lamark ift befanntlid) Der erfte, ber biefe Meinung beutlich ausgefprod)en bat. (5r ließ ůber

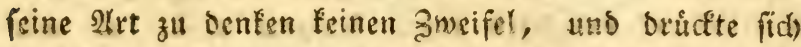
Daruber in feinem Snftem ber. Thiere olne Belente unb am Schlufe feineb Memoires liber bie Dinten=

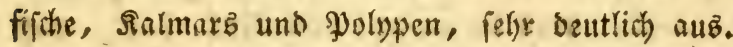

Der gelelirte (5uvier fieft bas. Thier bes Đapier=

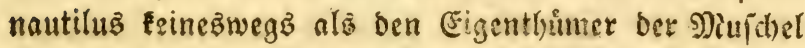

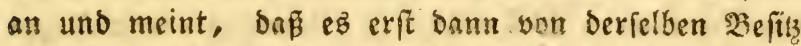
genommen håtte, alz ber wahre Beffice auz Dexielben wertrieben worben wäre.

Shas Bojc auf ben vier Seiten fagen will, um

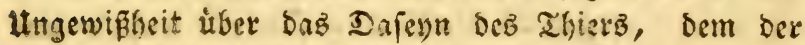
2(rgonaute eigenthuimlich gehourt, zu verbreiten, weis ich felbft nid)t. *) Er ift einer ber lekzten Zfutoren, bie über biejen Biegenfitand ichrieben. Zallez, waz er ủber biejes Molluă gejdrieben hat, wimme!t von Srtthumetn. Zawifchen feiner Meinung, feinen $\mathfrak{S}_{c}=$ (d)reibungen und Figuren, herrid)t wenig Hebcreisi=

*) Bosc, Hist. nat. des coquilles, tom. III, pag. 257. etc. 
fitmmung. Soch ift feiner'seobndtung bie breite Sout, an ben Enden ber beysen sirme, nidyt ent= 3anger.

Sin) felbft habe auf meinen Seijen oft nuf bet sheriacice bes Reers argonauten (d)wimmen felin. Son Der ferne fonnte id illere sewegungen immer

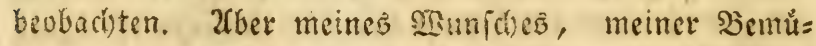
bungen ungend)tet, cinz bieier a Ihiere habhaft zu werben, uno fo oft idi) mich bealhalb aud) ilym fowimmend nalste, und $\mathrm{ez}$ sutd) bie gefdbidteften (i) wimmer verfolgen liế, bennod) wollte es̉ mir nid)t gelingen, ein cinzizes mix zu verichaffen, um ç zum Gegenftande meiner Seobad)tungen zu ma=

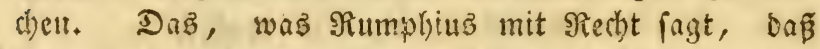
biefes abier fidwer zu fangen ift, habe id) alfo felbft

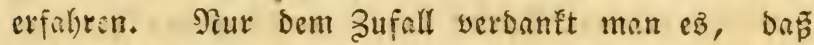

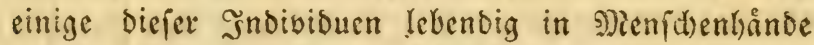
gefallen fint. SBill man fid) folwimmeno dem Irgo= nauten nelsn, won weldick Seise, yon binten ober

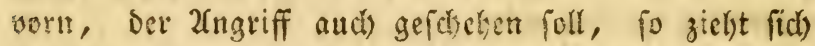
bos Thier in einet Entfernung won brenpig Sd)ritten wit ber grofoten Sd)nelligfeit zujammen: $\mathfrak{e} B$ finft in Die Iirfe; vergebenz taucht man fid mit unter, unt

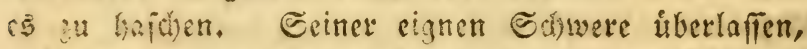
"cipt es bie angiefiende (Eentralfraft, Durd) zunely=

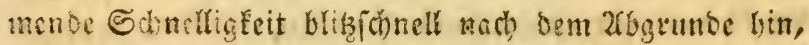

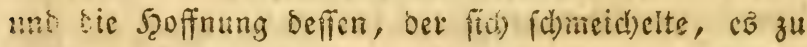
faffen, if getåuicht.

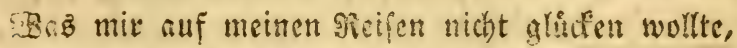
bob jelang andorn, Denel bas Shngefint in biefer Sinfild gunftiger war, als mir. Şa ben Esten sir sisturalienfammlung zu waris, fielyt man zwen 
in ifrecn Mufcheln befinoliche Srgonnuten; der eine, ein Yapiemutilus, welcher ein $\mathfrak{B e i b d}$ en ift, wird

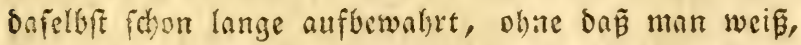
wo cr ferfommt: ber anbere fidreift fid) aus bem Sabinet bes Prinzen won Dranien her, Dem ex zur

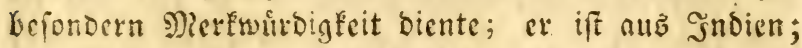

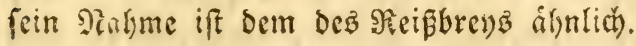

Eamart erlaubte mirs, Dof id biefin Alrgonat: ten aus bem Secher ziehn burfte, in bem er aufbe= wahrt wird, um ihn genater zu unterfuchen, da id) bie 2(bfid)t lyatte, ihn nahl ber Pintur zu jeichnen.

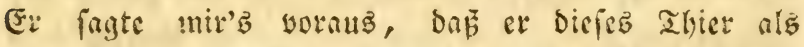

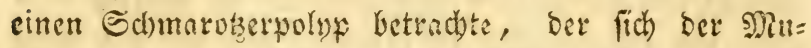
(d)el nach ifrem (Evbauer, bemniditigt hatte, um fo mehe, ba Euvier baffelbe audi) in ben Şanden getrabt habe, und feiner Bicinung beituste. Da id abst

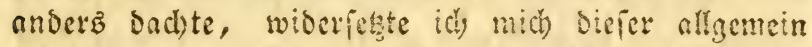
angenommenen Meinung, uno entichlop midi), die

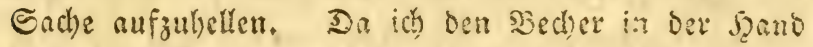
lielt, nalym id) Den Irgonauten heraus, zog ihn

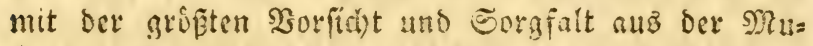
(d)el, um ein fo feltenes Etuce nibt zu bej(b)abigen.

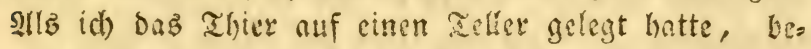

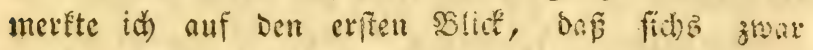

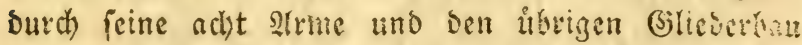

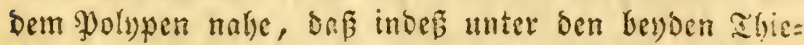
ren ein geniffer unteridjed hermide, ber melge firg! =

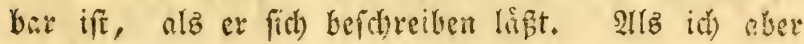

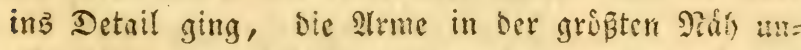

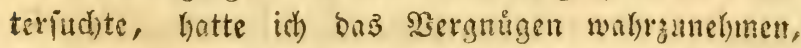
Das bie zwey Strme son ben achten, die binter bem Ropfe entipringen, fich our feire sidution endiyzen, bie aufgeroltt maren, bie, indom, iă fie auzenaners. 
wictelte, mid) die breiten uno merfwirbigen Şåate

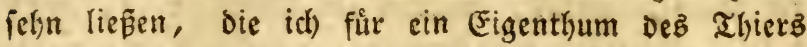
bielt, weldhes bie suluh hel berwohnt, bie unter bem Ptalsmen bes \apiernautilub befannt ift. Da id) jeşt an biejer Iflatfad)e nidht zweifelte, io zeichnete id biez Mollusk ab. Der $\mathfrak{E}$ ejer wird einen slict auf Die benden Supfertafeln, nenilid) Die XXXVII. unb XXXVIII. werfen, die in biefem Banbe entyalten

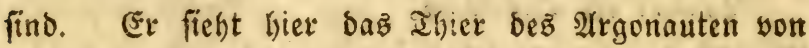
sorn und hinten, feiner $\Re$ Rufdel bernubt, vollfig ent= blöst, in feiner ganzen Geftalt; bie fo merfwurbis gen, breiten Şåute, mit benen zwey) von feinen $\mathfrak{A}^{\mathrm{r}}=$ men bejeţt find, bie bem Mollubi zu Gegeln bies nen, um auf ber See zu falyen, uno fid) mit befto

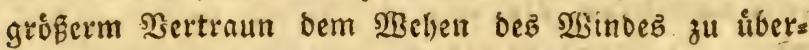
Iaffen, ba ber Schiffiruch fur baffelbe nur eine an= bere 2 ret bes beftehens wirb, wenn ber Gturm $\mathfrak{e}$ zwingt, fidd) in bie Tiefz zu ftürzen. *) SBir werben auf genauere umftånbe Rliefid)t nel)men, wenn wir

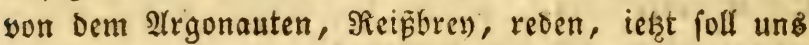
Der \$apiernnutilus bejhåftigen, ben wir auf bee XXXV. Tafel vorgeftellt haben, ủber bas DBaffer erbaben, mit yollen Segeln, indem ex bab (Sileichgewicht burch

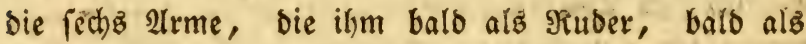
Eteuer bienen, behauptet. Diez ift ber Arrgonaut bes̉ mittellándifchen Meeresె; uno ba er von bem

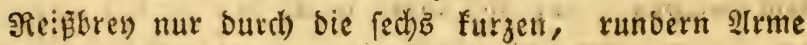

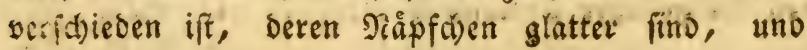

*) Sn unfern אupfern, Iafer XXLVII. umo XXLVIII. fiebt man nur fieben ganze, unverlebte 2rome bicfez 2frgonauten; ber achte ift verftummelt, viels

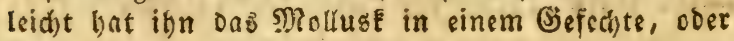
ourdi) einen andern aufall vertoren. 
Die Blatte ber Reifen feiner Mujdel, fo werben wir immer wieber, indem wir den झुapiernautilus beichreiben, nuf bie åufere und innere form beš jwenten jurúcfweifen, weil wir biejen mit ber grós= ten feichtigfeit unteriuchen fonnten. Itm bie 2lbbil= bungen nid)t unnůk zu vermetren, habe ich oen $\ggg a=$ piernautiluz unter vollem Segel auf einer Iafel, uno allf ber andern, wie er fich in ben slbgruns ftirzt, worgeftellt; inber man ben vom secisberen

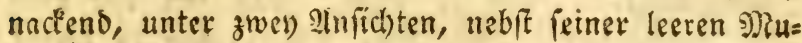
fdjel, auf einer britten zafel fielyt.

Bor biefem 2(bichnitt fielit man ben झapiernauti= lus, Der fanft auf Dem 3oben feiner Miufdel ruht, bie ex diber bie Trafferfliche ertheben will, um Daz felbit mit vollen Segeln zu fahren, um fid) Der $\mathfrak{S}_{e}=$ wegung ber 2 binde und Dem Stope ber Wellen zu

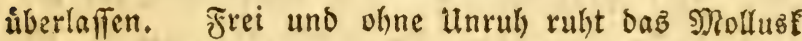
auf bem Booen feiner leidjten Barke auzgeberjnt nuf

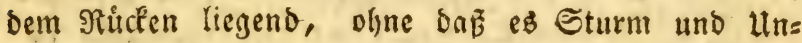
gewitter fücd)tet. Nachoem es die beyben Iltrme hins ter bem אopfe in bie \&uit geftreclt und fie nad) bee innern Seite zu feft an cinander georucfet bat, io ift bie J̧aut, mit ber fie verielin find, móglich it nuछ̉geipannt. Der Şauch bez Zeplyre, Der in bie= fem 2 tugenblicfe faum bie Dberflacthe Dez शreres fråujelt, fpielt in Den Falten bieję håutigen ভegelż, baz einen purpurnen und blauen 2 (nftrid) bat. Dieiez fanfte 23 ehen reid)t lin, um Daz leid)tefte, ziers lichite Fabrzeug von allen Fohrzeugen, bie auf ber See ichmimmen, fortzutreiben; einer Barfe, Deren Eigenthůmer Steuermann und Fưfyer er ift, fo wie ex

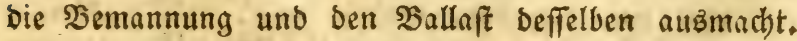
2I 


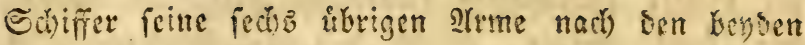
Seiten feines Édjiffes bin, won belten ifjm auf iever Eeite Drey zum গindern unb Etenern bienen mirfen. Durd) fie erristt er fid) int volligen (Sjletd)= gewicht und fdwimmt auf ber פrafferflsd)e, wie ez̉ fdeint, nur zu feitem Norgtuigen umber. Scine Mufdel, bie meifser wie (e!fenbein und burbifidig und leid)t ift, veritattet $e B$ ifym, vermoge ifree

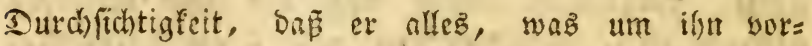
gelyt, wabrnimt. Da feine Sinne ebea fo fodorf find, wie die ber Dintenfifiche und Sुolypen, fo ift baz Geficht Dę Irgonauten felyr ourdjoringetto. In Der Rage, bie ex bat, matien feine slugen, Die nach) ben beyden Eeiten Der Miuld bel hingeridtet fins,

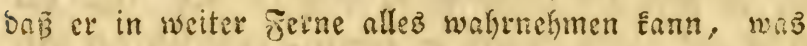
frixem Reben und feiner Eidyerbeit beobt. Ēं ift

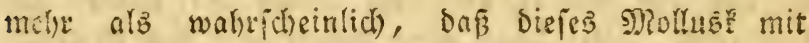
einer aufferordentlid)en empfindiamest begatt if, bie befonder in Den Gefullborganen; oder vielmelus in bem ganzen Siberen feines Rorpers berbreitet iff.

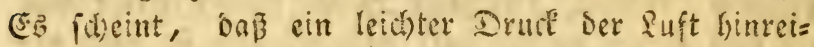
chend ift, um ifgm cine Gejalys anzuEindigen. *)

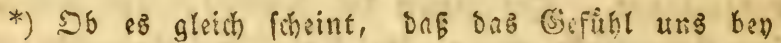
gewiffen Ihieten (rwie bey Dem Menfchen, in ben Jingerpiben) in Den hafferfien. Sheilen vergugtich fich finost; to ift es boch ganiB, bas biefe outli=

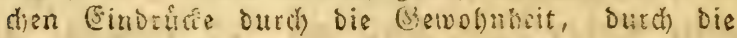

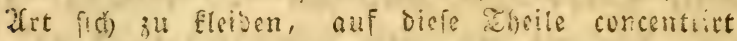

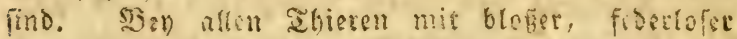
Şaut, ift biefe Scant hodut empfindian, nno

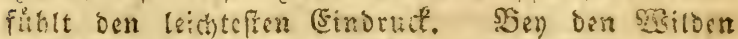
finoet fid) bise feine (s)fithl noch. 2Bie fhatf oas (Gefulln bel) mandjem SBlinben iff, leĭ)ren melsere Bevfpiele. 


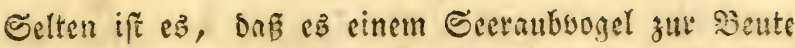
wirb. Es verifelst die Sunft, Den filuten, bem fdharien Sdinabel biefer rathiditigen Diebe, cben fo zu entgehn, wie es bem Eturme und feiner 2311 th ou entfommen weis. SBeldes aud bie gegenwirtige

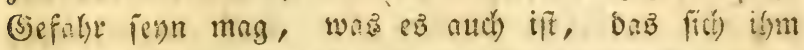
zeigt, Der Alrgonate rollt burd) founelle Beweguns gen, rafd wie ber Biedante, bie Segel nad́ itjer ganzen suzbernung anf isoer Esite feiner fleinen Calere zufammen, uno zieht die Trme und Seiten ein. Die fondlffe Bewegung fefrt ben untern Ibeil

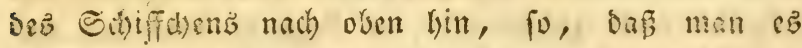
faum mit ben 2fugen verfolgen fann, wenn fid) ber Argonaute in bie Ziefe, wie in cinen Sichertheitzhas fen hinabftiryt, wo et won ben Eturmen uno fein= ben, bie ein anderes Element, alb bas feine iñt, bewolynen, nibis megre ju firrchten hat.

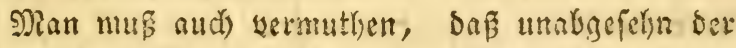
med)anifden Milter, bie in ber Bewalt bes Progos

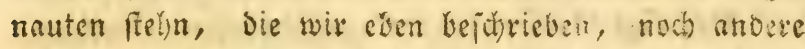
Şulfomittel ifyn zu Gielote frelyn, die er nmondet, stm fich) hiber bas sisaffer zu beben, ober fich in basela

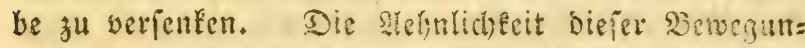
gen mit ber Der firiche, vie fich nad) Seltieben heben und fenten, lept un gleid) ifnen, irgens ein sjettel hat, eine sjortion luft in feinem Siotper gefangen zu halten, Die er

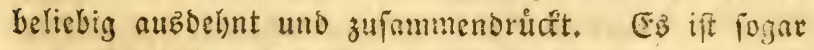

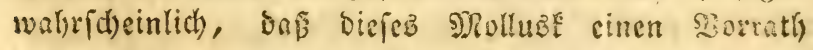

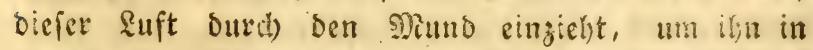
irgend einer Blafe odec innerer Infide aufzubewahren.

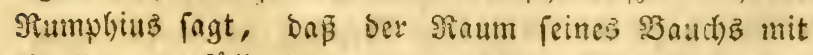

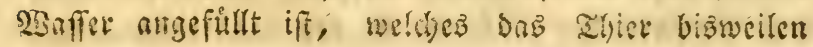


burch) ben ausfühtrenben Sanal, mit bent ç, wie bie andern leberbáutigen Ploflušen, Die wir bishler

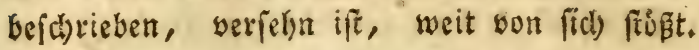

Der Rơper bes afrgonanten ift wie Der bes Po: lnpen, in einen Mantel ober Sact eingejd)loben,

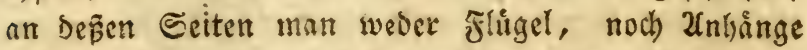
fiel)t; allein bie Gieftalt beß̧elben ift etwaß̧ linger

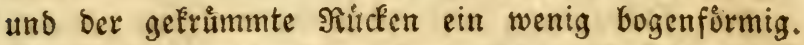

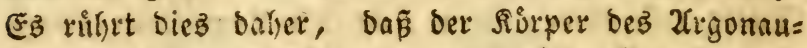
ten in einer Nujdal liegt. Das shier hångt mit bet פiufdel nicht zufammen, eह liegt in berfelben nur

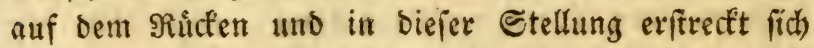
Der Şintertheil feines אišperz, nad) Dem Şintertheil

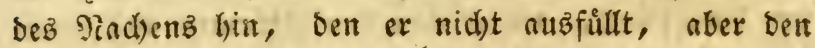
er burch Den Druct Des untern Rórperz burchaus ver=

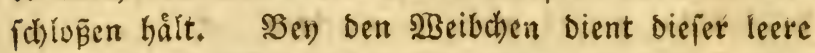

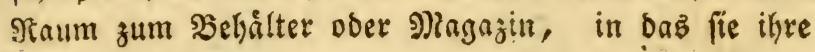
Ever legent.

Bermige biefer innern" getrummten Stellung, ragt ber Unterleih ein wenig herbor, und bildat bier cine glatte uno vollig runbe errhabenlyeit. Der Sact voer Mantel faließt fid), wie bery ben Poinpen, úber

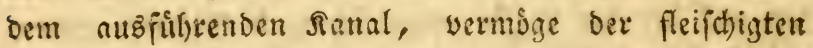

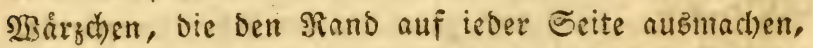

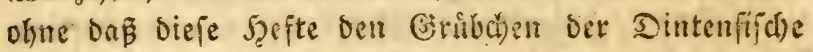
und Den Snorpeln Dev Ralmaris gleicheit. Dev aubz= fülyende Sanal if bey ben Jrgenauten nach Serkatt=

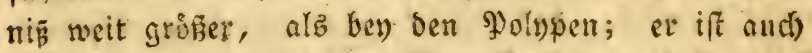
weiter, uno innerhalb nach aufien lin, mit zwey fleifdsigten siswen oder Rlappen verjelyn, die bem Thiere baz̧u bienen, Die Sefnung zu verfalieñen.

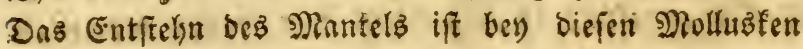


fo fidt)tbar, wie bey ben Salmarz; er entfpringt, wie bey ilynen, bey ben Argonauten, hinter ben Benid unb låpt ben Siopf frei. Diefer Sopf ift hin= långlich) groz, gerunost, mit zwey herbor/tehenoen 2tugen veriskn, sber, wie bey Den Dintẹnfiichen,

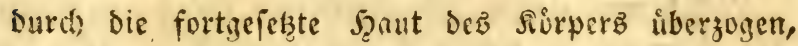
bie aber áufferft fein wirb, wo fie fid) ůber bie 2 fu= gen linzieht, fo, dap̃ fie bas Thier Durchauz am Selin nid)t binbert. Wrir haben foron angemerft, Dap ber Sinn bes Eelienz bey ben argonauten jel)e fd)arf uno fein ift, bấ fie weit in bre Ferne' jeln, ol)ne daf bie Szaut, bie bie Zlugen bebeft', ober

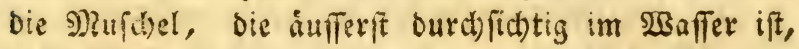
ifjen fürabet.

Zuf bem Sopfe fiteln adjt 2irme, bie fed)z Spiz= zen haben eine gleid)e fånge, fino sollig runo, mit

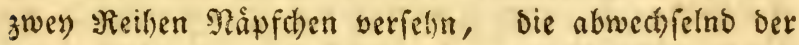

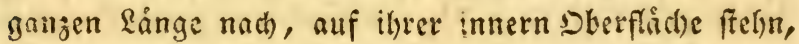

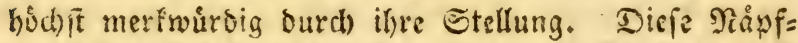
(i) plart. Die andern beyben ?(rme, bie nemlid) hin= ter Dem Ropfe, find von ben fedis Urmen felfe ver= (d) ededen, die wir beidrieben baben; fratt bar diefe

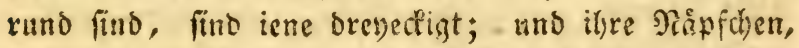
ftatt in $3^{\text {wey }}$ গeithen alif Der flachen oder innern Seite zu ftelyn, befinden fid) an ben Seiten in einer $a b=$ wed) felnden Stelfung; fie ragen aud ferte berwa: Das merfwitroiglte Rennzsit)en, was Das (Gefd)leá)t DeE 2rgonauten beftimmt uno es yon tim ber Din= tenfifche, Salmarz uno Yolypen trennt, i iț, Daß bieje beyden 2 rrme an ityen Enden cine brsite Şaut haben, an ber fid) feia গ:ipfden ober Sdlropflopf befindet, bie bey grofen 2irgonauten bie \$reite ciner 


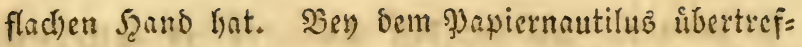
fen biefe beysen sleme in 2(bfit)t der Ringe bie fect)B andern; bey einigen andern 2irten find fie weniger lang.

Jch) war einige Zeit zweifellaft, ob ith aus bie: fen Thieren cin neues (Sejd)led)t mad)te; benn id) hatte beidslufen, fie zu Den Joinpen zu redinen,

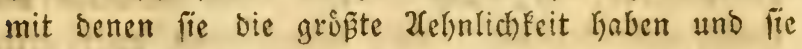

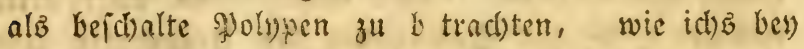
Der Erelarung bez Eharnfters der গুolypen anzeigte. Lamark wiberrietl) mir bies uno id) weigerte mida) nid)t, ber Meinung biefez getehrten, (charfiididigen Nannez Veyzutreten, bejonbers weil er mir sorftell=

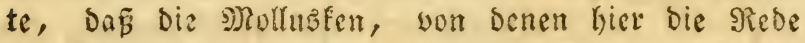

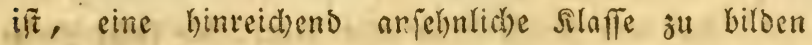
fcheinta, Deren einzelne Snbividuen, melye als bie \$olypen, mit ber breiten fraut begabt find, die ifnen zum Segeln bient, nebli einem (Siebåule, bas ifmen neue (Siejchidétid) Eeiten giebt, als bie, trodien

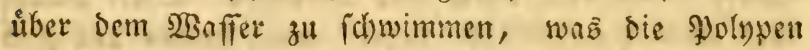

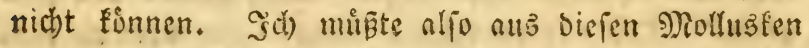
ein neues (Gejchlect)t machen. Do ich aber ein natitr= licker Feind neuer Benennungen bin, mit denen man nicht fparfam genug fenn fann, will man bie $23 i f=$

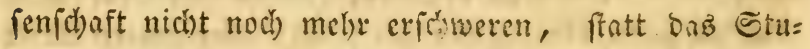
Dium berielben zu erleidjtern; jo ivilite id) ben

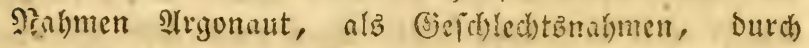

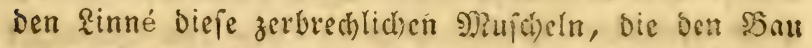
einez Sootez haben, andentet, uno fiigte fiur sie

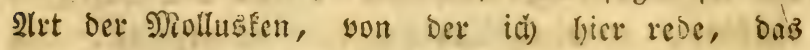
Beywort papiernen hingl, Daburd wirb die

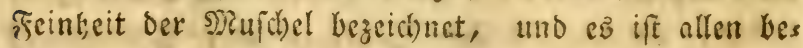
funnt, fur bie bie Nenturgefchichle গieize rjat. 
Die 3rgmanten haben mit ben \$oluwen sie

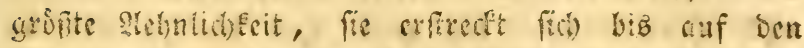
Diuns, det, wie bey bicfen Moffusten, hier mit cimem flateren, getogenen Eabnabel veriehn ifi, bet

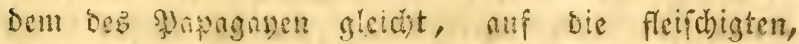
tmoen sippen, bie ihn an feiter Safiz umringen,

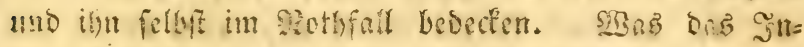
nere bes Ritwers betrift, fo ronute ith wegea Der

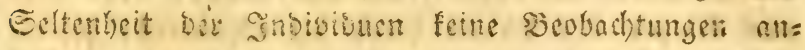
ftelten, die ibre genze Drganifation betreffen; allein

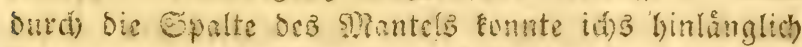

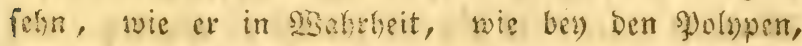

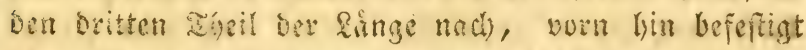
iit, wie ber Tridber eben fo einen aheil der vor= nehmfen (Eingeweioe beoccit; wie bie Jielymen, noes Die Sigane bes I!themiolens eben fo zurammengeorelyt uno eine jebe feitwarto bingeftellt ift; wie alfem aln=

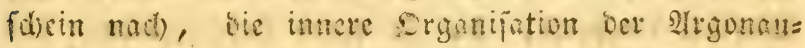
ten, fo wie bas stenfere, bem ber sgolypen fors:

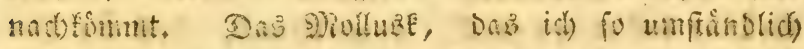
unterfuchen fonnte, war cin Peiścury (un argonaute à grains de riz). Althes nutílight miă) zal glauben,

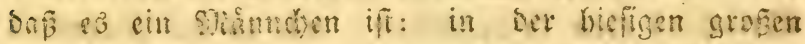

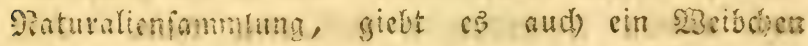
nus bum mitteffindifhen Neer; es ift baffelbe, son

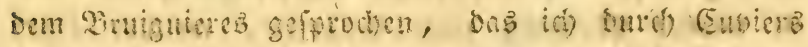

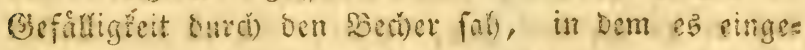

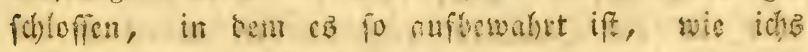
auf Der XXYVI. Siupfertafel biefẻ Dombes, vorge= fiellt rabe. Dian fiest es nuf berfelben, wie es

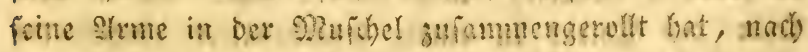

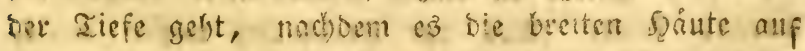
beir Eeiten feiner Consel niebrughnten hat. Ein

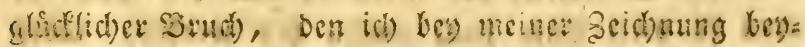
$\sqrt{2} 2$ 


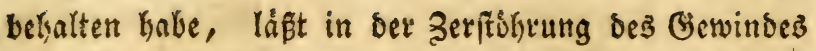

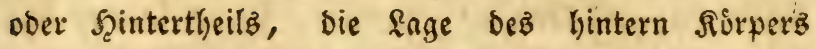
febn, ber eine åufierfit feine, mit Enern gefúllte

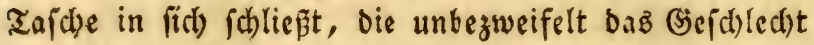

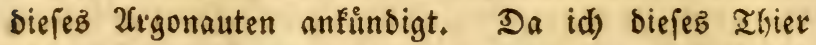
nid)t in ben Şånden gehabt habe, fo fann idd) nicht wiffen, ob biefe Tafde ifolirt ift, ober ob fie von einem innern Eyerftod" fortgelekt wirb, ober aus

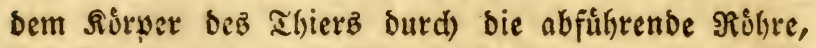
oder bie Defnung bes Miantelż herwortritt; hiez wiro uns bie zeit lefren. Darf id) unterbeffen meine Mieinurg fagen, fo bin ich geneigt zu glauben, baß biefe mit Eyern angefillte Iaide won bein Thiere auf einmal und ifolirt gelegt wurbe, wie ber Din= tenfifch feine Trauben legt: uno daß ber weiblide 2Irgomaute, nad)bem er fid) won bem Slumpen (5yer befreit hat, fie in bie Epitse bez \$ordertheil's Der

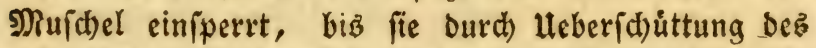
månnlichen Saamens, befruditet fino. Starfe

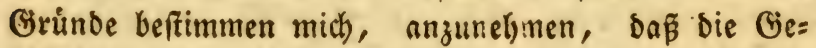
(c)lechter ben biejen Thieren won cinanber getrennt find und baß ber mánnliche 2 rgrnaut bie Eyer feinez Weibchens eben fo befruchtet, wie eż bie Månnchen

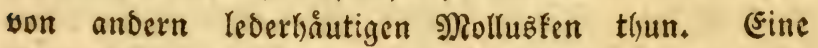

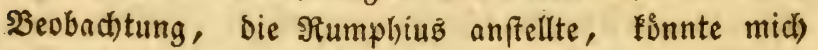
in meiner Meinung nod) beftarten, weld)er fagt: baß̧ er zu gleidher zeit, (Fyer, bie in eine Tajd)e ober in ein Szåuthen eingefd)lofien uno nad) bet

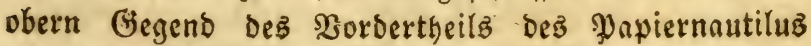
bingebrud't waren, und andere Eyer bie in bem leibe bes Thierş in einem Eyerbehálter eingefpert waren, fano. 2luz ber Erfahrung wiffen wir'sె,

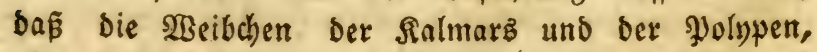
eben to siele (Eyer nad) auffen hin werfen, indes 
in ifren (Enerftedten nod) anbere cingeidloffen find. Diefe Ener bez Strgonauten find gelb, won ber Grïg̃e eines Rubraamentorns; in jebem finvet fid ein fleiner, fdon mit feiner $\mathfrak{R u j d}$ el befleibeter Embryo. Sllleb bewegt uns zu glauben, Daß bieje fo einge= (d)loffenen, burih ben månntichen Saamen befrud)tete Ever, an Dem Drte, wo fie nufbewalyt, wo fie, fo zu fagen, ourd) bie uninittelbare Berrilyrung bez Rurpers ber Mutter augagebrittet werben, 孔u wad) fen allfangen; Daß bie Ëmbryonen alle auf einmal baż Leben erhalten, on fie alle zu gleidher zeit gelegt find; fie alle haben, wie bie Eyer, in benen fie verborgen waren, eine Grispe.

Sluffer ber Alnficht ber Ever, giebt uns biefelbe Supfertafel ein billo von ber Manier, wie ber $\mathfrak{l}(r=$ gonaute feine Slrme legt, wenn er in ber Mufchel

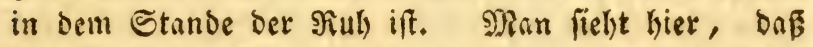
Dex Miund ben grittelpunft behauptet, uno baz bie feft an einanber gebricten Sirme, nach aufen zu

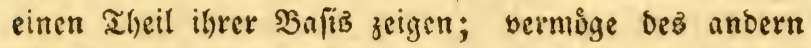
Brutbz an ber Muidel, ben iđh mir eingebilbet

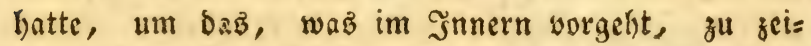
gen, fann man fid) von ber 2 trt und 2 beife, wie Der Argonaute, Die breiten Şåute feiner beyden arme

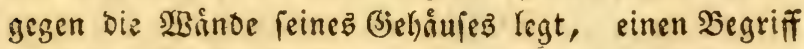
machen. Er ftrect't fie ba aแs, insem er bag Snnere Durch bie Mianier, wie er bie Afme aufrollt, bie bamit verielyn find, mit einer Iapete belegt. Die fechs andern Strme, wowon in natirlicher Dronung brey nuf ieber Seite ftehn, haben fidh faft nach ihyer ganzen Rånge gegen bie breite Şaut bin aufgerollt: ba fie vollfommen runb finb, fo bilden fie eine Itrt von Etreifen in berfelben; uno yon bicfer ganz ein=

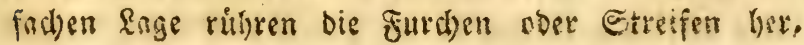




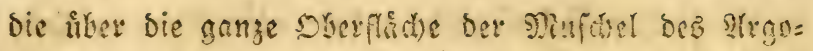
nautin hinlaufen: bey bem sjapiemantitus fino bieje

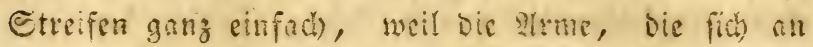
bie Eeiten anlegen, an fich ferter runo unb nibt

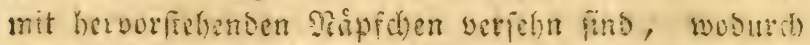

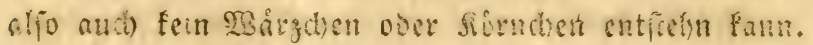

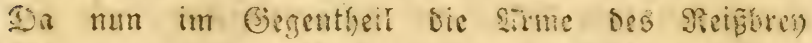
(argonaute à grains de riz), nie wir forfu meroen,

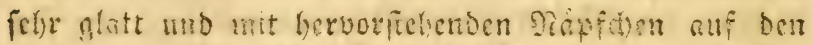

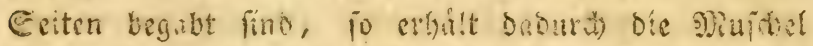

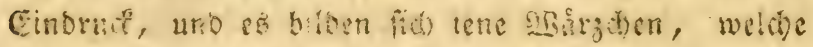

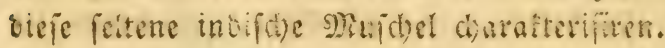

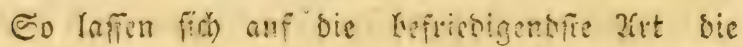
sitsungen der zalfreichen, mely voer weniger idjat=

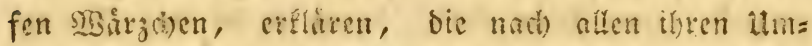

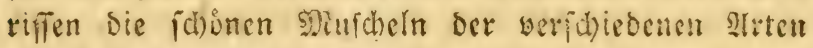
won 2 rrgonauten fdyulden.

SBsir haben gefehn, baz bie kegben syme nad) ser siuctienfeite bin, nicht nut mit breiten f̧äuten

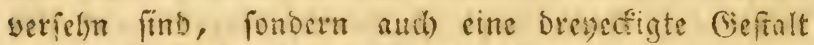
uno auf ben Esiten Prapfdhen ober Sdropfropfe,

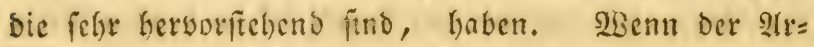
gonaut in feine, Mujdel eingeichloffen iff, fo liegt cr in Derfelben auf bem siluten, unb bie Stiele biefer Irme legen fith nad) binten zu, gerabe an

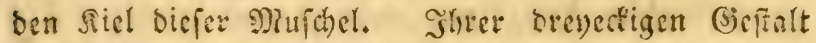
gemán uno dev Daranz entfelyenien edfigen Figur,

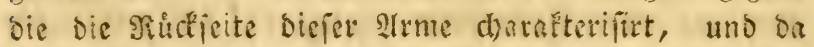
fie feit an cinander gebruoft find, berbindan fie fict)

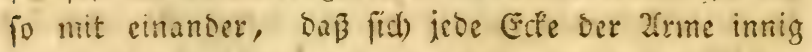

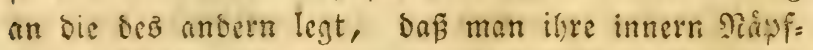
den nioùt gewalge wirs, und nad) auffen zu nut bie 
Echrewffinfe yon einer Seite fietht, bie vermugge biefer Stellung unbebedit bleiben. In Dicfem 3uftande Dez Zujammengiefins und nach ben hervorfethenden Junt= ten, feellen fie bie formen bar, nad) benen fid) bie NBirzd)en bes Jielz aborutefen, ie nachbem bex

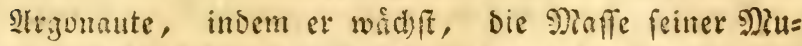
fobel buth) falfartige stusbouffungen vergrofert.

Sid) fage falfartig, Denn bicfe Murded liefert nach ber bymifden slufojung, wie bie ber anbern Ed)antthiete, eine grope Jienge falfartigen Etoffs

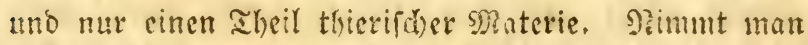
bie Ereflirung won ber sirt und 1 Beife an, wie ber slrgonaute, in fein Bebranfe eingefdloffen, ba feine breiten Sånte und feine Strme verbirgt, fo muz man noib) zugeben, Daf die einzigen aheile dicfes a I hiers, die gemeiniglid) biefe falfartige Niaterie und bieje Zusbinftung abję̧en, eben bie benben Şåute uno bie beyben Stiele find, bie bie beyben afrme nušma= d)en, mit benen fie verfernn find. Unterfudit man mit 2ufmerffamfect bie Mlufchel des Argonauten, fo firkt man da halbcirkelfurmige Streifen, Dic fo fein als leidst, innerhalb fidstharet als aufferthalb find, bie man felbft in bem fiele findet; cin offenbarer Seweis der nach und nach zunelymenden నergrü̧erung biefes (Bjehåufes; und da biefe Streifen inmerhalb Durd) feine falfartige Tund)e ausgelofidst find, wie

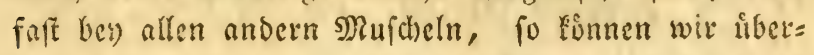

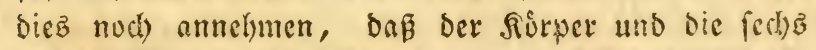

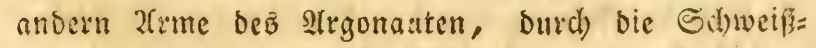

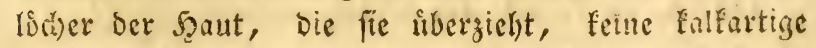

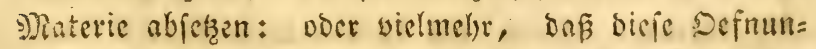
gen, die den Ealeartigen Stoff nusfityen, weoer

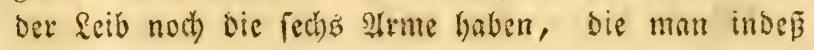


an Dem Diantel, ben Şilşftucte und oft an bem ganzen fiviper fait aller anbern beriba!ten sjolluşen findet. Der fiurper bez Irrgonauten lactirt alfo das

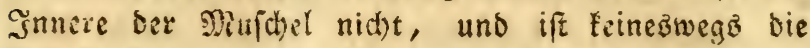
Urfact)e ber neuen seglatteten, oft perlenmutterartis

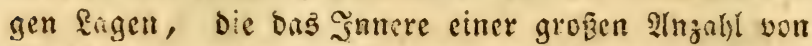

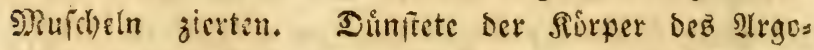
nauten cimen falfartigen Etoff aus, fo mupite ber

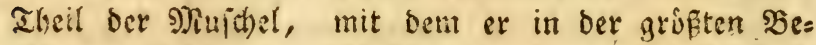
ruflyrung. ftelyt, am ftarffien feun, weil fid) nads uno nad) Dafelbit Ralthlagen an eimander geid)miegt båtten; allein iuft bier ift bie feinfte Etclle ber Niufdel; fie bat felbft ba ifre uriprunglitbe Dicte in einem Grabe verloren, Daß̃ die 2 Bärzchen Des

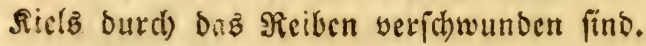

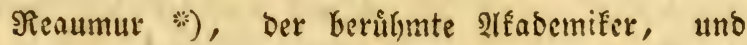

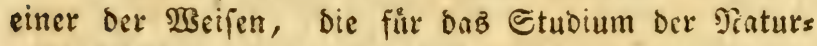
gefdridte fo viel fiebe eingeflobt haben, weil er in einer fo reinen, jierlid)en Spradbe zuerfit bie gró $B=$ ten Rleinigfeiten zu fidilbern berftand, an bie et feffelt, ob fie gleid) ber treflid)fte seobad)ter bes fibreift, Dem nur ber fd)arffinnige uno unermúbete Eyonet in feinem Fad)e, was bie Snjecten betrift, wirbig nadiffolgte, ber ein ganzes $\mathfrak{B} u c h$ liber bie SDeidenraupe farieb, won bem einer ber neuern Ina= tomifer fagt, Daß $\mathfrak{C B}$ fein überflüiges $\mathfrak{B}$ ort ent= bålt **); গenumur fage id), hat uns einige நeob=

*) Bon ber Bitoung und fim $\mathfrak{B a} a$ fen ber Mufcheth. (enem. de l'acad. des scines, année 1709.)

**) Cuvier, chém. sur la nutrition dans les insectes, inséré dans ceux de la société d'hist. nat, de Paris, pag. 38. 


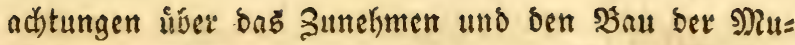

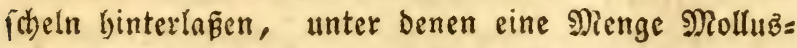
fen mit begriffen findo. SBruiguierez *), indem er Die von Sienumur angezeigten $\mathfrak{B e r f u d h e ~ w i e d e r b o l t e , ~}$ fiellte einige neue an, bie ify angeforen, burd)

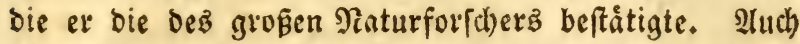
ich) habe, indem id) ber Epur biejer berilbmten Mån=

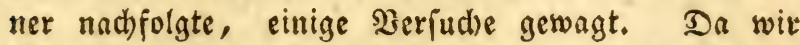

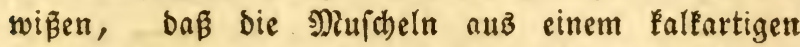
Stoffe beftelyn und wie bie Thiere ihn hervorbringen, fo bưrfen wir nur noch anzeigen, wie er ilfnen zur Bedectung ober zum Sdulse bient, uro fich iene ftcinartigen ąweige und idsunen Mlujcheln bi!sen, die fid) Die Mollußłen, bie gallerattigen Thiere, baut. sBir wollen bier nid)t von ber Manier reben, wie fich bie Eyer bey ben Bigeln fo åuferft fdunell in bem Hugenblide, wo fie burdh ben sehálter gehn, ber biefe Materie enthalt, mit siner Falfartigen Ed)ale

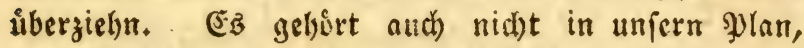
Das T3ad)stthum ber Snochen gut beichreiben, wir re=

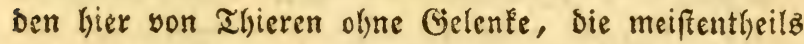
mit einer falfartigen Raterie liberzogen find, bie fie meifteng felbft hervorbrad)ten, ber fie táglich eine gewiểe Billoung geben; bie Materie enthålt faft alle Erolagen des Ylaneten, ben wir bewolgnen; mit iebem 2 ugenblide ideint fie zuzunehmen. Sekt wol= len wir unterfud)en, auf weld)e $23 e i f e$ bie befoldalten Nollušcen bie kalfartige Naterie herworbringen.

2ule bie nit $\mathfrak{R u}$ (d)eln veriehenen Molluaken, bie

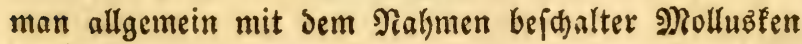

*) Encyc. méthodique. Hist, nat. des vers, töm. VI. conchyliologie, pag. 508. et 548. Formation de coquilles. 
(mollusques testacés) bezcid'net, birben dicfe barte, fteinigte ltugebung ourcì cine falfortige slusbinfung,

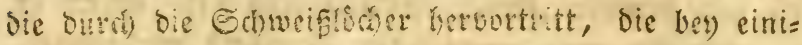

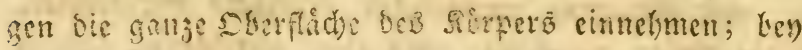

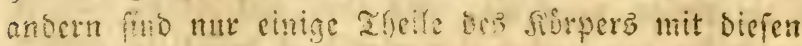

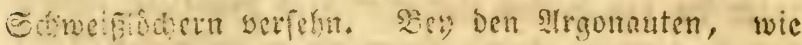
wit gefelu baben, beforinfen fich biefe ansfibuizen=

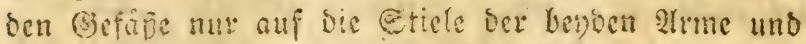
bic breiten soute, mit benen fie nn iflen Enden verfern fino; bes oet Meereidel uno ber Sdhecte, iff ber ganze Seintertheil bes fivryers in einem botsen Grabe mit biefer a:tsoluffenden firaft verfers!n u. . w. ç) will fier nid)t iene Fragen, von bem sln=

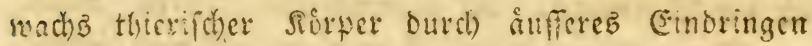
3ewif̈et Eafte in benfelben, in slnegung bringen, wofit fo mandse ftimnten, bie die semungen be= rufluter Panturforfder treiften. Diefe Fragen find

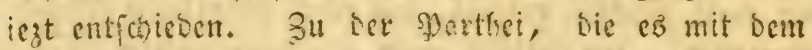

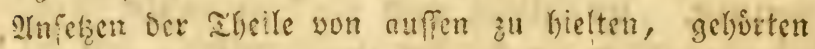

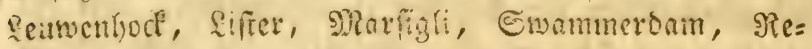
numur, 2tonnion, und Bonnet. Ser leâtere verlicßß

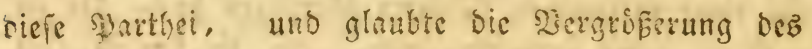

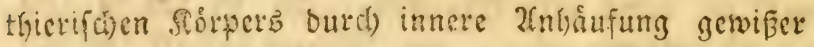

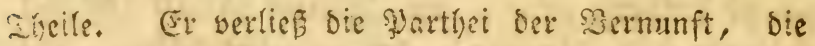
Silein gettend mad)ts, uns bie ouras bie betrigeri=

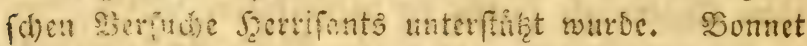

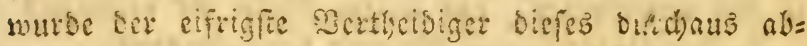
furben Siftems.

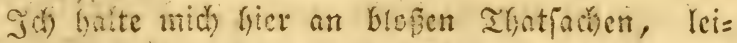

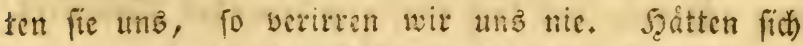
einige Der berifymten Splanmer nicht ben Eingebungen ber cinbiloungefunt iberlafen, fo murben fie fid) nie wen ber 23 argheit entfernt gaben, fie batten nie

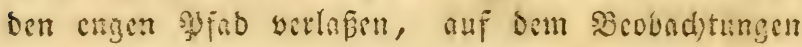




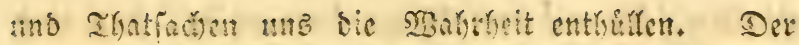

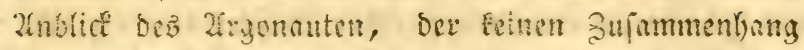

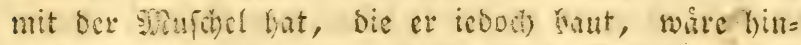
reichend gervele:, unt anf immer die Jeeinumg ber

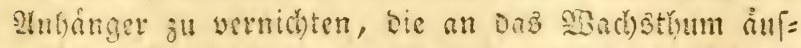
foret abcile var inwenoig, wab Rlein befantet, glauben. Eie metynen an, bnj sie gMuid)eln bie

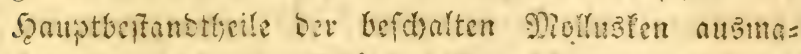

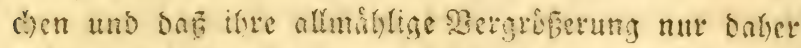

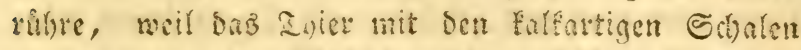

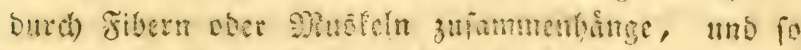
mit Den Ifiere cinan firmer rirbe, noourd) bas

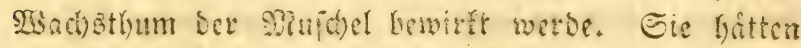

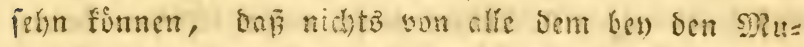

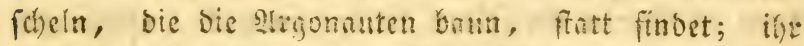
Enftem wåre zufammengefurt, sicfer cintgige Sce weig bafte ifuen Die Alugen bifnen, uno fie zul bet Seinung, Dex Senumur ben Cieg veriobaffe, zu=

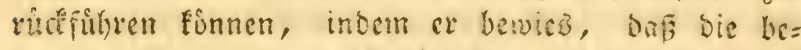

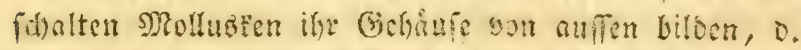
1). Dafi fie immer neue fialflagen an die alten anjez=

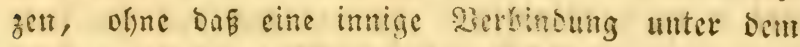

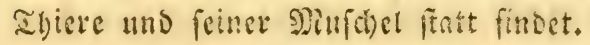

So bången die Edhnedien *) in Ecinem Bunfte mit ifren (sibrufen zufammen; fic werben ourd) feine Fieber, ourd) feine Tjub̌el an biefelbe befeftgt, fondern einzig, butch oas fpiralformige 3ujammen=

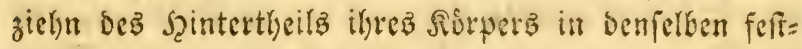

*) Helix pomatia, helix aspera, helix pisana, helix pellis serpentis, helix caracolla, helix algira, etc. 
gehalten, bie mit kem ahiere fortwadb)en, baz aber

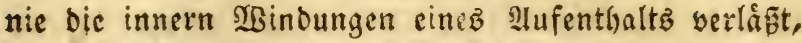
zu bem ez nidht wieber zuideffehren finnte, wenn eż benjelben einen Alugenblid verlię̃e.

W3enn wir nun bas Manoubre biefer Sdneden bey ber Berfertigung ilfere Mufdyel uno bie Mittel betrachten, die fie anmenben, fie hervorzubringen,

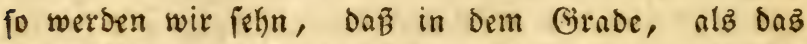

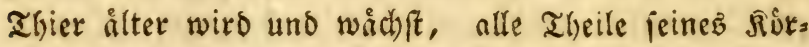
pers groferer werden und an 2husbelynung gewinnen.

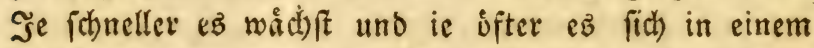

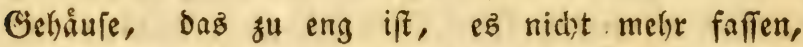
uno peinen ganzen Sörper nicht melite ichủizen fann, wenn ez fich in bempelben verbergen will, unberuem fúllit, befto el)er ift es gezmungen, feinen Sivrper

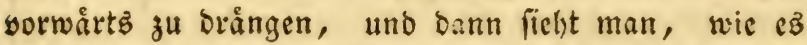
burch eine melje thierifche, alb Ealfartige, oft ge=

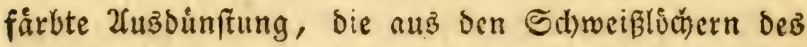

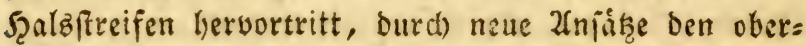

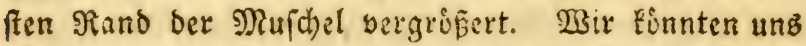

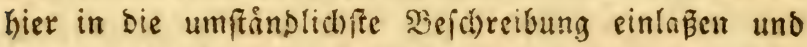

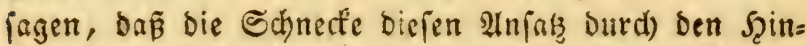
tertheil bes sopfä grade macht, indem ex mel)eere= mal auf bein Ranbe linfólint, wiez ein geichicfter Naurer zu thun pflegt, wenn er mit feiner Refle bie Tindhe, ober bie Decte glatt fireichen will; allein biefe Thatjachen liberlafen wir der bejondern bese (d)ichte biefer Thiere, um hier nur zu bemerfen, bas bie Mollugken, wenn fie fo auf irgend eime 2 beile

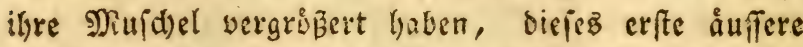
Biebáube burch allmållige fagen fefter mechen, wo= burd) bieje erfte gefirrbte Szaut, Lie unter bem Irude

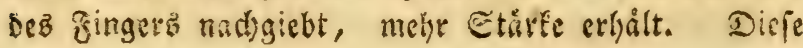


innere Tundse ift in ser 2 Bein $=$ und (Sinterifdnede nid)t gefarebt, fie ift im Gegentheil weißz, wie bey einigen andern, Die nach auffen fu colurirte Sd)at= tirungen zeigen; allein biefe جunche ift von ben auffern Infirken inmer Durd) nnoere Farben und ourd) ein glattereb, feiteres Gierobe verichieden, was augen=

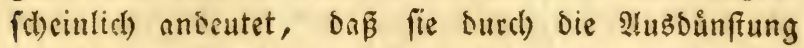
bes̉ ůbrigen Theilz bes Rorpers crzeugt muroen, Der

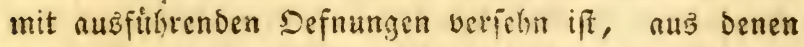
cine Materie tritt, die falEartiger ifr, alb die,

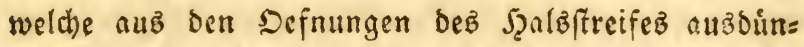

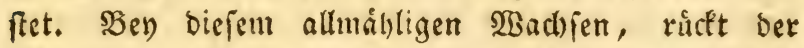
Fiorper immer ein wenig vorwäts: Daz hintere Ende Deb̉elben verlå日િt den (Srund Der lezten Mindung Der Muidel, mit ber er in feinem 3ufammenlonnge frebt und in Den lezten Rebensialyren bes Thiers, lyat fich Diefer Theil won bem Srte feines urfprunglid)en Iluf= enthalts, felye zuruedigezogen. Siev einigen långli= d)en Schnecten, wo bie Epike ber sBindung fely flein geblieben ift, wurbe diefe iufferfte Seite zer= brocien: Das Thier war Dann gegroungen, diefe Defnung zuzuftopfen, uno man fielst, Daź es bie: felbe ourch eine neue falfartige 2lusoinftung zu wers

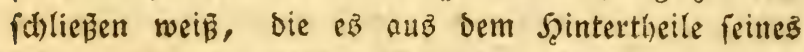

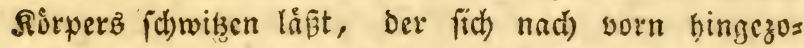
gen uno die Spitze diejer SBindung leer gehaßen batte.

Sey andern befdnalten Mollubien ift bas Ende bev Binoung feft, mit einer Ealfartigen Materie an= gefüllt, weld)e phatenartig iff, uno an Saarte bem Marmor nid)ts nad)giebt. Dies fann id) mit einer Renge Muid)eln beweifen, bie id) zerfd)lagen habe

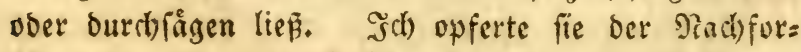
id)ungen auf, Die ich liber bie 2irt und IBcife an= 


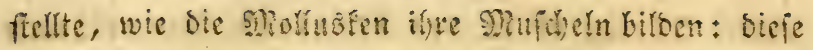
Shafopferungen haben wir viele Dinge entoctit; ich

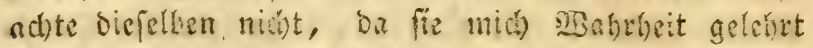

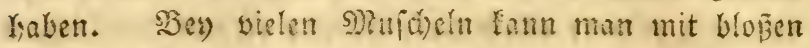
Slugen Den Unterfoted ber nuf cimander folgenoen

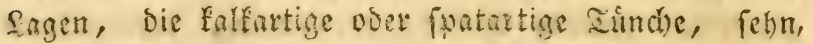
Die die giolusten anfugten, um fie biciter, fefter

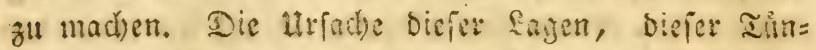
d)e, liegt it Der aแb ifrem Rorper nub̆bunftenden

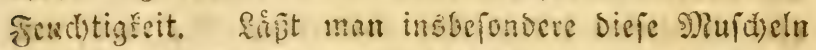
Der Range nad) in zwey) Stude fingen; fo itberzeugt man fiit) felye Deutich) yon biefer med)anifchen $\mathfrak{2}$ auart.

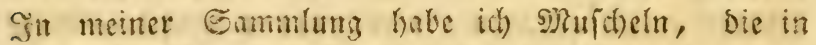
Diefer Şinficht fefor merfwurd: find. Setht eben liegt

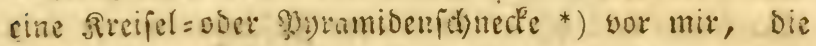

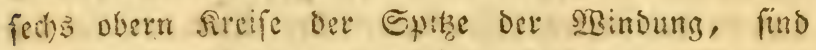
maffif uno mit ciner fo folonen folfartigen materie

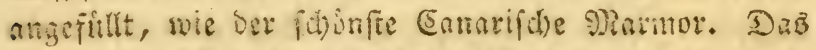
Shice, weldies bie Gehiruje betwohnte, hatte bicfe Sibinoungen nari) und mad) fo angefurt, ie nacibocm

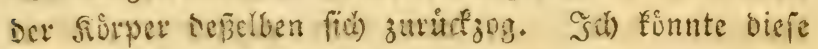
Eache auf bie mertwirbigite sistipe on einer andern

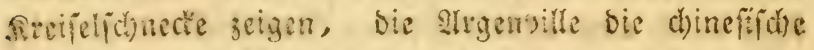
Snobye nunnte **) eben fo aud an einem felfr gropen

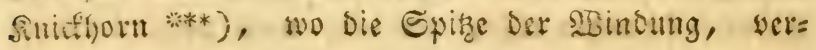

*) Trochus niloticus. Lin. Syst. nat, pag. 3566 , gen. 326. sp. 1.

**) d'Argenvilie, Conch. p. 216. et pl. VIII. Fig C.

***) Bucinum maculatum. Lin. Tereb. raaculata de Bruiguieres et de Lamarck. 
múge ber Ztusboinfung, ebenfollz mit cines matmos: åbnliden Sjuterie angefullt ifr.

2rndere Pufheln bieten neue Erfdeinnngen bar. Die Diertrompete *) hat nid)t allein bie anferefer STinoung mit ciner feferen snaterie angefiut, fonbern in bem Grabe alb bab zhier, baz fie bewohnt, êfrer

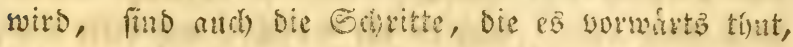

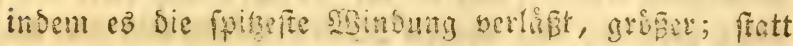

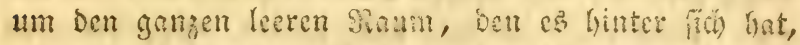

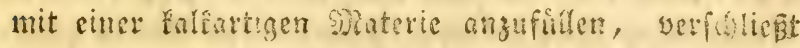

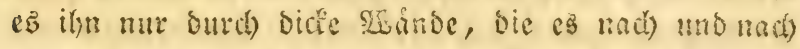

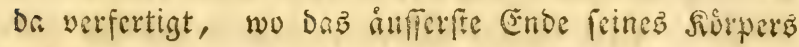
rubt.

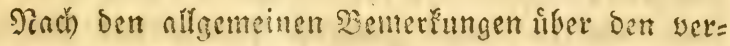
(â)iedenen Bau Der Minfibln itberbaut, fomme ich wieber auf ben zirgonanten zurid. Zerbridgt Dureh

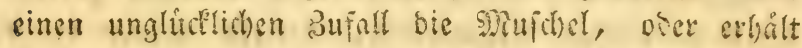
fie Durd) irgend cinen Stö cine Epalte ober cincn Brud), fo weif ber 2frgonatt ben Edbasen frige gut

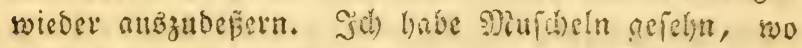
rechs Finger lange Epalten wiaber anbुgefinft waren.

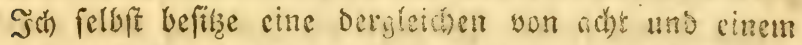

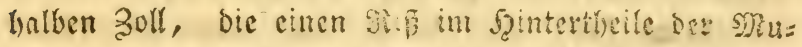

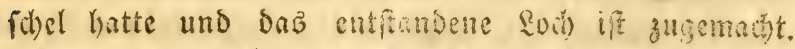

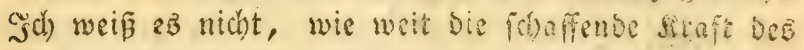
Irgonauten reicht; aber, waB mir ber stmpmerfom= feit werth fdeint, ift, Dẩ biefer siruch fratt found,

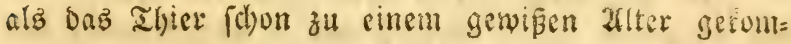

*) Murex Tritonis. Lin. Verm. test. pag. 354,9, Nro. 89 . 
men war, wo ber Şintertheil feines Sîrpers nidist mel)r ben Şintertheil beछ গRad)ens einnalym, Der bem

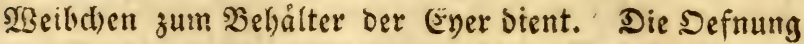
ift indế bon inwendig mit ciner neuen alfartigen

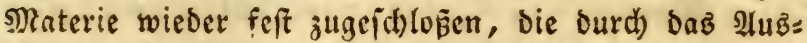

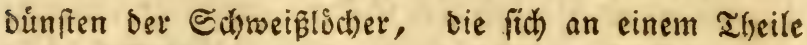
Des Rorpers lier fanden, Dajelbft abgejegrt wurbe.

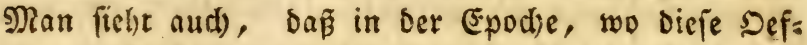
nung geid)aly, die beyben breiten Şäute uno die $2(x=$ me, nid)t mebr an Dem Srte waren, weil Die neue Stelle leine Streifen ober. Epuren won Armen zeigt,

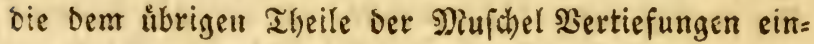
oridien. Man finnte glauben, Daß in gewiben Fâl= len und burd) grope Infitrengung, aud) andere Sive= pertbeile, auffer oen breiten Şăuten und iljren Sities

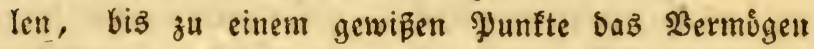
erlyalten, eine falfartige Materie auछีzuichwiken, uno

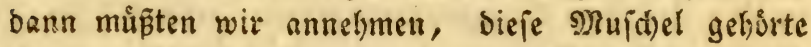
cinem róbliă)en 2lrgonauten, ber fie wieser Durd) ben Stoff ausbebern Fonnte, ben bie Tafä) oder bie Sgaut, in Der fich Die Eyer befinden, entbielt. Sft dieje Sermutifung giultig, Dann welse Dom månnli= d)en Irgonauten, Dem cin ånnlidbes Unglud an ber= iellen Stelle trift! Er fann Die Defnung nicht wie=

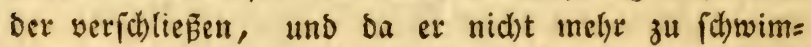
men im Stande iff, wirb ei fein Reben iat ben Mels ren enden.

Sm gejunben, Eraftoollen Suftanbe bebient fïl) Der Irgonaut feiner Slrme, um in bein Girunde bes Mecres zu verweilen. MBeit vfter findet man ihn auf bem bohen Neere, unb in ven gristen şaffertiefen, als๋ in ber গåke Der filften. Er zielst auch Den fait sigen Grund bem felfigten vor, weil er won biefem 
alles zu furditen lyat unó nird er an bie Felfen ges fdimettert, fo if fein Untergang unvermeidlid). 2(ud) findet man ifin nicht an Den Siiften ber Snfeln, (wie eż z. $\mathfrak{B}$. bey Martininue der Fall ifit) Deren vulcani= fothe Iiefen mit Felfen bejekgt uno fo Damit angefiult

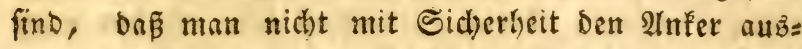
werfen fann, weil bie ftåtfiten Infericile in furzer Zeit bajelbft abgeichnitten werben. Slber man trift ben Mapiernautilus unter gropen Sanoftrichen, in ben Tiefen Deş Neerz von Jnbien, 2lmerifa, bes fonbers auf ber hohen See, unter bem sBendezirfel, in Dem nưrblichen aheile von St. Domingo an. Bon Dalier brací)te Der (Sieneral. Sounganville Die grüpten befannten \$olypen mit, bie er ber reichen ธamm= lung in \$ariz fodenfte. Der Papiernautiluz lebt auch im mittellinbijd)en Neer, im abriatifden Neer= bujen, an ben Snieln Corfira, Mariorfa und Mi=

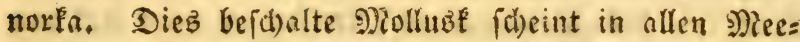

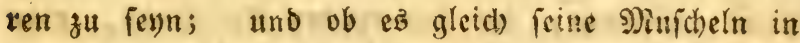
werid)iedenen (Eroftrid)en baut, fo gleidhen fie fid)

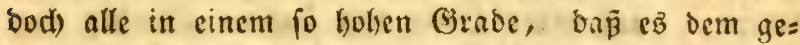
libteften Muid)elfenner nid)t miglich ift, fie zu un= terid)eiben uno in veridhievene Slrten zu theilen; benn wir nehmen hier feine Ridfifd)t auf bie mehr ober weniger feinen Streifen, bie fid) melye nalhe obet son einanber entfernen, alb auf beftumte Mert: male, bie man nufnelmen fann, um bie Murcheln ficher anzugeben, ob fie aus den earopailichen, ames rifanifjen oder inbifden Miceren fommen.

Die Niufdel bes Strgonanten if cine ber zierlid)= fien und fdionften von allen Denen, bie unjere Somm. lungent bereichern; bie binne, leichte, faft wapiers ne Sdbale, ift fo zetbrechlich, Daz man fie nuk 


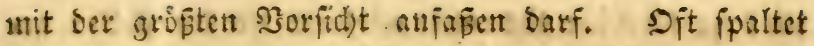
fie surd) zu grop̉e Trodfenteit son felbft und Dant

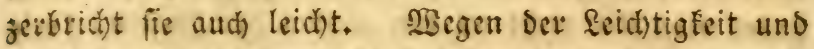
Gieftalt, bie Diefe Mujdel bellauptet, hat man fie \$apiernautilub genannt. Eie ift in Der Form antifer Cdiffe gebaut, beren Sgintertheil fehr erbaben war;

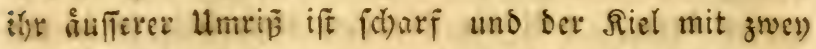
Feiben MBargct):n geziert, bie binlanglid) itith fint uns in abgemeffenen Entfernungen won einanber fielsn. Die obere Seite ber SBinbung ober beకె Jintertlyeils, ift gewornclid) rotbfalyl, ober braun geflectit. Die ganje Mujuel ifi platt, ober auf Bevben Seiten in gleiden Girabe zujammengeiritt, bie ourdh einfache Reifen, ober Etreifen, Durdburdst werben, dicie fiebt man beutlid), bisweilen fino fie doppelt und

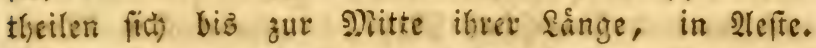
Dieje ungemein glatten Etreifen laufen bon iebem

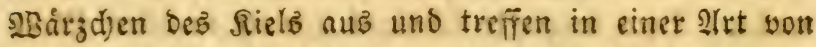

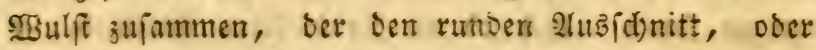
Das Shr im Salbzirkel begrengt, weld)es fich nad) Finten, auf ieder Ceite bes iuffern Randes Der

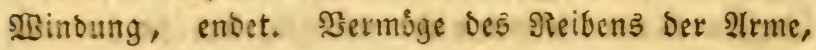
die Dem strgonauten ju Rubert Dienen, ift diefer Sulft ganz runs. Diejes Dftere Ateiben muzt aud

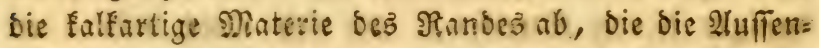
faite ber breiten Sgiute an Denfelben abjetht, wohin bas Thicr beftantig feine fech)s 2(rme, won gleicher Grofie legt; felic beutlici) fielst man aud) auf ber ganzen Dberfitde biefer Nuif)el die auf einander

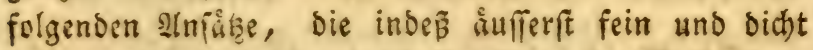
auf einander liegen, son benen biejes. Mollus̆ ie

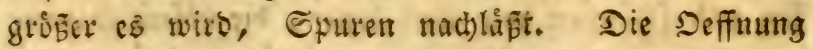
ober bet Niuns ber Nufthel, if faif brenmal länger, ale ef breit iff;. ef fielft eine slit you lánglichem 
Iriangel, in Geittalt eines Schilbes bar, bas aup einem Szelm fielt. Die ganje Nuithel hat eine mildi)=

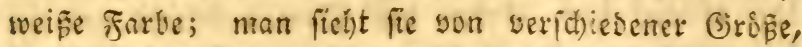

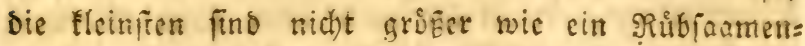

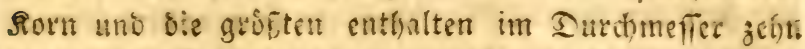

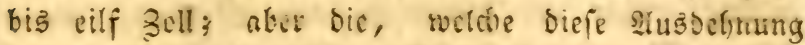

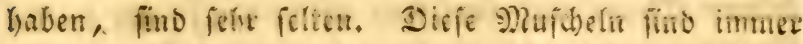

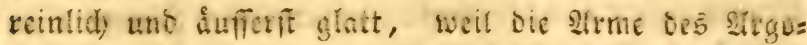
nauten, inbern fie rubern, immer liter iflete sbers

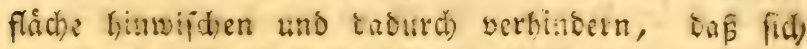
ein frenter ageit an biejelben anjetsen fam.

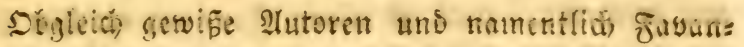
nes, Diefe Mapierargonauten in mefrere 2iten baben theilen woilea, invem fiz fid bery unbedeutenden $2(6=$ weid)ungen auphielten, fo giel)n wir bennodh die Niels mutrg Sruiguiere for, bie unz ber Wablitleit ari

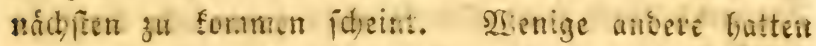

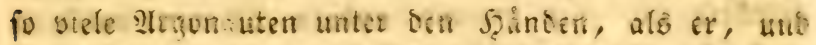

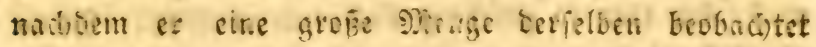
hatte, fals er, Ea

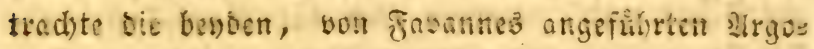

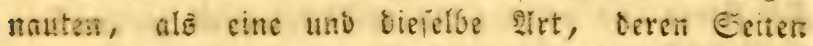
mir mele ober watiget jactid)t bey einigen Jnsibi=

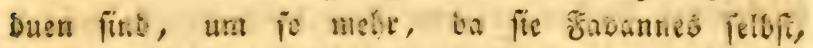

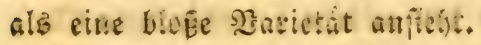

Der Argonnute bat die Farbent unb Citten ber ภ̧ulupen. Die ganze Dberflib̆e feimes Rórpers, Dic roth und blau ubergogen ifr, if brastigetippelt oses punctirt. Etarfigefìrbte Junfte finot man auf ben

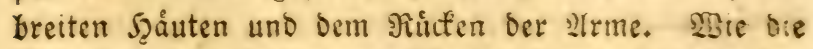
golupen, bemåntigt er fich ber Beute vermoge ber

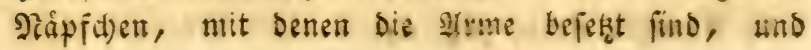


ob ex gleio nux cine feire beịdrånfte Brợe hat, fo ift er bennodis ein verwuftendes a jier. Mid)t genug,

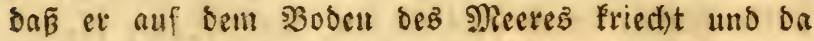
בhiere wirgt, treibt ifn aud fidher feine Moroluft zur 3eit Der SBindittle, eher als iebe andere Neran= lafung, iber bie Dberfląche bes $\mathfrak{B a f f e r s , ~ w e n n ~}$ andere rbiere auf berielben erfderinen, um ba bie

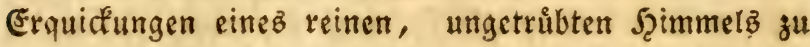
genieß̊n. Da wir Den Xrgonauten alz ein blutbur= ftigez Ihier fennen, fo iff ez gewiß̄ nicht bas $\mathfrak{B}$ er= gnugen allein, was il)n auf ben Dafferipiegel hins fưfyrt. Es ift wabrfidseinlid), Dẩ er auf Demielben nur erfdeint, weil ex einen Fang zu mad)en hofft, mit ber Şeute ftirgt fid) Der liftige Seeráuber bann in bie riefe bes Mecrs, um fie ba ungeftofhrt zu geniefen, 2rlein oa in Der Natur alles in einem ge=

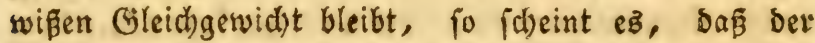
2rgonaut surch peine Schale nicht gegen alle 2ingriffe gefichert ift, bie er bon andern Ihieren ausifteln

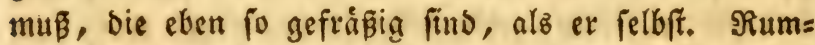
Whiub *) bebauptet, onß̧ er nicht nur bie Beute einis get Fifde wirb, fondern auch ber Raubvogel, bie fid) feiner mit ungemeiner (sefd)iclid) feit zu bemád)= tigen wiffen. SYZenn Der Xrgonaute in Den Xugen= bliden der Giefalyr, einen Zrm verliert, fo wád)ft ex wieber, wie ę bey Den anbern leberhåutigen Mol= lusken ber Gall ift, Die id) befdrieben habe, Diefe

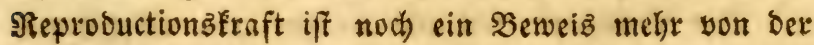
Uelsntid)Eeit, bie ex mit Den Dintenfifiten, Salmarz und \$olypen bat.

*) Rumph. Amb. pag. 64. 
Ser 2trgonoute fann fick, gong in feine $\$$ Rut

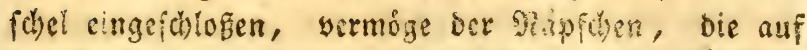
Der saftis feiner atrme ftefln, wie fie alf ser XXXVI. Supfertafel abgezeidunct find, an feiner Beute fefts balten. Sie foleinen, in ber crwattung ber Seute, nad) yo:n hin gerid)tet zu fron, ober and bebigló, un bie 2ngriffe ber feinbe zuridfuhalten, intem fie nicht mur ben Siorper, fonbern auch Die Epitäen ber

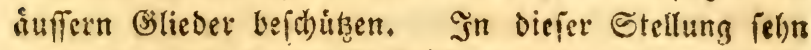
wir, wie fich biefes Midluak, vermuge ber Schropf= foufe, an Dem lesbe gropert Fifche befeftigt, bejon=

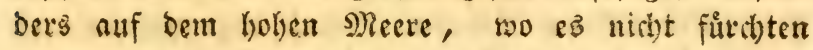

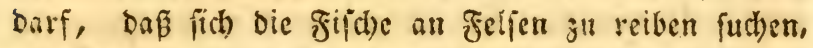
um fith son einer fo unbequemen $\mathfrak{R} a$ if zu befrein, und

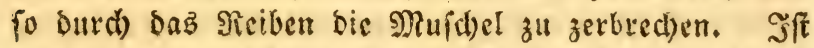
eả fo an Dem Siurper Der fifd)e befefrigt, und mit ciner Sdale, wie mit einer Egibe bedectt, Dann mact)t $\mathfrak{e B}$ (Bebrauch von feinen graufamen Sgaffen, um mit ifuen in bas Fleifd) Diejer Fiphe einzubringen und ez mit feinem getrúmten Silnabel zu zerreiffen.

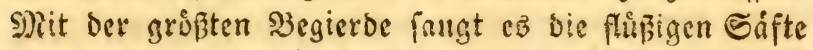

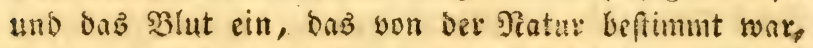

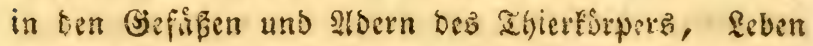
3u verbreiten. Dies bhtogierige, unerfinttliche Mlol=

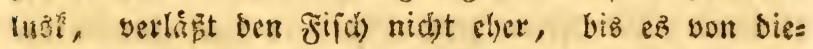
fen filipingteiten ganz woll ift, und ez bergleichen

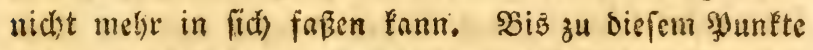
ift es unmiglid), Daß̃ fid) Die unglưd wohner won einem fo Gartnådrigen Feinde logizumad)en verfud)en. Shre fdnelle Flud)t burch bie Mafiermaffe, felbit bie beftigiten $\mathfrak{3 e w e g u n g e n , ~ f i n n e n ~ l i e ~ n i d ) t ~}$

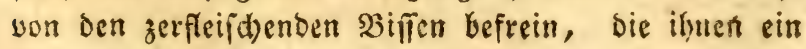
Thier bribringt, Das nur 3erftohrung athmet, Das nicist zufrieben ift, fie zu quálen, fondern fie aud 


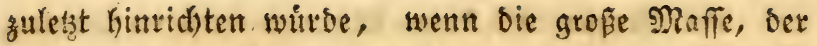

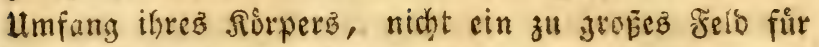
feine şhutbegieros wåre.

Snoem id) biefe Gefibichte von bem Ârgonauten enbigen will, fillt mir ein Şurnal*) ber Siatur= geiditidte, was in Englano erichienen und von Dem Doctor Shaw, einem Nitgliede der funiglid)en $\mathfrak{Z}$ ca bemie zu fonoon hernusgeacben worben ift, in bie Scande, Die Supfer fino von Dem botanifchen Mals=

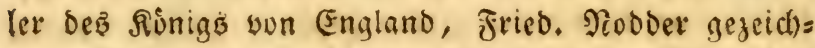
net. Der Sripg, Der bie Serbundung zwifhen den besben Mationen, Den Englånbern uno Franzolen aufgeloben hat, bersubte uns bieies Joumals uno vieler andern 2 Gerfe, die uns mit neuen Gejejopfen befannt gemacht batten, bie bie Englånder auf ihren weiten Falurten entbecften. In ber orey) uno oreypaigs=

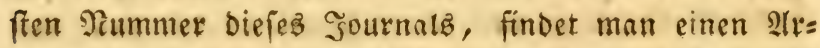

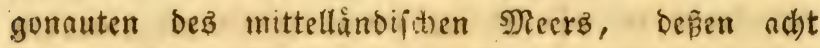
Ilrme aus ber Miuchel herborngen; zwey won illnen baben bie breiten Şåtute, und fie beftimmen midt), biepes ahier für baß̧elbe zu balten, waz id) beịd)rie: ben habe; Dies Molfubl ift auf ber Supfertafel 101. Der Tammer bez angefithrten Journals, fd) (ed)t ge= geidinet. Die 2trme fino bafelbft in Dem Stande Der Rul) porgeftellt, Die benden F̧åute gleid)en einem Myrtenblatt uno geben feinen $\mathfrak{x}$ egriff von ber 2 luš befaung biefer tharateriftifden Zheile. Dogleidh bie Eajropffipfe ridtig geftell find uno auf ben fechs

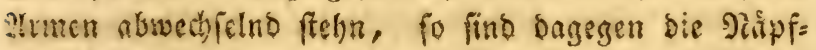

*) Naturalist miscellany, to be continuel monthly; London, by George Shaw. 
(h) ber beyoen mit ben Şăuten begabter 2 (rme, fid) lecht angebeutet, fie felyn nicht auf ben Sciten berfelben, fonbern auf ber platten f̧lâd)e und glei= d)en villig ben andern, da fie bod) melye herworra= gen. Heberbiez hatte man bas Mulluž aus ber Mu= fchel gezogen und was fonberbar ift, man hat es

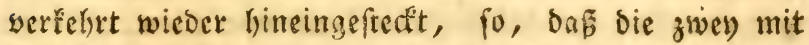
Sriuten begabten 2trme, nai) Dem Stintertheil bin uno bie fechs anbern borwaits liegen. Dieş ift walls= haftin bie Rage bez 2!rgonauten nid)t, beßen (ech) Ilrme im Gegentheil bie Rage haben, baj brey auf

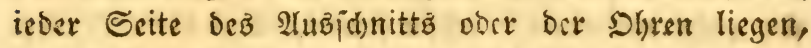
bie in Tlooberz 3eid)nung Yeer gelapen find. Shan,

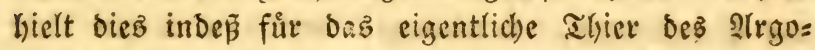
nauten *), wab Sinné vermuthete uno Rumphius bejctrieb. In einer furzen engliften uno lateinifden 2rnzeige, Dic bie, jigur begleitet, lagt Slyaw; obgleid) bie alfiere, beren Familien fid) einander nalyn, unter cinander stebnlid) feit haben, fowohl was bie Gieftalt im allfgemeinen oder cinige bejondere Theile betrift, fo entfernen fie fid) bod) won einan= Der, befonders bey Den Sdhalthieren. Die Serwoly= net ber einfchaligen Shujdeln, fagt biefer stutor,

*) Argonauta argo. Character genericus animal sepia. Testa univalvis, spiralis, involuta, membranacea, unilocularis. Lin. Syst. nat. p. 1161. - Character specificus. Argonauta carina utrinque subdentata. Gmel. Syst. nat. pag. 3367. Nautilus sulcatus. Klein, Ostra t. 1 Fig. 3. Nantilus tenuis. Rumph. Mus. t. XVIII, Fig. 1, 4. A. B. - Animal extremely resembling a sepia. - The paper nautilus. Nautile papiracé. Argenv. t. V. Shaw, Natur. miscel. numb. 35. tab. 101. 
gethuren zu bem (Biphledite ber Earnedien unb bie ber

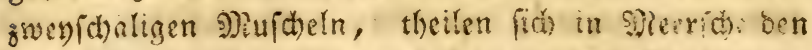

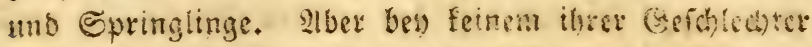
entfernt fid bie Geftalt son ber al!gemeinen sirloung melye, alb bis ber bez 2urgonaten, ber unter som

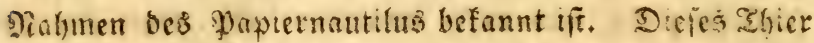
unterfd)eibet fici) ourd) feire $50 \mathrm{rm}$ won allen, bie ju peinen strten getioren, fo, don man fid) nid)t wun= Dern baxf, nenn wan ez fo fdwer glaubt, ob

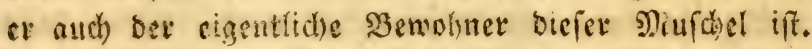
Nad) bem, wab Sinné gefthrieben Kat, fann man

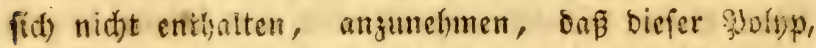

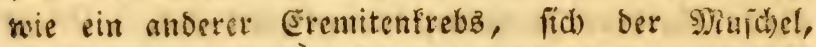

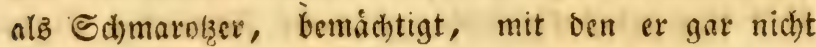
verkunben iff, wenn e३s viele ב̧eugen nid)t beftitigs ten, dar fie ben Arigonauten fegelno gefelga haben.

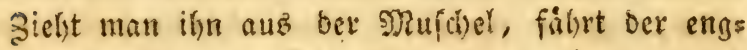
rifd)e 2(utor fort, fo fielst man, Daß

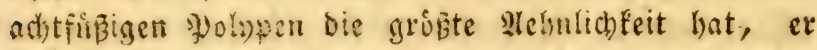

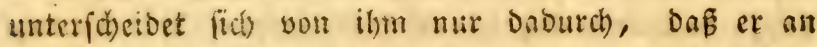
Den sufferften Enden ber beyden Lreme, ovale Şriute bat, un aแf Dem Reere zu fohwimmen, inbem cr

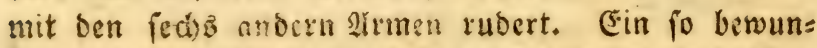
Dernswirbiger Utinftand, fonnte ben $\mathfrak{B l i d e n}$ ber Men= ihen nid)t vertorgen bleiben. Biefes Maniste ift auch) son melyern slutoren beidrieben worben, aber won feinem mit einet fold)en Eleganz, wie ez plis niub that. Dieje Mluidhel, bie Dem waljren Alrgo= nauten gehort, barf nid)t melis mit bent gewóknli= d)en Nautilus serwed) felt watben, biefe Suichel ift in Sammern abgetheilt und won eirece ganz veridjic: benen 21rt. Man finbet 2 (rgonauten yon einem bis 
adyt zoll larig. Sie werben in bem mittellandifchen Dieer und ben indifd)en Ineeren angetroffen.

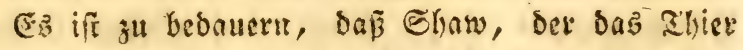

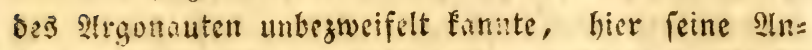

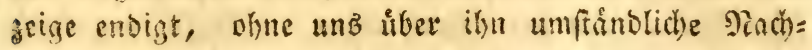
rid)ten zu ertfeilen, obne angussigen, woher et bies

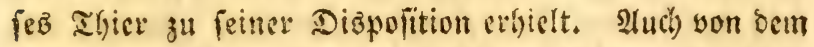

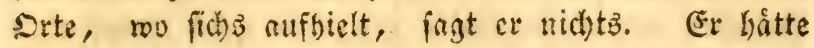

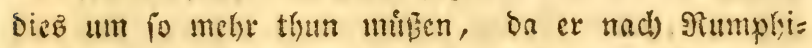

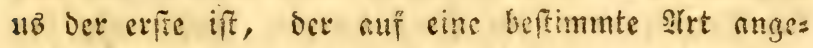
zeigt hat, weldes bie Unterftcisungejzeid)en fins,

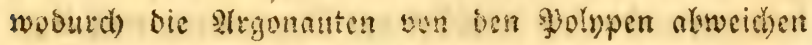
uno ber es zuerfe iffentlicí) betonnt mad)te, wie bie

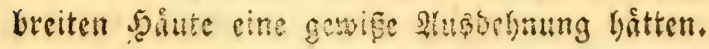

Bey ben grten war ser-grganante cin heiliges Thier. Die Matrofen betradisten ibn, alß cinen

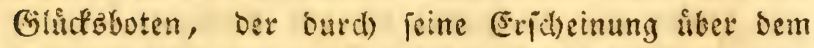
$2 B a f$ er, ihnen anbalteno gute srsitterung anzeigte, Todb betrad)teten fie ify als bas Thier, weld)ez ben Menichen die erften Segriffe, Den erften Unterrid)t,

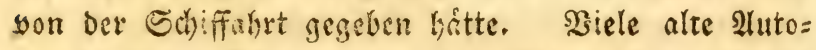
ren bebienten fich feiner in ifren Sergleichen und peit ben heroifichen 3eiten, erregte sicper immerwahrende Sdiffer, Die slufmertamfeit uno Benunberung Der Denfchen, die keinen 2uftand nalymen, ifym nacts. zualymea.

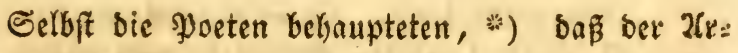
gonaute bie smenichen gelehrt håtte, mit bem E̊:

*) Plaustra maris_naves qui_primus, reperit; ille 


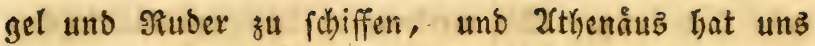
ein Epigram Des (Sallimachus in diejer Scinfid)t bin=

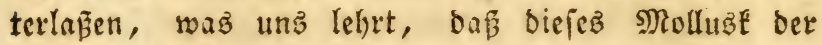
গ̇enus geweigt war. Eine in Demielben Epigram

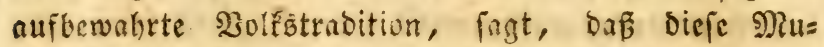

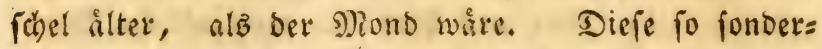
bare MReinung, Die lidjerlich icheinen funnte, ling nod) mit andern Irabitionen zufammen, die bey ben (Siried)en won einem 3olfe zum andern fid) fortpflangte und wir finden bavon Epuren im Doid, סaß́ fich bie Rucanier fü cin Molf bielten, Daż, ehe der S)ono war, exiftirte. *) Die Einwolsner von $\mathfrak{a m}=$ boina erweifen der Nuid)el bes argonauten nod) cine gewiß̈e Serebrung .

Sive Deus seu mortali de semine natus Audax auravit fluctus tranare marinos Navigum spectans piscis: dum robura nectit, Fecit opus simile. Hinc et ventis vela tetendit Junibus, aperuit retro de hinc frena carinae, Oppianus citatus a Lilio Gregorio Gyraldo.

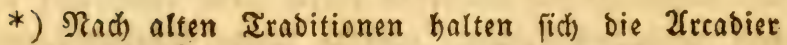
für bas åltefte $\mathfrak{B}$ olf auf ber Eros. Sie jagten, ihre Borfabren batten bie Erbe bewohnt, eh ber Dionb ibr Irabant geworben wåre. Rucian uno Svib baben uns Diefe Irabition úberliefert. SDib fagt:

Orta prior luna, de se si credatur ipsi, et magnus tellus, arcade nomen habet.

Iin einem andern site beift $\mathrm{cb}^{3}$ :

Ante Iovem genitum terra habuisse fermntur Arcades, et lunagens prior illa fuit. 
Eretarung Der fưnf und brenß̧igften Supfertafer.

Der গ̧⿻上丨ierargonaute.

Nan ficlyt ryes bicfen 2trgonnuten, ber aแż bem

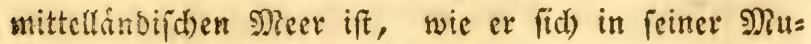

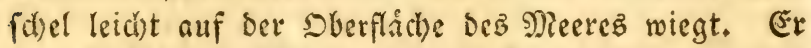
liegt nuf bem stitcen uno bat fich naith bem zurictigezogen, nacboem et feine 2lime nach auffen hin geftrectet hat, bie ihm zu Rubern bienen. Stuf ieder Eeite find ifyer brey) und ragen aus ben Dheen herwor, die biefer Mufchel angehoren.

Die beyoen, mit breiten f̧ąten werjelsenen S(rme,

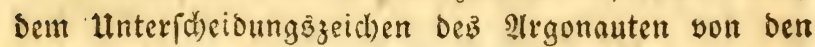
Syolypen, find in bie Rujt geftrectit; biefe Şåute find in ber (Seftalt cincz Eegels vorgeftellt; Der BBind fdisellt fie auf. Der argonaute rubert und fteuert lier und wenbet alle Mittel an, bie ifym zu (jebote fielnn, Damit feine Sarke auf bem ruligen SBafferipiegel fortgleitst.

Tod) mus man auf berfelben Rupfertafel bie

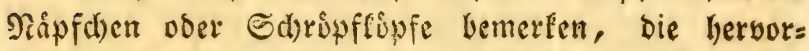
ftelin und fids) auf ben Eeiten Der benden 2(rme be= finden, Die bas Gegel trigen. Won ifrem Jeervor=

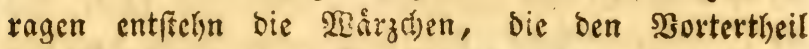
ber Mufdel zieren. Die Pånfdben ber anbern 2(rme fins platter, ftelin wenig hersor, und laffen auf. ben Seiten ober ben glatten Etreifen ber Mujmel biefer Itrgonantenart, feine Epuren zurict?

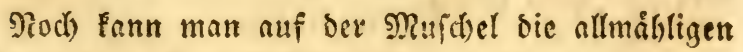
2lnfintse felfn, fie find felse fein, diclit an einander,

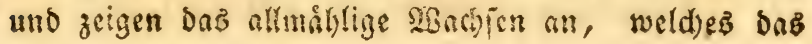


Thitr surd) Sie Earfortige 9lusoinftung feinet breiten

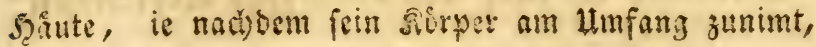
befirtert:

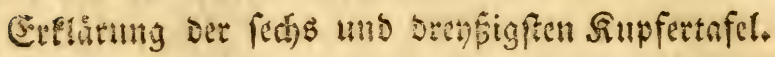

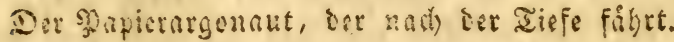

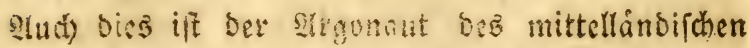

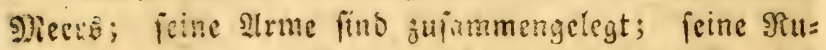
Der, feine Eegel find cimged ifft uno bie Mufdal ift fchon. zur forifte unter bem şoffer, wo fie fich balo untirfenen wirb, um fict) in bie Tiefe ber See zu futurzen. Juf ber am meifen ethabenen Seite, fiel)t man ben Rand cinet Der Seiute, die in Dem

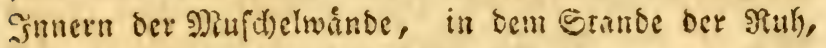
fich anlegen. S(th babe mix eine Exalte an ber Esite gebasist, Die wofffommen onrgeftellt ift, um defto gennuer bie Rnge ber breiten Jaaut auf Der Eeite hier Darzuffellen; fie iff hier burd) oen (Einbrude ber 2lrme yeftreift, woer mit Reifen yerfelyn. SDen am Siel fiect man cinen anoern somu, fier liegen bie Ener

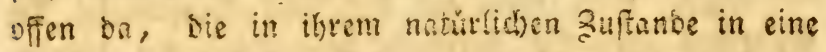

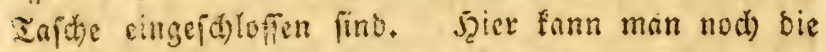
hintere, runde Seite bes నivperz bemerten, Der

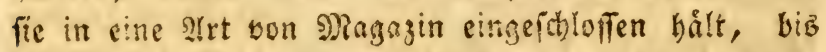
fie auzgebritet find. Die Emuryonea laben oa foun

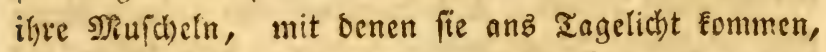
wie $e^{3}$ auch bey ben fleinen Edyedten und andern bejd)alten Mloilluşen, fo wohl einichaligen, alz suerid)aligen, Der Fall if, bie im Niutterleibe fidon

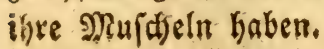


Der Keif́bry. *)

L'Argonaute a Grains de Riz.

Dies ift Der Slrgonaut, Den id) oufs genatifte unterfuctiben fonnte; ez̉ gefiel mir auth, ilgn nupers halb ber Mufchel abzujeichnen. Man fieht ilyn unter

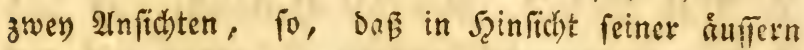
Formen, nicht3 zu wünchen librig bleibt. Diefe beysen Figuren, verbunben mit ben zwey andern, bie ifren vorangefin, freflen uns biefe Mollubfen in Dem suftande der Sewegfamfeit vor, wie fie ůfer

*) Nautilus sulcatus, verrucosus in striis rectis et elatis, carinae angulis profunde seriatis. Klein, Ostrac. pag. 3, no. 4. - Cymbium profunde striatum, striis latis et bullatis, spina lata et serrata, candidum. Gualtieri, Index test. pag. 12, tab. 12. Litt. B. Nautilus tenuis qui a grumo oryzoe coctae cognominatur, rystembry hoorn. Seba, Thes. tom. III, pl. LLXXIV, Fig. 4. Cochliis plana intorta mono. thalamia, sive nautilus pápyraceus, carina latiore obtuse serrata, lateribus costis flexuosis et tuberculosis distinctis. Martini, Conchyl. tom. 1, pag. 229. tab. 17, Fig. 156. et tab. 18. Fig. 160. - Davila, Catal. pag. tog, no. 88. - Favannes, Conch. tom. I, seconde partie, pag. 714 , et planch. VII. Fig. A, 9. - Nautile à caréne large et cotês tu. berculées. Bruguiéres; Encycl. method. vol. VI, pag. 123. - Latour d'Auvergne, Catal. pag. 51. no. 248, le second. Nautilus papyraceus, inauritus, admodum convexus, striis granulatis, carina laevi mediocriter lata aculeis brevioribus et obtusis munita, et apertura maxime expansa insignis. Favart d'Herbig ny, Dict, tom. II, pag. 426 . 


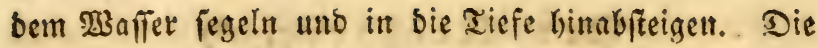
neun und orensigite Iafel ift beftimmt, bie benden

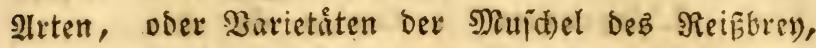

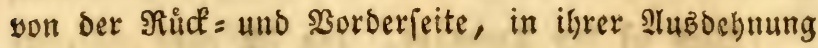
vorzuftellen.

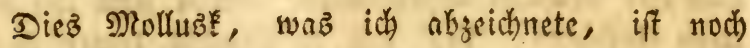
in feine Nu(d)el eingefdloffen lund mad)t eine vor=

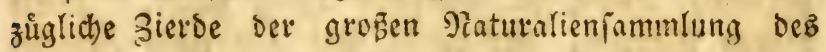
botanifd)en Garteng in Yarib aus Diefer 2frgonaute

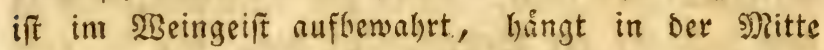

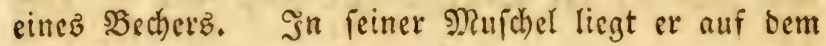

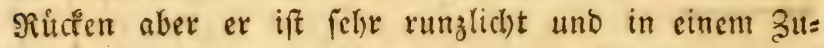
ftande bes zufanmenfahrumpfenz, weld)ez von bem SEeingeifte lerruibut, in ben $\mathfrak{e r}$ gleid) nadber, alb er gefangen worocn war, verfentt wurbe. (5B war mir erlaubl, ihn nus der Miufdel zu zielin, uno id) verburge bie Giennuigfeit der zeid̈)nungen, bie meine Befdreibung begleiten, wei! ich mir bie grospte

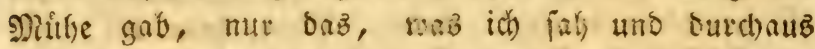
nidt)t melse, Darguffellen. Der Irgonaute mit ben

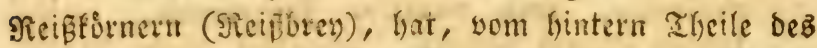

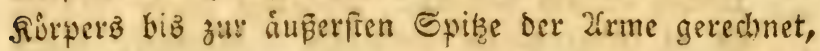
eine finge yon fitben 3oll. Der \&eib ift jwell 3oll lang und miêt viei 3olf in Hmpange. Der fiopf

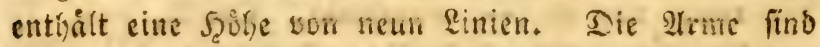
bier 3oll uno cinige sinien lang. 3)ie breiten f̧åute an ben eriben ber slrme, waren in ifler naturluthen

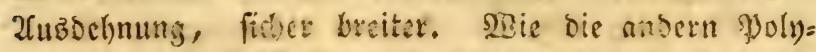

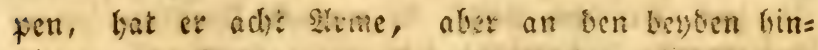

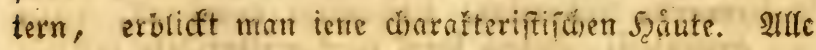
biefe arrne find nidit runs, forbern platt und $a b=$ wedfelno ftel)n bie Sinpflien auf ityen Geiten. Die beyben breyedfigen, mit san Sgånten begubten 9lrme, 


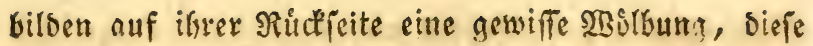
Bisfalt ribgrt von bem 3ujammenoruden berjelben her,

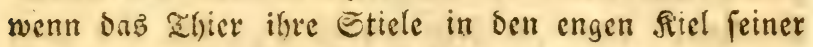

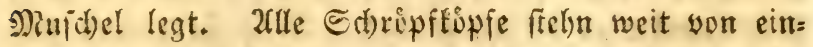
ander, und find fefre erhaben. In bem Mittelpunfte ber Arme befindet fich ber Muns, was auch bey an= Dern Bolypen der Fall ift; feine Ëner fino runs. Ere ift mit einem hounigten Schnabel 'verfeln, ber,

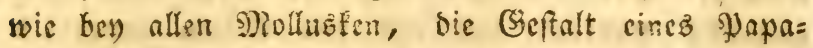
gayenichnabels hat. Der Sact, ober Mantel, Der ber Breite nach), wie bey ben Solypen, geofnet ift, ift ebenfallz burch fleifdigte Faben befeftigt, bie ilgn liber bem Trid)ter feftrulten. $\mathfrak{B e y}$ biefem Mollubl entfergt er von binten her, mely in ber Nåke ber Ilugen, bie'man feldr beutlich fieht, ob fie gleid)

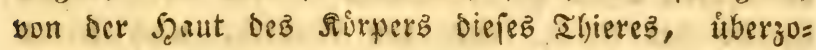
gen werben. Der gemeine aubfuilyrende Sanal, ift felye ftark uno weit, ber feib ifi nad) worn hin ge: bogen, bies ift bie naturliche Folge ber gef́rummten \&age, bie Der 2rgonaut befránbig in feiner Mufchel hat. Ilnterifucht man bie strme, fo baben fie alle auf ilyer platten Seite eine Fuge oder Galze und fint

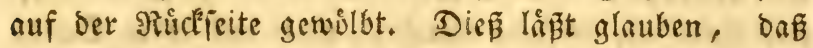
Diejer Irgonaute bie Inme in feiner Mufthel zufam: men legt und fie mitten in jeine Şåute einfolie inbem er zwey und zwey) nach iffrex ganzen \&ánge uber einander felbj binlegt.

Die J̧aut biefę Irgonauten hat bie lieblidbften Farben. Zlbwechfelno wirft fie eine rofentothe, weil= chenblaue Farbe zuritc. Diejes jind die allgemeinen Sd)attirungen, und fie finb iber Den ganzen Rơrper

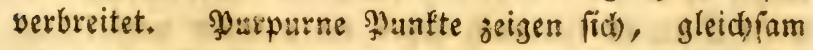
wie eine Eticterei, auf biefem erfien Ed)mudte. 


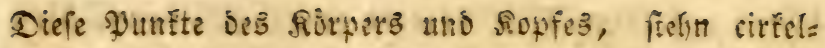
fôrnig uno zwar io, baj̃ isber Umfreis yon fleiner

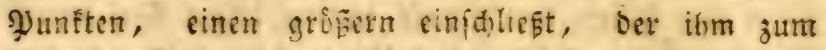
Mittelpunte ju bienen id)eint. Dieị ąsid)nung fin= Det man aud am Reibe, wo inteffen bie Eirfel ein= anser náber fieln, bie Punfte nicht fo weit son ein= anber entfernt uns weit fleiner finb, nls auf bem গlutfer. Die strme fint auf iffer 2hipenjeite unre= gelmi̊ñig punftirt uno auf Den Geiten innerhalb (d) wach getipjelt. Die breiten Şålute find nid)t punf:

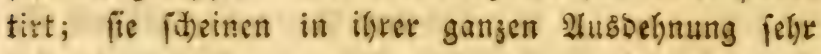
nersigt ju jeyn.

Co biel es mir moiglich wat, fuctste idj bie sage ber imnern Dheile zu erforichen, inbem idh in biejer S(bfit)t Den Sact, oder Den Mantel, nad) feinter naturlid)en Deffnung son einander id)lug. Den brits ten Thetl ber Range nad), was id) verfichern fann, bingt biejer Sact, wie bey ben yolypen, mit bem Sorper zujammen, uno ift allein nact) ber obern Eeite hin frei. Die Jiehmen, ober Die 2lierfyeuge bes Ditlymatis, theilen fiti) ebenfalts in zwey Siorper, und feésn auf bicielbe wiseife, eine auf irber Seite. Sou ber fonftigen innern Sriganifution, weip ids nid)tb, weil id) hüd)it vorjiditig mit sem fo feltenen

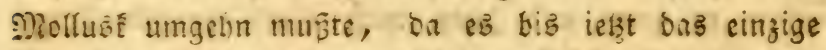
in uniern Rabinettern Der Naturgeichichte ifr.

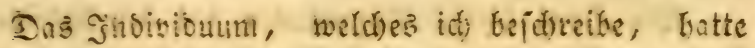

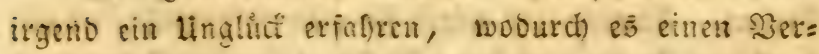

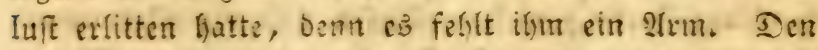

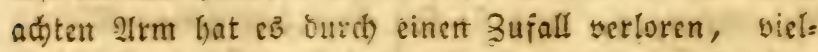
leid)t buspte es ifgn auch gegen e:nen ieiner naturtichen

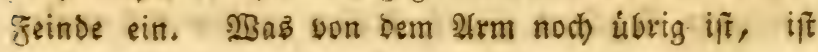


bemerft, Der Etummel fing füjon an, fid wiebes

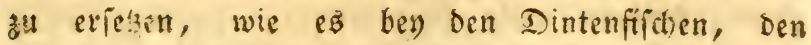
Sialmarz und झolippen der zall iff, Denen baz vers lorne bilico wieder wiechit. Diefe 3erftummlung habe id) in meiner Zeichnung beibehalten, fie lehrt unz,

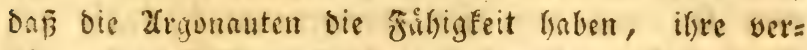
fümmelten iuffern CSlieder, wie bie andern leber:

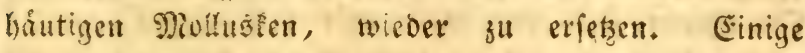
Miollušten, wie die Seefterne uno Molupen, befitzen

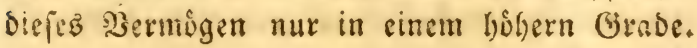

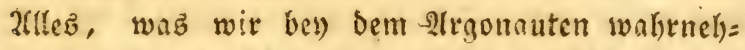
men, unb ie forgfinltiger wir feine imffere Beftalt prifen, defto melse liberzengen wir uns von feiner

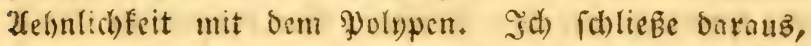
Dấ bie 2 (rgonauten mit einem Gietirn begabt fino, Dem gemeinjohafttden Mittelpunte Der Empfindun=

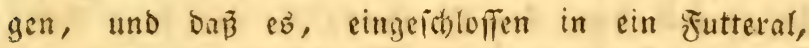
wie in eime fnorplicte Sdodtel, von ba feine ners vighten 3weige biz nail) ben sufferften Theilen bez

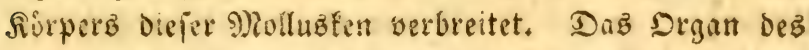
Selhens foleint bey ithen eben fo beid) affen zu fernt.

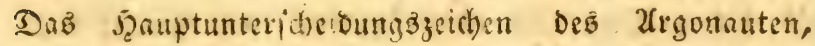
befreht in ben breiten Scauten, die eine falfartige Materie ausfowithen, mit denen bie benben arme

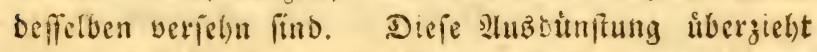
feinen forper mit einer fo gierlid)en, alz letd)ten Shichelid)ale.

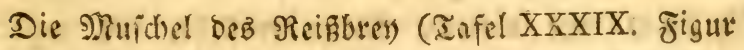
1.) iff zerbrechlid)er uno Dimner, alá die dez $\oiint_{a}=$ pictnatitluz uno ebenfallz wie ein soot geftaltet. Der Siel ift etwas bretter uns bat nud) zwey Re(hen

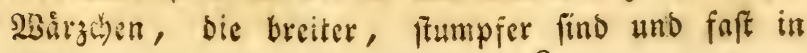
$\mathfrak{A}$ 


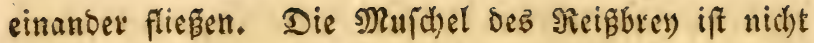
glatt, fonbern melye bogenfurmig, bauchig. Die Streifen find nid)t glatt, fondern mit naly aneinan=

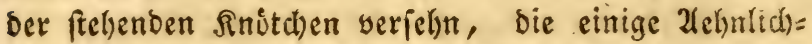

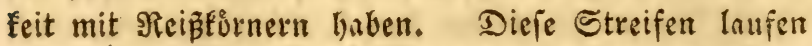
eben fo, wie bey bem Japiernautiluz, hiber bie Muidhel bin, fie theilen fich ebenfallz in âwrige.

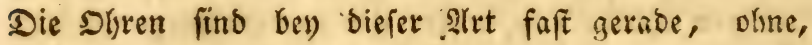
wie es̉ beis andern Irten ber Fall ift, fids nath auffen

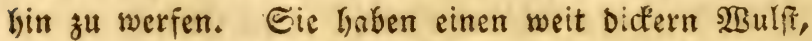
als ber ibrige Theil ber Slujthel, er ift glatt, gleid)= fam polirt uno von weißggelblid)er Farbe. Man kann bie allmåhligen Infåtz̨e, burch) bie baż Thier bie

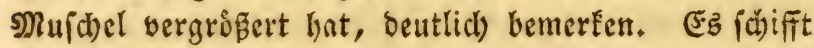
mit Derfelben auf bem \$iecre. Der erthabenere aheif Derielben ift oft io gefårbt, alz wåre er burch sen Raud) gezogen. Sie erreid)t eine fånge von neut

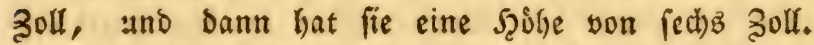
Da, wo fie am weitefiten iff, betrágt die Deffnung

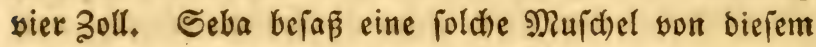
Utmfange, er fal) fie als eine Seltenlyeit an und be= trad)tete diejenige, bie er in $\mathfrak{s u p f e r}$ fted)en ließ, als bie gri̊s̆te, Die man Eannte, und fpridot yon

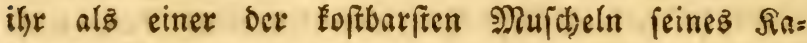
binetz. *)

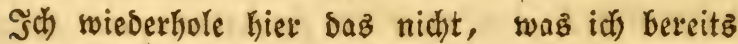

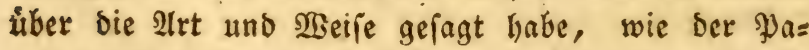
piernautilus feine Mufd)el baut, da bie Mufd)el deż

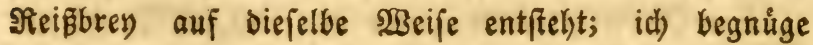

*) Seba, Thes, tom. III, pag. 176, pl. LXXXIV. Fig. 4. 
mid) an bie Maniev zu erinnern, wie siejez Rol= fแbł nack Der Form und der Erbabentheit ber Prápf= d)en ber 3 a fiz ber mit Den ḩåuten verfehenen 2frme,

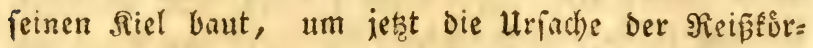
net anzuzeigen, bie in Den Streifen diefer Muidheln

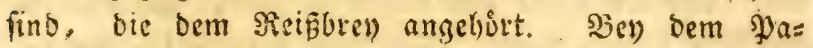
picrnautilus find bieje Etreifen glatt uno einfach, weil bie sianfdhen ber fed) rubernten 2 trme nidht hervorftehend, fondern glatt find; ben bem Reifbren felin fie felye hervor, fie orutten folglich gegen bie

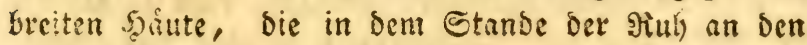
innern ş? bas Geprage ibrer Boripringe mittlyeilen, bie cin regeimápigež Duincump bilden.

Diele zuverligfige Ertlirung faheint mir Gintei= (t)end zu fenn, um sie 3iloung ber 2 Bargden beut= lid) zu machen, bie biefe Sirgonauten von andern unterideciben. Dieș beftâtigt unfere verhergehenden Eâtze.

Die Niten haben bieje Sregonautenart nidjt ge: fannt. Unfere Raturalienjammlungen erfielten fie erit felfe fuat, uno nod) findet man fie in benjelben fel=

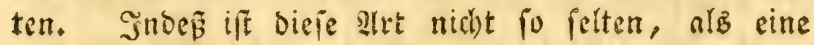
andere, beren Dreen weit fino und nadi) anfien bin fallen. Cine britte 2irt if nod) feltener, beren Rơrs ner, wie auf cinander gerollt fäseinen, die Scalma

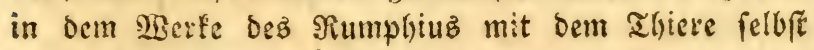
in Rupfer fiechen lię̧, weld)ez mit ben strgonauten,

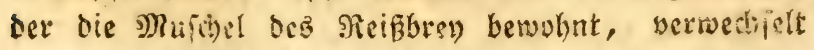
worben iff, won bent id) eż untericheide, woyot id) Frater reden werbe. Einige Naturforiber haben biejen Unteridhied bereitz gealinoet. 
Fabinnes fagt แnछे, Dẫ Det 2rgonaute, von bem bier die SRede iff, won Der Jufel Jmioina fommt. *) Sruiguiers belgautet an feiner Seite in Der Encyclopedie, Daß man ifn in ben indifisen Meeren findet. Die fdjonen Nuidheln bes Argonau= ten, fommen fict)er aแb biefen 9) Reeren, wo man fie nur felse fit)wer fingt, weil ber argonaut, ber fic bewolnt, weit feltener auf Der sberflache des 2 Baj: fers eridbeint, als Der Paxiernautiluś, der faft alle Neere betwobnt. Favannes bat von diefer Mufuel cine fleine Figur geliefert, die faft nid)t zu fennen ift. **) Die befte 3eid)nung y roanfen wir Seba. 2lud) bie Figur beB (Gualtierie verbient betrad)tet 34 werben. Sruiguieves unterfibeibet Die Irgonauten mit ben sieibformern niat von einander, er begreift fie alle unter einer Şenennumg. und betrad)tet fie al' eine eingige art.

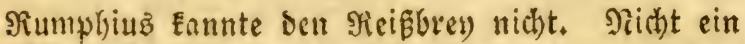
2Bort Des hollandijhen Textes in feinem Serfe zeigt Dab Dajeun Diefer Muibel an. Dieje Seluauptung fdeint jonberbar, Da auf ocr achtzelonten Supfertofel

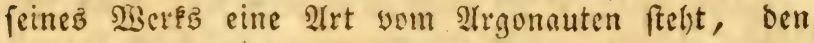
id) bier bejareibe, Deffen Mruidael auf ben Eeiten

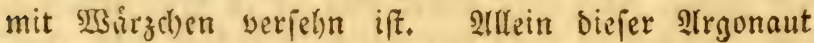
wurbe von J̧alma bafingeftellt, ***; wie ez ber

*) Favannes, Conchyl. volume I, partie 2, pag. 714 .

**) Favannes, Conchyl. pl. VII, Fig. A. 9. (5. ift eine smisgeburt.

***) Der verfterbene $\mathfrak{B}$ olferb, ließ unz diefe Ihiere

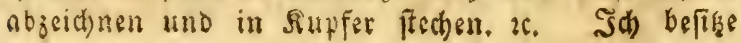




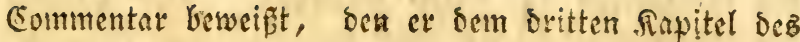

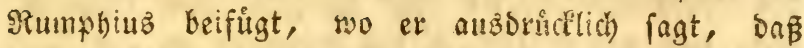
Diefe zeichnung, bie Sauri verfertigte, ifm won Nolfertz mitgetheilt wurbe, ber fie nach) ber Natur abbilden ließs. Sie nad) ben Zeid)nungen Sabryz ge= frodenen אupfertafeln, entbielten cine Menge ande= rev Murcheln won lischfier Seltenleeit, und befanden

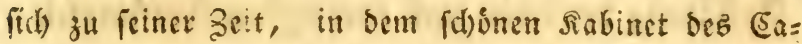
faille, ber eine obrigfeitlid)e Etelle in ber Stabt Delft verwaltete. Dies beweiß̧t unz immer melye bie

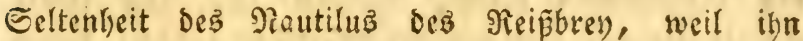
Rumnhius nid)t Eannte.

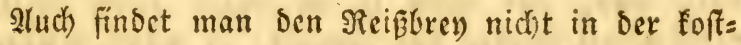
baren Sammlung ber feltenften Mufdeln, bie Negen= fuß dem \$ublifum übergab. Diefer finpferfted)er dez Rioniģ yon Dånnemare, furicht von Demielben nid)t. *) 2(uch won Sorn erwâlynt feiner nid)t. Nur bie hollanbifd)en Rabinette bejaß̧en bie Muiphel, uno Eeba giebt uns von ifo eine fdjone atblit: oung.

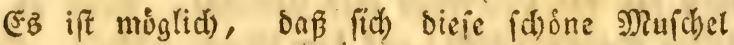
in ben inbifd)en Meeren nid)t finder, uno baß̃ wir fie vielmelyr bem Reere Afrif́ag verdanfen, ienfeit

bavon sinen Supferfid), ben ith biex bem Ju= blifum nun unter গum. r. mittbsile. HaIma, Commentaire sur le troisième chapitre de Rumphius.

*) Tuserlefene Echnecten, Murdeln uno mbere Sobalthiere, von Franz, sudiaet şegenfus. Sin Folio. 
Des Norgebirgs der guten Şoffnung. Der Ratulng Des Praturalienfubinetz Deš IJrinzen won Dranien,

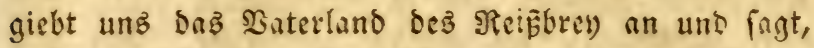
Daḱ el won bein Norgebirge ber guten Scoffinung formut. Jan $\mathfrak{b o f}$ Serfe freht ebenfalis fein siburt

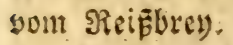

\section{Ereflatung Der fitben und beenß̧igften Siupfertafel.}

Ser Slrgonaute, Deffen Mafchel mit Erhobungen Den Seleffurnarn gleich, vericlin ift, aus feiner Ed)ale gezogen uno yon ber Rritifeite gefelin; fieben Ifrme breiten fich nad) ifrer ganjen Bolftommenleit hin, aus̄; Der achte ifit in irgeno cinem Gefed)te yerifummelt worben und benarbt, er wáds fit wieber.

Die berben breiten Şåute ber bersen s!rme,

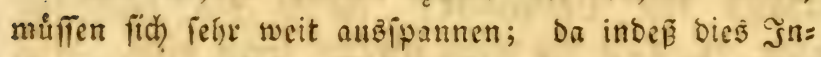
Sivioum, waz im SBeingeift anfbewahrt wird, in Demielben felhr jujammengeidrumpft ifĩ , und id) nid)tz geid)nete, was id) nicht wirklich falb, fo bemerfe id)

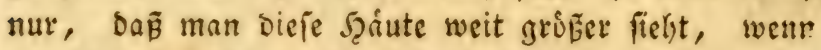
man bey der $\mathfrak{L}$ indffille biez Rolluš, wenn es mit wollen Cegeln (d)ifft, nuf bem 囚rere erblicft. Eeine glatten Irme, bie Xåpfchen ober Echropffipfe, mit benen fie auf ber Seite begabt find, bie auf ben

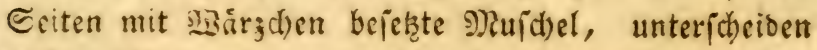

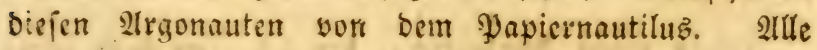
bieie siseridiedentseiten baben mich bered)tigt, ben

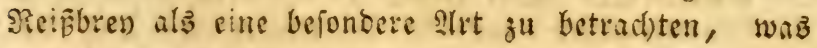
aud) (id)on alle PRajd)elfenner getian baben. 
Frtelorung ber aht und brenkigften Supfertafel.

Diefe Tafel ftellt uns benfelben Argonauten von vorn bar. Sibenn id) ifn unter zwey $2(n$ fid thten zeich)= nete, fo batte idy babey bie 1 (bficht, ilyn fo ferntlids 3̆u mad)en, alb es mir móglich war, und ieben 3 weifel ůber bie åuffere G̈eftalt biejes wertannten ahie= reš wegzuráumen.

9) 2rm. Man fief)t hier nudb ben Falz ober bie Fuge, voer innere Falte, bie fids auf ben juiammengelegten Sl:men ber ganzen fainge nad) findet. Diefe Enge baben bie 2rme, wenn fich bas Thier in bie Mujdhel zurictigezogen hat. Maan fiekt cuch hier bie Deffnung

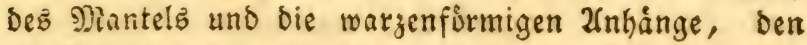

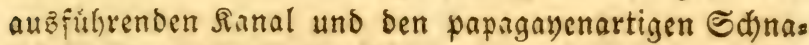
bel. Surch biefe Theile naln fid) bie 2(rgonauten ben Polypen ungemein. 2luf biejer Figur fteht Dee Unterleib hervor und hat eine gewiffe Runoung; es ift bies bie naturlid)e Folge ber fage, die biejez Nollust in feiner Puid)el annimt.

Ereläung Det neun und breybigften Supfertafel.

Szier habe id) zwey 2(rten won Muid)eln barges

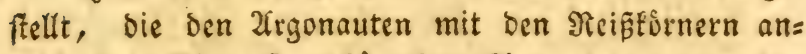
gefouren. Die erfie getgort bem 2rgonauten an, ben wir even befdrieben haben; fie fam mit bem shiere won Dem Dorgebirge ber guten Şeffnung her. Man

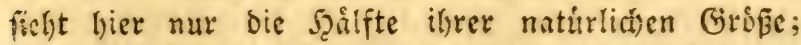

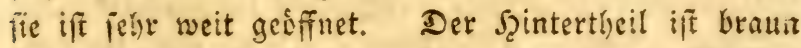
uno riuchrig angelaufen; übrigens iff bie Mujthel surchlithtig uno weiñ bet Siel ift ziemlid) breit uno 


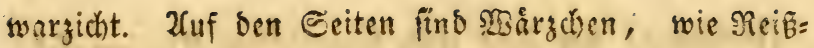
forner geftaltet, Deutlid) zu unterfdeioen und von sinander getrennt.

Die andere Mufdiel bes Trgonuten, Figur zwey auf Derielben rafel, gleidt ber borhergehenden ungemein; fie ift inoef biditer, nebr geuffneten und bie ungemein bemerfsaren shren, fallen nad) Den Seiten bin; biez jekgt eine neue Sejonffenljeit ber fechs rubernden 2rme biefeß argonauten vornus, woriber wir nun einige Nad)rid)ten mittlyeilen wollen.

\section{Det geof̧rte 2frgonaute. *)}

Argonaute a oreilles,

Diefe Nuidsel, die einem 2rigonouten angebort, ben wir noch niobt Eennen, ift weit feltener, als

*) D'Argenville, Conchyl. planch, V, Fig. C. Favannes, planch. VII, Fig. A, 7. - Gualtieri Index. test, conch. tab. 12, litt. 13. - Cymbium profundi striatum, striis latis et bullatis spina lata et serrata, candidum. - The auriculated paper nautilus. Hill. Hist. of anim. t. III, pl. VII, pag. 122. - Davila, Catal, tom. I, pag. 108 . et 109 , art. 85 . et 86. Favannes, Catal. de Latour d'Auvergne: Nautilus papyraceus, auritus, admodum convexus, striis latis, tuberosis vel potius verrucosis, carina levi, lata et ex utraque parte, mucronibus obtusis, subnigris instructa distinctus; Favaft d'Herbigny, Dict. des testaces, tom. II, pag. 425. - Dom Pernetty, Voyage aux, îles Malouines, tom, I, pag. 314. 
bie vorkergebente, inbef finset fie fid) boch in einis gen Rabinettern, wo man fie, feit ifser errichei= nung, immer vom reişerey unterichieden bat, ob fie Derifelben gleich in melirerer Szinfidst gleicht; in Der Befdureibung Derfelben halte id) mid) bey ben wenig auzzeidhnenden $\mathfrak{s e r i d ) i e b e n h e i t e n . ~ n i d ) t ~ a u f ; ~}$

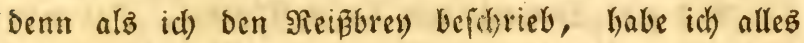
bas, was biefen benden Muf(heln gemein ift, an=

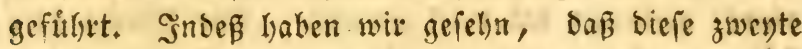

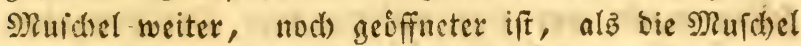

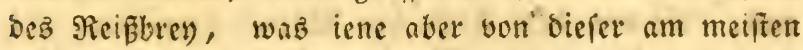
unterficheibet unb ez nid)t verftattet, fie bende fur

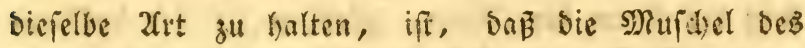
argonauten, den id) iekzt bej(breibe, nad) ifyer bintern Definung zu, mit zwey herworftehenden felye langen Dhren, werferhn ift, bie, indem fie auf ieber Eeite horizontal vortreten, bišweilen faft cinen Zoll nach auffen fich hinwerfen. ${ }^{*}$ ) Sie fint wie eine Dad)rinte ausgeljott, endigen fich fpits, uno fino fanft nad) unten zu gebogen.

Dicfe Mufdiel war vor 2llterz nicht befannt. Bualtieri bat fie zuerit abgezeichnet. In ben alten bollindifden Shaturalienfammlungen findet man fie nitbl und in ben neuern trift man fie nut felten an. Şill und Favart b'Szerbigny haben fie gefannt, ihre Sefdreibungen, Die fie won berjelben liefern, bes weifen bies unbezweifelt. Der lekgtere irrt fid), Daß̧ ex fie mit Şalmaz Nautilus ober Irgonauten, vers wechielt. 2(tad) Irgenaille fonnte fie nad) ber Natur zeid)nen; man findet fie in Dem 9 Berf feinç fort=

*) Favannes, Conch. tom. I, part. 2, pag. 716. 
Fetzers. Noch if fie in den Ratalogen bes Dasila und Latour angezeigt. Die Muichel, bie nad) Dem Satalogen dez (Sirafen Ratour zum \̧erkauf angeboten wurbe, war melje als fect) 3oll lang; id) glaube fie ift nach) England getommen.

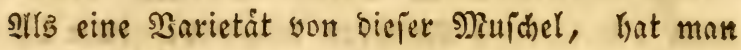
cine andere fleinere angefer)n, beren Riel nid)t braun war: vielleid)r hat man umed)t. Der 2Bud)s Der= felben mad)t nur eine unbebeutende $\mathfrak{B e r i d h i e d e n b e i t ~}$

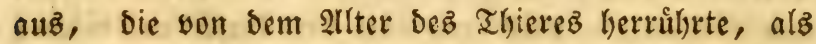
ez in Die Gewalt Des Nenfd)en fam. Denn in Şin= ficht ber form ber Dlyren, gleidhen fie fid wollém= men. Dieje herworftehende Dhren fekzen eine ganz andere Beid)affenlyeit ber rubernden Arme voraus,

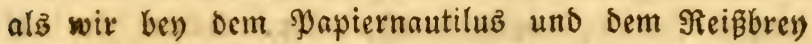
finden. Unterfudien wir bie Mlufdel genau, fo fonnen wir nid)t zweifeln, bas̃ zwey von biefen $\mathfrak{A l}^{2}=$ men gróp̃ex uno ftårfer, alz bie ỉbrigen, vielleicht aud) filtzer fino, uno baß biefe beyden Arme ihre

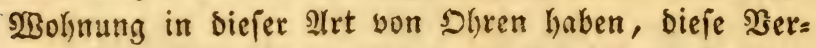
muthung iff nach) ber ilgnen eingebruidten Geftalt,

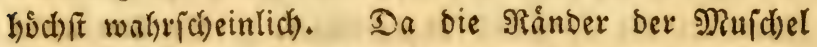
glatter, ftârfer und bie nuf einander folgenden 2 In=

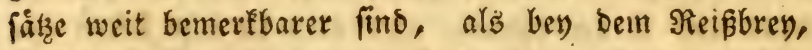
fo fơnnen wir glauben, baß̃ bie vier andern yon bie= fen 2frmen rubern, yon benen zwey auf ieber Seite ftehn, inbem fie ber ganzen \&ange nad), liber bie

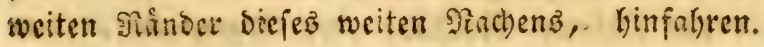

Diefer 2legenaute lebt in ciniger Entfernung von ben Siliten yon \$Pozambique, tiln bie Jrifeln won Frantreich uno Mabagagfas. Scfonders fieft man

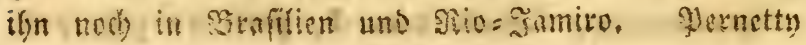


fand iln an ben Siften ber Snfel Mraldonat. Diefe Mujdel findet fich in wenigen Naturalienjamulungen.

Det 2rgonaute mit unterbrod)enen Jurd)en. *)

L'Argonaute a Sillons brisés.

Sd) glaubte biejen alrgonauten won bem beż Rein= brey trennen zu minen, mit bem ilin alle 2lutoren verwedbielt haben, und ibm eine bejondere Stelle uns ter biejen leberhsiutigen, id)aligten Mollušen ein= råumen zu Fonnen, nidjt allein weil feine Mufdsel auffallende Beridsiebentyeiten barbietet, fondern weil bie Arme biefez Thierez aud) nur mit einer Reife Råpfden verielin find. Dies Sndividuum wurbe, wie id) glaube, zwork gezeidlnet, aber nicht bejdries

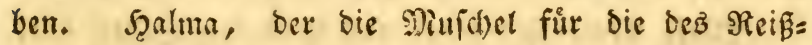
brey bielt, ber zu feimer aeit in ben bollánbifider Raturalienfammlungen unenolid) felten war, ließ̄ fie

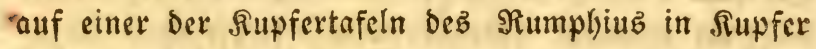
fitechen, obgleid) biefer Paturforicher, was wir idjon

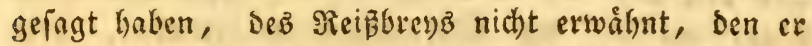

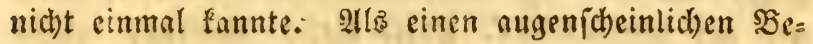

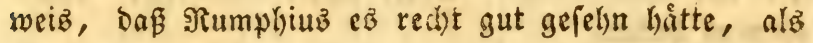
er bie \$eichreibung lieferte, Daß ber Mapiernautiluz

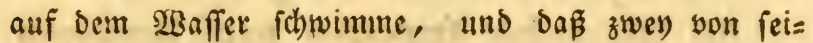
nen $2 \mathfrak{r m e n}$ mit breiten Şåuten serfefhn wåren, lię̃

*) Halma, Commentaire sur le troisième chapitre de Rumphius, pag. 67 , planch. XVIII. Fig. 1. copiée dans l'Encyclopedie, recueil des planches, tom. VI, planch. LXVII, Fig. 15. 


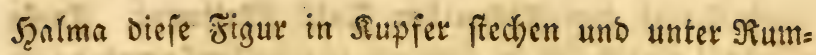
phus 3eidunungen ftellen.

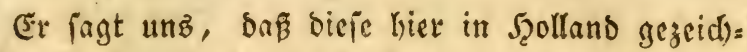
net wurbe, Daß bie figur surd) Bolferks Beforgung zu Stande fam, Deren Driginal fid) in feinem $\mathfrak{R} a=$ binet befand, was nadbler, nebit andern feltenen शiujdeln, in Rafaillez Rabinct Fam. Selyn wir bie Figur iekst genau an, fo iff ez̉ unleugbar, da pa fie bie Itbbiloung feines vofflommenen Iirgonauten, fon= bern einez zujammengefbrumpften, uno balb ver:

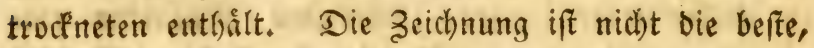

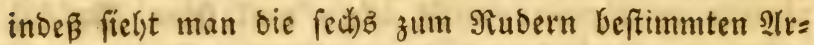
me, bie mit ciner Reike scipfden verfekn fino. Die breiten Şåute, Die bem Iflere zum Segeln bienen and bie Muid)el felbit, iff vollfommen gezeid)net.

Diefe Strme find platt und nach ben Enden hin, wo fie in eine fdarfe Spikze auslaufen, franzicht. Sie find hinlånglid) lang, inwendig mit einer Reilye, bidbt an einander ftehender Sd)ropffiupfe oder गápf= d)en verielyn, die in sibficht iffere (Beftalt und iljer

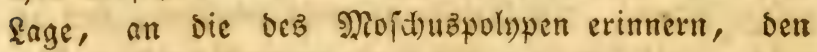
wir auf ber XXXIV. Zafel biefez Sanbez, abge= feiduret baben.

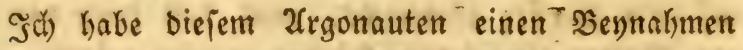
gegeben, Der won ber Befd)affentyeit ber Furdsen jei=

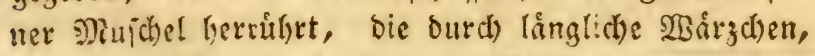
bie andera firo, wie bic som reişbren, unterbro=

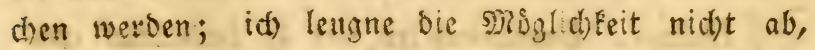
Daß̧ er nod) beß̧er darafterifirt werben Eann; andere fino burin vielleidyt glitclicher, als id). Mir ift $\mathrm{eb}$

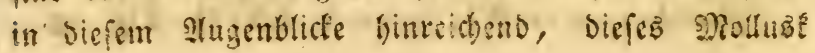


aut Dem Şaufen ber Strten hervorgezogen zu baben, mit benen man ez̉ immer vermedblelt hat. Nian bitte

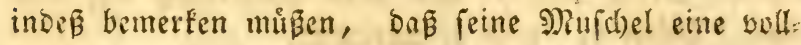
fommenere Sd)eibe bildet uno nid)t fo langlith gewun. Den ifi, wie bie ber andern Irgonauten, bie im

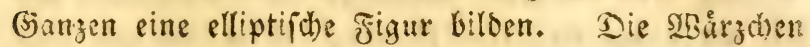

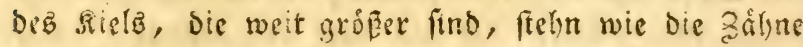

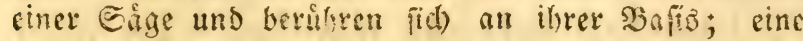
foldhe Etellung hoben fie bey dell andern Irgonauten

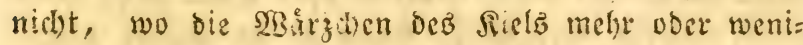
ger you einander entfernt find. Eine 2 ret von Pabel lápt auch nod) mely bie fireife ber Istindung fehn,

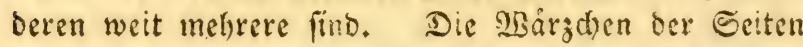
ftehn nid)t in einem Duincuni, fie ziel)n ficí furden= artig, ober alอె erkabene Rånber, fort. Cie find fo efen won cinander getrennt, ih) Alnblid zeigt es Deutlid) an, baß̧ fie ilgre befondere (Seftalt ber lage bex Niåpflyen an ben $\mathfrak{A}$ rmen verbanfen, yon benen zwey und zrwey, ober orey und brey, feft an ein= ander georidt find, burch ifsen Druct gegen bie

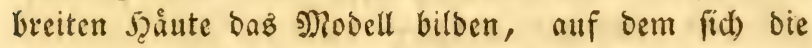

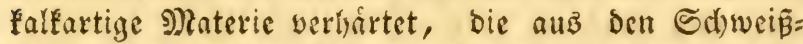

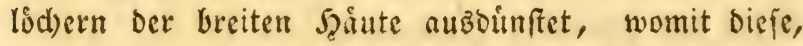
ifrem ganzen lumfange nach, veriflyn find.

Die 3eid)nung von Savry, bie uns von Şăma liberliefert worden ift, ftellt uns olne SBiberrebe, cinen britten 2 rgonauten bar. Die Art, wie bie=

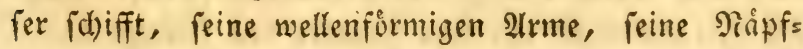
chen, fein frummer Schnabel, verftatten $\mathfrak{e}^{\mathfrak{B}}$ uns nicht, ifm andere Sitten beizulegen, als bie, wel= the ben Thieren eigen fino, bie ifm fo feht gleid)en. $2 B$ ie fie, madt) aud er fidt) ben Seebewolynern furd)t=

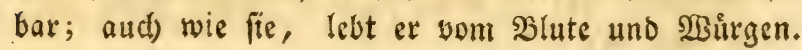


Sein Serantman ift furchterlich, weil er, swie fie, ewigen Srrieg fưfyt, uno feine Errbaltung alf Das Itnlyeil grinoet, waz er anridatet.

Da bież ber legte Bewolyner bet Argonauten ift, ben wir haben entoecten fonnen, fo misen wir cine Frage unterfucben, bie aแs bem Biegenfande, ben wir behandeln, von felbft entipringt. Der argo= naute hångt mit feiner Nuichel nicht zujammen, Eann et fie beliebig verlapen? Sann er fie wieder baun, menn cr fie Durch einen beftigen Stož, ober burds irgend cinen ansern 3ufall verloren bat?

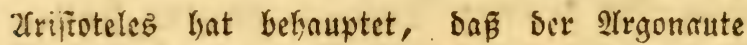

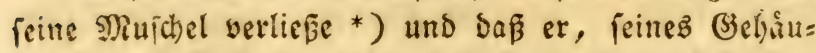
fes cutledigt, jeine Rahrung auf bem Eande, am Ufer bez 刃eerz und Dem (seftade, fuche. Dieje SNeinung, bie weiter nid)tz als cin Sartlsum ift, wurbe von biefen Mhilofophen verbreitet, weil er bie 2ligonauten, wie Đolypen betrad)tete, uno fie zum Theil mit ifnen verwed)felte; da biefe ans Iano fas = men, und felbĩ bie grôpern, wie wir eż in Det (bie= idid)te Dez gemeinen \$ुolypen gefelyn haben, Epu=

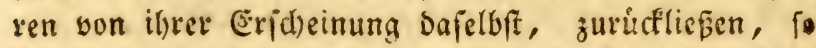
fonnte 2riftoteles glauben, Dổ bie Irgonauten eben= fallz aufz Land giengen, um ba ihye T?ahrung zu fuchen. Stber nichts fann die Niollužten zwingen, von benen wir fpredisen, ifre Muicthel zu verlä̉en, sweil fie, wenn fie nli Dem Grunbe Des Meeres Eric=

*) Sepius is juxta terram pascitur, unde fit, ut in eam a fluctibus ejiciatur, et testa excussa capiatur, vel in terra pereat. Arist. Hist, lib. 4, cap, 1. 


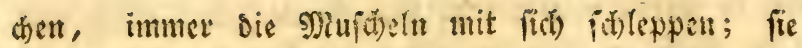
swirden biezz ebenfallz auf bem Sande thun. Siur ba, wo DaB $2 B$ affer aufferit tief ift, fiest man fie auf

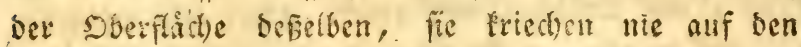

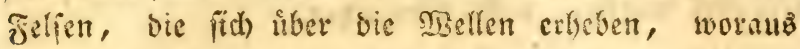

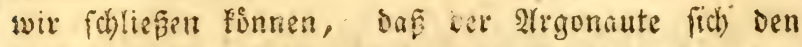
Felfen niobte nabt, weil ba fein Padien zeturodien uno er in bie $23 a f f e r t i e f e$ geftirzt wurbe, of ne hof= fen zu bitifen, fich ie wieber zur Dlerflecte bea Meerez erheben ju fonnen, wolin er, wie es idjeint,

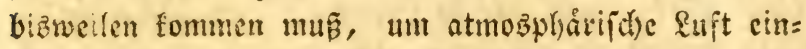
zuathmen, bie mehr שeverfraft hat, als bie er in Der Tiefe ber See eingiefn fanm. MBenn die Mujdel bent 2rgonauten aljo unentbelyrlid iff, um zur Dber= flíd)e bes Meerb emporzufteigen, fo verlápt fie bab

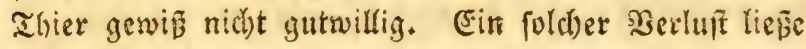
fich) nid)t wieber in jeinem ganzen umfange erjetzest.

Sch) fage, in jeinem ganzen llmfange, weil ein alter 2trgonaute, Der bie Spiţe Der SiBinoung nid)t wicber lierifellen fonnte, waz die Frud)t ber Arbeit in feinem jugenolid)en gilter ift, bie cr einige 3eit yor feiner Gieburt zu bilben anfängt, "mit ber grof́s=

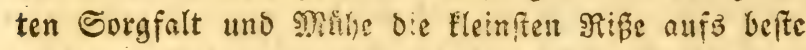

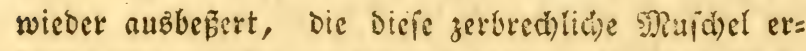

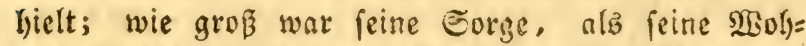
nung befthibigt war und ronnen wir's auch nur ver:

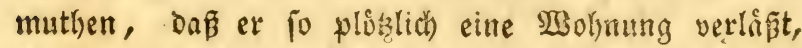
bie ilfut fo viel zu erbauen foltet, und bie ex gleich)= fam an iebem Inge feines Rebanz crweitert? SBenn er baz Werk feiner Strbeiten verließ̧e, můn̈ten wir nid)t eine Menge Mufdeln von Den 2irgonauten fin ben, ganze, mungelfafte, cutffellte, die biefe

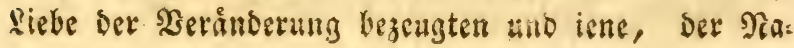




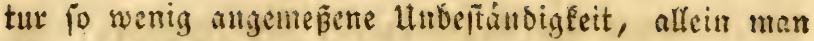
fann dieje in Şinfint eineb Sjebrudez, b.? mit fo grop̧en Siofen, burch faft tågliche Urbeiten uno obus freitig auf Untoften won einem Theil Dex Exiftenz, errichtet wurbe, nicht sermutben.

Rac) biefen erften Betrad)tungen, wirs eรี แnธี nid)t fidwer fallen, Die zwebte Frage nuiguligen, nemlid): baut ber 3rgonaute fein. Gebaule wicber, wenn er's verloren bat? Sicher thut bab unglidelidbe Thiet alleb, um eine fo zierliche, als leichte 2 Boh)= nung wicoer su erbalten, die ifm fo unentbefurlids

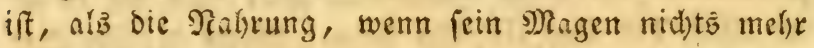
zu verbauen uno die geftrifden Sifte nichtz mehr aufaulofen haben. $\mathcal{I}$ (h) glaube einen sewsib auffel= len zu fơmen, dap̃ er eine Mujd)el wieder baut.

Sim Rumplitub *) findet man cine Slot von unges fralteter S) Suid)el, bie unter bie Slrgonauten mit auf= genommen worben ift. Şatma bat fie efenfalls cins geid)obcu, man fann fich davon uberzeugen, wenn

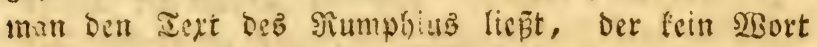

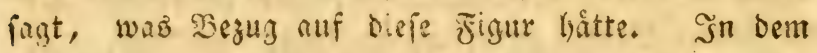

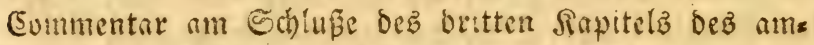
bonifden Rabinetz, lefen wir bie slivete: "wir

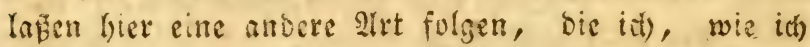
glaube, viclleidst allein befite, bie id unter ?am=

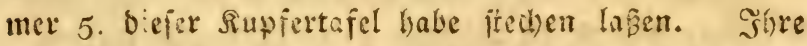
(Sieftalt gleid)t Dem Soute einer Disturin vom Maffer= Innoc; (waterlandsche bocrinne Kap.) Diefe 21rt hat eine weite Deffunng, ift auf Der ebenen Esite fal:

*) Rumph. Amb. planch. XVIII, Fig. V. 


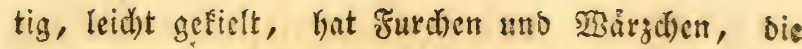
beyden Seiten find aber ničst cinander gleida), wie

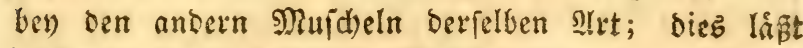

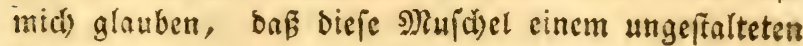
sirgonauten geljort."

Şalma, indem er bieje ungeftaltete Nufthel bes

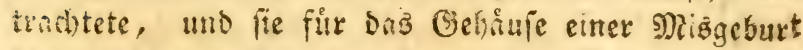
biclt, (d)cint fid), nach meiner Decinung, ber

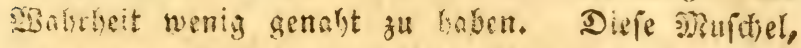
wie wit gejehn haben, ift iregulare, o. ho ihce Eci= ten fino ungleid); man nimmt wahk, Dấ fie nods who mach gemad)t ift; fratt auf bem Stintertfieile ges

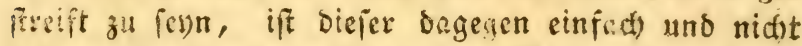
fo gerandet, wie ber ber andern Argonauten und fiellt befrimmt bie Form ber heitern Seite bez א̦or= perb eines biefer Mollualen bar, biek bat fid) biefer alugebrioft; unter gewibeti Umftủnden, ift ber ganze Siorper ourd) grofe stnftrengung fớlig, eine falfar:

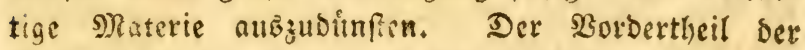
Mnichel ift eben fo mişgeftaltet uno verfripwelt. In=

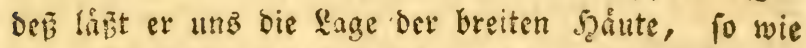

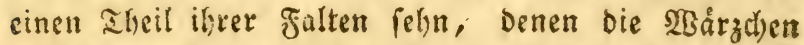

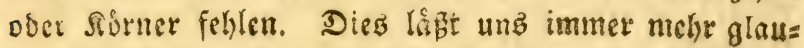

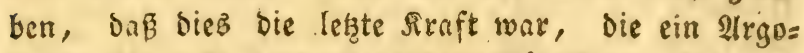
naute mit nicht herworfekenben Nåpfden, bie aud ber S)apierargonaute nitbt hat, aufbot, um fich mieber cin nettes Gẹåuje zu baun. Unter bent zabls reichen Mufcheln in Den Siaturalienfammlungen, fin: Det man viele ungeftaltete, uno fie werben won oen

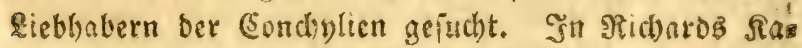
binet fand id eine fónone Stachelfdineple (bécasse

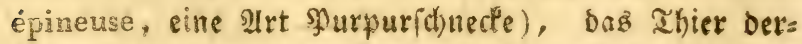
ferten war berwundet, aber nid)t geftorben. उur 
Şâfte war $e^{5}$, nads feinct Genefung, verfinmmelt

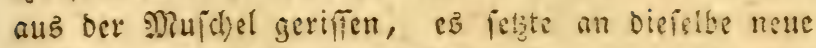
Rånoer einer falfartigen Materie an, madte cine neue Sefnung, bie aber nad) Der Geffalt bes ficr= pers bejonbers uno ungefíaltet ifi uno legte on bie Seite ber alten Ninne, einen eben fo langen Somal, bet fich aber ructwairtz, wie sin Szaken, neigt. S(d)

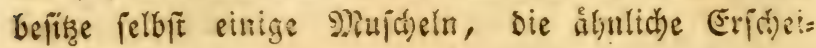
nungen Darbictert.

Dieje beyben Seyiptele, yon benen ich nod) cine Nenge anfubren fonnte, mogen hinteid)end feyn, meine Neinung ju befátigen.

Erflárung Det viergigften Sîpfertafel.

Man fieft hier ben S(rgonauten nad) Savryis

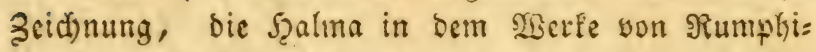
us ben \$Jublifum libergab, iegelno. Die rubern=

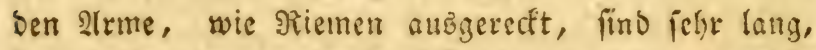

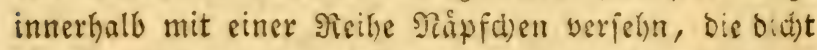
an einander fter)n. Die obere, einfache Eeite Der

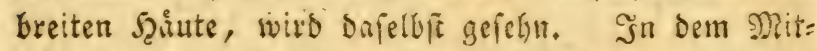
telpunfte ber Irme erlyebt fith ein farter, gebogener Echnabel, wie ifn alle Thlere ber sirt haben. Die Nuichel hat feine ellintifche Geitalt, fie ift vielmelie

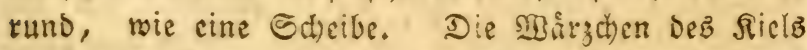
find groz̃, ftart und hervorfiehend. Die Furdien auf sen Eciten werben unterbrod)en, Da ifre $2 B$ årzdien ungleid), langlich fino, fie ftelin nid)t in einem

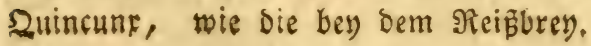


Son einigen Itrgonantenmuraefn, Deten Thiere noch niát becannt fino.

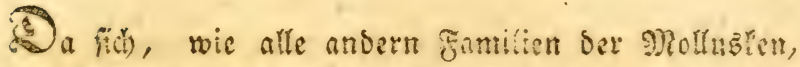
Die ber sirgonauten unter ber Feter ber Sacobadter

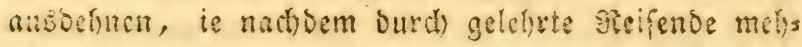
rere entoectit werben, fo dinfen wir hoffen, bas wir

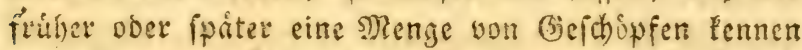

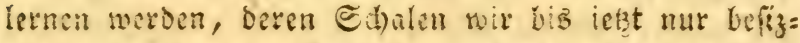
gen. Diele, Da fie ferter, alg bie fiets weichen,

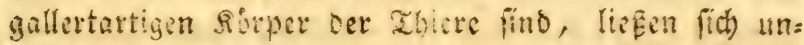

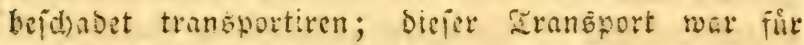
bie Ihiere felbet unnoglith, bie tigre sBitsung verlie= ren uno fith in bem Xlugenblide, wo fie gefangen

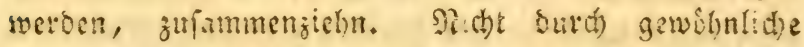
ßeifenos, ober burd) Secleute, bie fid ausichlici= fend ifferm Etande weifa, cribalten wir bie fait lan=

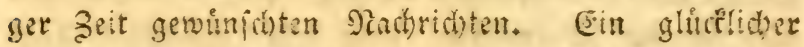
3ufall mü bieje zhistaten einem gefobiteten Patur=

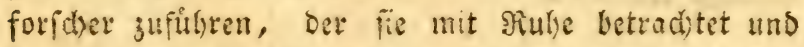
rid)tig jeidunet, ber ourch feinen Grifiel bie åufern fo fliditigen formen aufzufafien und feitzuhalten wer:

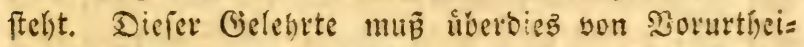
len, frei jern, weil bieje uns oft Dinge felln lap̃en, bie in ber WBitelid) feit nicht fratt finden und weil fie

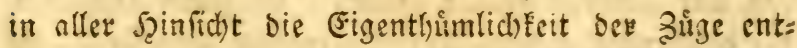
fteflen, Durd) bie man ung Die Gegenfrånbe hat yor=




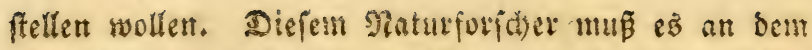
binreichenden @oharfinn nicht mangeln, um feime exlangten Renntriffe auf Daß zu verwenden, was ihm in einem oft flidhtigen $\mathfrak{A}$ ugenblicfe zu feljn ver: gơnt iff. Die Ueberlegung und bie 2unalogie, Dured Sheisheit uno Slugheit geleitet, bie nid)t immer bes trught, flårt ifn alf und erfaubt ifgm, Thatjact)en und Formell malyrzunefymen, bie nur bem genibteften Blidfe nidyt entgelyn.

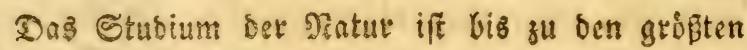
Sleinigfeiten extraben, in ifrnen findet man oft bic ganze Erhabenheit ber Nitte! Der Natur wieber. Eie belolynt ben auf bie freigebigfte IBseife, ber vertrau=

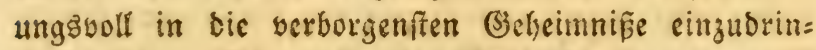
gen jud)t. WBenn aljo Die Gefd)idte Der Jenntnis̄ ber Natur bey Den Nen(d)en die Fortichritte nidjt gemnah)t hat, bie man won biefen, bem Mienid)en eigentlyumlid)en Wiffenbourfe, erwarten funnte, fo

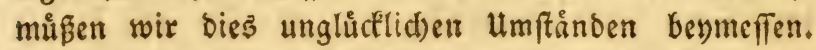
Der Szorizont bes SBiffenz wirb in unfern Iagen

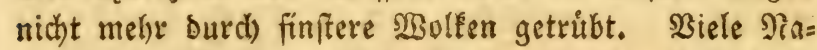
turforidoer fins von allen Piationen in alle $\mathfrak{B e l t g e s}$ genden auf Entbectungen aus̈gegangen. SBir birfen

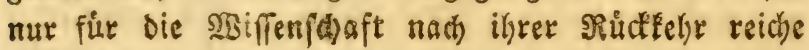
Sibåkge erwarter.

Bis ietzt fonnen mis nut bie Gefiufe Det mit Sen Iirgonauten verwandten Mollusten anzeigen, weil wit ifre Iljiere nod) nicht fennen. SIJir werben aber ifree 2 ret nicht eine folche Jubbelinung geben, wasె foft alle stutoren getban baben. Es giebt Miuid)eln, bie ofmftreitig anbern argonautenarten angehioren, fie 
find aber felse felten und matt finset pe in unfern Paturatienfommlungen nidye biufig.

\section{Das Lofdopapiet.}

I'Argonaute papier brouillard.

2iefer 2trgonaute hat in bet fronzofifiden Sprade ben seinalymen, ben id) beibelielt, Das esfdupas

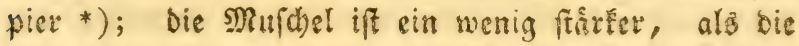
Der andern 2lrgonauten, und fie if nad) ifferm 1 tm

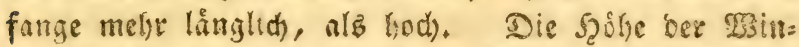

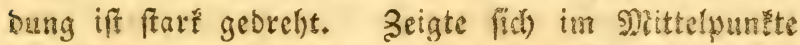
Der SBinoung ein Peabel, fo wurbe ifire Sieftalt ge:

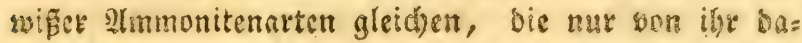
ourd) fid) unteridjeiben, bof fie in fammern abge: theilt fins, und bå man fie nur serfeinert findet.

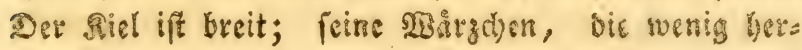

*) Rumphius, Amb. tab. 18, Fig. B. - Seba, Thes. tom. III, tab. 84, Fig 8, 9, 10, 11, 1.2, pag. 176 - Lister, Hist. corich, tab. 555. Nautilus minor auritus, magnis et eminentibus striis donatus. - I'etiver, Gaz. nat. part tab. 10, Fig. 3. - Gualtieri, Jnd. test. conch. tab. 12, Litt. c, c. Cymbium striatum striis.. crassioribus, spina satis lata et $8 \mathrm{er}$ rata, fragilissimum, pellucidum, sebahirto colore splendens. - D'Argenvilie, Conch. planch. v, Fig. D. - Favannes, Gonch. planch. VII, Fig. A, 6. - Favannes, Catal, de Latour d'Auvengue, pag. 57, No. 248. et 249, - Breed gekielde nautibus, des hollanda:5. the course brittle saylor, des anglais. 
voritchn, fino sueit son cinander entfernt, wellen= furmin, etwas gevogen, alle lauprn nath ber glitte

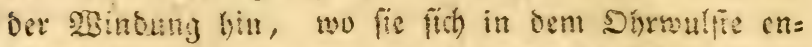
bigen, bet nut rit wenig nach aufen binfelt. Dicis Estan obez ginuen, fins gewifunlich gans cinfuch, aber oft fins fie aud gefurtit, wie bey Dem slapict=

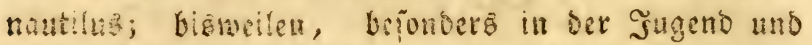
ben eriten firelien Dor 2B:nsung, hüren bicie Etrei= fen aur, erlofiben auf ber Şâfte bez 2 begz uno

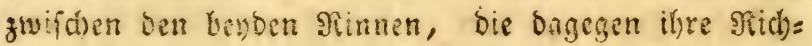
tung bis anz Enoe fortiphen, inbem fie vour Riele aub!nfen uno ilib) zu ben Dlorvillften bingielsn; bie

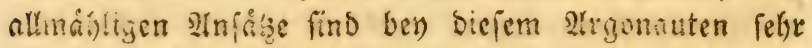
fichtsat. Die Dinifiel iff orey Bolf lang uno gwey Soll hod; grizer. fdeint fie nicht zu werben, benn id) babe meliere gejelin, Die fleiner, aber feine, welche groferer war. Die Deffnung ober ber Illuno, ift faft oblong, bey Den grupten 2 rgonauten Der Irt iff er gwen Soll lang und einen Bull breit. Sb biefe

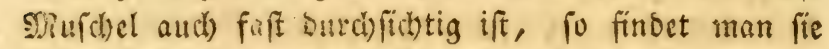

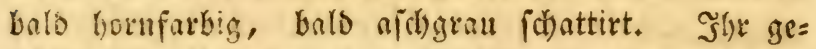

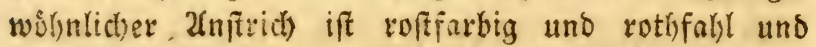
naht fï) ber Farbe bes sofdopapierz, eben baber erhielt fic aud ben Zeinalymen, Rofd)papier. Sies gen Den Mittelpunft ber Mufdel wirb diefe Fatbe friter und iff ba wiel brịner.

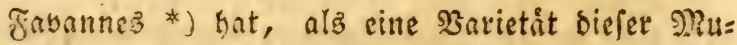
fiot, eine nnopre angezeigt, die won ben merica=

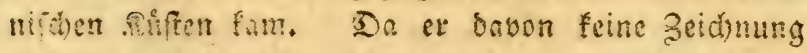

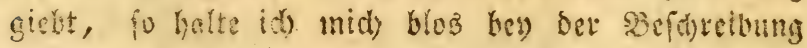

* Y Tarannes, Conch. Volume I, partie 2, pag. ?12. 
ouf, bie er bason liefert, indem er eitre andere

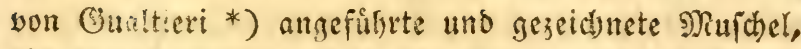

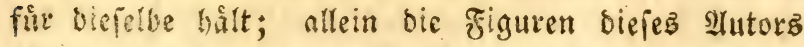
(d) Rofit) apier anzubeuten, die Gualtieri unter brey 2 (nfitioter zeich)nen liế, inbem er fie zu berielben 2ret gehorig onfiekt, die Rumphiuz ofne Beichrei= bung auf ber XVIII, Tafel, unter ben Budbifaben

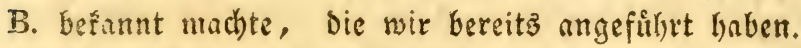
sob bie Deffnung biejes sirgonnuten aud) viel weiter, Der $\mathfrak{B u c h}$ se bezelben Eleiner ift, bie Garben bleid)er, bie mittlern Furzen Streifen zwilchen Den beyden an= bern soltfommern zeigen, fo färeiben wir biefe unbe= beutenden $\mathfrak{B e r i c h i e b e n l i c i t e n ~ b e m ~ 2 f l t e r ~ z l l ~ u n d ~ t r e n = ~}$ nen Muid)eln nicht von einander, bie mit einander

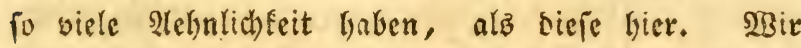
wiberipred)en alfo ber Meinung bez Javannez und balten bicfe Muid)eln fur eine unb biejelbe strt.

STie uns Favannez beridtet, fo leben bie Str:

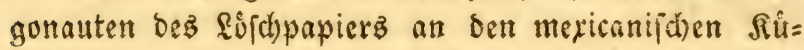
ften, allein bie Şollęnder haben von ben mollukifichen Inieln, vorzuglich yon suro uno Manippo, ber=

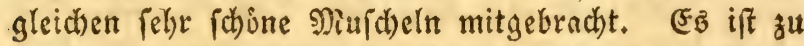

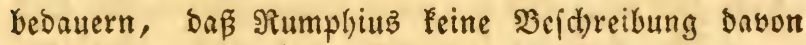
binterlaß̃en hat, benn ficher båtte er einige Befon= berheiten won bem Ifiere angefuilyt. Sid)er ifit aud) bieje Figur von bem (5omentator untergeid)oben. Sim Gegentheil fuilye id) eine andere פlrt an, bic auf

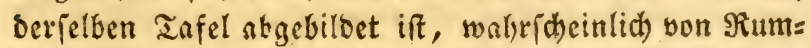
phius, bie er in melyeen bolla

*) Gualt, tab. 12. Fig. C. C. 


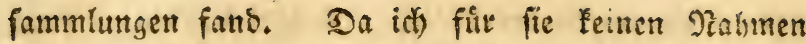

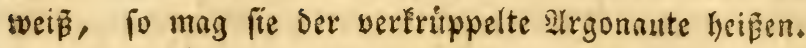

\section{Der verkrippelte 2(rgonaute. ${ }^{*}$ )}

L'Argonaute chiffonné.

Diefe Mufdyel fofeint eine ber feltenfen won allen

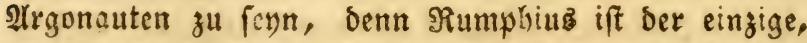

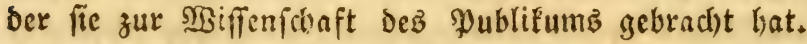

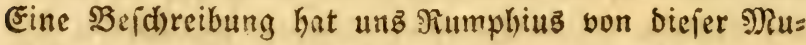
fhel nidjt geliefert. Diefe zeidjnung, bie bie eimzige

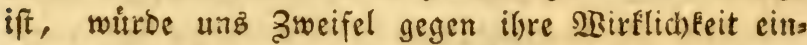

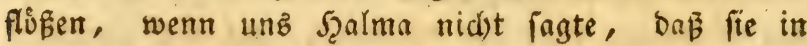

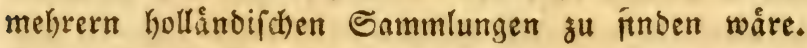

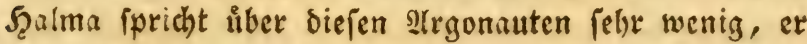

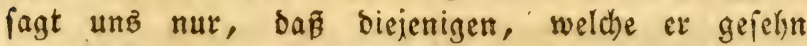
hat, weit feiner, als alle vorhergchende fint. Daß Der אiel breiter, Der feib aufgeblajener, bie Jarbe weiser ift.

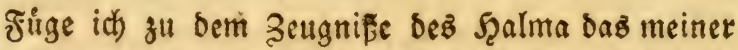
Alugen kinzu, fo felye ich, baßs bieje Muichel brits tehalb zoll lang uno ein = uno cinen halben zoll boch

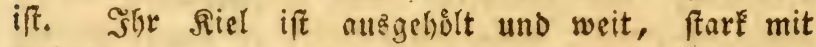

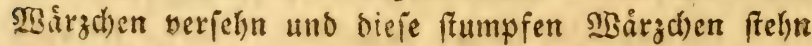
eitranber feht nah. Glatte, melye oder weniger vers Eruppelte Streifen, lnufen liber bie Eeiten ber Nu= (d)el bin; fie fliesen in cinanber, is nachoem fie

*) Rumphius, Amb. Rariteyt-kamer, pl. XVIII, Eig. 4 . 


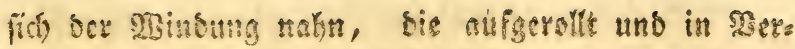
gleid)wng mit bet Mirdtel flein iff, beren Deffnung

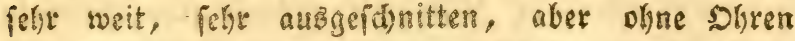

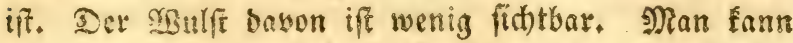
bieje Nuidel von allen andern babuech unterid)eiben, bas fie felie gebogen und aufgeblafen ift, felbft on, no lie vom Siel auglånt, wie man ez an ber Figur, bie feltr gut geftod)en ift, felgn fann, bie mir sum Gegenftande Der Sicobactumgen siente. Sith habe Diefen ichonen Argonauten it feinem Sabinet Frant= rethe grielnn; er fdesint fidh allein in ben hollsnbis fthen Eammlungen ju finter. Eein Taterlano fino

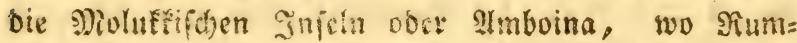
phitus meryere bergleiden fammelte. Dies ift um fo walurfideinlid)er, ba bie Eeltenlyeit und 3erbrechlid)= feit diefer Mufchel, $\mathfrak{e s}^{3}$ nod nid)t verfettet haben, fie in die franzififhen Sommlungen zu bringen, in benen fie fid) fider befinde, wenn fie aus $2($ merifix ober Afrutia seme, wo bie Franzofen eben fo auss: (d) liep̃eno einige Eroftriche befithen, wie die Szollin= ber inte mollutfifiben Snjeln.

Diefe Mufuchel ift cine Geltenbeit, ob ez gleid) noch eine Barietit Derielben zu geben fdheint, fo fonn id) aud) biefe nu: fir bie sirt felbft halten. Dieje Sarictát, fagt Sgaluna, gleicht ber Mufded, bie wir eben bejdyribuen, ungemein, aber ifre Riet ift (d)maler, bie Eeiten boben ungemein feine Snšp: c)en und zeigen feine Striemen. Man finbet fie in Don horrlid)en Sammlungen deß Şertn 2lquet unb Teytemsz, die griphte won allen biefen Muidteln, Die betant fino, in ber Sammlung Der Sungfer Dortman. 
2(uch) Fasannes unterfuchts, wie ids, biefe Mu:

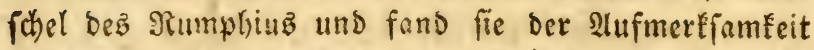
wirbig; allein er betrad)tete fie olbु cine Barietát

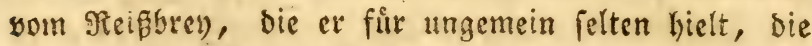
fich) Der yon ber Siffe von Mocambique nabe. *) Jasannez hat dieje Miuchel feloft nicht angetroffen.

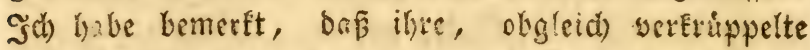
Bertiefungen platt find, tmo bas fie folglich) zu ben

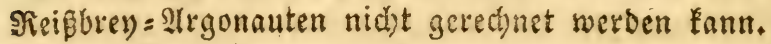

Эd) rebe hier nod) won einer andern Nuidsel, bie ebenfallz felten ift, bie Eeba zuerft in Supfer ftechen lię ${ }^{* *}$ ), bie Favanneb nach ilym iffentlich befannt machte, allein bey ifym ift fie faum wieber zu fenmen. ***) Favannez nennt fie ben einfachen Nautiluz, ob fie gleid) ungeftaltete und wenig exhas bene Streifen hat; allein eben biefe machen bas 4 ln =

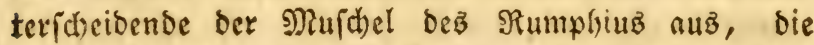
wir anfúflyrten, und wie bieje, hat aud) iene einen breiten, tiefen Siel, if auf beyoen Seiten mit her= vorfpringenden 3 årachen beferzt, bie etwas ftumpf

*) Favannes, Conch. vol I, pant. e, pag. 714 . 715 .

**) Seba, Thes. 3. tab. 84, Fig. 2, pag. 176.

***) Der einfache Nautilus "(Ĩafel VII. Şuchit. A. 10.), wegen ber ungeffalteten ober wenig hervor= fergendin Erteifen to genannt, ift nefferit fein.

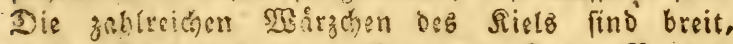
menig beroorfehend. SGon ber anfel Borneo. Favannes, Conch. Vol. I. part. 2, pag. 713) « Şat ber Zfrgonaute ungefraltete Streifen, fa Eann er nidjt der einfache Nautilus bsifen. 


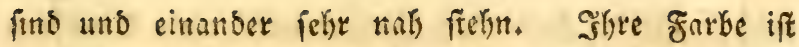
gelblich) und Favannez belgauptet, Das̃ fie von bet Sinfel Sorneo formmt, Seba, Der zuerit die atbbil= bung berfelben lieferte, legt ihr eime finge yon bren und eine 5̧ible von zwey Zall bey. Die Deffnung be= trigt in bie Ringe brittehalb uno cin = und einen hals ben 3oll in bie Breite. Diefe Sinngeichen machen fie alle unferm werfrippelten alrgonauten årnlid).

\section{Det zunef̧mende 2ligonaute. *)}

\section{L'Argonaute croissant.}

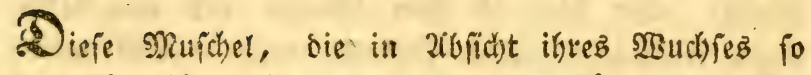
fonderbar ift, bie man wegen ihere langlidern Ges= ftalt und ben auffallenden Siel mit feinex anbern ver= wed) feln fann, wurbe zuerit bon eifter uno bann vou Favannes bekannt gemad)t. Eifter lat unz feine $\mathfrak{D e}=$ fdreibung won ihe hinterlafen. Favannes fagt uns nue wenig won iht; ba ex fie inder felbft geịelyn hat, fo ibbertrift feine 2lbbiloung von ifh, bie bes \&ifter, und er fagt unz, baß fie sichfarben, felten ift, aแక Dem Drient fommt, ein = uno cinen halben 3 olf lang uno neun sinien bod) iff. Diefer franzuffiche (E) ufftifeller mennt fie wachisus, (zunebmend) id babe biefen Nabmen beibehalten.

Der zunchmenbe Irgonaute Deż Favanneż, ift eine nieblidbe, feltene Minichel, bie man in weni= gen Sabinettern finset, aber boch) Sfter in Frant=

*) Lister, Hist. conch, tab. 555. - Favannes, Conch. vol. I, part. 2, pag. 213. et planch. VII, lett. A, 1 . 
reid), als in Sollams. Cie hat niöt vicle Etreifen, fie find aud nidit herborfeheno, ftatt Der Dुertie: fungen fielon groiflibn ibnen mulfartige Erbaberheiten, bies ift iuf Das Gegentigeil Des Arrgorauten, Det Rofdpapier beibt. Der Sicl if mefse wellenfurmig

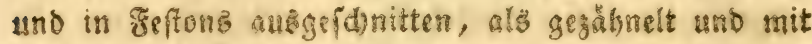

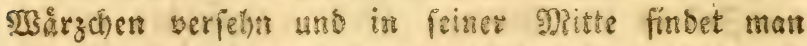
cine Furche, bie cthoben rach ausิwåtร låuft und

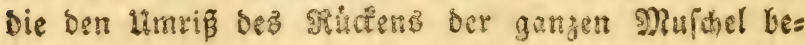
fờreibt, bie fid) bis nach ber InBindung bin verlàn gert. Der leţte ltmereis Der Mardsel if sormårts geridistet unb an bem Srte Der Dhren finbet man ben IBulff; aber bier ift fein Sand, bet von iebet

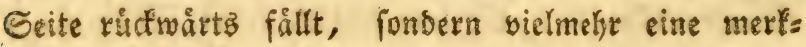
lidje sertiefung, wo bie rubernden arme mehr 9raun Gaban, alb bey ben andern Irgonauten, uno folg:

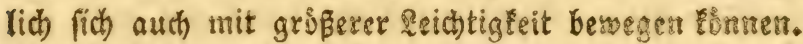
Die längliche Seftalt biefer Mguid)el, indem fie am Umfang zunimmt, dicfe befondere Rage oss malfeg,

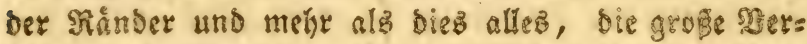

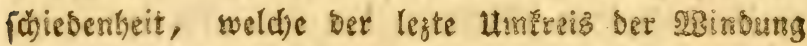
ober bes Şintertheilb, in feinem 3unetymen, Dar=

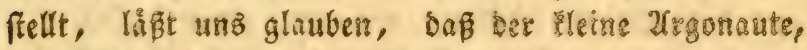
ber Figenthuimer biefer Muid)e!, bis gu bers lezten

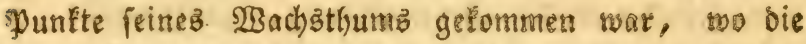

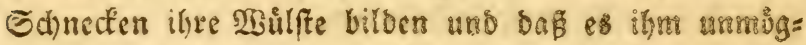

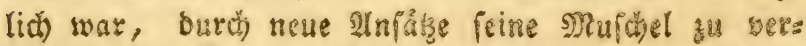
grôfern. Tritt man Diefer Deinung bey, fo fanat man einer nndern IIrgonnuten, Den Favannes unter

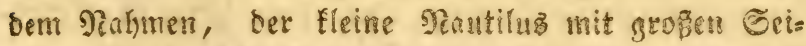

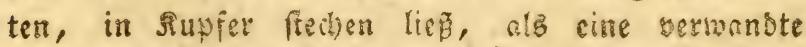
art betraditen. Ilud biefen hait er firt eime Ealten=

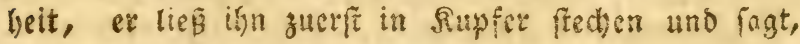


baf er von Den Manillen fam. *) Ëben po, wie be: zunclomende 2trgonaut, if er irregulie gefrimmt bie S3ephaffenheit Des Siels uno Dei Eeiten, iff bie felbe. Sielleid)t ift'z ein junger, zunel)menoer 2 (r: gonaute, bem einige 20 njåkge fehlen, ber ben falf: artigen Stoff nod) nicht hatte, um fie zu bitben.

\section{Die Tafferfd)aufel. **)}

L'Argonaute Ecope de Batelier.

Dies ift eine beftimmte 2regonautenart. Die Nu= fichel ift eine ber nieblidjften, bie wir Kennen. Sie ift fo leid)t,

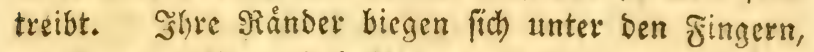
wie ber mit Gummi beftrid)ene בafft. Sie ift eime ber feltenften Nufdeln. Sie ift ourbfiditig, faft perlmutterartig, bie Jarbe if weiplich), Die $2 \mathfrak{B a ̊ r}=$ d)en Deş Rielś find braun und duntel. Nie babe idh cine gefeln, bie uber acistzelin finien lang und über fed) B Rinien hod) wat. Nach hinten 3 if it ifre Deff=

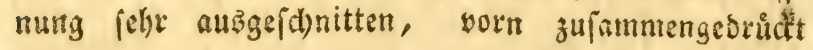

*) Favannes, Conch. tom. I, part. 2, pag. $7^{17}$, ?18, planch. VII, Lett. A, 5 .

**) Seba, Thes. 3, planch. LXXXIV, No. 8, pag. 176. - Favannes, Conch. tom. 1, part. 2. 716 , et planch. VII, lett. A, 3. F'avannes, Catal. de Latour, pag. 57, art. 249, indiquant la pl. VIII, de Favannes, au lieu de la VIIe. 
und faft oreyectig, eimen Boll breit und einen long.

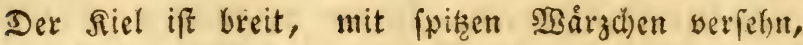
bie einander fefir naly fefyn, won benen, um mach Den SBilften Der Shren zu laufen, fo feine als leidite Streifen gehn. Dieje SISUlfe follen nach binten bin und filt auf Dem Rande Der Dhren, bie ausge= (d)nitten find, wie ein rechter S্Binfel mit Den Ran= bern der lippen uno fino faft eben fo gefrummt wie

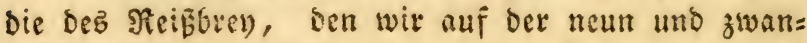
jigften Supfertafel yorgeftell baben. Die slelynlid)= feit ber Mufdel mit ciner furzfticligen Edjaufel, be= ren fich bie Echiffer bebienen, um Daz 2 Baffer aแв ibren Falyrzeugen zu dhaffen, hat bieier nieblidjen,

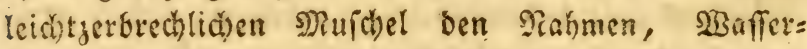
(d)aufel, gegeben. Favannes hat bicje Senenmung beibelalten, id babe diefen Tabmen um fo mebs

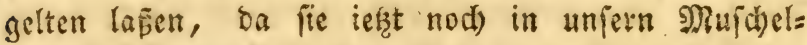
fommlangen feinen andern firbet.

Eeba hatte biefe Majdel zuerit in feinem siabi= net. Da ex fie mit Fecht alB cine bejondere 2irt be=

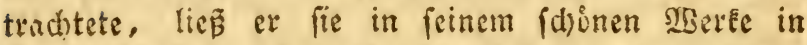

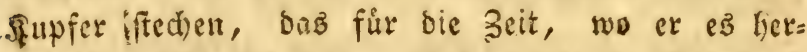
ausignb, felfr gut war. Seba zeigte ifyr Materlatio nid)t an, el bemerte nur, Daj fie fehe felten und wegen ihrer shren, die fie an ben Eerten ihres ers Gabenen நintertbeilz ober ifrer erhabenen SBinoung batte, bie fo fpitz fino, wie man fie alt ansern Slrgonautermu[ấ) ln nid)t finoct, befonders merrwirs Dig iff. *)

*) Seba, Thes. 3, pag, 176. 


\section{Det Zirgonaute vou SRimini, *)}

\section{L'Argonaute de Rimini.}

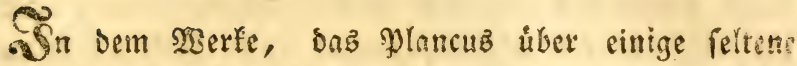
Siufdelarten befannt madte, finden wir cine fobst gezeid)nete Figur von einet Silu(d)el, bie ex als bis

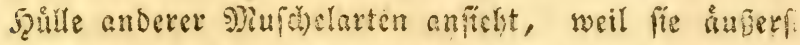
glatt ift, uno weil fie weyen ifreer Etreifen vorzing= (id) ben Gebáufen ciniger Sdy wimmidnecten gletdlt.

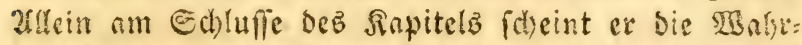
beit feiner exifern Meinung zu bezweifeln. Sal hase bergleid)en SRuid)eln in Menge, aber verfteitrent, gefunoen. Gidher gehort bieje Mufdel einem $2 \mathrm{rr} 3 \mathrm{O}=$ nauten. Diefer 2frgonaute ift felge glatt, wie cin

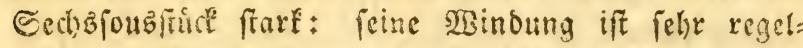
måpig. Die seffmung betright bren Rinien in bir Ringe. Wer siel ift platt, aber glatt, uns vide Streifen laufen regelmasig nuf den beyben Seiten feincr Nånder hin, un fich im Mittelpunfte zu ver:

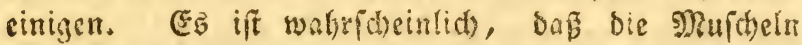
won bem llfer won Finini burch bie Sonne aubge= bleid)t waren und ilye farbe verloren hatten, Denn Plancus fagt uns nidht, ba⿱⺈ cr Farben an ihner bemerfte. Die verfeinerten, bie won bem Meere serlaffen und in ben Eand cingegraben waren, baben nod) ifle Farben, auf cinem weip̧gelolichen Grunbe find fie rothgeflamint. Berfecinert finoet man biefe

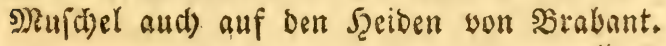

*) Xuf bir 41. Suppertofel, §ig 5, ifĩ biefer ver. fleinerte 2frgonnute norgeffellt. 
Die Berịteinerung Des Xigonauten, ift vielletibt eine oer feltenfen, die wir fennen. Sein Ed)rift= fteller bat won einet Berfteinerung bes 2rigonauten 3rgo gefprodien uns bie funf $\mathfrak{B e t f f e i n c t u n g e n , ~ b i e ~}$ id) auf bet ein und viergigften זafel geliefert babe, wurisen ton mix auf meinen litfologild)en SReifen ges finmme!t. Grof̈e Ilrgonautitin (verfeinerte 9Muid)cin

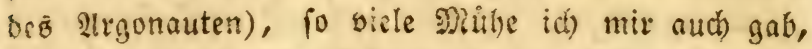
habe ids unter Den Irummern und Heberreften ber Ilicticit, bie Durd Sabrhunderte auf cimander ge= folithet fins, unter Den Nautiliten, Den ungelseuren Zinmonshurnetn, won Denen einige cinen Durd)meffer

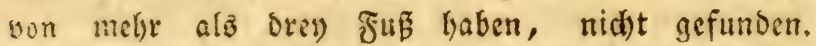
Gribere Sirgonautiten, als von orittehalb 3oll, habe (id) nid)t gejelyn, die anbern alle, bie idb fand, worsa fleiner.

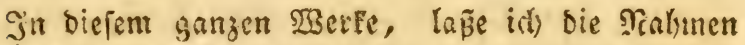
ser verfteinerten sivrper in ite endigen, (als 2lrgo= nautite) und werbe fie immer ber Thierchife nadjol= gen laffen, zu Der fie geloren, weil Diefe Merfeci= nerungen erft bas Ganze bilben, uno, wenn $i d b \mathfrak{b}$ ju fagen wagen barf, ben intereifanten, plilofo=

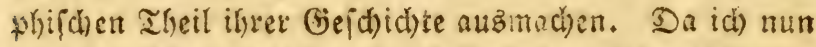
von ben 2ligonauten gefprod)en babe, finge id mun

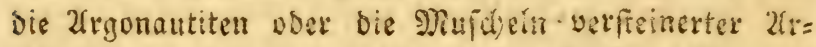
gonauten lingu; fo folgt anf Den Santilus ber Tautibit; auf bas 2rmmonblyorn bem 2tmmonit. Sies

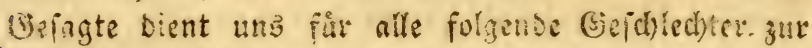

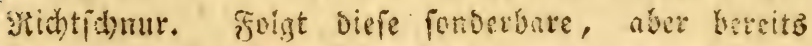
angenommene Enoigung eines Jialimens in ite fogieids

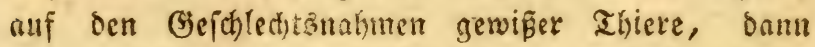

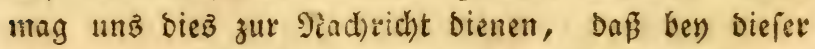
Tlierart nur von Foffitien die \$lebe iff, ba wir bie 
lebendigen Ihiere berfelben nidht mehr fenner. In Dem sierten Sande finden wir mehrere Seifpiele von Dergleidsen Folfilien, die eheden ofnftreitig spuldeln waren, die bon Thieren bewolint warden, die man iest in ilyeem lebenden, natirlidien 3ufande nid)t metir fent, entweber wolinen fie nod) in Den grojs: ten Meerestiefen, wohin ber Slenid) nidht fommen Eann und berillen die Sberfadse der See nie, oder fie baben aud) in einer Bevolution, bes ber unauf=

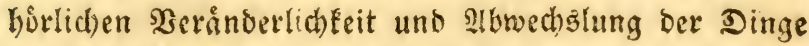
Die (Geftalten, bie fie urfpringlich batten, nid)t be= Galten, und nach und nach ein anoeres̄ SInjeln be= fonmen, was fie zuleķt in unfern Augen unfennt= (id) madite.

Soldhe Setrad)tung, bie moglidit fortgefponnen werben. fonnen, bieten fid) uns oft bar. Bey fols d)en (B) legenbeiten fónnen wir fie mit melyr Sortbeil itr Iinregung bringen, weil fie Der Gegenftand, won bem die Rebe ift, felbit erzeugt uno bey ber Ertala= rung von Thatiachen erbalten wir neue affid)luffe. Epatex hin fonnen wir alle diefe Zhatfadjen unter

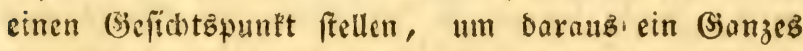
von fichern Beobad)tungen und unbegweifelten That= fad)en aufautellen, weldbeß uns iner bie Theorie Der Silloung ber Erde, wenn wir die \$itloung Det

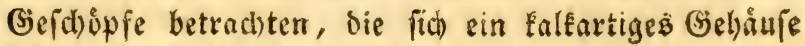
baun, cin bellerez ̊ich̆t gebrn fann.

råglid) felin wir $\mathfrak{e B}$, wie fith diefe Materie noch) vor unfern slugen bilbet; fie wiro burch Şulfe ber Thiere, tåglich in ungebeurer Menge hervorges brad)t. গtlle bieienigen, weld)e fie berworbringen, 
thun $e^{3}$ nicist auf cin un' biefelbe 2 rt, und unter ifnen giebt ez weld)e, bie ez lange zeit nad) andern thaten, weil es mathematifd) und phyfiid unmoglid) iff, baz fie alfe auf einmal entitanden.

Sn ben veridicbenen Erblagen, die auf einan= ber gehåuft find, finden wir bie Heberrefte von Thiergefchlechtern, die vor unz lebten, diefie muiffen wir alz authentifhe Documente betrach)ten, bie $\mathfrak{e}^{3}$

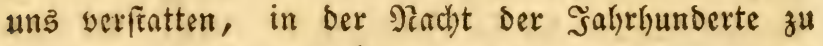
lejen, und biefe unzábligen nicht zu beftimmenden

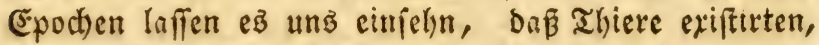
beren fefte Trimmern wir wieber entbecken. Solse gegenwårtiges Dofesn ift unbejweifelt uns ihre ehma= lige Erriftenz eben fo gut erwieien. Sie wohnten aljo peit unbenelid)en zeiten allf ber (Froe; ifre (siefchled)= ter haben fid) auf berielben exhalten; in ihrer ur= fprunglic)en Gieftalt fino fie biż zu unz gefommen.

2lber unter biejen Trúmmern ber 3eiten uno alter, findet man, wie ich bemerft habe, felye biele, beren ahiere in ber Iiefe bez Meerz unz werborgen fino, vielleid)t in ben Einuben 2ffrifas,

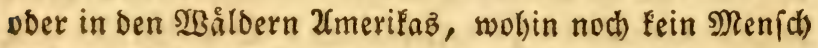
fam. Unter biefen Trummern find vielleid)t einige, bie ahieren angehurten, Deren Geichlechter untergin= gen uns zu unz nidst fommen fonnten, weil fie

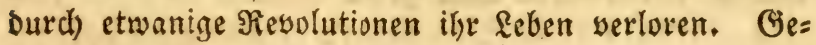
ben wir Diefe ahatjachen ganz oder nux zum Theil ju, fo milfen wir biejen Thieren, yon benen wir noch) Heberbleibjel finden, ein weit hujherez alter, alß Denienigen beilegen, beren Geifbled)ter biz auf uns gefommen fino, unb die zeit, bie alleş zers 


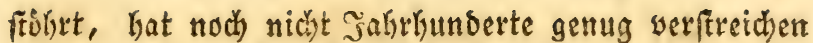
laffen, um ilye Bieftalt zu veråndern, doer fie zu wernid)ten.

Șent wir ůber ben Gang bet 3eitalter nachben= fen, fo felyn wir, baßz zu beftinmten und won cinan= ber getrennten Epodien, nach und nach die Geridjopie Bewolner ber Eroe geworben find; bies beweipt,

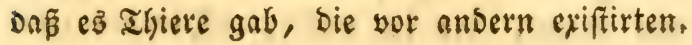

\section{Der faltige 2frgonautite.}

L'Argonautite plissé.

S.d) habe auf ber ein und vierzigften Rupfertafel,

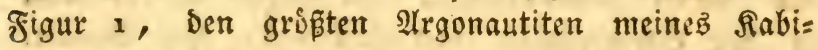
netz in Supfer fted)en laffen. Meliere befitze id won ber Jrt, allein fie fino alle fleiner. (5r) ift ourd)aus werfteinert, er beftano aus einer Ealf = ober thonartigen Naterie, Denn, wenn man ily naß macht, bat er einen thomartigen (beruch). (5re ift feft und yon grauer, gelblid)er Farbe. Nod) fann man

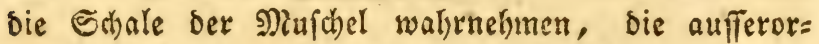
bentlid) Dinn, faft wie bie ber IBßafferidgaufel war.

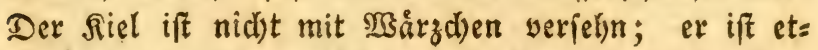
wab glatter und einfacher, alb bie Seiten ber $\mathfrak{M}$ hu= (d)el, bie mit Furchen, ober nah an einander ftes henben Streifen, weld)e eine frumme, wellenfurs mige Bieftalt haben, in einanber laufen, bejekgt fino. Şon ber Seite bes Rielż lyer treten furze, Dajwifhen laufende Falten regelmåpig unter bie ans 
bern. Die Deffmung oder ber Muns biejer Mufduel, ift langlich. Sie ift boppelt fo lang, alz ber librige

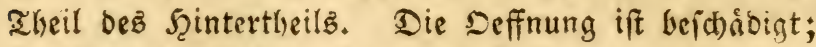
fie ift unfenntlid) uno es waire (it)wer, bie wahre Eage ber Shren anzubeuten, die indeß da gewejen find; Da aber bie Muicteln ber alrgonauten åuferft zerbect)lich finb, fo glaube ich nid)t, D.aß man fie

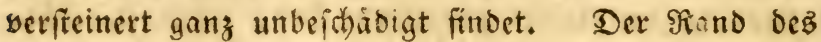
Munbez bey Denen, Die ich befitze, ift immer zeks brod)en. Dicfer Ilrgonautite ift brittehalb 3oll lang uns ziwanzig sinien lood), bie Deffnung ift foft zwen Zoll lang und fects finien breit. Man fieht im Mittel= punfte ber Nlufchel eine (d)wache IBinbung, bie wåkreno bem reben bes Ihiers, bem fie angehiorte, zum Iheil burch bie Shren bebect war. Sal fand fie an zwey veridliebenen Drter in Der Tormandie, bie fleine anderthalb Ricucz von Divez, bie grópte yon biefen Argonoutiten, bie Figur 1. vorftellt, in ben Eteinbrichen von Eaumont, bey Bouille, einet fleinen sier \&ieues yon Rouen entfernten Stabt. 


\section{Der geftirnte 2frgonaltite, *)}

L'Argonautite étoilé.

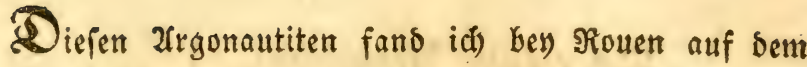
frantenberge in einer unermeslid)en Sdjid)te von Echiniten, Meerigeln ober Subenfteinen, Ilufterftei= nen, mit einigen ebenfallz verfteinerten $\mathfrak{R}$ ujdele sermifd)t. Şlore Subftanz iff falfartig und thonnid)t, wie bie bes faltigen 2lrgonautiten, aber bie Farbe if weniget grou und gelber. 2luf bem Berge Renard (Fud) bुberge) ift fie nod) gelber. 2luf ben Bergen fammelte ich ein Dutzend von bergleichen 2rgonautiten,

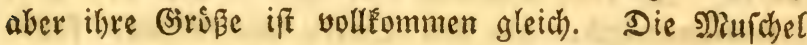
ifte ein = und einen balben zoll lang und einen 3oll hod), fie liegt fellyr feft in Den Steinlagen. Der

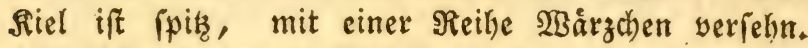

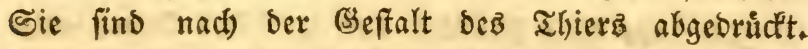
Die Streifen, oder Furchen, sie feldr fein find, lau=

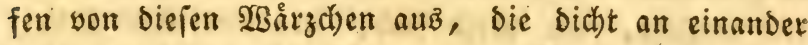
ftehn, uno wie bie åålne cinct Sảge geftaltet find. Itber bieje Streifen, bie einander gleid) find, ver= lieren fich auf ber Nitte Der Seiten, und exftrecten fid) nid)t biż zum 2 Bulfite Der Shren; im Gegentheif nelymen fie ba unterwártz bie Geftalt eines Sterns an, beshalb babe ich ihn aud) ben geftirnten 2 (rigo= nautiten genannt. Seine Deffnung ift vier Rinien

*) Traft XLI, Figur 2. 
breit uns adyt finten lang. Die ringe ber SMin= sung find in bem Mittelpunkte ctwas zu merfen. Diefe Nuifhel, waz man nod) in ilyer Seriteines

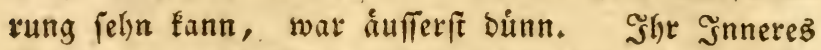
if EalEartig criftallifirt. Die Dhren uno ihre 2 Bulfite find weit fid)tbarer, alz bie Des faltigen 2irgonaus titer.

\section{Det gelielte 2rgonantite. *)}

L'Argonautite caréné.

Diefe nieblide Muid)el hat fid treflich exhaltert.

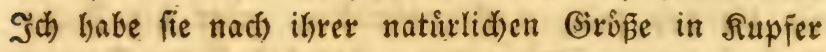
fted)en la pen und fonnte nur ein Exemplar erhalten. Man fiebt es auf ber ein und vierzigften Tafel, Fi: gur 3. Int bem Eingnnge ber Etrinbrůche bez St. Eatharinenbergz, wor ben $\mathfrak{I}$ horen won rouen, fand ic) fie, in einer balb freiben = halb thonartigen Maffe.

Sd) habe Diefe Nuidjel ben gefielten 2rogonauti=

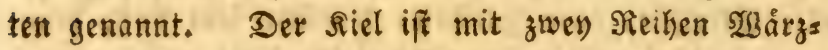
d)en vericlyn, bie breit finb, yon cinander ftels, und ppith berworragen. Die Seiten ber Mujd)el find melyr platt, alz aufgeblajen. (ङz laufen auf beríl= ben, weit yon einanoer entfernte Streifen hin. Fad ber Eeite bes $\mathfrak{W}$ ulftes bin, nalin fie fich aus bem Srunbe einander mekr, weil ber \$aum ba fleiner wirb. Die Deffnung ift foft vieredig. Der Şinter= theil ift felye erbaben und lápt bie singe Der SBin=

*) Iafel XLI, Figur 3 . 
bung fefhn. Diefer 2lrgonautite ift åufferft binn, uns

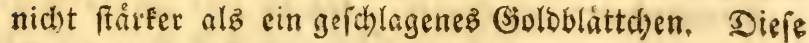
saucbel iff ifabellfarbig.

\section{Der glatte 2frgonautite. *)}

L'Argonautite lisse.

$\mathbb{C}_{\mathfrak{r}}$ ift wie eine Bondel gebaut, mit einem fpitzen, (d) neibenden Siel, nad) yorn hin und auf ben Sei= ten aufgeblajen. Er bat bie Groepere wie ein 3 wilfiouza ftůck. Eeine Sindung if faum bemerfbar, aber ber crhabene \̧intertheil ift, wie Der aller 2irgonauten, gewunden. Die Dhren ftehn fehr hervor und fallen nad) binten bin. Sid fand biejen Irgonautiten auf Der. Strape von Rouen nach St. Suin unter bem Miergel und Stcinen. Ex ift gelblich), falfartig, wenig thonicht.

Erfflirung Der ein uno vierzigften Supfertafel.

Figux 1. Dex faltige 21rgonautite won Eaumont, nah

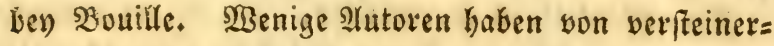
ten 2 rggonauten gefprochen. Sie find felfe felten. Diefer ift ber grōpte, ben id) befikese. Seine Far= be ift grau.

Figur 2. Der geftirnte 2 (rgonautite vom Sranfenberge und Fuchsberge bey Rouen. Gri ift wegen bes Sterns, Der Den Mittelpunft bildet, felyr merk = múrbig. Ex iff gelb.

*) Tafel XLI, Figur 4. 
Figur 3. Der gefielte 2Irgonautite yon bem Sit. Cas tharinenberge bey Rouen. (5z ift cine ieltene 2 er= feinerung, nur eine Nujchel ber sirt habe id bis ielzt geielin. Seine Farbe ift weís.

Figur 4. Ein glatter Alrgonautite won Dem Felien, Die am 2 sege zwijd)en গouen uno St. Suin ftelyn. Seine garbe ift gelblid).

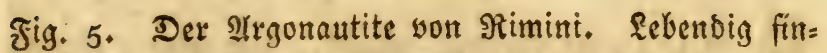

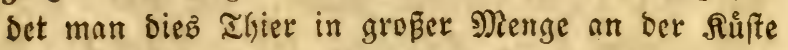
won Rimini. \$b er gleids, verfteinert ift, fo hat er bod) reine Garben belsalten. Der Grund ift gelb, rotrigeflammt.

รigur 6, uUb 7. 3̧wey Drbuliten von Lamart, bie Solbari in bem Cande bes mittellåndifhen Mree= res̉ fano, die man mit den 2 Immoniten verwed)= reit bat. Cie find ourd)fichtig.

Figur 8. Eine bejondere Irt Drburiten, bie Sol= Dani in Dem Sanbe und ben Salmammfteinen son fiborno fand. Eie ift pelten. J占) traf fie in bem Corallenmoore auf Eorfifa, aber nur jelten, an. Die Purdel ift ourdfifdtig, etwab perlemmutter= artig. Zlle bren Irten fino felfe vergrósert bar: geftellt.

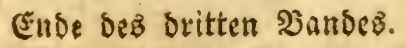


R.27 B. III. S.15

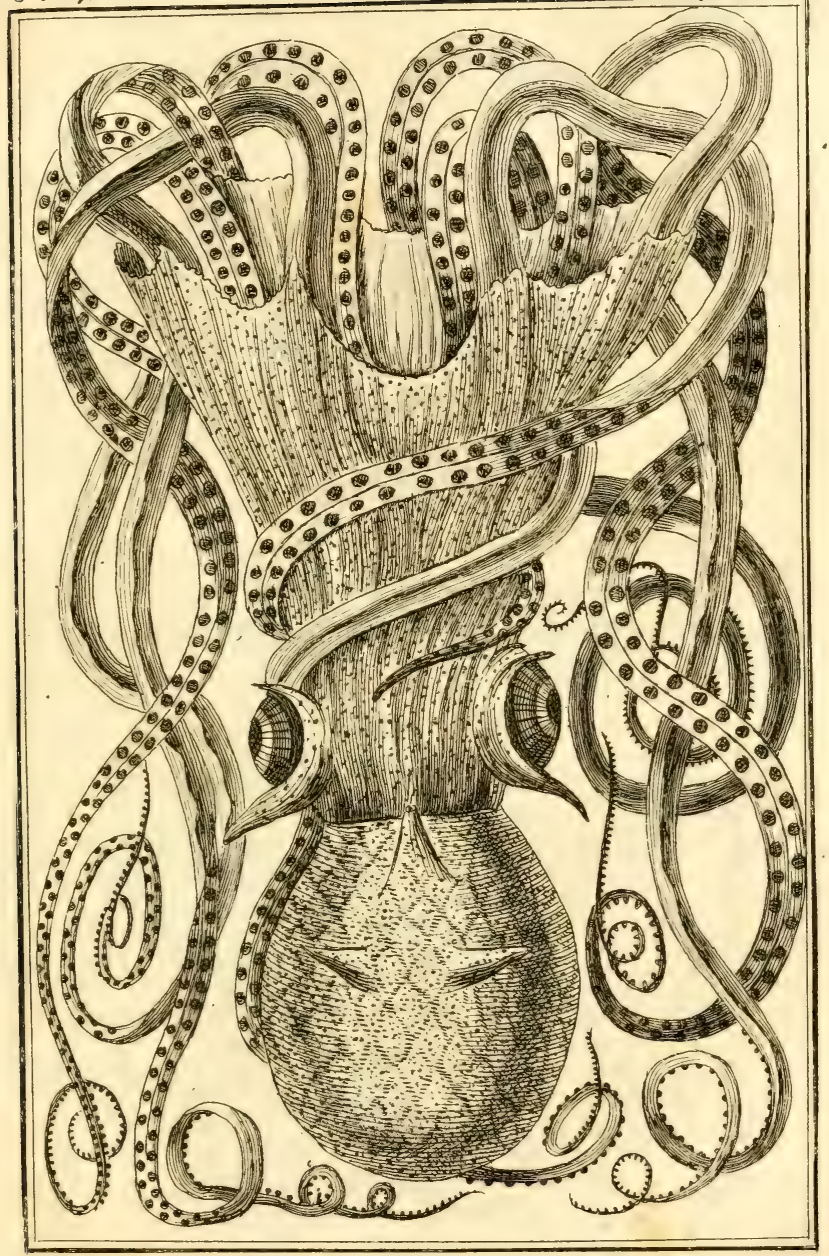

Le Poulpe fraízé. 


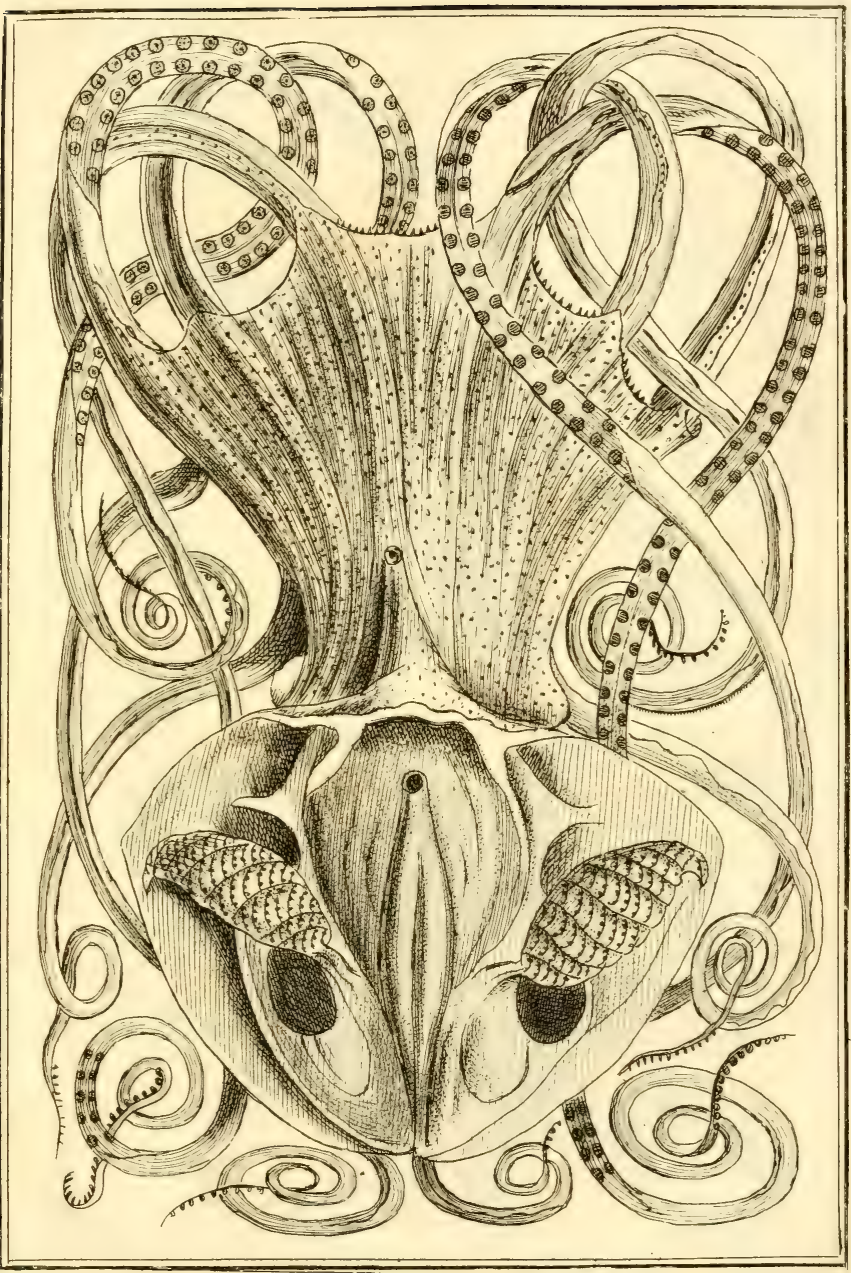

Le Poulpe fraizé, vu par devant 


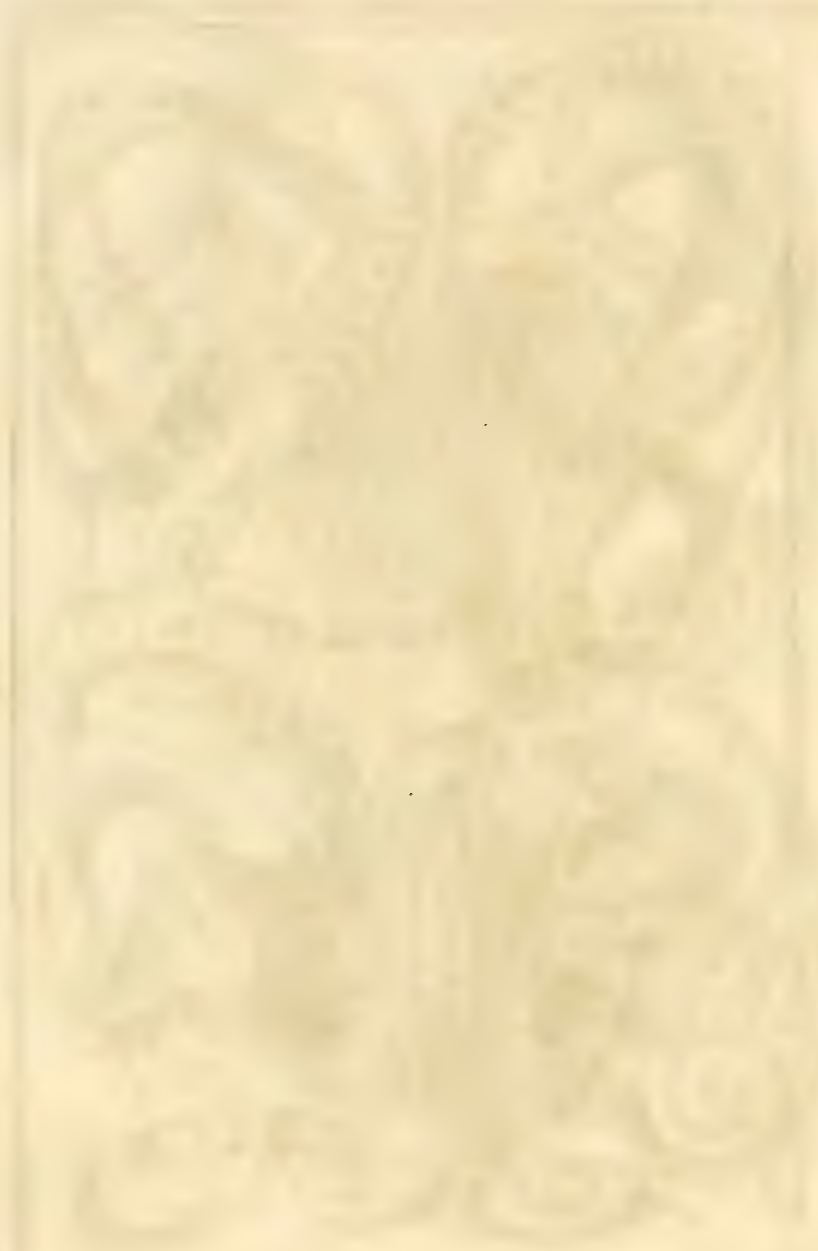



P. 20
Bd III. 21

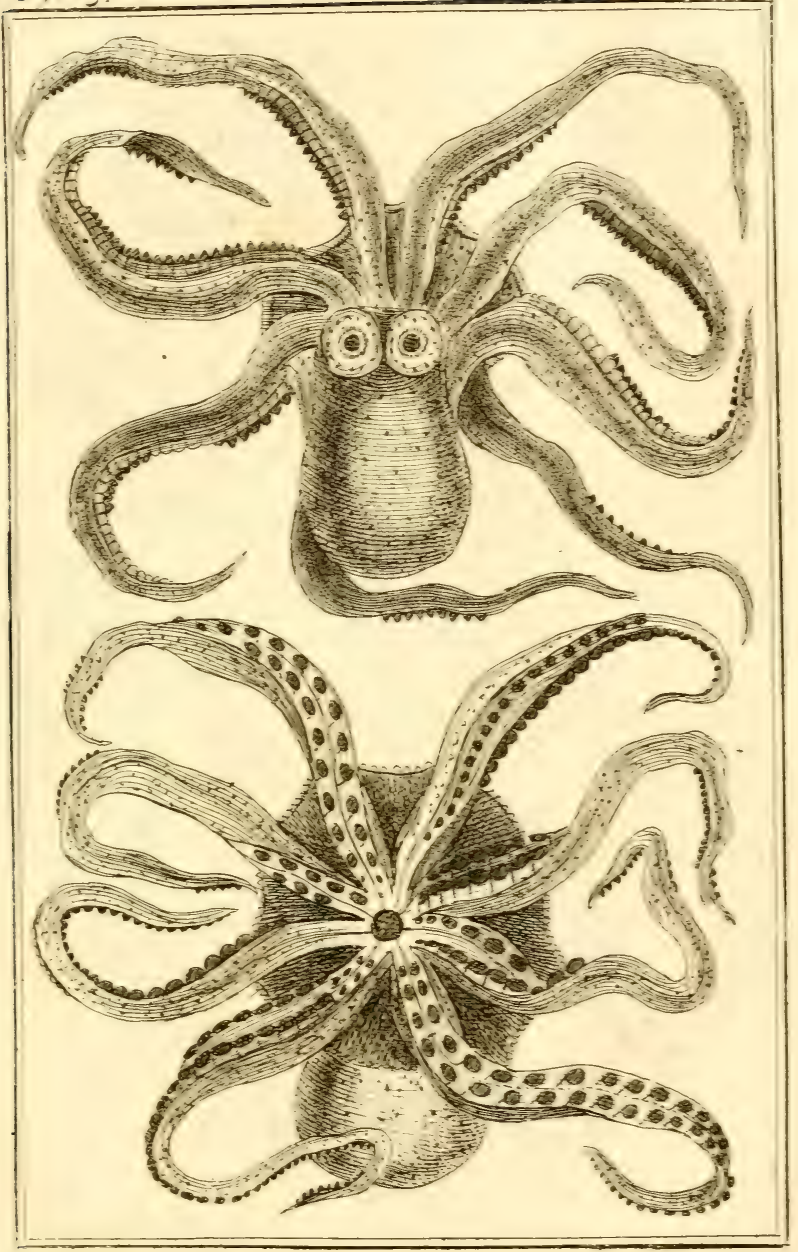

Le Poulpe Crasulenx. 



$$
\text { (1) }
$$




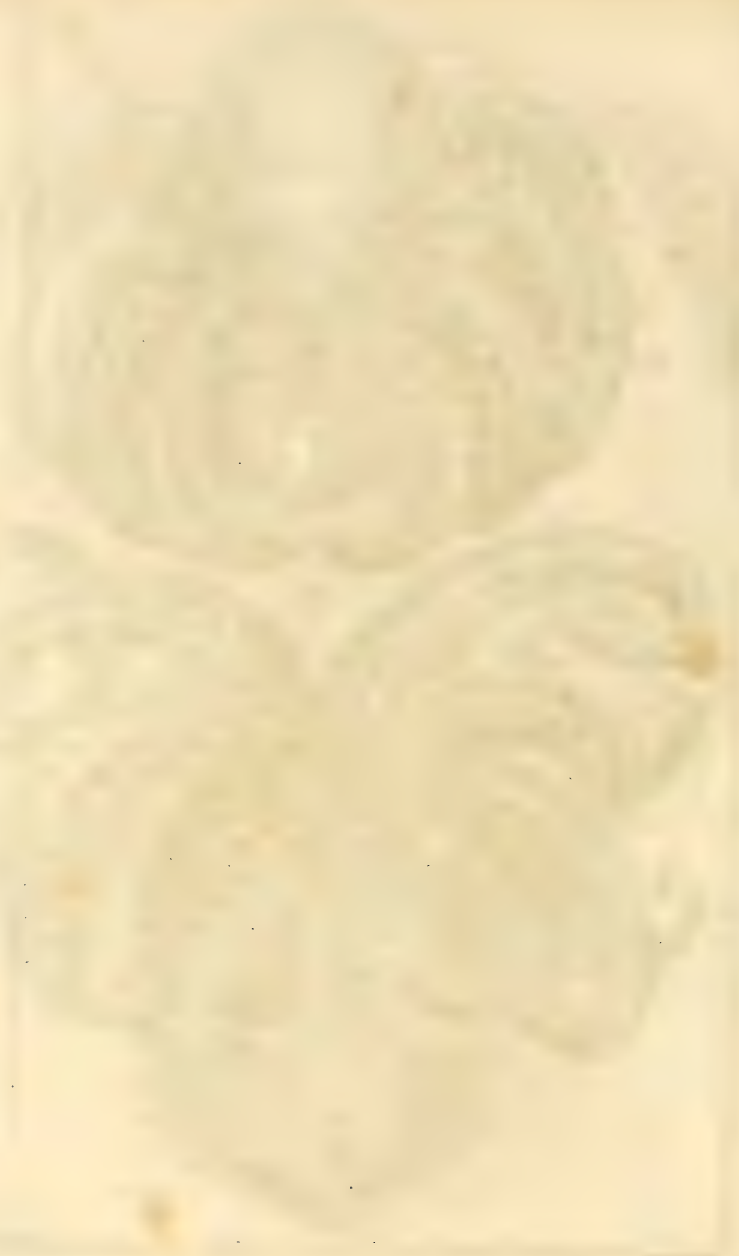




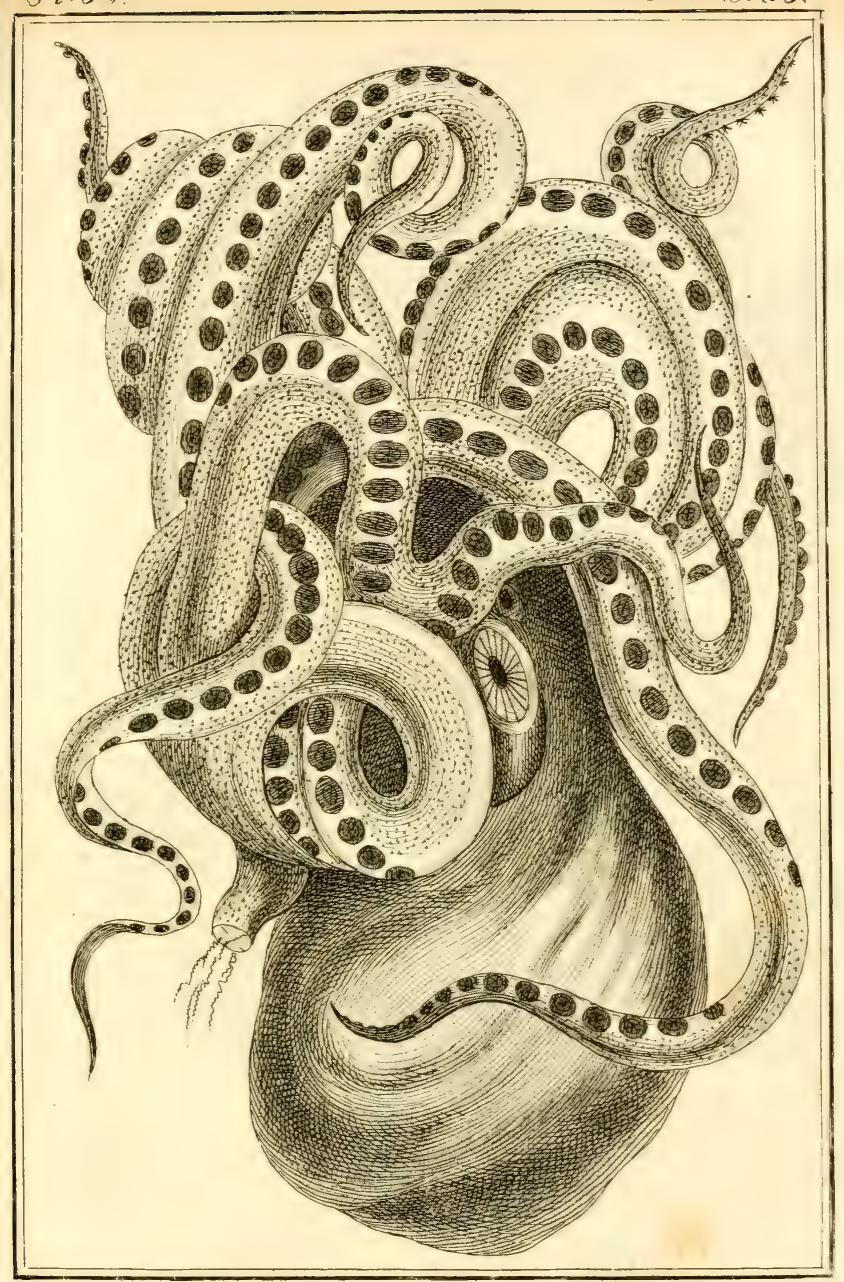

Le Poilpe J'Alarovonde 
$\sqrt{2}+x^{2}$

s

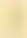




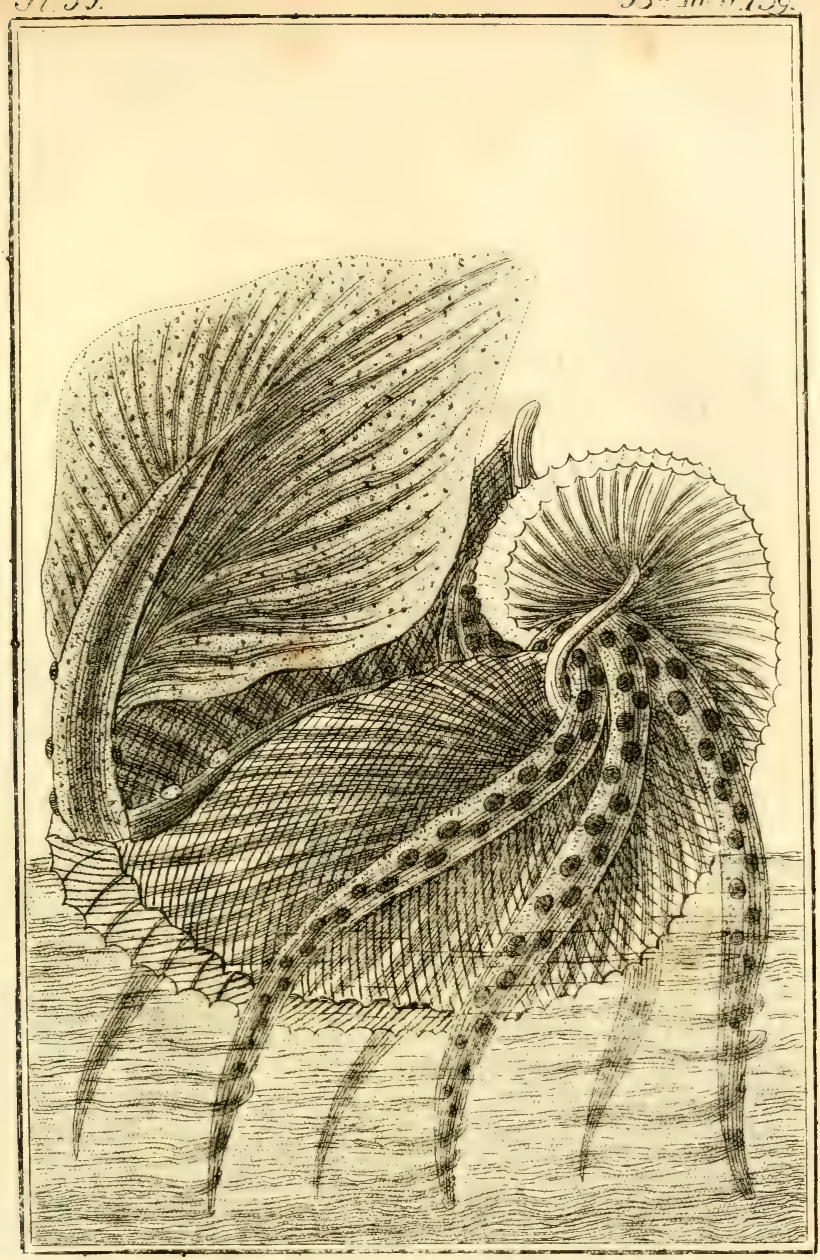

L'Areformonte l'apuracé. 



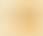




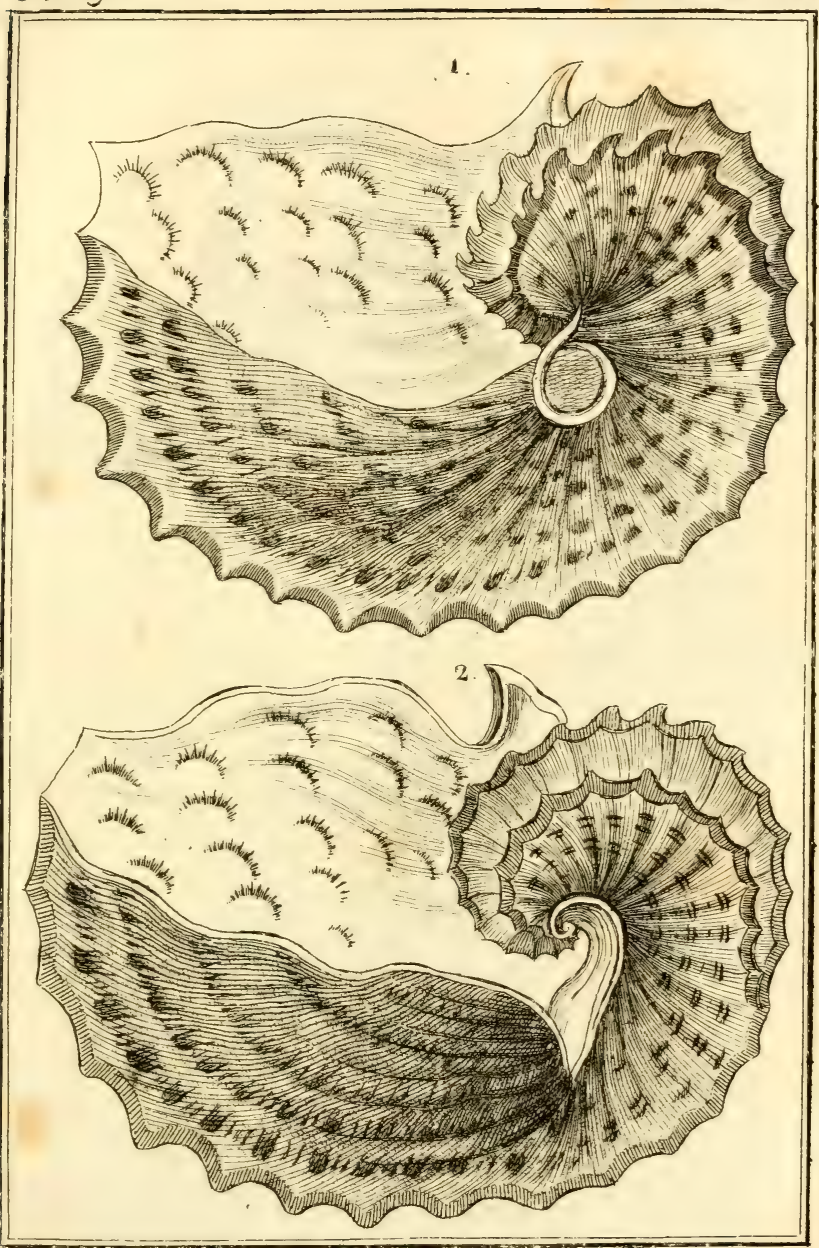

1. Coquille de Liargonaute a grains de ris.

2. Autre Coquille a orcilles evasées. 
: 

D. 40.
Bd III If.62

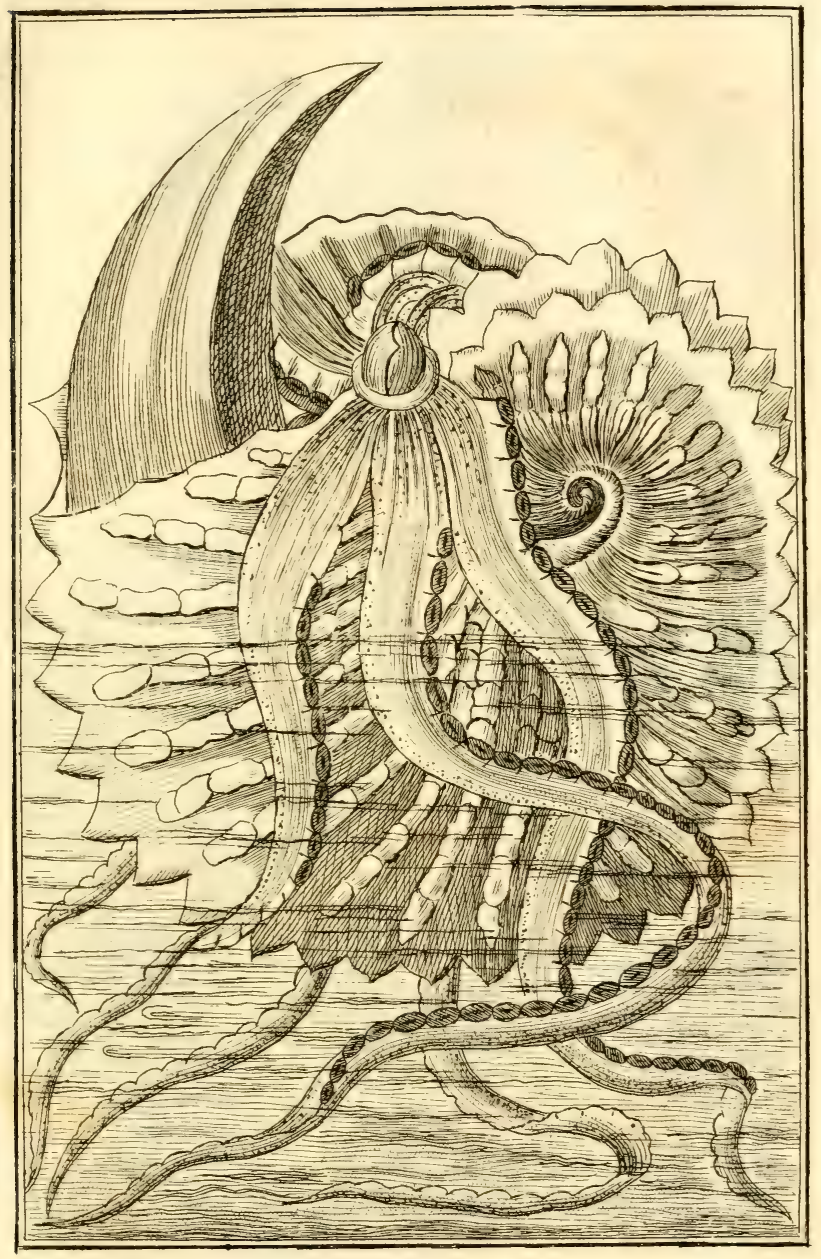

Argonarte a filloms bisés. 



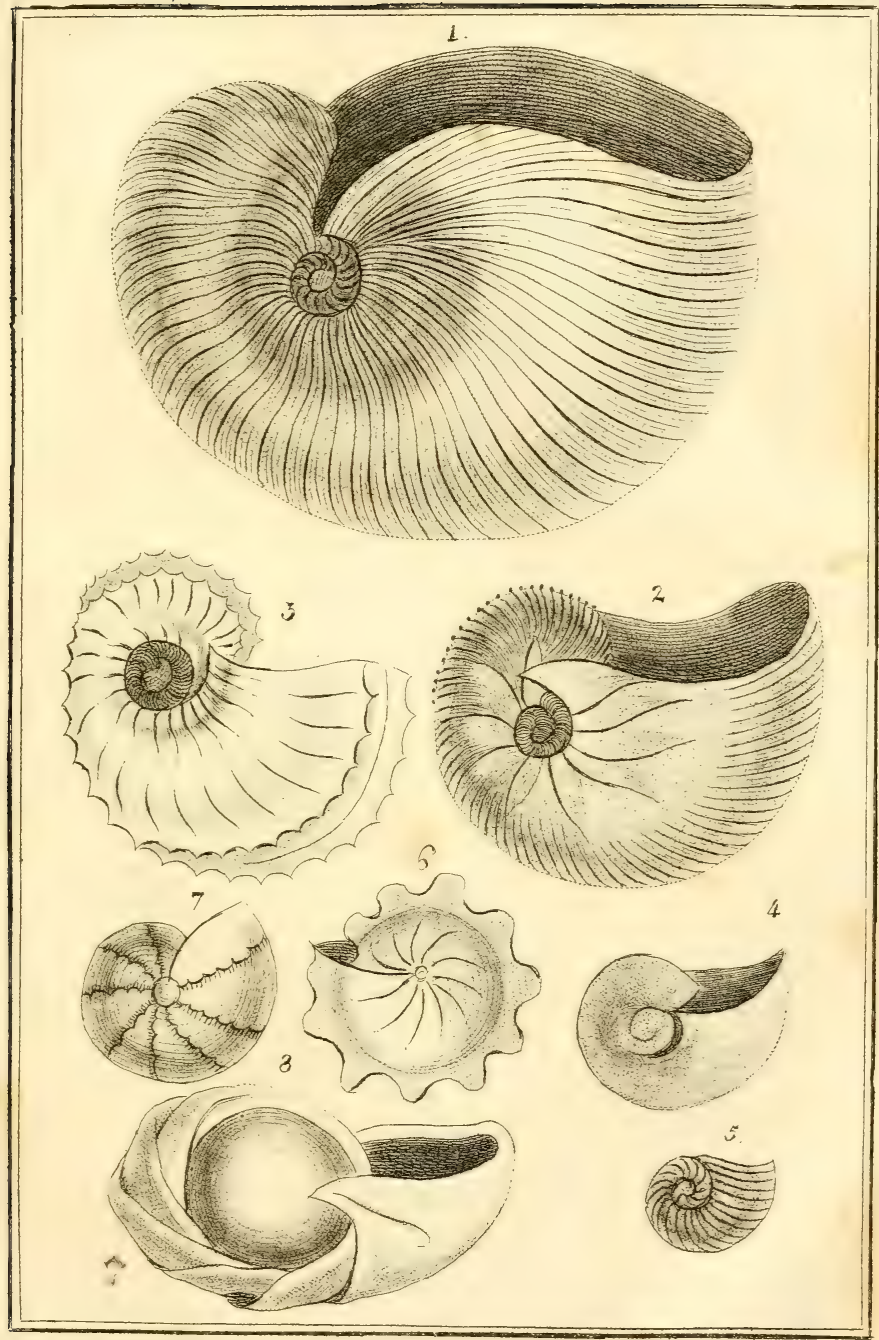

1.2.3. 4.5 Asgonartiter.

6.7. Orbulictes.

8. Autre Orbulite 




\section{Dent}

allgemeine und befonbere

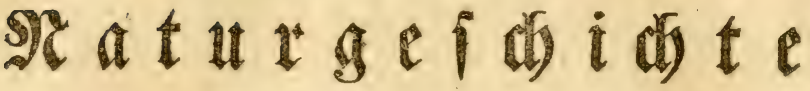

Det

\section{SGeiditwitmer (Mollusques)}

a 13

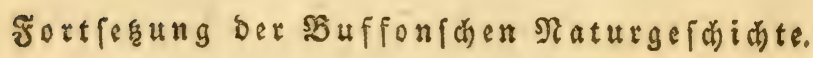

Mit e inigen

2nmertungen, Erthuterungen uno 3ufâken

h้อ $\boldsymbol{x}$ a

v.on

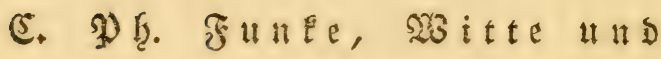

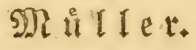

2 ierter 23 an

Mituieren $\cong$ uf

Sุamburg und 2yltona,

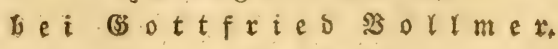

$x 808$. 


\section{eccreres von situfon}

allgemeine uns befondere

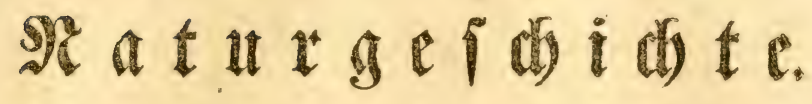

Fortgefert

son einet Beferlidaft won (Sielebrten

uns

berausgegebeแ von Sonnini.

24us̃ bem Frangoffichen uberfeģt uno mit 2tnmerEungen,

(Erlåuterungen uno sufígen vermebrt

vo.n

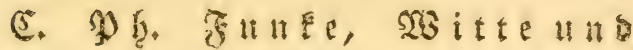

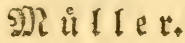

Bierter SBano.

Sitwieren S S p fern.

Santourg uns 2rtona,

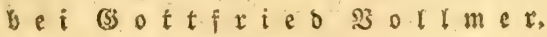

I $8 \circ 8$. 



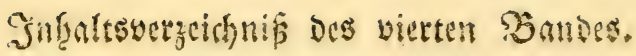

3u allen Beiten baben bie mifrofcopifden (Bes

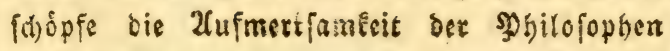
auf fith gerogert.

Scite 2

X'rgonaute yon Rimini.

Boulangerz SBeobactungen iber die mifroftopis fhen Murucheln

Erethrung Det XLII Supfertafel

Durchfictige Nautiluffe auf ber XLIII Rupfer: tafel 
\$bepartibung befelben uns grope Eeltenbeit Esite 24

D' 2rgenville bat biefe Mufönt justif in Sitpfer fateden lapen

Sie fómmt vont 2 mbroina

Der Eapitain Sctron

Erklianng Der XLIII Sitpfertafe!

Die Juermutterfonedé fegetno auf ber XLIV Supfertafel

Dev Nautilus auferbalb Dev SMrufert, auf bet XLV $\mathfrak{2} a f e !$

Iriftoteles Eannte ifn

Delon erwaibnt feiner unter ben Sieuern gueeft

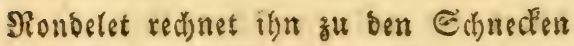

Siumpluts ift ber sinzige, der bejtinmte Sonnt= niße ůber bies ahier liefert

40

3Debon und Einnée baten alle Enmmerigen Mu= (d) 2 In unter cinander geworfen

SBefchreibung bet \$ुertmuttermu[chet

Die mit Sd)ropifoppen yerfehenen Z(rme bes Mols lubts 
Er formmt nid) von ben antilen

Er lebt in Gefellforaft

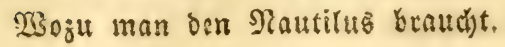

50

Serffeinerte গautiliten

71

Bon Eourtagnon

74

Son Esrignon

${ }^{6} 6$

S3on Ehaumont

$3^{6}$

Bon Iurin

78

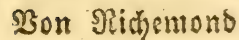

79

Son St. Zegibius b. Btuffet

80

Bon Şaure

81

Bon Rouen

83

3on Mondsberge in Egampagne

84

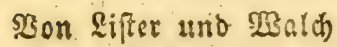

85

Bon Malta uno Eaen

86

Sadjez গRoires in Der Nermandie

86

Bon Ehatillon in ber Dauphine

88

Som St, Şetersberge bei Maftridts

$9^{9}$ 
Bon Melsbroct und Lo

Son Boutornois

Son Rontbaro in Bourgogne

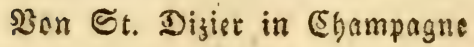

Won $\mathfrak{B}$ offtin in Der Ethrois

Son গaniut

Bon Neufçatel in ber Eưneiz

Finore lies einen Rautilub yom Ëtteręberg in ภupfer ftediden

Bayer begoleid)en einen andern von zltoorf bei \&enfenberg

Ein Nautilus von M̧eubing bei NRimberg

Erklinung oer XLIV und XLV Iafal

Der Rautilus mit Dbren

Ee fommt yon ben SD?albiren

Sbefdrieben von Fauannes

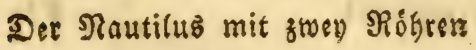




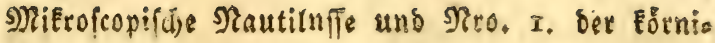
ge (Exaule) Sautilus auf ber XLTII זafel, Figut 1.

Suerit yon \$olancuz beid)rieber

Der Dornige Nautilus

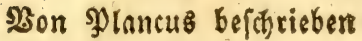

Der Nautilit von Dak

D' 2rgenvilfe hat feinet ertwånt.

Det wellenfortmige Rautilit

Erelarung ber XLVI Tafel

Der mưkenformige Nautilit von Namur auf ber XLVII anfel

Det গautilit mit ber Etiderei

Der Nautilit von Narbonne

Erelårung Det XLVIII Tafel

Der auegeidnweifte Nautilit yon Ȩina

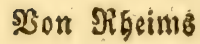

Det nabelformige Nautilus

Erelérung bet XLIX זัafet. 
Der triangelfónnige Mautilit

Der georictete Rautilit.

2 und 3 .
Seite

142

Iafer I, Figue

149

( ) 


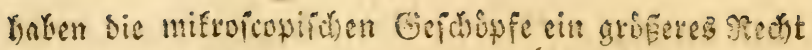

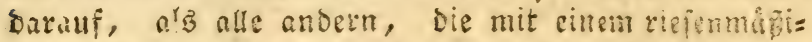
gen Bjfieberbau begabt fins. Sirenu siefe flemen

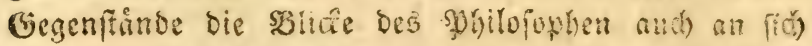
zielsn, fo feffeln fie nidit in bem Grabe bie Thif=

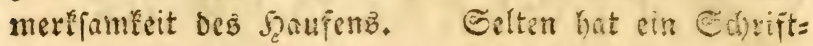
fteller liber biefe Materie gefwredsen, olste vortier feis

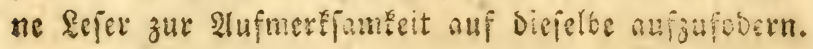

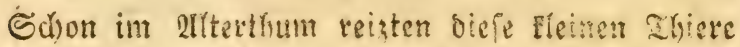

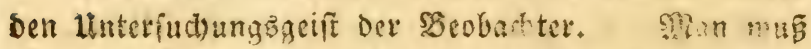
fich) beyn Pachiuden und bem Etudum bicjer Ihiet:

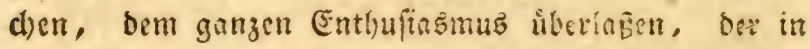
bent Girabe aufgeregt wird, a!ß̉ man cine neue Ents bectung in der fo verichiedenen formen, ifreen fo be= fondern Sitten, in ihren fo sielfachen srganen uno ihrex erftaunenzwerthen Menige mabt. Ser Menich, svie ez gliniug fefye ridutig fagt, *) berwundert den Elephanten, feine breiten Echultern, ben ungeheu= sen Racken, ouf bem man Jiturme baute: ei ligt

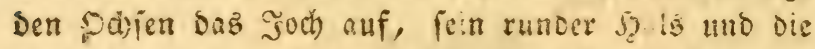

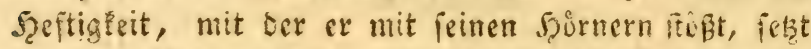

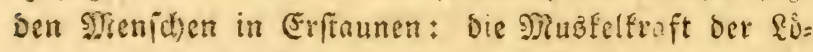

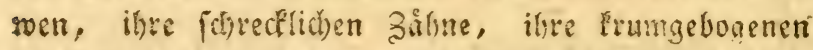
stallen, fo wie bie fratternoen shiánen, zwonen

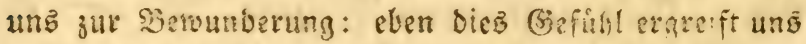

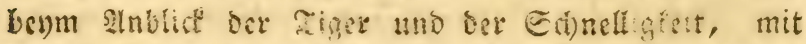

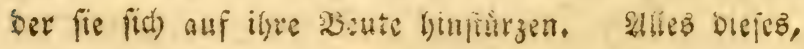

*) Plin. Hist, nat. "'j, II, cap. 2 . 


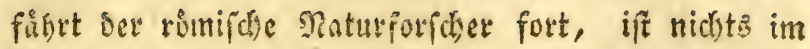
Dergleith) mit ben unentlid) fleinen Ifieren, wo (ich Die Patur in ifres ganzen \$ollfommenheit gezeigt hat.

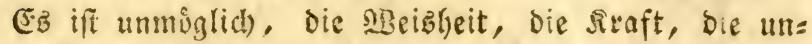
erElirtere Sollfommenheit ju beareifen, bie bie fdhaf= fende Miad)t hier zacigt. SIio find ben biefen Eleinen Thieren bie Sebålter ber Empfindungen burd) bie

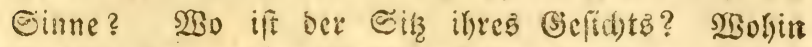
fino die Drgane bes Sefdinadiz verlegt, mit Denen fie fo vorzínglid) begabt find? 230 findet fich bey ifinen

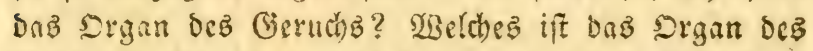

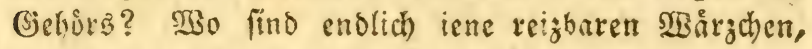
Die bey) ocr Feinheit ilyres (jefully eine fo wid)tige शolle fpielen? Faft alle find mit furchtbaren 2 gaffen uno bem Zerfiónrungzitriebe verfelyn. Einige trad)ten nach) bem Solute ber Thiere, auf bie fie immer auf= gebrad)t find, andere żernagen bie hârteften (Eid)en, bie fefteften Etrine. 2ullentlalben bejaleunigen fie

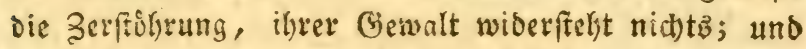
Dennod) fielot man biefe åtrferfî fleinen, aber in ihrex

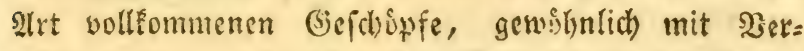
adbtung an: aber bey ber Betrachtung ber Natur

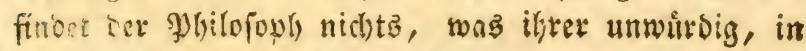

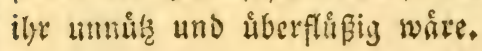

Unter biejen naturltiden Errgeugniß̧en, bie in f̧in

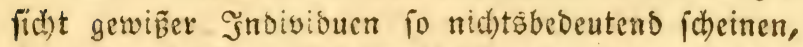

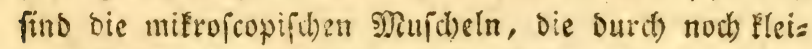
nere Mollusken, als iene felbit fino, gebaut wurben und weldhen fie zur Bedectung oienen, ohnftreitig bie mertwurbigften und bewundernswertleften: fie fpielen bey ber aheorie unjerer Erofugel, auf Der fie burch 
Didite Saget gonte Cutridje beverfert, cine widtins

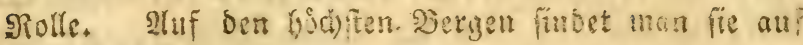

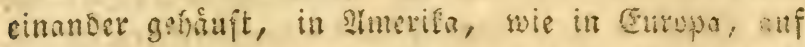

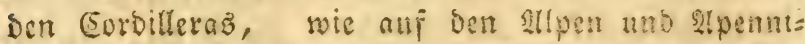
nen *) Sair werben alf biefe DRaterien wieder zu:

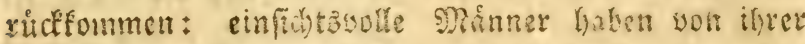
wunberamen tnemegficheit cine teberfiate gu geten

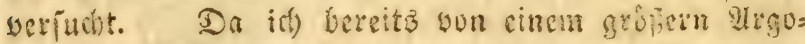
nauten, ben man auf Dem Gejate son Samini les bend und suf ben Syeiben in ber Geneno von arnt= werpen verffeinert findet, gefprodien babe; fo werbe

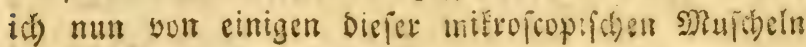

*) Dubitarunt nonnulli, an praealti $\Lambda$ pennini montes in Thuscia ex aquis marinis originem duxerint .... his enim, quaecumque extiterit causa, fere omnia carent Apenninorum strata. Contra, haec ipsa saepe redurdant marinis corpusculis minimis in editissimis locis, ut in co, cui nomen il foresto prope scaturiginem perennis fontis, ex quo Arnus ortum ducit, 'et in ipsis rupibus Alrerniae montis, in illa ejus parte, quae dicitur la penna: ibi, irquan, vel integra apparent strata lapideo-calcaria, aut arenaria, utraque aliquando conchylifera conchyliis minimis. Quo sane fit, ut jure merito Apenninos nostros, magna salten ex parte, ab aquis, olin genitos judicemus." Soldani, Testaceo, tom I, Prolegomena, pag. 11 et 12 . 


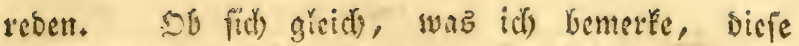
Alronatuten pelle vermetien, was die Rienge berfel= beu anzeigt, fo find fie bods nicist mit ber Sermels= rung vieler anbern fleinen SMufdeln ju vergleitben, Die fict unenol th zarletreicher fortpflanzen, als bie

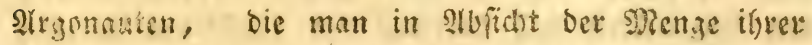

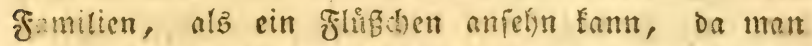

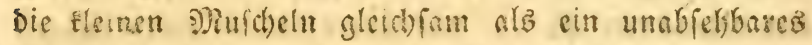

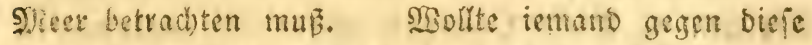
ISbablyeit 3weifel erfeben, fo fonnen ifn rebenie Eewele wiberlegen. Eoldani, Cuperior uns 2 tbt Der Guimale enfer, befaunset in ciner gedructert

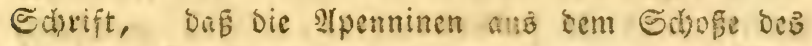
Dieerç hersorftiegen; uno der angenommenen Mei= nung ungenditet, bie bie verfdiebenen fagen in bie= fen Sergen nicht zugeben wollte, fand $\mathrm{er}$ an werfochie= Denen Drten, bald fandige, buld verffeinerte Sist=

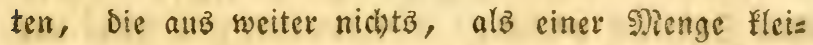
nev Mufdeln beftanden. (Ev fobliest Daraus mit

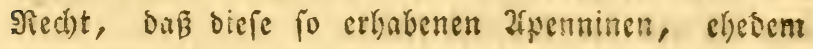
unter bem 2 Saffer lagen. 
3on einigen vorgélichen Zrgonanten.

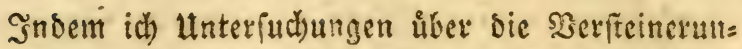
gen anfterte, bemerte ich, bus eine Mufalsel exiftirt,

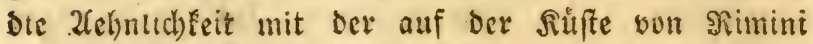

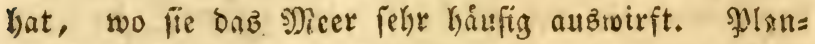

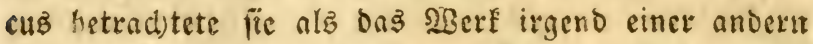
Shichel. Diefe Dieinung wirbe ich angenommen baben, båtte ich) bicje verifeinerte Nuichel nicht mit

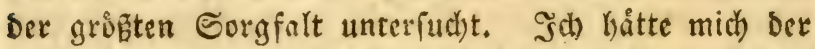
von Plancus befannt gemadjten figur nicht einmal el= innert, und fie zu Den Serfteinerungen gerechnet, zu Denen man feine 2efonlid) feiten finbet, Die man Mrillionenweife auf ben Sandiftichen bey ber Stabt Intwerpen antrift: allein id) fand in bem 2 Berfe won গुlancus biefen 9 lrgonautiten in feinem naturli= d)en auftande wieder, ben wirflid) fein alyter vor Dem Zuftanibe ber serfteinerung verloren hatte. Setzt rebe ich yon bet Mujthel felbit.

Sd)eud)zer hat in feimer Naturlefire, im etfen Sande, auf Det LV. Supfertafel, Figur 6o. eine

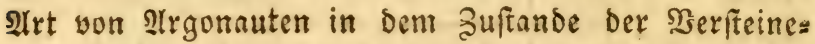
rung vorgeffellt. Er fagt: biefer verfteinerte Sive= per ift eine Mufdal mit bem Siel, ober zuruedgebo=

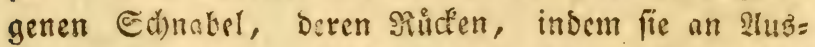

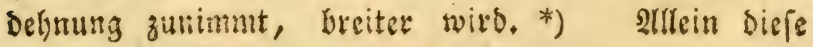

*) Scheuchzer, Biblia sacra, vol. I, pag. 52. 


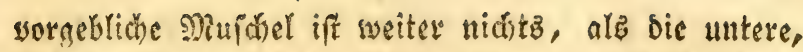
ifolirte Silappe einer 2 let werfeinerter Zufterid)ale, Die man in großer Nenge auf Dem Petersberge bey Mafricht findet, bie ůurigenz burd) bie auf ber Eeite zuritugebogene Epithe felfe fenntlich) ift. Die

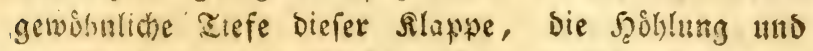

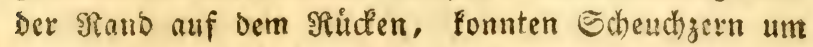

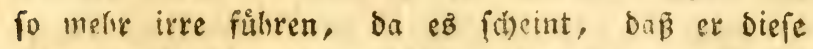
Ill xpe olyne bie andere Szailfte, die ihre zum Dectel Desat, vor Mlugen hatte. Nir ift ca Darum unmig=

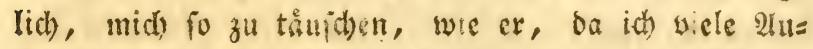
ftritititen vor mur habe, bie fids in meiner Samm= lung befinder, und oie ich faft nlle felbit fammelte.

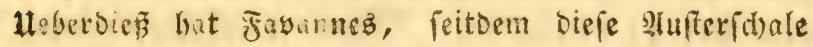

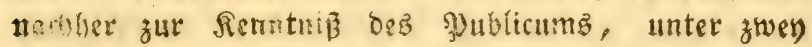
Infichten, gebradht, bie eine feellt fie von hiuten, in ber sage, wie fie Scheudzer befannt madhte, bar, die andere von oer 3 zorderfette, burdh die obez

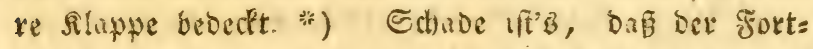

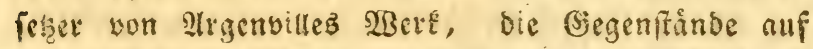
cine tabelbafte Mranier barftellt, man erthâlt burd) Die 3cidnungen keine ridjtige Borféllung von boc

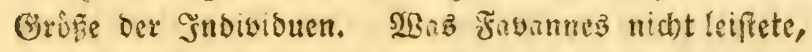
ift ourd) Fuins Sanit = Fund auşgefullyt, in bem flimen Berke ůber bie ßerfteincrungen, die Der \$etersberg bey Daftrid)t entbailt, wo obefer weife Geologe unz bie untere Slappe biefer slufteridale

*) Favannes, Figures, deuxième planche des Fossiles, lettre $\mathrm{E}_{2}$ et 3 . 
mittbeilt, bie ijolint ift, wie sie bon Gibendyzer, son innen gefelin uno in ibrer nativlid)en Grobe ge= fodber. Die iritte und fiebente Figur berjelben Supfert:fel *) fillt uns zwe!s anbere alrten von গllu= fterichalen bar: wor biefen beyber neuen Jubisiduen,

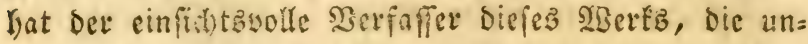

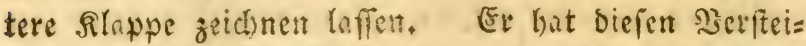
nerungen Die wote Etelle in ber Mufdhellebre cinge= råumt; Denn, indem er ifuen Den Nafbmen Siarif

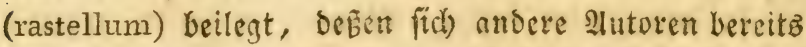

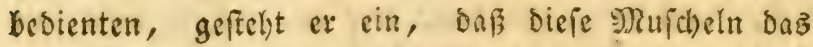
9)ittel zwiflen Den Sluficrn uno (Sruphiten **) be= Gaupten, uns bas cE recht war, fie alz cine befon= Sere 2lrt zu betrad)ten. SIBaz bie Rlawpe betrift, bie et unter Nummer 3 . vorftellen liế, ob fie gleids

*) Faujas Saint - Fond, Hist. nat. de la mont. de S. Pierre de Maestrich, planch XXVIII, Fig. 5 .

**) Figur 5. ift sine 21rt von Sarft (rastellum) Der jwifoen best alufern uno (Sryphiten in oer Mitte ou febn forint.

Figut 7. Der Ratif falt vout Iriangelform. 23eiter obsm, ซig. 5 , frelt et sine merfwirdige

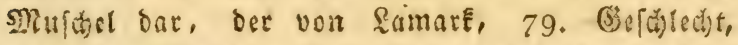
unter Dam STahmen Saliotioe angezeigt, fris áfn= lic). (Faujas Saint-Fond. Hist. nat. pag. 338 et 119.) 


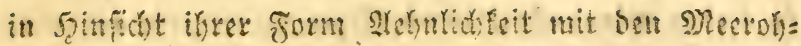
ren (Saliotioen) hat, fo nafit fie fidi) ben formen Der beyben anoern slufteriü)alen, uno ith felge fie

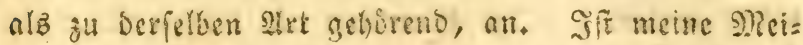
nung, sic mir ammelmitid fofeint, ribtig, fo hort aller zmeifel it Stofidet bicfer solufichel nuf, Deren cuffere Beffalt in ber aliat pomberbar iff, uno wir baben ban isye eigentlicbe Cetelle gefunden.

Det hischfen Esltenlyeit ber Alrgonnutiten unge=

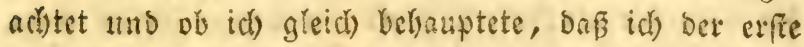

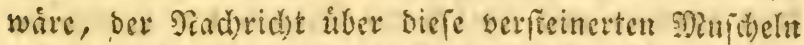
gab, fo fann man mach einer Stelle Şertranús*)

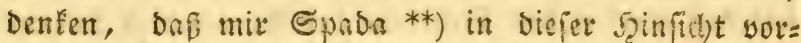
angegangen ift, wenn man bejonderb bebenft, mit

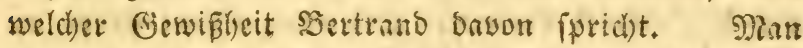
findet, fagt er, nur zwen 2reten werfeinerter शau= tiliten: Die erfte ift felse gemein, Die anoere fehe felten. Der sautilite olye befimmte ober fichtbare Sammern, ift yon Eproa befürieben, als ein eins fammriger Proutilus, mit cinem foft runben Ricten, gefchuppt 2c. Stbenn wir nach ben Ilnjeigen, bie fo

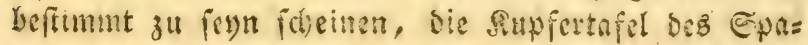
ba, bie ourd) Sertwan nugeseutet if, sufichtagen,

*) Dictionair. Orycthologique. tom II. pag. 69 , col. premiere, art. nautilite.

**) Spada. Agri veronensis Catalogus corporum lapidefactorum, pag. 20 , Nro. 2 , tab. 5. 
fo finsen wir anftott eines Srgonautiten, cinell ser= fteinerten Sautilus mit frumnen Sammern, Der zu ber slrt berer gefort, woson wir in biefem Banoe reben wollen. Die Sammern yon biefem Pauttlus find un: fo fichtbarex, da ber inffere Ropf burd) bie Terfereinerung abgeftorben uno iebe Trammer bey bie: fem Snots:oumm merflid) ift: ez ftelit baher zu glau= ben, Daßs Epada, indem er auf Diejer Supfertafel Diefen vorgeblidien Irgonautter als Giegenfiute Der wahren Siautiliten auffellt, Die ibren Ropf bebseiten, bie nach ber stuffemfeite glatt forinen, Diefen (Son= traft benuksen und folglich bie Spuren Dex Sammern, als Strelfen ober Furchen anfihn woltte, bie fid auf bell Seiten ber Mlujheln Der 9 lrgonauten finden.

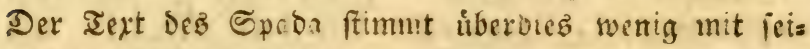
ner siupfertafel uiberein, und man nimmt ba wilye, Db ek gletd) auf Derielben nur funf शautiliten, und offenbar Den unter Nummer 2, bezeid)neten, anoeus tet, er yon allen fagt, dapi fie nur etne Sammer baben, (unius anfractus).

\$on allen ben Stutoren ift Sayer, Der Soln, Derjenige, Der iffentlich son verfteinerten Sistpern gefprod)en hat, bie fid den Irgonnuten am meiften

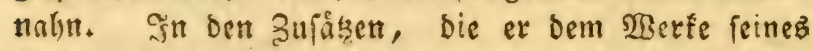
Sater *) beifugt, fieht man eine niebliche Serftei=

*) Ferd. Bayer, Oryct. noric. in Suppl. pl. XI, Fig. 4, et pag. 18. E maxime raro sulcatorum genere considerandus venit, Fig. 4. Nau. 


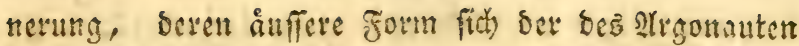
ungemein nalyt. Ex felbif vergleid)t ifn mit Dent,

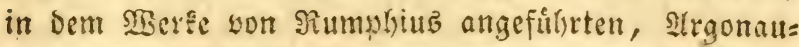
ten. (Tajel XVIII, Yammer 4.) Sie Sad) (d)eint mir indes nid)t entfdieben zu fenu, im Begentbeir bin id) einet entgegengefebten Peinung uno betrad)te Diefe 2 serfteimerung meflr nlb eit Almmonshorn, Dem fie wentgftens ungemein gleid)t, als citen 2ligonau= ten. Linabgefelyn ber fideinbaren Ringe der SBin= oung, ift bie åufiere Edjale, Die biefe Serffeine= rung beibebalten hat, bie ç verbindert, Daß man bie Sammern nidjt fefn fann, um fidi) felbft georelst, wie bey alfen 2 (mmoniten. Det Siel ift nud) nicht

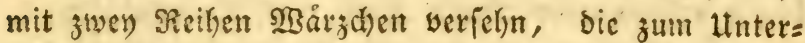

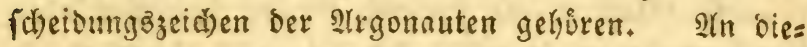
fer Serfteincrung entbect man orer Reiken Sunfte, diefe aber finden wir bey allen 2 mmoniten.

Sm Snork *) finde id) einell S(mmoniten, ber

tilites verrucosus striis undosis vel flexnosis. Et enim penes carinam erumpunt protuberantiae quaedam rotundae, verrucis animalium similes, unde agnomen obtinuit. Utriusque tam umbilicati laevis, quam verrucosi nautili picturas venustae tradiderunt. Listerus histor. Conch. tab. 552. Fig. 4, et Rumph. Amb. tab. 18, Nro. 4, quibuscum hi petrificati comparari possunt."

*) Knorr de Pet. vol. II, sect 1, pl. A, Fig. 15 , et pag. $4^{1 .}$ 


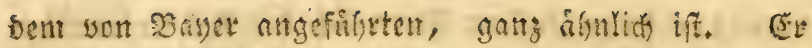
felbit bielt ifn fir cinen feltenen Irmmonten. Die Figut, bie ber şerfaffer Dnyon liefert, bemeift Dieß willig.

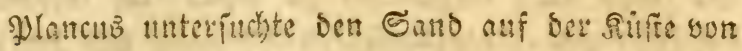

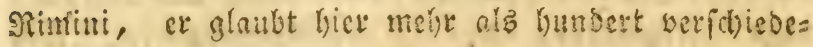
ne Arten mifkofcopifd)er Mufloblu entoed zu baben, sod) ganz vorfommen, die nods unberannt waren und fid bafelbit in eimet fo srofen Menge fanben,

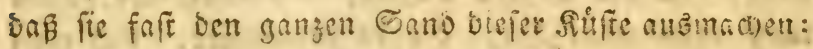
benn in fechs Itnzen Sano fontute cr mehr als gooo

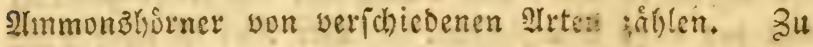

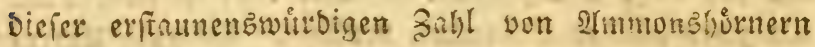
rechnete Jlancus die andern fleinen Najüeln ober Secturperchen nid)t mit, die bie fed) 1 Inzen Sano entbielten. Ev verwanote weit wenger Afufmerlfant= feit auf fie, alb

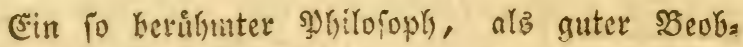

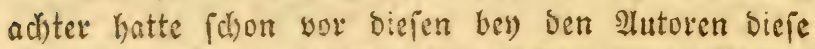

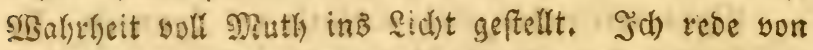
soulanger, ber alb Stuffeher ber SBruden uno Egauffeen, Gelegentieit batte, viele Erbftrid)e zu unterfuchen. Nar mit Erffnumen betrachtet man bie Beobuctutungen, Die Dicfer geiftudle Mann beym 2 n= blict Dex Cteinlagen anftert, Die gariz won mifroficos

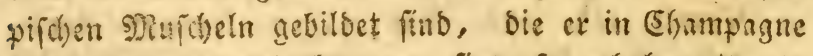

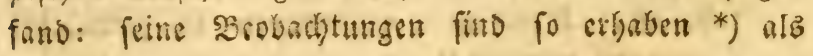

*) Die Befdaffenbeit aller Eroftrithe, dic bas Mar= 
ricitig uns guverliefig; fie fointen mur won einent Shanta fommen, Det ituel fein Sobribundert exbaben

nethat burthroufen von Soinvilfe ì Eaint= Diziet, beficht in einem toeifen mufaldatigen Etein, von

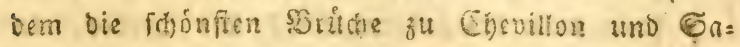
vonniises fid fintorn; unterfuct man oie Eteine Diejer Saridje, fo finost man, bap die ollare Irupre, die anoese Zhere bebeds, bie man fum S\$ou betwenost, aus eimeu feinen Faman vou

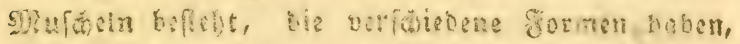
moifens obet obnt uno bob! frno; Diefer Eaame

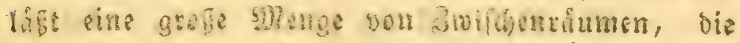

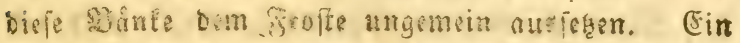
Sourfal voa ber Grofe pines 3alls fann 125,000

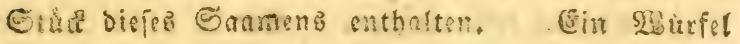

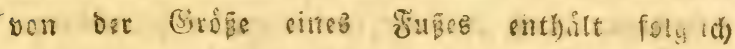

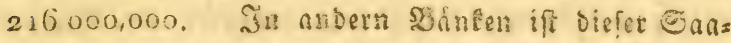
me mit arbern for gebiloeter siducheln vermengt,

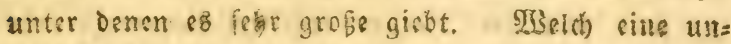

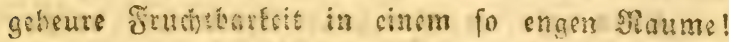
23 ena man nun nitht b!os eimen sibural von ei= nem 3olt im Dutomeffer verrachet, fonoern die

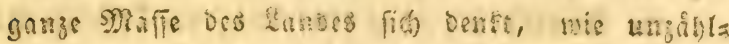

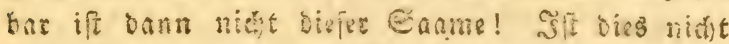

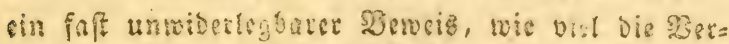
megrung ber Eemufuelu, die poult ins folis Rano bedecten, cazu bengetrangen Gaben, an bie Rager

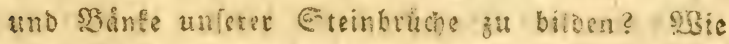

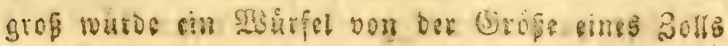




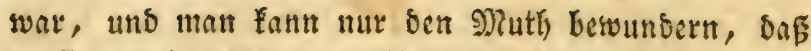
et fie zu einet 3eit anz Rid)t ftellte, wo in Den SूSifs

geworben feyn, wenn biefer verfeinerte Nufchel= faame nur eine Mittelgróse erreicht båtte. Unter= - fucht man die andern Sbinte des Lander, fo fieft man leicht ein, doß fie aus Eeinem andern Stoff gebildet find. Die, Deren Saamen nod) feiner ift, beffebn aus bemielben zerbrochenen Eaamen und andern zerftuceten und ganz vernichteten श्रlu: fajeln.

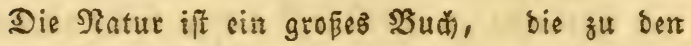
9) Renfchen biefelbe Sprathe fpridht, und bie mit Denfelben ๔d)riftzigen fur alle bie farcibt, bie in Demielben lefen wollen. Co ift nioht ju verwuns bern, oas ibre oft von cinanoer entfernten, fid) unbefannter, nicht mit sinander im SBriefwestel fiebende Beobaditer, Diefelben Dhbenomene entoacen, uno von ber Natur benfelten Unterrid)t erbalten. Eben ofher machen unfere Jenntnibe fo rafoue, faft fichere Fortfetritte in Dingen, bie unfere Eroe be= treffen, uno man erbâlt faif tåglid unwiocrlegli= che SBeweife ubber ben Urfprung oer meifen Erola= gen ...

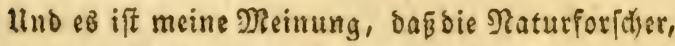
Die bereits geforieben baben, baß unfere (Erbe fid unter dem 2 baffer gebildet bátte, in aller Şinfitht fefor zu entfouldigen find, wenn fis fich oariu 


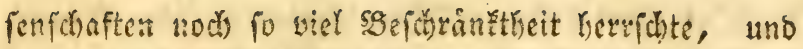
wo icoer eole cifer fo fehe unterorid wat war. Sou=

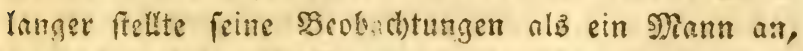

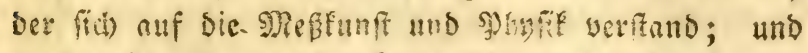

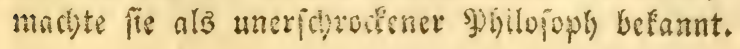

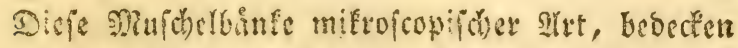

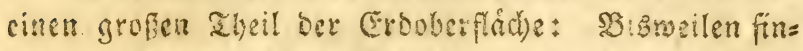
bet man barin groffere Mrurdeln, und ohne Mergri=

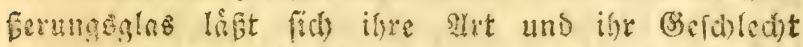

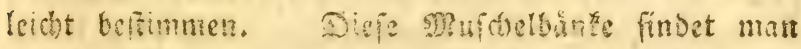

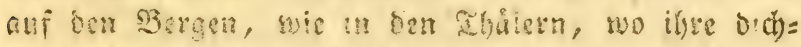

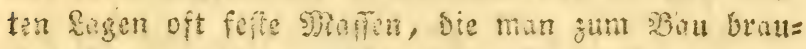

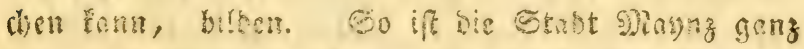
wou ciner Eremat crbaut, bie sub flemen Dufbein

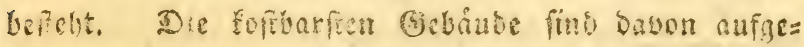
fitict. Etatt an ber Ruft abjureódeln, wird fie an Ez: Rtift fefter, fo, Dafo man fit) zum Bau feit unbenffichan Jciton feiner anvern Steine bebient bat.

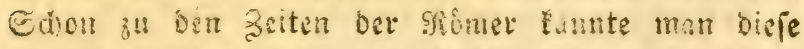

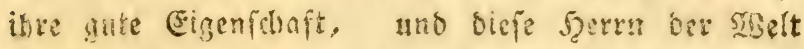
monoten fie za Domumentan an, bie noch ba feter.

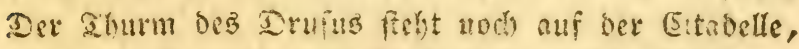
nicht Die (Flemente, nicht Das Fener ber Menfdien,

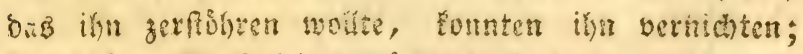
oer foume 28 afferletter mirte noci ba feyn, wenn,

irten. Die Erbiagen, bie mit Geefócperts an= gefült fino, berseifen fủr fir. (Boulanger, Mercure de France 1753.) 


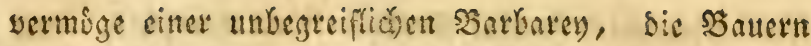

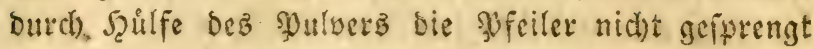
batten, un fich befto leid)ter Steine zum Şauen zu veridhaffen, die fic aแs ben Steinbrudben nidit her: beibohlen wollen.

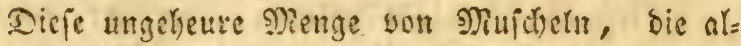
lein bie fraltuante diefer Gegenón bilben, füfren unz zu Dem fibuften SLerte, twas liber bie mifro= fcopifden SNufcheln beronnt gemadit worben ift, $\mathfrak{c}$ iff zugleid) aud) Segenfand cridsien. Eoldani theilte diefe Murd)eln in viex Slaffen, fleine, mittlere, mifrofcopifute unb unendiá) fleine *); unter ben fleinen begreift

*) Testas itaque alias in hoc opere distributas organicas moleculas divido in minusculas (aliquando praemitto grandiusculas, dum nempe accuratiori opus est divisione, ut in turbinutis testis et aliis rarioribus corpusculis accidit) medias, Microscopicas et minimas. seu, quod idem, prorsus microscopicas. Voco minusculas; quae triticei grani magnitudinem circiter aequant; medias quae millịi granu aemulantur; microscopicas, quae per foramina ope communis aciculae chartae inflicta transeunt; minimas, quae per foramina solo apice aciculae minimae folio chartaceo impacta sibi aditum parant ... 
er bie, bie man mit einem SBeikgentorn in 2lbficht Der (Sirúbe vergleidhen fonn; bie muttlern nalyn fich in ilyrer Gieftalt einem Şirefetorn; alle mifrojcopif hen la Sapier geftodyen hat, fieben; wab bie flemiten be= trift, fo fallen biefe burch bie fleinen Rúd)er sines \$apiers, bas won ber feinften Nabel burd)ftod)en ifr. Alebrigenz findet man bey Soldani feine fyltematifche

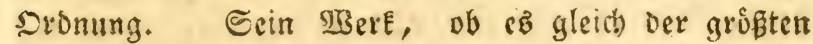
2lufmerffameet wơrbig ifit, wiro lnnge zeit fur bie

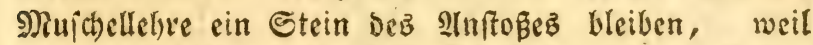

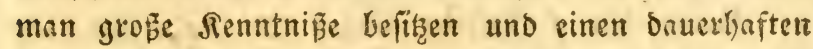
Fleifi, Der faft bem feinen gleid)t, anwenden muß, um alle Rurper infematifo zu oronen, die ber $\mathfrak{A} a=$ turforicher Siennoiz befannt gemad)t bat.

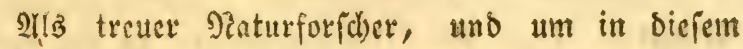
İerke dic Etufe anzudeuten, wie weit wir mit Der श?atulkenntnis gebielsen find, habe ich) allez, waz Soldani befant gemadit hat, mit vieler 2 lumert" =

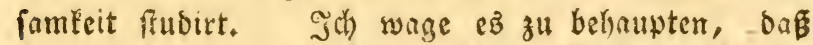
meine Sammlung in biefem fache, fait ber feinen gleid) fommt, uno wenn or Dinge foh, bie idh nid)t anfülyre, fo befize id andere, bie ifm entgingen. *)

Sold, test. vol. I. Init. praef tom. prim.

*) Soldan: Test. vol. I.

Classis prima. Testacea univalvia non polythalamia. 


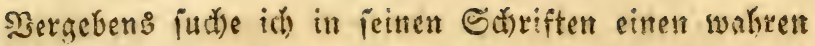
Irgonauten. Ulnter ben zallloren mifrofices ichen Maicheln, die id) allentbalben gefammelt habe, find id) Eemen, weber in Eurowa, Ifrifa, nod) 2(me= rita. IBenn id) Die Rupfertafeln Soldon:'s unret= fud)e, fo finde $i$ d) in feiner erften (Eloffe der sirges Gåu'ten uno nid)t mit fammern variehenen Edale thiere, nut einige Mujd)eln, uns zivar in geringer Babl, beren Epitge fidt nads suifen bin, nid)t auf bie eille voer andere Geite, Dreht.

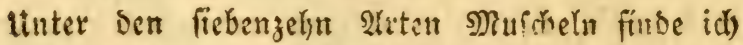
feine 2lrgonauten; Inan fann fid inber auf Solba=

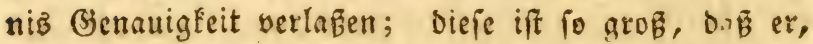
wenn ex butd) Die ftete fleinfleit ber Gnoiviouen, die er beobachtet, zu einem Srrthum verlestet zu werben furchtet, fie in 3weifel zieht und fie zu ben fanm= rigen श)(u[d)eln red)net, wowon eB ifm moglid) (d)eint,

Cochleae. Tab. 15, Fig. 104 k Tab. 16, Fig. $105 \mathrm{k}$ 1061 $106 \mathrm{~m}$ $106 \mathrm{n}$

Tab. 18, Fig, 118 y, z, a. b. Tab. 20, Fig. 119 A. B.

An forte. Patellae. Tab 13, Fig. 123 A. B.

Et tubuli. Tab. 29, Fig, 143 P. Q. Tab, 30, Fig. $143 \mathrm{Z}$.

Fig. 14366 . 


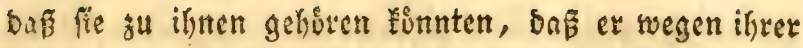

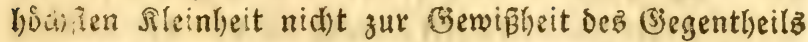
gelungen fann. Şnoem id) reinem Seifpiel folge, fo finve id) einige aufferlithe formen unter ihnen, bie benen bes Irgonauten gleid)en; allein wenn Sol= Dani in ber Sache zu entid)eiden, es nidjt zewagt

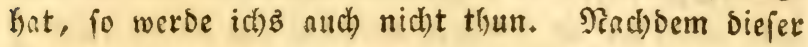
Senturforflcer in peiner zroenten Elaffe, bie Figur Der Mufdeln geliefert hat, yon beren innern Bau ex fid) unterrichten Fonnte, fo ftellt er bie auf, Die iffm nod) zweifelfaft fint. ") SBie er, zeigen wir bloz bieienigen an, die man, da fie mekr befannt fins, zu ben ârgonauten red)nen fonnte. Zuf diefe Siucheln folgen anhere, bie fo fonberbar und barof fino, D响 ote Naturforid)er lange 3eit Daruber fei= nen fictern sluffidlue erhalten werben, man mus fie

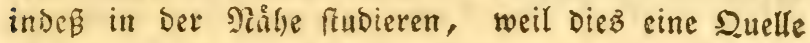
ift, aus ber man filopfen fann, um yon ben gros= forn verfifeinerten fibpern etwas mit Bewisheit fagen fu fonnen, die ihnen gleichen, die man in einigen Reeren, in vielen RalfbånEn findet, aus benen man

*) Soldani. Volumen primum. Classis secunda testacea polythalamia ac etiam unilocularia minima.

Testae fossilesque. Tab. 65, Fig. $200 \mathrm{~V}$.

Fig. 203 i i

Tab. 66, Fig. $205 \mathrm{~m} \mathrm{~m}$

Fig. $207.4 \mathrm{q}$ 
fie in einige Sabinctte ge(rrach)t hat, wo man fie alb Eonderbarfeiten betradbtet, wcil fie von Den betann= ten Formen abweichen.

Jit ber achten Figur, Zafal XLI. bes vortiten Sandez, habe idb cine fefte fonderbare Mujchel ge= zeidhnet, bie id befithe, Soldani hat fie aud, ths id) muf̈ feiner (Sienauigfeit alle J̧uloigung erweifen,

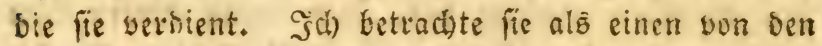
Hebergången ter Irgonauten zu ben Nautiltfen, in= DeÊ fich) ifhe Definnung auf eine gleichjettige, regel= máp̧ige 2lrt vorwirft; allein fie ifit, wie ber Nau=

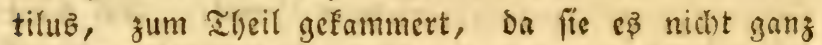

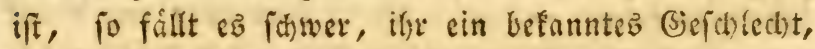
zu bem lie gehort, anzumeifen. Der Mufdelfenner 'Siennoiz *) hilt fie furr einen Piautilus, uno giebt

*) Vas. 150 , tab. $6 \tilde{3}$, A. D. Nautili (Ienticulae marginatae) miniusculi, quos in saggio oryctographico appendice, Mro. 6 et 7 . Diximus circum alatos, seu marginatos, seu ibi insculptos dedimus. Tab. I, sub lit. O. Qui in hoc vase continentur sunt testae vix marginatae, laeves, naiura sua lucidissinae et aliquando vitreo nitore fulgentes, quarum figura exprimitur per $\mathrm{A}$ et $\mathrm{B}$; earum rero raras varietates indicant $C$. et D. Eruuntur ex fundo maris ad portum Ferrarium et ad portum Liburni, in quibus locis raree, in littore vero maris rariores, frequentiores in concretioniblis 
ihe ben Palgmen gerinberte ober befligelte Sinfe. Ee find fie in Ceefande bez J̧afenz von Ferrajo unb R.vurno, wo fie eine Seltenleit ift; binfiger traf er tie in ben Ectwåmmen uno bem Seeforf biefer Sưfen an. Sch) habe fie in ben forallenmoos woit Sorfitia, wo fie boch nidst allzubarufig ift, gefunden. (s:nige, bie id) fand, hatten die (sirüze ciner flei= nen finfe. Die 2 fbbildung, die ich banson mittheile, iff nicht fo grob, als bie yon Soldani befannt ges madite. Die Nuid)el ift Dinn uno bureffidtig, io Daß man nicht allein ilje Rammern, fondern auth

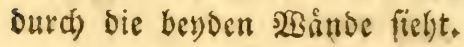

Utm ben Uebergang bizె zu ben গautiluffen nach

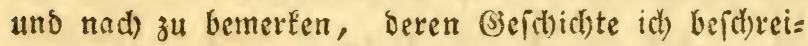
ben will; fo babe id) auf ber XLI. Tafel biefez

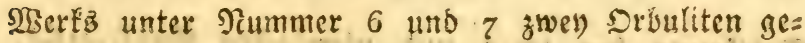
zeidunet, beyse find bein Solbani *) entterint, weit uแb biejer \$erfaffer Den meiften sluffchluz über bieje

Zoophyticis. Sunt multo minores is quae in collibus senensibus copiosissime reperiuntur, cum quibus tamen quoad testam lucidam ac vitream optime conveniunt. Soldani, Test. Vol. I, pag. 54, et pl.XXXIII, Fig. 150, D.

*) Soldani test. vol. I, tab. 35, Fig. 151, aa, et tab. 34, Fig. 154, ee. 
Muidjeln gegeben hat. Ere zeichnete fie nacb şnoi= sibuen, die faum ein Sandfornden grop waren. Sianchi, unter Dem $\mathfrak{T a h m e n ~} \mathfrak{N}$ lancus betannt, Lange, Bourguet, hatten weit gröBere Mluicheln ber Sirt vor fich), indes fino Soldanis Figuren weit richtiger, als oie ibren.

Samark *) ift ber erfte, ber, da er fie mit ben 2 tmmonshowrnern auz bem $\mathfrak{B}$ affer zog, unter bes nen fie fich befanden, fie als ein befonderez Ges febled)t unter bem Piakmen Der Srbuliten aufgeftellt

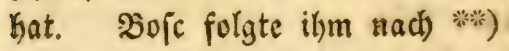

Erelátung ber zwen und vierzigftent Supfertafel.

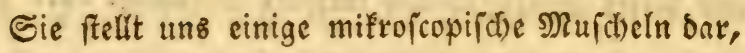
bie Soldani zu unjerer Renntnis gebracht hat, bie ex in zahlreicher Menge unter bem Sande am Mee: resulfer fand. Şre (Seftalt naht fich ber ber Ilrgo= nauten; und weil biefer Berfaffer feime Sammern an ifyen fand, fo fonnen wir fie für ieşt, als

*) Lamark, Syst. des anim, sans vert. pag Ioo, genere 86. Orbulite.

*) Bosc, Hist. nat. des coq. tom. V. pag. 167 . 
mifrofopifthe Zlrgonauten amjeth.

( Man felle bie anmerfung, pag. Soldani. Volumen primum etc.)

\section{Der Sutdffictige Pantilus, *)}

Nautile vitré.

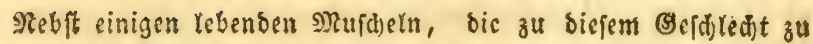
geboren fdjeinen.

S̈n bem aweifel, worin wir unz befinden, uns ben id) firr gegrumbet halte, babe idh biefe fdjone Mufdal, eine ber felteniten, bie befannt find, nicht

*) Nautile vitré. D'Argenville, App. planch. I, Fig. B, Conchyl. pag. 383. - Patella cristata. Lin. Syst. nat. verm. test. pag. 3710 , sp. 96. - Argonauta vitreus. Gmel. spec. 2. - Martini, Conch. I, tab. 18, Fig. 162, pag. 239. - Favannes. Conch. planch. VII, Fig. C, 2. Legrand nautile vitré vol. I, part. 2, pag. 719. - Carinaire, carinaria vitrea. Lamarck, Syst, des anim. sans vert. pag. 98, gen. 8j. - Corinaire vitrée. Bosc, Hist. natur. des coq. tom. III, pag. 244, figure d'après d' Argenville, pl. XXVI, chif. 3 . 


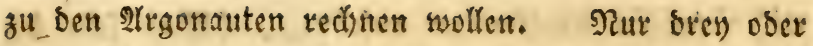
biere záblt man bobon in Europa, und ibre Befither legen eimen fo bohen SBerth Darauf, Daß neulid) eine in Şolland fur die Gumme won 3000 Risres veréraft sworben ift Sie ift buchit zerbred)lich, ourchfichtig wie Ģłas, etmas perlmutterartig, hat cinigermaben

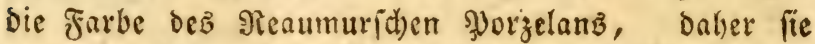

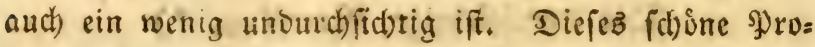

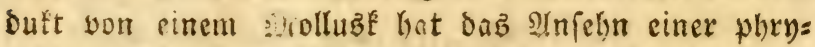

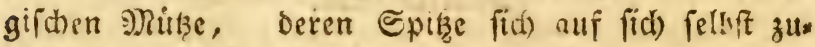

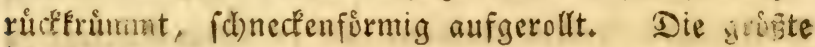
befannte, sie Dem Inonnet angeigurte, maĩ zroey Zoll, zelyn Rinien in die fange, Die Deffmung betrug fwey 3oll. Die, weld)e man in bem groß̧en Sia= turalienfabinet zu \$ariz fielst, ift nid)t fo großs. Die an ben Eeiten bemerbaren, etwas berborfpringenoen Galten, Deuten Die Nergróberungen Der Mujchel an, bie fie nad) auffen zu nad) ilyrem ganzen llmfange umaurten; Daz Snnere iff einfad) uno man entoceft ba nux leife Spuren, ber allimåliget falfortigen 21n= fåke. Der Nund ftellt fein ver!ångertes Sval Dar,

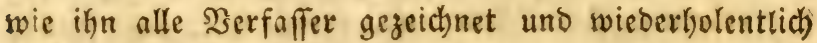
bejdrieben baben, indem fie $\$$ Irgenbille copirten, wielmels bat ef eine Birnformige Geftalt, ift runo, erweitert an einer feiner 2 luffenfeiter und endigt fie an ber Eeite Des Sammi in cinen Junft, Der wie Jlopeffocrn erlaben ift, uno fith nach der ganzen länge biefer zerbrechlichen Diufdel bingiebt: Diefer

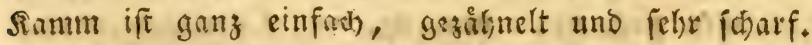
Deil id) Dดs Exemplar in Der Taturalienfaminlung

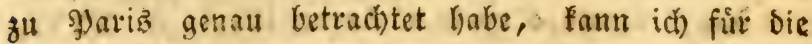

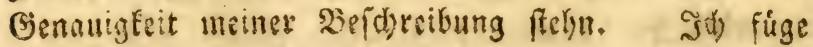




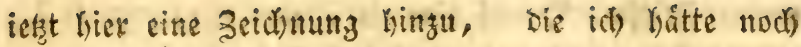
zurict'salten funnen, bis wir genauere Renntnib̄e

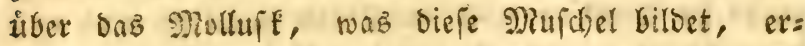
bielten. Man fann ưbrigens bie 3cidsmungen von

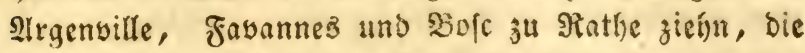
alle brey genta biefelben fins, bie hinreid)en, meine Soeen iber bie Formen berielben zu begrinden, wo naan inbeß nid)t vergeben mus, bas die Deffnung bey sllen Diefen Shutoren fd)led)t gezeid)net ift.

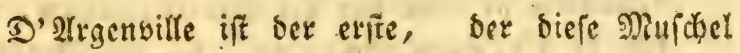

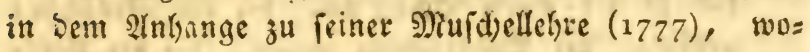

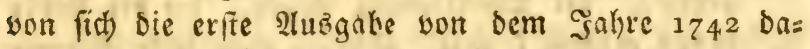

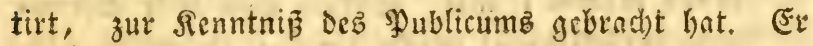

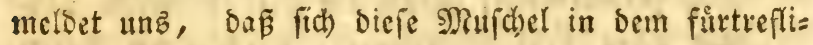
d)en Sinbinet Eyonnets fand, und Dẩ Der SBefther fie alz einzig unt nut in feiner Sammlung fid) befin: beno, betrad)tete. Iluch) Favannez rebet won biejer Nufdel syonnetz; allein zu gleid)er 3eit fagt $\mathfrak{e x}$ nuch, Daper eine zweyte tenne, bie fid) in bem Sabinet bes झुaul Meyer zu 2 mifterbam befinde und yon IImboina fomme; id) bemerke hiet nut, Dñ গฺแน

Favannes Ingabe ift inder befiummt und wirs

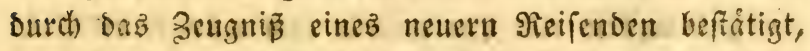
nemlich) bez Eabillarbière, bex zu Detren gefourte,

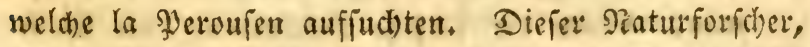
ben nid)t Der Ioo, nidbt phyjifde und politifde Grintme, Denen er ausgeferzt war, hinrichteten, und Deह̃en IInftrengungen und $3 e m u i l$ ungen die Englånder, 
anjere Feinde, *) auf eine fo coelmuthige Sbeife re=

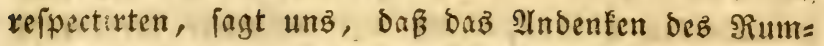
phius zu 2 (mboina noch in Erbren gelsalten wirb uno Dazu bentrågt, bie Riebe zat Naturgejdichte, bie

*) Das Shngefaht dez Siriegz batte alle Samm.

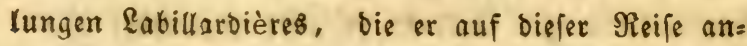
legte, in bic Bsewalt ber Englinner geliefert. Man betradtete fie nicht nur al\& \$ुrivateigenthum, man fah fie als einen Schas an, ber ber Menthbeit gehórte, der Befchreibung wegen, bie ber $\mathfrak{B}$ eife bavon machen fonnte. Sobalo man biefe Samms

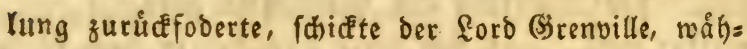
reno eines beftigen Rrieges, burdh einen sparle= mentair bie Rałten bes̄ franzofitichen Staturaliften nach) Scavre. Sie wurben bier auzgelaben, inrem Eigenthimer wieber gegeben, uno bas Sdiff fahlug feloft bie Selohnung aus, bie inm das franzófis fide (Solvernement anbot. Sobald bie Raften am Eanbe maren, giengen bie Englánder wieber unter Segel. Şeil uno Eghe ber Nation, Die

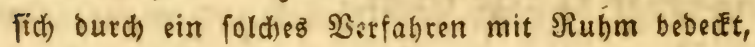
indem fie fo bie Miffenfhrften refpectirt. Mo ten bod in allen, befonderz in Eeceriegen, bie

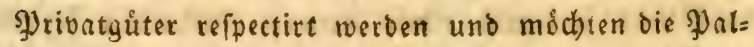
me bet (Sefedte nux Arieger von Rriegern anneh= men, Damit ber fleißige Raufmann, ber $\mathfrak{W e i f e}$ und Neifende nid)t die SBeute elender Eorfarea wurbe, bie eben foldhe Eepraiuber find, wie bie von Marocco, Tunis uno 2ligiet. 
Die నage biefes alten Feturfreundes veridjonte, fut unterbalten: ${ }^{*}$ ) pein Brob, in ber Nåke Der Etcsot, war nod) $b a$, umringt won lieblid)em (seftraiud), ein fo rübender, funftlojer unb eines Mannez fo wirs

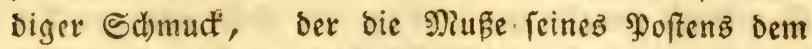
Studium Der Erzeugniffe ber Matur weilte, in beren

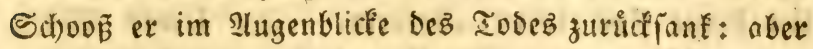

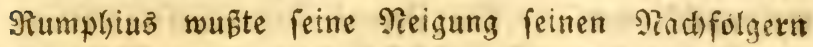
cinzuflösen; die Dberbåupter von 2 mboina befitzen

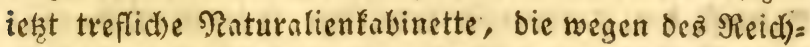
thumb uno der Menge von Muldheln merfwirbig find. Der Secretait bez Eonjeilz befaß grope Sammlungen.

Der Eapitain Şuon, Der Daz zwente Schiff bie: fer Unternehmung comanbirte, fd)loß mit biefem Se= cretuire ein engez Freundfd)aftäbinonis, Der fich eir Bergnitgen baraus machte, ihm viele $\Re$ Mrd)eln von Eeltenlyeit, fut geben, yon benen ber burchfichtige

*). Ein Eleiner Spastergang, fublich yon ber Stabt, in ber Måke beg Biertels, das bie Europaer be= wohnen, geniebt man ben 2fnblide bez (Srabmahts yon Rumphius. Die Einfachbeit biefeg Monu= ments erinnerte uns an bie ungefunffelten Sitten biefes gefdidéten Srobachters ber Matur. Sein (Brab war mit lieblidem (Beftråuch, waz untee bem Nahmen panax fructicosum befannt iff, um= geben. Labillardiére, Relation du voyage à la recherche de la Perouse, tome premier, pag. 296, in 80. 
Nautilus die foftbarfite war. Dex ebelmúthige Enpis tain, ber gejuličte Eecmann, Der eร̃ würbig war, anz pon ben Edbiffer einer unternelsmung zu com= mandiren, bie Der Nenjichleit uno ber iffentlid)en STdoblfabret geweilgt war, erlag ben 2 tnftrengungen ber

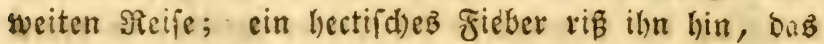
ihn lange zeit fdbon abzelyte, ohne feinen Muth nieberzulchlagen. 2 II’ Freund ber $2 B$ iffenid)aften, fo wie fetner Sunfit *) fal) er mit faltem Slute bie 2Infunft des Todes uno vermechte in einem Teftamen=

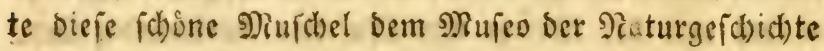

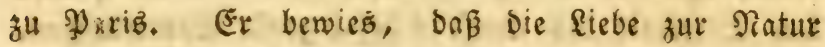

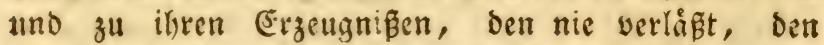

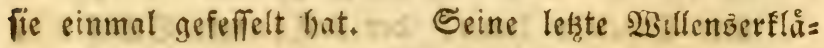

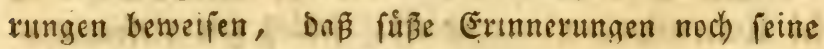
lekzten 2lugenblide aubfiullten. Surch) biefe feine Giute, freun wir uns alle biefer foftbaren Muidel, bie mun ein Erigentf)um aller geworben ift. Mit bek grofisten Serelyrung babe id) fie unterjucht, und im= mer wirb fie unz an bie Malme bes Nuthes uno bie Sitrgerfrone erinnern, die Das beid)eidene Grabmahl Des Niannes in barbarifgen, unwirtlbaren Begen= ben bectt.

*) Er wurbe nad) feinem Ieftamente gegen bie Mit= te ber Snfel \$pubycum in oer Nacht begraben. Er wůnfthte Écin Rionument, weil er furrdetete, bie Einwolner von গeu $=$ Ealebonien, módten ben Begrábni的lą entoecten. (Labillardière, Voyage ì la recherche, etc. tom. II, pag. 238.) 
In Den Nact)richten, bie unz Cabillarbière won bem burd)fichtigen Pautiluz giebt, finbe ich won bem Ihiere nid)ts, was biefe Mufd)el baut. Andern Reifenden ift es vorbeljalten, unz in biefer Szinficht

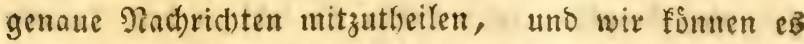

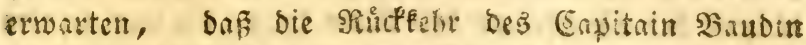

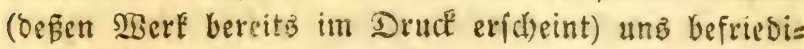
gen wirb. Bontet, ein junger beobaditer, eir Eleve der Eentraliftule von Eeine und Sife, det fich als Mitgehulfe ber Siaturgeidichte auf dem Sulfie, wab bicfer Enpitain. commandirt, cingefin ift hat, hat gefdrieben, baß man bei) der lleberfabrt won

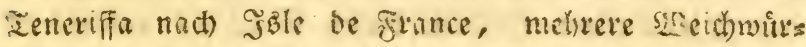
mer von grofere Eeftenthest gefanmelt uno beob.chtet bat; unter andarn aud) ben, ber bie fortige sous = (i)el, bie unter bem Jahymen sy pirrnautilue betannt ift, bilbet; aber ber junge Naturforicher, hat zu Stefer bloben Semertung, weber sine Befdretbung, noch 3eidnung hingugefugt. Seht fonnen wir unz

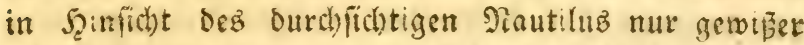

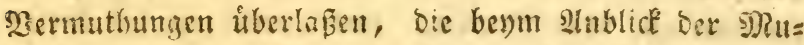
fdet enticelin. Nan macht atts bem ahiere, dą fie bewolnt, ein neteb (sef(b)led)t, Das man Bullea

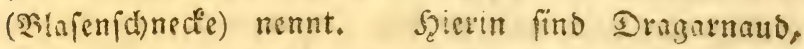

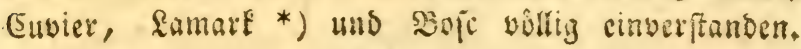

*) Neuvieme genre. Bullée, bullea. Eir friechender, ovaler, loinglickter, rund enfrabener, mit J̦åuten an ben Eciten befezter fórper, bie ibn einfdiefer. Ein naçter sopf, obne făhl= 


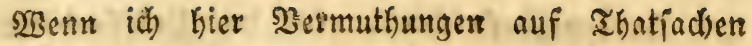

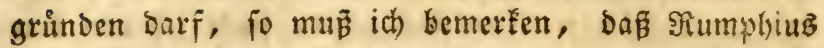

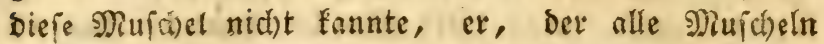
won 2 mboina und ber umliegenden Biegenden pletedt fammlen fonnte. SABir finben fie ieţ⿸ in ben Samm=

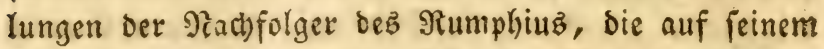
Syfade wandeln, und mit (Eifer bie (d)aligten SBehaus

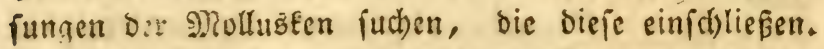

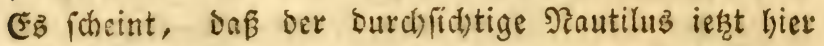
fo befannt ift, alz er unbefannt war, als ber Tias

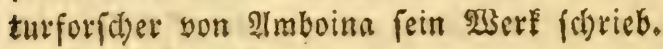

Die áufere. Beftalt biefes Nonutiluz crlaubt ez nid)t, ify unter bie $\mathfrak{A}(r$ gonauten zu red)nen. $\quad \mathfrak{D a}$

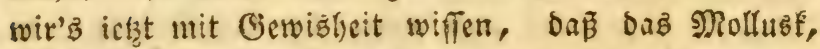
was die 2lrgonauterimujdel bewolgnt, auf ber bohen See fehwimmt, fo funnen wir ifhn nicht mit ben ein= fhaligen Nuitheln vermengen, Die unter bem Miak= men Cabochons befannt find. Die Thiere von eini= gen berielben fino Moltuşen mit făhlhornern verfelhn, fried)en auf bem Sauche, fino immer an bie Felien gekeftet, auf benen fie Fried)eno umberf(b)leid)en, nad) 2trt ber Sdinecten. - Sie getjuren weber zu Den S(buffielmufdeln nod) zu ben Alegonauten.

Bruguiéres wuste ebenfallb nidjt, zu weldjer

Górner. Şinten mit einem weiten Eace verfefhn, ber bie Shren bedect, ber einen mufdelartigen So̊rper enthîlt. (Lamarck, Syst. pag. 63.) 
(Elaffe er bieg \$lolluite redinen follte. " Ere hat bie Muichel nicht in Supfer fted)en lasen. In Dem Iheile bez Textez ber Encuclopebie, Den wir von ilnm haben, rebet er nicht savon. Diejer geidjictite Mu= fidelfenner erwartste von ber 3eit Anfeloirungen, Die

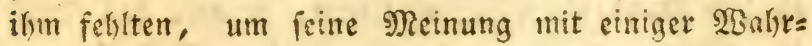

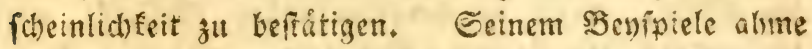
id) rad), obgleid) Ramnet aus bem ourd) fichtigen Pau= tiluz ein beíonieres (Sefuleded gemad)t hat uno Sofe if) nadigefolgt ift.

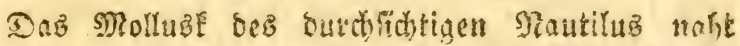
(idi) vielleidit eben fo Den IMeorien, wie ben Migo= nauter:, oder bilbet eine allferorbentlid)e 2lrt, bie burchaus won ollen Denen verictieden ift, die wir fennen.

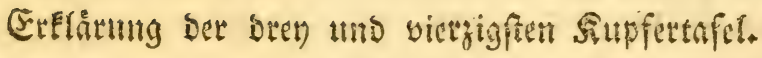

Figur x. Ein burbfidstiger Noutilub. Diefe 3eid)nung ift nach) Dem Driginal, bas ber Eapitain Szuon bem Mujeo vermadyte, gentbeitet. Die Seff= nung defelben if nidyt zufummengedridt, wie ihn

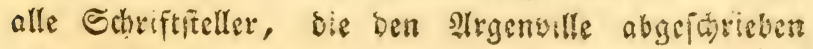
Gaben; Dariftellen. 


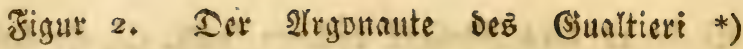
Figur 4. Die Dragonermithe (Bonnet de Dragon.), Die alle 2lutoran zu ber Sd)ůfiflmuichel red)nen; aber ifre formen, fowohl äufferlich alz innerlich, bie immer glatt und polirt fino und bie zålhne, indem fie ben Ranb ber Nuíd)l fieren, Gindern bas Thlet am G̈ely, wenn ez ein friechendes Molluft, wie bie anbern einjd)aligen Ruid)eln, wåre. Diez

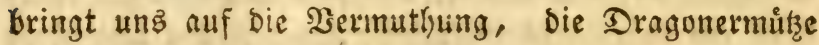
fiur eine innere Nufdel zu halten. Die zeit unb bie Beobachtung allein fann biefe Bermuthung beftátigen Doer fidwichen, bie id) mir nad) Den Grünoen, bie id) anfuhgen will, ellauben zu finnen glaubte.

*) Cymbium minimum, complanatum, angustum, ipsa puppe parum in principio subrotunda, deinde aliquantulum per lineam rectam extensa; a qua sulcis, vel striae undatim, et irregulariter usque ad marginem deducuntur, striatum striis minimis transversis, margine acuto aliquando fimbricato; ex subalbido cinereum. Gualt. Ind. test, Conch. tab. 12, let. D. 


\section{Sdaligte, Iebethåutige Mollufent.}

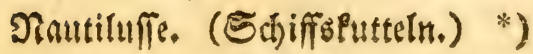

Nautiles.

TBenn eine Ruichel ba ift, fo mu官 fie son ei=

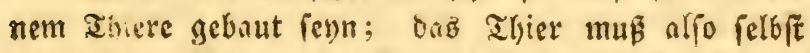
cbenfalls exiftiren: ber Paturforfder, wenn ifm in

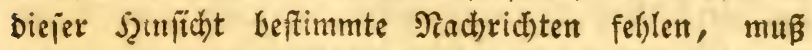
burch) angeftrengte 刃(ůl) und porgfo̊ltige Unterjuchun= gen Dann bie Sdjwirrigfeiten befiegen, bie fid) illnt entgegenftellen. SYBenn er fich mit Eiffer und vertraungazyoll feinen Forid)ungen i̊berlåpt, fo wirb ę ilym gelingen, ins J゙nnere Der Natur zu bringen; uno verbirgt fie bis̈weilen noch einen aheil ihrer (bes

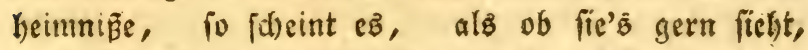
Daß̂ man mit einer gewiß̨er Gewalt nuf fie einoringt; benn immer erbålt man von ily, ober entreist ifye einige (S)unftbezseigungen, die uns reid)lid) fur bie Siuly belobnen, die man anwandte, un fie zu ers balten.

*) æafel LIIV. 


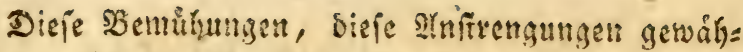
ren bie fineften Bienabe; fie find fo rein und fitll

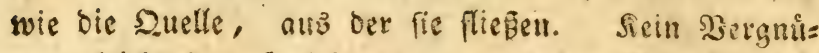
gen gleid)t bem fo lebroften, was ben Ilaturforider ergeeift, wenn er endida, auf rauden, fienigten SPaben, zu bem Gesenftande feiner Wuinflbe gelangt, befonderz wenn er vergmeifette, ifh ie zu etreid)en; bie Dornet, bie iljn melse alB sinmat im fout rets ten hinderten, verwandeln fich fogleith in গolen; ftatt ber Dornen pfluctit et num mur Şlumen. So

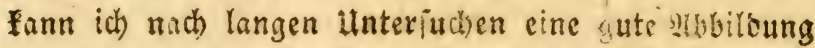

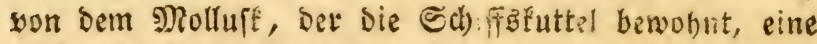
rothfable Farbe hat, im Jnnetn iunfel, perlmut= terartig iff, lieferm. Sic foll unz als 20 orbits zunt (Sefd)led)te Det Nautiluffe bienen, indem wir unz ber (j)eichlechtakennjeichen bebienen, Die Diez Ihyer son allen andern פlollufen unterfuseiben.

Det Siorper dez Siautiluz ift getundet, wie bex ser \$olnpen uno in einen musfulojen Eade einge= fc)loßen, Der Feime andere Deffrnung but, als ben bie Unreinigleiten abfübrenben Ranal. Die Rutcten= haut verlingert fid hinter bem Sopfe her in eine wei=

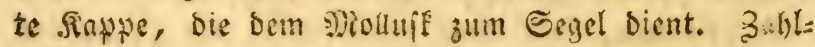
reiche, gefingerte arterte fielyn nuf bem Siopie, um Den Mand, Det mit cinem hornartigen, gefogenen Sidnabel verfern iff. Der Riviper lơuft an feiner

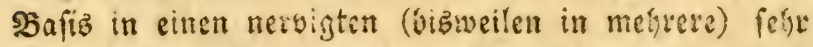

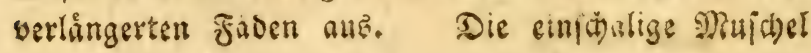


bat bie Geftalt einer erhabenen Flåche; ber nicht

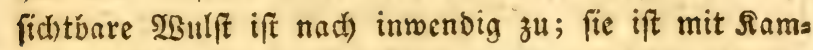
mern veriegn und alle fiammern Durchzieft ein nes= sigter Faden, Der Dem ahiere baju bient, fid) feft: zuljalten.

Das Suiffsboot, bie Perlmutterfanede, sie Sdiffistuttel. *)

Le grand Nautile flambé.

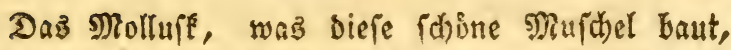
gehort zu ben fonderbarfen yon allen Denen, bie nach

*) Nautilus pompilius. Lin. Syst. nat. verm. test. gen. 318 , sp. 1 , pag. 3369. - Nautilus alter. Belon, Aquat. tab. 382. - Nautilus alter. Arist. lib. 4, c. 1. Nautilus alter. Aldrovand. de test. lib. 3 , cap. 4, pag. 263, 265 et 266 . - Cochlea margaritifera, \$ lermutterínnede. Rondelet, seconde partie de l'Hist. ent. de poissons, liv. 2, chap. 22, pag. 63. - Nautilus major crassus. Rumph. Amb. tab. 18, Fig. A, C. - Ionston. de Exang. aquat. tab. 1o, Fig. 3 et 4 . - Coch. mar- 
und nach gezeidinet werben; burch ifre Silsuna beus tet uns biefe Mufdel an, Dof fie eitnem foiffenden

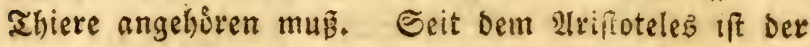
ঐabme berjelben bis auf unjere Beiten unverîndert gefommen. Ex bătte ieden, vermige feines 2Injeins

gar. Gesner, de crustatis, pag. 251, Fig. 2. - Lister, Hist. conchyl. tab. $55^{\text {I }}$ et $55^{\circ}$, Fig. 3. - Gualtiéri, Index. test, tab. 17. Lit. A. - Petiver, Amb. aquat. 3, Fig. 7. - Bonnani, Recre. ment. et oc. class. 1, nos 1 et 2, pag. 88 - 89. - Kircher, Mus. class. I, Fig. I - 2, pag. $500-\mathrm{Seba}$, Test. tom. III, tab. $84.1-2-3$, pag. ${ }_{175}$ - ${ }_{776}$ - Knorr, Del. des yeux et de l'esp. part. 1, pl. I, pag. 5 et 6; et delic. de phys. tom. I, pl. B, Fig. I - 2, pag. 38 - 39. - Martini. Conch. I, tab. 18, Fig. 164 , et tab. 19, Fig. $165-166$, et pag. 222, - Klein, Method. ostrac. tab. 1, Fig. 1. 2. - D'Argenville, Conch. pl. V. Fig. D E F, p. 201, - Favannes, Catal. de Latour d'Auv. pag. 59. art. 255, 256, 257. - Valmont de Bomare, Dict. - Lamarck, Syst. des an. sans vert. gen. 85, pag. 99. Cuvier, cinquième tableau, Leçons d'an. comp. tom. I. - Bosc, Hist. nat. des coq. tom V. pag. 162, et pl. XLII, Fig. 1. - Scheuchzer, Bib. sacr, vol. I, pag, 20 , et tab, 19, Fig. A. 
zurucfljalten misert, ber auf ben fonberbaren Einfall fam, Diez Thier unb feine Sd)ale zu ben Schnedent unb Eriechenten Molluften zo red)uen.

Zfriftotelez iff ber cinzige Schriftfteller bez allter: thums, ber uns sinige (d)riftlid)e iad)rid)ten yon Der Sduncte binterlaß̧en hat, er nennt fie Pautilus Doer Shwinmer uno giebt unz bamit einen \$Beweiz, Daß̈ er Dasె Thier auf Der See fdrwimmen fah. Ulms fonft beginnt man cinen Etreit áber biefen \$unft: frine Sluzbraide fino beftumt; nid)tz ift fo genif

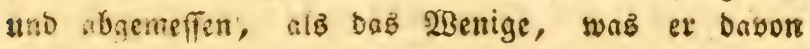
fdiriftlich binterlapen rat; einige SBorte waren ihm

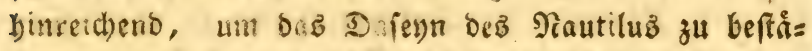
tigen, won Dem wir hier reben. "Es giebt, fagt Diefer Whilofowh, zwey Arten won Wolnpen, bie in Muid)eln eingefdloffen find; bie Sd alhutlle bes cinen Diejer slrten if wertieft und hångt mit feinem zhiere nid)t zufammen; bas andere ift nit einer bid)ten uns frarten souichel bebecft, Die ez nie verlåpt, uno beanight fich) bloz bamit, biżneilen peine altme aแb Detferben bersorzuftectén.

Set) Der (Befchid)te Dez Syapierargonauten habelt wir's gé์ ret 3eit, allgemein angenommen war, baß ber $\mathfrak{A} r=$

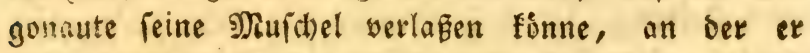
niwht befeftigt fen, ober das fie bie Beute irgend cines Sd)maroterpolypen wútbe, ber mit ilys nicht in genauer Serbindung ftel. $\quad$ (d) werbe bagegen

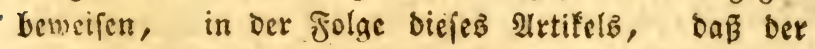
Niautilus mit feinet feften, farfen Mufchel zufam= 
mentångt, und bafi man nidbt vermuthen fann, ex werbe lie gutwillig, felbit bev gewion (Belegenheiten,

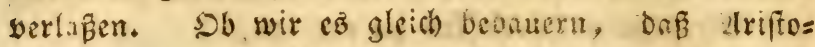

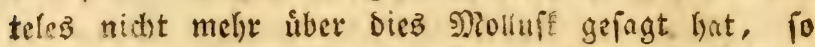

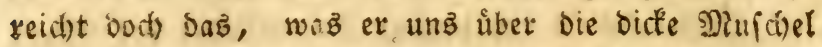
fagt, bie bem Thiere zum 2lufentlyalt bient, Kin, um ieben żweifel nieberzuichlagen, alsె ob er won bieịer Muichel nicht båtte reben wollen. Scine Eor= refpondenz crittectite fich) bis nad) Jnoten, wo man

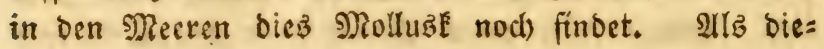

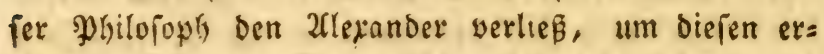

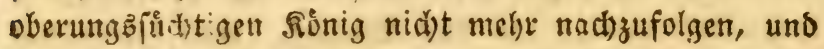

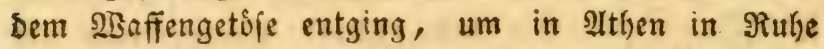
(id) bem Studium Der Paturgefdichte zu ůberlapen; fande ifm Illexanber nid)t allein 800 aalente, eine fel)e grope Summe fur bie bamalige 3eit, bie faft eine halbe Million ned) unierel Mrinze ausmadyt, um ihn bey den gropen Roften, die bies Stubium fodert,

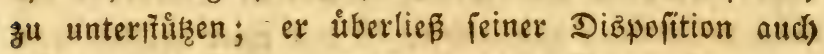
Såger uno Fifd)er, Damit biefe গad)forid)ungen, weldhe ex ihnen auftrug, auftellen fonnten.

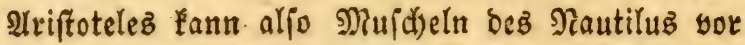
2lugen gehabt haben, bie mit geid)riebenen Nad)rich= ten ůber baz $\mathfrak{T}$ hiter, waริ fie eimfdloffen, begleitet waren, bie ifm feine Eorrefponbenten aus Jnoien

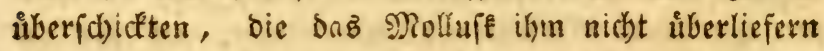
connten, die aber, im Gefolge beż Antexanders, bies Thier auf ber See fidwimmen felin fonnten. 2lrifto= telez fteft aud) nidyt an, bem ghicte ben Fafymen Pantiluz zu geben, ber ihm am angemelfenften ift.

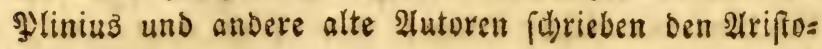


te'ez, ab, allein fie elwaingth bes indifthen Nautilus

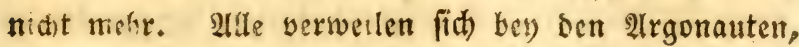
Depen 2 (rt zu fdiffen und Bewegungen fie mit fo vic: Ier Eleganz als (s)enauigfeit befhreiben. Sciner von il) nen id)rieb eine allgemeine Thiergeichid)te. Dens felben Plautiluz finden wir nod) ietzt in ben afrifani=

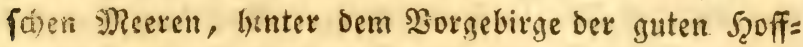
nutig; bie griechifd)en und rómifhen 2lutoren hätten ihn eben fo gut, wie Irriftoteles, fennen lernen forn= nen; alleia ben ifren poetipden erzalblungen, war ez iffnen naturlid)er, Die Sthiloerung einez fd)iffen= Den Thturb zu liefern, alz bie 2trten, bie fie alz mituermand anfalin, genau zu befdreiben; diefe ges nauere Befdreibung war aubid)liefene bem গatur: forider vorbelyalten, ber allem bie charafterifififhen Meribuebenlyetten angeben fann.

Belon, inbem ex biefez trefliche Stubium wies ber won neuem belebte, wo er ber Epur dez dieifto=

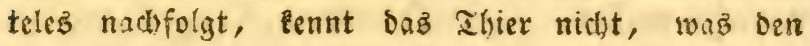
Neautilus bewohnt, allein ex lies ifm Den Taljwen, weld)en 2 triftotelez bemfelben gegeben hatte; um ihn nid)t mit Dem Des 9 lrggonauten zu verwech felt, nannte

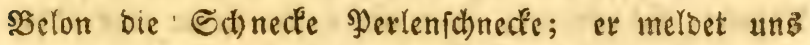

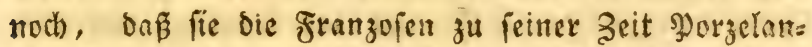

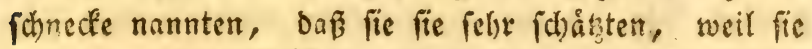
Daraus foftbare Gefine verfertigten, um Domit ilyre Silberid)råne auzzufd)múden uno fie legten cinen fo

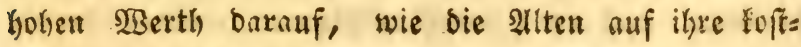
barjen Tringefå̉e.

ఇonoelet, Dex Durchnus mit 3elon uncinig ift, 


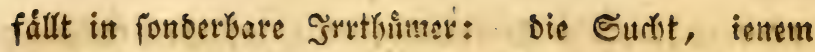

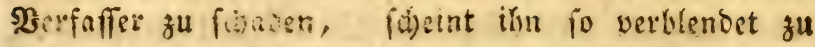
haben, onẽ er bie buyben, won Irriftotelez angezeig=

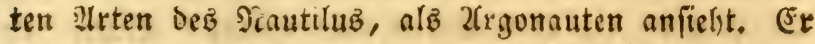
fülyet eine Mluichel ber alten Rreifelichnede an, ietert unter DeII Tahmen Sugelid)nedfe betannt, bie Favan= - nes auf oer XXVII Siupfertafel, Budlifabe B, hat

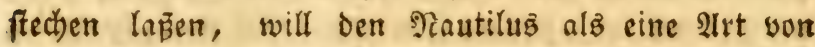
Ed)nedfe anjelin und leugnet burchaus, baß fie zu

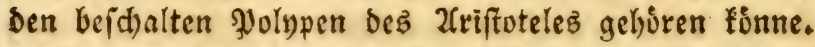
WBeiter erwånnt ex yon Dem Molluf́, Das bieje Schnedé båtten bauen funnen, nichtz, Denen ex ben Nabmen, perlenfarbige Sdhnedfe giebt. Ronbes let und Belon erflíren, cin ieber nach feiner $\mathfrak{M a}=$ nier, Den 2rriftotelez, und entfernen fid) yon ber

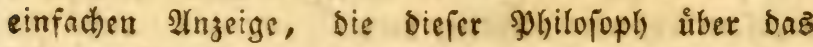
Ihter gab: fie war ifmen binteid)eno uno fie wollter stid)t tiefer in ihren Giegenftano einoringen. Son

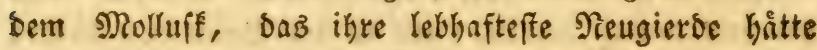

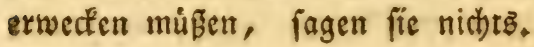

23ergebenz fud)t Ŝtbrovanbi bey biejen 2tutoren Stoff zu feinen Eompilationen; ihr Sthweigen ift bie Utrache bes feinen; und er weilyt faum eitne balbe

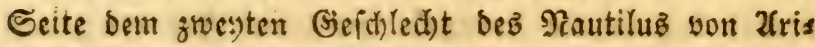

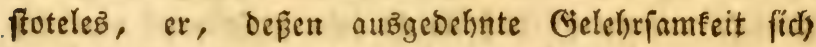
nft ůber weniger mertwintoige Biegenftánde, als bies fer hier ift, werbreitet. Er treibt bie Sorglofigfeit

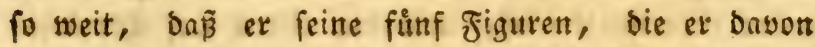
liefert, nid)t einmal mit einer Sefdreibung werief)n hat und zeigt fie nur init wenigen $2 B o x t e n$ an. $\mathfrak{M a n}$

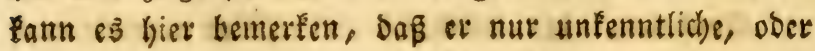




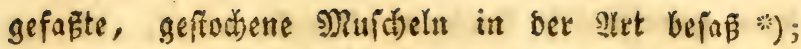
Die Rånber, von benen ber beyden exften Figuren

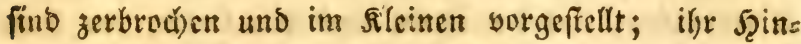
tertheil if zerbrod)en und $\mathrm{ez}$ fd)eint, baß er fie bier alz zwey veridbiedene 2 trten barfifllen will, weil bie eine nod) ifree flammige Bebectung, Da bie andere nut Daż \$ुerlemmutterartige nod) bat, Dnzె fich unter ber erften Pinbe findet. Şinter biefer finbet man

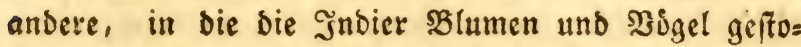
chen haben. Sie berben barauf folgenden Jiguren finb lehrreider; fie geben uns einen in Der Mitte Durchfögten Nautiluz, Dex unż feine innere Drgani= fation Darfelit: Diefe Figuren find reabt gut; wenig= ftenz liefern fie eine beutliche Soee von Dem, waż Der Serfaffer hat vorftellen wollen. Die bintere Sammer ift inder felglethaft.

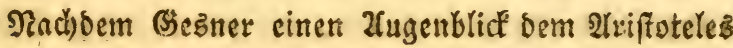
nad)geiprod)en hat, wermengt er mit biefen MiolluFs fen ben 2regonaten und feine Miufdel; aber er frellt Die Dez Nautiluz untet bie Sd)althiere. Die zweyte

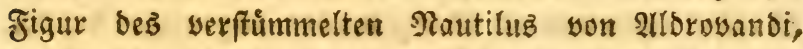

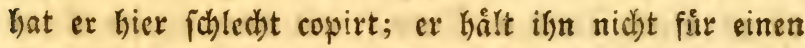
Rautilub, aber man fieft, ex hat ben Belon und Nondelet gelefen." Diefe Nurchel, fagt ex, bie

*) Nautilus testa rudi cortice obtecta, ac variegata castaneo colore. - Nautilus alter laevigatus. Uterque operta perfracta prora. Aldrov. de tert, lib. 3, p. 265 , Fig. 1 et 2. 


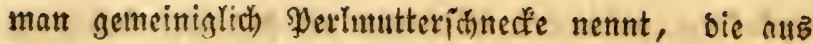

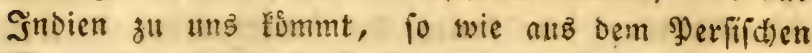
Meerbuien, hat die Farbe und ben (3) lanz Der Dyer= len, allein man findet bergleichen nid)t in ihrem Srn. nern; ez giebt 9lutoren, fugt ex hinzu, bie fie alb cine zmente Slrt Des Эiautilus betrad)ten, allein dies ift unrid)tig. Fn diefer irrigen Meinung giebt (Siç= ner Diefer Muidid ben Naflmen Meeridonede.

Co ift unier פoutilus alfo berabgeretzt. Treil

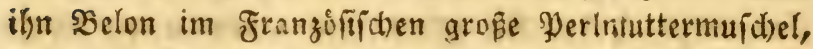
Sorzelan = und Perlenid)ned'e nennt, fo mad)en Ron= belet und Gesiner aus ifym eine Sdnedie uno leugnen, Daß fic ein Pautilue fel. So viel Grrthumer fann bie Rerånderung des PRohmenz erzeugen! Selbit die

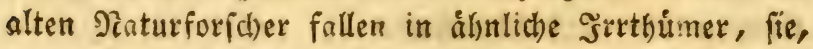
sie nid)t in Dem Grade von ber frantheit der Teue= rungşud)t angeftedt waren, bie gewıbe ieţige Sd)rift= fteller plagt.

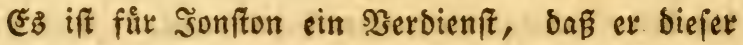
) Rufdel ibren wahren Rang wicber angewiefen hat *), ob ex gleid) in bem zexte, mit bem er bie Figu= ren begleitet, nur wenig son iljr fagt. Fr neigt fich auf 2lriftoteles und Belons Seite, copirt aud) Die fd)ablafte Figur 2llorobanbiz, aber in ber $2 \mathfrak{A b}=$

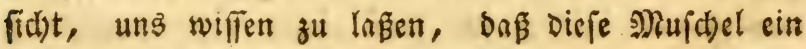

*) Ionston, Hist. nat. de exang. aquat. pag. 3o, tab. 10; Fig. 3 et 4 . 
Sautilug ifr, fu bem ex eine gute Jigur, bie gang wolf ommen iff, won bem Ed)iffaboot linzufugt. Sie if mit einer marmornen, Eaftanienfarbenen Dede iberzogen uns ilyee Spitze if perlenmutterartig, fd wars oder blau fdjilderno.

Rifter, Sonnani und Fird)er mad)ten ez eben

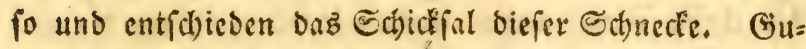

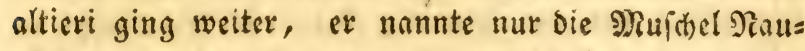
tilug, won ber wir reocn, trennte fie von ben 2 tre gonauten, Denen er Den Pialinen Boot ertheilte. Diefe 2 ret zu felnn, muß̧te neturlid) auf Sinnée ifren

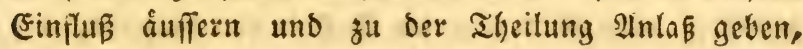
bie ber berilymte Paturforid)er amabm, und bie iekzt fo allgemein angenommen ift.

Rumphiuz. lelyte unz endlich umftånolich uno beftimmt bas నhicy fennen, weld)es fid) ein fo rei= (ไ)

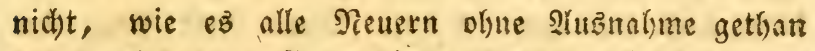
haben, ber) eimer Figur bieję Paturforicher ver verwe len, bie man für cine SRisgeburt gelhalten hat, bie man in feinem $\mathfrak{2 B e r f e}$;) auf Der XVII Supfertafel, Sigur B fielst; fie fteflt wirtlid) bies Molluje bar, aber burch) bas zufammenf(c)rumpfen verborben, Den fid) alle biefe ahiere, fobald fie fid) gefangen refin,

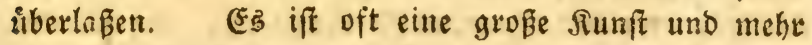
alb Gebuld nothig, um fie zu vermógen, fich) noch

*) Rumph, Amboin, tab. 17, Fig, B。 
einmal in bem 3uftanbe ber \$lusbefunng ben Şlicten besె Beobachterş zu zeigen. S̄in Allgenectnen, wenn bie Molluffen gefangen fino, zielsn fie fich in fich felbit zufamnen, rollen und falten ihre åuffert (s)lie= Der liber einander uno beharren in biefem Zujtande

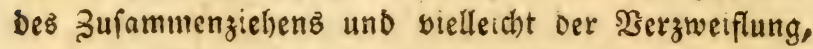
Dhne bie (s)lieber ferner nod) ausftreden zu wollen,

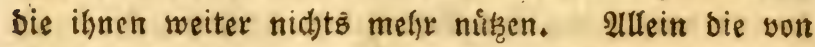

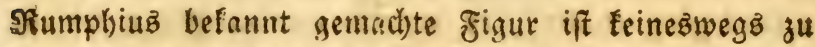
weraditen uno serbient bie \$orwurfe nid)t, die man

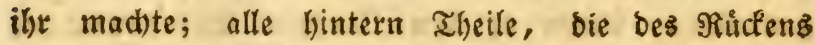
uno bez Maftorarmz, fino mit Sienauigeit hier bar= geftellt; man fielst hier bie (jeftalt beร sBaudb), bie bie ber Sammern uno ihrer Nitfammern befitimmt; Der Nerven, Der fich burch iebe berfelben fortzieht, obgleid). zerriffen, boch vollfommen abgezeidynet. MRan Fann bie zu[nmmengej()rumptte Rúctenhaut fichtbar bemerken, fie ift zujammengezogen; ez̉ låßt fich ein felye hervorfpringendez 2 uge entbeclen uno ber Mafts barm liegt ohne 3weifel ba. Wenn bieje gigur, bie man fo fel)e verad)tet hat, etwaz zu wánfhen úbrig låpt, fo iff's in 2(bfict)t ber vorbern Theile, in be=

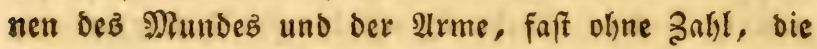

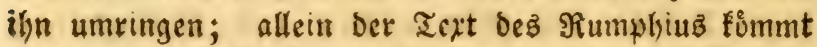
แกร bier zu Şülfe und nid)tż gleid)t (einer Deutlid)= feit, wie man felfn wirb. Allb ber Bewohner eines Randes, wo ber Sautilus fo haufig ift, wo fid) bie

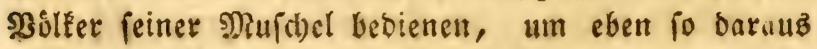

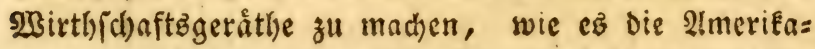

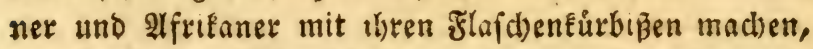

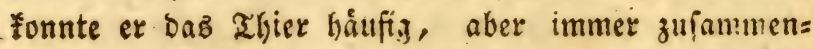

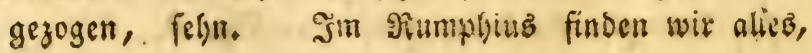




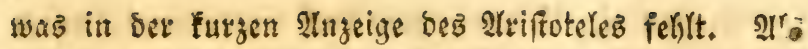

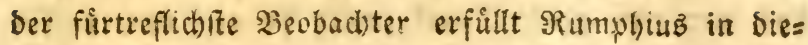

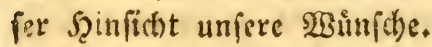

(5: Gatte es wollfom=

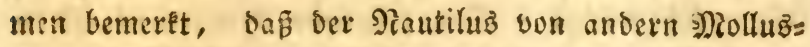

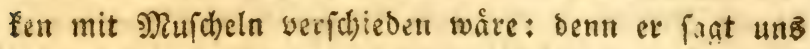

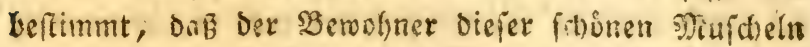
eine 2(rt פolvpe ift, ober wenigftens ein Thier, bas bieien raubfudutigen Molluffen jefse ualy fonnit. WBir

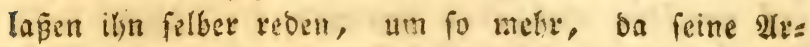

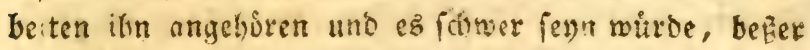

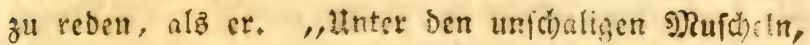
if ber Mautilus bie merimutroigfte, Denn er a:eazt

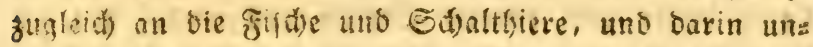
terfideitet er fith won biejer. Det Bewolyner, nels

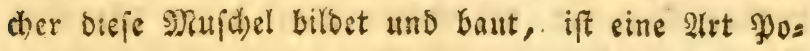
lope.

"Die Perlenmuttermuichel wollen wir in ber art

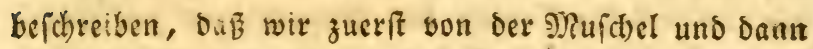
won bem Molluif reben, waz fie bewohnt. Die fri= gur biefer Muid)el ift ichnedenartig, allein fie nalt fich) melix bell fo ftarken, bie unter bem Nabmen "!tm= monshborner bekant fino, ober vichmehr einem Soste olye Riel. SGhre Grefipe yon sorn biz hinten hin,

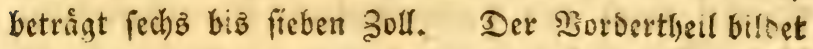
Das Boot, waz oben vier biz fün Queerfinger breit iff. Der Szintertheil bebt fid) úber biefe Deffnung empor, fteigt wie eine runbe Esmede it bie Sgưly, bie fich auf fici) felbit zufammenrollt.

"Diefer erhabene STintertheil iff yon ber Dertic=

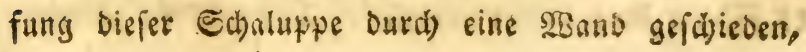


¿ Det man ein fleites runbes fod) wahrnimmt, burdh Daş man eine grofe গabel ftecten Eann, nad) auffen zu ift $\mathfrak{e}$ weiter alb inwendig, wo $\mathfrak{e B z}$ in eine furge

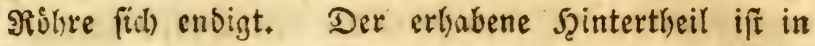
feinem Snnern burch eine Nenge fleiner Sammern, bie burdh ålyntiche $\mathfrak{B B a}^{2}$ be gebilbet werben, abgetheilt,

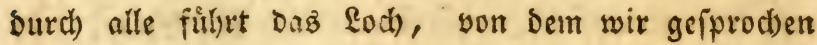
haben. Die Miujdel hat zwey (Sewainder, bie feft mit eistanter verbunden fino und bie Stiorde cinez Meffers haben. Die auffere bebectung ift grob, wie bey andern Ruj(beln, leicht runzlid)t, Durchaus nicht glitt und won id)maksig meip̄er Farbe, unten burch breite und braune Strid)e geflammt, sie an Soreite verlieren, ie radjoen fie fid) nad) Dem Şit= tertheil bingieln: Der innere Iheil biejeß fdunecten= formigen Şintertheils, ift (c) swars uno unten perlmuts

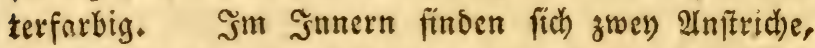

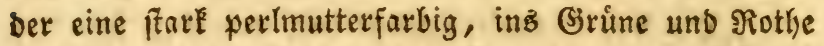

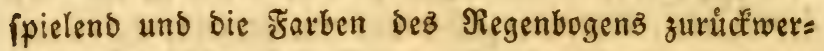
fent; fo idjon biefe Ed)ale ift, bie \$erlmutterfarbe ift nidjt burd)fid)tig und. Kat bie Şålfte ber Stårfe

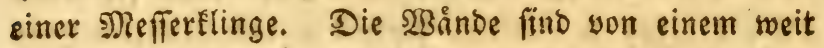
weitern, idsunern, glatten, leud)tenden, wie Sil=

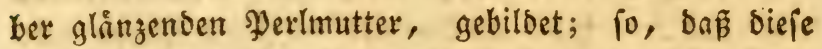

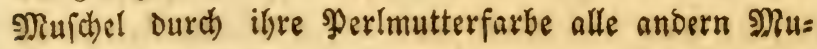
(d) eln hibertrift."

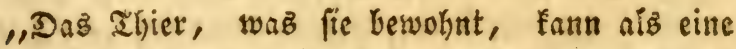
2ixt yon şolyp angefefin wetben, cs hat aber ein

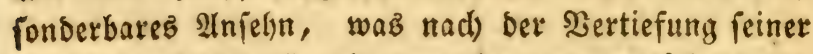
Muid)el gebilbet ift, bie eह nid)t ganz ausfüllt, wenn

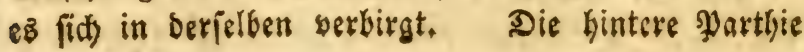




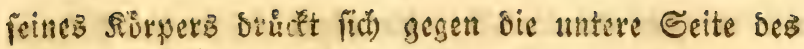
Şintertheilz, indef⿱⺊口灬 feime obern Theile (Die bie untern fino, wenn bas Thier auf Dent Meeteggrunbe frted)t) melis glatt, obgleidh nodh rund, faltig, finorpelid)t fine. Eie find braun ober rotigelb, mit felbazzen Strid)en geflect, bie in einanber fließ̈en, wie bey Den Puinpet. Der Bordertheil dez Sirpepz, 'Det

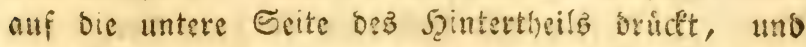
Der beym (selyn folglid) ber obere Theil wirb, ift cud etwas fnompelidut, aber nidjt fo, raic bie vorterges henben Theile, bic mit viclen Ëdrupfrupfen beragt

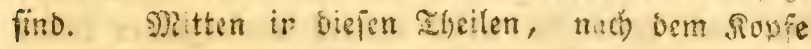

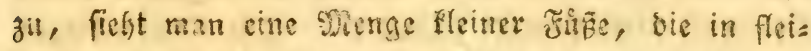
fdidide Enppen, bie auf einanber liegen, auzlaufen unb pon ieber Geite ben sinunb bebeden. Seder bies

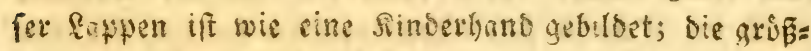
ton unter ifren, bie cuffern, endigen fict) in zwan= zig biefer Finger ober fleiner. Fibpe, alle haben bie finge eineb rarben suerfingers, bie Didte cinez Errobbalmb, fino runb, glatt und baben bte Sdrupf=

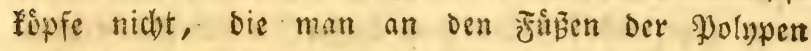
wahrnimmt, aber gegen bas Enje find fie ruberar= tig platt. Meber bicien grofen, fleifchigten Enppen liegen anbere firrzere. Die Zally ver finger yon biefen ift geringer, fie baben beren nur fechizelin; auf biele folgen andere noch fürgere, sie fida biz

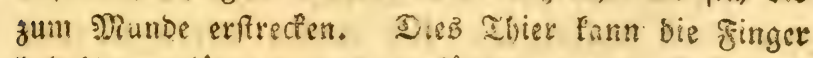
beliebig verlángern uno verituren, Denn fie bienen

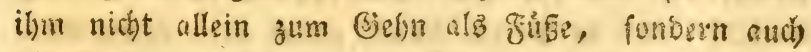

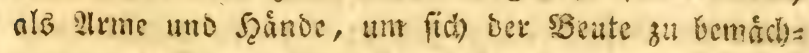
tigen und fie zum monde zu firgen. Der gghuns ift mit einsm fely: getrimuten Sdynabl bewaffuct, 
wie ber ber Dintenfijabe; bie obere Şålfte bez Shnna: belz ift großß, gebogen, an ben Råndern gezålynelt, bie untere, weit fleinere Şålfte, ift gleid) fam in bem Sberfhnabel verborgen, berbe find fpits, ge= bogen, fo, Daß fie bas fleifa) leid)t durdboringen fonnen. Diefer Sd)nabel if hart, von fowwarglid)s blauer Farbe, yon Ripwen umgeben, die weiś, flets ich)at, leberartig und bisweilen fo lang find, da fie ben ganzen Sdunubel-bebecten, ber übrigenz im= mer in einer gallertartigen Iindie, fo wie in ber Nenge ber Finke, bie il)n umringen, vrrborgen liegt,

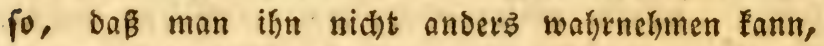
als wenn man Biewalt braucht. Die Ilugen liegen etwas tiefer, auf beyden Seiten, fino felyr grof, aber man findet bavin feine 2 ugentugel, ob man gleich) bie Scheibe barin wahrnelymen fann, bie mit

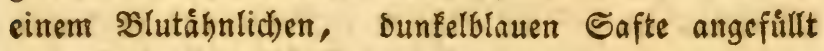

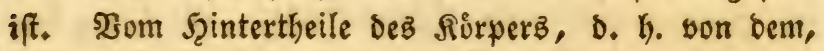
Der auf ber erfen Rammer ruljt, låuft ein felle wer:

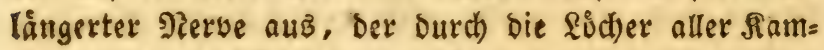

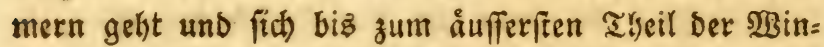

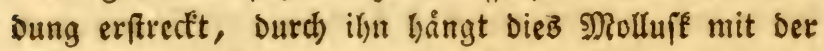
Nuidel zufammen. Die andern Sainmern find gang Keer. Diejer Netwe zerrei

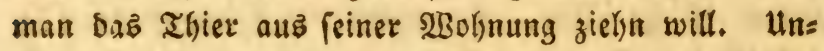

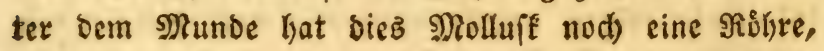
voer einen fleifbigten, faft runben Strang; feine Sarbe ift, wie bey Den Dintenfifichen uno झolnpen, sweiß̄lich, und in biejem Sanal finbet man einen 2 (นรిs wuct) in Beftalt einer ăunge; diefer Ranal bient biejen zhieren, fo wie Den Dintenfifd)en unbezmei= 
felt bazu, um ben fhwarzen Saft fortzu(d)affen. Der Bzauth hat feine horizontale Serfinung.

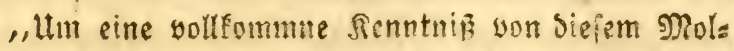
lugk zu geben, zeid)nen wi. ş het in berfelben Stellung, bie irm gewuibnlid) ift, wenn ç auf bem Sisaffer fibmimmen will, nemlid) bie Seffnung feines

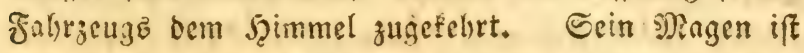
mit Eano, fleinen Etcinen und ben Utebereften son

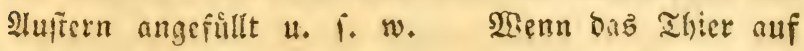

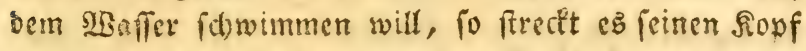
und alle feine Fajern ăb ber 9 Mufhel; eB breitet fie alf bem Meere aub, uno hâlt immer baş Şin= tertheil auf ber Dberfinche. DBill co ouf bem Diees rebgrumbe fried)en, fo nimmt eह̉ eine entgegengefegte Eteflung an, bedectit ficl) albdann mit feiner Mu= fibl, fein Sopf und feine Fafern rulin bann auf Dem Sanbe, hiber Den ea fünell gemug hingeht. Zuf Dem Inecreşgrunde balt fidt) am liebften auf uns

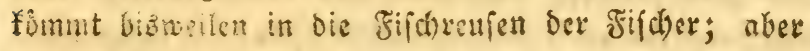
nad) cinem Etum, wenn bie গulh wieber hergeftellt ift, fieft man siefe Triere haufenwe auf Der See

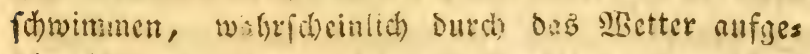
fisentht, unb ifiren tefen 3ufluctsonorten entriffen,

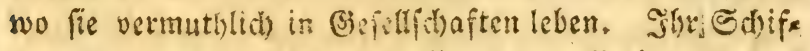
fen if won furzer Daner; fie zielun alle iflere Fafern ein und cilen in bie siefe. Dft finbet man bie $\mathfrak{M}$ u= fhet bez I

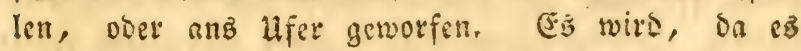
Dhne হSBaffen iff, Die Beate Der Sirabben, Jeayen,

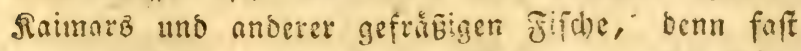

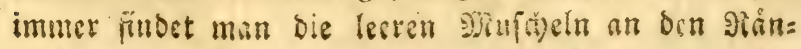




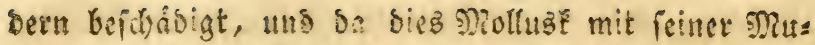
fchet mue in einem Sounte zujammenhingt, fo fallt

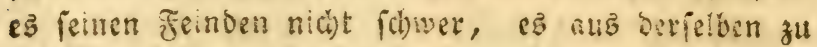
reiffen, um es gut veriblingen, inbem fie bie Edyale

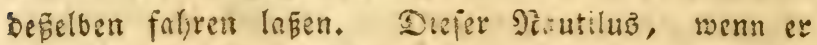
noch jung ift, uno faum oie Grupere cines zwolf Soub= Ertite erreicht bat, iff inwensig uno aubs roendig perimutterartig. '(Rumph. Amb. livr. 2, chap. 59,60 et 61.)

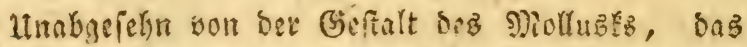
sen गiautiluz bemohnt, beß̧en vorbere Theile zufum= mengefdrumpft fino, hat פiunph uz einen fürteefi= d)en Supferfitich) von ter Mnuichel binzugefúgt; die, weldye ex barfiteflt *), ift etre ber niedich)iten utis fd)onfere, bie wir fennen; ilse Etrelfen, won roth)= fabler, faftanienartiger Fantue, zieren die åufere

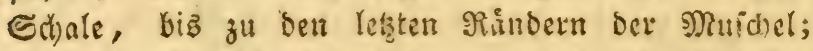
uno man bemerft ba volffommen bas allmaltge $\mathfrak{Z}_{\mathfrak{n}}=$ wad)ien, bas mit iedem slugenblicfe, fo lange daz

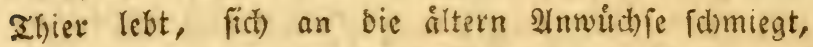
inden es ben Lmfang ber SMufdel vergribert, Die.

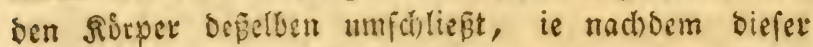

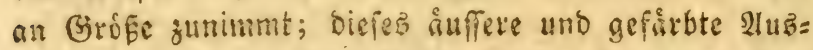

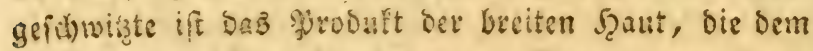

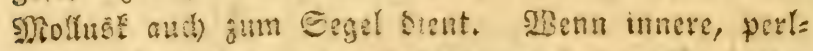
mutterartige Saget die Fefingleit ber Maifdel befor = bern, fo baben fich bisfe fpatern rengen burd) cin

*) Rumph. Amb. pl, XVII, Fig. A. 


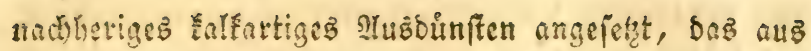

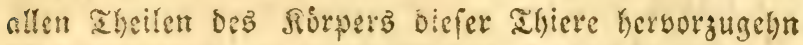
f(i)eint; wit werben ifre arbeit beobad)ter, wenn wir you ber Manier resen, auf bie fie dic einanber fo malgftende Rammern bilden, die ifre Muidieln

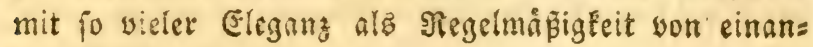
Set fdesiocn.

Gealua bat uns nuf berfelben Supfertafel bes

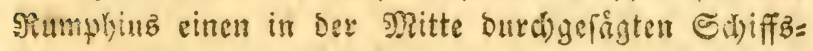
Iuttel geliefert; Die Figur ift gut genug; man fins bet barit cinen 23 eweis feines Sd)arfinns uno feines

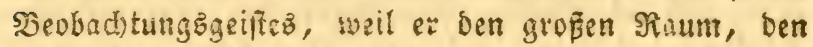
Det fiorper Desె నดier cinnimmt, weld)er in ber lesten fommer ruht, Gat vorftellen lafen, und ber eimen hinleinglid) gropేen গaum bebarf, inn zu be= berbergen.

Snocm wir die Soriftfeller ourdigelyn, bie nach numpritub uber bie Raturgefdichte gefdrieben haben, fo fieht man, daff die Figur, bie ex in feinen Sberte besinnt machte, immer ifre Tesugierde errent hat.

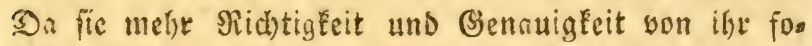
Derten, fo baben fie einige zll etfláren gefucht und andere ganz vermorfen. Die, weldse fie anmalymen,

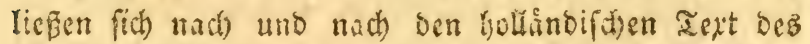

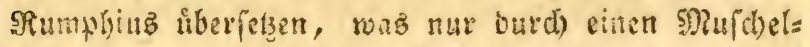
fenner geidselyn fonnte; uno on ite wabricheinlich bar zu Den erften, beften Heóerfekge nalumen, fo fanoen fie in ber Heberfetzung now) mefre Sunfelfeit, als in

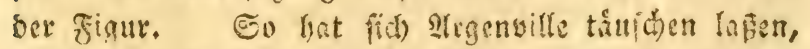
fonberbare Bemerengen-und irrige sofibreibungen 


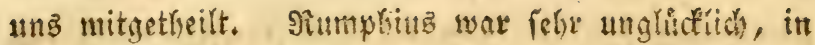
bie Jånde eines fo unfundigen Heberiekers zu follen. Da nun unfere Echriftitefler Den Sintritus nur in Irgenville geleien haben, fo baben alle die gigur

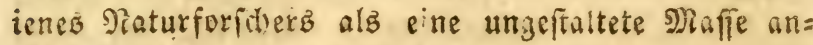
gejerti, die nur verwerflid) fen.

Fraannez, Der bie Rammern, it bie baz Sins nere ber Siufde! getheilt ift, gezåhlt hat, ingt, Daß fich) Deren 30 bis 40 in Dem Pautilus Derfelben Siut finden; bierin frimmt er mit 2 trgenville ilverain; al= Iein won ber anoern Ecite fagt unz Şalma, Sos er Deren biz 50 zállte, und er gliubt, Da $\tilde{B}$ in beut

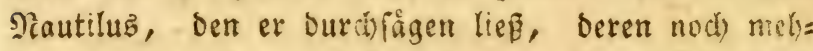
rere waren, da nemlich inehrere, ob er fid gleids ber feinften Saige bebiente, nach ber Spitge ter 283 !n = bung, bie von aufferfter Zartheit waren, zerúradien.

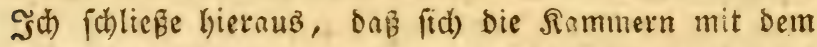

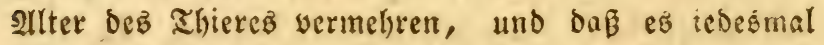
eine neue bilbet, wenn fein Siorper gejwungen ift, fich) zu Der weiten Recre ju etheben, die fernen 21 uf= entyalt aแżmact)t. (5in junger Natutilus Eann in 2Sahrheit nicht fo viele fiammern haben. als? etn al= ter unt braudit fie aud) nidit, weil er fich nod nid)t grobe Sammern hat verfertigen founen, die immer Dem Durchmeffer Der Niufacl angemefien uno bie

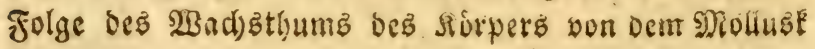
find.

2ुab bie İiefe von 3 biz 6 3oll betrift, bie F̧asannes der Seffinung ober bem Theile ber Niufchel beilegt, wo bas ahler wohnt, wenn es zu feitret 
grobten Entwidflung gesiern ift, fo ridstet fich bieje Iicfe nad) benfelben (sicietzen uno muß nad) ber $\mathfrak{B} e=$

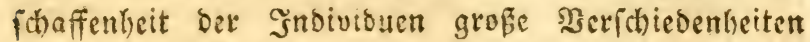

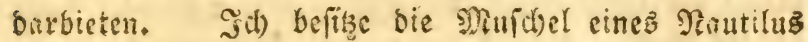
won stutuoinn, bie eine Tiefe son melnt a!s fieben Soll und eine Deffnung won $3^{\frac{1}{3}}$ Boll bat. Diez finent mir bie erffe Grofe cines Nautilus zu fenn.

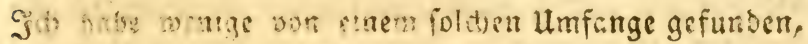
inbeb (d) in mainer Sammlung ungeheuer greß̈e, ver: feinerte gautifiten bube, die faft einen Fuz lang find. Fabannes hat indeß die Entfernung zwifbel bis refiter unb erien firmmern bollfommen beobad)= tet, fo nis uch bie geriumige Wbobnung, bie melyt

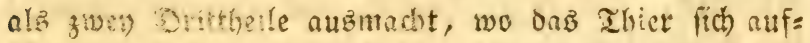
halt, inbmis ş

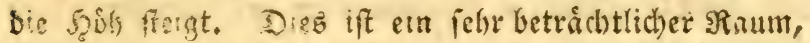
wie wit hat ten ben Jlmmonghornern und allen शRu= fdjelit biefer sirt finben.

Ramart, inbem ex yon bem Prattiluz, wie es̀ aut) (ivultien und finné gethan haben, bic Mill=

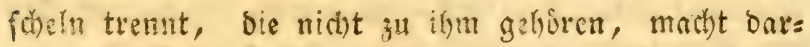

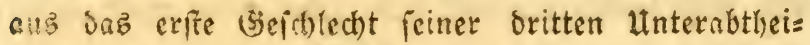
lwn. Er gitot feine volfommnen, d)arafterififchen Sennzidt)en an. Den einzigen (Sharatter, ben idj

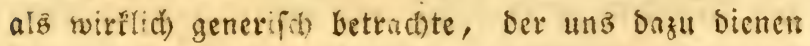
funt, Diefe Thiere gewiffermab̈en zu chrffficiren,

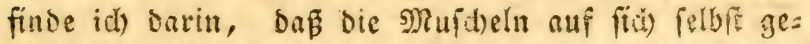
rolit und fammerig find. Daf die Rammern ourch: lod)ert find utid Dẩ bie lekte $2 B$ indung alle andern

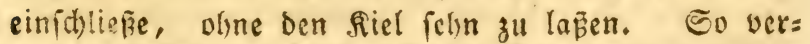
einigen fids bie Drbuliten mit.Dem Pratitilue, mit bem 


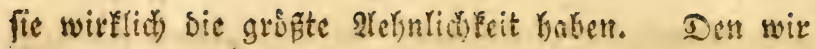

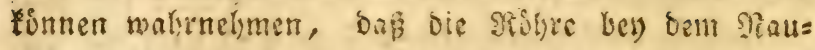

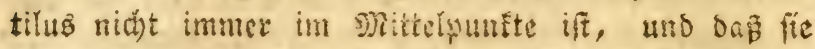
biszweilen nicht allein bo ifr. Syldein Eamarê hatte

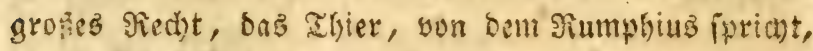
Dlyne EinjŏbånÉung anzuneburn, uno $e B$, ob es gleid) in cinem zufammengeid)rumpften aufande war, alz ein mit cinem flopfe weriêlienez Molluz̨ zu bes trad)ten, uno indem er feinen Drbutiten ein álynfidjes Thier zum Sewolner- gab.

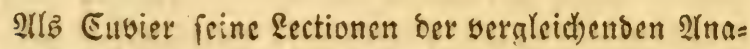
tomie mit Gemilloen bercid)erte, fonnten wir nicht crwarten, Daß er Die Racfen, die peine erfte Familie Der Mlollublen barbot, fogleid) ausfüllen werbe; in bie zwente Dronung *) freilte er bie giuf(u) 2lrgonauten uno Dez Tautilus, in Der Şoffrnusg,

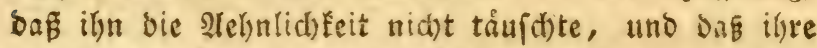
Bewolner fie cinft zurudfobern wirben. Diefer

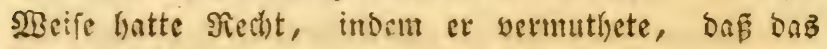

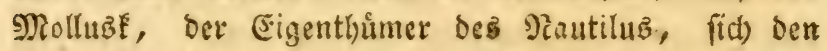
Dintenfifd)en, Salmars, গুolypen, waz aud) bey Den 2 legonauten ber Fall iff, fehr nahen múpee.

Deborn **a), wie Sinnée, verband alle fommri=

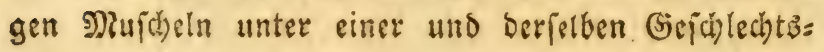

*) Cuvier, tom. I, 5. Gicmålde.

**) Dehorn, Test. mus caes. pag. 14.1. 
benennung. Utntex Dem Nakmen Nautilus begreife

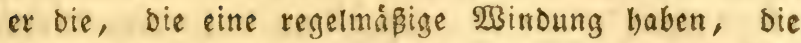
fid) liber bie SBinoung verlangern, uno felbft bie, Die fiti) won ber graden einie nidjt entfernen.

שะ fugt ilnen bie ganze Renge ben, bie Slancus in Dem Sande won Rimini beobadbtete; wenn Dellore ben Sulbani gefannt håtte, wie milrbe er bns (5e: fchlecht bez Nautilus bereichert haben! Ex felbit ex= ftante uiber ben unzorllbaren Reichthum, Den er za

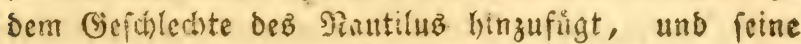
Unermesild)feit, fogt ei, bewelst uns eben fo bie

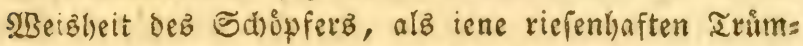
mern, bie Sinod)en Der Frofugel und bie 2 BBunber Der Natur.

Nach biefem frommen 2tuskuf und nachbem ex mit weniger 230 orten bie charateriftifde 3 efonreibung

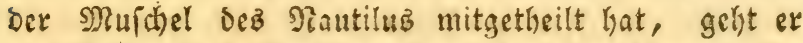

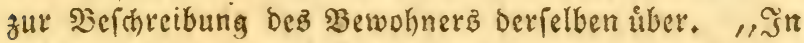

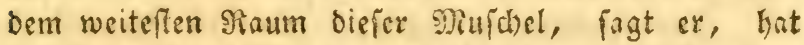
cin Thier feine 280 bnung nufgefdlagen. Sin bem

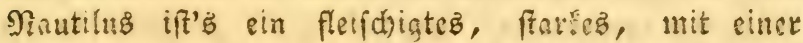
Membrane und zahlloien 24rmen bewaffnetes Mollube, bie ps belicbig ausftredten uno zuridezichn Ennn; fie

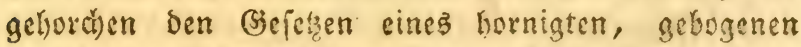
uno fpiţen Sd)nabels. (Eine nad) Der lineren fiano gevichtete Robre, forigt weit hin bell fowirgeften Saft; blaue, tieftegende Jugen fajwisen einen bits

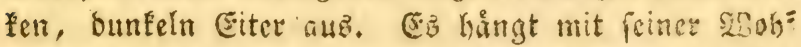

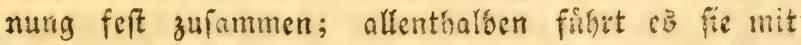
fiid); ez ift feine feiner zableció)en fammera, bie ez nidjt bewolgnt, ez geht yon ifjm cin Faben aus, 
mit bèm ç ant lintertheile feines feibes verfehn iff.

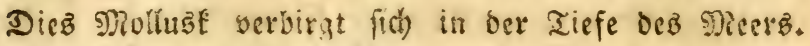
(5) erf(t)eint nur nach einem Eturm úber Dem $28 a f f e r$.

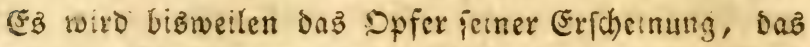

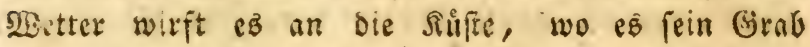
finoet.

Unftreitig hat ber beutiche Naturforidhet peime

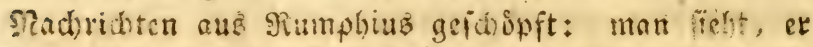
hatte biefen slutor gelefen; er ninme feine seforet= buna an; ex fap̧t fie zujammen, un Darnad) Den

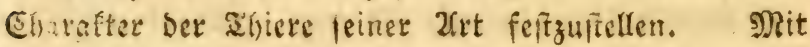

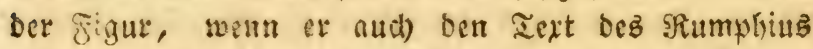
annabm, wergâlt fict's anders. Selorn wartet auf 2iaturforider, bie auf feinen yfaden wandeln, uno cine besere zeichnung won bicjem I Ifiere liefern follen,

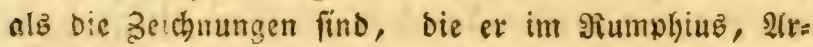
gendilfe und Martini findet.

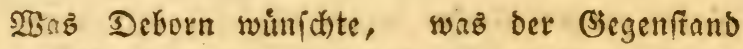
meiner sibunfle war, bas habe id erfalten. Ehee= ters von গotterbam, ben ber Tob, zu frull fir bie Sisifenichaft, hingeriffen hat, mad)te mir baz Ge=

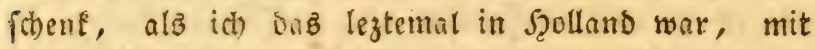

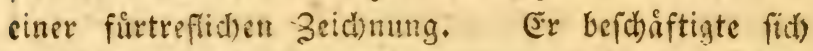

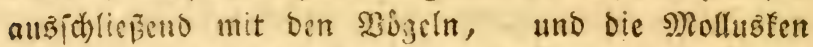
zogen feine 2 lufmerflameit nut wenig auf fich). Stlo er mir bie 3ecthnung wise, crfannte id) in berfelben

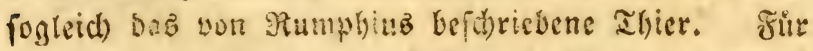
Diez Gejd)

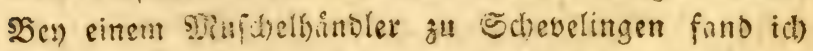
aud einen fols: gropen, formen fommigen Pontis 


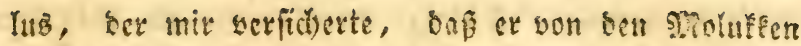

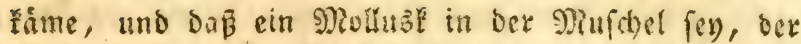
eine breite jeaut in Geftalt einez̉ Segelō babe. war ber von Rumplius beid)riehen. Nach oer 3eid)=

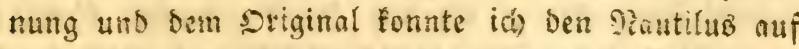

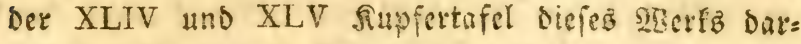
ftellen, bie an Dex Epise diefes Banús fielyn.

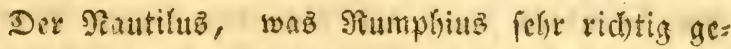
fagt hat, iff cin Mothêt, was ficl) ben gyolywen

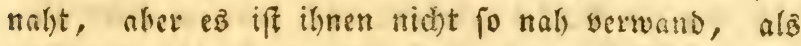
bie Irggonauten; wie ben ben Dolypen finset man bey bem venutilus bie Eingeweibe in einen musfulo= fen, fleifongten Sact eingeidloben, der eben fo bea

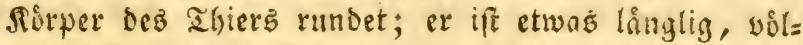
lig runo, endigt fich) aber. an bem Şirtertheile bez

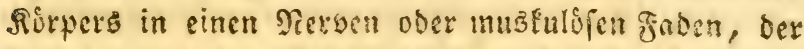

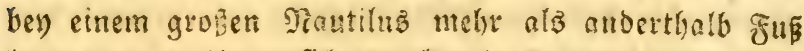
lang ift, weil ex fich burdy alle Sammern oer Miu= fibel fortzieft, um fich an ber Epitze Der sgintoung zu halten, wenn auch Dดz Mollust all Çrofice zu= nimmt: Diefer Foben, ber ba, wo er aubläuft, bie Stårfe ciner Biolinfaite bat, ift an feinen couj= ferften Ende fo fein wie ein $\mathfrak{S}_{2} a \mathrm{ar}$; er ift baz cinzi=

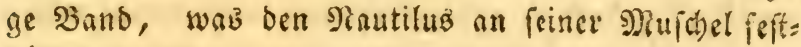
bålt.

Der Cadt biefez Nidluątz ift nid)t horizontal ge= fpalten, wie ber ber Dintenfifche, Statmars, Po= Inpen uno 2trgonauten; im Biegentlyeil ift er ver= follofen und ganz won sinem Sticte, ex hat feine andere Seffinng, alz Durd) Den abfưhrenden, allen 
IGieren gemeinen Sanal, Ser bey biefem Tentilus åfierft herborfpringens iff. Gben fo wie ber 21rgo= noute, liegt audi) ber Noutitus in feiner Nufdel auf bem ridfen, uns ob man gleich) yon linten feine \$eroinnung fiert, bie ben ŞalB andeuten funnte;

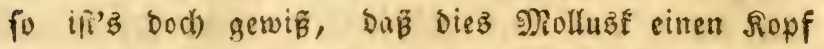
bat, aber ex verliert fidd in ben breiten Shauten, bie uber ifn binfallen: Der Sot, wo ber Sopf iff, låpt fid) befonders burch) bie Rage bet stugen bemerfen, Die etwas auf ber Seite felht, felyr grop find uno fich wie ein sBurfel erleben: id) fann eร̃ mid)t glau=

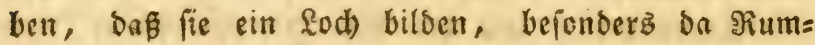
phiuz fagt, baß fie mit einer wåfrigten, blutigen Feuditigeit angefüllt find, Die an ber Stelle ber Fryftallenen und glasartigen felin, bie Dab Drgan Des̉ Selnes bey vielen Zhieren auşmacht; wir fónnen gluuben, baß́ biefe slugen benen ber Polypen glei=

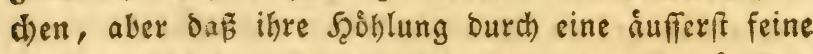
Şaut verfd)loken ift, bie bey dem geringften áuffern Stô zeripringt. Ueber bie 2 lugen erhebt fid) eine breite Szaut, in Sieftalt einer Sappe, beren fid) bas Mollub bey feiner Eurzen Ericheinung auf Der Dber=

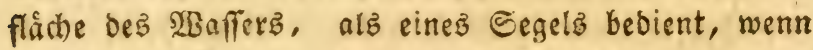

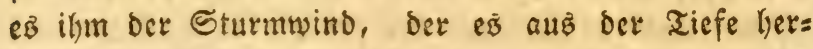
sorrif, geftattet, zu fohwimmen und bann wieber ğ verjenen, wenn ę feinen Sidherheitzort wieber gefunden zu haben glaubt.

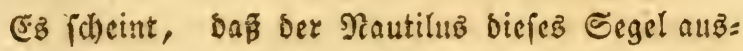
fpanmen fann, um feinem Sopfe eine trid)terformi= ge Geftalt geben zu esonnen. 2luf bem Baudi)e fin= bet man nods einige zheile, ater weniger lang uno 
cr erinnert an bie Şant in Brofien, bie die 2trme ciniger Bolnpen an ifrer $\$$ afiz vereinigt. Dieje breite Srout if sufferlich glatt, nber im Sonnern iff

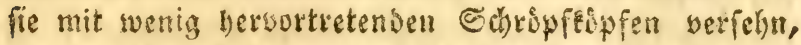
Die im Sinfed fethn, und bie key Dem Shantilus an Det Stelle berjenigen fins, mit benen bie ?trme an=

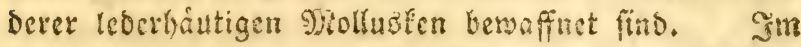

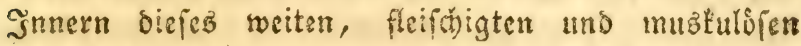
Irichers, nach) vorn zu urb faft in Dex Mitte, fin= Det man ben gebogenen, fergnideten uno hormartigen Schnabel, ben idh bis ietze bey allen biejen Thteren gefunden babe, er feejt im Mittelpunfte Der runben Ripper. Diejer Muno if mit viclen fappen ober platten Il:men umringt, bie in Finge: auEllaufen; Faum finbet man beren zwey in Der Roflye Der \&ippen, aber in bem (sirade, alz fie fich won siejen entfers nen, bebecten fie fitt) im Secrabfallen einamber, uns bie langften, zuleşt fitekenden, Gaben zmanzig yon Diefen langen Fingern, won bet Didfe eines Stroly= halms und gejen bie Switze find fie etwes glatt. Aluf Der XIV Zafel fielyt man einen biefer silne augezeid)= net, ber mit vierzehn Fingern verfertn iff. 2llle Dicfe Slrme ureiten fich) wie cine Pofe un Den Pluno son bem Moluse, won welbsun wir reben; dued) itre Rage und iyse stofufung, erinnern fie uts an iene fdusnen 2 mmonen, beer vielnely an teneb Stern= fraut von Éfinn, weldeb unfere Gåten ziert. Die (S)ånebtumd)en ftellen unz ibre Şlumenblatter nid)t

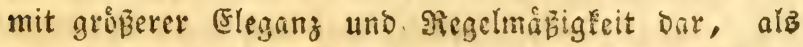
Der Dioutilub feine 2trme, wenn el fie in volliger

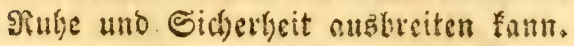




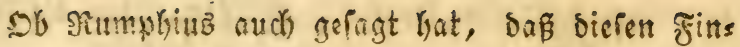
gern Die Sdrippfoupfe fehlten, of ex fie gleich als cin 9)ittel zum Greifen fur biefe Iistere betrachtet,

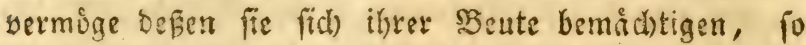
glaube ith Dagegen, Daş Diefe finger allerbingb mit Ed)ropffupfen bewaffuct fins, die aber vermoge ifrer fleinleit won bem beften sluge nicht gefelyn werben fonnen. Die Innlogie verftattet mir hier biefe $\mathfrak{B e r}$

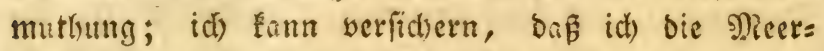
anemonen febr genau betrad)tet Gabe, Denen man bie Gibropfeppfe ebenfolls abfuridt, uno bey) denen id) fie unter Den armen in zablreidher Menge gefunden habe; man fann fid won ber Mafhelfeit biefer Alnga=

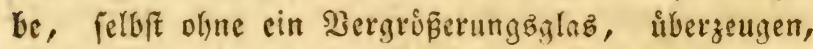
wenn man mit einem Finger ber 2 inmone unter ben

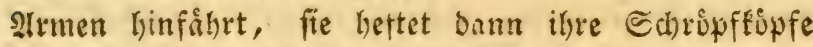
baran, dies slnbangen fullt man fefre ftare, wenn man ben finger funell juridgiebt, ben man eben sorgeftrecft Gat: man fiblt $e^{3}$ bann, wie diefe Schropfiopfe won ber Şaut lożaßen, an bie fie fich eben feftgeiogen hatten. Eben fo werbirtt fich's auch mit ben Forallenpolnxen; indem man fie in eine Schuffel woll Meerwaffer legt, fann man mit cinent

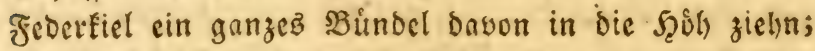
Die 2irme biefer solypen find mit ungemein Eleinen Gothropfoupen verfelin, aber fie baben eben bie Ein= rid)tung wie die oer Sintenfifhe uno Slolypen; uno wit werben ez felyn, wenn $i d$ bon biefen I Theren rebe, ben let3ien Eproffen auf ber feiter ber Dol=

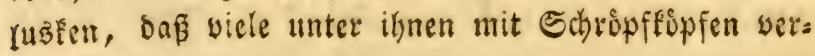
felsn fins. 
Denten funner wir es unz alpo, wenn fich ber Diautiluz feiner gefingerten 2 trme, alz gewtifer tref= feln bedient, um fitib feine Seute zu unterwerfen, er ez nich)t anderz thun fann, als weil biefe Arme mit Estrupffipfen verietn fins, ob, man fie auch

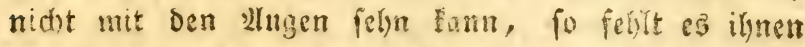
Doch an Der notllingen Etirfe nidt, un ein spfer, wenn ez eimmal ergriffen if, feftzuhalten uno ihm

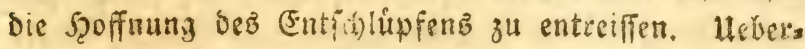

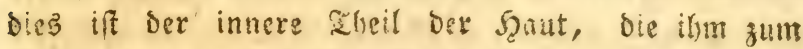
Segel bient, mit frurfen Echropifupfen veriehn, die,

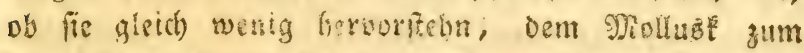

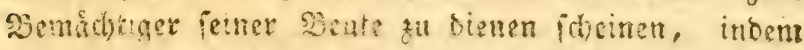

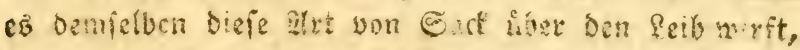

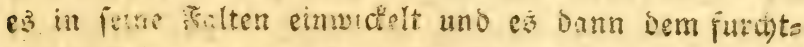
baren Edhabal zum Serreiffin iberliefert.

Seht foine Garken gieren ben Sivper bez Nau=

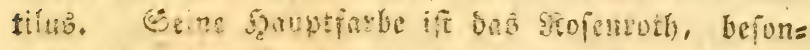

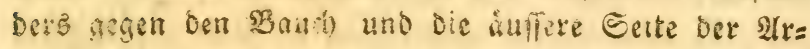
me bitn. Dis ganz", felse glatte Saaut, iff mit Syurpurarbe gititsfelt unb braun gefledt, mit bunf= lern Stellen; Die fidt auf Der Ringe tes Rütens binziefin, uno fich folbft auf cinen zheil ber shem= brane, bie ithm zum Eegel Dient, erfiretien. Dipfe Sgaut ift auf oer innern Esite mit Sdroppfepipien verfelin, bie finctrifh gefsellt find. Durd) Daß

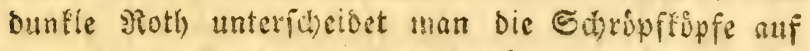

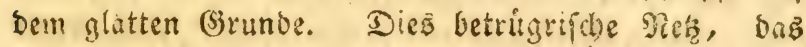
cben fo gefát)rlit) ift, alz bie Alrme ber syolnwer

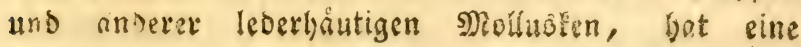
Fleifthfarbe. 


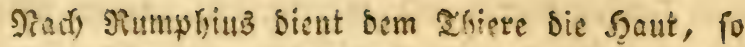

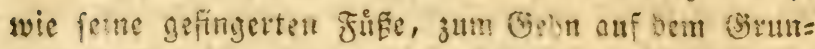
be bes Decers, wo eb mit vieler Szurtigleit, intem

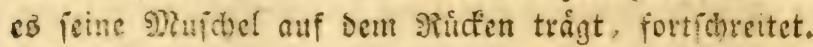

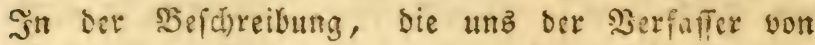

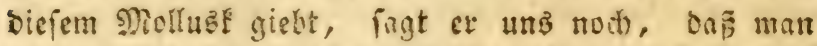
in bem ?ftetfamal, bet bem Ilyiere baju bient, einen

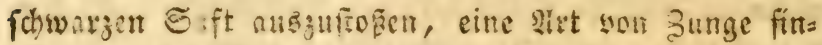

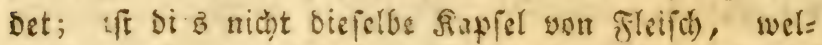
che Danjelben Sinnal bey cinigen Sarmars verid)liçt?

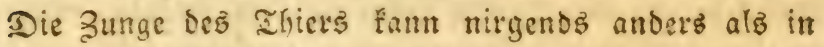

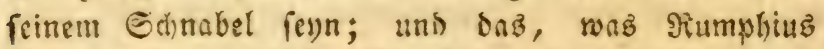

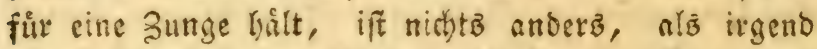

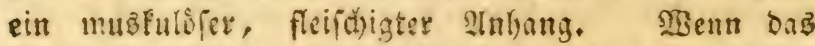

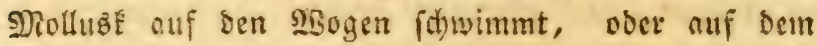

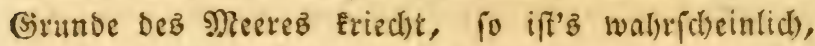
Daß̧ hervorfteccit, Samit fid) bie 2lugen diber Den SRand berjelben erkeben, um stlfez fel)n zu fonnen, waz um bafalbe sorgeht: wie fonnte es jonft ber Giefaly entogelyn; wie fich der sgeute nalin, beren fich feine

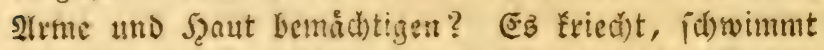
und feinen ङiten fonmen iene Fertigfeiten nidjt fer)=

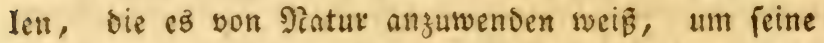
şeute ju verfolgen, die meht von bemielben zuridt= sweid)t, als fie fïh) ifm unlit, weil bie siatur allen

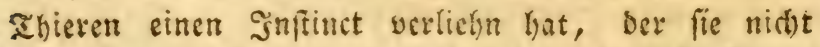

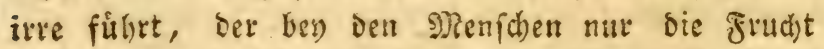
einer langen Erfalyrung ift. Jfle wiffen, ofhe 24us= nalyme, ifyen Feindet ju entwi(d)en, fennen felys oft die Edylingen, dic bieje ifnen legen unb fuchen 


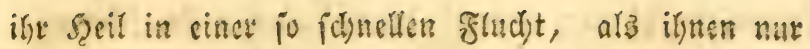
miglid) ift.

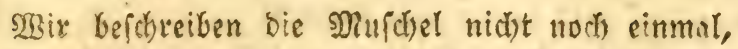
fie tif zul bekannt, um eine weitlånftige Sd)ilberung werlangen zu funnen, uno ps herricht in Şinficht Derfelben fein 3rweifel. 9Man findet fie von verichie= Dener Grópe, uns bie 2lutoren irren fid), bie fie in grope und fleine theilen wollen, oa bie form ders felben fich) gleid) bleibt. Die obern Ránter ber

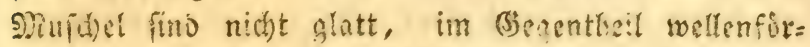
mig, inbem fie vom sRittelpante zu Der ltmfañs=

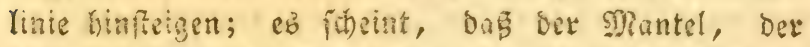

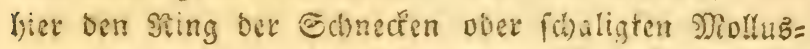

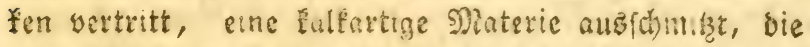
bald eine butfle srangenfarbe hat, bald wie ein

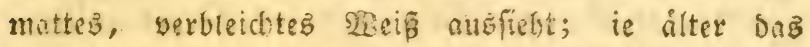

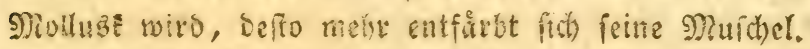

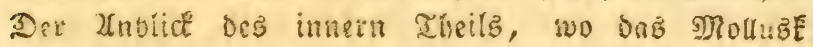
woint, fann un cinen SEegriff won ben untern Thei= Icn feines Surperb geben; man fieht Da, Dar feine ganze Şaut nete falf = und perlmutterartige Ragen nbient, bie fich feft an bie iuffere sisand anfdimies

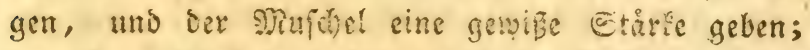
man fann felbft bemerten, Dấ die stimmung dez Seintertheils mit bichten Eagen won ciner fóbieferarti= gen, fdwarzen perlmutterartigen Shaffe vebecert iff,

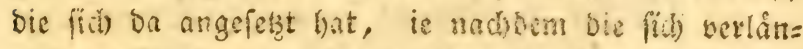
gernde Miembrane, Die bab Eegel, Dust bie Sappe bitbet, feuditigfeiten ausiowntlete, bie fich audh, mas ith berits angefinet habe, auf bem Sauche, aber weit finger, jeigt; Diefer Merimuter ift walye= 
forinlid forwarz, weil barauf ber exfe (d)warge Saft iprist, ben bas zhier ausftupt; es ift mogs=

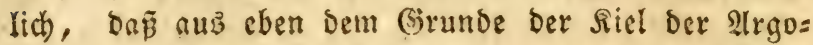
nauten, oft braun und rothfall gefórbt ift. WBeil

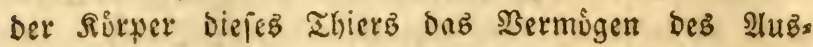
fdhwikgeng in cinem holfen (Grabe hat und weil ber bintere Theil feines Rovpers hetsorrngeno zu jenn fcheint, Darum fann eb bie $23 a ̊ n d e$ bilben, jwifhen betren fo bemertbare Sommern find, â gewisen 3̧eiten, bie wir nicht fenmen, allein bie iålyrlich in bem $\mathfrak{R}$ eben Des Thiers einzutreten id)einen, vielleicht

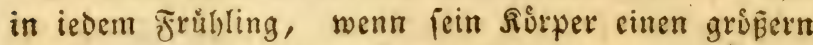
Uumfang als bas vorkergelsende Sahre erreidit hat, er=

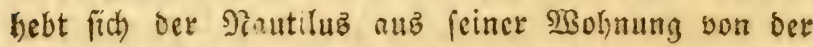
Şơhe eines 3ollz, wenn er nemlich f(t)on alt uns nicht melgr jung iff: Der hintere Nerve hat fid) ver: långert, er ift gewad)fen, uno ber אürper berifiryt

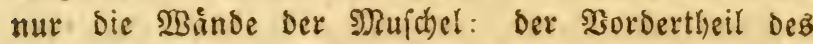
Siverpers idswebt gleich)am in ber fuft, haingt aber

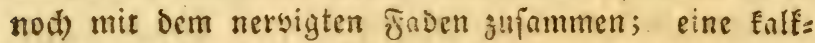
und perhmutterartige Shateric (d)wikgt aus ben untern

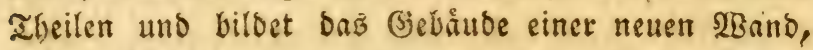
bie burch) bie auf einanber liegenden fagen tåglid)

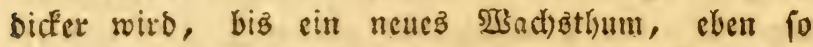
fd)nell, wie bas beid)riebene, bas Mtolluŝt jwingt,

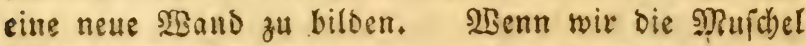
sffnen, fie nach ilyer ganzen sange fpalten, fo fin=

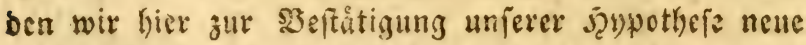

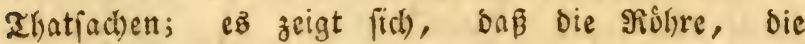
Surd) iebe 2 Bano geht, nicht fortgefeght iff; fuum serlangert fie fich eine finie unter einer ieden berfel= ben und eine blope Szaut ber animalifden Naterie 
madjt bie Fortietzung bia zu ber folgenónen Sammex

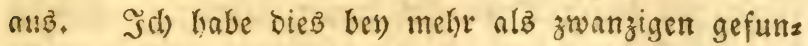
ben, bie ich iffnete; und biefer $\mathfrak{B o r f p r u n g ~ b e u t e t ~}$

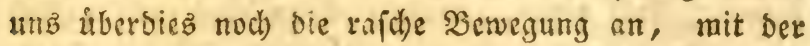
Das Miolluş vorwirts gegangen ift, obgleid) biejer

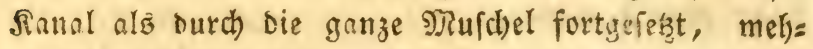
were vorgefrellt haben. Favannez hat fid) in bieferm \$unfte geirrt, inoem er uns fagt, bop bie nad) ifrer ganzen \&ånge teere গiólue, nur aus einem Ethit'e gebildet ift, ob fie gleid) aus fleinen Irict)= tern, bie auf einonder gejekst find, zu beftehen

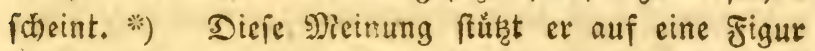
in feiner 3oomorphofe. **) Allorovandis Figuren fino

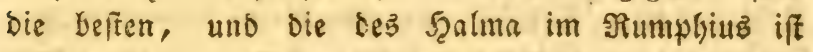
yollémmen. Deborn irrt wie Favantez, indem ex uns in cinem silbe, bas feinen zept beglei=

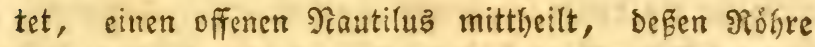
fortgejeegt iff; biez, idi) wieberhohle es, findet bey Diejer Z(rt nic)t fratt.

Srenn, auf ber andern Sate ber hintere Theil won einigen Pinutiliffen nidst vollig rund iff, wenn er einige SBinel und Fortfintse zeigt, wie ce beftimmt

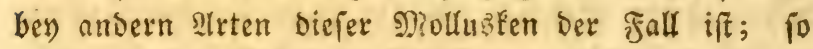
mu官 man Den gandenden biefe Form anjeln, auf be=

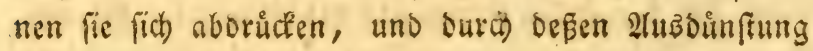

*) Favannes, tom. 1, part. 2, pag. 690.

**) Favannes, Zoomorph, pl. LXIX; Fig. A 2. 
fie entfanden. Sies werben wir hernach aus ber

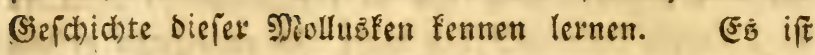
berielbe Fall, wenn fich ilye אurper in zwey nerbigte Faben, ffatt eines, endigt; Dann muß man natir=

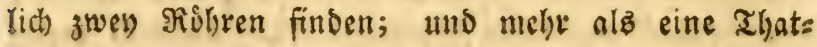
fache betweift Diez.

Faft alle Sluturen haben bie Seld)ichte ber IIntil=

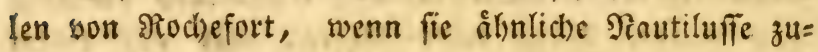
foumenftellten, angefúfit; und wirḱlid), wenn wir

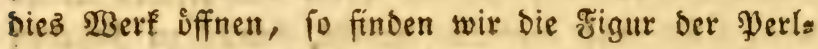
imuttermuidhel zu zwey verid)iebenen malen angefuthet, ber eine ftelyt Syagina 2r6, Siapitel 19, Der andere Syagina 146, אapitel 14, wo biejer Rautiluz bem

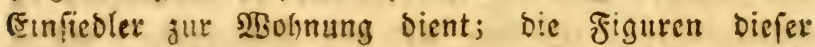

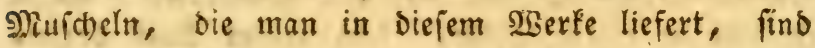

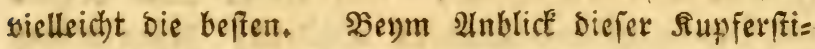

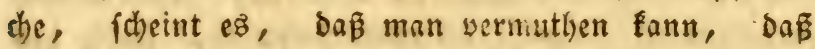
fid) biejer গiautiluz auf ben sintillen uno ben ameri= fanifd)en Jnieln audb findet, allein ich habe ifyn bas felbft nie geielnn uno glaube verfichern zu fonnen, Dấ man ifhn ba nicht antrift. Der 3eichner war

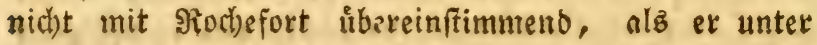
bem Nalymen Ed)iffafuttel (burgau) bie \$erimutter= muidjel zeichnete; in uniern amerifanifchen Eolonien finbet fich ber Echiffâtuttel als bie Mujchel, bie un=

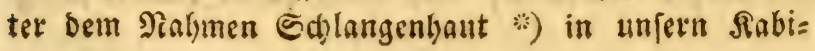

*) Turbo pica. Lin. Syst. nat, verm. test. spec. 39. pag. 3598 . 
nettern beẼannt ift; und bie Nufchel *) bie wir Echiffifuttel (burgau) nennen, formmt nid)t von Dem=

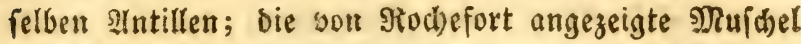

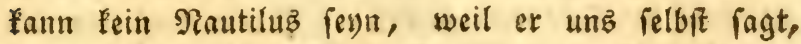
Don pein Sd)iffafuttel bie Geftalt einer Sdunecte hat.

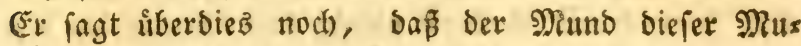
fdiel, bie idbunften झुerten zeigt. Diefe Schlangen=

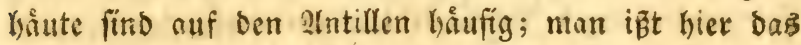
Mollubit biefer Mufdeln und finbet fie oft leer auf

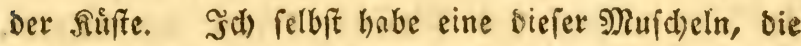
felte fart find, von Rartinique mitgebrad)t, in bie cin Einfiedler gezogen ift, der, weil eg iflm (se=

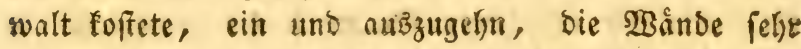
abgenukgt hat. Der (Einfiedlerferebs wailt fid) aud)

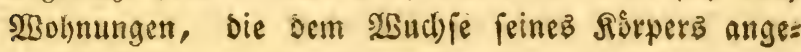
meffen fint.

Der Nautilus unterf (d)eitet fich noch baburd) son Dem Argonauten, Das biejer einjant lebt, und bek erftere cin gejellf(d)aftlid)ez Reben zu lieben idheint. Wenn ber Sturm gewithet und allentlyalben hin reine Serkeerungen werbreitet Gat und bie Stille tritt banm wieber ein, Dann fommen bie Matrojen weeder zue Sefinnung: fủr biesెmal iff ihre alngft geembigt, fie finb nicht bie SBeute der Schlinnde bez Mieptunz ge=

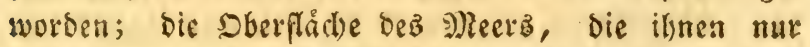
lobe berge und tiefe 2lbgruinde barbot, gleid)t iefat

*) Turbo olearius. Lin. Syst. nat. ibidem, spec.

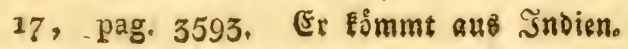


ciner Ebene, anf ber fein Munft herwortert, faum

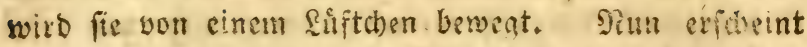
eine zalylofe \$enge von Miollublett, bie den unab= fekbazen SEaffripiegel belebt. Unter Den sieerbe= wohnern glánzt ber Nautilus, SImpl triten \& Reblng. Die form feines Plachens gleicht bem xis gen ber fie= besguttin; wie fie, fieht man, Dos er ein Grgel,

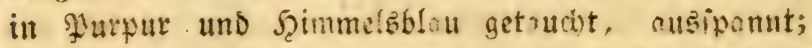

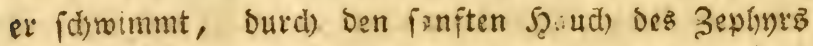
fortbewegt, auf Dem $\mathfrak{W}$ affer, ber in oan purpul: nen uno wellenformigen Falten von me!rern hunbert Eegelt, foin Epiel treibt, inbem er ben J̧inter= theil und bie erhabenen Setten bieier fo retchen alz eleganten barfen liebfolt; aber eben fo vorgingl d)

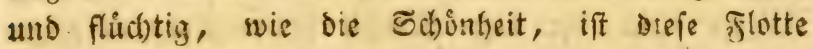
mit feinen Sd)iffern nur einen 2ugenblict fid)tbars; fie lapaen bie Segel nicber unb verfinfen in dan So, oo Des Miecrs, ihren Sid)erheitzort, zu Dę̧en (d)ơn= ften Sindern fie geluuren.

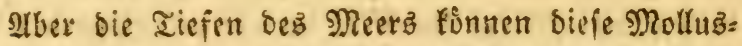
fen nid)t gegen bie singriffe ber Jienidien ichủken; ivie alle anbern गुolnwen i⿱艹

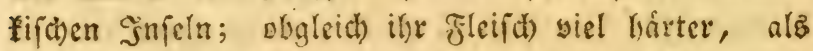
Das ber Dintenfifiche uno idbwerer zu verbanen ift.

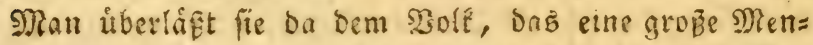
ge Davon foingt, weil die Tautiluffe, indem fie auf bem Sober beg Meerib fried)en, in bie Fichreulen fommen, wo fie fich bergeftalt in ben sieten ver=

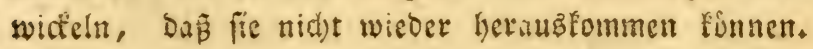

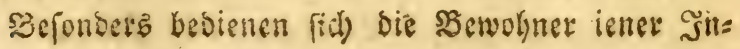




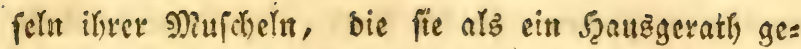
brauctien, fie fchlagen ben $\mathfrak{g}$ interthell $a b$, fo, Daß fie cine strt yon grofen Liffel baraus biloen, ben fie

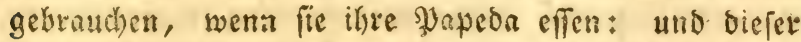
Gebraud) if fo allgemeen, Das bie Mluicheln barnach

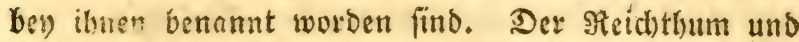
\&uxus beruste fonft auch bicje (sel)åufe; fie lielten es med untvitroig, fid) iener Muidheln zu bedienen, bie lange 3ett in ben Şånden Der Jnfulaner gewejen waren. 2un erbselten fie eine ichunere \$olttur. Be= fonders wurden bie gebraucht, bie nicht von einer Slat fleimer Meereid)eln geftod)en waren, bie fich bizz

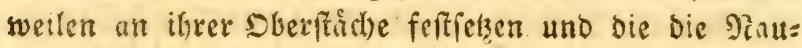
tilufe nicht io wegnifchen fonnen, wie ez bie $\mathfrak{A l}:$ gonauten thun. Dieje (Fid)eln burdjitedsen fie ganz und fie find bonn niç) mehe zu gebr uchen, weil isbe Feuchtigleit Dann burdy bie Rod)et triafelt.

Sn sinigen Fabinettern finben wir nod) Beweife yon Dem ?uxus unferer \$orfabecn, die Diefer Pat:=

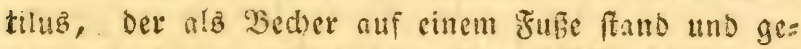

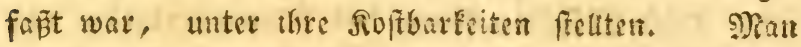
garnirte fie mit Bold, fetzte fie auf fitberne Suifse, bie mit Euftlithen Eteinen bereid)ert waren; uno nachoem man fie ber aufirn Sinbe beraubt und thue! die Gelinalt einez Szelmb gegeben hatte, grub man nuf ben glatten Perfmutter Figuren, Bilder, Feftonz, Dis ber gefdicfteite (Siraliftidel bilocte. Seponbere

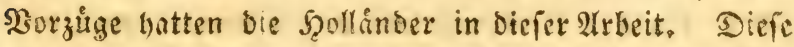
eleganten $\mathfrak{b e d} e r$ zierten bann bie Iafeln, bie Sir

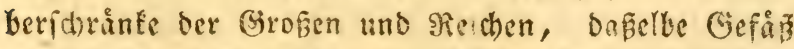
entilelt ben beften SEem, rulte auf einem mit Dis 
manten sergierten goldenen fufe, war cine herrlic)e - Bente aus bem Thierretde uno fo fah man veristic= Dene Stidte aus orey Natureid)en vereinigt. Epa:= ter loat man fich Diejer Gefápe nidht mehr bedient. Die Urfache bavon liegt nid)t in ifrer Zerbredhlid) feit. Эd) glaube, man mad)t wegen bes Geefalzes, yon Dem bie. Wånbe ber Muid)el bura)orungen finb uno Das bey feud)ter wie Rumplius fagt *), feinen (Gekraud) mefle von ifnen. Diefe Erfdeinung, Die allen Erzengnisent

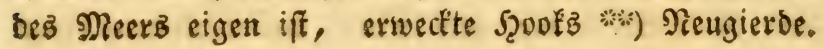

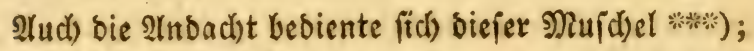

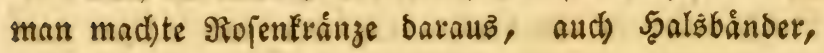
Dhrgebånge.

Nan findet Diejen Nautiluz in bielen Neeren, bejonberz in ben indifdjen, in ber Nåke Der Mol=

*) Diefe Mufdutta haben bas Eigenthủmliche, dá̧ (fie bey naffer W3itterung Waffertropfen ausfd)wif= zen, fo lange man fie aud) gebabt bat, fo forg= fältig man fie abswifat. Eine falgichte Feuchtig=

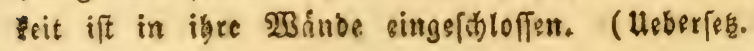

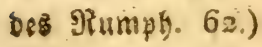

**) Hook, Philosophical experiments, and observations, pág. 306 .

***) Rond. de Pisc. part. 2, pag. 9\%. 


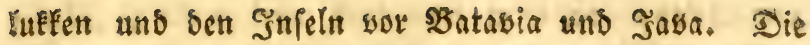
EGinejen fammeln fie anf ihren Sirften. Nan trift fie aud) bey ben franzofifid)en Sinieln, auf bet Silite Der Raffern, Dem \$orgebirge Der guten Scoffmung an, wo fie inber feltener fino.

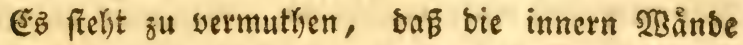

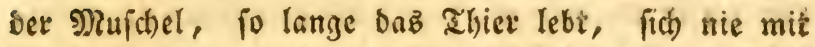
SBaffer anfilllen, Denn $\mathfrak{e s ~ g i e b t ~ f u ̈ ~ D a f e l b e ~ E e i n e ~}$ Deffnung zum Einoringen. Sind Die Sammern mit \&uft angefüllt, fo muß bieje fo eingefdloffene \&uft

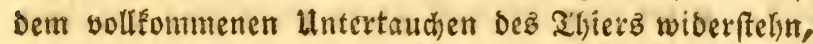
wenn fic ber Plautilus umgefélyrt bat, um in bie

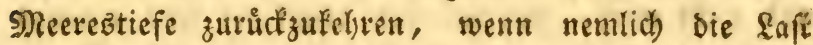

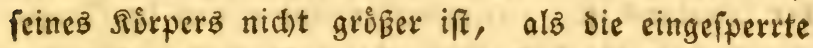
Ruftmaffe; biefe Sermutliung wiro badurd) beftåtigt,

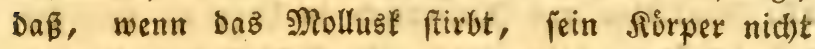
melye in bem Biefáuje ift, fo fómmt bicíez hafer baz SBaffer empor und wirb fo lange baz Spiel ber $28 \mathrm{el}=$

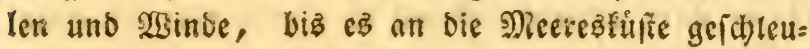
bert ift.

Dic Nautiliten *) find nich) fo felten als bic $2 \mathfrak{t}=$

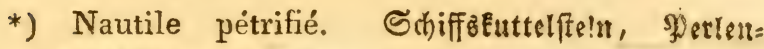
fohnefenftein, Fabrêttelffein. - Nautilite, de Bertrand, Dict. Oryct, - DArgenville, Conch. coquil. fossiles. pl. XXIX, Fig. 15. p. 349. - Favannes, coq. foss. p. LXVI, Fig. C. - Knorr. Pet. vol. II, sect. 1, 
gonautiten, ob man iene bods aud nicht zu hiufig finbet. Yiele, bie man alz poldie anfuityrt, gelyo=

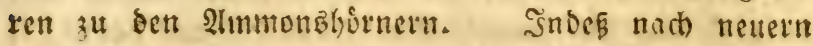
Plad)iud)ungen befitzen wir boch wirflid) Piautiliten. Ertnige, boch nur wenige, baben ganz unbejd) bete

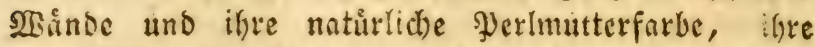
Sammern find nicht mit Sand, Sd)lamm angefullt:

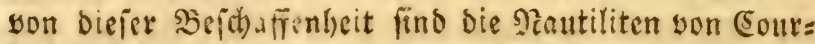
tagnon, in Der Nahe von Siheimb, won Grignon

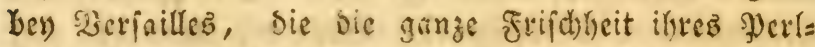
mutterichmucts in cinem (bivite besbehalten haben, Dafe, wentr man fie aud) gegen cinen ě̉en aus bent Mecre gefifditen Nantilus legt, man ungewis ift und nicht weiñ, weldhes ber Siautllite uno weld)es Der Pantilus ift. Dergleiden findet man in Eham= pagne und in bem झुayz de Shartrain im Sande. Die Nautiliten yon Rid)emorb in Englano uno bie won Imin, haben noch die \$erlmutterfarbe uno folgtich) Den Sopf ilyrer Nufchel, aber bie 3wifd)en=

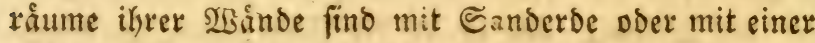
anbern thomartigen, fotligen Froe angefillt, uno fie find zu einer feften, fdweran Maffe geworben. Sie Rammern ber Mufchelt, Die man bei) Szavke und in ber (jiegeno von Rouen findet, find mit Sireibe uno Salftrummern angefưllt; auf शalta uno

p. 1, Fig. 3. - Klein, Specimen petref. Gedanensium, tab. 2. - Breyn, de Polyt. tab. 2, Fig. 1, 35 . 


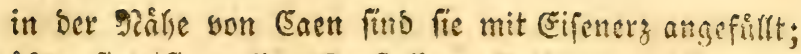
ifter find fie voller Siryftalle, Sialépath u. $j$. w.

Soic alle werfecinerte Sisper, haben aucb bic

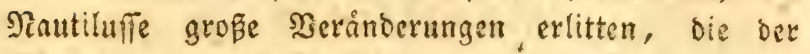
Gegeno, wo man fie finbet angemeffen fino. Szoltte mon alle biefe Bariationen anzeigen, fo nurbe man fict) in einen Sragarten vertieren, uno muste ein be=

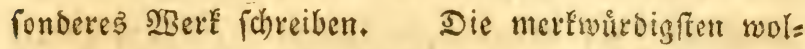
len wir nur bemerten; id) zeige nur an, daß man beren felse gropere findet, bie an 2luzbelynung bey weiten biejenigen ůbertreffen, bie wir in ifrem no= turrfichen zuftande finten. 


\section{Na t tiliten.}

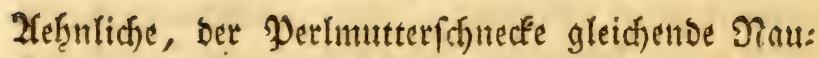

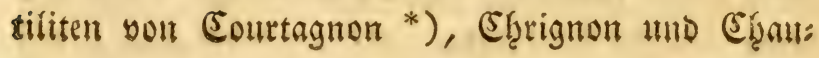
mont.

Daz Bebirge yon Courtngnon liegt brey Rieues

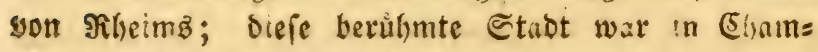
ponne unter ben stabten bie zwente; fie liegt in eis ner wilten, trodfnen uno menid)enleeren Gegend, bier fiellt man feinen $\mathfrak{B}$ aum, findet feinen Sd)atten, und Der Slabited Derfelben erinnert an Sandwiften; alfenthalben, wo man feine Rreibe antrift, erblidft man nur Sand, uno blefer iff voller $\Re$ Mudjeln. Bejonbers aber auf bent Biebirge Courtagnon fcheint

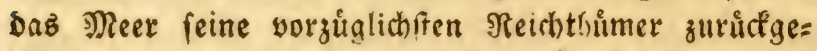
laffen zu baben; man finbet huer bie Mujd)eln aus

*) Nautilus pompilius, סer fammerige Nautilus. (Hist. nat. de la montagne de Saintpierre de Maist. Catal. de coq. foss. Nro, 26, pag. 96.) 
Gnbien, mit Deten beß Sceang berrinigt, ein Bొes mifb una unenolids vieten unbefornten Murdheln, alfe

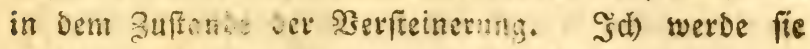

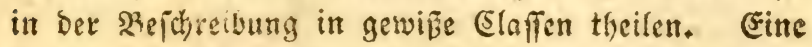
Dame von Sourtagnon beĩä z̆ 2trgenvilles Zeiten cin fhinez Sabiact, weld)ez unter andern গatur:

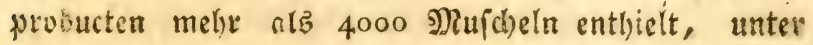
biejen befanden fith bie verffeinerten, bie fie auf ifrem fanogute gefammelt hatte. Danit extheilte fie Den Naturforichern eine firtreflidye Relire, inben fie fie to einlub, bie Begenfinde Der Naturgeid)idte zu fammeln, bie fich in ber Begend fanden. Sie befaß alle verffeinerte Muid)eln, bie man noăi po

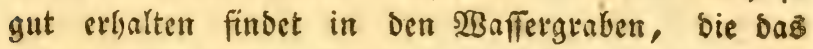
Regenwaffer in ben Sand biefę Giebirgez gråbt. Die Ertben Der Dame von Eourtagnon hatten iheen Ge= (ch)mact für bie Raturge(d)id)te nicht; ilfr Sabinet

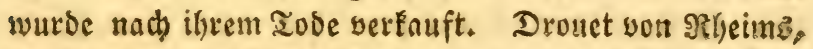
faufte Den grôsten aheil, bsfonbers Die in feincy Nad)barichaft befindlichen Berfteinerungen. Biefer Saufmann war cin Freund Der Siaturge(d)id)te, und bewaljete feine Sammlung mit Sorgfalt. In Dron: etż Sabinet habe id) cin halb Dutzend Nautiliten son Der Perlmutteriftinedie, Die zerbrochen uno verfium: melt waren, gefunden, allein es find biejelben, bie man in ben indijden uno africanifden Meeren

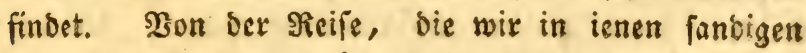
(Gegenden thaten, Faują Saint = Frond and id), brad)= ten wir einer iener fdhơnen Nautiliten mit zurick, be: fiic) iekgt in ber Sammlung ienez berifinten Natur= foricherz befindet. Sein \$ुerlmutterid)mude, wie

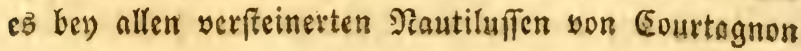


ift, hat fich bottig extralten. Der 3wifdyenraum

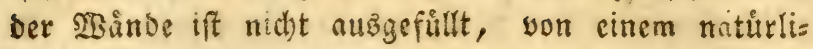
d)en Nautiluz låst er fich gar nid)t unterfdeciben.

(Ehyignon, Daz srey Siettes won Serfaille liegt, cinen \$art, ein Schloß uno klenç Dorf enthålt, weldies, wie in Sireibe und Riefelfteinen verloren zil feyn (d)eint, erinnert burch feinen. Sand an ben von Courtagnon; indez iff bas Rand melix holzigt uno bewohnter. Shier findet man Nuicheín, bie fich firtreflic) erhalten haben. Die Bank oon falfigten und unbeichådigten Muicheln ift unermeslich, fie zeigt fich in \$icmont immer unter berfelben Geftalt, bildet bie Uffer dez arno, Den Boden won_zlorenz unb yerwandelt fich in bem Thal be la æonca und

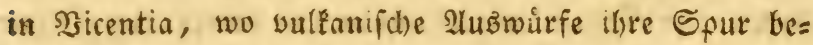
bectit und unterbrodien haben, in Marmor. Iuf

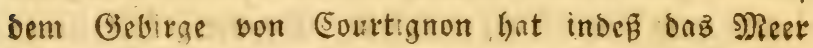

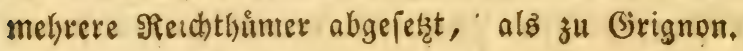

Sd) befitge firtreflid)e tteberrefte verfteinert, won bex \$yerlmutterichnecle, aus bem orientalijchen, afri= fanifden Neeren, die id) liter fand. Sie find nod) beß̄er erhalten, als̉ bie von (Sourtagnon.

Ilud) zu (5haumont, ciner fleinen zerfifbrten Etobt, Deren Soben uno erhabene Şigel, bie an biejelbe ftö̈n, aub Sand befteln, ber voller anbe= xer (d)uner פiuicheln ift, findet man Ueberrefte beß Nautiluz. S(d) befitze beren felfr ftarke, bie id) am

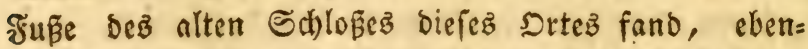
falls auch auf bem feilften 2 lbhange bes Şügelb, wo 
ez crbant war. Sie alle gleichen benen won (S)rigs non. Steuferlich find fie mit ben Nôken ber Meer= wirmer liberlaben, die nod) feft baran fitzen. Die= fer Heberzug won Wharmern ober Mollus̆fen, beweift

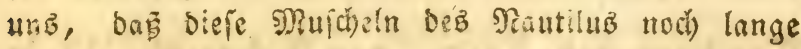
Seit baz' Epiel ber steflen waren, el' fie in Den Enno ihrer Tiefen begraben wurben; weil fid Ed)marobertliere ouf bie åufern $2 B$ ånde ber vertä̧e=

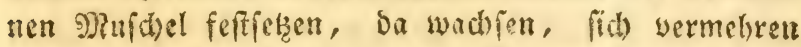

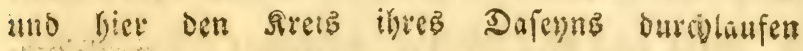
fonnter. *)

*) Allion, Oryct. pedem. Nautilites. Traité des pétrifcations, à Paris $174^{2}$, pag. 57 . 
Tautiliten yon Sutin *), Sictemons ${ }^{*}$ ) in

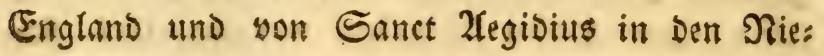
Dertanden.

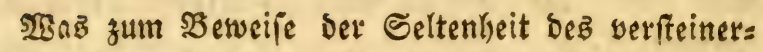

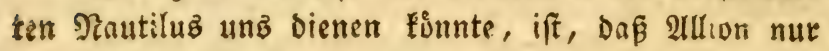
sine 2lrt bavon in feiner Befdreibung ober in bem Satalogen von \$ुiemont anzeigen fonnte. §n Det (begend von Turin fanb biefer 2 lutor endide einen Nautiliten in feiner ganzen Lnverlektzeit; feine größz= ren 2 Bände waren mit einer fandigen Erbe angefillt uno bie fleinften, bie Dez J̄nnern, mit falfigten

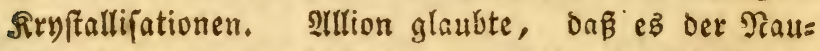

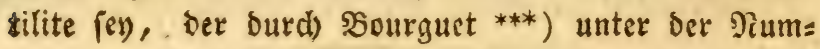
mer 252 abgebildet ift. Der \$iemontejer burd)wúfilt eine Menge verfteinerter Miufdeln, cinige find bea

*) Knorr. tom. II, sect, $x$, pl. A IV**, Fig. I.

**) Burtin, Oryctographie de Bruxelles, pl. VIII, lettre i.

***) Bourguet, Traité des petrific. Nro. 252. 
Eannt, anoere ferte fremb. 2lltion fonnte nur ein

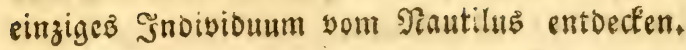

Einer meiner Freande war in England glectlis

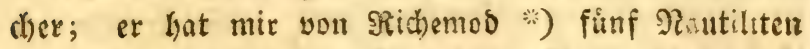
yon ber \$erlmutteriftnede mitzebracht, bie er in eis net gropen $\mathfrak{B a n t}$ von Thon uns Rufcheln Dafelbit fand. Das eine won ben brudiftuten, bat feine ganze Sdbunkeit. IIn einigen Etellen bat Diefer

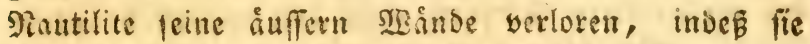
an andern Detel nod) vorbanden finb. Surai bie Deffnungen fielt man die perlmutterartigen $\mathfrak{B a ̊ n}^{2}$, tie nod) wollfommen feft find; alle Rammern fins mit einem (d)warzen, thonigten Scthmus angefullt; alle perimutterartigen Stellen (d)uppen fich ab uns

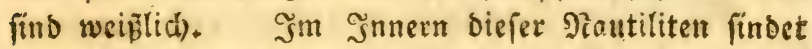
man, wie ben benen yon Iurin, falfortige, fwa=

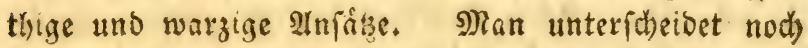
iebe $28 a n d$, aber bie Spitge ift ganz Eryftallifirt.

Snore, in Ser erfteat Albtheilung feinez zwenten

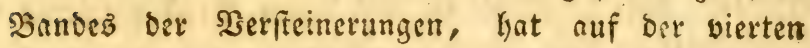
Supfertafel, Der erffen Figur, eine furtreflid)e zeid)=

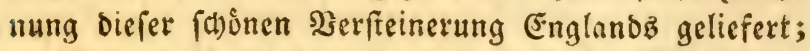

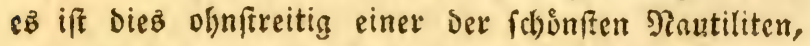
bie exiftiren, ex ift melyr alb acht zoll lang; feine

*) Faujas Saind-Fond, Hist, nat. de S. Pierre de Maïst. Fol, pag. 96. 


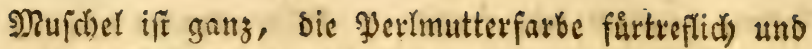
er bat ficl) volffommen erfalten.

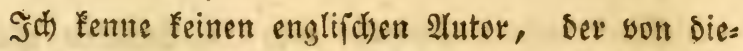
fer szerfeinerung gefprodsen bat; umponft habe ids in Ruid *) gefucht, Der eine großße. Menge yon \$̧ers

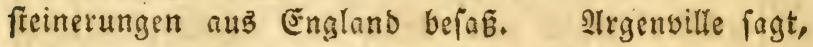
Doßß mon in Ruio feinen Prantiliten fánbe. ${ }^{* *}$ ) Ruio nennt alle $2(m m o n s$ forner $\mathfrak{T a u t i l i t e n}$ uno macht unter Den verffeinerten Rurpern nid)t Den mindeften linter= fd)ieo. Die fdounen నetfeinerungen von Richemono werlieren oft in bem Rabinet ihre Sdjonljeit unb zer= fallen. Sluf biefe SBeife verlor idh (d) on melyere; allein id) befikge alth) andere, bie fid) erbalten.

Mit Diejen Mautiliten mus man nod) Den ver:

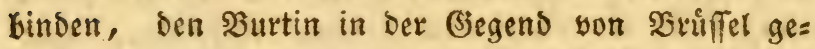
funden bat. Nan findet an Den Nuicheln, unter benen ex lag, nod) Den ganzen Sopf, ihre Farben.

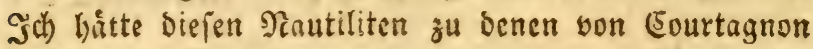
und Grignon rechneat tunnen, weil ex fid fo fehre erbalten hat, allein cr bat einen Girab größeren Serfteinerung uno alle feine Sammern fino mit einem

*) Edwardi Luidii apud oxonienses cimeliarchae ashmoleani lithophylaccii britannici ichnographia.

**) Argenville, Conchyl. prem. partie, fossiles, pag. 349 ; la note marginale. 
feften Stoff angefurtt. Burting Sinbisiduum war nod) felfe jung, als $\mathfrak{c}$ in bie Erobingen verjenft wur= De, wo er's fand.

SRautifitu yon Şavte, yon Souten unb Dem Mondsberge in Elgampagne.

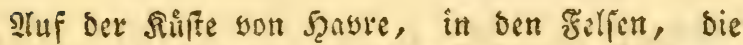
fie begrenzen, findet man fojone verffeinerte Nauti= liten; hier find fie wsniger felten, als irgend wo; Die von Den Felfen fino ganz in Salfipath vetwantelt, uno ber CSlang beg झুerlmutterb ift ganz verichwun= Den, ob man gleid) faft an allen nod) einen gropen

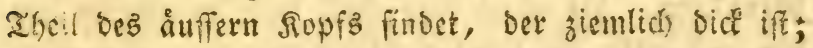
bie şBinde nimmt man beutlich walge, und fie find suf ben soberfád)en mit siryftallifationen bebedit; fie waren sufferft dinn uno bie siofte, bie burch) fie

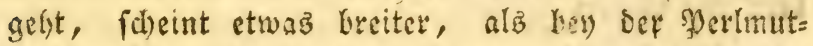
terichnede zu fenn, bie wir fennen; Lorigens berricht

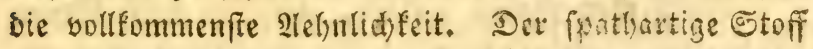
wou Diefen Nantilit hat eine fómukigh tweipe, ins Graue fallende Farbe. Die Finfrallifation, bie bie

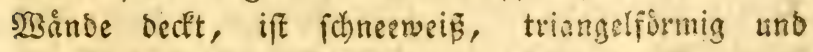
eine Rinie farf. Siefe ganz verficinerten Nautiliten baben fid) trefid erralten. Man funn fie mit sic: 
Yex feichtigfeit won bem freljen losmachen, man fint:

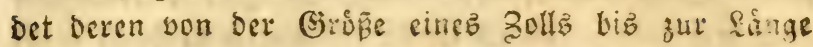

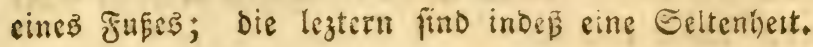

Nicht fo iff's auf bet Ritre uns an Ercibiaten Sorten, wo man andere Mautilitin findet, Die vom SEaffer befplitt fino. Diefe haben Durdhaus ithe siru= fchel verluren und zeigen weber Epuren won einem Ropfe, nod) von 2Banben; blop̣e Etride, Die rely

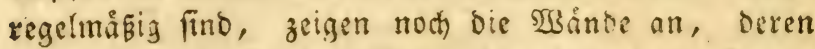
23eichaffenleit fie barftellen; wir betrod)ten fie alz bloze Ereibenartige Serne, an benen man rod) bie Form ber Mujchelu finot, bie fid) in fie abgedructet baben.

Die făhwarzen Jyunte auf ber Ereibenartigen Maffe biejer Nautiliten, madhen eine niedidhe wir= fung. Sie erinnern an bie Etepperei, die bie Şaut ber Mollubłen d)agrinirt, bic biefe Muicheln beworynen. Nan findet auf ber Riule bergletchen Siautiliten, bie andertbalb Fũ im Durchmeffer ha= ben und mely als funfzig Nfund wiegen. Sie find, sweil fie tiglid) ber sbbe und fluth ausgeiest find, oft fugetruno, man mus aus ifgnen nid)t eine bejonz Dere atrt mad)en wollen.

2 genn man Scavre ver! [äbt, um fid nach Rouen ful begeber, findet man in Den treibigten 3 ergen, uno im Snnern Deb Eandes, Diefelben Tautiliten oder Serne, aber gang wei⿱艹 wir fónnen glauben, Daß̧ diefe auf Dem Girunbe bes

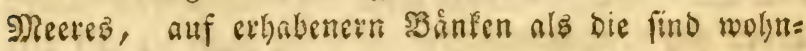


ten, Deren Mufhel mit mehreern Eubftanzen uno Ueberreften von fownizen Steinen angefüllt finb. Dicje gatz freibenartigen Nautiliten, haben bismei= len einen Theil ifres Ropfz, Der wein, aber ent=

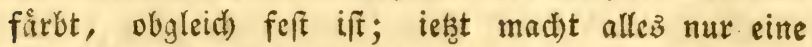
Maffe aนs, weil Die Nreide in Die fleinften Rammern gebrungen ift; bey. einigen findet man inder Sryftals lifationen am triangelfurmigen Salfipath. E̋̉ giebt yon biejen Rautiliten welche, Die ungeheucr groß uno zu fdiwer fino, um trangెportirt zu werben. J̧(t) bafe Dergleidien won żwey fuß im Durd)meffer und

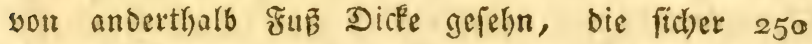

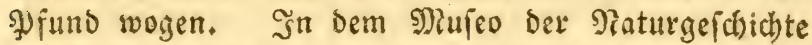
z̆

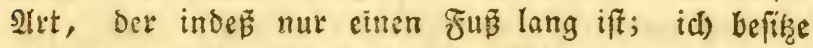
auci) cinen, Der firi) biejem an Silloung nabt.

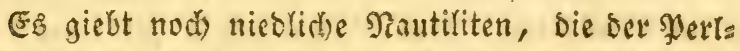
mutterid)necke gleichen, in ber freiben = uno Ealfartis

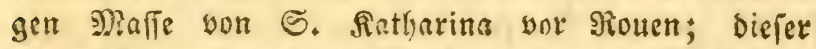
Berg iff eine ungeheure Maffe verfteinerter Mufd)elt, bie fid) in einem $\mathfrak{B o d e n j a t s}$ won Freibe befinden. Der Berg ried)t felgr nad) alyon, ben man jelbft auf bet 3ange fuhbit. Diefe Piautiliten liegen hier unter serferinerten 2(ufterid)alen, IImmoniten und andern Muid)eln, die ber Penturforider alb Sewoliner bez tieffen Meeres betrachtet. Man finbet biefelben yon

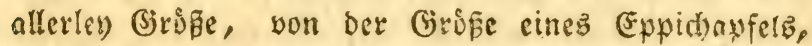

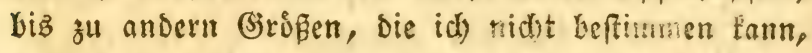

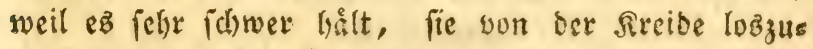
mad)en, mit ber fie aufz innigfte verbunden find: alle jerbred)en unter bem sanmmer. 


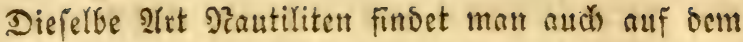
Monoberge (Mont de la Lune), Der in Ehampagne zwifd)en Nenehauld und Nheimb liegt; biejer פerg

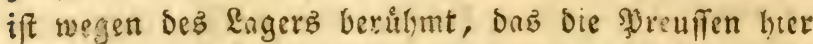
nuficllugen und burd) feine zugerunbete Form, dic

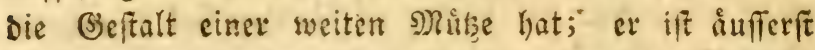
bitre, unberwoint unb ganz von freeibe; und ba man yon feirrem Gitpfel nur den J̧immel alz Şoris

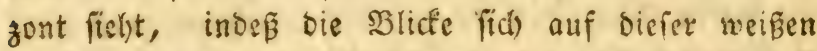

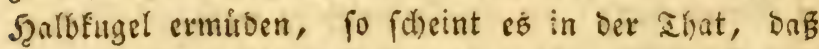
man alf cine Echribe bin veriegrt ift, bie an bie bes 2lonbes erinnert; baljer bat er aud) feinen Piabmen.

Diefer Serg, ber ganz yon Srecibe ift, wie faft ber gange Sooden won Ehampagne, faß̈t viele Mabregoren im fpattjigen zuitande und einige verftei= nerte Mlufcheln in fich, bejonbers 2lmmonsiturner, felten Noutiliten. Son Yekztern belikze id) einen, ber ad)t Zoll lang und vier Zoll breit iff; ev ift benen, bie id) jwifhen Rouen und Şavre fand, ganz ålne

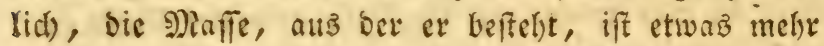
unvein. Man findet auf ihm biefelten fownarzen

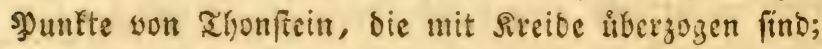
es ift bies cine fonderbare errid)einumg, bie in zhey, son einander weit entfernten Biegenden fatt findet, aber berbe find gruptentheils Durch bab 3erreiben und Die Heberrefte der Mruidheln gebuldet, Die ben erfiten Stoff zur Sreibe Darboten. Der Nautilit vom Mond= berge hat cinige yon ben fanmern, bie mit Falfars

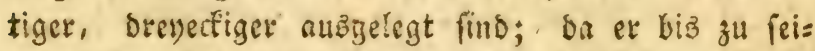
net erfen Sammer zerbrod)en iff, fo fann man vers = muthen, Daß fein Durchmefler megr a!s cimen Juß 


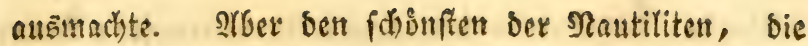
Den fopf verloren baben uno bisweilen einen sheil ifrer SBinoung, weil bie Rammern bason getrennt find, ift ber won Rifter bef́annt gemachte *): ex ift

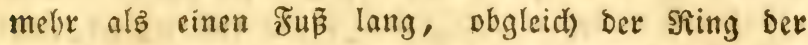
SBinoung ganz felylt; feine fiammern find mit einer freibenartigen Materie angefullt, und bie merfwút: Digite von allen, bie weitefte, bie bem Thiere zum leften 2 lufenthalt biente, ift mel)e alz acht Zoll lang und eben fo Dict. So inber Rifter bloz diefen গau= tilit gezeidnet hat, obne den Sort anzubeuten, wo er gefunoen wurbe, fo felzen wir ihn liet unter bie 3albl Derienigen, benen cr am meiften gleid)t.

EFben fo wenig fent man bie Esegend ber benbert Rautiliten, non benen Riffer **) 2(bbildungen gelies fert hat. S্Boodward hatte fie ilym zugciand und $\mathrm{cz}$ (d)eint, Dǻ biefe benden 2 seifen eine innige und angaltende Correipondenz mit cinander unterlielten; Die bie Mufchellet)re betreffende Siachrichten Rifters

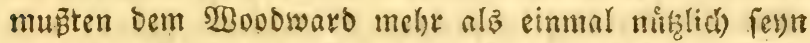
und if)m beftimmte Senntnise liber verfieinerte \$u= ficheln gewåhren, bie biefer serfaffer ber Therie bet Eroe fo oft antreffen mufte. Diefe beyben פauti= liten won Siffer, haten in ifrem groferten Dourchmeffer nux brey 3oll eånge, bet cue ift in ber Mitte bur(b)=

*) Lister, Conch. Fig, 1047.

**) Lister, Conch, pl, 1049 , 24, et 1050,25 . 
gefåght, Damit man bie innern אammern fełn fann; ber erfitere hat faft ganz feinen sopf befalten, uns

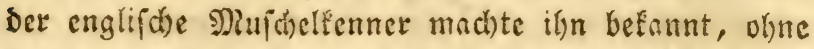
Den Srt anzubeutert, wo er ifin gefunder hatte; ez

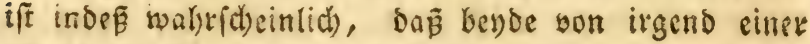

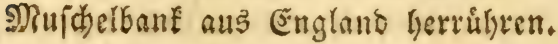

Nautiliten von Malta ben Eaen, von 3 adjes गloires uno Dem ßerge vou Ethatillon in Der Dauphine.

Sch) Eentre wenige Sorte, bie fo reid) an Berffei= nerungen find, alక̄ Nalta bey Eaen; bie Felien um bies Dorf enthalten fürtreflide 2 Immonzhorner, viele

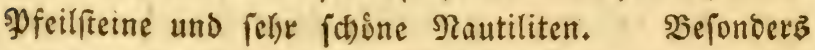
auf ben Felfen, bie ben Flǘ begrenzen, fann man eine anfehnliche Sammlung von Serfteinerungen ma= c)en; aber $\mathfrak{e}$ if $\mathfrak{\text { Mill }}$ uno Arbeit bamit verbunden. Faft an unzuginglid)en Stellen habe id) eine Mine gefprengt, und babe Daraus bie fdunften simmons:

*) Degenton, Memoire sur les fossiles, du bas Dauphiné, pag. 44 et $4 \mathrm{~S}$. 
Goirnes erlalten, bie in meinem Sabinet fins uns vielleidst in $g: n z$ Europa; id) fenne beren groferere, aber feine habe the gefelyn, bie mit ifnen verglichen werben finnten. Sch habe von bafer auch zwey Nautiliten mitgebracht, ben einen won einer Range won ber und ben andern von fect) zoll. Şerfeincrung haben Diefe Nentiliten ifren Ropf ver=

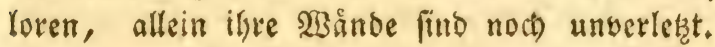

Die gelbliche Farbe ber Rautiliten yon SRalta,

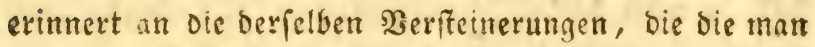

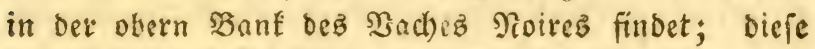
bier find in Salfifein verwandelt, ber inmendig grau und åufferlid), wenn fie ber \&uft exponirt waren, rofrig ift; bie SBainde im Snnern fino biäweilen mit faltartigem Fivyfall bedectit, yon einer Dicke von

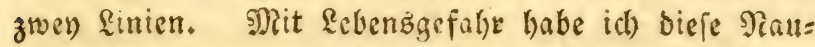
triliten erbalten, weil ber Fels, nuf Dem fie fich bes

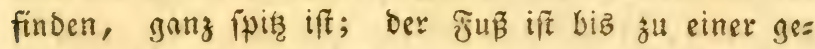
wilen Seorn fdwarz und thonid), woller (Srupfiter uno einiger 2tmmoniten; aber bie obern Ragen fins gelblich) und enthalten bie fitsonften 3erfecinerungen.

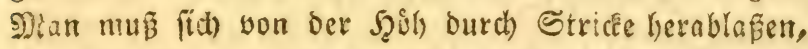
Die man ilber ein Flok rollen låăt, Danit fie nicht yon Dem fipizen, herworragenden felfen zerichnitten werben. Eetn verwúnfiter normannfither פoner, oen id) mit zwen andern gemietlyet lyatte, unir mich bin= abzulaßen, trank am Piorgen zu siel Brantewein;

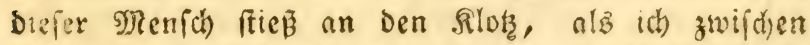
S? mmel und Eroe bieng. Ere flog fo fdinelt, wie

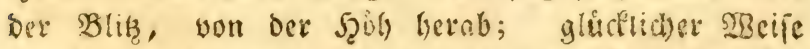
fal) ich ily fommen; invem id) ben supf anf sie 
Seite bribte, erbielt id ben Edylang anf sie Edul= ter, bie bovon fobr zeripuctiăt untoe. Dlue bie majdinenmafige Bewegung, vermige ber id bie Slugen aufhob, als bie Baucrn cin (bifcher ausftic= fen, ba ser Rlot Gerabiangte, wire id) erjalagen worden; inoen, id) mad)te meine (Ente. J(h) wonote mein gangeŝ faltes S3anern zu berufigen, bent ber britte war geflid)= tet. Sinoem idf mit bieler sitbe ifnen juipract), gelang es mis, fie zu berulsigen unb zu vermogen,

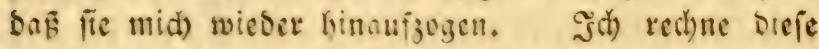

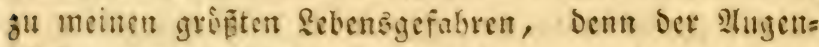
blice, wo bie Reute alle logliefen, id) batu in ben slogruno firrjte, war fo entiernt nid)t. Sd) wirt= be jerf(c)mettert worden ferst.

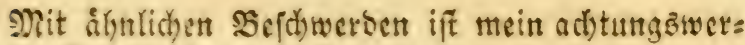
ther Freuns Depenton in Der Prieber = Danphiné um=

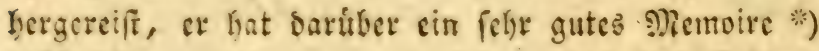

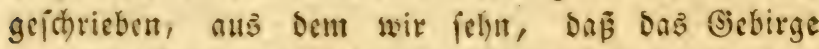

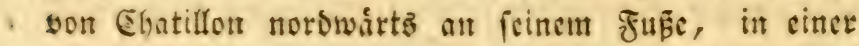
flemen Erthobung, Die burch Ragen von feftem Sans

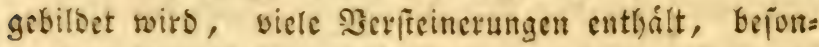
bers Soffemuld)elt, (Ed)initen, ungeleure stmmoni=

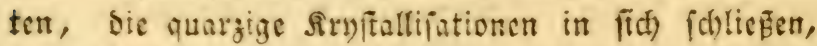

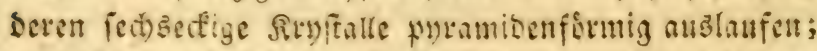

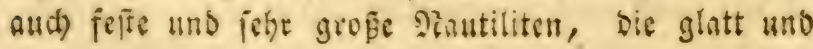

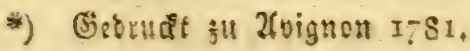


fammerig find, in beren Befjåttern man ebenfallb Siryftallipationen yon 2uarz uno Epatl) finoet.

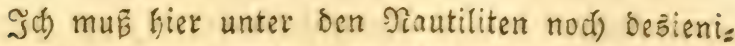
gen erwálynelt, ten Sifter *) befannt gemad)t hat;

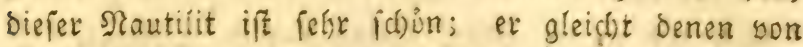
Nalta bey (Enen; wie bieje bat er auch feinen sopi mefre und peine Sammern find mit einem fôrnichten

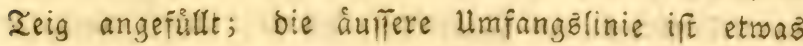
mehr niebergebriaft, wie ber) Der Derlmutterichnecle,

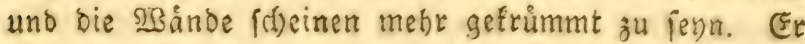
bat neun zoll \&ánge; aber ફifter zeigt ben Srt nicht an, wo ex ifn fand.

*) Lister, Hist. conch. pl, XIII, g, aim Enbe unter ben ITmmoniten. 
פattiliten vout St. Wetersberge ben Maftridt *) And Der unliegenden Giegend von "Sruffel, **)

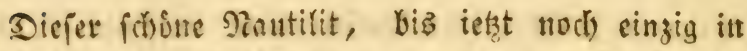

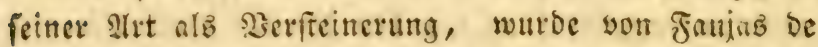

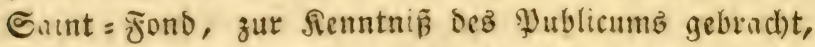
ber ihn, nadbeem er ihn beidhrieben hatte, in bie Sammlungen ber Paturgeidrid)te zu Daris niederlegte, wo wir ifn nun alle unteriuden founen. Mared)al hat ifm anferorbentlid) fition gezed(d)net uno (5oquet in Supfer geftod)en. Diefer Plautitit, Der g.umg Siefelftein uno in einen Riefel von derjelben Materie eingeid)lofien ift, giebt unb cinen åufereft merfwitr= Digen beweis won Den Serwandungen ber Matur. Diefer Siantlit war unbezweifelt falfartig und ieght iff er in cinen Riefel wermandelt, uno bat unter allen biejen Serinberungen feine formen uno faft feine

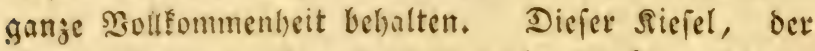
aufferbalb raud) ift uni cine grobe Decfe Darbictet, wurbe in eitret ber Szoblen bes Serges son Diaftrid)t

*) Faujas, Hist. oat. de la mont. de S. Pierre. Mäestricht, pl. XXI, Fig. 1, et pag. 100.

**) Burtin, Oryst. de Bruxelles, pag. 102, pl. XIV. 


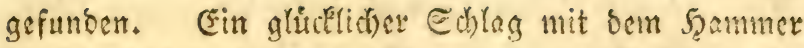

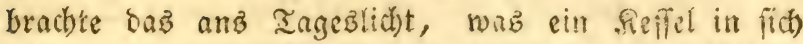

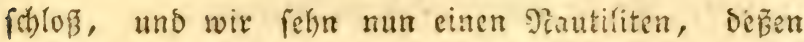
Sertiefung, die SBobnung bes̃ Thierß, mit fremb= artigem Ctoff angefüllt ift, aber bes̃en sBince un berifint find, und Degen Sammern leer fretin: Diefe Wanne haben fich, wie allez anbere, in sticfel ver: wantelt; in ieder fieht man die Deffnung nod), burd)

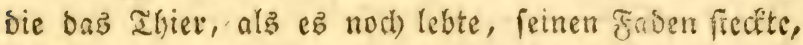

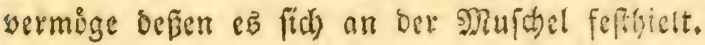

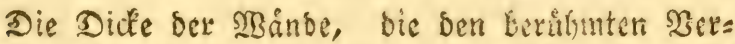
faffer zweifeinaft madhte, ob er biejen Piautiliten alz

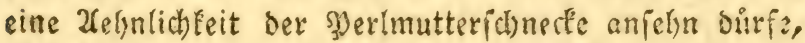
ruffren nach) unferer sReinung won ben firyfallifatio=

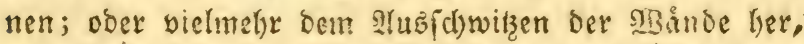

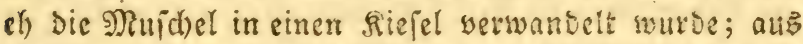
eben Den Grunde ift bie Deffnung Derielben aud) griv= fer, alz bey bem gewớnliden fammerigen Panti=

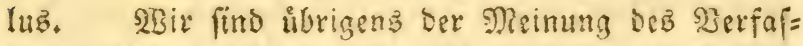
ferb, dof man biefen spautilit zu ber slrt bon giau= tiluffen rechnen mus, wovon die sriginale im inbis (d)en und afrifanifden Mecre noch exifiren.

Butrtin bat auch sinen firtreflid)en Nautiliten in Supfer fted)en lapen, ber mit Dem bez Jaujas riva= lifirt; allein ba feine X̧ainde unverleţ̧ fino, uno Fine Deffnung haben, fo tann man nid)t in fein

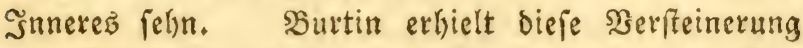

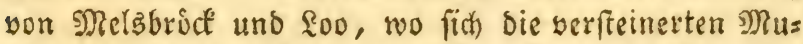
ficheln in fel) betråd)tlid)en Tiefen finden. Stllez bes weipt, Daf bie Diollublen, wetche fie bauten, in 
Gamilien auf biefem alten Bebiete Ser Necre lebten, fo wie fie fich iestat noch in ben Iiefen ber See auf= balten, wo fie ballfenweife umberfried)en.

Diefe Tautiliten ber unrliegenden Gégend won Briffel, finben fid) nod) z" Soluwe St. Etephan, Et. Ilegibuts und find oa in Fiefelftein verwandelt.

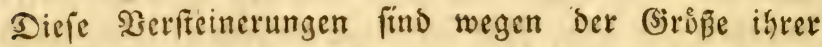
शiofye merfwurbig, und in ihe (Slaffe fonnen wir

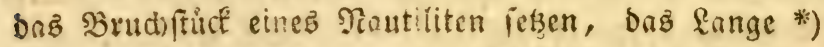
befannt gemad)t hat, won ber Riuffecte gefehn, Defen

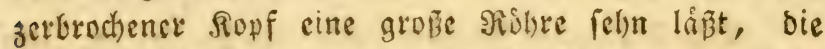
surch eine ber Sammern gelyt, bie lier wertieft find.

Diefes find bie cinzigen Nautiliten, bie wir in sen Fiefelartigen Zuttanbe fennen; eb giebt wohl cini= ge 2 Immonahoorner von berfelben Naffe, ober in Elya= Yiedon verwandelt, zu şaure; allein nod) haben wir feine Nautiliten angetroffen, bie biefe Nserwandlung erlitten båtten, nufler benen von Faujas Saint = Fons und benen, wou weldean \$ourtin fprid)t.

*) Lang. Hist. lap. figurat. helv. et ejus viciniae, tab. 29, Fig. 2, pag. I02. 
Diantititen yon Boutomais mo Miontbati in פourgogne.

Sit Boulonnais, auf bem 2 bege, bet yon Cas tais uad) Boulogne firgrt und in Der (jegrno von Marmuife, habe id fegr foune, ganj fefte Pautilis ten feiammelt. Sb bie ganz unuefdidadeten aud eine Seltenteit fino, fo findet man bod) viele mit ben

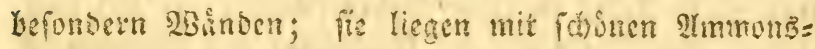

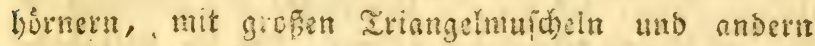
Derteinerungen vermifot, bie fait alle cinte robtolidge Farbe haben. Defe Dinutiliten haben of cine Ringe bon adt 3oll uns cine seffrung won bren 3oll: und

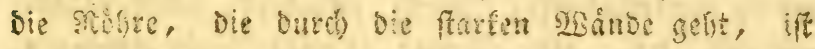

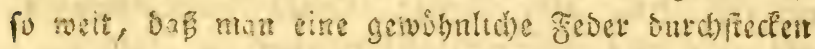

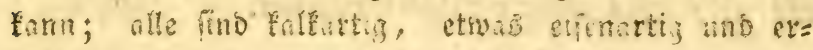
Yhalten in ber freien \&uft Die ritbide Furbe, in ben

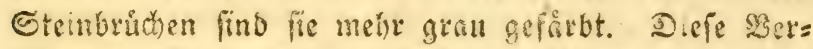
frenesungen, da fie mit Sialf coer shamor ganz an= sefiut fino, obne alle fwathifbe sivgitallifation find fdi)wer uns mafirio; fie bingen aud uit ben soanten, bie fie in fid faffen, feft gufammen; Durd) einen Schleng mit bem Şammer uno burch einen grictlichen 3ufall, crhailt man fie bisiweilen unbefdistoigt; fie machen mit bem Geftein cine Maffe; felten láp bie Seriteinerung ganz yon Demielben loß. Der Etein berfelben ift fo felt, Das bie einzelnen warnde flingen. 
Die Sehriftet von Mufdelmarmor, bie bie \$et=

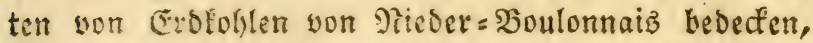
find jeîr mestwarbig, weil fie auf einen fpátern Ilb=

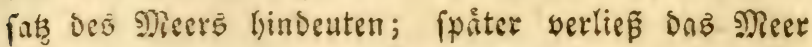
Dieb șett.

Stuch sul Montbuto in Sourgogne findet man fichone Niautiliten; wie bie andern, gleiduen aud) fie bet झerlmutterfdinecte, allein fie fino viel grổer, baben eine weitere seffmung, als es iłre relativen

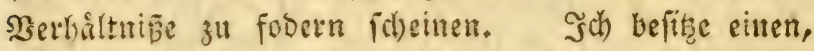

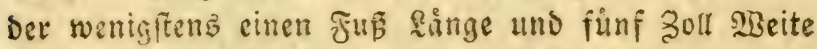
bat. Shan Eunnte, wie bey dent vorkergehenden,

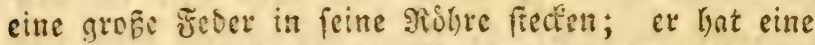
rôthere Farbe, alb bic Der Stautiliten yon Boulonnaiz

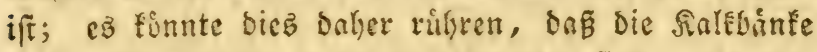
sicjer Niecresufer nid)t fo eifenartig fino, als bie, Die ben 3oben yon Montbard aummachen: Dicje finto unt fo metrwindiger, ba fie ungeheure 2 (mmonghors = net enthalten, cine Dienge atiberex Merfteinerungen

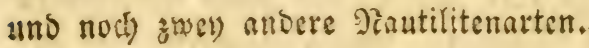


Diantiliten von Saint: Dizits in Effampagne *) und von Sostfein in Der Sdyroeiz.

Dob gange Bisbict biejer Heinen Etast in Eham= pagne, wo die smarne ein Fahrzeng zu tragen an= fangt, ift eifenartig. Solb lyabe bier Santiliten in bem zover) fachen 3ufanbe verfúficbener setifenerung gefunder.

Einige biefer Nautititen fins falswer, ganz ver: wandelt, mit ichunkzigem Eifenerz angefüllt, Daz weit reichbaltiger zu fenn foheint, als die ocherartige Eroe, in ber fie begraben liegen; die Summern find ůberbies mit åuferft feinem Meeriano angefullt, in

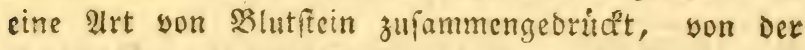
Fnrbe ciner Ddbienleber. Dief́e Sautliten, ange= fuilt mit einer eifenartigen Materie, fino feffe (d)wer unb ganz unbefchidigt; bald findet man fie mit ibrem

*) Bourguet, Traité des pet. tab. 38, Nro. 251; Dhne Ifngeige des \$rte. Lang. Hist. lap. tab. 29, Fig. 1, pag 102, - Knorr, de Pet. tom III, sect. 1, Fig. 2; pl. 1, ogne 2nnzeige Des Sortz. 
Sowfe, und anbere, ofhe bie âffere Sdjale; man fielyt ifye zalylreid)en Sammern.

Snotr *) Gat uns ziven Tautiliten mitgettreilt, bie benett won S. Dizier felye gleichen; Der eine, ben ef unter Nummet 2 anzeigt, ift vielleid)t ber= felbe, von bem id) bier rebe; wie ber meine, ift auch) ef eifenartig, und gleid)t ifłm ůbrigenz voll= fonmen; ber andere unter $\mathfrak{x}$ tunmer 1 ift in feinem Banzen mely zugerunbet, aber fein Bau if berjelbe, und feine leidst gebogenen Sgande, haben die Form wie die bez Nautiliten you "Enint = Digier. Şende (d)einen inde巨 weniger eifenartig, fie find vielleid)t

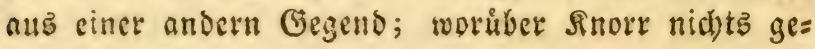
fagt lyat.

2ule bieje Nautiliten fino inber nibiet eifenartig, einige beftelgn aus falfartiger Materie; bazu gefyurt Der yon ennge *a) bejchriebene uno ber, wie bie an=

*) Planch. 1, Nro. 1, iff ein 2fmmonit mit balb= runden Ctreifen, mit sinem runben, glatten SRitén, wo man Eeine Robre bemerit. Die Etreifen gleichen benen einer getwiąen 2 frt von Nautilus, Die Frarbe brionlich. Summer 2. Derfelben Iafel. Er fteht zwifäen Den 2rmmonis ten und Nautiluffer in oer Mitts. (Knoxr, de Pet. vol. II, sect. 1, pag. 38 , et pl. x. Fig. I et 2.

**) Lange, Hist, lap. 29, Fig. I, et pag. 
Dern, ohue fiopf war, fo baß̈ einige Ringe bek WBinbung, die man fall, ifyn irte madjten, uno ex bicien Di utilt zo ben stmmonshornern rechnet, ob

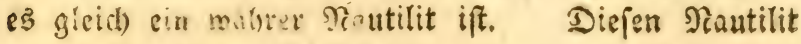
erbielt \&ange bon 3 butitein.

Die andere Infidt, unter ber fith bie Mroutilis ten yon Eaint Dizur żeigen, iil hidef fonberbar;

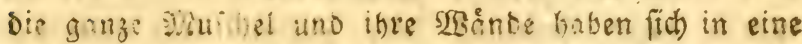

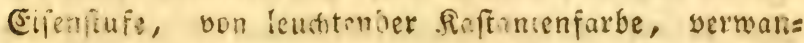
belt. De sammeru firs mit einer Foon= und fult:

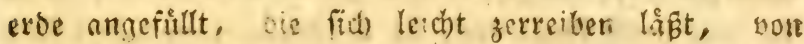
gelber Furbe, of viel Witriol cnthålt. Die Rotye iff yoll Suarz. Sal) habe keine grope Nautiliten yon bieier Irt gefunoen. Der grisgte, ben ich bafithe, ift bren zoll lang und anderthalb zoll breit. 2lllein id) zweifle nid)t, Das man grüpere finden fann.

102. „Nautilus squamatus, sine striis, ma. jor, subcinereus, unius anfractus. 


\section{פRautiliten yon গTomut.}

Diele find gang in Marmor werwandelt, ser bie Garbe ciner Sarjelnus hat; fie find ferle glatt und fel)e polirt, oft mit fleinen stufterid)alen bededt; ifhe

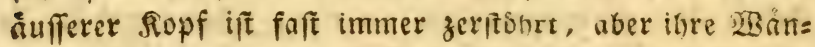
De fely bemerfbar, weil fie in Sireibe verwandelt fins, Deren weip̃e Striche fie von oem Marmor unterfdeci= Den, ber bie Sammern angefúllt hat. Defe dop:

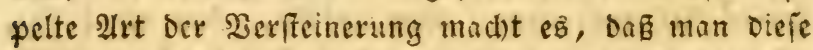
Nautiliten felten ganz findet, weil bie kectoenartigen ŞBande bişweilen in Staub zufaumenfailen uno binn

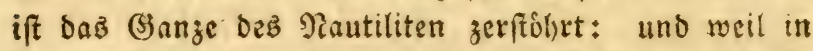
bem Galle nod) mehrere fammern mit einander zu= fammenhången, bie abnekmend rund find, fo fiellen fie einen verfímmelten Sirper bar, Den man Stebs= id)roanz genaunt loat.

In Dem Gebiete Namur findet man mod) eine andere verffeinerte 2 lrt, aber melye wlatt, beren Sammern meft grfrimmt find und boppelt auf fich felbit gefaltet. 
Nantiliten Der Sthweiz, Des Ettersbergs in Serrogtḩum rseimar, von Zlltoorf, Noubingen ber) Dilirnberg uno $\mathfrak{B}$ erona.

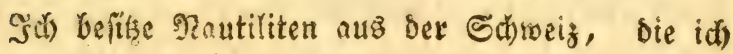
aus ber (Begeno yon Neufchatel erfielt *); man fin= bet fie bajelbft von veridiebener (3rioge, idh habe Dergleichen yon żwen Fuß \&ånge, die cine Deffnung won melye alz zelnn Zoll baben; gewílntid) find fie mit einer firufte, ober ciner Eiezartigen Dedfe diber: zogen, ilfere alte 2luffenfeite bat fich in biefe Naterie verwandelt: ein andermal ift biefe Decte falffpath= ortig, grau uno enthålt fieß̉ortige SBg̊nde, viele

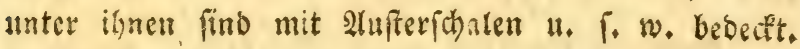

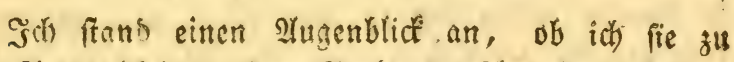

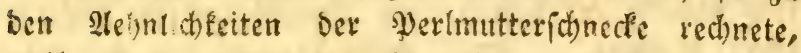

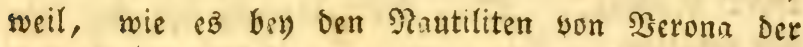

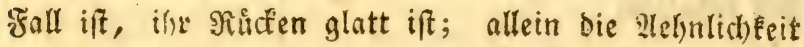

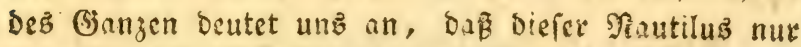
eine Barietåt iff, bie zu wenig Unteridgeidendes hat, um befonders claffificirt zu werden.

*) Bertrand, Dict. oryct. tom. II, pag. 69, colli. 
ฐd) habe einige won biefen Pautiriten burding anen lazen uno oft hat fich ilhe Sinneres vollfommen erhals ten; bie bůnen 2 Gånde find in Riefel oder Ralffpath verwandelt; einige fammern find leer, andre find ganz ober zur bålfte mit firyffall uno Ẽuth ange= fillt: noch fann man bie Stîrfe ber Mupitsel anges ben, bie vollemmen bie ber Perlnuttermurchel ift. Die Rukre, bismeilen mit frembartiger Materie an= gefillt, fheint etwas grổer, wie bey unjerm Tiau= tilus; betrad)tet man bicje ßerfteinerungen aber in

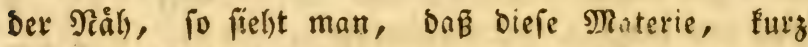
nad) bem Tobe bez Thiereb, in bie Ruhre georun= gen ift; daß fie bie Membrane, die ber giólhe zur Fortjekzung bient, wak wir, alz wir yon bem Mol=

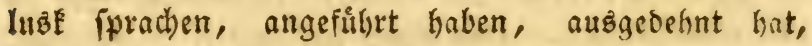
nicht in bie Sammern brang, Die bagegen ganz leer, Doer mit fpåtern Siryftallifationen, vorzåglid) gegen ben Mittelpunft ber Mlujd)el, angefúllt find.

Snore *) Gat aud einen fehr fdubnen Plautilus

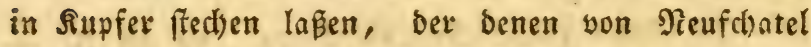
fehr ăhnelt; er formmt vom Etterb̈berge im Seerzug= thum SBeimar. Dieje Werfenerung hat fid) felse gut erbalten.

Sayer liefert uns in feine Dryctographie won

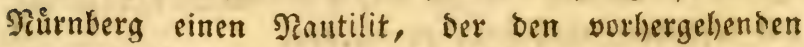

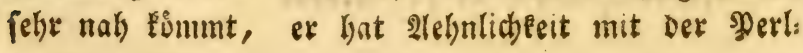

*) Knorr, Pet, tom. II, sect. 1, pl. A IV. 
muttermuidel. Ere erhielt ifn son alto borf bey fen= tzenberg. Diefer $\mathfrak{N}$ utulit batte faft fetnen iuffern

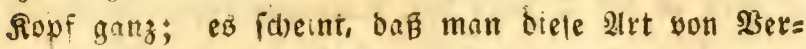
fienerungen hier won allerley Biro̊pen findet. San bem Lierfe Fayerz finven fid) nachahmungşwirbige 3eichnungen, *)

Itber feinem Cohne, Ferbinand Bayer, war

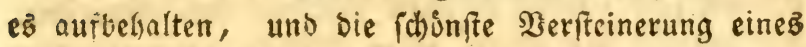
Nautilus befannt zu machen: in bem 2 nhange, wo=

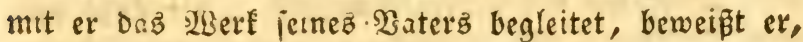
bas̃ er wưrbig ift, feiner Spur nad) zufolgen, uno auf ber zelinten Supfertafel liefert er ung Den fưr

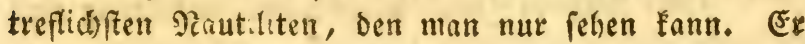
hat nod) feinen åuffern Sopf, ber wenig wor feimer Farbe veranbert hat, ev ift Raftanienfarbig, Dent forb:gen Flammen gleid), bie bie idhone Mufchel

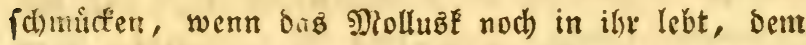
fie ihr Dajenn verbantt. Diefe Berfteincrung ift

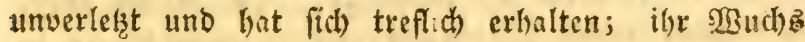
ift riefenlyaft, Denn ige gropster Durdjuneffer betriggt

*) Bayer, Oryctographia norica, pl. II, Fig. 1 et pag. 30. Nautili vulgatioris figuram ... maximam partem testa sua pertenui vestitum, ex saxo praegrandi, prope Altdorfium, versus Lentzenberg, excussi .... ceterum ut multo minora hujus nautilitae specimina, sic quoque ingens habeo fragmentum, novem unciarum longitudine. 
sierzehn 3old, biefen ift ihre sånge angemeffen. Diefe treflic) Serfteinerung finmt von Woeubingen, einem Flecten in ber Gegend won Plimberg. *)

Sn ber zweyten Figur berielben Rupfertafel, lies

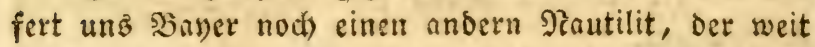

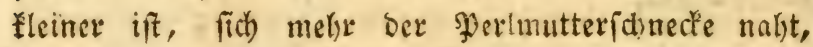
bie wir fennen. Sil feiner eriten nammer findet (iid) ein fel) Eleiner Fautilit von berielben 21rt, Der, wie iener, Daz Spfer einer গevolution war, bie biefe Heberrefte ber Meereghewohner in bie Erbe ver= grub. In biefer abjuffung brener veridbiebener

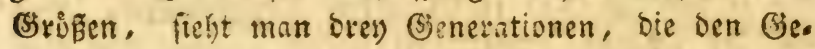
reţen einer allgemeinen, plitglidiben Zerfforgrung un= terlagen.

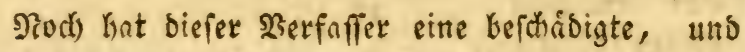

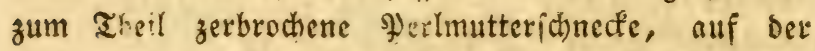
eilften Suppertafel, Sigur orey ***; bargelfellt. Diez Şruct) ftud extnnert an basienige, was Snorr ebens

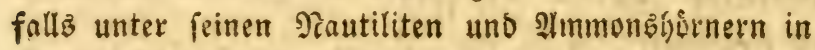
গupfer fteden lię, ****)

*) Ferd. Bayer, suppl. oryct. noric. tab. 10, Fig. 1 et $2 . .$. et pag. 17 .

**) Suppl. in oryct. noric. tab. 11, Fig. 3, et pag, 17 .

***) Knorr, de Pet. vol. II, sect. 1, Fig. 5, et pag. 38 , Nro. 3 . 
Indere $\mathfrak{T}$ autiliten auz ber Sd)weiz, finb ganz

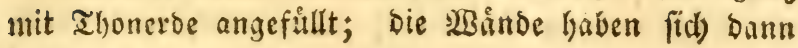
in Riez verwandelt.

Mir Raben Nautiliten von Berona, die benen

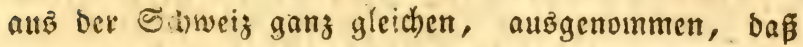
fie ganz mit Illon angefillt uno von ihm burd)orun= gen find. Der Sopf und die Mande fino nur etwaz brăunlidb, alle anbern ฐheile baben eine gråulich weipe farbe:

Sb wir hier gleid) cine betrådbtlicbe Mienge yon Nautiliten angezeigt haben, unb wir nod) anbere, felix ponberbare anzeigen wollen, bie fogat unbef́annt fino, fo mi̊zen wir'z boch hier wiedertsolen, Daß fie weit feltener find, als bie 2lmmonz̧)orner. Die 2lutoren, bie über die Derfteinerungen geqd)rieben baben, zeigen unz beren nur wenige an. Bergro: pere id) Daz Nathmenverzeid)nis berfelben, fo ift bies bie frucht meiner beid)werlichen Wanderungen, viel=

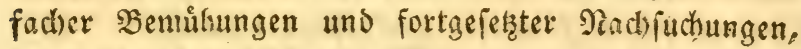
Durch bie ich endlich eine Menge von 2 erfteinerungen erhielt, bie ich) fo gern mit beat unverfteiterten $\mathfrak{M u}_{\text {us }}$ fdjeln vergleiche. 
Ereflátung Der yier unb fúnf und vict: zigfen Supfertafel.

\section{Der fegetnde Nautilus *)}

\section{Le Nautile à la voile.}

Er fdiwimmt auf bem fillen, ruhigen $\mathfrak{S}_{\text {nffer, }}$ auf ber Dberflache ber See, wo er nad einem Eturm,

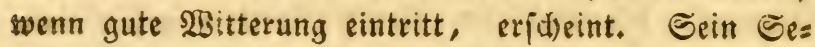
gel, baz im Snnern mit Ed)ropffiupfen verielnn ift, ift suggefpannt; eE fängt ben leifen $\mathfrak{B}$ ind auf, wel= cher weht. Ex fdhifft auf bem 2 Baffer, in Deperr Siefe ex fid) bald wieder zurictefturzen neiro.

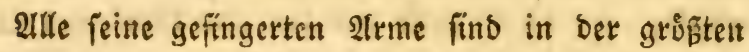
2lusbelynung; im Mittelpunte fann man Den hor: nigten Sd)nabel bez Ilierž bemerken, ber ringšum= her mit ciner runden fippe werieln iff, wie bey ben Dintenfif hen, Ralmarz, Şolnpen und Irgonauten, mit Denen bię̧ Mollubł viel Hebercinftimmendez bat.

*) Rupfertafer XLIV. 
Der Szintertheil ber Nlufdel ift mit ciner $\mathfrak{L a g e ~ v o n ~}$ Syerlmutter liberjogen, Dab das Segel, wenn ez fith

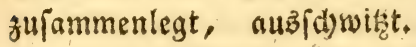

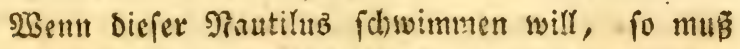
ex in feiner 2 Bofmung feife hod) emperfeigen, lam feine 2fugeat nad) aufien hin zu wenden und uber ben

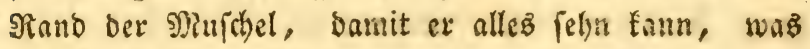
um ifgn ber vorgeht.

Die funf und vierzigfte Tafel, Figut I.

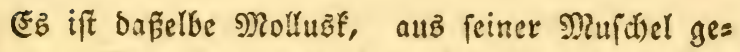
zogen. Man fann hier bie Roblee, oder ben ab= fuilyrenden Sanal jelin; ob man gleidh sorn am Reibe Şåutchen wahenimmt, fo ift er boch niçst horizontal geiffnet, wie bie anderen lederbiantigen, nacten ober

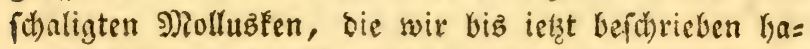
ber. Unten ain Siverper fielt man einen Iheir bes Nerven ober mublulofen Fabenz, ber fich burch alle

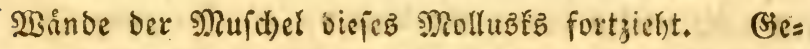
gen ben Sopf hin, auf ber Seite, ift cine herwor= fpringende Stelle ober $5 B$ arge, bie cine von Den Ilus gen Dez Molluäłz anzeigt. Seine fingrigten 2 trme find auzgeipannt, wie bie auf ber vorigen glbbil= bung. Die Form Dez Unterleibes bentet die 21rme an, an benen fid) bie İande abdrůden: biejer $\mathfrak{u n}=$ terleib ift getigert, wit ichwargen Flecter beipuengt, wie bie Refrefeite Der Şaut, die zum Eegel Dient

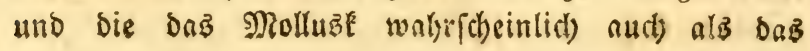




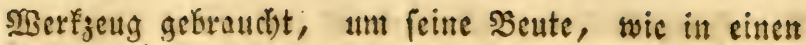
Sade einzuwiafeln.

Die zwente arbbitoung Derfelben Infel fielt cinen 2yrm, ober einen gefingerten Lappen bar. Er hat nut vierzelin Finger, ez giebt beren, die zwanzig baben; Die untere Seite iff punftirt, wie cz bie ganze Şaut son biefem Mlolluş ift.

\section{Det Nauttilus mit Shreer. *)}

Le Nautile à Oreilles.

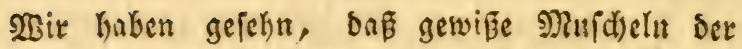
2lrgonauten, Deren Thiere wir nod) nid)t fenten, (id) nach) linten hin fo verlangern, Daßs fie zwey $2 \mathfrak{r}=$ ten von slyen bilben, bie unz bazu bienten, fie

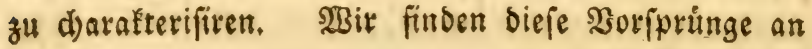

*) Favannes, Conch. vol. I, part. 2, pag. 723 , et. pl. VII, Fig. D 4. - Gualtieri, Index. test. tab. 18, Fig. 3 , et tab. ${ }_{17}$, Fig, A. 


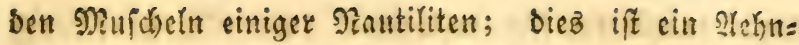

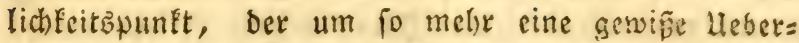
cinftinmung und grope stnneibrungen unter biejen ver=

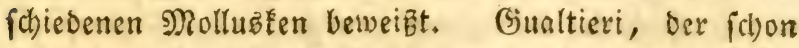
frủlzeitig fưrtrefliche Mlujd)eln zu feiner Dispofition

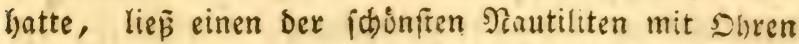
burd) fågen; [ein Snneres gleid)t Der Đer(muttermus fchel. Die 2lbbilbungen, die Der MBelie von biejem

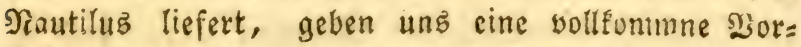

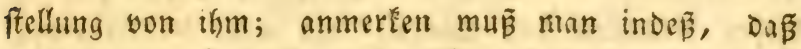
cr ihm eine åufferft grobe Roblyre bailegt, die er in Den Mittelpuntt Der 28 inde geftellt het. Favannez ift von ben Franzolen ber erfte, Der bicie Muichel uns genau bejchrieben hat, bie grógten, bie er fal, waren finf zoll lang. S5strad)tet man die 2 bbbil= bung biefes Trautilus, ber auf ber fiebenten Siupfer: tafel fetht, fo g!aubt man nid)t, Das er hice cine - fo peltene und fdoune Nuichel barftellen wollte; er

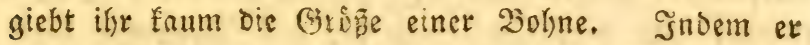
bieien Siautiluz mit anbern zufammenftellt, bie ets

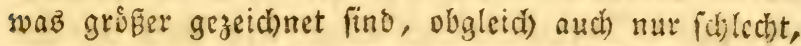
fo giebt er linz feine Sore von einer Mujdel, bie

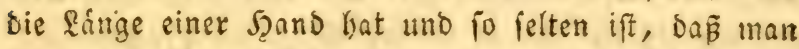
fie in ben fürtreflid)fen Sammlungen oft nicht findet.

Diefer Pautilub fummt, wie ex pagt, yon ben

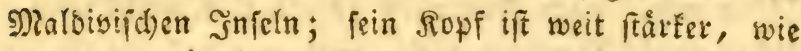
Dex bes gewífnlid)en Rautilus. Die Deffnung ift nach) ber Mitte hin ausgejesweift *), fie ift bauchight:

*) Favannes, Conch. tom. 1, part. 2, pag. 723. 
bann Sridft fie fich) zufammen, um fid) bann nad) hinten $z u$ in Geftalt von Dluen wieder $\mathfrak{z} u$ erweitern; bos Innere ift perlmutterartig, inbe巨s bie åuffere mat= te uno weibliche Bebectung von gelbbraunen Etrelfen wellenformtg geziert ift. Ser obere Theil beछิ Şin= tertheilb, if mit einer glänzenoen, mattgelben, et= mas braunen Farbe iberzogen.

Sobgleid) Fanannez ber Meinung war, baß̈ ex biefen Nautiluz mit Dlyen, alb eine Barietåt bes grofen, ober gewo linlid)en $\mathfrak{P}$ sut luz anzeigen fonnte, fo bin idh mit ifhm bod) nicht einverftenden: bie Dh)= ren, ober bie Art bon feorner, find ein zu fels in bie 2lugen fpringenbez und auffallendez siennzetchen, bie bern Thieren Derfelben art unterfdeibet. Die Ihiere, bie mit Şörnern bewaffnet find, bilben unter ben sierfübigen Thieren und Den Filchen befondere 2 rten; swarum follte biez nid)t audh bey ben Nolluaken fratt finden, bie auf biejelbe ribeife ihre ichaligten Geháuje bewaffnen? (Sualtieri hat baher aud) ohne beben=

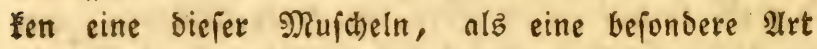
'zeid)nen laß̧en, bie er in ber Mitte burd) fågen liễ: uno da er bey ben beyden Individuen, bie er zeichnen

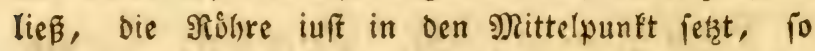

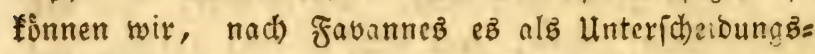

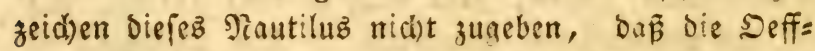

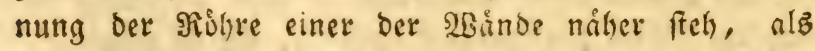

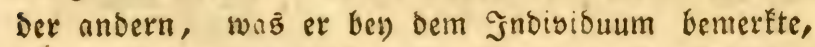

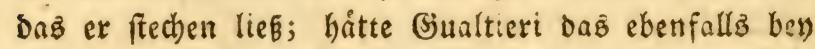
Dem Nautilus gefunden, Den ex burd)iánen lię̧; fo

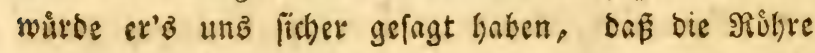


ben biejem Nautilus nid)t in bem Mittelpunft fey. Der Tautilus son Franannes weid)t aud) etwas ab unb if nud sull: gleidjecitig. Die Nufdel ift son Dem Moiluse fellerb it gebildet. Die ungeftalteten

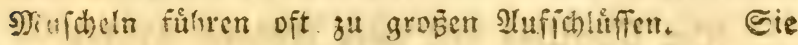
wertan oft von ben Mogen bin = und beraeworten, in

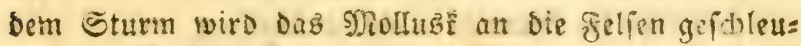

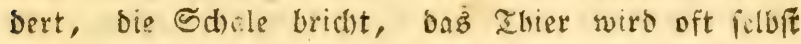
Durch Den Etoz verletgt; eg baut die sMufhel mies Dor, fost nach uns nad) neue fagen an, Die ber feillerbaften form feinez Rurperz angemefien fino. Son diejem શautilus fenne id) fene Serfieme= sunger. 


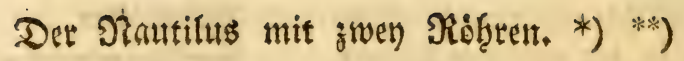

Le Nautile à deux Siphons.

Die Mufdel biefes Nautiluz entfernt find yon benen allen andern; und of er gleich Die ganze form Der Werlmutterid)necte lyat, fo ift er badurd) von iffe verid)ieben, Das zwey Roliren bey biejer Sirt burd)

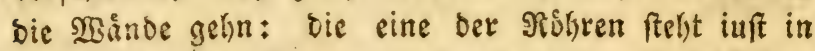
Der Nitte Der NBand, bie andere, nath berfelben Ridjtung, zieht fid) nad) Der 2 Bindung hin.

Itmionft haven aljo bie gelehrteften Ilutoren, be= ponders saruguieres und Ramark, fici) bemíryt, bie

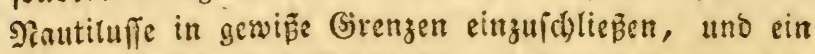
fir fid) befreijendes (Befhled)t aแs benenfelben zแ bil= ben; fitr fie, wie fiur alle andere $2 B e f e n$, ift bies unmóglid); vergebens fuchte man bie Sennjeid)en gc=

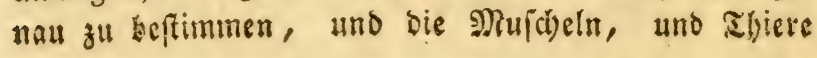

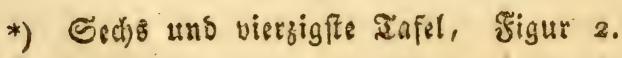

**) Gualtieri, Index. test. tab, 18, Fig. 4. Favannes, Der grofe Rautiluz mit z(wei) Róhren. Conch. tom. I, part. 2, p. 724 , et pl. VII, lett. D 5 ; et Zoomorph. pl. LXIX, Fig. A 4 . 
in ifnen son allen ansern 2lrter abzujonoern; hiex ift gleid) ein Tautilus, ber ibre Sentütungen nte= berreipt, unb wir finben beren nod mebrere. Die

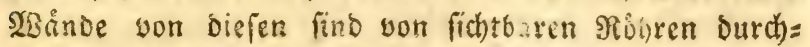
bolst, bie eine findst fid im j)ittelpunfte, bie ans bere liegt tiefer: wir weroen bals febn, mie diefe

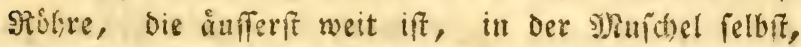
cine innere givid)el zu bilben fdeint; bie abgefumpfo ten $\mathfrak{M}_{B}$ ande erinnern ung an Die 2 Ammonbhorner. Det

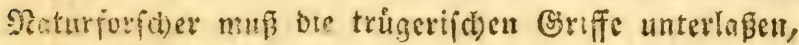
Die die Natur nicht berfattet.

(Sistalticri ift Der cinzige, Det cine Mufdiel mit

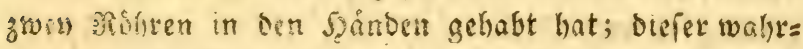

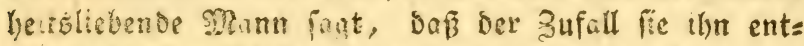

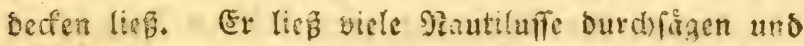

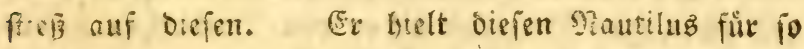

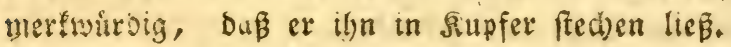

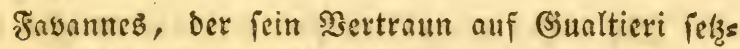
te, hat Disicn boppelrobligen Rautilus als eine be=

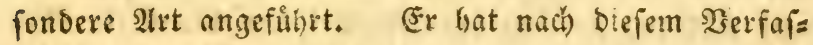
fer, eine felor gute SBefdreibung Davon geliefert, bie er mit einer fdjled)ten, Fleinen, miggefalteten $2(b=$ biloung begleitete, die won ber åufferf feltenen Niu= fdel, bie er fenntbar madjen wolle, feimen SBegriff giebt.

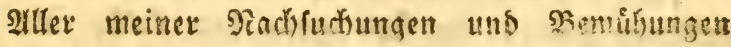
ungeadytet, babe id) sieien Rautlus nie antrefien fonnen; aber Dob, wab ith von Der lebenden PTatur

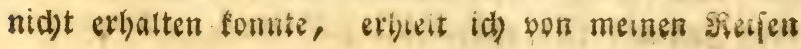


auf ben (Biebirgen; ich befitse brey 2lrten won Naul=

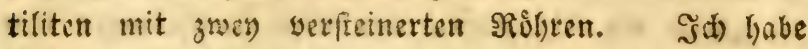
mihrere einjelne Studfe won ieber Alt gejammelt.

\$b id) gleich, wie (bualtieri, nicht bie lebende Suifhe! beifize, fo habe id) boch auf ber XLIV Rup= fertafel, Sigut a biefez Dandez, einen Pautiliten

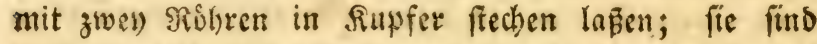
son Combrenon in Sourgogne: id) glaubte an fei=

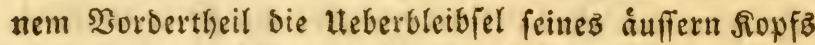
vorfteflen zu můzen, mit bem biefe verfteinerte Puu f(hel nod) verielin ift. Diefer Sopf ift befhádigt,

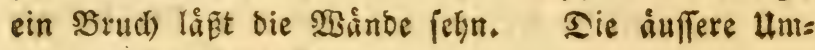
gebung ift recht bicf.

Indere Nautiliten nit zwen Robren habe idi) in ben (d)warzen Marmorbrůd)en yon Sarbançon in ben Şíflen bet Arbennen gefunden.

Bey) Dicjen Rautiliten find Die Rolyen felye fitht= bar, wie ein gropêz Sd)rotforn weit uno gef)n Durd)

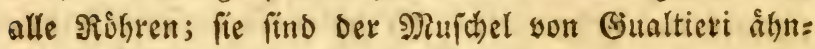
(id), bie er aแอ ben orientalif ben Meeren crlbielt; ¿hre Ránge betrågt viertebalb und bie Deffunng zwey Soll; in ifren Sammern yon idwwarzem Marmor, find fpatlige, falfige Sryftallifationen entjalten.

Dieje Pautiliten von Sombrenon haben eine roth)= gelblidue garbe; fie find ganj yon Fale, ifle noch sueislict)er Jopf ift fein quadrillirt, bie meiften haben ihn noci) ganz; bie lleinen baben eine Långe von irey 3olf und fino andertljalb zoll breit. Unter bem 
Şammer verbreiten fie einen fitnFenden (Bernd). Sath

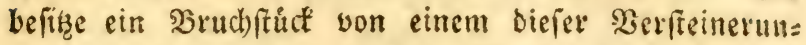
gen, waz anoentet, baß̃ bie siujchel in ifyem volls

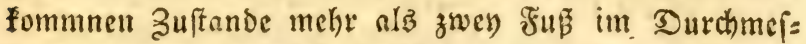
fer hatte. Die Ditfe betright mel)r alż ăwey Sinien, unb bie åufere quabrillirte umgebung gleidht bem grobeften Fanesus.

Sin ber Giegend yon Srififel habe id eine britte Irt won biefem Nautiliten gefunben; er gleicht Dem

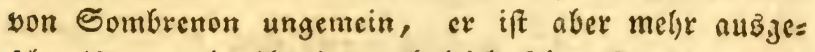
fchweift, mehr thonigt, obgleidh ieine Sammern mit Falfartigen Sryftallifationen angefillt fino; Der Sopf if berfelbe, nut bie Etreifen etwas feârer; auch iff er melye ocherartig.

Durch) meine Serifeinerungen, Dieje jwestólyri= gen Nautiliten, wird Gualtierib Ingabe beffitigt.

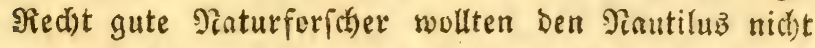
gelten lap̃en. Favannes glaubte cinen 2lugenblite,

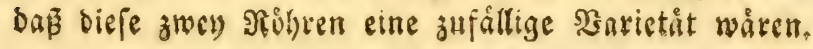


Son ben mictofcopifáen Dautifurfen.

\section{Der Eraufe গautilus." ***)}

Le nạutile granuleux.

Ilnter ber allgemeinen Ueberfdrift, wollen wir

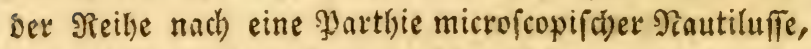
aud) foldse, bie etwas gruperer fino, allf einander

*) Iafel XLVII, Fig, 1 .

**) Plancus, de Conch. Min. not. tab. 1, Fig. 2, lit. D E F. - Gualtieri. Ind. test. conch. tab. 19, lit. A. - Ledermüller, Amusemens microscopiques, (Microfcopifde Belufti= gungen) pl. VIII, Fig. 6. - Linn. Syst. nat. vermes, test. pag. 3370 . Naut, tert. - Favannes, Conch. tom. I, part.' 2, pag. 728 . $e_{t}$ pl, VII, Fig. B. 1. - Bosc, Hist. nat. des coq. tom. 5, pag. 165 . - Soldani, Test. micros. tom. I, pag. 54 , vas. 153 , tab. 35 . F. teb. 34. G, H. et vas, 154. tab. $34,1$. 
folgen laßen, won ocnen Plancus, (Stualticri, $\mathfrak{e}=$ Dermulller, Solbani, Schroeter uno einige andere 2lutoren bereitz gefprod)en haben. Sali) werbe meine

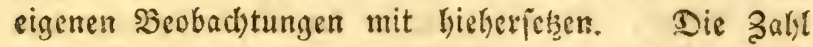
biejer Mautiluffe ift uncrmeşlid). Sie bilben oft als lein grofe Sandfelder. Siur bie vornelymften von iljnen werbe id, anzeigen uno saz mit um fo melyerm Ited)t, Da \&inneé, Favannes und Bojic fie nid)t wurbigten, ibnen eine Stelle in bem Pamenregifter

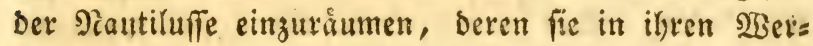

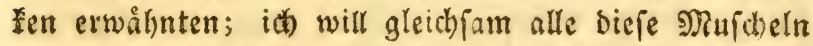

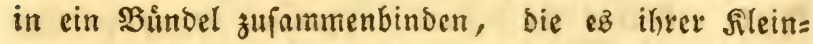
heit ungead)tet, Dennoch yerbienen, dafis fie ber $\mathfrak{T a}=$ tuxforidber betrad)tet.

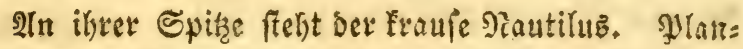
cus ift ber exfe, Der won ihm gefprod)en hat uno er bielt ihn fur ein 2 (mmonshorn. *) Gr fand ihn auf

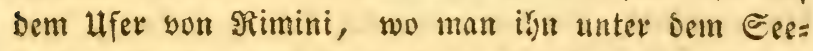
fanbe antrift, won bem er einen grosen Theil aubs mact)t. Pach glancus hat er bie Grobe eines glo= Ben Stedinadelfnopfs, unt ith weis nid)t, warum ihn grananes nue halb fo flein hat in Siupfer fred)en lẩen. Ex ift faft runo, auf Den Eciten ctwas glatt, bie Durd) erlyabene Etreifen gefurcht fino, die fich von bem umfreis zum Mittelpunfte binzielsn; fie find furnigt. Sin feiner Biefralt gleid)t er cinet

*) Explicatio omnium figurarum, tab. prim. Fig. 8, Plancus de Conch. Min, nat, p. 120. 
Snospe. शrufferbalb glånzen biefe fleinen Nenfd)eln yon einer braunen Jarbe, aber bas Jnnere ift perls mutterartig und fammerig. Durch) bie 2 Bainbe geht sine Rofre, bie fid) nid)t in Der Mitte findet, font= Dern feft an bem Şintertheil ber Miufd)el fitzt, beren seffnung faft gan’ burd) bie Trimmern Dez Riels angefưllt ift, ber bebectit und ba zufamenengerollt ift.

Эa) habe Diefe fleite Muldyel bier in Sutpfer ftes d)en lapen, olyne meine Refer auf andere Driginal= fdriftifeller zu werweifen. Die, welche glancus an= fullyrt, if eine ber beften. Wlancus mennt bie Er: babenlecit im Mittelpunte eimen hervorffelyenden Mas

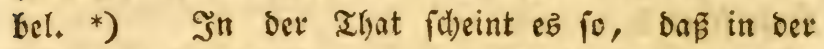
Ritte ein Nunft ift, um Den fid) Die Ranmern ber Muichel zielgn. Die crolagen, aแz Denen ber Berg Eorignano in ber Sachbarid)aft won Rimini befteht, fino mit einer Menge von biefen niedlid)en Pautilul= fen angefillt, bie hier, als bie See zurúdftrat, ver= fteinert find, und man fann in ciner einzigent Unze sun biefer Erobe, 500 Stict fammeln. 2luf Den Bese= filben won \$yifa, ber) De!n Srte Sain Ssiovanni bella Sona genannt, findet man fie aud), won wo fie Sualtieri und \$incent Eaggoni bem झुłancuz zufand= ten. Nann fincet fie auf Berggipfeln, bie fonft yom Meer beipult wuiben, und ieģt trocten baftelin.

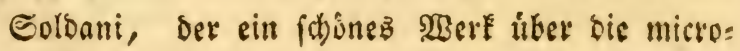

*) Planc, de Conch. min, not. p. 1I, 


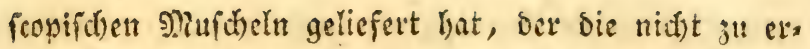
múbende sebulb befą, fie aus dem Sande zu lefen unb von cinanber zu trennen, giebt นแร ธier 2 teten won bem franjen Rautilus. Ex nent fie gemeine, geftreifte Mautiluffe. Diefe smujheln fino Secmu= (c)eln, und benen von झlancus befduricbenen, sitn=

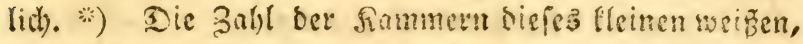
Durdfid)tigen Rautilus if werichicoen. SSalo findet

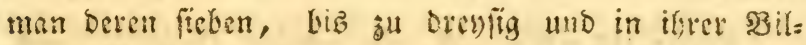

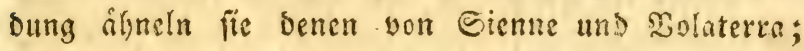
befonbers bie, welche man im Topfertion antrift. Man findet biefe Mautiluffe ju Morto = Ferrajo, aû Der Seite bez Uferz, bie unter bem Mafrnen Follu= nica berinnt iff, oft an ben Gorgunen und slabre= poten feffitzen. Sinn mus unter ifnen cine ofrt

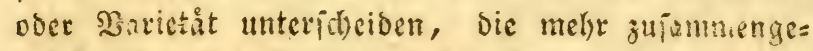
oriccit ift, bie Soldani metir für eit Ilmmonshorn als cimen Piautilus z̆แ borten fobeint.

*) Soldani, T'est, vol, r'. pag, 54, col. 2. 
Det Dornige Trautilus. *) **)

Le nautili épireux.

Diefer srantilus ift son runder Ceeftalt, und nuf Dem Siculen mit Erhabenheiten, die oft weit son einander fergn, bie fid) aber and) bisweilen einan= ber melye nalyn, methe dóer weniger lang find, was mefrere $\mathfrak{B}$ orietiten beftimmen fónte, verfolyn. Daz Snnere if perfmutterartig uno ourd) bie $2 B$ ante gelft

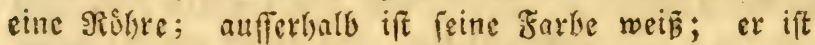

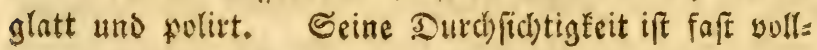

*) Iafel XLVII, Fig. 2 .

**) Cornu hammonis littoris ariminensis tertium. Plancus, de Conch. pag. 12, pl. 1, Fig. 3 . et 4. - Gualtieri, Index. test. tab. XIX, let. C. - Ledermüller. Amus. mirros. pl. VIII, let, C. - Nautilus calcar, Lin, Syst, nat. verm, test. pag. $337^{\circ}$, sp. 2. - Martini, Conch, 1, tab. 19, Fig, 168 et 169. - Favannes, Gonch, tom. I, part. 2, pag. 712, et pl. VII, Litt. B, 3.- Soldani. Test. tab. 33 , vas, $151, \mathrm{E}$. An. vas, $152, \mathrm{n}, \mathrm{n}$. 


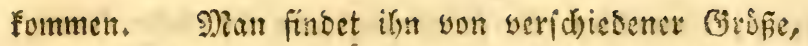

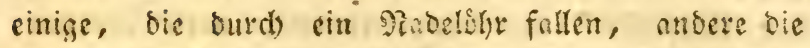
wie cine farté Rinfe grof fins. Bylancub batte ber=

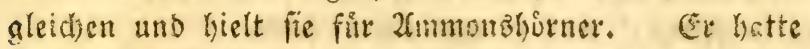
fie in bem Sante auf bem Ufer von Rimini gefun=

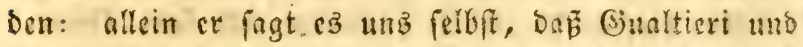

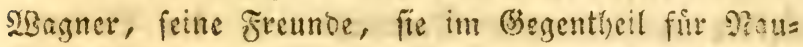
tiluffe bielten. Er gatte ifonen feine milrofoppishen Entoecfungen mitgetheilt, und befiegt burch ibse

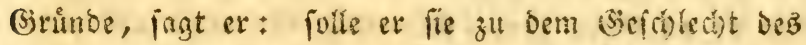
Sautilus rechnen, fo fonme er fie nicht unter bie

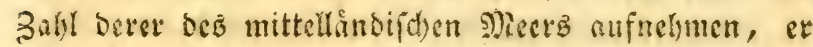

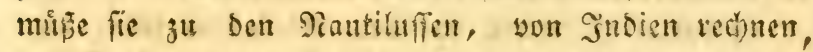

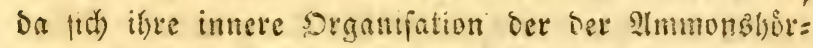

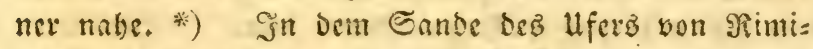
ni findet man fie in ungelfeurer Menge. Sn fed b

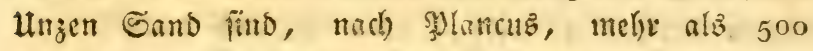
enibalten. Sorfeinert fins fie feltener, unb faum finbet man in einigen Unjen Eand son Eorigano cinige.

S:t Hebrecenftummung mit Simnée fingen wie bick

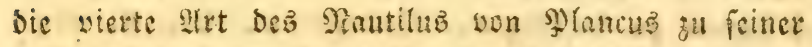

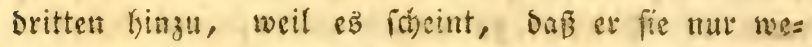
gell ilyeer Geftalt von einanoer gefdjieben hat. Int fechs ltnjen Eand fand man nicht melye n!b 120 ; in= Dep bieje fleine 3ahl an (jewicitt ben 500 Der worigent

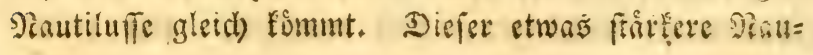

*) Plancus, de Conch. pag. I2 et 15 . 


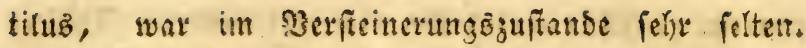
Der Berfeffer, ben wir anfüluen, hatte ihn nut auf bem serge (corignano gefunden: nud) bier war or fo feltert, Das er mur einige fand.

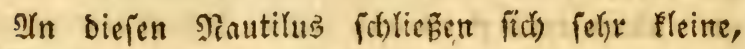
wireflid) mifrofoppiftbe Nautilufe an, bie Solbani

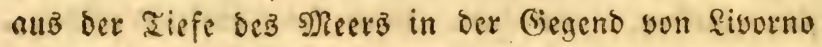
uno Porto = Ferrajo zog, wo fie indé felten fino, wo man fie an Gorgunen, fteinartige Pflanzen uno So: rallemmooz befeftigt, findet. Soldani nannte biefe bier Strablenmufd)eln." Sie fino rund, mit ein=

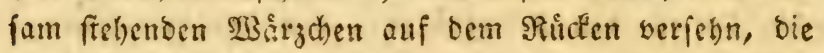
ungleich) uno won benen einige fehr lang fino. Mlan fann fie mit blozen 2 lugen foum fefn. Cic fino

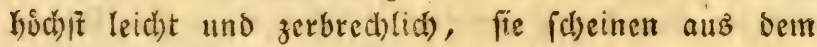
reinften Siryfafl geblafer, Denn fie fino ourchfidstig wie (Blngె; fie banngen fid) lieber an bcz forallen: mooz feft, als baß fie fict) im Sande auffalten, und sielleicht findet man fie nur bann in Semielben, wenn fie toot find. Diefe 2 rt z"ll leben, auf bem Sorat= Yenmooz zu friechen, fith oa zaljleteid) zu fammeln, fid) baran zu befeftigen, funbigt an, Dấ fie ben 2lrmen ber Syolypen zu trolzen wiffen, und baß fie

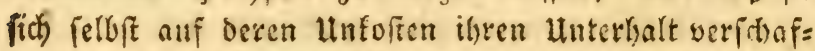

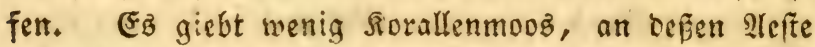

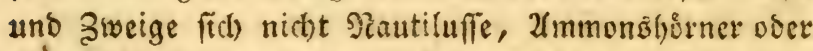
Sid)alwurmer angingen, hie: wadjen, fidh forts

*) Soldani, Test. vol. 1, pag. 54, col. 1. 
Wfanzen in biefem bidsten 2 Balbe, ber fin alle an=

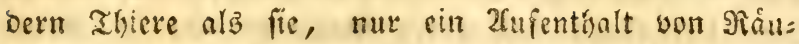
bern und eine Jighle beg నLbes fesn wirbe.

Gualdieri *), Eroermifller **), Favannes ****), baben aus ber vierten 9let bẻ Plautiluz son glan: cus ${ }^{* * * *}$ ) einen befondern ?hattilub gemadit: wir ba= ben bereitz angefültrt, bof ilsn finnée mit bem brit= ten verbintet unb baben feine Mrcinung angenommen,

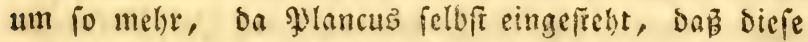

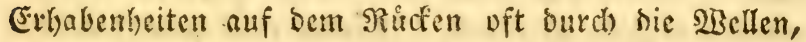

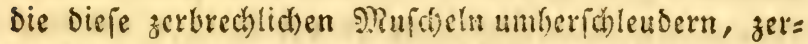
brocken fitud, uno ba Daß bie, bie derfelben beraubt fino, einzig daz

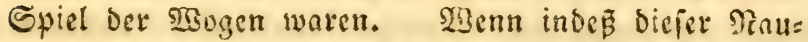

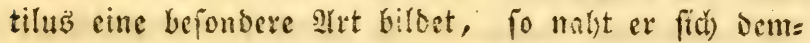
jenigen, Den Whlancus alb eine britte 2 rat won benen anzeigt, die man in Dem Sande von rimini finder.

IIngefieuer fonnte man bą̧ Sapitel bex mifrofeco

*) Gualt. Index. test. tab. 19, litt. B.

*) Lederm. Armus. micros. pl. VIII, let. D.

****) Favannes, Conch. tom. 1, partie 2, p. $73^{0}$.

****) Plancus, de Conch. tab. 1, Fig. 4, I M. N. 
pifchen Pautiluffe und Pautiliten wergrofern. Sol= bani hat innen falt einen Band geweibt. Man

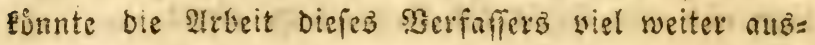
befnen. Stllenthalben fintet man ia mitrofcopilid)e Tautilufie und 2tmmonghorne: Das fiorallenmoos, bie (joagonen, Das (5irab in allen Meeren, ift oft bavon angefullt uno bebectit; inoep̉ mus man dieje fammerigen SNufdeln nid)t mit benen verwecbleln, bie $\mathfrak{e}$ natcht fino, ob fie gleich founectenformig ge=

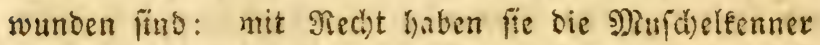
yon ber lestern getrennt. Dafler mú man bie mi= frofopifdyen Mautiluffe ganz in Der Niallye, mit Den

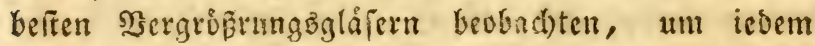
feinen beftimmten গang anzumeifen. Siele neue

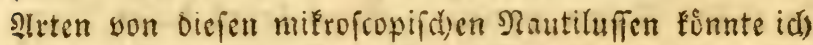

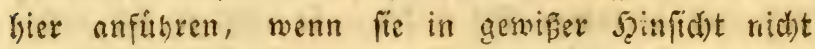
mit benen ubercinftimmten, von oenen Solonni fipricht: wir haben fdon einige von bemielben ange=

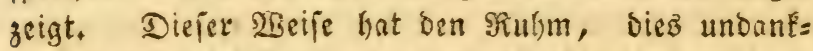
bare fand son nellem ungeriffen zu haben, uno nocis fann man ihn in Soinfid)t ber mitrofcopifhen stauti= lufe zu গisthe zichn, Die alle fo befitritten fino, wie bie, bey benen wir uns bis ieger serweilt haben, bie

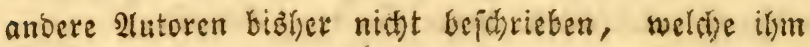
allein angehóren.

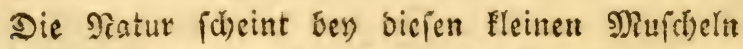

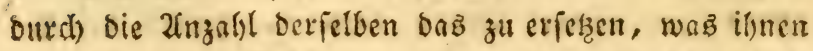
in sibfid)t ber Grübe mangelt; benn alle biefe flei= nen शautifuffe werben in andern Seeftriden nie gris Bet, als bie in ben Meeren bet heipen 3one, wo

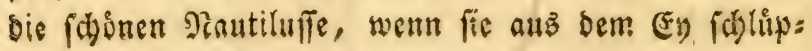


feit, alle eben fo flein find, alg bie mifrofopifd)en

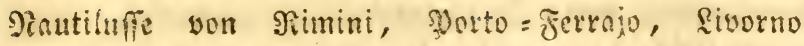
und vieler andern Reerbuien ocb mittellindifinen Meerce. In biejen weniget heipen Gegenten, fobent bie Pature fid) gemiffe (sirenzen gezogen zu baben, die fie nidht liberfpringen wifl, unb diefe flemen Mauti= luffe gleithen hier faft ben Evlemeren, bie in einem

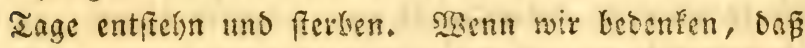

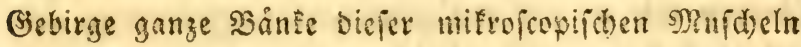
cutbalten, fo wiro

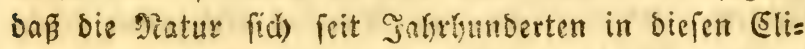

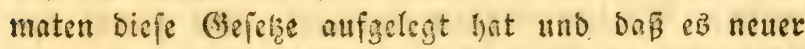
Sievolutionen bebarf, Damit fie sa ilye ganje firaft

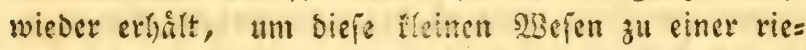
fenlaften Grope zu bringen, bie ben werfeinerten Rautiliten son \$iemont uns einigen andern Nautili= ten in Stalien gleicht. Diefe ietzigen, fabon fo mis frofcopifaten Rautiluffe, ergeugen fith sinrisbenweife und biloen ganze Etrid)e. NSie Elein mî̉en nun nicht bie (5yer fenn, aus benen fo viele fleine $\mathfrak{R u}$

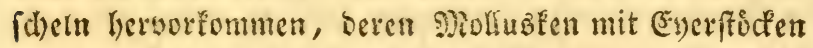
verielyn fint und bie erner in Nenge legen, wenn wir uns anf bie stnalogie beziclin burfen, die inber lier feimen âweifel ubrig zu laffen id)eint, weil biefe Heinen, fanbeornerartigen Mufdeln biefelben in iffer. NTeinleit fino, a!z bie Siufd)eln ber Slrgonauten und Nautiluffe, an beren formen unb silloung fie er: innern?

Son ifyer unglaublid)en 2 ermelirung fonnen wie

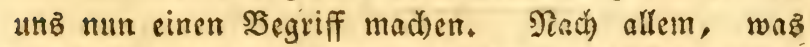
wir gejefn baben, fann man bie Alnzahl diefer fleie 
nen SPidjeln mit bex ber Ennbfornet bes Meers bergleidoen, wenn fie bicielbe nidit itbertreffen. IBie

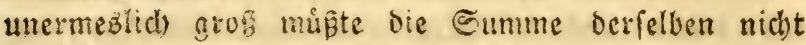

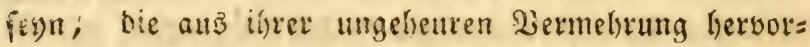
geht, weun die. Dafenende Nenge, fich nach शaks= gabe ifrer gegenwairtigen, nid)t zu bered)nenden $2(n=$ zalyl, wermelyrte? Mlber wenn auf Der einen Seite bie fo ergiebige Refenşquelle unerfdupflid) (d)eint, fo

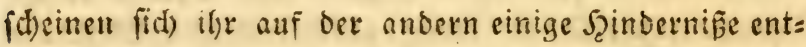

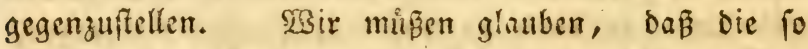
Eleinen, leberfointigen, mit Sd)alen verielsenen Mol=

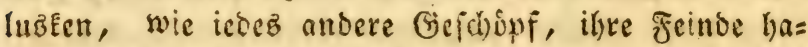

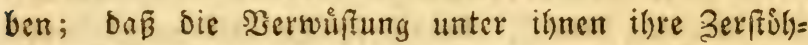

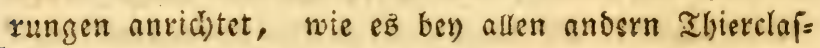
fen ber Fall ift, uno bicfe Berwuffung mus unter

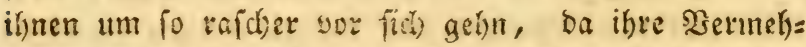
rung fo fí)nell erfolgt. Snlirben bie mifrofcopifd)en Sentituff: niá)t bie Deute anocrer abiere, bie fich won ifuen ernilfrten; whrben fie nid)t bie Spfer Der SutEbef

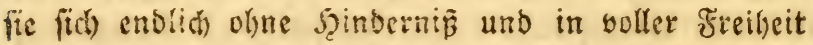
fort, fo witrden bieje faft atomifare SEefen, bie Xecte austrucinen, bas fêfe Rano verbinden, in= bem fie ourch iffere Irummern vidste Ragen fu ben

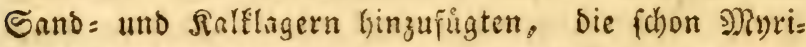
aben von ifreen Benerotionen zum (Siube bienten. Db fie gleich faft faum zu felnn find, fo whirbe es ifrer allein nur bedurfen um burch ibre unermeslicbe Nien= ge eine Rugel zu bilben, bie unferer (5rbe ågnlid) ift. 
Erelárung Der fieben und viergigften $\mathfrak{s u p f e r t a f e l}$.

\section{Mifrofcopifate Rautilufle.}

Erfte Figur. Der Eraufe Tautilus, betråd)tlid) wergrofipert.

3̧weste Figur. Der bornige Nautilus, burd) ein Wergró ßerungảglą gefelgn.

Die anbern Figuren fellen mifrofropifhe Rauti= luffe vor, bie fdhon von Solbani betannt gemadjt worben fino, fie find aus Der glitte aller berjenigen gegriffen, bie biefer Metfaffer zeid)nen ließs. Die Junfte, die auf ber Ceite von iedem biefer mifro=

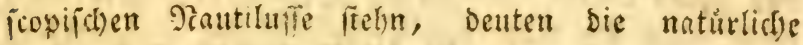
Grube diefer fleinen Mujdeln an. 
Der Sautilus von Dar. ") **)

Nautilite de Dax.

Setht bejd)reibe id) eigentlid) fo genante Tauti= luffe, folche, Deren lekgte Sd)neckenwindung alle an= bern einfoliest und bie alle int frengen Sinne z্cu ben lederbarutigen, mit Sd)alen veriekenen Molluš Een, gehoren. Wir fitlo von bem gewúlynlichen ঐautilus aus̆gegangen, baben alle bieienigen betract)=

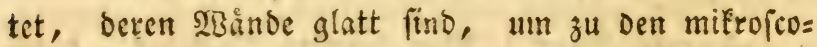

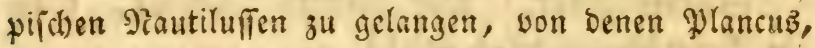
Gualtieri, Eebermúller, Edjruter, Rinnée, Fas wannez und Soldani melye als ieder andere, it ihren gelehrten Sdiften gerebet baben. Shir haten im= mer bie ârnlid)en Berfteinerangen, bie wir als fol= d)e erfannten, jujammengeftell: mun muß̧en wir,

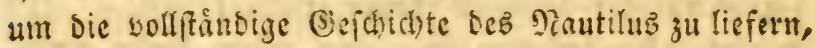
yon beten reben, mugen fie lebendig voer verfeinert fenn, bie fich won Den uripringlid)en Egarafteren auf irgend eine $\mathfrak{z}_{3 e i f e}$ entfernen. Sieje biet find

*) Infal XLVI, Figur 1-

**) D'Argenville, Oryctologie, planche VII. Fig, C. 
won ben erftern surch \$erticfungen, Unuegelmafig=

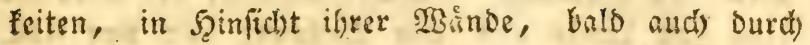

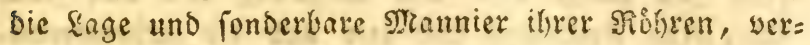
fdicosn; andere weichen won ihrem uripringlidien (Eharatter burd) einen (d)wachen, faum ficitbaren Nabel ab, oder Durch) áuffere befondere formen.

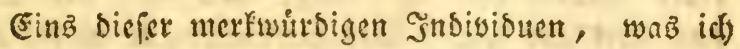
auf ber vier und vierzigften Iafel, Figur 1 gezeid)= net babe, gefourt licher; ez ift verfteinert und Eommt yon Dax. Sid) habe es mitten burd) fingen lapen uno ez̉ in Mittelpunfte zerbrochen, Damit man bie weite

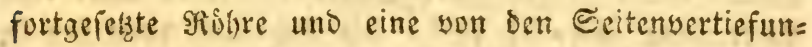
gen, bie trid)terformig gebilbet iff, felon Eann. Diefe Derticfungen gehn won ieber Seite burch) Die BBinde,

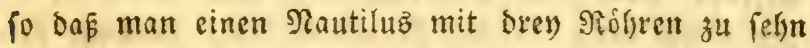
walynt, won benen jwets auf ben Seiten find und Die britte gegen bie ŞSindung bes Fitels geftellt ift. Sm natirlichen suftande habe id) biefen Pautiluz nid)t gefelyn.

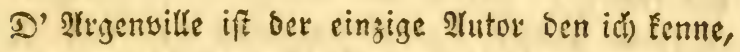
Der in eimer fdled ten rbbildung, bic er suf ber fies benten זafel, Figur C, feiner Sryctologie in אup. fer ftechen lię̧, bavon cine Joee gegeben bat. IIE tein ber zext ift fo armfelig, Daß er zux Ereflårung Der Figur nints beytri̊gt.

(id) will bie Befdreibung biefes Nautiluz nad) bem Snoisioum liefern, bas id) vor stugen habe uno wab fid in meiner Eammlung finbet. SPan

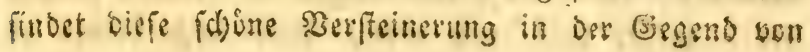


Dax, in Guifenne. Diejer Pantilit bat mehye als zelin 3oll Ringe uns eine Deffmung won viev 3oll. Sllte peine sommert find leev uno bie zerbrodtenen, find mit einem rothgelben, nicl)t feftancinanderbån= gendem Sande angefillt; er bat jeinen ganzen \$erl= mutter behalten. Ser Mittelpunt bat bie form cinez গabelz uns ber Slopf, wie aud) bie 28 ånbe find ftat und feft. Das mertwirbigfte ift bie breite

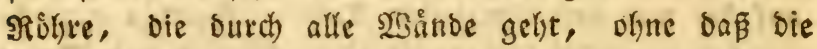
Fortjetzung unterbrochen wirb; in ben lezten Sam= mern ift fie fo weit, Daß nan einen Finger hinein=

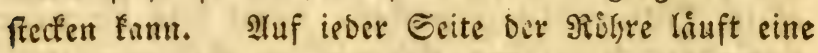
Sertiefung mit iffr fort, bie fid) nad) yorn hin in

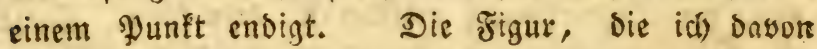
liefere, ftellt biefe \$sertiefungen, aber nur yon ci= ner Seite bar, fo wie fie fid in ieber Sammer fin= bet. Seym erfien Inblict follte man glauben, in

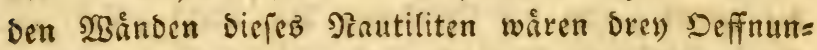
gen. Piach Diefer Bilbung Der Mujchel funnen wir glauben, Daß ber Sôruer Dicies Nantilus fid) in ei= ner runden, farten uno diffen Pierve enoigte, Der in feiner ganzin stubbelnung cine faltartige Materie

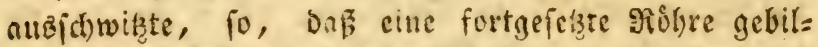
bet nutbe, bie Durd) nlle Sisinde gefit. Unabge= felyn won biefem Siersen wat ber Sgintertheil you bie= fem গ⿻ำ

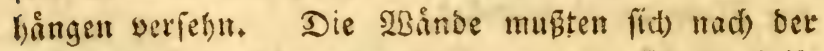
Billoung feincz Sivrpers richten, auf bie fich bic talf:

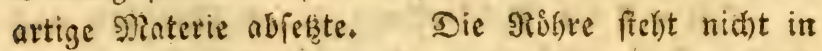
ber Mitte Der $23 a b^{2}$, fie findet fid) an be: 2afiz berfelben, wie wir'z ben cinigen 2 mmoniten finden, seren Robre balb nad) vorn, bald nach finten zu 
feetst. Der Nautilit won Dax ift aud etwas glatter

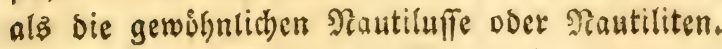

Det wellunformige Dimtilus. *) **)

Le Nautilite ondúlé.

Diejer nieblidse Niautilit ift gang in Slutfein verwandelt. Seine నammern find zum Theil leer, andere entyalten Eifentheile. Ere foumt aus ber Giegend yon (El)arleroi, wo man ilin in ciner fdumutici=

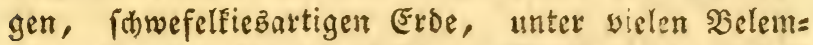
niten finbet, Die ebenfalls in Stutitein verwandelt

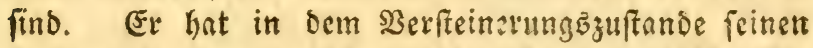
åuffern Ropf eingebúpt, baher fann man die SBe=

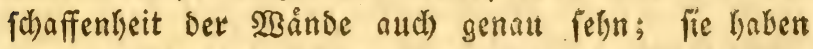

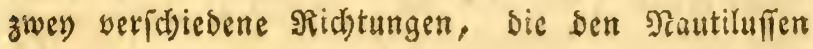

*) Tafel XLVI, Jigut 3 .

**) Klein, Polyth. tab. 2, Fig. 4. $\oint 38$. Rumphius, Amb. p. LX, Fig. E. - Bayer, Oryct. noric. tab. 2, Fig, 2.

$$
\Im
$$


gewoinnliche unb bann eine wellenformige; bies theilt

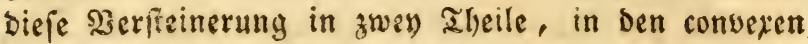
uno concaven. NBie bey ben Tautiluffen feht bie

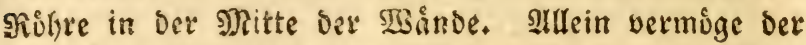
fonberbaren Structur der $\mathfrak{2 B a ̊ n b e , ~ a ̊ ̉ n e l t ~ b i e j e r ~ N a u s ~}$ tilit ungenrein den 2Hmmonbl)ornern; er unterfdectoet fich son ifnen burch bie leste Trinoung beb Sqinter=

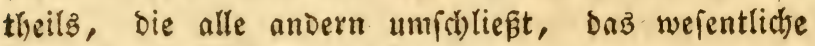
Sennzeid)en, was ben গRatiluffen zufonmt, was felbft das einzige ift, woran man fie fennt. Şd habe mebrere biefer eifenartigen $\mathfrak{s e r f t e i n e r u n g e t t ~ g e = ~}$ fammelt, id) befike welche die eine Lange von zwey 3oll und eine Deffnung won zelyn నinien baben. Sie haben fich sorlig extralten. Shre Farbe ift oft buts feldbotolaben. EB giebt vielleicht weld)e, of man fie gleich felten findet, die größer als bie meinigen find. Diefe Neinung fdeint mix um fo walrid)ein= lidjer, $b a$ idh Dem mellenformigen Jautilub einen andern an bie Seite fetzen fann, ber won Alein be: fannt gemad)t, aber (d)led)t gezeid)net ift. *)

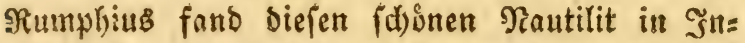
bien ${ }^{*}$, allein in Siefelftein verwandelt, und fd)lug man mit bem Stahl Daran, fo gab er Funten. Ex bat uns cine \&bbiloung Dabon auf feiner XL fupfer:

*) Klein, de Polyth. tab. 2, Fig. $4, \S 38$.

**) Rumphius, Amb. pl, LX, Fig. E, et pag. 318 . 
tafel unter bent Sudjftaben E gegeben; er bat foum

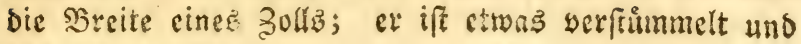
(b)led)t gezeid)net.

SBir fügen biefem einen Pautiliten bey, ber et: waz (d)aohaft ift, weichen Sayer zeid)nen lięি und Den er in ber 2frt anbeutet, Daß ex bloge, wellen= formige linien hat. *) (Er war ganz in weisfararbigen Marmor verwandelt. Der Şerfaffer fand ifin auf bem Serge Siblipfaberg, bey ben Dirfern Miteben

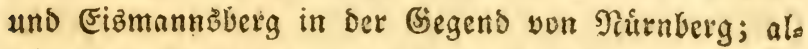
lein biefe $\mathfrak{s e r f t e i n e r u n g ~ i f t ~ f a u m ~ k e n n t b a r . ~}$

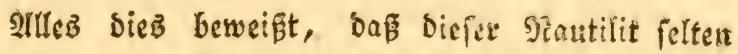
ift uno wenige stutoren haben won ihm gefproden.

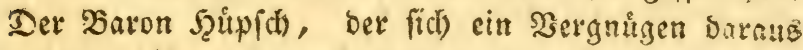
machte, feltene obar fonderbare Pautiliten zu fuchen, bat einen von biefen niedliclen veriteinerten Rautilis ten betannt gemad)t; er ift, wie ber meine, eifen. artig unb hat bie Farbe beg $\$$ ihm einen Sseynat,men, Der mit bem meimem biber=

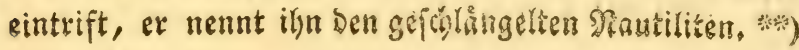

*) Bayer ‘ Oryct. noric. tab. 2, Fig. 2, eह pag. 3o. Nautilites superificie laevi, lineis simplicibus undosis. - Lapillus est albicans, marmoreus, e monte Schlipfsberg : inveni etiams inter pagos Rieden ế Eismansberg.

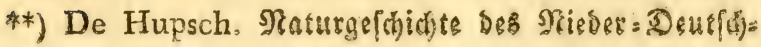




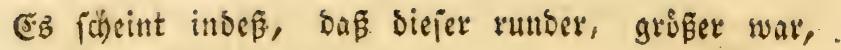
alz ber meine.

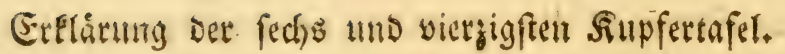

Figur 1. Der গautilit bon \$ax mit fortgeiekter Rorke, Dev fänge nach gefpalten uno gegen ben Mitte(punft hin zerbrod)en, Damit man ben innern

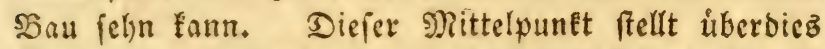

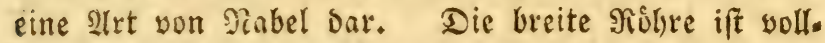
fommen und liegt offen da. In ieder Rammer zei= gen fit) Die Bertiefungen in Irichterform, unverleţt, bie bie siofre zur Red)ten und Rinfen begleiten; bier fielst man nur cine Ecite.

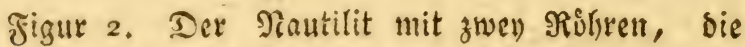
cine ifi in Der Mitte, Die andere an ber Bafiz ieber 2̇and. Diefer Siautilit hat cinen Theil feineb Ropfz behalten, Der fefie bick uno quabriflitt ift. Die Sammern ftelyn offen.

rand8. Band 1, Tafel 2, Figur 17 und 18, und §ag. 23, §30. 
Figur 3. Det Pantilit uon Eharteroi mit wel=

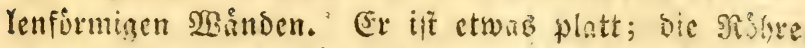

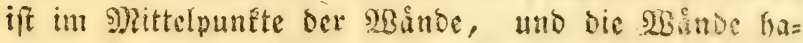
ben cine boppelte Shefdraffentgeit, bie ciue ift conver uno bie anbere concas.

\section{Der fappenfirmige Tantilit. *)}

\section{Le Nautilite encapuchonné.}

23ir haben bey bem medenformingen Pautilit ge:

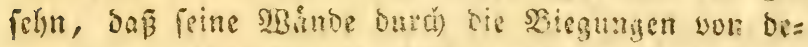
nen ber gewöhnfichen ghatifnfe werifhicben fino; wir ftellen hier einen andern wor, befen şbente cin noth

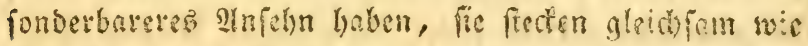
Sd)arteln oder Muken in cinander. Stumnt ie ein

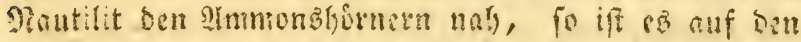

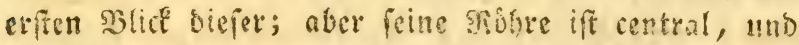

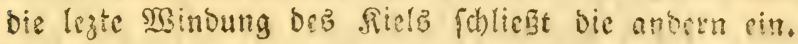

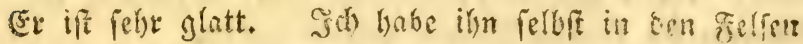

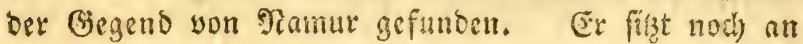

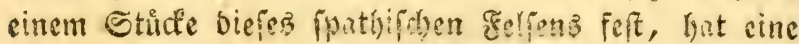
fd)warggraue Farbe und wenn man barauf (d)ligt giebt er cinen ferbe fitinenoen (seruch gon fid. 
Die serfteinerung if weit melye funtfif d)er, alz ber harte Narmor, in bem ex eingeid)lofen ift: feine Farbe ift zimmetfarbig. Der åmfere Sopf ift ver= nidjtet. Die angefuillten und feften Kammern haben

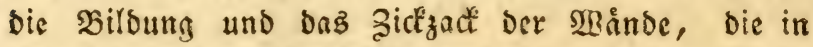
einander laufen und hochfit regelmåping fino. Diefer Tautilit gleid)t ciner vollig runben Echeife. Sein gróster Durch)meffer ift zwey) Zoll und bie Deffnung

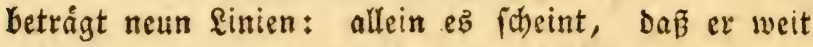
größer wird, weil die lezten SBinde fellen, wie

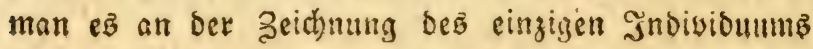
fieht, bas id) mir verid)affen fonnte.

Sd) Galte biejen Prautilit fure fefre felten; er iff ber einzige, Den idh gefelyn habe, ber cinzige, den id) finden fonnte, unb id) treffe ifhn in feinem slu= tor befárieben, ober in Supfer geftod)en an. Shla Eeltenleeit babe id ifn hier auch bargeffellt, ex ift

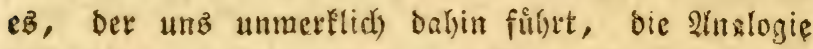

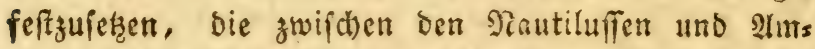
monzhơrnern fratt findet, et bient zum Seweife, Daß

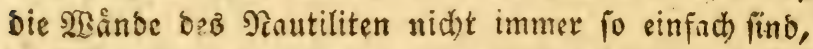

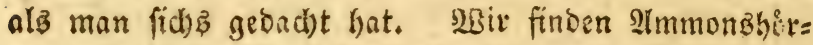
nex, Deren mainte ebenfallz ganz grabe fins, aber auch anoere, bie wellenformige, zerftud delte $2 x_{B}$ inte baben; uno biefe fulfren unz endtid) zu ben 9 (mmo= niten, Deren atbetgeilungen fo runzlicbt fint, Daß bie

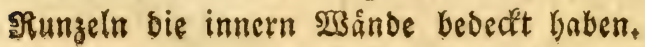




\section{Der Sautilit mit Der Etideret. *)}

\section{Le Nautilite Brodé.}

Ge melir wir bie șreten futdieren, befto melye waxunclyen fith, fo zulagen, die cinzelnen Gattun= gen; Denn bie fortgeielzten Unteriud)ungen fulbren zu Entoeclungen, oft if man ganz erfaunt, unwer: bofite Gegenftanbe zu fehm, bie fid) natirtid an bie

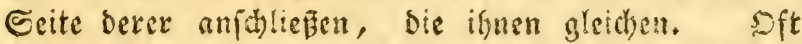
hat man ę̧ bemerten ronnen, Dafí Die Sndisionen, bie man fir yerlapen lyolt, Siadburn erbalten has ben, bie biakger unféfnant waren uno fich mit ifynen

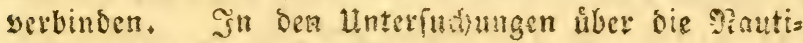

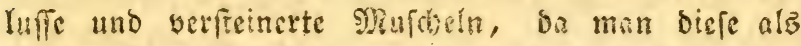
Seltenfseiten betrochtete, finost fichs, bar fie cben

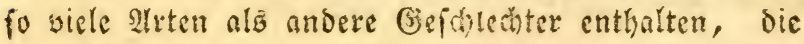

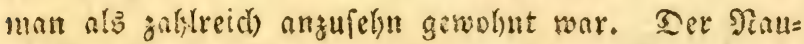
tilit mit ber Sticferei, ifte einet ber fdionften und feltenften von allen $\mathfrak{B e r f f e i n e r u n g e n . ~ ( 5 x ~ i f t ~ f e l y e ~}$

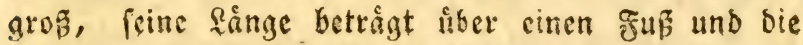
Seffung act)t zoll. Statt baß fein Sopf glatt iff. was man bey sndern Sautiluffen finbet, ober quas = srillitt, wie's bey gewišen Thautiliten bet fall ift,

*) Kafel XlVIII, Fig. 2, 
fo ift ex biclutely mit einer Eticferei, wie sinige Melonen, werfern. Gegen ben Mittelpunft bin fin=

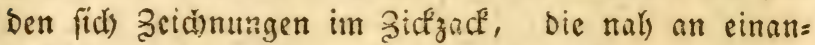
ber frelsn, aber breiter fino, ebabener, beutlich an= gebeutet, weld)e fid) gegen ben runbe'n aiuden bex

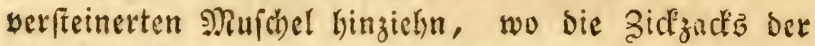
beyden Geiten zu[ammenlaufen, uno fid) in cinen ftumpfen $\mathfrak{Z s i n f e l}$ vereinigett.

Dex Ropf iff beftådigt, man fonn bie Shanbe felyn, Die glatt, obne J̧alten und Siegungen fino. Die Refrite iff in ber Mitte. Diejer Minutilit ift fehr fichwer, weil ex ganz maffis ift; dab S̈nnere ber $23 a^{2}$ be war mit einer gelblict)en Erbe angefurlt, bie zu Stein geworben ift, allez ift an biefer Sereffeine:

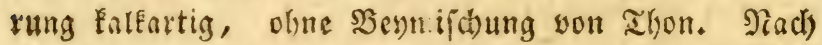
S) Tapgabe feiner Range if bicfer Pautilit fer)e breit.

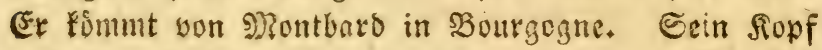
und feine Şånde fdeinen wenig bicht zu (eyn. Sid) halte ifn fur felten, um fo melje, da iaj) ifin bey. feinem 2lutor gefunden babe.

Die gelbe uns feurige Farbe biefes Nantiliten

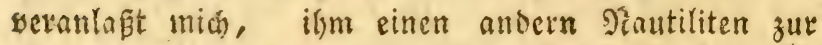
Scite zu ftellen, Der, wie ex, bon 2ourgogne fismmt. SNan glaubt, er befand fid) in demielben Strintruch, gehorte zo bemfelben (sejd)lecht, wenn

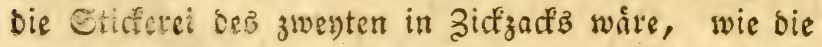
bey Dem erfern; fie ift nod) mehr erbaben; allein ftatt mehrere Eccen zu bilben, zeigt ex zulammenge= brůcte uno regelmáäige Seiten, etwaz̉ gebogen, bie (id) auch nuf Dem Rluden in einch ftumpfen 2 Binfer 
wereinigen. Hebrigens ift bie form dicfes Pantili=

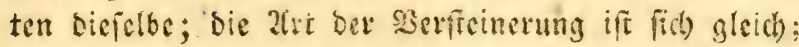

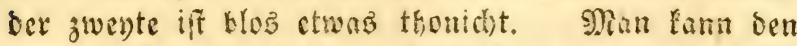

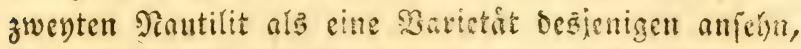
Der auf Der XLVII Sunfertafel vorgeftelit ift, obcr ifh als cine 2 bart betraditen uno ifm cinen anoern

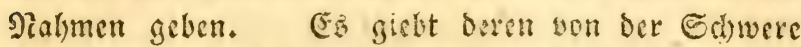

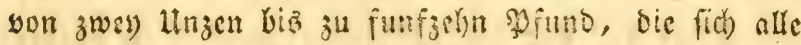

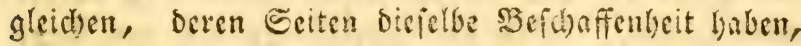
und bie won cinander nibt verjoteden fint.

Denfelben Tautilit findet man in ben Gegenden won Narbonne in Den Mlatmorubuechen. Diefe Paus

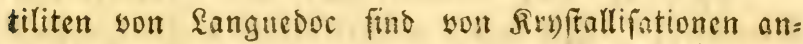

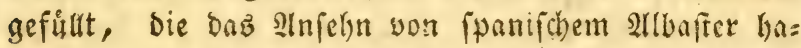
ben, zu anderer seit findet man weldhe, bie mit einer thon = und feetoartigen Erbe libergogen find, weld)e faft rojenfarsig ift. Einige fino von einet

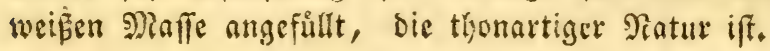


Ereflatunt der fieben uno sietgigften Supfertafel.

Figur 1. Ser fappenfurmige Nautilit in nature tider Gripere. Shan fiellt vollfommen uno bem slige

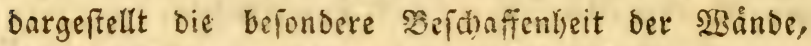
bie wie Maktsen auf einanber gefthoben finb.

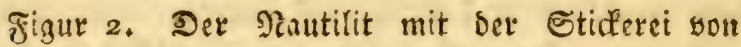
Montbard. Die ganze hintere Eeste biejer Merftei= nerung hat bie Stidersi ifreb alten fupfz, bie vor= bere Scite ift gejffret unb man fann bie risinde

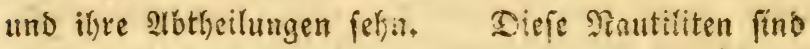
ganz verffeinert. 
Der ausgefdneifte Dantilit.

Le Nautilite évasé,

(c) habe biefen Tautiliten niojt gezeichnet, weil

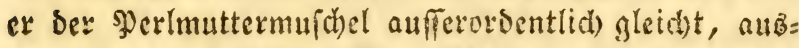

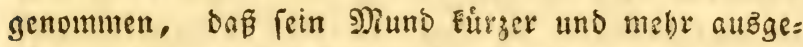
fchweift iff; er hat Daz in ber Breite, was ber le= bende Pautilus in ber Range hat. Seine Rainge be= trågt cinen Zoll und bie Deffnung zwel) Zoll. (Fx hat nod) feine ganze åufiere Geftalt; sllein er ift in gelben Salfipath) vermandelt, bod) fo, bã man

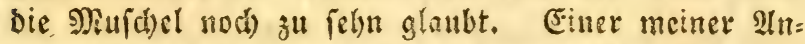
verwandern hat ifn aus Erina mitgebracht. Die Def= nung ift fo mit Sivftallifationen angefullt, da官 man Die Etelle nid)t felgn Enn, wo bie Ribre ift. Die Deffnung betrågt zwer) 3oll in ber פ̇eite. Diefe serffeinerung ift voultig unverlest: id fenme feinen 2autilus,, Der inn glid)e: 
Der Nantilit mit baแçigem Şintertheit.

Le Nautilite a poupe renflée.

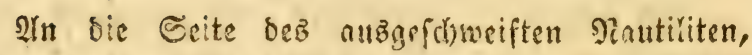
ftellen wir bas biegenftü z" bemfellon. Diejen

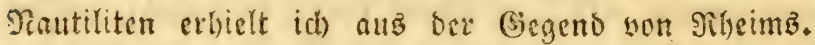

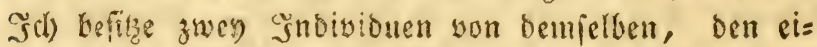
nen von ber (sirópe cinez 3olls uno ben anbern yon

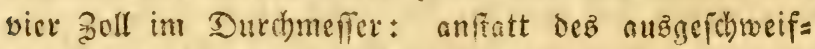
ten Plunoes, ben alle anbern Nautilufe haben, jielst

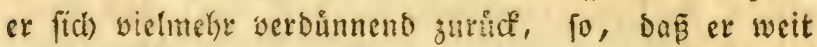
enger an ber Deffnung als ben Shintertlyeile iff, ait bem ex fich anidrtiebt. Şey einigen Sd)neden fin= ben wir biefelbe Erforinung. ISBie die Menidyen, fo haben auch Die Thiere eine zeit ber Reife uno bez Honebmenz, in Ser şlittie des febenz, im fraft= wollen sitter, freuen fie fich aller ilyer Sirffe uno bey) volligem Sisorlbefinoen musen audi bie Ed)ueden in bem beften 3uffande feyn. SBem baร Alter funmt, bann werben bie 3ige runzficht und bie Ģfieber ver: bornen. Şon nun an ift es nicht mel)r (d)wer zu begreifen, wie einige Sdhneden fo weit gefommen fino, ifren Sicl zu serfleinern, is nactbocm bus Thiet burch bas 2llter verkleinert warben ift. Diefe

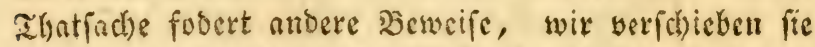

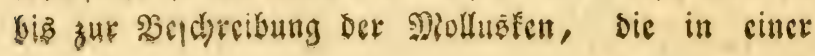


gewip̈en febenşperiobe Befangene weroct, die bant bie seffnung iffer Schneffen fo eng mathen, Daf̧ es ifnen nicht melye muglich iff, aแb Derfelben zu

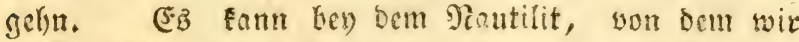
reben, berfelbe fall gemeien fesn; er iff forbiben= runo, mit falfortigen, sechectigen Sruftallifationen won einer freidenartigen SPateric angeriblt, bie viel Thon entialt; im solittelpunfte findet man eine leichte

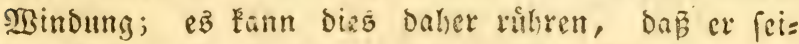
nen auffern Sopf verloren bat. Der Nunb, ober

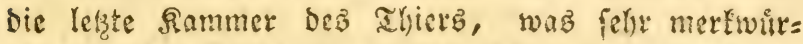
big iff, wirs fomaler, fatt fich zul erweitern uns iff im Durd)fonitt ein Drittheil Fleinet alB Das Jृin= tertheil ber Siufdel. Sich befise ielst Dabon zwey Sndiviouen, unb betrachte biefe sildoung nidit alb

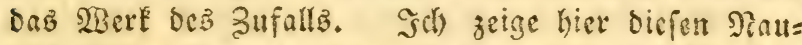
tilit in Der Erwartung an, Das man it)m noch andere au bie Seite feken mird. Soldani *) bat unz einis ge mifrofcopifde Tautiluffe geliefert, Die foft vet:

*) Soldani, Test. Mic. vol, 1.

$$
\begin{aligned}
& \text { Tab. 56. vas, 189, O. R. } \\
& \text { 57. 189. S. S. s. } \\
& \text { 58. 191. g. g. } \\
& \text { Tab. 59. 195. S. S. } \\
& \text { 6r. } 198 \text {. O. }
\end{aligned}
$$

unb vielleidnt alle bis, die mit ber LXVII Tufet anfangen und fich Scite $6 j$ endigen; bann ê ift fithtbar, baß fie in einer geroipen 3eit sofangene

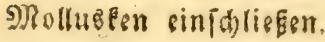




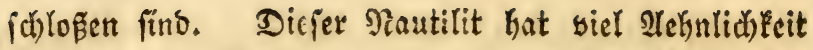
mit bem won Parbonne, won bem ia) gerebet babe.

Det nabelföruige Dautilus, *)

Le Nautile Ombiliqué.

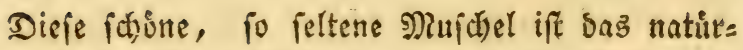
liche SBild ber 2tmmonzhorner, an Deren Spitze wir

*) Lister, Hist. de conch. tab. 550, Nro. 1. Petivier, Gazoph. nat. part. 1, tab. 99, Fig. 9. - Valentin, Amboin. cop. univ: Fig. 4. - Knorr. Delic. des yeux, part. 1, pl. 11, Fig. 3, pag. 8; et Delic. de phys. tom. 1, pl. B 1, Fig. 2, pag. 40. - Gualtieri. $t_{4}$ 1. p. 107 , art. 79. - Favannes, Conch. vol. 1, part. 2, pag. 2, pag. 725. - D'Argen-

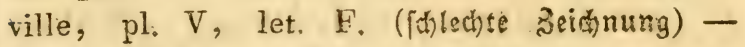
Catal. de Latour d'Auvergne, pag. 59, art. $252-253$ et 254. Favant d' Herbigny, Dict. tom, 11, pag. 418 . 
fie fitlletr. Es foll hier nue bon ben Pautifufien bie Rede feyn, in beren Mittelpunfte (id) ein fleiner Nabel jeigt, beshalb habe ich) Den allgemeinen aner= Fannten Pabmen, nabefformiger Mautilus, beybe= halten. Diefe niebriche, feitene Muichel wird nie niber zwey, brei) zoll lang, man findet fie noch weit fleiner, fie hat im Durdmeffer faum einen

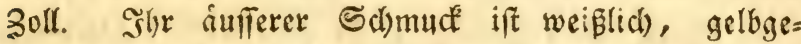
flammt uno feuerfarben. Sm Sonnern ift fie grau per'mutterfarben, und fdis und fanft polirt. Dev Seintertleil ift mattoraun. Durch die Sammern gelyt im Pittelpunfte eine Rofre, wodurch alle $\mathfrak{B a ̊ n d e}$ mit einander verbunden werben. Diefer Nautiluz ift fait fugelformig getunbet; feine Seiten fino felye aubigeichweift und bie Deffrung ift faft runb. Som Mittelpunfte ift er mit cinem Sabel serfefin, Dured) ben man einen Faben ziehn fann. Diefer Fabel ife ber eigenthåmliche Eharafter von biefer Irt beв Itau= tiluz. Man mad)t diejen Nabel Durch Sinft bey ben fleinen \$erlmutterictnecten nach, und man mu苗

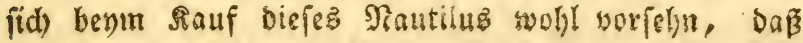
nian nicht betrogen wirb.

Diefer nistlide Tautitus fimmt uon Den Mo= luferen. so ifn 9umphits audi) nidit beidrieben

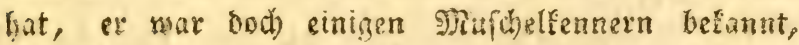
bie ifrn alb cinte Ealkentreit angezeigt haber. Sinnée,

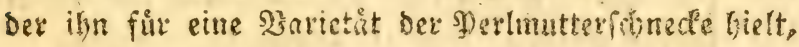
bejeichnete ifn mit fenem andern Sialmsn. Sserfeis

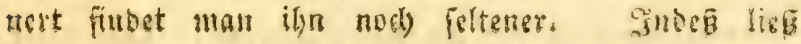


Soreyn *) cinen in Supfer fecten, ber cinen unge= mein fleinen $2 B u d$ ) b hat, faft biefem lebenden Tau= tilus gleid)t, won bem man ilyn als eine walyre 2(elytt= (id) feit anjelyn fann; er bat fid bollfommen erbalten.

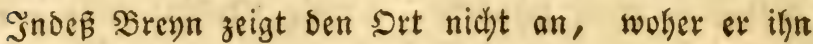
erliclt.

Unter ben zalitreiden, fo unfellerhaft gezcidjnes ten Serfteinerungen, Dic Şayer **) befannt madte, finden wir einen Trautiliten mit Deabelform, Den er alz einen jungen Siautilue betrad)tet, Der Der grobeen

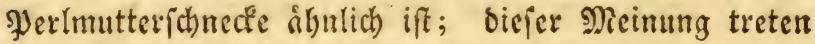

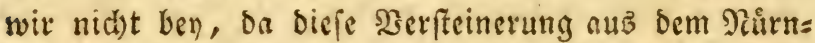
berger Bjebiet vollig fenntbar und ganz unverletget ift. Sein Soln liefert uns orey nabelfurmige Ninutili= ten ***); fie fino ganz unbeichabigt unb haben ifyen Sopf fait ganz behalten. Schabe, Das ber sit, wo fie gefunben wurden, nicht bemerft ift.

Fa giebt in feften, fteinigten und falfigten $\mathfrak{L} a$ gen nabelfurmige 2iautiliten won betraed)tlicher (sitépe.

*) Breyn, de Polyth. tab. 2, Fig. $3, \S 38$.

**) Bayer, Oryct. norica. pl. 11, Fig. 8, et pag. 31. Der Drt, wo bis Tereffeinerung ges funden murbe, ift nicht angezeigt.

***) Ferd. Bayer, in Supl. tab. 10, Fig. 3, 4, 5 et pag. 17. 
Ituf Der eilften בafel ber 3ufåtze zur Sunctogranrie

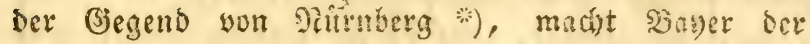
Colnn zwey Pautiliten befannt; Der eine iff faft gans erlyalten, man fiest bie einfade, glatte fo:m bet SBande; ber Plabel ift unverlennbar: ber zuseyte Rautilit auf berfelben Iofel iff halb burd)gefigt uns man fieft nur Daß Sontere ber Sammern. Die

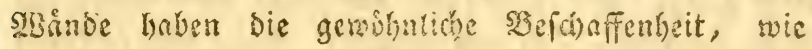
bey ben Pautiliten. Den sut, noher bieje fidis.

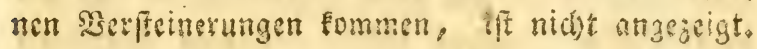

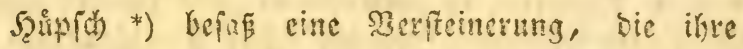
ganze Geffalt nod hatte. So fie gleidh in Solne= felfies berwandelt ifi, fo ift fie bennoch felle feft. Inth) er zeigt ben Sort, woher fie riffert, niejt an.

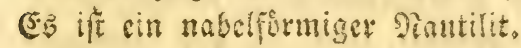

Eeinet Geltenheit ungerd,tet, finsen wir biefen

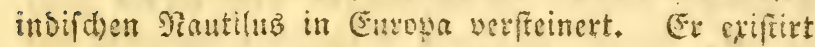

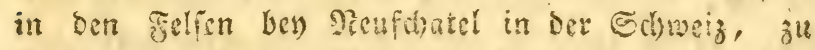
Ilristorf in Canton Solel. fnow bat cinen fehe grober Dawon betannt gemad)

*) Ferd. Bayer, in Supl, tab. 1, 2 et pag. 17.

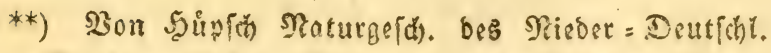
sBand 1, Iaf 3, ซึigut 19, und Esite $25, \S 33$.

***) Knorr, de Pet. vol, II, sect. 1, pag. 4.4, et pl. A IV*, Fig. 1. 


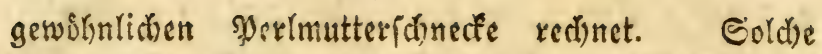
grope, wie finorr, ber fie im Eanton Bajel fams melte, befitze id) nid)t; sllein id habe einen yor mir, Der yon Nenflbatel fam. Seine Formen find felhr gut erbalten; ex ift fuinf 3oll lang und bie Seff= nung betriggt 3 3oll, er hat feinen åmfern Sopf noch gallz, ber in grauen Salfipath verwandelt ifí, feine Sammern' find won grauer, thon = unb Ealeartis gex Erobe angefuillt, bie eben nid)t hart if tino fich mit bem Neffer ichneiben lågr. Einige Rammern fino in Sd)wefelfieg verwandeit, wie bie ber andern פiautiliten berfelben Gegeno. Der awifdenraum ber

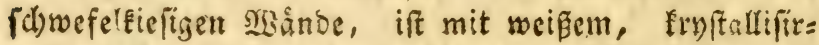
ten Saleipath angefüllt. Diefer Nantilit ift weit grós= B̂er, svie man den nabelformigen গautilub lebend findet; ittops biefe Sidwierigkeit iff bald gelyuben, wenn wir bemerfen, doz viele Nujcheln, die wir serfteinert finden, im slgemeinen weit grö̧er fino, alz bie, bie wir in ifrem natirlichen 3uftande fin= ben; ez̉ ift eben fo mit Den Merfteinerungen, bie

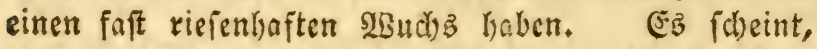

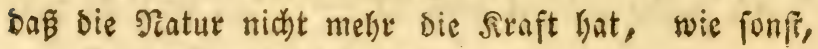
wo allez grop uno riejengaft war. 


\section{Der triangelformige Nautilit. *)}

\section{Le Nautile triangulaire.}

3u Şaser fand id) biefe fohoure Serfteinerung, am Fuge ber Felfen, bie fo viele Trummern antifer Generationen in fït) föliễen. Er hat fedse zoll in Durd)meffer, bie seffung, weldhe triangelformig ift, entlyilt brittelgalb Zall. Gergen ben Rlucen ber

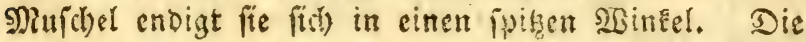
Rolhe ift im Mittelpunte bar MBonde. Die 2 sande find felfe concas und bie Fiander cinfact). Dex fopf ift nid)t mefre oa, die Sammern find mit einer freio=

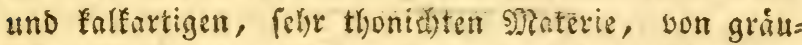
lider Farbe angefintt, die mit fleinen idwarzen Sơrnern Durd) fået iff.

*) Iafel XLIX, Figur 2 . 


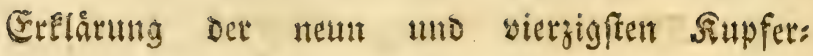
tafel.

گigur 1. Ein nabelformiger Thautilit aus ธchwedert.

Figur 2. Der triangelformige Nautilit von Şavre. Ex ift dine auffern fopf. Der פound ferit. 


\section{Det georidefe Satutilit. *)}

Le Nautilite de primé.

Det Durchmefier ift bew bicfem Tantilit weit breiter, alz ex lang ifr. Exe ift cinen zoll lang und anberthalb 3oll breit. Der Mund belgnt fich in ci= nen Szalbzirfer aub. 2tuf Den Seiten fethn zwen

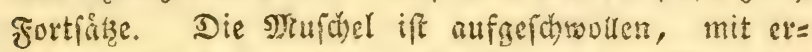
babenen Fuchen veifern, die fids in der Mitte Deb

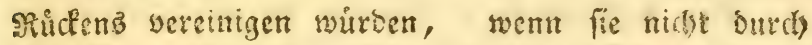
eine fleine fiette yon furnern unterbrotiden wirdon, bie ben Ritcen in zwen gleiche Şatften thrilt, Der ganzen Rânge nad). Der Sopf ift eine lemie ftart.

Sgir haben anf ber funfrigften Zafel, Æigut 1. mod) cinen fd)onen 2 (mmoniten Dargeftefit, ber som

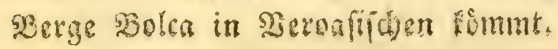

*) Tafat $L$, gigut 2 und 5 . 


\section{Eteklarung Det funfzigfter Supfertafer.}

Fitgur 1, Der $\mathfrak{2}$ mmonit yon $\mathfrak{B}$ oli.

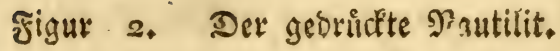

Die fortbauernoen Itnruln ber Einquartierung und bie (d)wad)e Bifundheit bez Berfafferz, erlaub= ten Diejem Sande gatts zu endigen. Ës ferjen nod) 60 Seiten, bie, wenn eb Der Şimmel will, in rulji= gern Beiten, im 5. Bande nachgeliefert werden follen.

Ende bes̊ vierten Bandę, 


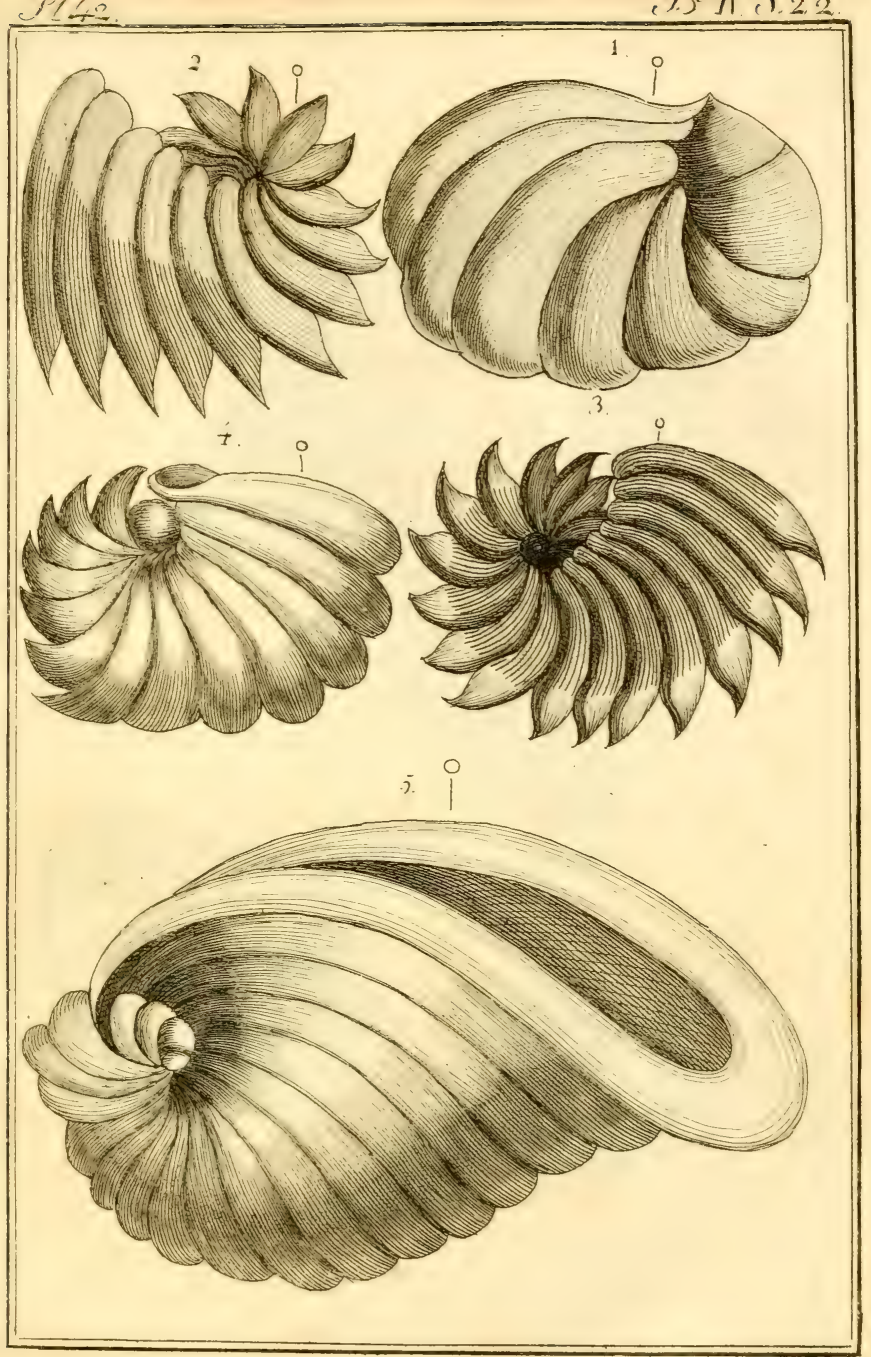

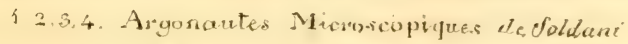

5. Autre Arqunaute, plus fortement grossi. 



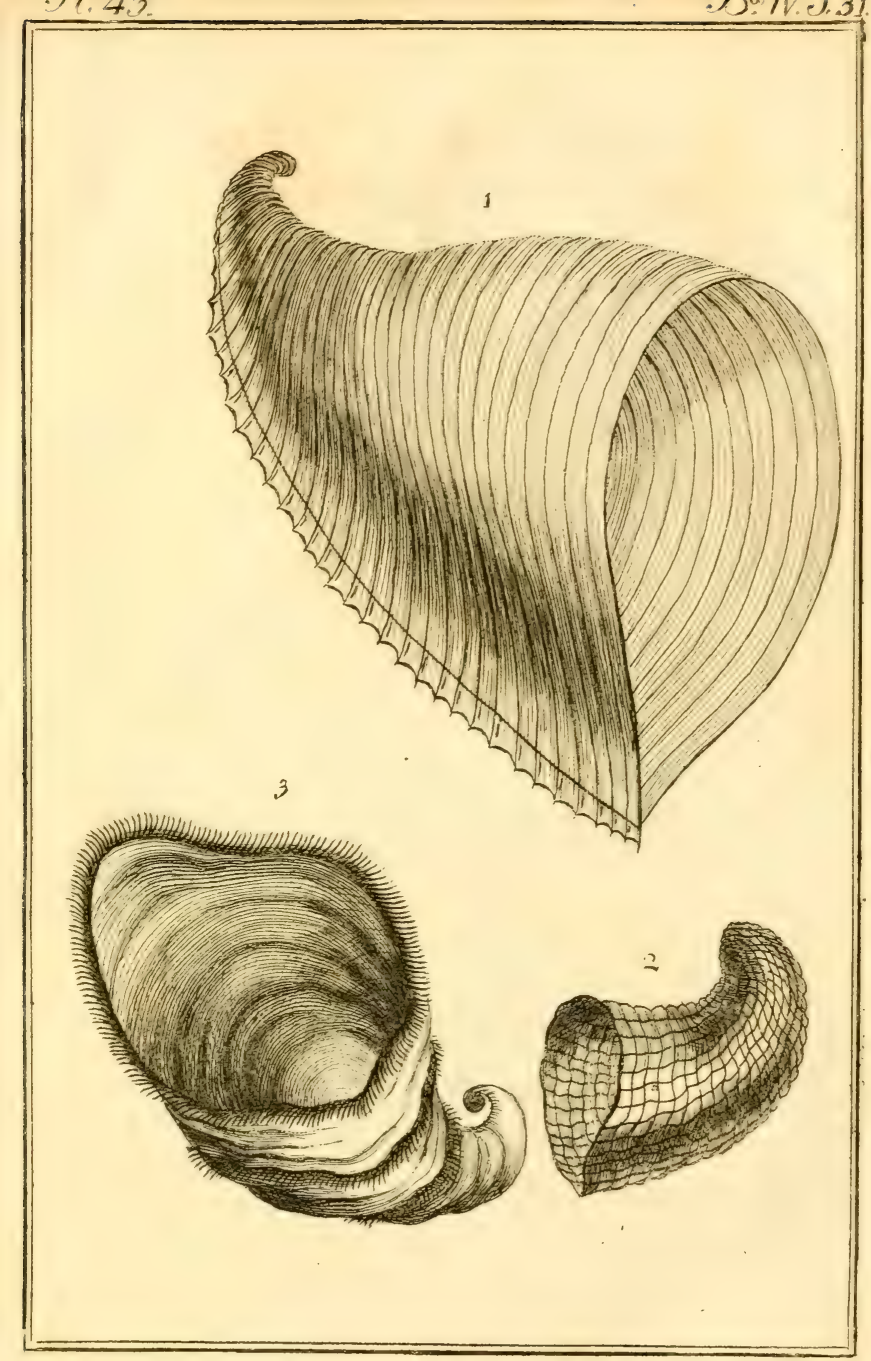

1. Carinaire Vitree

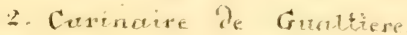

3. Bonnet de Droqon. 


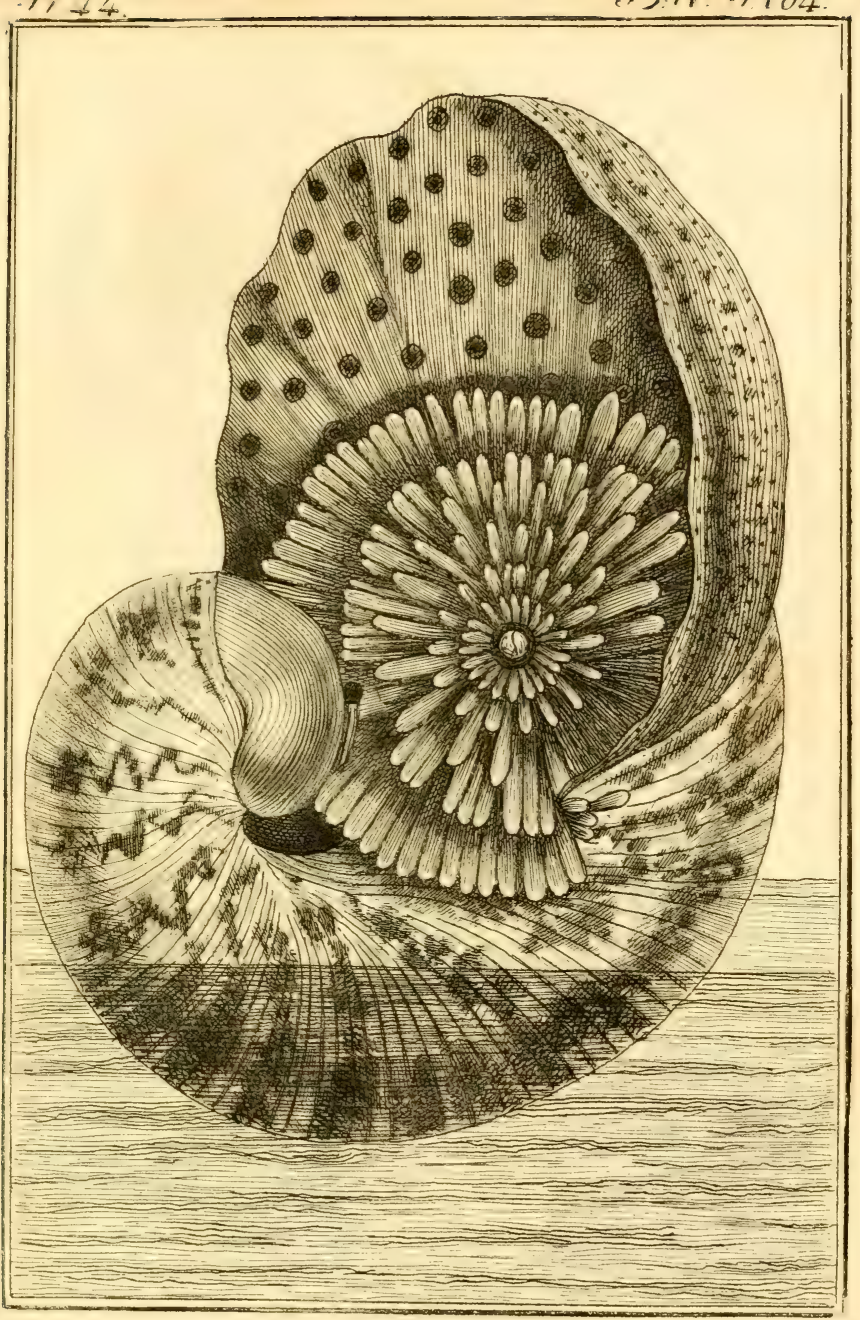

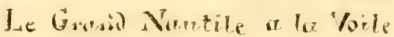





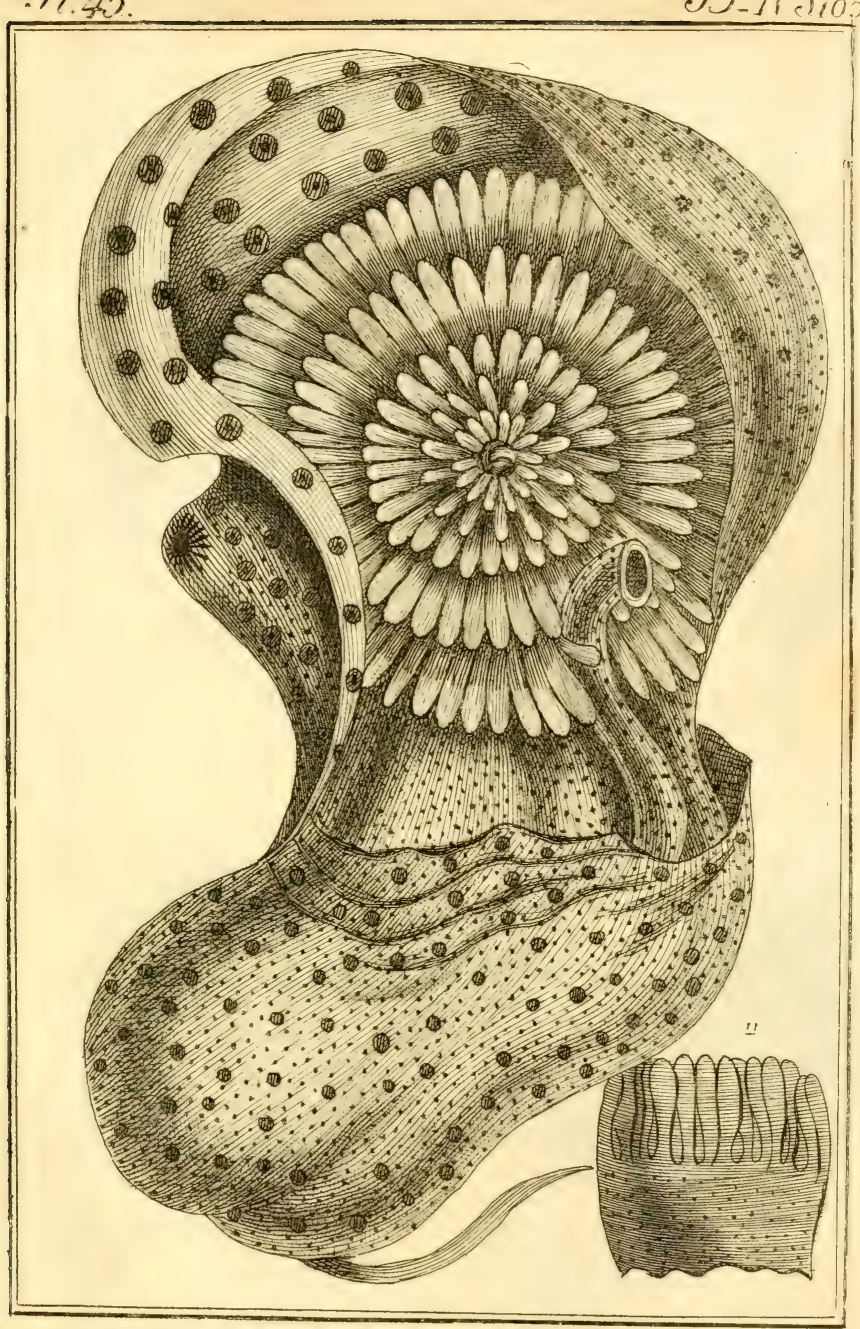

1. Nantile Hors de sa Coquille

2. Un de ses Bras Digites. 



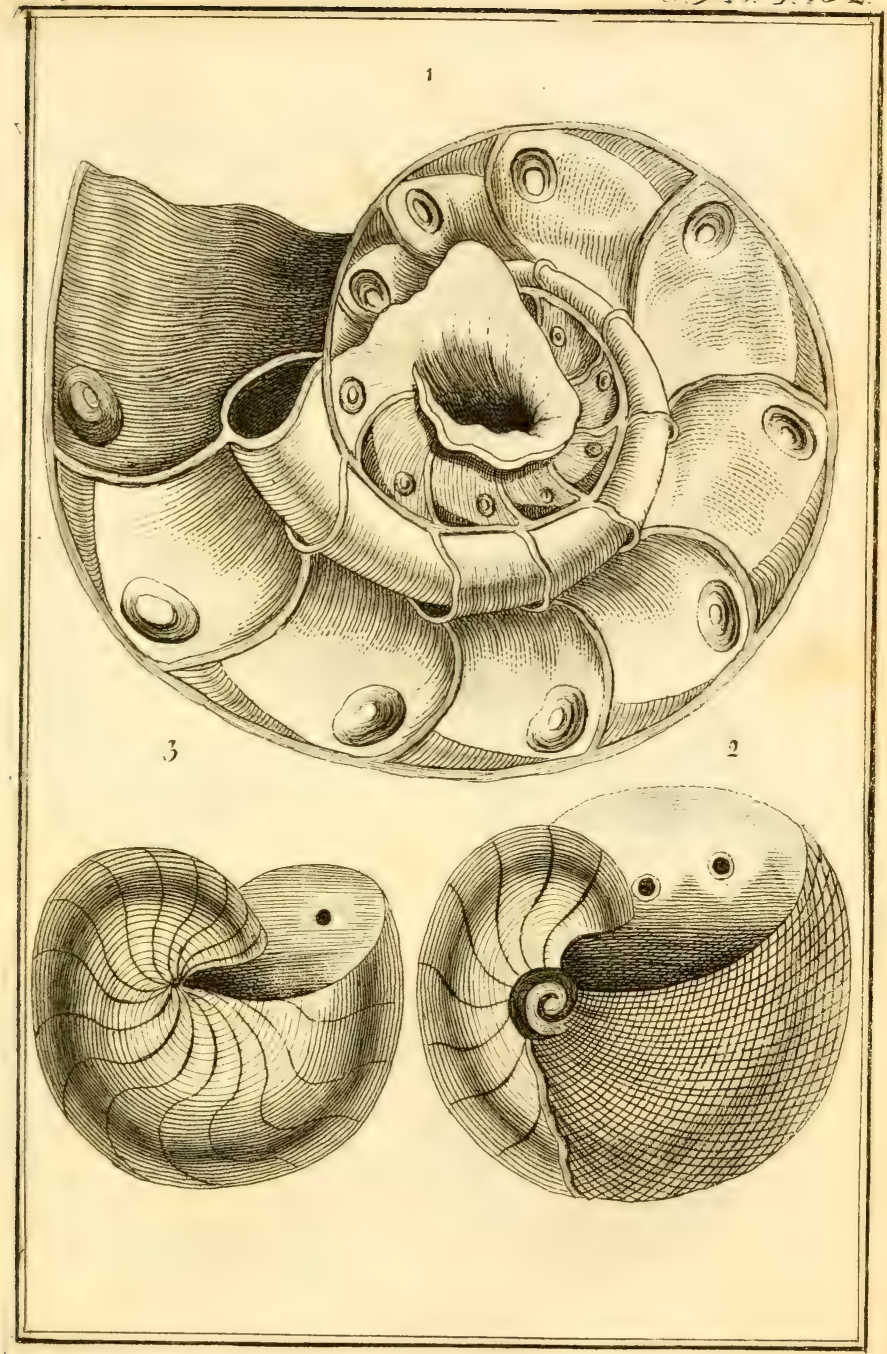

1. Nentulite Asupios Cosition dedec

2. Noretilite a beux sypions.

3. Neretilite Acloisoss. osederlés 




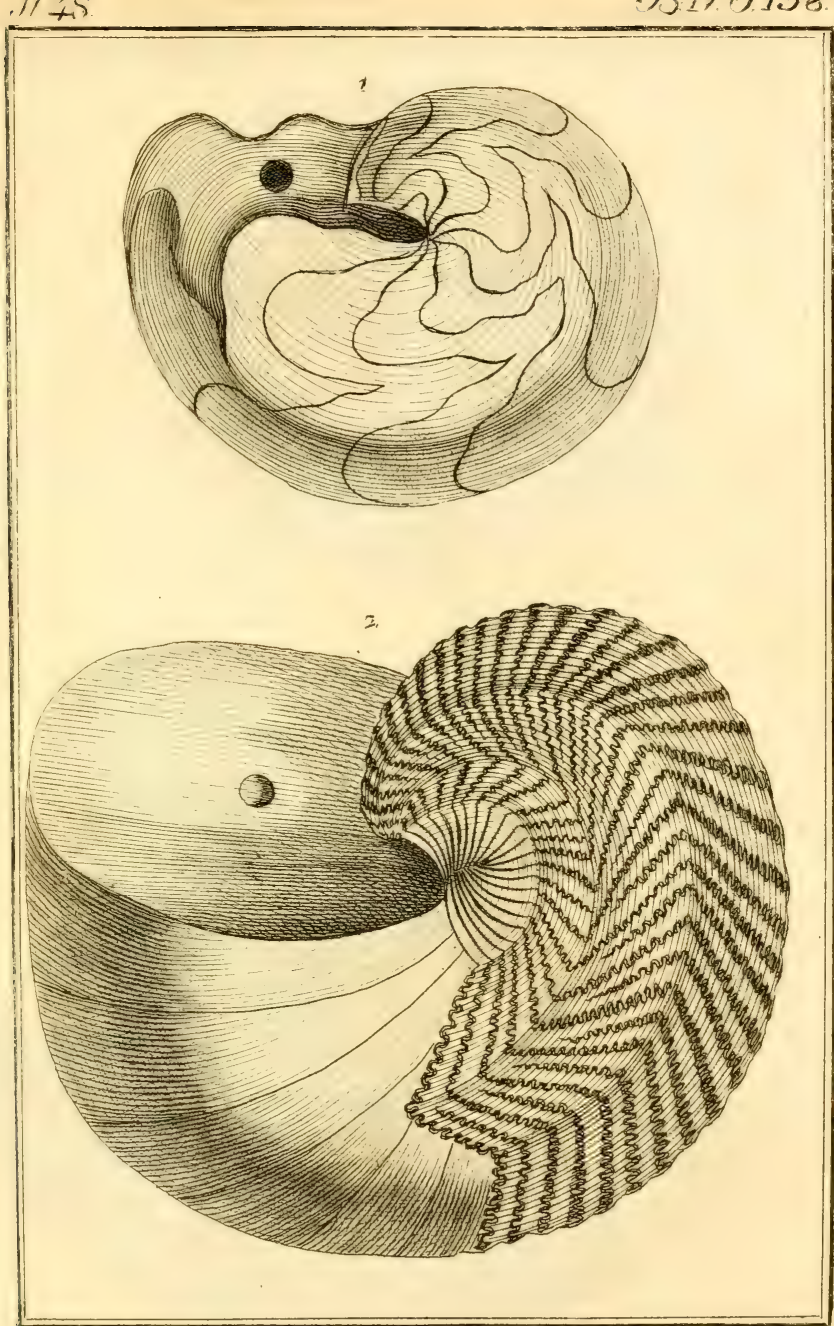

1. Nartilite en Capueclessine

- Nirntilite leselé. 



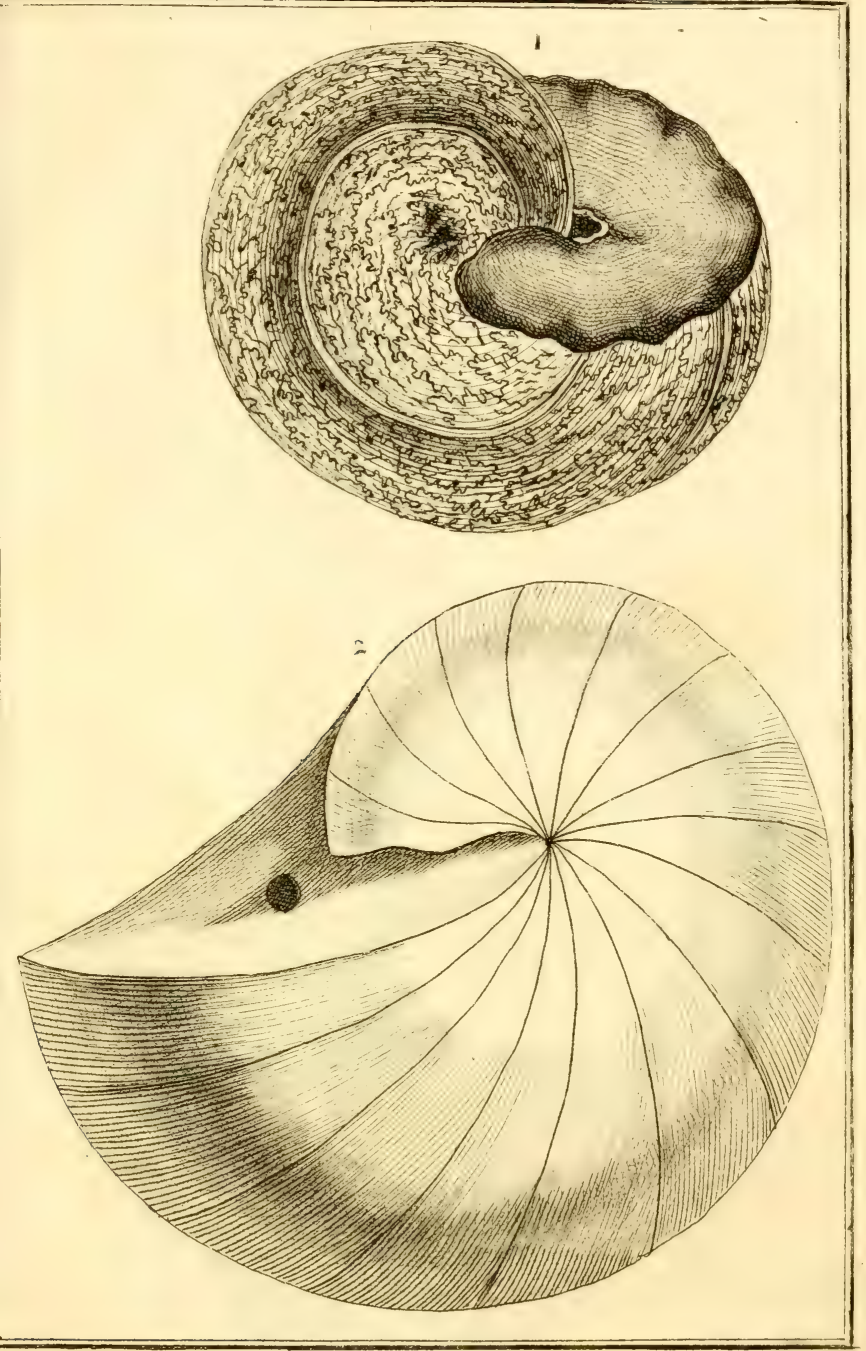

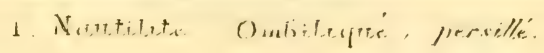

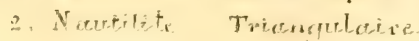





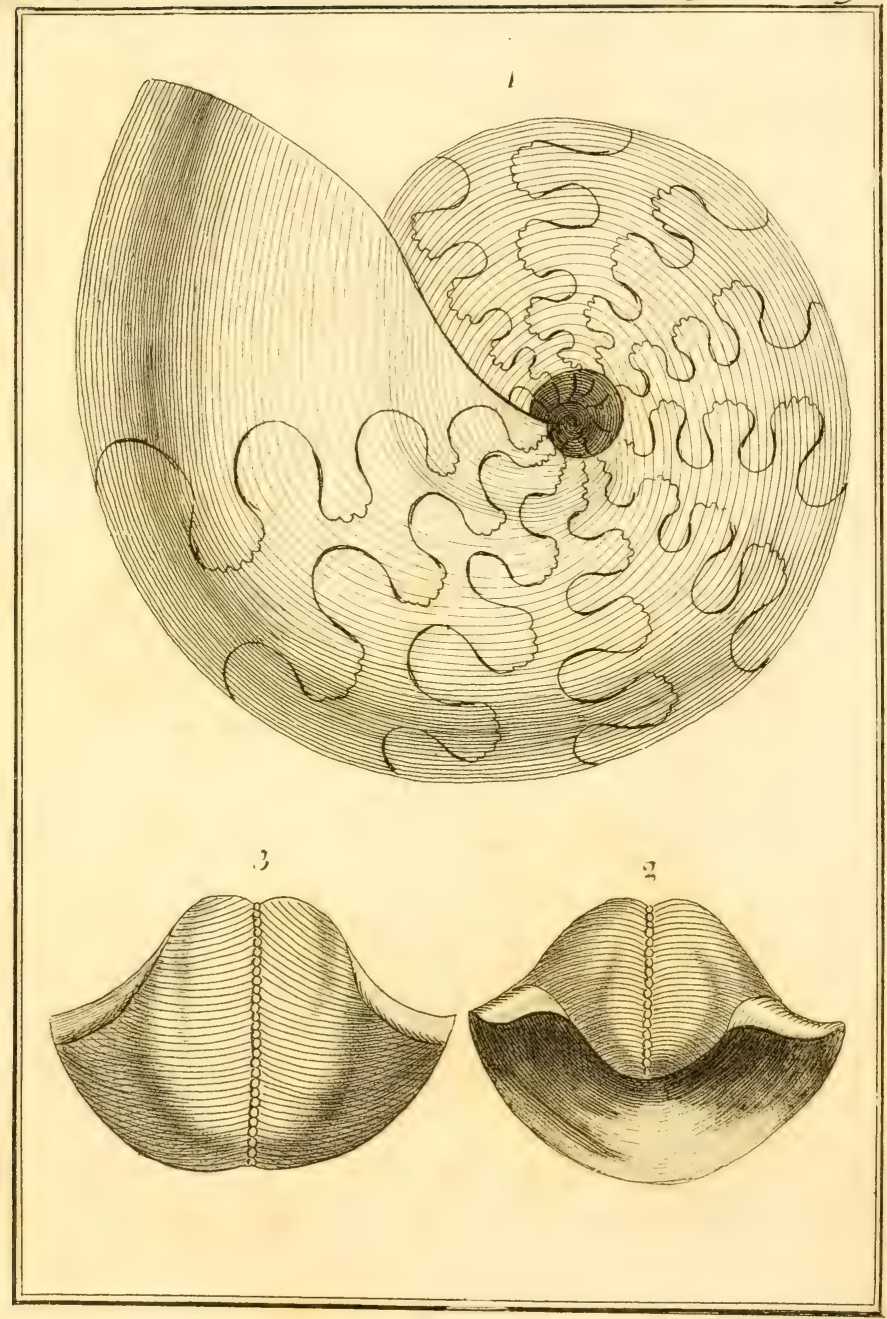

1. Anumonits Ni-Post:

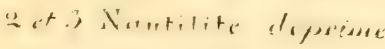




Oardea 

